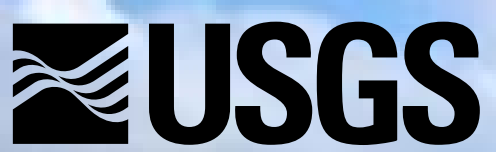

science for a changing world

Development and Application of a Decision Support System for Water Management Investigations in the Upper Yakima River, Washington

By Ken D. Bovee, Terry J. Waddle, Colin Talbert, James R. Hatten, and Thomas R. Batt

Open-File Report 2008-1251

U.S. Department of the Interior U.S. Geological Survey 


\section{U.S. Department of the Interior DIRK KEMPTHORNE, Secretary}

\section{U.S. Geological Survey \\ Mark D. Myers, Director}

\section{U.S. Geological Survey, Reston, Virginia 2008}

For product and ordering information:

World Wide Web: http://www.U.S. Geological Survey.gov/pubprod

Telephone: 1-888-ASK-U.S. Geological Survey

For more information on the U.S. Geological Survey-the Federal source for science about the Earth, its natural and living resources, natural hazards, and the environment:

World Wide Web: http://www.U.S. Geological Survey.gov

Telephone: 1-888-ASK-U.S. Geological Survey

Suggested citation:

Bovee, K.D., Waddle, T.J., Talbert, C. Hatten, J.R., and Batt, T.R., 2008, Development and Application of a Decision Support System for Water Management Investigations in the Upper Yakima River, Washington: U.S. Geological Survey Open-File Report 2008-1251, 289 p.

Any use of trade, product, or firm names is for descriptive purposes only and does not imply endorsement by the U.S. Government.

Although this report is in the public domain, permission must be secured from the individual copyright owners to reproduce any copyrighted material contained within this report. 


\section{Contents}

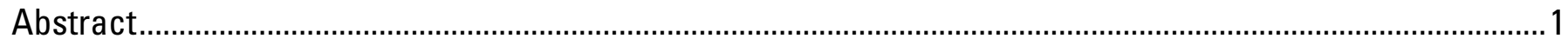

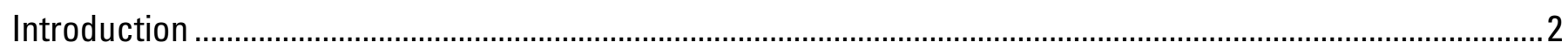

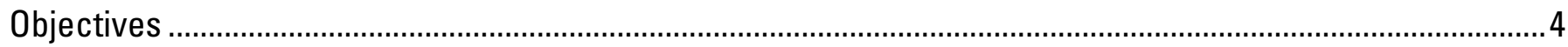

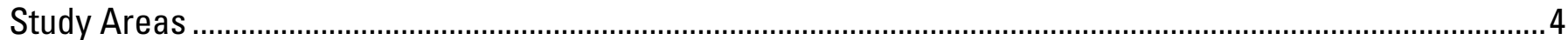

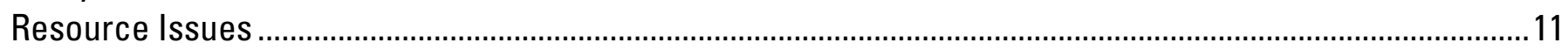

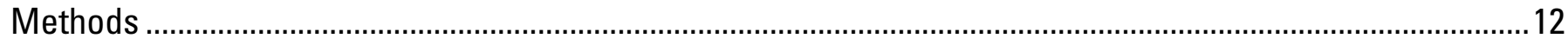

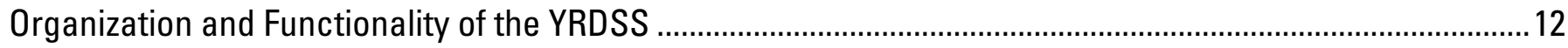

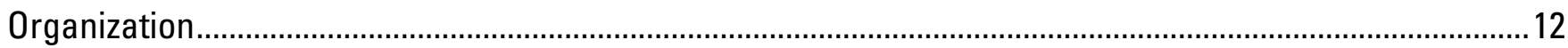

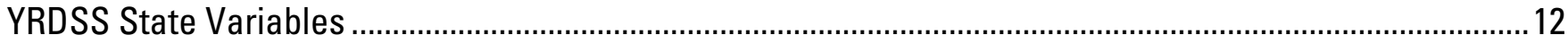

Functionality of YRDSS Components ............................................................................................... 14

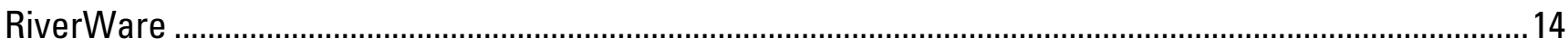

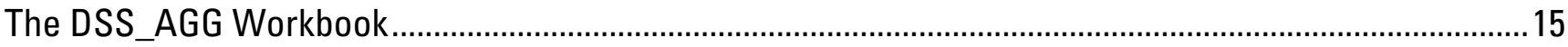

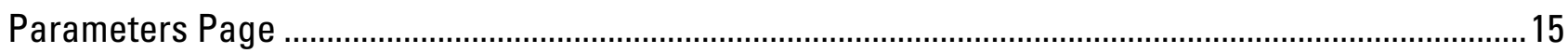

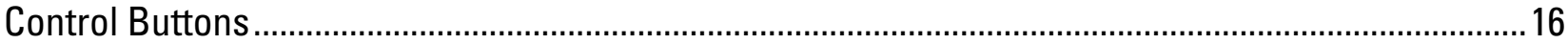

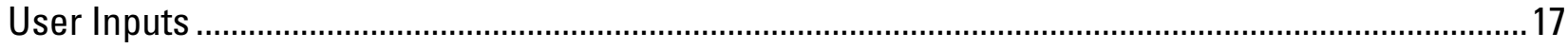

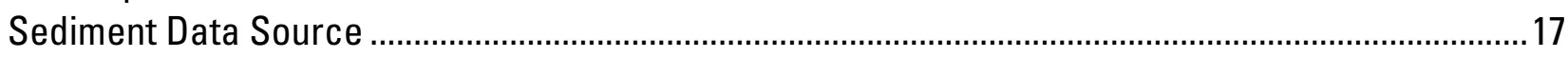

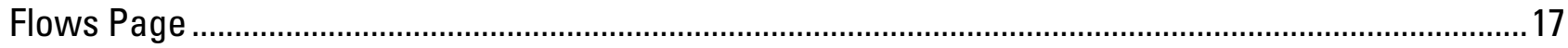

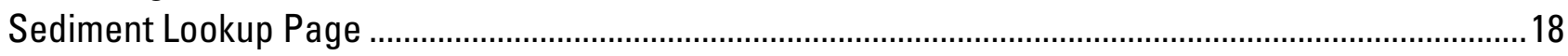

Sediment Calculations Page ......................................................................................................... 18

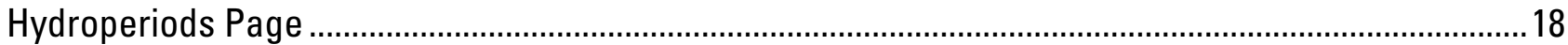

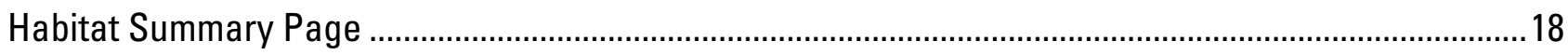

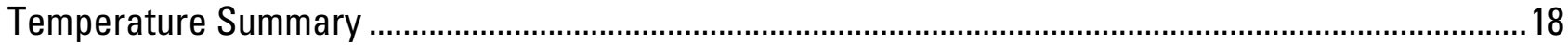

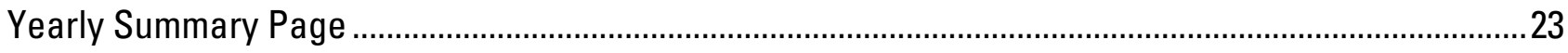

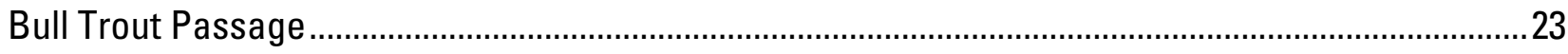

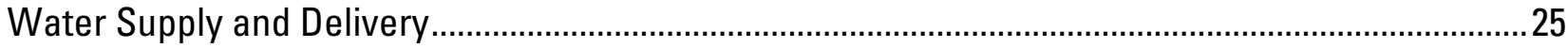

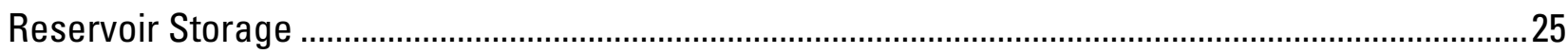

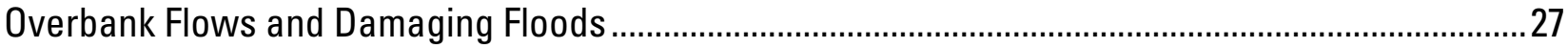

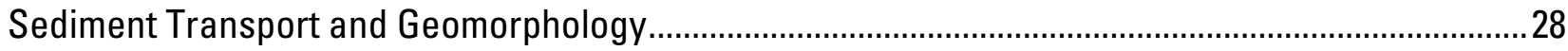

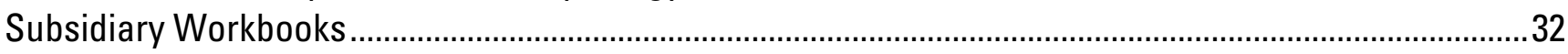

Site-Specific Yearly Habitat Summaries..........................................................................................32

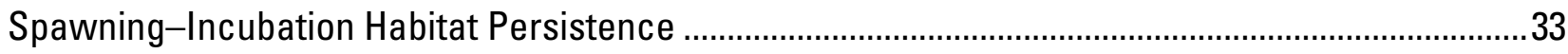

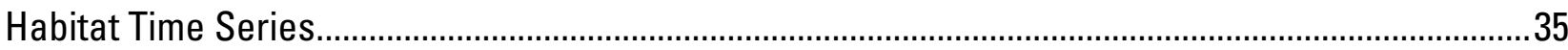

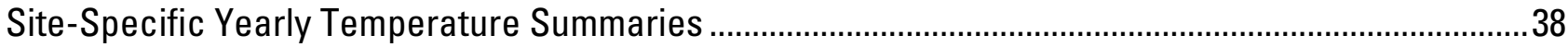

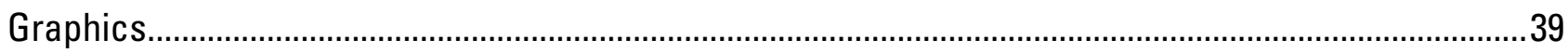

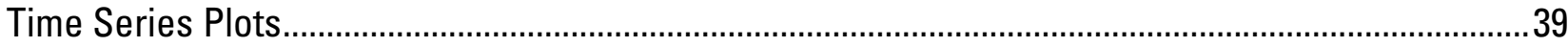

Habitat- and Flow-Duration Curves ……………………............................................................

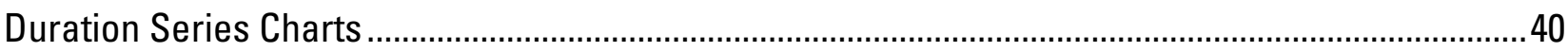

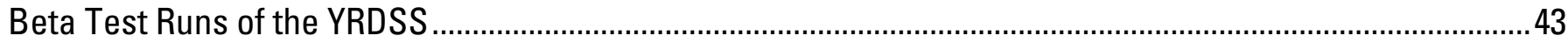

Operational Comparisons .......................................................................................................................... 43

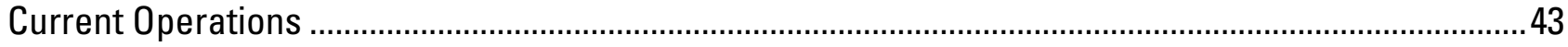

The No Action Alternative ................................................................................................................. 44 


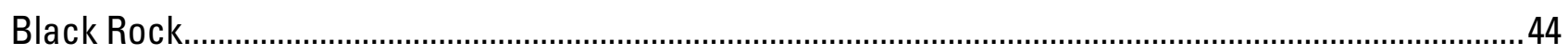

Wymer_1

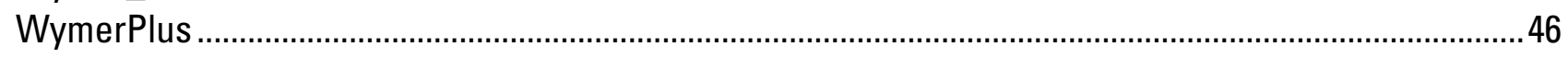

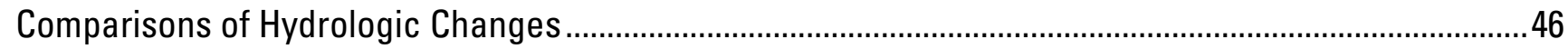

Low Flow Characteristics .............................................................................................................. 46

Maximum Flow Characteristics......................................................................................................... 47

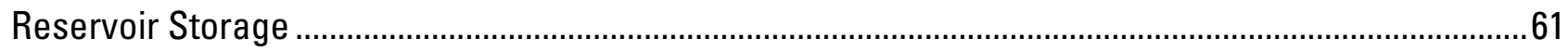

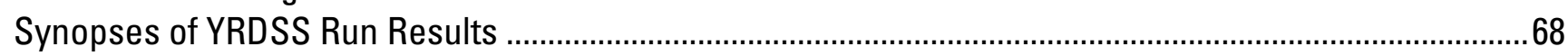

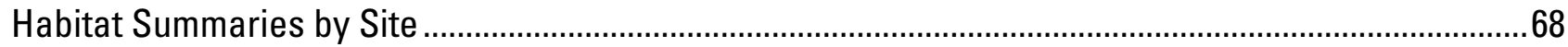

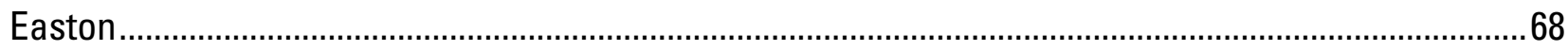

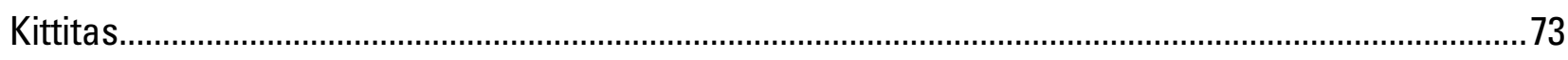

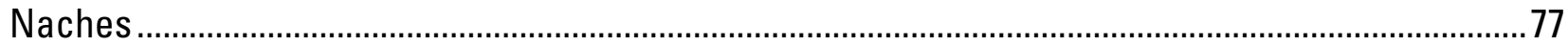

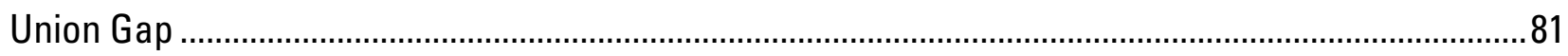

Wapato

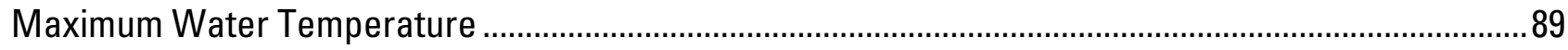

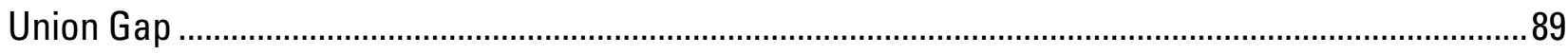

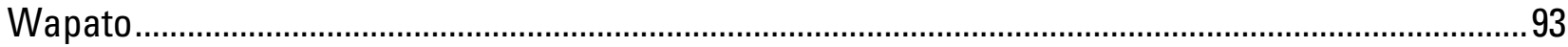

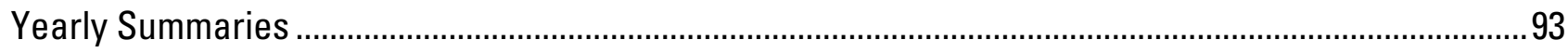

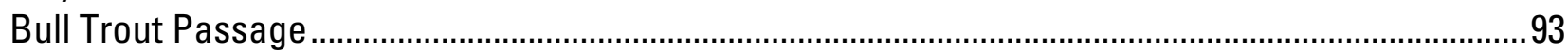

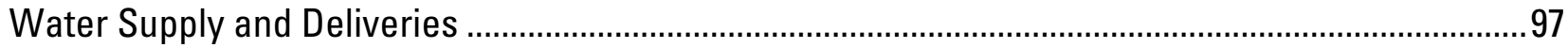

Reservoir Carryover and Cle Elum Critical Storage ..........................................................................97

Overbank Flows and Damaging Floods .........................................................................................99

Potential Fine-Sediment Transport.......................................................................................... 100

Geomorphic Adjustment ................................................................................................................ 102

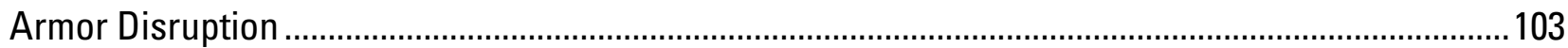

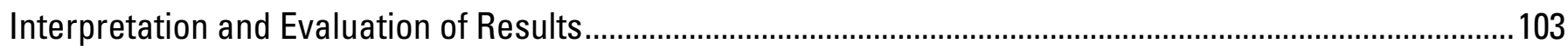

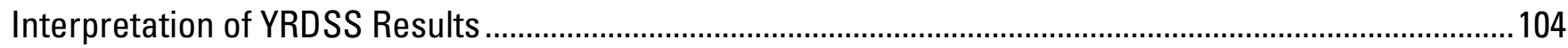

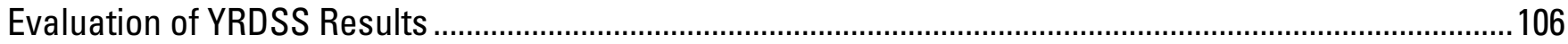

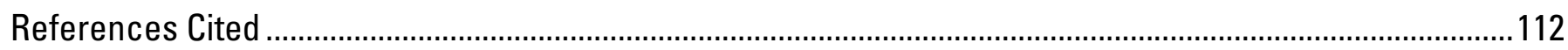

Appendix 1. Two-Dimensional Hydraulic Simulations of the Union Gap and Wapato Reaches .....................115

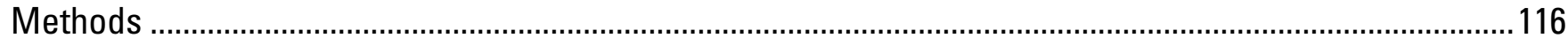

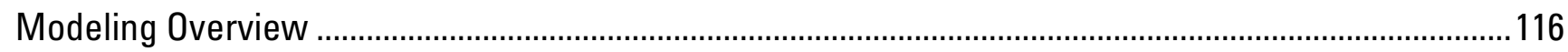

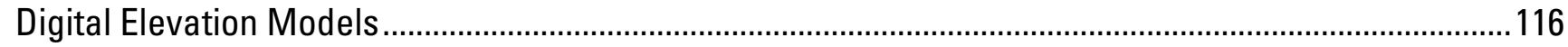

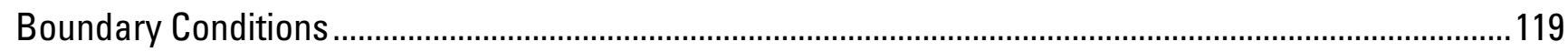

River2D Mesh Construction ............................................................................................................. 119

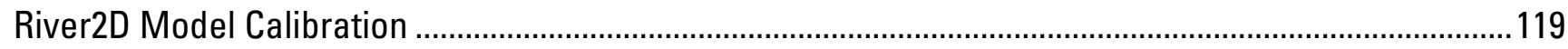

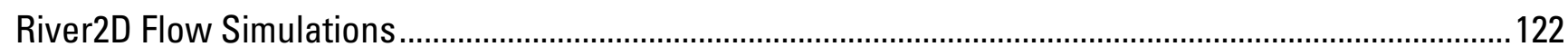

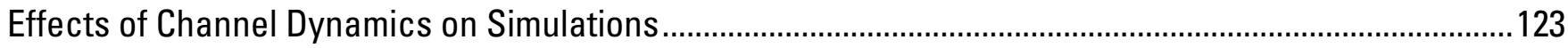

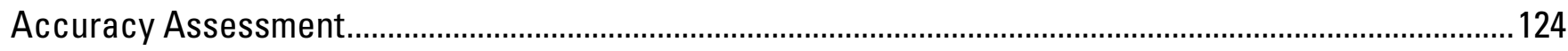

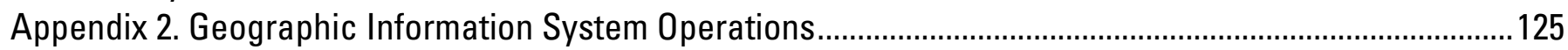

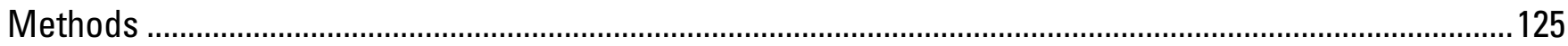

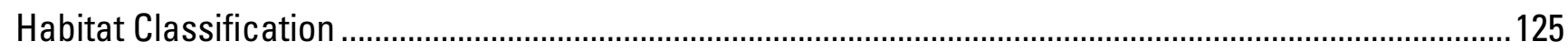

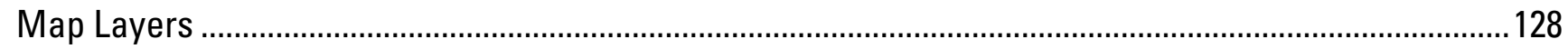




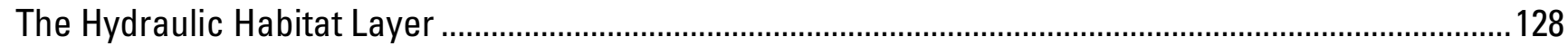

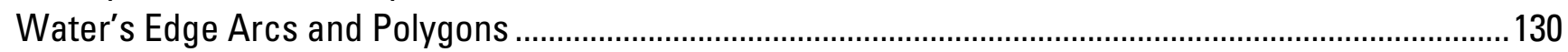

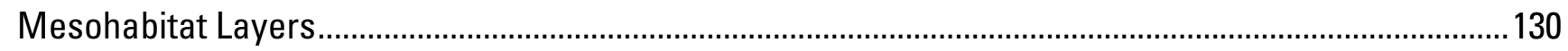

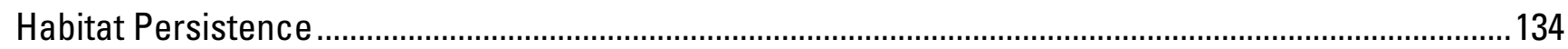

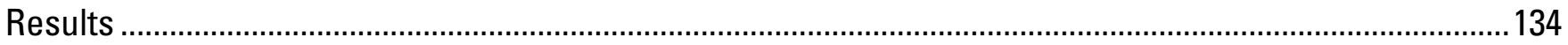

Appendix 3. Sediment Transport Lookup Tables from the SIAM Model........................................................204

Appendix 4. YRDSS Run Results for the Blackrock_2 Scenario ......................................................................214

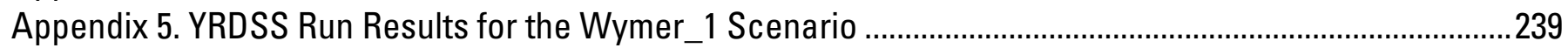

Appendix 6. YRDSS Run Results for the WymerPlus Scenario ..........................................................................264

\section{Figures}

1. Map of the upper Yakima River Basin showing locations of Yakima Project reservoirs and

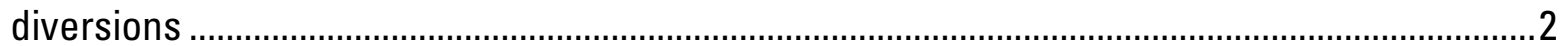

2. Map of the upper Yakima River Basin showing locations of study sites...................................... 5

3-6. Aerial photographs of a portion of the:
3. Upper Yakima-Teanaway flood plain showing the extent of the Easton site....................

4. Kittitas valley flood plain showing the extent of the Kittitas site.............................................7

5. Lower Naches flood plain showing the extent of the Naches site.......................................... 8

6. Union Gap flood plain showing the extent of the Union Gap site...........................................

7. Wapato flood plain unit showing the extent of the Wapato site....................................................10

8. Organization of workbooks and information flow of the YRDSS ...............................................13

9. Contents of the Dss_Agg.xls workbook................................................................................15

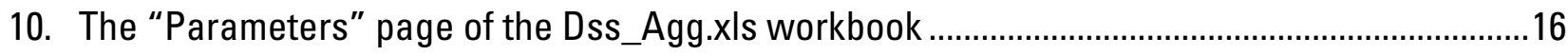

11. The "Hydroperiods" page of the Dss_Agg.xls workbook ............................................................19

12. The upper portion of the "HabSummary" page, showing the arrangement of biological state variables and site information ............................................................................................. 20

13. The lower portion of the "HabSummary" page, showing the arrangement of hydrologic and

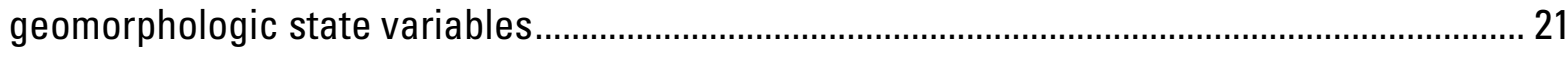

14. A portion of the "TempSummary" page, showing the arrangement of temperature data arrayed by relevant hydroperiods for target species and life stages ....................................... 22

15. The bull trout passage table for Kachess, Keechelus, and Rimrock Reservoirs, as found on the Yearly Summary page of the DSS_Agg spreadsheet...................................................... 24

16-21. Portions of the annual scoring tables found on the "Yearly Summary" page of the DSS_Agg spreadsheet for:

16. Average proration percentage and total water supply available ........................................26

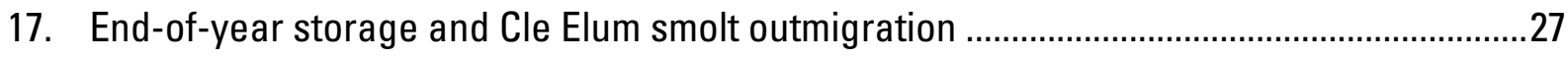

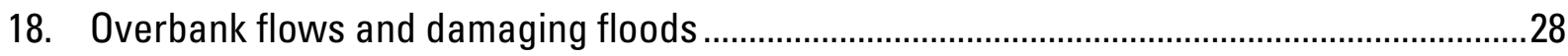

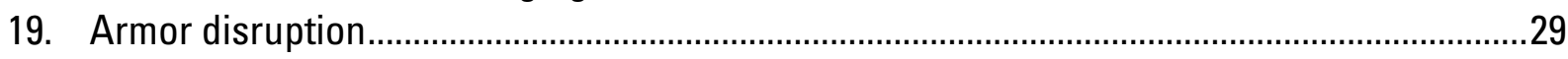

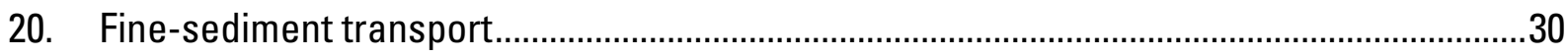

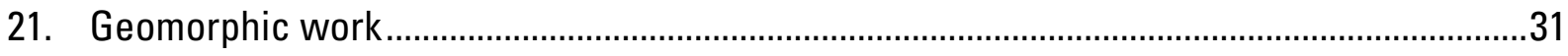

22. Portion of the yearly habitat summary page for the Easton reach ..............................................32 
23. Example of an intersection map depicting persistent reproduction habitat in a portion of the Easton reach with a spawning flow of 500 cubic feet per second and an incubation flow of 150 cubic feet per second

24. Portion of a spawning-incubation persistence table showing the interpolation diagonals used to compute persistent habitat for a spawning discharge of 325 cubic feet per second and an incubation discharge of 167 cubic feet per second.

25. Elements used in the construction of a habitat time series: $A$, flow time series, $B$, habitat relative to flow function, and $C$, the resulting habitat time series.

26. Averaging interval from cumulative probability distribution (from figure 25-c) used as the scoring metric in the YRDSS habitat time series analysis

27. Portion of a yearly temperature page of the Union Gap subsidiary notebook...... 38

28. Portions of hydrologic time series plots from the "Flows" page of the DSS_Agg spreadsheet showing relationships between storage volume at Keechelus Reservoir (A) and discharges at the Kittitas reach (B).

29. A flow-duration chart for the Union Gap reach, from the "DurCurve Chart" page of the "DSS_UnG" subsidiary spreadsheet.

30. Controls on the "DurCurve pages of the subsidiary spreadsheets used to generate duration curves for life stage-specific habitat or for discharges

31. A flow duration series chart for the Union Gap reach, from the "DurSerChart" page of the "DSS_UnG" subsidiary spreadsheet.

32-36. Flow-duration series of flows in the:

32. Easton reach, comparing the Black Rock_2 (A), Wymer_1 (B), and WymerPlus (C) scenarios with the No Action baseline.

33. Kittitas reach, comparing the Black Rock_2 (A), Wymer_1 (B), and WymerPlus (C) scenarios with the No Action baseline.

34. Naches reach, comparing the Black Rock_2 (A),Wymer_1 (B), and WymerPlus (C) scenarios with the No Action baseline.

35. Union Gap reach, comparing the Black Rock_2 (A), Wymer_1 (B), and WymerPlus (C) scenarios with the No Action baseline.

36. Wapato reach, comparing the Black Rock_2 (A), Wymer_1 (B), and WymerPlus (C) scenarios with the No Action baseline.

37-41. Maximum 10-day discharges in the:

37. Easton reach, comparing the Black Rock_2,Wymer_1, and WymerPlus scenarios with the No Action baseline

38. Kittitas reach, comparing the Black Rock_2,Wymer_1, and WymerPlus scenarios with the No Action baseline

39. Naches reach, comparing the Black Rock_2, Wymer_1, and WymerPlus scenarios with the No Action baseline.

40. Union Gap reach, comparing the Black Rock_2, Wymer_1, and WymerPlus scenarios with the No Action baseline

41. Wapato reach, comparing the Black Rock_2, Wymer_1, and WymerPlus scenarios with the No Action baseline. 
42-46. Reservoir storage-duration curve (A) for all years and 1991-97 storage time series

(B) for the baseline and Black Rock_2, Wymer_1, and WymerPlus scenarios at:

42. Bumping Lake Reservoir ...................................................................................................62

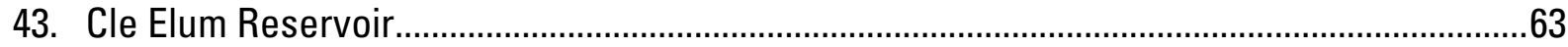

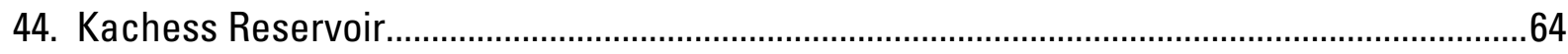

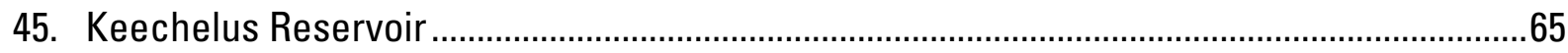

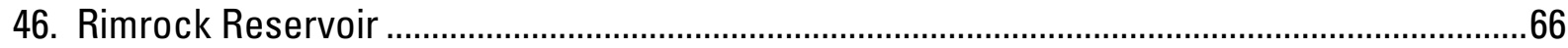

47. Habitat summaries comparison of the Black Rock_2 (BR_2), Wymer_1 (WY_1), and

WymerPlus $(W Y+$ ) scenarios, expressed as percentage change from the No Action baseline.

48-62. Annual habitat summaries comparing the Black Rock_2 (BR_2), Wymer_1 (WY_1), and WymerPlus $(W Y+)$ scenarios relative to the baseline for:

48. Spring chinook and coho in the Easton reach .................................................................

49. Steelhead and resident rainbow trout in the Easton reach...................................................71

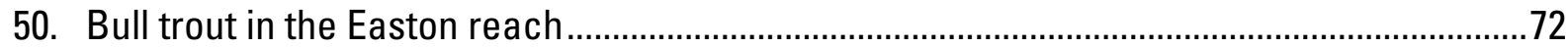

51. Spring chinook and coho in the Kittitas reach ..................................................................

52. Steelhead and resident rainbow trout in the Kittitas reach......................................................

53. Bull trout in the Kittitas reach..........................................................................................76

54. Spring chinook and coho in the Naches reach................................................................78

55. Steelhead and resident rainbow trout in the Naches reach ...............................................79

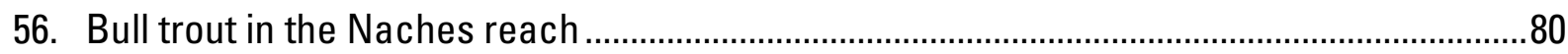

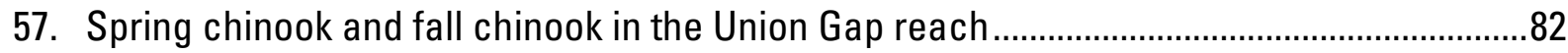

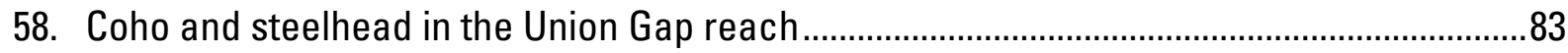

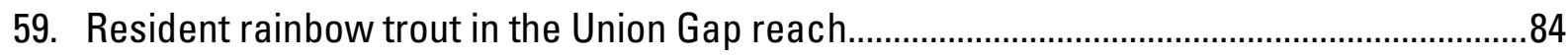

60. Spring chinook and fall chinook in the Wapato reach .......................................................8

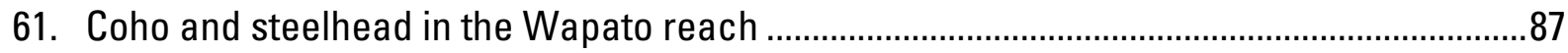

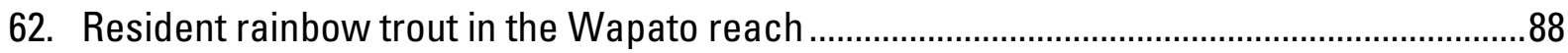

63-68. Annual temperature summaries comparing the Black Rock_2 (BR_2), Wymer_1 (WY_1), and WymerPlus (WY+ ) scenarios relative to the baseline for:

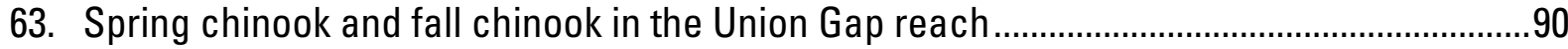

64. Coho and steelhead in the Union Gap reach ..................................................................... 91

65. Resident rainbow trout in the Union Gap reach.................................................................92

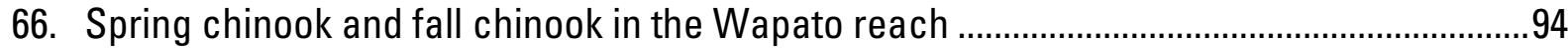

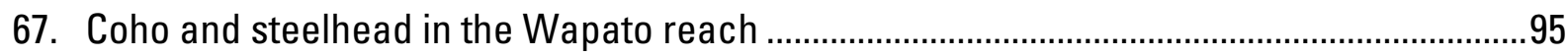

68. Resident rainbow trout in the Wapato reach ................................................................96

69-77. Yearly summaries for the Black Rock_2 (BR_2), Wymer_1 (WY_1), and WymerPlus (WY+) scenarios, expressed as percentage change from the No Action baseline for:

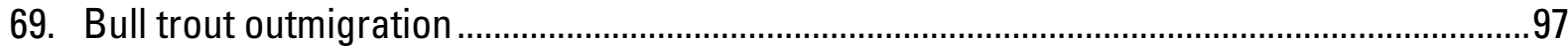

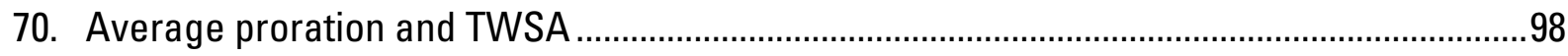

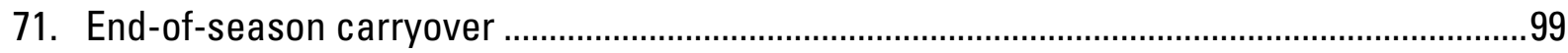

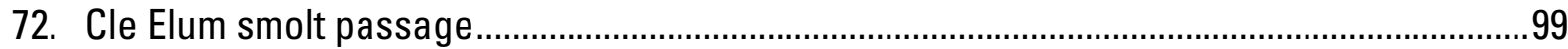

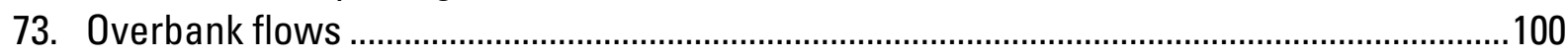

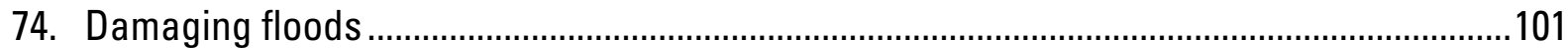


75. Fine-sediment transport

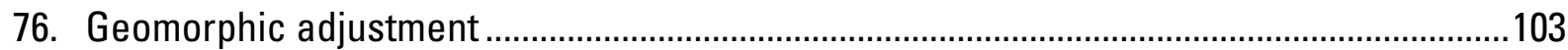

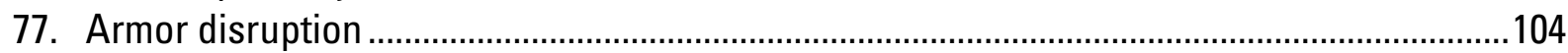

78. Shoreline length as a function of discharge at the Easton and Kittitas reaches ........................105

79. Discharge and habitat time series for subyearling coho in the Kittitas reach during the summer of 1992, comparing the No Action baseline and the Black Rock_2 alternative ..........106

80. An example of an evaluation matrix, showing side-by-side comparisions of the Black Rock_2, Wymer_1, and WymerPlus alternatives..

81. A compilation of classifications from the evaluation matrix illustrated in figure 80 .

82. A compilation of classifications from the evaluation matrix illustrated in figure 80 , with redd scour at Easton and Union Gap removed and double-weighting on bull trout...

83. A compilation of classifications from the evaluation matrix illustrated in figure 80 , with redd scour at Easton and Union Gap removed and double-weighting on Easton and Kittitas .........110

84. A compilation of classifications from the evaluation matrix illustrated in figure 80 , with redd scour at Easton and Union Gap removed and double-weighting on Union Gap and Wapato.

85. Maximum monthly storage volumes at Cle Elum Reservoir, water years 1985-95.

\section{Appendix Figures}

1-1. Aerial map of the Union Gap reach between the 24th Street Bridge and Union Gap. .117

1-2. Aerial map of the Wapato reach between the Wapato and Toppenish bridges

1-3. An example of a variable-sized mesh in the Wapato reach at a discharge of 300 cubic feet per second.

1-4. Measured and simulated water-surface profiles at the Union Gap site for calibration discharges of 1,490 and 3,420 cubic feet per second.

1-5. Measured and simulated water-surface profiles at the Wapato site for calibration discharges of 1,491 and 2,450 cubic feet per second

2-1-2-6. Suitable depth and velocity ranges as determined by the Yakima River Delphi committee for:

2-1. Six life stages of spring chinook (Oncorhynchus tshawytscha)

2-2. Four life stages of fall chinook (Oncorhynchus tshawytscha) ........................................126

2-3. Four life stages of coho (Oncorhynchus kisutch) ...........................................................126

2-4. Four life stages of steelhead (Oncorhynchus mykiss) ....................................................127

2-5. Four life stages of resident rainbow trout (Oncorhynchus mykiss) ................................127

2-6. Five life stages of bull trout ( Salvelinus confluentus) ...................................................128

2-7. Conversion of depth and velocity grids to a hydraulic habitat polygon shapefile in ArcGIS ...129

2-8. Example of the intersection between suitable hydraulic habitat for fry with a shoreline buffer

2-9. Correspondence between spring chinook redd locations observed at approximately 300 cubic feet per second and Froude number categories calculated for 2,000 cubic feet per second in a portion of the Easton reach

2-10. Proportions of spring chinook redds, available areas, and normalized electivity indexes, arrayed by Froude number category for the Easton reach of the Yakima River 
2-11. Illustration of a habitat persistence map for spring chinook spawning at a discharge of 500 cubic feet per second with an incubation discharge of 150 cubic feet per second in a portion

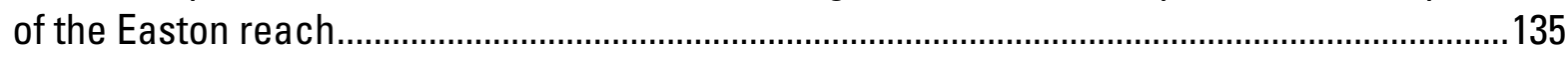

2-12-2-36. Total habitat area as a function of stream discharge for:

2-12. Three life stages of bull trout ( Salvelinus confluentus) in the Easton reach ...................136

2-13. Three life stages of coho (Oncorhynchus kisutch) in the Easton reach..........................137

2-14. Four life stages of spring chinook (0. tshawytscha) in the Easton reach .......................138

2-15. Four life stages of resident rainbow trout ( 0 . mykiss) in the Easton reach.....................139

2-16. Five life stages of steelhead ( 0 . mykiss) in the Easton reach........................................ 140

2-17. Three life stages of bull trout ( $S$. confluentus) in the Kittitas reach ...............................141

2-18. Three life stages of coho (O. kisutch) in the Kittitas reach ........................................... 142

2-19. Four life stages of spring chinook (O. tshawytscha) in the Kittitas reach ......................143

2-20. Four life stages of resident rainbow trout ( 0 . mykiss) in the Kittitas reach ....................144

2-21. Five life stages of steelhead ( 0 . mykiss) in the Kittitas reach....................................... 145

2-22. Three life stages of bull trout ( $S$. confluentus) in the Naches reach..............................146

2-23. Three life stages of coho (O. kisutch) in the Naches reach..........................................147

2-24. Four life stages of spring chinook (0. tshawytscha) in the Naches reach......................148

2-25. Four life stages of rainbow trout (0. mykiss) in the Naches reach................................. 149

2-26. Five life stages of steelhead (O. mykiss) in the Naches reach ....................................... 150

2-27. Three life stages of coho (O. kisutch) in the Union Gap reach ...................................... 151

2-28. Two life stages of fall chinook (0. tshawytscha) in the Union Gap reach....................... 152

2-29. Overwintering spring chinook (O. tshawytscha) subyearlings in the Union Gap

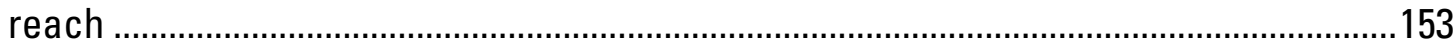

2-30. Four life stages of resident rainbow trout ( 0 . mykiss) in the Union Gap reach ...............154

2-31. Overwintering steelhead (0. mykiss) subyearlings in the Union Gap reach....................155

2-32. Three life stages of coho $(0$. kisutch) in the Wapato reach............................................156

2-33. Two life stages of fall chinook (0. tshawytscha) in the Wapato reach ..........................157

2-34. Overwintering spring chinook (0. tshawytscha) subyearlings in the Wapato reach.....158

2-35. Four life stages of resident rainbow trout (0. mykiss) in the Wapato reach................... 159

2-36. Overwintering steelhead (0. mykiss) subyearlings in the Wapato reach ........................160

2-37-2-55. Spawning-incubation response surfaces for:

2-37. Bull trout (S. confluentus) in the Easton reach............................................................162

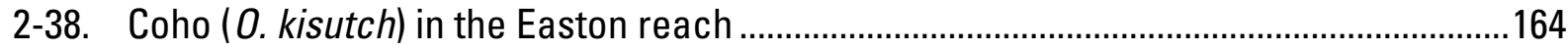

2-39. Spring chinook (O. tshawytscha) in the Easton reach ...................................................166

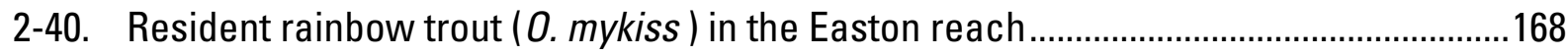

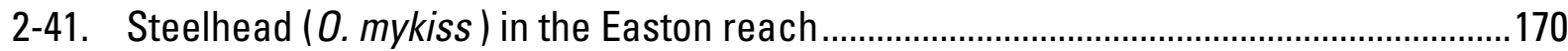

2-42. Bull trout (S. confluentus) in the Kittitas reach ..........................................................172

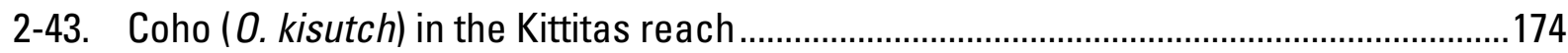

2-44. Spring chinook (O. tshawytscha) in the Kittitas reach..................................................176

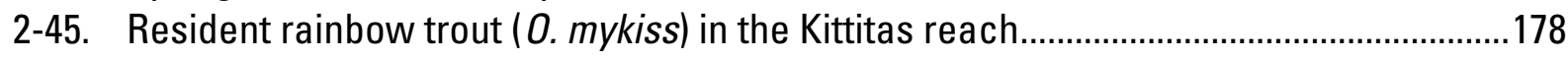

2-46. Steelhead (0. mykiss) in the Kittitas reach................................................................180

2-47. Bull trout ( $S$. confluentus) in the Naches reach ........................................................... 182

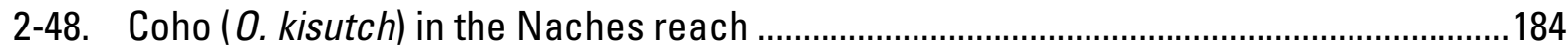


2-49. Spring chinook (O. tshawytscha) in the Naches reach ................................................186

2-50. Resident rainbow trout (O. mykiss) in the Naches reach ............................................... 188

2-51. Steelhead (0. mykiss) in the Naches reach ...............................................................190

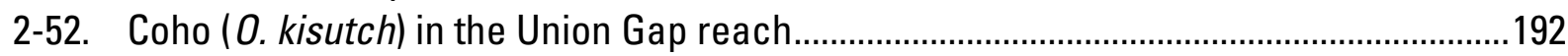

2-53. Fall chinook (O. tshawytscha) in the Union Gap reach ..................................................194

2-54. Resident rainbow trout (O. mykiss) in the Union Gap reach ............................................. 196

2-55. Coho (O. kisutch) in the Wapato reach ....................................................................... 198

2-56. Fall chinook (O. tshawytscha) in the Wapato reach.......................................................20

2-57. Resident rainbow trout (0. mykiss) in the Wapato reach...............................................202

4-1. Habitat summary page for the Black Rock_2 scenario ..........................................................215

4-2. Temperature summary page for the Black Rock_2 scenario ...................................................216

4-3-4-7. Yearly summaries for the Black Rock_2 scenario:

4-3. Bull trout outmigration, proration, and TWSA tables ...................................................217

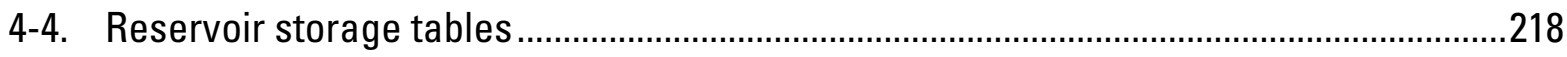

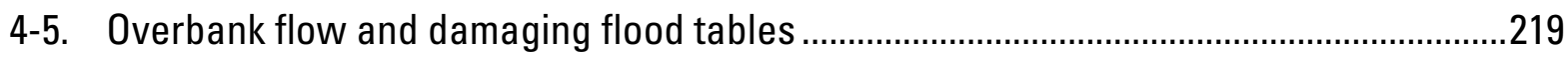

4-6. Fine-sediment transport and geomorphic adjustment tables .........................................220

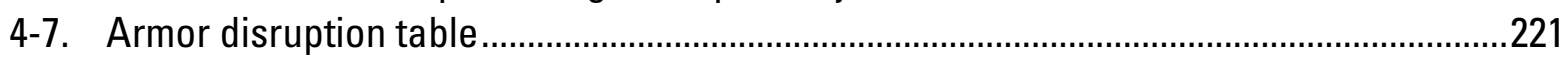

4-8-4-20. Annual habitat summaries for the Black Rock_2 scenario for:

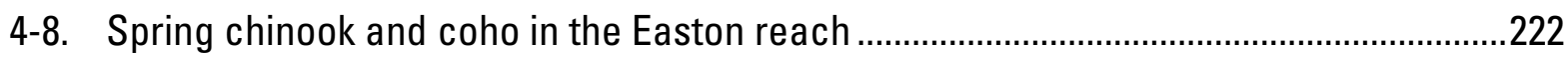

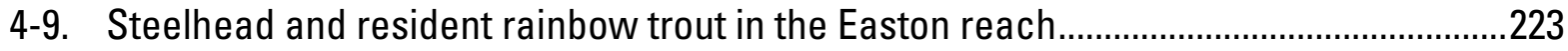

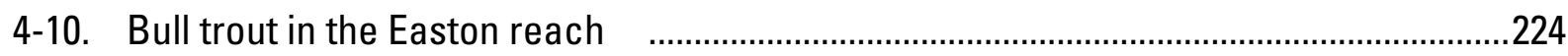

4-11. Spring chinook and coho salmon in the Kittitas reach ................................................225

4-12. Steelhead and resident rainbow trout in the Kittitas reach ............................................226

4-13. Bull trout in the Kittitas reach .................................................................................227

4-14. Spring chinook and coho salmon in the Naches reach..................................................228

4-15. Steelhead and resident rainbow trout in the Naches reach..........................................229

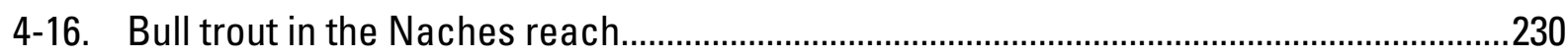

4-17. Fall chinook and coho salmon in the Union Gap reach.................................................231

4-18. Steelhead and resident rainbow trout in the Union Gap reach......................................232

4-19. Fall chinook and coho salmon in the Wapato reach .....................................................233

4-20. Steelhead and resident rainbow trout in the Wapato reach .........................................234

4-21-4-24. Annual temperature summaries for the Black Rock_2 scenario for:

4-21. Fall chinook and coho salmon in the Union Gap reach................................................235

4-22. Steelhead and resident rainbow trout in the Union Gap reach......................................236

4-23. Fall chinook and coho salmon in the Wapato reach .....................................................237

4-24. Steelhead and resident rainbow trout in the Wapato reach ...........................................238

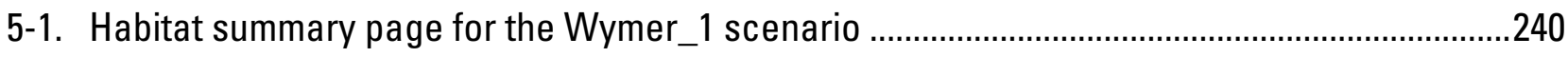

5-2. Temperature summary page for the Wymer_1 scenario .........................................................241

5-3-5-7. Yearly summaries for the Wymer_1 scenario for:

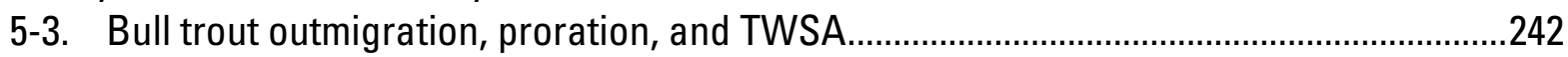

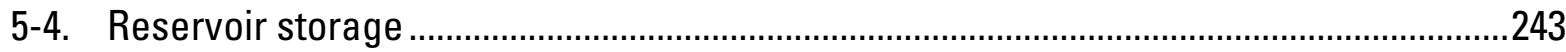

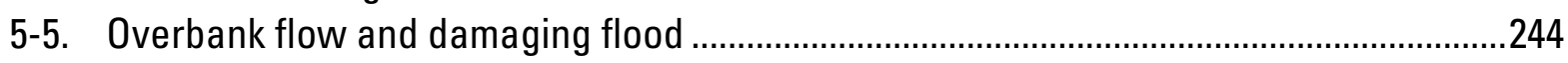

5-6. Fine-sediment transport and geomorphic adjustment ...................................................... 245 


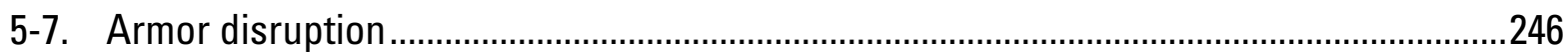

5-8-5-20. Annual habitat summaries for the Wymer_1 scenario for:

5-8. Spring chinook and coho in the Easton reach ............................................................24

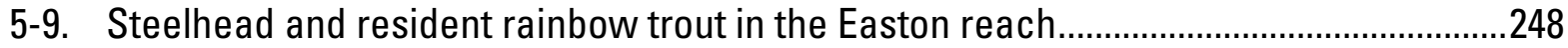

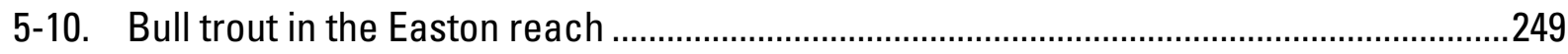

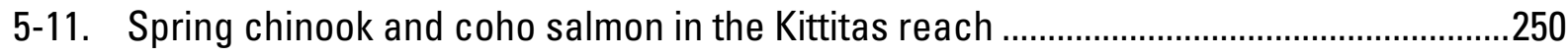

5-12. Steelhead and resident rainbow trout in the Kittitas reach ...........................................251

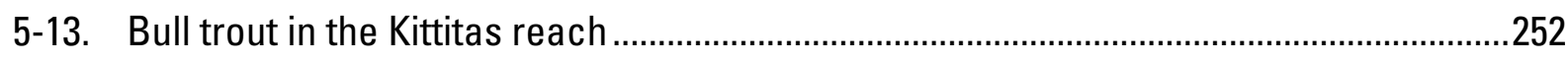

5-14. Spring chinook and coho salmon in the Naches reach................................................253

5-15. Steelhead and resident rainbow trout in the Naches reach..........................................254

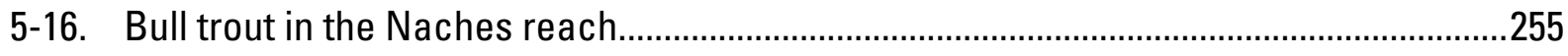

5-17. Fall chinook and coho salmon in the Union Gap reach...............................................256

5-18. Steelhead and resident rainbow trout in the Union Gap reach.....................................257

5-19. Fall chinook and coho salmon in the Wapato reach ....................................................258

5-20. Steelhead and resident rainbow trout in the Wapato reach .........................................259

5-21-5-24. Annual temperature summaries for the Wymer_1 scenario for:

5-21. Fall chinook and coho salmon in the Union Gap reach..................................................260

5-22. Steelhead and resident rainbow trout in the Union Gap reach......................................261

5-23. Fall chinook and coho salmon in the Wapato reach ......................................................262

5-24. Steelhead and resident rainbow trout in the Wapato reach .........................................263

6-1. Habitat summary page for the WymerPlus scenario .....................................................26

6-2. Temperature summary page for the WymerPlus scenario …………………….............266

6-3-6-7: Yearly summaries for the WymerPlus scenario for:

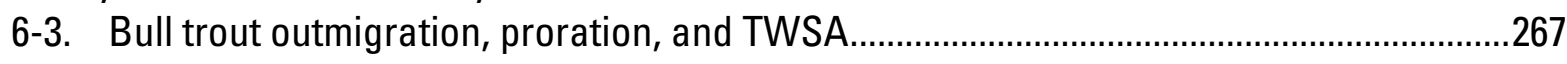

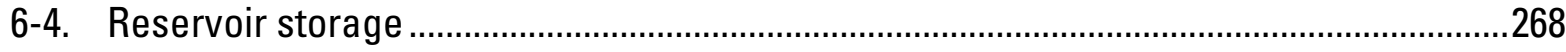

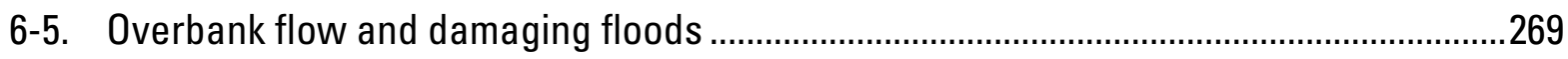

6-6. Fine-sediment transport and geomorphic adjustment ...................................................270

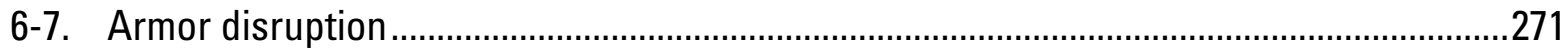

6-8-6-20. Annual habitat summaries for the WymerPlus scenario for:

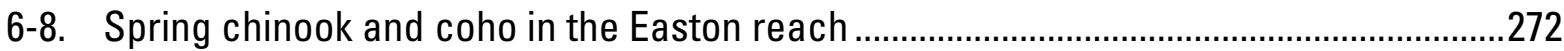

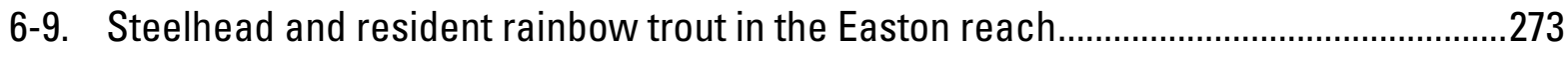

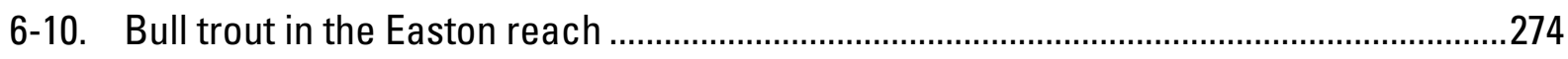

6-11. Spring chinook and coho salmon in the Kittitas reach ...............................................275

6-12. Steelhead and resident rainbow trout in the Kittitas reach ...........................................276

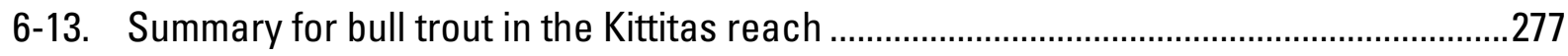

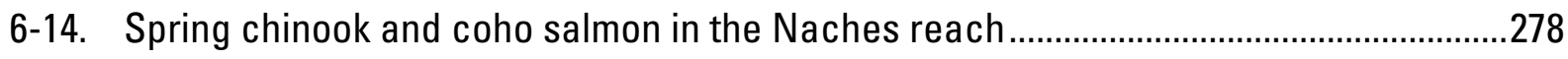

6-15. Steelhead and resident rainbow trout in the Naches reach..........................................279

6-16. Bull trout in the Naches reach....................................................................................28

6-17. Fall chinook and coho salmon in the Union Gap reach...............................................281

6-18. Steelhead and resident rainbow trout in the Union Gap reach.......................................282

6-19. Fall chinook and coho salmon in the Wapato reach .....................................................283

6-20. Steelhead and resident rainbow trout in the Wapato reach ............................................284 
6-21-6-24. Annual temperature summaries for the WymerPlus scenario for:

6-21. Fall chinook and coho salmon in the Union Gap reach................................................285

6-22. Steelhead and resident rainbow trout in the Union Gap reach......................................286

6-23. Fall chinook and coho salmon in the Wapato reach .......................................................287

6-24. Steelhead and resident rainbow trout in the Wapato reach ...........................................28

\section{Tables}

1. Target species and life stages of interest in the five flood plain sites analyzed for the YRDSS.

2. Listing and categorization of state variables incorporated in the YRDSS ................................14

3. Criteria and information sources used for conditional formatting of maximum temperatures $\left(T_{\max }\right)$ on the "TempSummary" page of the DSS_Agg spreadsheet. Cells with grey backgrounds indicate hydroperiods for which no temperature data were available from SNTEMP.

4. Bull trout passage matrix for Keechelus Reservoir, found on the "BTPassLookup" page of the DSS_Agg spreadsheet

5. Threshold discharges for incipient motion from SIAM model, found on the "Parameters" page of the DSS_Agg spreadsheet. $\mathrm{Ft}^{3} / \mathrm{s}=$ cubic feet per second.

6. Low-flow statistics for the Easton reach for the No Action baseline and Black Rock 2, Wymer 1, and Wymer Plus alternatives

7. Low-flow statistics for the Kittitas reach for the No Action baseline and Black Rock 2, Wymer 1, and Wymer Plus alternatives.

8. Low-flow statistics for the Naches reach for the No Action baseline and Black Rock 2, Wymer 1, and Wymer Plus alternatives.

9 Low-flow statistics for the Union Gap reach for the No Action baseline and Black Rock 2, Wymer 1, and Wymer Plus alternatives.

10. Low-flow statistics for the Wapato reach for the No Action baseline and Black Rock 2, Wymer 1, and Wymer Plus alternatives.

1-1. Calibration history for the Union Gap and Wapato hydrodynamic models. 121

1-2. Boundary condition data used for flow simulations in the Union Gap reach 122

1-3. Boundary condition data used for flow simulations in the Wapato reach 123

2-1. Total habitat lookup table for bull trout (S. confluentus) in the Easton reach. $\left[\mathrm{ft}^{3} / \mathrm{s}\right.$, cubic feet per second]

2-2. Total habitat lookup table for coho (0. kisutch) in the Easton reach. [ $\mathrm{ft}^{3} / \mathrm{s}$, cubic feet per second]

2-3. Total habitat lookup table for spring chinook (0. tshawytscha) in the Easton reach. $\left[\mathrm{ft}^{3} / \mathrm{s}\right.$, cubic feet per second].

2-4. Total habitat lookup table for resident rainbow trout (0. mykiss) in the Easton reach. [ $\mathrm{ft}^{3} / \mathrm{s}$, cubic feet per second]

2-5. Total habitat lookup table for steelhead (0. mykiss) in the Easton reach. [ $\mathrm{ft}^{3} / \mathrm{s}$, cubic feet per second]

2-6. Total habitat lookup table for bull trout (S. confluentus) in the Kittitas reach. $\left[\mathrm{ft}^{3} / \mathrm{s}\right.$, cubic feet per second]. 
2-7. Total habitat lookup table for coho (0. kisutch) in the Kittitas reach. [ $\left[\mathrm{ft}^{3} / \mathrm{s}\right.$, cubic feet per second].

2-8. Total habitat lookup table for spring chinook (0. tshawytscha) in the Kittitas reach. $\left[\mathrm{ft}^{3} / \mathrm{s}\right.$, cubic feet per second]

2-9. Total habitat lookup table for resident rainbow trout (0. mykiss) in the Kittitas reach. $\left[\mathrm{ft}^{3} / \mathrm{s}\right.$, cubic feet per second]

2-10. Total habitat lookup table for steelhead (0. mykiss) in the Kittitas reach. [ $\mathrm{ft}^{3} / \mathrm{s}$, cubic feet per second]

2-11. Total habitat lookup table for bull trout ( $S$. confluentus) in the Naches reach. $\left[\mathrm{ft}^{3} / \mathrm{s}\right.$, cubic feet per second]

2-12. Total habitat lookup table for coho (0. kisutch) in the Naches reach. $\left[\mathrm{ft}^{3} / \mathrm{s}\right.$, cubic feet per second]

2-13. Total habitat lookup table for spring chinook (0. tshawytscha) in the Naches reach. [ $\mathrm{ft}^{3} / \mathrm{s}$, cubic feet per second]

2-14. Total habitat lookup table for resident rainbow trout (0. mykiss) in the Naches reach. $\left[\mathrm{ft}^{3} / \mathrm{s}\right.$, cubic feet per second]

2-15. Total habitat lookup table for steelhead (0. mykiss) in the Naches reach. [ $\mathrm{ft}^{3} / \mathrm{s}$, cubic feet per second]

2-16. Total habitat lookup table for coho (0. kisutch) in the Union Gap reach. $\left[\mathrm{ft}^{3} / \mathrm{s}\right.$, cubic feet per second].

2-17. Total habitat lookup table for fall chinook (0. tshawytscha) in the Union Gap reach. $\left[\mathrm{ft}^{3} / \mathrm{s}\right.$, cubic feet per second]

2-18. Total habitat lookup table for overwintering spring chinook ( 0 . tshawytscha) subyearlings in the Union Gap reach. [ $\mathrm{ft}^{3} / \mathrm{s}$, cubic feet per second]....

2-19. Total habitat lookup table for resident rainbow trout (0. mykiss) in the Union Gap reach. $\left[\mathrm{ft}^{3} / \mathrm{s}\right.$, cubic feet per second].

2-20. Total habitat lookup table for overwintering steelhead (0. mykiss) subyearlings in the Union Gap reach. [ $\mathrm{ft}^{3} / \mathrm{s}$, cubic feet per second]

2-21. Total habitat lookup table for coho (0. kisutch) in the Wapato reach. [ $\mathrm{ft}^{3} / \mathrm{s}$, cubic feet per second]

2-22. Total habitat lookup table for fall chinook (0. tshawytscha) in the Wapato reach. $\left[\mathrm{ft}^{3} / \mathrm{s}\right.$, cubic feet per second]

2-23. Total habitat lookup table for overwintering spring chinook ( 0 . tshawytscha) subyearlings in the Wapato reach. [ $\mathrm{ft}^{3} / \mathrm{s}$, cubic feet per second].

2-24 Total habitat lookup table for resident rainbow trout (0. mykiss) in the Wapato reach. [ $\mathrm{ft}^{3} / \mathrm{s}$, cubic feet per second]

2-25. Total habitat lookup table for overwintering steelhead (0. mykiss) subyearlings in the Wapato reach. [ $\mathrm{ft}^{3} / \mathrm{s}$, cubic feet per second].

2-26. Spawning-incubation persistence table for bull trout ( $S$. confluentus) in the Easton reach

2-27. Spawning-incubation persistence table for coho (0. kisutch) in the Easton reach 165

2-28. Spawning-incubation persistence table for spring chinook (0. tshawytscha) in the Easton reach 
2-29. Spawning-incubation persistence table for resident rainbow trout (0. mykiss) in the Easton reach. .169

2-30. Spawning-incubation persistence table for steelhead (0. mykiss) in the Easton reach ........171

2-31. Spawning-incubation persistence table for bull trout ( $S$. confluentus) in the Kittitas reach

2-32. Spawning-incubation persistence table for coho (O. kisutch) in the Kittitas reach 175

2-33. Spawning-incubation persistence table for spring chinook (0. tshawytscha) in the Kittitas reach

2-34. Spawning-incubation persistence table for resident rainbow trout ( 0. mykiss) in the Kittitas reach

2-35. Spawning-incubation persistence table for steelhead (0. mykiss) in the Kittitas reach .......181

2-36. Spawning-incubation persistence table for bull trout (S. confluentus) in the Naches reach

2-37. Spawning-incubation persistence table for coho (O. kisutch) in the Naches reach 185

2-38. Spawning-incubation persistence table for spring chinook (0. tshawytscha) in the Naches reach

2-39. Spawning-incubation persistence table for resident rainbow trout (0. mykiss) in the Naches reach. 189

2-40. Spawning-incubation persistence table for steelhead (0. mykiss) in the Naches reach......191

2-41. Spawning-incubation persistence table for coho (O. kisutch) in the Union Gap reach.........193

2-42. Spawning-incubation persistence table for fall chinook (0. tshawytscha) in the Union Gap reach.

2-43. Spawning-incubation persistence table for resident rainbow trout (0. mykiss) in the Union Gap reach

2-44. Spawning-incubation persistence table for coho (O. kisutch) in the Wapato reach. 199

2-45. Spawning-incubation persistence table for fall chinook (0. tshawytscha) in the Wapato reach

2-46. Spawning-incubation persistence table for resident rainbow trout (0. mykiss) in the Wapato reach.

3-1. Potential fine-sediment transport rates, in megatons per day, as functions of discharge and simulated alternative from the SIAM model, for the Easton and Kittitas reaches. [ft3/s, cubic feet per second]

3-2. Potential fine-sediment transport rates, in megatons per day, as functions of discharge and simulated alternative from the SIAM model, for the Naches reach. [ft3/s, cubic feet per second]

3-3. Potential fine-sediment transport rates, in megatons per day, as functions of discharge and simulated alternative from the SIAM model, for the Union Gap and Wapato reaches. [ft3/s, cubic feet per second].

3-4. Geomorphic work, in foot-megatons per day, as functions of discharge and simulated alternative from the SIAM model, for the Easton and Kittitas reaches. [ $\mathrm{ft} 3 / \mathrm{s}$, cubic feet per second]

3-5. Geomorphic work, in foot-megatons per day, as functions of discharge and simulated alternative from the SIAM model, for the Naches reach. [ft3/s, cubic feet per second].......209 
3-6. Geomorphic work, in foot-megatons per day, as functions of discharge and simulated alternative from the SIAM model, for the Union Gap and Wapato reaches. [ft3/s, cubic feet per second]

3-7. Depth of redd scour, in feet, as functions of discharge and simulated alternative from the SIAM model, for the Easton and Kittitas reaches. [ft3/s, cubic feet per second].

3-8. Depth of redd scour, in feet, as functions of discharge and simulated alternative from the SIAM model, for the Naches reach. [ft $3 / \mathrm{s}$, cubic feet per second].

3-9. Depth of redd scour, in feet, as functions of discharge and simulated alternative from the SIAM model, for the Union Gap and Wapato reaches. [ft3/s, cubic feet per second] ....213 


\section{Conversion Factors}

\section{Inch/Pound to SI}

\begin{tabular}{|c|c|c|}
\hline Multiply & By & To obtain \\
\hline \multicolumn{3}{|l|}{ Length } \\
\hline foot $(\mathrm{ft})$ & 0.3048 & meter $(\mathrm{m})$ \\
\hline mile (mi) & 1.609 & kilometer $(\mathrm{km})$ \\
\hline \multicolumn{3}{|l|}{ Area } \\
\hline acre & 4,047 & square meter $\left(\mathrm{m}^{2}\right)$ \\
\hline acre & 0.4047 & hectare (ha) \\
\hline square foot $\left(\mathrm{ft}^{2}\right)$ & 0.09290 & square meter $\left(\mathrm{m}^{2}\right)$ \\
\hline square mile $\left(\mathrm{mi}^{2}\right)$ & 259.0 & hectare (ha) \\
\hline \multicolumn{3}{|l|}{ Volume } \\
\hline cubic foot $\left(\mathrm{ft}^{3}\right)$ & 0.02832 & cubic meter $\left(\mathrm{m}^{3}\right)$ \\
\hline acre-foot (acre-ft) & 1,233 & cubic meter $\left(\mathrm{m}^{3}\right)$ \\
\hline \multicolumn{3}{|l|}{ Flow rate } \\
\hline acre-foot per day (acre-ft/d) & 0.01427 & cubic meter per second $\left(\mathrm{m}^{3} / \mathrm{s}\right)$ \\
\hline foot per second (ft/s) & 0.3048 & meter per second $(\mathrm{m} / \mathrm{s})$ \\
\hline cubic foot per second $\left(\mathrm{ft}^{3} / \mathrm{s}\right)$ & 0.02832 & cubic meter per second $\left(\mathrm{m}^{3} / \mathrm{s}\right)$ \\
\hline $\begin{array}{l}\text { cubic foot per second per square } \\
\text { mile }\left[\left(\mathrm{ft}^{3} / \mathrm{s}\right) / \mathrm{mi}^{2}\right]\end{array}$ & 0.01093 & $\begin{array}{l}\text { cubic meter per second per } \\
\text { square kilometer }\left[\left(\mathrm{m}^{3} / \mathrm{s}\right) / \mathrm{km}^{2}\right]\end{array}$ \\
\hline $\begin{array}{l}\text { million gallons per day } \\
(\mathrm{Mgal} / \mathrm{d})\end{array}$ & 0.04381 & cubic meter per second $\left(\mathrm{m}^{3} / \mathrm{s}\right)$ \\
\hline
\end{tabular}




\section{SI to Inch/Pound}

\begin{tabular}{|c|c|c|}
\hline Multiply & By & To obtain \\
\hline \multicolumn{3}{|l|}{ Length } \\
\hline meter $(\mathrm{m})$ & 3.281 & foot $(\mathrm{ft})$ \\
\hline kilometer $(\mathrm{km})$ & 0.6214 & mile (mi) \\
\hline \multicolumn{3}{|l|}{ Area } \\
\hline square meter $\left(\mathrm{m}^{2}\right)$ & 0.0002471 & acre \\
\hline hectare (ha) & 2.471 & acre \\
\hline square meter $\left(\mathrm{m}^{2}\right)$ & 10.76 & square foot $\left(\mathrm{ft}^{2}\right)$ \\
\hline hectare (ha) & 0.003861 & square mile $\left(\mathrm{mi}^{2}\right)$ \\
\hline \multicolumn{3}{|l|}{ Volume } \\
\hline cubic meter $\left(\mathrm{m}^{3}\right)$ & 35.31 & cubic foot $\left(\mathrm{ft}^{3}\right)$ \\
\hline cubic meter $\left(\mathrm{m}^{3}\right)$ & 0.0008107 & acre-foot (acre-ft) \\
\hline \multicolumn{3}{|l|}{ Flow rate } \\
\hline cubic meter per second $\left(\mathrm{m}^{3} / \mathrm{s}\right)$ & 70.07 & acre-foot per day (acre-ft/d) \\
\hline meter per second $(\mathrm{m} / \mathrm{s})$ & 3.281 & foot per second (ft/s) \\
\hline cubic meter per second $\left(\mathrm{m}^{3} / \mathrm{s}\right)$ & 35.31 & cubic foot per second $\left(\mathrm{ft}^{3} / \mathrm{s}\right)$ \\
\hline $\begin{array}{l}\text { cubic meter per second per } \\
\text { square kilometer }\left[\left(\mathrm{m}^{3} / \mathrm{s}\right) / \mathrm{km}^{2}\right]\end{array}$ & 91.49 & $\begin{array}{l}\text { cubic foot per second per square } \\
\text { mile }\left[\left(\mathrm{ft}^{3} / \mathrm{s}\right) / \mathrm{mi}^{2}\right]\end{array}$ \\
\hline cubic meter per second $\left(\mathrm{m}^{3} / \mathrm{s}\right)$ & 22.83 & million gallons per day (Mgal/d) \\
\hline
\end{tabular}

Temperature in degrees Celsius $\left({ }^{\circ} \mathrm{C}\right)$ may be converted to degrees Fahrenheit $\left({ }^{\circ} \mathrm{F}\right)$ as follows:

${ }^{\circ} \mathrm{F}=\left(1.8 x^{\circ} \mathrm{C}\right)+32$

Temperature in degrees Fahrenheit $\left({ }^{\circ} \mathrm{F}\right)$ may be converted to degrees Celsius $\left({ }^{\circ} \mathrm{C}\right)$ as follows:

${ }^{\circ} \mathrm{C}=\left({ }^{\circ} \mathrm{F}-32\right) / 1.8$

Vertical coordinate information is referenced to the "North American Vertical Datum of 1988 (NAVD 88)"

Horizontal coordinate information is referenced to the North American Datum of 1983 (NAD83)"

Elevation, as used in this report, refers to distance relative to the vertical datum.

NOTE TO U.S. Geological Survey USERS: Use of hectare (ha) as an alternative name for square hectometer $\left(\mathrm{hm}^{2}\right)$ is restricted to the measurement of small land or water areas. 



\title{
Development and Application of a Decision Support System for Water Management Investigations in the Upper Yakima River, Washington
}

\author{
By Ken D. Bovee, ${ }^{1}$ Terry J. Waddle, ${ }^{1}$ Colin Talbert, ${ }^{2}$ James R. Hatten, ${ }^{3}$ and Thomas R. Batt ${ }^{3}$
}

\begin{abstract}
The Yakima River Decision Support System (YRDSS) was designed to quantify and display the consequences of different water management scenarios for a variety of state variables in the upper Yakima River Basin, located in central Washington. The impetus for the YRDSS was the Yakima River Basin Water Storage Feasibility Study, which investigated alternatives for providing additional water in the basin for threatened and endangered fish, irrigated agriculture, and municipal water supply. The additional water supplies would be provided by combinations of water exchanges, pumping stations, and off-channel storage facilities, each of which could affect the operations of the Bureau of Reclamation's (BOR) five headwaters reservoirs in the basin. The driver for the YRDSS is RiverWare, a systems-operations model used by BOR to calculate reservoir storage, irrigation deliveries, and streamflow at downstream locations resulting from changes in water supply and reservoir operations. The YRDSS uses output from RiverWare to calculate and summarize changes at 5 important flood plain reaches in the basin to 14 state variables: (1) habitat availability for selected life stages of four salmonid species, (2) spawning-incubation habitat persistence, (3) potential redd scour, (4) maximum water temperatures, (5) outmigration for bull trout (Salvelinus confluentus) from headwaters reservoirs, (6) outmigration of salmon smolts from Cle Elum Reservoir, (7) frequency of beneficial overbank flooding, (8) frequency of damaging flood events, (9) total deliverable water supply, (10) total water supply deliverable to junior water rights holders, (11) end-of-year reservoir carryover, (12) potential fine sediment transport rates, (13) frequency of events capable of armor layer disruption, and (14) geomorphic work performed during each water year. Output of the YRDSS consists of a series of conditionally formatted scoring tables, wherein the changes to a state variable resulting from an operational scenario are compiled and summarized. Increases in the values for state variables result in their respective backgrounds to turn green in the scoring matrix, whereas decreases in the values for state variables result in their respective backgrounds turning red. This convention was designed to provide decision makers with a quick visual assessment of the overall results of an operating scenario. An evaluation matrix and a variety of weighting strategies to reflect the relative importance of different state variables are also presented as options for further distillation of YRDSS results during the decision-making process.
\end{abstract}

\footnotetext{
${ }^{1}$ U.S. Geological Survey, Fort Collins Science Center, 2150 Centre Avenue, Building C, Fort Collins, Colo., 80526.

${ }^{2}$ ASRC Management Services, Inc., 2150 Centre Avenue, Building C, Fort Collins, Colo., 80526.

${ }^{3}$ U.S. Geological Survey, Columbia River Research Laboratory, 5501 Cook-Underwood Road, Cook, Wash., 98605.
} 


\section{Introduction}

The Yakima River is a 5th-order stream located in south-central Washington, draining an area of approximately $6,120 \mathrm{mi}^{2}(1,585,080 \mathrm{ha})$. Its source lies in the Cascade Mountains, and it flows southeasterly to its confluence with the Columbia River, near the city of Richland, Washington. The Yakima Project, operated by the Bureau of Reclamation (BOR), includes five major storage facilities: Keechelus and Kachess Reservoirs in the headwaters of the Yakima River, Cle Elum Reservoir on the Cle Elum River, Bumping Lake on the Bumping River, and Rimrock Reservoir on the Tieton River (fig. 1). In addition, the Yakima Project serves six major irrigation divisions with a combined area of approximately 464,000 acres: Kittitas, Tieton, Sunnyside, Roza, Kennewick, and Wapato. Other project features include five diversion dams, canals, laterals, pumping plants, drains, two powerplants, and transmission lines. The Wapato Division is operated by the Bureau of Indian Affairs but receives most of its water supply from the Yakima Project for irrigation of 136,000 acres of land. Over 45,000 acres not included in the divisions are irrigated by private interests under water supply contracts with BOR (Bureau of Reclamation, 1976).

The Yakima Basin historically sustained diverse and abundant salmon and steelhead runs. Since 1900, however, anadromous fish runs have declined or have been extirpated. Although numerous external mechanisms such as overfishing, impediments to migration, and introduced species may be involved in the deterioration of anadromous fish stocks, in-basin changes in the characteristics and dynamics of the riverine habitat have been identified as primary causes of population declines.

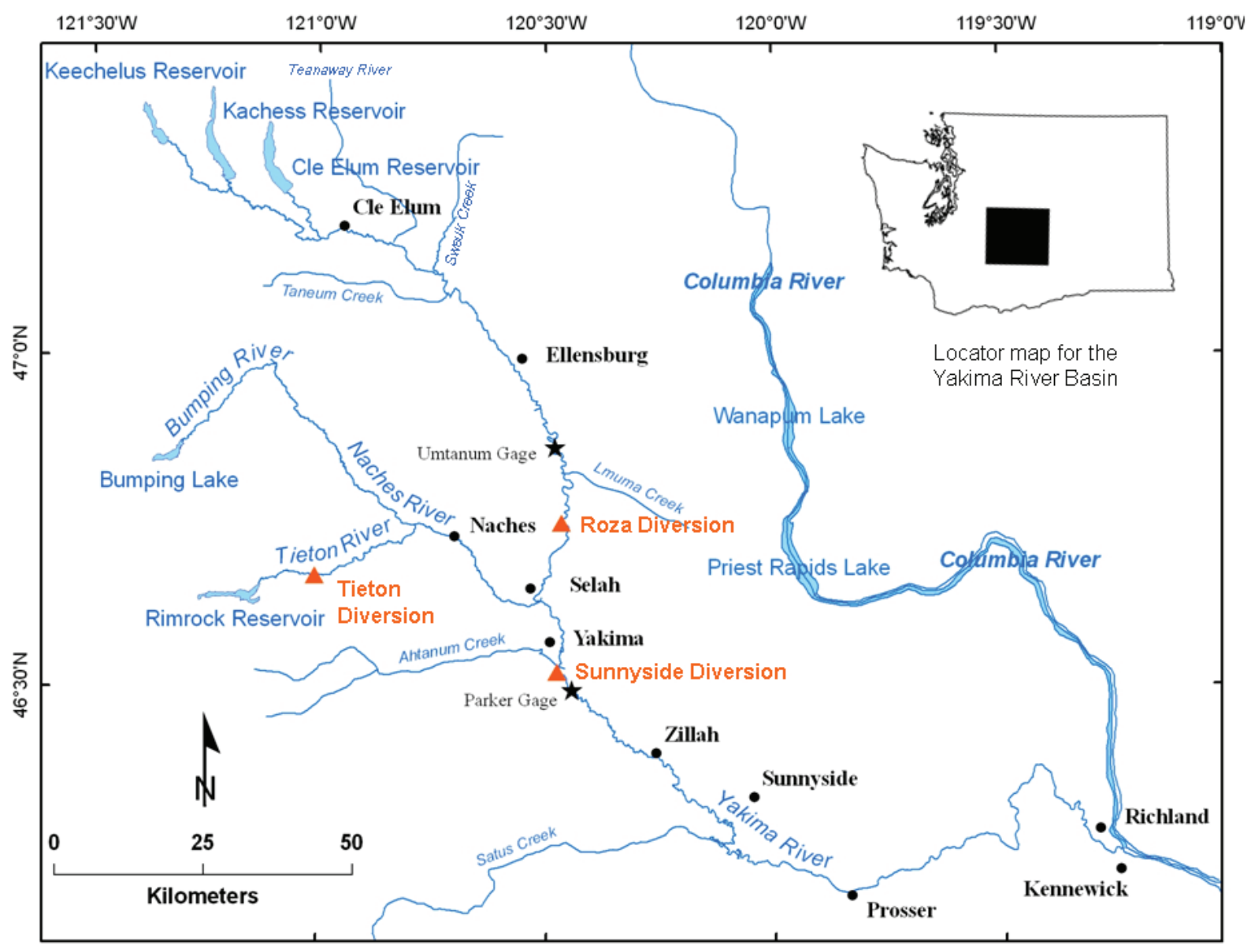

Figure 1. Map of the upper Yakima River Basin showing locations of Yakima Project reservoirs and diversions. 
The BOR Yakima River Basin Water Enhancement Project (YRBWEP) was assigned the task of improving flow and habitat for the basin's remaining anadromous fisheries. In a related, but separate effort the Systems Operation Advisory Committee (SOAC) recommended a process to determine target flows for the Yakima River. The flows were intended to enhance and restore habitat for anadromous salmonids. In 2001, a synthesis report was prepared for BOR by the Flathead Lake Biological Station, University of Montana (Snyder and Stanford, 2001). The objectives of the synthesis were to compile and analyze existing information for the Yakima River system in the context of contemporary stream ecological theory, identify factors likely to be limiting to salmonid production, determine river reaches critical for salmonid production, and identify data gaps from the literature (Snyder and Stanford, 2001).

An inescapable conclusion of the Snyder and Stanford report was that flow regulation in the Yakima River has resulted in spatial and temporal disconnection of habitats necessary for anadromous salmonids. A paramount issue on the spatial scale was the loss of connectivity between the main channel and the flood plain. From the temporal perspective, the flow regime of the Yakima River has been altered such that floods are not as large or frequent as they were historically and base flows have been augmented. Because of reservoir storage, the frequency, magnitude, and duration of flood plain inundation has been reduced, which in turn has affected the availability of high-quality habitat for young fish. The authors also present compelling evidence that lack of flood plain inundation by cold snowmelt runoff has resulted in temperature elevation in the main channel later in the year. At the other end of the hydrologic spectrum, most irrigation water is supplied to the lower basin during late summer and early fall, when the river would naturally be approaching base flow.

As an overarching concept, Snyder and Stanford (2001) present concepts of a "normative" condition that allows the reestablishment of natural functions, such as reconnecting channels with their flood plains when they would naturally be connected. The purpose of a normative condition is not restoration of a pristine, predevelopment flow regime or channel configuration. Rather, the goal was to restore key ecosystem functions and dynamics that have been lost or displaced temporally (functions and dynamics have been shifted in time). In the larger sense, this means approaching a more naturalized flow regime by modification of water allocations and reservoir operations.

Following the completion of the two studies conducted by Snyder and Stanford (2001) and Stanford and others (2002), BOR adopted two strategies to examine management options for habitat restoration. Both involved the coupling of a reservoir operations and flow-routing model, RiverWare, with habitat response models. The first strategy was initiated by the Yakama Nation and Mobrand Biometrics to develop an Ecosystem Diagnostic and Treatment Model (EDT). Development of this model actually predated the Stanford studies and was to be used to determine feasibility and effectiveness of various management alternatives. One key piece of information required for the EDT model was wetted area as a function of discharge in a variety of habitat units, such as riffles, pools, and side channels.

The second strategy and subject of this report was the development of a prototype decision support system for the Yakima River Basin (YRDSS). Development of the YRDSS evolved as a result of a Congressional act (Section 214 of the Act of February 20, 2003, PL 108-7) that directed the Secretary of the Interior, acting through BOR, to conduct a feasibility study of additional water-storage alternatives for the basin. The YRDSS was intended to supplement EDT by providing more detailed and comprehensive information at key locations in a format designed for quick and easy comparisons of the effects of different water-management strategies. Fundamental differences between the YRDSS and the EDT model are that: the YRDSS quantifies the effects of altered flow regimes on specific habitat types for important target species; effects on daily temperatures during important biological time periods are displayed; and other information relevant to evaluating the effects of management alternatives, such as end-of-year storage, water availability, irrigation deliveries, sediment transport, and reservoir 
outmigration, are compiled and integrated from a variety of physical process models that have been applied to the river system.

\section{Objectives}

The goal of this project was to develop an integrated water management/habitat response tool that would allow BOR to quantify the feasibility, effectiveness, and risks associated with various water management alternatives. Potential scenarios might include reregulation of reservoir releases under current water supplies and demand scenarios, potential increases in water availability of 500-800 thousand acre-feet through exchange of water from the Columbia River, construction of additional storage facilities within the Yakima River Basin, or combinations thereof. This study would meet two primary objectives necessary to achieve this goal:

1. Development of habitat response models capable of quantifying habitat area for selected life stages and target species in response to altered flow regimes.

2. Development of a prototype decision support system, compatible with RiverWare, that can be used to quantify and display the consequences of different management scenarios for a variety of relevant state variables.

\section{Study Areas}

Snyder and Stanford (2001) identified eight major flood plain units in the Yakima system having high potential for creating and maintaining shallow-water habitats. The potential for restoration in these reaches was judged on several factors, including level of human development, size, location, current condition, and feasibility of reconnection by alternative water management, water augmentation, and removal of revetments. Of these, five reaches were considered to be critical for productivity of juvenile salmon and steelhead and were selected for examination in this study (fig. 2). Brief descriptions of all eight flood plain units and rationale for their inclusion or omission from this study follow.

1. Upper Yakima-Teanaway. According to the descriptions provided by Snyder and Stanford (2001), this complex flood plain actually contains two separate units, Easton and Cle Elum. The entire flood plain complex extends from Easton Dam to a location approximately midway between the Teanaway River and Swauk Creek, a total valley distance of approximately $35 \mathrm{~km}$. In 1999, the extent of the active flood plain at Easton had an estimated area of 1,046 ha, and at Cle Elum the flood plain size was 717 ha. Both flood plain units were approximately 40 percent intact compared to pristine conditions. The Easton reach has the most returns of spring chinook spawners in the Yakima system (Snyder and Sanford, 2001). For this reason, we chose the Easton reach for inclusion as a study site to represent this flood plain unit (fig. 3). The total river length within the upper Yakima-Teanaway flood plain reach is slightly over $53 \mathrm{~km}$, of which $16.4 \mathrm{~km}$ (about 31 percent) is represented by the Easton study site. The lower end of the Easton flood plain unit has been confined by the Interstate highway and numerous gravel pits and is the only study site containing a large portion of single-thread channel.

2. Kittitas Valley. This large flood plain unit extends from Taneum Creek (fig. 2) to the upstream end of Yakima Canyon, a valley distance of approximately $24 \mathrm{~km}$. The active flood plain at Kittitas in 1999 was estimated to be 31.5 percent intact compared to pristine conditions, having an area of 1,708 ha (Snyder and Stanford, 2001). The upstream end of the Kittitas study site (fig. 4) is approximately 24 river $\mathrm{km}$ downstream from Taneum Creek and occupies a total length of slightly over $7 \mathrm{~km}$ (22.1 percent) of the total channel length in this flood plain unit. 


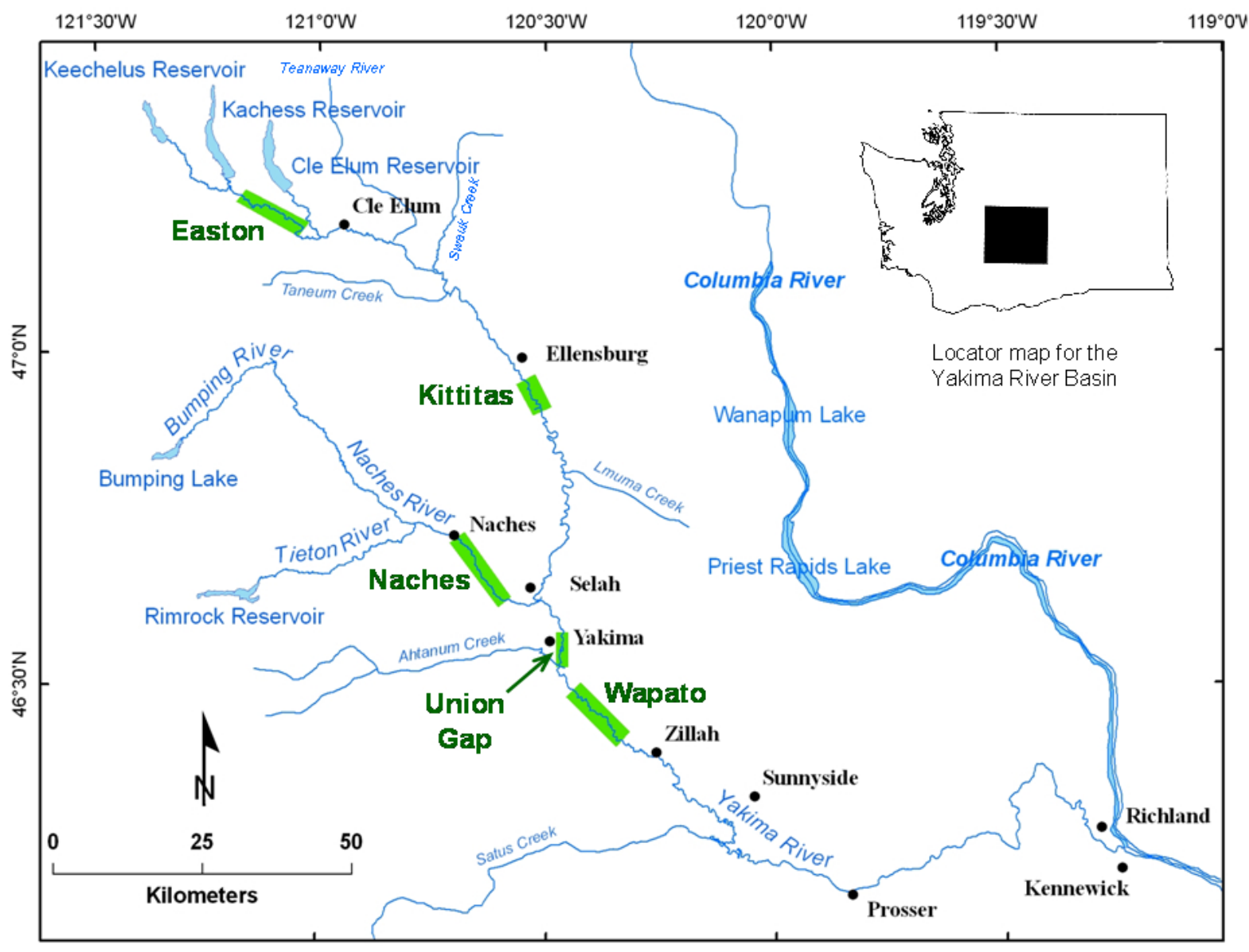

Figure 2. Map of the upper Yakima River Basin showing locations of study sites. 


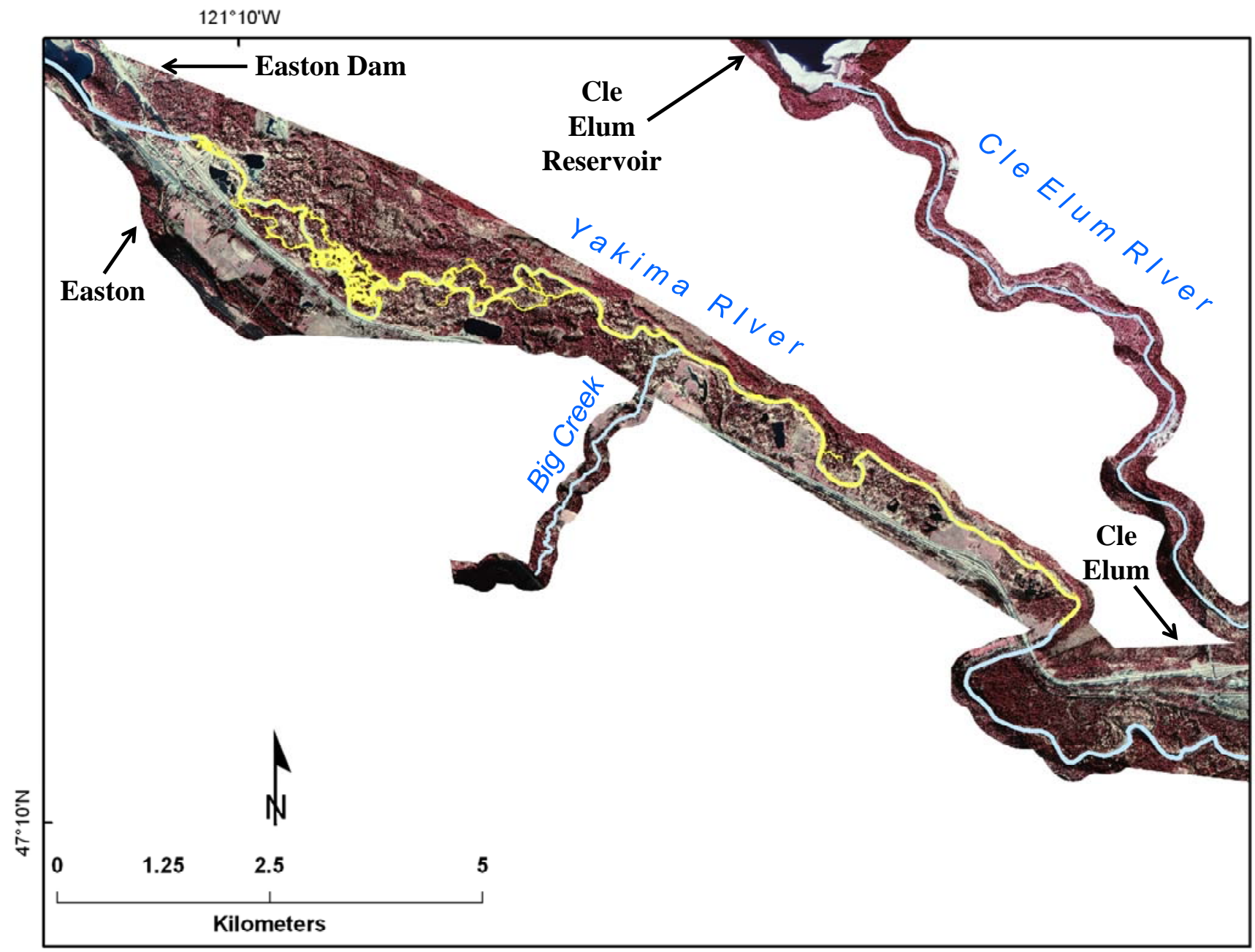

Figure 3. Aerial photograph of a portion of the upper Yakima-Teanaway flood plain showing the extent of the Easton site.

3. Selah. The Selah flood plain reach begins at the lower end of Yakima Canyon, approximately 8 $\mathrm{km}$ downstream from Roza Dam, and ends at Selah gap, about $1 \mathrm{~km}$ upstream from the confluence of the Naches River (fig. 1). The area of this flood plain unit was estimated to be 389 ha in 1999 and has been substantially modified by gravel mining (Snyder and Stanford, 2001). Owing to its small size and relatively low rehabilitation potential, no study site was established in this flood plain unit. 


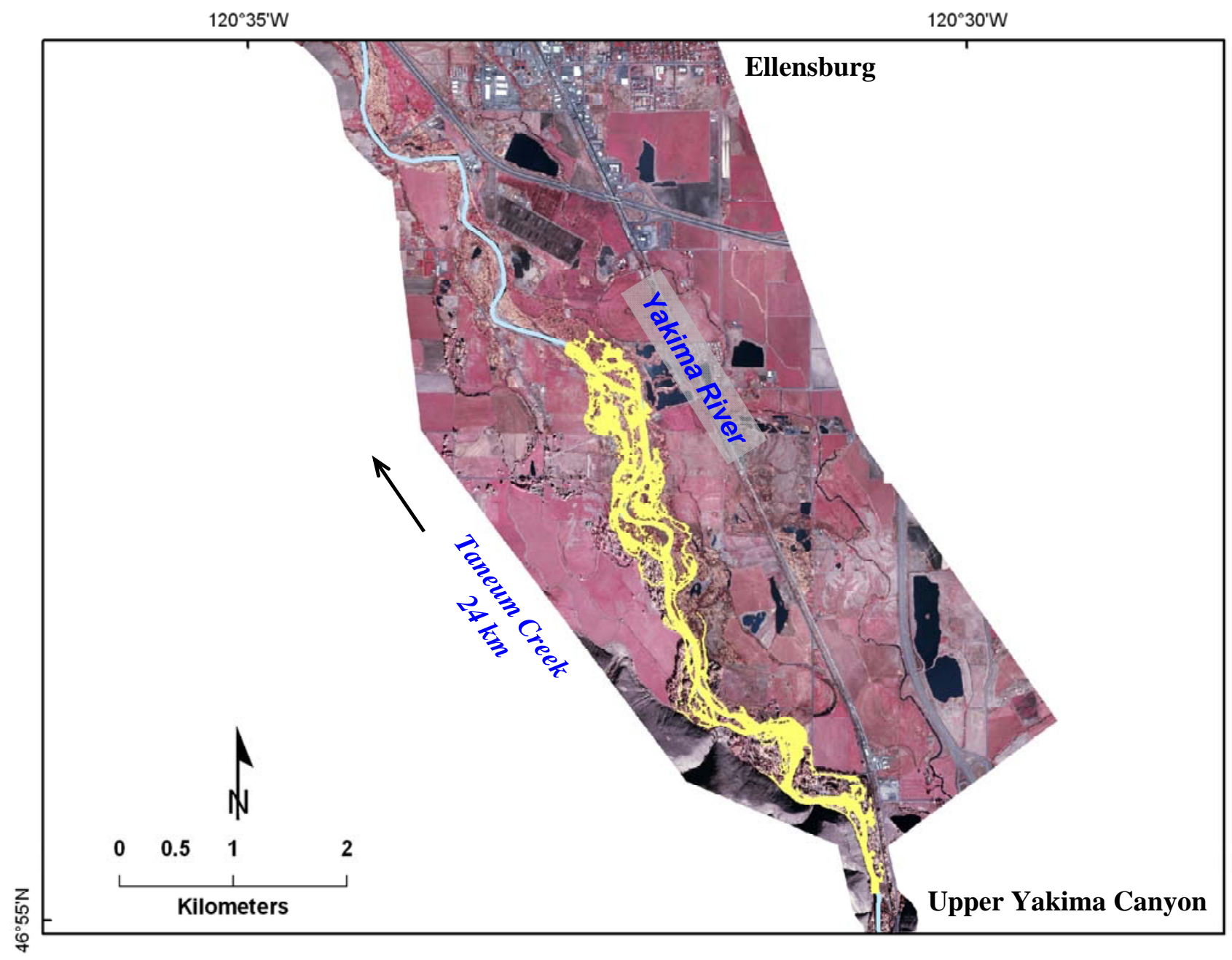

Figure 4. Aerial photograph of a portion of the Kittitas valley flood plain showing the extent of the Kittitas site.

4. Upper and Lower Naches. Similar in many respects to the Yakima-Teanaway unit, the Naches is divided into two distinct flood plain units. The upper Naches unit occupies a 6-km valley length, centered at the confluence of Rattlesnake Creek. The lower unit is far more extensive, occupying the valley for approximately $27 \mathrm{~km}$ between the Tieton River confluence and the terminus of the Naches River at Yakima. The lower Naches flood plain reach was described as being reasonably intact (Snyder and Stanford, 2001). Historical flood plain information provided by the authors, however, suggested that this flood plain had retained a greater proportion of its pre-1884 area (42.6 percent) than any of the others. The Naches study site (fig. 5) is in a $15.5-\mathrm{km}$ reach (river distance) starting approximately $7.8 \mathrm{~km}$ downstream from the Tieton River confluence. The study site occupies slightly more than 52 percent of the total river length in the lower Naches flood plain unit. 


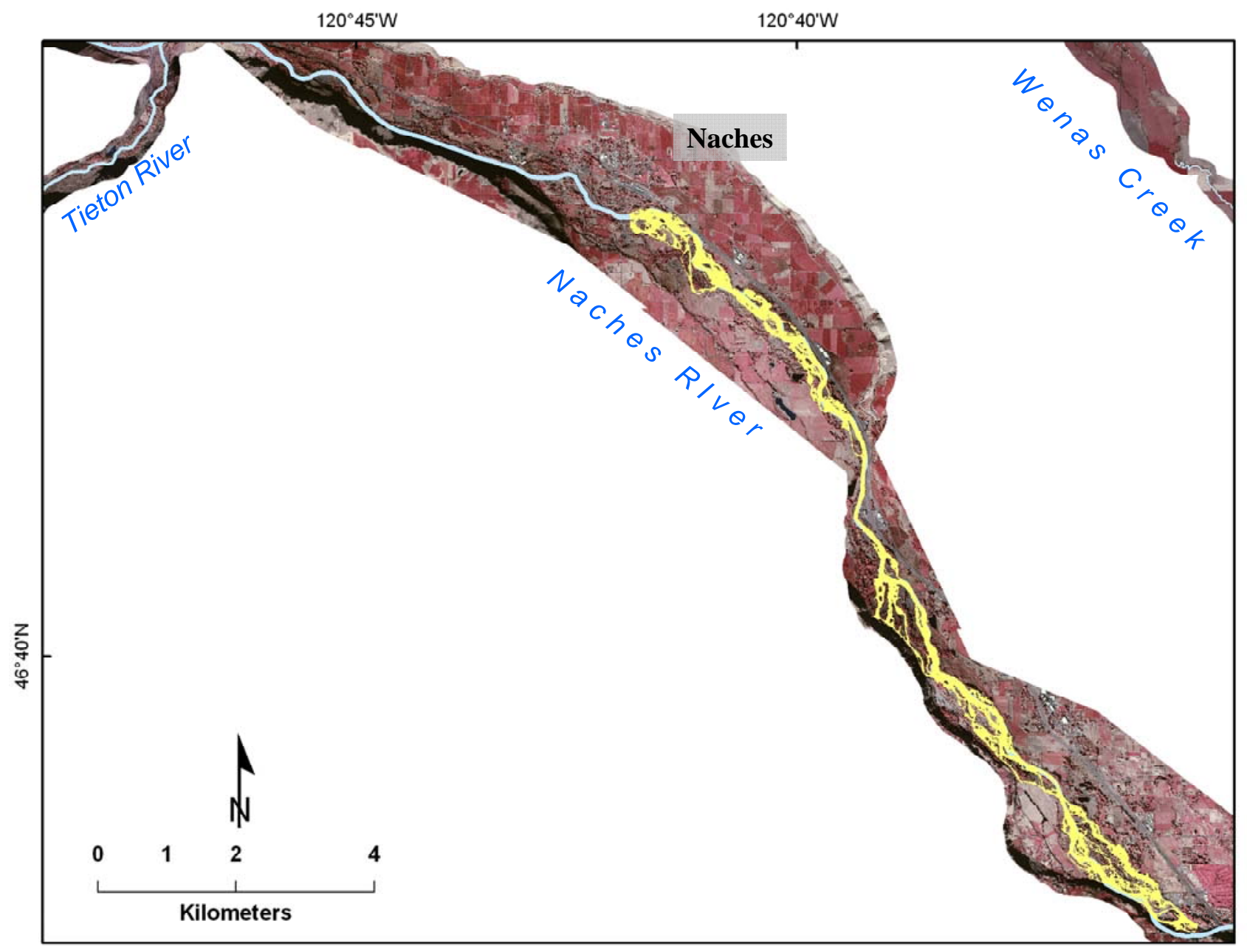

Figure 5. Aerial photograph of a portion of the lower Naches flood plain showing the extent of the Naches site.

5. Union Gap. This large flood plain is located between the Naches-Yakima confluence and Union Gap, a channel constriction approximately 14 river km downstream. Despite extensive urban encroachment and revetment, there are numerous secondary channels in this reach that remain interconnected at relatively low discharges. Snyder and Stanford (2001) determined the area of this flood plain unit to be 1,592 ha or 39.6 percent intact compared to pristine conditions. The study site for this flood plain unit extends upstream from Union Gap a total of $6.2 \mathrm{~km}$ or slightly more than 43 percent of the main channel length through the reach (fig. 6). 


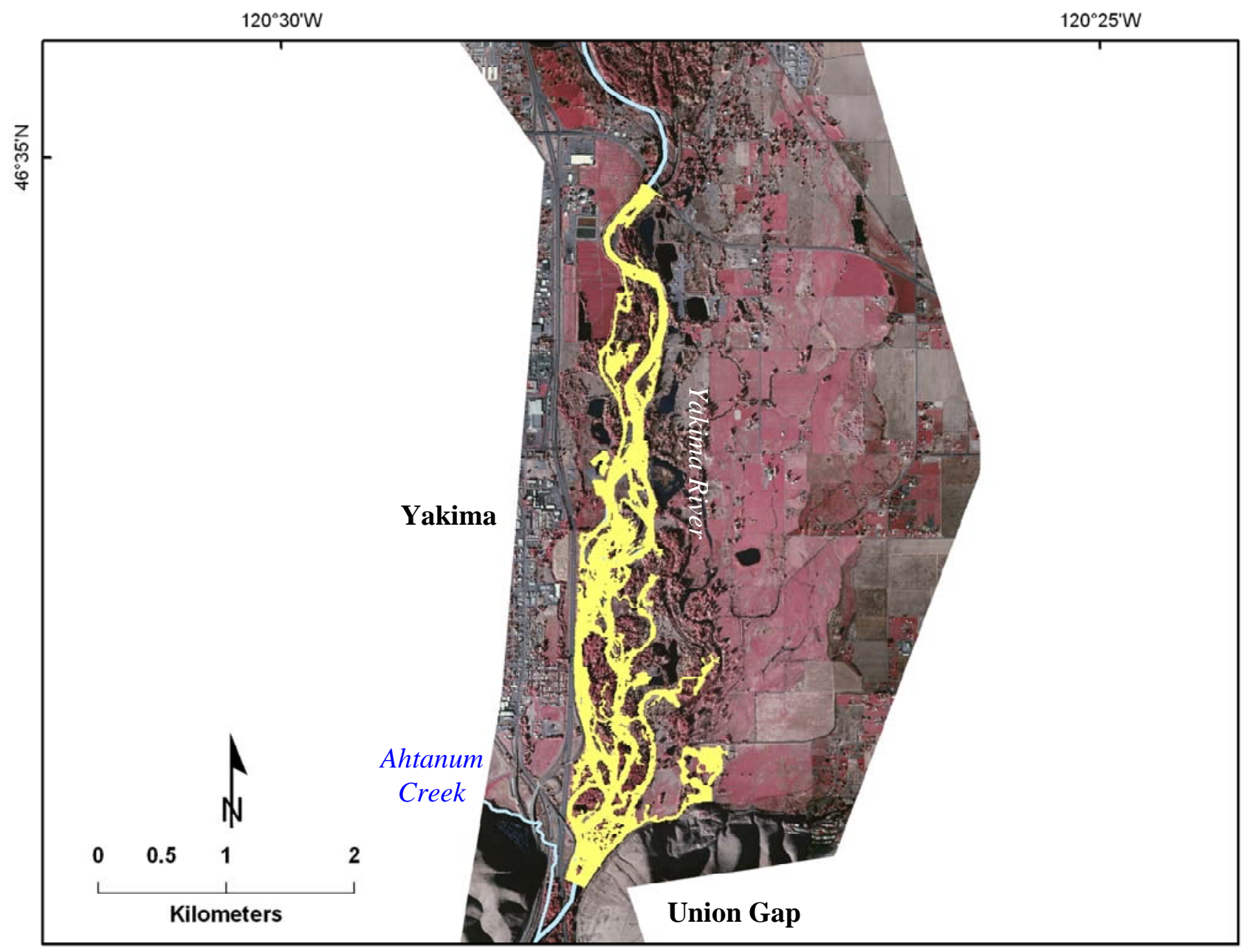

Figure 6. Aerial photograph of a portion of the Union Gap flood plain showing the extent of the Union Gap site.

6. Wapato. The total valley length of the Wapato flood plain unit is approximately $35 \mathrm{~km}$, extending from Union Gap to the confluence of Satus Creek, near Sunnyside, Washington (fig. 2). At 3,969 ha (1999 measurement), the Wapato flood plain is the largest of the flood plains in the Yakima basin (Snyder and Stanford, 2001). The flood plain was described by Stanford and others (2002) as being the most complex and physically intact of all the Yakima flood plain units. It is undeniably complex, but information provided by Snyder and Stanford (2001) suggests that the Wapato flood plain was much larger (26,869 ha) prior to 1884 . Stanford and others (2002) concluded that the Wapato reach had significant restoration potential, primarily because there was very little encroachment or development in this area. The Wapato study site (fig. 7) occupies nearly $16 \mathrm{~km}$ of the total $63.6 \mathrm{~km}$ (25.1 percent) of main channel contained within this flood plain unit. 


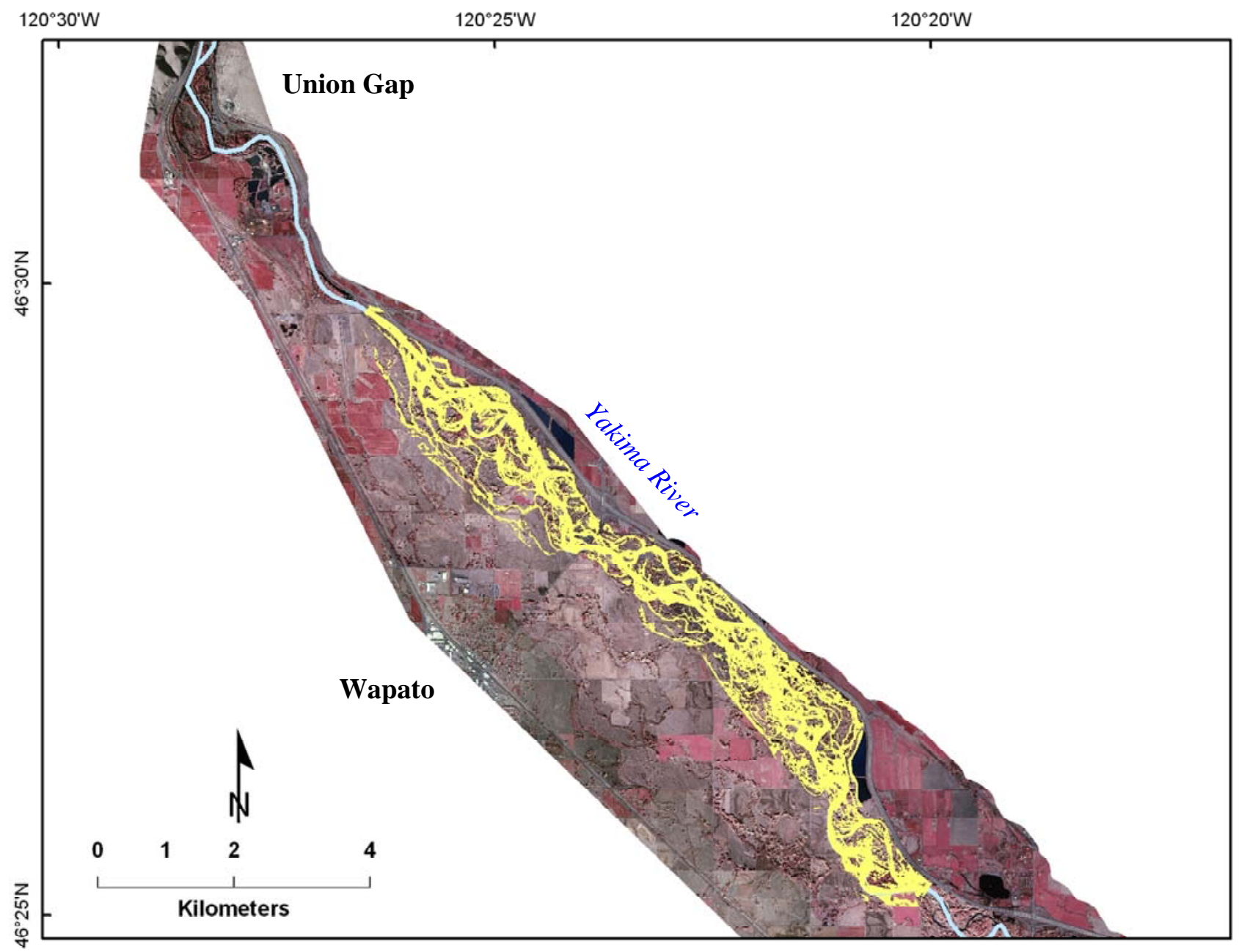

Figure 7. Aerial photograph of a portion of the Wapato flood plain unit showing the extent of the Wapato site.

7. Ahtanum Creek. This flood plain occupies a $10-\mathrm{km}$ reach downstream from the confluence of the North and Middle Ahtanum Creeks (fig. 2). Although the flood plain lies within the general study area of the present study, its rehabilitation potential was described as marginal (Snyder and Sanford, 2001), and streamflow in Ahtanum Creek would not be directly affected by any water management alternatives under consideration by BOR. Consequently, no study site was established in Ahtanum Creek.

8. Yakima Mouth. The exact extent of the flood plain at the confluence of the Yakima and Columbia Rivers was not specified by Snyder and Sanford (2001). The authors described this reach as being extensively modified by inundation and erosion from McNary Dam on the Columbia for about 3 kilometers up the Yakima. Descriptions of the reach suggested that rehabilitation potential was relatively low. No study site was established in this flood plain unit. 


\section{Resource Issues}

The natural resource issues associated with the Yakima River Basin involved four species of salmonids, although the species and life stages considered important varied by location within the system. Chinook salmon (Oncorhynchus tshawytscha) were represented by a spring run and a fall run, thereby dividing this species into separate target species on the basis of their life history strategies. Similarly, the species Oncorhynchus mykiss was subdivided into two stocks, resident rainbow trout and anadromous steelhead. The other two species of interest included coho salmon (Oncorhynchus kisutch) and bull trout (Salvelinus confluentus). Table 1 illustrates the species and life stages of interest in each of the five flood plain reaches.

Table 1. Target species and life stages of interest in the five flood plain sites analyzed for the YRDSS.

\begin{tabular}{|c|c|c|c|c|c|c|}
\hline \multirow[b]{2}{*}{ Target species } & \multirow[b]{2}{*}{ Life stage } & \multicolumn{5}{|c|}{ Flood plain reach } \\
\hline & & Easton & Kittitas & Naches & Union Gap & Wapato \\
\hline \multirow{7}{*}{$\begin{array}{l}\text { Spring chinook } \\
\text { (Oncorhynchus tshawytscha) }\end{array}$} & Spawning & $\mathrm{X}$ & $\mathrm{X}$ & $\mathrm{X}$ & & \\
\hline & Incubation & $\mathrm{X}$ & $\mathrm{X}$ & $\mathrm{X}$ & & \\
\hline & Fry & $X$ & $\mathrm{X}$ & $\mathrm{X}$ & & \\
\hline & Subyearling (summer) & $\mathrm{X}$ & $\mathrm{X}$ & $\mathrm{X}$ & & \\
\hline & Subyearling (winter) & $X$ & $\mathrm{X}$ & $\mathrm{X}$ & $X$ & $\mathrm{X}$ \\
\hline & Adult holding & $\mathrm{X}$ & $\mathrm{X}$ & $\mathrm{X}$ & & \\
\hline & Spawning & & & & $\mathrm{X}$ & $\mathrm{X}$ \\
\hline \multirow{5}{*}{$\begin{array}{c}\text { Fall chinook } \\
\text { (Oncorhynchus tshawytscha) }\end{array}$} & Incubation & & & & $\mathrm{X}$ & $\mathrm{X}$ \\
\hline & Fry & & & & $X$ & $\mathrm{X}$ \\
\hline & Subyearling (summer) & & & & $\mathrm{X}$ & $\mathrm{X}$ \\
\hline & Spawning & $\mathrm{X}$ & $\mathrm{X}$ & $\mathrm{X}$ & $X$ & $\mathrm{X}$ \\
\hline & Incubation & $\mathrm{X}$ & $\mathrm{X}$ & $\mathrm{X}$ & $\mathrm{X}$ & $\mathrm{X}$ \\
\hline \multirow{5}{*}{$\begin{array}{c}\text { Coho } \\
\text { (Oncorhynchus kisutch) }\end{array}$} & Fry & $\mathrm{X}$ & $\mathrm{X}$ & $\mathrm{X}$ & $\mathrm{X}$ & $\mathrm{X}$ \\
\hline & Subyearling (summer) & $\mathrm{X}$ & $\mathrm{X}$ & $\mathrm{X}$ & $\mathrm{X}$ & $\mathrm{X}$ \\
\hline & Subyearling (winter) & $\mathrm{X}$ & $\mathrm{X}$ & $X$ & $X$ & $\mathrm{X}$ \\
\hline & Spawning & $\mathrm{X}$ & $\mathrm{X}$ & $\mathrm{X}$ & & \\
\hline & Incubation & $\mathrm{X}$ & $\mathrm{X}$ & $\mathrm{X}$ & & \\
\hline \multirow{7}{*}{$\begin{array}{c}\text { Steelhead } \\
\text { (Oncorhynchus mykiss) }\end{array}$} & Fry & $\mathrm{X}$ & $\mathrm{X}$ & $\mathrm{X}$ & & \\
\hline & Subyearling (summer) & $X$ & $\mathrm{X}$ & $\mathrm{X}$ & & \\
\hline & Subyearling (winter) & $\mathrm{X}$ & $\mathrm{X}$ & $X$ & $X$ & $\mathrm{X}$ \\
\hline & Subadult & $\mathrm{X}$ & $\mathrm{X}$ & $\mathrm{X}$ & & \\
\hline & Adult holding & $\mathrm{X}$ & $\mathrm{X}$ & $\mathrm{X}$ & & \\
\hline & Spawning & $\mathrm{X}$ & $\mathrm{X}$ & $\mathrm{X}$ & $X$ & $\mathrm{X}$ \\
\hline & Incubation & $\mathrm{X}$ & $\mathrm{X}$ & $\mathrm{X}$ & $\mathrm{X}$ & $\mathrm{X}$ \\
\hline \multirow{6}{*}{$\begin{array}{l}\text { Resident rainbow trout } \\
\text { (Oncorhynchus mykiss) }\end{array}$} & Fry & $\mathrm{X}$ & $\mathrm{X}$ & $\mathrm{X}$ & $\mathrm{X}$ & $\mathrm{X}$ \\
\hline & Subyearling (summer) & $X$ & $\mathrm{X}$ & $\mathrm{X}$ & $X$ & $\mathrm{X}$ \\
\hline & Subyearling (winter) & $\mathrm{X}$ & $X$ & $\mathrm{X}$ & $X$ & $\mathrm{X}$ \\
\hline & Subadult & $X$ & $\mathrm{X}$ & $\mathrm{X}$ & $X$ & $X$ \\
\hline & Spawning & $\mathrm{X}$ & $\mathrm{X}$ & $\mathrm{X}$ & & \\
\hline & Incubation & $\mathrm{X}$ & $\mathrm{X}$ & $\mathrm{X}$ & & \\
\hline \multirow{3}{*}{$\begin{array}{c}\text { Bull trout } \\
\text { (Salvelinus confluentus) }\end{array}$} & Fry & $\mathrm{X}$ & $\mathrm{X}$ & $\mathrm{X}$ & & \\
\hline & Subyearling (summer) & $X$ & $\mathrm{X}$ & $\mathrm{X}$ & & \\
\hline & Subyearling (winter) & $\mathrm{X}$ & $\mathrm{X}$ & $\mathrm{X}$ & & \\
\hline
\end{tabular}




\section{Methods}

Inputs to the YRDSS were derived from a variety of sources and required the construction and calibration of a number of independent models by a relatively autonomous group of modelers. Construction of the habitat models for the target life stages involved data collection and calibration of two-dimensional hydraulic models, the outputs from which were used as inputs to ArcGis ${ }^{\circledR}$, version 9.2 (ESRI, 2006), which was used to generate maps of suitable habitat for each life stage, for each discharge simulated with the hydraulic models. Some of the hydraulic simulations were conducted by BOR's Sedimentation and Hydraulics Group (Hilldale and Mooney, 2007a) and some by the U.S. Geological Survey Columbia River Research Laboratory (see Appendix 1). All the ArcGis modeling was performed at the U.S. Geological Survey Fort Collins Science Center (see Appendix 2). A stream temperature network model, SNTEMP (Theurer and others, 1984; Bartholow, 1989), was used to generate maximum daily temperatures for baseline and alternative water management scenarios by the U.S. Geological Survey Washington Water Science Center (Frank Voss, U.S. Geological Survey Washington Water Science Center, written commun. October 19, 2007). Algorithms pertaining to sediment transport were developed by the Sedimentation and Hydraulics Group (Hilldale and Mooney, 2007b). Other variables used in the YRDSS were obtained directly from the RiverWare model, which was run for tested scenarios by BOR's Ephrata Area Office. Descriptions of methods and pertinent results for each of these components can be viewed in the Appendices or in the references cited previously.

\section{Organization and Functionality of the YRDSS}

\section{Organization}

The YRDSS consists of a series of MS Excel $₫$ workbooks that are linked and manipulated by Visual Basic macros (fig. 8). The YRDSS is organized as a master spreadsheet (Dss_Agg.xls) and five subsidiary spreadsheets for each of the river segments (Dss_Eas for Easton, Dss_Kit for Kittitas, Dss_Nch for Naches, Dss_UnG for Union Gap, and Dss_Wpt for Wapato). Reformatted output from RiverWare, water temperature data from SNTEMP, and user-supplied parameters are entered directly to the master spreadsheet, but the calculations for each of the state variables occur in the subsidiary spreadsheets. Results from all the computations in the subsidiary spreadsheets are then returned to the master spreadsheet, both as a whole system summary and as site-specific annual scores. Thus, the user can review the overall system response to an alternative and also examine the details about each site.

\section{YRDSS State Variables}

A state variable represents some issue or resource value considered to be important to decisionmakers when evaluating the consequences of a change in water management. YRDSS scores are based on the amount of change each state variable exhibits between the alternative and the baseline over a specified time period.

The first category of state variables incorporated in the YRDSS included potential effects to habitat characteristics or viability of the target species listed in table 1 . This category incorporated water temperature, critical-period habitat areas, potential passage of bull trout from reservoirs during spawning, potential outmigration of spring chinook smolts from Cle Elum Reservoir, occurrence of beneficial overbank flooding events, and potential scour of salmonid redds during the spawning and incubation periods. The second category was oriented toward effects to water users, water managers, and riparian property owners along the river. State variables in this category included end-of-year 
storage, total water supply available for irrigation, deliveries to junior water-right holders, potential for damaging floods, and aspects of sediment transport related both to biology and geomorphology, such as fine-sediment transport, armor layer disruption, and geomorphic (channel-forming) adjustment (table 2).

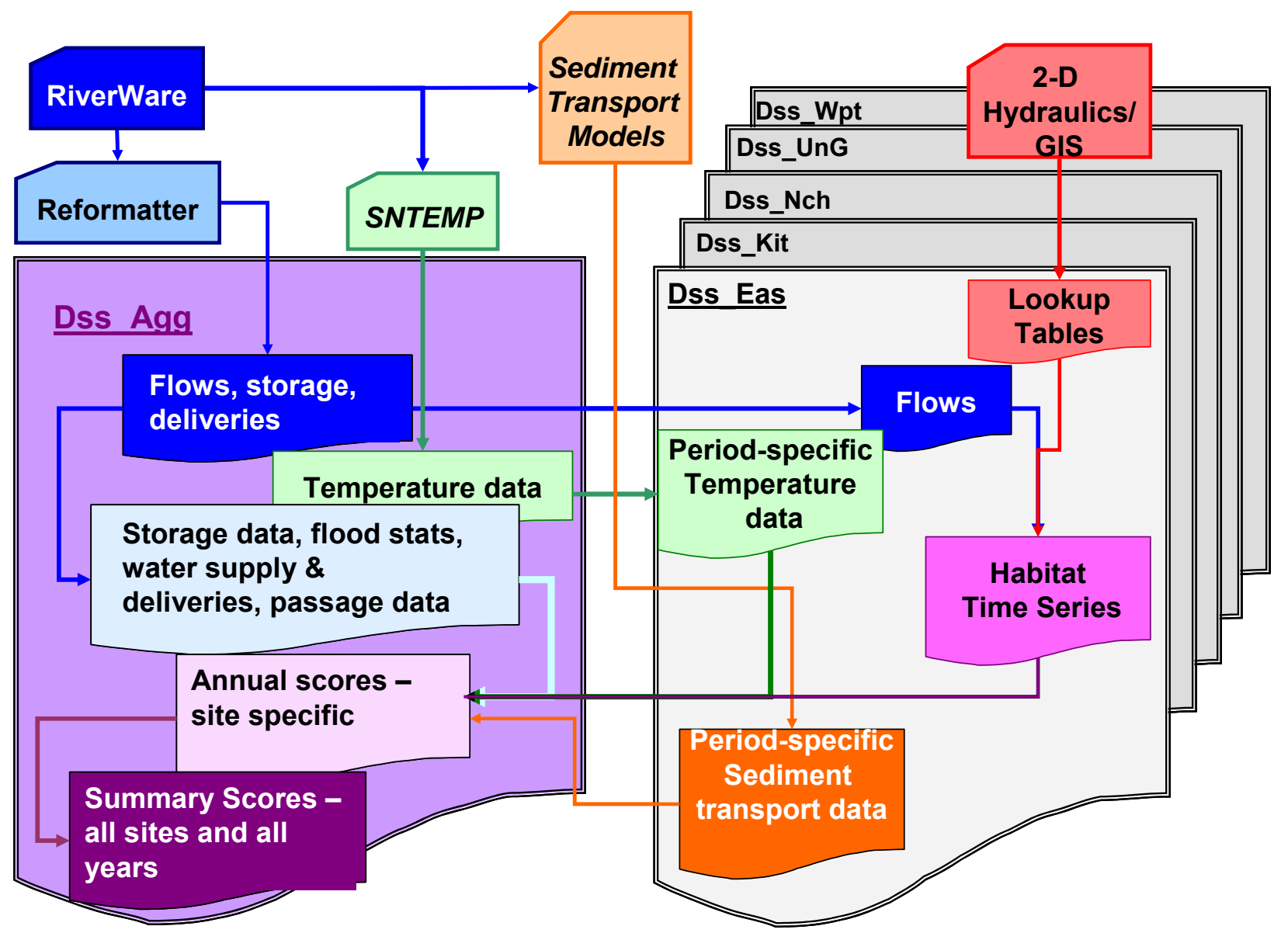

Figure 8. Organization of workbooks and information flow of the YRDSS. 
Table 2. Listing and categorization of state variables incorporated in the YRDSS.

\begin{tabular}{|c|c|c|}
\hline Category & State variable & Description \\
\hline Biological & $\begin{array}{l}\text { Redd scour } \\
\text { Habitat time series } \\
\text { Spawning-Incubation } \\
\text { Stream temperature } \\
\text { Bull trout outmigration } \\
\text { Cle Elum smolt } \\
\text { outmigration }\end{array}$ & $\begin{array}{l}\text { Maximum depth of redd scour during incubation. } \\
\text { Habitat area during critical time periods, by life stage. } \\
\text { Persistence of suitable spawning and incubation areas under conditions } \\
\text { of unsteady flow. } \\
\text { Maximum temperatures during specified time periods. } \\
\text { Frequency of suitable inflows and reservoir elevations. } \\
\text { Frequency of suitable reservoir elevations at Cle Elum Reservoir. }\end{array}$ \\
\hline $\begin{array}{l}\text { Overbank flow } \\
\text { and floods }\end{array}$ & $\begin{array}{l}\text { Overbank flows } \\
\text { Potential flood damage }\end{array}$ & $\begin{array}{l}\text { Frequency of overbank flows. } \\
\text { Frequency of potentially damaging floods. }\end{array}$ \\
\hline $\begin{array}{l}\text { Management } \\
\text { and delivery }\end{array}$ & $\begin{array}{l}\text { Total deliverable water } \\
\text { supply (TWSA) } \\
\text { Total deliverable to junior } \\
\text { water rights } \\
\text { Reservoir carryover }\end{array}$ & $\begin{array}{l}\text { Total water supply available for deliveries, by month. } \\
\text { Proration of deliverable water supplies, by month. } \\
\text { End-of-water-year storage volume. }\end{array}$ \\
\hline $\begin{array}{l}\text { Sediment } \\
\text { transport }\end{array}$ & $\begin{array}{l}\text { Fine sediment transport } \\
\text { Armor disruption } \\
\text { Geomorphic adjustment }\end{array}$ & $\begin{array}{l}\text { Total mass transport of sand, silt, and clay. } \\
\text { Frequency of events capable of erosion of armor layer. } \\
\text { Maximum 15-day sum of geomorphic work, by year }\end{array}$ \\
\hline
\end{tabular}

\section{Functionality of YRDSS Components}

\section{RiverWare}

RiverWare is a systems operations model that combines elements of reservoir mass balance and flow routing to produce mean daily discharges at specified output nodes (for example, at gaging stations and diversions). In addition, RiverWare calculates residual storage volumes in each of the system reservoirs on a daily basis and several metrics related to irrigation deliveries within the system. RiverWare is the driver for all calculations performed by the external models, such as SNTEMP, or within the YRDSS itself. The initial run of the RiverWare model is used to generate a baseline condition, which for most applications of the YRDSS represent a "No Action" case. The "No Action" case used as input the existing rules for reservoir operations and downstream delivery requirements, and approximated (but did not replicate) historical hydrologic conditions within the basin. Subsequent RiverWare simulations involved adjusting the rules for reservoir operations (primarily), water allocations (secondarily), or both. These RiverWare simulations provided the basis for the alternative water-management scenarios, the results of which were compared to the results of the baseline run to determine the amount of change transmitted to each of the YRDSS state variables. Scenarios simulated with RiverWare were conducted by BOR's Ephrata Area Office (Roger Sonnichsen, Bureau of Reclamation, Ephrata Area Office, written commun. August 2007). 


\section{The DSS_AGG Workbook}

The Dss_Agg.xls workbook performs three essential functions. First, this workbook serves as a focal point for all information originating from external models that are used as input for the scoring algorithms contained in the YRDSS. Second, the Dss_Agg.xls workbook contains the scores for each of the state variables generated by the YRDSS. Third, all parameters and default overrides that control scoring thresholds, critical time periods, and run documentation are set in this workbook. The YRDSS operates on the same 22-year period of record simulated in RiverWare (water years 1982-2003) and displays output annually as well as a summary for the entire period. The layout of the Dss_Agg.xls workbook is shown in figure 9, and the components are described below in the order that they appear in the workbook.

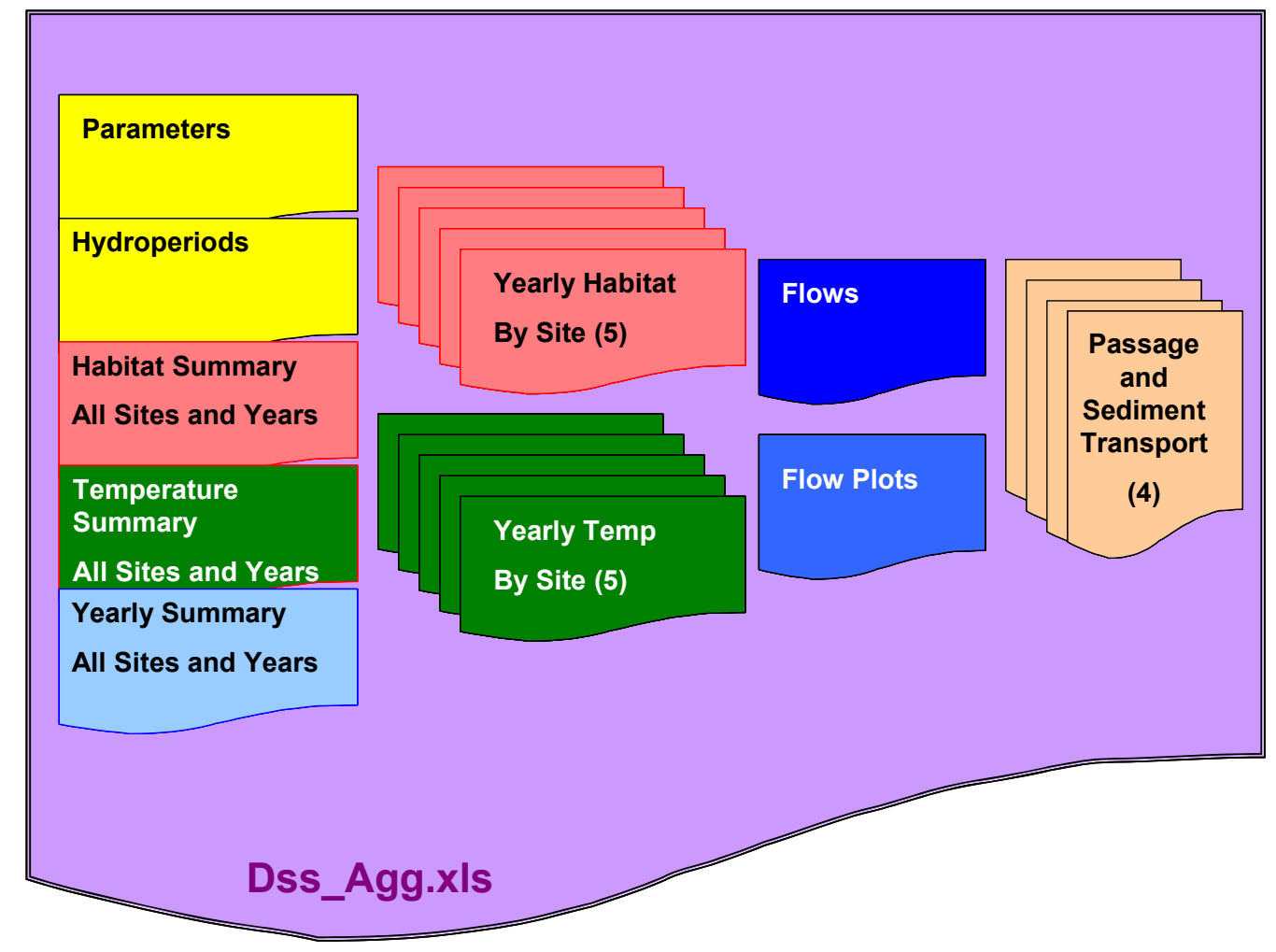

Figure 9. Contents of the Dss_Agg.xls workbook.

\section{Parameters Page}

Several functions vital to a YRDSS run are performed on the "Parameters" page (fig. 10). These include importing hydrologic data from RiverWare and temperature data from SNTEMP, documenting run details, setting or overriding system defaults, specifying sediment-transport data sources, and launching the run. 


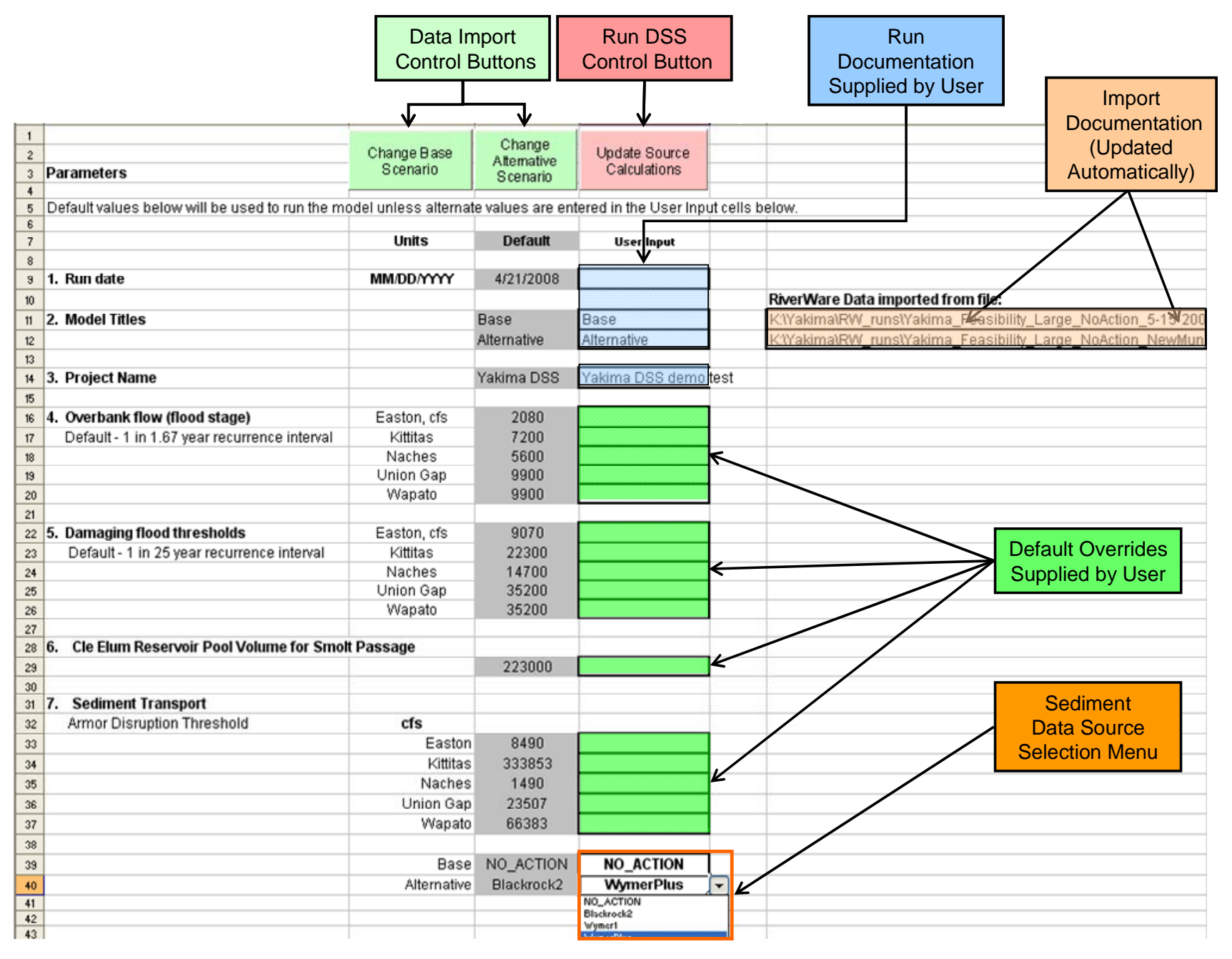

Figure 10. The "Parameters" page of the Dss_Agg.xls workbook.

\section{Control Buttons}

Outputs from RiverWare and SNTEMP cannot be used directly in the YRDSS and must be formatted according to the layout of data on the "Flows" page of the DSS_Agg spreadsheet. In the case of RiverWare output, a utility program, "XLwriter.exe," is used to convert the single-column text file (with extension ".rdf") to an Excel spreadsheet with the same name (with extension ".xls"). The spreadsheet produced by XLwriter contains all the hydrologic data required by the YRDSS but also contains a large volume of data that is not needed and can be cumbersome to manipulate. Each RiverWare run depicts a single operational and hydrologic scenario. In virtually all runs of the YRDSS, the baseline condition generated by RiverWare will be defined as the "No Action" case. An alternative may contain the "No Action" nomenclature in the file name, but will contain more specific information in the title, such as "Blackrock_2_6-12-2007," indicating that the run depicts the operational and hydrologic conditions for the Blackrock_2 alternative, as simulated on June 12, 2007. A similar naming convention is typically used for SNTEMP runs that are likewise produced individually (for example, a "No Action" SNTEMP run would be used as the baseline).

The two green control buttons at the top of the page (highlighted in light green in figure 10) are used to import data from RiverWare and SNTEMP and copy the data to the appropriate locations on the "Flows" page. The green button on the left is used to import data for the baseline, and the one on the 
right for the alternative. Clicking on either button will activate a browsing window, allowing the user to navigate to the location of the desired data set. After selecting the input file, the "Flows" page is automatically updated. When the update has been completed, the path and names for the imported files, as well as the time and date of the import, are automatically updated in the cells delineated with a tan background in figure 10. The pink control button is used to start the YRDSS run, and is activated only when all imports and user updates have been completed. A complete run of the YRDSS can take as long as 45 minutes, so it is important not to activate this button until all of the updates have been completed.

\section{User Inputs}

Two types of user input can be inserted on the "Parameters" page. The first type is generically described as "Run Documentation," as highlighted in the blue box in figure 10. This documentation consists of a run date and meaningful names for the baseline and alternative. The default value for the run date is the actual date on which the run was made, and it is rarely changed. The names assigned to the baseline and alternative must be supplied by the user, with a nomenclature that adequately describes the scenario. This information is copied to virtually every page of the YRDSS, including the subsidiary spreadsheets, so it is important that these cells contain accurate depictions of the baseline and alternative. For example, "Blackrock_2" is a more meaningful name than "Alternative2," provided that the user knows what "Blackrock_2" means. Past experience has shown that it is helpful for the user to write a small "README" file for each scenario that describes the baseline and alternative in sufficient detail to distinguish them from other alternatives developed in the RiverWare runs. The consequence of inadequate documentation can be as serious as obtaining a promising outcome in the YRDSS with no idea of how it was derived.

The second category of user inputs, delineated by green highlighting in figure 10, are default overrides. The default values are thresholds defining overbank flows, damaging floods, critical pool volume for smolt passage at Cle Elum, and critical discharges for redd scour and armor disruption. Override cells are provided for user inputs for any of the default values. Entries in these cells are used in place of the defaults wherever called upon in the DSS scoring or documentation summaries.

\section{Sediment Data Source}

Immediately below the default override box for armor disruption is a field labeled "Sediment Data Source (outlined in orange in figure 10). This field instructs the YRDSS which sediment lookup tables to use for the sediment-transport algorithms and scoring components. Each lookup table is specific to a particular scenario, the default being the "No Action" case as the baseline and "Blackrock_2" as the alternative. A different scenario can be selected by clicking on the "Base" or "Alternative" boxes next to the defaults. A browsing menu will appear, allowing the user to select one of the alternative scenarios to override the default data sources. When running the YRDSS for any scenario other than "Blackrock_2," specifying the alternative sediment data source is mandatory. Failure to specify the sediment data source will result in a mismatch between the scenario being run and the sediment data used for the scenario.

\section{Flows Page}

The "Flows" page contains all the data pertinent to the YRDSS that originated from RiverWare and SNTEMP. These data are compiled in two large arrays, one block for the baseline and one for the alternative. Data fields include mean daily streamflow for each of the five flood plain reaches, daily storage volume in the five headwater reservoirs (with placeholders for the proposed Wymer and Blackrock Reservoirs), daily proration rates (an index of water deliveries to junior water-rights holders) and total water supply, and temperature data generated by SNTEMP. Several manipulations of dates are also contained on the "Flows" page, such as arraying a date by month, day, year, water year, and Julian 
day. Such manipulations were necessary to synchronize and subdivide water years according to biologically important time windows, discussed in the "Hydroperiods" section.

\section{Sediment Lookup Page}

This page contains the lookup tables for three sediment-related functions, sand transport, geomorphic work, and active layer depth (redd scour). These functions are arrayed by stream reach and scenario. Except for special cases, such as running a scenario not on the selection menu of the "Parameters" page, these tables should never be modified. Unless modifications are made with great care, errors can be introduced or the format altered to the point that the YRDSS will not run.

\section{Sediment Calculations Page}

This page, labeled "SedimentCalc" on the DSS_Agg workbook, is where all the calculations related to sediment processes and scoring values take place. Complete descriptions of the scoring algorithms for this component are provided in the discussion of the "Yearly Summary" page. As with the Sediment Lookup page, nothing on the "SedimentCalc" page should be altered, at the risk of rendering the YRDSS partially or totally inoperable.

\section{Hydroperiods Page}

The "Hydroperiods" page (fig. 11) is the second location in the Dss_Agg.xls workbook where user inputs can be made to override system defaults. Hydroperiods refer to blocks of time during which different biological functions take place. It is important to identify these critical periods correctly because they are used to define the intervals for which habitat areas are computed and summarized on the YRDSS scoring pages. This page is similar to the "Parameters" page in that entries in the columns labeled "user inputs" will override the defaults. In this case, user inputs can consist of a different starting date for a life stage or activity (yellow highlighted column), a different ending date (tan highlighted column), or both.

\section{Habitat Summary Page}

The "HabSummary" page contains the average of the lowest 50 percent of the habitat areas occurring in each year (see Habitat Time Series) and percent changes thereof for the entire period of record, arrayed by target species and site (fig. 12). This page also contains the average scores for flood metrics, water division deliveries, reservoir storage, and sediment transport (fig. 13). Information related to the run details are shown at the top of the page (fig. 12), including the scenarios used as the baseline and the alternative, the date of the run, and the starting and ending dates for the period of record used in the analysis. The cells on this page are conditionally formatted so that an improved condition, such as an increase in habitat area under the alternative scenario, causes the cell to turn green. A worsening of a state variable, such as an increase in damaging floods, causes the cell to turn red. In most cases, a change to a scoring metric of less than 10 percent $( \pm)$ is considered to be undetectable, so the cell color remains unchanged. Some of the cells have grey backgrounds, indicating inapplicable cases where the target organism does not occur or was not considered.

\section{Temperature Summary}

The temperature summary page (TempSummary) records the maximum temperature for the baseline and alternative period of record (fig. 14). For the present study, temperature data were available only for the Union Gap and Wapato reaches, but the YRDSS was designed with placeholders for the remaining reaches in the event that temperature data become available in the future. Temperatures are arrayed according to the hydroperiods associated with each life stage and target organism occupying the reach. The maximum temperature for the hydroperiod is recorded for the baseline and alternative. 


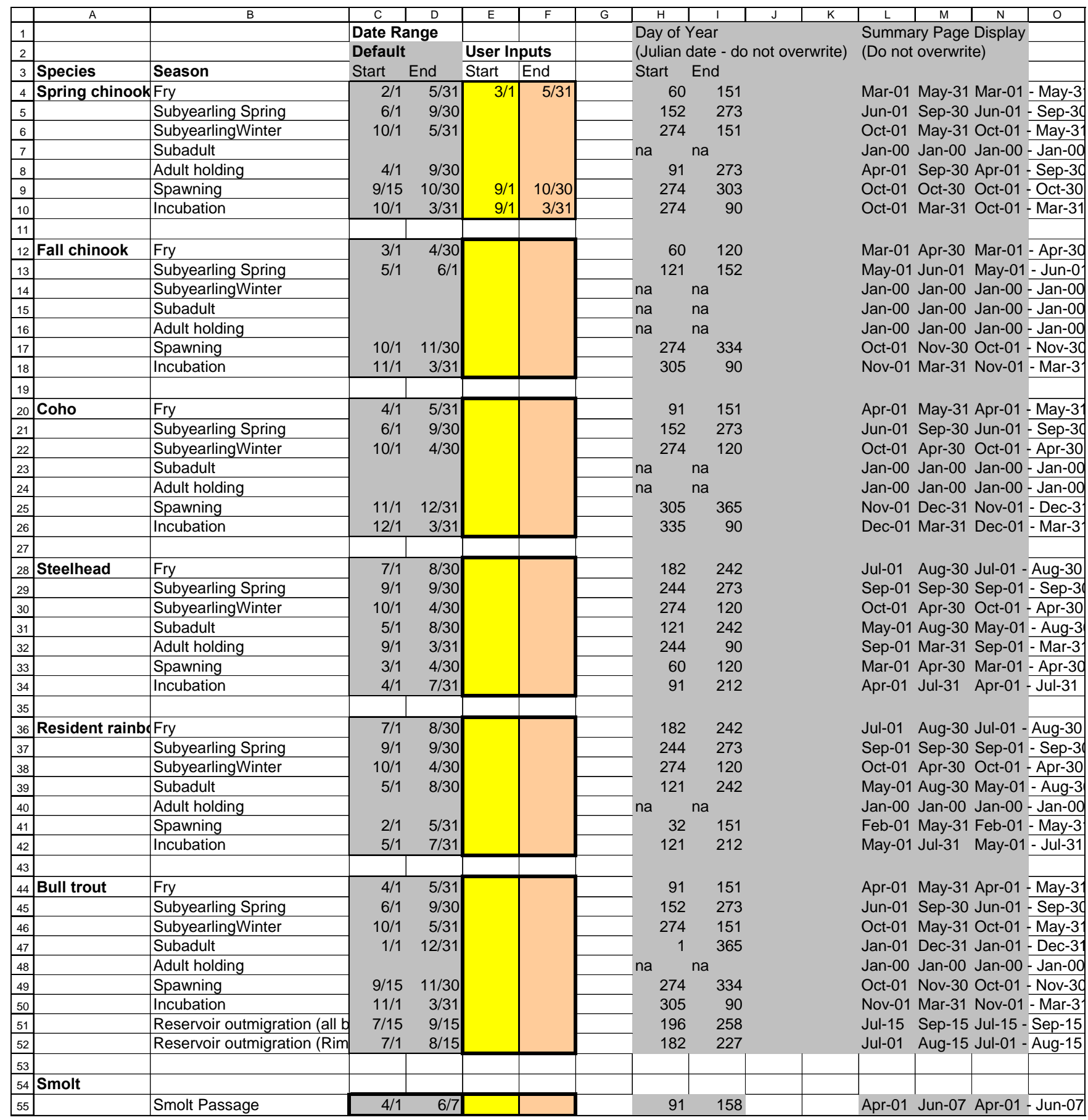

Figure 11. The "Hydroperiods" page of the Dss_Agg.xls workbook. 


\begin{tabular}{|c|c|c|c|c|c|c|c|c|}
\hline & $\mathrm{A}$ & $\mathrm{B}$ & $\mathrm{C}$ & $\mathrm{D}$ & $\mathrm{E}$ & $\mathrm{F}$ & $\mathrm{G}$ & $\mathrm{H}$ \\
\hline 1 & Yakima DSS demo test & & & RunDate: & & 04/21/08 & & \\
\hline 2 & & & & Baseline: & & Base & & \\
\hline 3 & Summary & & & Alternative: & & Alternative & & \\
\hline 4 & & & & & & & & \\
\hline 5 & & & & & \multicolumn{3}{|c|}{ Stream Reach } & \multirow[b]{4}{*}{ Pct Chg } \\
\hline 6 & Resource category & Hydroperiod & & Easton & & & Kittitas & \\
\hline 7 & & & & & & & & \\
\hline 8 & Spring chinook & & Base & Alternative & Pct Chg & Base & Alternative & \\
\hline 9 & Redd scour depth (ft) & Oct-01-Mar-31 & 0.033 & 0.067 & $101.5 \%$ & 0.008 & 0.008 & $-3.1 \%$ \\
\hline 10 & Spawning/incubation* & Oct-01-Mar-31 & 45.8 & 43.6 & $-4.9 \%$ & 23.4 & 23.0 & $-1.5 \%$ \\
\hline 11 & Fry & Mar-01 - May-31 & 2.5 & 2.4 & $-3.3 \%$ & 1.7 & 1.8 & $6.4 \%$ \\
\hline 12 & Subyearling (Spring-summer) & Jun-01 - Sep-30 & 47.9 & 52.6 & $9.7 \%$ & 14.0 & 13.7 & $-2.1 \%$ \\
\hline 13 & Subyearling (winter) & Oct-01 - May-31 & 8.7 & 8.2 & $-6.1 \%$ & 4.0 & 3.9 & $-2.2 \%$ \\
\hline 14 & Adult holding & Apr-01 - Sep-30 & 7.3 & 7.4 & $0.7 \%$ & 6.6 & 6.8 & $3.1 \%$ \\
\hline \multicolumn{9}{|l|}{15} \\
\hline 16 & Fall chinook & & & & & & & \\
\hline 17 & Redd scour depth (ft) & Oct-01-Mar-31 & & & & & & \\
\hline 18 & Spawning/incubation* & Oct-01-Mar-31 & & & & & & \\
\hline 19 & Fry & Mar-01 - Apr-30 & & & & & & \\
\hline 20 & Subyearling (Spring-summer) & May-01 - Jun-01 & & & & & & \\
\hline \multicolumn{9}{|c|}{21} \\
\hline 22 & Coho & & & & & & & \\
\hline 23 & Redd scour depth (ft) & Nov-01-Mar-31 & 0.028 & 0.048 & $70.9 \%$ & 0.007 & 0.007 & $-4.3 \%$ \\
\hline 24 & Spawning/incubation* & Nov-01-Mar-31 & 38.8 & 37.4 & $-3.7 \%$ & 14.8 & 14.2 & $-4.0 \%$ \\
\hline 25 & Fry & Apr-01 - May-31 & 2.6 & 2.4 & $-8.6 \%$ & 1.7 & 1.8 & $5.9 \%$ \\
\hline 26 & Subyearling (Spring-summer) & Jun-01 - Sep-30 & 16.1 & 18.2 & $13.1 \%$ & 4.6 & 4.2 & $-7.6 \%$ \\
\hline 27 & Subyearling (winter) & Oct-01 - Apr-30 & 5.4 & 5.4 & $-0.9 \%$ & 2.6 & 2.5 & $-2.5 \%$ \\
\hline \multicolumn{9}{|l|}{28} \\
\hline 29 & Steelhead & & & & & & & \\
\hline 30 & Redd scour depth (ft) & Mar-01-Jul-31 & 0.028 & 0.039 & $36.9 \%$ & 0.006 & 0.006 & $-1.5 \%$ \\
\hline 31 & Spawning/incubation* & Mar-01-Jul-31 & 53.0 & 53.0 & $-0.1 \%$ & 31.7 & 32.7 & $3.2 \%$ \\
\hline 32 & Fry & Jul-01 - Aug-30 & 4.1 & 4.4 & $7.5 \%$ & 2.2 & 2.1 & $-3.8 \%$ \\
\hline 33 & Subyearling (Spring-summer) & Sep-01 - Sep-30 & 57.9 & 63.9 & $10.3 \%$ & 20.2 & 26.1 & $29.4 \%$ \\
\hline 34 & Subyearling (winter) & Oct-01 - Apr-30 & 7.8 & 7.7 & $-1.1 \%$ & 3.5 & 3.4 & $-4.4 \%$ \\
\hline 35 & Subadults & May-01 - Aug-30 & 57.3 & 59.0 & $3.0 \%$ & 19.1 & 19.2 & $0.3 \%$ \\
\hline 36 & Adult holding & Sep-01 - Mar-31 & 22.6 & 22.4 & $-0.9 \%$ & 9.7 & 9.6 & $-1.4 \%$ \\
\hline \multicolumn{9}{|l|}{37} \\
\hline 38 & Resident rainbow & & & & & & & \\
\hline 39 & Redd scour depth (ft) & Feb-01-Jul-31 & 0.017 & 0.022 & $28.2 \%$ & 0.006 & 0.006 & $-1.5 \%$ \\
\hline 40 & Spawning/incubation* & Feb-01-Jul-31 & 47.8 & 44.7 & $-6.5 \%$ & 18.7 & 17.2 & $-8.1 \%$ \\
\hline 41 & Fry & Jul-01 - Aug-30 & 5.2 & 5.5 & $7.0 \%$ & 2.5 & 2.4 & $-3.9 \%$ \\
\hline 42 & Subyearling (Spring-summer) & Sep-01 - Sep-30 & 57.2 & 63.2 & $10.6 \%$ & 19.9 & 25.7 & $28.9 \%$ \\
\hline 43 & Subyearling (winter) & Oct-01 - Apr-30 & 9.1 & 9.0 & $-0.7 \%$ & 4.4 & 4.2 & $-3.9 \%$ \\
\hline 44 & Subadults & May-01 - Aug-30 & 30.5 & 31.4 & $2.9 \%$ & 8.1 & 7.8 & $-3.4 \%$ \\
\hline \multicolumn{9}{|l|}{45} \\
\hline 46 & Bull trout & & & & & & & \\
\hline 47 & Redd scour depth (ft) & Oct-01 - Mar-31 & 0.033 & 0.067 & $101.5 \%$ & 0.008 & 0.007 & $-2.7 \%$ \\
\hline 48 & Spawning/incubation & Oct-01 - Mar-31 & 36.4 & 34.8 & $-4.4 \%$ & 13.4 & 12.3 & $-8.5 \%$ \\
\hline 49 & Fry & Apr-01 - May-31 & 4.9 & 4.5 & $-6.8 \%$ & 2.5 & 2.6 & $5.9 \%$ \\
\hline 50 & Subyearling (Spring-summer) & Jun-01 - Sep-30 & 61.9 & 66.1 & $6.9 \%$ & 20.5 & 20.3 & $-1.0 \%$ \\
\hline 51 & Subyearling (winter) & Oct-01 - May-31 & 8.6 & 8.1 & $-5.8 \%$ & 4.3 & 4.2 & $-2.1 \%$ \\
\hline
\end{tabular}

Figure 12. The upper portion of the "HabSummary" page, showing the arrangement of biological state variables and site information. Scoring metrics for the Naches, Union Gap, and Wapato sites have been truncated to improve legibility. 


\begin{tabular}{|c|c|c|c|c|c|c|c|c|}
\hline & $\mathrm{A}$ & $\mathrm{B}$ & $\mathrm{C}$ & $\mathrm{D}$ & $\mathrm{E}$ & $\mathrm{F}$ & $\mathrm{G}$ & $\mathrm{H}$ \\
\hline 56 & Resevoir outmigration & & & & & & & \\
\hline 57 & Inseason days impassable & & Base & Alternative & Pct Chg & & & \\
\hline 58 & Kachess & Jul-15 - Sep-15 & 18 & 15 & $-15.4 \%$ & & & \\
\hline 59 & Keechelus & Jul-15 - Sep-15 & 37 & 38 & $0.5 \%$ & & & \\
\hline 60 & Rimrock & Jul-01 - Aug-15 & 3 & 3 & $-1.6 \%$ & & & \\
\hline \multicolumn{9}{|l|}{61} \\
\hline \multicolumn{9}{|l|}{62} \\
\hline 63 & Flood metrics & & & Easton & & & Kittitas & \\
\hline 64 & & & Base & Alternative & Pct Chg & Base & Alternative & Pct Chg \\
\hline 65 & Overbank flow & days & 91 & 113 & $24.2 \%$ & 90 & 95 & $5.6 \%$ \\
\hline 66 & Damaging flood & days & 0 & 2 & $200.0 \%$ & 0 & 0 & $0.0 \%$ \\
\hline \multicolumn{9}{|l|}{67} \\
\hline \multicolumn{9}{|l|}{68} \\
\hline 69 & Water division deliveries & & & April & & & May & \\
\hline 70 & & & Base & Alternative & Pct Chg & Base & Alternative & Pct Chg \\
\hline 71 & Proration & Percentage & $90 \%$ & $96 \%$ & $5.7 \%$ & $89 \%$ & $95 \%$ & $6.2 \%$ \\
\hline \multicolumn{9}{|l|}{72} \\
\hline 73 & TWSA & Acre feet & $2,910,719$ & $3,035,923$ & $4.3 \%$ & $2,494,500$ & $2,599,714$ & $4.2 \%$ \\
\hline \multicolumn{9}{|l|}{74} \\
\hline \multicolumn{9}{|l|}{75} \\
\hline 76 & Reservoir storage & & & Bumping & & & Cle Elum & \\
\hline 77 & End-of-season carry over & (af) & Base & Alternative & Pct Chg & Base & Alternative & Pct Chg \\
\hline 78 & & Average & 9,614 & 11,427 & $18.9 \%$ & 100,028 & 177,433 & $77.4 \%$ \\
\hline \multicolumn{9}{|l|}{79} \\
\hline \multicolumn{9}{|l|}{80} \\
\hline \multicolumn{9}{|l|}{81} \\
\hline 82 & Sediment transport & & & Easton & & & Kittitas & \\
\hline 83 & & & Base & Alternative & Pct Chg & Base & Alternative & Pct Chg \\
\hline 84 & Fine-material transport & Total tons & 227 & 259 & $13.8 \%$ & 2,111 & 2,074 & $-1.8 \%$ \\
\hline \multicolumn{9}{|l|}{85} \\
\hline 86 & Geomorphic adjustment & Highest 15-day period & 63,270 & 74,732 & $18.1 \%$ & 508,081 & 501,925 & $-1.2 \%$ \\
\hline \multicolumn{9}{|c|}{$x_{0}$} \\
\hline 88 & Armor disruption & Day count & 0 & 3 & $300.0 \%$ & 0 & 0 & $0.0 \%$ \\
\hline
\end{tabular}

Figure 13. The lower portion of the "HabSummary" page, showing the arrangement of hydrologic and geomorphologic state variables. Scoring metrics for the Naches, Union Gap, and Wapato sites have been truncated to improve legibility.

Columns labeled "Year" (columns N and Q, for example) document the water years associated with the highest baseline temperatures. Cells containing the maximum temperature data are color-coded to indicate potentially unsuitable high temperatures. A green background indicates that the maximum temperature is within a suitable range for the individual life stage. A pink background indicates that the maximum temperature exceeded the upper threshold for the life stage. Temperatures of intermediate suitability are highlighted with a yellow background. Cells with grey backgrounds indicate that the life stage or species does not occur at a site, or temperature data were not produced for the location or the hydroperiod of the life stage. Temperature thresholds and the information sources used for each of the pertinent life stages are listed in table 3. 


\begin{tabular}{|c|c|c|c|c|c|c|c|c|}
\hline & A & $\mathrm{B}$ & $L$ & $\mathrm{M}$ & $\mathrm{N}$ & $\mathrm{O}$ & $\mathrm{P}$ & $\mathrm{Q}$ \\
\hline 1 & Yakima DSS demo test & & & End date & & & & \\
\hline 2 & & & & $9 / 30 / 2003$ & & & & \\
\hline 3 & Summary & & & $9 / 30 / 2003$ & & & & \\
\hline \multicolumn{9}{|l|}{4} \\
\hline \multicolumn{9}{|l|}{5} \\
\hline \multicolumn{2}{|r|}{ Resource category } & Hydroperiod & & Union Gap & Year & & Wapato & Year \\
\hline \multirow{2}{*}{7} & & & & & & & & \\
\hline & Spring chinook & & Base & Alternative & & Base & Alternative & \\
\hline 9 & Spawning & Oct-01 - Oct-30 & & & & & & \\
\hline \multicolumn{9}{|l|}{10} \\
\hline 11 & Maximum temperature ${ }^{\circ} \mathrm{C}$ & & & & & & & \\
\hline 12 & Incubation & Oct-01 - Mar-31 & & & & & & \\
\hline \multicolumn{9}{|l|}{13} \\
\hline 14 & Maximum temperature ${ }^{\circ} \mathrm{C}$ & & & & & & & \\
\hline \multirow{2}{*}{\begin{tabular}{l|l|}
15 & \\
6
\end{tabular}} & Fry & Mar-01 - May-31 & & & & & & \\
\hline & & & & & & & & \\
\hline 17 & Maximum temperature ${ }^{\circ} \mathrm{C}$ & & & & & & & \\
\hline \multirow{2}{*}{$\begin{array}{ll}18 \\
19\end{array}$} & Subyearling (Spring-summer) & Jun-01 - Sep-30 & & & & & & \\
\hline & \multicolumn{8}{|c|}{9} \\
\hline 20 & Maximum temperature ${ }^{\circ} \mathrm{C}$ & & & & & & & \\
\hline 21 & Subyearling (winter) & Oct-01 - May-31 & & & & & & \\
\hline 22 & & & & & & & & \\
\hline 23 & Maximum temperature ${ }^{\circ} \mathrm{C}$ & & 16.9 & 16.9 & 1993 & 20.7 & 19.0 & 2001 \\
\hline 24 & Adult holding & Apr-01 - Sep-30 & & & & & & \\
\hline 25 & & & & & & & & \\
\hline 26 & Maximum temperature ${ }^{\circ} \mathrm{C}$ & & & & & & & \\
\hline 27 & & & & & & & & \\
\hline 28 & Fall chinook & & & & & & & \\
\hline 29 & Spawning & Oct-01 - Nov-30 & & & & & & \\
\hline 30 & & & & & & & & \\
\hline 31 & Maximum temperature ${ }^{\circ} \mathrm{C}$ & & 14.9 & 15.1 & 1993 & 16.8 & 17.0 & 1993 \\
\hline 32 & Incubation & Nov-01 - Mar-31 & & & & & & \\
\hline 33 & & & & & & & & \\
\hline 34 & Maximum temperature ${ }^{\circ} \mathrm{C}$ & & 0.0 & 0.0 & No Data & 0.0 & 0.0 & No Data \\
\hline 35 & Fry & Mar-01 - Apr-30 & & & & & & \\
\hline 36 & & & & & & & & \\
\hline 37 & Maximum temperature ${ }^{\circ} \mathrm{C}$ & & 15.0 & 15.3 & 1987 & 17.4 & 16.6 & 2001 \\
\hline 38 & Subyearling (Spring-summer) & May-01 - Jun-01 & & & & & & \\
\hline 39 & & & & & & & & \\
\hline 40 & Maximum temperature ${ }^{\circ} \mathrm{C}$ & & 17.4 & 17.2 & 1992 & 20.7 & 19.1 & 1992 \\
\hline 41 & & & & & & & & \\
\hline 42 & Coho & & & & & & & \\
\hline 43 & Spawning & Nov-01 - Dec-31 & & & & & & \\
\hline 44 & & & & & & & & \\
\hline 45 & Maximum temperature ${ }^{\circ} \mathrm{C}$ & & 0.0 & 0.0 & No Data & 0.0 & 0.0 & No Data \\
\hline \begin{tabular}{l|l}
46 & 1 \\
\end{tabular} & Incubation & Dec-01 - Mar-31 & & & & & & \\
\hline 47 & & & & & & & & \\
\hline 48 & Maximum temperature ${ }^{\circ} \mathrm{C}$ & & 0.0 & 0.0 & No Data & 0.0 & 0.0 & No Data \\
\hline 49 & Fry & Apr-01 - May-31 & & & & & & \\
\hline 50 & & & & & & & & \\
\hline 51 & Maximum temperature ${ }^{\circ} \mathrm{C}$ & & 16.9 & 16.9 & 1993 & 20.7 & 19.0 & 2001 \\
\hline 52 & Subyearling (Spring-summer) & Jun-01 - Sep-30 & & & & & & \\
\hline 5.3 & & & & & & & & \\
\hline
\end{tabular}

Figure 14. A portion of the "TempSummary" page, showing the arrangement of temperature data arrayed by relevant hydroperiods for target species and life stages. 
Table 3. Criteria and information sources used for conditional formatting of maximum temperatures $\left(T_{\max }\right)$ on the "TempSummary" page of the DSS_Agg spreadsheet. Cells with grey backgrounds indicate hydroperiods for which no temperature data were available from SNTEMP.

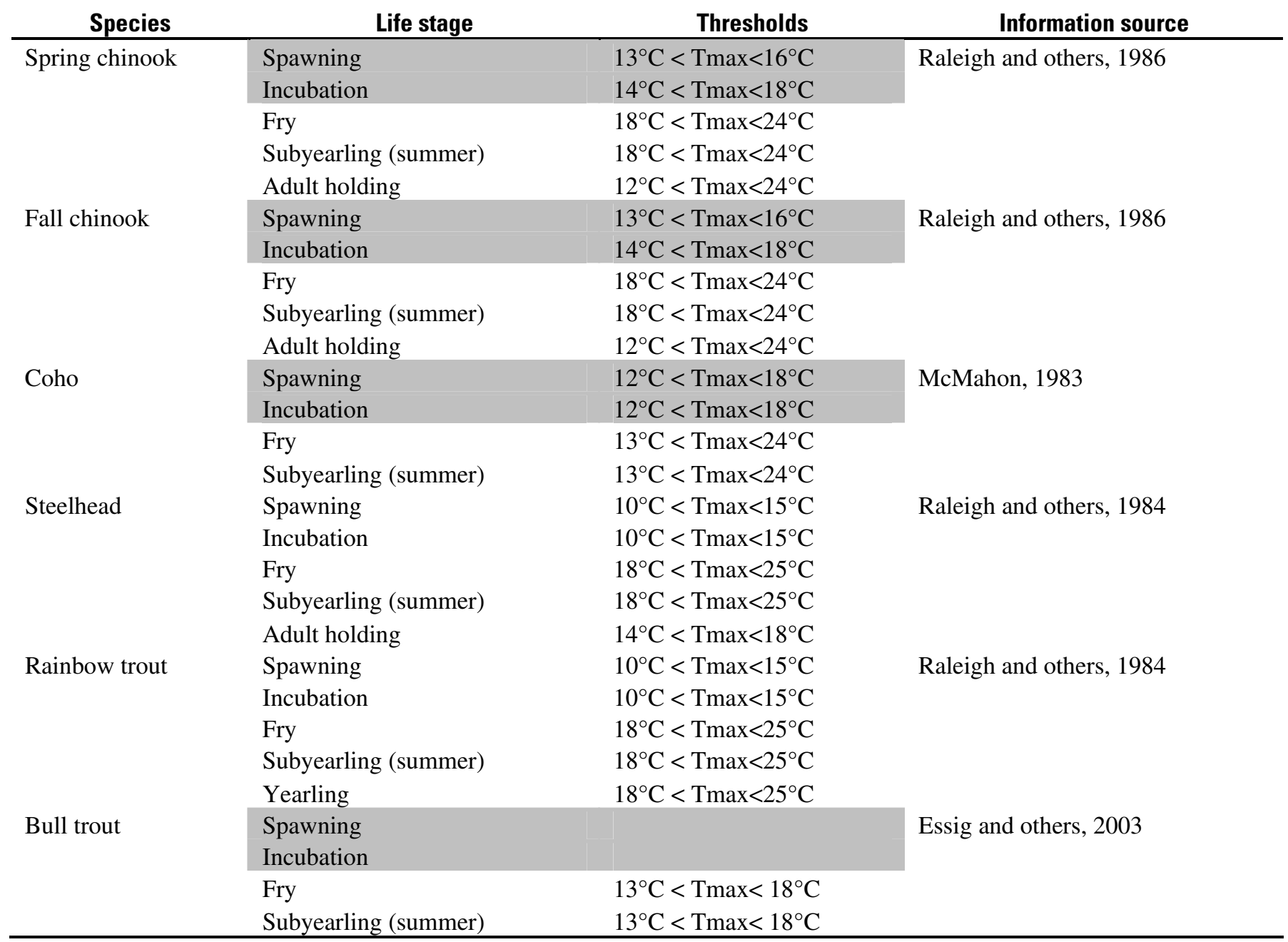

Yearly Summary Page

The "Yearly Summary" page contains information for all state variables not related to instream fish habitat or temperature and arrays the information year-by-year for the period of record.

\section{Bull Trout Passage}

The first table on the "YearlySummary" page (fig. 15) contains a count of the days when passage for migrating bull trout from Kachess, Keechelus, or Rimrock Reservoirs would not be possible or would be seriously impaired. The derivation of a passable or impassable condition is based on binary (either passable or impassable) matrix tables located on the page labeled "BTPassLookup," the penultimate page of the DSS_Agg spreadsheet (table 4, for example). These tables were produced from a combination of observations and professional judgment provided by Jeff Thomas, U.S. Fish and Wildlife Service, Yakima field office (written commun. April 25, 2007). Passable conditions from each of the reservoirs were defined by a combination of reservoir elevation and inflow (Table 4). For example, if the reservoir elevation was relatively high and inflow neither too high nor too low, passage 


\begin{tabular}{|c|c|c|c|c|c|c|c|c|c|c|c|c|}
\hline & $\mathrm{A}$ & $\mathrm{B}$ & $\mathrm{C}$ & $\mathrm{J}$ & $\mathrm{K}$ & $\mathrm{L}$ & $\mathrm{M}$ & $\mathrm{N}$ & $\mathrm{O}$ & $\mathrm{P}$ & $\mathrm{Q}$ & $\mathrm{R}$ \\
\hline 1 & Yakima DSS demo test & & & Start date & & & End date & & & & & \\
\hline 2 & Version & & & $10 / 1 / 1981$ & to & & $9 / 30 / 2003$ & & & & & \\
\hline 3 & Yearly Summary & & & $10 / 1 / 1981$ & to & & $9 / 30 / 2003$ & & & & & \\
\hline \multicolumn{13}{|l|}{$\frac{4}{5}$} \\
\hline 6 & Bull trout outmigration & & & & Kachess & & & Keechelus & & & Rimrock & \\
\hline 7 & inseason days impassable & & year & Base & Alternative & Pct Chg & Base & Alternative & Pct Chg & Base & Alternative & Pct Chg \\
\hline 8 & & & 1982 & 0 & 0 & $0.0 \%$ & 0 & 20 & $2000.0 \%$ & 0 & 0 & $0.0 \%$ \\
\hline 9 & & & 1983 & 2 & 2 & $0.0 \%$ & 29 & 32 & $10.3 \%$ & 0 & 0 & $0.0 \%$ \\
\hline 10 & & & 1984 & 0 & 0 & $0.0 \%$ & 14 & 28 & $100.0 \%$ & 0 & 0 & $0.0 \%$ \\
\hline 11 & & & 1985 & 29 & 29 & $0.0 \%$ & 49 & 49 & $0.0 \%$ & 0 & 0 & $0.0 \%$ \\
\hline 12 & & & 1986 & 17 & 17 & $0.0 \%$ & 43 & 43 & $0.0 \%$ & 0 & 0 & $0.0 \%$ \\
\hline 13 & & & 1987 & 33 & 22 & $-33.3 \%$ & 54 & 54 & $0.0 \%$ & 0 & 0 & $0.0 \%$ \\
\hline 14 & & & 1988 & 49 & 42 & $-14.3 \%$ & 60 & 40 & $-33.3 \%$ & 0 & 0 & $0.0 \%$ \\
\hline 15 & & & 1989 & 13 & 13 & $0.0 \%$ & 42 & 27 & $-35.7 \%$ & 0 & 0 & $0.0 \%$ \\
\hline 16 & & & 1990 & 14 & 14 & $0.0 \%$ & 46 & 51 & $10.9 \%$ & 1 & 1 & $0.0 \%$ \\
\hline 17 & & & 1991 & 15 & 15 & $0.0 \%$ & 35 & 43 & $22.9 \%$ & 0 & 0 & $0.0 \%$ \\
\hline 18 & & & 1992 & 29 & 11 & $-62.1 \%$ & 55 & 57 & $3.6 \%$ & 0 & 0 & $0.0 \%$ \\
\hline 19 & & & 1993 & 30 & 9 & $-70.0 \%$ & 61 & 42 & $-31.1 \%$ & 0 & 0 & $0.0 \%$ \\
\hline 20 & & & 1994 & 47 & 43 & $-8.5 \%$ & 61 & 61 & $0.0 \%$ & 18 & 17 & $-5.6 \%$ \\
\hline 21 & & & 1995 & 9 & 9 & $0.0 \%$ & 58 & 57 & $-1.7 \%$ & 0 & 0 & $0.0 \%$ \\
\hline 22 & & & 1996 & 4 & 4 & $0.0 \%$ & 38 & 39 & $2.6 \%$ & 0 & 0 & $0.0 \%$ \\
\hline 23 & & & 1997 & 11 & 11 & $0.0 \%$ & 14 & 14 & $0.0 \%$ & 0 & 0 & $0.0 \%$ \\
\hline 24 & & & 1998 & 31 & 31 & $0.0 \%$ & 44 & 47 & $6.8 \%$ & 0 & 0 & $0.0 \%$ \\
\hline 25 & & & 1999 & 4 & 4 & $0.0 \%$ & 9 & 9 & $0.0 \%$ & 0 & 0 & $0.0 \%$ \\
\hline 26 & & & 2000 & 23 & 23 & $0.0 \%$ & 20 & 22 & $10.0 \%$ & 0 & 0 & $0.0 \%$ \\
\hline 27 & & & 2001 & 25 & 25 & $0.0 \%$ & 32 & 32 & $0.0 \%$ & 44 & 44 & $0.0 \%$ \\
\hline 28 & & & 2002 & 3 & 3 & $0.0 \%$ & 17 & 20 & $17.6 \%$ & 0 & 0 & $0.0 \%$ \\
\hline 29 & & & 2003 & 7 & 7 & $0.0 \%$ & 40 & 38 & $-5.0 \%$ & 0 & 0 & $0.0 \%$ \\
\hline
\end{tabular}

Figure 15. The bull trout passage table for Kachess, Keechelus, and Rimrock Reservoirs, as found on the Yearly Summary page of the DSS_Agg spreadsheet.

Table 4. Bull trout passage matrix for Keechelus Reservoir, found on the "BTPassLookup" page of the DSS_Agg spreadsheet.

\begin{tabular}{ccccccccccc}
\hline $\begin{array}{c}\text { Inflow, } \\
\text { in } \mathbf{f t}^{\mathbf{3}} / \mathbf{s}\end{array}$ & \multicolumn{10}{c}{ Storage volume, in acre-feet } \\
\hline & $\mathbf{0}$ & $\mathbf{1 0 , 0 0 0}$ & $\mathbf{1 8 , 0 0 0}$ & $\mathbf{2 8 , 5 0 0}$ & $\mathbf{4 3 , 0 0 0}$ & $\mathbf{5 5 , 0 0 0}$ & $\mathbf{6 5 , 0 0 0}$ & $\mathbf{7 4 , 0 0 0}$ & $\mathbf{1 0 2 , 5 0 0}$ & $\mathbf{1 5 8 , 0 0 0}$ \\
\cline { 2 - 11 } $\mathbf{0}$ & 0 & 0 & 0 & 0 & 0 & 0 & 0 & 0 & 0 & 0 \\
$\mathbf{5 0}$ & 0 & 0 & 0 & 0 & 0 & 0 & 0 & 0 & 0 & 0 \\
$\mathbf{7 0}$ & 0 & 0 & 0 & 0 & 0 & 1 & 1 & 1 & 1 & 1 \\
$\mathbf{1 0 0}$ & 0 & 0 & 0 & 0 & 0 & 1 & 1 & 1 & 1 & 1 \\
$\mathbf{1 3 3}$ & 0 & 0 & 0 & 0 & 0 & 1 & 1 & 1 & 1 & 1 \\
$\mathbf{1 4 1}$ & 0 & 0 & 0 & 0 & 0 & 1 & 1 & 1 & 1 & 1 \\
$\mathbf{1 5 0}$ & 0 & 0 & 0 & 0 & 0 & 1 & 1 & 1 & 1 & 1 \\
$\mathbf{2 0 0}$ & 0 & 0 & 0 & 0 & 0 & 1 & 1 & 1 & 1 & 1 \\
$\mathbf{4 0 0}$ & 1 & 1 & 1 & 1 & 1 & 1 & 1 & 1 & 1 & 1 \\
$\mathbf{1 , 5 0 0}$ & 1 & 1 & 1 & 1 & 1 & 1 & 1 & 1 & 1 & 1 \\
\hline
\end{tabular}

out of the reservoir was considered to be possible. Conversely, if reservoir elevation and inflow were both low, passage from the reservoir would be impossible.

The scoring algorithm for bull trout passage from the three reservoirs is based on the following sequence:

1. Each day of the year is flagged according to the defined hydroperiod as being inside or outside the window for bull trout spawning.

2. If the day falls within the spawning window, total reservoir inflow from all sources and storage volume are recorded. Inflow data and storage volumes were derived from RiverWare output. 
Because inflow data were not measured but were calculated by mass balance, values from RiverWare were smoothed with a 3-day running mean to eliminate unrealistic fluctuations that appeared in the time series. Both variables are recorded on the "Flows" page of the DSS_Agg spreadsheet.

3. The daily inflow and storage volume are then subjected to a threshold test using the lookup tables for bull trout passage. If the flow and volume are less than the passable thresholds, the day is counted as being impassable. For example, if the inflow to Kachess Reservoir was $90 \mathrm{ft}^{3} / \mathrm{s}$ and the storage volume was 125,000 acre-feet, the scoring algorithm would count the day as being passable. However, with the same inflow, but with a storage volume of 119,000 acre-feet, the day would be considered impassable. It is noteworthy that the threshold values are fixed; there is no leeway for "almost passable" conditions. With an inflow of $90 \mathrm{ft}^{3} / \mathrm{s}$, a storage volume of 119,999 acre-feet would be impassable, but 120,000 acre-feet would be passable.

4. The number of impassable days are summed for each year, under the baseline and alternative conditions, and recorded on the "YearlySummary" page. If the count of impassable days increases by 10 percent or more under the alternative, the cells in the "Pct Chg" column are conditionally formatted to turn red. If the count decreases by 10 percent or more, the cells turn green. Otherwise, the percent change is simply recorded with no change in cell color.

\section{Water Supply and Delivery}

Two tables on the Yearly Summary page refer to water supply and delivery statistics (fig. 16). The table captioned as "Average proration \%" refers to the delivery of water to holders of junior water rights within the Yakima River Basin. The table captioned "TWSA" refers to "Total Water Supply Available." Values for both variables are derived directly from RiverWare output and are recorded daily on the "Flows" page. These data are summarized by month and year on the Yearly Summary page. Months included in these tables encompass the irrigation season, April-September. Scoring for the "Average Proration" table is based on the average of all the daily values for each month and year. Cells for the baseline and alternative in this table are conditionally formatted to turn red if the average is less than 70 percent and green if the average is greater than or equal to that threshold. Scoring for the "TWSA" table is based on the sum of the daily values for each month and year. In both tables, cells under the "Pct Chg" column are formatted to turn red if the alternative results in a reduction of 10 percent or more and green if the result is an increase of 10 percent or more.

\section{Reservoir Storage}

Reservoir storage statistics are contained in two tables on the "YearlySummary" page (fig. 17). The first table documents differences in end-of-year storage under baseline and alternative operating rules. This variable accounts, in part, for year-to-year carryover storage within the system. The second table contains information pertinent to smolt outmigration from Cle Elum Reservoir. End-of-year storage is obtained directly from RiverWare output as the volume of each reservoir on October 20. The same type of conditional formatting described earlier is applied to the "Pct Chg" column of this table. The second table in the group, entitled "Critical Reservoir Storage" is a compilation of days where storage at Cle Elum Reservoir is insufficient to provide downstream passage for smolts (target species coho, spring chinook, steelhead, bull trout, and potentially, sockeye). Most of the calculations for scoring this variable occur on the "Passage" page of the DSS_Agg spreadsheet:

1. Each day in the period of record is categorized as being inside or outside the hydroperiod for smolt outmigration. The default dates for this hydroperiod are April 1-June 7 (but can be overridden by the user on the Hydroperiods page). 


\begin{tabular}{|c|c|c|c|c|c|c|c|c|c|c|c|c|}
\hline & A & $\mathrm{B}$ & C & $\mathrm{J}$ & $\mathrm{K}$ & $\mathrm{L}$ & $\mathrm{M}$ & $\mathrm{N}$ & $\mathrm{O}$ & $\mathrm{P}$ & $\mathrm{Q}$ & $\mathrm{R}$ \\
\hline 32 & & & & \multicolumn{3}{|c|}{ June } & \multicolumn{3}{|c|}{ July } & \multicolumn{3}{|c|}{ August } \\
\hline 33 & Average proration & & Year & Base & Alternative & Pct Chg & Base & Alternative & Pct Chg & Base & Alternative & Pct Chg \\
\hline 34 & & & 1982 & $100.0 \%$ & $100.0 \%$ & $0.0 \%$ & $100.0 \%$ & $100.0 \%$ & $0.0 \%$ & $100.0 \%$ & $100.0 \%$ & $0.0 \%$ \\
\hline 35 & & & 1983 & $100.0 \%$ & $100.0 \%$ & $0.0 \%$ & $100.0 \%$ & $100.0 \%$ & $0.0 \%$ & $100.0 \%$ & $100.0 \%$ & $0.0 \%$ \\
\hline 36 & & & 1984 & $100.0 \%$ & $100.0 \%$ & $0.0 \%$ & $100.0 \%$ & $100.0 \%$ & $0.0 \%$ & $100.0 \%$ & $100.0 \%$ & $0.0 \%$ \\
\hline 37 & & & 1985 & $100.0 \%$ & $100.0 \%$ & $0.0 \%$ & $100.0 \%$ & $100.0 \%$ & $0.0 \%$ & $100.0 \%$ & $100.0 \%$ & $0.0 \%$ \\
\hline 38 & & & 1986 & $91.7 \%$ & $100.0 \%$ & $9.0 \%$ & $90.6 \%$ & $100.0 \%$ & $10.4 \%$ & $90.3 \%$ & $100.0 \%$ & $10.8 \%$ \\
\hline 39 & & & 1987 & $70.7 \%$ & $82.6 \%$ & $16.8 \%$ & $69.8 \%$ & $82.6 \%$ & $18.4 \%$ & $69.2 \%$ & $82.6 \%$ & $19.3 \%$ \\
\hline 40 & & & 1988 & $73.9 \%$ & $91.9 \%$ & $24.4 \%$ & $72.8 \%$ & $91.9 \%$ & $26.3 \%$ & $72.3 \%$ & $91.9 \%$ & $27.0 \%$ \\
\hline 41 & & & 1989 & $97.8 \%$ & $100.0 \%$ & $2.2 \%$ & $96.7 \%$ & $100.0 \%$ & $3.4 \%$ & $96.3 \%$ & $100.0 \%$ & $3.9 \%$ \\
\hline 42 & & & 1990 & $100.0 \%$ & $100.0 \%$ & $0.0 \%$ & $100.0 \%$ & $100.0 \%$ & $0.0 \%$ & $100.0 \%$ & $100.0 \%$ & $0.0 \%$ \\
\hline 43 & & & 1991 & $100.0 \%$ & $100.0 \%$ & $0.0 \%$ & $100.0 \%$ & $100.0 \%$ & $0.0 \%$ & $100.0 \%$ & $100.0 \%$ & $0.0 \%$ \\
\hline 44 & & & 1992 & $70.4 \%$ & $80.9 \%$ & $15.0 \%$ & $69.7 \%$ & $80.4 \%$ & $15.2 \%$ & $69.7 \%$ & $80.3 \%$ & $15.3 \%$ \\
\hline 45 & & & 1993 & $60.0 \%$ & $74.0 \%$ & $23.2 \%$ & $58.9 \%$ & $74.0 \%$ & $25.5 \%$ & $58.1 \%$ & $73.6 \%$ & $26.6 \%$ \\
\hline 46 & & & 1994 & $29.2 \%$ & $70.0 \%$ & $140.0 \%$ & $29.2 \%$ & $70.0 \%$ & $140.0 \%$ & $28.9 \%$ & $70.0 \%$ & $142.6 \%$ \\
\hline 47 & & & 1995 & $100.0 \%$ & $100.0 \%$ & $0.0 \%$ & $100.0 \%$ & $100.0 \%$ & $0.0 \%$ & $100.0 \%$ & $100.0 \%$ & $0.0 \%$ \\
\hline 48 & & & 1996 & $100.0 \%$ & $100.0 \%$ & $0.0 \%$ & $100.0 \%$ & $100.0 \%$ & $0.0 \%$ & $100.0 \%$ & $100.0 \%$ & $0.0 \%$ \\
\hline 49 & & & 1997 & $100.0 \%$ & $100.0 \%$ & $0.0 \%$ & $100.0 \%$ & $100.0 \%$ & $0.0 \%$ & $100.0 \%$ & $100.0 \%$ & $0.0 \%$ \\
\hline 50 & & & 1998 & $100.0 \%$ & $100.0 \%$ & $0.0 \%$ & $100.0 \%$ & $100.0 \%$ & $0.0 \%$ & $100.0 \%$ & $100.0 \%$ & $0.0 \%$ \\
\hline 51 & & & 1999 & $100.0 \%$ & $100.0 \%$ & $0.0 \%$ & $100.0 \%$ & $100.0 \%$ & $0.0 \%$ & $100.0 \%$ & $100.0 \%$ & $0.0 \%$ \\
\hline 52 & & & 2000 & $100.0 \%$ & $100.0 \%$ & $0.0 \%$ & $100.0 \%$ & $100.0 \%$ & $0.0 \%$ & $100.0 \%$ & $100.0 \%$ & $0.0 \%$ \\
\hline 53 & & & 2001 & $45.9 \%$ & $70.0 \%$ & $52.4 \%$ & $45.9 \%$ & $70.0 \%$ & $52.5 \%$ & $45.3 \%$ & $70.0 \%$ & $54.4 \%$ \\
\hline 54 & & & 2002 & $100.0 \%$ & $100.0 \%$ & $0.0 \%$ & $100.0 \%$ & $100.0 \%$ & $0.0 \%$ & $100.0 \%$ & $100.0 \%$ & $0.0 \%$ \\
\hline 55 & & & 2003 & $93.8 \%$ & $100.0 \%$ & $6.6 \%$ & $92.2 \%$ & $100.0 \%$ & $8.5 \%$ & $92.1 \%$ & $100.0 \%$ & $8.6 \%$ \\
\hline \multicolumn{13}{|l|}{56} \\
\hline 57 & & & & & & & & & & & & \\
\hline 58 & & & & & June & & & July & & & August & \\
\hline 59 & TWSA & & Year & Base & Alternative & \begin{tabular}{|l|} 
Pct Chg \\
\end{tabular} & Base & Alternative & Pct Chg & Base & Alternative & Pct Chg \\
\hline 60 & & & 1982 & $2,458,618$ & $2,476,460$ & $0.7 \%$ & $1,765,875$ & $1,830,854$ & $3.7 \%$ & $1,271,330$ & $1,378,682$ & $8.4 \%$ \\
\hline 61 & & & 1983 & $2,309,257$ & $2,362,682$ & $2.3 \%$ & $1,709,447$ & $1,741,349$ & $1.9 \%$ & $1,236,846$ & $1,336,683$ & $8.1 \%$ \\
\hline 62 & & & 1984 & $2,479,559$ & $2,417,495$ & $-2.5 \%$ & $1,779,942$ & $1,845,278$ & $3.7 \%$ & $1,277,044$ & $1,383,246$ & $8.3 \%$ \\
\hline 63 & & & 1985 & \begin{tabular}{|l|}
$1,998,693$ \\
\end{tabular} & $2,059,093$ & $3.0 \%$ & $1,505,885$ & $1,554,254$ & $3.2 \%$ & $1,065,032$ & $1,179,393$ & $10.7 \%$ \\
\hline 64 & & & 1986 & $1,804,030$ & $1,898,846$ & $5.3 \%$ & $1,358,767$ & $1,450,724$ & $6.8 \%$ & 921,826 & $1,080,335$ & $17.2 \%$ \\
\hline 65 & & & 1987 & $1,530,345$ & $1,639,674$ & $7.1 \%$ & $1,141,415$ & $1,266,278$ & $10.9 \%$ & 748,243 & 910,892 & $21.7 \%$ \\
\hline 66 & & & 1988 & $1,567,951$ & $1,731,972$ & $10.5 \%$ & $1,175,239$ & $1,354,760$ & $15.3 \%$ & 771,408 & 982,021 & $27.3 \%$ \\
\hline 67 & & & 1989 & $1,822,870$ & $1,921,480$ & $5.4 \%$ & $1,393,574$ & $1,458,556$ & $4.7 \%$ & 952,442 & $1,082,371$ & $13.6 \%$ \\
\hline 68 & & & 1990 & $2,172,464$ & $2,118,525$ & $-2.5 \%$ & $1,617,139$ & $1,595,261$ & $-1.4 \%$ & $1,166,841$ & $1,217,519$ & $4.3 \%$ \\
\hline 69 & & & 1991 & $2,167,928$ & $2,154,416$ & $-0.6 \%$ & $1,664,369$ & $1,659,526$ & $-0.3 \%$ & $1,202,653$ & $1,276,063$ & $6.1 \%$ \\
\hline 70 & & & 1992 & $1,538,304$ & $1,599,827$ & $4.0 \%$ & $1,152,100$ & $1,225,080$ & $6.3 \%$ & 762,107 & 880,225 & $15.5 \%$ \\
\hline 71 & & & 1993 & $1,430,982$ & $1,554,193$ & $8.6 \%$ & $1,066,030$ & $1,186,303$ & $11.3 \%$ & 695,869 & 844,607 & $21.4 \%$ \\
\hline 72 & & & 1994 & $1,145,307$ & $1,284,348$ & $12.1 \%$ & 862,326 & 924,077 & $7.2 \%$ & 571,196 & 596,439 & $4.4 \%$ \\
\hline 73 & & & 1995 & $2,022,644$ & $2,014,053$ & $-0.4 \%$ & $1,510,108$ & $1,522,800$ & $0.8 \%$ & $1,050,094$ & $1,142,233$ & $8.8 \%$ \\
\hline 74 & & & 1996 & $2,131,115$ & $2,150,230$ & $0.9 \%$ & $1,615,539$ & $1,625,032$ & $0.6 \%$ & $1,171,852$ & $1,246,473$ & $6.4 \%$ \\
\hline 75 & & & 1997 & $2,621,883$ & $2,699,331$ & $3.0 \%$ & $1,912,826$ & $1,977,675$ & $3.4 \%$ & $1,381,597$ & $1,465,311$ & $6.1 \%$ \\
\hline 76 & & & 1998 & $2,009,134$ & $2,073,149$ & $3.2 \%$ & $1,500,375$ & $1,512,630$ & $0.8 \%$ & $1,065,654$ & $1,139,485$ & $6.9 \%$ \\
\hline 77 & & & 1999 & $2,843,055$ & $2,908,033$ & $2.3 \%$ & $2,111,556$ & $2,176,534$ & $3.1 \%$ & $1,478,312$ & $1,550,457$ & $4.9 \%$ \\
\hline 78 & & & 2000 & $2,200,665$ & $2,208,697$ & $0.4 \%$ & $1,615,996$ & $1,663,689$ & $3.0 \%$ & $1,166,148$ & $1,266,759$ & $8.6 \%$ \\
\hline 79 & & & 2001 & $1,310,142$ & $1,362,392$ & $4.0 \%$ & 982,608 & $1,001,321$ & $1.9 \%$ & 650,165 & 676,322 & $4.0 \%$ \\
\hline 80 & & & 2002 & $2,292,068$ & $2,287,638$ & $-0.2 \%$ & $1,644,665$ & $1,701,494$ & $3.5 \%$ & $1,178,350$ & $1,264,281$ & $7.3 \%$ \\
\hline 81 & & & 2003 & $1,834,265$ & $1,919,904$ & $4.7 \%$ & $1,375,890$ & $1,458,962$ & $6.0 \%$ & 940,958 & $1,090,892$ & $15.9 \%$ \\
\hline
\end{tabular}

Figure 16. Portions of the annual scoring tables for average proration percentage and total water supply available, found on the "Yearly Summary" page of the DSS_Agg spreadsheet.

2. The threshold for passable storage volume at Cle Elum was set at 233,000 acre-feet, based on the elevation necessary to spill water over an experimental passage structure constructed to facilitate smolt outmigration.

3. For dates falling within the smolt migration window, Cle Elum storage is tested against the 233,000 acre-ft criterion. If the volume is less than the threshold, the day is counted as "below threshold." The total number of "below threshold" days for each water year is tallied on the Yearly Summary page.

4. Cells in the "Pct Chg" columns of the "End of year Storage" table are conditionally formatted to turn red if the alternative results in a decrease in carryover of 10 percent of more and green if the alternative results in a comparable increase in carryover. Conditional formatting in the Cle Elum "Critical Storage" table is just the opposite, as the scoring is based on frequency of days below the threshold. Consequently, an increase in the day-count under the alternative results in the cell turning red and green for a decrease. 


\begin{tabular}{|c|c|c|c|c|c|c|c|c|c|c|c|c|}
\hline & A & $\mathrm{B}$ & C & $\mathrm{D}$ & $\mathrm{E}$ & $\mathrm{F}$ & G & $\mathrm{H}$ & $\mathrm{I}$ & $\mathrm{J}$ & $\mathrm{K}$ & $\mathrm{L}$ \\
\hline 85 & Reservoir storage & & & & Bumping & & & Cle Elum & & & Kachess & \\
\hline 86 & End-of-season carryover & & Year & Base & Alternative & Pct Chg & Base & Alternative & Pct Chg & Base & Alternative & Pct Chg \\
\hline 87 & & & 1981 & 10,563 & 12,024 & $13.8 \%$ & 52,640 & 121,868 & $131.5 \%$ & 112,061 & 148,548 & $32.6 \%$ \\
\hline \begin{tabular}{|l|}
88 \\
\end{tabular} & & & 1982 & 14,883 & 15,217 & $2.2 \%$ & 160,780 & 293,228 & $82.4 \%$ & 118,393 & 153,703 & $29.8 \%$ \\
\hline 89 & & & 1983 & 11,601 & 15,094 & $30.1 \%$ & 152,349 & 266,418 & $74.9 \%$ & 109,269 & 144,071 & $31.8 \%$ \\
\hline 90 & & & 1984 & 13,285 & 14,617 & $10.0 \%$ & 162,323 & 292,375 & $80.1 \%$ & 112,808 & 150,057 & $33.0 \%$ \\
\hline 91 & & & 1985 & 10,858 & 12,671 & $16.7 \%$ & 77,663 & 177,812 & $129.0 \%$ & 92,510 & 127,112 & $37.4 \%$ \\
\hline \begin{tabular}{|l|}
92 \\
\end{tabular} & & & 1986 & 7,810 & 11,315 & $44.9 \%$ & 22,361 & 129,394 & $478.7 \%$ & 92,465 & 117,238 & $26.8 \%$ \\
\hline 93 & & & 1987 & 3,115 & 7,363 & $136.3 \%$ & 4,613 & 43,569 & $844.6 \%$ & 28,564 & 130,758 & $357.8 \%$ \\
\hline 94 & & & 1988 & 5,564 & 10,061 & $80.8 \%$ & 35,587 & 99,466 & $179.5 \%$ & 29,531 & 138,874 & $370.3 \%$ \\
\hline 95 & & & 1989 & 8,461 & 11,034 & $30.4 \%$ & 38,835 & 118,308 & $204.6 \%$ & 97,628 & 117,577 & $20.4 \%$ \\
\hline \begin{tabular}{|l|}
96 \\
\end{tabular} & & & 1990 & 14,742 & 15,149 & $2.8 \%$ & 142,357 & 216,166 & $51.8 \%$ & 121,753 & 146,822 & $20.6 \%$ \\
\hline \begin{tabular}{|l|}
97 \\
\end{tabular} & & & 1991 & 9,978 & 12,092 & $21.2 \%$ & 134,231 & 250,439 & $86.6 \%$ & 105,208 & 137,660 & $30.8 \%$ \\
\hline 98 & & & 1992 & 3,249 & 7,216 & $122.1 \%$ & 12,303 & 64,774 & $426.5 \%$ & 29,546 & 124,464 & $321.3 \%$ \\
\hline \begin{tabular}{|l|}
99 \\
\end{tabular} & & & 1993 & 2,116 & 6,702 & $216.7 \%$ & 4,672 & 12,214 & $161.4 \%$ & 9,951 & 135,302 & $1259.7 \%$ \\
\hline 100 & & & 1994 & 2,136 & 2,132 & $-0.2 \%$ & 6,087 & 4,256 & $-30.1 \%$ & 4,514 & 9,781 & $116.7 \%$ \\
\hline 101 & & & 1995 & 14,392 & 14,868 & $3.3 \%$ & 144,122 & 226,712 & $57.3 \%$ & 78,164 & 98,129 & $25.5 \%$ \\
\hline 102 & & & 1996 & 12,083 & 12,917 & $6.9 \%$ & 132,560 & 224,318 & $69.2 \%$ & 102,781 & 138,221 & $34.5 \%$ \\
\hline 103 & & & 1997 & 15,349 & 15,923 & $3.7 \%$ & 250,810 & 358,039 & $42.8 \%$ & 136,887 & 169,910 & $24.1 \%$ \\
\hline 104 & & & 1998 & 9,492 & 11,419 & $20.3 \%$ & 89,032 & 162,938 & $83.0 \%$ & 96,430 & 124,581 & $29.2 \%$ \\
\hline 105 & & & 1999 & 15,395 & 12,569 & $-18.4 \%$ & 315,201 & 379,165 & $20.3 \%$ & 136,128 & 153,709 & $12.9 \%$ \\
\hline 106 & & & 2000 & 13,226 & 15,035 & $13.7 \%$ & 131,073 & 227,677 & $73.7 \%$ & 117,533 & 145,969 & $24.2 \%$ \\
\hline \begin{tabular}{|l|}
107 \\
\end{tabular} & & & 2001 & 2,217 & 3,101 & $39.9 \%$ & 8,494 & 8,449 & $-0.5 \%$ & 17,813 & 66,271 & $272.0 \%$ \\
\hline 108 & & & 2002 & 10,986 & 12,873 & $17.2 \%$ & 122,529 & 225,940 & $84.4 \%$ & 110,427 & 134,957 & $22.2 \%$ \\
\hline \multicolumn{13}{|l|}{109} \\
\hline \multicolumn{13}{|l|}{110} \\
\hline 111 & & & & & & & & & & & & \\
\hline \begin{tabular}{|l|}
112 \\
\end{tabular} & Critical reservoir storage & & & & Cle Elum & & & & & & & \\
\hline 113 & Smolt passage & & Year & Base & Alternative & Pct Chg & & & & & & \\
\hline 114 & Days below threshold & & 1982 & 29 & 43 & $48.3 \%$ & & & & & & \\
\hline 115 & & & 1983 & 0 & 0 & $0.0 \%$ & & & & & & \\
\hline 116 & & & 1984 & 0 & 0 & $0.0 \%$ & & & & & & \\
\hline 117 & & & 1985 & 12 & 0 & $-100.0 \%$ & & & & & & \\
\hline 118 & & & 1986 & 0 & 0 & $0.0 \%$ & & & & & & \\
\hline 119 & & & 1987 & 32 & 27 & $-15.6 \%$ & & & & & & \\
\hline 120 & & & 1988 & 51 & 66 & $29.4 \%$ & & & & & & \\
\hline \begin{tabular}{|l|l|}
121 \\
\end{tabular} & & & 1989 & 19 & 19 & $0.0 \%$ & & & & & & \\
\hline 122 & & & 1990 & 2 & 0 & $-100.0 \%$ & & & & & & \\
\hline 123 & & & 1991 & 0 & 0 & $0.0 \%$ & & & & & & \\
\hline 124 & & & 1992 & 0 & 0 & $0.0 \%$ & & & & & & \\
\hline 125 & & & 1993 & 47 & 62 & $31.9 \%$ & & & & & & \\
\hline \begin{tabular}{|l|}
126 \\
\end{tabular} & & & 1994 & 51 & 66 & $29.4 \%$ & & & & & & \\
\hline 127 & & & 1995 & 12 & 41 & $241.7 \%$ & & & & & & \\
\hline 128 & & & 1996 & 0 & 0 & $0.0 \%$ & & & & & & \\
\hline \begin{tabular}{|c|}
129 \\
\end{tabular} & & & 1997 & 0 & 0 & $0.0 \%$ & & & & & & \\
\hline 130 & & & 1998 & 0 & 0 & $0.0 \%$ & & & & & & \\
\hline 131 & & & 1999 & 0 & 0 & $0.0 \%$ & & & & & & \\
\hline 132 & & & 2000 & 0 & 0 & $0.0 \%$ & & & & & & \\
\hline 133 & & & 2001 & 66 & 66 & $0.0 \%$ & & & & & & \\
\hline \begin{tabular}{|l|}
134 \\
\end{tabular} & & & 2002 & 23 & 55 & $139.1 \%$ & & & & & & \\
\hline 135 & & & 2003 & 0 & 0 & $0.0 \%$ & & & & & & \\
\hline
\end{tabular}

Figure 17. Portions of the annual scoring tables for end-of-year storage and Cle Elum smolt outmigration, found on the "Yearly Summary" page of the DSS_Agg spreadsheet.

\section{Overbank Flows and Damaging Floods}

Two tables on the "YearlySummary" page contain information on overbank flows and damaging floods (fig. 18). Both tables are scored as counts of days when the discharge equals or exceeds the thresholds listed on the "Parameters" page for overbank flow or damaging floods, respectively. The threshold for overbank flow for each flood plain reach was estimated as the mean daily flow from the historical record having a recurrence interval of 1.67 years. Damaging floods were similarly estimated as the mean daily flow from the historical record having a 25-year return period. Both tables are conditionally formatted, but with opposite criteria. Overbank flows were considered beneficial, so the "Pct Chg" cells turn green if the alternative results in an increase of 10 percent or more in the frequency of such events and red if the converse is true. In contrast, an increase of 10 percent or more in the frequency of damaging floods results in the cell turning red. In addition, the columns containing the frequencies of damaging floods, labeled baseline and alternative, are formatted to turn red if any of the frequencies exceed zero. This feature was added to alert the user of the occurrence of damaging floods, regardless of whether the alternative results in an increase in their frequency. 


\begin{tabular}{|c|c|c|c|c|c|c|c|c|c|c|c|}
\hline & A & $\mathrm{B}$ & $\mathrm{C}$ & $\mathrm{D}$ & $\mathrm{E}$ & $\mathrm{F}$ & G & $\mathrm{H}$ & $\mathrm{I}$ & $\mathrm{J}$ & $\mathrm{K}$ \\
\hline \begin{tabular}{|l|l|}
138 \\
\end{tabular} & & & & Easton & & & Kittitas & & & Naches & \\
\hline 139 & Overbank flow & Year & Base & Alternative & Pct Chg & Base & Alternative & Pct Chg & Base & Alternative & Pct Chg \\
\hline 140 & Day count, $Q>=1.67 \mathrm{yr}$ flood & 1982 & 0 & 0 & $0.0 \%$ & 4 & 0 & $-100.0 \%$ & 8 & 7 & $-12.5 \%$ \\
\hline 141 & & 1983 & 0 & 2 & $200.0 \%$ & 0 & 0 & $0.0 \%$ & 9 & 9 & $0.0 \%$ \\
\hline 142 & & 1984 & 0 & 4 & $400.0 \%$ & 1 & 6 & $500.0 \%$ & 0 & 0 & $0.0 \%$ \\
\hline 143 & & 1985 & 0 & 0 & $0.0 \%$ & 0 & 0 & $0.0 \%$ & 2 & 2 & $0.0 \%$ \\
\hline 144 & & 1986 & 0 & 0 & $0.0 \%$ & 0 & 0 & $0.0 \%$ & 6 & 4 & $-33.3 \%$ \\
\hline 145 & & 1987 & 0 & 0 & $0.0 \%$ & 0 & 0 & $0.0 \%$ & 0 & 0 & $0.0 \%$ \\
\hline 146 & & 1988 & 0 & 0 & $0.0 \%$ & 0 & 0 & $0.0 \%$ & 0 & 0 & $0.0 \%$ \\
\hline 147 & & 1989 & 0 & 0 & $0.0 \%$ & 0 & 0 & $0.0 \%$ & 0 & 0 & $0.0 \%$ \\
\hline 148 & & 1990 & 7 & 13 & $85.7 \%$ & 0 & 0 & $0.0 \%$ & 2 & 2 & $0.0 \%$ \\
\hline 149 & & 1991 & 21 & 22 & $4.8 \%$ & 8 & 11 & $37.5 \%$ & 1 & 1 & $0.0 \%$ \\
\hline 150 & & 1992 & 0 & 0 & $0.0 \%$ & 0 & 0 & $0.0 \%$ & 0 & 0 & $0.0 \%$ \\
\hline \begin{tabular}{|l|}
151 \\
\end{tabular} & & 1993 & 0 & 0 & $0.0 \%$ & 0 & 0 & $0.0 \%$ & 0 & 0 & $0.0 \%$ \\
\hline 152 & & 1994 & 0 & 0 & $0.0 \%$ & 0 & 0 & $0.0 \%$ & 0 & 0 & $0.0 \%$ \\
\hline \begin{tabular}{|l|l|}
153 \\
\end{tabular} & & 1995 & 0 & 0 & $0.0 \%$ & 0 & 0 & $0.0 \%$ & 8 & 8 & $0.0 \%$ \\
\hline \begin{tabular}{|l|l|}
154 \\
\end{tabular} & & 1996 & 25 & 31 & $24.0 \%$ & 26 & 31 & $19.2 \%$ & 24 & 27 & $12.5 \%$ \\
\hline 155 & & 1997 & 21 & 20 & $-4.8 \%$ & 35 & 35 & $0.0 \%$ & 34 & 34 & $0.0 \%$ \\
\hline 156 & & 1998 & 0 & 0 & $0.0 \%$ & 0 & 0 & $0.0 \%$ & 8 & 12 & $50.0 \%$ \\
\hline \begin{tabular}{|l|l|}
157 \\
\end{tabular} & & 1999 & 5 & 5 & $0.0 \%$ & 7 & 7 & $0.0 \%$ & 20 & 20 & $0.0 \%$ \\
\hline \begin{tabular}{|l|}
158 \\
\end{tabular} & & 2000 & 12 & 15 & $25.0 \%$ & 8 & 5 & $-37.5 \%$ & 0 & 2 & $200.0 \%$ \\
\hline \begin{tabular}{|l|}
159 \\
\end{tabular} & & 2001 & 0 & 0 & $0.0 \%$ & 0 & 0 & $0.0 \%$ & 0 & 0 & $0.0 \%$ \\
\hline 160 & & 2002 & 0 & 1 & $100.0 \%$ & 1 & 0 & $-100.0 \%$ & 4 & 4 & $0.0 \%$ \\
\hline \begin{tabular}{|l|l|}
161 \\
\end{tabular} & & 2003 & 0 & 0 & $0.0 \%$ & 0 & 0 & $0.0 \%$ & 3 & 3 & $0.0 \%$ \\
\hline \multicolumn{12}{|l|}{\begin{tabular}{|l|}
162 \\
\end{tabular}} \\
\hline \multicolumn{12}{|l|}{\begin{tabular}{|l|}
163 \\
\end{tabular}} \\
\hline \begin{tabular}{|l|}
164 \\
\end{tabular} & & & & Easton & & & Kittitas & & & Naches & \\
\hline \begin{tabular}{|l|l|}
165 \\
165 \\
\end{tabular} & Damaging flood & Year & Base & Alternative & Pct Chg & Base & Alternative & Pct Chg & Base & Alternative & Pct Chg \\
\hline 166 & Day count, $Q>=25 \mathrm{yr}$ flood & 1982 & 0 & 0 & $0.0 \%$ & 0 & 0 & $0.0 \%$ & 0 & 0 & $0.0 \%$ \\
\hline \begin{tabular}{|l|}
167 \\
\end{tabular} & & 1983 & 0 & 0 & $0.0 \%$ & 0 & 0 & $0.0 \%$ & 0 & 0 & $0.0 \%$ \\
\hline 168 & & 1984 & 0 & 0 & $0.0 \%$ & 0 & 0 & $0.0 \%$ & 0 & 0 & $0.0 \%$ \\
\hline \begin{tabular}{|l|}
169 \\
\end{tabular} & & 1985 & 0 & 0 & $0.0 \%$ & 0 & 0 & $0.0 \%$ & 0 & 0 & $0.0 \%$ \\
\hline 170 & & 1986 & 0 & 0 & $0.0 \%$ & 0 & 0 & $0.0 \%$ & 0 & 0 & $0.0 \%$ \\
\hline 171 & & 1987 & 0 & 0 & $0.0 \%$ & 0 & 0 & $0.0 \%$ & 0 & 0 & $0.0 \%$ \\
\hline 172 & & 1988 & 0 & 0 & $0.0 \%$ & 0 & 0 & $0.0 \%$ & 0 & 0 & $0.0 \%$ \\
\hline 173 & & 1989 & 0 & 0 & $0.0 \%$ & 0 & 0 & $0.0 \%$ & 0 & 0 & $0.0 \%$ \\
\hline \begin{tabular}{|l|}
174 \\
\end{tabular} & & 1990 & 0 & 0 & $0.0 \%$ & 0 & 0 & $0.0 \%$ & 0 & 0 & $0.0 \%$ \\
\hline \begin{tabular}{|l|}
175 \\
\end{tabular} & & 1991 & 0 & 2 & $200.0 \%$ & 0 & 0 & $0.0 \%$ & 0 & 0 & $0.0 \%$ \\
\hline \begin{tabular}{|l|}
176 \\
\end{tabular} & & 1992 & 0 & 0 & $0.0 \%$ & 0 & 0 & $0.0 \%$ & 0 & 0 & $0.0 \%$ \\
\hline \begin{tabular}{|l|l|}
177 \\
\end{tabular} & & 1993 & 0 & 0 & $0.0 \%$ & 0 & 0 & $0.0 \%$ & 0 & 0 & $0.0 \%$ \\
\hline 178 & & 1994 & 0 & 0 & $0.0 \%$ & 0 & 0 & $0.0 \%$ & 0 & 0 & $0.0 \%$ \\
\hline 179 & & 1995 & 0 & 0 & $0.0 \%$ & 0 & 0 & $0.0 \%$ & 0 & 0 & $0.0 \%$ \\
\hline 180 & & 1996 & 0 & 0 & $0.0 \%$ & 0 & 0 & $0.0 \%$ & 0 & 0 & $0.0 \%$ \\
\hline \begin{tabular}{|l|}
181 \\
\end{tabular} & & 1997 & 0 & 0 & $0.0 \%$ & 0 & 0 & $0.0 \%$ & 0 & 0 & $0.0 \%$ \\
\hline \begin{tabular}{|l|l|}
182 \\
\end{tabular} & & 1998 & 0 & 0 & $0.0 \%$ & 0 & 0 & $0.0 \%$ & 0 & 0 & $0.0 \%$ \\
\hline \begin{tabular}{|l|l}
183 \\
\end{tabular} & & 1999 & 0 & 0 & $0.0 \%$ & 0 & 0 & $0.0 \%$ & 0 & 0 & $0.0 \%$ \\
\hline \begin{tabular}{|l|l}
184 \\
\end{tabular} & & 2000 & 0 & 0 & $0.0 \%$ & 0 & 0 & $0.0 \%$ & 0 & 0 & $0.0 \%$ \\
\hline \begin{tabular}{|l|}
185 \\
\end{tabular} & & 2001 & 0 & 0 & $0.0 \%$ & 0 & 0 & $0.0 \%$ & 0 & 0 & $0.0 \%$ \\
\hline \begin{tabular}{|l|}
186 \\
\end{tabular} & & 2002 & 0 & 0 & $0.0 \%$ & 0 & 0 & $0.0 \%$ & 0 & 0 & $0.0 \%$ \\
\hline \begin{tabular}{|l|}
187 \\
\end{tabular} & & 2003 & 0 & 0 & $0.0 \%$ & 0 & 0 & $0.0 \%$ & 0 & 0 & $0.0 \%$ \\
\hline
\end{tabular}

Figure 18. Portions of the annual scoring tables for overbank flows and damaging floods, found on the "Yearly Summary" page of the DSS_Agg spreadsheet.

\section{Sediment Transport and Geomorphology}

Information for this component was derived from the Sediment Impact Analysis Methods model (SIAM), which was run for the "No Action" baseline and three alternative scenarios by BOR's Sedimentation and River Hydraulics Group. Four aspects of sediment transport and geomorphology are considered in the YRDSS: incipient motion, flushing flow, geomorphic work, and redd scour.

Incipient motion is a threshold defined as the critical discharge required to initiate movement of the surface substratum over the majority of the bed. This variable is referred to as the "Armor Disruption Threshold." The default threshold discharges for each of the five flood plain reaches (table 5) are entered on the "Parameters" page. SIAM output for the Easton reach consisted of separate thresholds for five subreaches contained within the boundaries of the study site. To accommodate the need for a single threshold value in the YRDSS, we determined the threshold discharge for this reach as a lengthweighted mean of the discharges provided for each subreach. 
Table 5. Threshold discharges for incipient motion from SIAM model, found on the "Parameters" page of the DSS_Agg spreadsheet. $\mathrm{Ft}^{3} / \mathrm{s}=$ cubic feet per second.

\begin{tabular}{cc}
\hline Flood plain reach & Threshold discharge for incipient motion, in ft3/s \\
\hline Easton & $8,490^{1}$ \\
Kittitas & 333,853 \\
Naches & 1,490 \\
Union Gap & 23,507 \\
Wapato & 66,383 \\
\hline
\end{tabular}

${ }^{1}$ Length-weighted mean of threshold discharges.

Scoring for this component is performed by counting the number of days when the discharge at a reach equals or exceeds the threshold discharge (fig. 19). The day-count is recorded in the "Armor Disruption" table for each year for the baseline and the alternative, and a percent change is recorded in the "Pct Chg" column of the table. If the frequency of armor disruption increases under the alternative by a factor of 10 percent or more, the "Pct Chg" cells turn green. The cells turn red if the frequency decreases by 10 percent or more.

Flushing flow refers to the potential transport of fine materials over the course of a year under the flow regimes representing the baseline and alternative cases. The biological basis for this component is that removal of sand and smaller materials cleanses the substrate, thereby enhancing egg viability during the incubation period, and may provide more suitable conditions for aquatic macroinvertebrates (Reiser and others, 1989; Simpkins and Hubert, 2000). The transport potential is a measure of the river's ability to move sand and smaller material, assuming an infinite potential supply and no interference from other grain classes.

Scoring for fine-sediment transport (fig. 20) is based on the total potential transport of sand and smaller material over the course of a year. This information is derived from the lookup tables contained on the "SedimentLookup" page of the DSS_Agg spreadsheet (App 3). The SIAM model produced separate lookup tables for the "No Action" baseline and each of the alternatives. The values shown in Appendix 3 have been standardized to a single array of simulated discharges (the tables provided from

\begin{tabular}{|c|c|c|c|c|c|c|c|c|c|c|c|}
\hline & A & B & $\mathrm{C}$ & $\mathrm{D}$ & $\mathrm{E}$ & $\mathrm{F}$ & G & $\mathrm{H}$ & $\mathrm{I}$ & $\mathrm{J}$ & $\mathrm{K}$ \\
\hline 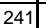 & & & & Easton & & & Kittitas & & & Naches & \\
\hline 242 & Armor Disruption & Year & Base & Alternative & Pct Chg & Base & Alternative & Pct Chg & Base & Alternative & Pct Chg \\
\hline 243 & Days above threshold & 1982 & 0 & 0 & $0.0 \%$ & 0 & 0 & $0.0 \%$ & 162 & 155 & $-4.3 \%$ \\
\hline 244 & & 1983 & 0 & 0 & $0.0 \%$ & 0 & 0 & $0.0 \%$ & 187 & 152 & $-18.7 \%$ \\
\hline 245 & & 1984 & 0 & 0 & $0.0 \%$ & 0 & 0 & $0.0 \%$ & 179 & 163 & $-8.9 \%$ \\
\hline 246 & & 1985 & 0 & 0 & $0.0 \%$ & 0 & 0 & $0.0 \%$ & 87 & 94 & $8.0 \%$ \\
\hline 247 & & 1986 & 0 & 0 & $0.0 \%$ & 0 & 0 & $0.0 \%$ & 111 & 117 & $5.4 \%$ \\
\hline 248 & & 1987 & 0 & 0 & $0.0 \%$ & 0 & 0 & $0.0 \%$ & 88 & 76 & $-13.6 \%$ \\
\hline 249 & & 1988 & 0 & 0 & $0.0 \%$ & 0 & 0 & $0.0 \%$ & 75 & 82 & $9.3 \%$ \\
\hline 250 & & 1989 & 0 & 0 & $0.0 \%$ & 0 & 0 & $0.0 \%$ & 85 & 107 & $25.9 \%$ \\
\hline 251 & & 1990 & 0 & 0 & $0.0 \%$ & 0 & 0 & $0.0 \%$ & 135 & 131 & $-3.0 \%$ \\
\hline 252 & & 1991 & 0 & 3 & $300.0 \%$ & 0 & 0 & $0.0 \%$ & 207 & 198 & $-4.3 \%$ \\
\hline 253 & & 1992 & 0 & 0 & $0.0 \%$ & 0 & 0 & $0.0 \%$ & 53 & 60 & $13.2 \%$ \\
\hline 254 & & 1993 & 0 & 0 & $0.0 \%$ & 0 & 0 & $0.0 \%$ & 51 & 46 & $-9.8 \%$ \\
\hline 255 & & 1994 & 0 & 0 & $0.0 \%$ & 0 & 0 & $0.0 \%$ & 50 & 47 & $-6.0 \%$ \\
\hline 256 & & 1995 & 0 & 0 & $0.0 \%$ & 0 & 0 & $0.0 \%$ & 191 & 168 & $-12.0 \%$ \\
\hline \begin{tabular}{|l|}
257 \\
\end{tabular} & & 1996 & 0 & 0 & $0.0 \%$ & 0 & 0 & $0.0 \%$ & 262 & 234 & $-10.7 \%$ \\
\hline \begin{tabular}{|l|}
258 \\
\end{tabular} & & 1997 & 0 & 0 & $0.0 \%$ & 0 & 0 & $0.0 \%$ & 205 & 188 & $-8.3 \%$ \\
\hline 259 & & 1998 & 0 & 0 & $0.0 \%$ & 0 & 0 & $0.0 \%$ & 150 & 152 & $1.3 \%$ \\
\hline 260 & & 1999 & 0 & 0 & $0.0 \%$ & 0 & 0 & $0.0 \%$ & 202 & 173 & $-14.4 \%$ \\
\hline \begin{tabular}{|l|}
261 \\
\end{tabular} & & 2000 & 0 & 0 & $0.0 \%$ & 0 & 0 & $0.0 \%$ & 168 & 167 & $-0.6 \%$ \\
\hline \begin{tabular}{|l|l|l|l|l|l|}
262 \\
\end{tabular} & & 2001 & 0 & 0 & $0.0 \%$ & 0 & 0 & $0.0 \%$ & 29 & 34 & $17.2 \%$ \\
\hline 263 & & 2002 & 0 & 0 & $0.0 \%$ & 0 & 0 & $0.0 \%$ & 128 & 123 & $-3.9 \%$ \\
\hline 264 & & 2003 & 0 & 0 & $0.0 \%$ & 0 & 0 & $0.0 \%$ & 147 & 136 & $-7.5 \%$ \\
\hline
\end{tabular}

Figure 19. Portion of the annual scoring table for armor disruption, found on the "Yearly Summary" page of the DSS_Agg spreadsheet. 


\begin{tabular}{|c|c|c|c|c|c|c|c|c|c|c|c|}
\hline & $\mathrm{A}$ & $\mathrm{B}$ & $C$ & $\mathrm{D}$ & $\mathrm{E}$ & $\mathrm{F}$ & G & $\mathrm{H}$ & 1 & $\mathrm{~J}$ & $\mathrm{~K}$ \\
\hline 191 & & & & Easton & & & Kittitas & & & Naches & \\
\hline 192 & Fine-material transport & Year & Base & Alternative & Pct Chg & Base & Alternative & Pct Chg & Base & Alternative & Pct Chg \\
\hline 193 & Tons per day & 1982 & 9 & 12 & $36.9 \%$ & 108 & 105 & $-2.9 \%$ & 64 & 64 & $0.0 \%$ \\
\hline 194 & & 1983 & 8 & 10 & $27.5 \%$ & 110 & 111 & $0.4 \%$ & 66 & 65 & $-1.8 \%$ \\
\hline 195 & & 1984 & 10 & 12 & $15.5 \%$ & 111 & 108 & $-2.8 \%$ & 56 & 57 & $0.9 \%$ \\
\hline 196 & & 1985 & 7 & 6 & $-15.5 \%$ & 74 & 73 & $-0.7 \%$ & 35 & 36 & $3.8 \%$ \\
\hline 197 & & 1986 & 7 & 7 & $1.8 \%$ & 81 & 80 & $-0.8 \%$ & 42 & 41 & $-1.4 \%$ \\
\hline 198 & & 1987 & 10 & 6 & $-34.4 \%$ & 63 & 61 & $-2.5 \%$ & 36 & 33 & $-8.2 \%$ \\
\hline 199 & & 1988 & 6 & 5 & $-19.9 \%$ & 58 & 51 & $-11.4 \%$ & 27 & 29 & $7.1 \%$ \\
\hline 200 & & 1989 & 6 & 10 & $51.6 \%$ & 75 & 76 & $1.2 \%$ & 37 & 41 & $12.6 \%$ \\
\hline 201 & & 1990 & 11 & 15 & $40.9 \%$ & 100 & 102 & $2.2 \%$ & 47 & 46 & $-3.9 \%$ \\
\hline 202 & & 1991 & 21 & 30 & $43.1 \%$ & 133 & 137 & $2.6 \%$ & 53 & 51 & $-3.6 \%$ \\
\hline 203 & & 1992 & 11 & 6 & $-49.9 \%$ & 76 & 70 & $-7.9 \%$ & 24 & 23 & $-5.3 \%$ \\
\hline 204 & & 1993 & 7 & 4 & $-36.6 \%$ & 57 & 54 & $-5.5 \%$ & 24 & 23 & $-5.8 \%$ \\
\hline 205 & & 1994 & 7 & 8 & $2.9 \%$ & 43 & 46 & $6.5 \%$ & 20 & 22 & $9.2 \%$ \\
\hline 206 & & 1995 & 6 & 6 & $1.2 \%$ & 87 & 78 & $-10.3 \%$ & 63 & 61 & $-3.1 \%$ \\
\hline 207 & & 1996 & 23 & 30 & $31.8 \%$ & 206 & 208 & $1.0 \%$ & 111 & 114 & $2.4 \%$ \\
\hline 208 & & 1997 & 21 & 26 & $26.0 \%$ & 177 & 173 & $-1.9 \%$ & 106 & 106 & $-0.2 \%$ \\
\hline 209 & & 1998 & 9 & 10 & $11.5 \%$ & 99 & 98 & $-0.7 \%$ & 61 & 64 & $4.6 \%$ \\
\hline \begin{tabular}{|l|}
210 \\
\end{tabular} & & 1999 & 13 & 17 & $31.4 \%$ & 113 & 113 & $0.5 \%$ & 91 & 89 & $-2.2 \%$ \\
\hline \begin{tabular}{|l|}
211 \\
\end{tabular} & & 2000 & 14 & 18 & $24.6 \%$ & 119 & 113 & $-5.2 \%$ & 56 & 59 & $4.9 \%$ \\
\hline \begin{tabular}{|l|}
212 \\
\end{tabular} & & 2001 & 11 & 8 & $-27.9 \%$ & 47 & 53 & $13.1 \%$ & 15 & 15 & $-2.6 \%$ \\
\hline \begin{tabular}{|l|}
213 \\
\end{tabular} & & 2002 & 7 & 10 & $47.7 \%$ & 93 & 84 & $-9.8 \%$ & 55 & 55 & $0.8 \%$ \\
\hline \begin{tabular}{|l|}
214 \\
\end{tabular} & & 2003 & 5 & 5 & $-7.8 \%$ & 81 & 78 & $-3.6 \%$ & 46 & 46 & $1.0 \%$ \\
\hline
\end{tabular}

Figure 20. Portion of the annual scoring table for fine sediment transport, found on the "Yearly Summary" page of the DSS_Agg spreadsheet.

SIAM contained similar but different discharges for each alternative), and a length-weighted average was used to generate a single transport rate for flood plain sites containing multiple reaches or subreaches from the SIAM model. Values for cells having blue backgrounds in Appendix 3 were stipulated, whereas those highlighted in pink were found by linear extrapolation.

The scoring algorithm for fine-sediment transport is based on the following sequence:

1. The reach discharge is determined for each day of the year from the "Flows" page of the DSS_Agg spreadsheet.

2. A corresponding transport rate for fine sediment is determined by linear interpolation of the lookup tables on the "SedimentLookup" page and recorded daily on the "SedimentCalc" page.

3. The total potential transport, in megatons, is found by summing all the daily values for the year and recorded in the "Fine-material transport" table of the DSS_Agg spreadsheet for the baseline and alternative conditions.

4. If potential annual transport of fine sediment under the alternative increases by 10 percent or more, the "Pct Chg" cell associated with the site and year turns green. If it decreases by 10 percent or more, the cells turn red.

Geomorphic work refers to the ability of the river to maintain or alter the morphology of the channel over time. Stream power was used as a measure of the daily energy expended by flowing water in performing sediment transport functions. Stream power is a function of hydraulic radius (approximately the average water depth), the energy gradient, mean channel velocity, wetted perimeter, longitudinal channel length, and duration of time, modified by an efficiency term, and is expressed in units of foot-megatons per day (Hilldale and Mooney, 2007b).

Scoring for this component was somewhat more complex than for other variables in the YRDSS for several reasons. First, most channel-forming or maintenance work occurs at relatively high discharges over a relatively short period of time. Although all work performed over the course of a year can add up to a significant expenditure of energy, the work performed at low flows that occur with high frequency are ineffective for channel-forming or maintenance functions (Leopold and others, 1964). For 
this reason, the computations of annual work in the YRDSS are restricted to the largest sum of work performed over a continuous 15-day interval for each year.

Second, too little geomorphic work can result in sediment storage, vegetation growth, or other factors that may lead to channel aggradation, an undesirable consequence of failing to provide sufficient flows to maintain a channel in a state of dynamic equilibrium. Leopold and others (1964) provided a guideline that the most effective discharge for channel maintenance in alluvial channels was the bankfull discharge, approximated by the maximum annual discharge having a recurrence interval of 1.5 years. We estimated the bankfull discharge for each site by determining the 1.5-year recurrence interval from the period of record of gage data for each site. Leopold and others (1964), however, stipulated that the 1.5-year recurrence interval was based on natural, unregulated flows. Virtually all of the gage records available to us were affected in part or in total by flow regulation, so our estimates of bankfull discharge may be in error. As a threshold value to depict a deficiency of critical stream power, we determined the average of the maximum 15-day values of geomorphic work for years in which the maximum daily flow was at or near our estimate of the bankfull level. The threshold for insufficient (or ineffective) stream power was then set at 75 percent of the 15-day maximum for these years.

A third complication in the geomorphic work category was that too much stream power can also be undesirable. From a biological perspective, very large values of stream power may be beneficial because they may signal events when side channels are scoured out or new channels formed by avulsion. However, too much stream power could result in bank erosion, channel avulsion, and meander migration that would not be viewed as a beneficial process by landowners along the river. Therefore, we also set an upper threshold for geomorphic work. For this threshold, we selected water year 1997 as one that probably resulted in significant channel modification. The threshold was arbitrarily set at 75 percent of the 15-day maximum energy expenditure for that year. Cells for geomorphic work under the baseline and alternative are color-coded, such that total work for a year below the threshold turn red, those in the "effective but not damaging" window turn green, and those that are above the maximum threshold turn orange (fig. 21). These formats do not necessarily depict good or bad conditions, but are designed to alert decisionmakers of potential issues that might arise.

\begin{tabular}{|c|c|c|c|c|c|c|c|c|c|c|c|}
\hline & $\mathrm{A}$ & $\mathrm{B}$ & $\mathrm{C}$ & $\mathrm{D}$ & $\mathrm{E}$ & $F$ & G & $\mathrm{H}$ & $\mathrm{I}$ & $\mathrm{J}$ & $\mathrm{K}$ \\
\hline 216 & & & & Easton & & & Kittitas & & & Naches & \\
\hline 217 & Geomorphic Adjustment & Year & Base & Alternative & Pct Chg & Base & Alternative & Pct Chg & Base & Alternative & Pct Chg \\
\hline 218 & ft-megaton per day & 1982 & 2,169 & 2,576 & $18.8 \%$ & 28,267 & 21,968 & $-22.3 \%$ & 26,444 & 26,129 & $-1.2 \%$ \\
\hline 219 & & 1983 & 1,862 & 3,324 & $78.5 \%$ & 20,541 & 23,186 & $12.9 \%$ & 27,727 & 27,077 & $-2.3 \%$ \\
\hline 220 & & 1984 & 2,094 & 3,371 & $61.0 \%$ & 29,298 & 23,137 & $-21.0 \%$ & 19,683 & 15,796 & $-19.7 \%$ \\
\hline 221 & & 1985 & 1,491 & 1,278 & $-14.3 \%$ & 16,861 & 15,978 & $-5.2 \%$ & 16,914 & 16,827 & $-0.5 \%$ \\
\hline 222 & & 1986 & 1,541 & 1,862 & $20.9 \%$ & 20,500 & 22,323 & $8.9 \%$ & 21,906 & 19,254 & $-12.1 \%$ \\
\hline 223 & & 1987 & 2,981 & 1,573 & $-47.2 \%$ & 15,064 & 11,583 & $-23.1 \%$ & 21,102 & 20,152 & $-4.5 \%$ \\
\hline \begin{tabular}{|l|}
224 \\
\end{tabular} & & 1988 & 1,363 & 1,517 & $11.3 \%$ & 14,748 & 13,203 & $-10.5 \%$ & 10,830 & 11,171 & $3.1 \%$ \\
\hline 225 & & 1989 & 1,769 & 3,480 & $96.7 \%$ & 16,437 & 19,509 & $18.7 \%$ & 14,135 & 16,952 & $19.9 \%$ \\
\hline \begin{tabular}{|l|l|}
226 \\
\end{tabular} & & 1990 & 3,908 & 5,448 & $39.4 \%$ & 23,391 & 26,709 & $14.2 \%$ & 20,177 & 19,098 & $-5.3 \%$ \\
\hline \begin{tabular}{|l|}
227 \\
\end{tabular} & & 1991 & 6,306 & 10,556 & $67.4 \%$ & 33,455 & 45,280 & $35.3 \%$ & 11,899 & 12,157 & $2.2 \%$ \\
\hline \begin{tabular}{|l|}
228 \\
228 \\
\end{tabular} & & 1992 & 3,114 & 980 & $-68.5 \%$ & 15,855 & 15,441 & $-2.6 \%$ & 7,507 & 8,361 & $11.4 \%$ \\
\hline \begin{tabular}{|l|}
229 \\
\end{tabular} & & 1993 & 2,619 & 1,028 & $-60.7 \%$ & 15,104 & 10,766 & $-28.7 \%$ & 13,243 & 13,803 & $4.2 \%$ \\
\hline 230 & & 1994 & 2,900 & 1,873 & $-35.4 \%$ & 10,293 & 10,133 & $-1.6 \%$ & 8,133 & 8,449 & $3.9 \%$ \\
\hline \begin{tabular}{|l|}
231 \\
\end{tabular} & & 1995 & 1,613 & 1,766 & $9.5 \%$ & 19,374 & 20,680 & $6.7 \%$ & 21,146 & 22,020 & $4.1 \%$ \\
\hline \begin{tabular}{|l|l|}
232 \\
\end{tabular} & & 1996 & 4,059 & 5,711 & $40.7 \%$ & 49,294 & 49,764 & $1.0 \%$ & 36,404 & 37,152 & $2.1 \%$ \\
\hline \begin{tabular}{|l|}
233 \\
\end{tabular} & & 1997 & 6,135 & 6,704 & $9.3 \%$ & 43,268 & 44,142 & $2.0 \%$ & 38,135 & 38,518 & $1.0 \%$ \\
\hline 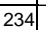 & & 1998 & 2,568 & 2,947 & $14.8 \%$ & 25,532 & 23,646 & $-7.4 \%$ & 25,612 & 26,902 & $5.0 \%$ \\
\hline 235 & & 1999 & 3,714 & 4,378 & $17.9 \%$ & 33,970 & 33,838 & $-0.4 \%$ & 29,814 & 30,620 & $2.7 \%$ \\
\hline 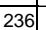 & & 2000 & 4,342 & 6,582 & $51.6 \%$ & 25,439 & 26,713 & $5.0 \%$ & 17,858 & 18,439 & $3.3 \%$ \\
\hline \begin{tabular}{|l|}
237 \\
\end{tabular} & & 2001 & 3,948 & 3,028 & $-23.3 \%$ & 11,486 & 12,628 & $9.9 \%$ & 5,915 & 6,305 & $6.6 \%$ \\
\hline \begin{tabular}{|l|}
238 \\
\end{tabular} & & 2002 & 1,474 & 3,308 & $124.5 \%$ & 23,429 & 16,180 & $-30.9 \%$ & 17,423 & 18,936 & $8.7 \%$ \\
\hline \begin{tabular}{|l|}
239 \\
\end{tabular} & & 2003 & 1,301 & 1,440 & $10.7 \%$ & 16,474 & 15,117 & $-8.2 \%$ & 21,320 & 21,156 & $-0.8 \%$ \\
\hline
\end{tabular}

Figure 21. Portion of the annual scoring table for geomorphic work, found on the "Yearly Summary" page of the DSS_Agg spreadsheet. 
The scoring algorithm for the geomorphic work component functions as follows:

1. The flow for each day, corresponding to the baseline or one of the scenarios, is read from the "Flows" page, and the rate of work, expressed in foot-megatons per day, is determined by linear interpolation of values in the appropriate lookup table. For example, if the scenario under investigation is the "No Action" baseline compared to the "Blackrock_2" alternative, the YRDSS would use the daily flows and lookup tables for those two data sets. Resulting values for geomorphic work are recorded for each day of each year on the "SedCalc" page.

2. The largest sum for a continuous 15-day period each year is recorded to the "Geomorphic Work" table of the "Yearly Summary" spreadsheet under the columns for baseline and alternative. These cells are conditionally formatted to change color according to the color-coding scheme described previously.

3. A percent change between the alternative and baseline is calculated in the "Pct Chg" column, and conditionally formatted to turn the cell red if the alternative results in a decrease in geomorphic work or green if the alternative results in an increase (fig. 21). Note that there is no difference in conditional formatting even if the total work exceeds the upper threshold for either the baseline or the alternative. Therefore, it is possible to obtain an apparently beneficial change in geomorphic work, as expressed by green cell background in the "Pct Chg" column, even though the upper threshold was exceeded.

\section{Subsidiary Workbooks}

\section{Site-Specific Yearly Habitat Summaries}

Five pages of the DSS_Agg spreadsheet are devoted to annual habitat summaries and scores for each of the life stages and target species associated with the flood plain reaches. The name of each page is prefaced by the name of the reach to which the data apply. For example, the habitat summaries for the Easton reach are contained on the page labeled "EastonYearlyHab," as illustrated in figure 22. The values and scores contained on the site-specific habitat summary pages are calculated in the subsidiary workbooks (DSS_Eas.xls for the Easton reach, for example) and copied to the corresponding pages in the DSS_Agg spreadsheet. The habitat calculations and scoring mechanisms in all five of the subsidiary

\begin{tabular}{|c|c|c|c|c|c|c|c|c|c|c|c|c|c|c|c|c|}
\hline \multirow{3}{*}{$\frac{2}{3}$} & A & B & C & $\mathrm{D}$ & $\mathrm{E}$ & $\mathrm{F}$ & G & $\mathrm{H}$ & 1 & $\mathrm{~J}$ & K & $\mathrm{L}$ & $M$ & $\mathrm{~N}$ & $\mathrm{O}$ & $\mathrm{P}$ \\
\hline & Spring Chinook & \multicolumn{3}{|c|}{ Redd Scour } & \multicolumn{3}{|c|}{ Spawning/incubation } & \multicolumn{3}{|c|}{ Fry } & \multicolumn{3}{|c|}{ Subyearling (Spring-summer) } & \multicolumn{3}{|c|}{ Subyearling (winter) } \\
\hline & Year & Base & Alternative & Pct Chg & Base & \begin{tabular}{|l|} 
Alternative \\
\end{tabular} & Pct Chg & Base & Alternative & Pct Chg & Base & \begin{tabular}{|l|} 
Alternative \\
\end{tabular} & Pct Chg & Base & Alternative & Pct Chg \\
\hline 4 & 1982 & 0.008 & 0.017 & $112.9 \%$ & 47.6 & 48.7 & $2.47 \%$ & 2.2 & 2.2 & $-2.69 \%$ & 51.2 & 51.1 & $-0.08 \%$ & 6.9 & 6.4 & $-6.93 \%$ \\
\hline 5 & 1983 & 0.018 & 0.030 & $72.8 \%$ & 45.1 & 39.0 & $-13.60 \%$ & 2.2 & 2.4 & $7.65 \%$ & 60.4 & 59.6 & $-1.44 \%$ & 7.5 & 7.7 & $2.85 \%$ \\
\hline 6 & 1984 & 0.010 & 0.047 & $387.2 \%$ & 46.1 & 40.1 & $-12.90 \%$ & 2.4 & 2.3 & $-1.63 \%$ & 45.3 & 48.1 & $6.11 \%$ & 6.9 & 6.9 & $-1.40 \%$ \\
\hline 7 & 1985 & 0.008 & 0.008 & $-0.3 \%$ & 52.9 & 52.9 & $0.00 \%$ & 2.9 & 2.4 & $-15.34 \%$ & 39.1 & 52.1 & $33.05 \%$ & 11.9 & 10.1 & $-15.48 \%$ \\
\hline 8 & 1986 & 0.008 & 0.008 & $-0.3 \%$ & 52.9 & 52.9 & $0.00 \%$ & 2.3 & 2.2 & $-2.58 \%$ & 43.4 & 56.5 & $30.15 \%$ & 9.0 & 7.5 & $-16.78 \%$ \\
\hline 9 & 1987 & 0.008 & 0.008 & $-0.3 \%$ & 49.0 & 49.0 & $0.00 \%$ & 2.4 & 2.3 & $-1.64 \%$ & 38.0 & 52.0 & $36.98 \%$ & 9.7 & 8.8 & $-9.19 \%$ \\
\hline 10 & 1988 & 0.008 & 0.008 & $-0.3 \%$ & 52.9 & 52.9 & $0.00 \%$ & 2.3 & 2.3 & $-0.02 \%$ & 48.8 & $\overline{60.4}$ & $23.92 \%$ & 10.3 & 9.7 & $-5.68 \%$ \\
\hline 11 & 1989 & 0.008 & 0.008 & $-0.3 \%$ & 52.2 & 52.9 & $1.24 \%$ & 2.9 & 2.5 & $-15.61 \%$ & 55.8 & 52.1 & $-6.61 \%$ & 8.0 & 7.5 & $-6.37 \%$ \\
\hline 12 & 1990 & 0.008 & 0.022 & $177.8 \%$ & 47.3 & 48.1 & $1.61 \%$ & 2.6 & 2.5 & $-3.08 \%$ & 49.9 & 52.9 & $6.12 \%$ & 7.4 & 7.3 & $-2.40 \%$ \\
\hline 13 & 1991 & 0.188 & 0.525 & $178.7 \%$ & 5.2 & 4.8 & $-8.25 \%$ & 2.5 & 2.4 & $-4.77 \%$ & 60.4 & 59.6 & $-1.38 \%$ & 6.8 & 6.9 & $1.11 \%$ \\
\hline 14 & 1992 & 0.008 & 0.008 & $-0.3 \%$ & 52.9 & 52.9 & $0.00 \%$ & 2.6 & 2.5 & $-5.11 \%$ & 36.7 & 60.4 & $64.49 \%$ & 8.2 & 7.6 & $-6.52 \%$ \\
\hline 15 & 1993 & 0.008 & 0.008 & $-0.3 \%$ & 50.3 & 50.3 & $0.00 \%$ & 2.7 & 2.6 & $-3.23 \%$ & 37.2 & 54.4 & $46.34 \%$ & 11.6 & 10.8 & $-6.78 \%$ \\
\hline 16 & 1994 & 0.008 & 0.008 & $-0.3 \%$ & 51.2 & 51.2 & $0.00 \%$ & 2.4 & 2.4 & $-0.81 \%$ & 42.5 & 37.8 & $-11.02 \%$ & 10.6 & 9.5 & $-10.60 \%$ \\
\hline 17 & 1995 & 0.008 & 0.009 & $15.0 \%$ & 52.9 & 52.9 & $0.00 \%$ & 2.5 & 2.4 & $-0.46 \%$ & 60.4 & 60.3 & $-0.22 \%$ & 7.7 & 7.7 & $0.00 \%$ \\
\hline 18 & 1996 & 0.102 & 0.128 & $25.7 \%$ & 15.5 & 5.3 & $-66.07 \%$ & 2.6 & 2.5 & $-1.64 \%$ & 59.8 & 58.6 & $-2.11 \%$ & 7.0 & 7.2 & $2.52 \%$ \\
\hline 19 & 1997 & 0.186 & 0.333 & $78.8 \%$ & 29.7 & 20.7 & $-30.15 \%$ & 2.3 & 2.4 & $4.05 \%$ & 46.6 & 47.3 & $1.62 \%$ & 7.3 & 7.6 & $3.07 \%$ \\
\hline 20 & 1998 & 0.008 & 0.022 & $182.4 \%$ & 52.9 & 44.3 & $-16.21 \%$ & 2.4 & 2.4 & $0.21 \%$ & 53.2 & 58.6 & $10.12 \%$ & 7.8 & 7.3 & $-5.72 \%$ \\
\hline 21 & 1999 & 0.008 & 0.019 & $131.1 \%$ & 52.9 & 47.8 & $-9.57 \%$ & 2.3 & 2.2 & $-2.73 \%$ & 43.7 & 46.0 & $5.18 \%$ & 6.9 & 6.6 & $-4.46 \%$ \\
\hline 22 & 2000 & 0.104 & 0.241 & $131.5 \%$ & 43.0 & 36.6 & $-14.87 \%$ & 2.6 & 2.6 & $-2.94 \%$ & 46.0 & 48.3 & $4.92 \%$ & 8.6 & 8.1 & $-5.33 \%$ \\
\hline 23 & 2001 & 0.008 & 0.008 & $-0.3 \%$ & 52.9 & 52.9 & $0.00 \%$ & 2.7 & 2.5 & $-7.98 \%$ & 33.8 & 40.0 & $18.50 \%$ & 12.0 & 10.3 & $-13.91 \%$ \\
\hline 24 & 2002 & 0.008 & 0.008 & $-0.3 \%$ & 54.1 & 54.1 & $-0.04 \%$ & 2.7 & 2.7 & $-1.65 \%$ & 46.6 & 40.2 & $-13.64 \%$ & 8.9 & 8.8 & $-1.09 \%$ \\
\hline 25 & 2003 & 0.008 & 0.008 & $-0.3 \%$ & 48.7 & 48.7 & $0.00 \%$ & 2.5 & 2.5 & $-2.99 \%$ & 55.2 & 60.3 & $9.15 \%$ & 10.2 & 9.3 & $-8.78 \%$ \\
\hline
\end{tabular}

Figure 22. Portion of the yearly habitat summary page for the Easton reach. Units of redd scour are in feet. Units of habitat area are in acres. 
notebooks are identical, with the exception that different target species and life stages are considered from reach to reach.

Three types of habitat statistics are displayed in the yearly habitat summaries (fig. 22). The first, redd scour, is an estimate of the depth of the active surface layer made up of substrate materials of the size typically found in salmonid redds. Redd scour was placed on the yearly habitat summary pages because of its link to reproductive success in salmonids. Spawning and incubation are treated as a combined life stage, with habitat values for each year determined as a function of habitat persistence, described in Appendix 2. Habitat values for the remaining life stages are derived from a habitat time series analysis, described below.

Redd scour is computed as the depth (in $\mathrm{ft}$ ) of bed material disturbance (active layer thickness) for representative flow rates due to sediment transport. It is noteworthy that redd scour, as treated in the SIAM model, is a generalized term representing an average value for the entire stream reach. It is not spatially explicit, meaning that redd scour is not confined to locations where redd construction might actually occur. The active layer thickness used in the YRDSS system considers a volumetric balance based on sediment load with an effective width engaged in transporting particles and a time of active transport (Hilldale and Mooney, 2007b). Lookup tables for active layer depth, arrayed by discharge and scenario, can be found in Appendix 3. As with the other sediment-related lookup tables, the values shown in Appendix 3 for redd scour are standardized to a single column of discharges and are lengthweighted averages for reaches containing multiple SIAM reaches or subreaches. Cells highlighted in light blue contain stipulated values, whereas those highlighted in pink were determined by linear extrapolation.

The scoring algorithm for redd scour operates according to the following sequence:

1. Each day of the year is flagged as being inside or outside the hydroperiod window for incubation (from the "Hydroperiods" page), by species and site.

2. For each day within the incubation period, the depth of the active layer is determined by linear interpolation of values contained in the appropriate lookup table, located on the "SedimentLookup" page of the DSS_Agg spreadsheet. Values for active layer depth are returned for each day of the incubation period on the "SedCalc" page of this spreadsheet.

3. The maximum active layer depth for each year is recorded to the "Redd Scour" tables for each target species, located on the "site-specific habitat summary" pages. The columns containing the maximum scour values in figure 22 are conditionally formatted to turn red if the depth of scour exceeds $0.33 \mathrm{ft}$ for salmon species or $0.16 \mathrm{ft}$ for trout or steelhead. These are thresholds used in the EDT model to depict redd-damaging scour depths (Joel Hubble, Bureau of Reclamation, written commun. August 7, 2007.)

4. The percent change in maximum scour depth is calculated in the "Pct Chg" column of the "Redd Scour" table. Cells in this column are conditionally formatted to turn red if the depth of scour increases by 10 percent or more under the alternative, or green if the depth of scour decreases by 10 percent or more.

\section{Spawning-Incubation Habitat Persistence}

Habitat persistence for spawning and incubation is based on the concept that successful reproduction in salmonids depends on the sustained suitability of spawning sites during the subsequent incubation period (Becker and Neitzel, 1985; Jager and others, 1999; Conner and others, 2001; Conner and Pflug, 2004). If areas that were suitable for spawning in the fall become unsuitable for incubation during the winter, for example, those areas have an effective value of zero. Thus, the areas of persistent habitat shown in the lookup tables of Appendix 2 represent habitat patches that remain suitable for both 
reproductive functions at combinations of discharges that occur during the spawning and incubation periods, respectively (fig. 23).

Persistent habitat areas are determined annually by finding the smallest composite area associated with the spawning flow for a species and the extreme flows during the subsequent incubation period:

1. The spawning and incubation hydroperiods for each species are determined from the "Hydroperiods" page and in-period dates flagged on the "HabTS_per" page for a target species ("SCHabTS_per" for spring chinook habitat persistence).

2. A spawning flow is calculated as the trimmed mean of the central 67 percent of the flows occurring within the spawning hydroperiod. The maximum and minimum discharges occurring within the incubation period are recorded as incubation flow extremes.

$121^{\circ} 10^{\prime} \mathrm{W}$

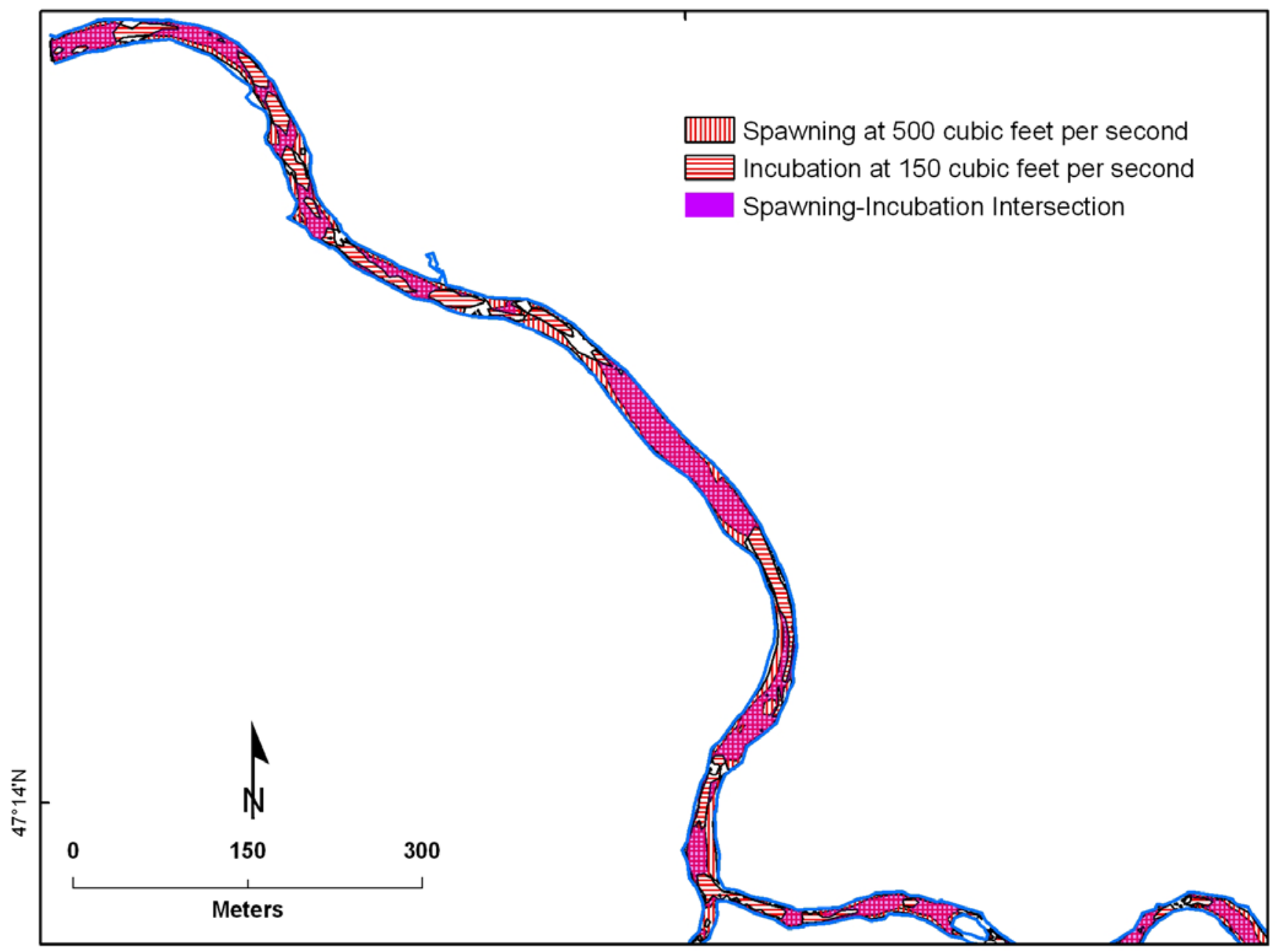

Figure 23. Example of an intersection map depicting persistent reproduction habitat in a portion of the Easton reach with a spawning flow of 500 cubic feet per second and an incubation flow of 150 cubic feet per second. 
3. A persistent habitat value is determined by linear interpolation along the diagonals of bracketing cells of the persistence table (fig. 24) for the spawning flow combined with the maximum incubation flow. A second persistent habitat value is found for the combination of the spawning flow and the minimum incubation flow. The lesser of these two values is then written to the spawning-incubation table as the composite persistent area for the species on the "YearlyHabitat" page of the subsidiary notebook and copied to the "<site_name>YearlyHab" page in the DSS_Agg workbook.

4. A percent difference between the persistent habitat values for the baseline and alternative is calculated in the "Pct Chg" columns of the yearly habitat tables and is conditionally formatted such that an increase under the alternative of 10 percent or more produces a green background and a decrease by a like amount results in a red background.

\begin{tabular}{|c|c|c|c|c|c|c|c|}
\hline \multirow{11}{*}{ 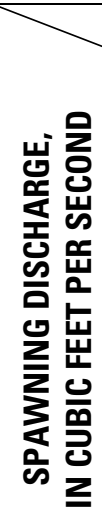 } & & \multicolumn{6}{|c|}{ INCUBATION DISCHARGE, IN CUBIC FEET PER SECOND } \\
\hline & \multirow[b]{2}{*}{0} & $\mathbf{0}$ & 150 & 167 & 300 & 400 & 500 \\
\hline & & \multicolumn{2}{|r|}{0.01} & & 0.01 & 0.01 & 0.01 \\
\hline & 150 & \multirow{3}{*}{$\begin{array}{l}0.01 \\
0.01\end{array}$} & \multicolumn{2}{|l|}{42.31} & 41.88 & 41.33 & 40.78 \\
\hline & 300 & & \multicolumn{2}{|c|}{36.73} & \multirow[t]{2}{*}{47.58} & \multirow[t]{2}{*}{47.16} & \multirow[t]{2}{*}{46.74} \\
\hline & 325 & & & 37.29 & & & \\
\hline & 400 & 0.01 & 27.61 & & 38.77 & 39.91 & 41.06 \\
\hline & 500 & 0.01 & 18.49 & & 29.95 & 32.66 & 35.38 \\
\hline & 600 & 0.01 & 10.95 & & 20.35 & 23.08 & 25.82 \\
\hline & 700 & 0.01 & 3.41 & & 10.75 & 13.50 & 16.26 \\
\hline & 900 & 0.01 & 0.58 & & 4.22 & 6.21 & 8.19 \\
\hline & 1100 & 0.01 & 0.17 & & 1.28 & 2.51 & 3.73 \\
\hline
\end{tabular}

Figure 24. Portion of a spawning-incubation persistence table showing the interpolation diagonals (yellow background) used to compute persistent habitat for a spawning discharge of 325 cubic feet per second and an incubation discharge of 167 cubic feet per second (tan background).

\section{Habitat Time Series}

The habitat time series is the fundamental building block for quantifying the effect of an alternative on the habitat for a target organism (Bovee and others, 1998). Construction of a habitat time series (fig. 25) is relatively straightforward, requiring two essential components: a time series of discharges (either baseline or alternative) and a relationship between discharge and habitat area. For every discharge in the flow series, there is a corresponding habitat value from the discharge-habitat function. Assembling a time series of habitat is merely a matter of translating the discharges for each time step into their associated habitat values and recording the translated values back to the time step. 


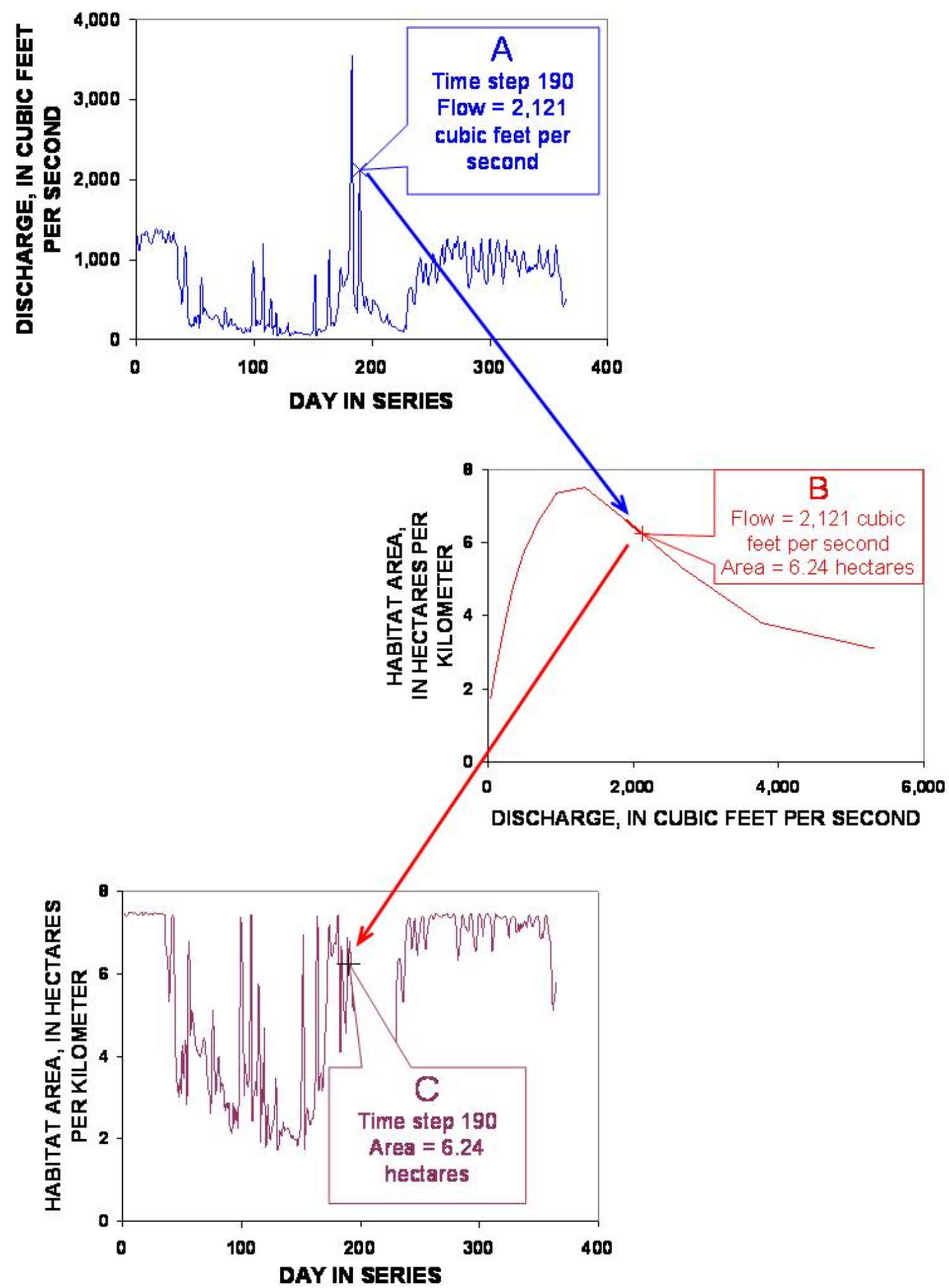

Figure 25. Elements used in the construction of a habitat time series: $A$, flow time series, $B$, habitat relative to flow function, and $C$, the resulting habitat time series. 
Scoring for the elements of the habitat time series was based on the following:

1. Each day of the year is flagged as being inside or outside the hydroperiod window for each life stage (from the "Hydroperiods" page).

2. The discharge for that date and location is found on the "Flows" page for both the baseline and the alternative condition.

3. The corresponding habitat area, in acres, for that flow and date is determined by linear interpolation of the lookup table for the species and life stage (Appendix 2) and recorded under a habitat time series column for each day in the hydroperiod.

4. The habitat area recorded on the yearly habitat summary page (and copied to the " $<$ site name>YearlyHab" page of DSS_Agg is the average of the lowest 50 percent of the values recorded for each year in the time series (fig. 26). This metric was used because the most likely habitat limitations for a life stage or species occur during periods when habitat is most restricted (Bovee and others, 1998). These habitat bottlenecks are defined by episodes when the habitat value falls below the median of the habitat time series.

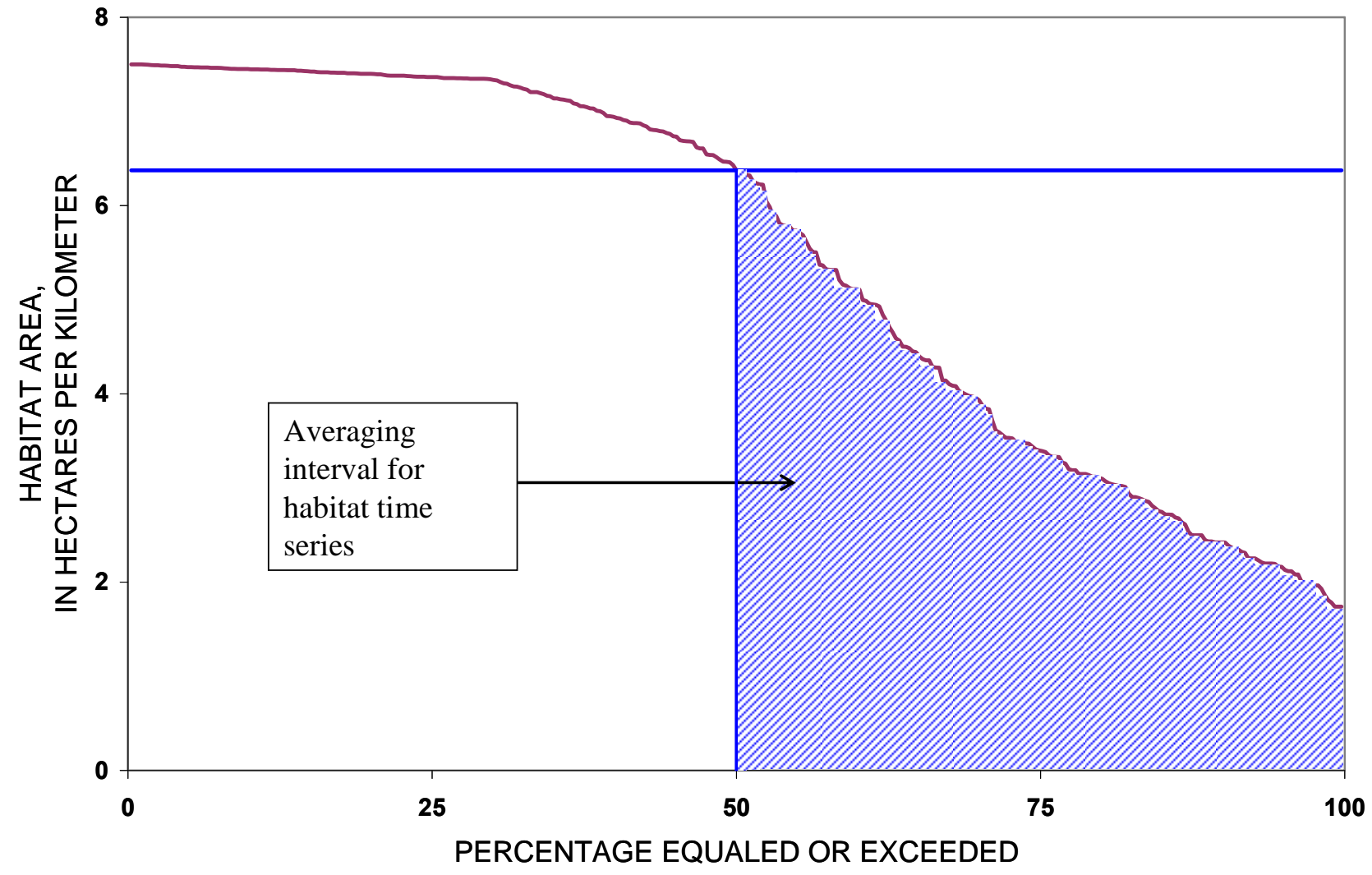

Figure 26. Averaging interval from cumulative probability distribution (from figure 25-c) used as the scoring metric in the YRDSS habitat time series analysis. 
5. A percent difference between the below-median average for the baseline and alternative is calculated in the "Pct Chg" columns of the yearly habitat tables and conditionally formatted such that an increase under the alternative of 10 percent or more produces a green background and a decrease by a like amount results in a red background.

\section{Site-Specific Yearly Temperature Summaries}

The four SNTEMP runs performed to date (the "No Action" baseline and the three alternatives), produced estimates of the maximum daily temperatures, in degrees Celsius, for the period from April 1 through September 30 each year for the Union Gap and Wapato reaches. Like the annual habitat summaries, temperature information and scoring for each reach is performed in the subsidiary workbooks and copied to one of the five "YearlyTemp" pages in the DSS_Agg workbook. Temperature data from SNTEMP are recorded originally on the "Flows" page of the DSS_Agg spreadsheet (see discussion of the "Parameters" page) and are copied to a similar "Flows" page in the subsidiary notebooks. Scoring of temperature data is based on the maximum temperature occurring within the hydroperiod for a given life stage and therefore represents the most extreme temperature condition (the highest maximum daily temperature) for the time period:

1. Each day of the year is flagged as being inside or outside the hydroperiod window for each life stage from the "Hydroperiods" page.

2. The maximum daily temperature occurring within the window for each year is arrayed by life stage on the "YearlyTemp" page of the subsidiary notebook (fig. 27).

3. The columns labeled "Base" and "Alternative" on the YearlyTemp page are color-coded to depict temperatures in the suitable range for a life stage (green), suboptimal conditions (yellow), or potentially lethal conditions (red). The "Alt-Base" columns contain the temperature differential between the alternative (Alt) and the baseline (Base) for the hydroperiod. If the maximum temperature under the alternative increases by $0.5^{\circ} \mathrm{C}$ or more, the cells are conditionally formatted to turn red. Conversely, if the maximum temperature decreases by 0.5 ${ }^{\circ} \mathrm{C}$ or more, the cells turn green. Changes in temperature less than that amount were considered undetectable based on evidence provided by Bartholow (1989). Evaluation of the biological

\begin{tabular}{|c|c|c|c|c|c|c|c|c|c|c|c|c|c|}
\hline & A & $\mathrm{B}$ & C & $\mathrm{D}$ & $E$ & $\mathrm{~F}$ & $\mathrm{G}$ & $\mathrm{H}$ & $\mathrm{I}$ & $\mathrm{J}$ & $\mathrm{K}$ & $\mathrm{L}$ & $M$ \\
\hline 102 & Resident Rainbow & & Spawning & & & Incubation & & & Fry & & Subyea & rling (Spring & summer) \\
\hline 103 & Year & Base & Alternative & Alt - Base & Base & Alternative & Alt - Base & Base & Alternative & Alt - Base & Base & Alternative & Alt - Base \\
\hline 104 & 1982 & 0.0 & 0.0 & No Data & 0.0 & 0.0 & No Data & 0.0 & 0.0 & No Data & 0.0 & 0.0 & No Data \\
\hline 105 & 1983 & 0.0 & 0.0 & No Data & 0.0 & 0.0 & No Data & 0.0 & 0.0 & No Data & 0.0 & 0.0 & No Data \\
\hline 106 & 1984 & 17.6 & 16.9 & -0.8 & 23.1 & 22.4 & -0.7 & 23.1 & 22.4 & -0.7 & 19.0 & 18.5 & -0.4 \\
\hline 107 & 1985 & 18.5 & 17.9 & -0.6 & 23.6 & 22.7 & -0.9 & 23.6 & 22.7 & -0.9 & 18.0 & 17.3 & -0.7 \\
\hline 108 & 1986 & 18.6 & 18.9 & 0.2 & 22.6 & 21.6 & -1.1 & 23.5 & 22.6 & -0.9 & 19.9 & 19.0 & -1.0 \\
\hline 109 & 1987 & 17.4 & 16.9 & -0.5 & 23.0 & 21.8 & -1.2 & 22.9 & 21.8 & -1.1 & 20.9 & 20.4 & -0.5 \\
\hline 110 & 1988 & 17.7 & 16.8 & -0.9 & 22.9 & 21.9 & -1.0 & 22.9 & 21.9 & -1.0 & 20.8 & 20.0 & -0.7 \\
\hline 111 & 1989 & 19.0 & 17.4 & -1.7 & 22.7 & 21.6 & -1.1 & 22.7 & 21.6 & -1.1 & 18.6 & 17.7 & -0.8 \\
\hline 112 & 1990 & 16.7 & 15.5 & -1.2 & 23.5 & 22.9 & -0.6 & 23.5 & 22.9 & -0.6 & 20.3 & 19.5 & -0.7 \\
\hline 113 & 1991 & 16.6 & 16.4 & -0.2 & 22.4 & 21.6 & -0.8 & 23.0 & 22.3 & -0.7 & 20.0 & 19.4 & -0.6 \\
\hline 114 & 1992 & 20.3 & 18.5 & -1.8 & 23.8 & 22.5 & -1.3 & 23.7 & 23.0 & -0.7 & 19.4 & 19.2 & -0.2 \\
\hline \begin{tabular}{|l|}
115 \\
\end{tabular} & 1993 & 19.3 & 19.0 & -0.3 & 21.1 & 20.0 & -1.2 & 22.3 & 21.7 & -0.7 & 20.1 & 19.5 & -0.6 \\
\hline \begin{tabular}{|l|}
116 \\
\end{tabular} & 1994 & 19.3 & 18.2 & -1.1 & 23.8 & 23.1 & -0.7 & 23.8 & 23.1 & -0.7 & 20.2 & 20.0 & -0.2 \\
\hline \begin{tabular}{|l|}
117 \\
\end{tabular} & 1995 & 16.6 & 16.5 & -0.1 & 23.3 & 22.4 & -0.9 & 23.3 & 22.4 & -0.9 & 20.3 & 19.5 & -0.8 \\
\hline 118 & 1996 & 16.9 & 16.6 & -0.2 & 23.2 & 22.3 & -0.9 & 23.2 & 22.3 & -0.9 & 19.2 & 18.8 & -0.5 \\
\hline 119 & 1997 & 15.6 & 15.8 & 0.1 & 22.2 & 21.6 & -0.6 & 23.7 & 23.0 & -0.7 & 20.8 & 20.2 & -0.5 \\
\hline 120 & 1998 & 17.1 & 17.0 & -0.1 & 24.9 & 23.9 & -1.1 & 24.9 & 23.9 & -1.1 & 21.5 & 20.7 & -0.9 \\
\hline \begin{tabular}{|l|}
121 \\
\end{tabular} & 1999 & 16.0 & 16.1 & 0.1 & 21.6 & 21.3 & -0.3 & 22.5 & 21.9 & -0.6 & 18.2 & 18.1 & -0.1 \\
\hline \begin{tabular}{|l|}
122 \\
\end{tabular} & 2000 & 17.8 & 16.8 & -1.1 & 23.5 & 22.5 & -1.0 & 24.3 & 23.2 & -1.1 & 19.6 & 18.9 & -0.7 \\
\hline \begin{tabular}{|l|}
123 \\
\end{tabular} & 2001 & 20.7 & 18.9 & -1.8 & 23.1 & 22.1 & -1.0 & 23.1 & 22.7 & -0.4 & 21.2 & 21.0 & -0.3 \\
\hline \begin{tabular}{|l|l}
124 \\
\end{tabular} & 2002 & 16.3 & 16.3 & 0.0 & 24.0 & 23.4 & -0.5 & 24.0 & 23.4 & -0.5 & 20.6 & 19.8 & -0.8 \\
\hline \begin{tabular}{|l|l}
125 \\
\end{tabular} & 2003 & 19.1 & 17.7 & -1.4 & 24.4 & 23.4 & -1.0 & 24.4 & 23.4 & -1.0 & 21.9 & 20.9 & -1.0 \\
\hline
\end{tabular}

Figure 27. Portion of a yearly temperature page of the Union Gap subsidiary notebook. 
significance of a temperature change involves examination of both types of information. An increase in temperature, for example, may be beneficial provided that the baseline temperature and that of the alternative are both in the suitable temperature range. Conversely, a temperature change that shifts the color-coding from green under the baseline to yellow or from yellow to red under the alternative should alert the user to a potentially undesirable situation, regardless of the temperature differential (temperatures for rainbow trout fry in 2002 in figure 27, for example). Likewise, a shift from red in the baseline to yellow in the alternative (or yellow to green) would indicate an improvement (1985 for spawning and fry, for example).

\section{Graphics}

Graphics in the YRDSS are primarily useful for interpretation and diagnosis of results. On occasion, the scoring algorithms for one or more state variables may show unanticipated or counterintuitive results. For example, an alternative designed to improve late summer habitat for a life stage may actually result in its decline. Further inspection might show that the reason for the decline was because late summer flows were excessively low, which in turn were the result of reservoir depletion earlier in the year. Ferreting out these cause and effect relations can be tedious, but inspection of graphic depictions of a variable over time can facilitate the process.

\section{Time Series Plots}

The most elementary type of graphics provided in the YRDSS is a day-by-day time series of reservoir storage, streamflow, and maximum daily temperatures (in order of appearance) at each of the hydrologic nodes in the system. A series of these time series plots can be found on the "FlowPlots" page of the DSS_Agg spreadsheet (fig. 28). These are relatively long displays and not particularly legible when printed to hard copy. However, the window for this page is locked, allowing the user to scroll back and forth across the time series to view specific time periods. The time series plots are formatted such that the series for the baseline is shown as a blue line and the alternative as a pink line. Where only a pink line shows, values for the baseline and alternative are the same. Temperature data were not available for the Easton, Kittitas, or Naches reaches, so these plots flat-line at zero. The graphs are included as placeholders in the event that temperature data become available at a later time.

\section{Habitat-and Flow-Duration Curves}

Habitat- and flow-duration curves, such as the one shown in figure 29, are generated on the "Dur Curve Chart" pages of the subsidiary spreadsheets. A duration curve shows the probability that a habitat value or discharge will be equaled or exceeded over the entire period of record and is a compact method of summarizing differences between the baseline and alternative. There are several noteworthy attributes of these charts as they are displayed in the YRDSS:

1. These charts are ephemeral. Each time a chart update is performed, the previous chart is overwritten. If a permanent copy of a chart is desired, it must be printed out or saved electronically (copying the chart to a Powerpoint ${ }^{\circledR}$ file is a good option).

2. The scale of the chart can be modified manually to accentuate a particular portion of the chart (using the "Format Axis" function in Excel). For example, the total range of flows used to generate the chart in figure 29 was from 0 to $35,000 \mathrm{ft}^{3} / \mathrm{s}$, but the chart scale was set for a maximum of $10,000 \mathrm{ft}^{3} / \mathrm{s}$ to obtain a better view of the low-flow events.

3. When interpreting duration curves, be aware that the chronology of events is destroyed in this type of graph. If the timing of events is important, either the time series plots or the duration series plots, discussed in the next section, should be examined in addition to the duration plots. 

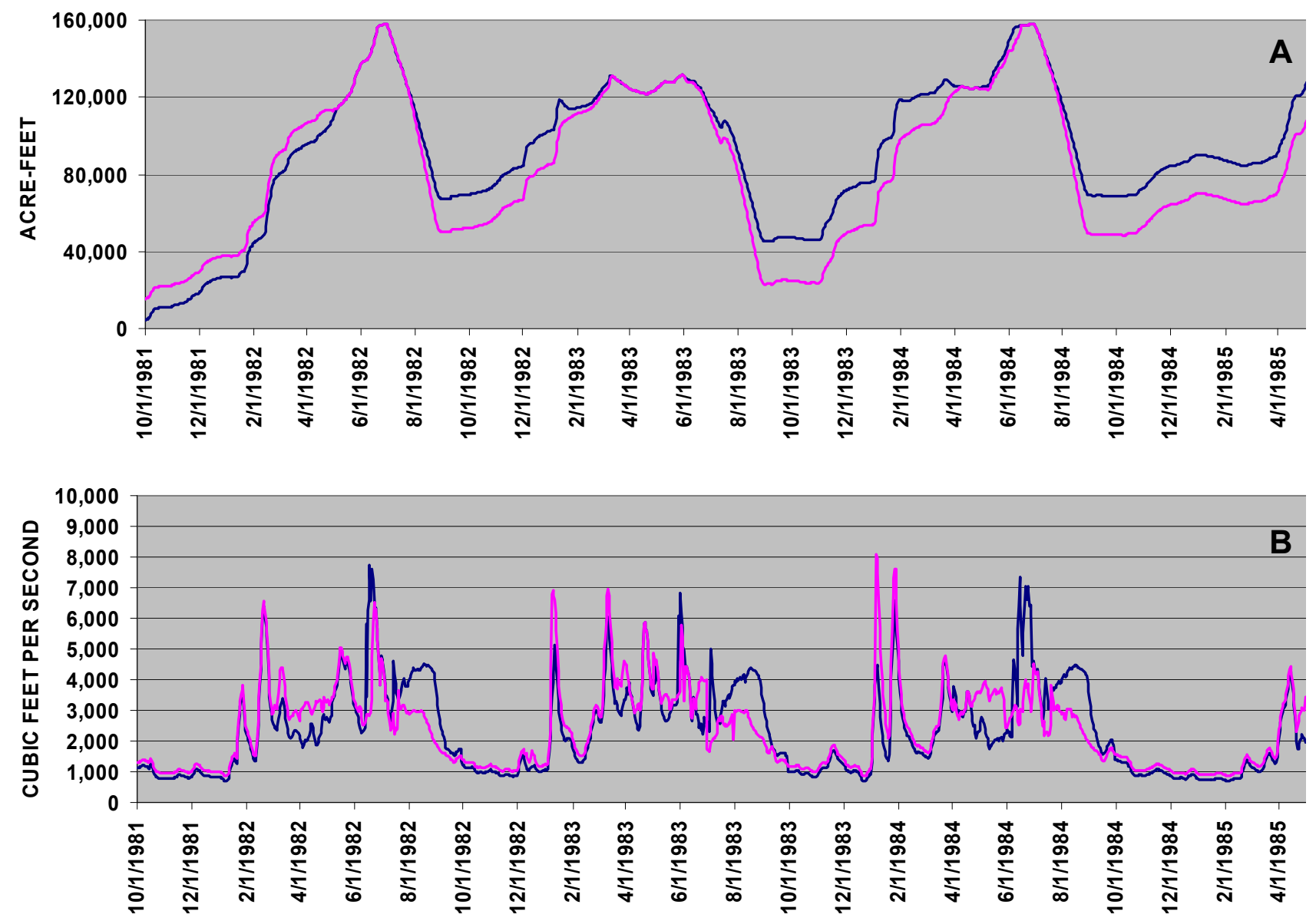

Figure 28. Portions of hydrologic time series plots from the "Flows" page of the DSS_Agg spreadsheet showing relationships between storage volume at Keechelus Reservoir (A) and discharges at the Kittitas reach (B).

The stepwise process for generating a duration chart in the YRDSS is illustrated in figure 30. For the most part, the sequence is straightforward. A caveat in using the duration curve macro is that if flows are selected in step 2, they must also be selected in step 4 or the macro will return an error message. Likewise, if a species is selected in step 2, a life stage (not Flows) must be selected in step 4.

\section{Duration Series Charts}

The difference between a duration series chart and a duration curve is that the former arrays values for each day of the record rather than combining them into a single curve. In essence, a duration series consists of small duration curves compiled for every day of the year. This type of display allows one to examine the daily probability that an event will be equaled or exceeded. Although a duration series chart can be subdivided into very small increments of probabilities, too many of them make the chart garish if not unreadable. For this reason, the duration series charts available in the YRDSS show only the time series of values in the lowest quartile (values between the minimum and those having a 75-percent probability of being equaled or exceeded). An example of a flow-duration series is shown in figure 31 . The light blue shaded area corresponds to the lowest 25 percent of the flows under the baseline condition, whereas the red and black solid lines bracket the flows for the alternative. Where 


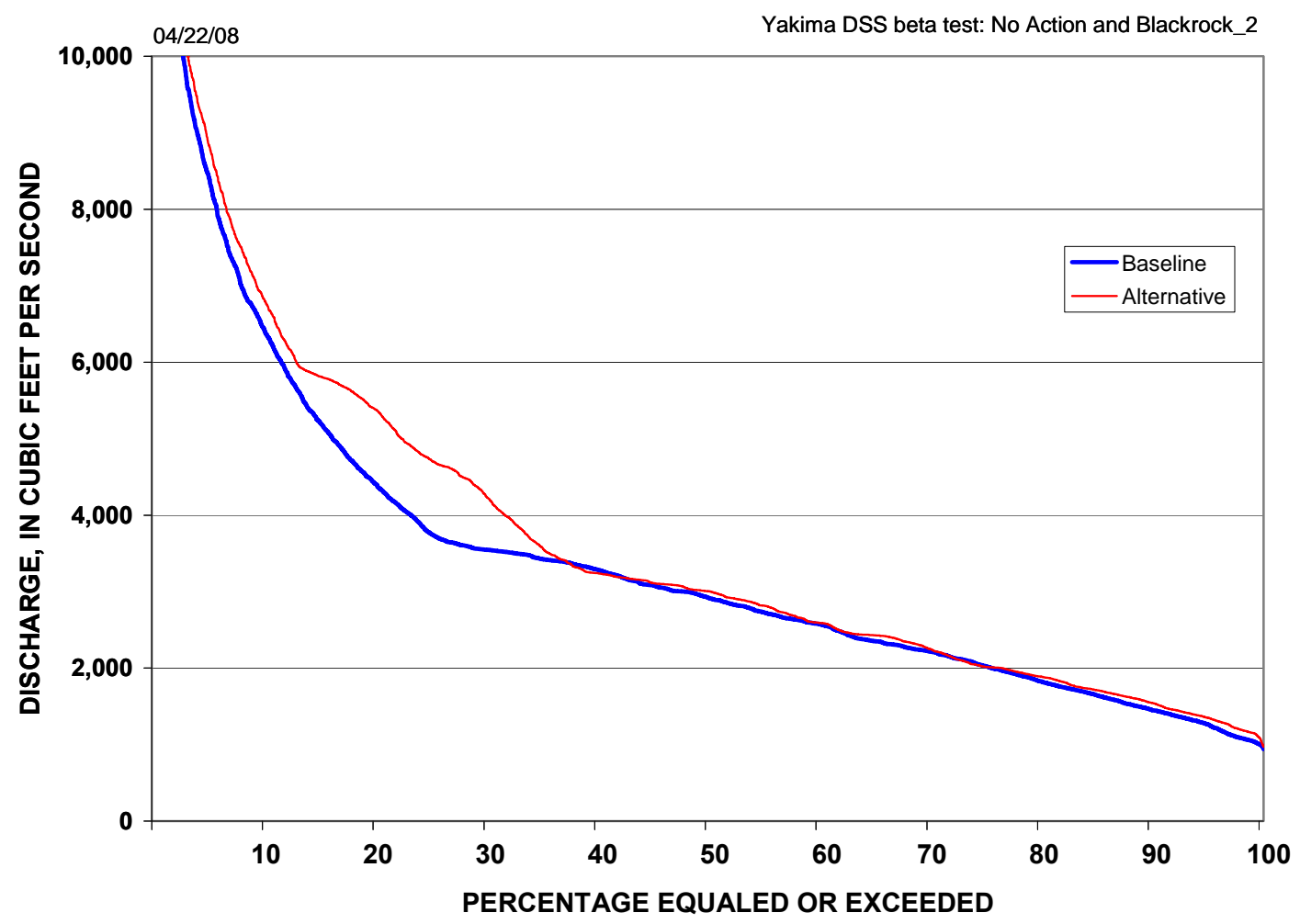

Figure 29. A flow-duration chart for the Union Gap reach, from the "DurCurve Chart" page of the “DSS_UnG" subsidiary spreadsheet.

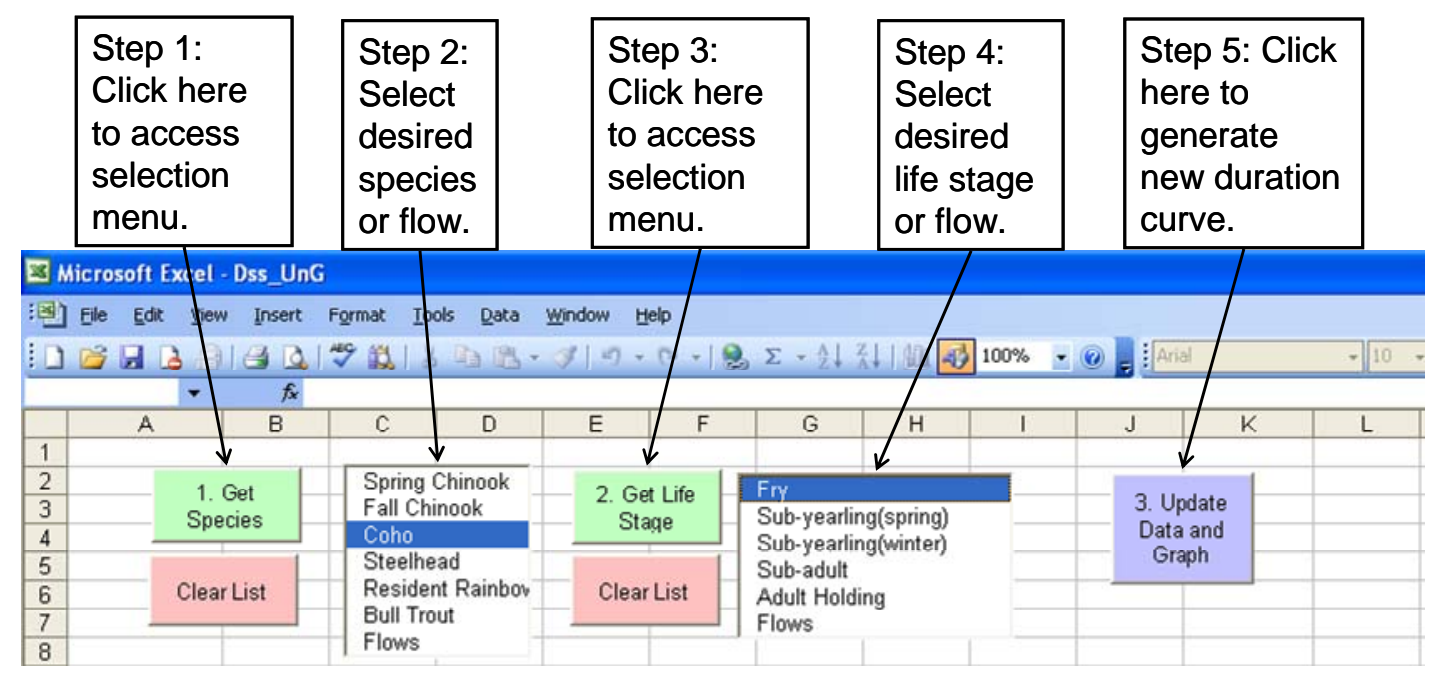

Figure 30. Controls on the "DurCurve pages of the subsidiary spreadsheets used to generate duration curves for life stage-specific habitat or for discharges. 
patches of blue appear above the black line, the lowest flows under the alternative are lower than they were under the baseline. Patches of blue below the red line indicate that the lowest flows under the alternative are higher than they were under the baseline. In the example shown in figure 31, the lowest quartile flows under the alternative were slightly higher than the baseline from mid-October to late March, much higher than the baseline between April and July, and lower than the baseline from August through the first part of October. The average low flows for July are probably about the same for both scenarios, but flows under the baseline are more variable, as indicated by patches of blue above the black line and below the red line. The steps for generating a duration series chart are identical to those described in figure 30 except that the selection and update control buttons are located on the "DurSer" pages of the subsidiary spreadsheets. As typical of the duration curves, the duration series charts are ephemeral and must be saved electronically or to hard copy if they are to be retained for future reference.

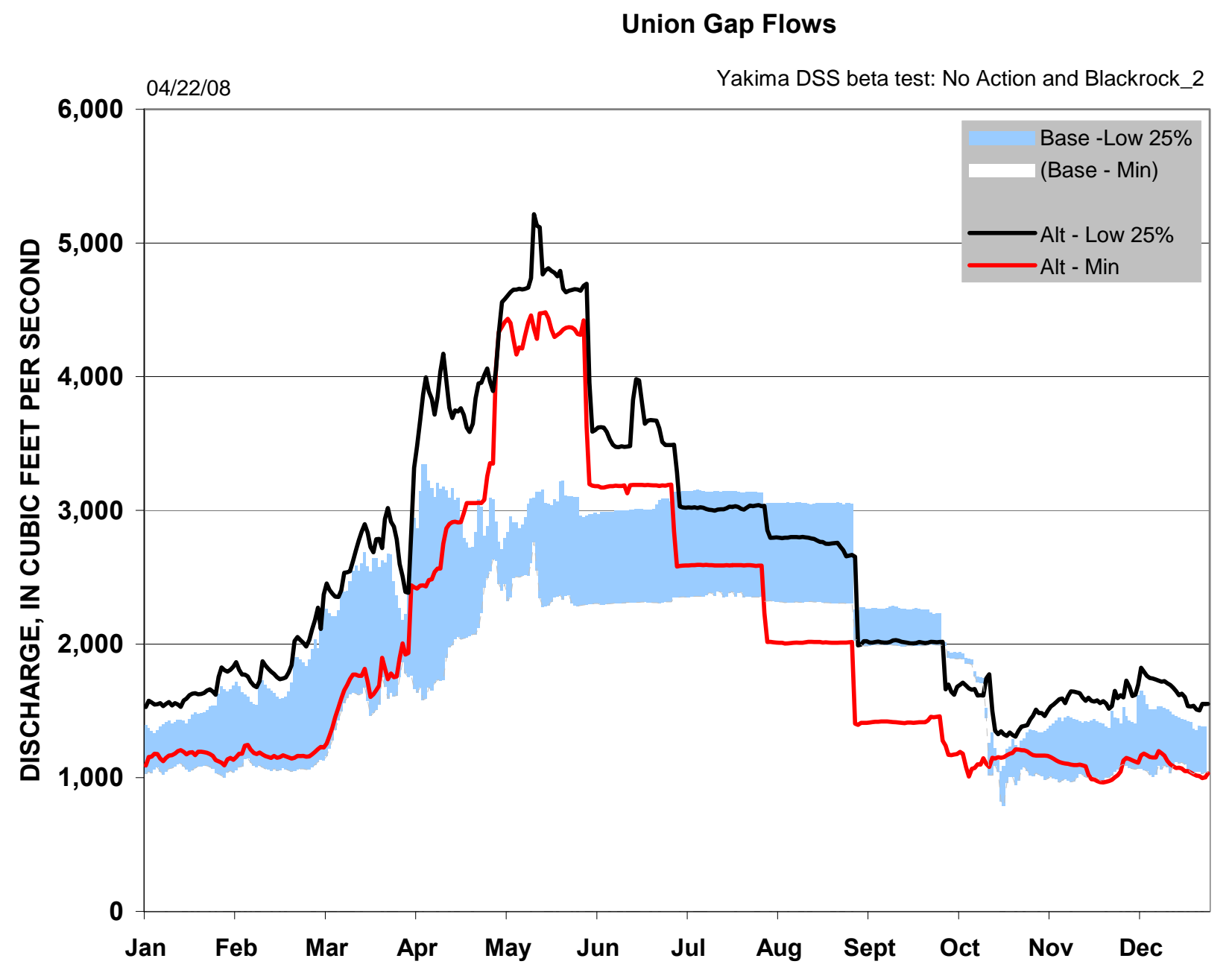

Figure 31. A flow duration series chart for the Union Gap reach, from the "DurSerChart" page of the “DSS_UnG" subsidiary spreadsheet. 


\section{Beta Test Runs of the YRDSS}

Four scenarios were simulated in RiverWare, SNTEMP, and SIAM, the results of which were used as input to three comparative analyses in the YRDSS. The scenarios as depicted in the YRDSS runs were:

1. No Action (baseline) compared with the Blackrock_2 alternative, henceforth the Blackrock_2 run,

2. No Action (baseline) compared with the WymerOnly_1 alternative, henceforth Wymer_1, and

3. No Action (baseline) compared with the WymerPlus alternative, henceforth WymerPlus.

\section{Operational Comparisons}

Descriptions of the operations associated with the four scenarios were provided by way of an internal BOR report (Larry Vinsonhaler, Bureau of Reclamation, written commun. August 22, 2007) and are summarized below.

\section{Current Operations}

Current operations of the Yakima system differ somewhat from the No Action scenario and are described here primarily to distinguish the two. Current operations were not used for any of the scenarios in the YRDSS. Runoff from the watershed upstream from the five major Yakima Project reservoirs is stored, subject to flood control space requirements, beginning in October and continuing through the early spring months with the multiple objectives of filling the reservoirs to capacity, meeting instream flow targets downstream, and providing reservoir space for possible flood control operations

During the initial part of the irrigation season, starting around April 1, unregulated runoff from tributaries below the five reservoirs is generally adequate to meet irrigation diversion demands and the instream flow targets at Parker (fig. 1). Once the unregulated flows fail to meet these demands, reservoir releases must be made, resulting in depletions in the stored water supply. The time when releases are made for irrigation deliveries is commonly referred to as the storage-control period and typically begins around the third week in June.

From the beginning of the storage-control period until the first of September, releases from Cle Elum Dam are maximized to the extent possible to meet main stem Yakima River water entitlements extending from the Cle Elum River confluence to the Sunnyside Diversion Dam (fig. 1). Most of these water entitlements are located in the middle Yakima River Basin, downstream from the Roza diversion (fig. 1). These water deliveries amount to approximately 1.46 million acre-feet, resulting in a large volume of water being transported by the Yakima River from the upper basin to the middle basin during the irrigation season. During peak demand periods, more than $3,500 \mathrm{ft}^{3} / \mathrm{s}$ is conveyed by the river for irrigation diversions.

On or around August 25, the Yakima Project moves into what is called the flip-flop operation. At this time, releases from Cle Elum Reservoir are reduced from approximately $3,000 \mathrm{ft}^{3} / \mathrm{s}$ to $220 \mathrm{ft}^{3} / \mathrm{s}$. Concurrently, releases from Rimrock Reservoir are substantially increased by $1,000 \mathrm{ft}^{3} / \mathrm{s}$ to $2,000 \mathrm{ft}^{3} / \mathrm{s}$ to meet the September-through-October irrigation demands downstream from the confluence of the Naches and Yakima Rivers. The purpose of the flip-flop operation is to encourage upper Yakima River spring chinook to spawn in the main channels of the upper Yakima and Cle Elum Rivers rather than in areas vulnerable to dewatering at the end of the irrigation season when storage accumulation begins.

During the storage-control period until September 1, a similar operation, referred to as mini flipflop, is performed between Keechelus and Kachess Reservoirs in years of sufficient water supply. Greater releases are initially made from Keechelus Reservoir to meet upper basin demands, and releases from Kachess are restrained. In September and October, the opposite is done with greater releases being 
made from Kachess to meet upper basin demands and releases from Keechelus reduced to provide suitable spawning flows in the Yakima River between Keechelus Dam and Lake Easton. Concurrent with the September shift in releases from Keechelus Reservoir to Kachess Reservoir, excess water is diverted around the Easton reach by way of the Kittitas Reclamation District's main canal, resulting in a nearly steady spawning flow of approximately $220 \mathrm{ft}^{3} / \mathrm{s}$ throughout the Easton reach.

\section{The No Action Alternative}

The starting point for all of the YRDSS scenario runs was the No Action baseline as simulated in RiverWare. This baseline represents the hydrologic characteristics of the river as simulated with current and anticipated operating rules for reservoir releases and deliveries as input variables to the model. RiverWare output then became input to SNTEMP, SIAM, and the habitat-related components of the YRDSS. It is noteworthy that RiverWare depicts the hydrology of the Yakima basin for the water years 1982-2003 as though the No Action operations had persisted for the entire 22-year period. Because actual operations changed from time to time during that period, the No Action baseline does not match the historical flow record exactly.

The No Action Alternative includes the future implementation of voluntary water conservation measures by Yakima basin entities. Also included as part of the alternative is an instream flow target at the Parker gage (fig. 1) of 394 to $736 \mathrm{ft}^{3} / \mathrm{s}$ (Joel Hubble, Bureau of Reclamation, written commun. January 3, 2008), depending on the estimated water supply for the irrigation season. The No Action Alternative operation criteria are the same as current Yakima Project operations with the following exceptions:

1. Irrigation diversions are reduced in wet and average water years by the total volume of conserved water (157,200 acre-feet). In dry years, the diversion reduction reflects only the instream flow portion of the conserved water (84,700 acre-feet). Generally, in the April-June part of the irrigation season, water needs are met by diverting the unregulated flows of tributaries downstream from Yakima Project reservoirs or by reservoir inflow that must be spilled. Because of the inability to manage streamflows during this period, all of the conserved water remains instream and increases flows in the specific reach of the river in which the conservation action occurred, from the point of diversion to the last point of operational discharge.

2. Once unregulated streamflows fail to meet diversion demands and instream flow targets at Parker (fig. 1), the deficit is made up from reservoir storage releases. Under the No Action scenario, releases continue to be made for the instream flow portion of the conserved water, with the intent of increasing the flow in the specific reaches where the conservation measures were implemented. In contrast, the portion of the conserved water that would normally be released for irrigation can be retained in storage in wet and average years. In dry years, the conserved water is released for use by the conserving entity. In this fashion, the No Action alternative operates somewhat as a water banking arrangement. These conservation measures are implemented to improve year-to-year carryover in the Yakima Project reservoirs. Once carried over, however, conserved water loses its identity to a specific entity and becomes a part of the total water supply available (TWSA).

3. No specific stored water releases are required in the No Action alternative operation to "make up" return flow deficiencies downstream from the river reaches where conservation measures are implemented.

\section{Black Rock}

The Black Rock project involves construction of an off-channel storage reservoir having an active storage capacity of 800,000 to 1,300,000 acre-feet in eastern Yakima County. Inflow for the 
reservoir would be provided by water pumped from the Priest Rapids Dam pool of the Columbia River (fig. 1), when such water is available in excess of current instream flow targets. Water from the reservoir would be used by participating irrigation entities within portions of the lower Yakima Basin in exchange for water currently diverted by those entities from the Yakima River under existing water rights. Yakima River water released by this exchange would then be available to achieve a number of objectives, including:

1. Improving anadromous fish habitat by increasing streamflow and creating a more natural flow regime,

2. Improving reliability of water supplies for junior water rights holders, and

3. Improving water supplies in anticipation of growing demands for municipal water supply.

With the Black Rock alternative, filling of Yakima Project reservoirs would be unchanged from the current operation, but several changes to the release rules would be implemented:

1. Water sources for irrigation districts would be redefined. The water supply for lands upstream from the Roza Canal (fig. 1) would continue to be diverted from the Yakima River. The water supply for lands downstream from and including Roza Canal would be delivered from Black Rock Reservoir. When the April 1 TWSA is greater than 3.2 million acre-feet, discharges in excess of the Parker target flows would be diverted from the Yakima River to supply the Sunnyside Division's irrigation demands. Residual water supply necessary to meet Sunnyside Division's irrigation demands would be delivered from Black Rock Reservoir when the April 1 TWSA is less than 3.2 million acre-feet.

2. The irrigation goal is to provide not less than a 70 percent dry year water supply for all Yakima Project users with proratable entitlements with the exception of the Tieton Division (fig. 1) on the Naches River.

3. From mid-October through May, releases from Cle Elum Reservoir would be increased by $185-$ $200 \mathrm{ft}^{3} / \mathrm{s}$ in order to approximately double instream flows in the Cle Elum River.

4. Reservoir operations after July 1 would decrease summer flows in the Cle Elum and upper Yakima Rivers because downriver irrigation demands would be met through Black Rock. This change in operation is intended to lessen the effect of flip-flop by changing the proportion of flow contributed from Cle Elum and Rimrock Reservoirs.

Wymer_1

Located approximately 12 miles south of Ellensburg, Wash., at Lmuma Creek (fig. 1), Wymer Reservoir would be an off-channel reservoir with an active storage volume of 162,500 acre-feet. Under the Wymer_1 alternative, source water for Wymer Reservoir would originate within the Yakima River Basin:

1. From October 1 through May 31, releases from Cle Elum Reservoir would be increased by the same amounts described for the Black Rock alternative, 185-200 ft ${ }^{3} / \mathrm{s}$.

2. These supplemental discharges would be intercepted at a pumping plant located near the confluence of Lmuma Creek and the Yakima River. Approximately half of the total active storage volume (approximately 83,000 acre-feet) would be filled from this source each year.

3. The residual 80,000 acre-feet of Wymer Reservoir capacity would be filled by pumping when Yakima River flows exceed 1,475 $\mathrm{ft}^{3} / \mathrm{s}$ at the Umtanum gage between January 1 and March 31 . The design capacity of the Wymer pumping plant is $420 \mathrm{ft}^{3} / \mathrm{s}$. 
4. Storage at Wymer Reservoir would be partitioned into two parts. During normal water years, 82,500 acre-feet of Wymer Reservoir storage would be released during July and August at a rate of approximately $1,000 \mathrm{ft}^{3} / \mathrm{s}$ to meet downstream irrigation demands and instream flow targets at Parker. This operation would subsequently reduce summer demands on Cle Elum Reservoir, resulting in flow reductions in the Kittitas reach by an average of about $650 \mathrm{ft}^{3} / \mathrm{s}$.

5. Eighty thousand $(80,000)$ acre-feet of storage is reserved for use only in dry years, defined in this case by proration levels less than 70 percent. Wymer Reservoir contents from this 80,000 acre-feet of storage space are included in the TWSA estimate only in those dry years.

6. Like Black Rock_2, the irrigation goal is to provide a 70 percent dry year water supply for all Yakima Project users with proratable entitlements.

\section{WymerPlus}

Under this alternative, the water supply for Wymer Reservoir is obtained from the Yakima River in the same manner described for Wymer_1. The "Plus" part of the WymerPlus alternative refers to an additional pump exchange, whereby a pumping plant would be installed at the mouth of the Yakima River near Kennewick and a dual pipeline system constructed to convey the pumped water upstream to the Sunnyside area (fig. 1). This scheme is based on a potential water exchange between the Roza and Sunnyside Divisions of $1,200 \mathrm{ft}^{3} / \mathrm{s}$. The water exchange operation is based on the following daily exchanges:

1. Roza Division would receive its daily diversion demand, minus $200 \mathrm{ft}^{3} / \mathrm{s}$ or $550 \mathrm{ft}^{3} / \mathrm{s}$, whichever is smaller, from the exchange from the Sunnyside Division.

2. The Sunnyside Division would receive the lesser of $750 \mathrm{ft}^{3} / \mathrm{s}, 1,200 \mathrm{ft}^{3} / \mathrm{s}$ minus the Roza Division exchange, or the Sunnyside Division's daily demand from the pump-back exchange at the mouth of the Yakima River. An instantaneous discharge exchange at the mouth of the Yakima River would begin when water is first diverted and would continue throughout the irrigation season. Water currently diverted by these two divisions would remain in the river for instream flow purposes.

3. The instream flow target at Parker would be set at $1,500 \mathrm{ft}^{3} / \mathrm{s}$ during the irrigation season to improve instream habitat and water quality in the Yakima River. The pump exchange project would deliver a total up to $1,200 \mathrm{ft}^{3} / \mathrm{s}$ in increments at various points along the pipeline route.

\section{Comparisons of Hydrologic Changes}

Significant changes to low flow regimes and peak flows occurred with varying degrees of magnitude under each of the alternatives. The effects of the alternatives with respect to the baseline on the timing and relative magnitude of low flow regimes and peak flow characteristics are summarized in the following sections.

\section{Low Flow Characteristics}

Effects on low flow characteristics are compiled in tables 6-10 and figures 32-36. The tables contain the monthly averages for minimum flows and first quartile flows under the baseline and each alternative and also summarize the percent change from the baseline. Where the alternative results in an increase of 10 percent or more compared to the baseline, the change is emphasized by a light blue background. Conversely, a tan background is used to accentuate flow reductions of 10 percent or more under the alternative. The figures show the flow-duration series curves for each scenario and study site. 
- Generally, the relative amount of change, whether an increase or a decrease, became progressively larger from upstream to downstream. Deviations from the baseline were smallest at Easton and largest at Wapato under all three scenarios.

- At Easton, minimum flows remained unchanged under all three scenarios. First quartile flows were significantly increased under the Black Rock_2 scenario from April-June (table 6 and fig. 32).

- Minimum and first quartile flows were generally elevated during winter and early spring months and reduced during the summer under all three scenarios at the Kittitas reach (table 7 and fig. $33)$.

- Minimum flows were increased substantially under the Black Rock _2 alternative from April through August in the Naches reach, and first quartile flows were increased significantly during May and August under this alternative (table 8 and fig. 34). Minimum flows were reduced from December through February by about the same amount under all three scenarios although first quartile flows remained about the same as the baseline. Minimum and first quartile flows were both smaller under the Black Rock_2 scenario during September and October, whereas first quartile flows were reduced in August under the Wymer_1 and WymerPlus scenarios.

- At Union Gap, minimum flows were increased significantly from April through June under the Black Rock_2 scenario and from May through August under WymerPlus (table 9 and fig. 35). Neither minimum nor first quartile flows at Union Gap were significantly affected by the Wymer_1 alternative. First quartile flows were generally increased from November through June with Black Rock_2, but were reduced from August through October.

- The Black Rock_2 and WymerPlus alternatives both produced large increases in minimum and first quartile flows at the Wapato site, whereas changes associated with Wymer_1 were unremarkable (table 10 and fig. 36). Increases in minimum and first quartile flows were observed during all months with Black Rock_2 and from March through October with WymerPlus. The large increases in low flow at this site, compared to Union Gap, are attributable to the reduction of withdrawals for the Sunnyside diversion, which is located between these two reaches.

\section{Maximum Flow Characteristics}

Analysis of high flows in the Yakima system was complicated by the climate and geography of the basin. Periods of high flow in the Yakima were not as consistent as they would have been in a purely snowmelt-driven hydrologic system. In some years, the maximum discharges occurred during spring in response to snowmelt runoff. In other years, they occurred in the winter as a result of rain or rain on snow events, and sometimes they occurred during summer, presumably in response to thunderstorm activity.

High flows were analyzed using the maximum 10-day average for each year rather than the single-day peak. Some of the single-day values appeared to be somewhat spurious with regard to their magnitude and timing, so we used the 10-day maximum as a more accurate representation of overall high-flow events. High flows were affected differentially, depending on the alternative, the location, and the type of water year associated with the baseline. Differences in high-flow characteristics were manifested as changes in magnitude, changes in timing, or both. Patterns of change were more difficult to discern than they were for low-flow characteristics, but some were evident nonetheless. 
Table 6. Low-flow statistics for the Easton reach for the No Action baseline and Black Rock 2, Wymer 1, and Wymer Plus alternatives.

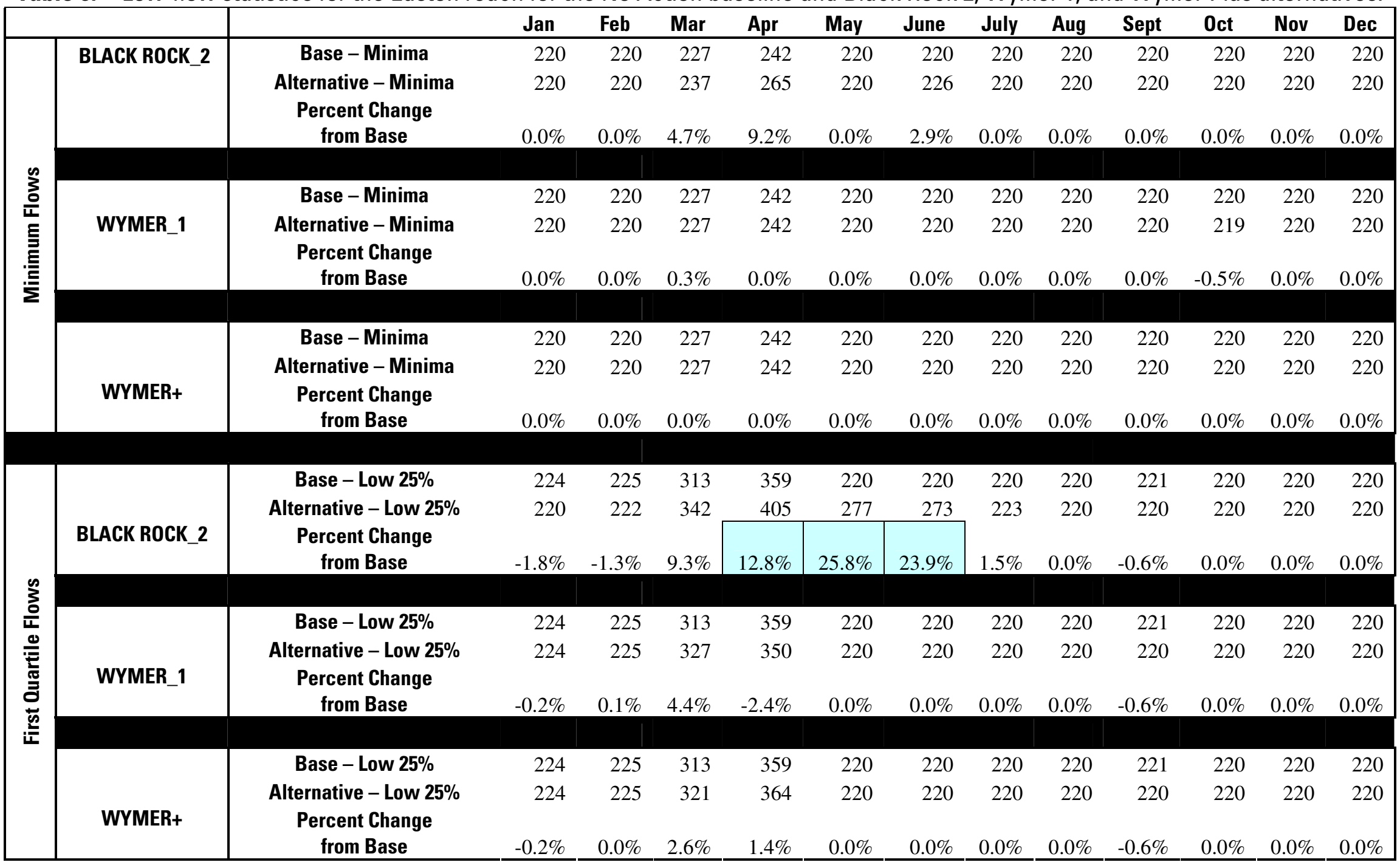



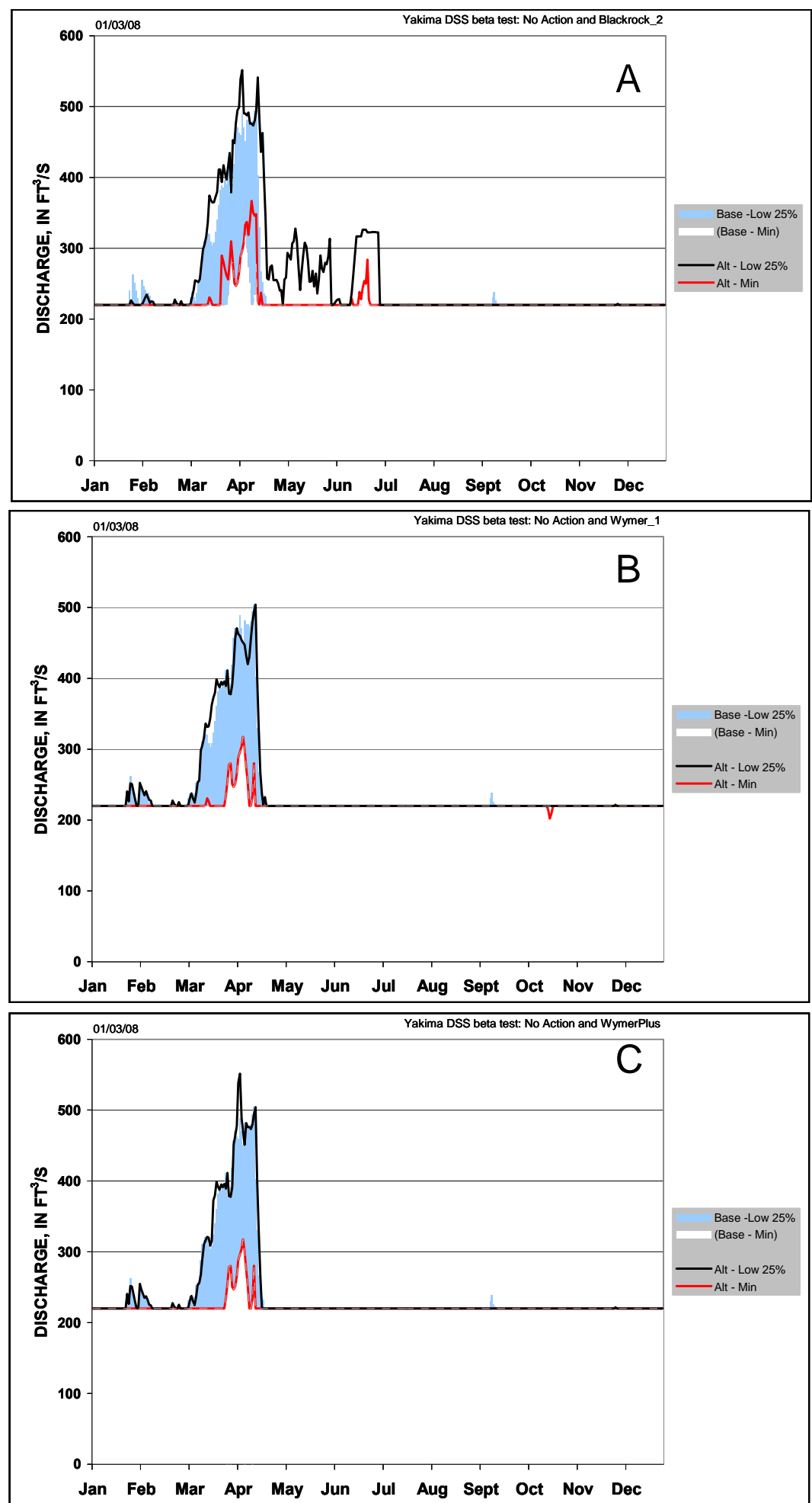

Figure 32. Flow-duration series of low flows in the Easton reach, comparing the Black Rock_2 (A), Wymer_1 (B), and WymerPlus (C) scenarios with the No Action baseline. 
Table 7. Low-flow statistics for the Kittitas reach for the No Action baseline and Black Rock 2, Wymer 1, and Wymer Plus alternatives.

\begin{tabular}{|c|c|c|c|c|c|c|c|c|c|c|c|c|c|c|}
\hline & & & Jan & Feb & Mar & Apr & May & June & July & Aug & Sept & Oct & Nov & Dec \\
\hline \multirow{10}{*}{ 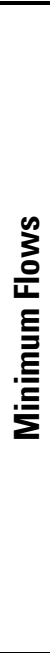 } & \multirow{3}{*}{ BLACK ROCK 2} & Base - Minima & 665 & 730 & 1,115 & 1,558 & 1,380 & 1,799 & 2,536 & 2,575 & 1,224 & 614 & 551 & 680 \\
\hline & & Alternative - Minima & 748 & 823 & 1,287 & 1,861 & 2,163 & 1,758 & 1,864 & 1,581 & 953 & 593 & 622 & 708 \\
\hline & & $\begin{array}{c}\text { Percent Change } \\
\text { from Base }\end{array}$ & $12.6 \%$ & $12.7 \%$ & $15.3 \%$ & $19.5 \%$ & $56.8 \%$ & $-2.3 \%$ & $-26.5 \%$ & $-38.6 \%$ & $-22.1 \%$ & $-3.4 \%$ & $13.0 \%$ & $4.0 \%$ \\
\hline & & & & & & & & & & & & \multirow{3}{*}{$\begin{array}{l}614 \\
581\end{array}$} & \multirow[b]{2}{*}{551} & \\
\hline & \multirow{3}{*}{ WYMER_1 } & Base - Minima & 665 & 730 & 1,115 & 1,558 & 1,380 & \multirow{2}{*}{$\begin{array}{l}1,799 \\
1,648\end{array}$} & 2,536 & 2,575 & \multirow{2}{*}{$\begin{array}{l}1,224 \\
1,138\end{array}$} & & & 680 \\
\hline & & Alternative - Minima & 694 & 812 & 1,258 & 1,743 & 1,713 & & 2,021 & 1,893 & & & 548 & 690 \\
\hline & & $\begin{array}{c}\text { Percent Change } \\
\text { from Base }\end{array}$ & $4.4 \%$ & $11.2 \%$ & $12.8 \%$ & $11.9 \%$ & $24.2 \%$ & $-8.4 \%$ & $-20.3 \%$ & $-26.5 \%$ & $-7.0 \%$ & $-5.4 \%$ & $-0.5 \%$ & $1.4 \%$ \\
\hline & & Base - Minima & 665 & 730 & 1,115 & 1,558 & 1,380 & 1,799 & 2,536 & 2,575 & 1,224 & 614 & 551 & 680 \\
\hline & WYMER+ & Alternative - Minima & 696 & 813 & 1,258 & 1,660 & 1,699 & 1,514 & 1,986 & 1,777 & 1,195 & 642 & 559 & 693 \\
\hline & & $\begin{array}{c}\text { Percent Change } \\
\text { from Base }\end{array}$ & $4.7 \%$ & $11.3 \%$ & $12.8 \%$ & $6.6 \%$ & $23.1 \%$ & $-15.9 \%$ & $-21.7 \%$ & $-31.0 \%$ & $-2.4 \%$ & $4.6 \%$ & $1.5 \%$ & $1.9 \%$ \\
\hline & & Base - Low 25\% & 834 & 1,013 & 1,523 & 2,002 & 2,023 & 2,460 & 3,191 & 3,340 & 1,708 & 795 & 826 & 800 \\
\hline & BLACK ROCK 2 & Alternative - Low 25\% & 1,000 & 1,173 & 1,711 & 2,359 & 2,861 & 2,558 & 2,522 & 2,380 & 1,260 & 971 & 1,004 & 988 \\
\hline & & $\begin{array}{c}\text { Percent Change } \\
\text { from Base }\end{array}$ & $19.8 \%$ & $15.8 \%$ & $12.3 \%$ & $17.8 \%$ & $41.4 \%$ & $4.0 \%$ & $-21.0 \%$ & $-28.7 \%$ & $-26.2 \%$ & $22.1 \%$ & $21.6 \%$ & $23.5 \%$ \\
\hline$\sum_{3}^{\infty}$ & & & & & & & & & & & & & & \\
\hline 은 & & Base - Low 25\% & 834 & 1,013 & 1,523 & 2,002 & 2,023 & 2,460 & 3,191 & 3,340 & 1,708 & 795 & 826 & 800 \\
\hline$\stackrel{\omega}{=}$ & WYMER_1 & Alternative - Low 25\% & 978 & 1,159 & 1,715 & 2,242 & 2,250 & 2,350 & 2,662 & 2,847 & 1,675 & 909 & 983 & 955 \\
\hline 苛 & & $\begin{array}{c}\text { Percent Change } \\
\text { from Base }\end{array}$ & $17.2 \%$ & $14.4 \%$ & $12.6 \%$ & $12.0 \%$ & $11.2 \%$ & $-4.5 \%$ & $-16.6 \%$ & $-14.7 \%$ & $-1.9 \%$ & $14.3 \%$ & $19.0 \%$ & $19.4 \%$ \\
\hline ì & & & & & & & & & & & & & & \\
\hline & & Base - Low 25\% & 834 & 1,013 & 1,523 & 2,002 & 2,023 & 2,460 & 3,191 & 3,340 & 1,708 & 795 & 826 & 800 \\
\hline & WYMER+ & Alternative - Low 25\% & 977 & 1,154 & 1,711 & 2,220 & 2,148 & 2,425 & 2,495 & 2,726 & 1,658 & 942 & 992 & 964 \\
\hline & & $\begin{array}{c}\text { Percent Change } \\
\text { from Base }\end{array}$ & $17.0 \%$ & $13.9 \%$ & $12.3 \%$ & $10.9 \%$ & $6.2 \%$ & $-1.4 \%$ & $-21.8 \%$ & $-18.4 \%$ & $-2.9 \%$ & $18.4 \%$ & $20.2 \%$ & $20.6 \%$ \\
\hline
\end{tabular}



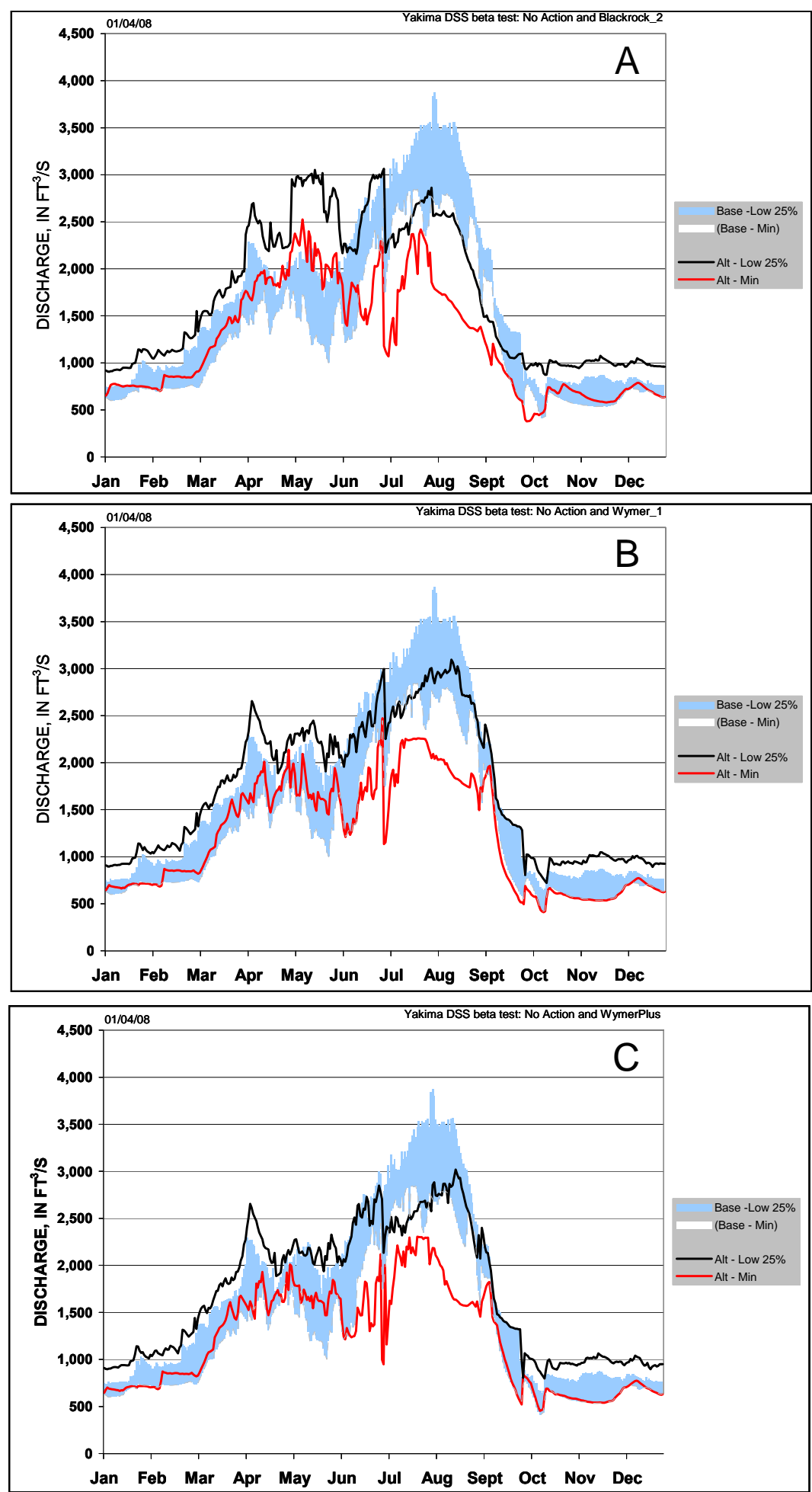

Figure 33. Flow-duration series of low flows in the Kittitas reach, comparing the Black Rock_2 (A), Wymer_1 (B), and WymerPlus (C) scenarios with the No Action baseline. 
Table 8. Low-flow statistics for the Naches reach for the No Action baseline and Black Rock 2, Wymer 1, and Wymer Plus alternatives.

\begin{tabular}{|c|c|c|c|c|c|c|c|c|c|c|c|c|c|c|}
\hline & & & Jan & Feb & Mar & Apr & May & June & July & Aug & Sept & Oct & Nov & Dec \\
\hline \multirow{10}{*}{ 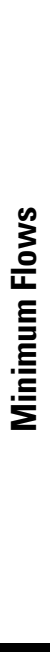 } & \multirow{3}{*}{ BLACK ROCK 2} & Base - Minima & 309 & 320 & 454 & 598 & 1,132 & 562 & 341 & 295 & 775 & 443 & 230 & 294 \\
\hline & & Alternative - Minima & 264 & 284 & 436 & 822 & 1,619 & 861 & 499 & 376 & 506 & 309 & 246 & 261 \\
\hline & & $\begin{array}{l}\text { Percent Change } \\
\text { from Base }\end{array}$ & $-14.6 \%$ & $-11.4 \%$ & $-4.0 \%$ & $37.4 \%$ & $43.0 \%$ & $53.4 \%$ & $46.2 \%$ & $27.3 \%$ & $-34.7 \%$ & $-30.3 \%$ & $7.2 \%$ & $-11.1 \%$ \\
\hline & \multirow{4}{*}{ WYMER_1 } & & & & & & & & & & & & & \\
\hline & & Base - Minima & 309 & 320 & 454 & 598 & 1,132 & 562 & 341 & 295 & 775 & 443 & 230 & 294 \\
\hline & & Alternative - Minima & 264 & 272 & 436 & 594 & 1,130 & 558 & 354 & 279 & 842 & 447 & 197 & 259 \\
\hline & & $\begin{array}{l}\text { Percent } \\
\text { Change from Base }\end{array}$ & $-14.6 \%$ & $-15.1 \%$ & $-4.0 \%$ & $-0.8 \%$ & $-0.2 \%$ & $-0.6 \%$ & $3.8 \%$ & $-5.5 \%$ & $8.6 \%$ & $0.9 \%$ & $-14.1 \%$ & $-12.0 \%$ \\
\hline & \multirow{3}{*}{ WYMER+ } & Base - Minima & 309 & 320 & 454 & 598 & 1,132 & 562 & 341 & 295 & 775 & 443 & 230 & 294 \\
\hline & & Alternative - Minima & 264 & 284 & 436 & 598 & 1,244 & 588 & 355 & 284 & 694 & 447 & 207 & 260 \\
\hline & & from Base & $-14.6 \%$ & $-11.4 \%$ & $-4.0 \%$ & $-0.1 \%$ & $9.9 \%$ & $4.6 \%$ & $4.0 \%$ & $-3.9 \%$ & $-10.5 \%$ & $0.9 \%$ & $-9.7 \%$ & $-11.5 \%$ \\
\hline \multirow{10}{*}{ 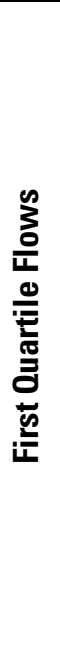 } & & Base - Low 25\% & 458 & 534 & 780 & 1,421 & 1,701 & 1,479 & 806 & 416 & 1,174 & 763 & 439 & 446 \\
\hline & BLACK ROCK 2 & Alternative - Low 25\% & 464 & 535 & 781 & 1,495 & 2,026 & 1,607 & 731 & 684 & 938 & 503 & 424 & 449 \\
\hline & & $\begin{array}{c}\text { Percent Change } \\
\text { from Base }\end{array}$ & $1.3 \%$ & $0.1 \%$ & $0.0 \%$ & $5.2 \%$ & $19.1 \%$ & $8.6 \%$ & $-9.3 \%$ & $64.5 \%$ & $-20.1 \%$ & $-34.1 \%$ & $-3.4 \%$ & $0.6 \%$ \\
\hline & & & & & & & & & & & & & & \\
\hline & \multirow{3}{*}{ WYMER_1 } & Base - Low 25\% & 458 & 534 & 780 & 1,421 & 1,701 & 1,479 & 806 & 416 & 1,174 & 763 & 439 & 446 \\
\hline & & Alternative - Low $25 \%$ & 452 & 534 & 784 & 1,421 & 1,705 & 1,478 & 774 & 358 & 1,238 & 767 & 420 & 435 \\
\hline & & from Base & $-1.2 \%$ & $0.0 \%$ & $0.5 \%$ & $0.0 \%$ & $0.2 \%$ & $-0.1 \%$ & $-3.9 \%$ & $-14.0 \%$ & $5.4 \%$ & $0.5 \%$ & $-4.3 \%$ & $-2.4 \%$ \\
\hline & \multirow{3}{*}{ WYMER+ } & Base - Low 25\% & 458 & 534 & 780 & 1,421 & 1,701 & 1,479 & 806 & 416 & 1,174 & 763 & 439 & 446 \\
\hline & & Alternative - Low 25\% & 464 & 535 & 781 & 1,425 & 1,710 & 1,487 & 784 & 344 & 1,152 & 755 & 422 & 449 \\
\hline & & from Base & $1.3 \%$ & $0.1 \%$ & $0.0 \%$ & $0.3 \%$ & $0.5 \%$ & $0.5 \%$ & $-2.7 \%$ & $-17.4 \%$ & $-1.9 \%$ & $-1.1 \%$ & $-3.8 \%$ & $0.6 \%$ \\
\hline
\end{tabular}



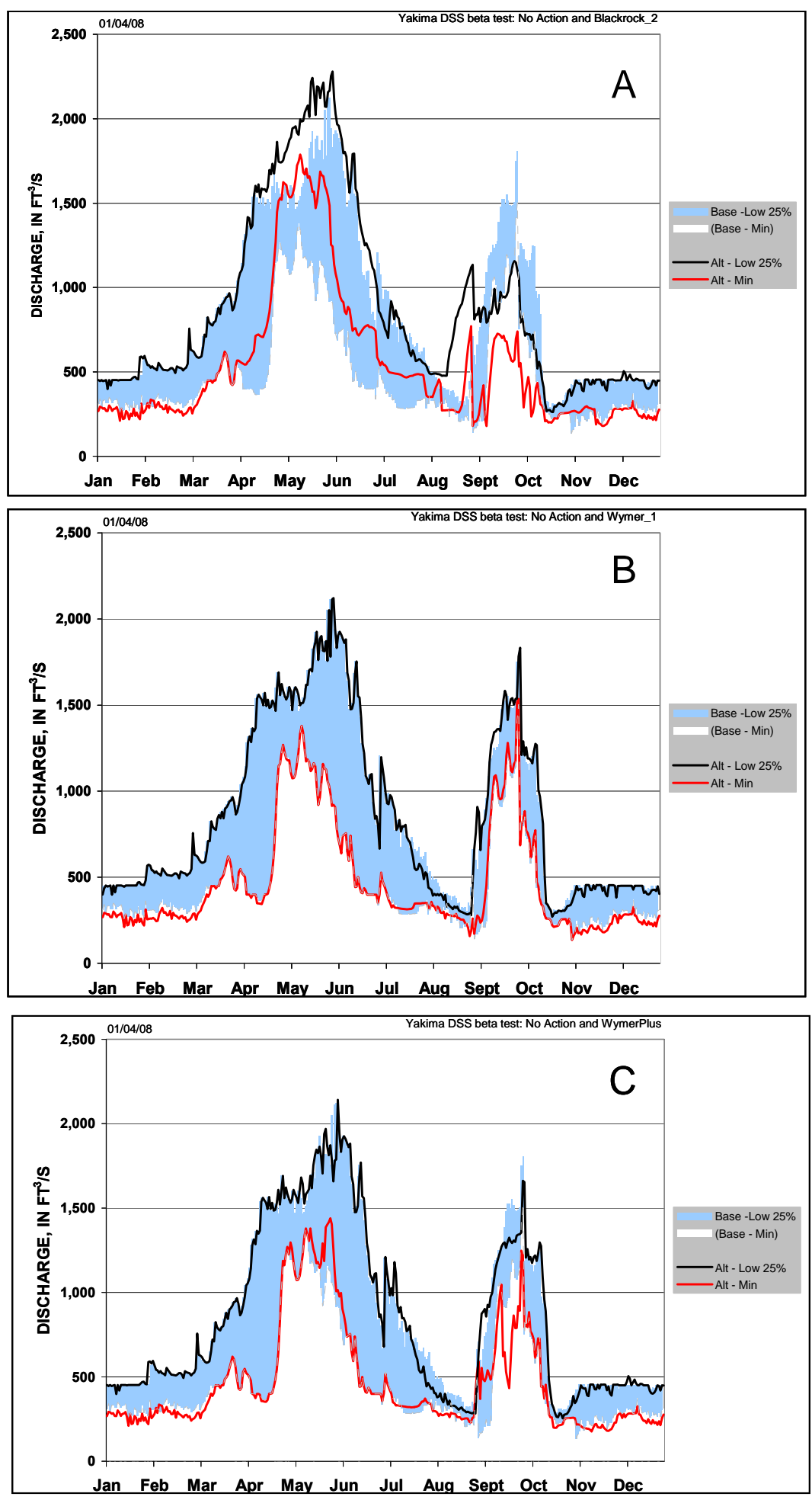

Figure 34. Flow-duration series of low flows in the Naches reach, comparing the Black Rock _2 (A), Wymer_1 (B), and WymerPlus (C) scenarios with the No Action baseline. 
Table 9. Low-flow statistics for the Union Gap reach for the No Action baseline and Black Rock 2, Wymer 1, and Wymer Plus alternatives.

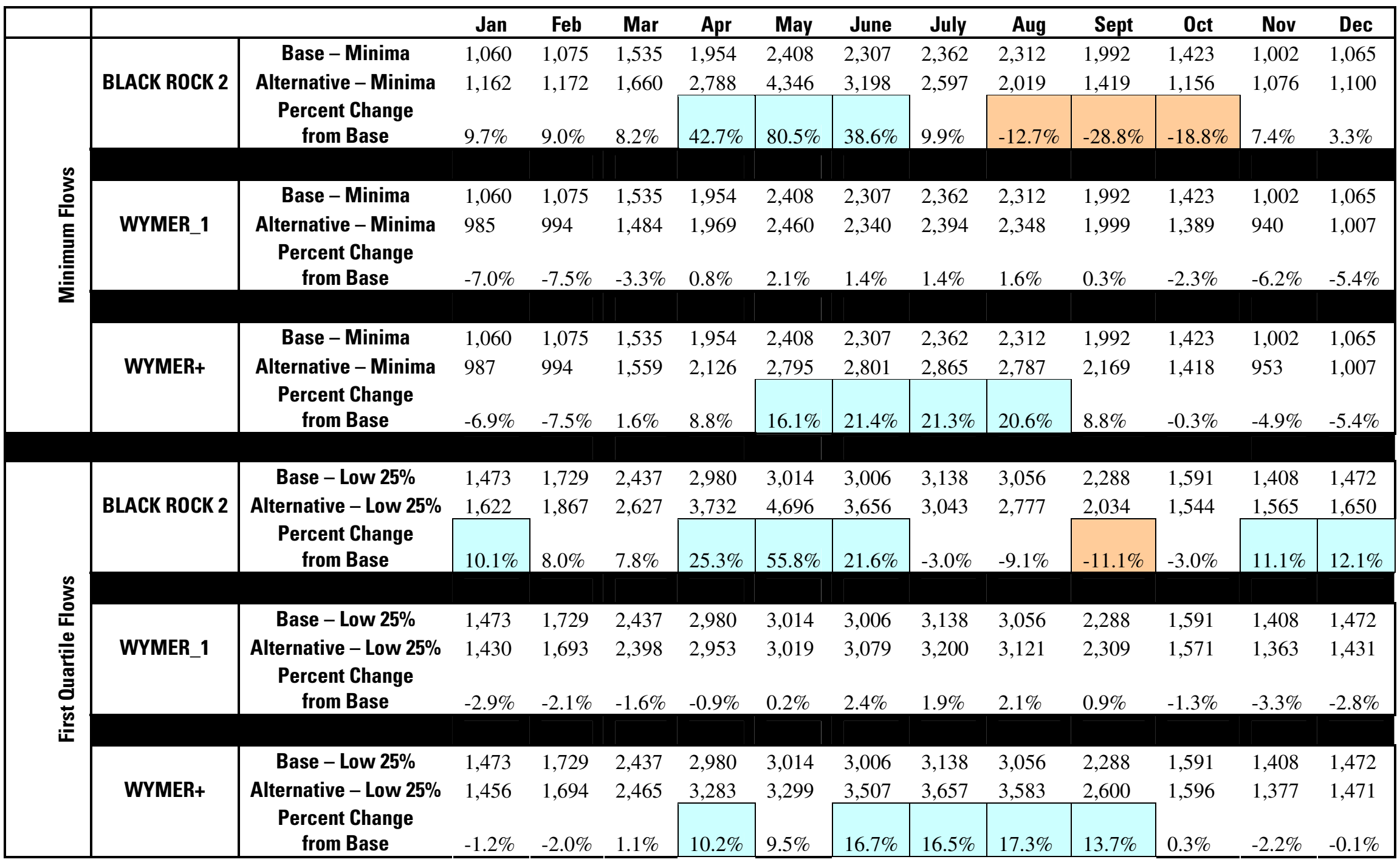



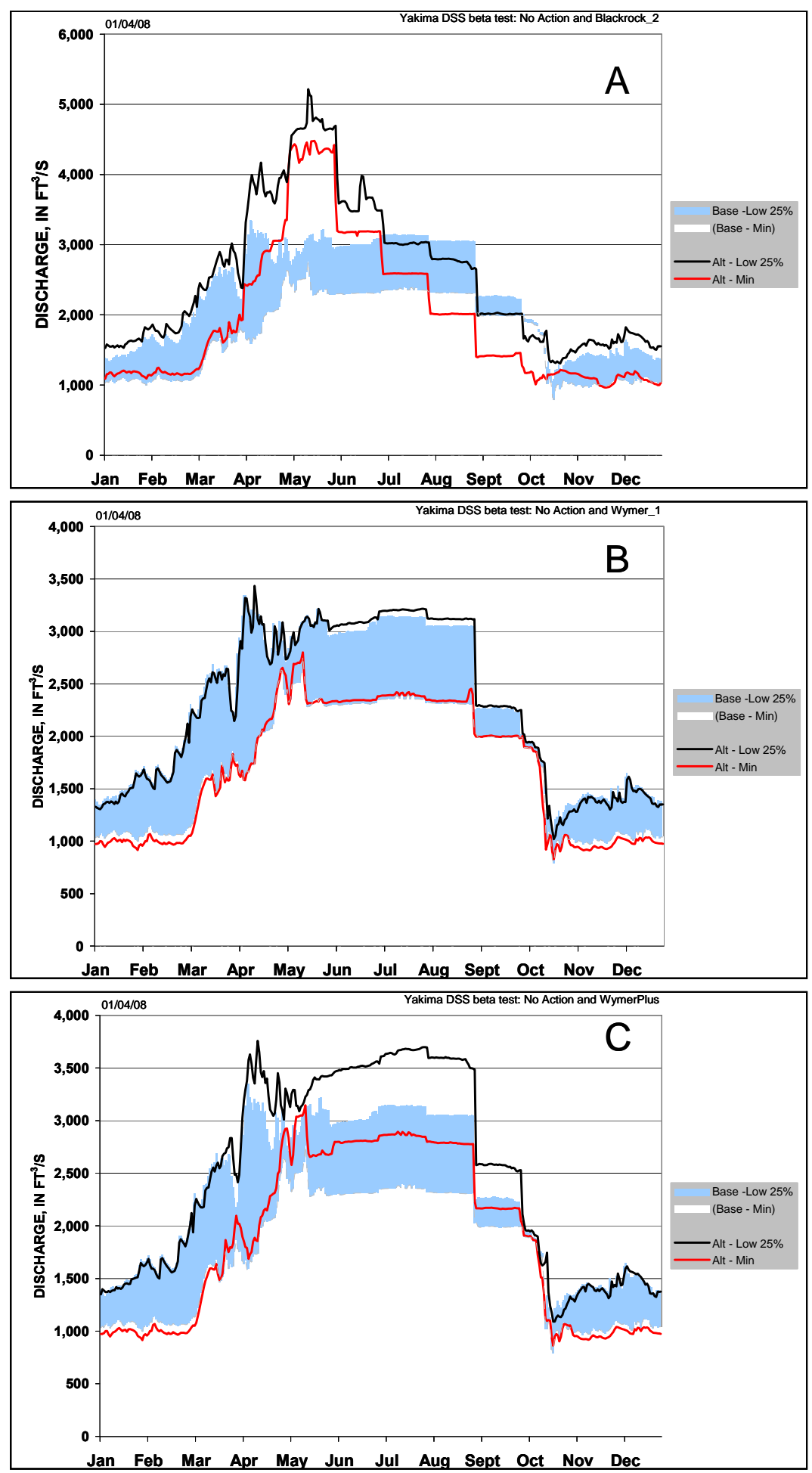

Figure 35. Flow-duration series of low flows in the Union Gap reach, comparing the Black Rock_2 (A), Wymer_1 (B), and WymerPlus (C) scenarios with the No Action baseline. 
Table 10. Low-flow statistics for the Wapato reach for the No Action baseline and Black Rock 2, Wymer 1, and Wymer Plus alternatives.

\begin{tabular}{|c|c|c|c|c|c|c|c|c|c|c|c|c|c|c|}
\hline & & & Jan & Feb & Mar & Apr & May & June & July & Aug & Sept & Oct & Nov & Dec \\
\hline \multirow{11}{*}{ 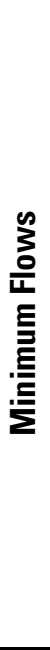 } & \multirow{3}{*}{ BLACK ROCK 2} & Base - Minima & 1,075 & 1,098 & 1,277 & 573 & 485 & 466 & 471 & 463 & 458 & 650 & 1,013 & 1,082 \\
\hline & & Alternative - Minima & 1,177 & 1,195 & 1,402 & 2,037 & 2,989 & 1,727 & 1,019 & 522 & 514 & 817 & 1,086 & 1,114 \\
\hline & & $\begin{array}{c}\text { Percent Change } \\
\text { from Base }\end{array}$ & $9.5 \%$ & $8.9 \%$ & $9.8 \%$ & $255.4 \%$ & $515.7 \%$ & $270.5 \%$ & $116.2 \%$ & $12.7 \%$ & $12.1 \%$ & $25.7 \%$ & $7.2 \%$ & $3.0 \%$ \\
\hline & & \multirow{4}{*}{$\begin{array}{c}\text { Base - Minima } \\
\text { Alternative - Minima } \\
\text { Percent Change } \\
\text { from Base }\end{array}$} & & & & & & & & & & & & \\
\hline & \multirow{3}{*}{ WYMER_1 } & & 1,075 & 1,098 & 1,277 & 573 & 485 & 466 & 471 & 463 & 458 & 650 & \multirow{2}{*}{$\begin{array}{l}1,013 \\
950\end{array}$} & \multirow{2}{*}{$\begin{array}{l}1,082 \\
1,025\end{array}$} \\
\hline & & & 1,000 & 1,017 & 1,226 & 570 & 489 & 469 & 474 & 470 & 459 & 618 & & \\
\hline & & & $-7.0 \%$ & $-7.4 \%$ & $-4.0 \%$ & $-0.5 \%$ & $0.8 \%$ & $0.5 \%$ & $0.5 \%$ & $1.5 \%$ & $0.1 \%$ & $-4.8 \%$ & $-6.2 \%$ & $-5.3 \%$ \\
\hline & \multirow{4}{*}{ WYMER+ } & & & & & & & & & & & & & \\
\hline & & Base - Minima & 1,075 & 1,098 & 1,277 & 573 & 485 & 466 & 471 & 463 & 458 & 650 & \multirow{2}{*}{$\begin{array}{l}1,013 \\
962\end{array}$} & \multirow{2}{*}{$\begin{array}{l}1,082 \\
1,025\end{array}$} \\
\hline & & Alternative - Minima & 1,001 & 1,017 & 1,482 & 1,346 & 1,456 & 1,502 & 1,503 & 1,493 & 1,320 & 1,069 & & \\
\hline & & $\begin{array}{c}\text { Percent Change } \\
\text { from Base }\end{array}$ & $-6.8 \%$ & $-7.4 \%$ & $16.0 \%$ & $134.9 \%$ & $199.8 \%$ & $222.2 \%$ & $218.9 \%$ & $222.3 \%$ & $188.0 \%$ & $64.5 \%$ & $-5.0 \%$ & $-5.3 \%$ \\
\hline \multirow{11}{*}{ 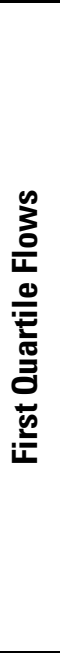 } & \multirow{3}{*}{ BLACK ROCK 2} & Base - Low 25\% & 1,501 & 1,774 & 2,267 & 1,658 & 655 & 526 & 522 & 517 & 508 & 749 & 1,424 & 1,491 \\
\hline & & Alternative - Low 25\% & 1,651 & 1,912 & 2,464 & 3,007 & 3,170 & 1,969 & 1,218 & 1,047 & 1,033 & 1,167 & 1,579 & 1,674 \\
\hline & & $\begin{array}{c}\text { Percent Change } \\
\text { from Base }\end{array}$ & $10.0 \%$ & $7.8 \%$ & $8.7 \%$ & $81.4 \%$ & $383.9 \%$ & $274.1 \%$ & $133.5 \%$ & $102.5 \%$ & $103.1 \%$ & $55.9 \%$ & $10.9 \%$ & $12.2 \%$ \\
\hline & & & & & & & & & & & & & \multirow{4}{*}{$\begin{array}{l}1,424 \\
1,378 \\
-3.2 \%\end{array}$} & \multirow{4}{*}{$\begin{array}{l}1,491 \\
1,453 \\
-2.6 \% \\
\end{array}$} \\
\hline & \multirow{3}{*}{ WYMER_1 } & \multirow{3}{*}{$\begin{array}{c}\text { Base - Low 25\% } \\
\text { Alternative - Low 25\% } \\
\text { Percent Change } \\
\text { from Base }\end{array}$} & 1,501 & 1,774 & 2,267 & 1,658 & 655 & 526 & 522 & 517 & 508 & 749 & & \\
\hline & & & 1,456 & 1,739 & 2,229 & 1,624 & 648 & 528 & 522 & 522 & 512 & 734 & & \\
\hline & & & $-3.0 \%$ & $-2.0 \%$ & $-1.7 \%$ & $-2.0 \%$ & $-1.0 \%$ & $0.3 \%$ & $0.1 \%$ & $0.9 \%$ & $0.8 \%$ & $-1.9 \%$ & & \\
\hline & & & & & & & & & & & & & & \\
\hline & \multirow{3}{*}{ WYMER+ } & Base - Low 25\% & 1,501 & 1,774 & 2,267 & 1,658 & 655 & 526 & 522 & 517 & 508 & 749 & \multirow{3}{*}{$\begin{array}{l}1,424 \\
1,393 \\
-2.2 \% \\
\end{array}$} & \multirow{3}{*}{$\begin{array}{l}1,491 \\
1,493 \\
0.1 \% \\
\end{array}$} \\
\hline & & Alternative - Low 25\% & 1,481 & 1,740 & 2,456 & 2,562 & 1,633 & 1,511 & 1,507 & 1,504 & 1,494 & 1,216 & & \\
\hline & & $\begin{array}{c}\begin{array}{c}\text { Percent Change } \\
\text { from Base }\end{array} \\
\end{array}$ & $-1.3 \%$ & $-1.9 \%$ & $8.3 \%$ & $54.6 \%$ & $149.3 \%$ & $187.2 \%$ & $188.7 \%$ & $191.0 \%$ & $193.9 \%$ & $62.5 \%$ & & \\
\hline
\end{tabular}



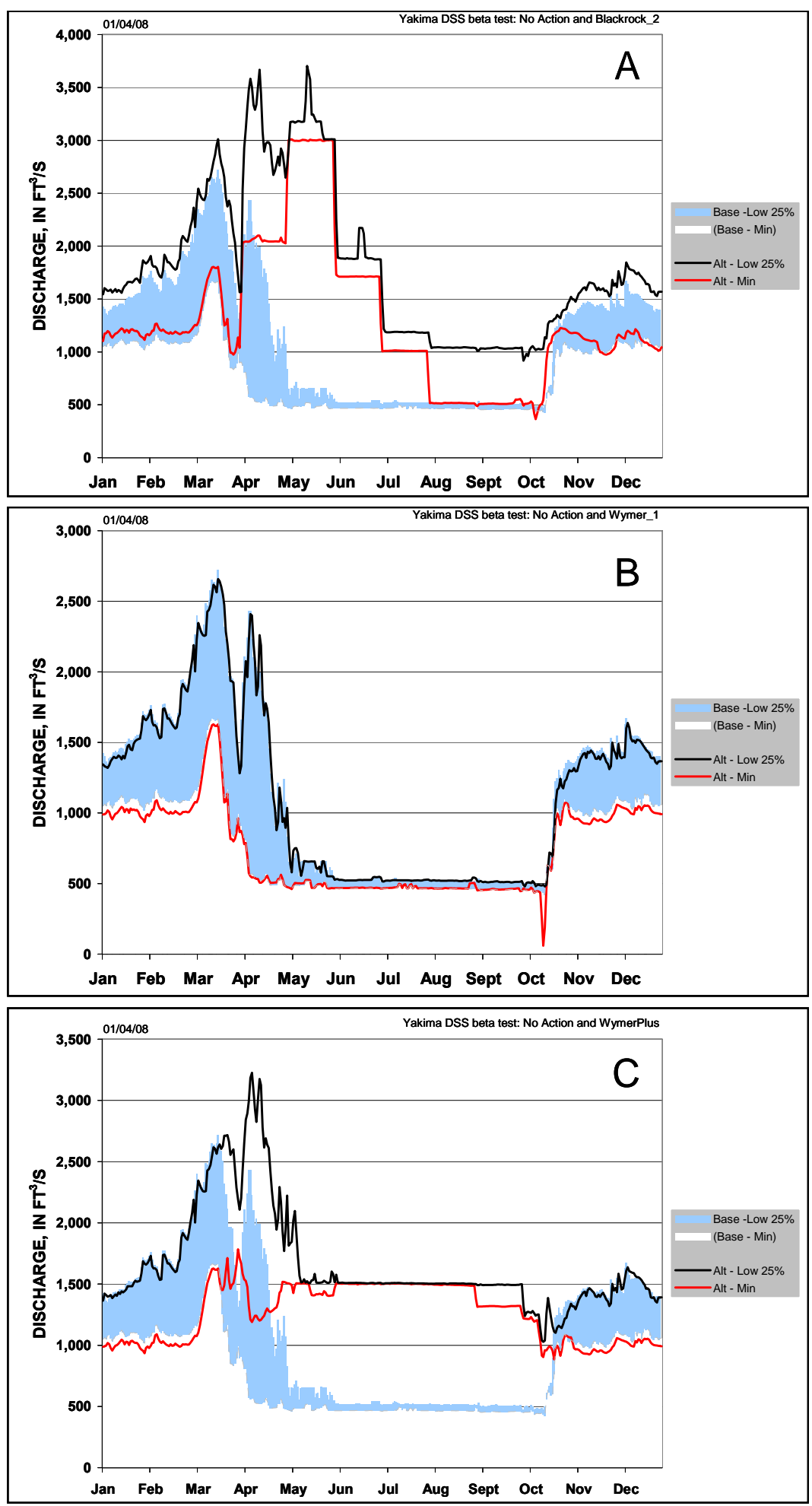

Figure 36. Flow-duration series of low flows in the Wapato reach, comparing the Black Rock_2 (A), Wymer_1 (B), and WymerPlus (C) scenarios with the No Action baseline. 
Changes in the timing and magnitude of maximum 10-day flows for each alternative and study site, relative to the No Action baseline, are illustrated in figures 37-41. Two types of color coding were used in these figures to highlight specific types of changes and are described in the legends at the bottom of each figure. The first type highlights changes in the periodicity of the highest flow events during each year. A gold background for the columns labeled "Date of Maximum" and "Offset" connotes that the maximum 10-day averaging period for an alternative ended within 30 days ( \pm ) of the maximum flow end date for the No Action baseline. A pink background indicates that the maximum flow period was chronologically advanced by more than 30 days under the alternative. A lavender background indicates that the maximum flow period was delayed by more than 30 days compared to the baseline. The actual numbers of days involved in the periodicity shift are enumerated under the "Offset" columns. The second color-coding theme highlights the relative magnitude of change in maximum flows associated with each alternative. A blue background indicates a reduction in maximum flows under the alternative, whereas tan or orange depicts an increase compared to the baseline. The intensity of the color categorizes the degree to which the alternative deviated from the baseline. A pale yellow background indicates that the maximum flows under the alternative were within 10 percent $( \pm)$ of the baseline.

- When changes in periodicity of high flow events were recorded, there was a general tendency for them to occur earlier in the water year under the alternatives than under the baseline at the Easton (fig. 37), Kittitas (fig. 38), and Union Gap (fig. 40) reaches. [The reader is reminded that the water year begins in October, so December precedes August as depicted for 1992 in figure 37. Confusing water years with calendar years can lead to the erroneous conclusion that the high flow period was delayed, when it was actually advanced.] In contrast, high-flow time periods at the Wapato site (fig. 41) tended to occur later in the water year when periodicity shifts were noted. The most consistent changes in timing were recorded at the Kittitas site (fig. 38) where the high flow periods under all three scenarios routinely occurred earlier than under the baseline, sometimes by several months.

- At the Easton and Kittitas sites, high flows were increased and decreased about equally under the Black Rock_2 alternative, both in terms of magnitude and frequency (figs. 37 and 38, respectively). Reductions in maximum flows were more common and of a larger magnitude at Easton under the WymerPlus alternative but were about the same at the Kittitas reach. Maximum flows remained unchanged at the Easton reach (fig. 37) and were altered infrequently at the Kittitas reach under the Wymer_1 alternative (fig. 38).

- Alterations in high flows at the Naches reach (fig. 39) were unremarkable, both in terms of periodicity shifts and magnitude of change.

- Maximum flows were significantly and frequently increased under the Black Rock_2 alternative at the Union Gap (fig. 40) and Wapato (fig. 41) sites. Such increases were also recorded with the WymerPlus alternative, but the changes were less frequent and of smaller magnitude than the Black Rock_2 alternative. The Wymer_1 alternative resulted in consistent reductions in maximum flows at both sites, but none of the changes were greater than 10 percent. The tendency for maximum flows to be increased under Black Rock_2 and WymerPlus and reduced under Wymer_1 probably reflects a combination of high flow capture under Wymer_1 and water exchanges with the Roza and Sunnyside Divisions associated with Black Rock_2 and WymerPlus. 


\begin{tabular}{|c|c|c|c|c|c|c|c|c|c|c|c|c|c|c|}
\hline & \multicolumn{2}{|c|}{ No Action Base } & \multicolumn{4}{|c|}{ Black Rock_2 } & \multicolumn{4}{|c|}{ Wymer_1 } & \multicolumn{4}{|c|}{ WymerPlus } \\
\hline $\begin{array}{l}\text { Water } \\
\text { year }\end{array}$ & $\begin{array}{c}\text { Date of } \\
\text { maximum }\end{array}$ & $\begin{array}{c}\text { Discharge } \\
\left(\mathrm{ft}^{3} / \mathrm{s}\right)\end{array}$ & $\begin{array}{c}\text { Date of } \\
\text { maximum }\end{array}$ & $\begin{array}{c}\text { Discharge } \\
\left(\mathrm{ft}^{3} / \mathrm{s}\right)\end{array}$ & $\begin{array}{l}\text { Offset } \\
\text { (days) }\end{array}$ & $\begin{array}{c}\Delta \text { from Base } \\
\text { maximum }\end{array}$ & $\begin{array}{c}\text { Date of } \\
\text { maximum }\end{array}$ & $\begin{array}{c}\text { Discharge } \\
\left(\mathrm{ft}^{3} / \mathrm{s}\right)\end{array}$ & $\begin{array}{l}\text { Offset } \\
\text { (days) }\end{array}$ & $\underset{\text { maximum }}{\Delta \text { from Base }}$ & $\begin{array}{c}\text { Date of } \\
\text { maximum }\end{array}$ & $\begin{array}{c}\text { Discharge } \\
\left(\mathrm{ft}^{3} / \mathrm{s}\right)\end{array}$ & $\begin{array}{l}\text { Offset } \\
\text { (days) }\end{array}$ & $\begin{array}{c}\Delta \text { from Base } \\
\text { maximum }\end{array}$ \\
\hline 1982 & 23-May & \begin{tabular}{l|l}
1,346 \\
\end{tabular} & 16-Mar & 1,385 & 68 & $2.9 \%$ & 23-May & 1,346 & 0 & $0.0 \%$ & 23-May & 1,346 & 0 & $0.0 \%$ \\
\hline 1983 & 17-Jan & 1,193 & 17-Mar & 1,677 & -59 & $40.6 \%$ & 17-Jan & 1,193 & 0 & $0.0 \%$ & 18-Mar & 1,444 & -61 & $21.0 \%$ \\
\hline 1984 & 31-Jan & 1,301 & 1-Feb & 1,819 & -1 & $39.8 \%$ & 31-Jan & 1,301 & 0 & $0.0 \%$ & 26-Mar & 1,206 & -55 & $-7.3 \%$ \\
\hline 1985 & 13-Jul & 907 & 28-May & 891 & 46 & $-1.7 \%$ & 13-Jul & 907 & 0 & $0.0 \%$ & 13-Jul & 786 & 0 & $-13.3 \%$ \\
\hline 1986 & 22-Aug & 923 & 2-Jun & 1,172 & 81 & $27.0 \%$ & 22-Aug & 923 & 0 & $0.0 \%$ & 4-Jun & 962 & 79 & $4.3 \%$ \\
\hline 1987 & 28-Aug & 1,650 & 29-Nov & 993 & 272 & $-39.8 \%$ & 28-Aug & 1,650 & 0 & $0.0 \%$ & 29-Nov & 993 & 272 & $-39.8 \%$ \\
\hline 1988 & 18-Apr & 846 & 18-Apr & 846 & 0 & $0.0 \%$ & 18-Apr & 846 & 0 & $0.0 \%$ & 18-Apr & 846 & 0 & $0.0 \%$ \\
\hline 1989 & 14-Apr & 1,059 & 15-Apr & 1,713 & -1 & $61.7 \%$ & 14-Apr & 1,059 & 0 & $0.0 \%$ & 14-Apr & 1,059 & 0 & $0.0 \%$ \\
\hline 1990 & 21-Apr & 2,288 & 18-Apr & 2,420 & 3 & $5.7 \%$ & 21-Apr & 2,288 & 0 & $0.0 \%$ & 20-Apr & 2,418 & 1 & $5.7 \%$ \\
\hline 1991 & 1-Dec & 3,843 & 1-Dec & 5,231 & 0 & $36.1 \%$ & 1-Dec & 3,843 & 0 & $0.0 \%$ & 1-Dec & 4,408 & 0 & $14.7 \%$ \\
\hline 1992 & 24-Aug & 1,712 & 13-Dec & 627 & 255 & $-63.4 \%$ & 24-Aug & 1,712 & 0 & $0.0 \%$ & 21-Aug & 806 & 3 & $-53.0 \%$ \\
\hline 1993 & 30-Aug & 1,565 & 20-Aug & 599 & 10 & $-61.7 \%$ & 30-Aug & 1,565 & 0 & $0.0 \%$ & 25-Aug & 1,237 & 5 & $-21.0 \%$ \\
\hline 1994 & 30-Aug & 1,674 & 16-Aug & 1,044 & 14 & $-37.6 \%$ & 30-Aug & 1,674 & 0 & $0.0 \%$ & 26-Aug & 1,090 & 4 & $-34.8 \%$ \\
\hline 1995 & 26-Feb & 1,059 & 26-Feb & 1,059 & 0 & $0.0 \%$ & 26-Feb & 1,059 & 0 & $0.0 \%$ & 26-Feb & 1,059 & 0 & $0.0 \%$ \\
\hline 1996 & 14-Feb & 2,361 & 18-Jan & 2,375 & 27 & $0.6 \%$ & 14-Feb & 2,361 & 0 & $0.0 \%$ & 4-Dec & 2,413 & 71 & $2.2 \%$ \\
\hline 1997 & 25-Mar & 3,636 & 24-Mar & 3,360 & 1 & $-7.6 \%$ & 25-Mar & 3,636 & 0 & $0.0 \%$ & 24-Mar & 3,371 & 1 & $-7.3 \%$ \\
\hline 1998 & 2-May & 1,453 & 31-Mar & 1,463 & 32 & $0.6 \%$ & 2-May & 1,453 & 0 & $0.0 \%$ & 31-Mar & 1,558 & 32 & $7.2 \%$ \\
\hline 1999 & 29-May & 2,194 & 29-May & 2,194 & 0 & $0.0 \%$ & 29-May & 2,194 & 0 & $0.0 \%$ & 29-May & 2,194 & 0 & $0.0 \%$ \\
\hline 2000 & 21-Dec & 2,623 & 22-Dec & 3,226 & -1 & $23.0 \%$ & 21-Dec & 2,623 & 0 & $0.0 \%$ & 21-Dec & 2,628 & 0 & $0.2 \%$ \\
\hline 2001 & 21-Aug & 2,033 & 21-Aug & 1,599 & 0 & $-21.3 \%$ & 21-Aug & 2,033 & 0 & $0.0 \%$ & 26-Aug & 1,306 & -5 & $-35.8 \%$ \\
\hline 2002 & 10-Jul & 952 & 9-Jun & 1,545 & 31 & $62.3 \%$ & 10-Jul & 952 & 0 & $0.0 \%$ & 21-Jun & 1,476 & 19 & $55.1 \%$ \\
\hline \multirow[t]{4}{*}{2003} & 5-Feb & 927 & 5-Feb & 927 & 0 & $0.0 \%$ & 5-Feb & 927 & 0 & $0.0 \%$ & 5-Feb & 927 & 0 & $0.0 \%$ \\
\hline & & & & & & & \multicolumn{8}{|c|}{ Maximum Flow Differential } \\
\hline & \multicolumn{5}{|c|}{ Time Differential } & & \multicolumn{8}{|c|}{ Within \pm 10 Percent of Base } \\
\hline & \multicolumn{5}{|c|}{$\begin{array}{l}\text { Within } 30 \text { Days of Base Maximum } \\
30 \text { Days or More Earlier Than Base Maximum } \\
30 \text { Days or More Later Than Base Maximum }\end{array}$} & & & \multicolumn{3}{|c|}{$\begin{array}{l}10-25 \text { Percent Lower Than Base } \\
25 \text { - } 50 \text { Percent Lower Than Base } \\
>50 \text { Percent Lower Than Base }\end{array}$} & \multicolumn{4}{|c|}{$\begin{array}{l}10-25 \text { Percent Higher Than Base } \\
25 \text { - } 50 \text { Percent Higher Than Base } \\
>50 \text { Percent Higher Than Base }\end{array}$} \\
\hline
\end{tabular}

Figure 37. Maximum 10-day discharges in the Easton reach, comparing the Black Rock_2, Wymer_1, and WymerPlus scenarios with the No Action baseline.

\begin{tabular}{|c|c|c|c|c|c|c|c|c|c|c|c|c|c|c|}
\hline & \multicolumn{2}{|c|}{ No Action Base } & \multicolumn{4}{|c|}{ Black Rock_2 } & \multicolumn{4}{|c|}{ Wymer_1 } & \multicolumn{4}{|c|}{ WymerPlus } \\
\hline $\begin{array}{c}\text { Water } \\
\text { year }\end{array}$ & $\begin{array}{c}\text { Date of } \\
\text { maximum }\end{array}$ & $\begin{array}{c}\text { Discharge } \\
\left(\mathrm{ft}^{3} / \mathrm{s}\right)\end{array}$ & $\begin{array}{c}\text { Date of } \\
\text { maximum }\end{array}$ & $\begin{array}{c}\text { Discharge } \\
\left(\mathrm{ft}^{3} / \mathrm{s}\right)\end{array}$ & $\begin{array}{l}\text { Offset } \\
\text { (days) }\end{array}$ & $\begin{array}{c}\Delta \text { from Base } \\
\text { maximum }\end{array}$ & $\begin{array}{c}\text { Date of } \\
\text { maximum }\end{array}$ & $\begin{array}{c}\text { Discharge } \\
\left(\mathrm{ft}^{3} / \mathrm{s}\right)\end{array}$ & $\begin{array}{l}\text { Offset } \\
\text { (days) }\end{array}$ & $\begin{array}{c}\Delta \text { from Base } \\
\text { maximum }\end{array}$ & $\begin{array}{c}\text { Date of } \\
\text { maximum }\end{array}$ & $\begin{array}{l}\text { Discharge } \\
\left(\mathrm{ft}^{3} / \mathrm{s}\right)\end{array}$ & $\begin{array}{l}\text { Offset } \\
\text { (days) }\end{array}$ & $\begin{array}{c}\Delta \text { from Base } \\
\text { maximum }\end{array}$ \\
\hline 1982 & 25-Jun & 6,755 & 24-Feb & 5,459 & 121 & $-19.2 \%$ & 24-Feb & 5,450 & 121 & $-19.3 \%$ & 24-Feb & 5,451 & 121 & $-19.3 \%$ \\
\hline 1983 & 8-Jun & 5,173 & 16-Mar & 5,720 & 84 & $10.6 \%$ & 17-Mar & 5,225 & 83 & $1.0 \%$ & 17-Mar & 5,409 & 83 & $4.6 \%$ \\
\hline 1984 & 24-Jun & 6,388 & 1-Feb & 5,882 & 144 & $-7.9 \%$ & 24-Jun & 6,379 & 0 & $-0.1 \%$ & 1-Feb & 6,871 & 144 & $7.5 \%$ \\
\hline 1985 & 16-Aug & 4,238 & 17-Apr & 3,871 & 121 & $-8.7 \%$ & 17-Apr & 3,862 & 121 & $-8.9 \%$ & 12-Jun & 4,925 & 65 & $16.2 \%$ \\
\hline 1986 & 7-Mar & 4,885 & 7-Mar & 5,056 & 0 & $3.5 \%$ & 7-Mar & 5,048 & 0 & $3.3 \%$ & 7-Mar & 5,048 & 0 & $3.3 \%$ \\
\hline 1987 & 12-Aug & 3,524 & 29-Jun & 3,038 & 44 & $-13.8 \%$ & 29-Jun & 3,486 & 44 & $-1.1 \%$ & 29-Jun & 3,381 & 44 & $-4.1 \%$ \\
\hline 1988 & 20-Jul & 3,531 & 21-Apr & 3,454 & 90 & $-2.2 \%$ & 21-Apr & 3,690 & 90 & $4.5 \%$ & 21-Apr & 3,692 & 90 & $4.5 \%$ \\
\hline 1989 & 7-Aug & 4,023 & 17-Apr & 4,660 & 112 & $15.8 \%$ & 17-Apr & 4,050 & 112 & $0.7 \%$ & 17-Apr & 4,047 & 112 & $0.6 \%$ \\
\hline 1990 & 20-Apr & 5,450 & 18-Apr & 5,781 & 2 & $6.1 \%$ & 20-Apr & 5,627 & 0 & $3.2 \%$ & 20-Apr & 5,754 & 0 & $5.6 \%$ \\
\hline 1991 & 1-Dec & 8,894 & 1-Dec & 10,686 & 0 & $20.1 \%$ & 1-Dec & 9,955 & 0 & $11.9 \%$ & 1-Dec & 10,067 & 0 & $13.2 \%$ \\
\hline 1992 & 5-Aug & 3,905 & 30-May & 3,648 & 67 & $-6.6 \%$ & 29-Jun & 3,955 & 37 & $1.3 \%$ & 29-Jun & 3,841 & 37 & $-1.6 \%$ \\
\hline 1993 & 15-Jul & 3,530 & 29-Jun & 2,935 & 16 & $-16.9 \%$ & 29-Jun & 3,199 & 16 & $-9.4 \%$ & 29-Jun & 3,418 & 16 & $-3.2 \%$ \\
\hline 1994 & 29-Jul & 2,843 & 10-May & 2,820 & 80 & $-0.8 \%$ & 9-Apr & 2,567 & 111 & $-9.7 \%$ & 9-Apr & 2,567 & 111 & $-9.7 \%$ \\
\hline 1995 & 27-Feb & 4,916 & 27-Feb & 5,088 & 0 & $3.5 \%$ & 27-Feb & 5,102 & 0 & $3.8 \%$ & 27-Feb & 5,103 & 0 & $3.8 \%$ \\
\hline 1996 & 14-Feb & 11,003 & 14-Feb & 11,044 & 0 & $0.4 \%$ & 14-Feb & 11,093 & 0 & $0.8 \%$ & 14-Feb & 11,095 & 0 & $0.8 \%$ \\
\hline 1997 & 19-May & 10,433 & 19-May & 10,074 & 0 & $-3.4 \%$ & 19-May & 10,307 & 0 & $-1.2 \%$ & 19-May & 10,674 & 0 & $2.3 \%$ \\
\hline 1998 & 2-May & 5,970 & 3-May & 5,503 & -1 & $-7.8 \%$ & 2-May & 5,506 & 0 & $-7.8 \%$ & 2-May & 5,510 & 0 & $-7.7 \%$ \\
\hline 1999 & 31-May & 8,211 & 31-May & 8,180 & 0 & $-0.4 \%$ & 31-Мay & 8,222 & 0 & $0.1 \%$ & 31-Маy & 8,222 & 0 & $0.1 \%$ \\
\hline 2000 & 22-Apr & 6,255 & 23-Dec & 6,866 & 121 & $9.8 \%$ & 22-Dec & 5,625 & 122 & $-10.1 \%$ & 23-Dec & 6,046 & 121 & $-3.3 \%$ \\
\hline 2001 & 17-Jul & 2,986 & 10-May & 3,171 & 68 & $6.2 \%$ & 26-Jun & 2,957 & 21 & $-1.0 \%$ & 26-Jun & 2,980 & 21 & $-0.2 \%$ \\
\hline 2002 & 23-Jun & 5,528 & 18-Apr & 4,025 & 66 & $-27.2 \%$ & 18-Apr & 4,039 & 66 & $-26.9 \%$ & 4-Jul & 4,207 & -11 & $-23.9 \%$ \\
\hline \multirow[t]{4}{*}{2003} & 4-Aug & 4,212 & 6-Feb & 3,883 & 179 & $-7.8 \%$ & 6-Feb & 3,874 & 179 & $-8.0 \%$ & 6-Feb & 3,874 & 179 & $-8.0 \%$ \\
\hline & & & & & & & \multicolumn{8}{|c|}{ Maximum Flow Differential } \\
\hline & \multicolumn{5}{|c|}{ Time Differential } & & \multirow{2}{*}{\multicolumn{4}{|c|}{$\begin{array}{l}\text { Within } \pm 10 \text { Percent of Base } \\
10-25 \text { Percent Lower Than Base } \\
25-50 \text { Percent Lower Than Base } \\
>50 \text { Percent Lower Than Base }\end{array}$}} & \multirow{2}{*}{\multicolumn{4}{|c|}{$\begin{array}{l}10-25 \text { Percent Higher Than Base } \\
25 \text { - } 50 \text { Percent Higher Than Base } \\
>50 \text { Percent Higher Than Base }\end{array}$}} \\
\hline & & $\begin{array}{l}\text { Within } 30 \text { Days } \\
30 \text { Days or More } \\
30 \text { Days or More }\end{array}$ & $\begin{array}{l}\text { fBase Maxin } \\
\text { Earlier Than } \\
\text { Later Than B }\end{array}$ & $\begin{array}{l}\text { m } \\
\text { se Maximum } \\
\text { e Maximum }\end{array}$ & & & & & & & & & & \\
\hline
\end{tabular}

Figure 38. Maximum 10-day discharges in the Kittitas reach, comparing the Black Rock_2, Wymer_1, and WymerPlus scenarios with the No Action baseline. 


\begin{tabular}{|c|c|c|c|c|c|c|c|c|c|c|c|c|c|c|}
\hline & \multicolumn{2}{|c|}{ No Action Base } & \multicolumn{4}{|c|}{ Black Rock_2 } & \multicolumn{4}{|c|}{ Wymer_1 } & \multicolumn{4}{|c|}{ WymerPlus } \\
\hline $\begin{array}{c}\text { Water } \\
\text { year }\end{array}$ & $\begin{array}{c}\text { Date of } \\
\text { maximum }\end{array}$ & $\begin{array}{c}\text { Discharge } \\
\left(\mathrm{ft}^{3} / \mathrm{s}\right)\end{array}$ & $\begin{array}{c}\text { Date of } \\
\text { maximum }\end{array}$ & $\begin{array}{c}\text { Discharge } \\
\left(\mathrm{ft}^{3} / \mathbf{s}\right)\end{array}$ & $\begin{array}{l}\text { Offset } \\
\text { (days) }\end{array}$ & $\begin{array}{c}\Delta \text { from Base } \\
\text { maximum }\end{array}$ & $\begin{array}{c}\text { Date of } \\
\text { maximum }\end{array}$ & $\begin{array}{c}\text { Discharge } \\
\left(\mathrm{ft}^{3} / \mathrm{s}\right)\end{array}$ & $\begin{array}{l}\text { Offset } \\
\text { (days) }\end{array}$ & $\begin{array}{c}\Delta \text { from Base } \\
\text { maximum }\end{array}$ & $\begin{array}{c}\text { Date of } \\
\text { maximum }\end{array}$ & $\begin{array}{c}\text { Discharge } \\
\left(\mathrm{ft}^{3} / \mathrm{s}\right)\end{array}$ & $\begin{array}{l}\text { Offset } \\
\text { (days) }\end{array}$ & $\begin{array}{c}\Delta \text { from Base } \\
\text { maximum }\end{array}$ \\
\hline 1982 & 24-Jun & 6,205 & 24-Jun & 6,144 & 0 & $-1.0 \%$ & 24-Jun & 6,205 & 0 & $0.0 \%$ & 24-Jun & 6,205 & 0 & $0.0 \%$ \\
\hline 1983 & 3-Jun & 6,612 & 3-Jun & 6,477 & 0 & $-2.0 \%$ & 3-Jun & 6,612 & 0 & $0.0 \%$ & 3-Jun & 6,612 & 0 & $0.0 \%$ \\
\hline 1984 & 29-Jun & 4,793 & 1-Jul & 3,953 & -2 & $-17.5 \%$ & 29-Jun & 4,793 & 0 & $0.0 \%$ & 29-Jun & 4,793 & 0 & $0.0 \%$ \\
\hline 1985 & 14-Jun & 4,620 & 15-Jun & 4,416 & -1 & $-4.4 \%$ & 12-Jun & 4,652 & 2 & $0.7 \%$ & 12-Jun & 4,652 & 2 & $0.7 \%$ \\
\hline 1986 & 5-Jun & 5,624 & 5-Jun & 5,253 & 0 & $-6.6 \%$ & 5-Jun & 5,597 & 0 & $-0.5 \%$ & 4-Jun & 5,862 & 1 & $4.2 \%$ \\
\hline 1987 & 15-May & 4,958 & 14-May & 4,681 & 1 & $-5.6 \%$ & 15-May & 5,469 & 0 & $10.3 \%$ & 15-May & 4,681 & 1 & $-5.6 \%$ \\
\hline 1988 & 22-Apr & 3,130 & 22-Apr & 3,132 & 0 & $0.1 \%$ & 22-Apr & 3,130 & 0 & $0.0 \%$ & 22-Apr & 3,130 & 0 & $0.0 \%$ \\
\hline 1989 & 22-Apr & 3,844 & 23-Apr & 4,322 & -1 & $12.4 \%$ & 22-Apr & 3,844 & 0 & $0.0 \%$ & 22-Apr & 3,844 & 0 & $0.0 \%$ \\
\hline 1990 & 21-Apr & 4,888 & 21-Apr & 4,849 & 0 & $-0.8 \%$ & 21-Apr & 4,889 & 0 & $0.0 \%$ & 22-Apr & 4,819 & -1 & $-1.4 \%$ \\
\hline 1991 & 1-Dec & 3,632 & 1-Dec & 3,632 & 0 & $0.0 \%$ & 1-Dec & 3,632 & 0 & $0.0 \%$ & 1-Dec & 3,640 & 0 & $0.2 \%$ \\
\hline 1992 & 8-May & 2,315 & 8-May & 2,496 & 0 & $7.8 \%$ & 8-May & 2,314 & 0 & $0.0 \%$ & 8-May & 2,794 & 0 & $20.7 \%$ \\
\hline 1993 & 21-May & 3,565 & 21-May & 3,578 & 0 & $0.4 \%$ & 21-May & 3,564 & 0 & $0.0 \%$ & 21-May & 3,564 & 0 & $0.0 \%$ \\
\hline 1994 & 26-Apr & 2,559 & 26-Apr & 2,556 & 0 & $-0.1 \%$ & 26-Apr & 2,560 & 0 & $0.0 \%$ & 26-Apr & 2,559 & 0 & $0.0 \%$ \\
\hline 1995 & 5-Jun & 5,344 & 5-Jun & 5,479 & 0 & $2.5 \%$ & 5-Jun & 5,344 & 0 & $0.0 \%$ & 5-Jun & 5,344 & 0 & $0.0 \%$ \\
\hline 1996 & 16-Feb & 8,666 & $16-\mathrm{Feb}$ & 8,661 & 0 & $-0.1 \%$ & $16-\mathrm{Feb}$ & 8,667 & 0 & $0.0 \%$ & 16-Feb & 8,672 & 0 & $0.1 \%$ \\
\hline 1997 & 21-May & 9,214 & 21-May & 9,176 & 0 & $-0.4 \%$ & 21-May & 9,217 & 0 & $0.0 \%$ & 21-May & 9,217 & 0 & $0.0 \%$ \\
\hline 1998 & 7-May & 6,508 & 7-May & 6,724 & 0 & $3.3 \%$ & 7-May & 6,508 & 0 & $0.0 \%$ & 7-May & 6,508 & 0 & $0.0 \%$ \\
\hline 1999 & 1-Jun & 7,066 & 1-Jun & 7,066 & 0 & $0.0 \%$ & 1-Jun & 7,066 & 0 & $0.0 \%$ & 1-Jun & 7,066 & 0 & $0.0 \%$ \\
\hline 2000 & 21-Apr & 4,536 & 21-Apr & 4,536 & 0 & $0.0 \%$ & 21-Apr & 4,536 & 0 & $0.0 \%$ & 21-Apr & 4,536 & 0 & $0.0 \%$ \\
\hline 2001 & 1-Oct & 1,895 & 18-May & 1,865 & -228 & $-1.6 \%$ & 1-Oct & 1,928 & 0 & $1.7 \%$ & 1-Oct & 1,717 & 0 & $-9.4 \%$ \\
\hline 2002 & 21-Apr & 4,776 & 21-Apr & 4,928 & 0 & $3.2 \%$ & 21-Apr & 4,927 & 0 & $3.2 \%$ & 21-Apr & 4,928 & 0 & $3.2 \%$ \\
\hline 2003 & 6-Jun & 5,059 & 6-Jun & 5,073 & 0 & $0.3 \%$ & 7-Jun & 4,987 & -1 & $-1.4 \%$ & 2-Jun & 5,211 & 4 & $3.0 \%$ \\
\hline
\end{tabular}
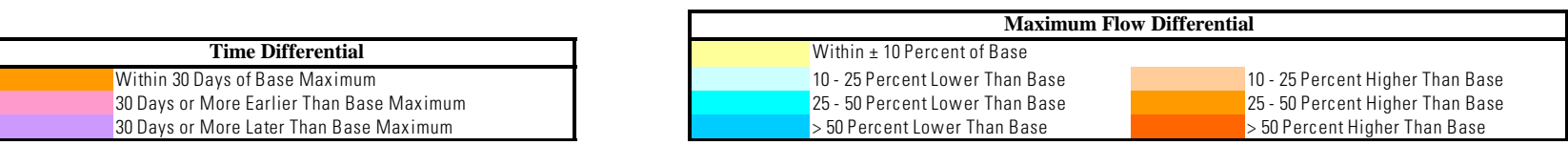

Figure 39. Maximum 10-day discharges in the Naches reach, comparing the Black Rock_2, Wymer_1, and WymerPlus scenarios with the No Action baseline.

\begin{tabular}{|c|c|c|c|c|c|c|c|c|c|c|c|c|c|c|}
\hline & \multicolumn{2}{|c|}{ No Action Base } & \multicolumn{4}{|c|}{ Black Rock_2 } & \multicolumn{4}{|c|}{ Wymer_1 } & \multicolumn{4}{|c|}{ WymerPlus } \\
\hline $\begin{array}{l}\text { Water } \\
\text { year }\end{array}$ & $\begin{array}{l}\text { Date of } \\
\text { maximum }\end{array}$ & $\begin{array}{c}\text { Discharge } \\
\left(\mathrm{ft}^{3} / \mathrm{s}\right)\end{array}$ & $\begin{array}{c}\text { Date of } \\
\text { maximum }\end{array}$ & $\begin{array}{c}\text { Discharge } \\
\left(\mathrm{ft}^{3} / \mathrm{s}\right)\end{array}$ & Offset (days) & $\begin{array}{c}\Delta \text { from Base } \\
\text { maximum }\end{array}$ & $\begin{array}{c}\text { Date of } \\
\text { maximum }\end{array}$ & $\begin{array}{c}\text { Discharge } \\
\left(\mathrm{ft}^{3} / \mathrm{s}\right)\end{array}$ & $\begin{array}{l}\text { Offset } \\
\text { (days) }\end{array}$ & $\begin{array}{c}\Delta \text { from Base } \\
\text { maximum }\end{array}$ & $\begin{array}{c}\text { Date of } \\
\text { maximum }\end{array}$ & $\begin{array}{c}\text { Discharge } \\
\left(\mathrm{ft}^{3} / \mathrm{s}\right)\end{array}$ & $\begin{array}{l}\text { Offset } \\
\text { (days) }\end{array}$ & $\begin{array}{c}\Delta \text { from Base } \\
\text { maximum }\end{array}$ \\
\hline 1982 & 25-Jun & 11,508 & $25-\mathrm{Feb}$ & 11,682 & 120 & $1.5 \%$ & 26-Feb & 11,309 & 119 & $-1.7 \%$ & 26-Feb & 11,340 & 119 & $-1.5 \%$ \\
\hline 1983 & 6-Jun & 10,531 & 17-Mar & 10,841 & 81 & $2.9 \%$ & 6-Jun & 10,210 & 0 & $-3.0 \%$ & 5-Jun & 10,761 & 1 & $2.2 \%$ \\
\hline 1984 & 27-Jun & 10,529 & 1-Feb & 10,362 & 147 & $-1.6 \%$ & 27-Jun & 10,496 & 0 & $-0.3 \%$ & 1-Feb & 11,151 & 147 & $5.9 \%$ \\
\hline 1985 & 15-Jun & 6,462 & 18-Apr & 6,774 & 58 & $4.8 \%$ & 15-Jun & 6,017 & 0 & $-6.9 \%$ & 13-Jun & 8,800 & 2 & $36.2 \%$ \\
\hline 1986 & 7-Mar & 9,658 & 7-Mar & 9,818 & 0 & $1.7 \%$ & 7-Mar & 9,638 & 0 & $-0.2 \%$ & 7-Mar & 9,638 & 0 & $-0.2 \%$ \\
\hline 1987 & 9-May & 6,268 & 9-May & 6,957 & 0 & $11.0 \%$ & 14-May & 6,576 & -5 & $4.9 \%$ & 9-May & 6,702 & 0 & $6.9 \%$ \\
\hline 1988 & 22-Apr & 5,933 & 22-Apr & 6,552 & 0 & $10.4 \%$ & 22-Apr & 5,900 & 0 & $-0.6 \%$ & 22-Apr & 6,258 & 0 & $5.5 \%$ \\
\hline 1989 & 19-Apr & 7,237 & 21-Apr & 8,739 & -2 & $20.8 \%$ & 19-Apr & 7,203 & 0 & $-0.5 \%$ & 20-Apr & 7,541 & -1 & $4.2 \%$ \\
\hline 1990 & 21-Apr & 9,541 & 21-Apr & 10,145 & 0 & $6.3 \%$ & 21-Apr & 9,509 & 0 & $-0.3 \%$ & 21-Apr & 9,891 & 0 & $3.7 \%$ \\
\hline 1991 & 2-Dec & 13,210 & 1-Dec & 14,898 & 1 & $12.8 \%$ & 1-Dec & 14,004 & 1 & $6.0 \%$ & 1-Dec & 14,145 & 1 & $7.1 \%$ \\
\hline 1992 & 6-Feb & 4,255 & 30-May & 4,634 & -114 & $8.9 \%$ & 20-Mar & 4,153 & -43 & $-2.4 \%$ & 20-Mar & 4,172 & -43 & $-2.0 \%$ \\
\hline 1993 & 21-May & 4,777 & 21-May & 5,515 & 0 & $15.4 \%$ & 21-May & 4,666 & 0 & $-2.3 \%$ & 21-May & 5,135 & 0 & $7.5 \%$ \\
\hline 1994 & 26-Apr & 3,686 & 20-May & 4,450 & -24 & $20.7 \%$ & 26-Apr & 3,659 & 0 & $-0.7 \%$ & 26-Apr & 4,007 & 0 & $8.7 \%$ \\
\hline 1995 & 27-Feb & 10,663 & 27-Feb & 10,812 & 0 & $1.4 \%$ & 27-Feb & 10,405 & 0 & $-2.4 \%$ & 27-Feb & 10,405 & 0 & $-2.4 \%$ \\
\hline 1996 & $15-\mathrm{Feb}$ & 21,249 & $15-\mathrm{Feb}$ & 21,270 & 0 & $0.1 \%$ & 15 -Feb & 20,896 & 0 & $-1.7 \%$ & $15-\mathrm{Feb}$ & 20,902 & 0 & $-1.6 \%$ \\
\hline 1997 & 20-May & 20,607 & 20-May & 20,767 & 0 & $0.8 \%$ & 20-May & 20,379 & 0 & $-1.1 \%$ & 20-May & 21,169 & 0 & $2.7 \%$ \\
\hline 1998 & 7-May & 11,566 & 8-May & 12,017 & -1 & $3.9 \%$ & 8-May & 11,018 & -1 & $-4.7 \%$ & 8-May & 11,499 & -1 & $-0.6 \%$ \\
\hline 1999 & 1-Jun & 14,259 & 1-Jun & 14,861 & 0 & $4.2 \%$ & 1-Jun & 14,096 & 0 & $-1.1 \%$ & 1-Jun & 14,649 & 0 & $2.7 \%$ \\
\hline 2000 & 22-Apr & 10,653 & 23-Dec & 10,499 & 121 & $-1.4 \%$ & 22-Apr & 9,724 & 0 & $-8.7 \%$ & 22-Apr & 10,225 & 0 & $-4.0 \%$ \\
\hline 2001 & 13-Jul & 2,684 & 30-May & 4,488 & 44 & $67.2 \%$ & 12-Jul & 2,913 & 1 & $8.5 \%$ & 12-Jul & 3,406 & 1 & $26.9 \%$ \\
\hline 2002 & 20-Apr & 8,737 & 20-Apr & 9,544 & 0 & $9.2 \%$ & 20-Apr & 8,920 & 0 & $2.1 \%$ & 20-Apr & 9,264 & 0 & $6.0 \%$ \\
\hline 2003 & 6-Feb & 8,252 & 6-Feb & 8,465 & 0 & $2.6 \%$ & 6-Feb & 8,020 & 0 & $-2.8 \%$ & 6-Feb & 8,029 & 0 & $-2.7 \%$ \\
\hline
\end{tabular}
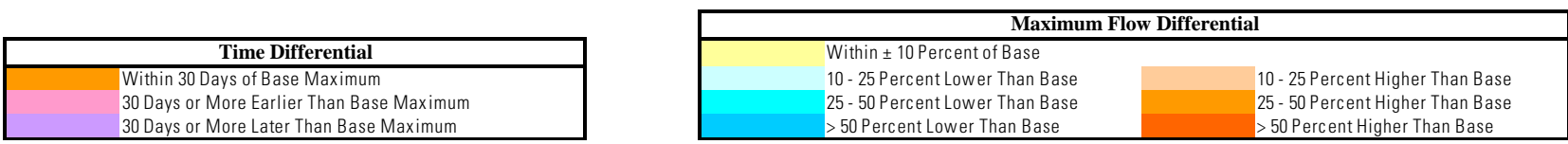

Figure 40. Maximum 10-day discharges in the Union Gap reach, comparing the Black Rock_2, Wymer_1, and WymerPlus scenarios with the No Action baseline. 


\begin{tabular}{|c|c|c|c|c|c|c|c|c|c|c|c|c|c|c|}
\hline & \multicolumn{2}{|c|}{ No Action Base } & \multicolumn{4}{|c|}{ Black Rock_2 } & \multicolumn{4}{|c|}{ Wymer_1 } & \multicolumn{4}{|c|}{ WymerPlus } \\
\hline $\begin{array}{l}\text { Water } \\
\text { year }\end{array}$ & $\begin{array}{l}\text { Date of } \\
\text { maximum }\end{array}$ & $\begin{array}{c}\text { Discharge } \\
\left(\mathrm{ft}^{3} / \mathbf{s}\right)\end{array}$ & $\begin{array}{c}\text { Date of } \\
\text { maximum }\end{array}$ & $\begin{array}{c}\text { Discharge } \\
\left(\mathrm{ft}^{3} / \mathrm{s}\right)\end{array}$ & $\begin{array}{l}\text { Offset } \\
\text { (days) }\end{array}$ & $\begin{array}{c}\Delta \text { from Base } \\
\text { maximum }\end{array}$ & $\begin{array}{c}\text { Date of } \\
\text { maximum }\end{array}$ & Discharge $\left(\mathrm{ft}^{3} / \mathrm{s}\right)$ & $\begin{array}{l}\text { Offset } \\
\text { (days) }\end{array}$ & $\begin{array}{c}\Delta \text { from Base } \\
\text { maximum }\end{array}$ & $\begin{array}{c}\text { Date of } \\
\text { maximum }\end{array}$ & $\begin{array}{c}\text { Discharge } \\
\left(\mathrm{ft}^{3} / \mathrm{s}\right)\end{array}$ & $\begin{array}{l}\text { Offset } \\
\text { (days) }\end{array}$ & $\begin{array}{c}\Delta \text { from Base } \\
\text { maximum }\end{array}$ \\
\hline 1982 & 25-Feb & 11,872 & 25-Feb & 12,161 & 0 & $2.4 \%$ & 26-Feb & 11,794 & -1 & $-0.7 \%$ & 26-Feb & 11,825 & -1 & $-0.4 \%$ \\
\hline 1983 & 17-Mar & 10,569 & 17-Mar & 11,321 & 0 & $7.1 \%$ & 17-Mar & 10,472 & 0 & $-0.9 \%$ & 17-Mar & 10,641 & 0 & $0.7 \%$ \\
\hline 1984 & 1-Feb & 9,904 & 1-Feb & 10,550 & 0 & $6.5 \%$ & 1-Feb & 9,809 & 0 & $-1.0 \%$ & 1-Feb & 11,339 & 0 & $14.5 \%$ \\
\hline 1985 & 17-Apr & 4,687 & 18-Apr & 6,146 & -1 & $31.1 \%$ & 17-Apr & 4,654 & 0 & $-0.7 \%$ & 13-Jun & 6,723 & -57 & $43.4 \%$ \\
\hline 1986 & 7-Mar & 10,071 & 7-Mar & 10,230 & 0 & $1.6 \%$ & 7-Mar & 10,050 & 0 & $-0.2 \%$ & 7-Mar & 10,050 & 0 & $-0.2 \%$ \\
\hline 1987 & 16-Mar & 5,068 & 9-May & 5,608 & -54 & $10.7 \%$ & 16-Mar & 5,046 & 0 & $-0.4 \%$ & 9-May & 5,296 & -54 & $4.5 \%$ \\
\hline 1988 & 22-Apr & 4,519 & 22-Apr & 5,784 & 0 & $28.0 \%$ & 22-Apr & 4,486 & 0 & $-0.7 \%$ & 22-Apr & 5,490 & 0 & $21.5 \%$ \\
\hline 1989 & 19-Apr & 6,017 & 19-Apr & 8,120 & 0 & $35.0 \%$ & 19-Apr & 5,984 & 0 & $-0.6 \%$ & 19-Apr & 6,942 & 0 & $15.4 \%$ \\
\hline 1990 & 20-Apr & 8,194 & 21-Apr & 8,784 & -1 & $7.2 \%$ & 20-Apr & 8,163 & 0 & $-0.4 \%$ & 20-Apr & 9,169 & 0 & $11.9 \%$ \\
\hline 1991 & 2-Dec & 13,224 & 1-Dec & 14,912 & 1 & $12.8 \%$ & 1-Dec & 14,018 & 1 & $6.0 \%$ & 1-Dec & 14,159 & 1 & $7.1 \%$ \\
\hline 1992 & 6-Feb & 4,282 & 19-Mar & 4,374 & -42 & $2.1 \%$ & 19-Mar & 4,194 & -42 & $-2.1 \%$ & 20-Mar & 4,232 & -43 & $-1.2 \%$ \\
\hline 1993 & 25-Mar & 2,706 & 21-May & 4,015 & -57 & $48.4 \%$ & 25-Mar & 2,672 & 0 & $-1.2 \%$ & 21-May & 3,623 & -57 & $33.9 \%$ \\
\hline 1994 & 18-Mar & 2,102 & 25-Apr & 3,247 & -38 & $54.5 \%$ & 18-Mar & 2,068 & 0 & $-1.6 \%$ & 25-Apr & 3,052 & -38 & $45.2 \%$ \\
\hline 1995 & 27-Feb & 11,076 & 27-Feb & 11,225 & 0 & $1.3 \%$ & 28-Feb & 10,818 & -1 & $-2.3 \%$ & 28-Feb & 10,818 & -1 & $-2.3 \%$ \\
\hline 1996 & $15-\mathrm{Feb}$ & 22,152 & $15-\mathrm{Feb}$ & 22,173 & 0 & $0.1 \%$ & $15-F e b$ & 21,799 & 0 & $-1.6 \%$ & $15-\mathrm{Feb}$ & 21,805 & 0 & $-1.6 \%$ \\
\hline 1997 & 20-May & 18,613 & 20-May & 18,773 & 0 & $0.9 \%$ & 20-May & 18,385 & 0 & $-1.2 \%$ & 20-May & 19,865 & 0 & $6.7 \%$ \\
\hline 1998 & 7-May & 9,754 & 8-May & 10,203 & -1 & $4.6 \%$ & 8-May & 9,204 & -1 & $-5.6 \%$ & 8-May & 10,426 & -1 & $6.9 \%$ \\
\hline 1999 & 1-Jun & 11,937 & 1-Jun & 12,539 & 0 & $5.0 \%$ & 1-Jun & 11,775 & 0 & $-1.4 \%$ & 1-Jun & 12,977 & 0 & $8.7 \%$ \\
\hline 2000 & 23-Dec & 9,884 & 23-Dec & 10,555 & 0 & $6.8 \%$ & 23-Dec & 9,227 & 0 & $-6.6 \%$ & 23-Dec & 9,669 & 0 & $-2.2 \%$ \\
\hline 2001 & 17-Mar & 1,610 & 11-May & 3,008 & -55 & $86.9 \%$ & 18-Mar & 1,554 & -1 & $-3.5 \%$ & 31-Mar & 1,831 & -14 & $13.8 \%$ \\
\hline 2002 & 19-Apr & 7,441 & 19-Apr & 8,288 & 0 & $11.4 \%$ & 19-Apr & 7,666 & 0 & $3.0 \%$ & 19-Apr & 8,627 & 0 & $16.0 \%$ \\
\hline 2003 & 6-Feb & 8,587 & 6-Feb & 8,800 & 0 & $2.5 \%$ & 6-Feb & 8,355 & 0 & $-2.7 \%$ & 6-Feb & 8,364 & 0 & $-2.6 \%$ \\
\hline & & & & & & & & & & um Flow & Differential & & & \\
\hline & & Time & Differential & & & & & Within \pm 10 Percen & t of Base & & & & & \\
\hline & & $\begin{array}{l}\text { Within } 30 \text { Days } \\
30 \text { Days or More } \\
30 \text { Days or More }\end{array}$ & $\begin{array}{l}\text { fBase Maxim } \\
\text { Earlier Than B } \\
\text { Later Than Ba }\end{array}$ & $\begin{array}{l}\text { as Maximum } \\
\text { ase Maximum }\end{array}$ & & & & $\begin{array}{l}10-25 \text { Percent Lov } \\
25 \text { - } 50 \text { Percent Lov } \\
>50 \text { Percent Lowe }\end{array}$ & $\begin{array}{l}\text { er Than Ba } \\
\text { er Than Ba } \\
\text { Than Base }\end{array}$ & & & $\begin{array}{l}10-25 \text { Percent } \\
25-50 \text { Percent } \\
>50 \text { Percent Hic }\end{array}$ & $\begin{array}{l}\text { ligher Thar } \\
\text { ligher Thar } \\
\text { her Than B }\end{array}$ & $\begin{array}{l}\text { Base } \\
\text { Base } \\
\text { ase }\end{array}$ \\
\hline
\end{tabular}

Figure 41. Maximum 10-day discharges in the Wapato reach, comparing the Black Rock_2, Wymer_1, and WymerPlus scenarios with the No Action baseline.

\section{Reservoir Storage}

Reservoir storage was analyzed using two different techniques. The first approach utilized duration curves (figs. 42A-46A) to generalize differences in daily storage over the period of record without regard to chronology. The second approach examined seasonal differences by means of a monthly time series (figs. 42B-46B). The time series plots were truncated to the period 1991-98 for better legibility and resolution. This period contains a drought (1993-94) and two above-average water years (1996-97).

- With a few exceptions, reservoir storage was generally higher at all the reservoirs under all three alternatives than under baseline operations (figs. 42A-46A). The largest increases in storage were observed at Cle Elum (fig. 43A) and Kachess Reservoirs (fig. 44A), where net storage rose by 14 to 20 percent under the Blackrock_2 alternative.

- At Bumping Lake, storage was retained at a higher level than the No Action baseline approximately 95 percent of the time under the Black Rock_2 alternative, over 99 percent of the time under Wymer_1, and 100 percent of the time under WymerPlus. Net increases in storage were largest with the Black Rock_2 scenario, however, with an overall increase of 4.5 percent above the baseline.

- Despite the net increase at Cle Elum, storage at this reservoir was lower than the baseline for 12.3 percent of the time under the Black Rock_2 alternative and 13.3 percent of the time with WymerPlus (fig. 43A). Storage reductions associated with Black Rock_2 were confined to periods when the reservoir was full or nearly full, whereas reductions associated with WymerPlus occurred when lake levels were low (below 45,000 acre-feet). Cle Elum volume under the Wymer_1 alternative was lower than baseline 68.5 percent of the time, resulting in a net reduction in volume of slightly more than 2 percent. Volume reductions associated with Wymer_1 were scattered across the full range of pool levels. 

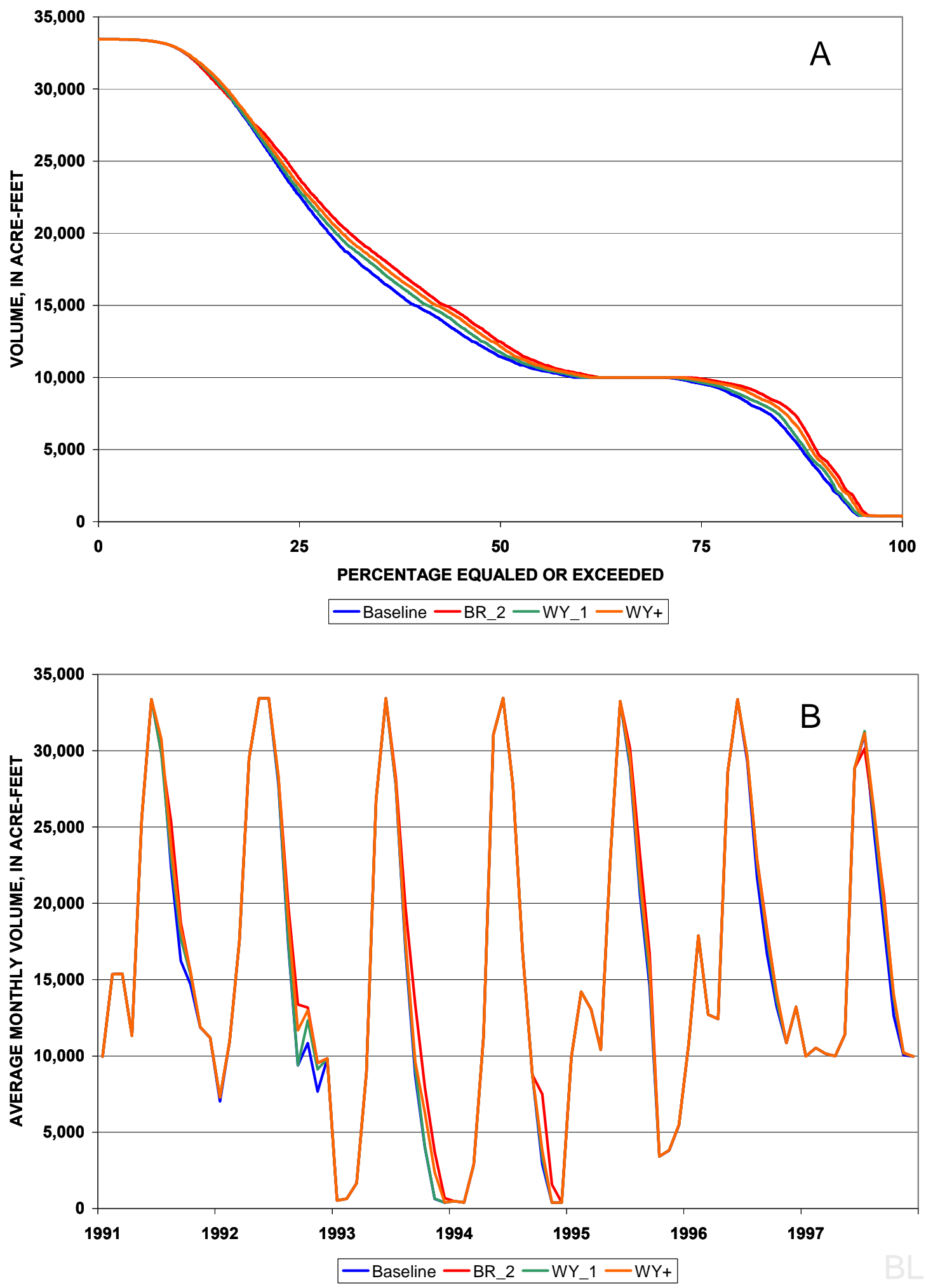

Figure 42. Reservoir storage-duration curve (A) for all years and 1991-97 storage time series (B) for the baseline and Black Rock_2, Wymer_1, and WymerPlus scenarios at Bumping Lake Reservoir. 


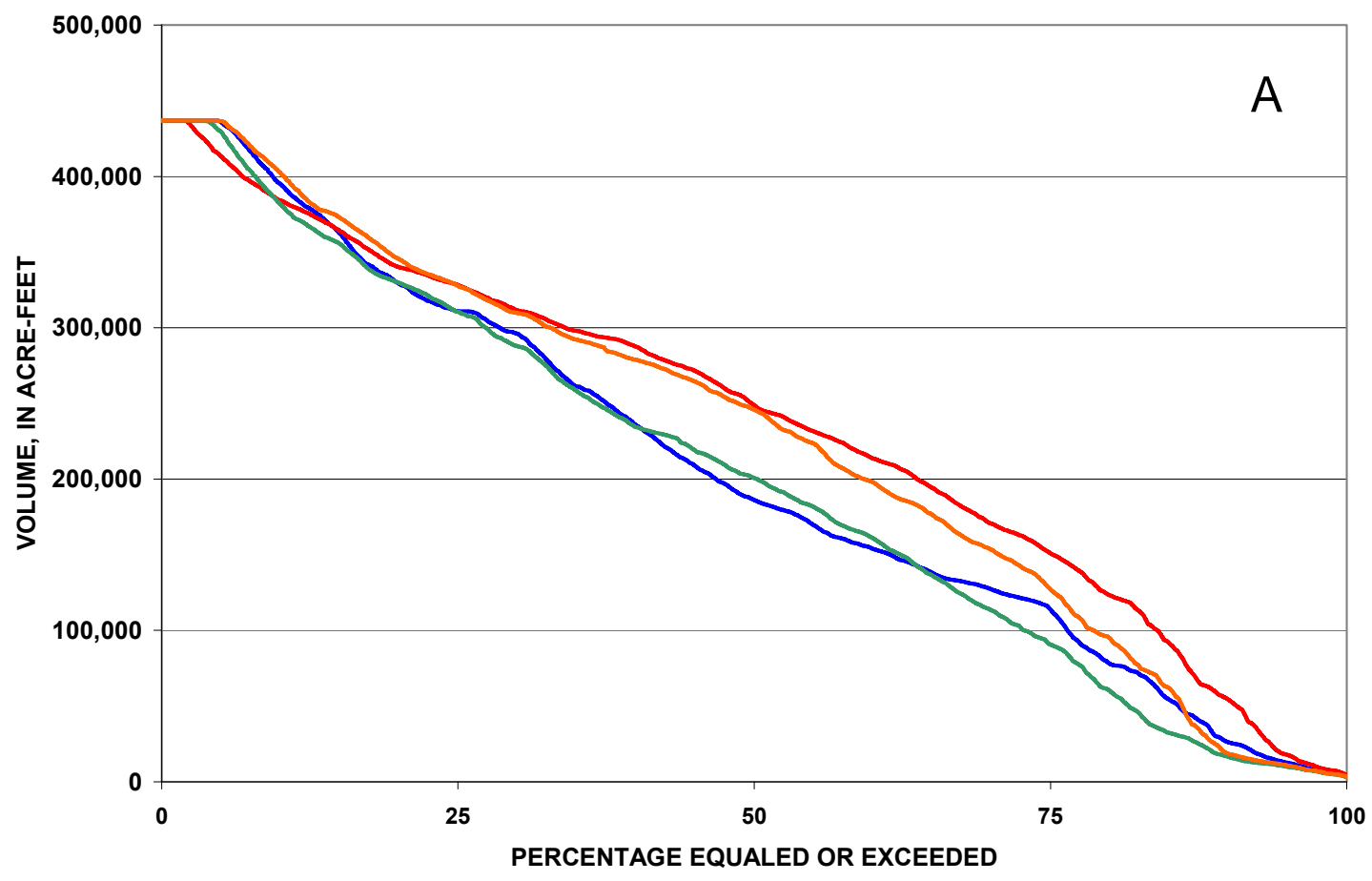

- Baseline -BR_2 -WY_1 -WY+

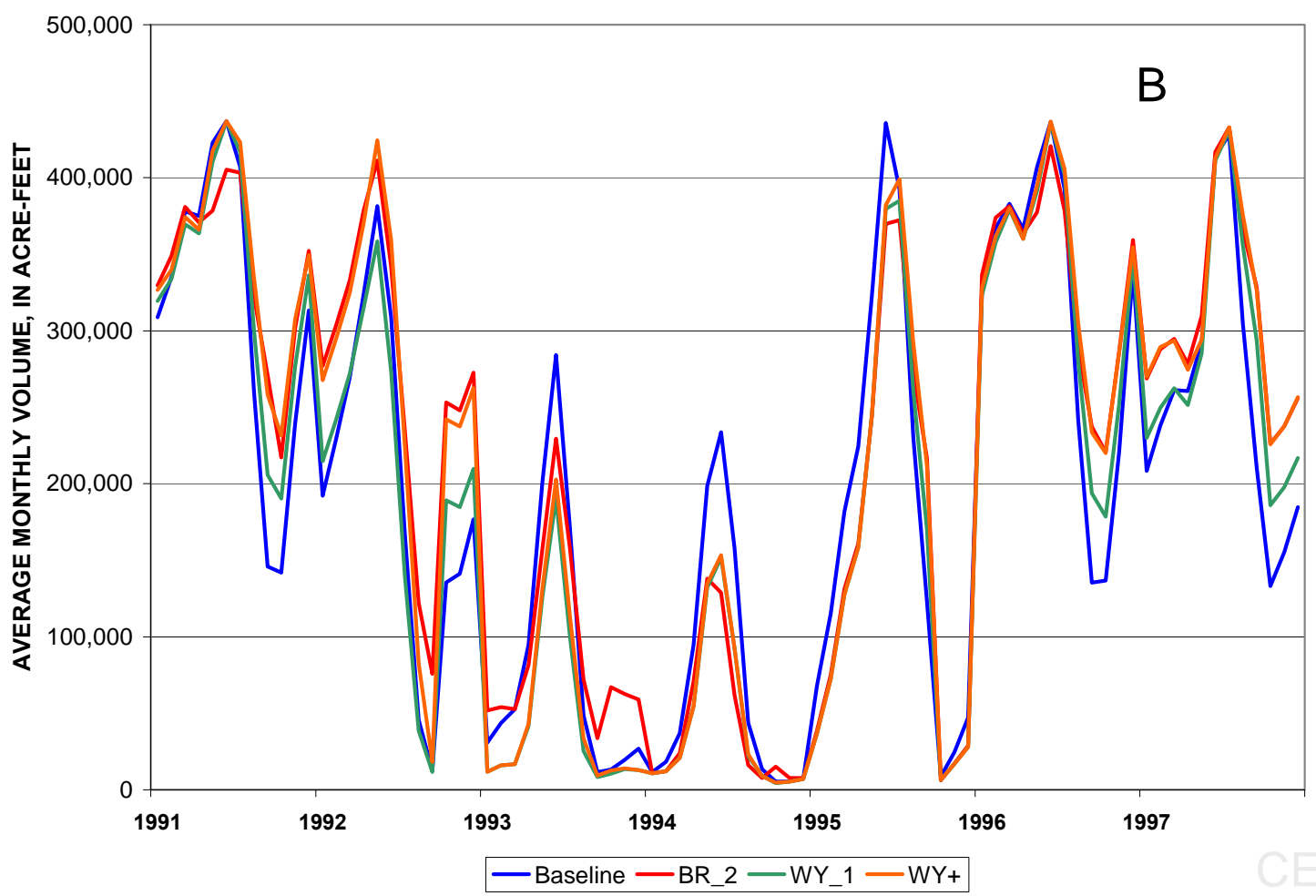

Figure 43. Reservoir storage-duration curve (A) and 1991-97 storage time series (B) for the baseline and Black Rock_2, Wymer_1, and WymerPlus scenarios at Cle Elum Reservoir. 

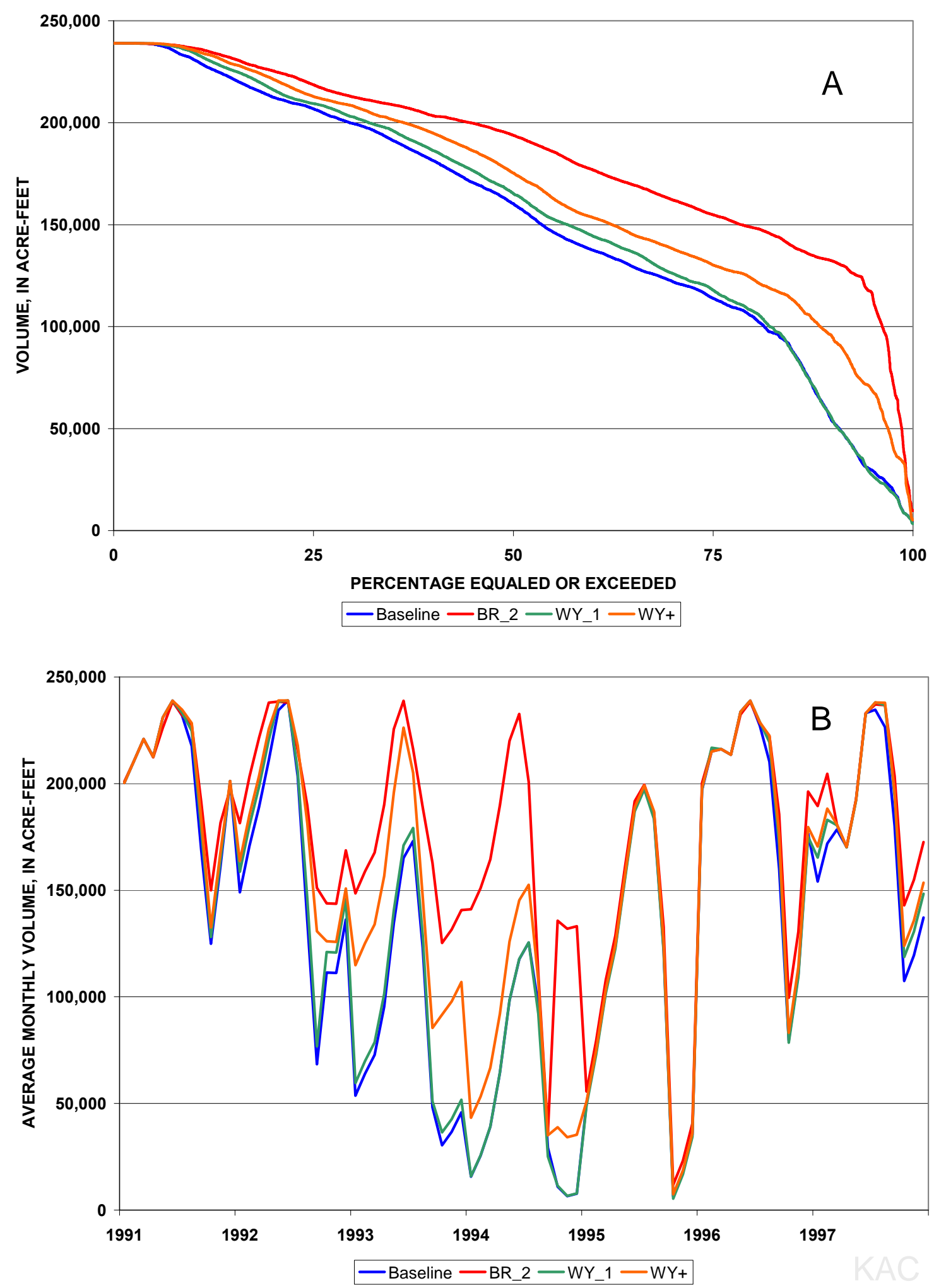

Figure 44. Reservoir storage-duration curve (A) and 1991-97 storage time series (B) for the baseline and Black Rock_2, Wymer_1, and WymerPlus scenarios at Kachess Reservoir. 

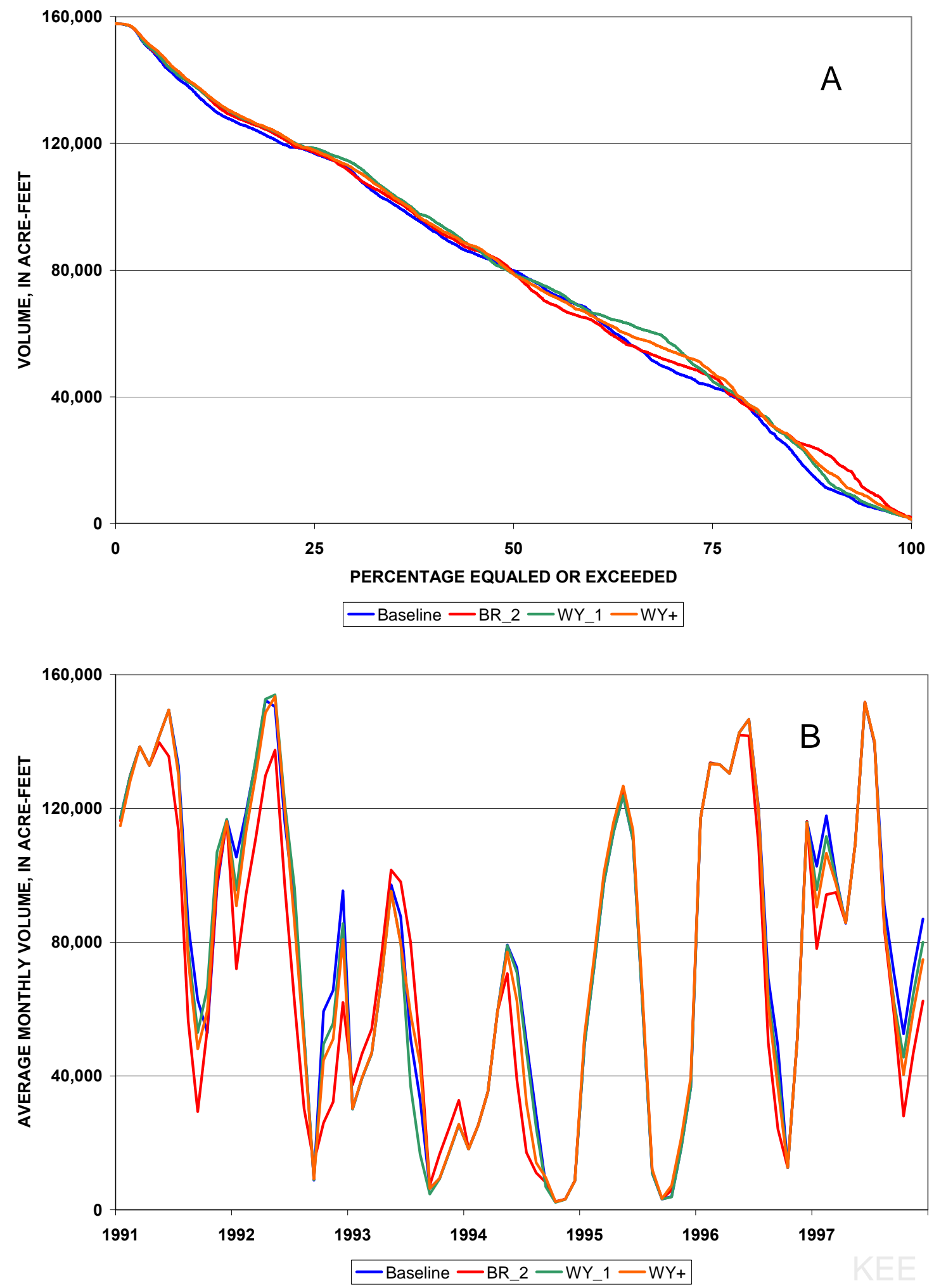

Figure 45. Reservoir storage-duration curve (A) and 1991-97 storage time series (B) for the baseline and Black Rock_2, Wymer_1, and WymerPlus scenarios at Keechelus Reservoir. 

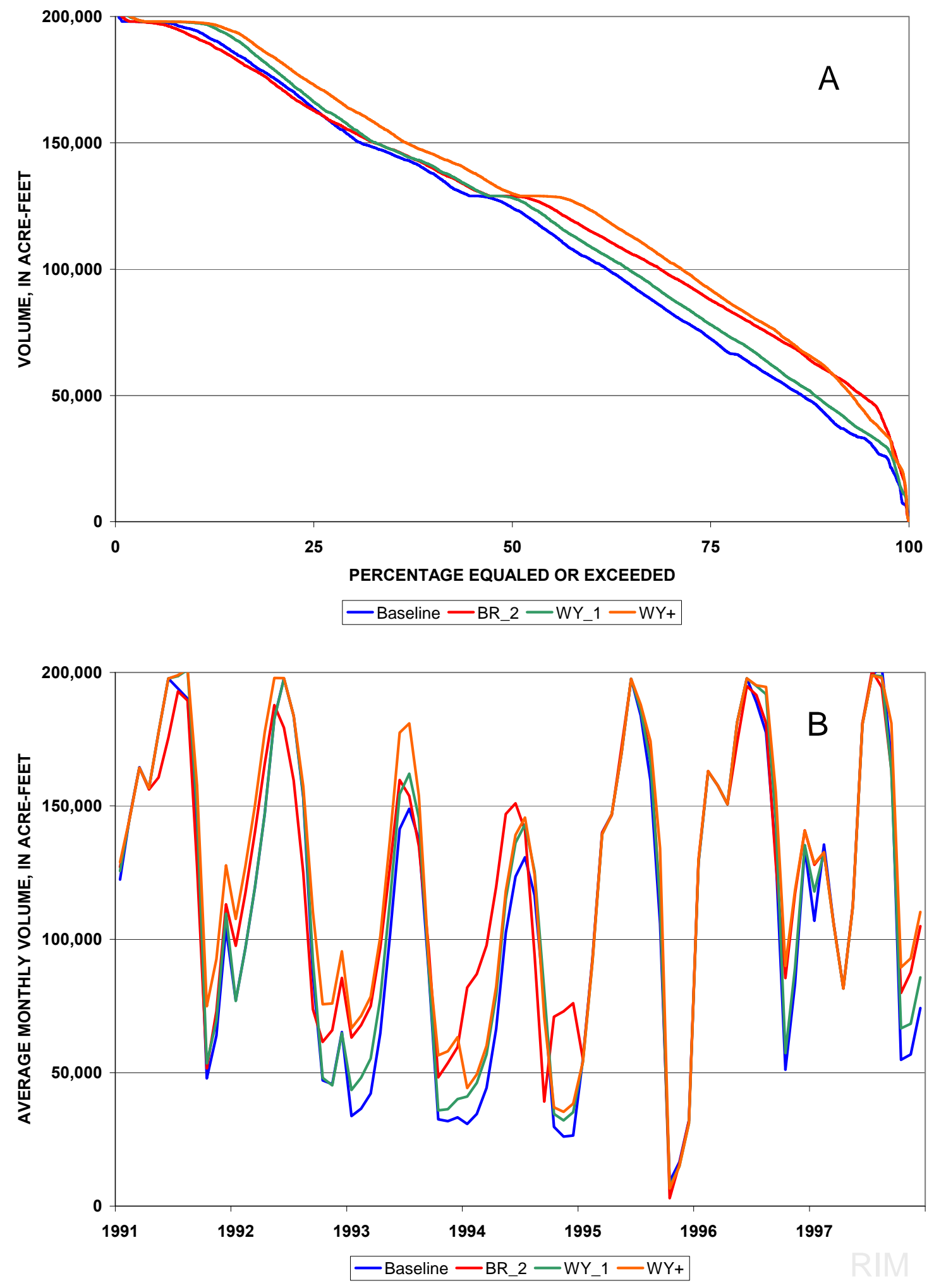

- Figure 46. Reservoir storage-duration curve (A) and 1991-1997 storage time series (B) for the baseline and Black Rock_2, Wymer_1, and WymerPlus scenarios at Rimrock Reservoir. 
- Storage at Kachess Reservoir was higher than the baseline approximately 97 percent of the time under the Black Rock_2 alternative and was always higher with Wymer_1 (fig. 44A). The net difference in storage was an increase of 20.4 percent associated with Black Rock_2 and 9.7 percent with WymerPlus. Like Cle Elum, reductions associated with Black Rock_2 occurred only at full or nearly full pool. In contrast, pool volume at Kachess was reduced under the Wymer_1 alternative when pool levels were low (less than 92,600 acre-feet), accounting for approximately 11.5 percent of the time. Nevertheless, net volume at Kachess Reservoir was increased by slightly more than 2 percent with Wymer_1.

- At Keechelus Reservoir, the net increases in storage above the No Action baseline were 1.8 percent, 2.9 percent, and 2.7 percent for the Black Rock_2, Wymer_1, and WymerPlus alternatives, respectively (fig. 45A). Under the Black Rock_2 alternative, however, storage at Keechelus Reservoir was lower than the baseline 21.6 percent of the time, with most of the reductions occurring when the reservoir was about half full (less than 80,400 acre-feet). Storage was lower than the baseline 9.3 percent of the time under Wymer_1 and 11.7 percent of the time under WymerPlus. Storage reductions under these two alternatives occurred in approximately the same range of volumes as observed for Black Rock_2.

- Net storage at Rimrock Reservoir was slightly increased above the baseline under all three scenarios: 5.9 percent under Black Rock_2, 3.3 percent under Wymer_1, and 10 percent under WymerPlus. Despite the overall increases in net storage, actual storage was lower than the baseline slightly over 24 percent of the time under Black Rock_2 but less than 1 percent of the time under the two Wymer alternatives. Interestingly, all three alternatives resulted in minimum pool levels much lower than observed for the baseline, virtually evacuating the entire reservoir storage in the most extreme cases. Under the baseline, storage volume was never lower than 2,230 acre-feet. In contrast, storage fell below 300 acre-feet under all three scenarios, with a minimum of 137 acre-feet recorded for the Black Rock_2 alternative. Inexplicably, all three cases of extreme drawdown occurred in October 1995, a full year after the 1993-94 drought.

- Monthly storage volumes for the period 1991-98 at Bumping Lake differed only slightly among the baseline and the alternatives (fig. 42B). Under the Blackrock_2 and WymerPlus alternatives, the rate of drawdown was slower during drought years (1994 and 1995, for example) resulting in a delay in the date at which minimum pool volumes were reached. The fill cycles at Bumping Lake were essentially identical for the baseline and all three alternatives.

- During normal to wet water years, maximum storage at Cle Elum Reservoir tended to be equal to or higher under the alternatives than under the baseline (fig. 43B). In contrast, maximum pool levels under the baseline were consistently higher than any of the alternatives during drought years. In most years, minimum pool levels were maintained at higher levels under the alternatives than they were under the baseline. In this respect, year-to-year carryover was highest with the Blackrock_2 and WymerPlus alternatives, although the former was the only alternative to maintain minimum pool volumes higher than the baseline during the 1993-94 drought.

- The fill and drawdown pattern at Kachess Reservoir deviated more from the baseline than at any of the other reservoirs (fig. 44B). Maximum and minimum pool volumes both tended to be higher than the baseline during droughts, resulting in relatively large amounts of carryover. This tendency was strongest with the Blackrock_2 scenario but was repeated to a lesser extent under WymerPlus. The fill and drawdown pattern under Wymer_1 was only marginally different from the baseline.

- Net storage and the fill and drawdown patterns at Keechelus Reservoir showed the least overall change from the baseline (fig. 45B). However, in normal and above-average water years, the reservoir was drawn down to lower volumes than the baseline under all three of the alternatives, 
the most extensive drawdown being associated with Black Rock_2 (1991, 1992, 1997 and 1998, for example). In these years, carryover would have been lower under the alternatives than it would have been under the baseline.

- Rimrock Reservoir responded to the alternatives in a manner similar to Kachess Reservoir, except that WymerPlus supplanted Blackrock_2 as the more influential alternative during many years (fig. 46B). Maximum pool levels were either equal to or greater than the baseline under all the alternatives, but the fill cycle appeared to be initiated earlier in the year under WymerPlus and Black Rock_2. Conversely, drawdown to minimum pool levels occurred at the same time or somewhat earlier than the baseline under these two alternatives, but carryover was consistently higher under the alternatives than under the baseline.

\section{Synopses of YRDSS Run Results}

Complete run results for each of the scenarios can be found in Appendices 4, 5, and 6, for the Black Rock_2, Wymer_1, and WymerPlus comparisons, respectively. The following sections summarize those runs, compiled as side-by-side comparisons of the three scenarios, expressed as a percent change with respect to the baseline. Figure 47 contains the comparisons as presented on the "whole-period" summary pages of the YRDSS (the HabSummary, TempSummary, and YearlySummary pages). Subsequent sections are arrayed by site and subdivided according to YRDSS state variables. These sections contain the site-specific yearly summaries extracted from the subsidiary notebooks. For easier interpretation, comparisons of the state variables described below are formatted the same as the tables in the appendices but contain only the percent change from the baseline for each alternative rather than the actual metrics displayed in the appendices. In our discussions regarding the relative magnitudes of change, we use the term "significant change" in the context of a difference in excess of 10 percent. Our use of this term does not necessarily imply statistical significance.

\section{Habitat Summaries by Site}

\section{Easton}

- Maximum redd scour was significantly increased for all species at the Easton reach under all three scenarios (figs. 47-50), but in only a few cases did redd scour exceed the critical threshold indicating potential damage (appendix figs. 4-8-4-10, 5-8-5-10, and 6-8-6-10). As illustrated in the appendix figures, spring chinook and bull trout were affected by scour exceeding the thresholds under all three scenarios. Coho, steelhead, and resident rainbow trout were affected only under the Wymer_1 scenario (Appendix figs. 5-8-5-10).

- Spawning-incubation persistent habitat was significantly reduced for spring chinook, coho, resident rainbow trout, and bull trout in several years under the Black Rock_2 scenario but was relatively unaffected under Wymer_1 and WymerPlus (figs. 48-50). Spawning-incubation habitat for steelhead was essentially unchanged from the baseline under all three scenarios (fig. 49).

- For the period of record, fry habitat was reduced slightly for spring chinook and coho under the Black Rock_2 alternative, increased slightly for steelhead and resident rainbow trout, and remained relatively unchanged for bull trout (fig. 47). A similar pattern of change was observed for the WymerPlus alternative, but to a lesser relative magnitude. Fry habitat for steelhead and resident rainbow trout increased slightly under the Wymer_1 alternative, but was not altered much for spring chinook, coho, or bull trout (fig. 47). Small reductions in spring chinook fry habitat occurred in a majority of years under Blackrock_2, although only two were more than 10 percent (fig. 48). Small increases in spring chinook fry habitat prevailed under the other two 


\begin{tabular}{|c|c|c|c|c|c|c|c|c|c|c|c|c|c|c|c|c|}
\hline \multirow[b]{2}{*}{ Resource Category } & \multirow[b]{2}{*}{ Time Window } & \multicolumn{15}{|c|}{ Stream Reach } \\
\hline & & \multicolumn{3}{|c|}{ Easton } & \multicolumn{3}{|c|}{ Kittitas } & \multicolumn{3}{|c|}{ Naches } & \multicolumn{3}{|c|}{ Union Gap } & \multicolumn{3}{|c|}{ Wapato } \\
\hline Spring Chinook & & BR_2 & WY_1 & WY+ & BR_2 & WY_1 & WY+ & BR_2 & WY_1 & WY+ & BR_2 & WY_1 & WY+ & BR_2 & WY_1 & WY+ \\
\hline Max redd scour depth (ft) & Oct-01-Mar-31 & $99.5 \%$ & $58.7 \%$ & $59.7 \%$ & $-1.3 \%$ & $\mid-1.5 \%$ & $-3.4 \%$ & $10.0 \%$ & $-0.2 \%$ & $13.5 \%$ & & & & & & \\
\hline Spawning/incubation & Oct-01-Mar-31 & $-4.9 \%$ & $-1.5 \%$ & $-1.2 \%$ & $-1.5 \%$ & $-0.7 \%$ & $2.8 \%$ & $-1.4 \%$ & $-16.2 \%$ & $-10.1 \%$ & & & & & & \\
\hline Fry & Mar-01 - May-31 & $-3.3 \%$ & $0.5 \%$ & $0.4 \%$ & $6.4 \%$ & $4.5 \%$ & $3.9 \%$ & $3.7 \%$ & $0.2 \%$ & $0.7 \%$ & & & & & & \\
\hline Subyearling (spring-summer) & Jun-01 - Sep-30 & $9.7 \%$ & $2.8 \%$ & $6.2 \%$ & $-2.1 \%$ & $-1.7 \%$ & $-2.4 \%$ & $-0.8 \%$ & $0.3 \%$ & $0.1 \%$ & & & & & & \\
\hline Subyearling (winter) & Oct-01 - May-31 & $-6.1 \%$ & $0.4 \%$ & $0.5 \%$ & $-2.2 \%$ & $-2.5 \%$ & $-2.9 \%$ & $0.1 \%$ & $1.4 \%$ & $1.2 \%$ & $1 \%$ & $0 \%$ & $0 \%$ & $13 \%$ & $-1 \%$ & $8 \%$ \\
\hline Adult holding & Apr-01 - Sep-30 & $0.7 \%$ & $-1.7 \%$ & $-2.1 \%$ & $3.1 \%$ & $2.7 \%$ & $3.9 \%$ & $0.7 \%$ & $-0.6 \%$ & $1.0 \%$ & & & & & & \\
\hline \multicolumn{17}{|l|}{ Fall Chinook } \\
\hline Spawning/incubation & Oct-01-Mar-31 & & & & & & & & & & $7.2 \%$ & $-6.6 \%$ & $-2.9 \%$ & $44.9 \%$ & $-1.5 \%$ & $52.2 \%$ \\
\hline & Mar-01 - Apr-30 & & & & & & & & & & $-2.4 \%$ & $0.2 \%$ & $-0.9 \%$ & $3.7 \%$ & $0.0 \%$ & $3.2 \%$ \\
\hline Subyearling (spring-summer) & May-01 - Jun-01 & & & & & & & & & & $12.1 \%$ & $-0.2 \%$ & $2.6 \%$ & $38.3 \%$ & $-1.0 \%$ & $8.9 \%$ \\
\hline \multicolumn{17}{|l|}{ Coho } \\
\hline Max redd scour depth (ft) & Nov-01-Mar-31 & $51.6 \%$ & $46.9 \%$ & $40.6 \%$ & $-3.2 \%$ & $-3.6 \%$ & $-3.4 \%$ & $-2.7 \%$ & $1.8 \%$ & $0.9 \%$ & $-4.4 \%$ & $-1.6 \%$ & $3.5 \%$ & $-3.0 \%$ & $4.4 \%$ & $-1.8 \%$ \\
\hline Spawning/incubation & Nov-01-Mar-31 & $-3.7 \%$ & $-1.0 \%$ & $-0.8 \%$ & $-4.0 \%$ & $-3.3 \%$ & $-2.9 \%$ & $\mid 51.7 \%$ & $-17.3 \%$ & $-13.2 \%$ & $1.6 \%$ & $-7.7 \%$ & $-9.7 \%$ & $23.5 \%$ & $-0.9 \%$ & $25.3 \%$ \\
\hline Fry & Apr-01 - May-30 & $-8.6 \%$ & $0.0 \%$ & $-0.2 \%$ & $5.9 \%$ & $3.6 \%$ & $3.1 \%$ & $6.4 \%$ & $0.1 \%$ & $0.8 \%$ & $-4.5 \%$ & $0.3 \%$ & $-1.8 \%$ & $13.8 \%$ & $0.0 \%$ & $10.7 \%$ \\
\hline Subyearling (spring-summer) & Jun-01 - Sep-30 & $13.1 \%$ & $7.9 \%$ & $12.2 \%$ & $-7.6 \%$ & $-5.4 \%$ & $-7.2 \%$ & $-8.5 \%$ & $2.3 \%$ & $-2.1 \%$ & $-3.1 \%$ & $0.2 \%$ & $2.3 \%$ & $-0.7 \%$ & $-0.6 \%$ & $3.1 \%$ \\
\hline Subyearling (winter) & Oct-01 - Apr-30 & $-0.9 \%$ & $0.6 \%$ & $0.9 \%$ & $-2.5 \%$ & $-2.2 \%$ & $-2.1 \%$ & $-1.1 \%$ & $1.8 \%$ & $2.0 \%$ & $1.0 \%$ & $-0.3 \%$ & $0.0 \%$ & $8.3 \%$ & $-0.9 \%$ & $6.2 \%$ \\
\hline \multicolumn{17}{|l|}{ Steelhead } \\
\hline Max redd scour depth (ft) & Mar-01-Jul-31 & $25.0 \%$ & $38.2 \%$ & $33.9 \%$ & $-1.6 \%$ & $1.3 \%$ & $1.2 \%$ & $-3.1 \%$ & $4.7 \%$ & $0.4 \%$ & & & & & & \\
\hline Spawning/incubation & Mar-01-Jul-31 & $-0.1 \%$ & $0.0 \%$ & $0.1 \%$ & $3.2 \%$ & $2.7 \%$ & $3.2 \%$ & $9.8 \%$ & $-12.3 \%$ & $-10.1 \%$ & & & & & & \\
\hline Fry & Jul-01 - Aug-30 & $7.5 \%$ & $6.4 \%$ & $6.8 \%$ & $-3.8 \%$ & $-2.2 \%$ & $-3.1 \%$ & $-1.2 \%$ & $0.7 \%$ & $0.8 \%$ & & & & & & \\
\hline Subyearling (spring-summer) & Sep-01 - Sep-30 & $10.3 \%$ & $1.2 \%$ & $4.9 \%$ & $29.4 \%$ & $1.8 \%$ & $3.0 \%$ & $3.2 \%$ & $0.0 \%$ & $0.2 \%$ & & & & & & \\
\hline Subyearling (winter) & Oct-01 - Apr-30 & $-1.1 \%$ & $0.6 \%$ & $0.9 \%$ & $-4.4 \%$ & $-3.6 \%$ & $-3.6 \%$ & $-1.8 \%$ & $1.3 \%$ & $0.8 \%$ & $1.0 \%$ & $-0.3 \%$ & $0.0 \%$ & $7.7 \%$ & $-0.9 \%$ & $5.5 \%$ \\
\hline Subadults & May-01 - Aug-30 & $3.0 \%$ & $0.6 \%$ & $1.8 \%$ & $0.3 \%$ & $0.9 \%$ & $0.8 \%$ & $0.2 \%$ & $-0.1 \%$ & $-0.4 \%$ & & & & & & \\
\hline Adult holding & Sep-01 - Mar-31 & $-0.9 \%$ & $-0.1 \%$ & $0.1 \%$ & $-1.4 \%$ & $-4.6 \%$ & $-4.8 \%$ & $7.0 \%$ & $-1.2 \%$ & $-1.1 \%$ & & & & & & \\
\hline \multicolumn{17}{|l|}{ Resident Rainbow } \\
\hline Max redd scour depth (ft) & Feb-01-Jul-31 & $18.3 \%$ & $33.2 \%$ & $29.9 \%$ & $-1.4 \%$ & $0.4 \%$ & $1.3 \%$ & $-5.9 \%$ & $5.0 \%$ & $0.2 \%$ & $-4.2 \%$ & $-3.4 \%$ & $4.8 \%$ & $-18.0 \%$ & $20.5 \%$ & $-22.3 \%$ \\
\hline Spawning/incubation & Feb-01-Jul-31 & $-6.5 \%$ & $-1.3 \%$ & $-0.8 \%$ & $-8.1 \%$ & $-5.1 \%$ & $-2.2 \%$ & $\mid 12.9 \%$ & $-17.6 \%$ & $-10.7 \%$ & $-6.1 \%$ & $-6.8 \%$ & $-6.6 \%$ & $40.2 \%$ & $1.2 \%$ & $44.4 \%$ \\
\hline Fry & Jul-01 - Aug-30 & $7.0 \%$ & $5.5 \%$ & $6.2 \%$ & $-3.9 \%$ & $-2.4 \%$ & $-3.3 \%$ & $-0.8 \%$ & $0.4 \%$ & $0.5 \%$ & $0.5 \%$ & $0.0 \%$ & $-1.5 \%$ & $17.5 \%$ & $0.7 \%$ & $26.2 \%$ \\
\hline Subyearling (spring-summer) & Sep-01 - Sep-30 & $10.6 \%$ & $1.2 \%$ & $4.9 \%$ & $28.9 \%$ & $1.8 \%$ & $2.9 \%$ & $2.9 \%$ & $0.0 \%$ & $0.1 \%$ & $-1.1 \%$ & $0.1 \%$ & $0.9 \%$ & $1.1 \%$ & $0.1 \%$ & $1.3 \%$ \\
\hline Subyearling (winter) & Oct-01 - Apr-30 & $-0.7 \%$ & $0.6 \%$ & $0.9 \%$ & $-3.9 \%$ & $-3.1 \%$ & $-3.2 \%$ & $-1.7 \%$ & $1.3 \%$ & $1.0 \%$ & $0.8 \%$ & $-0.3 \%$ & $0.0 \%$ & $7.3 \%$ & $-0.8 \%$ & $5.3 \%$ \\
\hline Subadults & May-01 - Aug-30 & $2.9 \%$ & $3.3 \%$ & $5.3 \%$ & $-3.4 \%$ & $-2.4 \%$ & $-2.9 \%$ & $-1.9 \%$ & $1.2 \%$ & $1.9 \%$ & $-0.4 \%$ & $0.0 \%$ & $2.1 \%$ & $-5.7 \%$ & $-0.3 \%$ & $-8.8 \%$ \\
\hline \multicolumn{17}{|l|}{ Bull Trout } \\
\hline Max redd scour depth (ft) & Oct-01 - Mar-31 & $99.5 \%$ & $58.7 \%$ & $59.7 \%$ & $-0.9 \%$ & $-3.0 \%$ & $-3.5 \%$ & $6.4 \%$ & $0.0 \%$ & $9.7 \%$ & & & & & & \\
\hline Spawning/incubation & Oct-01 - Mar-31 & $-4.4 \%$ & $-1.1 \%$ & $-1.2 \%$ & $-8.5 \%$ & $-8.5 \%$ & $-7.7 \%$ & $47.4 \%$ & $-18.0 \%$ & $-13.9 \%$ & & & & & & \\
\hline Fry & Oct-01 - Nov-30 & $-6.8 \%$ & $0.1 \%$ & $-0.2 \%$ & $5.9 \%$ & $2.3 \%$ & $-2.5 \%$ & $6.8 \%$ & $0.1 \%$ & $0.2 \%$ & & & & & & \\
\hline Subyearling (spring-summer) & Jun-01 - Sep-30 & $6.9 \%$ & $1.8 \%$ & $4.3 \%$ & $-1.0 \%$ & $-1.0 \%$ & $-1.4 \%$ & $0.4 \%$ & $0.0 \%$ & $-0.3 \%$ & & & & & & \\
\hline Subyearling (winter) & Oct-01 - May-31 & $-5.8 \%$ & $0.4 \%$ & $0.6 \%$ & $-2.1 \%$ & $-2.0 \%$ & $-2.4 \%$ & $-0.1 \%$ & $1.7 \%$ & $1.8 \%$ & & & & & & \\
\hline
\end{tabular}

Resevoir outmigration

\begin{tabular}{|c|c|c|c|c|}
\hline \multicolumn{2}{|l|}{ Inseason days impassable } & BR_2 & WY_1 & WY+ \\
\hline Kachess & Jul-15 - Sep-15 & $-15.4 \%$ & $-2.0 \%$ & $-17.7 \%$ \\
\hline Keechelus & Jul-15 - Sep-15 & $0.5 \%$ & $-1.5 \%$ & $-2.1 \%$ \\
\hline Rimrock & Jul-01 - Aug-15 & $-1.6 \%$ & $-74.6 \%$ & $-96.8 \%$ \\
\hline
\end{tabular}

\begin{tabular}{|c|c|c|c|c|c|c|c|c|c|c|c|c|c|c|c|c|}
\hline \multirow{2}{*}{\multicolumn{2}{|c|}{ Flood metrics }} & \multicolumn{3}{|c|}{ Easton } & \multicolumn{3}{|c|}{ Kittitas } & \multicolumn{3}{|c|}{ Naches } & \multicolumn{3}{|c|}{ Union Gap } & \multicolumn{3}{|c|}{ Wapato } \\
\hline & & BR_2 & WY_1 & WY+ & BR_2 & WY_1 & WY+ & BR_2 & WY_1 & WY+ & BR_2 & WY_1 & WY+ & BR_2 & WY_1 & WY+ \\
\hline Overbank flow $>1.67$ year flood & days & $24.2 \%$ & $0.0 \%$ & $3.3 \%$ & $5.6 \%$ & $-5.6 \%$ & $8.9 \%$ & $4.7 \%$ & $3.1 \%$ & $7.8 \%$ & $14.5 \%$ & $-10.2 \%$ & $8.9 \%$ & $20.4 \%$ & $-8.3 \%$ & $17.7 \%$ \\
\hline Damaging flood $>=25$ year flood & days & $200.0 \%$ & $0.0 \%$ & $0.0 \%$ & $0.0 \%$ & $0.0 \%$ & $0.0 \%$ & $0.0 \%$ & $0.0 \%$ & $0.0 \%$ & $0.0 \%$ & $0.0 \%$ & $0.0 \%$ & $0.0 \%$ & $0.0 \%$ & $0.0 \%$ \\
\hline
\end{tabular}

\begin{tabular}{|c|c|c|c|c|c|c|c|c|c|c|c|c|c|c|c|c|}
\hline \multirow[t]{4}{*}{ Water division deliveries } & & \multicolumn{3}{|c|}{ April } & \multicolumn{3}{|c|}{ May } & \multicolumn{3}{|c|}{ June } & \multicolumn{3}{|c|}{ July } & \multicolumn{3}{|c|}{ August } \\
\hline & Proration (\%) & BR_2 & WY_1 & WY+ & BR_2 & WY_1 & WY+ & BR_2 & WY_1 & WY+ & BR_2 & WY_1 & WY+ & BR_2 & WY_1 & WY+ \\
\hline & $\begin{array}{l}\text { Average for Month } \\
\text { TWSA (af) }\end{array}$ & $5.7 \%$ & $1.4 \%$ & $3.1 \%$ & $6.2 \%$ & $1.8 \%$ & $3.9 \%$ & $7.0 \%$ & $2.5 \%$ & $5.0 \%$ & $7.4 \%$ & $2.5 \%$ & $5.5 \%$ & $7.6 \%$ & $2.6 \%$ & $5.9 \%$ \\
\hline & Average of 1st of Months & $4.3 \%$ & $1.4 \%$ & $2.8 \%$ & $4.2 \%$ & $2.0 \%$ & $3.6 \%$ & $2.6 \%$ & $2.4 \%$ & $4.6 \%$ & $3.9 \%$ & $4.3 \%$ & $6.3 \%$ & $10.0 \%$ & $5.8 \%$ & $9.7 \%$ \\
\hline \multirow{3}{*}{$\begin{array}{l}\text { Reservoir storage } \\
\text { End-of-season carryover }\end{array}$} & \multirow{3}{*}{$\begin{array}{c}\text { (af) } \\
\text { Average }\end{array}$} & \multicolumn{3}{|c|}{ Bumping } & \multicolumn{3}{|c|}{ Cle Elum } & \multicolumn{3}{|c|}{ Kachess } & \multicolumn{3}{|c|}{ Keechelus } & \multicolumn{3}{|c|}{ Rimrock } \\
\hline & & BR_2 & WY_1 & WY+ & BR_2 & WY_1 & WY+ & BR_2 & WY_1 & WY+ & BR_2 & WY_1 & WY+ & BR_2 & WY_1 & WY+ \\
\hline & & $18.9 \%$ & $6.2 \%$ & $13.6 \%$ & $77.4 \%$ & $27.4 \%$ & $59.6 \%$ & $51.2 \%$ & $5.0 \%$ & $20.1 \%$ & $4.5 \%$ & $8.9 \%$ & $6.4 \%$ & $46.9 \%$ & $6.9 \%$ & $46.6 \%$ \\
\hline \multirow[t]{2}{*}{ Sediment transport } & & \multicolumn{3}{|c|}{ Easton } & \multicolumn{3}{|c|}{ Kittitas } & \multicolumn{3}{|c|}{ Naches } & \multicolumn{3}{|c|}{ Union Gap } & \multicolumn{3}{|c|}{ Wapato } \\
\hline & & BR_2 & WY_1 & WY+ & BR_2 & WY_1 & WY+ & BR_2 & WY_1 & WY+ & BR_2 & WY_1 & WY+ & BR_2 & WY_1 & WY+ \\
\hline Fine material transport & Total tons & $10.1 \%$ & $10.8 \%$ & $6.9 \%$ & $-3.4 \%$ & $-2.1 \%$ & $-2.1 \%$ & $-0.6 \%$ & $0.5 \%$ & $1.0 \%$ & $7.1 \%$ & $-2.2 \%$ & $7.7 \%$ & $26.8 \%$ & $-4.1 \%$ & $26.2 \%$ \\
\hline Geomorphic adjustment & Higest 15-day period & $16.7 \%$ & $14.6 \%$ & $8.3 \%$ & $-5.6 \%$ & $-3.7 \%$ & $-0.8 \%$ & $-0.9 \%$ & $1.6 \%$ & $2.3 \%$ & $-2.0 \%$ & $-3.4 \%$ & $2.1 \%$ & $1.4 \%$ & $-3.3 \%$ & $5.5 \%$ \\
\hline Armor disruption & Day count & $300.0 \%$ & $0.0 \%$ & $0.0 \%$ & $0.0 \%$ & $0.0 \%$ & $0.0 \%$ & $-5.0 \%$ & $1.3 \%$ & $-4.0 \%$ & $0.0 \%$ & $0.0 \%$ & $0.0 \%$ & $0.0 \%$ & $0.0 \%$ & $0.0 \%$ \\
\hline
\end{tabular}

Figure 47. Habitat summaries comparison of the Black Rock_2 (BR_2), Wymer_1 (WY_1), and WymerPlus $(\mathrm{WY}+$ ) scenarios, expressed as percentage change from the No Action baseline. 


\begin{tabular}{|c|c|c|c|c|c|c|c|c|c|c|c|c|c|c|c|c|c|c|c|c|c|}
\hline \multirow{2}{*}{ Spring Chinook } & \multicolumn{3}{|c|}{ Redd Scour } & \multicolumn{3}{|c|}{ Spawning/incubation } & \multicolumn{3}{|c|}{ Fry } & \multicolumn{3}{|c|}{ Subyearling (Summer) } & \multicolumn{3}{|c|}{ Subyearling (winter) } & \multicolumn{3}{|c|}{ Subadult } & \multicolumn{3}{|c|}{ Adult holding } \\
\hline & BR_2 & WY_1 & $\mathrm{wr}+$ & BR_2 & WY_1 & wY+ & BR_2 & WY_1 & $\mathrm{wY}+$ & BR_2 & WY_1 & wYt & BR_2 & WY_1 & wY+ & BR_2 & WY_1 & wY+ & BR_2 & WY_1 & wY+ \\
\hline 198 & $66.2 \%$ & $0.3 \%$ & $-0.3 \%$ & $2.5 \%$ & $0.0 \%$ & $0.5 \%$ & $-2.7 \%$ & $1.8 \%$ & $-1.6 \%$ & $-0.1 \%$ & $2.5 \%$ & $2.4 \%$ & $-6.9 \% \mid$ & $2.7 \%$ & $-2.8 \%$ & & & & $0.5 \%$ & $-0.4 \%$ & $-0.4 \%$ \\
\hline 198 & $50.8 \%$ & $19.2 \%$ & $14.2 \%$ & $-13.6 \%$ & $2.6 \%$ & $2.6 \%$ & $7.7 \%$ & $4.4 \%$ & $7.2 \%$ & $-1.4 \%$ & $0.0 \%$ & $0.0 \%$ & $2.8 \%$ & $-0.4 \%$ & $7.3 \%$ & & & & $0.0 \%$ & $0.0 \%$ & $0.0 \%$ \\
\hline 198 & $303.9 \%$ & $98.5 \%$ & 41.8\% & $-12.9 \%$ & $2.0 \%$ & $2.3 \%$ & $-1.6 \%$ & $2.1 \%$ & $-0.5 \%$ & $6.1 \%$ & $0.8 \%$ & $0.3 \%[$ & $-1.4 \%$ & $1.3 \%$ & $-0.4 \%$ & & & & $2.7 \%$ & $0.0 \%$ & $0.0 \%$ \\
\hline 198 & $0.0 \%$ & $0.3 \%$ & $-0.3 \%$ & $0.0 \%$ & $0.0 \%$ & $0.0 \%$ & $-15.3 \%$ & $-1.1 \%$ & $-5.3 \%$ & $33.0 \%$ & $18.3 \%$ & $27.6 \%$ & $-15.5 \%$ & $-0.5 \%$ & $-2.5 \%$ & & & & $-6.4 \%$ & $-8.6 \%$ & $-10.0 \%$ \\
\hline 198 & $0.0 \%$ & $0.3 \%$ & $-0.3 \%$ & $0.0 \%$ & $0.0 \%$ & $0.0 \%$ & $-2.6 \%$ & $-1.9 \%$ & $0.2 \%$ & $30.1 \%$ & $-3.9 \%$ & $21.2 \%$ & $-16.8 \%$ & $-2.9 \%$ & $-2.2 \%$ & & & & $3.0 \%$ & $0.7 \%$ & $0.1 \%$ \\
\hline 198 & $0.0 \%$ & $0.3 \%$ & $-0.3 \%$ & $0.0 \%$ & $0.0 \%$ & $0.0 \%$ & $-1.6 \%$ & $0.0 \%$ & $0.0 \%$ & $37.0 \%$ & $-8.1 \%$ & $12.8 \%$ & $-9.2 \%$ & $-0.2 \%$ & $0.0 \%$ & & & & $-2.1 \%$ & $-3.4 \%$ & $-7.7 \%$ \\
\hline 198 & $0.0 \%$ & $0.3 \%$ & $-0.3 \%$ & $0.0 \%$ & $0.0 \%$ & $0.0 \%$ & $0.0 \%$ & $0.0 \%$ & $0.0 \%$ & $23.9 \%$ & $-0.2 \%$ & $13.2 \%$ & $-5.7 \%$ & $0.0 \%$ & $0.0 \%$ & & & & $0.0 \%$ & $0.0 \%$ & $0.0 \%$ \\
\hline 198 & $0.0 \%$ & $0.3 \%$ & $-0.3 \%$ & $1.2 \%$ & $0.0 \%$ & $0.0 \%$ & $-15.6 \%$ & $0.0 \%$ & $0.0 \%$ & $-6.6 \%$ & $4.6 \%$ & $-5.6 \%$ & $-6.4 \%$ & $0.0 \%$ & $0.0 \%$ & & & & 7.0\% & $0.0 \%$ & $0.0 \%$ \\
\hline 199 & $130.9 \%$ & $0.3 \%$ & $-0.3 \%$ & $1.6 \%$ & $0.0 \%$ & $0.0 \%$ & $-3.1 \%$ & $0.0 \%$ & $-0.3 \%$ & $6.1 \%$ & $5.1 \%$ & $3.2 \%$ & $-2.4 \%$ & $0.0 \%$ & $0.1 \%$ & & & & $3.0 \%$ & $-0.1 \%$ & $-0.1 \%$ \\
\hline 199 & $227.6 \%$ & $90.8 \%$ & $101.1 \%$ & $-8.3 \%$ & $-0.9 \%$ & $-0.8 \%$ & $-4.8 \%$ & $0.0 \%$ & $-0.1 \%$ & $-1.4 \%$ & $0.0 \%$ & $0.0 \%$ & $1.1 \%$ & $0.1 \%$ & $0.3 \%$ & & & & $0.0 \%$ & $0.0 \%$ & $0.0 \%$ \\
\hline 199 & $0.0 \%$ & $0.3 \%$ & $-0.3 \%$ & $0.0 \%$ & $0.0 \%$ & $0.0 \%$ & $-5.1 \%$ & $-1.4 \%$ & $-1.9 \%$ & $64.5 \%$ & $-3.0 \%$ & $24.1 \%$ & $-6.5 \%$ & $0.9 \%$ & $0.8 \%$ & & & & $-4.8 \%$ & $0.1 \%$ & $-5.0 \%$ \\
\hline 199 & $0.0 \%$ & $0.3 \%$ & $-0.3 \%$ & $0.0 \%$ & $0.0 \%$ & $0.0 \%$ & $-3.2 \%$ & $0.0 \%$ & $0.0 \%$ & $46.3 \%$ & $10.5 \%$ & $9.8 \%]$ & $-6.8 \%$ & $0.0 \%$ & $0.0 \%$ & & & & $1.7 \%$ & $0.0 \%$ & $2.8 \%$ \\
\hline 199 & $0.0 \%$ & $0.3 \%$ & $-0.3 \%$ & $0.0 \%$ & $0.0 \%$ & $2.1 \%$ & $-0.8 \%$ & $0.0 \%$ & $0.1 \%$ & $-11.0 \%$ & $-0.5 \%$ & $-4.3 \%$ & $-10.6 \%$ & $-0.3 \%$ & $-0.5 \%$ & & & & $15.0 \%$ & $0.0 \%$ & $0.0 \%$ \\
\hline 199 & $0.0 \%$ & $4.2 \%$ & $15.0 \%$ & $0.0 \%$ & $-2.3 \%$ & $0.0 \%$ & $-0.5 \%$ & $0.0 \%$ & $0.0 \%$ & $-0.2 \%$ & $0.0 \%$ & $0.0 \%$ & $0.0 \%$ & $0.0 \%$ & $0.0 \%$ & & & & $0.0 \%$ & $0.0 \%$ & $0.0 \%$ \\
\hline 199 & $19.6 \%$ & $24.7 \%$ & $31.2 \%$ | & $-66.1 \%$ & $0.0 \%$ & $0.0 \%$ & $-1.6 \%$ & $0.0 \%$ & $0.0 \%$ & $-2.1 \%$ & $0.8 \%$ & $0.8 \%$ & $2.5 \%$ & $0.5 \%$ & $1.2 \%$ & & & & $0.0 \%$ & $0.0 \%$ & $0.0 \%$ \\
\hline 199 & $54.6 \%$ & $85.7 \%$ & $79.8 \%[$ & $-30.1 \%$ & $-29.6 \%$ & $-31.6 \%$ & $4.1 \%$ & $3.8 \%$ & $6.2 \%$ & $1.6 \%$ & $3.8 \%$ & $3.0 \%$ & $3.1 \%$ & $3.4 \%$ & $5.4 \%$ & & & & $0.2 \%$ & $-1.0 \%$ & $-0.8 \%$ \\
\hline 199 & $135.6 \%$ & $211.2 \%$ & $192.7 \%$ ] & $-16.2 \%$ & $0.0 \%$ & $0.0 \%$ & $0.2 \%$ & $1.5 \%$ & $0.7 \%$ & $10.1 \%$ & $13.6 \%$ & $13.6 \%$ & $-5.7 \%$ & $9.8 \%$ & $7.0 \%$ & & & & $-3.7 \%$ & $-3.7 \%$ & $-3.7 \%$ \\
\hline 199 & $86.4 \%$ & $38.3 \%$ & $131.1 \%$ & $-9.6 \%$ & $-12.6 \%$ & $-11.0 \%$ & $-2.7 \%$ & $-0.9 \%$ & $3.9 \%$ & $5.2 \%$ & $6.5 \%$ & $6.5 \%$ & $-4.5 \%$ & $-2.7 \%$ & $1.1 \%$ & & & & $-3.5 \%$ & $-4.3 \%$ & $-4.3 \%$ \\
\hline 200 & $104.5 \%$ & $40.9 \%$ & $33.1 \%$ & $-14.9 \%$ & $0.0 \%$ & $0.0 \%$ & $-2.9 \%$ & $0.0 \%$ & $0.0 \%$ & $4.9 \%$ & $5.3 \%$ & $11.4 \%$ & $-5.3 \%$ & $-2.4 \%$ & $-2.4 \%$ & & & & $-8.9 \%$ & $-12.4 \%$ & $-12.4 \%$ \\
\hline 200 & $0.0 \%$ & $0.3 \%$ & $-0.3 \%$ & $0.0 \%$ & $0.0 \%$ & $0.0 \%$ & $-8.0 \%$ & $2.9 \%$ & $3.2 \%$ & $18.5 \%$ & $-0.1 \%$ & $15.7 \%$ & $-13.9 \%$ & $1.2 \%$ & $1.4 \%$ & & & & $13.3 \%$ & $-1.8 \%$ & $-1.3 \%$ \\
\hline 200 & $0.0 \%$ & $0.3 \%$ & $-0.3 \%]$ & $0.0 \%$ & $0.0 \%$ & $0.0 \%$ & $-1.6 \%$ & $0.0 \%$ & $-0.1 \%$ & $-13.6 \%$ & $6.8 \%$ & $-9.7 \%$ & $-1.1 \%$ & $0.0 \%$ & $0.0 \%$ & & & & $0.3 \%$ & $-0.1 \%$ & $-0.1 \%$ \\
\hline 200 & $0.0 \%$ & $0.3 \%$ & $-0.3 \%]$ & $0.0 \%$ & $0.0 \%$ & $0.0 \%$ & $-3.0 \%$ & $0.0 \%$ & $0.0 \%$ & $9.1 \%$ & $0.2 \%$ & $9.4 \%$ & $-8.8 \%$ & $0.0 \%$ & $0.0 \%$ & & & & $0.0 \%$ & $0.0 \%$ & $0.0 \%$ \\
\hline \multirow{24}{*}{$\begin{array}{l}Y \\
1 \\
1 \\
1 \\
1 \\
1 \\
1 \\
1 \\
1 \\
1 \\
1 \\
1 \\
1 \\
1 \\
1 \\
1 \\
1 \\
1\end{array}$} & \multicolumn{3}{|c|}{ Redd Scour } & \multicolumn{3}{|c|}{ Spawning/incubation } & \multicolumn{3}{|c|}{ Fry } & \multicolumn{3}{|c|}{ Subyearling (Summer) } & \multicolumn{3}{|c|}{ Subyearling (winter) } & & adult & & Adu & t holding & \\
\hline & BR_2 & WY_1 & $w^{+}+$ & BR_2 & WY_1 & wY+ & BR_2 & WY_1 & wYt & BR_2 & WY_1 & wyt & BR_2 & WY_1 & $w^{+}+$ & BR_2 & WY_1 & wY+ & BR_2 & WY_1 & wY+ \\
\hline & $66.2 \%$ & $0.3 \%$ & $-0.3 \%$ & $-1.3 \%$ & $0.0 \%$ & $0.1 \%$ & $-3.2 \%$ & $3.5 \%$ & $-1.9 \%$ & $-2.8 \%$ & $5.0 \%$ & $4.4 \%$ & $-4.0 \%$ & $3.0 \%$ & $-2.8 \%$ & & & & & & \\
\hline & $50.8 \%$ & $19.2 \%$ & $14.2 \%$ & $-8.2 \%$ & $0.6 \%$ & $0.6 \%$ & $0.5 \%$ & $0.4 \%$ & $0.4 \%$ & $-6.4 \%$ & $0.0 \%$ & $0.0 \%$ & $4.0 \%$ & $0.2 \%$ & $7.9 \%$ & & & & & & \\
\hline & $303.9 \%$ & $98.5 \%$ & $41.8 \%[$ & $-8.3 \%$ & $0.5 \%$ & $0.5 \%$ & $-2.1 \%$ & $0.2 \%$ & $-0.2 \%$ & $6.1 \%$ & $0.5 \%$ & $-0.7 \%$ & $-0.8 \%$ & $1.1 \%$ & $-0.4 \%$ & & & & & & \\
\hline & $0.0 \%$ & $0.3 \%$ & $-0.3 \%$ & $0.0 \%$ & $0.0 \%$ & $0.0 \%$ & $-16.2 \%$ & $0.0 \%$ & $-6.5 \%$ & $58.0 \%$ & $19.7 \%$ & $49.7 \%$ & $-3.4 \%$ & $0.0 \%$ & $0.0 \%$ & & & & & & \\
\hline & $0.0 \%$ & $0.3 \%$ & $-0.3 \%[$ & $0.9 \%$ & $0.0 \%$ & $0.0 \%$ & $-20.2 \%$ & $-6.4 \%$ & $-4.9 \%$ & $53.3 \%$ & $-7.3 \%$ & $27.0 \%$ & $-5.1 \%$ ] & $0.0 \%$ & $0.0 \%$ & & & & & & \\
\hline & $0.0 \%$ & $0.3 \%$ & $-0.3 \%$ & $0.0 \%$ & $0.0 \%$ & $0.0 \%$ & $-10.4 \%$ & $0.0 \%$ & $0.0 \%$ & $29.2 \%$ & $-4.3 \%$ & $12.0 \%$ & $0.0 \%$ & $-0.1 \%$ & $0.0 \%$ & & & & & & \\
\hline & $0.0 \%$ & $0.3 \%$ & $-0.3 \%[$ & $0.0 \%$ & $0.0 \%$ & $0.0 \%$ & $-6.5 \%$ & $0.0 \%$ & $0.0 \%$ & $66.8 \%$ & $2.1 \%$ & $27.1 \%$ ] & $0.0 \%$ & $0.0 \%$ & $0.0 \%$ & & & & & & \\
\hline & $0.0 \%$ & $0.3 \%$ & $-0.3 \%$ & $2.3 \%$ & $0.0 \%$ & $0.0 \%$ & $-5.5 \%$ & $0.0 \%$ & $0.0 \%$ & $-14.7 \%$ & $12.5 \%$ & $-16.1 \%$ & $0.0 \%$ & $0.0 \%$ & $0.0 \%$ & & & & & & \\
\hline & $138.7 \%$ & $0.5 \%$ & $-0.5 \%$ & $-1.5 \%$ & $0.0 \%$ & $0.0 \%$ & $-8.5 \%$ & $0.0 \%$ & $0.6 \%$ & $9.8 \%$ & $20.8 \%$ & $17.0 \%$ & $1.5 \%$ & $0.0 \%$ & $0.0 \%$ & & & & & & \\
\hline & $21.0 \%$ & $39.6 \%$ & $1.1 \%$ & $-8.2 \%$ & $-0.9 \%$ & $-0.8 \%$ & $-15.8 \%$ & $0.0 \%$ & $0.0 \%$ & $-14.5 \%$ & $0.0 \%$ & $0.0 \%$ & $1.3 \%$ & $0.0 \%$ & $-0.3 \%]$ & & & & & & \\
\hline & $0.0 \%$ & $0.3 \%$ & $-0.3 \%$ & $2.7 \%$ & $2.7 \%$ & $2.7 \%$ & $-18.2 \%$ & $-3.0 \%$ & $-1.6 \%$ | & $92.1 \%$ & $-3.2 \%$ & $19.7 \%$ & $-1.0 \%$ & $1.9 \%$ & $4.9 \%$ & & & & & & \\
\hline & $0.0 \%$ & $0.3 \%$ & $-0.3 \%$ ] & $0.0 \%$ & $0.0 \%$ & $0.0 \%$ & $-12.3 \%$ & $0.0 \%$ & $0.1 \%$ & $54.2 \%$ & $4.9 \%$ & $3.2 \%$ & $-1.9 \%$ & $0.0 \%$ & $0.0 \%$ & & & & & & \\
\hline & $0.0 \%$ & $0.3 \%$ & $-0.3 \%$ ] & $0.0 \%$ & $0.0 \%$ & $0.6 \%$ & $-7.5 \%$ & $0.0 \%$ & $0.1 \%$ & $-29.6 \%$ & $-0.7 \%$ ] & $-13.8 \%$ & $0.6 \%$ & $-0.4 \%$ & $-0.7 \%]$ & & & & & & \\
\hline & $0.3 \%$ & $8.3 \%$ & $19.5 \%$ & $0.0 \%$ & $-0.2 \%$ & $0.0 \%$ & $-4.1 \%$ & $0.0 \%$ & $0.0 \%$ & $-6.0 \%$ & $0.0 \%$ & $0.0 \%$ & $0.0 \%$ & $0.0 \%$ & $0.0 \%$ & & & & & & \\
\hline & $19.6 \%$ & $24.7 \%$ & $31.2 \%$ & $-67.2 \%$ & $0.0 \%]$ & $0.0 \%$ & $-3.6 \%$ & $0.0 \%$ & $0.0 \%$ & $-6.9 \%$ & $7.5 \%$ & 7.50 & $1.6 \%$ & $0.4 \%]$ & $0.8 \%$ & & & & & & \\
\hline & $54.6 \%$ & $85.7 \%$ & $79.8 \%$ & $-31.2 \%$ & $-31.1 \%$ & $-31.5 \%$ & $1.1 \%$ & $0.6 \%$ & $0.9 \%$ & $0.2 \%$ & $4.4 \%$ & $3.1 \%$ & $3.1 \%$ & $3.3 \%$ & $5.3 \%$ & & & & & & \\
\hline & $138.2 \%$ & $214.8 \%$ & $196.0 \%$ & $-8.0 \%$ & $-1.0 \%$ & $2.0 \%$ & $-0.5 \%$ & $-0.2 \%$ & $-0.2 \%$ & $52.2 \%$ & $71.2 \%$ & $71.2 \%$ & $-6.1 \%$ & $10.3 \%$ & $7.2 \%$ & & & & & & \\
\hline & $86.4 \%$ & $38.3 \%$ & $131.1 \%$ & $-4.7 \%$ & $-5.4 \%$ & $-5.0 \%$ & $4.4 \%$ & $5.1 \%$ & $4.6 \%$ & $8.0 \%$ & $10.2 \%$ & $10.2 \%$ & $-4.8 \%$ & $-3.0 \%$ & $1.4 \%$ & & & & & & \\
\hline & $104.5 \%$ & $40.9 \%$ & $33.1 \%$ & $-16.1 \%$ & $0.0 \%$ & $0.0 \%$ & $-8.2 \%$ & $0.0 \%$ & $0.0 \%$ & $20.9 \%$ & $21.7 \%$ & $38.1 \%$ & $3.4 \%$ & $-2.4 \%$ & $-2.4 \% \mid$ & & & & & & \\
\hline & $0.0 \%$ & $0.3 \%$ & $-0.3 \%$ & $0.0 \%$ & $0.0 \%]$ & $0.0 \%$ & $-9.3 \%$ & $4.4 \%$ & $4.9 \%$ & $9.6 \%$ & $0.2 \%$ & $3.2 \%$ & $-4.4 \%$ & $0.3 \%$ & $0.4 \%$ & & & & & & \\
\hline & $0.0 \%$ & $0.3 \%$ & $-0.3 \%$ | & $0.0 \%$ & $0.0 \%$ & $0.0 \%$ & $-10.3 \%$ & $0.0 \%$ & $0.0 \%$ ] & $-5.5 \%$ & $21.5 \%$ & $7.1 \%$ & $-0.4 \%$ & $0.0 \%$ & $0.0 \%$ & & & & & & \\
\hline & $0.0 \%$ & $0.3 \%$ & $-0.3 \%$ | & $0.0 \%[$ & $0.0 \%$ & $0.0 \%$ & $-13.4 \%[$ & $0.0 \%$ & $0.0 \%$ & $34.0 \%$ & $-0.2 \%$ & $43.3 \% \mid$ & $0.0 \%$ & $0.0 \%$ & $0.0 \%$ & & & & & & \\
\hline
\end{tabular}

Figure 48. Annual habitat summaries for spring chinook and coho in the Easton reach, comparing the Black Rock_2 (BR_2), Wymer_1 (WY_1), and WymerPlus (WY+ ) scenarios relative to the baseline. 
Steelhead

\begin{tabular}{|c|c|c|c|c|c|c|c|c|c|c|c|c|c|c|c|c|c|c|c|c|c|}
\hline \multirow[b]{2}{*}{ Year } & \multicolumn{3}{|c|}{ Redd Scour } & \multicolumn{3}{|c|}{ Spawning/incubation } & \multicolumn{3}{|c|}{ Fry } & \multicolumn{3}{|c|}{ Subyearling (Summer) } & \multicolumn{3}{|c|}{ Subyearling (winter) } & \multicolumn{3}{|c|}{ Subadult } & \multicolumn{3}{|c|}{ Adult holding } \\
\hline & BR_2 & WY_1 & wY+ & BR_2 & WY_1 & wY+ & BR_2 & WY_1 & wyt & BR_2 & WY_1 & wY+ & BR_2 & WY_1 & wy+ & BR_2 & WY_1 & $w Y+$ & BR_2 & WY_1 & wY+ \\
\hline 1982 & $6.2 \%$ & $39.7 \%$ & $41.0 \%$ & $4.3 \%$ & $0.0 \%$ & $0.5 \%$ & $-3.0 \%$ & $5.3 \%$ & $4.6 \%$ & $0.0 \%$ & $0.0 \%$ & $0.0 \%$ & $-6.7 \%$ & $3.4 \%$ & $-3.3 \%$ & $-0.6 \%$ & $1.69 \%$ & $1.7 \%$ & $-8.8 \%$ & $0.0 \%$ & $-0.5 \%$ \\
\hline 1983 & $4.7 \%$ & $40.0 \%$ & $47.1 \%$ & $-2.0 \%$ & $2.7 \%$ & $2.7 \%$ & $-0.9 \%$ & $0.0 \%$ & & $0.0 \%$ & & & $4.5 \%$ & $0.2 \%$ & & & إل\% & إ & $-1.3 \%$ & $0.1 \%$ & - \\
\hline & $0.0 \%$ & $0.3 \%$ & & $-0.9 \%$ & $0.9 \%$ & 0.9 & -5.2 & -0.5 & & $0.0 \%$ & $0.0 \%$ & & 1 & & & & & & & & \\
\hline 985 & $0.0 \%$ & $275.2 \%$ & -0. & 0.0 & $0 . c$ & $0.0 \%$ & 16.3 & 2.4 & & $22.5 \%$ & $22.5 \%$ & 22. & 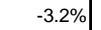 & & & & & 2.8 & & $\%$ & \\
\hline & $37.6 \%$ & 0.3 & 82.8 & $0.0 \%$ & $0.0 \%$ & $0.0 \%$ & 23.6 & -1.1 & 0. & $8.7 \%$ & $-13.3 \%$ & & 1 & & & & 0 & & & & \\
\hline & & & -0.3 & & $0.0 \%$ & 0.0 & $-10.4 \%$ & $4.9 \%$ & $-1.55^{\circ}$ & $39.7 \%$ & & & & & & & & & & $-1.4 \%$ & \\
\hline & 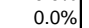 & & & & & & & & & & & & & & & & & & & & \\
\hline & $192.1 \%$ & $0.3 \%$ & $-0.3 \%$ & $0.4 \%$ & $0.0 \%$ & 0.8 & $-12.5^{\circ}$ & $13.6 \%$ & $-16.0 \%$ & 6 & $-0.8 \%$ ] & $-1.5 \%$ & -0.5 & & & & & & & & \\
\hline & 21 & & & & & & $12.5 \%$ & & & & & & & & & & & & & & \\
\hline 991 & $27.9 \%$ & 41. & 33. & & & & $-0.9 \%$ & & & & & & & & & & & & & & \\
\hline & $0.0 \%$ & & & & & & 42 & & & & $-5.7 \%$ ] & 14.2 & -0. & & & & & 15.4 & & & \\
\hline & & & & & & 0.0 & $10.5^{\circ}$ & $-0.4 \%$ & & & $27.2 \%$ & & 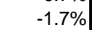 & & & & & 0.7 & & & \\
\hline yy & 0.6 & $0.3 \%$ & -0. & & $0.0 \%$ & & -16.7 & $-1.8 \%$ & $15.2 \%$ & 46. & & & & $-0.4 \%$ & & -1.1 .1 & -1.97 & -1.1 .1 & & 00 & \\
\hline & & & & & & & & & & & & & & & & & & & & & \\
\hline & 22.4 & & & & & & & $11.6 \%$ & 11. & & & & & & & & & & & & \\
\hline & 32 & & & & & & -0.8 & & & & & & & & & & & 2.6 & & & \\
\hline & & & & & & & 42.3 & . & 43.8 & & & & & $10.6 \%$ & & & & 0.0 & & & \\
\hline & & & & & & & & & & & & & & & & & & 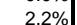 & & & \\
\hline & & & & & & & 19.8 & $13.7 \%$ & 28 & & & & & $2.9 \%$ & & & & . & & -1. & \\
\hline & 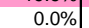 & 0. & & & 0.6 & & -8.6 & $2.4 \%$ & $2.1 \%$ & $58.4 \%$ & 3.6 & 6 & -4.3 & $0.3 \%$ & & $14.6 \%$ & $\%$ & 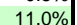 & $1+$ & $1.4 \%$ & \\
\hline & & & & & & & & & & & & & & & & & & & & & \\
\hline 2003 & $\begin{array}{r}r 3.0 \% \\
0.0 \%\end{array}$ & $0.3 \%$ & $\begin{array}{l}20<.470 \\
-0.3 \%\end{array}$ & $0.0 \%$ & $0.0 \%$ & $0.0 \%$ & $25.1 \%$ & $0.1 \%$ & $\begin{array}{l}15.49 \% \\
\end{array}$ & $\begin{array}{c}-0.9 \% \\
-\end{array}$ & $0.1 \%$ & $-0.9 \%$ & $0.0 \%$ & $0.0 \%$ & $0.0 \%$ & $0.0 \%$ & o. $00 \%$ & 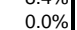 & $\begin{array}{l}0.0 \% \\
0.0 \%\end{array}$ & 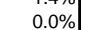 & \\
\hline
\end{tabular}

Resident Rainbow

\begin{tabular}{|c|c|c|c|c|c|c|c|c|c|c|c|c|c|c|c|c|c|c|c|c|}
\hline \multicolumn{3}{|c|}{ Redd Scour } & \multicolumn{3}{|c|}{ Spawning/incubation } & \multicolumn{3}{|c|}{ Fry } & \multicolumn{3}{|c|}{ Subyearling (Summer) } & \multicolumn{3}{|c|}{ Subyearling (winter) } & \multicolumn{3}{|c|}{ Subadult } & \multicolumn{3}{|c|}{ Adult holding } \\
\hline BR_2 & WY_1 & wY+ & BR_2 & WY_1 & WY+ & BR_2 & WY_1 & wYt & BR_2 & WY_1 & wY+ & BR_2 & WY_1 & wY+ & BR_2 & WY_1 & wyt & $\mathrm{BR}_{2} 2$ & WY 1 & wYt \\
\hline $6.2 \%$ & $39.7 \%$ & $41.0 \%$ & $-11.1 \%$ & $0.0 \%$ & $0.2 \%$ & $-2.4 \%$ & $5.0 \%$ & $4.3 \%$ & $0.0 \%$ & $0.0 \%$ & $0.0 \%$ & $-3.7 \%$ & $3.0 \%$ & $-2.8 \%$ & $-8.0 \%$ & $3.74 \%$ & $3.5 \%$ & & & \\
\hline $0.0 \%$ & $0.3 \%$ & $-0.3 \%$ & $-24.1 \%$ & $0.5 \%$ & $0.5 \%$ & $-0.8 \%$ & $0.0 \%$ & $0.0 \%$ & $0.0 \%$ & $0.0 \%$ & $0.0 \%$ & $4.4 \%$ & $0.4 \%$ & $8.6 \%$ & $-2.5 \%$ & $0.00 \%$ & $0.0 \%$ & & & \\
\hline $0.0 \%$ & $0.3 \%$ & $1.2 \%$ & $-24.5 \%$ & $0.4 \%$ & $0.5 \%$ & $-4.4 \%$ & $-0.2 \%$ & $-1.2 \%$ & $0.0 \%$ & $0.0 \%$ & $0.0 \%$ & $-0.9 \%$ & $1.3 \%$ & $-0.4 \%$ & $2.3 \%$ & $0.99 \%$ & $0.3 \%$ & & & \\
\hline $0.0 \%$ & $275.2 \%$ & $-0.3 \%$ & $0.0 \%$ & $0.0 \%$ & $0.0 \%$ & $15.9 \%$ & $3.3 \%$ & $8.5 \%$ & $23.2 \%$ & $23.2 \%$ & $23.2 \%$ & $-3.2 \%$ & $0.0 \%$ & $0.0 \%$ & $20.2 \%$ & $15.18 \%$ & $27.0 \%$ & & & \\
\hline $37.6 \%$ & $0.3 \%$ & $82.8 \%$ & $1.2 \%$ & $0.0 \%$ & $0.0 \%$ & $24.2 \%$ & $0.3 \%$ & $9.5 \%$ & $9.1 \%$ & $-13.5 \%$ & $9.9 \%$ & $-4.7 \%$ & $0.0 \%$ & $0.0 \%$ & $8.7 \%$ & $-6.96 \%$ & $4.5 \%$ & & & \\
\hline $0.0 \%$ & $0.3 \%$ & $-0.3 \%$ & $0.0 \%$ & $0.0 \%$ & $0.0 \%$ & $-8.6 \%$ & $1.9 \%$ & $-3.3 \%$ & $40.7 \%$ & $-9.4 \%$ & $7.8 \%$ & $0.0 \%$ & $-0.1 \%$ & $0.0 \%$ & $14.8 \%$ & $1.93 \%$ & $15.4 \%$ & & & \\
\hline $0.0 \%$ & $0.3 \%$ & $-0.3 \%$ & $0.0 \%$ & $0.0 \%$ & $0.0 \%$ & $31.2 \%$ & $1.6 \%$ & $18.7 \%$ & 21.1\% & $0.3 \%$ & $13.2 \%$ & $0.0 \%$ & $0.0 \%$ & $0.0 \%$ & $14.2 \%$ & $-0.24 \%$ & $10.1 \%$ & & & \\
\hline $1.8 \%$ & $0.3 \%$ & $-0.3 \%$ & $3.2 \%$ & $0.0 \%$ & $0.0 \%$ & $-11.0 \%$ & $11.9 \%$ & $-13.9 \%$ & $0.5 \%$ & $-0.8 \%$ & $-1.5 \%$ & $0.5 \%$ & $0.0 \%$ & $0.0 \%$ & $-20.2 \%$ & $6.74 \%$ & $-8.5 \%$ & & & \\
\hline$-16.6 \%$ & $39.2 \%$ & $42.2 \%$ & $-11.2 \%$ & $0.0 \%$ & $0.0 \%$ & $10.6 \%$ & $16.0 \%$ & $12.7 \%$ & $0.0 \%$ & $0.0 \%$ & $0.0 \%$ & $1.6 \%$ & $0.0 \%$ & $-0.1 \%$ & $-0.1 \%$ & $6.97 \%$ & $4.6 \%$ & & & \\
\hline $0.0 \%$ & $0.3 \%$ & $-0.3 \%$ & $-8.2 \%$ & $-0.9 \%$ & $-0.8 \%$ & $-0.8 \%$ & $0.0 \%$ & $0.0 \%$ & $0.0 \%$ & $0.0 \%$ & $0.0 \%$ & $1.5 \%$ & $0.0 \%$ & $-0.2 \%$ & $-5.9 \%$ & $0.00 \%$ & $0.0 \%$ & & & \\
\hline $0.0 \%$ & $0.3 \%$ & $-0.3 \%$ & $6.8 \%$ & $6.8 \%$ & $6.8 \%$ & $36.9 \%$ & $4.5 \%$ & $2.7 \%$ & $41.1 \%$ & $-5.7 \%$ & $14.3 \%$ & $-1.0 \%$ & $1.9 \%$ & $4.8 \%$ & $59.5 \%$ & $8.68 \%$ & $30.7 \%$ & & & \\
\hline $0.0 \%$ & $0.3 \%$ & $-0.3 \%$ & $0.0 \%$ & $0.0 \%$ & $0.0 \%$ & $11.9 \%$ & $-0.9 \%$ & $6.8 \%$ & $57.9 \%$ & $27.3 \%$ & $13.1 \%$ & $-1.7 \%$ & $0.0 \%$ & $0.0 \%$ & $21.8 \%$ & $2.45 \%$ & $0.4 \%$ & & & \\
\hline $0.0 \%$ & $0.3 \%$ & $-0.3 \%$ & $0.0 \%$ & $0.0 \%$ & $0.8 \%$ & $-14.9 \%$ & $-1.9 \%$ & $-14.0 \%$ & $46.8 \%$ & $9.3 \%$ & $23.6 \%$ & $0.5 \%$ & $-0.4 \%$ & $-0.6^{\circ}$ & $-27.6 \%$ & $-2.97 \%$ & $-8.4 \% \mid$ & & & \\
\hline $0.0 \%$ & $0.3 \%$ & $-0.3 \%$ & $0.0 \%$ & $0.0 \%$ & $0.0 \%$ & $-0.7 \%$ & $0.0 \%$ & $0.0 \%$ & $0.0 \%$ & $0.0 \%$ & $0.0 \%$ & $0.0 \%$ & $0.0 \%$ & 0.0 & $-0.5 \%$ & $0.00 \%$ & $0.0 \%$ & & & \\
\hline $0.0 \%$ & $0.3 \%$ & $-0.3 \%$ & $-66.4 \%$ & $0.0 \%$ & $0.0 \%$ & $7.8 \%$ & $9.7 \%$ & $9.7 \%$ & $0.0 \%$ & $0.0 \%$ & $0.0 \%$ & $1.7 \%$ & $0.5 \%$ & 0. & $-3.0 \%$ & $1.51 \%$ & $1.5 \%$ & & & \\
\hline $32.0 \%$ & $51.8 \%$ & $39.6 \%$ & $-43.0 \%$ & $-42.7 \%$ & $-43.8 \%$ & $-0.2 \%$ & $1.8 \%$ & $1.8 \%$ & $0.0 \%$ & $0.0 \%$ & $0.0 \%$ & $3.9 \%$ & $3.6 \%$ & 5.7 & $2.1 \%$ & $5.89 \%$ & $4.7 \%$ & & & \\
\hline $4.1 \%$ & $38.5 \%$ & $43.7 \%$ & $-22.4 \%$ & $-5.5 \%$ & $2.7 \%$ & $35.2 \%$ & $36.4 \%$ & $36.4 \%$ & $3.2 \%$ & $3.2 \%$ & $3.2 \%$ & $-6.0 \%$ & $10.9 \%$ & $7.7 \%$ & $12.0 \%$ & $18.40 \%$ & $18.4 \%$ & & & \\
\hline $18.0 \%$ & $30.0 \%$ & $26.3 \%$ & $-15.5 \%$ & $-16.1 \%$ & $15.8 \%$ & $6.3 \%$ & $7.6 \%$ & $7.6 \%$ & $0.0 \%$ & $0.0 \%$ & $0.0 \%$ & $-5.1 \%$ & $-3.1 \%$ & 1.8 & $2.8 \%$ & $4.25 \%$ & $4.2 \%$ & & & \\
\hline$-15.0 \%$ & $36.2 \%$ & $28.3 \%$ & $-33.6 \%$ & $0.0 \%$ & $0.0 \%$ & $16.8 \%$ & $11.7 \%$ & $24.2 \%[$ & $0.0 \%$ & $0.0 \%$ & $0.0 \%$ & $3.7 \%$ & -2.5 & -2.5 & $8.6 \%$ & $7.06 \%$ & $16.7 \%$ & & & \\
\hline $0.0 \%$ & $0.3 \%$ & $-0.3 \%$ & $0.0 \%$ & $0.0 \%$ & $0.0 \%$ & $-5.4 \%$ & $2.3 \%$ & $0.0 \%$ & $59.5 \%$ & $3.9 \%$ & $30.7 \%$ & $-4.2 \%$ & 0.3 & 0. & $-1.1 \%$ & $-1.69 \%$ & $12.9 \%$ & & & \\
\hline $215.3 \%$ & $0.3 \%$ & $62.4 \%$ & $0.0 \%$ & $0.0 \%$ & $0.0 \%$ & $1.3 \%$ & $14.4 \%$ & $13.2 \%[$ & $0.0 \%$ & $0.0 \%$ & $0.0 \%$ & $-0.4 \%$ & $0.0 \%$ & & & $8.48 \%$ & 0.0 & & & \\
\hline & $0.3 \%$ & $-0.3 \%$ & $0.0 \%$ & $0.0 \%$ & $0.0 \%$ & $21.7 \%$ & $0.1 \%$ & $22.5 \%$ ] & $-0.7 \%$ & $0.1 \%$ & & $0.0 \%$ & $0.0 \%$ & $00^{\circ}$ & $8.2 \%$ & $-0.34 \%$ & $9.8 \%$ & & & \\
\hline
\end{tabular}

Figure 49. Annual habitat summaries for steelhead and resident rainbow trout in the Easton reach, comparing the Black Rock_2 (BR_2), Wymer_1 (WY_1), and WymerPlus (WY+ ) scenarios relative to the baseline. 
Bull Trout

\begin{tabular}{|c|c|c|c|c|c|c|c|c|c|c|c|c|c|c|c|c|c|c|c|c|c|}
\hline \multirow[b]{2}{*}{ Yearl } & \multicolumn{3}{|c|}{ Redd Scour } & \multicolumn{3}{|c|}{ Spawning/incubation } & \multicolumn{3}{|c|}{ Fry } & \multicolumn{3}{|c|}{ Subyearling (Summer) } & \multicolumn{3}{|c|}{ Subyearling (winter) } & \multicolumn{3}{|c|}{ Subadult } & \multicolumn{3}{|c|}{ Adult holding } \\
\hline & BR_2 & WY_1 & $\mathrm{wY}+$ & BR_2 & WY_1 & wy+ & BR_2 & WY_1 & wY+ & BR_2 & WY_1 & wY+ & BR_2 & WY_1 & $\mathrm{wr}+$ & BR_2 & WY_1 & wYt & BR_2 & WY_1 & wYt \\
\hline 1982 & $66.2 \%$ & $0.3 \%$ & $-0.3 \%$ & $-5.4 \%$ & $0.0 \%$ & $0.0 \%$ & $0.0 \%$ & $-0.3 \%$ & $0.0 \%$ & $0.5 \%$ & $2.1 \%$ & $2.1 \%$ & $-2.7 \%$ & $2.2 \%$ & $-1.9 \%$ & & & & & & \\
\hline 1983 & $50.8 \%$ & $19.2 \%$ & $14.2 \%$ & $-11.4 \%$ & $-1.0 \%$ & $-1.0 \%$ & $0.0 \%$ & $0.0 \%$ & $0.0 \%$ & $-0.6 \%$ & $0.0 \%$ & $0.0 \%$ & $2.2 \%$ & $-0.2 \%$ & $7.2 \%$ & & & & & & \\
\hline 1984 & $303.9 \%$ & $98.5 \%$ & $41.8 \%$ & $-11.4 \%$ & $-0.8 \%$ & $-0.9 \%$ & $0.0 \%$ & $0.0 \%$ & $0.0 \%$ & $4.7 \%$ & $0.8 \%$ & $0.5 \%$ & $-2.1 \%$ ] & $0.7 \%$ & $-0.3 \%$ & & & & & & \\
\hline 1985 & $0.0 \%$ & $0.3 \%$ & $-0.3 \%$ & $0.0 \%$ & $0.0 \%$ & $0.0 \%$ & $0.0 \%$ & $0.0 \%$ & $0.0 \%$ & $21.0 \%$ & $13.0 \%$ & $17.3 \%$ & $-14.9 \%$ & $-0.3 \%$ & $-2.3 \%$ & & & & & & \\
\hline 1986 & $0.0 \%$ & $0.3 \%$ & $-0.3 \%$ & $-1.4 \%$ & $0.0 \%$ & $0.0 \%$ & $0.0 \%$ & $0.0 \%$ & $0.0 \%$ & $19.5 \%$ & $-0.6 \%$ & $14.9 \%$ & $-15.6 \%$ & $-2.7 \%$ & $-1.8 \%$ & & & & & & \\
\hline 1987 & $0.0 \%$ & $0.3 \%$ & $-0.3 \%$ & $0.0 \%$ & $0.0 \%$ & $0.0 \%$ & $0.1 \%$ & $-0.1 \%$ & $0.1 \%$ & $26.7 \%$ & $-7.0 \%$ & $8.7 \%$ & $-8.7 \%$ & $-0.2 \%$ & $0.1 \%$ & & & & & & \\
\hline 1988 & $0.0 \%$ & $0.3 \%$ & $-0.3 \%$ & $0.0 \%$ & $0.0 \%$ & $0.0 \%$ & $0.0 \%$ & $0.0 \%$ & $0.0 \%$ & $13.5 \%$ & $-0.8 \%$ & $8.5 \%$ & $-5.5 \%$ & $0.0 \%$ & $0.0 \%$ & & & & & & \\
\hline 1989 & $0.0 \%$ & $0.3 \%$ & $-0.3 \%$ & $-3.4 \%$ & $0.0 \%$ & $0.0 \%$ & $0.7 \%$ & $0.0 \%$ & $0.0 \%$ & $-4.7 \%$ & $2.4 \%$ & $-3.0 \%$ & $-4.8 \%$ ] & $0.0 \%$ & $0.0 \%$ & & & & & & \\
\hline 1990 & $130.9 \%$ & $0.3 \%$ & $-0.3 \%$ & $-4.9 \%$ & $0.0 \%$ & $0.0 \%$ & $1.0 \%$ & $0.0 \%$ & $1.0 \%$ & $5.5 \%$ & $3.5 \%$ & $2.2 \%$ & $-2.3 \%]$ & $0.0 \%$ & $-0.1 \%$ & & & & & & \\
\hline 1991 & $227.6 \%$ & $90.8 \%$ & $101.1 \%$ & $-8.2 \%$ & $-0.9 \%$ & $-0.8 \%$ ] & $0.0 \%$ & $0.0 \%$ & $0.0 \%$ & $-0.5 \%$ & $0.0 \%$ & $0.0 \%$ & $-0.3 \%$ ] & $0.1 \%$ & $1.1 \%$ & & & & & & \\
\hline 1992 & $0.0 \%$ & $0.3 \%$ & $-0.3 \%$ & $-1.3 \%$ & $-1.3 \%$ & $-1.3 \%$ & $0.0 \%$ & $0.0 \%$ & $0.0 \%$ & $41.8 \%$ & $-3.0 \%$ & $18.1 \%$ & $-6.7 \%$ ] & $0.0 \%$ & $0.0 \%$ & & & & & & \\
\hline 1993 & $0.0 \%$ & $0.3 \%$ & $-0.3 \%$ & $0.0 \%$ & $0.0 \%$ & $0.0 \%$ & $0.3 \%$ & $0.0 \%$ & $0.0 \%$ & $32.0 \%$ & $7.9 \%$ & $7.7 \%$ & $-6.9 \%]$ & $0.0 \%$ & $0.0 \%$ & & & & & & \\
\hline $\begin{array}{l}1994 \\
\end{array}$ & $0.0 \%$ & $0.3 \%$ & $-0.3 \%$ & $0.0 \%$ & $0.0 \%$ & $0.0 \%$ & $0.8 \%$ & $-0.5 \%$ & $-1.0 \%$ & $-6.2 \%$ & $-0.4 \%$ & $-1.8 \%$ & $-10.5 \%$ & $-0.3 \%$ & $-0.5 \%$ & & & & & & \\
\hline $\begin{array}{l}1994 \\
1995\end{array}$ & $0.0 \%$ & $4.2 \%$ & $15.0 \%$ & $0.0 \%$ & $0.0 \%$ & $0.0 \%$ & $0.0 \%$ & $0.0 \%$ & $0.0 \%$ & $\begin{array}{r}-0.2 \% \\
0.0 \%\end{array}$ & $\begin{array}{r}-.4 \% \\
0.0 \%\end{array}$ & $\begin{array}{r}-1.0 \% \\
0.0 \%\end{array}$ & $\begin{array}{r}-0.5 \% \\
0.0 \%\end{array}$ & $\begin{array}{r}0.5 \% \\
0.0 \%\end{array}$ & $\begin{array}{r}0.0 \% \% \\
0.0 \%\end{array}$ & & & & & & \\
\hline $\begin{array}{l}1996 \\
1996\end{array}$ & $19.6 \%$ & $\begin{array}{r}4.24 \% \\
24.7 \%\end{array}$ & $\begin{array}{l}13.0 \% \\
31.2 \%\end{array}$ & $-61.3 \%$ & $0.0 \%$ & $0.0 \%$ & $0.0 \%$ & $0.0 \%$ & $0.3 \%$ & -1.0\% & $0.2 \%$ & $0.2 \%$ & $0.8 \%$ & $0.5 \%$ & $0.9 \%$ & & & & & & \\
\hline 1997 & $54.6 \%$ & $85.7 \%$ & $79.8 \%$ & $-30.4 \%$ & $-30.5 \%$ & $-30.0 \%$ & $0.0 \%$ & $0.0 \%$ & $0.0 \%$ & $1.6 \%$ & $3.1 \%$ & $2.5 \%$ & $3.4 \%[$ & $2.1 \%$ & $3.4 \%$ & & & & & & \\
\hline 1998 & $135.6 \%$ & $211.2 \%$ & $192.7 \%$ & $0.0 \%$ & $-2.5 \%$ & $-3.0 \%$ & $0.0 \%$ & $0.0 \%$ & $0.0 \%$ & $4.5 \%$ & $6.0 \%$ & $6.0 \%$ & $-5.2 \%]$ & $9.8 \%$ & $6.9 \%$ & & & & & & \\
\hline 1999 & $86.4 \%$ & $38.3 \%$ & $131.1 \%$ & $-1.5 \%$ & $-0.1 \%$ & $-0.8 \%$ ] & $0.0 \%$ & $0.0 \%$ & $0.0 \%$ & $3.7 \%$ & $4.6 \%$ & $4.6 \%$ & $-2.9 \%$ ] & $-1.1 \%$ & $2.9 \%$ & & & & & & \\
\hline . & $104.5 \%$ & $40.9 \%$ & $33.1 \%$ & $-19.0 \%$ & $0.0 \%$ & $0.0 \%$ & $0.0 \%$ & $-0.9 \%$ & $-0.9 \%$ & $2.3 \%$ & $2.7 \%$ & $6.0 \%$ & $-5.3 \%]$ & $-1.8 \%$ & $-1.8 \%$ & & & & & & \\
\hline 200 & $0.0 \%$ & $0.3 \%$ & $-0.3 \%$ & $0.0 \%$ & $0.0 \%$ & $0.0 \%$ & $0.0 \%$ & $0.0 \%$ & $0.0 \%$ & $15.3 \%$ & $-0.4 \%$ & $13.3 \%$ & $-13.7 \%$ & $1.3 \%$ & $1.4 \%$ & & & & & & \\
\hline 2002 & $0.0 \%$ & $0.3 \%$ & $-0.3 \%$ & $0.0 \%$ & $0.0 \%$ & $0.0 \%$ & $1.2 \%$ & $0.0 \%$ & $0.0 \%$ & $-10.2 \%$ & $4.9 \%$ & $-8.1 \%$ & $-1.2 \%]$ & $0.0 \%$ & $0.0 \%$ & & & & & & \\
\hline 2003 & $0.0 \%$ & $0.3 \%$ & $-0.3 \%$ & $0.0 \%$ & $0.0 \%$ & $0.0 \%$ & $0.0 \%$ & $0.0 \%$ & $0.0 \%$ & $4.6 \%$ & $0.0 \%$ & $4.6 \%$ & $-9.1 \%$ & $0.0 \%$ & $0.0 \%$ & & & & & & \\
\hline
\end{tabular}

Figure 50. Annual habitat summary for bull trout in the Easton reach, comparing the Black Rock_2 (BR_2), Wymer_1 (WY_1), and WymerPlus $(W Y+$ ) scenarios relative to the baseline. 
alternatives. Habitat for coho fry was reduced significantly or nearly significantly during 10 years of the record under Blackrock_2, with the other alternatives resulting in little or no change (fig. 48). In contrast, fry habitat for steelhead and resident rainbow trout increased significantly in numerous years under all three alternatives, with only a few significant reductions under Black Rock_2 and WymerPlus (fig. 49). Habitat for bull trout fry was relatively unchanged under any of the scenarios (fig. 50).

- Significant or nearly significant increases in summer habitat for subyearlings of all species were recorded for the period of record under the Black Rock_2 alternative, and a significant positive increase was also noted for coho under the WymerPlus alternative (fig. 47). On an annual basis, summer subyearling habitat was significantly and frequently increased for all species, including bull trout, under the Black Rock_2 and WymerPlus alternatives. Changes to this habitat type were mostly positive for all species under Wymer_1, although very few of the changes were significant (figs. 48-50).

- Subyearling winter habitat for coho, steelhead, and rainbow trout was not appreciably influenced by any of the alternatives (figs. 48 and 49). Winter habitat for these species increased and decreased in roughly the same frequency and all changes were relatively small. Reductions in this habitat type for spring chinook (fig. 48) and bull trout (fig. 50) occurred more frequently than increases under Black Rock_2, with several losses in excess of 10 percent. The two Wymer scenarios produced mostly small positive changes for all species.

- Changes to subadult steelhead and rainbow trout habitat were mostly positive under all three scenarios, although significant changes were recorded predominantly under Black Rock_2 and WymerPlus (fig. 49). Significant increases occurred more frequently under Black Rock_2 than under WymerPlus, but this alternative also resulted in more significant decreases in rainbow trout habitat.

\section{Kittitas}

- Redd scour was generally reduced for all species at the Kittitas reach under all three scenarios (figs. 51-53). The most frequent and significant reductions affected reproductive habitat for spring chinook, coho, and bull trout, whereas habitat for steelhead and rainbow trout was less affected. Critical scour thresholds were never exceeded for any of the species under the baseline or any of the alternatives (Appendix figs. 4-11-4-13, 5-11-5-13, and 6-11-6-13).

- With the exceptions of steelhead and spring chinook under the WymerPlus alternative, spawning-incubation habitat was reduced slightly over the period of record for all species under all the three alternatives in the Kittitas reach (fig. 47). For spring chinook and coho, the number of years in which spawning-incubation habitat was significantly increased was approximately equaled by years when comparable reductions occurred under all three alternatives (fig. 51). The exception to this trend was for spring chinook under the WymerPlus alternative, where significant gains outnumbered losses by a considerable margin. Spawning-incubation habitat for steelhead was increased more often than decreased under all three scenarios, but increases of more than 10 percent occurred in only about 20 percent of the years (fig. 52). Resident rainbow trout and bull trout experienced frequent and significant reductions in spawning-incubation habitat under all three scenarios, the largest and most frequent of which were associated with Black Rock_2 (figs. 52 and 53).

- For the period of record, fry habitat was generally increased for spring chinook and coho and decreased for steelhead, resident rainbow trout, and bull trout under all three alternatives (fig. 47). Significant increases in fry habitat for spring chinook and coho were recorded for 5 years 


\begin{tabular}{|c|c|c|c|c|c|c|c|c|c|c|c|c|c|c|c|c|c|c|c|c|c|}
\hline \multirow[b]{2}{*}{ Year } & \multicolumn{3}{|c|}{ Redd Scour } & \multicolumn{3}{|c|}{ Spawning/incubation } & \multicolumn{3}{|c|}{ Fry } & \multicolumn{3}{|c|}{ Subyearling (Summer) } & \multicolumn{3}{|c|}{ Subyearling (winter) } & \multicolumn{3}{|c|}{ Subadult } & \multicolumn{3}{|c|}{ Adult holding } \\
\hline & BR_2 & WY_1 & WY+ & BR_2 & WY_1 & WY+ & BR_2 & WY_1 & WY+ & BR_2 & WY_1 & wY+ & BR_2 & WY_1 & wY+ & BR_2 & WY_1 & WY+ & BR_2 & WY_1 & WY+ \\
\hline 1982 & $-10.9 \%$ & $-10.9 \%$ & $-10.9 \%$ & $14.1 \%$ & $-22.0 \%$ & $18.7 \%$ & $2.7 \%$ & $0.7 \%$ & $2.4 \%$ & $-6.0 \%$ & $-4.5 \%$ & $-6.1 \%$ & $-14.2 \%$ & $-13.6 \%$ & $-13.5 \%$ & & & & $2.4 \%$ & $1.4 \%$ & $3.3 \%$ \\
\hline 1983 & $-4.6 \%$ & $-4.6 \%$ & $-4.6 \%$ & $-28.1 \%$ & $-17.5 \%$ & $-23.9 \%$ & $0.8 \%$ & $0.3 \%$ & $0.4 \%$ & $-1.2 \%$ & $-2.4 \%$ & $-3.6 \%$ & $-4.1 \%$ & $-5.2 \%$ & $-5.3 \%$ & & & & $1.8 \%$ & $1.6 \%$ & \\
\hline 1984 & $-11.9 \%$ & $-10.7 \%$ & $0.7 \%$ & $15.7 \%$ & $36.2 \%$ & $15.3 \%$ & $5.1 \%$ & $4.1 \%$ & $1.4 \%$ & $-6.8 \%$ & $-5.2 \%$ & $-5.6 \%$ & $-1.0 \%$ & $-3.9 \%$ & $-3.6 \%$ & & & & $0.9 \%$ & $2.1 \%$ & \\
\hline 35 & $-11.1 \%$ & $-11.1 \%$ & $-11.1 \%$ & $-1.4 \%$ & $-1.3 \%$ & $-1.3 \%$ & $6.7 \%$ & $5.6 \%$ & $4.1 \%$ & $-4.2 \%$ & $-2.0 \%$ & $-3.2 \%$ & $-8.8 \%$ & $-8.7 \%$ & $-8.8 \%$ & & & & $2.7 \%$ & $1.9 \%$ & 3.0 \\
\hline & $-12.3 \%$ & $-10.2 \%$ & $-11.1 \%$ & $-11.0 \%$ & $-9.8 \%$ & $-9.8 \%$ & $10.0 \%$ & $5.1 \%$ & $0.2 \%$ & $-5.5 \%$ & $-3.4 \%$ & $-4.4 \%$ & $-8.2 \%$ & $-9.5 \%$ & $-10.7 \%$ & & & & $4.0 \%$ & $1.8 \%$ & \\
\hline 1987 & $-16.4 \%$ & $-9.7 \%$ & $-16.4 \%$ & $-2.8 \%$ & $-2.1 \%$ & $-2.7 \%$ & $11.3 \%$ & $7.3 \%$ & $8.2 \%$ & $-2.5 \%$ & $-2.7 \%$ & $-2.5 \%$ & $-11.9 \%$ & $-9.3 \%$ & $-11.5 \%$ & & & & $4.4 \%$ & $2.8 \%$ & \\
\hline 1988 & $-15.4 \%$ & 7.4\% & $-2.0 \%$ & $13.5 \%$ & $-9.2 \%$ & $-8.2 \%$ & $13.4 \%$ & $15.7 \%$ & $15.6 \%$ & $7.2 \%$ & $-2.8 \%$ & $-1.3 \%$ & $-3.4 \%$ & $7.3 \%$ & $6.8 \%$ & & & & $8.4 \%$ & $2.0 \%$ & \\
\hline 1989 & $-13.9 \%$ & $1.1 \%$ & $-5.4 \%$ & $-13.6 \%$ & $3.1 \%$ & $2.6 \%$ & $9.9 \%$ & $5.1 \%$ & $4.9 \%$ & $-2.2 \%$ & $-3.1 \%$ & $-3.5 \%$ & $-0.8 \%$ & $-1.0 \%$ & $-1.2 \%$ & & & & $3.0 \%$ & $3.1 \%$ & 4.4 \\
\hline & $-11.0 \%$ & $1.2 \%$ & $-11.0 \%$ & $-5.3 \%$ & $14.3 \%$ & $13.9 \%$ & $4.7 \%$ & $2.1 \%$ & $2.6 \%$ & $-5.9 \%$ & $-4.1 \%$ & $-6.2 \%$ & $-3.6 \%$ & $-1.9 \%$ & $-3.7 \%$ & & & & $1.5 \%$ & $2.9 \%$ & \\
\hline 91 & $40.2 \%$ & $8.8 \%$ & $8.1 \%$ & $43.6 \%$ & $48.9 \%$ & $48.4 \%$ & $0.7 \%$ & $0.1 \%$ & $-1.0 \%$ & $-3.7 \%$ & $-1.4 \%$ & $-4.0 \%$ & $11.1 \%$ & $6.6 \%$ & $6.2 \%$ & & & & $2.6 \%$ & $2.1 \%$ & 3.7 \\
\hline 92 & $-6.7 \%$ & $-7.2 \%$ & $-7.2 \%$ & $15.0 \%$ & $15.3 \%$ & $15.3 \%$ & $15.1 \%$ & $9.2 \%$ & $6.9 \%$ & $-5.1 \%$ & $-3.2 \%$ & $-2.9 \%$ & $-3.6 \%$ & $-3.9 \%$ & $-4.2 \%$ & & & & $5.1 \%$ & $1.6 \%$ & \\
\hline & $-11.5 \%$ & $-1.1 \%$ & $-4.6 \%$ & $8.4 \%$ & $-1.1 \%$ & $-5.4 \%$ & $12.3 \%$ & $10.0 \%$ & $8.3 \%$ & $-0.9 \%$ & $-2.7 \%$ & $-2.3 \%$ & $-9.4 \%$ & $-4.0 \%$ & $-6.8 \%$ & & & & $6.0 \%$ & $4.8 \%$ & 4.0 \\
\hline & $-3.5 \%$ & $5.7 \%$ & $-0.6 \%$ & $-0.8 \%$ & $-9.5 \%$ & $-9.8 \%$ & $19.7 \%$ & $17.5 \%$ & $17.6 \%$ & $3.4 \%$ & $14.3 \%$ & $12.6 \%$ & $7.6 \%$ & $5.8 \%$ & $5.5 \%$ & & & & $-2.5 \%$ & $6.1 \%$ & \\
\hline 95 & $-1.2 \%$ & $7.5 \%$ & $0.0 \%$ & $-3.0 \%$ & $-36.7 \%$ & $-5.0 \%$ & $6.0 \%$ & $4.3 \%$ & $4.3 \%$ & $-1.1 \%$ & $-0.7 \%$ & $-0.5 \%$ & $1.4 \%$ & $1.6 \%$ & $0.9 \%$ & & & & $8.9 \%$ & $5.5 \%$ & \\
\hline & $7.6 \%$ & $-0.4 \%$ & $-0.2 \%$ & $-9.7 \%$ & $-4.0 \%$ & $-7.7 \%$ & $0.3 \%$ & $-0.6 \%$ & $-0.7 \%$ & $-1.9 \%$ & $-2.2 \%$ & $-3.8 \%$ & $7.3 \%$ & $2.0 \%$ & $2.8 \%$ & & & & $1.7 \%$ & $1.6 \%$ & 3.1 \\
\hline & $8.9 \%$ & $8.6 \%$ & $7.5 \%$ & $89.4 \%$ & $87.0 \%$ & $86.4 \%$ & $2.1 \%$ & $1.1 \%$ & $2.1 \%$ & $-1.9 \%$ & $-5.5 \%$ & $-2.4 \%$ & $-3.6 \%$ & $-4.4 \%$ & $-4.4 \%$ & & & & $5.4 \%$ & $3.5 \%$ & 5.6 \\
\hline & $-5.5 \%$ & $-4.3 \%$ & $-4.5 \%$ & $-28.0 \%$ & $5.0 \%$ & $4.3 \%$ & $1.9 \%$ & $2.1 \%$ & $1.8 \%$ & $-1.4 \%$ & $-1.8 \%$ & $-3.2 \%$ & $7.1 \%$ & $3.8 \%$ & $4.3 \%$ & & & & $3.3 \%$ & $2.4 \%$ & \\
\hline & $-10.1 \%$ & $-10.1 \%$ & $-10.1 \%$ & $-4.8 \%$ & $-4.0 \%$ & $-4.6 \%$ & $8.5 \%$ & $5.2 \%$ & $3.2 \%$ & $1.5 \%$ & $-0.8 \%$ & $0.9 \%$ & $0.7 \%$ & $-0.1 \%$ & $-0.8 \%$ & & & & $0.8 \%$ & $1.5 \%$ & 2.3 \\
\hline & $9.3 \%$ & $-9.4 \%$ & $-2.3 \%$ & $13.8 \%$ & $-13.2 \%$ & $33.0 \%$ & $3.0 \%$ & $2.0 \%$ & $0.6 \%$ & $-4.4 \%$ & $-2.1 \%$ & $-3.9 \%$ & $1.1 \%$ & $-0.6 \%$ & $0.6 \%$ & & & & $2.1 \%$ & $1.7 \%$ & 3.10 \\
\hline & $-10.5 \%$ & $-10.5 \%$ & $-10.5 \%$ & $16.4 \%$ & $16.3 \%$ & $16.3 \%$ & $9.7 \%$ & $5.4 \%$ & $5.1 \%$ & $7.7 \%$ & $5.0 \%$ & $4.7 \%$ & $-5.0 \%$ & $-6.4 \%$ & $-6.6 \%$ & & & & $2.5 \%$ & $6.0 \%$ & \\
\hline & $3.5 \%$ & $5.9 \%$ & $-2.0 \%$ & $-29.5 \%$ & $-17.3 \%$ & $-0.2 \%$ & $5.6 \%$ & $6.1 \%$ & $6.1 \%$ & $-4.1 \%$ & $-2.4 \%$ & $-5.4 \%$ & $-1.2 \%$ & $-1.0 \%$ & $-1.1 \%$ & & & & $1.0 \%$ & $0.1 \%$ & \\
\hline & $-6.5 \%$ & $-6.5 \%$ & $-6.5 \%$ & $-3.6 \%$ & $-3.5 \%$ & $-3.5 \%$ & $1.7 \%$ & $1.5 \%$ & $1.7 \%$ & $-4.9 \%$ & $-3.1 \%$ & $-4.7 \%$ & $-10.0 \%$ & $-9.7 \%$ & $-9.7 \%$ & & & & $3.6 \%$ & $1.4 \%$ & $2.8 \%$ \\
\hline
\end{tabular}

Coho

\begin{tabular}{|c|c|c|c|c|c|c|c|c|c|c|c|c|c|c|c|c|c|c|c|c|c|}
\hline \multirow[b]{2}{*}{ Year } & \multicolumn{3}{|c|}{ Redd Scour } & \multicolumn{3}{|c|}{ Spawning/incubation } & \multicolumn{3}{|c|}{ Fry } & \multicolumn{3}{|c|}{ Subyearling (Summer) } & \multicolumn{3}{|c|}{ Subyearling (winter) } & \multicolumn{3}{|c|}{ Subadult } & \multicolumn{3}{|c|}{ Adult holding } \\
\hline & BR_2 & WY_1 & WY+ & BR_2 & WY_1 & WY+ & BR_2 & WY_1 & wY+ & BR_2 & WY_1 & WY+ & BR_2 & WY_1 & WY+ & BR_2 & WY_1 & WY+ & BR_2 & WY_1 & WY+ \\
\hline 1982 & $-10.9 \%$ & $-10.9 \%$ & $-10.9 \%$ & $-13.3 \%$ & $-12.7 \%$ & $-12.7 \%$ & $3.3 \%$ & $0.4 \%$ & $3.2 \%$ & $-10.7 \%$ & $-7.9 \%$ & $-11.3 \%$ & $-11.7 \%$ & $-10.8 \%$ & $-11.1 \%$ & & & & & & \\
\hline 1983 & $-2.4 \%$ & $-2.3 \%$ & $-2.3 \%$ & $-21.3 \%$ & $-13.3 \%$ & $-18.1 \%$ & $0.3 \%$ & $0.0 \%$ & $0.0 \%$ & $-4.8 \%$ & $-4.4 \%$ & $-7.6 \%$ & $-2.4 \%$ & $-4.2 \%$ & $-4.4 \%$ & & & & & & \\
\hline 1984 & $-11.9 \%$ & $-10.7 \%$ & $0.7 \%$ & $1.1 \%$ & $13.7 \%$ & $0.9 \%$ & $3.4 \%$ & $2.8 \%$ & $-0.6 \%$ & $-12.2 \%$ & $-8.3 \%$ & $-12.4 \%$ & $-1.3 \%$ & $-2.6 \%$ & $-1.8 \%$ & & & & & & \\
\hline 1985 & $-11.1 \%$ & $-11.1 \%$ & $-11.1 \%$ & $-13.1 \%$ & $-12.4 \%$ & $-12.4 \%$ & $3.3 \%$ & $2.4 \%$ & $0.6 \%$ & $-9.5 \%$ & $-4.5 \%$ & $-6.4 \%$ & $-5.2 \%$ & $-4.9 \%$ & $-4.9 \%$ & & & & & & \\
\hline 1986 & $-12.4 \%$ & $-10.4 \%$ & $-11.2 \%$ & $-1.3 \%$ & $-0.3 \%$ & $-0.3 \%$ & $14.9 \%$ & $7.6 \%$ & $2.0 \%$ & $-10.6 \%$ & $-5.1 \%$ & $-7.5 \%$ & $-9.7 \%$ & $-9.2 \%$ & $-9.3 \%$ & & & & & & \\
\hline 1987 & $-9.5 \%$ & $-9.3 \%$ & $-9.5 \%$ & $-3.5 \%$ & $-2.7 \%$ & $-3.3 \%$ & $11.6 \%$ & $6.9 \%$ & $8.0 \%$ & $-8.3 \%$ & $-7.0 \%$ & $-5.3 \%$ & $-14.5 \%$ & $-11.8 \%$ & $-13.9 \%$ & & & & & & \\
\hline 1988 & $-6.3 \%$ & $4.1 \%$ & $-0.9 \%$ & $1.4 \%$ & $-6.9 \%$ & $-6.3 \%$ & $12.3 \%$ & $12.2 \%$ & $12.2 \%$ & $-1.3 \%$ & $-6.9 \%$ & $-5.2 \%$ & $-5.9 \%$ & $3.6 \%$ & $3.1 \%$ & & & & & & \\
\hline 1989 & $-2.4 \%$ & $-2.5 \%$ & $-2.4 \%$ & $-5.7 \%$ & $-2.0 \%$ & $-2.8 \%$ & $4.4 \%$ & $1.3 \%$ & $1.8 \%$ & $-8.2 \%$ & $-7.7 \%$ & $-8.1 \%$ & $0.1 \%$ & $-0.3 \%$ & $-0.5 \%$ & & & & & & \\
\hline 1990 & $-5.5 \%$ & $-5.4 \%$ & $-5.5 \%$ & $-7.7 \%$ & $-6.5 \%$ & $-3.6 \%$ & $1.5 \%$ & $-0.8 \%$ & $0.6 \%$ & $-15.2 \%$ & $-12.9 \%$ & $-14.4 \%$ & $-5.9 \%$ & $-2.8 \%$ & $-5.7 \%$ & & & & & & \\
\hline 1991 & $-3.1 \%$ & $-3.4 \%$ & $-2.8 \%$ & $31.8 \%$ & $38.1 \%$ & $37.4 \%$ & $-0.3 \%$ & $0.1 \%$ & $-1.4 \%$ & $-10.8 \%$ & $-4.2 \%$ & $-10.1 \%$ & $11.8 \%$ & $8.4 \%$ & $13.0 \%$ & & & & & & \\
\hline 1992 & $-7.2 \%$ & $-7.2 \%$ & $-7.2 \%$ & $-6.6 \%$ & $-6.2 \%$ & $-6.2 \%$ & $17.3 \%$ & $10.2 \%$ & 7.1\% & $-13.8 \%$ & $-7.7 \%$ & $-6.7 \%$ & $-7.5 \%$ & $-7.4 \%$ & $-7.3 \%$ & & & & & & \\
\hline 1993 & $-11.5 \%$ & $-1.1 \%$ & $-4.6 \%$ & $-5.0 \%$ & $-3.5 \%$ & $-20.7 \%$ & $18.4 \%$ & $15.0 \%$ & $12.7 \%$ & $-7.2 \%$ & $-7.4 \%$ & $-7.3 \%$ & $-13.2 \%$ & $-8.1 \%$ & $-9.7 \%$ & & & & & & \\
\hline 994 & $-1.7 \%$ & $3.8 \%$ & $-0.7 \%$ & $-13.7 \%$ & $-13.5 \%$ & $-13.7 \%$ & $30.2 \%$ & $19.7 \%$ & $19.6 \%$ & $2.7 \%$ & $9.8 \%$ & $8.9 \%$ & $-2.0 \%$ & $0.8 \%$ & $0.6 \%$ & & & & & & \\
\hline 995 & $-2.7 \%$ & $-2.7 \%$ & $-2.8 \%$ & $-2.1 \%$ & $-30.5 \%$ & $-3.6 \%$ & $8.1 \%$ & $5.6 \%$ & $5.6 \%$ & $-6.4 \%$ & $-0.1 \%$ & $-3.9 \%$ & $0.8 \%$ & $2.5 \%$ & $1.3 \%$ & & & & & & \\
\hline 9 & $7.6 \%$ & $-0.4 \%$ & $-0.2 \%$ & $-22.6 \%$ & $-9.3 \%$ & $-17.8 \%$ & $0.2 \%$ & $-0.3 \%$ & $-0.5 \%$ & $-7.3 \%$ & $-5.3 \%$ & $-9.3 \%$ & $5.9 \%$ & $3.3 \%$ & $5.6 \%$ & & & & & & \\
\hline 997 & $8.9 \%$ & $8.6 \%$ & $7.5 \%$ & $99.0 \%$ & $95.5 \%$ & $94.6 \%$ & $1.4 \%$ & $0.4 \%$ & $1.3 \%$ & $-9.4 \%$ & $-13.5 \%$ & $-12.8 \%$ & $-3.0 \%$ & $-3.8 \%$ & $-3.7 \%$ & & & & & & \\
\hline 1998 & $-6.5 \%$ & $-4.3 \%$ & $-4.5 \%$ & $10.0 \%$ & $20.2 \%$ & $16.0 \%$ & $-0.5 \%$ & $0.1 \%$ & $0.0 \%$ & $-5.8 \%$ & $-4.2 \%$ & $-7.0 \%$ & $14.3 \%$ & $8.9 \%$ & $10.7 \%$ & & & & & & \\
\hline 1999 & $-2.4 \%$ & $-2.3 \%$ & $-2.3 \%$ & $-8.0 \%$ & $-6.5 \%$ & $-7.5 \%$ & $-0.7 \%$ & $-1.5 \%$ & $-0.9 \%$ & $-2.7 \%$ & $-6.1 \%$ & $-3.8 \%$ & $-0.9 \%$ & $-1.2 \%$ & $-1.4 \%$ & & & & & & \\
\hline 2000 & $9.3 \%$ & $-11.2 \%$ & $-2.3 \%$ & $0.0 \%$ & $-9.9 \%$ & $11.8 \%$ & $-0.7 \%$ & $-0.2 \%$ & $-1.2 \%$ & $-10.1 \%$ & $-4.5 \%$ & $-9.4 \%$ & $3.2 \%$ & $0.1 \%$ & $0.2 \%$ & & & & & & \\
\hline & $-10.5 \%$ & $-10.5 \%$ & $-10.5 \%$ & $17.4 \%$ & $17.7 \%$ & $17.7 \%$ & $18.9 \%$ & $8.6 \%$ & $7.7 \%$ & $5.4 \%$ & $4.0 \%$ & $3.9 \%$ & $-10.3 \%$ & $-9.8 \%$ & $-9.8 \%$ & & & & & & \\
\hline & $-2.5 \%$ & $-2.7 \%$ & $-2.7 \%$ & $-18.3 \%$ & $-8.7 \%$ & $-0.4 \%$ & $0.2 \%$ & $0.5 \%$ & $0.5 \%$ & $-7.1 \%$ & $-6.2 \%$ & $-9.7 \%$ & $0.7 \%$ & 0.9 & & & & & & & \\
\hline & $-6.5 \%$ & $-6.5 \%$ & $-6.5 \%$ & $-6.2 \%$ & $-5.9 \%$ & $-5.9 \%$ & $-0.5 \%$ & $-0.6 \%$ & $-0.1 \%[$ & $-9.4 \%$ & $-4.9 \%$ & $-8.5 \%$ ] & $-8.4 \%$ & $-7.9 \%$ & $-8.0 \%$ & & & & & & \\
\hline
\end{tabular}

Figure 51. Annual habitat summaries for spring chinook and coho in the Kittitas reach, comparing the Black Rock_2 (BR_2), Wymer_1 (WY_1), and WymerPlus (WY+ ) scenarios relative to the baseline. 
Steelhead

\begin{tabular}{|c|c|c|c|c|c|c|c|c|c|c|c|c|c|c|c|c|c|c|c|c|c|}
\hline \multirow[b]{2}{*}{ Year } & \multicolumn{3}{|c|}{ Redd Scour } & \multicolumn{3}{|c|}{ Spawning/incubation } & \multicolumn{3}{|c|}{ Fry } & \multicolumn{3}{|c|}{ Subyearling (Summer) } & \multicolumn{3}{|c|}{ Subyearling (winter) } & \multicolumn{3}{|c|}{ Subadult } & \multicolumn{3}{|c|}{ Adult holding } \\
\hline & BR_2 & WY_1 & WY+ & BR_2 & WY_1 & wY+ & BR_2 & WY_1 & WY+ & BR_2 & WY_1 & WY+ & BR_2 & WY_1 & WY+ & BR_2 & WY_1 & wY+ & BR_2 & WY_1 & wY+ \\
\hline 198 & $-5.7 \%$ & $0.1 \%$ & $-2.6 \%$ & $-0.2 \%$ & $14.3 \%$ & $0.0 \%$ & $-4.4 \%$ & $-2.5 \%$ & $-4.5 \%$ & $26.5 \%$ & $-0.4 \%$ & $0.1 \%$ & $-15.1 \%$ & $-13.9 \%$ & $-14.3 \%$ & $-0.7 \%$ & $-0.5 \%$ & $-0.7 \%$ & $2.1 \%$ & $-3.4 \%$ & -3.45 \\
\hline 83 & $8.2 \%$ & $5 \%$ & $3.8 \%$ & $1.7 \%$ & $6 \%$ & $1.6 \%$ & $-3.9 \%$ & $-2.0 \%$ & $-3.1 \%$ & $20.3 \%$ & $-0.4 \%$ & $-2.8 \%$ & $-5.6 \%$ & $-6.1 \%$ & $-6.2 \%$ & $-0.2 \%$ & $-0.3 \%$ & $-0.4 \%$ & $-1.4 \%$ & $-2.8 \%$ & $-4.3 \%$ \\
\hline & $-6.1 \%$ & $-2.4 \%$ & $0.9 \%$ & $4.6 \%$ & & $4.5 \%$ & $-4.4 \%$ & $-3.1 \%$ & $-4.8 \%$ & $24.6 \%$ & $-2.0 \%$ & $1.5 \%$ & $-2.9 \%$ & $-4.1 \%$ & $-3.3 \%$ & $-0.9 \%$ & $-0.5 \%$ & $-0.5 \%$ & $-1.8 \%$ & $-3.3 \%$ & $-3.5 \%$ \\
\hline & $-7.6 \%$ & & & -1.6 & & & & & 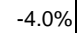 & & & & 70 & & & & & & & & \\
\hline & -2.50 & & & 14. & & 14.5 & -4 & -3 & -3.8 & & -2 & $1.7 \%$ & $-11.1 \%$ & $-11.9 \%$ & $-12.0^{\circ}-x-3 x-3$ & -0 & $\%$ & $-0.6 \%$ & & & \\
\hline & $-7.4 \%$ & $-2.4 \%$ & $-3.2 \%$ & & & $10.9 \%$ & $-2.1 \%$ & $-1.7 \%$ & $-1.5 \%$ & & $-3.4 \%$ & $-3.7 \%$ & $-15.1 \%$ & $-11.9 \%$ & $-14.4 \%$ & $0.2 \%$ & $-0.2 \%$ & $-0.3 \%$ & $-1.6 \%$ & $-5.5 \%$ & -5 \\
\hline & $-1.7 \%$ & -6.4 & $-6.6 \%$ & & & & & & & & & $4.1 \%$ & $-8.0 \%$ & & $3.1 \%$ & & & & & & \\
\hline & -7.4 & & & & & & & & & & & & & & & & & & & & \\
\hline & $-3.2 \%$ & & 2. & & & 4. & -4 & -3.1 & -4.9 & & & $6.5 \%$ & $-4.2 \%$ & -2 & $-4.1 \%$ & -0.7 & $-0.6 \%$ & $-0.8 \%$ & -3. & $-5.5 \%$ & -5. \\
\hline & $5.6 \%$ & & & -14.2 & & & & -1. & -3. & & -0 . & $2.6 \%$ & $8.4 \%$ & & $9.6 \%$ & -0. & & $-0.5 \%$ & & & \\
\hline & $-4.3 \%$ & & & & & & & & & & & & & & & & & & & & \\
\hline & $-7.9 \%$ & & -4 & & & -2 & -1. & -2 & & & & $9.8 \%$ & -14 & & -10.4 & & & & & & \\
\hline & $-13.4 \%$ & & -7 & & & $-4.4 \%$ & -8. & -1. & -4 & & & $13.5 \%$ & -1 & & $1.4 \%$ & 0.0 & $16.2 \%$ & $14.4 \%$ & 1. & $\%$ & -3. \\
\hline & $9.6 \%$ & & 11 & & & & -8 . & -4 & & & & & & & & $1.5 \%$ & & & & & \\
\hline & $-2.5 \%$ & 10. & & -2 & & & & -2.1 & & & & & & & & . & & -0 & & & \\
\hline & $4.4 \%$ & & & & & & & -4 & & & & & -4 & & & -0. & & & & & \\
\hline & 6.2 & & & 11 & & & & & & & & 10. & & & & -0.4 & & $-0.5 \%$ & & & \\
\hline & $2.5 \%$ & & 5.0 & & & & -1 & $-1.3 \%$ & -2 & & 0. & & & & 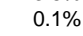 & 0.2 & & $0.2 \%$ & -6 & -7 & -5 . \\
\hline & $0.6 \%$ & & & & & & -3 & -1.6 & & & & & & & -0. & & & & & & \\
\hline & -5.1 & & & & & & & & & & & $16.7 \%$ & -10 & -10 & -11. & & & & & & \\
\hline & $-3.4 \%$ & 6. & $-1.2 \%$ & -8.7 & 0. & 5. & $-3.6 \%$ & $-1.7 \%$ & $-4.4 \%$ & 25. & -0.7 & $0.4^{\circ}$ & -0 . & -0. & $-0.6^{\circ}$ & -0.49 & $-0.1 \%$ & $-0.5 \%$ & $-2.4 \%$ & $-7.3 \%$ & -7 . \\
\hline & $-3.0 \%$ & $-0.2 \%$ & $-2.3 \%$ & $1.7 \%$ & $1.6 \%$ & $1.6 \%$ & $-4.2 \%$ & $-2.8 \%$ & $-3.7 \%$ & $31.4 \%$ & $-0.8 \%$ & $5.7 \%$ & $-8.9 \%$ & $-8.4 \%$ & $-8.4 \%$ & $-0.8 \%$ & $-0.5 \%$ & $-0.7 \%$ & $1.5 \%$ & $-4.0 \%$ & \\
\hline
\end{tabular}

Resident Rainbow

\begin{tabular}{|c|c|c|c|c|c|c|c|c|c|c|c|c|c|c|c|c|c|c|c|c|}
\hline \multicolumn{3}{|c|}{ Redd Scour } & \multicolumn{3}{|c|}{ Spawning/incubation } & \multicolumn{3}{|c|}{ Fry } & \multicolumn{3}{|c|}{ Subyearling (Summer) } & \multicolumn{3}{|c|}{ Subyearling (winter) } & \multicolumn{3}{|c|}{ Subadult } & \multicolumn{3}{|c|}{ Adult holding } \\
\hline BR_2 & WY_1 & WY+ & BR_2 & WY_1 & wY+ & BR_2 & WY_1 & wY+ & BR_2 & WY_1 & WY+ & BR_2 & WY_1 & wY+ & BR_2 & WY_1 & WY+ & BR_2 & WY_1 & WY+ \\
\hline $0.7 \%$ & $1.0 \%$ & $4.0 \%$ & \begin{tabular}{ll|}
$14.1 \%$ \\
\end{tabular} & $-27.6 \%$ & $20.2 \%$ & $-5.0 \%$ & $-2.8 \%$ & $-5.1 \%$ & $26.1 \%$ & $-0.4 \%$ & $0.1 \%$ & $-12.9 \%$ & $-11.9 \%$ & $-12.2^{\circ}$ & $-5.3 \%$ & $-3.5 \%$ & $-6.0 \%$ & & & \\
\hline $8.2 \%$ & $3.5 \%$ & $3.8 \%$ & $-34.8 \%$ & $-21.7 \%$ & $-29.7 \%$ & $-4.0 \%$ & $-2.2 \%$ & $-3.4 \%$ & $20.0 \%$ & $-0.4 \%$ & $-2.7 \%$ & $-5.3 \%$ & $-5.6 \%$ & $-5.6 \%$ & $-0.5 \%$ & $-1.0 \%$ & $-2.7 \%$ & & & \\
\hline$-6.1 \%$ & $-2.4 \%$ & $0.9 \%$ & $12.3 \%$ & $38.9 \%$ & $11.8 \%$ & $-5.0 \%$ & $-3.5 \%$ & $-5.4 \%$ & $24.2 \%$ & $-2.0 \%$ & $1.4 \%$ & $-2.7 \%$ & $-3.7 \%$ & $-3.0 \%$ & $-7.5 \%$ & $-4.8 \%$ & $-6.6 \%$ & & & \\
\hline$-8.2 \%$ & $0.0 \%$ & $-0.1 \%$ & $-6.0 \%$ & $-5.6 \%$ & $-5.6 \%$ & $-5.7 \%$ & $-3.1 \%$ & $-4.5 \%$ & $36.4 \%$ & $4.4 \%$ & $9.4 \%$ & $-7.0 \%$ & $-6.9 \%$ & $-6.9 \%$ & $-5.0 \%$ & $-3.2 \%$ & $-3.8 \%$ & & & \\
\hline$-2.5 \%$ & $0.3 \%$ & $0.3 \%$ & $-15.5 \%$ & $-14.0 \%$ & $-14.0 \%$ & $-5.4 \%$ & $-3.7 \%$ & $-4.4 \%$ & $33.5 \%$ & $-2.1 \%$ & $1.7 \%$ & $-9.2 \%$ & $-10.2 \%$ & $-10.4 \%$ & $-8.8 \%$ & $-5.1 \%$ & $-6.0 \%$ & & & \\
\hline$-8.4 \%$ & $-2.4 \%$ & $-3.2 \%$ & $-11.1 \%$ & $-8.8 \%$ & $-10.6 \%$ & $-2.3 \%$ & $-2.0 \%$ & $-1.7 \%$ & $15.6 \%$ & $-3.4 \%$ & $-3.7 \%$ & $-12.6 \%$ & $-10.1 \%$ & $-12.1 \%$ & $-4.4 \%$ & $-3.6 \%$ & $-2.9 \%$ & & & \\
\hline$-1.7 \%$ & $-6.4 \%$ & $-6.6 \%$ & $0.0 \%$ & $-14.3 \%$ & $-15.3 \%$ & $-1.5 \%$ & $-2.1 \%$ & $-1.7 \%$ & $24.7 \%$ & $3.1 \%$ & $4.1 \%$ & $-7.6 \%$ & $3.8 \%$ & $3.1 \%$ & $-0.4 \%$ & $-4.6 \%$ & $-3.6 \%$ & & & \\
\hline$-7.4 \%$ & $0.4 \%$ & $0.4 \%$ & $-19.3 \%$ & $-2.1 \%$ & $-3.0 \%$ & $-3.2 \%$ & $-2.7 \%$ & $-2.7 \%$ & $36.2 \%$ & $-1.1 \%$ & $-3.0 \%$ & $-1.1 \%$ & $-1.1 \%$ & $-1.2 \%$ & $-3.3 \%$ & $-3.8 \%$ & $-2.7 \%$ & & & \\
\hline$-3.2 \%$ & $3.5 \%$ & $2.5 \%$ & $-14.6 \%$ & $10.4 \%$ & $10.2 \%$ & $-5.3 \%$ & $-3.6 \%$ & $-5.5 \%$ & $32.5 \%$ & $4.8 \%$ & $6.4 \%$ & $-3.2 \%$ & $-1.9 \%$ & $-3.1 \%$ & $-4.0 \%$ & $-4.6 \%$ & $-4.7 \%$ & & & \\
\hline $6.9 \%$ & $-1.2 \%$ & $1.7 \%$ & $60.6 \%$ & $69.6 \%$ & $68.7 \%$ & $-4.7 \%$ & $-1.5 \%$ & $-4.2 \%$ & $31.5 \%$ & $-0.6 \%$ & $2.6 \%$ & $6.9 \%$ & $5.0 \%$ & $8.1 \%$ & $-5.7 \%$ & $-3.0 \%$ & $-5.4 \%$ & & & \\
\hline$-7.1 \%$ & $-3.0 \%$ & $-2.2 \%$ & $10.8 \%$ & $10.9 \%$ & $10.9 \%$ & $-4.0 \%$ & $-2.9 \%$ & $-2.0 \%$ & $30.1 \%$ & $-3.3 \%$ & $-8.4 \%$ & $-3.3 \%$ & $-3.4 \%$ & $-3.6 \%$ & $-4.9 \%$ & $-2.7 \%$ & $-2.2 \%$ & & & \\
\hline$-7.9 \%$ & $-6.1 \%$ & $-4.8 \%$ & $0.0 \%$ & $-1.9 \%$ & $-13.9 \%$ & $-2.0 \%$ & $-3.0 \%$ & $-2.0 \%$ & $28.5 \%$ & $15.9 \%$ & $9.6 \%$ & $-11.6 \%$ & $-6.7 \%$ & $-8.7 \%$ & $-4.8 \%$ & $-4.9 \%$ & $-4.3 \%$ & & & \\
\hline$-15.3 \%$ & $-6.7 \%$ & $-7.0 \%$ & $-13.0 \%$ & $-15.3 \%$ & $-15.5 \%$ & $-6.7 \%$ & $-0.2 \%$ & $-2.8 \%$ & $40.0 \%$ & $8.3 \%$ & $13.2 \%$ & $-1.5 \%$ & $1.7 \%$ & $1.5 \%$ & $0.6 \%$ & $11.2 \%$ & $9.6 \%$ & & & \\
\hline $11.8 \%$ & $10.5 \%$ & $13.7 \%$ & $-3.6 \%$ & $-42.4 \%$ & $-6.1 \%$ & $-7.8 \%$ & $-4.5 \%$ & $-5.1 \%$ & $22.1 \%$ & $0.1 \%$ & $1.2 \%$ & $-0.3 \%$ & $-0.5 \%$ & $-0.9 \%$ & $-3.5 \%$ & $-0.1 \%$ & $-1.8 \%$ & & & \\
\hline$-1.9 \%$ & $-1.7 \%$ & $-0.2 \%$ & $-19.2 \%$ & $-7.9 \%$ & $-15.2 \%$ & $-3.2 \%$ & $-2.4 \%$ & $-3.8 \%$ & $21.5 \%$ & $-0.3 \%$ & $1.0 \%$ & $3.7 \%$ & $1.7 \%$ & $3.6 \%$ & $-1.1 \%$ & $-2.7 \%$ & $-3.6 \%$ & & & \\
\hline $4.0 \%$ & $0.6 \%$ & $6.6 \%$ & $145.5 \%$ & $140.6 \%$ & $139.3 \%$ & $-4.3 \%$ & $-5.1 \%$ & $-2.5 \%$ & $24.2 \%$ & $0.4 \%$ & $-9.5 \%$ & $-4.7 \%$ & $-5.1 \%$ & $-5.1 \%$ & $-5.0 \%$ & $-7.4 \%$ & $-4.4 \%$ & & & \\
\hline $6.5 \%$ & $3.8 \%$ & $9.2 \%$ & $-35.0 \%$ & $3.9 \%$ & $2.7 \%$ & $-4.0 \%$ & $-2.1 \%$ & $-3.6 \%$ & $37.9 \%$ & $8.4 \%$ & $10.3 \%$ & $3.8 \%$ & $2.1 \%$ & $2.3 \%$ & $-2.5 \%$ & $-1.4 \%$ & $-2.9 \%$ & & & \\
\hline $2.5 \%$ & $6.6 \%$ & $5.0 \%$ & $-10.4 \%$ & $-8.7 \%$ & $-9.9 \%$ & $-1.5 \%$ & $-1.6 \%$ & $-2.0 \%$ & $25.4 \%$ & $0.8 \%$ & $3.4 \%$ & $0.6 \%$ & $0.4 \%$ & $0.0 \%$ & $-0.1 \%$ & $-3.2 \%$ & $-0.5 \%$ & & & \\
\hline $8.2 \%$ & $-0.3 \%$ & $1.9 \%$ & $10.0 \%$ & $-19.2 \%$ & $35.2 \%$ & $-4.1 \%$ & $-1.8 \%$ & $-3.0 \%$ & $28.0 \%$ & $4.4 \%$ & $6.3 \%$ & $-0.8 \%$ & $-0.4 \%$ & $-0.2 \%$ & $-4.8 \%$ & $-2.4 \%$ & $-3.7 \%$ & & & \\
\hline$-9.9 \%$ & $-2.7 \%$ & $-2.8 \%$ & $15.6 \%$ & $15.7 \%$ & $15.7 \%$ & $2.2 \%$ & $3.9 \%$ & $1.7 \%$ & $41.6 \%$ & $3.3 \%$ & $16.4 \%$ & $-9.0 \%$ & $-9.5 \%$ & $-9.6 \%$ & $3.4 \%$ & $3.9 \%$ & $3.6 \%$ & & & \\
\hline$-3.4 \%$ & $6.7 \%$ & $-1.2 \%$ & $-37.6 \%$ & $-24.8 \%$ & $-3.5 \%$ & $-4.1 \%$ & $-2.0 \%$ & $-4.9 \%$ & $25.2 \%$ & $-0.7 \%$ & $0.4 \%$ & $-0.6 \%$ & $-0.6 \%$ & $-0.6 \%$ & $-1.8 \%$ & $-1.0 \%$ & $-3.0 \%$ & & & \\
\hline$-3.0 \%$ & $-0.2 \%$ & $-2.3 \%$ & $-7.3 \%$ & $-7.0 \%$ & $-7.0 \%$ & $-4.8 \%$ & $-3.2 \%$ & $-4.3 \%$ & $30.9 \%$ & $-0.8 \%$ & $5.6 \%$ & $-7.5 \%$ & $-7.1 \%$ & $-7.2 \%$ & $-4.8 \%$ & $-4.1 \%$ & $-4.7 \%$ | & & & \\
\hline
\end{tabular}

Figure 52. Annual habitat summaries for steelhead and resident rainbow trout in the Kittitas reach, comparing the Black Rock_2 (BR_2), Wymer_1 (WY_1), and WymerPlus (WY+ ) scenarios relative to the baseline. 


\begin{tabular}{|c|c|c|c|c|c|c|c|c|c|c|c|c|c|c|c|c|c|c|c|c|c|}
\hline \multirow[b]{2}{*}{ Year } & \multicolumn{3}{|c|}{ Redd Scour } & \multicolumn{3}{|c|}{ Spawning/incubation } & \multicolumn{3}{|c|}{ Fry } & \multicolumn{3}{|c|}{ Subyearling (Summer) } & \multicolumn{3}{|c|}{ Subyearling (winter) } & \multicolumn{3}{|c|}{ Subadult } & \multicolumn{3}{|c|}{ Adult holding } \\
\hline & BR_2 & WY_1 & WY+ & BR_2 & WY_1 & wY+ & BR_2 & WY_1 & wY+ & BR_2 & WY_1 & wY+ & BR_2 & WY_1 & wY+ & BR_2 & WY_1 & wY+ & BR_2 & WY_1 & WY+ \\
\hline 1982 & $-10.9 \%$ & $-10.9 \%$ & $-10.9 \%$ & $-19.2 \%$ & $-17.9 \%$ & $-18.5 \%$ & $-4.1 \%$ & $-3.9 \%$ & $-4.0 \%$ & $-4.5 \%$ & $-3.4 \%$ & $-4.6 \%$ & $-11.8 \%$ & $-11.1 \%$ & $-11.2 \%$ & & & & & & \\
\hline 1983 & $-4.6 \%$ & $-4.6 \%$ & $-4.6 \%$ & $-27.7 \%$ & $-17.3 \%$ & $-23.6 \%$ & $-1.0 \%$ & $-1.0 \%$ & $-1.0 \%$ & $-0.9 \%$ & $-1.9 \%$ & $-2.6 \%$ & $-2.6 \%$ & $-3.9 \%$ & $-4.1 \%$ & & & & & & \\
\hline 1984 & $-11.9 \%$ & $-10.7 \%$ & $0.7 \%$ & $0.8 \%$ & $18.3 \%$ & $0.4 \%$ & $-1.6 \%$ & $-1.6 \%$ & $-1.6 \%$ & $-5.0 \%$ & $-3.9 \%$ & $-3.9 \%$ & $-0.2 \%$ & $-3.0 \%$ & $-2.6 \%$ & & & & & & \\
\hline 1985 & $-11.1 \%$ & $-11.1 \%$ & $-11.1 \%$ & $-18.1 \%$ & $-17.1 \%$ & $-17.1 \%$ & $-1.5 \%$ & $-1.6 \%$ & $-1.6 \%$ & $-3.1 \%$ & $-1.4 \%$ & $-2.4 \%$ & $-7.1 \%$ & $-6.8 \%$ & $-6.8 \%$ & & & & & & \\
\hline 1986 & $-12.3 \%$ & $-10.2 \%$ & $-11.1 \%$ & $-2.6 \%$ & $-1.2 \%$ & $-1.2 \%$ & $-2.5 \%$ & $-2.2 \%$ & $-2.2 \%$ & $-4.0 \%$ & $-2.5 \%$ & $-3.2 \%$ & $-7.9 \%$ & $-8.1 \%$ & $-8.5 \%$ & & & & & & \\
\hline 1987 & $-10.1 \%$ & $-9.9 \%$ & $-10.2 \%$ & $0.9 \%$ & $-6.0 \%$ & $1.2 \%$ & $-14.6 \%$ & $-12.2 \%$ & $-14.1 \%$ & $-1.3 \%$ & $-1.8 \%$ & $-1.7 \%$ & $-11.6 \%$ & $-9.1 \%$ & $-11.0 \%$ & & & & & & \\
\hline 1988 & $-9.4 \%$ & $5.1 \%$ & $-1.3 \%$ & $-10.2 \%$ & $-5.6 \%$ & $-4.7 \%$ & $-19.0 \%$ & $0.8 \%$ & $-1.9 \%$ & $7.8 \%$ & $-1.8 \%$ & $-0.3 \%$ & $-3.9 \%$ & $6.3 \%$ & $5.8 \%$ & & & & & & \\
\hline 1 & $-9.2 \%$ & $-8.9 \%$ & $-9.1 \%$ & $-0.4 \%$ & $-7.1 \%$ & $-8.3 \%$ & $-0.4 \%$ & $-0.6 \%$ & $-0.6 \%$ & $-1.3 \%$ & $-2.3 \%$ & $-2.6 \%$ & $-1.4 \%$ & $-1.7 \%$ & $-1.9 \%$ & & & & & & \\
\hline 1990 & $-11.0 \%$ & $1.2 \%$ & $-11.0 \%$ & $-20.9 \%$ & $-20.1 \%$ & $-13.0 \%$ & $-2.0 \%$ & $-2.0 \%$ & $-2.1 \%$ & $-4.2 \%$ & $-3.0 \%$ & $-4.6 \%$ & $-4.5 \%$ & $-1.9 \%$ & $-4.4 \%$ & & & & & & \\
\hline 1991 & $40.2 \%$ & $8.8 \%$ & $8.1 \%$ & $26.4 \%$ & $31.7 \%$ & $31.2 \%$ & $1.1 \%$ & $1.1 \%$ & $1.3 \%$ & $-2.5 \%$ & $-1.0 \%$ & $-2.9 \%$ & $9.5 \%$ & $6.5 \%$ & $6.2 \%$ & & & & & & \\
\hline 1992 & $-7.2 \%$ & $-7.2 \%$ & $-7.2 \%$ & $-20.5 \%$ & $-19.8 \%$ & $-19.8 \%$ & $-4.1 \%$ & $-4.1 \%$ & $-4.1 \%$ & $-3.6 \%$ & $-2.2 \%$ & $-2.1 \%$ & $-4.2 \%$ & $-4.2 \%$ & $-4.4 \%$ & & & & & & \\
\hline 93 & $-11.5 \%$ & $-1.1 \%$ & $-4.6 \%$ & $-5.8 \%$ & $-0.7 \%$ & $-18.9 \%$ & $-14.1 \%$ & $-10.4 \%$ & $-12.8 \%$ & $0.3 \%$ & $-1.7 \%$ & $-1.3 \%$ & $-9.6 \%$ & $-4.3 \%$ & $-6.4 \%$ & & & & & & \\
\hline 1994 & $-2.3 \%$ & $4.9 \%$ & $-0.5 \%$ & $-22.2 \%$ & $-21.1 \%$ & $-21.2 \%$ & $-10.2 \%$ & $-0.5 \%$ & $-1.3 \%$ & $3.1 \%$ & $13.7 \%$ & $12.1 \%$ & $4.7 \%$ & $4.8 \%$ & $4.6 \%$ & & & & & & \\
\hline 1995 & $-5.2 \%$ & $-4.6 \%$ & $-4.8 \%$ & $-2.8 \%$ & $-31.7 \%$ & $-4.7 \%$ & $-7.4 \%$ & $-6.9 \%$ & $-6.8 \%$ & $0.3 \%$ & $-0.2 \%$ & $0.6 \%$ & $1.9 \%$ & $2.6 \%$ & $1.1 \%$ & & & & & & \\
\hline 1996 & $7.6 \%$ & $-0.4 \%$ & $-0.2 \%$ & $-15.5 \%$ & $-6.4 \%$ & $-12.2 \%$ & $1.0 \%$ & $1.2 \%$ & $1.2 \%$ & $-0.9 \%$ & $-1.6 \%$ & $-2.6 \%$ & $5.6 \%$ & $2.0 \%$ & $2.3 \%$ & & & & & & \\
\hline 97 & $8.9 \%$ & $8.6 \%$ & $7.5 \%$ & $62.6 \%$ & $60.4 \%$ & $59.8 \%$ & $0.5 \%$ & $0.5 \%$ & $0.5 \%$ & $-1.0 \%$ & $-3.9 \%$ & $-0.9 \%$ & $-2.8 \%$ & $-3.4 \%$ & $-3.4 \%$ & & & & & & \\
\hline 1998 & $-6.5 \%$ & $-4.3 \%$ & $-4.5 \%$ & $7.5 \%$ & $11.7 \%$ & $5.9 \%$ & $9.0 \%$ & $8.1 \%$ & $9.0 \%$ & $-0.9 \%$ & $-1.4 \%$ & $-2.4 \%$ & $9.0 \%$ & $5.5 \%$ & $6.1 \%$ & & & & & & \\
\hline 1999 & $-10.1 \%$ & $-10.1 \%$ & $-10.1 \%$ & $-12.6 \%$ & $-19.3 \%$ & $-16.2 \%$ & $-0.7 \%$ & $-0.8 \%$ & $-0.8 \%$ & $1.7 \%$ & $-0.1 \%$ & $1.2 \%$ & $0.1 \%$ & $-0.7 \%$ & $-1.0 \%$ & & & & & & \\
\hline & $9.3 \%$ & $-11.2 \%$ & $-2.3 \%$ & $-0.8 \%$ & $-13.7 \%$ & $15.7 \%$ & $-1.2 \%$ & $-0.2 \%$ & $-0.2 \%$ & $-3.2 \%$ & $-1.6 \%$ & $-2.8 \%$ & $2.7 \%$ & $0.1 \%$ & $1.3 \%$ & & & & & & \\
\hline 001 & $-10.5 \%$ & $-10.5 \%$ & $-10.5 \%$ & $7.4 \%$ & $8.1 \%$ & $8.1 \%$ & $-2.8 \%$ & $-2.7 \%$ & $-2.7 \%$ & $7.7 \%$ & $5.0 \%$ & $4.6 \%$ & $-6.3 \%$ & $-6.6 \%$ & -6.70 & & & & & & \\
\hline 2002 & $-3.3 \%$ & $-3.4 \%$ & $-3.6 \%$ & $-11.0 \%$ & $-5.1 \%$ & $-4.9 \%$ & $-0.6 \%$ & $-0.6 \%$ & $-0.7 \%$ & $-3.1 \%$ & $-1.6 \%$ & $-4.1 \%$ & $-0.6 \%$ & $-0.4 \%$ & $-0.5 \%$ & & & & & & \\
\hline & $-6.5 \%$ & $-6.5 \%$ & $-6.5 \%$ & $-12.8 \%$ & $-12.1 \%$ & $-12.1 \%$ & $-4.0 \%$ & $-3.7 \%$ & $-3.7 \%$ & $-3.4 \%$ & $-2.4 \%$ & $-3.4 \%$ & $-8.6 \%$ & $-8.1 \%$ & $-8.1 \%$ & & & & & & \\
\hline
\end{tabular}

Figure 53. Annual habitat summary for bull trout in the Kittitas reach, comparing the Black Rock_2 (BR_2), Wymer_1 (WY_1), and WymerPlus (WY+ ) scenarios relative to the baseline. 
and 7 years, respectively, under the Black Rock_2 scenario, and 2 and 5 years, respectively, under the two Wymer alternatives (fig. 51). Reductions in fry habitat for these two species were small and infrequent. In contrast, small reductions in fry habitat for steelhead and resident rainbow occurred nearly every year with all three scenarios (fig. 52). Similar reductions were observed for bull trout, with several exceeding the 10-percent significance threshold (fig. 53).

- The annual statistics for summer subyearling habitat (figs. 51-53) demonstrated a dichotomy of effects among the target species. For spring chinook, coho, and bull trout, this habitat type was reduced in nearly every year under all three scenarios, with the largest and most frequent reductions affecting coho (fig. 51). In contrast, the Black Rock_2 alternative resulted in significant increases for steelhead and rainbow trout every year (fig. 52). Such increases were also recorded for the Wymer_1 and WymerPlus alternatives, but neither produced as many large increases as Black Rock_2.

- Overwinter habitat for subyearlings of all species was reduced by 2 to 7 percent over the period of record under all of the alternatives (fig. 47). This habitat type was generally reduced in a large majority of years for all species, but significant reductions occurred most frequently under the Black Rock_2 alternative and least under Wymer_1 (figs. 51-53).

- Habitat for subadult steelhead and resident rainbow trout was decreased in most years under all of the alternatives, but virtually all of the changes were insignificant (fig. 52).

\section{Naches}

- Figure 47 indicates that redd scour significantly increased in the Naches reach under the Black Rock_2 and WymerPlus alternatives during the spawning-incubation hydroperiods for spring chinook and bull trout. Other metrics in figure 47 indicate little or no effect by any of the alternatives on redd scour for the remaining target species. In both cases, the results shown for the period of record in figure 47 may be misleading. In the case of spring chinook and bull trout, the average used in the scoring device was skewed by a single event that caused a sixfold increase in scour depth. In most of the other years, scour depth was actually reduced (figs. 5456). Figure 47 also indicates that redd scour was not appreciably increased for other species under either of the Wymer alternatives, with the exception of spring chinook under WymerPlus. For the period of record, these results are correct in that the average amount of redd scour was the same or nearly the same in all cases besides the exception noted above. On an annual basis, however, redd scour was frequently increased by more than 10 percent under both Wymer alternatives (figs. 54-56). This apparent discrepancy resulted from the use of the average of all the annual redd scour values in the "whole-period" summary and demonstrated the potential for erroneous conclusions that might be drawn by examining the "whole-period" summary alone. The more relevant changes in redd scour are contained in the annual summaries (figs. 54-56), which indicate that redd scour was frequently and significantly reduced for all species under the Black Rock_2 alternative but significantly increased under the Wymer_1 and WymerPlus alternatives. For spring chinook and coho, critical scour thresholds were rarely exceeded under any of the alternatives (Appendix figs. 4-14, 5-14, and 6-14). In contrast, critical scour thresholds for steelhead, resident rainbow trout, and bull trout were exceeded regularly under the baseline and all three scenarios. In two cases (steelhead and resident rainbow trout in 1987, Wymer_1), critical thresholds were exceeded under the alternatives where they had not been exceeded under the baseline (Appendix fig. 5-15).

- For the period of record, spawning-incubation persistence was significantly increased for coho, resident rainbow trout, and bull trout, and nearly significantly for steelhead under the Black Rock_2 alternative. Significant decreases in this habitat type were recorded for all species under 


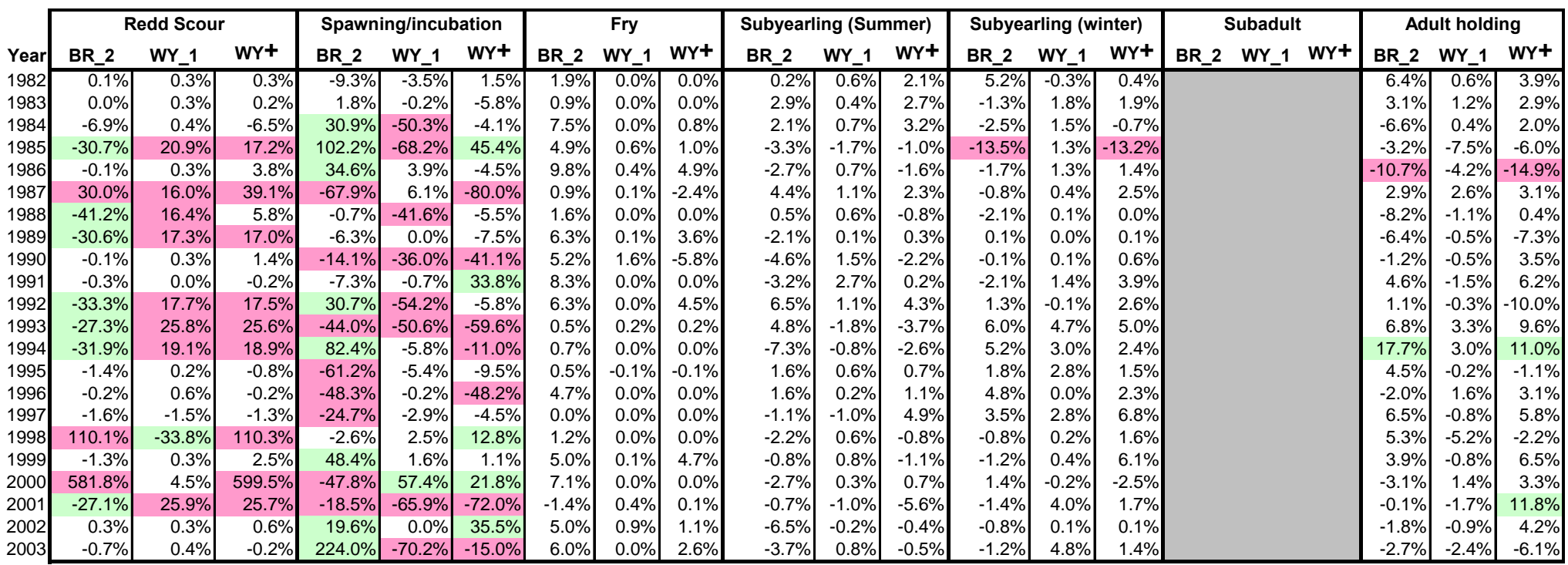

Coho

\begin{tabular}{|c|c|c|c|c|c|c|c|c|c|c|c|c|c|c|c|c|c|c|c|}
\hline \multirow[b]{2}{*}{ Year } & \multicolumn{3}{|c|}{ Redd Scour } & \multicolumn{3}{|c|}{ Spawning/incubation } & \multicolumn{3}{|c|}{ Fry } & \multicolumn{3}{|c|}{ Subyearling (Summer) } & \multicolumn{3}{|c|}{ Subyearling (winter) } & Subadult & \multicolumn{3}{|c|}{ Adult holding } \\
\hline & BR_2 & WY_1 & WY+ & BR_2 & WY_1 & wY+ & BR_2 & WY_1 & wY+ & BR_2 & WY_1 & WY+ & BR_2 & WY_1 & wYt & BR_2 WY_1 WY+ & BR_2 & WY_1 & wY+ \\
\hline 1982 & $0.1 \%$ & $0.3 \%$ & $0.3 \%$ & $-11.7 \%$ & $-4.3 \%$ & $1.9 \%$ & $3.1 \%$ & $0.0 \%$ & $0.0 \%$ & $-12.7 \%$ & $0.0 \%$ & $\begin{array}{l}-7.5 \% \\
\end{array}$ & $2.6 \%$ & \begin{tabular}{|c|c|}
$-0.1 \%$ \\
\end{tabular} & $1.1 \%$ & & & & \\
\hline 1983 & $0.0 \%$ & $0.3 \%$ & $0.2 \%$ & $411.7 \%$ & $-0.3 \%$ & $-8.3 \%$ & $1.4 \%$ & $0.0 \%$ & $0.0 \%$ & $-12.8 \%$ & $2.1 \%$ & $-6.6 \%$ & $0.7 \%$ & $1.5 \%$ & $3.8 \%$ & & & & \\
\hline 1984 & $-6.9 \%$ & $0.4 \%$ & $-6.5 \%$ & $187.8 \%$ & $-73.0 \%$ & $-5.9 \%$ & $9.9 \%$ & $0.0 \%$ & $0.0 \%$ & $-11.7 \%$ & $-0.4 \%$ & $-5.6 \%$ & $-1.8 \%$ & $2.1 \%$ & $2.4 \%$ & & & & \\
\hline 1985 & $-30.3 \%$ & $26.3 \%$ & $18.5 \%$ & $717.7 \%$ & $-85.7 \%$ & $248.9 \%$ & $15.5 \%$ & $0.0 \%$ & $1.4 \%$ & $-8.5 \%$ & $1.6 \%$ & $-0.8 \%$ & $-11.1 \%$ & $1.5 \%$ & $-10.3 \%$ & & & & \\
\hline 1986 & $-0.1 \%$ & $0.3 \%$ & $3.8 \%$ & $206.9 \%$ & $5.8 \%$ & $-6.9 \%$ & $12.8 \%$ & $0.6 \%$ & $5.9 \%$ & $0.8 \%$ & $1.9 \%$ & $2.6 \%$ & $-1.9 \%$ & $2.6 \%$ & $2.7 \%$ & & & & \\
\hline 1987 & $-28.1 \%$ & $17.6 \%$ & $17.2 \%$ & $-91.3 \%$ & $6.1 \%$ & $-97.5 \%$ & $1.3 \%$ & $0.0 \%$ & $-3.3 \%$ & $0.7 \%$ & $-0.4 \%$ & $1.9 \%$ & $-0.5 \%$ & $0.3 \%$ & $0.9 \%$ & & & & \\
\hline 1988 & $-30.2 \%$ & $18.5 \%$ & $18.2 \%$ & 7.1\% & $-63.2 \%$ & $-5.6 \%$ & $4.7 \%$ & $0.0 \%$ & $0.0 \%$ & $-1.3 \%$ & $-1.6 \%$ & $-1.4 \%$ & $-0.8 \%$ & $0.0 \%$ & $0.0 \%$ & & & & \\
\hline 1989 & $-25.9 \%$ & $21.2 \%$ & $20.7 \%$ & $-6.4 \%$ & $0.0 \%$ & $-7.6 \%$ & $8.4 \%$ & $0.1 \%$ & $4.3 \%$ & $-0.6 \%$ & $0.5 \%$ & $3.6 \%$ & $-0.1 \%$ & $0.0 \%$ & $0.3 \%$ & & & & \\
\hline 1990 & $-0.1 \%$ & $0.3 \%$ & $1.4 \%$ & $-21.4 \%$ & $-28.3 \%$ & $-84.9 \%$ & $19.4 \%$ & $0.0 \%$ & $0.0 \%$ & $-13.0 \%$ & $13.0 \%$ & $3.5 \%$ & $0.2 \%$ & $-0.2 \%$ & $0.2 \%$ & & & & \\
\hline 1991 & $-0.1 \%$ & $0.4 \%$ & $-0.7 \%$ & $103.3 \%$ & $-6.4 \%$ & $87.9 \%$ & $12.6 \%$ & $0.0 \%$ & $0.0 \%$ & $-15.1 \%$ & $8.7 \%$ & $-2.9 \%$ & $-4.4 \%$ & $2.0 \%$ & $6.0 \%$ & & & & \\
\hline 19 & $-25.8 \%$ & $23.1 \%$ & $22.6 \%$ & $188.0 \%$ & $-76.7 \%$ & $-8.3 \%$ & $9.9 \%$ & $0.0 \%$ & $5.8 \%$ & $3.4 \%$ & $1.2 \%$ & $7.8 \%$ & $-0.1 \%$ & $0.2 \%$ & $0.3 \%$ & & & & \\
\hline 1993 & $-27.3 \%$ & $25.8 \%$ & $25.6 \%$ & $-44.2 \%$ & $-68.9 \%$ & $-74.5 \%$ & $1.4 \%$ & $0.1 \%$ & $-0.1 \%$ & $-0.2 \%$ & $-7.9 \%$ & $-7.8 \%$ & $2.3 \%$ & $4.1 \%$ & $4.3 \%$ & & & & \\
\hline 1994 & $-27.9 \%$ & $24.7 \%$ & $24.5 \%$ & $573.6 \%$ & $-5.8 \%$ & $-11.0 \%$ & $7.6 \%$ & $0.0 \%$ & $-0.2 \%$ & $-14.3 \%$ & $-1.0 \%$ & $-9.5 \%$ & $1.5 \%$ & $4.1 \%$ & $3.3 \%$ & & & & \\
\hline & $-1.4 \%$ & $0.2 \%$ & $-0.8 \%$ & $-3.4 \%$ & $-6.7 \%$ & $-11.8 \%$ & $0.9 \%$ & $0.2 \%$ & $0.2 \%$ & $-8.4 \%$ & $3.3 \%$ & $-0.8 \%$ & $-0.9 \%$ & $2.1 \%$ & $1.3 \%$ & & & & \\
\hline & $-0.2 \%$ & $0.6 \%$ & $-0.2 \%$ & $-45.2 \%$ & $-0.5 \%$ & $-45.0 \%$ & $7.3 \%$ & $0.0 \%$ & $0.0 \%$ & $-9.1 \%$ & $3.5 \%$ & $0.0 \%$ & $0.4 \%$ & $0.1 \%$ & $2.6 \%$ & & & & \\
\hline & $-1.6 \%$ & $-1.5 \%$ & $-1.3 \%$ & $359.3 \%$ & $-4.2 \%$ & $-6.5 \%$ & $0.0 \%$ & $0.0 \%$ & $0.0 \%$ & $-18.0 \%$ & $-1.3 \%$ & $-2.8 \%$ & $1.7 \%$ & $3.3 \%$ & $6.4 \%$ & & & & \\
\hline & $-0.6 \%$ & $4.5 \%$ & $3.7 \%$ & $-3.1 \%$ & $3.0 \%$ & $3.3 \%$ & $1.7 \%$ & $0.0 \%$ & $0.0 \%$ & $-8.4 \%$ & $7.6 \%$ & $1.5 \%$ & $-0.3 \%$ & $0.0 \%$ & $1.2 \%$ & & & & \\
\hline & $-1.3 \%$ & $0.3 \%$ & $2.5 \%$ & $386.9 \%$ & $2.4 \%$ & $1.6 \%$ & $1.9 \%$ & $0.0 \%$ & $0.1 \%$ & $-12.9 \%$ & $1.6 \%$ & $-11.1 \%$ & $-1.1 \%$ & $0.5 \%$ & $6.9 \%$ & & & & \\
\hline & $0.2 \%$ & $0.6 \%$ & $2.8 \%$ & $188.8 \%$ & $221.0 \%$ & $164.1 \%$ & $10.4 \%$ & $0.0 \%$ & $0.0 \%$ & $-11.3 \%$ & $7.3 \%$ & $3.8 \%$ & $-0.2 \%$ & $-0.1 \%$ & $-1.9 \%$ & & & & \\
\hline & $-27.1 \%$ & $25.9 \%$ & $25.7 \%$ & $72.2 \%$ & $-85.8 \%$ & $-88.3 \%$ & $-2.5 \%$ & $0.0 \%$ & $-0.4 \%$ & $-7.9 \%$ & $-3.3 \%$ & $-15.6 \%$ & $-5.0 \%$ & $7.9 \%$ & $6.0 \%$ & & & & \\
\hline & $0.3 \%$ & $0.3 \%$ & $0.6 \%$ & $95.9 \%$ & $0.0 \%$ & $103.8 \%$ & $7.5 \%$ & $1.4 \%$ & $1.7 \%$ & $-15.4 \%$ & $6.8 \%$ & $-1.9 \%$ & $-0.2 \%$ & $0.0 \%$ & $0.1 \%$ & & & & \\
\hline & $-0.7 \%$ & $0.4 \%$ & $-0.2 \%$ & $1607.2 \%$ & $\mid-73.3 \%$ & $\mid-14.7 \%$ & $8.7 \%$ & $0.0 \%$ & $3.1 \%$ & $-1.4 \%$ & $4.8 \%$ & $7.8 \%$ & $-4.0 \%$ & $5.6 \%$ & $3.7 \%$ & & & & \\
\hline
\end{tabular}

Figure 54. Annual habitat summaries for spring chinook and coho in the Naches reach, comparing the Black Rock_2 (BR_2), Wymer_1 (WY_1), and WymerPlus (WY+ ) scenarios relative to the baseline. 
Steelhead

\begin{tabular}{|c|c|c|c|c|c|c|c|c|c|c|c|c|c|c|c|c|c|c|c|c|c|}
\hline \multirow[b]{2}{*}{ Year| } & \multicolumn{3}{|c|}{ Redd Scour } & \multicolumn{3}{|c|}{ Spawning/incubation } & \multicolumn{3}{|c|}{ Fry } & \multicolumn{3}{|c|}{ Subyearling (Summer) } & \multicolumn{3}{|c|}{ Subyearling (winter) } & \multicolumn{3}{|c|}{ Subadult } & \multicolumn{3}{|c|}{ Adult holding } \\
\hline & BR_2 & WY_1 & WY+ & BR_2 & WY_1 & WY+ & BR_2 & WY_1 & WY+ & BR_2 & WY_1 & WY+ & BR_2 & WY_1 & WY+ & BR_2 & WY_1 & WY+ & BR_2 & WY_1 & WY+ \\
\hline & $-0.3 \%$ & $0.0 \%$ & $.0 \%$ & $0.3 \%$ & $.2 \%$ & $\overline{1.4}$ & $2.1 \%$ & $0.0 \%$ & $0.0 \%$ & $2.5 \%$ & $1 \%$ & $1.7 \%$ & $4.7 \%$ & $-0.4 \%$ & $0.3 \%$ & $0.8 \%$ & $0.3 \%$ & $0.5 \%$ & $-0.1 \%$ & $2.6 \%$ & $1.0 \%$ \\
\hline & $-18.1 \%$ & & $0 \%$ & $58.9 \%$ & $-0.3 \%$ & $-7.8 \%$ & $.7 \%$ & $0 \%$ & $-0.5 \%$ & $.3 \%$ & & $.0 \%$ & $-1.6 \%$ & o & $.8 \%$ & $2 \%$ & $1 \%$ & $.3 \%$ & $4.1 \%$ & & $7.7 \%$ \\
\hline & $-54.7 \%$ & & -0 & $4.8 \%$ & $-47 . \varepsilon$ & $-5.6 \%$ & $\%$ & $-1.1 \%$ & -1 & & & $3 \%$ & & $\%$ & $\%$ & $\%$ & & $6 \%$ & & & $5.6 \%$ \\
\hline & $-8.6 \%$ & & $0.0 \%$ & $98.9 \%$ & $-67.2 \%$ & $50.2 \%$ & $-0.3 \%$ & $1.9 \%$ & $5.0 \%$ & $-0.5 \%$ & $0.0 \%$ & $-0.1 \%$ & $-16.1 \%$ & $0.0 \%$ & $-16.0 \%$ & $0.4 \%$ & $-2.2 \%$ & $-2.7 \%$ & .50 & $-5.3 \%$ & $-5.7 \%$ \\
\hline & $0.5 \%$ & & 0. & & & -6.4 & $\%$ & $0.6 \%$ & $1.3 \%$ & $-3.8 \%$ & $-0.8 \%$ & $-4.2 \%$ & & & $.2 \%$ & $-2.0 \%$ & $0 \%$ & $-2.2 \%$ & $3.9 \%$ & & 4.7\% \\
\hline & $-0.7 \%$ & 467 & $-0.2 \%$ & -70 & & $-80.3 \%$ & $0.3 \%$ & $-0.5 \%$ & $0.0 \%$ & 6 & & $.3 \%$ & & & $0 \%$ & $1.0 \%$ & $\%$ & $1.6 \%$ & 1.80 & & $5.9 \%$ \\
\hline & $-0.4 \%$ & & 1. & $-4.1 \%$ & 14.3 & $-5.8 \%$ & $0.5 \%$ & $-0.6 \%$ & $-0.2 \%$ & $.3 \%$ & -0. & & & & $0 \%$ & $-2.1 \%$ & $\%$ & $-0.9 \%$ & $1.0 \%$ & & $0.1 \%$ \\
\hline & $77.5^{\circ}$ & & & & & & $\%$ & $\%$ & & & & & & & & & & $-0.8 \%$ & $4.9^{\circ}$ & & $1.2 \%$ \\
\hline & $-0.6 \%$ & & -0 & $6.7 \%$ & $-c$ & $5.0 \%$ & 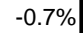 & 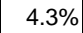 & $4.2 \%$ & & & & & & & $\%$ & & $-0.2 \%$ & -3. & & $-6.4 \%$ \\
\hline & -47 & & & & & $30.4 \%$ & 10 & $\%$ & 0.3 & & & -0 & & & & & & $0.0 \%$ & 1.19 & & $-1.1 \%$ \\
\hline & $-54.5 \%$ & & $4 \%$ & & $52.9 \%$ & $-7.8 \%$ & -0.1 & $1 \%$ & $1.3 \%$ & & & & & & 1.0 & $-1.6 \%$ & & $-1.9 \%$ & 20.3 & & $2.5 \%$ \\
\hline & $1.8 \%$ & & & & $-52.9 \%$ & $-61.5 \%$ & & $-1.0 \%$ & $-0.9 \%$ & & & -0 & & & & & & $0.9 \%$ & 9.70 & & $-2.9 \%$ \\
\hline & $-38.5 \%$ & & 4\% & 94 & $-5.8 \%$ & $-11.0 \%$ & $-4.4 \%$ & $-1.4 \%$ & $-3.3 \%$ & & & & & & 2.1 & $-1.0 \%$ & & $0.9 \%$ & $12.1 \%$ & & $-0.5 \%$ \\
\hline & $-0.2 \%$ & & & & & & & & & & & & & & & & & $-2.8 \%$ & $9.0 \%$ & & $1.9 \%$ \\
\hline & $-1.0 \%$ & & $-c$ & $\%$ & & $-12.1 \%$ & $\%$ & $\%$ & $2.3 \%$ & & & & & & 2 & $1.6 \%$ & & $0.9 \%$ & 60 & & $4.6 \%$ \\
\hline & $-0.2 \%$ & & & & $-3.9 \%$ & $-6.1 \%$ & & & & & & & & & & $-1.8 \%$ & & $-0.7 \%$ & 5.3 & & $3.3 \%$ \\
\hline & 8.0 & & & & & $17.8 \%$ & $\%$ & $1.6 \%$ & & & & & & & 0 & $1.1 \%$ & $\%$ & $-3.1 \%$ & $-1.8 \%$ & & $-5.4 \%$ \\
\hline & $-0.3^{\circ}$ & & & & & 1.5 & & 0.0 & 0. & & & & & & & $-0.4 \%$ & & -0.1 & 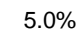 & & $-3.5 \%$ \\
\hline & $-0.4 \%$ & & & & $59.1 \%$ & 15 & -2 & $1.5 \%$ & & & & & & & -2 & & & & 3. & & 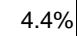 \\
\hline & $-51.4 \%$ & & & & $-66.7 \%$ & $-72.6 \%$ & $-0.7 \%$ & $2.1 \%$ & $-2.0 \%$ & & -1 & & & & $5 . C$ & $-3.5 \%$ & $-0.1 \%$ & $1.0 \%$ & $11.1 \%$ & & $-3.6 \%$ \\
\hline & $2.1 \%$ & & 2 & & $0.0 \%$ & 38.70 & $-2.0 \%$ & $4.0 \%$ & 2.3 & & & & & & $0 .($ & $1.5 \%$ & $-0.8 \%$ & -0.1 & $4.6 \%$ & & $-0.1 \%$ \\
\hline & 0.5 & & & $1.0 \%$ & -64.0 & -15.0 & $-0.1 \%$ & $0.3^{\circ}$ & 0.8 & -0.3 & & $0.4 \%$ & -4. & & .5 & $1.0 \%$ & $-0.1 \%$ & 0.3 & 2.70 & $-0.4 \%$ & .5 \\
\hline
\end{tabular}

\begin{tabular}{|c|c|c|c|c|c|c|c|c|c|c|c|c|c|c|c|c|c|c|c|c|}
\hline Resident Rainbow & \multicolumn{3}{|c|}{ Redd Scour } & \multicolumn{3}{|c|}{ Spawning/incubation } & \multicolumn{3}{|c|}{ Fry } & \multicolumn{3}{|c|}{ Subyearling (Summer) } & \multicolumn{3}{|c|}{ Subyearling (winter) } & \multicolumn{3}{|c|}{ Subadult } & \multicolumn{2}{|c|}{ Adult holding } \\
\hline Year & BR_2 & WY_1 & wY+ & BR_2 & WY_1 & wY+ & BR_2 & WY_1 & WY+ & BR_2 & WY_1 & WY+ & BR_2 & WY_1 & WY+ & BR_2 & WY_1 & WY+ & BR_2 & WY_1 WY+ \\
\hline 1982 & $-0.3 \%$ & $0.0 \%$ & $0.0 \%$ & $-10.0 \%$ & $-3.7 \%$ & $1.6 \%$ & $-1.4 \%$ & $0.0 \%$ & $0.2 \%$ & $2.2 \%$ & $0.1 \%$ & $1.5 \%$ & $4.1 \%$ & $-0.4 \%$ & $0.3 \%$ & $-7.6 \%$ & $0.6 \%$ & $1.3 \%$ & & \\
\hline 1983 & $-18.1 \%$ & $0.0 \%$ & $0.0 \%$ & $40.2 \%$ & $-0.3 \%$ & $-6.9 \%$ & $-2.4 \%$ & $0.0 \%$ & $-0.3 \%$ & $5.0 \%$ & $0.1 \%$ & $3.7 \%$ & $-1.1 \%$ & $1.0 \%$ & $2.3 \%$ & $-1.8 \%$ & $3.4 \%$ & $3.1 \%$ & & \\
\hline 1984 & $-54.7 \%$ & $0.4 \%$ & $-0.1 \%$ & $56.4 \%$ & $-60.8 \%$ & $-4.9 \%$ & $-2.1 \%$ & $-0.7 \%$ & $-1.0 \%$ & $4.0 \%$ & $0.3 \%$ & $2.5 \%$ & $-4.5 \%$ & $1.0 \%$ & $-1.0 \%$ & $6.0 \%$ & $1.3 \%$ & $1.5 \%$ & & \\
\hline 1985 & $-8.6 \%$ & $0.0 \%$ & $0.0 \%$ & $237.5 \%$ & $-77.1 \%$ & $80.5 \%$ & $-0.4 \%$ & $1.3 \%$ & $3.6 \%$ & $-0.6 \%$ & $0.0 \%$ & $-0.2 \%$ & $-14.4 \%$ & $0.4 \%$ & $-13.6 \%$ & $-1.4 \%$ & $5.0 \%$ & $7.6 \%$ & & \\
\hline 1986 & $0.5 \%$ & $0.8 \%$ & $0.7 \%$ & $63.6 \%$ & $4.7 \%$ & $-5.5 \%$ & $0.0 \%$ & $0.0 \%$ & $0.8 \%$ & $-3.6 \%$ & $-0.7 \%$ & $-3.9 \%$ & $-3.6 \%$ & $1.1 \%$ & $0.9 \%$ & $-0.1 \%$ & $1.5 \%$ & $4.1 \%$ & & \\
\hline 1987 & $-0.7 \%$ & $146.7 \%$ & $-0.2 \%$ & $-77.6 \%$ & $5.7 \%$ & $-89.8 \%$ & $-0.2 \%$ & $-0.3 \%$ & $-0.4 \%$ & $6.0 \%$ & $0.2 \%$ & $0.3 \%$ & $-1.1 \%$ & $0.4 \%$ & $2.3 \%$ & $2.5 \%$ & $1.2 \%$ & $3.0 \%$ & & \\
\hline 1988 & $-23.4 \%$ & $-25.1 \%$ & $-25.2 \%$ & $9.7 \%$ & $-49.7 \%$ & $-5.2 \%$ & $0.0 \%$ & $-0.2 \%$ & $-0.2 \%$ & $6.0 \%$ & $-0.2 \%$ & $0.4 \%$ & $-2.5 \%$ & $0.1 \%$ & $-0.1 \%$ & $-3.3 \%$ & $-0.1 \%$ & $-2.4 \%$ & & \\
\hline 1989 & $0.4 \%$ & $0.3 \%$ & $0.4 \%$ & $-6.0 \%$ & $0.0 \%$ & $-7.1 \%$ & $-1.0 \%$ & $-0.6 \%$ & $0.4 \%$ & $0.0 \%$ & $0.0 \%$ & $0.4 \%$ & $0.1 \%$ & $0.0 \%$ & $0.0 \%$ & $1.7 \%$ & $0.0 \%$ & $2.3 \%$ & & \\
\hline 1990 & $-62.3 \%$ & $0.6 \%$ & $1.2 \%$ & $-10.7 \%$ & $-39.9 \%$ & $-57.1 \%$ & $-0.7 \%$ & $2.1 \%$ & $1.8 \%$ & $-4.8 \%$ & $-0.6 \%$ & $-4.2 \%$ & $0.0 \%$ & $0.0 \%$ & $0.1 \%$ & $6.6 \%$ & $1.5 \%$ & $2.4 \%$ & & \\
\hline 1991 & $-65.7 \%$ & $0.5 \%$ & $0.7 \%$ & $13.3 \%$ & $-1.5 \%$ & $46.8 \%$ & $-1.9 \%$ & $0.7 \%$ & $0.1 \%$ & $-1.5 \%$ & $1.4 \%$ & $-0.9 \%$ & $-3.9 \%$ & $1.5 \%$ & $4.6 \%$ & $1.7 \%$ & $2.0 \%$ & $2.1 \%$ & & \\
\hline 1992 & $-54.5 \%$ & $13.3 \%$ & $11.4 \%$ & $56.4 \%$ & $-64.9 \%$ & $-6.9 \%$ & $-0.4 \%$ & $0.1 \%$ & $0.7 \%$ & $10.7 \%$ & $-1.3 \%$ & $0.5 \%$ & $-1.5 \%$ & $-0.1 \%$ & $0.1 \%$ & $-2.7 \%$ & $2.1 \%$ & $6.5 \%$ & & \\
\hline 1993 & $1.8 \%$ & $0.5 \%$ & $3.8 \%$ & $-43.0 \%$ & $-57.4 \%$ & $-65.2 \%$ & $-0.6 \%$ & $-0.2 \%$ & $-0.2 \%$ & $13.7 \%$ & $1.4 \%$ & $-0.8 \%$ & $2.7 \%$ & $2.6 \%$ & $2.8 \%$ & $-2.0 \%$ & $-5.6 \%$ & $-5.3 \%$ & & \\
\hline 1994 & $-58.6 \%$ & $12.4 \%$ & $10.4 \%$ & $165.9 \%$ & $-5.8 \%$ & $-11.0 \%$ & $-1.5 \%$ & $-0.6 \%$ & $-1.3 \%$ & $10.2 \%$ & $-0.5 \%$ & $1.5 \%$ & $0.8 \%$ & $2.7 \%$ & $2.1 \%$ & $-7.7 \%$ & $0.7 \%$ & $-3.2 \%$ & & \\
\hline 1995 & $-0.2 \%$ & $0.1 \%$ & $0.0 \%$ & $-58.5 \%$ & $-5.9 \%$ & $-10.3 \%$ & $-0.2 \%$ & $0.4 \%$ & $2.6 \%$ & $2.1 \%$ & $0.1 \%$ & $-0.8 \%$ & $-0.3 \%$ & $1.9 \%$ & $0.8 \%$ & $0.4 \%$ & $2.4 \%$ & $4.2 \%$ & & \\
\hline 1996 & $-39.9 \%$ & $0.3 \%$ & $0.4 \%$ & $-45.2 \%$ & $-0.7 \%$ & $-46.6 \%$ & $-2.0 \%$ & $1.1 \%$ & $1.3 \%$ & $3.8 \%$ & $0.2 \%$ & $1.5 \%$ & $1.6 \%$ & $0.0 \%$ & $2.6 \%$ & $2.1 \%$ & $3.1 \%$ & $4.2 \%$ & & \\
\hline 1997 & $-0.2 \%$ & $0.7 \%$ & $-0.1 \%$ & $6.2 \%$ & $-3.4 \%$ & $-5.3 \%$ & $-0.3 \%$ & $0.2 \%$ & $0.0 \%$ & $5.1 \%$ & $0.1 \%$ & $6.5 \%$ & $0.9 \%$ & $2.1 \%$ & $4.6 \%$ & $-10.9 \%$ & $-2.2 \%$ & $-0.3 \%$ & & \\
\hline 1998 & $8.0 \%$ & $0.0 \%$ & $0.0 \%$ & $-2.8 \%$ & $2.7 \%$ & $12.0 \%$ & $-0.9 \%$ & $1.2 \%$ & $2.4 \%$ & $-1.2 \%$ & $0.1 \%$ & $-1.0 \%$ & $-0.6 \%$ & $0.0 \%$ & $0.7 \%$ & $-3.5 \%$ & $5.9 \%$ & $9.9 \%$ & & \\
\hline 1999 & $-0.3 \%$ & $0.0 \%$ & $0.1 \%$ & $102.4 \%$ & $1.9 \%$ & $1.3 \%$ & $1.8 \%$ & $0.0 \%$ & $-0.1 \%$ & $0.0 \%$ & $0.6 \%$ & $-1.7 \%$ & $-0.6 \%$ & $0.6 \%$ & $6.2 \%$ & $-1.0 \%$ & $0.2 \%$ & $0.1 \%$ & & \\
\hline 2000 & $-7.9 \%$ & $0.3 \%$ & $0.7 \%$ & $-33.1 \%$ & $88.1 \%$ & $44.9 \%$ & $-2.4 \%$ & $0.7 \%$ & $0.6 \%$ & $-0.9 \%$ & $-0.1 \%$ & $-0.8 \%$ & $0.4 \%$ & $-0.3 \%$ & $-2.1 \%$ & $4.1 \%$ & $3.3 \%$ & $4.8 \%$ & & \\
\hline 2001 & $-51.4 \%$ & $9.5 \%$ & $8.0 \%$ & $-3.6 \%$ & $-76.1 \%$ & $-80.4 \%$ & $-0.4 \%$ & $1.8 \%$ & $-0.1 \%$ & $9.0 \%$ & $-1.1 \%$ & $-0.9 \%$ & $-7.8 \%$ & $6.8 \%$ & $4.2 \%$ & $-10.9 \%$ & $-2.4 \%$ & $-7.5 \%$ & & \\
\hline 2002 & $-1.9 \%$ & $0.3 \%$ & $0.6 \%$ & $32.8 \%$ & $0.0 \%$ & $53.9 \%$ & $-1.5 \%$ & $2.3 \%$ & $1.2 \%$ & $-1.4 \%$ & $0.3 \%$ & $-0.8 \%$ & $-0.3 \%$ & $0.0 \%$ & $0.1 \%$ & $-6.6 \%$ & $2.4 \%$ & $3.5 \%$ & & \\
\hline 2003 & $0.5 \%$ & $1.1 \%$ & $0.8 \%$ & $454.0 \%$ & $-66.3 \%$ & $-15.0 \%$ & $-0.4 \%$ & $-0.2 \%$ & $0.1 \%$ & $-0.3 \%$ & $0.5 \%$ & $0.4 \%$ & $-4.8 \%$ & $5.6 \%$ & $1.6 \%$ & $-0.2 \%$ & $0.6 \%$ & $1.8 \%$ & & \\
\hline
\end{tabular}

Figure 55. Annual habitat summaries for steelhead and resident rainbow trout in the Naches reach, comparing the Black Rock_2 (BR_2), Wymer_1 (WY_1), and WymerPlus (WY+ ) scenarios relative to the baseline. 


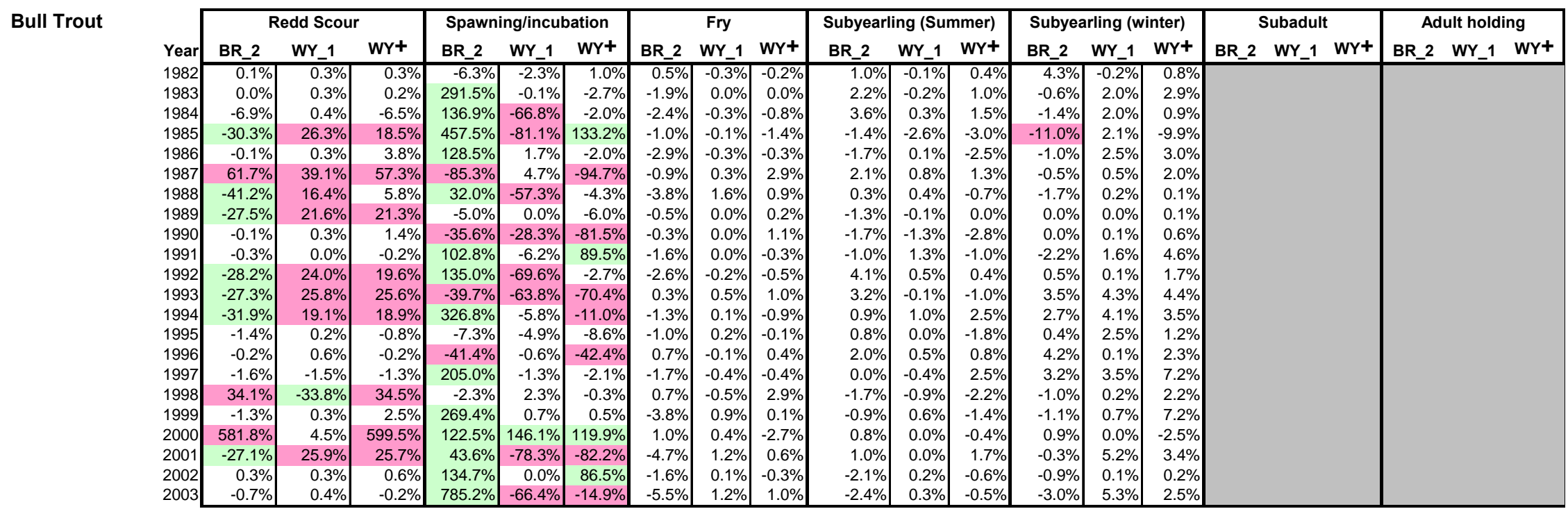

Figure 56. Annual habitat summary for bull trout in the Naches reach, comparing the Black Rock_2 (BR_2), Wymer_1 (WY_1), and WymerPlus (WY+ ) scenarios relative to the baseline. 
the Wymer_1 and WymerPlus alternatives (fig. 47). On an annual basis, significant gains and losses in spawning-incubation habitat were balanced for spring chinook under Black Rock_2, but significant decreases dominated under the other two alternatives (figs. 54-56). Very large proportional increases were recorded under Black Rock_2 for coho and bull trout (figs. 54 and 56). Significant reductions occurred much more frequently than comparable increases for all species under the Wymer_1 alternative, whereas such changes were more equally balanced under WymerPlus (figs. 54-56). In some years, increases in spawning-incubation habitat may be compromised by concurrent increases in redd scour (year 2000 bull trout under Black Rock_2 and WymerPlus in figure 56, for example). Likewise, years in which redd scour was reduced may be offset by comparable reductions in spawning-incubation habitat (year 1996 resident rainbow trout under Black Rock_2 in figure 44, for example).

- Fry habitat for spring chinook in the Naches reach was not significantly different from the baseline for any of the alternatives, although most of the changes were positive (fig. 47). From the yearly summaries, only fry habitat for coho under Black Rock_2 was increased significantly during a large number of years (fig. 54). Changes in this habitat type for the remainder of the species were generally small (figs. 54-56).

- Subyearling summer habitat was essentially unchanged for spring chinook or bull trout under any of the alternatives and was slightly increased for steelhead and resident rainbow trout under Black Rock_2 (figs. 54-56). Black Rock_2, however, resulted in a considerable number of significant reductions in this habitat type for coho (fig. 54). Similar reductions were recorded for coho under the WymerPlus scenario, although the frequency of significant reductions was considerably lower (fig. 54).

- With the exception of one or two years, subyearling winter habitat for all species and subadult habitat for steelhead and resident rainbow trout were not appreciably different from the baseline under any of the alternatives (figs. 54-56).

\section{Union Gap}

- For the period of record at Union Gap, redd scour was slightly reduced for fall chinook, coho, and resident rainbow trout under the Blackrock_2 and Wymer_1 scenarios and increased for those species under WymerPlus (fig. 47). On an annual basis, the largest and most frequent reductions in redd scour were recorded for fall chinook and coho under Black Rock_2, with comparable increases observed under WymerPlus (figs. 57 and 58). Reductions and increases in redd scour for resident rainbow trout were approximately balanced under all three scenarios (fig. 59). Critical scour thresholds were never exceeded for any species or alternative regardless of increased or decreased scour (Appendix figs. 4-17 and 4-18, 5-17 and 5-18, and 6-17 and 6-18).

- Spawning-incubation persistent habitat for fall chinook and coho showed net increases under the Blackrock_2 alternative, whereas a net decrease was recorded for resident rainbow trout (fig. 47). The Wymer_1 and WymerPlus scenarios resulted in overall declines in spawningincubation habitat for all three species, although none of the net decreases was greater than 10 percent (fig. 47). From the yearly summary, significant increases in spawning-incubation habitat were recorded in 6 years for fall chinook with no significant reductions under Blackrock_2 (fig. 57). Coho spawning-incubation habitat was significantly increased and decreased approximately equally, and resident rainbow trout experienced more reductions than increases under Black Rock_2 (figs. 58 and 59). In contrast, significant reductions outnumbered increases by a considerable margin for all three species under the Wymer_1 alternative (figs. 57-59). A similar pattern of habitat reduction was observed for fall chinook and coho under the WymerPlus alternative, with a ratio of reductions to increases of approximately two to one (figs. 57 and 58). 


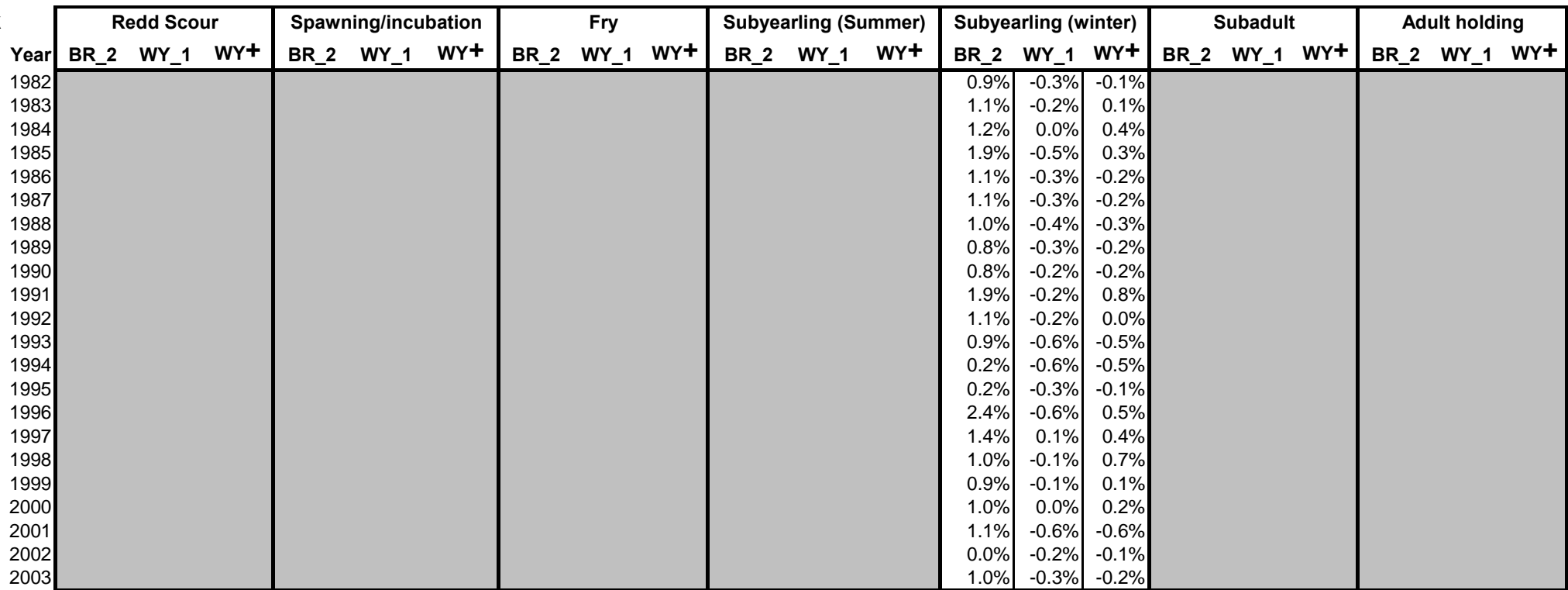

Fall Chinook

\begin{tabular}{|c|c|c|c|c|c|c|c|c|c|c|c|c|c|c|c|}
\hline \multirow[b]{2}{*}{ Year } & \multicolumn{3}{|c|}{ Redd Scour } & \multicolumn{3}{|c|}{ Spawning/incubation } & \multicolumn{3}{|c|}{ Fry } & \multicolumn{3}{|c|}{ Subyearling (Summer) } & Subyearling (winter) & Subadult & Adult holding \\
\hline & BR_2 & WY_1 & WY+ & BR_2 & WY_1 & WY+ & BR_2 & WY_1 & WY+ & BR_2 & WY_1 & WY+ & BR_2 WY_1 WY+ & BR_2 WY_1 WY+ & BR_2 WY_1 WY+ \\
\hline 1982 & $0.9 \%$ & $-1.1 \%$ & $-1.4 \%$ & $7.4 \%$ & $-0.6 \%$ & $-0.6 \%$ & $-4.5 \%$ & $1.1 \%$ & $0.3 \%$ & $5.5 \%$ & $-0.2 \%$ & $3.3 \%$ & & & \\
\hline 1983 & $7.6 \%$ & $0.8 \%$ & $-0.8 \%$ & $0.9 \%$ & $-0.3 \%$ & $-8.1 \%$ & $-2.2 \%$ & $-0.2 \%$ & $-1.7 \%$ & $8.2 \%$ & $-1.1 \%$ & $2.6 \%$ & & & \\
\hline 1984 & $10.5 \%$ & $1.5 \%$ & $17.3 \%$ & $-2.2 \%$ & $-9.1 \%$ & $-10.0 \%$ & $-2.0 \%$ & $-0.7 \%$ & $0.0 \%$ & $20.5 \%$ & $0.3 \%$ & $1.9 \%$ & & & \\
\hline 1985 & $-21.9 \%$ & $0.7 \%$ & $-1.3 \%$ & $7.2 \%$ & $-1.4 \%$ & $0.4 \%$ & $-4.8 \%$ & $0.1 \%$ & $-1.7 \%$ & $16.2 \%$ & $-0.1 \%$ & $2.1 \%$ & & & \\
\hline 1986 & $-11.5 \%$ & $-0.4 \%$ & $11.1 \%$ & $18.3 \%$ & $-40.2 \%$ & $6.3 \%$ & $-1.1 \%$ & $0.1 \%$ & $-0.4 \%$ & $13.8 \%$ & $0.2 \%$ & $1.9 \%$ & & & \\
\hline 1987 & $-13.6 \%$ & $-1.9 \%$ & $8.9 \%$ & $0.6 \%$ & $-0.9 \%$ & $-13.4 \%$ & $-1.8 \%$ & $0.1 \%$ & $-0.6 \%$ & $11.2 \%$ & $0.1 \%$ & $2.7 \%$ & & & \\
\hline 1988 & $-22.4 \%$ & $-2.9 \%$ & $6.8 \%$ & $0.5 \%$ & $-0.5 \%$ & $-1.1 \%$ & $-2.6 \%$ & $0.2 \%$ & $-1.4 \%$ & $11.4 \%$ & $-0.1 \%$ & $2.5 \%$ & & & \\
\hline 1989 & $-9.8 \%$ & $2.2 \%$ & $11.6 \%$ & $-1.5 \%$ & $-0.6 \%$ & $-0.6 \%$ & $-5.4 \%$ & $0.1 \%$ & $-1.2 \%$ & $15.2 \%$ & $0.0 \%$ & $3.0 \%$ & & & \\
\hline 1990 & $-14.6 \%$ & $-0.2 \%$ & $7.2 \%$ & $7.7 \%$ & $-1.0 \%$ & $2.1 \%$ & $-3.8 \%$ & $0.1 \%$ & $-0.8 \%$ & $21.4 \%$ & $0.0 \%$ & $1.6 \%$ & & & \\
\hline 1991 & $51.4 \%$ & $4.2 \%$ & $0.9 \%$ & $-8.4 \%$ & $-10.1 \%$ & $-8.3 \%$ & $-1.7 \%$ & $0.6 \%$ & $-0.3 \%$ & $20.2 \%$ & $0.7 \%$ & $1.6 \%$ & & & \\
\hline 1992 & $-11.5 \%$ & $1.4 \%$ & $10.7 \%$ & $5.3 \%$ & $-9.2 \%$ & $-9.1 \%$ & $-1.3 \%$ & $0.2 \%$ & $0.0 \%$ & $12.4 \%$ & $0.3 \%$ & $3.8 \%$ & & & \\
\hline 1993 & $-12.1 \%$ & $-1.1 \%$ & $12.1 \%$ & $3.2 \%$ & $-31.6 \%$ & $-33.8 \%$ & $-2.3 \%$ & $0.1 \%$ & $-0.8 \%$ & $12.5 \%$ & $0.1 \%$ & $2.7 \%$ & & & \\
\hline 1994 & $-7.7 \%$ & $-2.7 \%$ & $10.2 \%$ & $-1.3 \%$ & $-9.5 \%$ & $-19.5 \%$ & $-2.4 \%$ & $0.1 \%$ & $-1.2 \%$ & $14.7 \%$ & $0.1 \%$ & $2.3 \%$ & & & \\
\hline 995 & $0.9 \%$ & $-1.1 \%$ & $-1.6 \%$ & $-3.8 \%$ & $-29.8 \%$ & $-0.3 \%$ & $-1.4 \%$ & $1.2 \%$ & $0.5 \%$ & $5.7 \%$ & $-0.2 \%$ & $3.8 \%$ & & & \\
\hline 1996 & $0.8 \%$ & $-5.5 \%$ & $-5.4 \%$ & $81.4 \%$ & $-1.4 \%$ & $79.7 \%$ & $-0.6 \%$ & $1.5 \%$ & $0.7 \%$ & $17.2 \%$ & $0.0 \%$ & $2.5 \%$ & & & \\
\hline 1997 & $-2.9 \%$ & $-1.4 \%$ & $-1.4 \%$ & $11.8 \%$ & $-0.5 \%$ & $-6.1 \%$ & $-0.1 \%$ & $0.0 \%$ & $0.0 \%$ & $2.3 \%$ & $-0.8 \%$ & $1.6 \%$ & & & \\
\hline 998 & $33.4 \%$ & $8.8 \%$ & $28.6 \%$ & $3.3 \%$ & $-0.7 \%$ & $-4.1 \%$ & $-0.8 \%$ & $0.6 \%$ & $-0.9 \%$ & $5.9 \%$ & $0.5 \%$ & $4.7 \%$ & & & \\
\hline 1999 & $-11.1 \%$ & $0.2 \%$ & $11.6 \%$ & $8.2 \%$ & $-1.2 \%$ & $-7.5 \%$ & $-4.1 \%$ & $-0.9 \%$ & $-5.0 \%$ & $5.3 \%$ & $-4.6 \%$ & $2.0 \%$ & & & \\
\hline 2000 & $6.9 \%$ & $-2.9 \%$ & $-0.3 \%$ & $14.8 \%$ & $-0.2 \%$ & $1.4 \%$ & $-1.2 \%$ & $0.1 \%$ & $-1.3 \%$ & $18.9 \%$ & $-0.1 \%$ & $2.2 \%$ & & & \\
\hline 2001 & $-12.2 \%$ & $-1.2 \%$ & $12.2 \%$ & $16.4 \%$ & $-9.5 \%$ & $-6.6 \%$ & $-2.1 \%$ & $-0.1 \%$ & $-0.4 \%$ & $14.4 \%$ & $1.2 \%$ & $3.4 \%$ & & & \\
\hline 2002 & $-10.8 \%$ & $1.7 \%$ & $11.3 \%$ & $-4.2 \%$ & $-0.8 \%$ & $-0.8 \%$ & $-4.4 \%$ & $-0.2 \%$ & $-1.8 \%$ & $13.9 \%$ & $-0.2 \%$ & $3.6 \%$ & & & \\
\hline & $-13.7 \%$ & $-2.9 \%$ & $9.3 \%$ & $48.9 \%$ & $17.2 \%$ & $25.1 \%$ & $-1.6 \%$ & $1.0 \%$ & $-1.7 \%$ & $13.1 \%$ & $0.0 \%$ & $2.2 \%$ & & & \\
\hline
\end{tabular}

Figure 57. Annual habitat summaries for spring chinook and fall chinook in the Union Gap reach, comparing the Black Rock_2 (BR_2), Wymer_1 (WY_1), and WymerPlus (WY+) scenarios relative to the baseline. 
Coho

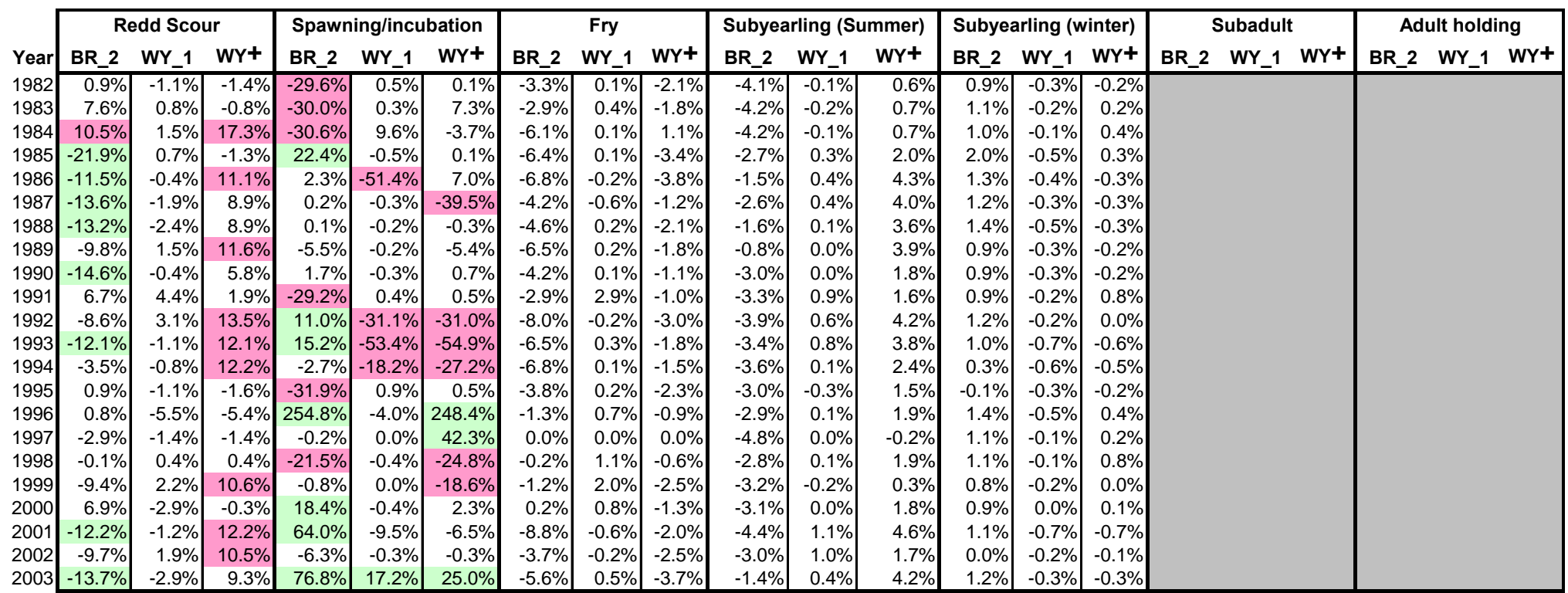

Steelhead

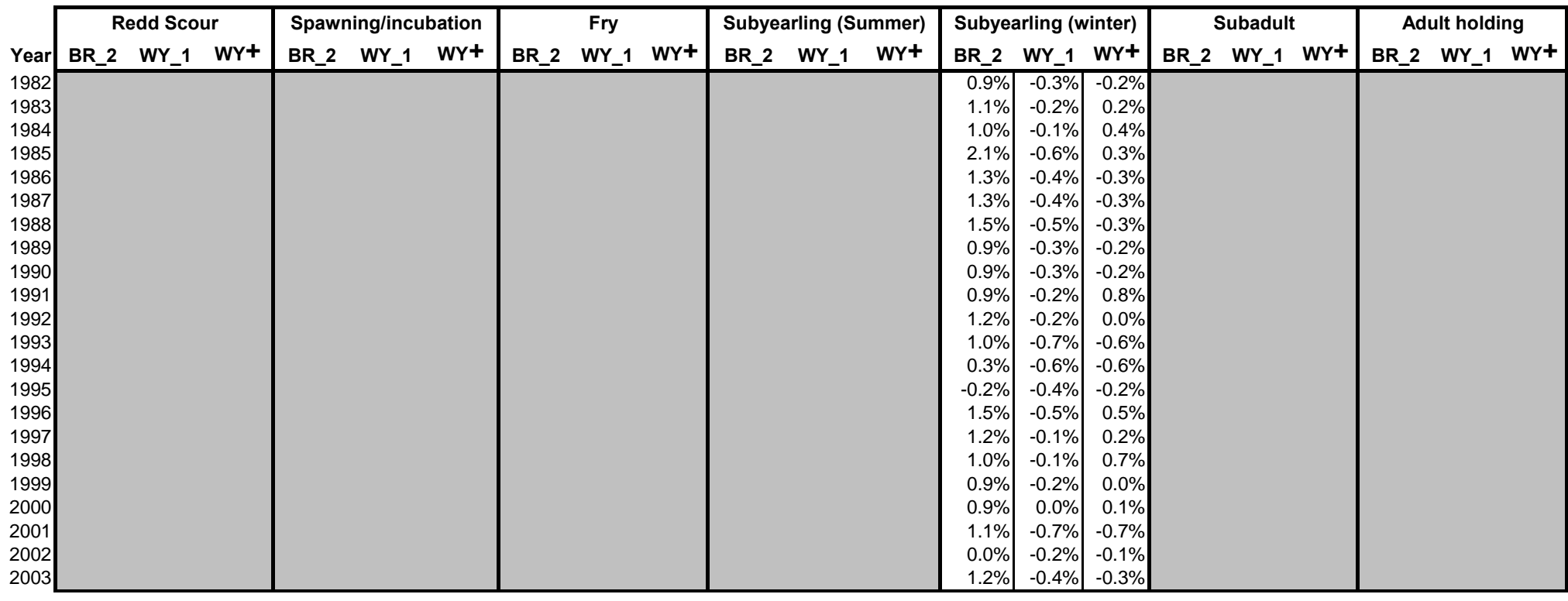

Figure 58. Annual habitat summaries for coho and steelhead in the Union Gap reach, comparing the Black Rock_2 (BR_2), Wymer_1 (WY_1), and WymerPlus (WY+ ) scenarios relative to the baseline. 


\begin{tabular}{|c|c|c|c|c|c|c|c|c|c|c|c|c|c|c|c|c|c|c|c|c|}
\hline \multirow{2}{*}{$\begin{array}{r}\text { Resident Rainbow } \\
\text { Year }\end{array}$} & \multicolumn{3}{|c|}{ Redd Scour } & \multicolumn{3}{|c|}{ Spawning/incubation } & \multicolumn{3}{|c|}{ Fry } & \multicolumn{3}{|c|}{ Subyearling (Summer) } & \multicolumn{3}{|c|}{ Subyearling (winter) } & \multicolumn{3}{|c|}{ Subadult } & \multicolumn{2}{|c|}{ Adult holding } \\
\hline & BR_2 & WY_1 & WY+ & BR_2 & WY_1 & WY+ & BR_2 & WY_1 & wY+ & BR_2 & WY_1 & WY+ & BR_2 & WY_1 & WY+ & BR_2 & WY_1 & WY+ & BR_2 & WY_1 WY+ \\
\hline 1982 & \begin{tabular}{|l|}
$-16.0 \%$ \\
\end{tabular} & $-28.4 \%$ & $-9.9 \%$ & $-35.1 \%$ & $1.5 \%$ & $0.2 \%$ & $-0.2 \%$ & $0.6 \%$ & $-0.9 \%$ & $-1.6 \%$ & $0.0 \%$ & $0.0 \%$ & $0.7 \%$ & $-0.2 \%$ & $-0.2 \%$ & \begin{tabular}{|c|c|}
$-0.4 \%$ \\
\end{tabular} & $-0.4 \%$ & $1.3 \%$ & & \\
\hline 1983 & $-8.3 \%$ & $-0.6 \%$ & $2.7 \%$ & $-35.7 \%$ & $0.8 \%$ & $51.2 \%$ & $1.5 \%$ & $0.6 \%$ & $-0.8 \%$ & $-1.6 \%$ & $0.0 \%$ & $0.0 \%$ & $0.9 \%$ & $-0.2 \%$ & $0.2 \%$ & $-1.8 \%$ & $-0.2 \%$ & $1.2 \%$ & & \\
\hline 1984 & $-35.0 \%$ & $2.4 \%$ & $5.5 \%$ & $-36.2 \%$ & $50.2 \%$ & $-2.1 \%$ & $-0.1 \%$ & $0.3 \%$ & $-0.9 \%$ & $-1.7 \%$ & $0.0 \%$ & $0.0 \%$ & $0.8 \%$ & $0.0 \%$ & $0.3 \%$ & $2.7 \%$ & $-0.2 \%$ & $1.2 \%$ & & \\
\hline 1985 & $-5.0 \%$ & $4.6 \%$ & $54.2 \%$ & $20.3 \%$ & $-0.4 \%$ & $0.1 \%$ & $1.4 \%$ & $0.0 \%$ & $-1.0 \%$ & $-1.1 \%$ & $0.0 \%$ & $0.6 \%$ & $1.6 \%$ & $-0.4 \%$ & $0.2 \%$ & $-1.2 \%$ & $0.2 \%$ & $1.7 \%$ & & \\
\hline 1986 & $16.1 \%$ & $3.4 \%$ & $23.0 \%$ & $-35.6 \%$ & $-37.8 \%$ & $29.3 \%$ & $1.4 \%$ & $-0.1 \%$ & $-1.6 \%$ & $-0.3 \%$ & $0.2 \%$ & $2.2 \%$ & $1.0 \%$ & $-0.3 \%$ & $-0.2 \%$ & $-0.7 \%$ & $0.3 \%$ & $2.5 \%$ & & \\
\hline 1987 & $8.8 \%$ & $15.0 \%$ & $5.5 \%$ & $2.8 \%$ & $0.6 \%$ & $-32.9 \%$ & $0.7 \%$ & $-0.3 \%$ & $-2.6 \%$ & $-1.3 \%$ & $0.1 \%$ & $1.8 \%$ & $1.0 \%$ & $-0.3 \%$ & $-0.3 \%$ & $-1.1 \%$ & $0.4 \%$ & $3.4 \%$ & & \\
\hline 1988 & $-10.0 \%$ & $0.8 \%$ & $-4.6 \%$ & $0.1 \%$ & $-0.2 \%$ & $-0.3 \%$ & $0.4 \%$ & $-0.1 \%$ & $-2.2 \%$ & $-1.4 \%$ & $0.0 \%$ & $1.7 \%$ & $1.1 \%$ & $-0.4 \%$ & $-0.2 \%$ & $-0.2 \%$ & $0.0 \%$ & $2.9 \%$ & & \\
\hline 1989 & $12.1 \%$ & $0.5 \%$ & $3.5 \%$ & $-11.3 \%$ & $-0.4 \%$ & $-11.0 \%$ & $0.9 \%$ & $0.0 \%$ & $-1.5 \%$ & $0.3 \%$ & $0.0 \%$ & $2.0 \%$ & $0.7 \%$ & $-0.2 \%$ & $-0.2 \%$ & $-0.7 \%$ & $0.0 \%$ & $2.4 \%$ & & \\
\hline 1990 & $-14.1 \%$ & $-21.6 \%$ & $7.2 \%$ & $-16.1 \%$ & $-0.3 \%$ & $0.6 \%$ & $1.8 \%$ & $0.3 \%$ & $-1.3 \%$ & $-1.1 \%$ & $0.0 \%$ & $0.6 \%$ & $0.7 \%$ & $-0.2 \%$ & $-0.1 \%$ & $-0.8 \%$ & $0.0 \%$ & $1.6 \%$ & & \\
\hline 1991 & $-7.3 \%$ & $-0.3 \%$ & $5.8 \%$ & $-33.8 \%$ & $0.9 \%$ & $1.0 \%$ & $2.6 \%$ & $0.0 \%$ & $-1.1 \%$ & $-1.1 \%$ & $0.6 \%$ & $0.6 \%$ & $0.8 \%$ & $-0.2 \%$ & $0.7 \%$ & $-1.0 \%$ & $0.5 \%$ & $1.3 \%$ & & \\
\hline 1992 & $-2.7 \%$ & $-0.1 \%$ & $-8.3 \%$ & $-0.4 \%$ & $-24.0 \%$ & $-23.7 \%$ & $1.0 \%$ & $-0.5 \%$ & $-2.7 \%$ & $-1.2 \%$ & $0.2 \%$ & $1.9 \%$ & $0.9 \%$ & $-0.2 \%$ & $0.0 \%$ & $-1.5 \%$ & $0.5 \%$ & $3.6 \%$ & & \\
\hline 1993 & $-0.4 \%$ & $0.1 \%$ & $-4.7 \%$ & $4.0 \%$ & $-50.3 \%$ & $-51.9 \%$ & $0.6 \%$ & $-0.8 \%$ & $-2.6 \%$ & $-0.8 \%$ & $0.4 \%$ & $1.9 \%$ & $0.8 \%$ & $-0.5 \%$ & $-0.5 \%$ & $-1.2 \%$ & $0.7 \%$ & $3.2 \%$ & & \\
\hline 1994 & $-11.0 \%$ & $-1.2 \%$ & $-9.7 \%$ & $-0.4 \%$ & $-18.7 \%$ & $-27.7 \%$ & $-1.0 \%$ & $-0.1 \%$ & $-2.0 \%$ & $0.3 \%$ & $0.0 \%$ & $0.9 \%$ & $0.2 \%$ & $-0.5 \%$ & $-0.4 \%$ & $0.1 \%$ & $0.2 \%$ & $2.5 \%$ & & \\
\hline 1995 & $10.7 \%$ & $1.4 \%$ & $7.6 \%$ & $-39.7 \%$ & $0.8 \%$ & $0.5 \%$ & $2.5 \%$ & $1.2 \%$ & $0.2 \%$ & $-1.1 \%$ & $0.0 \%$ & $0.6 \%$ & $-0.1 \%$ & $-0.3 \%$ & $-0.2 \%$ & $-2.3 \%$ & $-0.5 \%$ & $1.1 \%$ & & \\
\hline 1996 & $-21.0 \%$ & $1.5 \%$ & $6.8 \%$ & $245.4 \%$ & $-4.0 \%$ & $239.2 \%$ & $0.6 \%$ & $0.2 \%$ & $-1.4 \%$ & $-1.1 \%$ & $0.0 \%$ & $0.6 \%$ & $1.5 \%$ & $-0.5 \%$ & $0.5 \%$ & $-0.9 \%$ & $0.2 \%$ & $1.6 \%$ & & \\
\hline 1997 & $2.1 \%$ & $-2.2 \%$ & $9.8 \%$ & $-0.6 \%$ & $0.0 \%$ & $53.9 \%$ & $-2.2 \%$ & $0.5 \%$ & $-1.2 \%$ & $-2.2 \%$ & $0.0 \%$ & $-0.4 \%$ & $0.9 \%$ & $-0.1 \%$ & $0.2 \%$ & $0.8 \%$ & $-0.4 \%$ & $1.6 \%$ & & \\
\hline 1998 & $3.9 \%$ & $-3.5 \%$ & $-0.6 \%$ & $-36.5 \%$ & $-1.0 \%$ & $-10.4 \%$ & $0.8 \%$ & $0.0 \%$ & $-1.1 \%$ & $-1.1 \%$ & $0.0 \%$ & $0.6 \%$ & $0.9 \%$ & $-0.1 \%$ & $0.6 \%$ & $-1.7 \%$ & $0.1 \%$ & $1.5 \%$ & & \\
\hline 1999 & $6.4 \%$ & $-2.4 \%$ & $3.5 \%$ & $-4.0 \%$ & $0.2 \%$ & $27.7 \%$ & $-2.0 \%$ & $0.9 \%$ & $-1.2 \%$ & $-2.2 \%$ & $0.0 \%$ & $-0.5 \%$ & $0.7 \%$ & $-0.1 \%$ & $0.0 \%$ & $2.5 \%$ & $-2.2 \%$ & $2.1 \%$ & & \\
\hline 2000 & $-19.8 \%$ & $1.5 \%$ & $7.3 \%$ & $-3.0 \%$ & $-0.5 \%$ & $-2.9 \%$ & $-0.2 \%$ & $-0.7 \%$ & $-1.7 \%$ & $-1.1 \%$ & $0.0 \%$ & $0.6 \%$ & $0.7 \%$ & $0.0 \%$ & $0.1 \%$ & $-0.2 \%$ & $0.0 \%$ & $1.5 \%$ & & \\
\hline 2001 & $-4.8 \%$ & $-6.1 \%$ & $-13.2 \%$ & $53.7 \%$ & $-9.5 \%$ & $-6.6 \%$ & $0.2 \%$ & $-1.0 \%$ & $-3.2 \%$ & $-0.3 \%$ & $0.5 \%$ & $2.2 \%$ & $0.9 \%$ & $-0.5 \%$ & $-0.5 \%$ & $-1.0 \%$ & $1.2 \%$ & $3.8 \%$ & & \\
\hline 2002 & $-19.8 \%$ & $-26.0 \%$ & $-12.4 \%$ & $-24.0 \%$ & $-1.2 \%$ & $-1.1 \%$ & $-1.3 \%$ & $0.3 \%$ & $-1.1 \%$ & $-1.1 \%$ & $0.6 \%$ & $0.6 \%$ & $0.0 \%$ & $-0.2 \%$ & $-0.1 \%$ & $2.0 \%$ & $0.3 \%$ & $1.6 \%$ & & \\
\hline 2003 & $13.3 \%$ & $2.0 \%$ & $8.4 \%$ & $13.2 \%$ & $12.9 \%$ & $11.6 \%$ & $1.3 \%$ & $-0.1 \%$ & $-1.5 \%$ & $-0.2 \%$ & $0.2 \%$ & $2.1 \%$ & $1.0 \%$ & $-0.3 \%$ & $-0.2 \%$ & $-1.0 \%$ & $0.2 \%$ & $2.5 \%$ & & \\
\hline
\end{tabular}

Figure 59. Annual habitat summary for resident rainbow trout in the Union Gap reach, comparing the Black Rock_2 (BR_2), Wymer_1 (WY_1), and WymerPlus (WY+ ) scenarios relative to the baseline. 
Increases and decreases in spawning-incubation habitat for resident rainbow trout under WymerPlus occurred with equal frequency, but the increases were much larger than the decreases (fig. 59).

- Summer habitat for subyearling fall chinook was significantly increased in the majority of years under Black Rock_2 (fig. 57). Changes to the remainder of habitat types for all species were unsubstantial under all three scenarios (figs. 57-59).

\section{Wa pato}

- For the period of record, redd scour was reduced at Wapato under the Black Rock_2 and WymerPlus alternatives and increased under Wymer_1, significantly so for resident rainbow trout (fig. 47). Annually, significant decreases in redd scour for rainbow trout occurred in all years under Black Rock_2 and WymerPlus and significant increases occurred in all years under Wymer_1 (fig. 62). Changes in redd scour for fall chinook and coho were not as substantial, but followed similar patterns as rainbow trout (figs. 60 and 61).

- Spawning-incubation habitat persistence was significantly increased for fall chinook, coho, and resident rainbow trout with the Black Rock_2 and WymerPlus alternatives (fig. 47). Significant increases in this habitat type were recorded every year for fall chinook and nearly every year for coho and rainbow trout under Black Rock_2 and WymerPlus (figs. 60 and 62). Years having significant increases and decreases were roughly balanced under Wymer_1, resulting in little net change for the period of record (figs. 47 and 60-62). Some of the proportional increases realized under Black Rock_2 and WymerPlus were impressive, especially for coho and resident rainbow trout, where sixfold increases were recorded (figs. 61 and 62).

- Significant increases in fry habitat for fall chinook, coho, and resident rainbow trout resulted from the Black Rock_2 and WymerPlus alternatives over the period of record but remained essentially unchanged under Wymer_1 (fig. 47). On an annual basis, significant increases in fry habitat for fall chinook and coho occurred with equal frequency under Black Rock_2 and WymerPlus, but increases were slightly larger in association with Black Rock_2. In contrast, fry habitat for resident rainbow trout occurred more frequently and at slightly higher magnitudes under WymerPlus (figs. 60-62).

- Subyearling summer habitat for fall chinook was significantly increased in every year but one under the Black Rock_2 scenario (fig. 60). Significant increases in this habitat type were also recorded under the WymerPlus scenario, although they were smaller in magnitude and occurred less frequently (fig. 60). In contrast, the Black Rock_2 alternative resulted in a net reduction in subyearling summer habitat for coho and WymerPlus yielded a net increase. Significant reductions occurred in 2 years under Black Rock_2, and comparable increases occurred in 4 years with WymerPlus (fig. 61). The Wymer_1 alternative resulted in a nearly equal mix of small increases and decreases in summer subyearling habitat for all species (figs. 60-62). Small positive changes (none significant) occurred in all years under all scenarios for resident rainbow trout (fig. 62).

- Winter habitat for subyearlings of all overwintering species was increased over the period of record under the Black Rock_2 and WymerPlus alternatives, although the only significant increase was recorded for spring chinook under Black Rock_2 (fig. 47). From the yearly summaries, there was a general trend for winter subyearling habitat of all species to increase every year under the Black Rock_2 and WymerPlus alternatives and to decrease almost every year under Wymer_1 (figs. 60-62). Whereas a large number of the increases associated with Black Rock_2 and Wymer plus were significant or nearly significant, the majority of the reductions associated with Wymer_1 were less than 2 percent (figs. 60-62). 


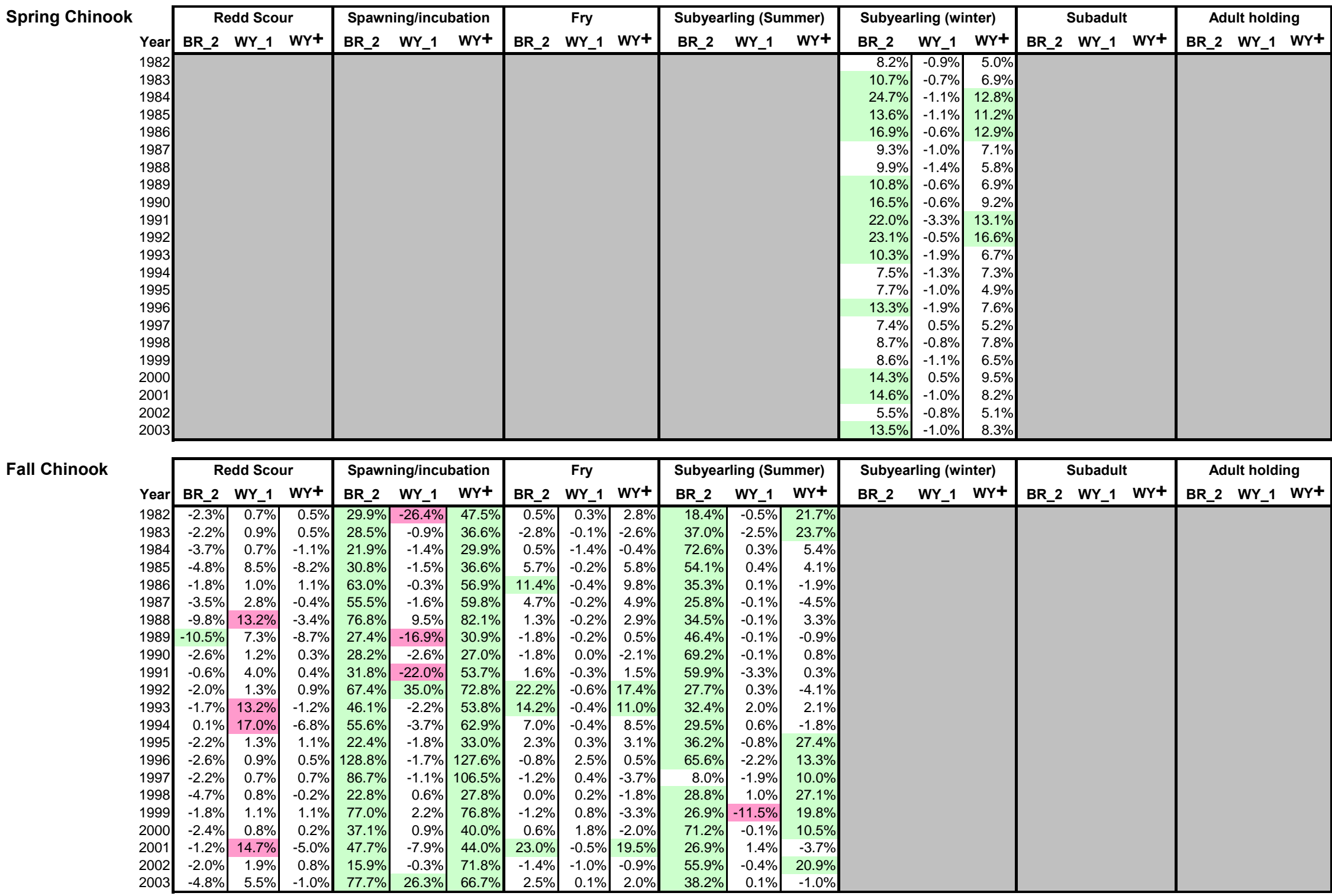

Figure 60. Annual habitat summaries for spring chinook and fall chinook in the Wapato reach, comparing the Black Rock_2 (BR_2), Wymer_1 (WY_1), and WymerPlus (WY+ ) scenarios relative to the baseline. 
Coho

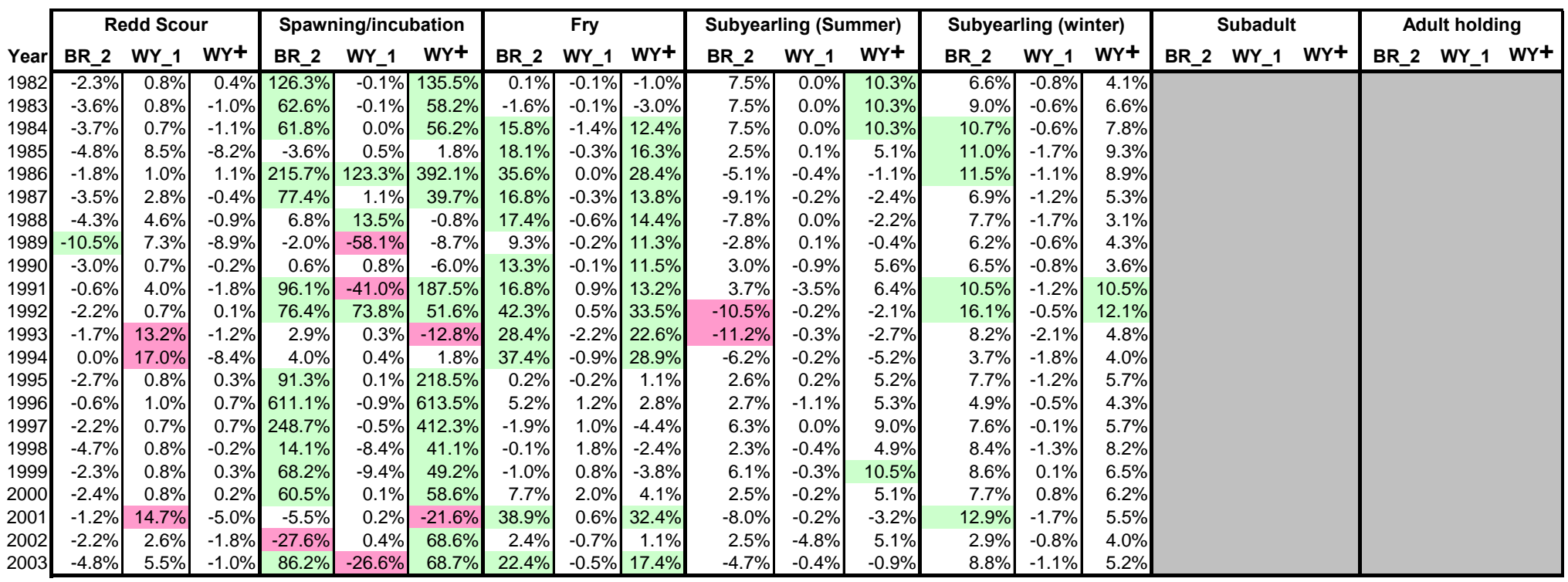

Steelhead

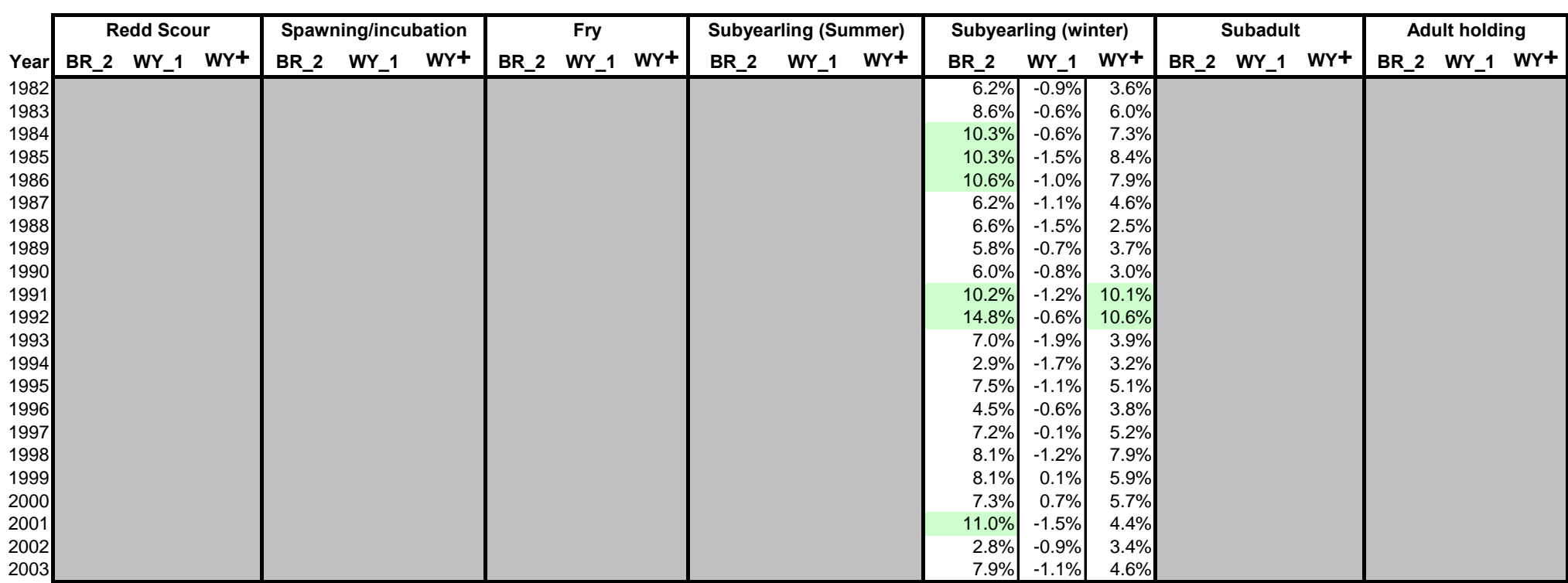

Figure 61. Annual habitat summaries for coho and steelhead in the Wapato reach, comparing the Black Rock_2 (BR_2), Wymer_1 (WY_1), and WymerPlus (WY+ ) scenarios relative to the baseline. 


\begin{tabular}{|c|c|c|c|c|c|c|c|c|c|c|c|c|c|c|c|c|c|c|c|c|}
\hline Resident Rainbow & \multicolumn{3}{|c|}{ Redd Scour } & \multicolumn{3}{|c|}{ Spawning/incubation } & \multicolumn{3}{|c|}{ Fry } & \multicolumn{3}{|c|}{ Subyearling (Summer) } & \multicolumn{3}{|c|}{ Subyearling (winter) } & \multicolumn{3}{|c|}{ Subadult } & \multicolumn{2}{|c|}{ Adult holding } \\
\hline Year & BR_2 & WY_1 & WY+ & BR_2 & WY_1 & WY+ & BR_2 & WY_1 & WY+ & BR_2 & WY_1 & wY+ & BR_2 & WY_1 & wY+ & BR_2 & WY_1 & WY+ & BR_2 & WY_1 WY+ \\
\hline 1982 & $-17.7 \%$ & $17.4 \%$ & $-19.1 \%$ & $173.1 \%$ & $0.3 \%$ & $188.1 \%$ & $12.7 \%$ & $0.0 \%$ & $17.0 \%$ & $0.2 \%$ & $0.0 \%$ & $0.2 \%$ & $5.9 \%$ & $-0.8 \%$ & $3.4 \%$ & $-1.6 \%$ & $0.2 \%$ & $-4.3 \%$ & & \\
\hline 1983 & $-17.7 \%$ & $17.3 \%$ & $-19.1 \%$ & $68.2 \%$ & $0.2 \%$ & $57.6 \%$ & $12.7 \%$ & $0.0 \%$ & $17.0 \%$ & $0.2 \%$ & $0.0 \%$ & $0.2 \%$ & $8.2 \%$ & $-0.5 \%$ & $5.7 \%$ & $-4.0 \%$ & $-0.1 \%$ & $-5.7 \%$ & & \\
\hline 1984 & $-17.7 \%$ & $17.4 \%$ & $-19.1 \%$ & $67.8 \%$ & $0.0 \%$ & $54.2 \%$ & $12.7 \%$ & $0.0 \%$ & $16.7 \%$ & $0.2 \%$ & $0.0 \%$ & $0.2 \%$ & $10.0 \%$ & $-0.6 \%$ & $7.0 \%$ & $1.7 \%$ & $-0.5 \%$ & $-6.5 \%$ & & \\
\hline 1985 & $-21.6 \%$ & $16.9 \%$ & $-23.9 \%$ & $-2.9 \%$ & $0.4 \%$ & $14.8 \%$ & $19.7 \%$ & $0.4 \%$ & $24.4 \%$ & $1.0 \%$ & $0.0 \%$ & $1.0 \%$ & $9.6 \%$ & $-1.5 \%$ & $7.9 \%$ & $-6.5 \%$ & $-1.3 \%$ & $-9.2 \%$ & & \\
\hline 1986 & $-20.6 \%$ & $23.5 \%$ & $-24.1 \%$ & $278.4 \%$ & $164.1 \%$ & $576.7 \%$ & $25.1 \%$ & $0.5 \%$ & $33.4 \%$ & $1.9 \%$ & $0.1 \%$ & $1.9 \%$ & $10.0 \%$ & $-0.9 \%$ & $7.5 \%$ & $-9.5 \%$ & $-0.2 \%$ & $-13.1 \%$ & & \\
\hline 1987 & $-17.4 \%$ & $24.8 \%$ & $-24.6 \%$ & $176.1 \%$ & $1.2 \%$ & $88.0 \%$ & $21.8 \%$ & $0.3 \%$ & $35.7 \%$ & $2.1 \%$ & $0.1 \%$ & $2.2 \%$ & $5.9 \%$ & $-1.0 \%$ & $4.4 \%$ & $-11.2 \%$ & $-0.1 \%$ & $-14.4 \%$ & & \\
\hline 1988 & $-18.5 \%$ & $25.0 \%$ & $-24.5 \%$ & $41.0 \%$ & $43.0 \%$ & $72.9 \%$ & $23.7 \%$ & $0.1 \%$ & $35.4 \%$ & $2.0 \%$ & $0.0 \%$ & $2.1 \%$ & $6.2 \%$ & $-1.4 \%$ & $2.4 \%$ & $-8.1 \%$ & $0.1 \%$ & $-11.5 \%$ & & \\
\hline 1989 & $-21.6 \%$ & $24.0 \%$ & $-24.0 \%$ & $12.6 \%$ & $-69.3 \%$ & $0.9 \%$ & $27.8 \%$ & $-0.1 \%$ & $32.8 \%$ & $1.8 \%$ & $0.0 \%$ & $1.9 \%$ & $5.5 \%$ & $-0.6 \%$ & $3.5 \%$ & $-8.4 \%$ & $-0.2 \%$ & $-11.0 \%$ & & \\
\hline 1990 & $-20.1 \%$ & $20.9 \%$ & $-21.5 \%$ & $10.9 \%$ & $1.0 \%$ & $-1.1 \%$ & $19.4 \%$ & $0.2 \%$ & $24.0 \%$ & $0.9 \%$ & $0.0 \%$ & $1.0 \%$ & $5.6 \%$ & $-0.7 \%$ & $2.9 \%$ & $-5.5 \%$ & $-1.2 \%$ & $-8.2 \%$ & & \\
\hline 1991 & $-19.7 \%$ & $14.0 \%$ & $-21.5 \%$ & $106.9 \%$ & $-41.8 \%$ & $215.8 \%$ & $19.2 \%$ & $6.1 \%$ & $23.8 \%$ & $0.9 \%$ & $0.8 \%$ & $1.0 \%$ & $10.0 \%$ & $-1.1 \%$ & $10.0 \%$ & $-3.9 \%$ & $-1.0 \%$ & $-6.4 \%$ & & \\
\hline 1992 & $-14.9 \%$ & $24.2 \%$ & $-24.8 \%$ & $160.4 \%$ & $127.8 \%$ & $101.9 \%$ & $18.3 \%$ & $0.5 \%$ & $35.8 \%$ & $2.0 \%$ & $0.1 \%$ & $2.1 \%$ & $13.9 \%$ & $-0.6 \%$ & $10.0 \%$ & $-10.6 \%$ & $0.0 \%$ & $-14.0 \%$ & & \\
\hline 1993 & $-15.2 \%$ & $24.4 \%$ & $-24.9 \%$ & $27.1 \%$ & $-0.2 \%$ & $22.5 \%$ & $18.9 \%$ & $0.8 \%$ & $36.8 \%$ & $2.4 \%$ & $0.3 \%$ & $2.5 \%$ & $6.6 \%$ & $-1.7 \%$ & $3.7 \%$ & $-9.5 \%$ & $0.1 \%$ & $-13.0 \%$ & & \\
\hline 1994 & $-11.7 \%$ & $26.1 \%$ & $-24.4 \%$ & $32.2 \%$ & $-0.3 \%$ & $30.0 \%$ & $5.2 \%$ & $0.1 \%$ & $39.6 \%$ & $1.3 \%$ & $0.0 \%$ & $3.4 \%$ & $2.8 \%$ & $-1.6 \%$ & $3.1 \%$ & $-9.1 \%$ & $0.1 \%$ & $-12.8 \%$ & & \\
\hline 1995 & $-19.0 \%$ & $20.8 \%$ & $-21.4 \%$ & $110.5 \%$ & $0.2 \%$ & $285.3 \%$ & $19.4 \%$ & $0.0 \%$ & $24.1 \%$ & $0.9 \%$ & $0.0 \%$ & $0.9 \%$ & $7.2 \%$ & $-1.0 \%$ & $4.8 \%$ & $-6.0 \%$ & $1.9 \%$ & $-8.6 \%$ & & \\
\hline 1996 & $-20.2 \%$ & $20.3 \%$ & $-21.6 \%$ & $656.9 \%$ & $-1.3 \%$ & $659.0 \%$ & $19.5 \%$ & $0.0 \%$ & $23.9 \%$ & $0.9 \%$ & $0.0 \%$ & $1.0 \%$ & $4.3 \%$ & $-0.6 \%$ & $3.7 \%$ & $-6.0 \%$ & $-1.7 \%$ & $-9.3 \%$ & & \\
\hline 1997 & $-15.1 \%$ & $14.0 \%$ & $-16.6 \%$ & $274.2 \%$ & $-0.6 \%$ & $471.0 \%$ & $10.2 \%$ & $0.0 \%$ & $14.3 \%$ & $0.1 \%$ & $0.0 \%$ & $0.1 \%$ & $6.9 \%$ & $0.0 \%$ & $5.0 \%$ & $0.3 \%$ & $-0.5 \%$ & $0.7 \%$ & & \\
\hline 1998 & $-20.2 \%$ & $20.7 \%$ & $-21.6 \%$ & $6.5 \%$ & $-12.0 \%$ & $54.2 \%$ & $19.5 \%$ & $0.1 \%$ & $24.1 \%$ & $0.9 \%$ & $0.0 \%$ & $1.0 \%$ & $7.9 \%$ & $-1.1 \%$ & $7.6 \%$ & $-8.3 \%$ & $-0.1 \%$ & $-10.8 \%$ & & \\
\hline 1999 & $-15.4 \%$ & $14.0 \%$ & $-20.8 \%$ & $125.9 \%$ & $-10.3 \%$ & $80.6 \%$ & $8.0 \%$ & $-1.2 \%$ & $10.7 \%$ & $0.1 \%$ & $0.0 \%$ & $0.1 \%$ & $7.7 \%$ & $0.1 \%$ & $5.7 \%$ & $8.9 \%$ & $-2.1 \%$ & $7.0 \%$ & & \\
\hline 2000 & $-20.1 \%$ & $20.5 \%$ & $-21.5 \%$ & $63.3 \%$ & $-0.3 \%$ & $58.7 \%$ & $19.5 \%$ & $0.1 \%$ & $24.0 \%$ & $0.9 \%$ & $0.0 \%$ & $1.0 \%$ & $7.0 \%$ & $0.7 \%$ & $5.4 \%$ & $-4.6 \%$ & $-0.3 \%$ & $-7.8 \%$ & & \\
\hline 2001 & $-11.9 \%$ & $24.5 \%$ & $-25.2 \%$ & $20.9 \%$ & $-0.7 \%$ & $-4.4 \%$ & $10.9 \%$ & $1.0 \%$ & $38.1 \%$ & $1.2 \%$ & $0.4 \%$ & $2.9 \%$ & $10.3 \%$ & $-1.4 \%$ & $4.2 \%$ & $-10.4 \%$ & $0.7 \%$ & $-14.1 \%$ & & \\
\hline 2002 & $-20.1 \%$ & $13.9 \%$ & $-21.5 \%$ & $\mid-29.7 \%$ & $0.5 \%$ & $159.6 \%$ & $19.5 \%$ & $6.0 \%$ & $24.0 \%$ & $0.9 \%$ & $0.8 \%$ & $1.0 \%$ & $2.7 \%$ & $-0.8 \%$ & $3.3 \%$ & $-4.7 \%$ & $-1.8 \%$ & $-8.1 \%$ & & \\
\hline 2003 & $-20.8 \%$ & $23.4 \%$ & $-24.1 \%$ & $151.9 \%$ & $-29.6 \%$ & $109.8 \%$ & $25.6 \%$ & $0.5 \%$ & $33.3 \%$ & $1.8 \%$ & $0.1 \%$ & $1.9 \%$ & $7.5 \%$ & $-1.0 \%$ & $4.3 \%$ & $-7.9 \%$ & $0.1 \%$ & $-11.4 \%$ & & \\
\hline
\end{tabular}

Figure 62. Annual habitat summary for resident rainbow trout in the Wapato reach, comparing the Black Rock_2 (BR_2), Wymer_1 (WY_1), and WymerPlus (WY+ ) scenarios relative to the baseline. 
- Subadult rainbow trout habitat was reduced over the period of record under all three scenarios, with the largest reduction associated with WymerPlus and the smallest with Wymer_1 (fig. 47). Annually, significant or nearly significant reductions in subadult rainbow trout habitat occurred in a majority of years with the WymerPlus alternative, in approximately one-fourth of the years under Black Rock_2, and never under Wymer_1 (fig. 62).

\section{Maximum Water Temperature}

Comparative analysis of temperature changes in the following section was performed using the annual maximum temperature tables from the YRDSS, which we believed to be more informative than the statistics for the period of record. The annual data were also more amenable to side-by-side comparisons. The reader is reminded that the SNTEMP model is generally accurate to $\pm 0.5^{\circ} \mathrm{C}$ (Bartholow, 1989) and temperature changes within that error envelope should be considered comparatively and not absolutely. It is also noteworthy that the conditional formatting for temperature follows the same color scheme as for the other state variables in the YRDSS. In the case of temperature, however, red does not necessarily equate to a reduction in suitability or biological value and green does not always mean an improvement. Rather, red simply indicates that the maximum temperature for a hydroperiod has increased by $0.5^{\circ} \mathrm{C}$ or more and green indicates a comparable decrease. Depending on when a temperature increase occurs, it could be beneficial for the targeted life stage and a reduction could be detrimental. More important, changes in temperature that shift the biological metric from suitable to marginal or marginal to unsuitable are probably of greatest importance (as are the opposite results). These results can only be found in Appendixes 4-6, but will be noted in the synopses where appropriate.

\section{Union Gap}

- The most notable temperature change at the Union Gap site was a systematic warming associated with the fall chinook spawning and spring chinook subyearling winter hydroperiods under the Black Rock_2 alternative (fig. 63). The default hydroperiod for fall chinook spawning extends from October 1 through November 30 in the YRDSS and for subyearling winter, the hydroperiod was defined from October 1 through the end of April. The simulation window for SNTEMP overlapped these hydroperiods only for the months of October and April. The increases in temperature reported for these hydroperiods are most likely related to a reduction in low flows during October under the Black Rock_2 alternative, as reported in table 9 and figure 35. Potentially important temperature shifts from suitable to marginal were recorded for fall chinook spawning under this alternative in nearly half the years simulated in the time series (Appendix fig. 4-21). A logical outcome from the increased temperatures noted during October might be a delayed spawning of fall chinook until later in the season. An important caveat, however, is that the maximum temperatures recorded for the spawning hydroperiod universally occurred during the first week of October and most occurred during the first day or two. Temperatures under all scenarios tended to drop rapidly after the first week in October, so the effect on spawning periodicity may be negligible.

- Although similar temperature increases were recorded during the winter subyearling hydroperiods, only a few resulted in shifts in temperature suitability for the affected life stages and species.

- Maximum temperatures at Union Gap remained essentially unchanged under the Wymer_1 alternative (figs. 63-65). The WymerPlus alternative also resulted in small increases and decreases in maximum temperatures, although only a few changes exceeded $0.5^{\circ} \mathrm{C}$ (figs. 63-65). This scenario produced a slight increase in October temperatures, similar to that experienced under the Black Rock_2 alternative but with much smaller increases. Although most of the 


\begin{tabular}{|c|c|c|c|c|c|c|c|c|c|c|c|c|c|c|c|c|c|c|c|c|c|}
\hline \multirow[b]{3}{*}{$\begin{array}{r}\text { Spring Chinook } \\
\\
1 \\
1 \\
1 \\
1 \\
1 \\
1 \\
1 \\
1 \\
1 \\
1 \\
1 \\
1 \\
1 \\
1 \\
1 \\
1 \\
1 \\
1 \\
2 \\
2 \\
2 \\
2\end{array}$} & \multicolumn{3}{|c|}{ Spawning } & \multicolumn{3}{|c|}{ Incubation } & \multicolumn{3}{|c|}{ Fry } & \multicolumn{3}{|c|}{ Subyearling (Summer) } & \multicolumn{3}{|c|}{ Subyearling (winter) } & \multicolumn{3}{|c|}{ Subadult } & \multicolumn{3}{|c|}{ Adult holding } \\
\hline & BR_2 & WY_1 & wYt & BR_2 & WY_1 & wY+ & BR_2 & WY_1 & wY+ & BR_2 & WY_1 & wY+ & BR_2 & WY_1 & wYt & BR_2 & WY_1 & wY+ & BR_2 & WY_1 & wY+ \\
\hline & & & & & & & & & & & & & \begin{tabular}{|r|} 
No Data \\
No Data \\
0.3 \\
0.4 \\
0.7 \\
0.2 \\
0.2 \\
-0.2 \\
-0.1 \\
0.0 \\
-0.2 \\
0.3 \\
0.1 \\
0.2 \\
0.2 \\
0.3 \\
0.2 \\
0.1 \\
0.0 \\
0.2 \\
0.1 \\
0.1 \\
\end{tabular} & \begin{tabular}{|r|} 
No Data \\
No Data \\
0.0 \\
0.1 \\
0.0 \\
0.0 \\
0.0 \\
0.0 \\
0.0 \\
-0.3 \\
0.0 \\
0.0 \\
0.0 \\
0.0 \\
0.0 \\
0.0 \\
0.0 \\
0.0 \\
0.1 \\
-0.1 \\
0.0 \\
0.1 \\
\end{tabular} & \begin{tabular}{r|} 
No Data \\
No Data \\
0.2 \\
0.3 \\
-0.4 \\
0.3 \\
0.2 \\
-0.2 \\
0.1 \\
0.0 \\
-0.1 \\
0.3 \\
0.1 \\
0.1 \\
0.1 \\
0.1 \\
0.1 \\
0.1 \\
0.1 \\
0.2 \\
0.1 \\
0.2 \\
\end{tabular} & & & & & & \\
\hline \multirow[t]{24}{*}{ Fall Chinook } & \multicolumn{3}{|c|}{ Spawning } & \multicolumn{3}{|c|}{ Incubation } & \multicolumn{3}{|c|}{ Fry } & \multicolumn{3}{|c|}{ Subyearling (Summer) } & \multicolumn{3}{|c|}{ Subyearling (winter) } & \multicolumn{3}{|c|}{ Subadult } & \multicolumn{3}{|c|}{ Adult holding } \\
\hline & BR_2 & WY_1 & wYt & BR_2 & WY_1 & wY+ & BR_2 & WY_1 & wY+ & BR_2 & WY_1 & wY+ & BR_2 & WY_1 & WY+ & BR_2 & WY_1 & wY+ & BR_2 & WY_1 & WY+ \\
\hline & No Data & No Data & No Data & No Data & No Data & No Data & No Data & No Data & No Data & No Data & No Data & No Data & & & & & & & & & \\
\hline & No Data & No Data & No Data & No Data & No Data & No Data & No Data & No Data & No Data & No Data & No Data & No Data & & & & & & & & & \\
\hline & 1.0 & 0.0 & 0.5 & No Data & No Data & No Data & 0.1 & 0.1 & 0.1 & 0.3 & 0.0 & 0.2 & & & & & & & & & \\
\hline & 1.0 & 0.0 & 0.5 & No Data & No Data & No Data & -0.2 & 0.1 & 0.0 & 0.4 & 0.1 & 0.3 & & & & & & & & & \\
\hline & 1.2 & 0.0 & 0.5 & No Data & No Data & No Data & 0.3 & 0.0 & 0.1 & 0.7 & 0.0 & -0.2 & & & & & & & & & \\
\hline & 0.4 & 0.0 & -0.4 & No Data & No Data & No Data & 0.3 & 0.1 & 0.2 & 0.2 & 0.0 & 0.3 & & & & & & & & & \\
\hline & 0.8 & 0.0 & 0.1 & No Data & No Data & No Data & 0.1 & 0.1 & 0.1 & 0.2 & 0.0 & 0.2 & & & & & & & & & \\
\hline & 0.0 & 0.0 & 0.0 & No Data & No Data & No Data & 0.0 & 0.0 & 0.0 & 0.1 & 0.1 & -0.3 & & & & & & & & & \\
\hline & 0.4 & 0.0 & -0.3 & No Data & No Data & No Data & 0.2 & 0.1 & 0.3 & -0.1 & 0.0 & 0.1 & & & & & & & & & \\
\hline & 0.8 & 0.0 & 0.3 & No Data & No Data & No Data & 0.1 & 0.0 & 0.1 & -0.1 & 0.0 & 0.1 & & & & & & & & & \\
\hline & 0.7 & 0.0 & -0.1 & No Data & No Data & No Data & 0.0 & 0.0 & 0.1 & -0.1 & 0.0 & -0.1 & & & & & & & & & \\
\hline & 0.2 & 0.0 & 0.0 & No Data & No Data & No Data & 0.1 & 0.0 & 0.2 & 0.3 & 0.0 & 0.3 & & & & & & & & & \\
\hline & 0.3 & 0.0 & 0.1 & No Data & No Data & No Data & 0.2 & 0.0 & 0.1 & 0.1 & 0.0 & 0.1 & & & & & & & & & \\
\hline & 0.6 & -0.1 & 0.2 & No Data & No Data & No Data & 0.2 & 0.1 & 0.3 & 0.2 & 0.0 & 0.1 & & & & & & & & & \\
\hline & 1.1 & 0.0 & 0.4 & No Data & No Data & No Data & 0.0 & 0.0 & 0.0 & 0.2 & 0.0 & 0.1 & & & & & & & & & \\
\hline & 1.0 & 0.0 & 0.4 & No Data & No Data & No Data & 0.1 & 0.0 & 0.1 & 0.3 & 0.0 & 0.1 & & & & & & & & & \\
\hline & 1.1 & 0.1 & 0.8 & No Data & No Data & No Data & 0.0 & 0.1 & 0.1 & 0.2 & 0.0 & 0.1 & & & & & & & & & \\
\hline & 1.0 & 0.0 & 0.3 & No Data & No Data & No Data & 0.2 & 0.1 & 0.3 & 0.1 & 0.0 & 0.1 & & & & & & & & & \\
\hline & 0.4 & 0.0 & 0.2 & No Data & No Data & No Data & 0.1 & 0.1 & 0.1 & 0.0 & 0.1 & 0.1 & & & & & & & & & \\
\hline & 0.9 & 0.0 & 0.3 & No Data & No Data & No Data & -0.1 & 0.1 & 0.1 & 0.2 & -0.1 & 0.2 & & & & & & & & & \\
\hline & 0.4 & 0.0 & 0.1 & No Data & No Data & No Data & 0.2 & 0.1 & 0.2 & 0.2 & 0.0 & 0.1 & & & & & & & & & \\
\hline & 0.8 & -0.1 & 0.3 & No Data & No Data & No Datal & 0.2 & 0.0 & 0.1 & 0.1 & 0.1 & 0.2 & & & & & & & & & \\
\hline
\end{tabular}

Figure 63. Annual temperature summaries for spring chinook and fall chinook in the Union Gap reach, comparing the Black Rock_2 (BR_2), Wymer_1 (WY_1), and WymerPlus (WY+ ) scenarios relative to the baseline. 
Coho

\begin{tabular}{|c|c|c|c|c|c|c|c|c|c|c|c|c|c|c|c|c|c|c|c|c|c|}
\hline \multirow[b]{2}{*}{ Year } & \multicolumn{3}{|c|}{ Spawning } & \multicolumn{3}{|c|}{ Incubation } & \multicolumn{3}{|c|}{ Fry } & \multicolumn{3}{|c|}{ Subyearling (Summer) } & \multicolumn{3}{|c|}{ Subyearling (winter) } & \multicolumn{3}{|c|}{ Subadult } & \multicolumn{3}{|c|}{ Adult holding } \\
\hline & BR_2 & WY_1 & wYt & BR_2 & WY_1 & wYt & BR_2 & WY_1 & wY+ & BR_2 & WY_1 & wYt & BR_2 & WY_1 & wYt & BR_2 & WY_1 & wYt & BR_2 & WY_1 & wYt \\
\hline 1982 & No Data & No Data & No Data & No Data & No Data & No Data & No Data & No Data & No Data & No Data & No Data & No Data & No Data & No Data & No Data & & & & & & \\
\hline 1983 & No Data & No Data & No Data & No Data & No Data & No Data & No Data & No Data & No Data & No Data & No Data & No Data & No Data & No Data & No Data & & & & & & \\
\hline 1984 & No Data & No Data & No Data & No Data & No Data & No Data & 0.3 & 0.0 & 0.2 & -0.1 & 0.0 & -0.1 & 0.8 & 0.1 & 0.3 & & & & & & \\
\hline 85 & No Data & No Data & No Data & No Data & No Data & No Data & 0.4 & 0.1 & 0.3 & -0.2 & 0.0 & 0.0 & 0.3 & 0.1 & 0.0 & & & & & & \\
\hline 86 & No Data & No Data & No Data & No Data & No Data & No Data & 0.7 & 0.0 & -0.4 & -0.3 & 0.0 & -0.1 & 0.3 & 0.0 & 0.1 & & & & & & \\
\hline 1987 & No Data & No Data & No Data & No Data & No Data & No Data & 0.2 & 0.0 & 0.3 & 0.0 & 0.0 & 0.0 & 0.3 & 0.1 & 0.2 & & & & & & \\
\hline 1988 & No Data & No Data & No Data & No Data & No Data & No Data| & 0.2 & 0.0 & 0.2 & 0.0 & 0.0 & 0.0 & 0.8 & 0.0 & 0.1 & & & & & & \\
\hline 89 & No Data & No Data & No Data & No Data & No Data & No Data & -0.5 & 0.0 & -0.2 & -0.1 & 0.0 & -0.1 & 0.0 & 0.0 & 0.0 & & & & & & \\
\hline 390 & No Data & No Data & No Data & No Data & No Data & No Datal & -0.1 & 0.0 & 0.1 & -0.3 & -0.1 & -0.2 & 0.4 & 0.0 & 0.1 & & & & & & \\
\hline 1991 & No Data & No Data & No Data & No Data & No Data & No Data| & 0.0 & -0.3 & 0.0 & -0.3 & 0.0 & -0.1 & 0.6 & 0.1 & 0.3 & & & & & & \\
\hline 1992 & No Data & No Data & No Data & No Data & No Data & No Data & -0.2 & 0.0 & -0.1 & -0.1 & 0.1 & 0.1 & 0.4 & 0.0 & 0.1 & & & & & & \\
\hline 93 & No Data & No Data & No Data & No Data & No Data & No Data & 0.3 & 0.0 & 0.3 & -0.1 & 0.0 & 0.0 & 0.2 & 0.0 & 0.0 & & & & & & \\
\hline 1994 & No Data & No Data & No Data & No Data & No Data & No Data & 0.1 & 0.0 & 0.1 & 0.1 & 0.0 & 0.2 & 0.2 & 0.0 & 0.1 & & & & & & \\
\hline 1995 & No Data & No Data & No Data & No Data & No Data & No Data & 0.2 & 0.0 & 0.1 & -0.1 & 0.0 & -0.1 & 0.6 & -0.1 & 0.2 & & & & & & \\
\hline 1996 & No Data & No Data & No Data & No Data & No Data & No Data & 0.2 & 0.0 & 0.1 & -0.2 & 0.0 & -0.1 & 0.3 & 0.0 & 0.2 & & & & & & \\
\hline 1997 & No Data & No Data & No Data & No Data & No Data & No Datal & 0.3 & 0.0 & 0.1 & -0.3 & 0.0 & -0.1 & 0.7 & 0.0 & 0.7 & & & & & & \\
\hline 98 & No Data & No Data & No Data & No Data & No Data & No Data & 0.2 & 0.0 & 0.1 & -0.3 & 0.0 & -0.2 & 0.7 & 0.0 & 0.3 & & & & & & \\
\hline 1999 & No Data & No Data & No Data & No Data & No Data & No Data & 0.1 & 0.0 & 0.1 & -0.6 & -0.2 & -0.4 & 1.0 & 0.0 & 0.3 & & & & & & \\
\hline 2000 & No Data & No Data & No Data & No Data & No Data & No Data & 0.0 & 0.1 & 0.1 & -0.2 & 0.0 & -0.2 & 0.4 & 0.0 & 0.2 & & & & & & \\
\hline 2001 & No Data & No Data & No Data & No Data & No Data & No Datal & 0.2 & -0.1 & 0.2 & -0.3 & 0.1 & 0.2 & 0.2 & 0.1 & 0.1 & & & & & & \\
\hline 02 & No Data & No Data & No Data & No Datal & No Data & No Datal & 0.1 & 0.0 & 0.1 & 0.2 & 0.1 & 0.1 & 0.4 & 0.0 & 0.1 & & & & & & \\
\hline \multirow[t]{3}{*}{2003} & No Data & No Data & No Data & No Data & No Data & No Datal & 0.1 & 0.1 & 0.2 & -0.3 & 0.0 & -0.1 & 0.5 & -0.1 & 0.0 & & & & & & \\
\hline & & & & & & & & & & & & & & & & & & & & & \\
\hline & \multicolumn{3}{|c|}{ Spawning } & \multicolumn{3}{|c|}{ Incubation } & \multicolumn{3}{|c|}{ Fry } & \multicolumn{3}{|c|}{ Subyearling (Summer) } & \multicolumn{3}{|c|}{ Subyearling (winter) } & \multicolumn{3}{|c|}{ Subadult } & \multicolumn{3}{|c|}{ Adult holding } \\
\hline $\operatorname{ar}$ & BR_2 & WY_1 & wYt & BR_2 & WY_1 & wYt & BR_2 & WY_1 & WY+ & BR_2 & WY_1 & wY+ & BR_2 & WY_1 & wYt & BR_2 & WY_1 & WY+ & BR_2 & WY_1 & wY+ \\
\hline $\begin{array}{l}1982 \\
1983 \\
1984 \\
1985 \\
1986 \\
1987 \\
1988 \\
1989 \\
1990 \\
1991 \\
1992 \\
1993 \\
1994 \\
1995 \\
1996 \\
1997 \\
1998 \\
1999 \\
2000 \\
2001 \\
2002 \\
2003 \\
\end{array}$ & & & & & & & & & & & & & \begin{tabular}{|r|} 
No Data \\
No Data \\
0.8 \\
0.3 \\
0.3 \\
0.3 \\
0.8 \\
0.0 \\
0.4 \\
0.6 \\
0.4 \\
0.2 \\
0.2 \\
0.6 \\
0.3 \\
0.7 \\
0.7 \\
1.0 \\
0.4 \\
0.2 \\
0.4 \\
0.5 \\
\end{tabular} & \begin{tabular}{|r|} 
No Data \\
No Data \\
0.1 \\
0.1 \\
0.0 \\
0.1 \\
0.0 \\
0.0 \\
0.0 \\
0.1 \\
0.0 \\
0.0 \\
0.0 \\
-0.1 \\
0.0 \\
0.0 \\
0.0 \\
0.0 \\
0.0 \\
0.1 \\
0.0 \\
-0.1 \\
\end{tabular} & \begin{tabular}{r|} 
No Data \\
No Data \\
0.3 \\
0.0 \\
0.1 \\
0.2 \\
0.1 \\
0.0 \\
0.1 \\
0.3 \\
0.1 \\
0.0 \\
0.1 \\
0.2 \\
0.2 \\
0.7 \\
0.3 \\
0.3 \\
0.2 \\
0.1 \\
0.1 \\
0.0 \\
\end{tabular} & & & & & & \\
\hline
\end{tabular}

Figure 64. Annual temperature summaries for coho and steelhead in the Union Gap reach, comparing the Black Rock_2 (BR_2), Wymer_1 (WY_1), and WymerPlus (WY+ ) scenarios relative to the baseline. 


\begin{tabular}{|c|c|c|c|c|c|c|c|c|c|c|c|c|c|c|c|c|c|c|c|c|c|}
\hline Resident Rainbow & \multicolumn{3}{|c|}{ Spawning } & \multicolumn{3}{|c|}{ Incubation } & \multicolumn{3}{|c|}{ Fry } & \multicolumn{3}{|c|}{ Subyearling (Summer) } & \multicolumn{3}{|c|}{ Subyearling (winter) } & \multicolumn{3}{|c|}{ Subadult } & \multicolumn{3}{|c|}{ Adult holding } \\
\hline Year & BR_2 & WY_1 & wY+ & BR_2 & WY_1 & wY+ & BR_2 & WY_1 & wY+ & BR_2 & WY_1 & wY+ & BR_2 & WY_1 & wY+ & BR_2 & WY_1 & wY+ & BR_2 & WY_1 & wY+ \\
\hline 1982 & No Data & No Data & No Data & No Data & No Data & No Data & No Data & No Data & No Data & No Data & No Data & No Data & No Data & No Data & No Data & No Data & \begin{tabular}{|l|} 
No Data \\
\end{tabular} & No Data & & & \\
\hline 1983 & No Data & No Data & No Data & No Data & No Data & No Data & No Data & No Data & No Data & No Data & No Data & No Data & No Data & No Data & No Data & No Data & No Data & No Data & & & \\
\hline 1984 & 0.3 & 0.0 & 0.2 & -0.1 & 0.0 & -0.1 & -0.1 & 0.0 & -0.1 & -0.1 & 0.0 & 0.0 & 0.8 & 0.1 & 0.3 & -0.1 & 0.0 & -0.1 & & & \\
\hline 1985 & 0.4 & 0.1 & 0.3 & -0.2 & 0.0 & 0.0 & -0.2 & 0.0 & 0.0 & -0.4 & -0.1 & -0.1 & 0.3 & 0.1 & 0.0 & -0.2 & 0.0 & 0.0 & & & \\
\hline 1986 & 0.7 & 0.0 & -0.4 & -0.1 & 0.0 & -0.1 & -0.3 & 0.0 & -0.1 & -0.2 & 0.0 & 0.1 & 0.3 & 0.0 & 0.1 & -0.3 & 0.0 & -0.1 & & & \\
\hline 1987 & 0.2 & 0.0 & 0.3 & 0.0 & 0.0 & 0.0 & 0.0 & 0.0 & 0.0 & 0.2 & 0.4 & 0.6 & 0.3 & 0.1 & 0.2 & 0.0 & 0.0 & 0.0 & & & \\
\hline 1988 & 0.2 & 0.0 & 0.2 & 0.0 & 0.0 & 0.0 & 0.0 & 0.0 & 0.0 & 0.1 & 0.0 & 0.1 & 0.8 & 0.0 & 0.1 & 0.0 & 0.0 & 0.0 & & & \\
\hline 1989 & -0.2 & 0.0 & -0.2 & -0.1 & 0.0 & -0.1 & -0.1 & 0.0 & -0.1 & -0.3 & 0.0 & 0.0 & 0.0 & 0.0 & 0.0 & -0.1 & 0.0 & -0.1 & & & \\
\hline 1990 & -0.1 & 0.0 & 0.1 & -0.3 & -0.1 & -0.2 & -0.3 & -0.1 & -0.2 & -0.2 & -0.2 & 0.0 & 0.4 & 0.0 & 0.1 & -0.3 & -0.1 & -0.2 & & & \\
\hline 1991 & 0.0 & -0.3 & 0.0 & -0.1 & 0.0 & -0.1 & -0.3 & 0.0 & -0.1 & -0.2 & 0.0 & 0.0 & 0.6 & 0.1 & 0.3 & -0.3 & 0.0 & -0.1 & & & \\
\hline 1992 & -0.2 & 0.0 & -0.1 & 0.0 & 0.0 & 0.1 & -0.1 & 0.1 & 0.1 & 0.2 & 0.1 & 0.2 & 0.4 & 0.0 & 0.1 & -0.1 & 0.1 & 0.1 & & & \\
\hline 1993 & 0.3 & 0.0 & 0.3 & 0.0 & 0.0 & 0.0 & -0.1 & 0.0 & 0.0 & -0.1 & -0.2 & -0.2 & 0.2 & 0.0 & 0.0 & -0.1 & 0.0 & 0.0 & & & \\
\hline 1994 & 0.1 & 0.0 & 0.1 & 0.1 & 0.0 & 0.2 & 0.1 & 0.0 & 0.2 & -0.1 & 0.0 & 0.0 & 0.2 & 0.0 & 0.1 & 0.1 & 0.0 & 0.2 & & & \\
\hline 1995 & 0.2 & 0.0 & 0.1 & -0.1 & 0.0 & -0.1 & -0.1 & 0.0 & -0.1 & -0.2 & 0.0 & 0.1 & 0.6 & -0.1 & 0.2 & -0.1 & 0.0 & -0.1 & & & \\
\hline 1996 & 0.2 & 0.0 & 0.1 & -0.2 & 0.0 & -0.1 & -0.2 & 0.0 & -0.1 & -0.1 & 0.0 & 0.0 & 0.3 & 0.0 & 0.2 & -0.2 & 0.0 & -0.1 & & & \\
\hline 1997 & 0.3 & 0.0 & 0.1 & -0.1 & 0.0 & -0.1 & -0.3 & 0.0 & -0.1 & -0.2 & 0.0 & 0.0 & 0.7 & 0.0 & 0.7 & -0.3 & 0.0 & -0.1 & & & \\
\hline 1998 & 0.2 & 0.0 & 0.1 & -0.3 & 0.0 & -0.2 & -0.3 & 0.0 & -0.2 & -0.3 & 0.0 & 0.0 & 0.7 & 0.0 & 0.3 & -0.3 & 0.0 & -0.2 & & & \\
\hline 1999 & 0.1 & 0.0 & 0.1 & 0.2 & 0.0 & 0.1 & -0.6 & -0.2 & -0.4 & 0.2 & 0.1 & 0.2 & 1.0 & 0.0 & 0.3 & -0.6 & -0.2 & -0.4 & & & \\
\hline 2000 & 0.0 & 0.1 & 0.1 & -0.2 & 0.0 & -0.1 & -0.2 & 0.0 & -0.2 & -0.1 & 0.0 & 0.0 & 0.4 & 0.0 & 0.2 & -0.2 & 0.0 & -0.2 & & & \\
\hline 2001 & 0.2 & -0.1 & 0.2 & 0.0 & 0.1 & 0.1 & -0.3 & 0.1 & 0.2 & -0.2 & 0.0 & 0.0 & 0.2 & 0.1 & 0.1 & -0.3 & 0.1 & 0.2 & & & \\
\hline 2002 & 0.1 & 0.0 & 0.1 & 0.2 & 0.1 & 0.1 & 0.2 & 0.1 & 0.1 & -0.3 & 0.0 & 0.0 & 0.4 & 0.0 & 0.1 & 0.2 & 0.1 & 0.1 & & & \\
\hline 2003 & 0.1 & 0.1 & 0.2 & -0.3 & 0.0 & -0.1 & -0.3 & 0.0 & -0.1 & -0.3 & 0.0 & 0.0 & 0.5 & -0.1 & 0.0 & -0.3 & 0.0 & -0.1 & & & \\
\hline
\end{tabular}

Figure 65. Annual temperature summary for resident rainbow trout in the Union Gap reach, comparing the Black Rock_2 (BR_2), Wymer_1 (WY_1), and WymerPlus (WY+ ) scenarios relative to the baseline. 
temperature changes associated with WymerPlus were small, several were sufficient to shift the temperature suitability for fall chinook spawning from the suitable category to the marginal category (Appendix fig. 6-21).

\section{Wapato}

- With the exception of the fall chinook spawning hydroperiod, maximum temperatures in the Wapato reach were generally decreased, often by more than $0.5^{\circ} \mathrm{C}$, under the Black Rock_2 and WymerPlus scenarios (figs. 66-68). These overall temperature decreases were likely associated with the relatively large increases in low flows experienced at Wapato under these two alternatives, particularly during the summer months (table 10 and fig. 36). The Wymer_1 alternative had little effect on maximum temperatures in this reach because it had little effect on flows during the simulation period used with SNTEMP.

- The increased temperatures under the Black Rock_2 alternative during the fall chinook spawning hydroperiod may seem counterintuitive. By all measures, discharges in this reach were increased during October under Black Rock_2, so a reduction in temperature would have been anticipated. A plausible (but not sole) explanation is that the inflow from the Union Gap reach was sufficiently high, and the two reaches close enough to one another, that the elevated temperatures at Wapato were artifacts from the higher temperatures experienced immediately upstream. As corroborating evidence, the years showing the largest increases in October temperatures at Wapato $(1984,1985,1986$, and 1998) also had the largest increases at Union Gap.

- Shifts in temperature suitability were rare under all three scenarios. For nonspawning life stages, most of the suitability transitions were positive, either from unsuitable to marginal or from marginal to suitable (Appendix figs. 4-23-4-24, 5-23-5-24, and 6-23-6-24). In the majority of cases, however, temperature suitability was the same under any of the scenarios as it was under the baseline.

Yearly Summaries

\section{Bull Trout Passage}

- The number of days having impassable conditions for bull trout decreased at Kachess Reservoir under all three scenarios, but significant reductions were recorded only for the Black Rock_2 and WymerPlus alternatives. Overall, outmigration potential from Kachess Reservoir was increased slightly more with WymerPlus (17.7 percent) than with Black Rock_2 (15.4 percent; figs. 47 and 69).

- At Keechulus Reservoir, the net change for bull trout outmigration was negligible under all three alternatives (fig. 47). This metric may be misleading, however, because significant increases and decreases in the number of impassable days occurred with each scenario (fig. 69). Under the Black Rock_2 scenario, the number of impassable days was significantly increased in 6 years and significantly reduced in 3 . The Wymer_1 alternative resulted in 2 years having significant reductions in impassable days and 1 year with a significant increase. Impassable days were significantly reduced in 3 years and increased in 2 under the WymerPlus scenario (fig. 69).

- Figure 47 indicated that large increases in the number of passable days at Rimrock Reservoir were achieved under the Wymer_1 and WymerPlus alternatives. Examination of the annual scoring table (fig. 69), however, reveals that large reductions in the number of impassable days occurred only in 2 years under these alternatives. For the remainder of the record, there was no difference in the day-count compared to the baseline. 


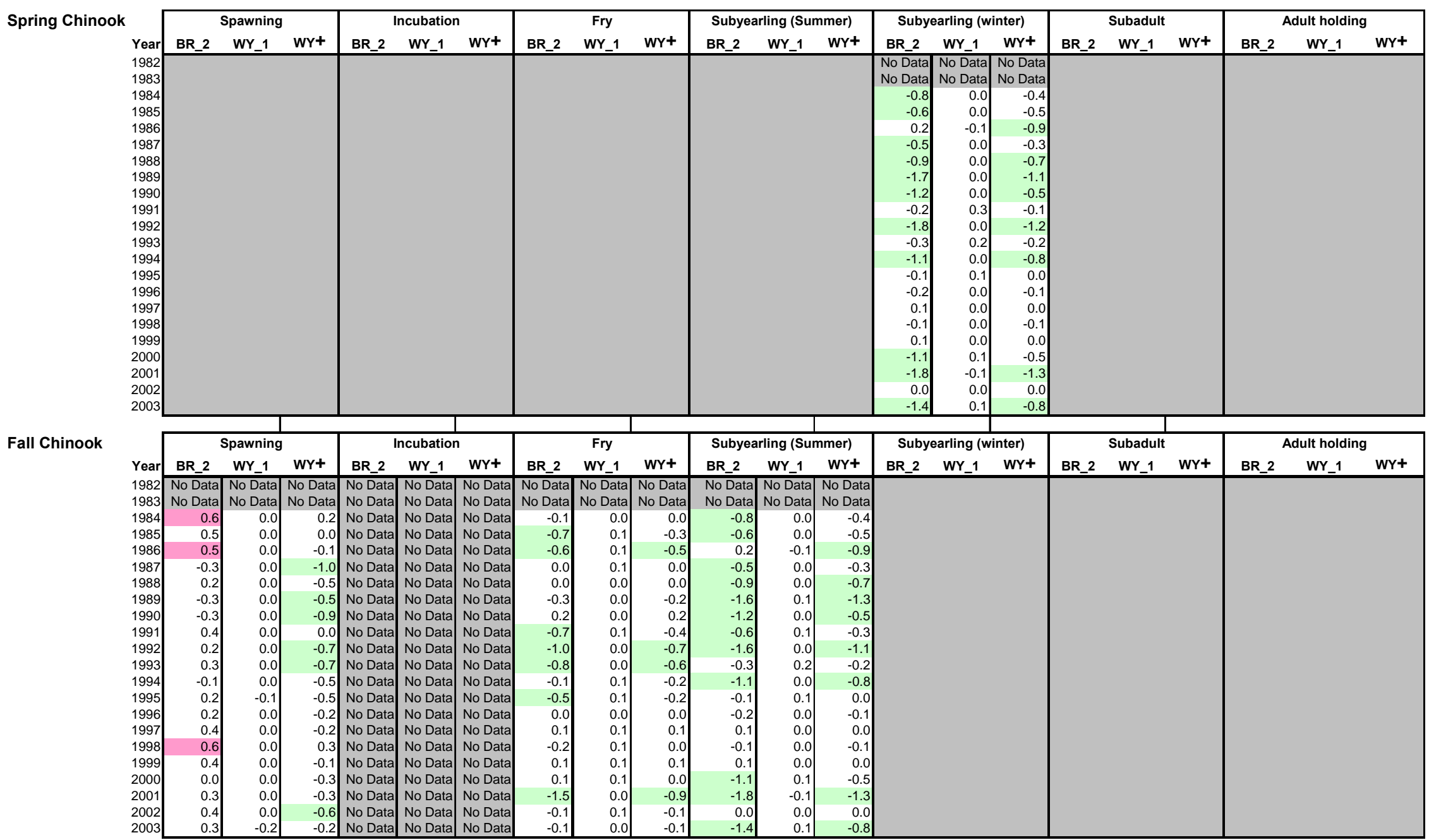

Figure 66. Annual temperature summaries for spring chinook and fall chinook in the Wapato reach, comparing the Black Rock_2 (BR_2), Wymer_1 (WY_1), and WymerPlus (WY+ ) scenarios relative to the baseline. 
Coho

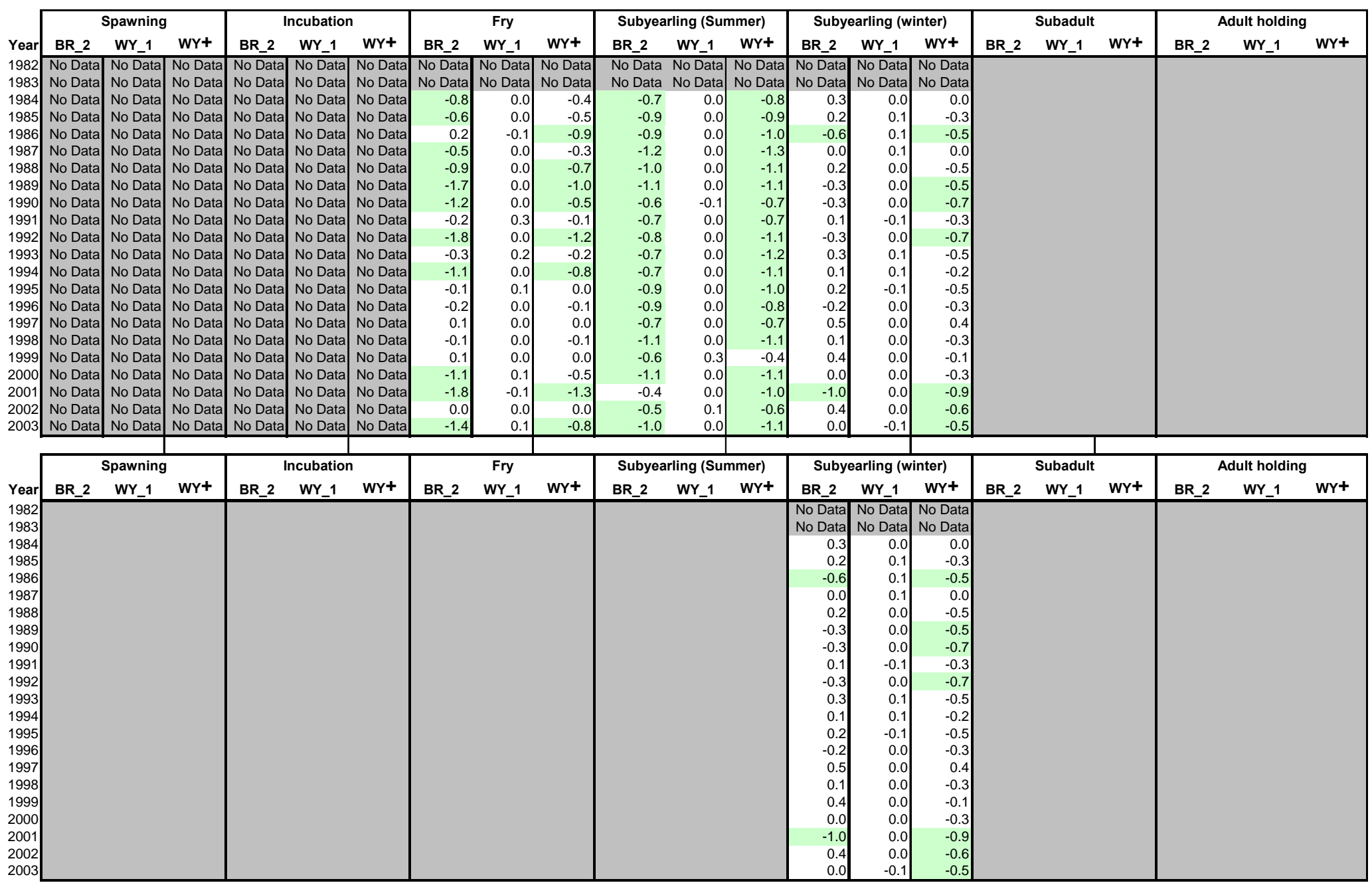

Figure 67. Annual temperature summaries for coho and steelhead in the Wapato reach, comparing the Black Rock_2 (BR_2), Wymer_1 (WY_1), and WymerPlus (WY+) scenarios relative to the baseline. 


\begin{tabular}{|c|c|c|c|c|c|c|c|c|c|c|c|c|c|c|c|c|c|c|c|c|c|}
\hline \multirow{2}{*}{ Resident Rainbow } & \multicolumn{3}{|c|}{ Spawning } & \multicolumn{3}{|c|}{ Incubation } & \multicolumn{3}{|c|}{ Fry } & \multicolumn{3}{|c|}{ Subyearling (Summer) } & \multicolumn{3}{|c|}{ Subyearling (winter) } & \multicolumn{3}{|c|}{ Subadult } & \multicolumn{3}{|c|}{ Adult holding } \\
\hline & BR_2 & WY_1 & wYt & BR_2 & WY_1 & wY+ & BR_2 & WY_1 & wYt & BR_2 & WY_1 & wYt & BR_2 & WY_1 & wY+ & BR_2 & WY_1 & wYt & BR_2 & WY_1 & WY+ \\
\hline 1982 & No Data & No Data & No Data & No Data & No Data & No Data & No Data & No Data & No Data & No Data & No Data & No Data & No Datal & No Data & No Data & No Data & No Data & No Data & & & \\
\hline 1983 & No Data & No Datal & No Datal & No Datal & No Data & No Datal & No Data & No Data & No Datal & No Datal & No Datal & No Datal & No Datal & No Data & No Data & No Datal & No Data & No Datal & & & \\
\hline 1984 & & & -0.4 & & & & & & & -0.4 & 0.0 & -0.4 & 0.3 & \begin{tabular}{|r|}
0.0 \\
\end{tabular} & & -0.7 & & -0.8 & & & \\
\hline 1985 & -0.6 & 0.0 & -0.5 & -0.9 & 0.0 & -0.9 & -0.9 & 0.0 & -0.9 & -0.7 & 0.0 & -0.5 & 0.2 & 0.1 & -0.3 & -0.9 & 0.0 & -0.9 & & & \\
\hline 1986 & 0.2 & -0.1 & -0.9 & -1.1 & 0.0 & -1.2 & -0.9 & 0.0 & -1.0 & -1.0 & 0.0 & -0.8 & -0.6 & 0.1 & -0.5 & -0.9 & 0.0 & -1.0 & & & \\
\hline 1987 & -0.5 & 0.0 & -0.3 & -1.2 & 0.0 & -1.3 & -1.1 & 0.0 & -1.2 & -0.5 & 0.3 & -0.6 & 0.0 & 0.1 & 0.0 & -1.2 & 0.0 & -1.3 & & & \\
\hline 1988 & -0.9 & 0.0 & -0.7 & -1.0 & 0.0 & -1.1 & -1.0 & 0.0 & -1.1 & -0.7 & 0.0 & -1.0 & 0.2 & 0.0 & -0.5 & -1.0 & 0.0 & -1.1 & & & \\
\hline 1989 & -1.7 & 0.0 & -1.1 & -1.1 & 0.0 & -1.1 & -1.1 & 0.0 & -1.1 & -0.8 & 0.0 & -0.6 & -0.3 & 0.0 & -0.5 & -1.1 & 0.0 & -1.1 & & & \\
\hline 1990 & -1.2 & 0.0 & -0.5 & -0.6 & -0.1 & -0.7 & -0.6 & -0.1 & -0.7 & -0.7 & -0.1 & -0.7 & -0.3 & 0.0 & -0.7 & -0.6 & -0.1 & -0.7 & & & \\
\hline 1991 & -0.2 & 0.3 & -0.1 & -0.8 & -0.1 & -0.9 & -0.7 & 0.0 & -0.7 & -0.6 & -0.1 & -0.6 & 0.1 & -0.1 & -0.3 & -0.7 & 0.0 & -0.7 & & & \\
\hline 1992 & -1.8 & 0.0 & -1.2 & -1.3 & 0.0 & -1.1 & -0.7 & 0.0 & -1.1 & -0.2 & 0.1 & -0.6 & -0.3 & 0.0 & -0.7 & -0.8 & 0.0 & -1.1 & & & \\
\hline 1993 & -0.3 & 0.2 & -0.2 & -1.2 & 0.0 & $\begin{array}{c}-1.2 \\
-1.2\end{array}$ & -0.7 & 0.0 & -1.2 & -0.6 & -0.1 & -1.2 & 0.3 & 0.1 & -0.5 & -0.7 & 0.0 & -1.2 & & & \\
\hline 1994 & -1.1 & 0.0 & -0.8 & -0.7 & 0.0 & -1.1 & -0.7 & 0.0 & -1.1 & -0.2 & -0.1 & -0.8 & 0.1 & 0.1 & -0.2 & -0.7 & 0.0 & -1.1 & & & \\
\hline 1995 & -0.1 & 0.1 & 0.0 & -0.9 & 0.0 & -1.0 & -0.9 & 0.0 & -1.0 & -0.8 & 0.0 & -0.7 & 0.2 & -0.1 & -0.5 & -0.9 & 0.0 & -1.0 & & & \\
\hline 1996 & -0.2 & 0.0 & $-0.1]$ & -0.9 & 0.0 & -0.8 & -0.9 & 0.0 & -0.8 & -0.5 & 0.0 & -0.5 & -0.2 & 0.0 & -0.3 & -0.9 & 0.0 & -0.8 & & & \\
\hline 1997 & 0.1 & 0.0 & 0.0 & -0.6 & 0.0 & -0.8 & -0.7 & 0.0 & -0.7 & -0.5 & 0.0 & -0.5 & 0.5 & 0.0 & 0.4 & -0.7 & 0.0 & -0.7 & & & \\
\hline 1998 & -0.1 & 0.0 & -0.1 & -1.1 & 0.0 & -1.1 & -1.1 & 0.0 & -1.1 & -0.9 & 0.0 & -0.7 & 0.1 & 0.0 & -0.3 & -1.1 & 0.0 & -1.1 & & & \\
\hline 1999 & 0.1 & 0.0 & 0.0 & -0.3 & 0.0 & -0.5 & -0.6 & 0.3 & -0.4 & -0.1 & 0.0 & -0.2 & 0.4 & 0.0 & -0.1 & -0.6 & 0.3 & -0.4 & & & \\
\hline 2000 & -1.1 & 0.1 & -0.5 & -1.0 & 0.0 & -1.0 & -1.1 & 0.0 & -1.1 & -0.7 & 0.0 & -0.7 & 0.0 & 0.0 & -0.3 & -1.1 & 0.0 & -1.1 & & & \\
\hline 2001 & -1.8 & -0.1 & -1.3 & -1.0 & 0.0 & -1.1 & -0.4 & 0.0 & -1.0 & -0.3 & 0.0 & -0.9 & -1.0 & 0.0 & -0.9 & -0.4 & 0.0 & -1.0 & & & \\
\hline 2002 & 0.0 & 0.0 & 0.0 & -0.5 & 0.1 & -0.6 & -0.5 & 0.1 & -0.6 & -0.8 & -0.1 & -0.6 & 0.4 & 0.0 & -0.6 & -0.5 & 0.1 & -0.6 & & & \\
\hline 2003 & -1.4 & 0.1 & -0.8 & -1.0 & 0.0 & -1.1 & -1.0 & 0.0 & -1.1 & -1.0 & 0.0 & -0.9 & 0.0 & -0.1 & -0.5 & -1.0 & 0.0 & -1.1 & & & \\
\hline
\end{tabular}

Figure 68. Annual temperature summary for resident rainbow trout in the Wapato reach, comparing the Black Rock_2 (BR_2), Wymer_1 (WY_1), and WymerPlus (WY+ ) scenarios relative to the baseline. 
Res Bull Trout outmigration Inseason days impassable

\begin{tabular}{|c|c|c|c|c|c|c|c|c|c|}
\hline \multirow[b]{2}{*}{ Year } & \multicolumn{3}{|c|}{ Kachess } & \multicolumn{3}{|c|}{ Keechelus } & \multicolumn{3}{|c|}{ Rimrock } \\
\hline & BR_2 & WY_1 & WY+ & BR_2 & WY_1 & WY+ & BR_2 & WY_1 & WY+ \\
\hline 1982 & $0.0 \%$ & $0.0 \%$ & $0.0 \%$ & $2000.0 \%$ & $0.0 \%$ & $0.0 \%$ & $0.0 \%$ & $0.0 \%$ & $0.0 \%$ \\
\hline 1983 & $0.0 \%$ & $0.0 \%$ & $0.0 \%$ & $10.3 \%$ & $3.4 \%$ & $6.9 \%$ & $0.0 \%$ & $0.0 \%$ & $0.0 \%$ \\
\hline 1984 & $0.0 \%$ & $0.0 \%$ & $0.0 \%$ & $100.0 \%$ & $0.0 \%$ & $85.7 \%$ & $0.0 \%$ & $0.0 \%$ & $0.0 \%$ \\
\hline 1985 & $0.0 \%$ & $0.0 \%$ & $0.0 \%$ & $0.0 \%$ & $0.0 \%$ & $0.0 \%$ & $0.0 \%$ & $0.0 \%$ & $0.0 \%$ \\
\hline 1986 & $0.0 \%$ & $0.0 \%$ & $0.0 \%$ & $0.0 \%$ & $0.0 \%$ & $0.0 \%$ & $0.0 \%$ & $0.0 \%$ & $0.0 \%$ \\
\hline 1987 & $-33.3 \%$ & $0.0 \%$ & $-33.3 \%$ & $0.0 \%$ & $0.0 \%$ & $0.0 \%$ & $0.0 \%$ & $0.0 \%$ & $0.0 \%$ \\
\hline 1988 & $-14.3 \%$ & $0.0 \%$ & $-12.2 \%$ & $-33.3 \%$ & $0.0 \%$ & $0.0 \%$ & $0.0 \%$ & $0.0 \%$ & $0.0 \%$ \\
\hline 1989 & $0.0 \%$ & $0.0 \%$ & $0.0 \%$ & $-35.7 \%$ & $9.5 \%$ & $-31.0 \%$ & $0.0 \%$ & $0.0 \%$ & $0.0 \%$ \\
\hline 1990 & $0.0 \%$ & $0.0 \%$ & $0.0 \%$ & $10.9 \%$ & $-13.0 \%$ & $8.7 \%$ & $0.0 \%$ & $0.0 \%$ & $0.0 \%$ \\
\hline 1991 & $0.0 \%$ & $0.0 \%$ & $0.0 \%$ & $22.9 \%$ & $14.3 \%$ & $22.9 \%$ & $0.0 \%$ & $0.0 \%$ & $0.0 \%$ \\
\hline 1992 & $-62.1 \%$ & $-24.1 \%$ & $-62.1 \%$ & $3.6 \%$ & $0.0 \%$ & $0.0 \%$ & $0.0 \%$ & $0.0 \%$ & $0.0 \%$ \\
\hline 1993 & $-70.0 \%$ & $-6.7 \%$ & $-40.0 \%$ & $-31.1 \%$ & $0.0 \%$ & $-31.1 \%$ & $0.0 \%$ & $0.0 \%$ & $0.0 \%$ \\
\hline 1994 & $-8.5 \%$ & $0.0 \%$ & $-8.5 \%$ & $0.0 \%$ & $0.0 \%$ & $0.0 \%$ & $-5.6 \%$ & $-94.4 \%$ & $-94.4 \%$ \\
\hline 1995 & $0.0 \%$ & $0.0 \%$ & $0.0 \%$ & $-1.7 \%$ & $0.0 \%$ & $-3.4 \%$ & $0.0 \%$ & $0.0 \%$ & $0.0 \%$ \\
\hline 1996 & $0.0 \%$ & $0.0 \%$ & $0.0 \%$ & $2.6 \%$ & $0.0 \%$ & $0.0 \%$ & $0.0 \%$ & $0.0 \%$ & $0.0 \%$ \\
\hline 1997 & $0.0 \%$ & $0.0 \%$ & $0.0 \%$ & $0.0 \%$ & $0.0 \%$ & $0.0 \%$ & $0.0 \%$ & $0.0 \%$ & $0.0 \%$ \\
\hline 1998 & $0.0 \%$ & $0.0 \%$ & $0.0 \%$ & $6.8 \%$ & $-6.8 \%$ & $-2.3 \%$ & $0.0 \%$ & $0.0 \%$ & $0.0 \%$ \\
\hline 1999 & $0.0 \%$ & $0.0 \%$ & $0.0 \%$ & $0.0 \%$ & $0.0 \%$ & $0.0 \%$ & $0.0 \%$ & $0.0 \%$ & $0.0 \%$ \\
\hline 2000 & $0.0 \%$ & $0.0 \%$ & $0.0 \%$ & $10.0 \%$ & $-45.0 \%$ & $-45.0 \%$ & $0.0 \%$ & $0.0 \%$ & $0.0 \%$ \\
\hline 2001 & $0.0 \%$ & $4.0 \%$ & $-76.0 \%$ & $0.0 \%$ & $0.0 \%$ & $9.4 \%$ & $0.0 \%$ & $-68.2 \%$ & $-100.0 \%$ \\
\hline 2002 & $0.0 \%$ & $0.0 \%$ & $0.0 \%$ & $17.6 \%$ & $0.0 \%$ & $0.0 \%$ & $0.0 \%$ & $0.0 \%$ & $0.0 \%$ \\
\hline 2003 & $0.0 \%$ & $0.0 \%$ & $0.0 \%$ & $-5.0 \%$ & $-10.0 \%$ & $-5.0 \%$ & $0.0 \%$ & $0.0 \%$ & $0.0 \%$ \\
\hline
\end{tabular}

Figure 69. Bull trout outmigration table from the yearly summary pages for the Black Rock_2 (BR_2), Wymer_1 (WY_1), and WymerPlus (WY+ ) scenarios, expressed as percentage change from the No Action baseline.

Water Supply and Deliveries

- The average proration rate (deliverable water to junior water rights holders) was increased for all months under all three alternatives, but none of the increases was greater than 10 percent (fig. 47). The largest monthly increases in the proration rate were associated with Black Rock_2, followed closely by WymerPlus. One of the delivery goals of BOR is to achieve a proration rate of 70 percent or higher (Joel Hubble, Bureau of Reclamation, oral commun. January 2007). Therefore, a positive result occurs not only when the proration rate is increased, but especially when the 70 percent goal is exceeded more often under an alternative than it was under the baseline. This result was achieved in all years under all of the alternatives (Appendix figs. 4-3, 5-3, and 6-3). Coincidentally, the years showing the largest increases in the proration rates in figure 70 were all years in which the baseline failed to deliver 100 percent of the targeted demand.

- The total available water supply (TWSA) was also increased monthly under all three scenarios (fig. 70). Gains in total water supply tended to accumulate from the beginning of the irrigation season to the end. Although these increases accumulated faster under the Blackrock_2 scenario, by September there were significant increases nearly every year with all three of the scenarios (fig. 70).

\section{Reservoir Carryover and Cle Elum Critical Storage}

- End-of-season carryover was increased at all five headwater reservoirs under the three alternatives, but the increases recorded at Keechelus Reservoir were all less than 10 percent for the period of record (fig. 47). The largest gains in carryover occurred at Cle Elum, Kachess, and Rimrock Reservoirs, with the largest of those increases associated with the Black Rock_2 


\begin{tabular}{|c|c|c|c|c|c|c|c|c|c|c|c|c|c|c|c|c|c|c|c|}
\hline \multirow[b]{2}{*}{ Average proration \% } & \multirow[b]{2}{*}{ Year } & \multicolumn{3}{|c|}{ April } & \multicolumn{3}{|c|}{ May } & \multicolumn{3}{|c|}{ June } & \multicolumn{3}{|c|}{ July } & \multicolumn{3}{|c|}{ August } & \multicolumn{3}{|c|}{ September } \\
\hline & & BR_2 & WY_1 & wY+ & BR_2 & WY_1 & wY+ & BR_2 & WY_1 & WY+ & BR_2 & WY_1 & $w Y+$ & BR_2 & WY_1 & $w Y+$ & BR_2 & WY_1 & wY+ \\
\hline by Month & 1982 & $0.0 \%$ & $0.0 \%$ & $0.0 \%$ & $0.0 \%$ & $0.0 \%$ & $0.0 \%$ & $0.0 \%$ & $0.0 \%$ & $0.0 \%$ & $0.0 \%$ & $0.0 \%$ & $0.0 \%$ & $0.0 \%$ & $0.0 \%$ & $0.0 \%$ & $0.0 \%$ & $0.0 \%$ & $0.0 \%$ \\
\hline & 1983 & $0.0 \%$ & $0.0 \%$ & $0.0 \%$ & $0.0 \%$ & $0.0 \%$ & $0.0 \%$ & $0.0 \%$ & $0.0 \%$ & $0.0 \%$ & $0.0 \%$ & $0.0 \%$ & $0.0 \%$ & $0.0 \%$ & $0.0 \%$ & $0.0 \%$ & $0.0 \%$ & $0.0 \%$ & $0.0 \%$ \\
\hline & 1984 & $0.0 \%$ & $0.0 \%$ & $0.0 \%$ & $0.0 \%$ & $0.0 \%$ & $0.0 \%$ & $0.0 \%$ & $0.0 \%$ & $0.0 \%$ & $0.0 \%$ & $0.0 \%$ & $0.0 \%$ & $0.0 \%$ & $0.0 \%$ & $0.0 \%$ & $0.0 \%$ & $0.0 \%$ & $0.0 \%$ \\
\hline & 1985 & $0.0 \%$ & $0.0 \%$ & $0.0 \%$ & $0.0 \%$ & $0.0 \%$ & $0.0 \%$ & $0.0 \%$ & $0.0 \%$ & $0.0 \%$ & $0.0 \%$ & $0.0 \%$ & $0.0 \%$ & $0.0 \%$ & $0.0 \%$ & $0.0 \%$ & $0.0 \%$ & $0.0 \%$ & $0.0 \%$ \\
\hline & 1986 & $0.0 \%$ & $0.0 \%$ & $0.0 \%$ & $0.7 \%$ & $0.7 \%$ & $0.7 \%$ & $9.0 \%$ & $6.2 \%$ & $9.0 \%$ & $10.4 \%$ & $6.5 \%$ & $10.4 \%$ & $10.8 \%$ & $6.7 \%$ & $10.8 \%$ & $10.8 \%$ & $10.8 \%$ & $10.8 \%$ \\
\hline & 1987| & $13.6 \%$ & $4.7 \%$ & $9.4 \%$ & $15.9 \%$ & $5.2 \%$ & $13.1 \%$ & $16.8 \%$ & $5.4 \%$ & $16.8 \%$ & $18.4 \%$ & $5.6 \%$ & $19.3 \%$ & $19.3 \%$ & $5.8 \%$ & $21.9 \%$ & $20.0 \%$ & $24.4 \%$ & $24.4 \%$ \\
\hline & 1988 & $17.4 \%$ & $0.5 \%$ & $6.5 \%$ & $22.4 \%$ & $0.8 \%$ & $8.4 \%$ & $24.4 \%$ & $0.9 \%$ & $10.2 \%$ & $26.3 \%$ & $1.0 \%$ & $12.2 \%$ & $27.0 \%$ & $1.2 \%$ & $14.3 \%$ & $27.4 \%$ & $16.2 \%$ & $16.2 \%$ \\
\hline & 1989 & $0.1 \%$ & $-0.1 \%$ & $0.1 \%$ & $1.3 \%$ & $-0.2 \%$ & $1.3 \%$ & $2.2 \%$ & $-0.7 \%$ & $2.2 \%$ & $3.4 \%$ & $-0.8 \%$ & $3.4 \%$ & $3.9 \%$ & $-0.7 \%$ & $3.9 \%$ & $4.2 \%$ & $4.2 \%$ & $4.2 \%$ \\
\hline & 1990 & $0.0 \%$ & $0.0 \%$ & $0.0 \%$ & $0.0 \%$ & $0.0 \%$ & $0.0 \%$ & $0.0 \%$ & $0.0 \%$ & $0.0 \%$ & $0.0 \%$ & $0.0 \%$ & $0.0 \%$ & $0.0 \%$ & $0.0 \%$ & $0.0 \%$ & $0.0 \%$ & $0.0 \%$ & $0.0 \%$ \\
\hline & 1991 & $0.0 \%$ & $0.0 \%$ & $0.0 \%$ & $0.0 \%$ & $0.0 \%$ & $0.0 \%$ & $0.0 \%$ & $0.0 \%$ & $0.0 \%$ & $0.0 \%$ & $0.0 \%$ & $0.0 \%$ & $0.0 \%$ & $0.0 \%$ & $0.0 \%$ & $0.0 \%$ & $0.0 \%$ & $0.0 \%$ \\
\hline & 1992 & $17.1 \%$ & $8.4 \%$ & $18.3 \%$ & $15.3 \%$ & $8.4 \%$ & $18.4 \%$ & $15.0 \%$ & $8.6 \%$ & $20.0 \%$ & $15.2 \%$ & $8.9 \%$ & $22.1 \%$ & $15.3 \%$ & $9.3 \%$ & $24.4 \%$ & $15.3 \%$ & $26.3 \%$ & $26.3 \%$ \\
\hline & 1993 & $25.4 \%$ & $4.6 \%$ & $14.5 \%$ & $24.4 \%$ & $14.8 \%$ & $17.2 \%$ & $23.2 \%$ & $17.0 \%$ & $18.8 \%$ & $25.5 \%$ & $17.4 \%$ & $21.3 \%$ & $26.6 \%$ & $18.0 \%$ & $24.1 \%$ & $27.1 \%$ & $26.2 \%$ & $26.2 \%$ \\
\hline & 1994 & $93.9 \%$ & $3.1 \%$ & $13.9 \%$ & $132.7 \%$ & $4.4 \%$ & $39.4 \%$ & $140.0 \%$ & $6.6 \%$ & $44.2 \%$ & $140.0 \%$ & $6.5 \%$ & $43.7 \%$ & $142.6 \%$ & $5.0 \%$ & $42.6 \%$ & $150.8 \%$ & $44.7 \%$ & $44.7 \%$ \\
\hline & 1995 & $0.0 \%$ & $0.0 \%$ & $0.0 \%$ & $0.0 \%$ & $0.0 \%$ & $0.0 \%$ & $0.0 \%$ & $0.0 \%$ & $0.0 \%$ & $0.0 \%$ & $0.0 \%$ & $0.0 \%$ & $0.0 \%$ & $0.0 \%$ & $0.0 \%$ & $0.0 \%$ & $0.0 \%$ & $0.0 \%$ \\
\hline & 1996 & $0.0 \%$ & $0.0 \%$ & $0.0 \%$ & $0.0 \%$ & $0.0 \%$ & $0.0 \%$ & $0.0 \%$ & $0.0 \%$ & $0.0 \%$ & $0.0 \%$ & $0.0 \%$ & $0.0 \%$ & $0.0 \%$ & $0.0 \%$ & $0.0 \%$ & $0.0 \%$ & $0.0 \%$ & $0.0 \%$ \\
\hline & 1997 & $0.0 \%$ & $0.0 \%$ & $0.0 \%$ & $0.0 \%$ & $0.0 \%$ & $0.0 \%$ & $0.0 \%$ & $0.0 \%$ & $0.0 \%$ & $0.0 \%$ & $0.0 \%$ & $0.0 \%$ & $0.0 \%$ & $0.0 \%$ & $0.0 \%$ & $0.0 \%$ & $0.0 \%$ & $0.0 \%$ \\
\hline & 1998 & $0.0 \%$ & $0.0 \%$ & $0.0 \%$ & $0.0 \%$ & $0.0 \%$ & $0.0 \%$ & $0.0 \%$ & $0.0 \%$ & $0.0 \%$ & $0.0 \%$ & $0.0 \%$ & $0.0 \%$ & $0.0 \%$ & $0.0 \%$ & $0.0 \%$ & $0.0 \%$ & $0.0 \%$ & $0.0 \%$ \\
\hline & 1999 & $0.0 \%$ & $0.0 \%$ & $0.0 \%$ & $0.0 \%$ & $0.0 \%$ & $0.0 \%$ & $0.0 \%$ & $0.0 \%$ & $0.0 \%$ & $0.0 \%$ & $0.0 \%$ & $0.0 \%$ & $0.0 \%$ & $0.0 \%$ & $0.0 \%$ & $0.0 \%$ & $0.0 \%$ & $0.0 \%$ \\
\hline & 2000 & $0.0 \%$ & $0.0 \%$ & $0.0 \%$ & $0.0 \%$ & $0.0 \%$ & $0.0 \%$ & $0.0 \%$ & $0.0 \%$ & $0.0 \%$ & $0.0 \%$ & $0.0 \%$ & $0.0 \%$ & $0.0 \%$ & $0.0 \%$ & $0.0 \%$ & $0.0 \%$ & $0.0 \%$ & $0.0 \%$ \\
\hline & 2001 & $52.4 \%$ & $28.8 \%$ & $45.8 \%$ & $52.4 \%$ & $31.0 \%$ & $48.1 \%$ & $52.4 \%$ & $31.0 \%$ & $47.9 \%$ & $52.5 \%$ & $30.0 \%$ & $48.0 \%$ & $54.4 \%$ & $30.5 \%$ & $49.9 \%$ & 56.9\% & $52.4 \%$ & $52.4 \%$ \\
\hline & 2002 & $0.0 \%$ & $0.0 \%$ & $0.0 \%$ & $0.0 \%$ & $0.0 \%$ & $0.0 \%$ & $0.0 \%$ & $0.0 \%$ & $0.0 \%$ & $0.0 \%$ & $0.0 \%$ & $0.0 \%$ & $0.0 \%$ & $0.0 \%$ & $0.0 \%$ & 0.0\% & $0.0 \%$ & $0.0 \%$ \\
\hline & 2003 & $0.0 \%$ & $0.0 \%$ & $0.0 \%$ & $0.0 \%$ & $0.0 \%$ & $0.0 \%$ & $6.6 \%$ & $5.9 \%$ & $6.6 \%$ & $8.5 \%$ & $6.9 \%$ & $8.5 \%$ & $8.6 \%$ & $7.3 \%$ & $8.6 \%$ & $8.6 \%$ & $8.6 \%$ & $8.6 \%$ \\
\hline
\end{tabular}

TWSA

\begin{tabular}{|c|c|c|c|c|c|c|c|c|c|c|c|c|c|c|c|c|c|c|c|}
\hline \multirow[b]{2}{*}{ Year } & & \multicolumn{3}{|c|}{ April } & \multicolumn{3}{|c|}{ May } & \multicolumn{3}{|c|}{ June } & \multicolumn{3}{|c|}{ July } & \multicolumn{3}{|c|}{ August } & \multicolumn{3}{|c|}{ September } \\
\hline & & BR_2 & WY_1 & WY+ & BR_2 & WY_1 & WY+ & BR_2 & WY_1 & WY+ & BR_2 & WY_1 & WY+ & BR_2 & WY_1 & WY+ & BR_2 & WY_1 & wY+ \\
\hline & 1982 & $2.6 \%$ & $-0.5 \%$ & $0.9 \%$ & $1.0 \%$ & $-0.4 \%$ & $0.9 \%$ & $0.7 \%$ & $-0.6 \%$ & $1.1 \%$ & $3.7 \%$ & $4.7 \%$ & $4.7 \%$ & $8.4 \%$ & 6.9\% & $8.2 \%$ & $22.1 \%$ & $15.8 \%$ & $15.8 \%$ \\
\hline & 1983 & $2.3 \%$ & $2.0 \%$ & $2.2 \%$ & $2.3 \%$ & $2.3 \%$ & $2.4 \%$ & $2.3 \%$ & $3.6 \%$ & $3.6 \%$ & $1.9 \%$ & $4.8 \%$ & $4.8 \%$ & $8.1 \%$ & $7.2 \%$ & $8.6 \%$ & $22.4 \%$ & $16.9 \%$ & $16.9 \%$ \\
\hline & 1984 & $1.9 \%$ & $1.9 \%$ & $1.2 \%$ & $1.5 \%$ & $2.4 \%$ & $2.4 \%$ & $-2.5 \%$ & $2.8 \%$ & $3.2 \%$ & $3.7 \%$ & $4.6 \%$ & $4.6 \%$ & $8.3 \%$ & $6.6 \%$ & $8.1 \%$ & $21.9 \%$ & $15.6 \%$ & $15.6 \%$ \\
\hline & 1985 & $6.3 \%$ & $3.0 \%$ & $5.3 \%$ & $5.7 \%$ & $3.5 \%$ & $5.9 \%$ & $3.0 \%$ & $4.0 \%$ & $6.9 \%$ & $3.2 \%$ & $5.3 \%$ & $5.7 \%$ & $10.7 \%$ & $7.3 \%$ & $9.9 \%$ & $28.9 \%$ & $19.8 \%$ & $19.8 \%$ \\
\hline & 1986 & $7.1 \%$ & $2.8 \%$ & $5.7 \%$ & $6.8 \%$ & $3.2 \%$ & $6.6 \%$ & $5.3 \%$ & $4.2 \%$ & $7.6 \%$ & $6.8 \%$ & $5.1 \%$ & $10.8 \%$ & $17.2 \%$ & $7.0 \%$ & $17.4 \%$ & $44.3 \%$ & $33.4 \%$ & $33.4 \%$ \\
\hline & 1987 & $6.6 \%$ & $2.2 \%$ & $4.4 \%$ & $7.0 \%$ & $2.6 \%$ & $5.1 \%$ & $7.1 \%$ & $2.4 \%$ & $7.3 \%$ & $10.9 \%$ & $2.7 \%$ & $9.8 \%$ & $21.7 \%$ & $2.6 \%$ & $12.4 \%$ & $57.8 \%$ & $19.5 \%$ & $19.5 \%$ \\
\hline & 1988 & $9.2 \%$ & $0.2 \%$ & $3.0 \%$ & $10.6 \%$ & $0.3 \%$ & $3.6 \%$ & $10.5 \%$ & $0.3 \%$ & $4.6 \%$ & $15.3 \%$ & $0.2 \%$ & $6.6 \%$ & $27.3 \%$ & $-0.1 \%$ & $8.9 \%$ & $65.1 \%$ & $15.1 \%$ & $15.1 \%$ \\
\hline & 1989 & $8.0 \%$ & $-0.2 \%$ & $2.0 \%$ & $7.3 \%$ & $-0.3 \%$ & $2.4 \%$ & $5.4 \%$ & $-0.4 \%$ & $3.3 \%$ & $4.7 \%$ & $-0.9 \%$ & $5.0 \%$ & $13.6 \%$ & $-1.4 \%$ & $9.1 \%$ & $36.9 \%$ & $19.3 \%$ & $19.3 \%$ \\
\hline & 1990 & $2.9 \%$ & $-0.7 \%$ & $1.6 \%$ & $2.6 \%$ & $-0.8 \%$ & $2.0 \%$ & $-2.5 \%$ & $-1.0 \%$ & $2.9 \%$ & $-1.4 \%$ & $5.1 \%$ & $5.1 \%$ & $4.3 \%$ & $7.1 \%$ & $8.5 \%$ & $16.3 \%$ & $16.1 \%$ & $16.1 \%$ \\
\hline & 1991 & $2.1 \%$ & $1.8 \%$ & $1.9 \%$ & $1.6 \%$ & $2.2 \%$ & $2.3 \%$ & $-0.6 \%$ & $3.8 \%$ & $3.8 \%$ & $-0.3 \%$ & $5.0 \%$ & $5.0 \%$ & $6.1 \%$ & $6.7 \%$ & $8.5 \%$ & $18.9 \%$ & $16.1 \%$ & $16.1 \%$ \\
\hline & 1992 & $7.7 \%$ & $3.5 \%$ & $7.6 \%$ & $7.2 \%$ & $3.7 \%$ & $8.9 \%$ & $4.0 \%$ & $3.9 \%$ & $9.5 \%$ & $6.3 \%$ & $4.6 \%$ & $12.6 \%$ & $15.5 \%$ & $4.6 \%$ & $16.1 \%$ & $47.4 \%$ & $26.0 \%$ & $26.0 \%$ \\
\hline & 1993 & $9.9 \%$ & $1.0 \%$ & $5.2 \%$ & $10.1 \%$ & $5.6 \%$ & $6.0 \%$ & $8.6 \%$ & $1.3 \%$ & 7.3\% & $11.3 \%$ & $6.8 \%$ & $8.5 \%$ & $21.4 \%$ & $6.5 \%$ & $10.1 \%$ & $57.3 \%$ & $14.1 \%$ & $14.1 \%$ \\
\hline & 1994 & $14.9 \%$ & $0.8 \%$ & $2.7 \%$ & $17.4 \%$ & $0.9 \%$ & $9.1 \%$ & $12.1 \%$ & $1.0 \%$ & $9.9 \%$ & $7.2 \%$ & $0.7 \%$ & $9.4 \%$ & $4.4 \%$ & $0.1 \%$ & $8.1 \%$ & $8.4 \%$ & $5.0 \%$ & $5.0 \%$ \\
\hline & 1995 & $0.7 \%$ & $-0.1 \%$ & $0.1 \%$ & $0.1 \%$ & $-0.1 \%$ & $0.1 \%$ & $-0.4 \%$ & $-0.1 \%$ & $0.1 \%$ & $0.8 \%$ & $3.0 \%$ & $3.9 \%$ & $8.8 \%$ & $5.5 \%$ & $8.9 \%$ & $25.9 \%$ & $18.4 \%$ & $18.4 \%$ \\
\hline & 1996 & $1.9 \%$ & $1.8 \%$ & $1.8 \%$ & $2.4 \%$ & $2.3 \%$ & $2.3 \%$ & $0.9 \%$ & $3.7 \%$ & $3.9 \%$ & $0.6 \%$ & $4.9 \%$ & $5.3 \%$ & $6.4 \%$ & $6.9 \%$ & $8.5 \%$ & $19.3 \%$ & 16. & $16.1 \%$ \\
\hline & 1997 & $2.1 \%$ & $1.3 \%$ & $1.9 \%$ & $2.1 \%$ & $1.5 \%$ & $2.1 \%$ & $3.0 \%$ & $2.8 \%$ & $3.0 \%$ & $3.4 \%$ & $4.3 \%$ & $4.3 \%$ & $6.1 \%$ & $6.3 \%$ & 7.1\% & $17.3 \%$ & $14.0 \%$ & $14.0 \%$ \\
\hline & 1998 & $1.9 \%$ & $1.5 \%$ & $1.7 \%$ & $2.4 \%$ & $2.7 \%$ & $2.7 \%$ & $3.2 \%$ & $4.0 \%$ & $4.0 \%$ & $0.8 \%$ & $5.4 \%$ & $6.0 \%$ & $6.9 \%$ & $7.5 \%$ & $10.1 \%$ & $22.4 \%$ & $20.2 \%$ & $20.2 \%$ \\
\hline & 1999 & $2.3 \%$ & $1.2 \%$ & $2.3 \%$ & $1.8 \%$ & $1.4 \%$ & $2.0 \%$ & $2.3 \%$ & $2.9 \%$ & $2.9 \%$ & $3.1 \%$ & $3.9 \%$ & $3.9 \%$ & $4.9 \%$ & $6.1 \%$ & $6.2 \%$ & $13.4 \%$ & $11.7 \%$ & $11.7 \%$ \\
\hline & 2000 & $1.0 \%$ & $1.7 \%$ & & $2.0 \%$ & $2.8 \%$ & $2.8 \%$ & $0.4 \%$ & $3.7 \%$ & $3.7 \%$ & $3.0 \%$ & $5.1 \%$ & $5.1 \%$ & $8.6 \%$ & $6.2 \%$ & $8.2 \%$ & $22.9 \%$ & $15.6 \%$ & $15.6 \%$ \\
\hline & 2001 & $10.7 \%$ & $4.4 \%$ & $8.4 \%$ & $10.5 \%$ & $9.8 \%$ & $14.6 \%$ & $4.0 \%$ & $10.0 \%$ & $15.5 \%$ & $1.9 \%$ & $9.6 \%$ & $16.2 \%$ & $4.0 \%$ & $8.8 \%$ & $17.7 \%$ & $18.5 \%$ & $21.9 \%$ & $21.9 \%$ \\
\hline & 2002 & $2.1 \%$ & $0.2 \%$ & $1.5 \%$ & $1.4 \%$ & $0.0 \%$ & $1.5 \%$ & $-0.2 \%$ & $0.0 \%$ & $1.8 \%$ & $3.5 \%$ & $5.0 \%$ & $5.1 \%$ & $7.3 \%$ & $7.1 \%$ & $8.7 \%$ & $20.6 \%$ & $16.4 \%$ & $16.4 \%$ \\
\hline & 2003 & $5.8 \%$ & $2.5 \%$ & $5.2 \%$ & $6.2 \%$ & $2.8 \%$ & $5.4 \%$ & 4.7\% & $3.7 \%$ & $6.7 \%$ & $6.0 \%$ & $4.8 \%$ & $8.3 \%$ & $15.9 \%$ & $6.5 \%$ & $13.7 \%$ & $41.2 \%$ & $26.7 \%$ & 26.70 \\
\hline
\end{tabular}

Figure 70. Average proration and TWSA tables from the yearly summary page for the Black Rock_2 (BR_2), Wymer_1 (WY_1), and WymerPlus (WY+ ) scenarios, expressed as percentage change from the No Action baseline. Note-the proration rate is also expressed as a percentage. The percent change refers to the change in the rate not the actual proration percentage. For example, if the proration rate increased from 70 percent to 80 percent, the change is 14.2 percent, not 10 percent.

alternative. At Cle Elum Reservoir, carryover was significantly increased with all three alternatives. Large increases were recorded at Bumping Lake, Kachess, and Rimrock only with Black Rock_2 and WymerPlus (fig. 47).

- On an annual basis, large increases in carryover occurred frequently under the Black Rock_2 scenario at all the reservoirs (fig. 71). At Keechelus Reservoir, however, significant reductions in carryover were also recorded, thereby reducing the net carryover for the period of record as indicated in figure 47. This phenomenon was also observed for the two Wymer scenarios at Cle Elum and at Keechelus Reservoirs (fig. 71).

- Critical storage at Cle Elum Reservoir was evaluated by the number of days during the smolt outmigration hydroperiod when the reservoir volume was not sufficient to allow passage over the dam. Smolt passage from Cle Elum Reservoir was reduced from baseline conditions under all three scenarios (fig. 72). The number of impassable days significantly increased during 6 years, with comparable reductions in 3 years under Black Rock_2. The count of impassable days increased in 10 years under Wymer_1 and in 8 years under WymerPlus (fig. 72). 
Reservoir storage

End of Season Carryover

\begin{tabular}{|c|c|c|c|c|c|c|c|c|c|c|c|c|c|c|c|c|}
\hline \multirow{2}{*}{ Year } & & \multicolumn{3}{|c|}{ Bumping } & \multicolumn{3}{|c|}{ Cle Elum } & \multicolumn{3}{|c|}{ Kachess } & \multicolumn{3}{|c|}{ Keechelus } & \multicolumn{3}{|c|}{ Rimrock } \\
\hline & & BR_2 & WY_1 & WY+ & BR_2 & WY_1 & WY+ & BR_2 & WY_1 & WY+ & BR_2 & WY_1 & WY+ & BR_2 & WY_1 & WY+ \\
\hline & 1981 & $13.8 \%$ & $0.6 \%$ & $8.6 \%$ & 131.5\% & $-39.6 \%$ & $39.9 \%$ & $32.6 \%$ & \begin{tabular}{|l|}
$-3.7 \%$ \\
\end{tabular} & $5.5 \%$ & $100.1 \%$ & $2.2 \%$ & $1.9 \%$ & $30.4 \%$ & $9.9 \%$ & $19.5 \%$ \\
\hline & 1982 & $2.2 \%$ & $1.1 \%$ & $2.1 \%$ & $82.4 \%$ & $41.3 \%$ & $69.6 \%$ & $29.8 \%$ & $9.2 \%$ & $14.4 \%$ & $-24.1 \%$ & $-8.1 \%$ & $-17.0 \%$ & $57.9 \%$ & $8.3 \%$ & $61.4 \%$ \\
\hline & 1983 & $30.1 \%$ & $22.3 \%$ & $26.1 \%$ & $74.9 \%$ & $40.1 \%$ & $68.5 \%$ & $31.8 \%$ & $11.2 \%$ & $16.0 \%$ & $-48.8 \%$ & $-26.7 \%$ & $-38.1 \%$ & $92.2 \%$ & $25.5 \%$ & $90.3 \%$ \\
\hline & 1984 & $10.0 \%$ & $6.0 \%$ & $11.7 \%$ & $80.1 \%$ & $40.5 \%$ & $71.2 \%$ & $33.0 \%$ & $9.9 \%$ & $14.4 \%$ & $-28.8 \%$ & $-12.5 \%$ & $-20.7 \%$ & $46.9 \%$ & $5.5 \%$ & $46.4 \%$ \\
\hline & 1985 & $16.7 \%$ & $8.6 \%$ & $15.1 \%$ & $129.0 \%$ & $49.1 \%$ & $91.6 \%$ & $37.4 \%$ & $10.3 \%$ & $11.0 \%$ & $265.6 \%$ & $165.7 \%$ & $312.4 \%$ & $27.9 \%$ & $-5.5 \%$ & $67.2 \%$ \\
\hline & 1986 & $44.9 \%$ & $17.6 \%$ & $35.3 \%$ & $478.7 \%$ & $68.3 \%$ & $405.8 \%$ & $26.8 \%$ & $15.1 \%$ & $6.3 \%$ & $413.9 \%$ & $10.1 \%$ & $174.3 \%$ & $-38.4 \%$ & $19.7 \%$ & $-35.2 \%$ \\
\hline & 1987 & $136.3 \%$ & $0.0 \%$ & $59.1 \%$ & $844.6 \%$ & $-6.2 \%$ & $9.7 \%$ & $357.8 \%$ & $-9.8 \%$ & $159.8 \%$ & $104.3 \%$ & $2.2 \%$ & $2.5 \%$ & $840.8 \%$ & $75.9 \%$ & $294.5 \%$ \\
\hline & 1988 & $80.8 \%$ & $-3.2 \%$ & $19.0 \%$ & $179.5 \%$ & $-19.9 \%$ & $-17.0 \%$ & $370.3 \%$ & $-22.4 \%$ & $145.5 \%$ & $98.0 \%$ & $0.8 \%$ & $2.6 \%$ & $86.6 \%$ & $8.9 \%$ & $35.1 \%$ \\
\hline & 1989 & $30.4 \%$ & $-3.7 \%$ & $15.5 \%$ & $204.6 \%$ & $-69.5 \%$ & $116.3 \%$ & $20.4 \%$ & $0.0 \%$ & $-1.4 \%$ & $1136.6 \%$ & $-0.2 \%$ & $99.4 \%$ & $-64.8 \%$ & $8.7 \%$ & $-31.8 \%$ \\
\hline & 1990 & $2.8 \%$ & $2.2 \%$ & $2.9 \%$ & $51.8 \%$ & $32.9 \%$ & $62.0 \%$ & $20.6 \%$ & $2.6 \%$ & $6.3 \%$ & $2.3 \%$ & $24.8 \%$ & $12.2 \%$ & $23.4 \%$ & $14.3 \%$ & $74.3 \%$ \\
\hline & 1991 & $21.2 \%$ & $14.7 \%$ & $21.4 \%$ & $86.6 \%$ & $39.0 \%$ & $78.4 \%$ & $30.8 \%$ & $9.1 \%$ & $13.9 \%$ & $-56.8 \%$ & $-16.7 \%$ & $-24.8 \%$ & $61.4 \%$ & $-1.9 \%$ & $86.2 \%$ \\
\hline & 1992 & $122.1 \%$ & $1.3 \%$ & $70.6 \%$ & $426.5 \%$ & $-25.9 \%$ & $-13.3 \%$ & $321.3 \%$ & $20.1 \%$ & $207.1 \%$ & $79.2 \%$ & $-0.2 \%$ & $1.8 \%$ & $72.0 \%$ & $11.6 \%$ & $89.3 \%$ \\
\hline & 1993 & $216.7 \%$ & $20.5 \%$ & $43.5 \%$ & $161.4 \%$ & $-13.9 \%$ & $-10.1 \%$ & $1259.7 \%$ & $1.7 \%$ & $277.8 \%$ & $3.9 \%$ & $-4.3 \%$ & $-0.7 \%$ & $183.2 \%$ & $18.8 \%$ & $31.4 \%$ \\
\hline & 1994 & $-0.2 \%$ & $0.0 \%$ & $0.0 \%$ & $-30.1 \%$ & $-25.7 \%$ & $-26.9 \%$ & $116.7 \%$ & $-23.7 \%$ & $16.8 \%$ & $71.0 \%$ & $-3.1 \%$ & $128.3 \%$ & $-32.3 \%$ & $-63.6 \%$ & $-62.9 \%$ \\
\hline & 1995 & $3.3 \%$ & $1.5 \%$ & $2.6 \%$ & $57.3 \%$ & $28.0 \%$ & $56.9 \%$ & $25.5 \%$ & $-1.4 \%$ & $4.5 \%$ & $0.2 \%$ & $0.0 \%$ & $0.4 \%$ & $75.4 \%$ & $11.8 \%$ & $80.0 \%$ \\
\hline & 1996 & $6.9 \%$ & $9.8 \%$ & $12.1 \%$ & $69.2 \%$ & $38.8 \%$ & $68.9 \%$ & $34.5 \%$ & $10.9 \%$ & $16.0 \%$ & $-47.2 \%$ & $-13.5 \%$ & $-23.4 \%$ & $68.0 \%$ & $25.4 \%$ & $79.7 \%$ \\
\hline & 1997 & $3.7 \%$ & $2.1 \%$ & $3.1 \%$ & $42.8 \%$ & $30.3 \%$ & $37.8 \%$ & $24.1 \%$ & $10.2 \%$ & $12.3 \%$ & $-14.2 \%$ & $-9.9 \%$ & $-11.4 \%$ & $15.2 \%$ & $-4.2 \%$ & $19.6 \%$ \\
\hline & 1998 & $20.3 \%$ & $12.1 \%$ & $20.3 \%$ & $83.0 \%$ & $33.9 \%$ & $85.2 \%$ & $29.2 \%$ & $3.3 \%$ & $10.0 \%$ & $369.1 \%$ & $705.5 \%$ & $566.7 \%$ & $39.5 \%$ & $0.9 \%$ & $88.6 \%$ \\
\hline & 1999 & $-18.4 \%$ & $1.9 \%$ & $1.8 \%$ & $20.3 \%$ & $13.6 \%$ & $19.5 \%$ & $12.9 \%$ & $0.0 \%$ & $0.0 \%$ & $7.7 \%$ & $9.7 \%$ & $9.7 \%$ & $76.7 \%$ & $-2.2 \%$ & $49.8 \%$ \\
\hline & 2000 & $13.7 \%$ & $9.2 \%$ & $12.4 \%$ & $73.7 \%$ & $26.8 \%$ & $53.7 \%$ & $24.2 \%$ & $0.8 \%$ & $5.7 \%$ & $30.3 \%$ & $55.1 \%$ & $58.4 \%$ & $41.2 \%$ & $1.3 \%$ & $51.4 \%$ \\
\hline & 2001 & $39.9 \%$ & $7.0 \%$ & $45.9 \%$ & $-0.5 \%$ & $-4.3 \%$ & $-2.4 \%$ & $272.0 \%$ & $3.0 \%$ & $235.0 \%$ & $3.6 \%$ & $1.7 \%$ & $-2.5 \%$ & $55.0 \%$ & $32.1 \%$ & $36.3 \%$ \\
\hline & 2002 & $17.2 \%$ & $8.9 \%$ & $13.1 \%$ & $84.4 \%$ & $33.4 \%$ & $74.3 \%$ & $22.2 \%$ & $2.3 \%$ & $6.9 \%$ & $7.3 \%$ & $39.7 \%$ & $20.9 \%$ & $36.0 \%$ & $-17.6 \%$ & $76.0 \%$ \\
\hline
\end{tabular}

Figure 71. End-of-season carryover table from the yearly summary page for the Black Rock_2 (BR_2), Wymer_1 (WY_1), and WymerPlus (WY+ ) scenarios, expressed as percentage change from the No Action baseline.

\begin{tabular}{|c|c|c|c|c|}
\hline Critical Reservoir Storage & & & Cle Elum & \\
\hline Smolt Passage & Year & BR_2 & WY_1 & WY+ \\
\hline Days below threshold & 1982 & $48.3 \%$ & $82.8 \%$ & $55.2 \%$ \\
\hline & 1983 & $0.0 \%$ & $0.0 \%$ & $0.0 \%$ \\
\hline & 1984 & $0.0 \%$ & $0.0 \%$ & $0.0 \%$ \\
\hline & 1985 & $-100.0 \%$ & $-16.7 \%$ & $-100.0 \%$ \\
\hline & 1986 & $0.0 \%$ & $0.0 \%$ & $0.0 \%$ \\
\hline & 1987 & $-15.6 \%$ & $25.0 \%$ & $-12.5 \%$ \\
\hline & 1988 & $29.4 \%$ & $29.4 \%$ & $29.4 \%$ \\
\hline & 1989 & $0.0 \%$ & $89.5 \%$ & $89.5 \%$ \\
\hline & 1990 & $-100.0 \%$ & $950.0 \%$ & $150.0 \%$ \\
\hline & 1991 & $0.0 \%$ & $0.0 \%$ & $0.0 \%$ \\
\hline & 1992 & $0.0 \%$ & $0.0 \%$ & $0.0 \%$ \\
\hline & 1993 & $31.9 \%$ & $40.4 \%$ & $40.4 \%$ \\
\hline & 1994 & $29.4 \%$ & $29.4 \%$ & $29.4 \%$ \\
\hline & 1995 & $241.7 \%$ & $241.7 \%$ & $241.7 \%$ \\
\hline & 1996 & $0.0 \%$ & $0.0 \%$ & $0.0 \%$ \\
\hline & 1997 & $0.0 \%$ & $0.0 \%$ & $0.0 \%$ \\
\hline & 1998 & $0.0 \%$ & $0.0 \%$ & $0.0 \%$ \\
\hline & 1999 & $0.0 \%$ & $2300.0 \%$ & $0.0 \%$ \\
\hline & 2000 & $0.0 \%$ & $0.0 \%$ & $0.0 \%$ \\
\hline & 2001 & $0.0 \%$ & $0.0 \%$ & $0.0 \%$ \\
\hline & 2002 & $139.1 \%$ & $113.0 \%$ & $113.0 \%$ \\
\hline & 2003 & $0.0 \%$ & $0.0 \%$ & $0.0 \%$ \\
\hline
\end{tabular}

Figure 72. Cle Elum smolt passage table from the yearly summary page for the Black Rock_2 (BR_2), Wymer_1 (WY_1), and WymerPlus (WY+ ) scenarios, expressed as percentage change from the No Action baseline.

\section{Overbank Flows and Damaging Floods}

- For the period of record, overbank flows were generally increased at all the sites under the Black Rock_2 and WymerPlus scenarios (fig. 47). The Black Rock_2 alternative produced significant increases in the frequency of overbank flows at Easton, Union Gap, and Wapato, whereas the WymerPlus alternative produced similar results only at Wapato (fig. 47). The Wymer_1 alternative reduced the frequency of overbank flows at Kittitas, Union Gap, and Wapato and increased them slightly at the Naches site (fig. 47). 
- Figure 73 demonstrates that the frequency of overbank events was significantly increased at all the sites under the Black Rock_2 and WymerPlus alternatives; but at the Kittitas and Naches reaches, years showing increased frequencies were often offset by years having decreased frequencies. The most consistent increases in overbank flows appear to have occurred at Union Gap and at Wapato. The Wymer_1 alternative generally resulted in a reduction in overbank flow events at most of the sites (fig. 73).

- One incident of increased damaging floods was observed among the reaches and alternatives, at Easton under the Black Rock_2 alternative (figs. 47 and 74). Although the day count for damaging floods indicated a 200-percent increase over the baseline, this was a single event that occurred on two consecutive days. This potentially damaging flood occurred on November 24 and 25, 1990 (water year 1991), when the average daily flow from the baseline was increased from approximately $6,000 \mathrm{ft}^{3} / \mathrm{s}$ to slightly over $9,100 \mathrm{ft}^{3} / \mathrm{s}$ under the Black Rock_2 alternative. The default threshold for damaging floods at Easton was set at $9,070 \mathrm{ft}^{3} / \mathrm{s}$, so the simulated discharge was only slightly above the threshold. Any potential increase for damaging floods, however, should warrant the attention of the water management community. Furthermore, this high-flow event may have contributed to increased redd scour and reduced spawning-incubation persistence for fall spawners during 1991, as indicated in figures 48 and 50.

\section{Potential Fine-Sediment Transport}

- The potential for fine-sediment transport varied from reach to reach and by alternative. At Easton, this metric generally increased under all the alternatives, but the increase was significant only under the Black Rock_2 and Wymer_1 scenarios (fig. 47). Whereas the overall change in fine-sediment transport was similar for the period of record under all three scenarios, the annual characteristics were quite different. Significant increases in fine-sediment transport were

\begin{tabular}{|c|c|c|c|c|c|c|c|c|c|c|c|c|c|c|c|c|}
\hline \multirow[t]{24}{*}{$\begin{array}{l}\text { Overbank flow } \\
>1.67 \text { yr flood }\end{array}$} & & \multicolumn{3}{|c|}{ Easton } & \multicolumn{3}{|c|}{ Kittitas } & \multicolumn{3}{|c|}{ Naches } & \multicolumn{3}{|c|}{ Union Gap } & \multicolumn{3}{|c|}{ Wapato } \\
\hline & Year & BR_2 & WY_1 & WY+ & BR_2 & WY_1 & WY+ & BR_2 & WY_1 & WY+ & BR_2 & WY_1 & WY+ & BR_2 & WY_1 & WY+ \\
\hline & 1982 & $0.0 \%$ & $0.0 \%$ & $0.0 \%$ & $-100.0 \%$ & $-100.0 \%$ & $-75.0 \%$ & $-12.5 \%$ & $0.0 \%$ & $0.0 \%$ & $5.9 \%$ & $-52.9 \%$ & $0.0 \%$ & $-33.3 \%$ & $-33.3 \%$ & $-25.0 \%$ \\
\hline & 1983 & $200.0 \%$ & $0.0 \%$ & $0.0 \%$ & $0.0 \%$ & $0.0 \%$ & $0.0 \%$ & $0.0 \%$ & $0.0 \%$ & $0.0 \%$ & $63.6 \%$ & $-9.1 \%$ & $18.2 \%$ & $44.4 \%$ & $-11.1 \%$ & $22.2 \%$ \\
\hline & 1984 & $400.0 \%$ & $0.0 \%$ & $0.0 \%$ & $500.0 \%$ & $0.0 \%$ & $500.0 \%$ & $0.0 \%$ & $0.0 \%$ & $0.0 \%$ & $-33.3 \%$ & $0.0 \%$ & $40.0 \%$ & $100.0 \%$ & $0.0 \%$ & $120.0 \%$ \\
\hline & 1985 & $0.0 \%$ & $0.0 \%$ & $0.0 \%$ & $0.0 \%$ & $0.0 \%$ & $200.0 \%$ & $0.0 \%$ & $0.0 \%$ & $0.0 \%$ & $0.0 \%$ & $100.0 \%$ & $300.0 \%$ & $0.0 \%$ & $0.0 \%$ & $200.0 \%$ \\
\hline & 1986 & $0.0 \%$ & $0.0 \%$ & $0.0 \%$ & $0.0 \%$ & $0.0 \%$ & $0.0 \%$ & $-33.3 \%$ & $-16.7 \%$ & $16.7 \%$ & $33.3 \%$ & $0.0 \%$ & $33.3 \%$ & $33.3 \%$ & $0.0 \%$ & $0.0 \%$ \\
\hline & 1987 & $0.0 \%$ & $0.0 \%$ & $0.0 \%$ & $0.0 \%$ & $0.0 \%$ & $0.0 \%$ & $0.0 \%$ & $400.0 \%$ & $0.0 \%$ & $0.0 \%$ & $0.0 \%$ & $0.0 \%$ & $0.0 \%$ & $0.0 \%$ & $0.0 \%$ \\
\hline & 1988 & $0.0 \%$ & $0.0 \%$ & $0.0 \%$ & $0.0 \%$ & $0.0 \%$ & $0.0 \%$ & $0.0 \%$ & $0.0 \%$ & $0.0 \%$ & $0.0 \%$ & $0.0 \%$ & $0.0 \%$ & $0.0 \%$ & $0.0 \%$ & $0.0 \%$ \\
\hline & 1989 & $0.0 \%$ & $0.0 \%$ & $0.0 \%$ & $0.0 \%$ & $0.0 \%$ & $0.0 \%$ & $0.0 \%$ & $0.0 \%$ & $0.0 \%$ & $0.0 \%$ & $0.0 \%$ & $0.0 \%$ & $0.0 \%$ & $0.0 \%$ & $0.0 \%$ \\
\hline & 1990 & $85.7 \%$ & $0.0 \%$ & $0.0 \%$ & $0.0 \%$ & $0.0 \%$ & $0.0 \%$ & $0.0 \%$ & $0.0 \%$ & $0.0 \%$ & $20.0 \%$ & $0.0 \%$ & $0.0 \%$ & $50.0 \%$ & $0.0 \%$ & $100.0 \%$ \\
\hline & 1991 & $4.8 \%$ & $4.8 \%$ & $4.8 \%$ & $37.5 \%$ & $37.5 \%$ & $37.5 \%$ & $0.0 \%$ & $0.0 \%$ & $0.0 \%$ & $0.0 \%$ & $0.0 \%$ & $0.0 \%$ & $12.5 \%$ & $0.0 \%$ & $12.5 \%$ \\
\hline & 1992 & $0.0 \%$ & $0.0 \%$ & $0.0 \%$ & $0.0 \%$ & $0.0 \%$ & $0.0 \%$ & $0.0 \%$ & $0.0 \%$ & $0.0 \%$ & $0.0 \%$ & $0.0 \%$ & $0.0 \%$ & $0.0 \%$ & $0.0 \%$ & $0.0 \%$ \\
\hline & 1993 & $0.0 \%$ & $0.0 \%$ & $0.0 \%$ & $0.0 \%$ & $0.0 \%$ & $0.0 \%$ & $0.0 \%$ & $0.0 \%$ & $0.0 \%$ & $0.0 \%$ & $0.0 \%$ & $0.0 \%$ & $0.0 \%$ & $0.0 \%$ & $0.0 \%$ \\
\hline & 1994 & $0.0 \%$ & $0.0 \%$ & $0.0 \%$ & $0.0 \%$ & $0.0 \%$ & $0.0 \%$ & $0.0 \%$ & $0.0 \%$ & $0.0 \%$ & $0.0 \%$ & $0.0 \%$ & $0.0 \%$ & $0.0 \%$ & $0.0 \%$ & $0.0 \%$ \\
\hline & 1995 & $0.0 \%$ & $0.0 \%$ & $0.0 \%$ & $0.0 \%$ & $0.0 \%$ & $0.0 \%$ & $0.0 \%$ & $0.0 \%$ & $0.0 \%$ & $0.0 \%$ & $0.0 \%$ & $0.0 \%$ & $0.0 \%$ & $-11.1 \%$ & $-11.1 \%$ \\
\hline & 1996 & $24.0 \%$ & $0.0 \%$ & $4.0 \%$ & $19.2 \%$ & $3.8 \%$ & $11.5 \%$ & $12.5 \%$ & $4.2 \%$ & $12.5 \%$ & $19.3 \%$ & $-8.8 \%$ & $0.0 \%$ & $15.3 \%$ & $-8.5 \%$ & $3.4 \%$ \\
\hline & 1997 & $-4.8 \%$ & $-4.8 \%$ & $0.0 \%$ & $0.0 \%$ & $2.9 \%$ & $8.6 \%$ & $0.0 \%$ & $2.9 \%$ & $2.9 \%$ & $12.7 \%$ & $-3.2 \%$ & $7.9 \%$ & $20.9 \%$ & $-4.7 \%$ & $18.6 \%$ \\
\hline & 1998 & $0.0 \%$ & $0.0 \%$ & $0.0 \%$ & $0.0 \%$ & $0.0 \%$ & $0.0 \%$ & $50.0 \%$ & $0.0 \%$ & $37.5 \%$ & $44.4 \%$ & $-11.1 \%$ & $33.3 \%$ & $120.0 \%$ & $0.0 \%$ & $100.0 \%$ \\
\hline & 1999 & $0.0 \%$ & $0.0 \%$ & $0.0 \%$ & $0.0 \%$ & $0.0 \%$ & $0.0 \%$ & $0.0 \%$ & $0.0 \%$ & $0.0 \%$ & $29.4 \%$ & $-11.8 \%$ & $11.8 \%$ & $14.3 \%$ & $0.0 \%$ & $71.4 \%$ \\
\hline & 2000 & $25.0 \%$ & $0.0 \%$ & $0.0 \%$ & $-37.5 \%$ & $-62.5 \%$ & $-50.0 \%$ & $200.0 \%$ & $0.0 \%$ & $200.0 \%$ & $16.7 \%$ & $-25.0 \%$ & $8.3 \%$ & $33.3 \%$ & $-22.2 \%$ & $22.2 \%$ \\
\hline & 2001 & $0.0 \%$ & $0.0 \%$ & $0.0 \%$ & $0.0 \%$ & $0.0 \%$ & $0.0 \%$ & $0.0 \%$ & $0.0 \%$ & $0.0 \%$ & $0.0 \%$ & $0.0 \%$ & $0.0 \%$ & $0.0 \%$ & $0.0 \%$ & $0.0 \%$ \\
\hline & 2002 & $100.0 \%$ & $0.0 \%$ & $100.0 \%$ & $-100.0 \%$ & $-100.0 \%$ & $-100.0 \%$ & $0.0 \%$ & $0.0 \%$ & $0.0 \%$ & $-16.7 \%$ & $-33.3 \%$ & $-33.3 \%$ & $0.0 \%$ & $0.0 \%$ & $33.3 \%$ \\
\hline & 2003 & $0.0 \%$ & $0.0 \%$ & $0.0 \%$ & $0.0 \%$ & $0.0 \%$ & $0.0 \%$ & $0.0 \%$ & $-33.3 \%$ & $0.0 \%$ & $0.0 \%$ & $0.0 \%$ & $0.0 \%$ & $0.0 \%$ & $0.0 \%$ & $0.0 \%$ \\
\hline
\end{tabular}

Figure 73. Overbank flow summary table from the yearly summary page for the Black Rock_2 (BR_2), Wymer_1 (WY_1), and WymerPlus (WY+ ) scenarios, expressed as percentage change in frequency from the No Action baseline. 


\begin{tabular}{|c|c|c|c|c|c|c|c|c|c|c|c|c|c|c|c|c|}
\hline \multirow{24}{*}{$\begin{array}{l}\text { Damaging flood } \\
\text { (>= 25 yr) }\end{array}$} & \multicolumn{4}{|c|}{ Easton } & \multicolumn{3}{|c|}{ Kittitas } & \multicolumn{3}{|c|}{ Naches } & \multicolumn{3}{|c|}{ Union Gap } & \multicolumn{3}{|c|}{ Wapato } \\
\hline & Year & BR_2 & WY_1 & WY+ & BR_2 & WY_1 & WY+ & BR_2 & WY_1 & WY+ & BR_2 & WY_1 & WY+ & BR_2 & WY_1 & WY+ \\
\hline & 1982 & $0.0 \%$ & $0.0 \%$ & $0.0 \%$ & $0.0 \%$ & $0.0 \%$ & $0.0 \%$ & $0.0 \%$ & $0.0 \%$ & $0.0 \%$ & $0.0 \%$ & $0.0 \%$ & $0.0 \%$ & $0.0 \%$ & $0.0 \%$ & $0.0 \%$ \\
\hline & 1983 & $0.0 \%$ & $0.0 \%$ & $0.0 \%$ & $0.0 \%$ & $0.0 \%$ & $0.0 \%$ & $0.0 \%$ & $0.0 \%$ & $0.0 \%$ & $0.0 \%$ & $0.0 \%$ & $0.0 \%$ & $0.0 \%$ & $0.0 \%$ & $0.0 \%$ \\
\hline & 1984 & $0.0 \%$ & $0.0 \%$ & $0.0 \%$ & $0.0 \%$ & $0.0 \%$ & $0.0 \%$ & $0.0 \%$ & $0.0 \%$ & $0.0 \%$ & $0.0 \%$ & $0.0 \%$ & $0.0 \%$ & $0.0 \%$ & $0.0 \%$ & $0.0 \%$ \\
\hline & 1985 & $0.0 \%$ & $0.0 \%$ & $0.0 \%$ & $0.0 \%$ & $0.0 \%$ & $0.0 \%$ & $0.0 \%$ & $0.0 \%$ & $0.0 \%$ & $0.0 \%$ & $0.0 \%$ & $0.0 \%$ & $0.0 \%$ & $0.0 \%$ & $0.0 \%$ \\
\hline & 1986 & $0.0 \%$ & $0.0 \%$ & $0.0 \%$ & $0.0 \%$ & $0.0 \%$ & $0.0 \%$ & $0.0 \%$ & $0.0 \%$ & $0.0 \%$ & $0.0 \%$ & $0.0 \%$ & $0.0 \%$ & $0.0 \%$ & $0.0 \%$ & $0.0 \%$ \\
\hline & 1987 & $0.0 \%$ & $0.0 \%$ & $0.0 \%$ & $0.0 \%$ & $0.0 \%$ & $0.0 \%$ & $0.0 \%$ & $0.0 \%$ & $0.0 \%$ & $0.0 \%$ & $0.0 \%$ & $0.0 \%$ & $0.0 \%$ & $0.0 \%$ & $0.0 \%$ \\
\hline & 1988 & $0.0 \%$ & $0.0 \%$ & $0.0 \%$ & $0.0 \%$ & $0.0 \%$ & $0.0 \%$ & $0.0 \%$ & $0.0 \%$ & $0.0 \%$ & $0.0 \%$ & $0.0 \%$ & $0.0 \%$ & $0.0 \%$ & $0.0 \%$ & $0.0 \%$ \\
\hline & 1989 & $0.0 \%$ & $0.0 \%$ & $0.0 \%$ & $0.0 \%$ & $0.0 \%$ & $0.0 \%$ & $0.0 \%$ & $0.0 \%$ & $0.0 \%$ & $0.0 \%$ & $0.0 \%$ & $0.0 \%$ & $0.0 \%$ & $0.0 \%$ & $0.0 \%$ \\
\hline & 1990 & $0.0 \%$ & $0.0 \%$ & $0.0 \%$ & $0.0 \%$ & $0.0 \%$ & $0.0 \%$ & $0.0 \%$ & $0.0 \%$ & $0.0 \%$ & $0.0 \%$ & $0.0 \%$ & $0.0 \%$ & $0.0 \%$ & $0.0 \%$ & $0.0 \%$ \\
\hline & 1991 & $200.0 \%$ & $0.0 \%$ & $0.0 \%$ & $0.0 \%$ & $0.0 \%$ & $0.0 \%$ & $0.0 \%$ & $0.0 \%$ & $0.0 \%$ & $0.0 \%$ & $0.0 \%$ & $0.0 \%$ & $0.0 \%$ & $0.0 \%$ & $0.0 \%$ \\
\hline & 1992 & $0.0 \%$ & $0.0 \%$ & $0.0 \%$ & $0.0 \%$ & $0.0 \%$ & $0.0 \%$ & $0.0 \%$ & $0.0 \%$ & $0.0 \%$ & $0.0 \%$ & $0.0 \%$ & $0.0 \%$ & $0.0 \%$ & $0.0 \%$ & $0.0 \%$ \\
\hline & 1993 & $0.0 \%$ & $0.0 \%$ & $0.0 \%$ & $0.0 \%$ & $0.0 \%$ & $0.0 \%$ & $0.0 \%$ & $0.0 \%$ & $0.0 \%$ & $0.0 \%$ & $0.0 \%$ & $0.0 \%$ & $0.0 \%$ & $0.0 \%$ & $0.0 \%$ \\
\hline & 1994 & $0.0 \%$ & $0.0 \%$ & $0.0 \%$ & $0.0 \%$ & $0.0 \%$ & $0.0 \%$ & $0.0 \%$ & $0.0 \%$ & $0.0 \%$ & $0.0 \%$ & $0.0 \%$ & $0.0 \%$ & $0.0 \%$ & $0.0 \%$ & $0.0 \%$ \\
\hline & 1995 & $0.0 \%$ & $0.0 \%$ & $0.0 \%$ & $0.0 \%$ & $0.0 \%$ & $0.0 \%$ & $0.0 \%$ & $0.0 \%$ & $0.0 \%$ & $0.0 \%$ & $0.0 \%$ & $0.0 \%$ & $0.0 \%$ & $0.0 \%$ & $0.0 \%$ \\
\hline & 1996 & $0.0 \%$ & $0.0 \%$ & $0.0 \%$ & $0.0 \%$ & $0.0 \%$ & $0.0 \%$ & $0.0 \%$ & $0.0 \%$ & $0.0 \%$ & $0.0 \%$ & $0.0 \%$ & $0.0 \%$ & $0.0 \%$ & $0.0 \%$ & $0.0 \%$ \\
\hline & 1997 & $0.0 \%$ & $0.0 \%$ & $0.0 \%$ & $0.0 \%$ & $0.0 \%$ & $0.0 \%$ & $0.0 \%$ & $0.0 \%$ & $0.0 \%$ & $0.0 \%$ & $0.0 \%$ & $0.0 \%$ & $0.0 \%$ & $0.0 \%$ & $0.0 \%$ \\
\hline & 1998 & $0.0 \%$ & $0.0 \%$ & $0.0 \%$ & $0.0 \%$ & $0.0 \%$ & $0.0 \%$ & $0.0 \%$ & $0.0 \%$ & $0.0 \%$ & $0.0 \%$ & $0.0 \%$ & $0.0 \%$ & $0.0 \%$ & $0.0 \%$ & $0.0 \%$ \\
\hline & 1999 & $0.0 \%$ & $0.0 \%$ & $0.0 \%$ & $0.0 \%$ & $0.0 \%$ & $0.0 \%$ & $0.0 \%$ & $0.0 \%$ & $0.0 \%$ & $0.0 \%$ & $0.0 \%$ & $0.0 \%$ & $0.0 \%$ & $0.0 \%$ & $0.0 \%$ \\
\hline & 2000 & $0.0 \%$ & $0.0 \%$ & $0.0 \%$ & $0.0 \%$ & $0.0 \%$ & $0.0 \%$ & $0.0 \%$ & $0.0 \%$ & $0.0 \%$ & $0.0 \%$ & $0.0 \%$ & $0.0 \%$ & $0.0 \%$ & $0.0 \%$ & $0.0 \%$ \\
\hline & 2001 & $0.0 \%$ & $0.0 \%$ & $0.0 \%$ & $0.0 \%$ & $0.0 \%$ & $0.0 \%$ & $0.0 \%$ & $0.0 \%$ & $0.0 \%$ & $0.0 \%$ & $0.0 \%$ & $0.0 \%$ & $0.0 \%$ & $0.0 \%$ & $0.0 \%$ \\
\hline & 2002 & $0.0 \%$ & $0.0 \%$ & $0.0 \%$ & $0.0 \%$ & $0.0 \%$ & $0.0 \%$ & $0.0 \%$ & $0.0 \%$ & $0.0 \%$ & $0.0 \%$ & $0.0 \%$ & $0.0 \%$ & $0.0 \%$ & $0.0 \%$ & $0.0 \%$ \\
\hline & 2003 & $0.0 \%$ & $0.0 \%$ & $0.0 \%$ & $0.0 \%$ & $0.0 \%$ & $0.0 \%$ & $0.0 \%$ & $0.0 \%$ & $0.0 \%$ & $0.0 \%$ & $0.0 \%$ & $0.0 \%$ & $0.0 \%$ & $0.0 \%$ & $0.0 \%$ \\
\hline
\end{tabular}

Figure 74. Damaging floods summary table from the yearly summary page for the Black Rock_2 (BR_2), Wymer_1 (WY_1), and WymerPlus (WY+) scenarios, expressed as percentage change in frequency from the No Action baseline.

recorded in many years under Black Rock_2 and WymerPlus, but the increases were offset by a comparable number of reductions. The Wymer_1 alternative resulted in fewer years having significant increases in fine-sediment transport but also resulted in fewer reductions (fig. 75).

- At Kittitas, potential transport of fine sediment was reduced slightly for the period of record under all three scenarios (fig. 47). Significant reductions occurred in 3 years under Black Rock_2 and in 2 years under Wymer_1. None of the reductions recorded for the WymerPlus alternative was significant in this reach (fig. 75). Very small reductions in fine-sediment

Fine-Sediment Transport

\begin{tabular}{|c|c|c|c|c|c|c|c|c|c|c|c|c|c|c|c|c|}
\hline \multirow[b]{2}{*}{ Yea } & & \multicolumn{3}{|c|}{ Easton } & \multicolumn{3}{|c|}{ Kittitas } & \multicolumn{3}{|c|}{ Naches } & \multicolumn{3}{|c|}{ Union Gap } & \multicolumn{3}{|c|}{ Wapato } \\
\hline & & BR_2 & WY_1 & WY+ & BR_2 & WY_1 & WY+ & BR_2 & WY_1 & WY+ & BR_2 & WY_1 & WY+ & BR_2 & WY_1 & WY+ \\
\hline & 1982 & $33.3 \%$ & $-0.4 \%$ & $8.8 \%$ & $-4.7 \%$ & $-9.5 \%$ & $-9.2 \%$ & $-1.6 \%$ & $0.3 \%$ & $-0.9 \%$ & $4.0 \%$ & \begin{tabular}{|c|}
$-7.7 \%$ \\
\end{tabular} & $0.2 \%$ & $20.2 \%$ & $-9.0 \%$ & $17.5 \%$ \\
\hline & 1983 & $22.9 \%$ & $8.9 \%$ & $13.6 \%$ & $-2.3 \%$ & $-1.6 \%$ & $-2.1 \%$ & $-2.3 \%$ & $-0.6 \%$ & $-1.5 \%$ & $7.3 \%$ & $-3.3 \%$ & $6.1 \%$ & $21.3 \%$ & $-3.7 \%$ & $24.2 \%$ \\
\hline & 1984 & $10.5 \%$ & $4.5 \%$ & $6.9 \%$ & $-5.2 \%$ & $-3.3 \%$ & $-3.1 \%$ & $0.5 \%$ & $1.0 \%$ & $3.0 \%$ & $7.6 \%$ & $-1.8 \%$ & $10.1 \%$ & $23.3 \%$ & $-1.7 \%$ & $28.4 \%$ \\
\hline & 1985 & $-17.3 \%$ & $-14.6 \%$ & $-23.4 \%$ & $-2.1 \%$ & $1.6 \%$ & $3.0 \%$ & $1.8 \%$ & $4.7 \%$ & $4.9 \%$ & $16.5 \%$ & $-1.1 \%$ & $16.5 \%$ & $93.5 \%$ & $-3.3 \%$ & $80.7 \%$ \\
\hline & 1986 & $-0.8 \%$ & $0.0 \%$ & $-3.9 \%$ & $-2.5 \%$ & $3.8 \%$ & $0.6 \%$ & $-0.7 \%$ & $-1.3 \%$ & $2.3 \%$ & $13.0 \%$ & $0.2 \%$ & $11.1 \%$ & $45.0 \%$ & $-0.5 \%$ & $35.7 \%$ \\
\hline & 1987 & $-35.0 \%$ & $14.1 \%$ & $-24.4 \%$ & $-2.9 \%$ & $2.2 \%$ & $5.5 \%$ & $-8.5 \%$ & $1.2 \%$ & $-4.0 \%$ & $12.4 \%$ & $4.2 \%$ & $17.8 \%$ & $57.8 \%$ & $2.2 \%$ & $48.9 \%$ \\
\hline & 1988 & $-21.9 \%$ & $1.3 \%$ & $-11.4 \%$ & $-11.4 \%$ & $-3.7 \%$ & $-5.7 \%$ & $6.5 \%$ & $2.2 \%$ & $2.9 \%$ & $12.7 \%$ & $1.1 \%$ & $15.7 \%$ & $72.1 \%$ & $-4.6 \%$ & $60.2 \%$ \\
\hline & 1989 & $48.4 \%$ & $-4.2 \%$ & $5.9 \%$ & $0.3 \%$ & $-3.3 \%$ & $-7.2 \%$ & $11.2 \%$ & $1.9 \%$ & $4.4 \%$ & $22.5 \%$ & $-0.1 \%$ & $11.1 \%$ & $76.2 \%$ & $-0.6 \%$ & $44.8 \%$ \\
\hline & 1990 & $37.3 \%$ & $6.6 \%$ & $9.5 \%$ & $0.1 \%$ & $-10.9 \%$ & $-6.9 \%$ & $-5.0 \%$ & $1.6 \%$ & $-0.6 \%$ & $8.8 \%$ & $-7.2 \%$ & $4.6 \%$ & $39.9 \%$ & $-10.6 \%$ & $25.1 \%$ \\
\hline & 1991 & $36.5 \%$ & $38.9 \%$ & $35.7 \%$ & $-1.3 \%$ & $1.0 \%$ & $0.6 \%$ & $-4.0 \%$ & $-0.2 \%$ & $-1.8 \%$ & $6.2 \%$ & $-0.3 \%$ & $7.0 \%$ & $23.5 \%$ & $-1.3 \%$ & $23.0 \%$ \\
\hline & 1992 & $-50.4 \%$ & $-2.8 \%$ & $-40.0 \%$ & $-8.3 \%$ & $3.6 \%$ & $2.8 \%$ & $-5.1 \%$ & $-3.2 \%$ & $0.4 \%$ & $10.0 \%$ & $2.1 \%$ & $17.1 \%$ & $47.0 \%$ & $-3.4 \%$ & $45.2 \%$ \\
\hline & 1993 & $-37.7 \%$ & $-16.4 \%$ & $-3.1 \%$ & $-5.5 \%$ & $-6.9 \%$ & $-3.4 \%$ & $-7.4 \%$ & $-1.8 \%$ & $-2.1 \%$ & $13.9 \%$ & $3.9 \%$ & $22.7 \%$ & $68.9 \%$ & $-6.6 \%$ & $74.6 \%$ \\
\hline & 1994 & $1.9 \%$ & $5.6 \%$ & $-7.3 \%$ & $8.4 \%$ & $-0.9 \%$ & $-2.0 \%$ & $7.8 \%$ & $-0.1 \%$ & $0.4 \%$ & $19.1 \%$ & $-1.6 \%$ & $15.2 \%$ & $74.2 \%$ & $-5.2 \%$ & $72.6 \%$ \\
\hline & 1995 & $0.4 \%$ & $-2.3 \%$ & $-0.5 \%$ & $-10.9 \%$ & $-5.3 \%$ & $-9.3 \%$ & $-3.7 \%$ & $-0.1 \%$ & $-1.3 \%$ & $1.4 \%$ & $-4.2 \%$ & $1.0 \%$ & $21.6 \%$ & $-9.5 \%$ & $14.3 \%$ \\
\hline & 1996 & $24.8 \%$ & $21.5 \%$ & $23.8 \%$ & $-1.8 \%$ & $-0.4 \%$ & $0.5 \%$ & $0.8 \%$ & $-0.7 \%$ & $2.7 \%$ & $-1.1 \%$ & $-3.9 \%$ & $1.1 \%$ & $6.0 \%$ & $-4.9 \%$ & 7.1\% \\
\hline & 1997 & $21.6 \%$ & $28.0 \%$ & $25.0 \%$ & $-4.0 \%$ & $-2.7 \%$ & $-1.8 \%$ & $-1.4 \%$ & $1.4 \%$ & $-0.5 \%$ & $1.9 \%$ & $-0.9 \%$ & $4.6 \%$ & $5.5 \%$ & $-1.9 \%$ & $12.8 \%$ \\
\hline & 1998 & $8.2 \%$ & $1.8 \%$ & $4.4 \%$ & $-2.3 \%$ & $-0.6 \%$ & $-2.7 \%$ & $3.3 \%$ & $1.5 \%$ & $6.0 \%$ & $8.4 \%$ & $-3.2 \%$ & $8.2 \%$ & $28.0 \%$ & $-1.1 \%$ & $30.7 \%$ \\
\hline & 1999 & $25.3 \%$ & $23.7 \%$ & $28.3 \%$ & $-0.7 \%$ & $-1.3 \%$ & $1.9 \%$ & $-3.2 \%$ & $0.7 \%$ & $-0.3 \%$ & $5.4 \%$ & $-1.0 \%$ & $6.4 \%$ & $17.5 \%$ & $-1.2 \%$ & $27.0 \%$ \\
\hline & 2000 & $22.3 \%$ & $14.0 \%$ & $11.6 \%$ & $-5.8 \%$ & $-1.4 \%$ & $-2.6 \%$ & $4.0 \%$ & $1.8 \%$ & $5.1 \%$ & $3.6 \%$ & $-3.5 \%$ & $5.8 \%$ & $23.0 \%$ & $-3.5 \%$ & $26.8 \%$ \\
\hline & 2001 & $-29.1 \%$ & $1.3 \%$ & $-34.7 \%$ & $12.7 \%$ & $8.7 \%$ & $5.5 \%$ & $-3.4 \%$ & $-2.0 \%$ & $-1.1 \%$ & $23.7 \%$ & $7.4 \%$ & $32.3 \%$ & $99.4 \%$ & $-6.6 \%$ & $100.8 \%$ \\
\hline & 2002 & $41.7 \%$ & $-6.8 \%$ & $37.6 \%$ & $-11.4 \%$ & $-10.5 \%$ & $-9.7 \%$ & $-0.7 \%$ & $1.5 \%$ & $-0.5 \%$ & $5.3 \%$ & $-5.5 \%$ & $3.7 \%$ & $25.6 \%$ & $-11.5 \%$ & $26.8 \%$ \\
\hline & 2003 & $-9.9 \%$ & $-1.6 \%$ & $-13.0 \%$ & $-5.1 \%$ & $1.9 \%$ & $-0.2 \%$ & $0.7 \%$ & $-1.4 \%$ & $4.6 \%$ & $9.4 \%$ & $-3.3 \%$ & $10.8 \%$ & $49.5 \%$ & $-6.9 \%$ & $39.6 \%$ \\
\hline
\end{tabular}

Figure 75. Fine-sediment transport table from the yearly summary pages for the Black Rock_2 (BR_2), Wymer_1 (WY_1), and WymerPlus (WY+ ) scenarios, expressed as percentage change from the No Action baseline. 
transport also tended to dominate at the Naches reach under all three scenarios, although one significant increase was recorded for the Black Rock_2 alternative. Beyond that solitary increase, the remaining changes in fine-sediment transport at Naches were negligible.

- The potential transport of fine sediment increased significantly in nearly half the years at Union Gap and in nearly all years at Wapato under the Black Rock_2 and WymerPlus alternatives (fig. 75). Relatively small reductions in fine-sediment transport dominated most of the years under Wymer_1.

\section{Geomorphic Adjustment}

- Overall, geomorphic work was increased under all the scenarios at the Easton reach but significant increases were recorded only for the Black Rock_2 and Wymer_1 alternatives (fig. 47). On an annual basis, changes in geomorphic work at this site (fig. 76) tracked closely with fine sediment transport (fig. 75). Examination of the geomorphic adjustment tables in Appendix figures 4-6, 5-6, and 6-6 illustrated that in years when geomorphic work and fine-sediment transport were reduced, especially under Black Rock_2, the minimum threshold for effective channel maintenance was not met (indicated by a color code shift from green to red), representing a potential for in-channel sediment storage. In several years, the color code shift in the appendix figures was from green to orange, signaling a potential for increased bank erosion.

- In contrast to Easton, geomorphic work was reduced in the Kittitas reach under the three scenarios for the period of record (fig. 47), also corresponding to the reduction in fine-sediment transport observed in figure 75. On an annual basis, reductions in geomorphic work were observed in 12 years under Black Rock_2, 10 of which were significant or nearly significant (fig. 76). Reductions were recorded in 14 years under Wymer_1, but only five were significant. Under the WymerPlus alternative, increases and decreases in geomorphic work were nearly evenly split, with 3 years having significant decreases and 3 years having comparable increases (fig. 76).

- The Black Rock_2 and Wymer_1 alternatives resulted in slight net decreases in the geomorphic adjustment metric for the period of record at Union Gap. A small net increase occurred under the WymerPlus alternative. On an annual basis, the Black Rock_2 scenario resulted in considerably more years having significantly increased geomorphic work than the other two alternatives, but the Black Rock_2 scenario also resulted in more years having large reductions (fig. 76). The relation between fine-sediment transport and geomorphic adjustment witnessed at the upstream sites was also apparent at Union Gap. During years when the geomorphic adjustment metric increased, the scores for fine-sediment transport reached their highest values. The lowest scores for fine-sediment transport corresponded to years when the geomorphic adjustment was negative.

- The effects of the Black Rock_2 and WymerPlus alternatives were mostly positive at the Wapato reach, with significant increases in geomorphic adjustment occurring in 8 and 9 years, respectively (fig. 76). Geomorphic work was reduced in most years under the Wymer_1 alternative, but only two of the reductions were significant.

For the purposes of the YRDSS, the state variables for fine-sediment transport and geomorphic work may be considered redundant even though they were intended to depict different aspects of channel processes. Data from the sediment lookup tables contained in the DSS_Agg workbooks indicate a strong correlation between the two variables $\left(r^{2}>0.999\right.$ for polynomial regressions). 


\begin{tabular}{|c|c|c|c|c|c|c|c|c|c|c|c|c|c|c|c|c|}
\hline \multirow{2}{*}{$\begin{array}{l}\text { Geomorphic } \\
\text { Adjustment }\end{array}$} & \multirow[b]{2}{*}{ Year } & \multicolumn{3}{|c|}{ Easton } & \multicolumn{3}{|c|}{ Kittitas } & \multicolumn{3}{|c|}{ Naches } & \multicolumn{3}{|c|}{ Union Gap } & \multicolumn{3}{|c|}{ Wapato } \\
\hline & & BR_2 & WY_1 & WY+ & BR_2 & WY_1 & WY+ & BR_2 & WY_1 & WY+ & BR_2 & WY_1 & WY+ & BR_2 & WY_1 & WY+ \\
\hline & 1982 & $19.5 \%$ & $12.2 \%$ & $14.4 \%$ & $-23.3 \%$ & $-23.4 \%$ & $-21.5 \%$ & $-2.6 \%$ & $-0.9 \%$ & $-1.2 \%$ & $-12.8 \%$ & $-0.9 \%$ & $-0.6 \%$ & $-4.0 \%$ & $1.4 \%$ & $1.4 \%$ \\
\hline & 1983 & $70.9 \%$ & $42.8 \%$ & $50.6 \%$ & $10.9 \%$ & $2.7 \%$ & $10.8 \%$ & $-2.1 \%$ & $3.0 \%$ & $-0.7 \%$ & $-7.1 \%$ & $-7.4 \%$ & $2.1 \%$ & $-9.3 \%$ & $-2.4 \%$ & $1.2 \%$ \\
\hline & 1984 & $54.6 \%$ & $20.2 \%$ & $4.9 \%$ & $-24.2 \%$ & $-3.7 \%$ & $0.5 \%$ & $-19.9 \%$ & $0.3 \%$ & $2.0 \%$ & $-13.2 \%$ & $-2.4 \%$ & $5.3 \%$ & $-4.6 \%$ & $-8.4 \%$ & $14.1 \%$ \\
\hline & 1985 & $-15.1 \%$ & $-11.1 \%$ & $-14.3 \%$ & $-10.4 \%$ & $-7.4 \%$ & $16.6 \%$ & $-4.8 \%$ & $6.8 \%$ & $10.5 \%$ & $8.5 \%$ & $-5.1 \%$ & $41.3 \%$ & $37.0 \%$ & $0.1 \%$ & $40.6 \%$ \\
\hline & 1986 & $16.9 \%$ & $-10.2 \%$ & $-4.9 \%$ & $1.9 \%$ & $5.3 \%$ & $8.9 \%$ & $-11.1 \%$ & $-4.0 \%$ & $-1.1 \%$ & $4.0 \%$ & $1.4 \%$ & $-1.7 \%$ & $3.8 \%$ & $1.8 \%$ & $0.5 \%$ \\
\hline & 1987 & $-48.6 \%$ & $18.5 \%$ & $-40.7 \%$ & $-24.4 \%$ & $-5.3 \%$ & $-6.4 \%$ & $-6.1 \%$ & $8.6 \%$ & $-4.5 \%$ & $18.0 \%$ & $6.8 \%$ & $7.4 \%$ & $25.9 \%$ & $0.2 \%$ & $11.9 \%$ \\
\hline & 1988 & $5.2 \%$ & $7.6 \%$ & $11.3 \%$ & $-12.9 \%$ & $-5.0 \%$ & $-3.5 \%$ & $2.1 \%$ & $0.5 \%$ & $1.7 \%$ & $13.5 \%$ & $0.9 \%$ & $7.3 \%$ & $32.6 \%$ & $-1.4 \%$ & $30.1 \%$ \\
\hline & 1989 & $94.5 \%$ & $8.9 \%$ & $12.5 \%$ & $14.3 \%$ & $-3.6 \%$ & $-1.5 \%$ & $15.7 \%$ & $2.1 \%$ & $7.9 \%$ & $27.7 \%$ & $0.5 \%$ & $5.5 \%$ & $44.3 \%$ & $2.0 \%$ & $20.3 \%$ \\
\hline & 1990 & $36.4 \%$ & $19.1 \%$ & $23.0 \%$ & $9.6 \%$ & $4.8 \%$ & $8.3 \%$ & $-8.0 \%$ & $0.5 \%$ & $-1.9 \%$ & $4.5 \%$ & $1.4 \%$ & $3.2 \%$ & $6.4 \%$ & $1.3 \%$ & $7.6 \%$ \\
\hline & 1991 & $62.1 \%$ & $52.2 \%$ & $44.9 \%$ & $16.8 \%$ & $12.7 \%$ & $14.2 \%$ & $1.0 \%$ & $0.9 \%$ & $3.4 \%$ & $1.0 \%$ & $6.1 \%$ & $6.6 \%$ & $1.0 \%$ & $7.1 \%$ & $6.6 \%$ \\
\hline & 1992 & $-69.8 \%$ & $3.6 \%$ & $-51.9 \%$ & $-4.4 \%$ & $1.5 \%$ & $0.4 \%$ & $10.7 \%$ & $-0.7 \%$ & $31.9 \%$ & $18.5 \%$ & $0.4 \%$ & $1.8 \%$ & $2.0 \%$ & $-1.1 \%$ & $2.6 \%$ \\
\hline & 1993 & $-61.9 \%$ & $-28.8 \%$ & $-7.3 \%$ & $-30.0 \%$ & $-12.4 \%$ & $-6.5 \%$ & $2.5 \%$ & $0.4 \%$ & $1.8 \%$ & $14.9 \%$ & $-2.4 \%$ & $8.7 \%$ & $56.6 \%$ & $-1.0 \%$ & $34.5 \%$ \\
\hline & 1994 & $-31.9 \%$ & $2.5 \%$ & $-25.6 \%$ & $-1.0 \%$ & $-13.3 \%$ & $-13.4 \%$ & $0.8 \%$ & $3.3 \%$ & $2.8 \%$ & $36.8 \%$ & $-0.2 \%$ & $15.1 \%$ & $58.8 \%$ & $-0.7 \%$ & $51.0 \%$ \\
\hline & 1995 & $6.8 \%$ & $6.2 \%$ & $9.5 \%$ & $2.7 \%$ & $5.5 \%$ & $6.7 \%$ & $3.4 \%$ & $-0.6 \%$ & $2.2 \%$ & $-5.4 \%$ & $-1.0 \%$ & $-2.2 \%$ & $-8.3 \%$ & $-10.5 \%$ & $-9.0 \%$ \\
\hline & 1996 & $41.5 \%$ & $19.4 \%$ & $20.6 \%$ & $-13.9 \%$ & $0.9 \%$ & $1.0 \%$ & $0.8 \%$ & $0.7 \%$ & $2.1 \%$ & $-14.7 \%$ & $-6.5 \%$ & $-3.8 \%$ & $-17.0 \%$ & $-7.5 \%$ & $-7.3 \%$ \\
\hline & 1997 & $14.6 \%$ & $20.5 \%$ & $9.8 \%$ & $1.9 \%$ & $0.0 \%$ & $4.2 \%$ & $3.2 \%$ & $3.1 \%$ & $1.0 \%$ & $-12.0 \%$ & $-2.5 \%$ & $1.1 \%$ & $-7.3 \%$ & $-5.4 \%$ & $4.2 \%$ \\
\hline & 1998 & $10.7 \%$ & $15.3 \%$ & $15.4 \%$ & $-9.3 \%$ & $-6.4 \%$ & $-6.6 \%$ & $2.4 \%$ & $1.2 \%$ & $4.6 \%$ & $-11.2 \%$ & $-16.9 \%$ & $-2.8 \%$ & $-1.0 \%$ & $-7.8 \%$ & $8.5 \%$ \\
\hline & 1999 & $13.3 \%$ & $17.0 \%$ & $17.9 \%$ & $1.3 \%$ & $-0.3 \%$ & $0.1 \%$ & $0.7 \%$ & $2.2 \%$ & $2.7 \%$ & $-8.5 \%$ & $0.4 \%$ & $0.7 \%$ & $-7.6 \%$ & $0.0 \%$ & $8.8 \%$ \\
\hline & 2000 & $55.7 \%$ & $15.7 \%$ & $15.2 \%$ & $5.9 \%$ & $-10.1 \%$ & $-7.3 \%$ & $0.7 \%$ & $1.7 \%$ & $3.3 \%$ & $-15.3 \%$ & $-18.2 \%$ & $-13.4 \%$ & $-7.3 \%$ & $-16.9 \%$ & $-3.8 \%$ \\
\hline & 2001 & $-25.9 \%$ & $-1.5 \%$ & $-36.6 \%$ & $7.1 \%$ & $-4.9 \%$ & $1.7 \%$ & $5.6 \%$ & $4.1 \%$ & $-10.7 \%$ & $102.8 \%$ & $15.5 \%$ & $51.9 \%$ & $126.4 \%$ & $-6.2 \%$ & $19.4 \%$ \\
\hline & 2002 & $119.3 \%$ & $-2.9 \%$ & $122.9 \%$ & $-34.4 \%$ & $-30.6 \%$ & $-28.7 \%$ & $3.0 \%$ & $4.9 \%$ & $8.4 \%$ & $-3.5 \%$ & $-7.8 \%$ & $-1.6 \%$ & $10.6 \%$ & $1.6 \%$ & $20.3 \%$ \\
\hline & 2003 & $6.8 \%$ & $5.7 \%$ & $10.7 \%$ & $-10.1 \%$ & $-8.1 \%$ & $-5.9 \%$ & $-1.1 \%$ & $-2.4 \%$ & $1.1 \%$ & $0.0 \%$ & $-8.4 \%$ & $-5.9 \%$ & $1.8 \%$ & $-4.7 \%$ & $-3.6 \%$ \\
\hline
\end{tabular}

Figure 76. Geomorphic adjustment table from the yearly summary pages for the Black Rock_2 (BR_2), Wymer_1 (WY_1), and WymerPlus (WY+ ) scenarios, expressed as percentage change from the No Action baseline.

\section{Armor Disruption}

- The only notable differences in armor disruption under any of the alternatives were associated with Black Rock_2 and WymerPlus at the Naches reach (fig. 77). This result was somewhat unexpected because this reach had exhibited the least change with regard to fine-sediment transport and geomorphic work. Furthermore, the metrics for armor disruption and potential redd scour should be related, but any relationship between the two is weak at best (for example, compare figure 77 with the redd scour columns in figures 54-56).

\section{Interpretation and Evaluation of Results}

Effective use of technical information in decisionmaking hinges on two important functions: interpretation and evaluation. Interpretation is mostly a matter of deciphering why a certain outcome was attained, literally of making the mental connections between an input variable, such as streamflow, and a state variable, such as subyearling habitat for steelhead. Interpretation can sometimes be difficult, especially when the driving mechanism for a state variable is buried several model layers deep within the system or the response variable is nonlinear (as most of them are). Evaluation of alternatives implies that some state variables or changes thereof, are more important than others. This is a value judgment (hence the common root with the word evaluation). Evaluation involves trade-offs and not necessarily simple ones such as increased fish habitat opposed to increased irrigation supplies. As demonstrated in the synopses of the alternatives, a positive response for one state variable, such as spawning habitat for spring chinook, can be accompanied by a negative response for a closely related variable in the same reach, such as spawning habitat for steelhead. Furthermore, opposing responses for the same state variables frequently occur from site to site. An alternative that produces mostly positive results at Easton may produce mostly negative results at Kittitas. The following discussions are intended to assist decisionmakers in both aspects of the decision process. 


\begin{tabular}{|c|c|c|c|c|c|c|c|c|c|c|c|c|c|c|c|c|}
\hline \multirow[t]{23}{*}{$\begin{array}{l}\text { Armor } \\
\text { Disruption }\end{array}$} & Year & BR_2 & $\begin{array}{c}\text { Easton } \\
\text { WY_1 }\end{array}$ & WY+ & BR_2 & $\begin{array}{l}\text { Kittitas } \\
\text { WY_1 }\end{array}$ & WY+ & BR_2 & $\begin{array}{l}\text { Naches } \\
\text { WY_1 }\end{array}$ & WY+ & BR_2 & $\begin{array}{l}\text { nion Gap } \\
\text { WY_1 }\end{array}$ & WY+ & BR_2 & $\begin{array}{l}\text { Wapato } \\
\text { WY_1 }\end{array}$ & WY+ \\
\hline & 1982 & $0.0 \%$ & $0.0 \%$ & $0.0 \%$ & $0.0 \%$ & $0.0 \%$ & $0.0 \%$ & $-4.3 \%$ & $-0.6 \%$ & $-13.0 \%$ & $0.0 \%$ & $0.0 \%$ & $0.0 \%$ & $0.0 \%$ & $0.0 \%$ & $0.0 \%$ \\
\hline & 1983 & $0.0 \%$ & $0.0 \%$ & $0.0 \%$ & $0.0 \%$ & $0.0 \%$ & $0.0 \%$ & $-18.7 \%$ & $0.5 \%$ & $-15.5 \%$ & $0.0 \%$ & $0.0 \%$ & $0.0 \%$ & $0.0 \%$ & $0.0 \%$ & $0.0 \%$ \\
\hline & 1984 & $0.0 \%$ & $0.0 \%$ & $0.0 \%$ & $0.0 \%$ & $0.0 \%$ & $0.0 \%$ & $-8.9 \%$ & $3.4 \%$ & $-8.4 \%$ & $0.0 \%$ & $0.0 \%$ & $0.0 \%$ & $0.0 \%$ & $0.0 \%$ & $0.0 \%$ \\
\hline & 1985 & $0.0 \%$ & $0.0 \%$ & $0.0 \%$ & $0.0 \%$ & $0.0 \%$ & $0.0 \%$ & $8.0 \%$ & $8.0 \%$ & $-5.7 \%$ & $0.0 \%$ & $0.0 \%$ & $0.0 \%$ & $0.0 \%$ & $0.0 \%$ & $0.0 \%$ \\
\hline & 1986 & $0.0 \%$ & $0.0 \%$ & $0.0 \%$ & $0.0 \%$ & $0.0 \%$ & $0.0 \%$ & $5.4 \%$ & $3.6 \%$ & $0.0 \%$ & $0.0 \%$ & $0.0 \%$ & $0.0 \%$ & $0.0 \%$ & $0.0 \%$ & $0.0 \%$ \\
\hline & 1987 & $0.0 \%$ & $0.0 \%$ & $0.0 \%$ & $0.0 \%$ & $0.0 \%$ & $0.0 \%$ & $-13.6 \%$ & $-4.5 \%$ & $-2.3 \%$ & $0.0 \%$ & $0.0 \%$ & $0.0 \%$ & $0.0 \%$ & $0.0 \%$ & $0.0 \%$ \\
\hline & 1988 & $0.0 \%$ & $0.0 \%$ & $0.0 \%$ & $0.0 \%$ & $0.0 \%$ & $0.0 \%$ & $9.3 \%$ & $1.3 \%$ & $-5.3 \%$ & $0.0 \%$ & $0.0 \%$ & $0.0 \%$ & $0.0 \%$ & $0.0 \%$ & $0.0 \%$ \\
\hline & 1989 & $0.0 \%$ & $0.0 \%$ & $0.0 \%$ & $0.0 \%$ & $0.0 \%$ & $0.0 \%$ & $25.9 \%$ & $2.4 \%$ & $15.3 \%$ & $0.0 \%$ & $0.0 \%$ & $0.0 \%$ & $0.0 \%$ & $0.0 \%$ & $0.0 \%$ \\
\hline & 1990 & $0.0 \%$ & $0.0 \%$ & $0.0 \%$ & $0.0 \%$ & $0.0 \%$ & $0.0 \%$ & $-3.0 \%$ & $1.5 \%$ & $-2.2 \%$ & $0.0 \%$ & $0.0 \%$ & $0.0 \%$ & $0.0 \%$ & $0.0 \%$ & $0.0 \%$ \\
\hline & 1991 & $300.0 \%$ & $0.0 \%$ & $0.0 \%$ & $0.0 \%$ & $0.0 \%$ & $0.0 \%$ & $-4.3 \%$ & $3.4 \%$ & $2.4 \%$ & $0.0 \%$ & $0.0 \%$ & $0.0 \%$ & $0.0 \%$ & $0.0 \%$ & $0.0 \%$ \\
\hline & 1992 & $0.0 \%$ & $0.0 \%$ & $0.0 \%$ & $0.0 \%$ & $0.0 \%$ & $0.0 \%$ & $13.2 \%$ & $0.0 \%$ & $9.4 \%$ & $0.0 \%$ & $0.0 \%$ & $0.0 \%$ & $0.0 \%$ & $0.0 \%$ & $0.0 \%$ \\
\hline & 1993 & $0.0 \%$ & $0.0 \%$ & $0.0 \%$ & $0.0 \%$ & $0.0 \%$ & $0.0 \%$ & $-9.8 \%$ & $-5.9 \%$ & $-9.8 \%$ & $0.0 \%$ & $0.0 \%$ & $0.0 \%$ & $0.0 \%$ & $0.0 \%$ & $0.0 \%$ \\
\hline & 1994 & $0.0 \%$ & $0.0 \%$ & $0.0 \%$ & $0.0 \%$ & $0.0 \%$ & $0.0 \%$ & $-6.0 \%$ & $6.0 \%$ & $-6.0 \%$ & $0.0 \%$ & $0.0 \%$ & $0.0 \%$ & $0.0 \%$ & $0.0 \%$ & $0.0 \%$ \\
\hline & 1995 & $0.0 \%$ & $0.0 \%$ & $0.0 \%$ & $0.0 \%$ & $0.0 \%$ & $0.0 \%$ & $-12.0 \%$ & $3.7 \%$ & $-3.7 \%$ & $0.0 \%$ & $0.0 \%$ & $0.0 \%$ & $0.0 \%$ & $0.0 \%$ & $0.0 \%$ \\
\hline & 1996 & $0.0 \%$ & $0.0 \%$ & $0.0 \%$ & $0.0 \%$ & $0.0 \%$ & $0.0 \%$ & $-10.7 \%$ & $-3.4 \%$ & $-8.0 \%$ & $0.0 \%$ & $0.0 \%$ & $0.0 \%$ & $0.0 \%$ & $0.0 \%$ & $0.0 \%$ \\
\hline & 1997 & $0.0 \%$ & $0.0 \%$ & $0.0 \%$ & $0.0 \%$ & $0.0 \%$ & $0.0 \%$ & $-8.3 \%$ & $2.9 \%$ & $-5.4 \%$ & $0.0 \%$ & $0.0 \%$ & $0.0 \%$ & $0.0 \%$ & $0.0 \%$ & $0.0 \%$ \\
\hline & 1998 & $0.0 \%$ & $0.0 \%$ & $0.0 \%$ & $0.0 \%$ & $0.0 \%$ & $0.0 \%$ & $1.3 \%$ & $0.7 \%$ & $1.3 \%$ & $0.0 \%$ & $0.0 \%$ & $0.0 \%$ & $0.0 \%$ & $0.0 \%$ & $0.0 \%$ \\
\hline & 1999 & $0.0 \%$ & $0.0 \%$ & $0.0 \%$ & $0.0 \%$ & $0.0 \%$ & $0.0 \%$ & $-14.4 \%$ & $0.5 \%$ & $1.0 \%$ & $0.0 \%$ & $0.0 \%$ & $0.0 \%$ & $0.0 \%$ & $0.0 \%$ & $0.0 \%$ \\
\hline & 2000 & $0.0 \%$ & $0.0 \%$ & $0.0 \%$ & $0.0 \%$ & $0.0 \%$ & $0.0 \%$ & $-0.6 \%$ & $2.4 \%$ & $-4.2 \%$ & $0.0 \%$ & $0.0 \%$ & $0.0 \%$ & $0.0 \%$ & $0.0 \%$ & $0.0 \%$ \\
\hline & 2001 & $0.0 \%$ & $0.0 \%$ & $0.0 \%$ & $0.0 \%$ & $0.0 \%$ & $0.0 \%$ & $17.2 \%$ & $6.9 \%$ & $-17.2 \%$ & $0.0 \%$ & $0.0 \%$ & $0.0 \%$ & $0.0 \%$ & $0.0 \%$ & $0.0 \%$ \\
\hline & 2002 & $0.0 \%$ & $0.0 \%$ & $0.0 \%$ & $0.0 \%$ & $0.0 \%$ & $0.0 \%$ & $-3.9 \%$ & $0.0 \%$ & $-3.9 \%$ & $0.0 \%$ & $0.0 \%$ & $0.0 \%$ & $0.0 \%$ & $0.0 \%$ & $0.0 \%$ \\
\hline & 2003 & $0.0 \%$ & $0.0 \%$ & $0.0 \%$ & $0.0 \%$ & $0.0 \%$ & $0.0 \%$ & $-7.5 \%$ & $0.0 \%$ & $-1.4 \%$ & $0.0 \%$ & $0.0 \%$ & $0.0 \%$ & $0.0 \%$ & $0.0 \%$ & $0.0 \%$ \\
\hline
\end{tabular}

Figure 77. Armor disruption table from the yearly summary pages for the Black Rock_2 (BR_2), Wymer_1 (WY_1), and WymerPlus (WY+ ) scenarios, expressed as percentage change from the No Action baseline.

\section{Interpretation of YRDSS Results}

A popular misconception about the relationship between fish habitat and streamflow is that the response function is always convex, resembling a skewed bell-shaped curve. With this type of function, habitat areas are small at low flows, rise to a peak at some intermediate flow, and then decrease as the discharge increases. The paradigm of the universality of this curve originated from early instream flow studies, which were almost always conducted in simple, single-thread channels because of the difficulty of modeling multiple channels with one-dimensional hydraulic simulation models. Indeed, the shape of the flow-habitat response curve in this type of channel usually was convex and bell-shaped. Making the connection between flow regimes and habitat changes was relatively easy with this type of curve. If low flows were increased or high flows decreased, the result was almost always an increase in habitat area.

In complex channels such as those modeled in the Yakima River, many of the response functions are concave or a combination of convex and concave, particularly for fry and subyearlings (refer to the figures in Appendix 2 for confirmation). There are two main reasons for the response functions to take this shape. First, early life history stages of most fish species depend on shallow, slow areas for successful rearing (Kwak, 1988; Nehring and Anderson, 1993; Bovee and others, 1994; Bowen, 1996; Freeman and others, 2001, Bowen and others 2003a, b). Stream hydraulics favor the development of shallow, slow areas at low flows. Shallow, slow areas largely disappear from the main channel at high flows, but in complex channels such areas develop extensively in newly watered secondary channels and inundated flood plain areas. For life stages that are associated with shoreline areas, the available length of shoreline can also increase rapidly as subsidiary channels are filled (see figure 78 , for example).

The concavity of the response functions associated with multiple channels adds a degree of complexity to interpreting time series results. An increase in flow may result in an increase or a decrease in habitat area, depending on the starting point, which by definition is the baseline discharge at 


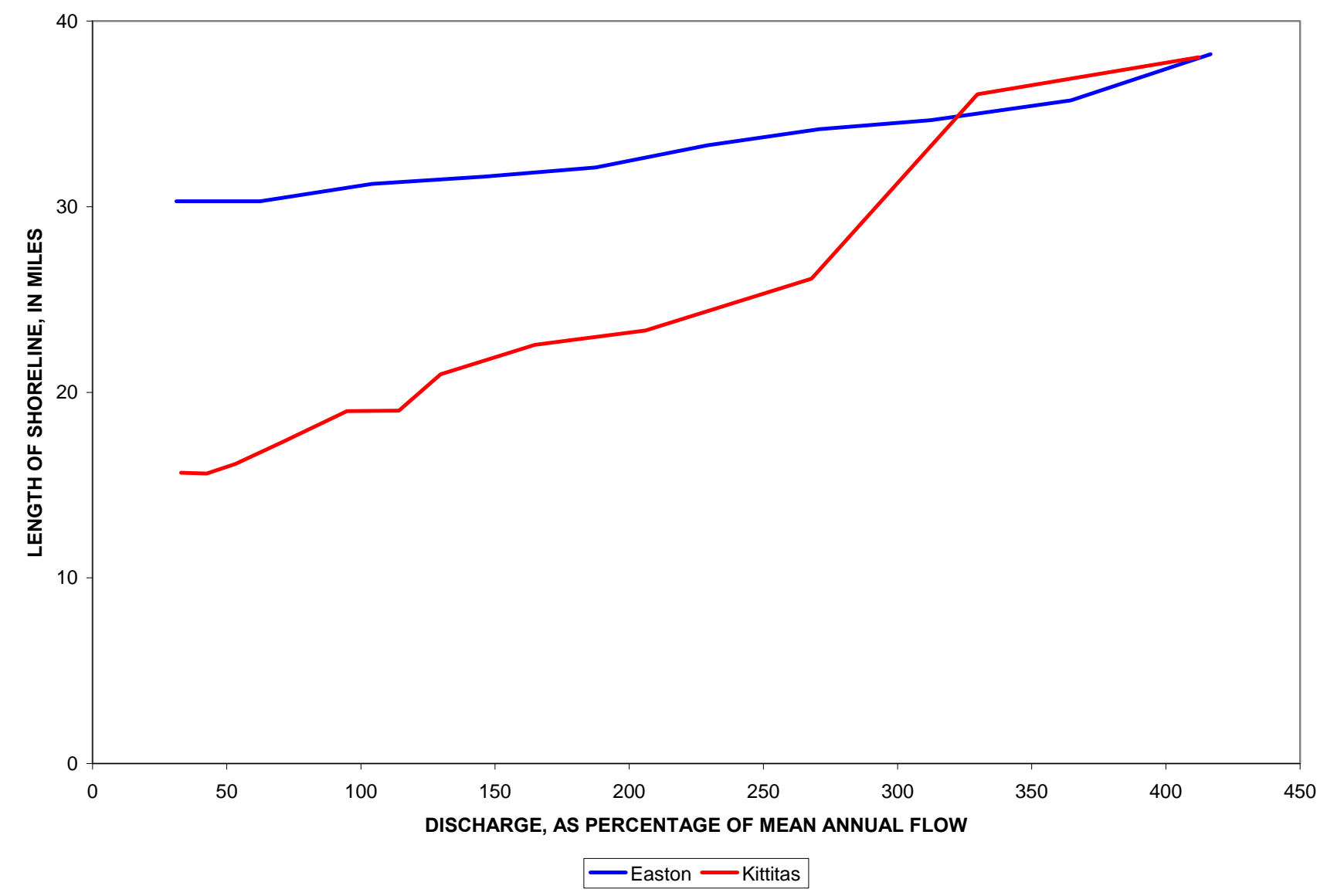

Figure 78. Shoreline length as a function of discharge at the Easton and Kittitas reaches.

any point in the time series. If the starting point happens to occur at the nadir of the curve, a change of flow in either direction is likely to result in an increase in habitat. A further complication is that the nadirs for different life stages occur at different discharges, so a unidirectional change in flow can have a multidirectional response across life stages. Owing to the somewhat unpredictable behavior of the flow-habitat relationship, it is difficult to say "this happened because of that" with any consistency, at least based on the habitat curve. In many cases, the simple knowledge that a state variable responded in a certain way is sufficient, and little further investigation is needed. However, when counterintuitive results are obtained, it may be useful to plot portions of the flow and habitat time series on the same graph. Although the graphics packages currently included in the YRDSS do not produce this type of overlay chart, the data to construct them can be extracted from the subsidiary spreadsheets with relatively little effort.

Figure 79 is an overlay of the flow and habitat time series for subyearling coho in the Kittitas reach during the summer of 1992. The No Action Baseline is shown in blue and the Black Rock_2 alternative in red. The scoring metric for that year and scenario, as reported in figure 51, indicated a habitat reduction of 13.8 percent under the alternative. Discharges under the baseline were consistently higher than the alternative, as indicated by the solid lines, but retained the same basic daily pattern and sequence of flows. From the first of June through the middle of August, the reduced discharges of the Black Rock_2 alternative resulted in a depression of habitat for subyearling coho. After August 15, discharge dropped precipitously under both scenarios, but habitat area under the alternative was higher 


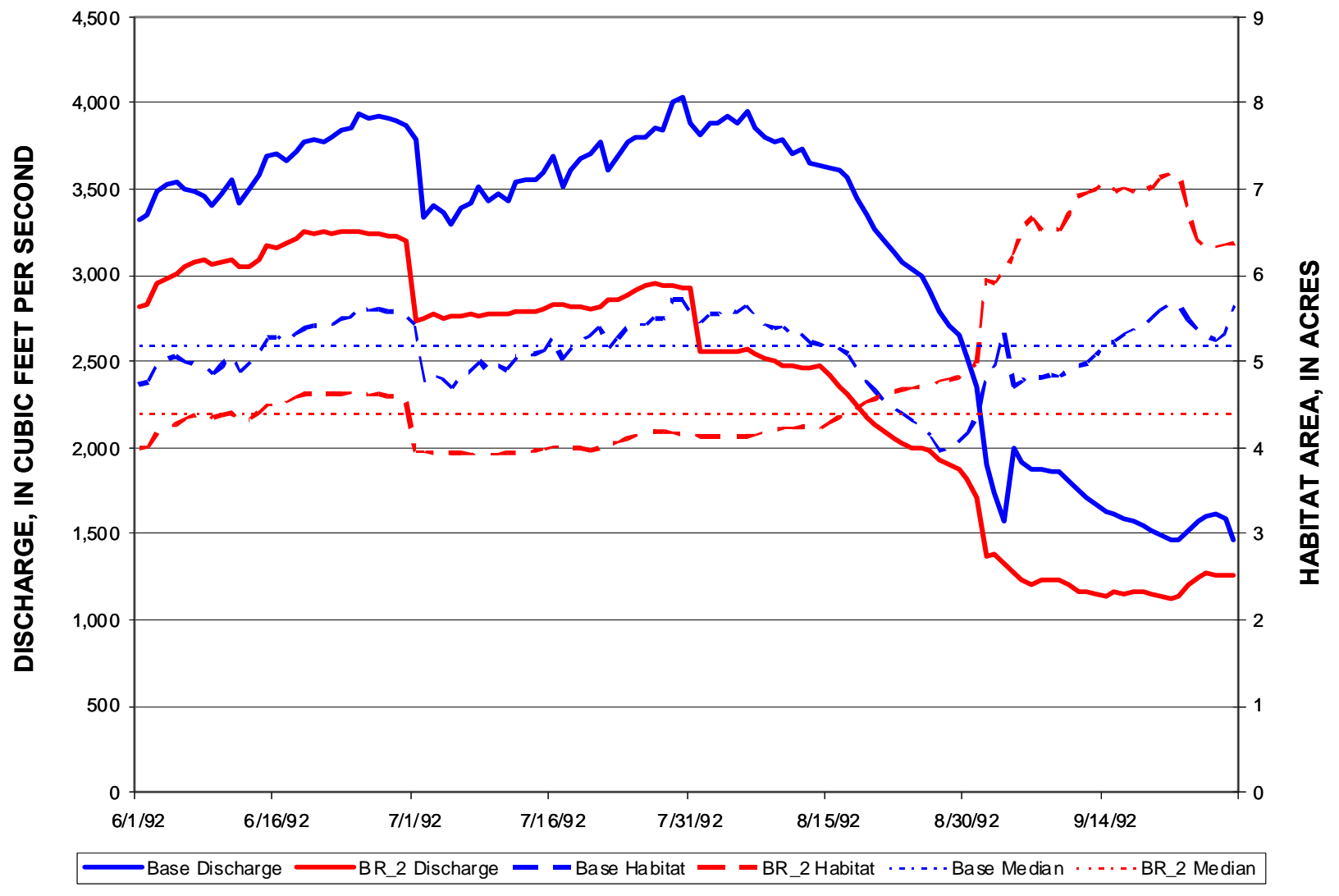

Figure 79. Discharge and habitat time series for subyearling coho in the Kittitas reach during the summer of 1992, comparing the No Action baseline and the Black Rock_2 alternative.

than the baseline even though the flow was lower. This apparent contradiction resulted from the algorithm used to calculate the scoring metric in the YRDSS; only the habitat events below the median (marked by the dotted lines in figure 79) are included in the scoring tabulation. Consequently, the habitat increases that were calculated after August 15 were included in the score for the year. If increasing habitat for subyearling coho were the only objective, figure 79 indicates that reducing the flow to a value between 1,000 and 2,000 $\mathrm{ft}^{3} / \mathrm{s}$ from June through mid-August would not be detrimental and might actually improve conditions for this life stage. In reality, the objectives would probably never be restricted to a single life stage as in this example and modifying the flow regime to turn this cell green in the scoring matrix would undoubtedly result in others (perhaps many others) turning red. Nonetheless, exercises like the one demonstrated in figure 79 can be useful in modifying alternatives to improve their performance.

\section{Evaluation of YRDSS Results}

An observation of decision support systems is that they are distilleries of information. The models used to generate information for the decision support system are simplifications of the real world. The annual scoring pages are distillations of the model outputs. The aggregate summary pages contain condensed information from the annual scoring pages. The synopses presented earlier for each of the alternatives further aggregate the material presented in the summary pages. While each distillation is intended to make it easier to compare alternatives, it is done at the risk of blurring the 
details, such as those illustrated in figure 79. Nonetheless, evaluations of alternatives are facilitated by some sort of side-by-side comparison. At the risk of oversimplification, an evaluation matrix is presented in figure 80 as an example of a side-by-side comparison that could be used in the evaluation process. The color coding in figure 80 was based on the results reported on the annual summary pages of the YRDSS. For this analysis, the net frequency of significant increases or decreases was calculated as the difference between the number of red and green cells for a state variable in the annual summary. As illustrated in the legend at the bottom of figure 80, a dark green background indicates a "Large Positive" change for a state variable. In order to qualify as a "Large positive," significant increases (large enough to trigger the conditional formatting of the cells) must outnumber decreases in the annual scoring tables by 10 or more years. A light green background indicates a "Positive" outcome, wherein the frequency of significant increases outnumbers comparable decreases by 3 to 9 years. A tan background represents a "Neutral" outcome, wherein significant increases and decreases are approximately balanced ( \pm 2 years). A pink background represents a "Negative" response, in which

\begin{tabular}{|c|c|c|c|c|c|c|c|c|c|c|c|c|c|c|c|c|}
\hline & & \multicolumn{5}{|c|}{ Black Rock_2 } & \multicolumn{5}{|c|}{ Wymer_1 } & \multicolumn{5}{|c|}{ WymerPlus } \\
\hline & & Easton & Kittitas & Naches & Union Gap & Wapato & Easton & Kittitas & Naches & Union Gap & Wapato & Easton & Kittitas & Naches & Union Gap & Wapato \\
\hline \multirow[t]{5}{*}{ Spring Chinook } & Redd Scour & & & & & & & & & & & & & & & \\
\hline & Spawning & & & & & & & & & & & & & & & \\
\hline & Fry & & & & & & & & & & & & & & & \\
\hline & Subyearling (s) & & & & & & & & & & & & & & & \\
\hline & Subyearling (w) & & & & & & & & & & & & & & & \\
\hline \multirow[t]{4}{*}{ Fall Chinook } & Redd Scour & & & & & & & & & & & & & & & \\
\hline & Spawning & & & & & & & & & & & & & & & \\
\hline & & & & & & & & & & & & & & & & \\
\hline & Subyearling (s) & & & & & & & & & & & & & & & \\
\hline \multirow[t]{5}{*}{ Coho } & Redd Scour & & & & & & & & & & & & & & & \\
\hline & Spawning & & & & & & & & & & & & & & & \\
\hline & Fry & & & & & & & & & & & & & & & \\
\hline & Subyearling (s) & & & & & & & & & & & & & & & \\
\hline & Subyearling $(w)$ & & & & & & & & & & & & & & & \\
\hline \multirow[t]{5}{*}{ Steelhead } & Redd Scour & & & & & & & & & & & & & & & \\
\hline & Spawning & & & & & & & & & & & & & & & \\
\hline & Fry & & & & & & & & & & & & & & & \\
\hline & Subyearling (s) & & & & & & & & & & & & & & & \\
\hline & Subyearling $(w)$ & & & & & & & & & & & & & & & \\
\hline \multirow[t]{5}{*}{ Resident Rainbow } & Redd Scour & & & & & & & & & & & & & & & \\
\hline & Spawning & & & & & & & & & & & & & & & \\
\hline & Fry & & & & & & & & & & & & & & & \\
\hline & Subyearling (s) & & & & & & & & & & & & & & & \\
\hline & Subyearling (w) & & & & & & & & & & & & & & & \\
\hline \multirow[t]{5}{*}{ Bull Trout } & Redd Scour & & & & & & & & & & & & & & & \\
\hline & Spawning & & & & & & & & & & & & & & & \\
\hline & Fry & & & & & & & & & & & & & & & \\
\hline & Subyearling (s) & & & & & & & & & & & & & & & \\
\hline & Subyearling $(w)$ & & & & & & & & & & & & & & & \\
\hline \multirow{2}{*}{\multicolumn{17}{|c|}{$\begin{array}{l}\text { Maximum Temperatures } \\
\text { Overbank Flow }\end{array}$}} \\
\hline & & & & & & & & & & & & & & & & \\
\hline \multicolumn{17}{|l|}{ Damaging Floods } \\
\hline \multirow{2}{*}{\multicolumn{17}{|c|}{$\begin{array}{l}\text { Fine-Sediment Transport } \\
\text { Geomorphic Work }\end{array}$}} \\
\hline & & & & & & & & & & & & & & & & \\
\hline \multirow{2}{*}{\multicolumn{2}{|c|}{ Armor Disruption }} & & & & & & & & & & & & & & & \\
\hline & & Lake & Elum & Kachess & Keechulus & Rimrock & Lake & Elum & Kachess & Keechulus & \begin{tabular}{|l|} 
Rimrock \\
\end{tabular} & \begin{tabular}{|l|} 
Bumping Lake \\
\end{tabular} & Cle Elum & Kachess & Keechulus & Rimrock \\
\hline \multicolumn{17}{|c|}{ Reservoir Outmigration } \\
\hline \multirow{4}{*}{\multicolumn{2}{|c|}{$\begin{array}{l}\text { Reservoir Carryover } \\
\text { Proration Rate } \\
\text { TWSA }\end{array}$}} & & & & & & & & & & & & & & & \\
\hline & & May & June & July & August & Sept & May & June & July & August & Sept & May & June & July & August & Sept \\
\hline & & & & & & & & & & & & & & & & \\
\hline & & & & & & & & & & & & & & & & \\
\hline & & & \multicolumn{12}{|c|}{ Legend } & & \\
\hline & & & & Large Posi & itive - Signific & ant increas & s outnum & er decrea & ses by 10 or & more years & in the annua & al scoring tables. & & & & \\
\hline & & & & Positive - S & Significant inc & reases ou & umber de & reases by & $3-9$ years & in the annual & scoring tab & bles. & & & & \\
\hline & & & & Neutral - S & Significant inc & reases and & decreases & approxim & tely balance & $d( \pm 2$ years $)$ & in the annu & Jal scoring tables & & & & \\
\hline & & & & Negative - & Significant de & creases o & tnumber i & creases b & $3-9$ years & in the annua & I scoring tat & bles. & & & & \\
\hline & & & & Large Neg & & & & ber incre & ses by 100 & more years & in the annu & ual scoring tables & & & & \\
\hline
\end{tabular}

Figure 80. An example of an evaluation matrix, showing side-by-side comparisions of the Black Rock_2, Wymer_1, and WymerPlus alternatives. Note that the color coding refers to qualitative changes for each state variable. For example, an increase in redd scour is considered a quality decrease. 
significant decreases in the annual summary are more numerous than significant increases in 3 to 9 years. A dark red background indicates a "Large negative" effect, where the number of significant decreases exceeds the number of significant increases by 10 or more years. Grey backgrounds, as in the YRDSS, represent nonapplicability of a state variable at a particular location.

An evaluation of the three scenarios depicted in this report can be deceptively simple or mindnumbing in its complexity, depending on the decision style and information processing tendencies of the decisionmakers. Perhaps the simplest evaluation possible would be to select from the three alternatives, the one with the least negative or the most neutral effects. If our search is only for the most benign alternative, WymerPlus would be a reasonable choice because it resulted in the fewest negatives, although Wymer_1 has the edge on neutral results (fig. 81).

Suppose that instead of merely selecting the most benign alternative, however, we are interested in selecting the one that provides the most benefits. In this case, the Black Rock_2 alternative might be a better choice were it not for the abundance of large negative effects associated with this option. Logical questions associated with the results in figure 81 might be "How important are those large negatives in the grand scheme of things?" or "Do the positive aspects outweigh the negatives?" At least three tactics can be employed to resolve such uncertainties, but all require a step back from the level of aggregation illustrated in figures 80 and 81 . These tactics can be defined as establishing context, prioritization, and iterative revision.

Establishing context is really a matter of redefining the evaluation matrix. For some state variables, such as proration rate and TWSA in figure 80, the same result was obtained under all three scenarios, so these cells may not contribute to the decision process and may actually dilute results that do. In other cases, a red cell in a scoring table or matrix is not necessarily a bad thing, nor is a green cell

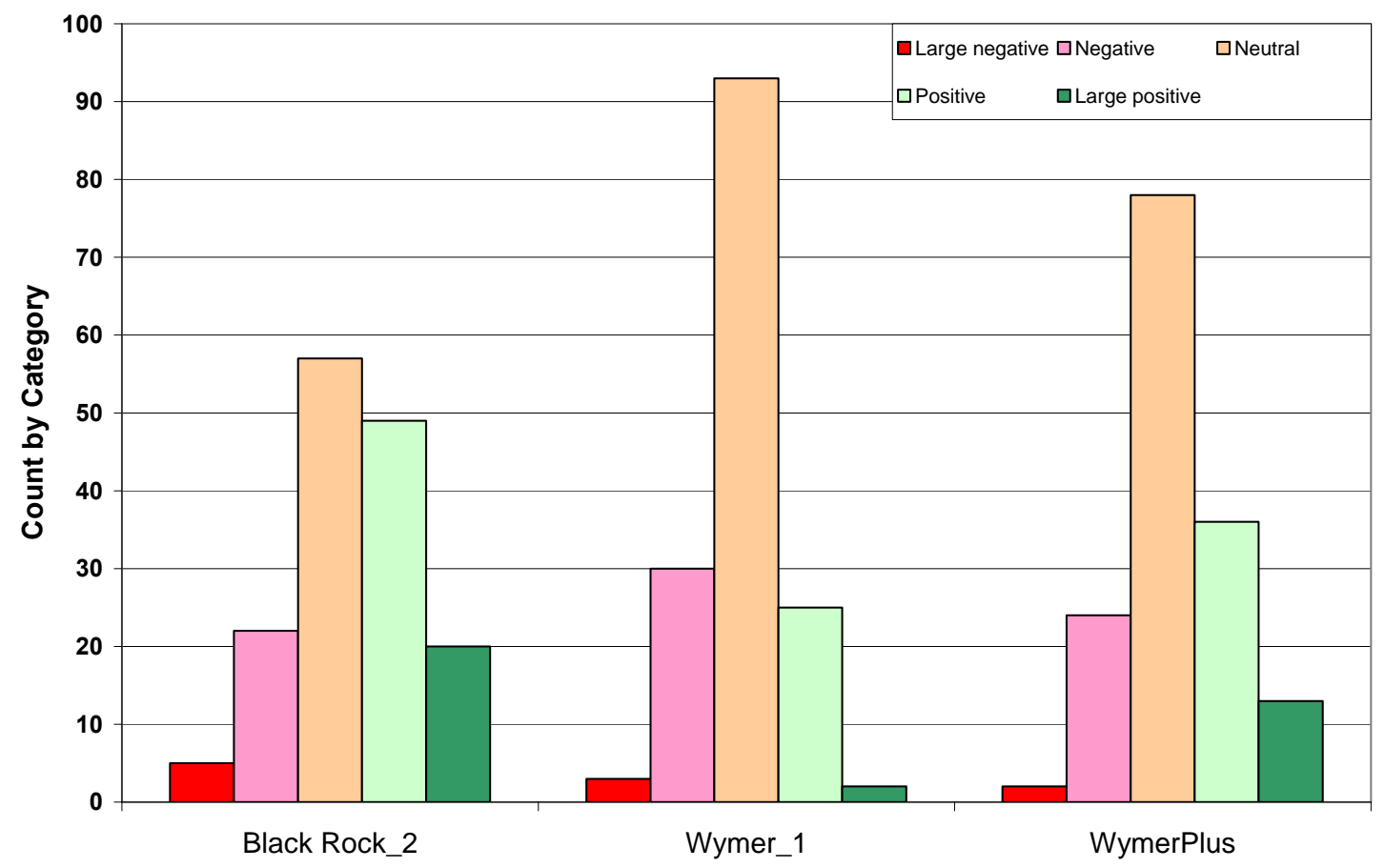

Figure 81. A compilation of classifications from the evaluation matrix illustrated in figure 80 . 
absolutely an improvement. The former case is exemplified by the dark red cells in figure 80 associated with redd scour at the Easton and Union Gap reaches. Examination of the annual habitat summaries in the appendixes reveals that despite the increases in redd scour, the critical thresholds for the target species were seldom exceeded. Therefore, the biological consequences of increased redd scour may be minor and could be ignored. If they are ignored, the cells they represent could be coded with a tan background and recounted or simply left blank.

Prioritization involves differential weighting of the state variables according to their perceived importance. Although prioritization can be conducted informally by simply paying more attention to the results for specific state variables, a more formal process such as applying numerical weights to specific state variables in the evaluation matrix will facilitate consistency. In the YRDSS, two different types of prioritization can be used. The first is weighting higher priority state variables by a factor representing their importance relative to other variables. For example, figure 82 is a compilation of the classifications from the original evaluation matrix, with cells for redd scour at Easton and Union Gap removed from consideration and bull trout given double the weighting of the other variables. Note that, with this weighting scheme, all bull trout cells are double-counted regardless of their color. Thus, "bad" conditions are twice as bad and "good" conditions twice as good.

The second prioritization option is to weight by location, placing greater importance on geography than on biology or other state variables. In figure 80, it is apparent that the various scenarios have different effects at different locations in the stream network. Figures 83 and 84 illustrate how the compilation of results from the evaluation matrix would change as a result of double weighting the Easton and Kittitas reaches (fig. 83) or the Union Gap and Wapato reaches (fig. 84).

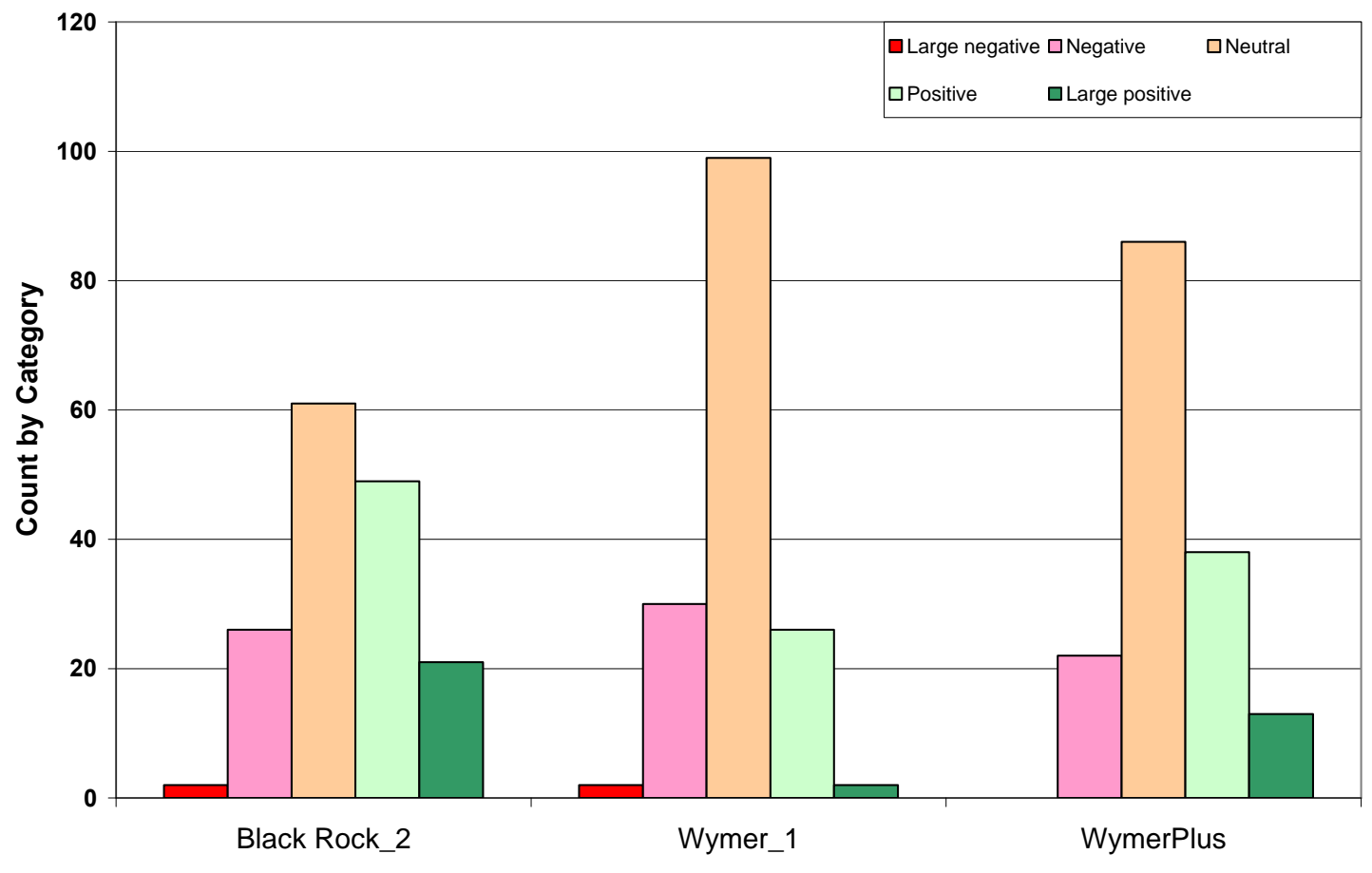

Figure 82. A compilation of classifications from the evaluation matrix illustrated in figure 80, with redd scour at Easton and Union Gap removed and double-weighting on bull trout. 


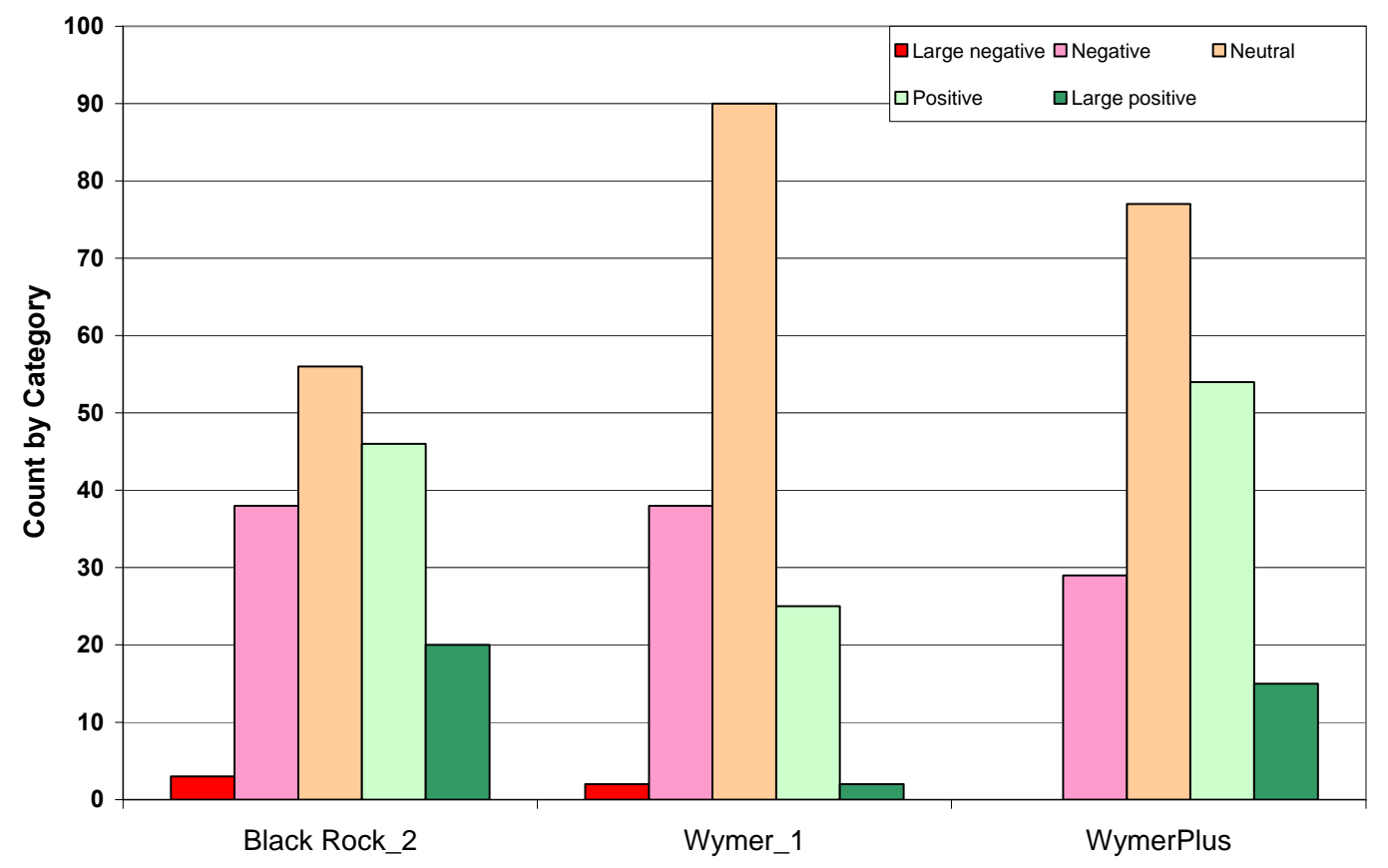

Figure 83. A compilation of classifications from the evaluation matrix illustrated in figure 80, with redd scour at Easton and Union Gap removed and double-weighting on Easton and Kittitas.

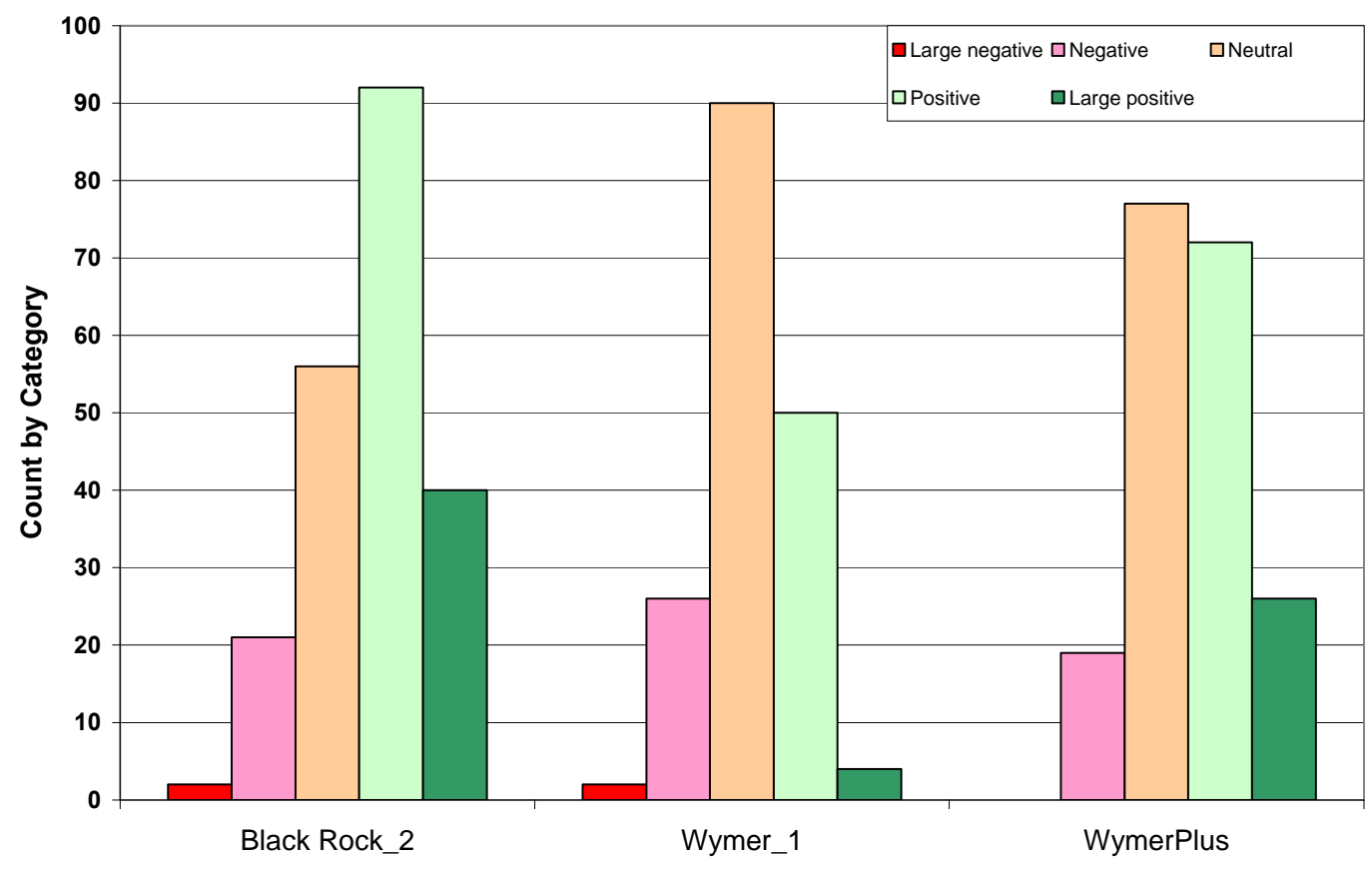

Figure 84. A compilation of classifications from the evaluation matrix illustrated in figure 80 , with redd scour at Easton and Union Gap removed and double-weighting on Union Gap and Wapato. 
Iterative revision can be the most difficult approach but ultimately may have the largest reward in terms of deriving an alternative that is effective in meeting management objectives, has a high probability of feasibility, and embodies manageable risks. This approach requires a good understanding of the relationships between systems operations as defined in RiverWare and the responses of the state variables in the YRDSS. The underlying concept of iterative revision is to build on successes of an alternative and to correct its deficiencies by modifying the driving variables to the YRDSS. In the case of the Yakima system, this process would involve identifying a deficiency, determining its underlying cause, modifying RiverWare to correct the problem, and rerunning the YRDSS to learn the consequences of the change. This last step is essential because it is entirely possible that the steps needed to correct one problem will cause another to surface.

An example of the first few steps of an iterative revision is illustrated in figure 85 . According to the annual habitat summaries in figure 72 and the evaluation matrix (fig. 80), smolt outmigration from Cle Elum Reservoir was decreased under all three scenarios compared to the baseline. Between 1985 and 1995, significant increases in passage potential occurred in 1985, 1987, and 1990 under the Black Rock_2 scenario (fig. 72). Significant decreases occurred in 1982, 1988, 1993, 1994, 1995, and 2002. Figure 85 shows the maximum monthly storage volume at Cle Elum for the water years 1985-1995. April and May, the two primary months of smolt outmigration, are indicated by the dark red and blue line segments within the time series. Years when the alternative produced more passable days than the baseline are shown in green typeface and those when the opposite occurred are presented in red

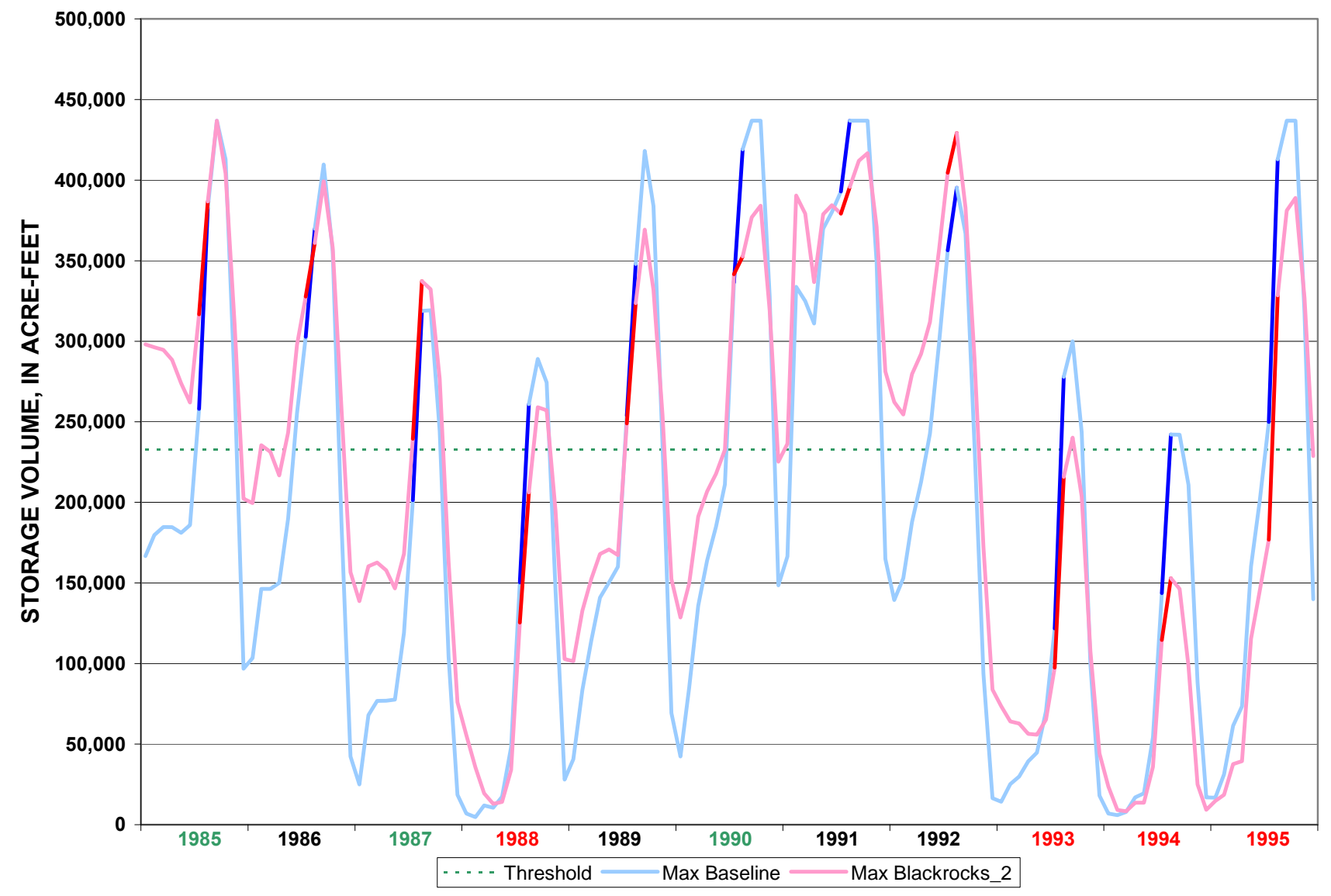

Figure 85. Maximum monthly storage volumes at Cle Elum Reservoir, water years 1985-95. 
typeface. Several factors influencing the increase or decrease in passable days were considered in this figure. First, end-of-year carryover was a contributing factor in several years, particularly in 1985 and 1987. The larger volume in the reservoir when filling began served to "jump start" the potential for reaching the passage threshold by April. Maximum annual storage was not a major influence in most years, but did have an effect during the drought years of 1993 and 1994. Two other factors influencing an increase or decrease in passable days appears to have been the date when reservoir filling was initiated and the rate at which it was filled. Close examination of figure 85 reveals that in the years when the baseline provided better passage conditions, the rate of filling was faster (see 1995, for example). In years when the alternative provided improved smolt outmigration (1985, for example), filling appeared to have started earlier (although the increased carryover may have played a more dominant role in these years).

To improve the scoring metrics for smolt passage in the YRDSS under the Black Rock_2 scenario, RiverWare would need to be reconfigured to increase the filling rate of Cle Elum Reservoir following periods of extreme drawdown. Unfortunately, the only obvious way to accelerate filling would be to further reduce the already-low outflow from Cle Elum during the fall and winter. At that time of year, spawning and incubation for fall spawners would be affected. So, if this were the only change made to the systems operation model, increasing smolt outmigration potential at Cle Elum could be at the expense of spawning-incubation habitat in the Kittitas reach. To prevent problems with spawning-incubation habitat, releases from Kachess and Keechelus Reservoirs could be increased to offset the reduced outflow from Cle Elum. Increased drawdown of these reservoirs, however, would affect carryover and could compromise bull trout outmigration the following year.

The foregoing example is what we term a "within-resource" conflict. Here, measures taken to improve overall salmon production by way of increased smolt outmigration may be counterproductive. At this point, decisionmakers should be encouraged to revisit the previous tactic, prioritization, to estimate which of the life history stages would be most important for achieving the overall goal of increased salmonid production (in this example, reproduction or smolt outmigration). It may be nearly impossible to make this determination with certainty, but the best judgment of the local professional biologists would eliminate at least some of the guesswork.

An important point of this discussion is that not all resource conflicts can be resolved, at least not all of the time. One way to manage around these seemingly irreconcilable conflicts is to modulate positive and negative effects from year to year. When conditions are favorable for enhancing smolt outmigration, for example, reservoir filling could be accelerated with the understanding that reproductive habitat might be compromised. In other years, especially when strong returns of spawners are expected, reservoir operations might favor reproductive habitat even though smolt outmigration would be reduced. The amount of scenario-testing that could be done under the rubric of YRDSS simulations is nearly endless, constrained primarily by deadlines and budgets, but secondarily by the imagination and persistence of the users.

\section{References Cited}

Bartholow, J.M., 1989, Stream temperature investigations-Field and analytic methods: U.S. Fish and Wildlife Service, Instream Flow Information Paper 13, Biological Report 89(17),139 p.

Becker, C.D., and Neitzel, D.A., 1985, Assessment of intergravel conditions influencing egg and alevin survival during salmonid redd dewatering: Environmental Biology of Fishes, V. 12, no. 1, p. 32-46.

Bovee, K.D., Newcomb, T. J., and Coon, T.G., 1994, Relations between habitat variability and population dynamics of bass in the Huron River, Michigan: U.S. Department of the Interior, National Biological Survey, Biological Report 21, 63 p. 
Bovee, K.D., Lamb, B.L., Bartholow, J.M., Stalnaker, C.B., Taylor, J., and Henriksen, J., 1998, Stream habitat analysis using the instream flow incremental methodology: U.S. Geological Survey, USGS/BRD/ITR-1998-0004, 130 p. http://www.fort.usgs.gov/Products/Publications/pub_abstract.asp?PubID=3910

Bovee, K.D., Waddle, T.J., and Jacobson, R.B., 2004, Quantification of habitat patch persistence in rivers affected by hydropeaking, in Lanfear, K.J., and Maidment, D.R., eds., GIS and Water Resources Conference III [Proceedings], Nashville, Tenn., 2004: Middleburg, Va., American Water Resources Association [not paginated]. Available only on CD-ROM. Ordering information: http://www.awra.org/proceedings/cdrom.html\#nash_2004

Bovee, K.D., Waddle, T.J., Bartholow, J., and Burris, L., 2007, A decision support framework for water management in the upper Delaware River: U.S. Geological Survey Open-File Report 2007-1172, 122 p. http://www.fort.U.S. Geological Survey.gov/ASTA/Products.asp.

Bowen, Z.H., 1996, Relations between fishes and habitat in the Tallapoosa River system, Alabama: Alabama, Auburn University, Ph.D. dissertation, 109 p.

Bowen, Z.H., Bovee, K.D., and Waddle, T.J., 2003a, Effects of flow regulation on shallow-water habitat dynamics and flood plain connectivity: Transactions of the American Fisheries Society, v. 132, p. 809-823.

Bowen, Z.H., Bovee, K.D., and Waddle, T.J., 2003b, Effects of channel modification on fish habitat in the upper Yellowstone River: U.S. Geological Survey, Open-File Report 2003-476, 30 p., appendices.

Bureau of Reclamation, 1976,Yakima Project Hydromet System, Bureau of Reclamation, accessed May 23, 2007 at http://www.usbr.gov/dataweb/html/yakima.html.

Conner, E.J., and Pflug, D.E., 2004, Changes in the distribution and density of pink, chum, and chinook salmon spawning in the upper Skagit River in response to flow management measures: North American Journal of Fisheries Management, v. 24, no. 3, p. 834-852.

Conner, W.P., Garcia, A.P., Connor, A.H., Garton, E.O., Groves, P.A., and Chandler, J.A., 2001, Estimating the carrying capacity of the Snake River for fall chinook salmon redds: Northwest Science, v. 75, no. 4, p. 362-371.

Environmental Systems Research Institute, Inc. (ESRI), 2006, ArcGIS: Redlands, Cal.

Essig, D.A., Mebane, C.A., and Hillman, T.W., 2003, Update on bull trout temperature requirements: Idaho Department of Environmental Quality, Final Report, 48 p.

Freeman, M.C., Bowen, Z.H., Bovee, K.D., and Irwin, E.R., 2001, Flow and habitat effects on juvenile fish abundance in natural and altered flow regimes: Ecological Applications, v. 11, no. 1, p. 179-190. Ghanem, A., Steffler, P., Hicks, F., and Katopodis, C., 1996, Two-dimensional simulation of physical habitat conditions in flowing streams: Regulated Rivers-Research and Management, v. 12, p. 185200.

Hilldale, R.C., and Mooney, D.M., 2007a, Identifying stream habitat features with a two-dimensional hydraulic model-A component of Yakima River Basin water storage feasibility study: Washington, Technical Series no. TS-YSS-14, Sedimentation and River Hydraulics Group, Bureau of Reclamation report to the Upper Columbia Area Office.

Hilldale, R.C., and Mooney, D.M., 2007b, One-dimensional hydraulic modeling of the Yakima basinA component of Yakima River Basin water storage feasibility study: Washington, Technical Series no. TS-YSS-14, Sedimentation and River Hydraulics Group, Bureau of Reclamation report to the Upper Columbia Area Office.

Ivlev, V.S., 1961, Experimental ecology of the feeding of fishes: New Haven, Connecticut, Yale University Press, 302 p. 
Jager, H.I., Van Winkle, W., and Holcomb, B.D.,1999, Would hydrologic climate changes in Sierra Nevada streams influence trout persistence?: Transactions of the American Fisheries Society, v. 128, no. 2, p. 222-240.

Kwak, T.J., 1988, Lateral movement and use of flood plain habitat by fishes of the Kankakee River, Illinois: American Midland Naturalist, v. 120, p. 241-249.

Leopold, L.B., Wolman, M.G., and Miller, J.P., 1964, Fluvial processes in geomorphology: W.H. Freeman and Company, San Francisco, 522 p.

McMahon, T.E., 1983, Habitat suitability index models-Coho salmon: U.S. Fish and Wildlife Service, FWS/OBS-82/10.49, 29 p.

Nehring, R.B. and Anderson, R.M., 1993, Determination of population-limiting critical salmonid habitats in Colorado streams using the Physical Habitat Simulation System: Rivers, v. 4, no. 1, p. 119.

Panfil, M.S., and Jacobson, R.B., 1999, Hydraulic modeling of in-channel habitats in the Ozark Highlands of Missouri-Assessment of physical habitat sensitivity to environmental change: U.S. Geological Survey, Columbia Environmental Science Center. View document online at http://www.cerc.U.S. Geological Survey.gov/rss/rfmodel/.

Raleigh, R.F., Hickman, T., Solomon, R.C., and Nelson, P.C., 1984, Habitat suitability informationRainbow trout: U.S. Fish and Wildlife Service, FWS/OBS-82/10.60, 64 p.

Raleigh, R.F., Miller, W.J., and Nelson, P.C., 1986, Habitat suitability index models and instream flow suitability curves-Chinook salmon: U.S. Fish and Wildlife Service, Biological Report 82(10.122), $64 \mathrm{p}$.

Reiser, D.W., Ramey, M.P., Beck, S., Lambert, T.R., and Geary, R.E., 1989, Flushing flow requirements for maintenance of salmonids spawning gravels in a steep, regulated stream: Regulated Rivers-Research and Management, v. 3, no. 1-4, p. 267-275.

Simpkins, D.G., and Hubert, W.A., 2000, Effects of a spring flushing flow on the distribution of radiotagged juvenile rainbow trout in a Wyoming tailwater: North American Journal of Fisheries Management, v. 20, no. 2, p. 546-551.

Snyder, E.B., and Stanford, J.A., 2001, Review and synthesis of river ecological studies in the Yakima River, Washington, with emphasis on flow and salmon habitat interactions: Final report submitted to U.S. Department of Interior, Bureau of Reclamation, Yakima, Washington. 118 p. plus appendix.

Stanford, J.A., Snyder, E.B., Lorang, M.N., Whited, D.C., Matson, P.L., and Chaffin, J.L., 2002, The reaches project-Ecological and geomorphic studies supporting normative flows in the Yakima River Basin, Washington: Final Report to U.S. Department of Interior, Bureau of Reclamation, Yakima, Washington. $152 \mathrm{p}$.

Steffler, P., 2002, R2D_Bed, Bed topography file editor user's manual: Edmonton, University of Alberta, 31 p. http://www.river2d.ualberta.ca/software/R2D_Bed.pdf.

Steffler, P and Blackburn, J., 2002, Two-dimensional depth averaged model of river hydrodynamics and fish habitat-Introduction to depth averaged modeling and user's manual: Edmonton, University of Alberta, 119 p. http://www.river2d.ualberta.ca/software/River2D.pdf.

Theurer, F.D., Voos, K.A., and Miller, W.J., 1984, Instream water temperature model: U.S. Fish and Wildlife. Service, Instream Flow Information Paper 16, FWS/OBS-84/15, 214 p.

Waddle, T. and Steffler, P., 2002, R2D_Mesh, mesh generation program for River2D two dimensional depth averaged finite-element hydrodynamic simulation-Introduction to mesh generation and user's manual: http://www.river2d.ualberta.ca/software/R2d_mesh.pdf. 31 p.

Zuboy, J.R., 1981, A new tool for fisheries managers: the Delphi technique: North American Journal of Fisheries Management, v. 1, p. 55-59. 


\section{Appendix 1. Two-Dimensional Hydraulic Simulations of the Union Gap and Wapato Reaches}

By James R. Hatten and Thomas R. Batt

U.S. Geological Survey

Western Fisheries Research Center

Columbia River Research Laboratory

Cook, WA 98605 


\section{Methods}

\section{Modeling Overview}

The Columbia River Research Laboratory (CRRL) was tasked in 2005 with conducting hydraulic simulations for the Union Gap and Wapato reaches of the Yakima River (figures 1-1 and 1-2, respectively). We used the River2D two-dimensional (depth-averaged) model developed at the University of Alberta (Ghanem and others, 1996; Steffler and Blackburn, 2002) to simulate depths and water velocities at unmeasured flows. We used existing LIDAR (LIght Distancing And Ranging) data that were supplemented by ground survey data as input to the bathymetry models (Digital Elevation Models) required by River2D. We entered the data into the River2D bed editor to smooth and remove contour anomalies. We generated a two-dimensional finite-element computational mesh for each site in an unstructured fashion, with the primary criterion for refinement being topographic matching, assessed visually by overlaying contour maps in the mesh generation program. Two calibration flows were run at low and medium discharges until they converged (convergence is defined as the discharge at the outflow matching the discharge at the inflow). Following convergence, the models were calibrated by adjusting model parameters until a reasonable match was obtained between simulated and measured water-surface elevations. Production runs were conducted once the calibrations were completed, producing spatially explicit distributions of hydraulic variables for a range of discharges. The last step involved converting the hydraulic layers (depths, velocities, Froude numbers, and water-surface elevations) into GIS point layers. These data were provided to the Fort Collins Science Center for input to the two-dimensional habitat layers, discussed in Appendix 2.

\section{Digital Elevation Models}

As a starting point for hydrodynamic modeling, the BOR provided the USGS with bathymetric (water-penetrating) LIDAR data for the Wapato reach. The bathymetric LIDAR data were collected in May 2005 and had a mean vertical error of 15-17 cm (Hilldale, R.C., and Raff, D., Bureau of Reclamation, written commun. January 2008). In addition, terrestrial LIDAR data having a vertical accuracy of approximately $30 \mathrm{~cm}$ were obtained in November 2004. The bathymetric LIDAR data were collected at a 2-m spot density with a SHOALS-1000T $®$ LIDAR unit mounted in a twin engine, fixedwing aircraft. The position and elevation of the aircraft were recorded with an RTK GPS system. In the Union Gap reach, we received terrestrial LIDAR data for much of the flood plain channel. In the Wapato reach, we were provided with both terrestrial and bathymetric LIDAR data.

The USGS Washington Water Science Center collected bathymetric data for several miles of the main channel in the Union Gap reach in 2004, using a boat-mounted echo sounder and an RTK GPS system. Data gaps in the terrestrial and bathymetric portions of the flood plain were filled using elevation data from a 10-m resolution USGS DEM, with supplemental ground-truth data obtained with RTK-GPS surveys. Field surveys were conducted in the Union Gap between September 2005 and February 2006 and in the Wapato reach between September 2006 and December 2006.

We appended the LIDAR and GPS survey data to create a single data set containing horizontal coordinates and elevations. We used the ArcGIS $®$ triangulated irregular network (TIN) algorithm to create a three-dimensional surface of the flood plain and converted the TIN into a digital elevation model (DEM) at a 10-m resolution. We carefully scrutinized the dataset for missing data. Data gaps above the waterline were filled using the 10-m resolution USGS DEM. Missing data below the waterline were filled with additional echo sounder and ground survey data. 


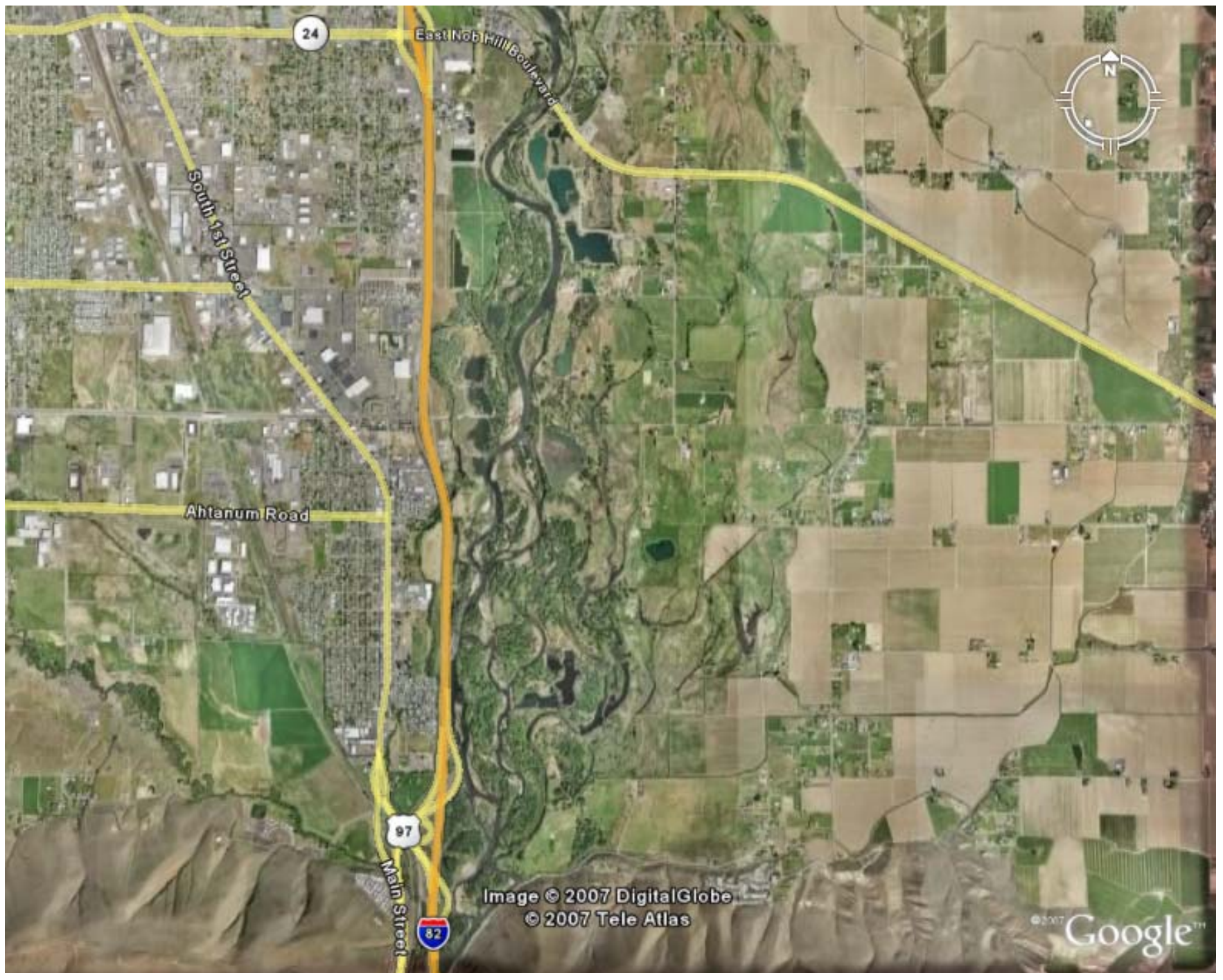

Figure 1-1. Aerial map of the Union Gap reach between the 24th Street Bridge and Union Gap (at bottom). 


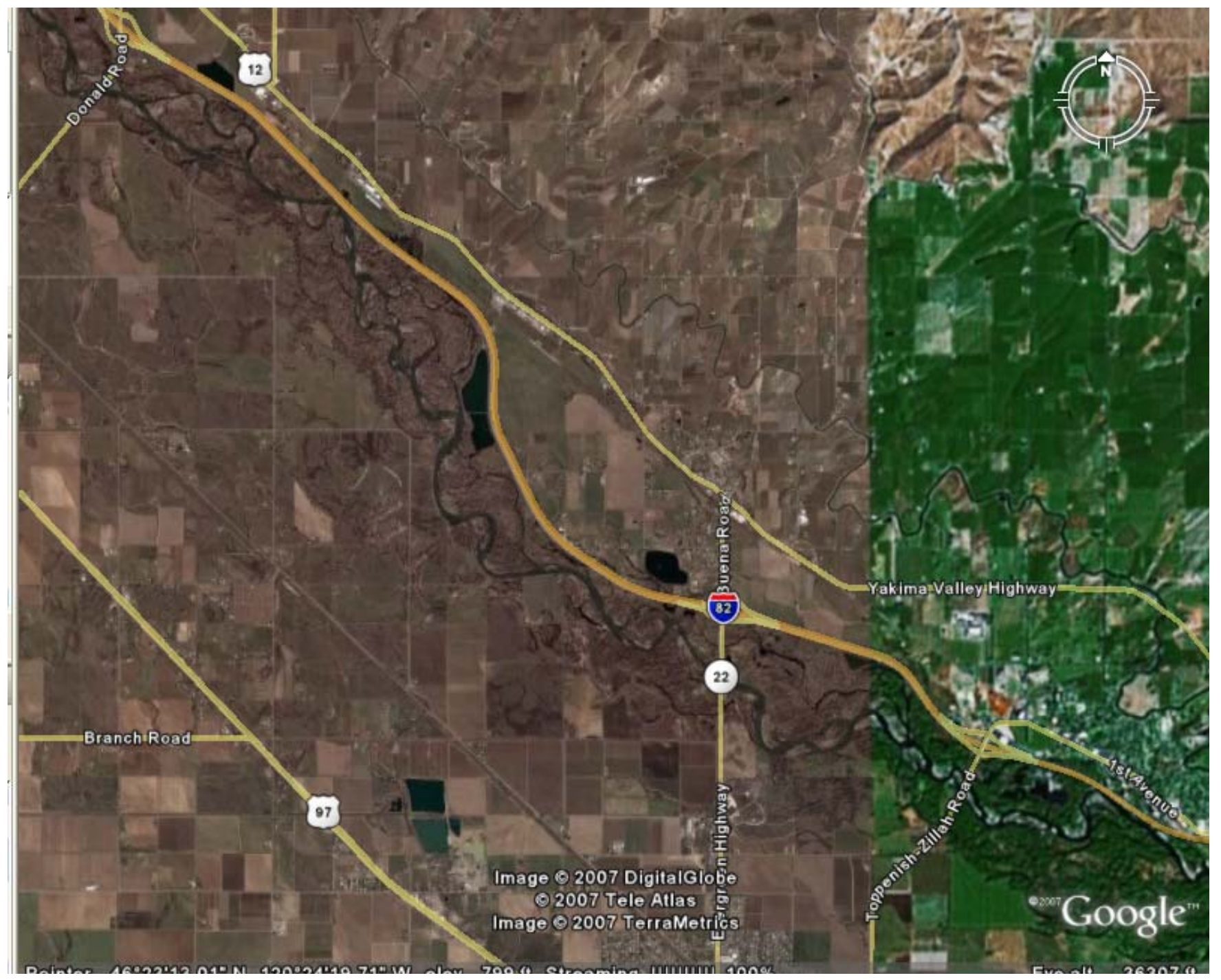

Figure 1-2. Aerial map of the Wapato reach between the Wapato (Donald Road) and Toppenish bridges. 


\section{Boundary Conditions}

Two types of boundary condition data are required for calibrating and performing hydraulic simulations with River2D. The first type consists of one or more longitudinal series of water-surface elevations measured at intervals from the bottom of the reach to the top (water-surface profiles) at known discharges. These data are used primarily for model calibration. The second type of data is a rating table or curve containing estimates of the water-surface elevation at the bottom of the site (the outflow) for each discharge to be simulated. These data are used primarily in the production runs, wherein hydraulic characteristics are simulated for a range of unmeasured discharges to be used in subsequent habitat simulations.

The water-surface profiles were surveyed using a Trimble 5700 RTK-GPS unit in "continuous topo" mode, in which the GPS unit records positions and elevations at fixed intervals of time or distance. The instrument height was determined from the top of the range pole to the water surface. By correcting for the instrument height, the GPS effectively created a continuous set of water-surface elevations and positions. Water-surface elevation data were collected at regular intervals in each site by drifting from top to bottom with the GPS unit. Calibration data for the Union Gap site were collected at $1,490 \mathrm{ft}^{3} / \mathrm{s}$ and $3,420 \mathrm{ft}^{3} / \mathrm{s}$ and for the Wapato site at $1,491 \mathrm{ft}^{3} / \mathrm{s}$ and $2,450 \mathrm{ft}^{3} / \mathrm{s}$.

For the production runs, we obtained stage-discharge data for Union Gap from unpublished USGS stream gage data. Output from a one-dimensional hydraulic model (Hilldale and Mooney, 2007b) was used to generate a rating table for the Wapato Reach.

\section{River2D Mesh Construction}

We used the River2D Bed and Mesh modules to import the xyz data, define the computational boundaries, and create a finite-element mesh (Steffler, 2002). Most of the bathymetric editing and point refinement was completed in a GIS, so besides general formatting, little work was actually performed in the River2D Bed editor. We used the River2D Mesh module to set the inflow and outflow boundary conditions for each flow simulation and create a finite-element mesh (Waddle and Steffler, 2002).

We supplied River2D with a discharge at the upstream boundary and a water-surface elevation at the downstream boundary for each flow simulation. The stage-discharge conditions are linked because River2D requires the upstream discharge to be the condition resulting in the downstream water-surface elevation at a steady-state streamflow.

Our mesh construction strategy was iterative. We started with a coarse 30-m mesh over the entire flood plain and then progressively refined the mesh by reducing the node spacing in wetted areas (Steffler and Blackburn, 2002). A variable-size mesh enabled us to reduce the computational effort of the model by creating a course mesh outside the wetted channel, and a finer mesh in the wetted areas (fig. 1-3). Specifically, we used high-resolution imagery to create a river polygon and then refined the mesh over the wetted channel to $15 \mathrm{~m}$. We ran the models for a day and then refined the mesh again to $7.5 \mathrm{~m}$ for all wetted areas shallower than $2.5 \mathrm{~m}$. In our last step, we refined the mesh in all wetted areas shallower than $1 \mathrm{~m}$ to approximately $3.75 \mathrm{~m}$. We included all isolated off-channel areas in all hydrodynamic flow simulations because River2D employs a simplified groundwater model that enables subterranean connections and disconnections between off-channel areas and the main channel as the flow changes.

\section{River2D Model Calibration}

With the measured inflow discharges and the measured outflow water-surface elevations as boundary conditions, River2D was run to produce predicted water-surface profiles corresponding to the measured profiles. Adjustments were made to the mesh where increased discreteness (that is, resolution) was warranted, and the parameter for roughness height adjusted upward or downward to alter the 


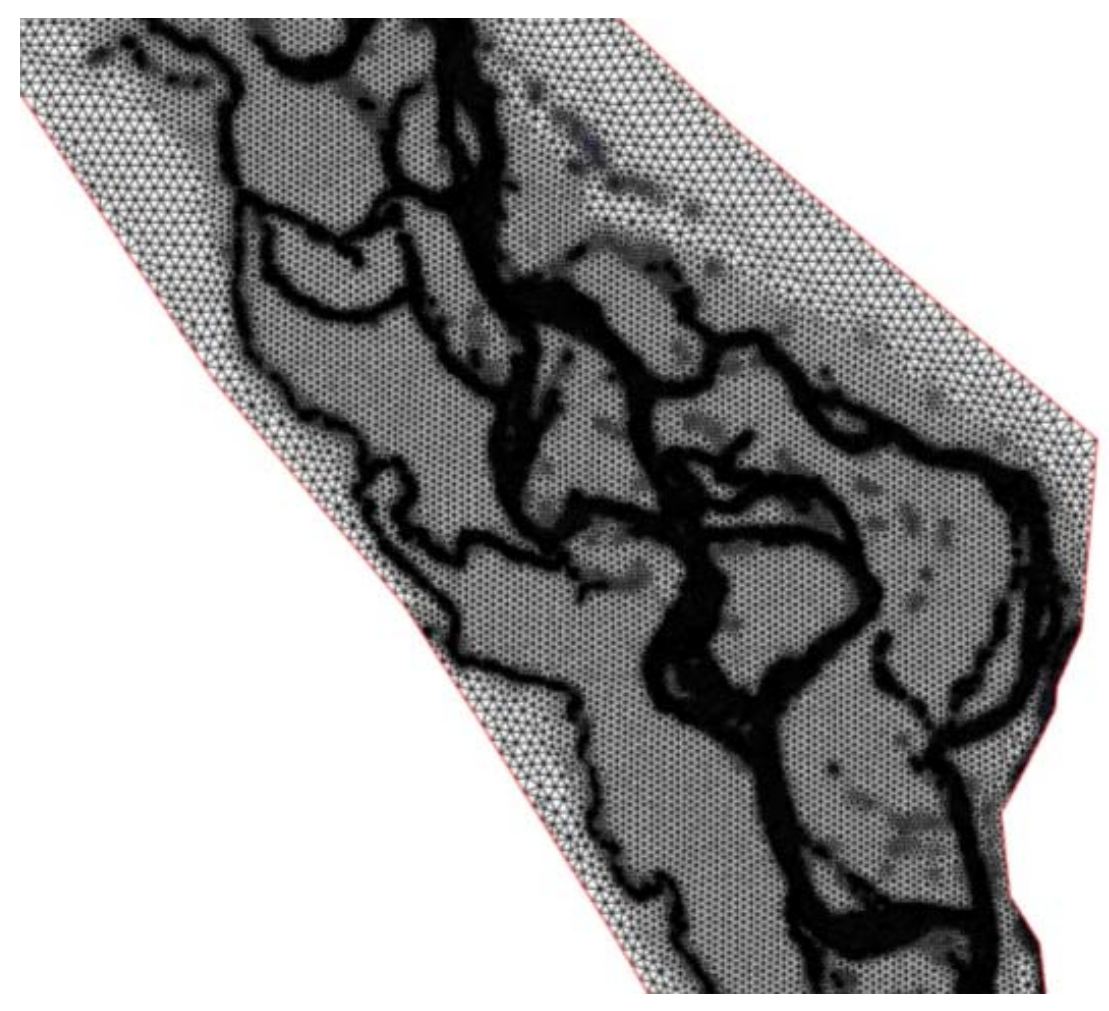

Figure 1-3. An example of a variable-sized mesh in the Wapato reach at a discharge of 300 cubic feet per second.

resistance to flow provided by friction. For example, if the predicted water-surface profile was uniformly lower than the measured profile, roughness height was increased. The increase in resistance caused the velocity to decrease and the depth to increase, thereby raising the elevation of the predicted water-surface profile. This procedure was repeated until a reasonable match between the predicted and measured water-surface profiles was obtained.

What constituted a reasonable match depended on the complexity of the profile, the elevation differential between the top of the site and the bottom, the behavior of the model during the calibration runs, and the potential error associated with individual water-surface elevation measurements. In general, we attempted to match the measured water-surface elevation to $\pm 10 \mathrm{~cm}$ or less at all measurement points, with the goal of minimizing residuals throughout the profile. It is possible to adjust the roughness at specific locations to match the predicted and measured water-surface elevations exactly. Past experiences, however, have demonstrated that doing so is inadvisable. Such tight calibration can introduce instabilities in the model that actually make subsequent simulations less accurate.

After setting the boundary conditions for each calibration flow, River2D was run to convergence, defined as a solution where the difference between the inflow and outflow discharges was less than 1 percent and the solution change per iteration was very small (Steffler and Blackburn, 2002). Calibration runs required between 24 to 432 hours before full convergence, but some never converged and were abandoned after 600 hours. After each model simulation was run to convergence, we computed the root mean square error for deviations between predicted and measured water-surface elevations along the water-surface profile. A history of the calibration runs for the Union Gap and Wapato sites is summarized in table 1-1. The best matches between simulated and measured watersurface elevations were obtained using a roughness height of $0.05 \mathrm{~m}$ at Union Gap and $0.1 \mathrm{~m}$ at Wapato. 
We attempted a calibration run at Wapato with a roughness height of $0.05 \mathrm{~m}$, but the model failed to converge. Figure 1-4 shows the measured and predicted water-surface profiles at Union Gap for our best fit calibration runs at 1,490 cubic feet per second and 3,420 cubic feet per second. The best fit calibration profiles for Wapato are illustrated in figure 1-5.

Table 1-1. Calibration history for the Union Gap and Wapato hydrodynamic models.

\begin{tabular}{ccccc}
\hline Site & $\begin{array}{c}\text { Run } \\
\text { date }\end{array}$ & $\begin{array}{c}\text { Calibration discharge } \\
\text { (cubic feet per second) }\end{array}$ & $\begin{array}{c}\text { Roughness } \\
\text { height }\end{array}$ & $\begin{array}{c}\text { Root mean } \\
\text { square error } \\
\text { (centimeters) }\end{array}$ \\
\hline Union Gap & 1-Mar-06 & 1,490 & 0.1 & 18.1 \\
Union Gap & 28-Apr-06 & 1,490 & 0.05 & 13.4 \\
Union Gap & 1-May-06 & 3,420 & 0.05 & 16.1 \\
Union Gap & 14-Jun-06 & 3,420 & 0.01 & \\
Wapato & 7-Apr-07 & 1,491 & 0.2 & \\
Wapato & 11-Apr-07 & 1,491 & 0.01 & \\
Wapato & 13-Apr-07 & 1,491 & 0.05 & 19.3 \\
Wapato & 18-Apr-07 & 1,491 & 0.1 & 29.8 \\
Wapato & 4-Apr-07 & 2,450 & 0.2 & 19.3 \\
Wapato & 19-Apr-07 & 2,450 & 0.1 & \\
\hline \multicolumn{7}{l}{}
\end{tabular}

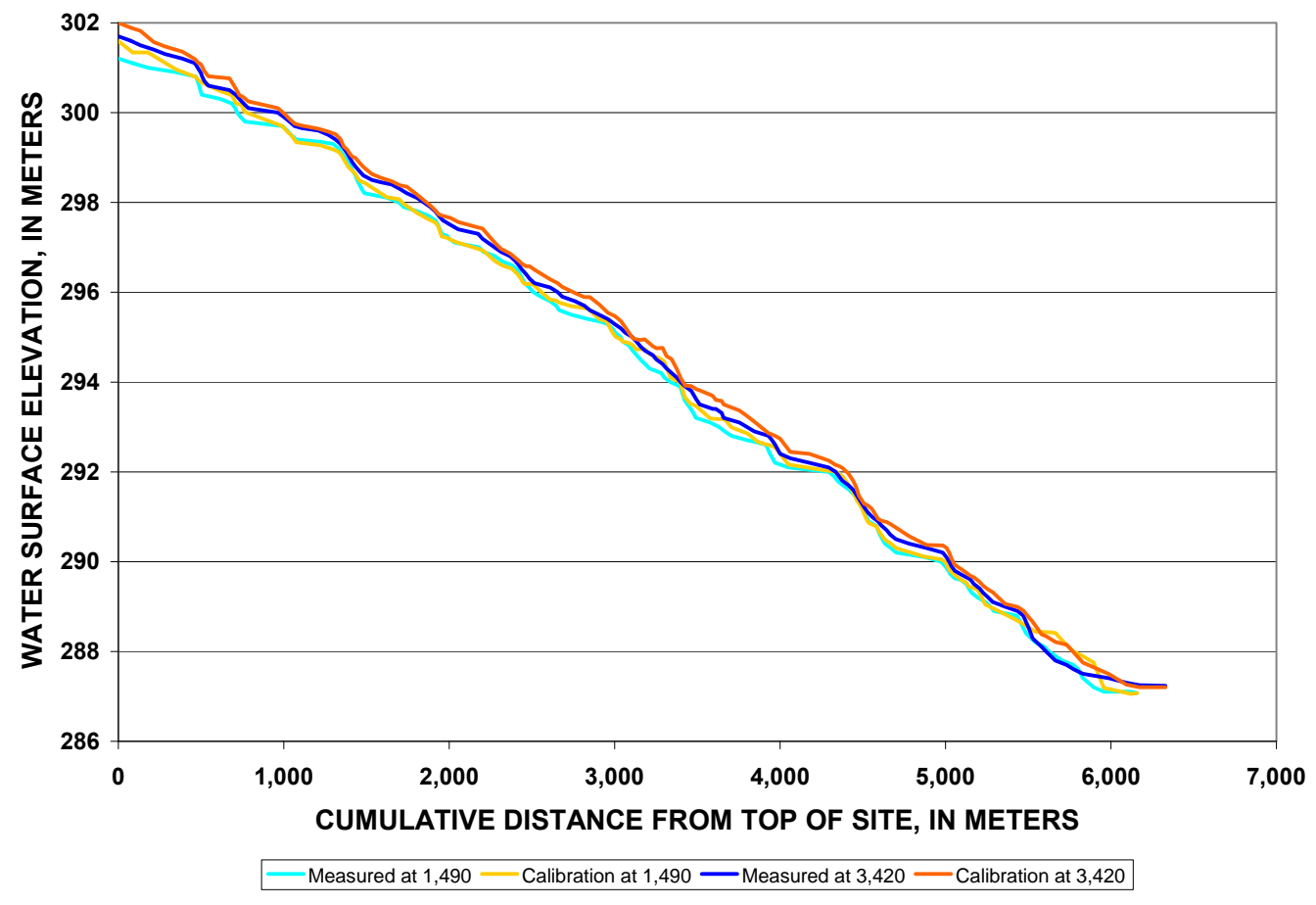

Figure 1-4. Measured and simulated water-surface profiles at the Union Gap site for calibration discharges of 1,490 and 3,420 cubic feet per second. 


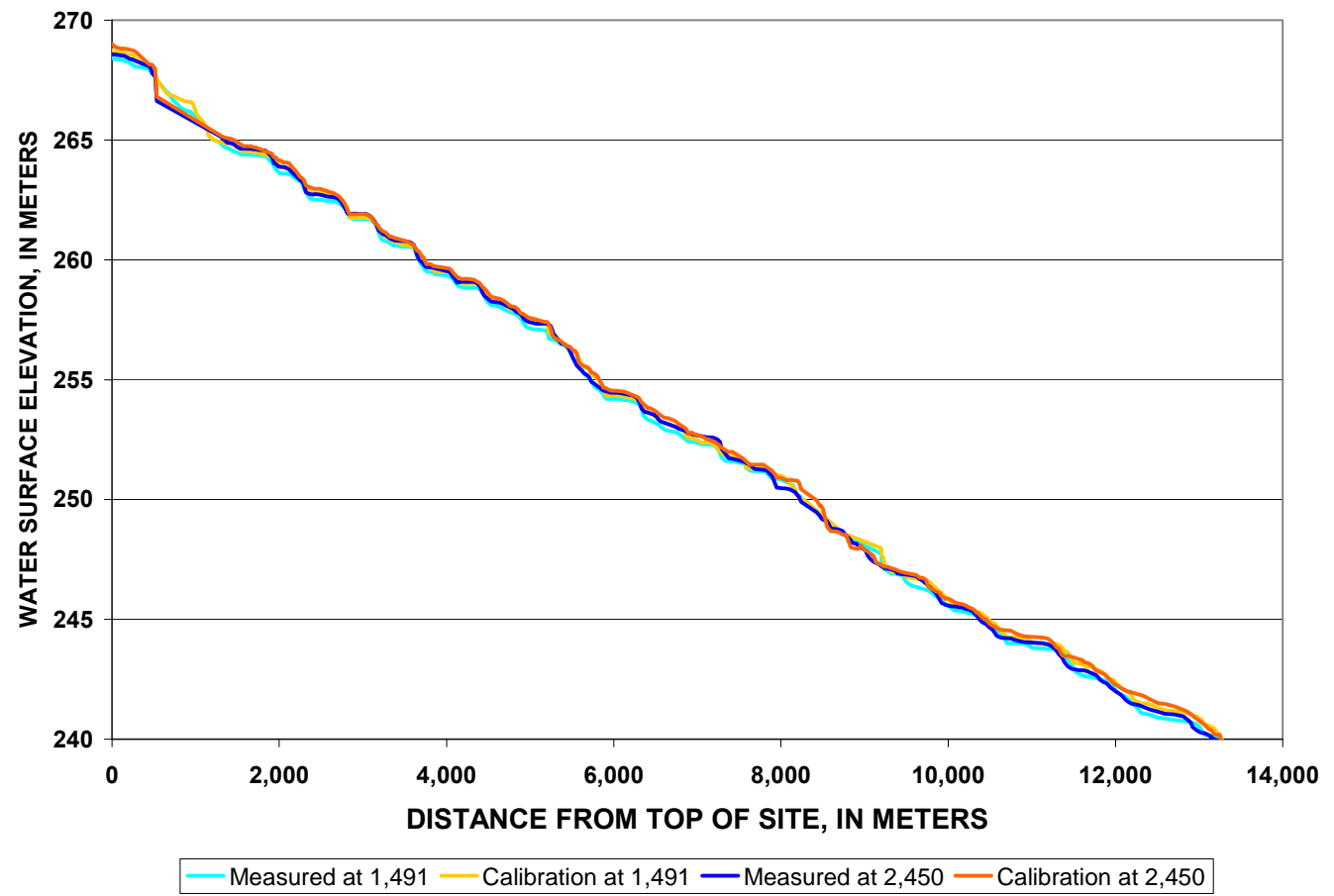

Figure 1-5. Measured and simulated water-surface profiles at the Wapato site for calibration discharges of 1,491 and 2,450 cubic feet per second.

\section{River2D Flow Simulations}

Once the model was calibrated, we simulated 10 discharges at the Union Gap site and 11 at Wapato. Simulated discharges approximately bracketed the range of exceedance probabilities from 5-90 percent. Boundary conditions were input from rating tables generated from stream gage data (tables 1-2 and 1-3). The low flow simulated for the Wapato reach was much smaller than at Union Gap because

Table 1-2. Boundary condition data used for flow simulations in the Union Gap reach.

\begin{tabular}{cccc}
\hline $\begin{array}{c}\text { Simulation discharge } \\
\text { at inflow in cubic feet } \\
\text { per second }\end{array}$ & $\begin{array}{c}\text { Simulation discharge at } \\
\text { inflow in cubic meters } \\
\text { per second }\end{array}$ & $\begin{array}{c}\text { Water-surface elevation } \\
\text { at outflow, in meters }\end{array}$ & $\begin{array}{c}\text { Simulated discharge } \\
\text { at outflow, in cubic } \\
\text { meters per second }\end{array}$ \\
\hline 1,000 & 28.317 & 286.80 & 28.409 \\
2,000 & 56.634 & 287.10 & 56.852 \\
3,000 & 84.951 & 287.30 & 85.543 \\
4,000 & 113.267 & 287.50 & 111.62 \\
5,000 & 141.584 & 287.70 & 139.99 \\
6,000 & 169.901 & 287.85 & 166.741 \\
7,000 & 198.218 & 288.05 & 195.642 \\
8,000 & 226.535 & 288.25 & 221.784 \\
9,000 & 254.852 & 288.35 & 251.664 \\
10,000 & 283.168 & 288.50 & 283.777 \\
\hline
\end{tabular}


Table 1-3. Boundary condition data used for flow simulations in the Wapato reach.

\begin{tabular}{cccc}
\hline $\begin{array}{c}\text { Simulation discharge } \\
\text { at inflow in cubic feet } \\
\text { per second }\end{array}$ & $\begin{array}{c}\text { Simulation discharge at } \\
\text { inflow in cubic meters } \\
\text { per second }\end{array}$ & $\begin{array}{c}\text { Water-surface elevation } \\
\text { at outflow, in meters }\end{array}$ & $\begin{array}{c}\text { Simulated discharge } \\
\text { at outflow, in cubic } \\
\text { meters per second }\end{array}$ \\
\hline 300 & 8.495 & 239.15 & 8.76 \\
500 & 14.158 & 239.26 & 14.48 \\
750 & 21.238 & 239.38 & 21.98 \\
1,500 & 42.475 & 239.66 & 42.68 \\
2,000 & 56.634 & 239.81 & 55.30 \\
2,500 & 70.79 & 239.89 & 68.25 \\
$3,000^{\mathrm{a}}$ & & & \\
$4,000^{\mathrm{a}}$ & & & \\
5,000 & 141.584 & 240.42 & 137.49 \\
7,500 & 212.376 & 240.76 & 215.97 \\
10,000 & 283.168 & 240.99 & 280.64 \\
12,500 & 353.961 & 241.18 & 357.10 \\
15,000 & 424.753 & 241.35 & 426.71 \\
\hline
\end{tabular}

${ }^{\mathrm{a}}$ Model would not converge.

the baseline discharges (those in the 90-percent exceedance range) were considerably lower in this reach owing to diversions between Union Gap and Wapato. Highest simulation flows ranged from 10,000 cubic feet per second in the Union Gap reach to 15,000 cubic feet per second in the Wapato reach. No problems occurred while running the flow simulations for Union Gap, but we were unable to achieve model convergence for the 3,000- or 4,000-cubic foot per second simulations in the Wapato reach. A lack of convergence indicated that there were computational abnormalities encountered that could not be resolved by the model. For each flow simulation, a file of node attributes was created for input to habitat mapping and spatial analysis programs.

\section{Effects of Channel Dynamics on Simulations}

The wide alluvial flood plains of the Union Gap and Wapato reaches are very dynamic, changing in shape and complexity on an annual basis. Between September 2005 and December 2007 we observed rapid and substantial changes in the Union Gap and Wapato reaches when flows exceeded 15,000 cubic feet per second. Changes in channel morphology were especially apparent in the side channels, and to a lesser degree in the main stem. In the winter and spring of 2006, a series of high-flow events caused some side channels to change course, widened or narrowed others, and created new channels through numerous island complexes. In November 2006, a flow of 23,000 cubic feet per second was observed. There were also pronounced changes in channel depths as the substrate was scoured, mobilized, and deposited throughout the reach. Channel changes also occurred to the main stem as banks were cut, trees fell in, and the channel shifted direction.

Changes in the side channels and main stem of both reaches also resulted from beaver activity in the active channels. The beavers caused many glides in side channels to become impounded, creating pools that sometimes extended hundreds of meters upstream. The beaver ponds appeared to provide suitable off-channel salmonid habitat as juvenile salmonids were observed on numerous occasions in them. 


\section{Accuracy Assessment}

The rapidly changing channel morphology in the Wapato reach made it impossible to accurately assess the LIDAR data because BOR had acquired it 1 year earlier than our field work began. As previously noted, large changes in the channel and flood plain following large storms created a dynamic environment where bed and flood plain elevations changed substantially. Therefore, the only reliable time to assess LIDAR accuracy was immediately after it was acquired, or previous to any large channelchanging flow events. For these reasons, the two-dimensional hydrodynamic model results can only represent an instantaneous "snapshot" of conditions in the modeled reaches. The dynamic nature of the channel forces the assumption that the bathymetry obtained for this study is typical of the range of channel configurations that occur at these study sites.

Errors in the LIDAR data, along with changes in the riverbed and flood plain, may have affected the accuracy and performance of our hydrodynamic models. For example, while most models converged after running for 100-300 hours, two moderate flows in the Wapato reach (3,000 and 4,000 cubic feet per second) would not converge regardless of how we adjusted model parameters. BOR assessed the LIDAR data during the time of acquisition and found between 15 and $39 \mathrm{~cm}$ error in the Easton and Kittitas reaches, usually biased high (Hilldale and Raff, Bureau of Reclamation, written commun. January 2008). We found in the model calibration stage that our errors in the modeled water-surface elevations were within $\pm 16.1-19.3 \mathrm{~cm}$ of the GPS survey data, and the error also tended to be biased high. Our calibration errors were comparable to those associated with the LIDAR data, indicating that the LIDAR data might have affected our modeling results in the Wapato reach.

In the Union Gap reach, our error rate was between 6.3 percent and 16.6 percent smaller than the Wapato reach, indicating that the bathymetric data we collected in the field were more accurate than the bathymetric LIDAR data we used in the Wapato reach. The coarser density of the field-collected data provided a more accurate, but less comprehensive depiction of the river bottom in the Union Gap reach compared with the Wapato reach. However, the more accurate field data allowed the Union Gap model to converge easier and be more accurate than the Wapato model.

Another factor that needs to be considered is the accuracy of the terrestrial LIDAR data under the forest canopy. In much of the Wapato reach, side channels meandered through thickly forested areas. If a side channel had water in it at the time the terrestrial LIDAR data were acquired, the laser would have reflected off the water surface, providing a higher elevation than the side-channel bottom (the intended target). This would result in areas where the streambed was measured (and modeled) higher than it really was. Specifically, we noticed that water began entering some of the side channels at approximately 2,500 cubic feet per second, but we could not get models to converge between 2,500 and 5,000 cubic feet per second. We suspect that the hydrodynamic models encountered higher than expected side-channel bottoms, forcing the water into shallow sheetflow over the artificial bottoms of these side channels. Shallow flow over large areas is known to present computational difficulties for two-dimensional hydraulic models. This obstacle was not overcome until we modeled a 5,000 cubic feet per second flow, indicating that the water surface had to rise by about 0.55 meter before the side channels flowed. This indicates that the estimated depths and velocities in some side channels may have been underestimated in flows greater than 2,500 cubic feet per second in the Wapato reach. 


\title{
Appendix 2. Geographic Information System Operations
}

\author{
By Ken D. Bovee
}

\section{Methods}

\section{Habitat Classification}

Ranges of suitable depths and velocities for each of the target species and life stages from table 1 (main text) were defined using the Delphi technique as described by Zuboy (1981). A small monitoring team devised a questionnaire that was sent out to a larger respondent group of experts. Each respondent was asked to provide his or her estimate of the maximum and minimum depths and velocities considered to be suitable for each of the target organisms and habitat use guilds. After the questionnaire was returned to the monitors, group opinion was summarized by providing the median and interquartile ranges of the initial responses. These estimates of group opinion were then returned to the respondents, who were asked to answer the questionnaire again in light of the new information. Anonymity of individual responses was maintained throughout this process to minimize the "bandwagon effect" associated with roundtable discussions. If a respondent's second response was outside the interquartile range of the previous round, he or she was asked to provide a brief explanation in support of the response. These explanations were provided to the respondent group, along with the revised median and interquartile ranges of the responses, and the process was repeated until the group converged to a consensus of opinion or at least attained stability in the distribution of responses. The habitat suitability bins that resulted from the Delphi exercise are shown in figures 2-1-2-6.

\begin{tabular}{|c|c|c|c|c|c|c|}
\hline \multirow[b]{2}{*}{ Spawning } & \multirow[b]{2}{*}{ Incubation } & \multicolumn{3}{|c|}{ Suitable depth range, in feet } & \multirow[b]{2}{*}{ Yearling } & \multirow[b]{2}{*}{ Adult } \\
\hline & & Fry & $\begin{array}{l}\text { Subyearling } \\
\text { (Summer) }\end{array}$ & $\begin{array}{c}\text { Subyearling } \\
\text { (Winter) }\end{array}$ & & \\
\hline 0.0 & 0.0 & 0.0 & 0.0 & 0.0 & & 0.0 \\
\hline 0.2 & 0.2 & 0.2 & 0.2 & 0.2 & & 0.2 \\
\hline 0.3 & 0.3 & 0.3 & 0.3 & 0.3 & & 0.3 \\
\hline 0.4 & 0.4 & 0.4 & 0.4 & 0.4 & & 0.4 \\
\hline 0.5 & 0.5 & 0.5 & 0.5 & 0.5 & & 0.5 \\
\hline 0.6 & 0.6 & 0.6 & 0.6 & 0.6 & & 0.6 \\
\hline 0.7 & 0.7 & 0.7 & 0.7 & 0.7 & & 0.7 \\
\hline 0.8 & 0.8 & 0.8 & 0.8 & 0.8 & & 0.8 \\
\hline 0.9 & 0.9 & 0.9 & 0.9 & 0.9 & & 0.9 \\
\hline 1.0 & 1.0 & 1.0 & 1.0 & 1.0 & & 1.0 \\
\hline 1.1 & 1.1 & 1.1 & 1.1 & 1.1 & & 1.1 \\
\hline 1.6 & 1.6 & 1.6 & 1.6 & 1.6 & & 1.6 \\
\hline 2.0 & 2.0 & 2.0 & 2.0 & 2.0 & & 2.0 \\
\hline 2.3 & 2.3 & 2.3 & 2.3 & 2.3 & & 2.3 \\
\hline 2.5 & 2.5 & 2.5 & 2.5 & 2.5 & & 2.5 \\
\hline 2.6 & 2.6 & 2.6 & 2.6 & 2.6 & & 2.6 \\
\hline 3.3 & 3.3 & 3.3 & 3.3 & 3.3 & & 3.3 \\
\hline 3.6 & 3.6 & 3.6 & 3.6 & 3.6 & & 3.6 \\
\hline 3.7 & 3.7 & 3.7 & 3.7 & 3.7 & & 3.7 \\
\hline 4.1 & 4.1 & 4.1 & 4.1 & 4.1 & & 4.1 \\
\hline 4.3 & 4.3 & 4.3 & 4.3 & 4.3 & & 4.3 \\
\hline \begin{tabular}{l|l}
4.6 &
\end{tabular} & 4.6 & 4.6 & 4.6 & 4.6 & & 4.6 \\
\hline 4.9 & 4.9 & 4.9 & 4.9 & 4.9 & & 4.9 \\
\hline 5.7 & 5.7 & 5.7 & 5.7 & 5.7 & & 5.7 \\
\hline \begin{tabular}{l|l}
6.6 &
\end{tabular} & 6.6 & 6.6 & 6.6 & 6.6 & & 6.6 \\
\hline 9.0 & 9.0 & 9.0 & 9.0 & 9.0 & & 9.0 \\
\hline 9.8 & 9.8 & 9.8 & 9.8 & 9.8 & & 9.8 \\
\hline 12.7 & 12.7 & 12.7 & 12.7 & 12.7 & & 12.7 \\
\hline 14.8 & 14.8 & 14.8 & 14.8 & 14.8 & & 14.8 \\
\hline 16.0 & 16.0 & 16.0 & 16.0 & 16.0 & & 16.0 \\
\hline 16.4 & 16.4 & 16.4 & 16.4 & 16.4 & & 16.4 \\
\hline 19.7 & 19.7 & 19.7 & 19.7 & 19.7 & & 19.7 \\
\hline
\end{tabular}

\begin{tabular}{|c|c|c|c|c|c|c|}
\hline \multirow[b]{2}{*}{ Spawning } & \multicolumn{5}{|c|}{ Suitable velocity range, in feet per second } & \multirow[b]{2}{*}{ Adult } \\
\hline & Incubation & Fry & $\begin{array}{c}\text { Subyearling } \\
\text { (Summer) }\end{array}$ & $\begin{array}{l}\text { Subyearling } \\
\text { (Winter) }\end{array}$ & Yearling & \\
\hline 0.0 & 0.0 & 0.0 & 0.0 & 0.0 & & 0.0 \\
\hline 0.2 & 0.2 & 0.2 & 0.2 & 0.2 & & 0.2 \\
\hline 0.3 & 0.3 & 0.3 & 0.3 & 0.3 & & 0.3 \\
\hline 0.4 & 0.4 & 0.4 & 0.4 & 0.4 & & 0.4 \\
\hline 0.5 & 0.5 & 0.5 & 0.5 & 0.5 & & 0.5 \\
\hline 0.6 & 0.6 & 0.6 & 0.6 & 0.6 & & 0.6 \\
\hline 0.7 & 0.7 & 0.7 & 0.7 & 0.7 & & 0.7 \\
\hline 0.8 & 0.8 & 0.8 & 0.8 & 0.8 & & 0.8 \\
\hline 0.9 & 0.9 & 0.9 & 0.9 & 0.9 & & 0.9 \\
\hline 1.0 & 1.0 & 1.0 & 1.0 & 1.0 & & 1.0 \\
\hline 1.1 & 1.1 & 1.1 & 1.1 & 1.1 & & 1.1 \\
\hline 1.3 & 1.3 & 1.3 & 1.3 & 1.3 & & 1.3 \\
\hline 1.6 & 1.6 & 1.6 & 1.6 & 1.6 & & 1.6 \\
\hline 2.1 & 2.1 & 2.1 & 2.1 & 2.1 & & 2.1 \\
\hline 2.2 & 2.2 & 2.2 & 2.2 & 2.2 & & 2.2 \\
\hline 2.3 & 2.3 & 2.3 & 2.3 & 2.3 & & 2.3 \\
\hline 2.4 & 2.4 & 2.4 & 2.4 & 2.4 & & 2.4 \\
\hline 2.5 & 2.5 & 2.5 & 2.5 & 2.5 & & 2.5 \\
\hline 2.6 & 2.6 & 2.6 & 2.6 & 2.6 & & 2.6 \\
\hline 2.7 & 2.7 & 2.7 & 2.7 & 2.7 & & 2.7 \\
\hline 2.9 & 2.9 & 2.9 & 2.9 & 2.9 & & 2.9 \\
\hline 3.0 & 3.0 & 3.0 & 3.0 & 3.0 & & 3.0 \\
\hline 3.1 & 3.1 & 3.1 & 3.1 & 3.1 & & 3.1 \\
\hline 3.3 & 3.3 & 3.3 & 3.3 & 3.3 & & 3.3 \\
\hline 3.9 & 3.9 & 3.9 & 3.9 & 3.9 & & 3.9 \\
\hline 4.1 & 4.1 & 4.1 & 4.1 & 4.1 & & 4.1 \\
\hline 4.5 & 4.5 & 4.5 & 4.5 & 4.5 & & 4.5 \\
\hline 5.2 & 5.2 & 5.2 & 5.2 & 5.2 & & 5.2 \\
\hline 8.0 & 8.0 & 8.0 & 8.0 & 8.0 & & 8.0 \\
\hline 8.4 & 8.4 & 8.4 & 8.4 & 8.4 & & 8.4 \\
\hline 8.9 & 8.9 & 8.9 & 8.9 & 8.9 & & 8.9 \\
\hline
\end{tabular}

Figure 2-1. Suitable depth and velocity ranges for six life stages of spring chinook (Oncorhynchus tshawytscha), as determined by the Yakima River Delphi committee. Suitable ranges are highlighted in green, unsuitable in tan. 

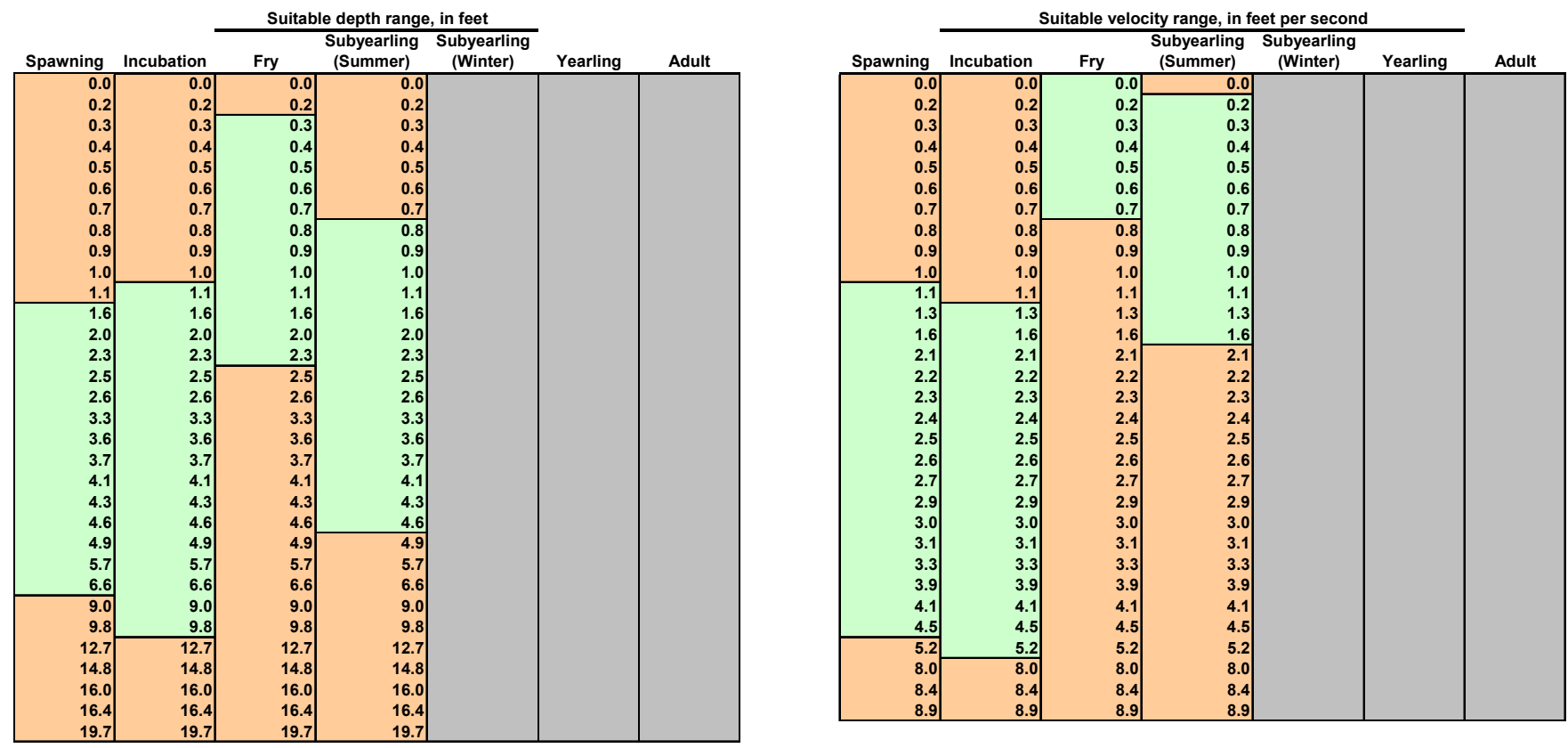

Figure 2-2. Suitable depth and velocity ranges for four life stages of fall chinook (Oncorhynchus tshawytscha), as determined by the Yakima River Delphi committee. Suitable ranges are highlighted in green, unsuitable in tan.
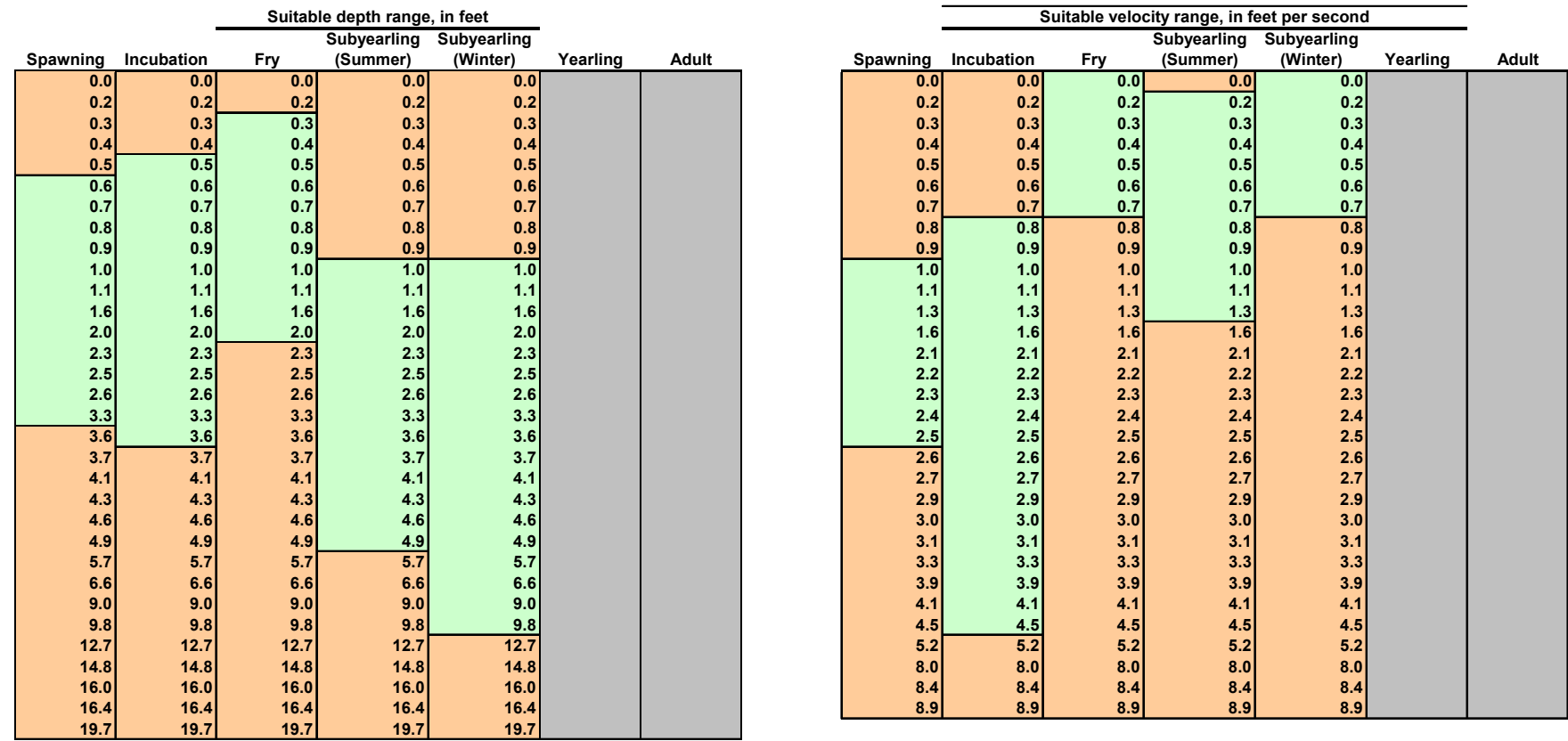

Figure 2-3. Suitable depth and velocity ranges for four life stages of coho (Oncorhynchus kisutch), as determined by the Yakima River Delphi committee. Suitable ranges are highlighted in green, unsuitable in $\tan$. 

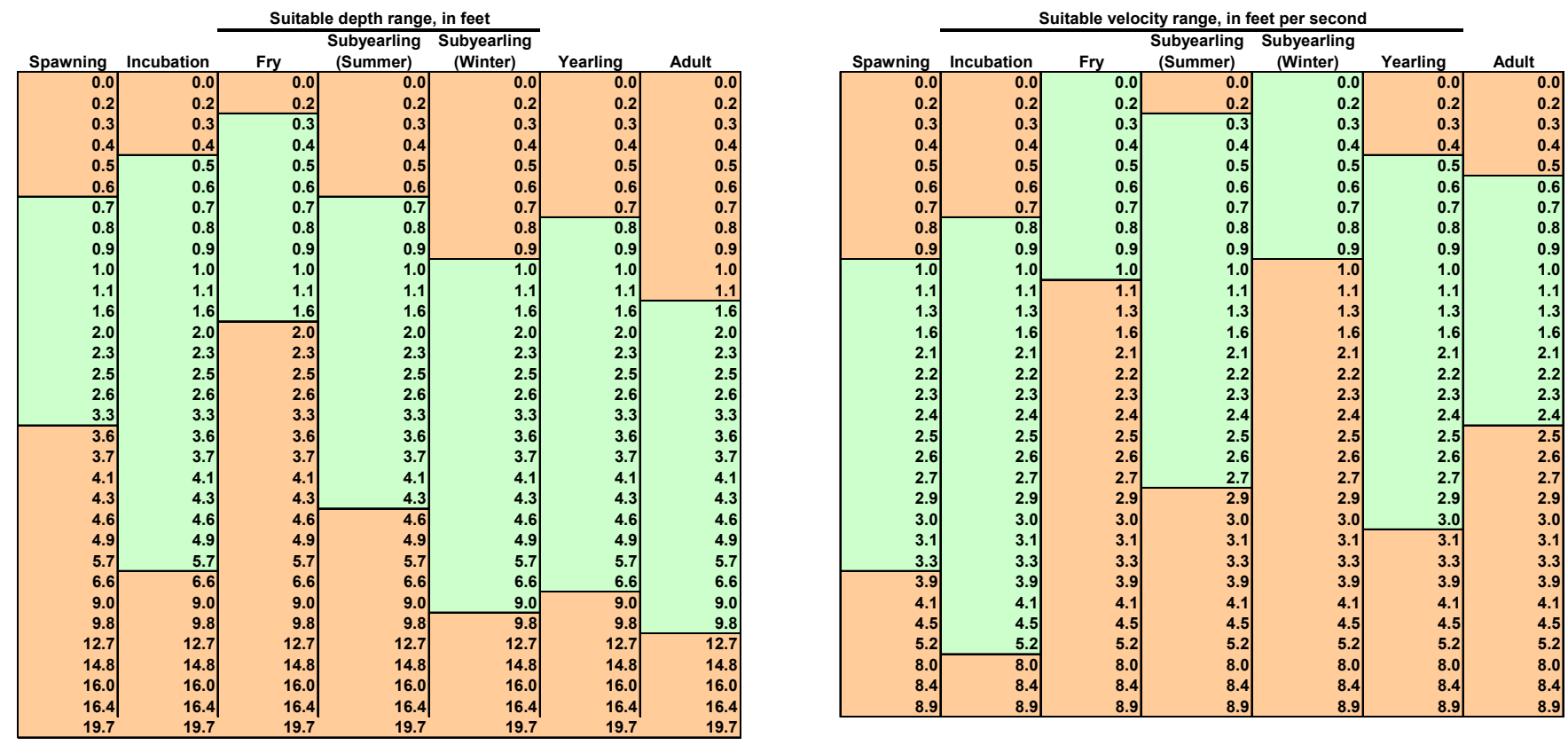

Figure 2-4. Suitable depth and velocity ranges for four life stages of steelhead (Oncorhynchus mykiss), as determined by the Yakima River Delphi committee. Suitable ranges are highlighted in green, unsuitable in tan.
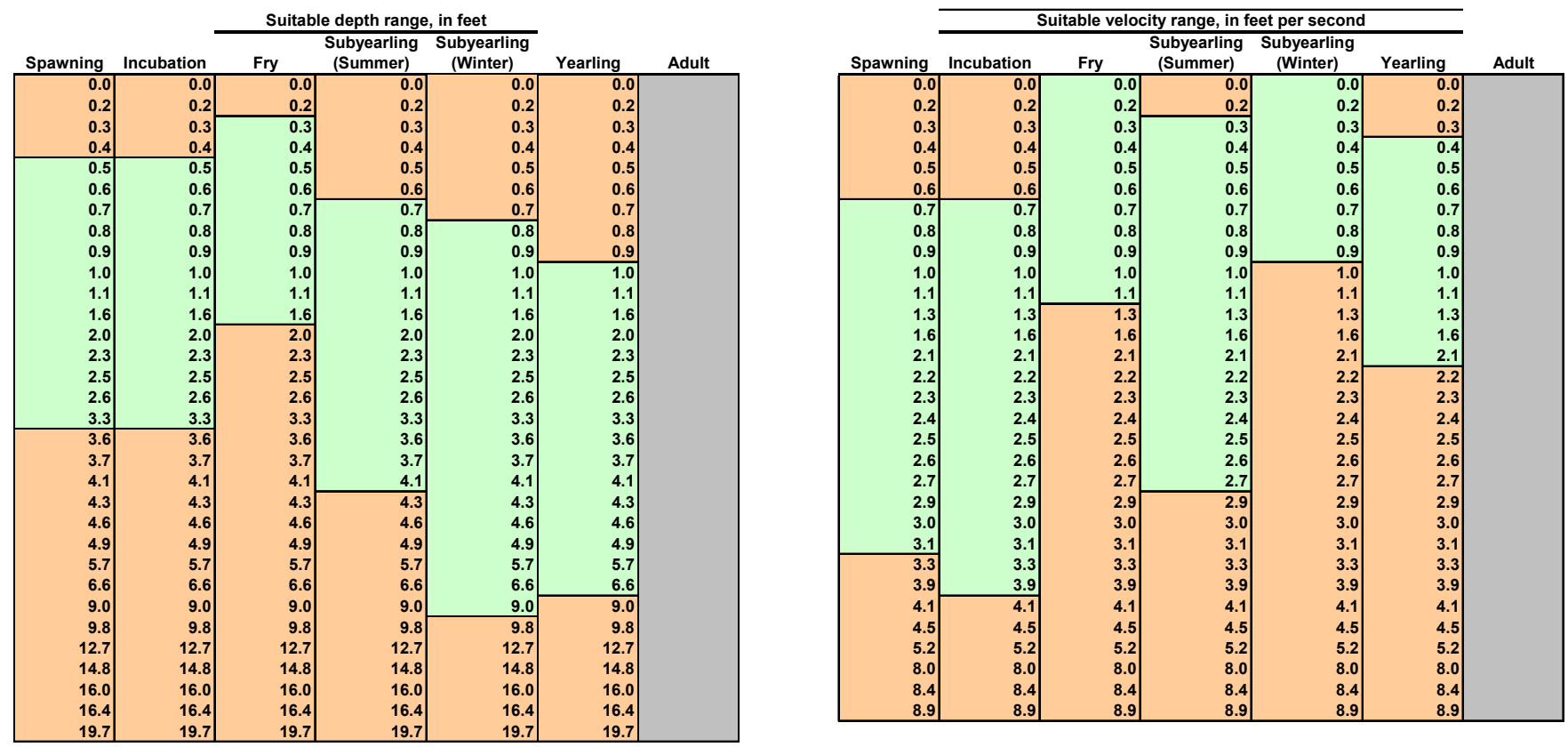

Figure 2-5. Suitable depth and velocity ranges for four life stages of resident rainbow trout (Oncorhynchus mykiss), as determined by the Yakima River Delphi committee. Suitable ranges are highlighted in green, unsuitable in tan. 

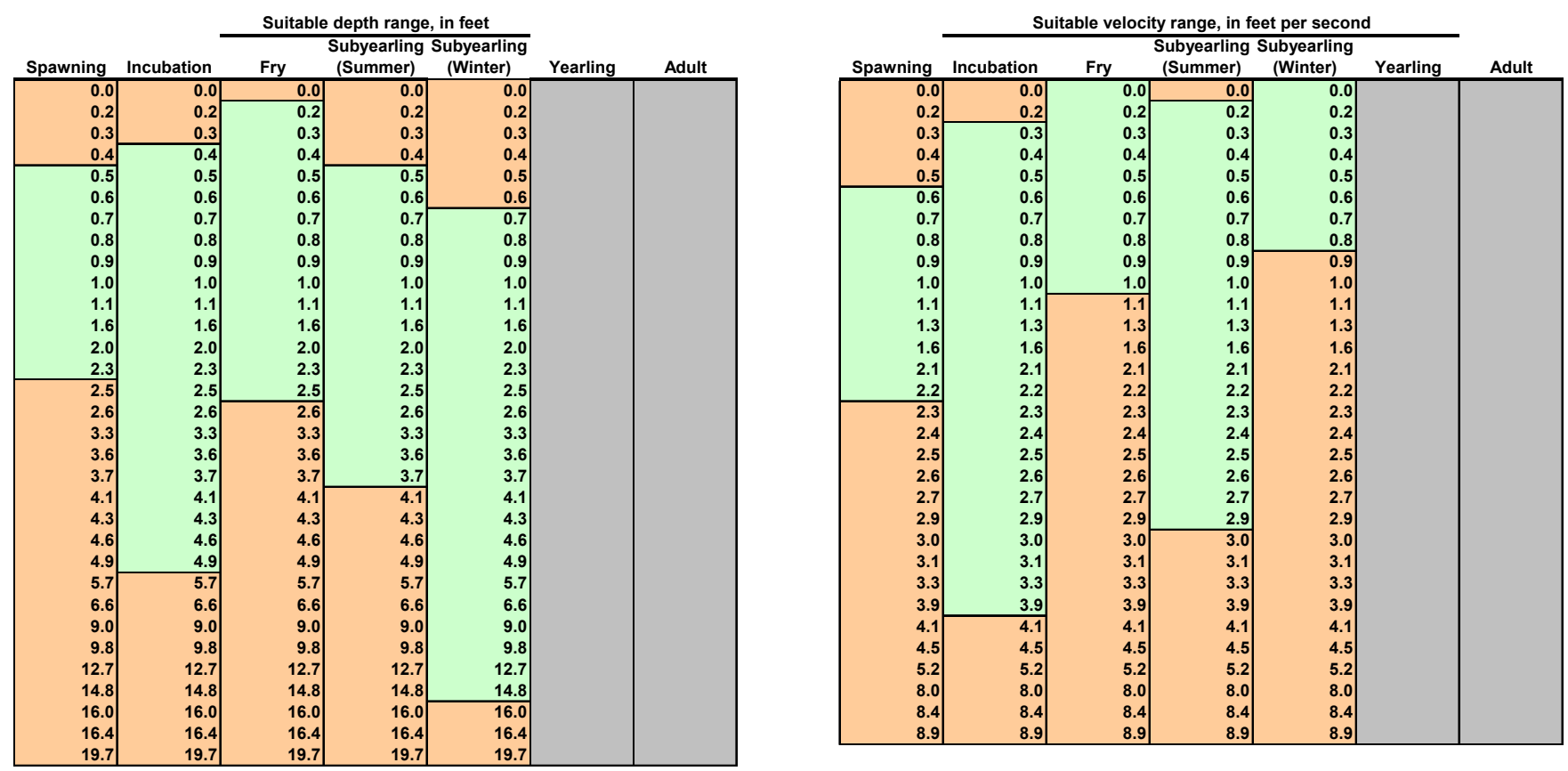

Figure 2-6. Suitable depth and velocity ranges for five life stages of bull trout (Salvelinus confluentus), as determined by the Yakima River Delphi committee. Suitable ranges are highlighted in green, unsuitable in tan.

\section{Map Layers}

Several types of map layers and intermediate products were generated under the general heading of habitat maps. The hydraulic habitat layer consisted of a series of habitat classification polygons depicting the spatial distribution of suitable depths and velocities for each target organism at each simulated discharge. The hydraulic habitat layer was the source of metrics considered to be steady-state functions of discharge (for example, total area of spring chinook fry habitat at a specific discharge). Mesohabitat layers, depicting specialized habitat features were constructed as refinements to some of the hydraulic habitat maps. Habitat persistence maps were constructed to quantify the spatial stability of spawning and incubation habitat for all species under conditions of unsteady flow.

\section{The Hydraulic Habitat Layer}

Output from a two-dimensional hydraulic simulation (River2D or GSTARW) of a particular discharge was exported as a text file containing the coordinates, depths, and velocities for each node in the computational mesh. This information was used to generate a map layer of the nodes and the attributes of depth, velocity, and Froude number . An interpolated surface (a Triangular Irregular Network, or TIN) was constructed for each hydraulic variable, using the nodal data as mass points. Each TIN was converted to a $5 \mathrm{ft}$ by $5 \mathrm{ft}$ grid, reclassified according to the habitat classification criteria (figs. 2-2-2-6), and the reclassified grids combined to create a single grid depicting suitable depth and velocity conditions for each target organism and life stage (fig. 2-7). The composite grids were converted to polygon format and the area for each polygon was calculated. The attribute tables were exported to a spreadsheet for subsequent extraction of habitat metrics and development of the flow-habitat lookup tables used in time series analysis. 

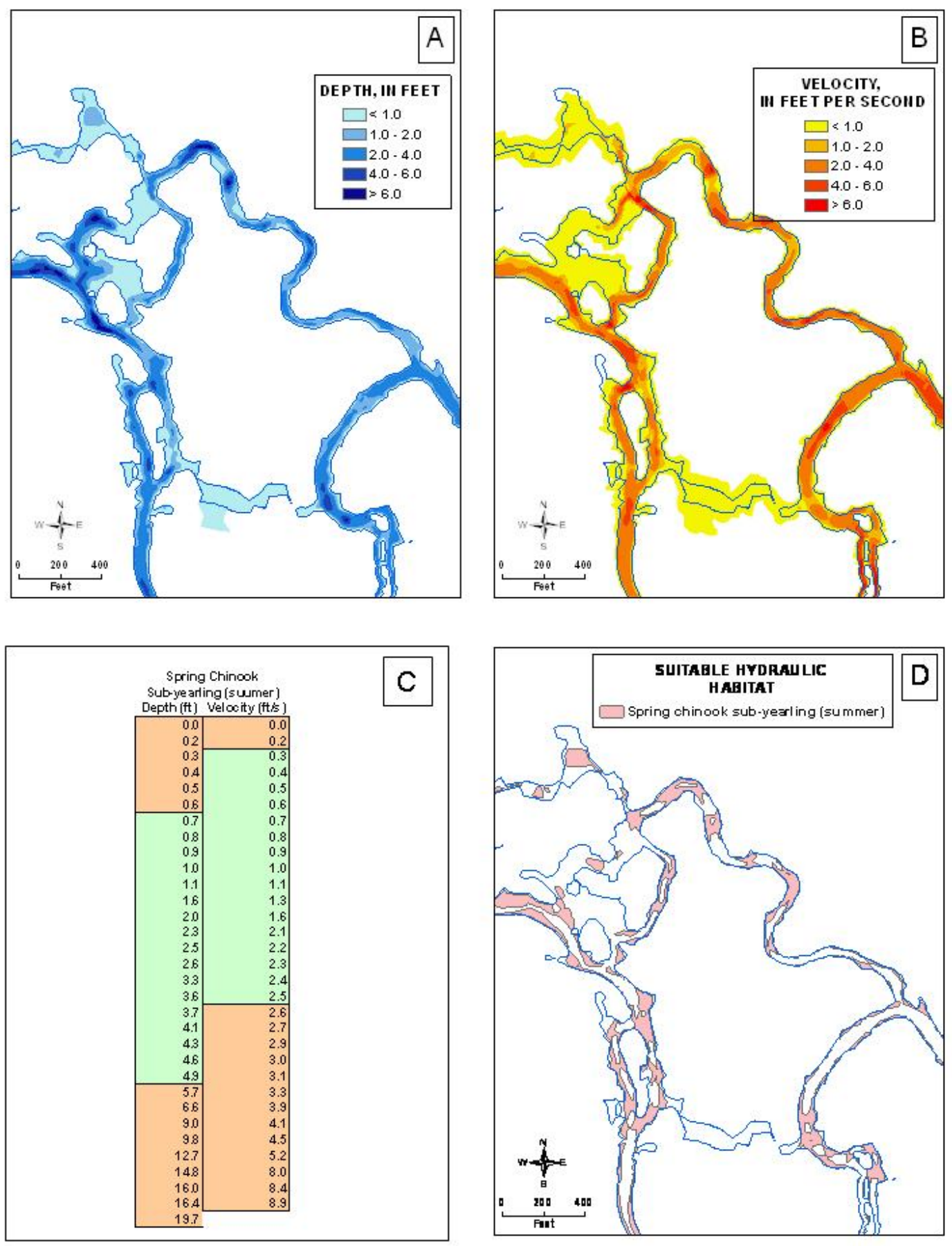

Figure 2-7. Conversion of depth and velocity grids to a hydraulic habitat polygon shapefile in ArcGIS. Depth and velocity grids $(A)$ and $(B)$ were reclassified according to the suitable habitat criteria (green ranges) for a life stage (C) and converted to polygon format (D). 


\section{Water's Edge Arcs and Polygons}

The water's edge arc defined the shorelines of all wetted areas for each simulated flow and was used to construct a shoreline mesohabitat layer for subsequent analysis. During the conversion of the reclassified hydraulic habitat grids to polygons, we observed a tendency for the polygons to "bleed" beyond the wetted margins of the stream. The water's edge polygon was used as a clipping layer to confine the hydraulic habitat polygons to the wetted surface area for a particular discharge.

The water's edge polygon was created by reclassifying the depth grid according to depths greater than zero and depths less than or equal to zero. The reclassified grid was converted to polygon format and polygons having depth less than or equal to zero were eliminated. Isolated polygons that were not connected to the main channel at the highest simulated discharge were also eliminated by intersecting the water's edge polygon for a particular discharge with the water's edge polygon for the highest simulated discharge. Our rationale for this procedure was that localized areas of standing water that rarely connected to the river might serve as stranding areas for the target species, and therefore, should not be considered as viable habitat. The water's edge arc was constructed from this clipped water's edge polygon using the polygon-to-polyline function in ArcGis.

\section{Mesohabitat Layers}

Two unique mesohabitat layers were formulated for refinement of the hydraulic habitat maps for fry and spawning. In the first case, there was a general consensus among the Delphi committee members that fry utilized shallow, slow areas in the river but were largely confined to a narrow zone along the shorelines. To simulate this constraint, we developed a buffered polygon $5 \mathrm{ft}$ wide around the water's edge arcs for each of the simulated discharges. The shoreline buffers were then intersected with the hydraulic habitat polygons for the fry of each species, resulting in maps of suitable depths and velocities located within $5 \mathrm{ft}$ of the shoreline (fig. 2-8).

The second type of mesohabitat layer was developed to refine the definition of suitable spawning areas for salmonids in the Yakima River. In a similar study of the Delaware River in New York, Bovee and others (2007) constructed a layer defined as a pool tail-out as a necessary condition for suitable spawning areas. The pool tail-out was defined as a reach of stream located between the deepest portion of a pool and the crest of the downstream riffle. Observations of trout redds in the Delaware River indicated that trout preferred these locations for spawning sites.

In 2005, Andy Dittman and Darran May, Northwest Fisheries Science Center, National Oceanic and Atmospheric Administration (NOAA) Fisheries, surveyed the locations of 574 spring chinook redds within the extent of the Easton habitat mapping reach, and provided this information to us (Andy Dittman, NOAA Fisheries, written commun. July 2006). We implemented a procedure similar to that developed by Panfil and Jacobson (1999) to delineate mesohabitat features that corresponded to the observed redd locations. The Panfil-Jacobson approach involves the use of the Froude number to define specific mesohabitat types. The Froude number is a ratio between potential and kinetic energy in a stream and is calculated as:

where, $\mathrm{F}=$ Froude number,

$$
\mathrm{F}=\mathrm{V} /(\mathrm{gD})^{1 / 2}
$$

$$
\begin{aligned}
& V=\text { velocity, } \\
& D=\text { depth, and } \\
& g=\text { the acceleration of gravity. }
\end{aligned}
$$




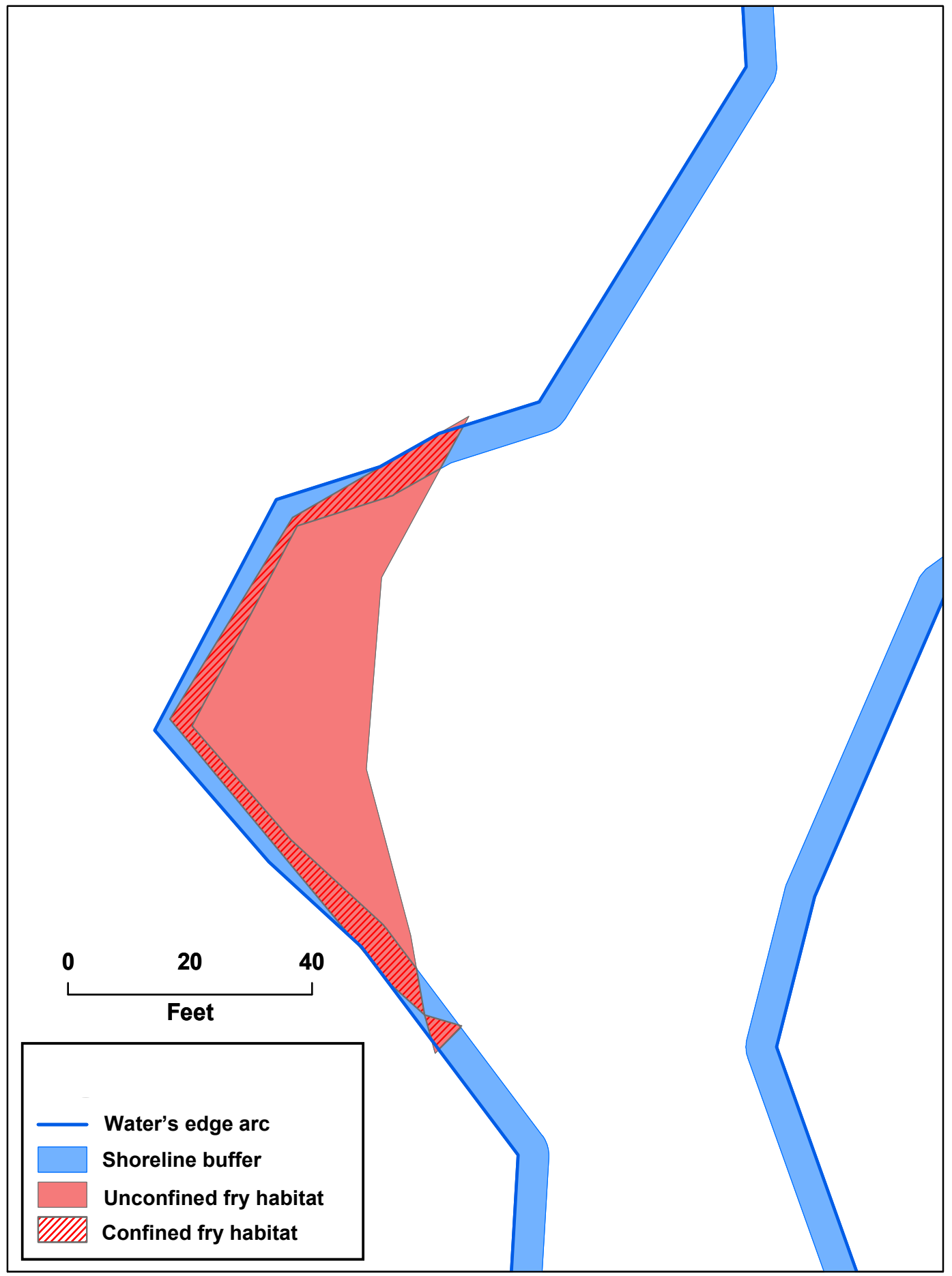

Figure 2-8. Example of the intersection between suitable hydraulic habitat for fry with a shoreline buffer. The solid coral polygon represents an area having suitable hydraulic conditions for fry. The polygons symbolized by red crosshatching represent the portion of the suitable hydraulic habitat polygon located within 5 feet of the shoreline. 
We developed a categorical GIS polygon layer of Froude numbers for each of the simulated discharges, classified by 0.1 (dimensionless) increments, but used only the layer for the highest simulation flow to test for redd correspondence. Our rationale for using the high-flow simulation was based on an assumption that the Froude number was associated with physical features of the stream known to be of importance for spawning areas, such as favorable substrate or hyporheic conditions. Low Froude numbers (for example, 0.2 or less) should be associated with fine substrates, whereas high Froude numbers (for example, 0.7 or greater) should be associated with coarse substrates, especially at the highest discharges, at which most of the geomorphic work is done. Panfil and Jacobson (1999) also found a high correspondence between Froude number and mesohabitat classifications, such as riffles, pools, and races (similar to our definitions of runs or pool tail-outs). We performed an intersection of the redd locations provided by May and Dittman with the Froude number polygons and found a high correspondence between redd locations and polygons having Froude numbers between 0.3 and 0.6 at the highest simulated discharge (fig. 2-9).

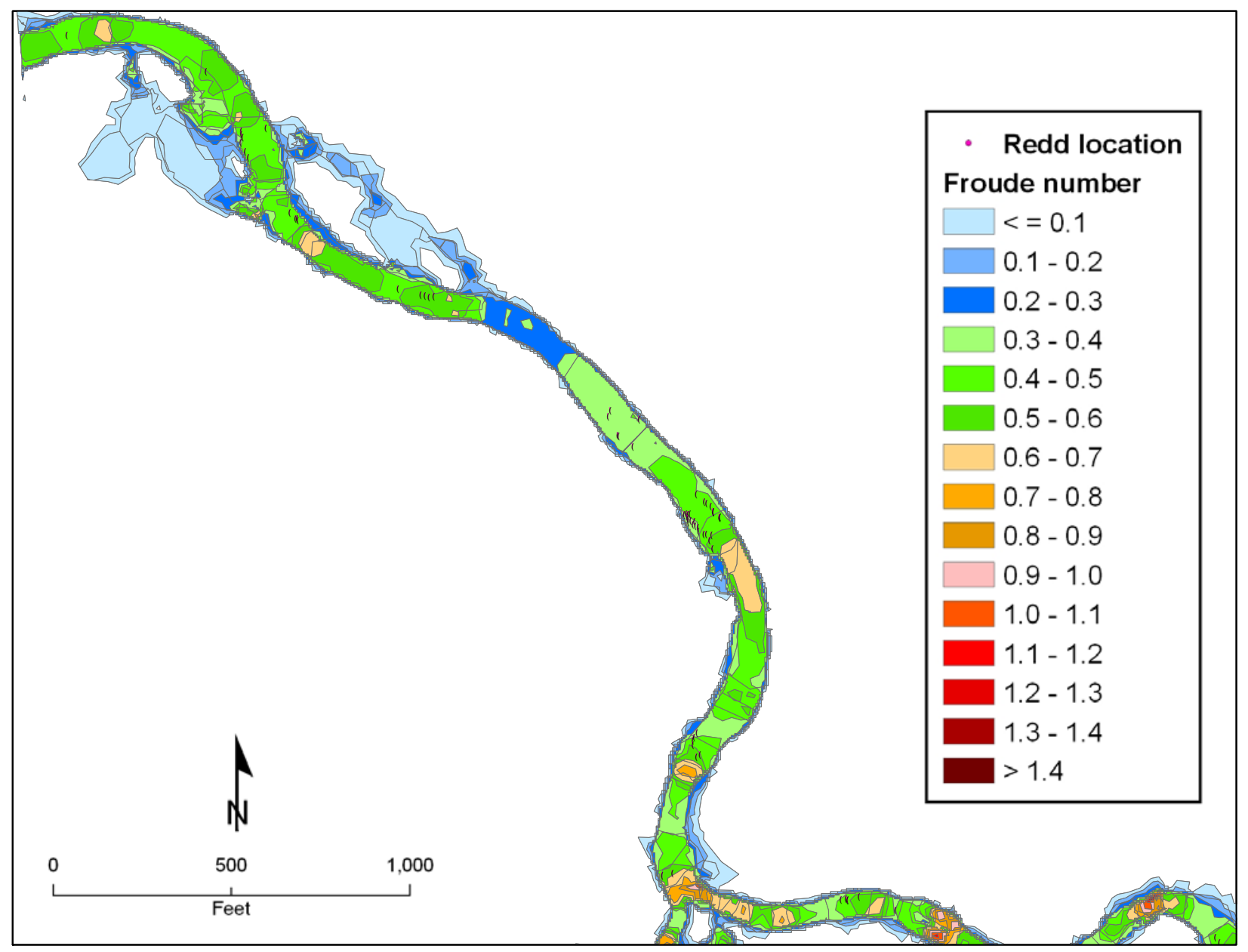

Figure 2-9. Correspondence between spring chinook redd locations observed at approximately 300 cubic feet per second and Froude number categories calculated for 2,000 cubic feet per second in a portion of the Easton reach. 
To test whether spring chinook were actively selecting areas having specific Froude numbers or simply using them in proportion to their availability, we calculated an electivity index for each Froude number class, using the approach developed by Ivlev (1961). The electivity index is simply a ratio between the proportion of a categorical variable utilized and the proportion of its availability:

Where $\mathrm{E}=$ the electivity index,

$$
\mathrm{E}=\mathrm{U} / \mathrm{A}
$$

$\mathrm{U}=$ the proportion of animals utilizing a resource or category, and

$\mathrm{A}=$ the proportion of the resource or category available to the animal.

If utilization is greater than availability, the animal is demonstrating selective behavior; if utilization is less than availability, the animal is demonstrating avoidance; when the two proportions are equal, the animal is utilizing the resource randomly, according to the definitions provided by Ivlev (1961). Figure 2-10 shows the proportions of redds, the proportional areas of polygons, and normalized electivity indexes (maximum electivity index set to 1.0 and all others prorated accordingly) found in each Froude number category. These data indicated that spring chinook spawners actively selected locations having Froude numbers between 0.3 and 0.6, avoided areas with Froude numbers less than 0.3 and either avoided or randomly utilized areas with Froude numbers greater than 0.6. Upon presenting this evidence to members of SOAC and the Delphi committee, a decision was made to extrapolate these findings to all salmonid species and all other study sites, even though the data were specific to spring chinook in the

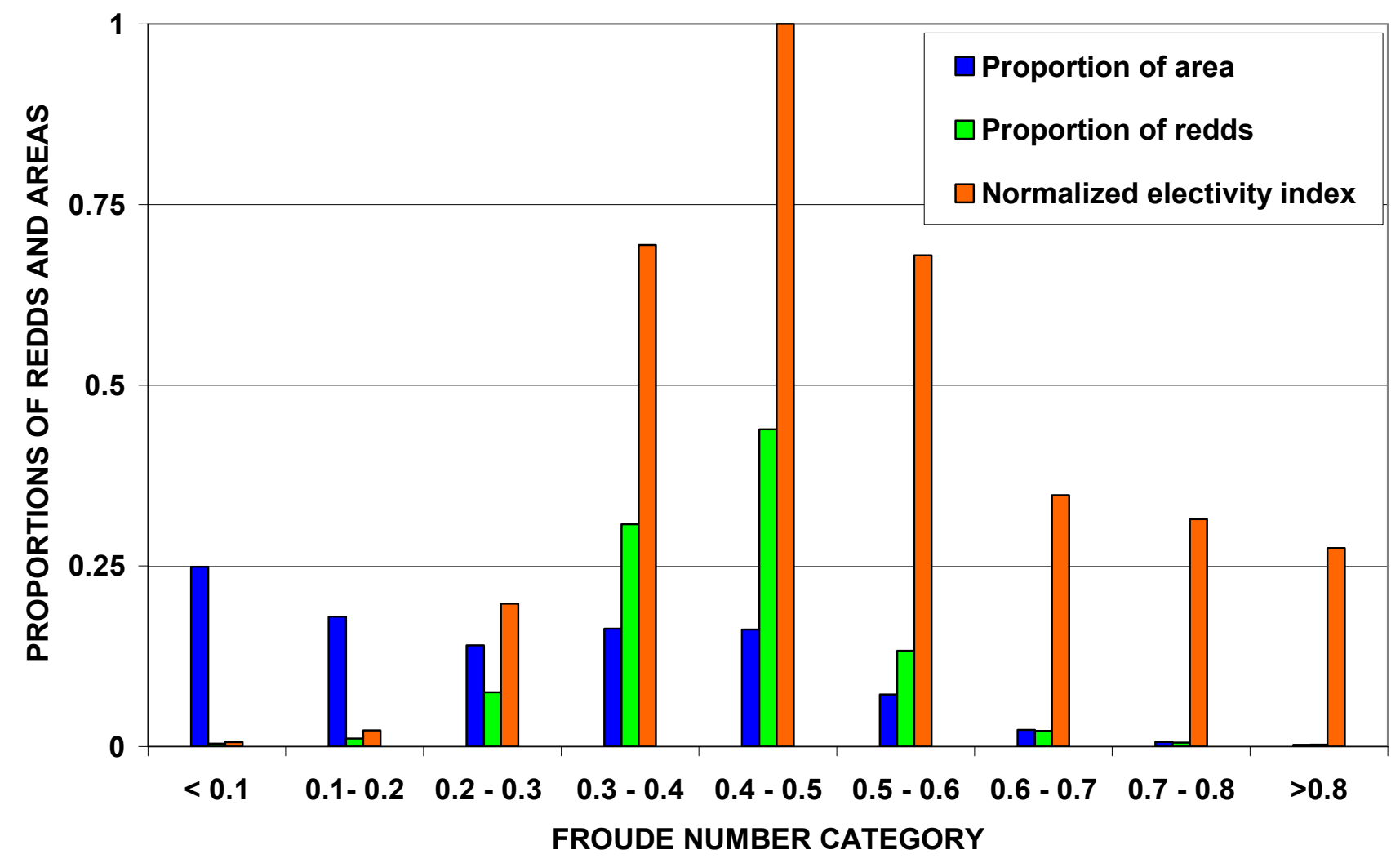

Figure 2-10. Proportions of spring chinook redds, available areas, and normalized electivity indexes, arrayed by Froude number category for the Easton reach of the Yakima River. 
Easton reach. Consequently, all spawning habitat maps for this study were based on the intersection of suitable depths and velocities for the species and polygons with Froude numbers between 0.3 and 0.6 , as calculated for the highest simulated discharge for each site.

\section{Habitat Persistence}

Habitat persistence is a measure of the stability of individual habitat patches, applicable primarily to organisms with limited mobility (Bovee and others, 2004). Although habitat persistence can influence the well-being of many organisms, we confined our analysis to spawning and subsequent incubation periods for the six target species. The conceptual model for the spawning-incubation analysis was that salmonids would spawn in suitable depths and velocities, confined to areas having suitable Froude numbers, and that hatching success would be related to the continued suitability of conditions over the redds throughout the incubation period. Incubation flows that were appreciably lower than the spawning flow could result in dewatering of redds, whereas high flows could result in their destruction by erosion.

To quantify the persistence of spawning-incubation habitat we performed a multilayer intersection of the suitable Froude number polygons, the suitable hydraulic habitat for spawning, and suitable hydraulic habitat for incubation, respectively (fig. 2-11). Persistence of spawning patches is a time- and flow-dependent phenomenon. That is, for the same combination of flows, habitat persistence differs depending on whether the spawning flow was higher or lower than the incubation flow. Consequently, it was necessary to construct overlay maps for all simulated spawning flows and all simulated incubation flows (an $\mathrm{N}$ by $\mathrm{N}$ cell matrix). Areas of persistent spawning-incubation habitat were calculated in the attribute table for each composite map layer and exported to a matrix table (Tables 2-26-2-46) for subsequent use in the time series analysis.

\section{Results}

Figures 2-12 through 2-36 show the discharge relative to habitat curves for pertinent target species and life stages in each of the five study sites. In nearly all cases, the amount of fry habitat was approximately an order of magnitude smaller than the areas for the rest of the life stages. To provide greater clarity of the relations between flow and fry habitat, fry habitat was plotted on a secondary yaxis (values on right sides of figures). Each figure is accompanied by the lookup table from which it was generated and used in the habitat time series computations in the YRDSS (tables 2-1 through 2-25). Owing to the nature of the algorithm used for the time series, the lookup tables were extrapolated beyond the bounds of the simulated discharges. This step was necessary to ensure that any discharge occurring in the flow time series would be bracketed within the lookup table. Failure to accommodate any discharge in the time series by interpolation within the lookup table would have resulted in a \#NA\# (not applicable) return for the time step, which in turn, would have created an error in the summary statistics. Generally speaking, the extrapolated flows occurred rarely, if ever, in the discharge time series. Consequently, the effect of the extrapolations should be minor and certainly better than the alternative. In addition, the YRDSS was formatted for a lookup table of 15 rows in length. When the number of simulated flows plus the extrapolated flows was less than 15, we filled the table by linear interpolation of adjacent simulated flows. Extrapolated values in the lookup tables are indicated by a pink background, whereas interpolations are indicated by a tan background. 


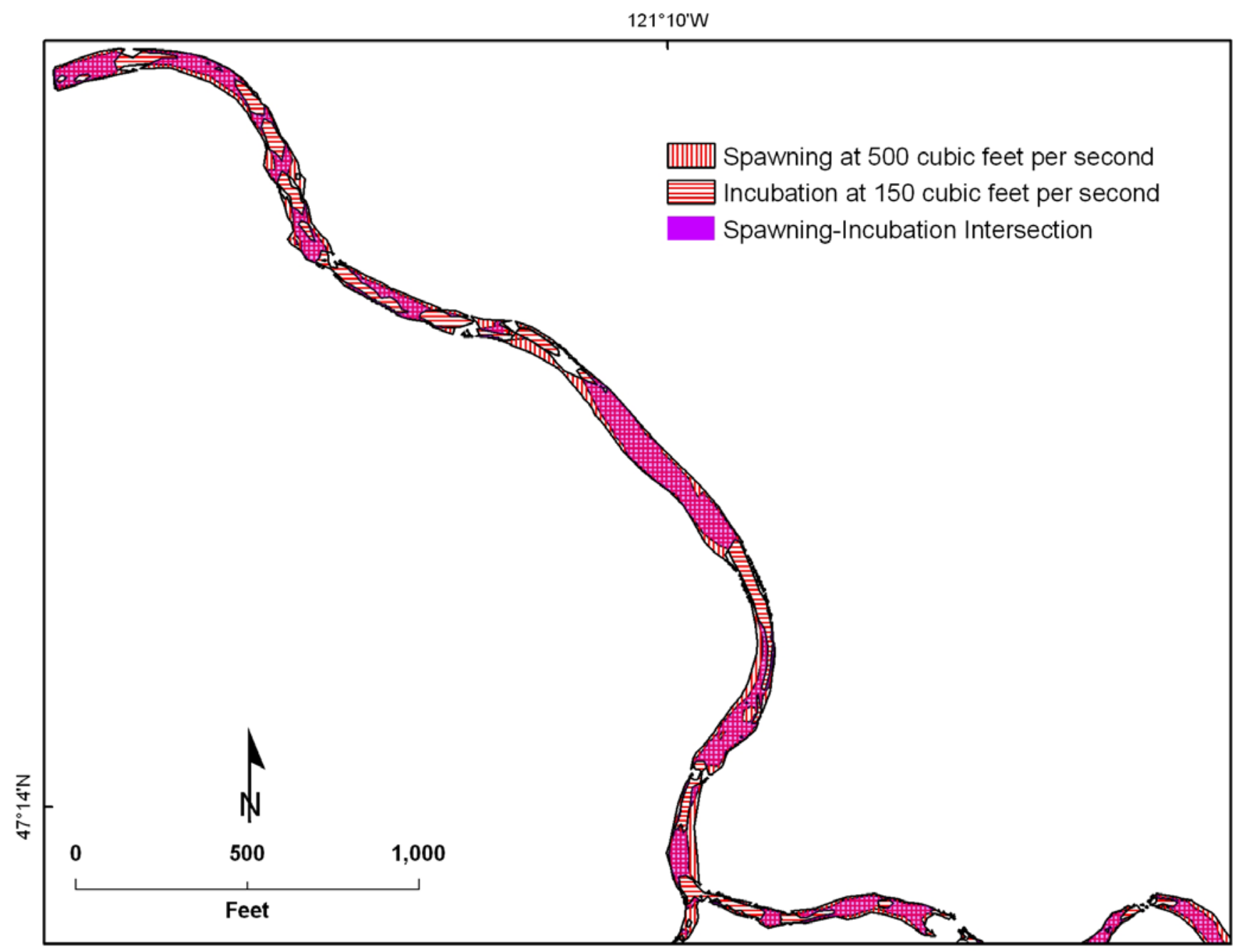

Figure 2-11. Illustration of a habitat persistence map for spring chinook spawning at a discharge of 500 cubic feet per second with an incubation discharge of 150 cubic feet per second in a portion of the Easton reach. 


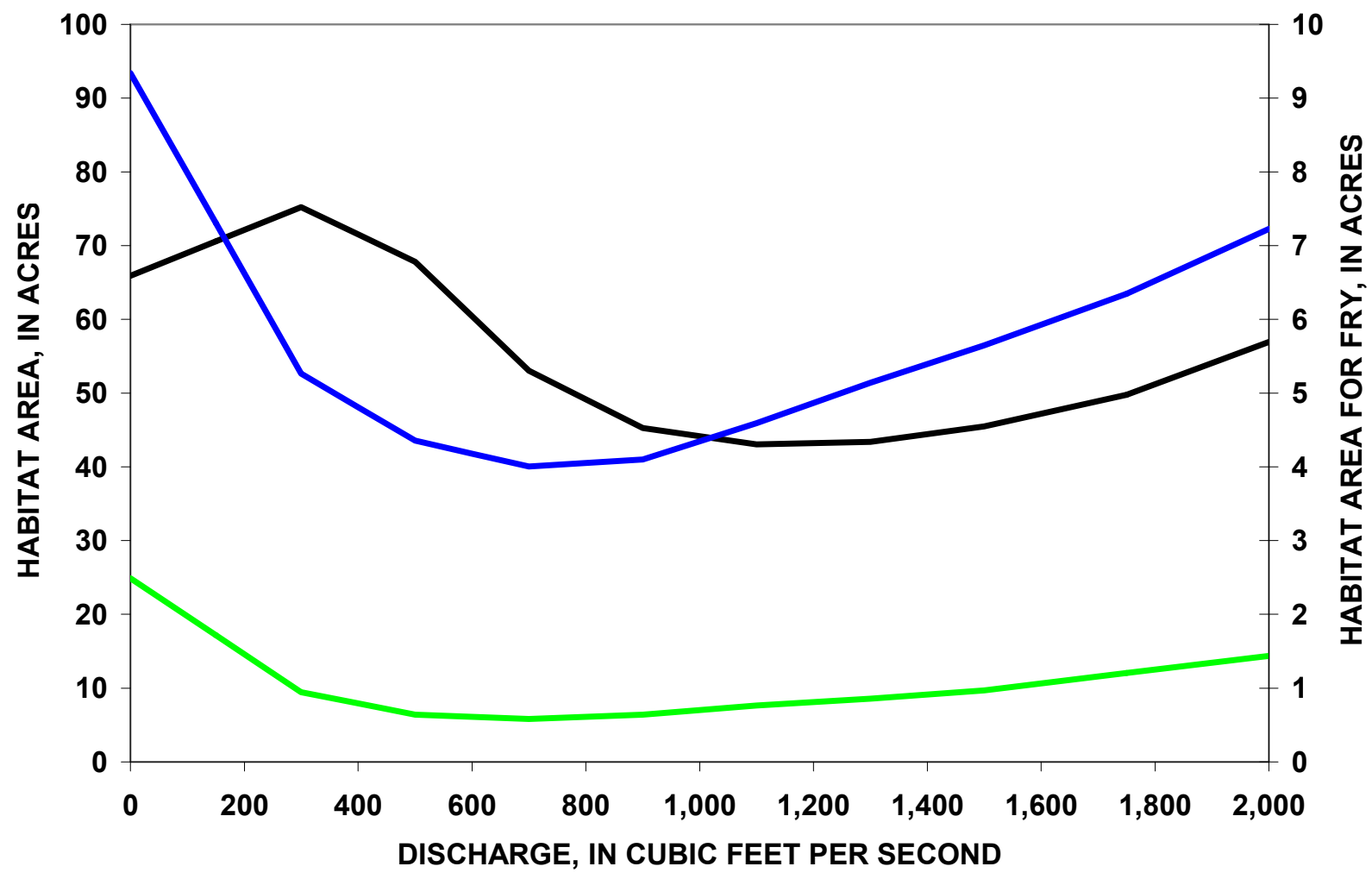

Subyearling winter $\longrightarrow$ Subyearling summer —Fry

Figure 2-12. Total habitat area as a function of stream discharge for three life stages of bull trout (Salvelinus confluentus) in the Easton reach.

Table 2-1. Total habitat lookup table for bull trout (S. confluentus) in the Easton reach. [ $\mathrm{ft}^{3} / \mathrm{s}$, cubic feet per second]

\begin{tabular}{rrrr}
\hline \multicolumn{4}{c}{ Habitat area, in acres } \\
\hline $\begin{array}{c}\text { Discharge, } \\
\text { in ft } \mathbf{3} \text { s }\end{array}$ & \multicolumn{1}{c}{ Fry } & $\begin{array}{c}\text { Subyearling } \\
\text { winter }\end{array}$ & $\begin{array}{c}\text { Subyearling } \\
\text { summer }\end{array}$ \\
\hline 0 & 9.34 & 24.89 & 65.91 \\
150 & 7.30 & 17.17 & 70.56 \\
300 & 5.27 & 9.44 & 75.22 \\
400 & 4.81 & 7.92 & 71.51 \\
500 & 4.35 & 6.41 & 67.79 \\
600 & 4.18 & 6.11 & 60.41 \\
700 & 4.01 & 5.82 & 53.04 \\
900 & 4.10 & 6.41 & 45.27 \\
1,100 & 4.59 & 7.64 & 43.04 \\
1,300 & 5.14 & 8.56 & 43.38 \\
1,500 & 5.65 & 9.68 & 45.47 \\
1,750 & 6.35 & 12.07 & 49.79 \\
2,000 & 7.23 & 14.37 & 56.93 \\
3,500 & 12.51 & 28.16 & 99.77 \\
11,500 & 17.80 & 41.95 & 142.61
\end{tabular}




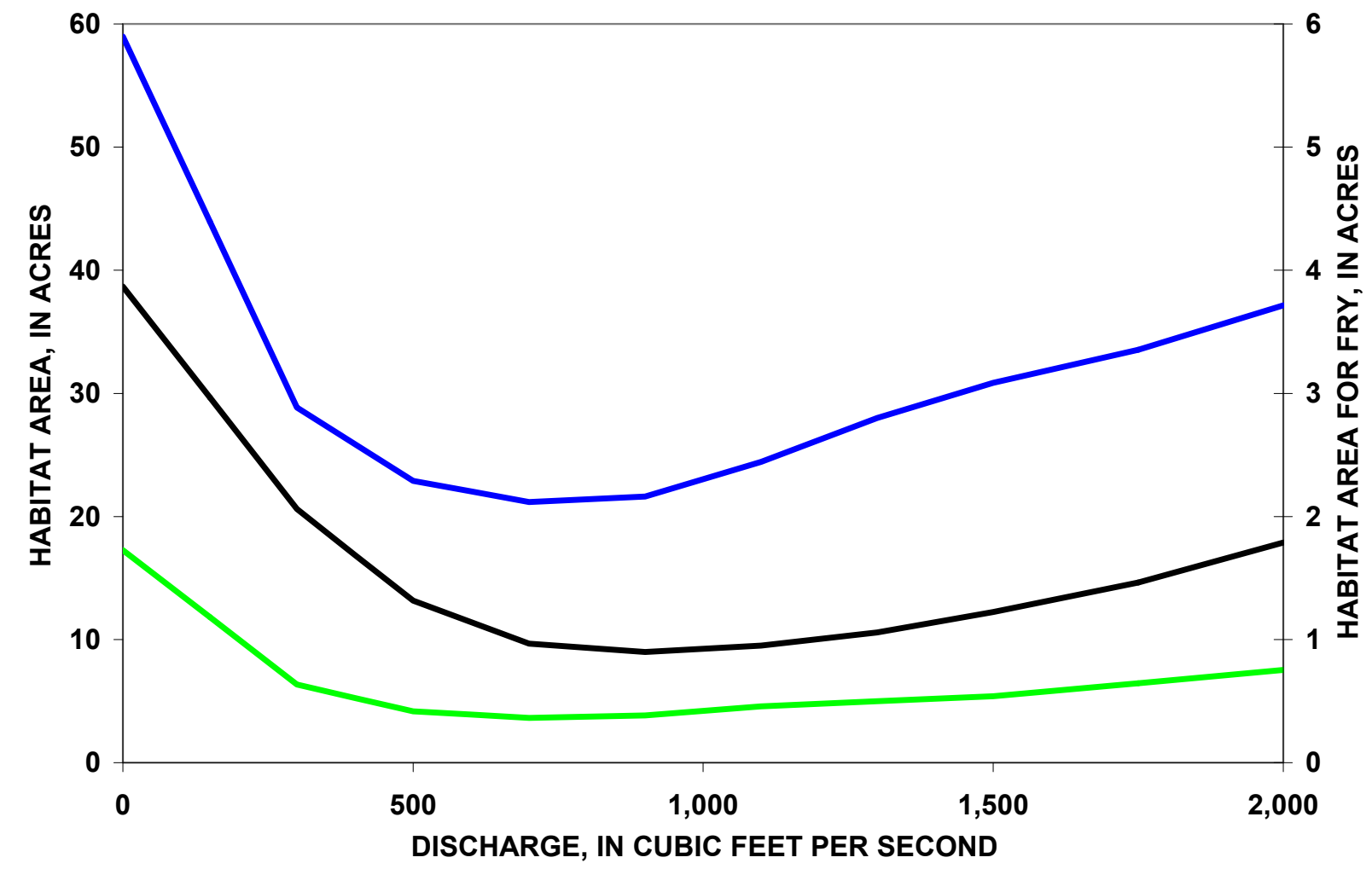

Subyearling winter $\longrightarrow$ Subyearling summer - Fry

Figure 2-13. Total habitat area as a function of stream discharge for three life stages of coho (Oncorhynchus kisutch) in the Easton reach.

Table 2-2. Total habitat lookup table for coho (0. kisutch) in the Easton reach. $\left[\mathrm{ft}^{3} / \mathrm{s}\right.$, cubic feet per second]

\begin{tabular}{rrrr}
\hline & \multicolumn{3}{c}{ Habitat area, in acres } \\
\hline $\begin{array}{c}\text { Discharge, } \\
\text { in } \mathbf{f t}^{\mathbf{3}} / \mathbf{s}\end{array}$ & Fry & $\begin{array}{c}\text { Subyearling } \\
\text { winter }\end{array}$ & $\begin{array}{c}\text { Subyearling } \\
\text { summer }\end{array}$ \\
\hline 0 & 5.90 & 17.26 & 38.67 \\
150 & 4.39 & 11.81 & 29.64 \\
300 & 2.89 & 6.35 & 20.60 \\
400 & 2.59 & 5.26 & 16.88 \\
500 & 2.29 & 4.17 & 13.16 \\
600 & 2.20 & 3.91 & 11.41 \\
700 & 2.12 & 3.65 & 9.67 \\
900 & 2.16 & 3.84 & 8.99 \\
1,100 & 2.44 & 4.58 & 9.53 \\
1,300 & 2.80 & 5.00 & 10.57 \\
1,500 & 3.09 & 5.41 & 12.23 \\
1,750 & 3.35 & 6.45 & 14.64 \\
2,000 & 3.71 & 7.55 & 17.87 \\
3,500 & 5.88 & 14.12 & 37.24 \\
11,500 & 8.05 & 20.69 & 56.61 \\
\hline
\end{tabular}




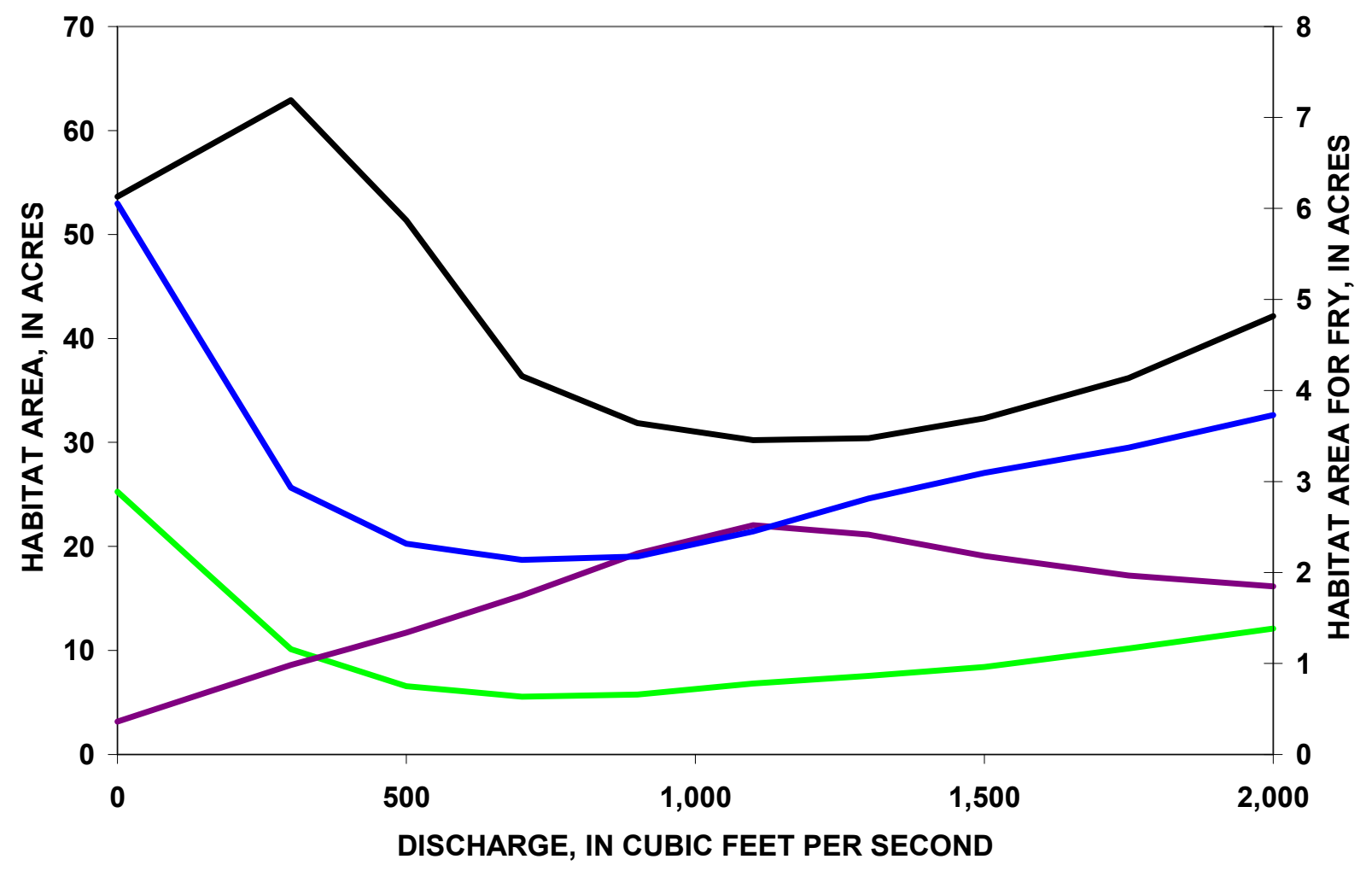

Subyearling winter $\longrightarrow$ Subyearling summer $\longrightarrow$ Adult holding —Fry

Figure 2-14. Total habitat area as a function of stream discharge for four life stages of spring chinook (0. tshawytscha) in the Easton reach.

Table 2-3. Total habitat lookup table for spring chinook (0. tshawytscha) in the Easton reach. [ $\mathrm{ft}^{3} / \mathrm{s}$, cubic feet per second]

\begin{tabular}{rrrrr}
\hline \multicolumn{5}{c}{ Habitat area, in acres } \\
\hline $\begin{array}{r}\text { Discharge, } \\
\text { in ft } \mathbf{s} \text { s }\end{array}$ & \multicolumn{1}{c}{ Fry } & $\begin{array}{c}\text { Subyearling } \\
\text { winter }\end{array}$ & $\begin{array}{c}\text { Subyearling } \\
\text { summer }\end{array}$ & $\begin{array}{c}\text { Adult } \\
\text { holding }\end{array}$ \\
\hline 0 & 6.05 & 25.27 & 53.64 & 3.16 \\
150 & 4.49 & 17.69 & 58.27 & 5.88 \\
300 & 2.93 & 10.11 & 62.91 & 8.60 \\
400 & 2.62 & 8.34 & 57.14 & 10.15 \\
500 & 2.32 & 6.58 & 51.37 & 11.70 \\
600 & 2.23 & 6.06 & 43.88 & 13.49 \\
700 & 2.14 & 5.55 & 36.39 & 15.28 \\
900 & 2.18 & 5.77 & 31.85 & 19.31 \\
1,100 & 2.45 & 6.82 & 30.21 & 22.04 \\
1,300 & 2.81 & 7.56 & 30.42 & 21.15 \\
1,500 & 3.09 & 8.42 & 32.34 & 19.09 \\
1,750 & 3.37 & 10.20 & 36.20 & 17.20 \\
2,000 & 3.73 & 12.10 & 42.14 & 16.17 \\
3,500 & 5.87 & 23.53 & 77.75 & 9.98 \\
11,500 & 8.02 & 34.96 & 113.37 & 3.79 \\
\hline
\end{tabular}




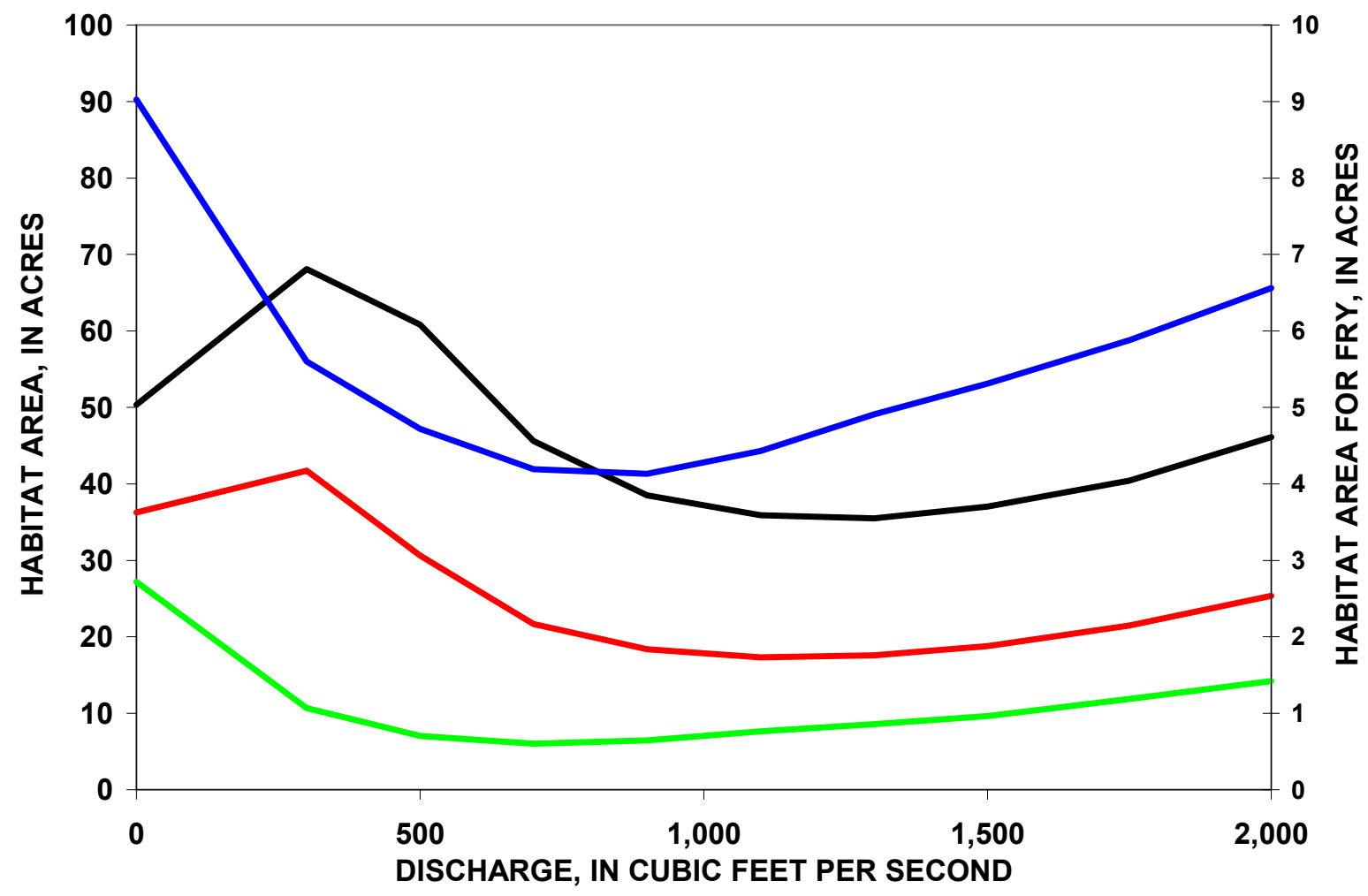

Subyearling winter $\longrightarrow$ Subyearling summer —Yearling —Fry

Figure 2-15. Total habitat area as a function of stream discharge for four life stages of resident rainbow trout (0. mykiss) in the Easton reach.

Table 2-4. Total habitat lookup table for resident rainbow trout (0. mykiss) in the Easton reach. [ $\mathrm{ft}^{3} / \mathrm{s}$, cubic feet per second]

\begin{tabular}{rrrrr}
\hline \multicolumn{5}{c}{ Habitat area, in acres } \\
\hline $\begin{array}{c}\text { Discharge, } \\
\text { in ft } \mathbf{s} \text { s }\end{array}$ & \multicolumn{1}{c}{ Fry } & $\begin{array}{c}\text { Subyearling } \\
\text { winter }\end{array}$ & $\begin{array}{c}\text { Subyearling } \\
\text { summer }\end{array}$ & Yearling \\
\hline 0 & 9.02 & 27.17 & 50.34 & 36.26 \\
150 & 7.31 & 18.93 & 59.20 & 39.00 \\
300 & 5.60 & 10.69 & 68.07 & 41.74 \\
400 & 5.16 & 8.86 & 64.43 & 36.19 \\
500 & 4.72 & 7.02 & 60.79 & 30.63 \\
600 & 4.46 & 6.54 & 53.19 & 26.16 \\
700 & 4.19 & 6.05 & 45.59 & 21.68 \\
900 & 4.13 & 6.47 & 38.50 & 18.37 \\
1,100 & 4.43 & 7.65 & 35.89 & 17.31 \\
1,300 & 4.91 & 8.57 & 35.49 & 17.58 \\
1,500 & 5.31 & 9.65 & 37.01 & 18.78 \\
1,750 & 5.88 & 11.87 & 40.44 & 21.47 \\
2,000 & 6.56 & 14.20 & 46.11 & 25.37 \\
3,500 & 10.64 & 28.18 & 80.16 & 48.72 \\
11,500 & 14.72 & 42.16 & 114.21 & 72.07 \\
\hline
\end{tabular}




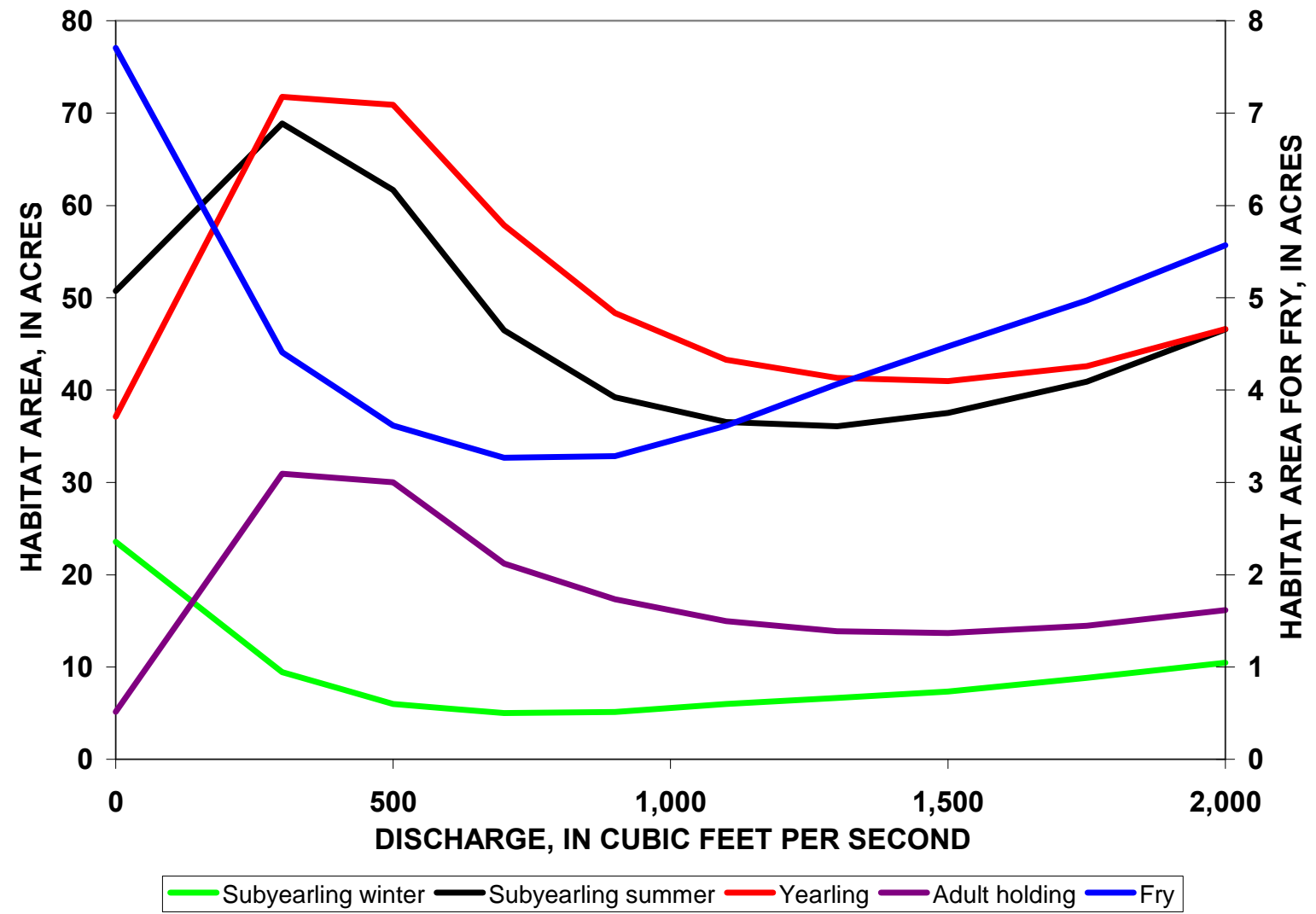

Figure 2-16. Total habitat area as a function of stream discharge for five life stages of steelhead $(0$. mykiss) in the Easton reach.

Table 2-5. Total habitat lookup table for steelhead (0. mykiss) in the Easton reach. [ $\mathrm{ft}^{3} / \mathrm{s}$, cubic feet per second]

\begin{tabular}{rrrrrr}
\hline \multicolumn{6}{c}{ Habitat area, in acres } \\
\hline $\begin{array}{c}\text { Discharge, } \\
\text { in } \mathbf{f t}^{\mathbf{3}} \mathbf{s}\end{array}$ & \multicolumn{1}{c}{ Fry } & $\begin{array}{c}\text { Subyearling } \\
\text { winter }\end{array}$ & $\begin{array}{c}\text { Subyearling } \\
\text { summer }\end{array}$ & Yearling & $\begin{array}{c}\text { Adult } \\
\text { holding }\end{array}$ \\
\hline 0 & 7.71 & 23.57 & 50.74 & 37.12 & 5.15 \\
150 & 6.06 & 16.51 & 59.80 & 54.43 & 18.04 \\
300 & 4.41 & 9.45 & 68.87 & 71.74 & 30.93 \\
400 & 4.01 & 7.73 & 65.27 & 71.32 & 30.47 \\
500 & 3.62 & 6.00 & 61.66 & 70.90 & 30.02 \\
600 & 3.44 & 5.51 & 54.07 & 64.38 & 25.62 \\
700 & 3.27 & 5.01 & 46.48 & 57.86 & 21.21 \\
900 & 3.29 & 5.12 & 39.23 & 48.34 & 17.36 \\
1,100 & 3.61 & 6.01 & 36.52 & 43.29 & 14.98 \\
1,300 & 4.06 & 6.65 & 36.06 & 41.30 & 13.87 \\
1,500 & 4.47 & 7.35 & 37.51 & 40.97 & 13.68 \\
1,750 & 4.97 & 8.84 & 40.91 & 42.58 & 14.45 \\
2,000 & 5.57 & 10.46 & 46.57 & 46.63 & 16.17 \\
3,500 & 9.15 & 20.20 & 80.57 & 70.94 & 26.51 \\
11,500 & 12.74 & 29.94 & 114.57 & 95.24 & 36.85 \\
\hline
\end{tabular}




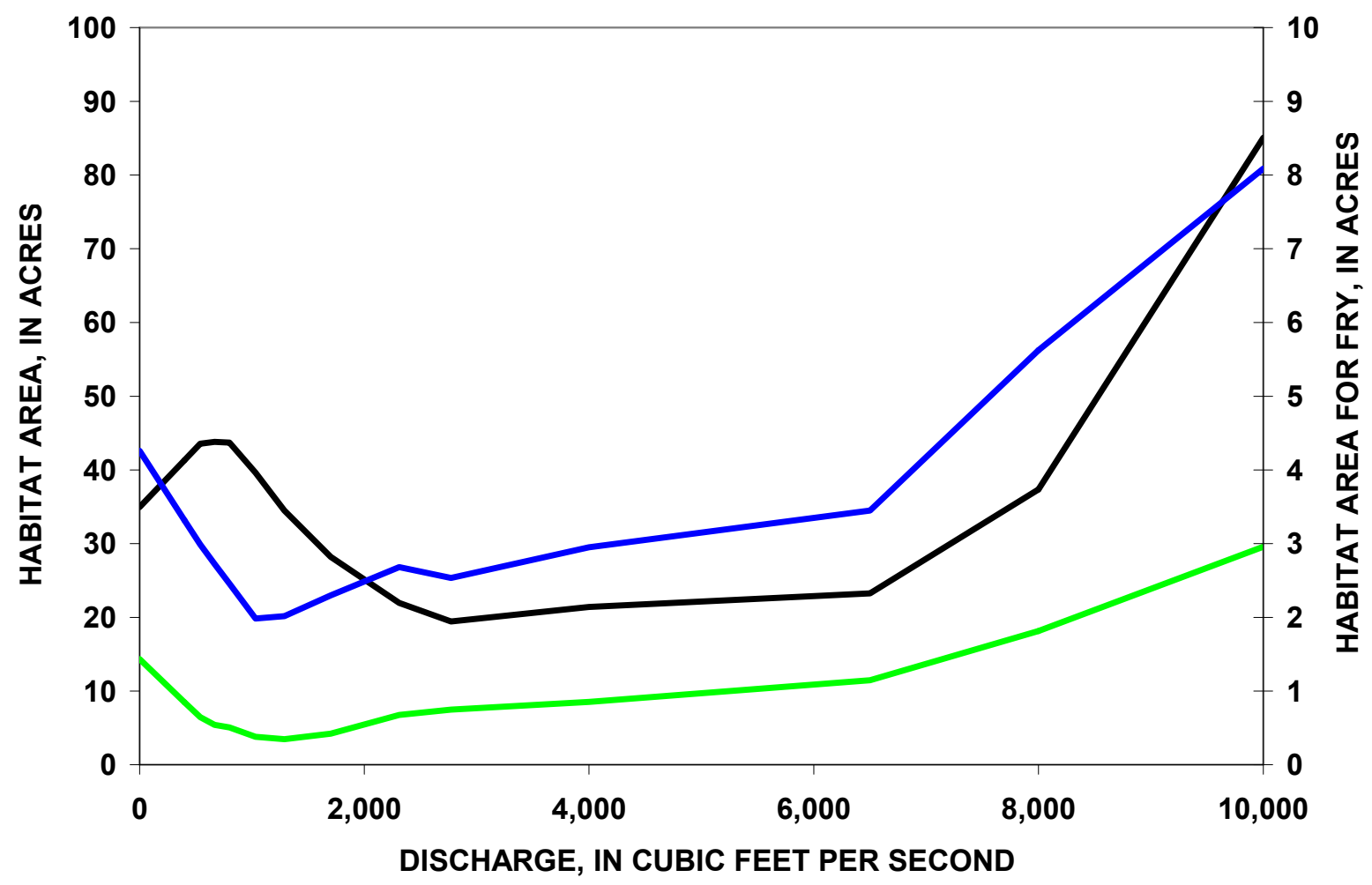

Subyearling winter $\longrightarrow$ Subyearling summer - Fry

Figure 2-17. Total habitat area as a function of stream discharge for three life stages of bull trout $(S$. confluentus) in the Kittitas reach.

Table 2-6. Total habitat lookup table for bull trout (S. confluentus) in the Kittitas reach. [ $\mathrm{ft}^{3} / \mathrm{s}$, cubic feet per second]

\begin{tabular}{rrrr}
\hline & \multicolumn{3}{c}{ Habitat area, in acres } \\
\hline $\begin{array}{c}\text { Discharge, } \\
\text { in } \mathbf{~ f t}^{3} / \mathbf{s}\end{array}$ & Fry & $\begin{array}{c}\text { Subyearling } \\
\text { winter }\end{array}$ & $\begin{array}{c}\text { Subyearling } \\
\text { summer }\end{array}$ \\
\hline 0 & 4.26 & 14.34 & 34.96 \\
400 & 3.32 & 8.51 & 41.32 \\
540 & 2.99 & 6.47 & 43.55 \\
667 & 2.72 & 5.40 & 43.80 \\
800 & 2.46 & 5.07 & 43.71 \\
1,032 & 1.98 & 3.79 & 39.62 \\
1,288 & 2.01 & 3.49 & 34.47 \\
1,700 & 2.30 & 4.22 & 28.22 \\
2,311 & 2.68 & 6.77 & 21.95 \\
2,770 & 2.53 & 7.50 & 19.43 \\
4,000 & 2.95 & 8.53 & 21.40 \\
6,500 & 3.45 & 11.47 & 23.26 \\
8,000 & 5.62 & 18.14 & 37.34 \\
10,000 & 8.09 & 29.58 & 85.05 \\
30,000 & 14.26 & 58.17 & 204.33 \\
\hline
\end{tabular}




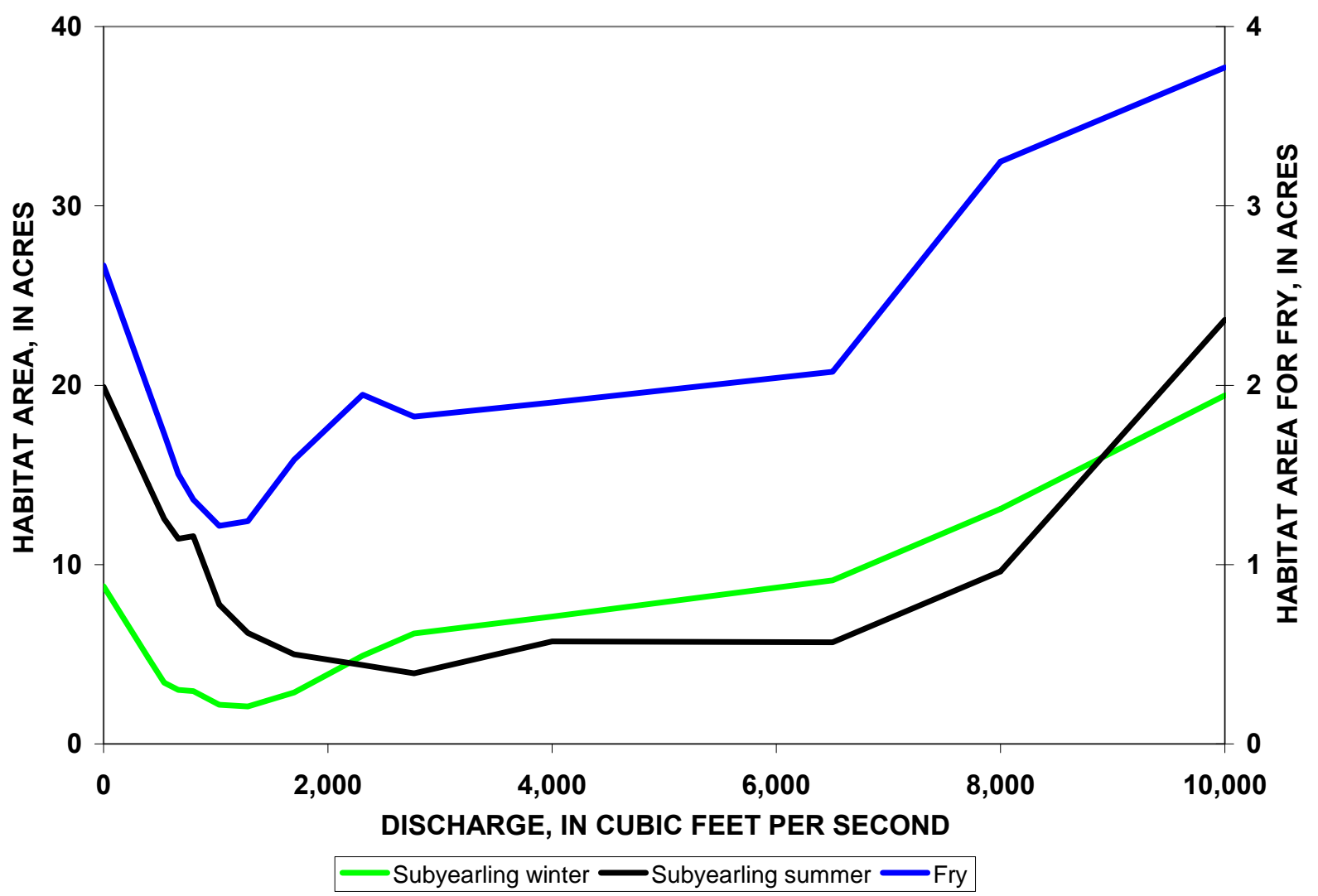

Figure 2-18. Total habitat area as a function of stream discharge for three life stages of coho ( 0 . kisutch) in the Kittitas reach.

Table 2-7. Total habitat lookup table for coho (0. kisutch) in the Kittitas reach. $\left[\mathrm{ft}^{3} / \mathrm{s}\right.$, cubic feet per second]

\begin{tabular}{|c|c|c|c|}
\hline & \multicolumn{3}{|c|}{ Habitat area, in acres } \\
\hline $\begin{array}{c}\text { Discharge, } \\
\text { in } \mathrm{ft}^{3} / \mathrm{s}\end{array}$ & Fry & $\begin{array}{l}\text { Subyearling } \\
\text { winter }\end{array}$ & $\begin{array}{l}\text { Subyearling } \\
\text { summer }\end{array}$ \\
\hline 0 & 2.67 & 8.80 & 19.92 \\
\hline 400 & 1.97 & 4.80 & 14.46 \\
\hline 540 & 1.73 & 3.41 & 12.55 \\
\hline 667 & 1.51 & 3.02 & 11.44 \\
\hline 800 & 1.36 & 2.95 & 11.59 \\
\hline 1,032 & 1.22 & 2.19 & 7.78 \\
\hline 1,288 & 1.24 & 2.09 & 6.18 \\
\hline 1,700 & 1.58 & 2.87 & 4.99 \\
\hline 2,311 & 1.95 & 4.92 & 4.39 \\
\hline 2,770 & 1.83 & 6.16 & 3.93 \\
\hline 4,000 & 1.90 & 7.10 & 5.72 \\
\hline 6,500 & 2.07 & 9.12 & 5.66 \\
\hline 8,000 & 3.25 & 13.10 & 9.63 \\
\hline 10,000 & 3.77 & 19.43 & 23.64 \\
\hline 30,000 & 5.09 & 35.27 & 58.68 \\
\hline
\end{tabular}




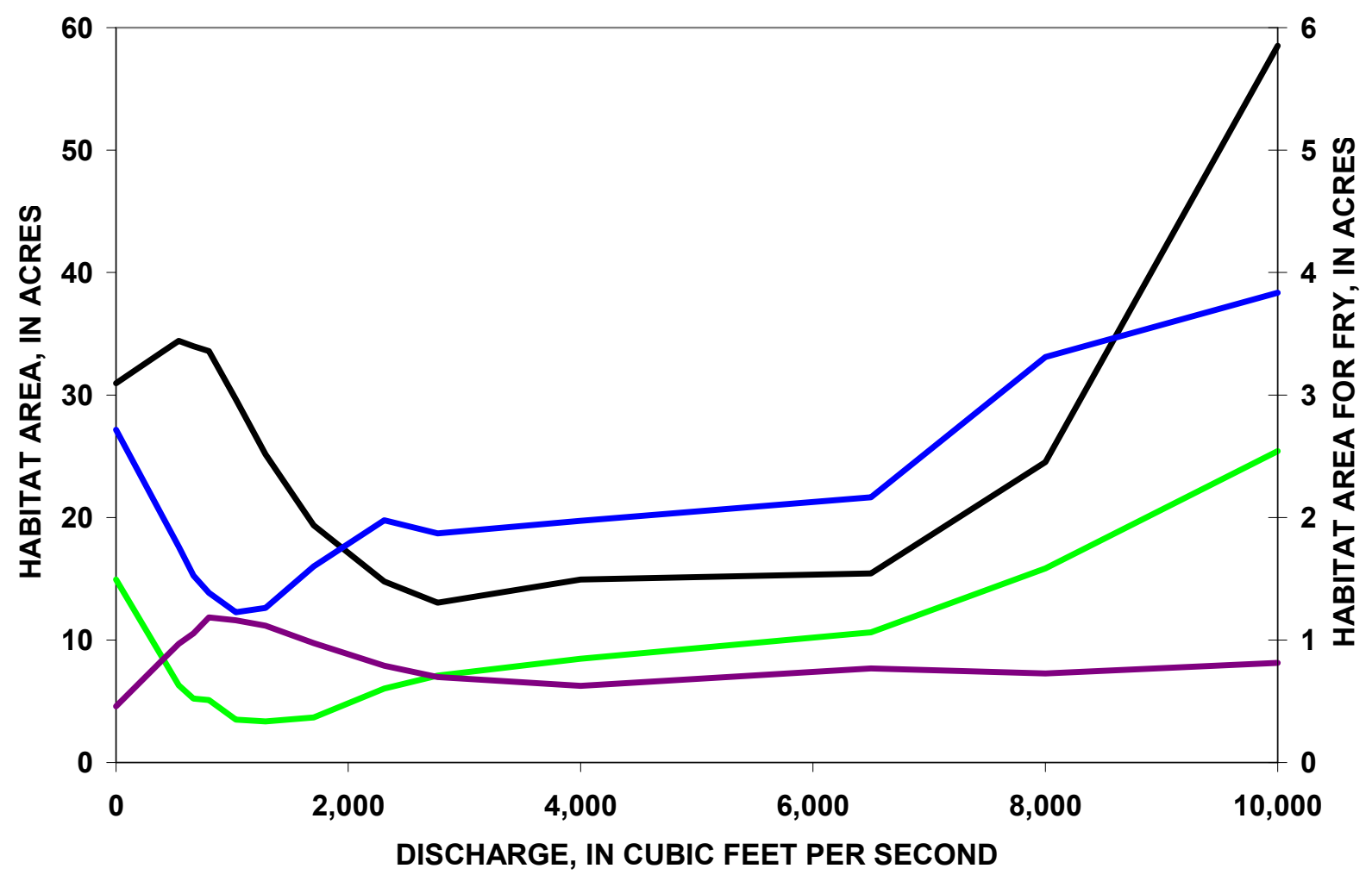

Subyearling winter $\longrightarrow$ Subyearling summer —Adult holding —Fry

Figure 2-19. Total habitat area as a function of stream discharge for four life stages of spring chinook (0. tshawytscha) in the Kittitas reach.

Table 2-8. Total habitat lookup table for spring chinook (0. tshawytscha) in the Kittitas reach. [ $\mathrm{ft}^{3} / \mathrm{s}$, cubic feet per second]

\begin{tabular}{rrrrr}
\hline $\begin{array}{c}\text { Hischarge, } \\
\text { in ft } \mathbf{f t}^{\mathbf{3}} / \mathbf{s}\end{array}$ & Fry & $\begin{array}{c}\text { Subyearling } \\
\text { winter }\end{array}$ & $\begin{array}{c}\text { Subyearling } \\
\text { summer }\end{array}$ & $\begin{array}{c}\text { Adult } \\
\text { holding }\end{array}$ \\
\hline 0 & 2.72 & 14.94 & 30.96 & 4.60 \\
400 & 2.01 & 8.55 & 33.52 & 8.38 \\
540 & 1.76 & 6.31 & 34.41 & 9.70 \\
667 & 1.53 & 5.22 & 34.00 & 10.55 \\
800 & 1.39 & 5.10 & 33.58 & 11.84 \\
1,032 & 1.23 & 3.50 & 29.65 & 11.61 \\
1,288 & 1.26 & 3.35 & 25.15 & 11.17 \\
1,700 & 1.60 & 3.68 & 19.37 & 9.74 \\
2,311 & 1.98 & 6.03 & 14.76 & 7.90 \\
2,770 & 1.87 & 7.08 & 13.04 & 6.98 \\
4,000 & 1.97 & 8.47 & 14.94 & 6.26 \\
6,500 & 2.17 & 10.64 & 15.44 & 7.69 \\
8,000 & 3.31 & 15.85 & 24.53 & 7.27 \\
10,000 & 3.84 & 25.41 & 58.52 & 8.13 \\
30,000 & 5.15 & 49.32 & 143.49 & 10.29 \\
\hline
\end{tabular}




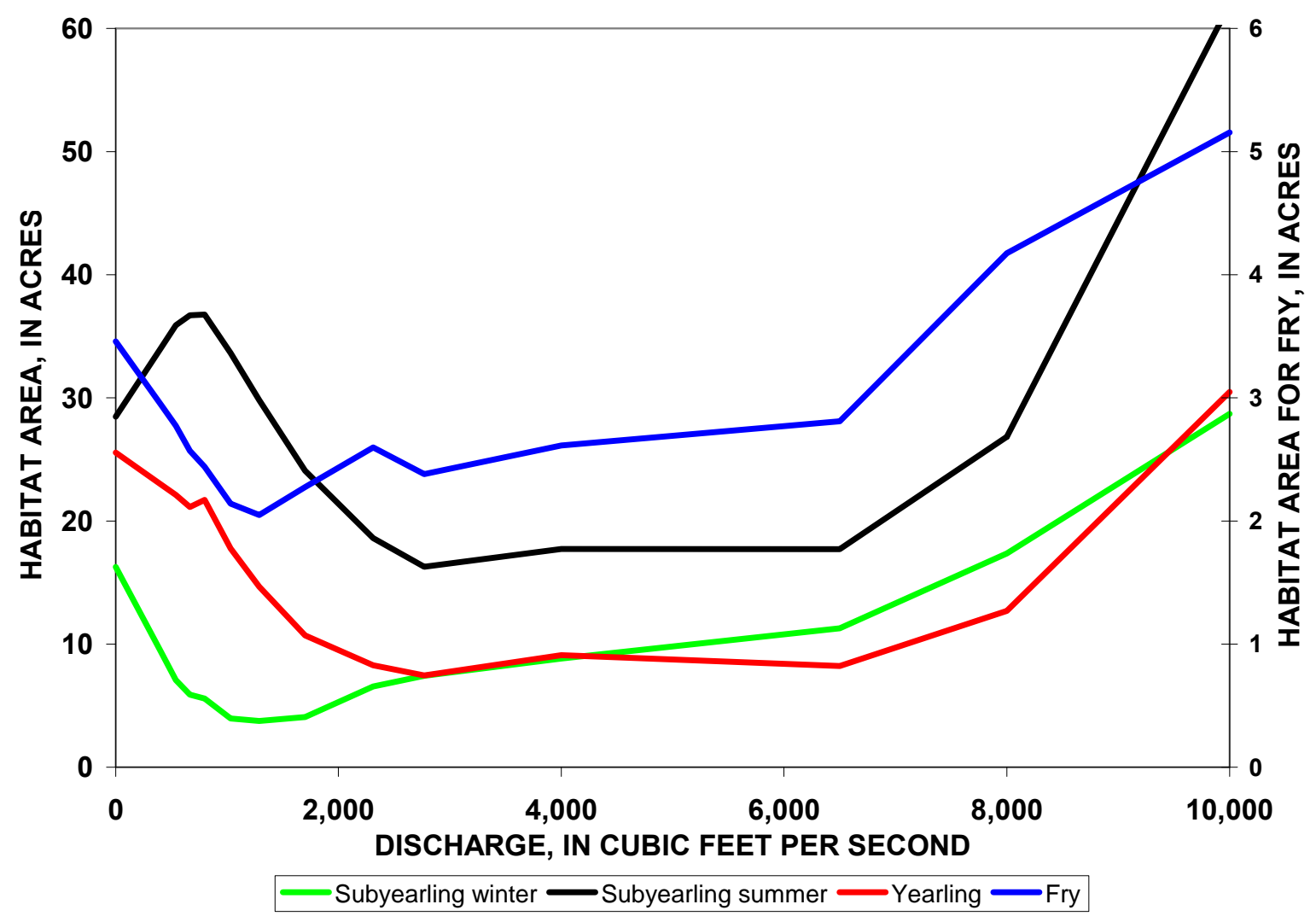

Figure 2-20. Total habitat area as a function of stream discharge for four life stages of resident rainbow trout ( 0 . mykiss) in the Kittitas reach.

Table 2-9. Total habitat lookup table for resident rainbow trout (0. mykiss) in the Kittitas reach. [ $\left[\mathrm{ft}^{3} / \mathrm{s}\right.$, cubic feet per second]

\begin{tabular}{rrrrr}
\hline \multicolumn{5}{c}{ Habitat area, in acres } \\
\hline $\begin{array}{c}\text { Discharge, } \\
\text { in ft } \mathbf{s} \text { /s }\end{array}$ & Fry & $\begin{array}{c}\text { Subyearling } \\
\text { winter }\end{array}$ & $\begin{array}{c}\text { Subyearling } \\
\text { summer }\end{array}$ & Yearling \\
\hline 0 & 3.46 & 16.27 & 28.48 & 25.55 \\
400 & 2.95 & 9.47 & 33.99 & 23.00 \\
540 & 2.77 & 7.09 & 35.91 & 22.11 \\
667 & 2.57 & 5.91 & 36.70 & 21.14 \\
800 & 2.44 & 5.58 & 36.76 & 21.72 \\
1,032 & 2.14 & 3.95 & 33.65 & 17.78 \\
1,288 & 2.05 & 3.75 & 29.83 & 14.66 \\
1,700 & 2.27 & 4.09 & 24.08 & 10.71 \\
2,311 & 2.60 & 6.57 & 18.62 & 8.29 \\
2,770 & 2.38 & 7.43 & 16.29 & 7.46 \\
4,000 & 2.61 & 8.82 & 17.74 & 9.11 \\
6,500 & 2.81 & 11.29 & 17.71 & 8.22 \\
8,000 & 4.18 & 17.37 & 26.84 & 12.70 \\
10,000 & 5.15 & 28.69 & 61.96 & 30.48 \\
30,000 & 7.60 & 56.99 & 149.76 & 74.94 \\
\hline
\end{tabular}




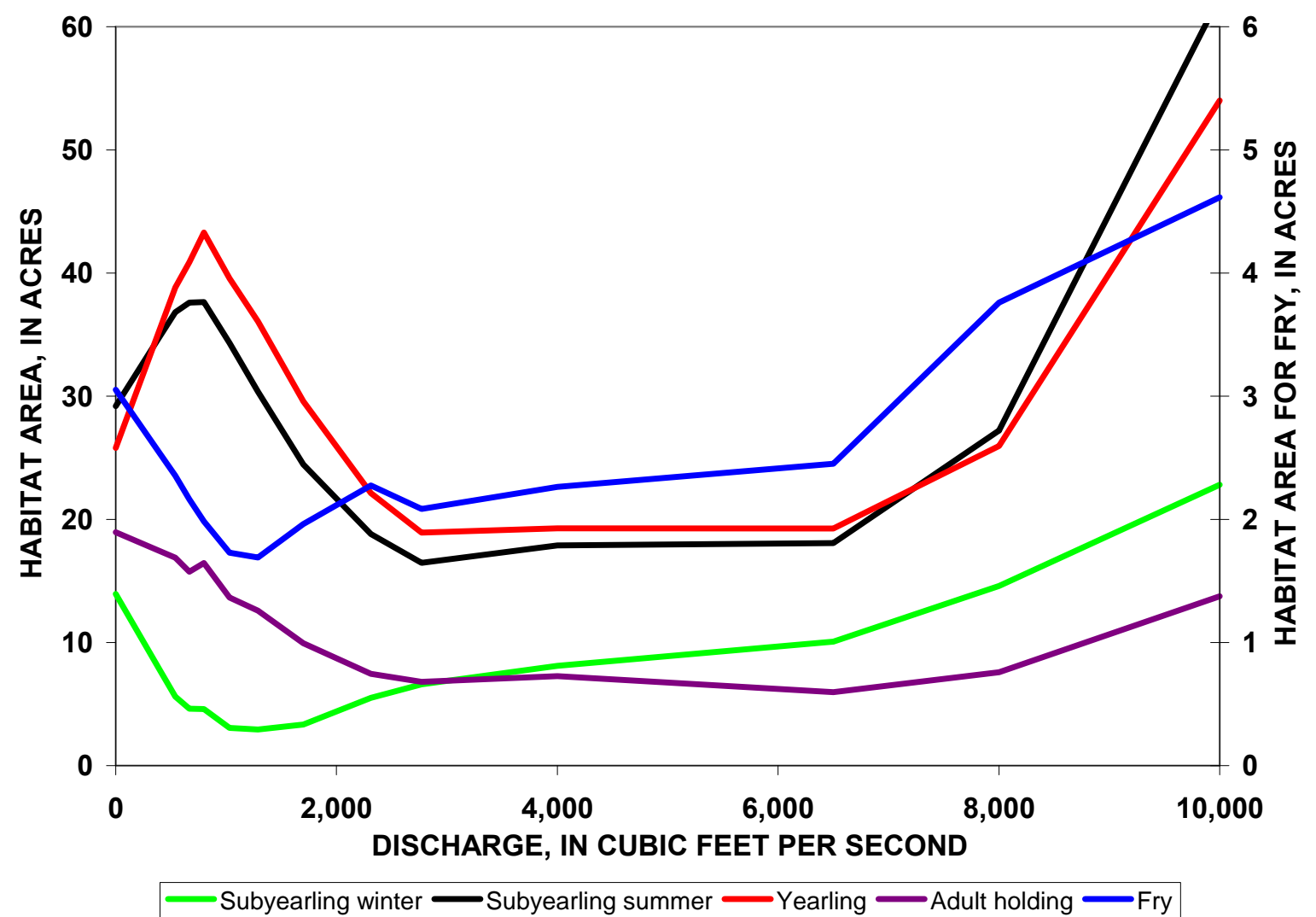

Figure 2-21. Total habitat area as a function of stream discharge for five life stages of steelhead $(0$. mykiss) in the Kittitas reach.

Table 2-10. Total habitat lookup table for steelhead (0. mykiss) in the Kittitas reach. $\left[\mathrm{ft}^{3} / \mathrm{s}\right.$, cubic feet per second]

\begin{tabular}{|c|c|c|c|c|c|}
\hline \multirow[b]{2}{*}{$\begin{array}{c}\text { Discharge, } \\
\text { in } \mathrm{ft}^{3} / \mathrm{s}\end{array}$} & \multicolumn{5}{|c|}{ Habitat area, in acres } \\
\hline & Fry & $\begin{array}{l}\text { Subyearling } \\
\text { winter }\end{array}$ & $\begin{array}{l}\text { Subyearling } \\
\text { summer }\end{array}$ & Yearling & $\begin{array}{c}\text { Adult } \\
\text { holding }\end{array}$ \\
\hline 0 & 3.05 & 13.96 & 29.20 & 25.79 & 18.96 \\
\hline 400 & 2.54 & 7.77 & 34.86 & 35.45 & 17.43 \\
\hline 540 & 2.36 & 5.61 & 36.83 & 38.83 & 16.90 \\
\hline 667 & 2.16 & 4.62 & 37.61 & 40.89 & 15.75 \\
\hline 800 & 1.98 & 4.61 & 37.65 & 43.29 & 16.44 \\
\hline 1,032 & 1.73 & 3.06 & 34.33 & 39.57 & 13.66 \\
\hline 1,288 & 1.69 & 2.94 & 30.36 & 36.06 & 12.58 \\
\hline 1,700 & 1.96 & 3.35 & 24.45 & 29.58 & 9.94 \\
\hline 2,311 & 2.28 & 5.50 & 18.81 & 22.14 & 7.46 \\
\hline 2,770 & 2.09 & 6.60 & 16.47 & 18.94 & 6.81 \\
\hline 4,000 & 2.26 & 8.11 & 17.89 & 19.27 & 7.26 \\
\hline 6,500 & 2.45 & 10.07 & 18.08 & 19.24 & 5.97 \\
\hline 8,000 & 3.76 & 14.59 & 27.22 & 25.96 & 7.58 \\
\hline 10,000 & 4.62 & 22.81 & 62.43 & 54.01 & 13.75 \\
\hline 30,000 & 6.75 & 43.37 & 150.45 & 124.12 & 29.19 \\
\hline
\end{tabular}




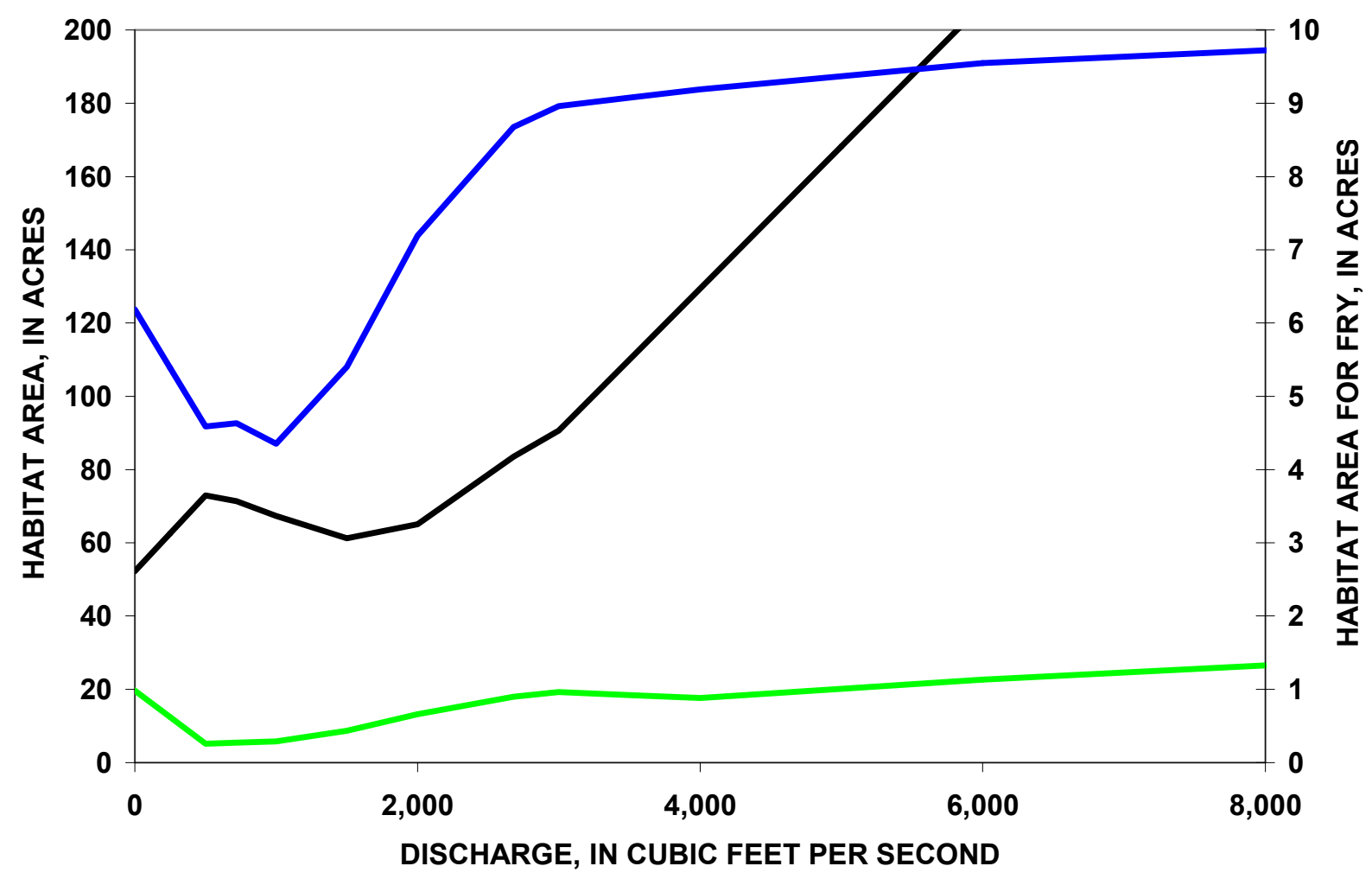

Subyearling winter - Subyearling summer - Fry

Figure 2-22. Total habitat area as a function of stream discharge for three life stages of bull trout $(S$. confluentus) in the Naches reach.

Table 2-11. Total habitat lookup table for bull trout (S. confluentus) in the Naches reach. [ $\left[\mathrm{ft}^{3} / \mathrm{s}\right.$, cubic feet per second]

\begin{tabular}{rrrr}
\hline & \multicolumn{3}{c}{ Habitat area, in acres } \\
\hline $\begin{array}{c}\text { Discharge, } \\
\text { in ft } \mathbf{~ f t}^{\mathbf{s}}\end{array}$ & Fry & $\begin{array}{c}\text { Subyearling } \\
\text { winter }\end{array}$ & $\begin{array}{c}\text { Subyearling } \\
\text { summer }\end{array}$ \\
\hline 0 & 6.19 & 19.67 & 52.25 \\
250 & 5.39 & 12.39 & 62.61 \\
500 & 4.59 & 5.12 & 72.97 \\
720 & 4.63 & 5.42 & 71.39 \\
1,000 & 4.35 & 5.79 & 67.34 \\
1,500 & 5.40 & 8.67 & 61.20 \\
2,000 & 7.19 & 13.21 & 65.08 \\
2,680 & 8.68 & 17.96 & 83.49 \\
3,000 & 8.96 & 19.24 & 90.62 \\
3,500 & 9.08 & 18.43 & 110.01 \\
4,000 & 9.19 & 17.61 & 129.40 \\
5,000 & 9.37 & 20.13 & 168.24 \\
6,000 & 9.55 & 22.65 & 207.07 \\
8,000 & 9.72 & 26.56 & 295.31 \\
27,000 & 9.90 & 30.47 & 383.54 \\
\hline
\end{tabular}




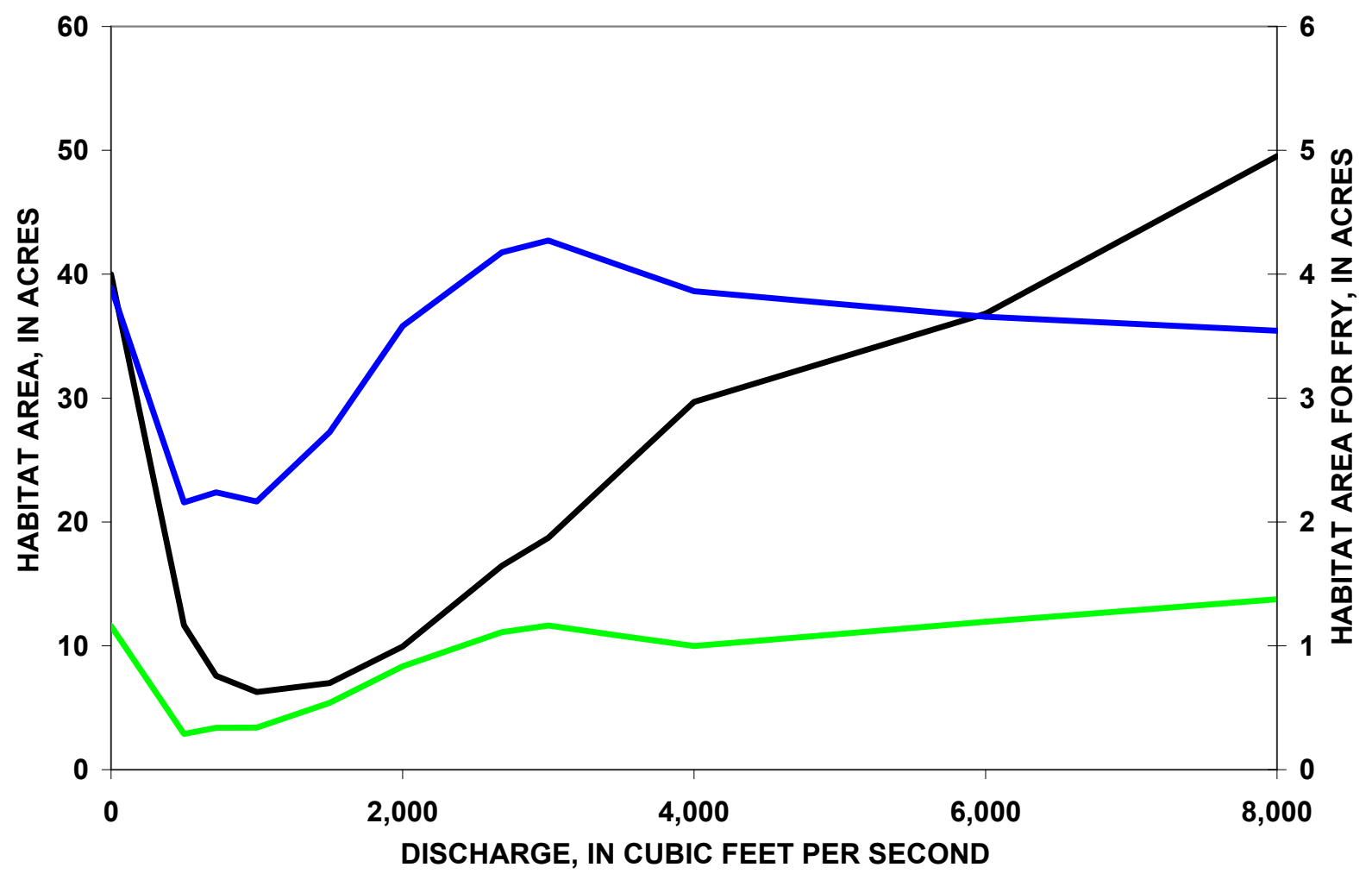

Subyearling winter $\longrightarrow$ Subyearling summer - Fry

Figure 2-23. Total habitat area as a function of stream discharge for three life stages of coho $(0$. kisutch) in the Naches reach.

Table 2-12. Total habitat lookup table for coho (O. kisutch) in the Naches reach. $\left[\mathrm{ft}^{3} / \mathrm{s}\right.$, cubic feet per second]

\begin{tabular}{rrrr}
\hline & \multicolumn{3}{c}{ Habitat area, in acres } \\
\hline $\begin{array}{c}\text { Discharge, } \\
\text { in ft } \mathbf{~ f t}^{\mathbf{s}}\end{array}$ & Fry & $\begin{array}{c}\text { Subyearling } \\
\text { winter }\end{array}$ & $\begin{array}{c}\text { Subyearling } \\
\text { summer }\end{array}$ \\
\hline 0 & 3.89 & 11.59 & 40.00 \\
250 & 3.03 & 7.24 & 25.83 \\
500 & 2.16 & 2.88 & 11.66 \\
720 & 2.24 & 3.38 & 7.58 \\
1,000 & 2.16 & 3.40 & 6.26 \\
1,500 & 2.72 & 5.39 & 7.01 \\
2,000 & 3.58 & 8.34 & 9.93 \\
2,680 & 4.18 & 11.09 & 16.46 \\
3,000 & 4.27 & 11.63 & 18.71 \\
3,500 & 4.07 & 10.80 & 24.20 \\
4,000 & 3.86 & 9.97 & 29.70 \\
5,000 & 3.76 & 10.95 & 33.26 \\
6,000 & 3.66 & 11.94 & 36.82 \\
8,000 & 3.54 & 13.75 & 49.52 \\
27,000 & 3.43 & 15.56 & 62.23 \\
\hline
\end{tabular}




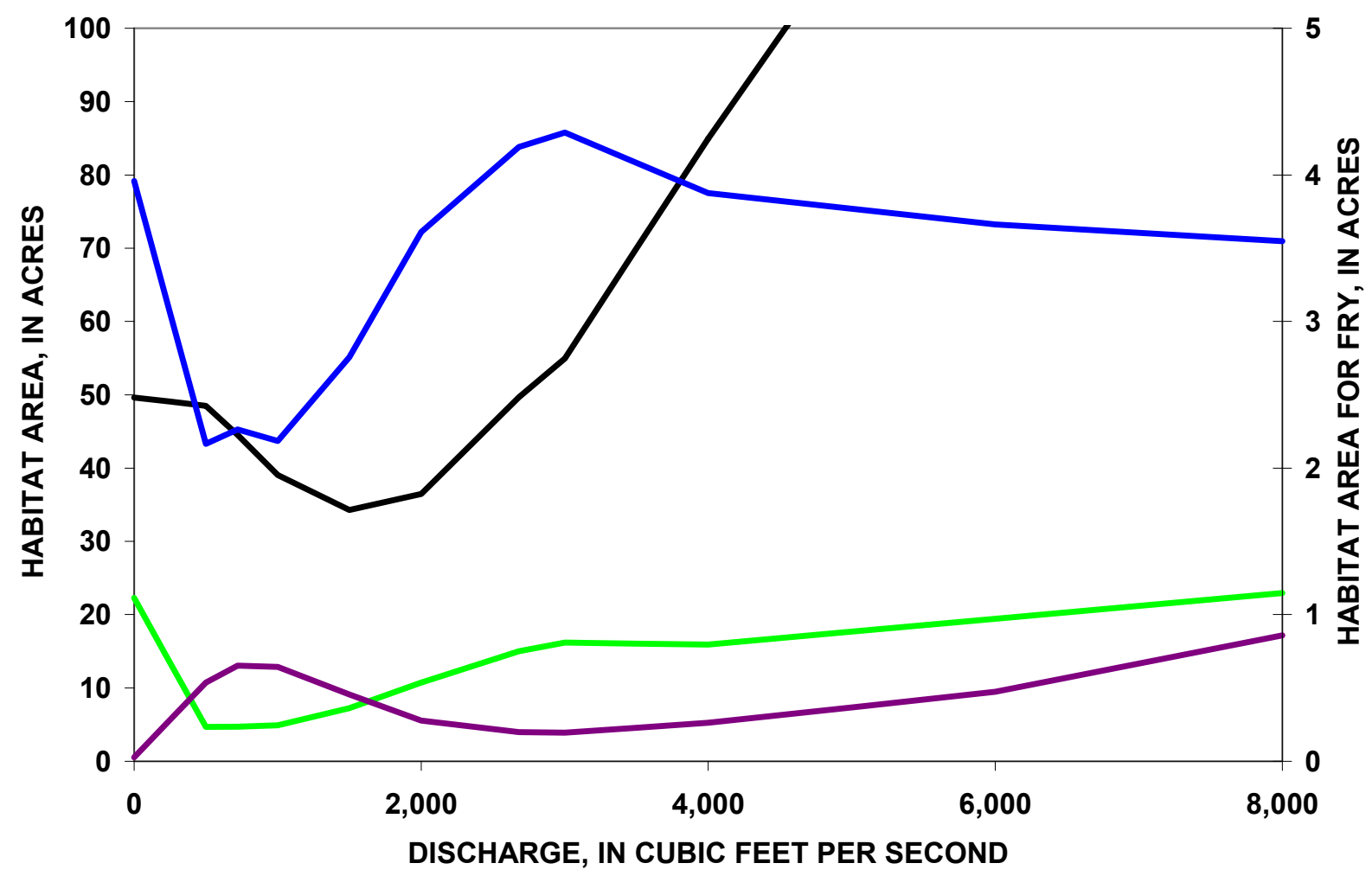

Subyearling winter — Subyearling summer —Adult holding — Fry

Figure 2-24. Total habitat area as a function of stream discharge for four life stages of spring chinook (O. tshawytscha) in the Naches reach. Scale of $y$-axis truncated to improve resolution.

Table 2-13. Total habitat lookup table for spring chinook (0. tshawytscha) in the Naches reach. [ $\mathrm{ft}^{3} / \mathrm{s}$, cubic feet per second]

\begin{tabular}{rrrrr}
\hline \multicolumn{5}{c}{ Habitat area, in acres } \\
\hline $\begin{array}{r}\text { Discharge, } \\
\text { in ft } \mathbf{s} \text { s }\end{array}$ & \multicolumn{1}{c}{ Fry } & $\begin{array}{c}\text { Subyearling } \\
\text { winter }\end{array}$ & $\begin{array}{c}\text { Subyearling } \\
\text { summer }\end{array}$ & $\begin{array}{c}\text { Adult } \\
\text { holding }\end{array}$ \\
\hline 0 & 3.96 & 22.28 & 49.61 & 0.53 \\
250 & 3.06 & 13.48 & 49.06 & 5.62 \\
500 & 2.17 & 4.68 & 48.50 & 10.72 \\
720 & 2.26 & 4.72 & 44.53 & 13.05 \\
1,000 & 2.18 & 4.92 & 39.04 & 12.87 \\
1,500 & 2.76 & 7.26 & 34.26 & 9.10 \\
2,000 & 3.61 & 10.75 & 36.47 & 5.56 \\
2,680 & 4.19 & 14.99 & 49.69 & 3.97 \\
3,000 & 4.29 & 16.20 & 54.98 & 3.89 \\
3,500 & 4.08 & 16.06 & 69.96 & 4.57 \\
4,000 & 3.88 & 15.93 & 84.93 & 5.25 \\
5,000 & 3.77 & 17.68 & 112.97 & 7.36 \\
6,000 & 3.66 & 19.42 & 141.01 & 9.47 \\
8,000 & 3.55 & 22.97 & 206.22 & 17.19 \\
27,000 & 3.43 & 26.52 & 262.59 & 24.90 \\
\hline
\end{tabular}




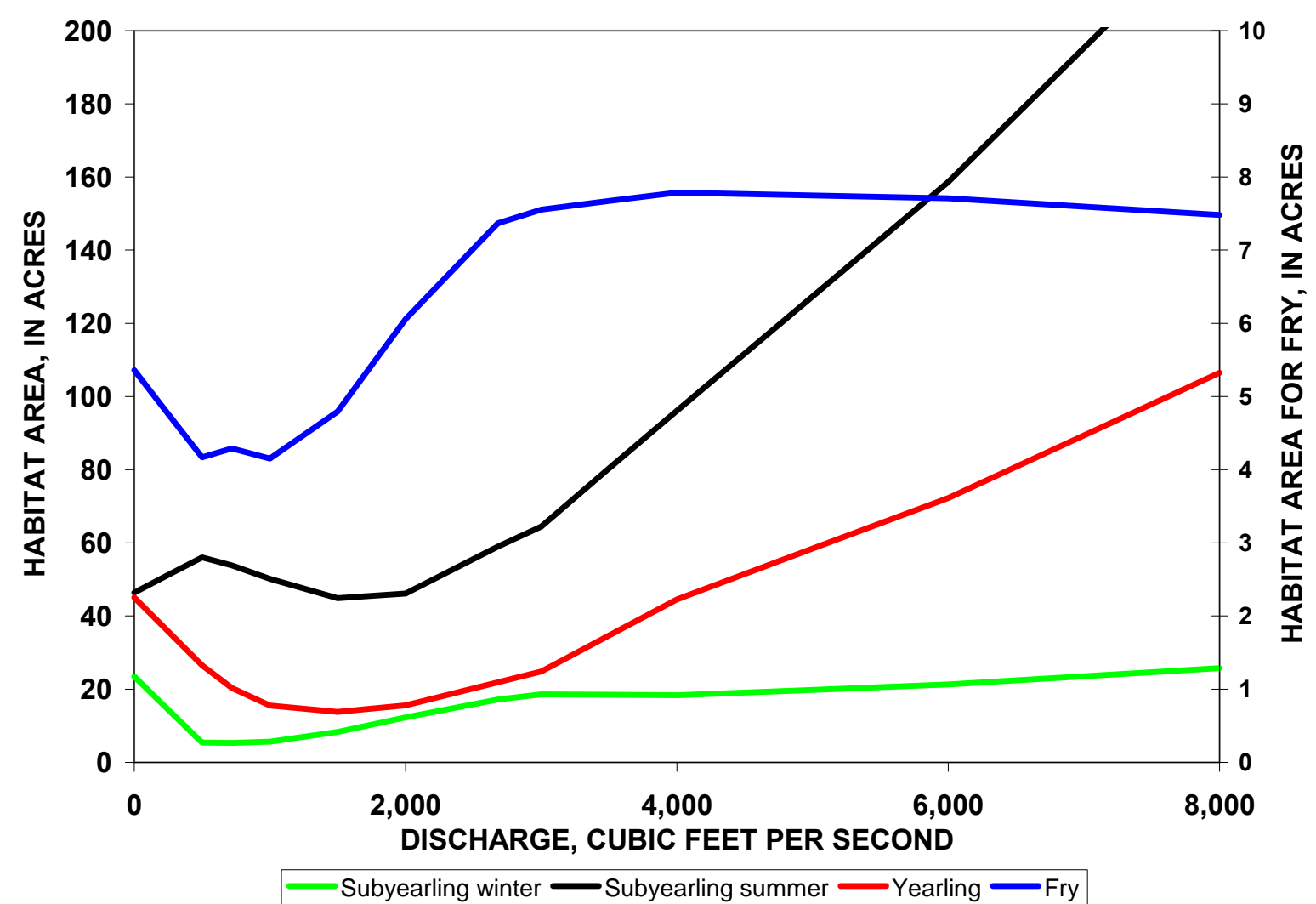

Figure 2-25. Total habitat area as a function of stream discharge for four life stages of rainbow trout (O. mykiss) in the Naches reach. Scale of y-axis truncated to improve resolution.

Table 2-14. Total habitat lookup table for resident rainbow trout (0. mykiss) in the Naches reach. [ $\mathrm{ft}^{3} / \mathrm{s}$, cubic feet per second]

\begin{tabular}{rrrrr}
\hline \multicolumn{5}{c}{ Habitat area, in acres } \\
\hline $\begin{array}{c}\text { Discharge, } \\
\text { in ft } \mathbf{s} \text { s }\end{array}$ & \multicolumn{1}{c}{ Fry } & $\begin{array}{c}\text { Subyearling } \\
\text { winter }\end{array}$ & $\begin{array}{c}\text { Subyearling } \\
\text { summer }\end{array}$ & Yearling \\
\hline 0 & 5.36 & 23.47 & 46.39 & 45.10 \\
250 & 4.76 & 14.44 & 51.21 & 35.83 \\
500 & 4.17 & 5.40 & 56.03 & 26.55 \\
720 & 4.29 & 5.34 & 53.84 & 20.37 \\
1,000 & 4.15 & 5.64 & 50.13 & 15.55 \\
1,500 & 4.79 & 8.36 & 44.91 & 13.82 \\
2,000 & 6.06 & 12.30 & 46.14 & 15.64 \\
2,680 & 7.37 & 17.24 & 58.97 & 21.86 \\
3,000 & 7.55 & 18.59 & 64.46 & 24.79 \\
3,500 & 7.67 & 18.46 & 80.30 & 34.69 \\
4,000 & 7.79 & 18.33 & 96.13 & 44.60 \\
5,000 & 7.75 & 19.79 & 127.37 & 58.41 \\
6,000 & 7.71 & 21.25 & 158.61 & 72.22 \\
8,000 & 7.48 & 25.73 & 231.89 & 106.48 \\
27,000 & 7.25 & 30.22 & 305.18 & 140.73 \\
\hline
\end{tabular}




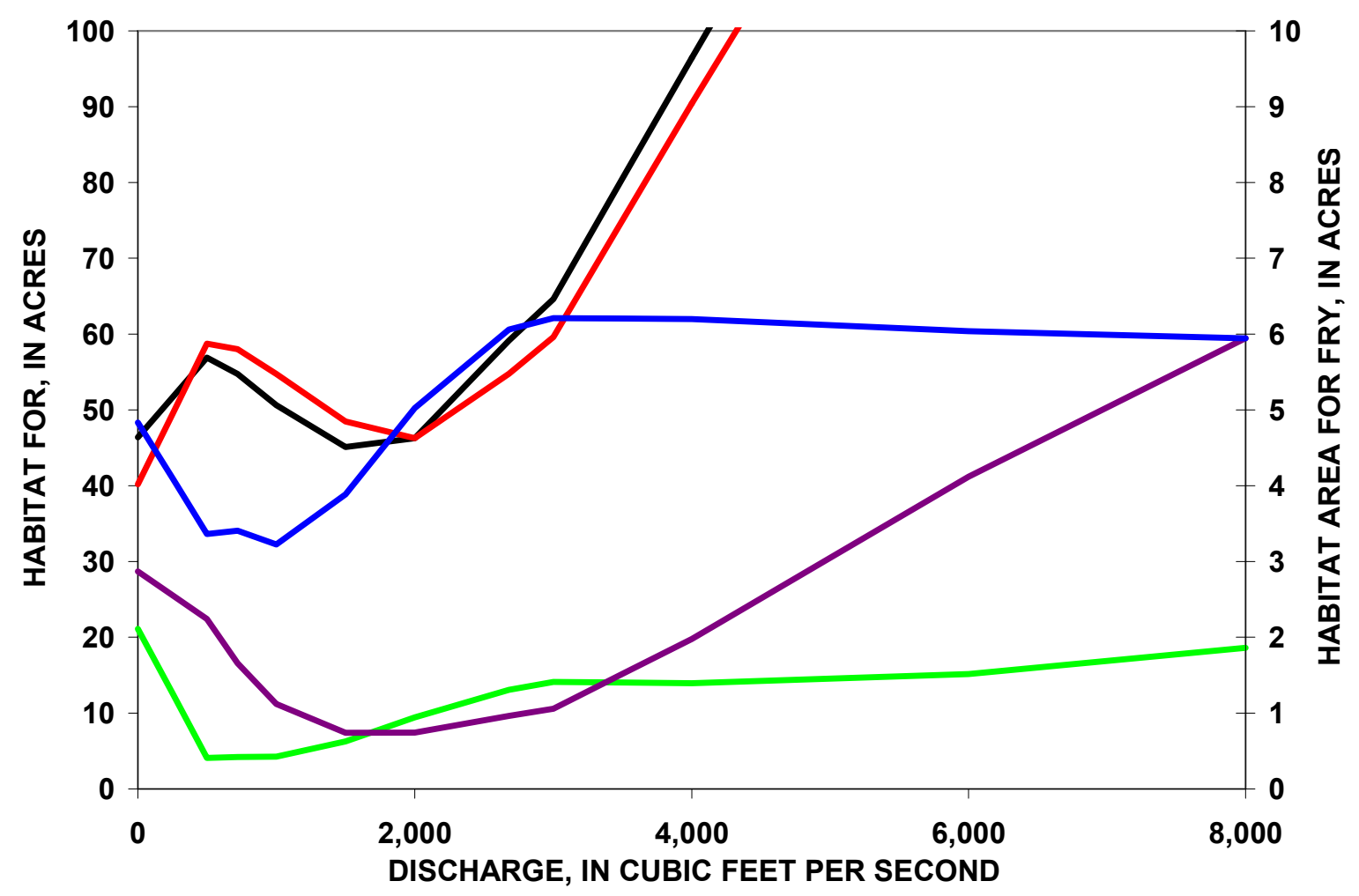

Subyearling winter $\longrightarrow$ Subyearling summer $\longrightarrow$ Yearling —Adult holding —Fry

Figure 2-26. Total habitat area as a function of stream discharge for five life stages of steelhead $(0$. mykiss) in the Naches reach. Scale of $y$-axis truncated to improve resolution.

Table 2-15. Total habitat lookup table for steelhead (0. mykiss) in the Naches reach. [ $\left[\mathrm{ft}^{3} / \mathrm{s}\right.$, cubic feet per second]

\begin{tabular}{|c|c|c|c|c|c|}
\hline & \multicolumn{5}{|c|}{ Habitat area, in acres } \\
\hline $\begin{array}{c}\text { Discharge, } \\
\text { in } \mathrm{ft}^{3} / \mathrm{s}\end{array}$ & Fry & $\begin{array}{l}\text { Subyearling } \\
\text { winter }\end{array}$ & $\begin{array}{l}\text { Subyearling } \\
\text { summer }\end{array}$ & Yearling & $\begin{array}{c}\text { Adult } \\
\text { holding }\end{array}$ \\
\hline 0 & 4.83 & 21.12 & 46.41 & 40.20 & 28.68 \\
\hline 250 & 4.10 & 12.61 & 51.66 & 49.46 & 25.54 \\
\hline 500 & 3.36 & 4.10 & 56.91 & 58.72 & 22.40 \\
\hline 720 & 3.41 & 4.21 & 54.74 & 57.99 & 16.56 \\
\hline 1,000 & 3.23 & 4.25 & 50.65 & 54.74 & 11.22 \\
\hline 1,500 & 3.89 & 6.28 & 45.10 & 48.46 & 7.39 \\
\hline 2,000 & 5.02 & 9.44 & 46.27 & 46.27 & 7.44 \\
\hline 2,680 & 6.06 & 13.06 & 59.13 & 54.76 & 9.64 \\
\hline 3,000 & 6.21 & 14.12 & 64.61 & 59.60 & 10.58 \\
\hline 3,500 & 6.21 & 14.03 & 80.52 & 75.01 & 15.18 \\
\hline 4,000 & 6.20 & 13.93 & 96.43 & 90.42 & 19.77 \\
\hline 5,000 & 6.12 & 14.53 & 127.73 & 120.22 & 30.49 \\
\hline 6,000 & 6.04 & 15.14 & 159.02 & 150.03 & 41.20 \\
\hline 8,000 & 5.95 & 18.61 & 232.53 & 223.93 & 59.46 \\
\hline 27,000 & 5.85 & 22.09 & 306.04 & 297.83 & 77.72 \\
\hline
\end{tabular}




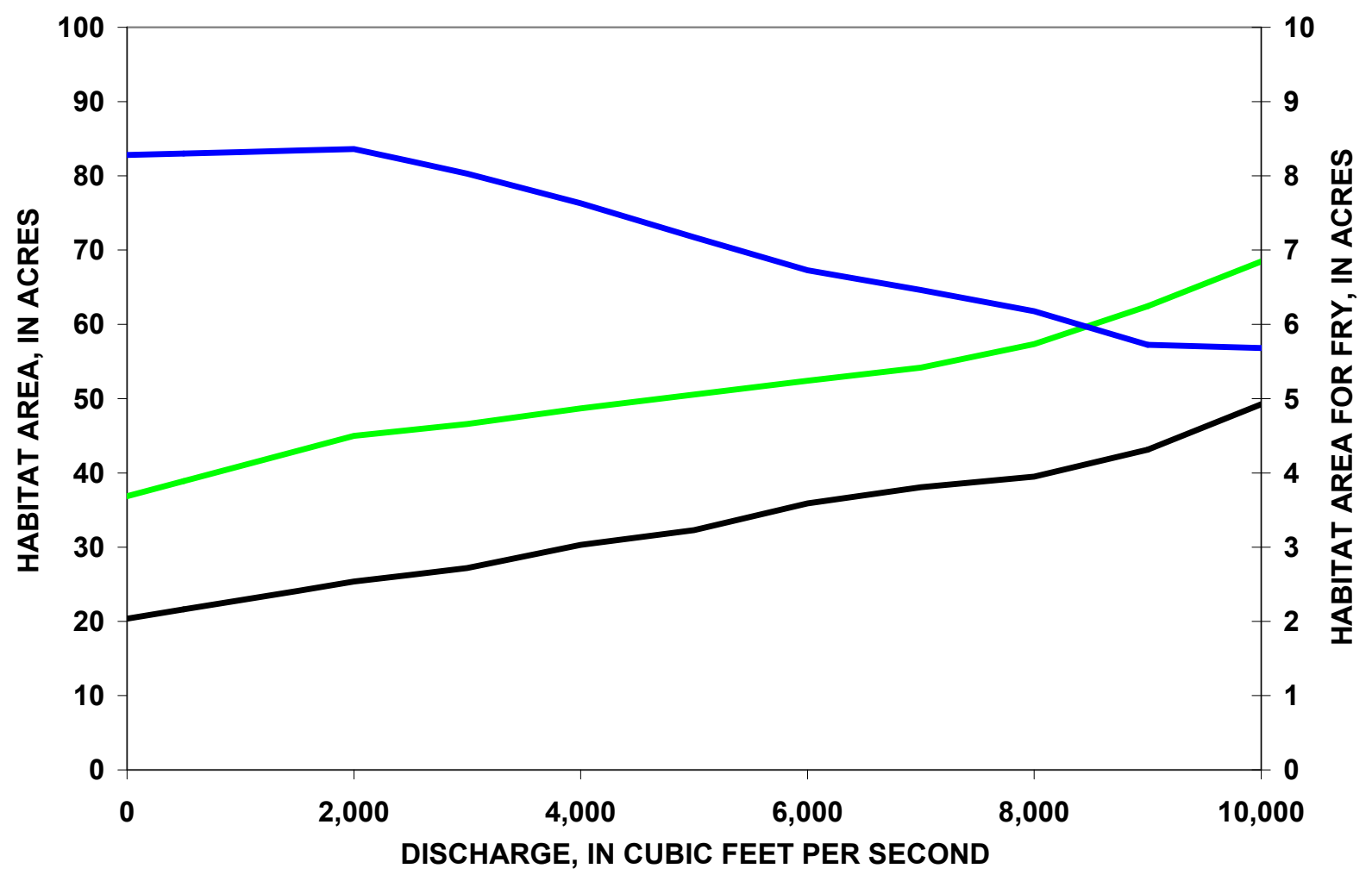

Subyearling winter $\longrightarrow$ Subyearling summer $\longrightarrow$ Fry

Figure 2-27. Total habitat area as a function of stream discharge for three life stages of coho $(0$. kisutch) in the Union Gap reach.

Table 2-16. Total habitat lookup table for coho (0. kisutch) in the Union Gap reach. [ft ${ }^{3} / \mathrm{s}$, cubic feet per second]

\begin{tabular}{rrrr}
\hline \multicolumn{3}{c}{ Habitat area, in acres } \\
\hline $\begin{array}{c}\text { Discharge, } \\
\text { in ft } \mathbf{3} \text { s }\end{array}$ & Fry & $\begin{array}{c}\text { Subyearling } \\
\text { winter }\end{array}$ & $\begin{array}{c}\text { Subyearling } \\
\text { summer }\end{array}$ \\
\hline 0 & 8.28 & 36.87 & 20.37 \\
500 & 8.30 & 38.90 & 21.62 \\
1,000 & 8.32 & 40.93 & 22.86 \\
1,500 & 8.34 & 42.96 & 24.11 \\
2,000 & 8.36 & 44.99 & 25.35 \\
2,500 & 8.20 & 45.78 & 26.27 \\
3,000 & 8.03 & 46.58 & 27.18 \\
4,000 & 7.63 & 48.68 & 30.30 \\
5,000 & 7.17 & 50.56 & 32.30 \\
6,000 & 6.73 & 52.41 & 35.88 \\
7,000 & 6.46 & 54.18 & 38.04 \\
8,000 & 6.18 & 57.36 & 39.49 \\
9,000 & 5.73 & 62.46 & 43.11 \\
10,000 & 5.68 & 68.47 & 49.26 \\
50,000 & 5.45 & 98.57 & 79.98 \\
\hline
\end{tabular}




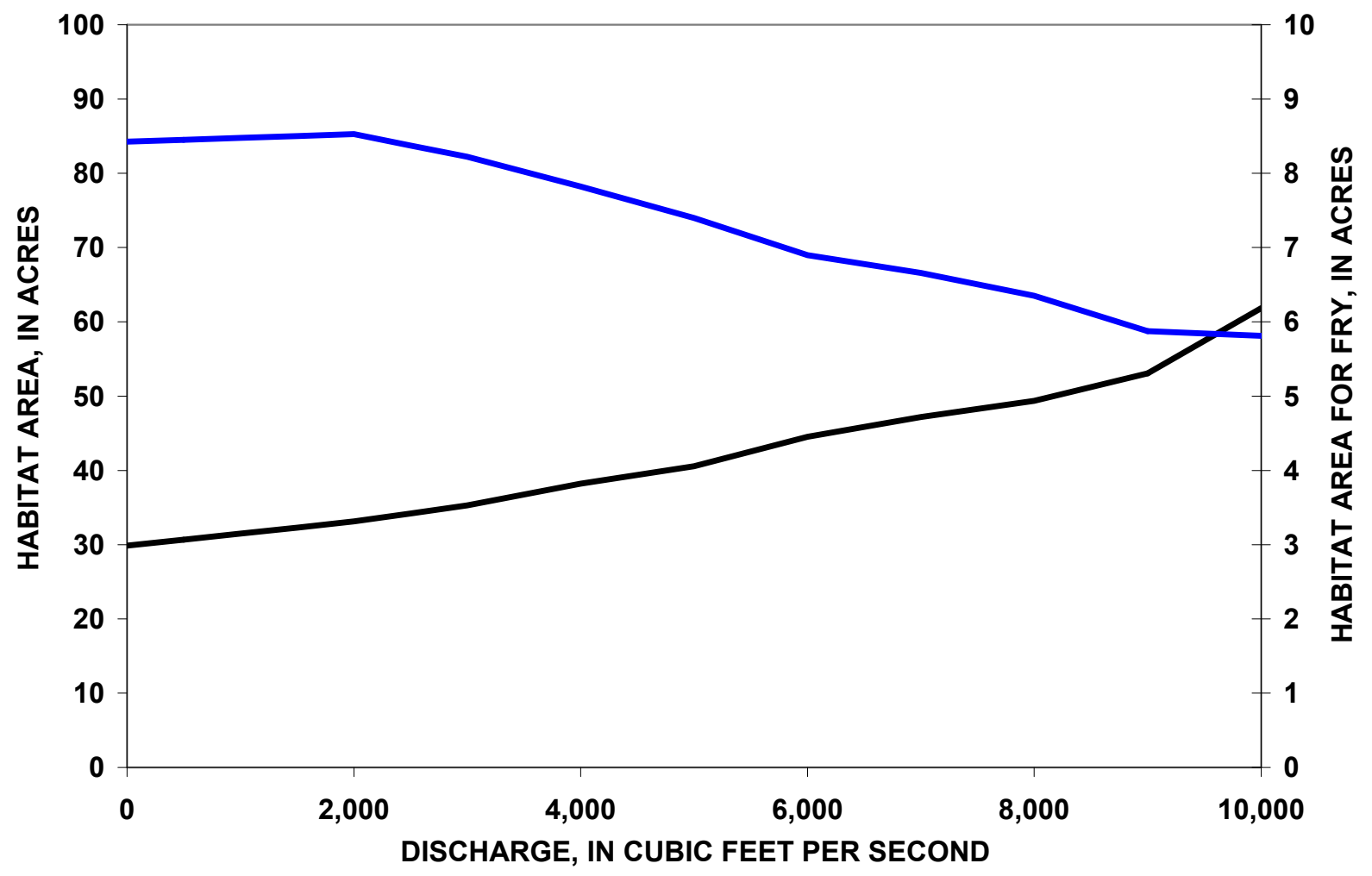

Figure 2-28. Total habitat area as a function of stream discharge for two life stages of fall chinook ( 0 . tshawytscha) in the Union Gap reach.

Table 2-17. Total habitat lookup table for fall chinook (0. tshawytscha) in the Union Gap reach. [ $\mathrm{ft}^{3} / \mathrm{s}$, cubic feet per second]

\begin{tabular}{rrr}
\hline \multicolumn{3}{c}{ Habitat area, in acres } \\
\hline $\begin{array}{r}\text { Discharge, } \\
\text { in ft } \mathbf{3} / \mathbf{s}\end{array}$ & Fry & $\begin{array}{c}\text { Subyearling } \\
\text { summer }\end{array}$ \\
\hline 0 & 8.43 & 29.85 \\
500 & 8.45 & 30.67 \\
1,000 & 8.48 & 31.49 \\
1,500 & 8.50 & 32.30 \\
2,000 & 8.53 & 33.12 \\
2,500 & 8.38 & 34.20 \\
3,000 & 8.22 & 35.29 \\
4,000 & 7.82 & 38.21 \\
5,000 & 7.40 & 40.54 \\
6,000 & 6.90 & 44.51 \\
7,000 & 6.66 & 47.18 \\
8,000 & 6.35 & 49.37 \\
9,000 & 5.87 & 53.06 \\
10,000 & 5.81 & 61.85 \\
50,000 & 5.50 & 105.81 \\
\hline
\end{tabular}




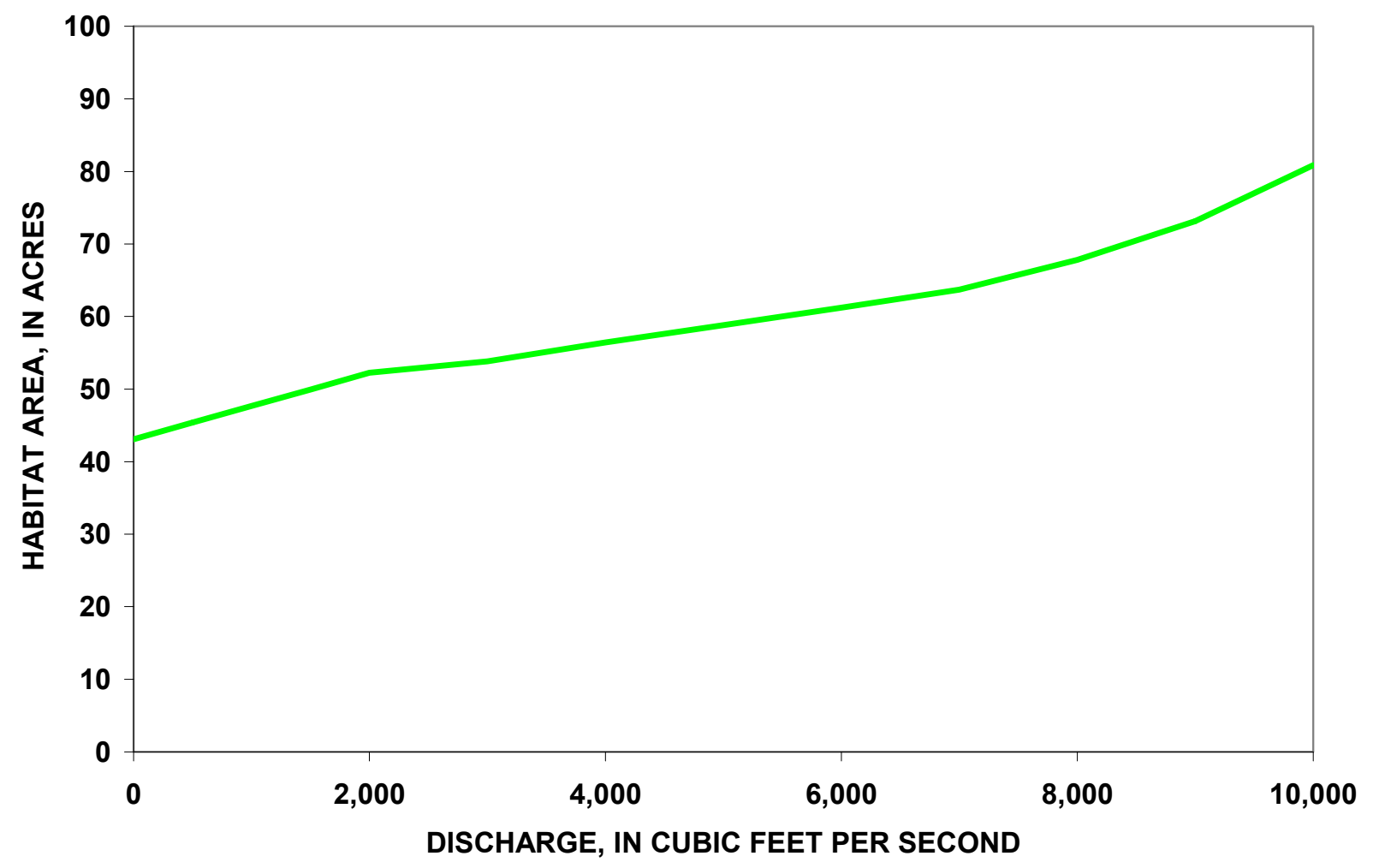

Subyearling winter

Figure 2-29. Total habitat area as a function of stream discharge for overwintering spring chinook $(0$. tshawytscha) subyearlings in the Union Gap reach.

Table 2-18. Total habitat lookup table for overwintering spring chinook (0. tshawytscha) subyearlings in the Union Gap reach. [ $\mathrm{ft}^{3} / \mathrm{s}$, cubic feet per second]

\begin{tabular}{rc}
\hline & Habitat area, in acres \\
\hline $\begin{array}{c}\text { Discharge, } \\
\text { in } \mathbf{f t}^{\mathbf{3}} \mathbf{s}\end{array}$ & $\begin{array}{c}\text { Subyearling } \\
\text { winter }\end{array}$ \\
\hline 0 & 43.06314 \\
500 & 45.36346 \\
1,000 & 47.66377 \\
1,500 & 49.96431 \\
2,000 & 52.26486 \\
2,500 & 53.0346 \\
3,000 & 53.80433 \\
4,000 & 56.43343 \\
5,000 & 58.83114 \\
6,000 & 61.23512 \\
7,000 & 63.70405 \\
8,000 & 67.78497 \\
9,000 & 73.1353 \\
10,000 & 80.85938 \\
50,000 & 119.4798 \\
\hline
\end{tabular}




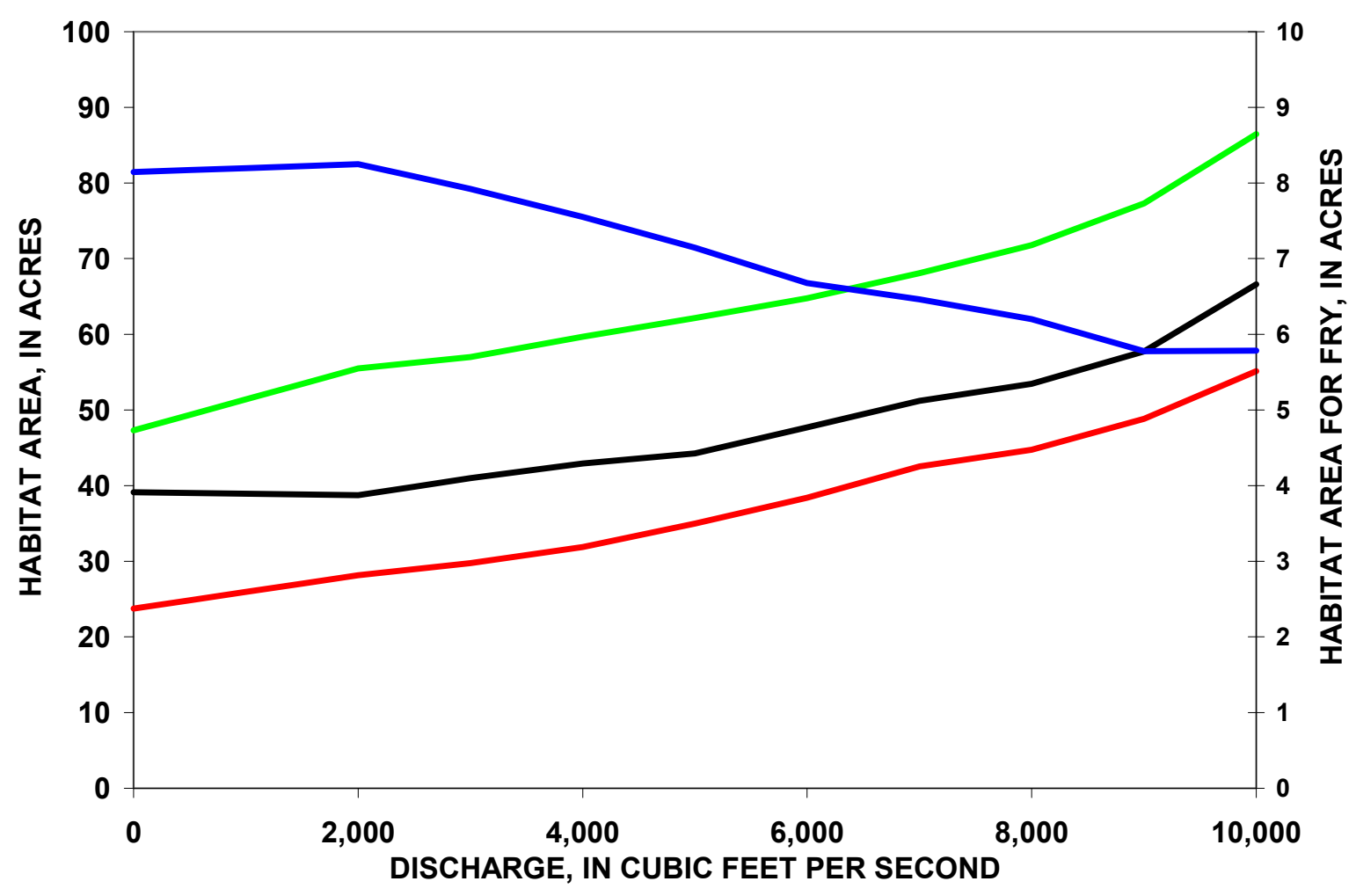

Subyearling winter $\longrightarrow$ Subyearling summer $\longrightarrow$ Yearling —Fry

Figure 2-30. Total habitat area as a function of stream discharge for four life stages of resident rainbow trout ( 0 . mykiss) in the Union Gap reach.

Table 2-19. Total habitat lookup table for resident rainbow trout (0. mykiss) in the Union Gap reach. $\left[\mathrm{ft}^{3} / \mathrm{s}\right.$, cubic feet per second]

\begin{tabular}{|c|c|c|c|c|}
\hline & \multicolumn{4}{|c|}{ Habitat area, in acres } \\
\hline $\begin{array}{c}\text { Discharge, } \\
\text { in } \mathrm{ft}^{3} / \mathrm{s}\end{array}$ & Fry & $\begin{array}{c}\text { Subyearling } \\
\text { winter }\end{array}$ & $\begin{array}{l}\text { Subyearling } \\
\text { summer }\end{array}$ & Yearling \\
\hline 0 & 8.15 & 47.30 & 39.12 & 23.75 \\
\hline 500 & 8.17 & 49.34 & 39.03 & 24.85 \\
\hline 1,000 & 8.20 & 51.39 & 38.93 & 25.95 \\
\hline 1,500 & 8.22 & 53.44 & 38.83 & 27.05 \\
\hline 2,000 & 8.25 & 55.49 & 38.74 & 28.15 \\
\hline 2,500 & 8.08 & 56.24 & 39.86 & 28.95 \\
\hline 3,000 & 7.92 & 56.99 & 40.98 & 29.76 \\
\hline 4,000 & 7.55 & 59.67 & 42.93 & 31.88 \\
\hline 5,000 & 7.15 & 62.14 & 44.25 & 35.00 \\
\hline 6,000 & 6.68 & 64.79 & 47.69 & 38.41 \\
\hline 7,000 & 6.46 & 68.09 & 51.20 & 42.52 \\
\hline 8,000 & 6.20 & 71.78 & 53.48 & 44.74 \\
\hline 9,000 & 5.78 & 77.31 & 57.72 & 48.83 \\
\hline 10,000 & 5.78 & 86.45 & 66.61 & 55.13 \\
\hline 50,000 & 5.82 & 132.16 & 111.01 & 86.62 \\
\hline
\end{tabular}




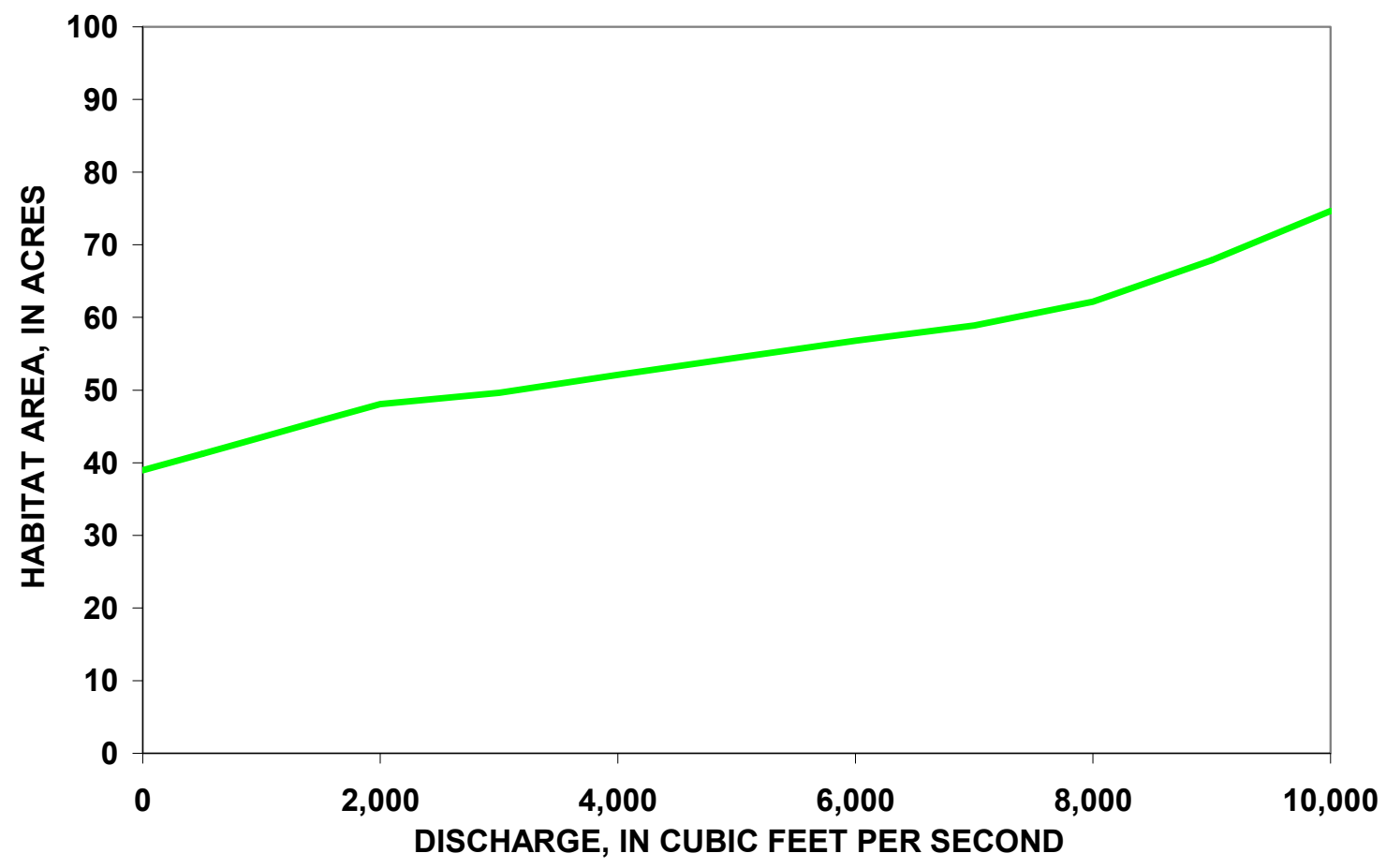

Subyearling winter

Figure 2-31. Total habitat area as a function of stream discharge for overwintering steelhead $(0$. mykiss) subyearlings in the Union Gap reach.

Table 2-20. Total habitat lookup table for overwintering steelhead (0. mykiss) subyearlings in the Union Gap reach. [ $\left[\mathrm{ft}^{3} / \mathrm{s}\right.$, cubic feet per second]

\begin{tabular}{rc}
\hline $\begin{array}{c}\text { Discharge, } \\
\text { in } \mathbf{~ f t}^{3} / \mathbf{s}\end{array}$ & $\begin{array}{c}\text { Subyearling } \\
\text { winter }\end{array}$ \\
\hline 0 & 38.95095 \\
500 & 41.23022 \\
1,000 & 43.50949 \\
1,500 & 45.78899 \\
2,000 & 48.06849 \\
2,500 & 48.83741 \\
3,000 & 49.60634 \\
4,000 & 52.08574 \\
5,000 & 54.44832 \\
6,000 & 56.79584 \\
7,000 & 58.90816 \\
8,000 & 62.15414 \\
9,000 & 67.86989 \\
10,000 & 74.67209 \\
50,000 & 108.6831 \\
\hline
\end{tabular}




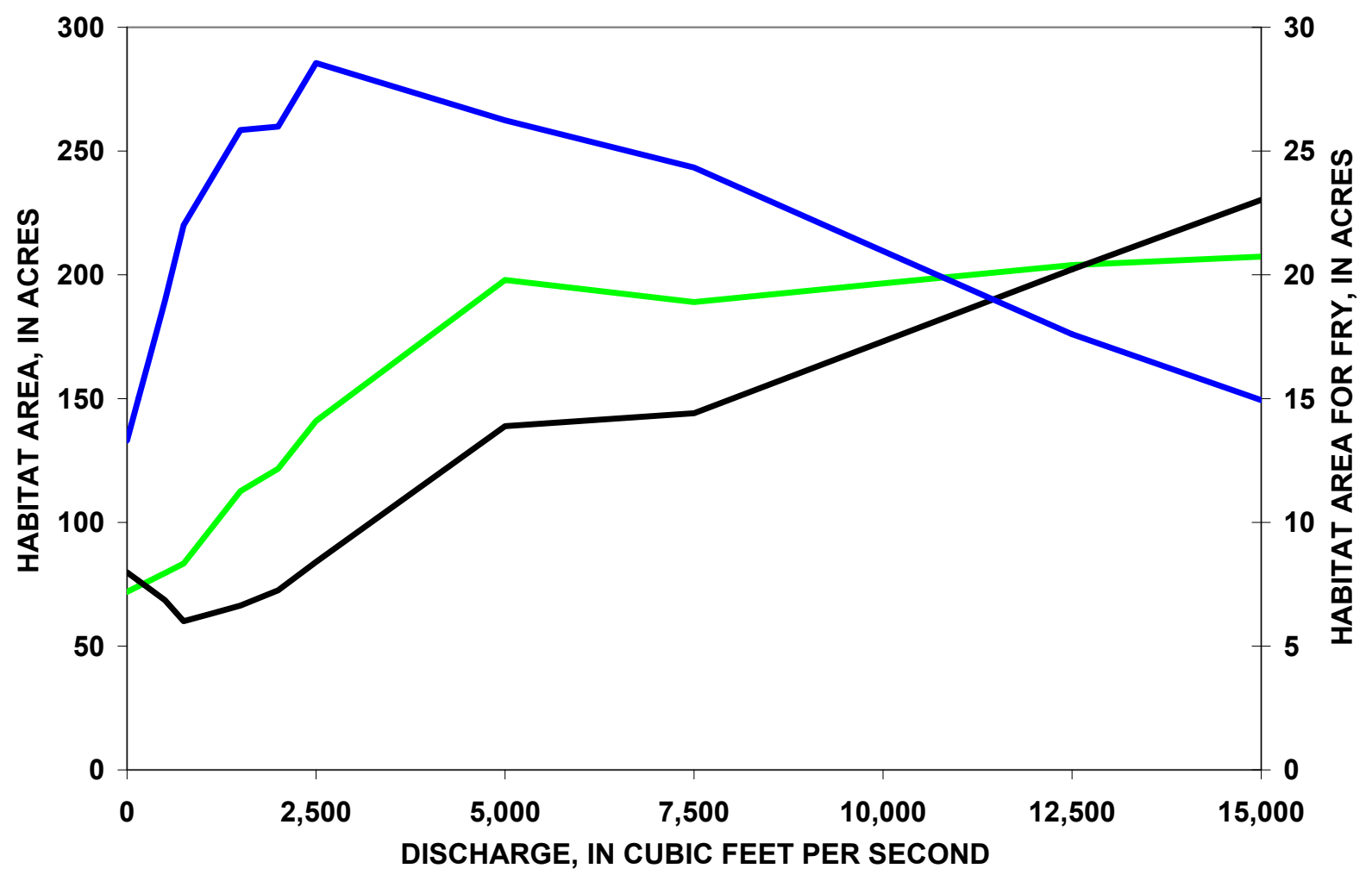

Subyearling winter $\longrightarrow$ Subyearling summer - Fry

Figure 2-32. Total habitat area as a function of stream discharge for three life stages of coho $(0$. kisutch) in the Wapato reach.

Table 2-21. Total habitat lookup table for coho (0. kisutch) in the Wapato reach. [ $\mathrm{ft}^{3} / \mathrm{s}$, cubic feet per second]

\begin{tabular}{rrrr}
\hline \multicolumn{4}{c}{ Habitat area, in acres } \\
\hline $\begin{array}{r}\text { Discharge, } \\
\text { in ft } \mathbf{t}^{\mathbf{3}} / \mathbf{s}\end{array}$ & \multicolumn{1}{c}{ Fry } & $\begin{array}{c}\text { Subyearling } \\
\text { winter }\end{array}$ & $\begin{array}{c}\text { Subyearling } \\
\text { summer }\end{array}$ \\
\hline 0 & 13.30 & 71.92 & 79.81 \\
150 & 15.00 & 74.20 & 76.43 \\
300 & 16.70 & 76.47 & 73.05 \\
500 & 18.96 & 79.51 & 68.54 \\
750 & 22.00 & 83.41 & 60.10 \\
1,125 & 23.93 & 98.01 & 63.23 \\
1,500 & 25.85 & 112.61 & 66.35 \\
2,000 & 26.00 & 121.64 & 72.55 \\
2,500 & 28.56 & 140.92 & 83.95 \\
5,000 & 26.24 & 197.89 & 138.83 \\
7,500 & 24.33 & 189.09 & 144.06 \\
10,000 & 20.97 & 196.49 & 173.16 \\
12,500 & 17.60 & 203.89 & 202.25 \\
15,000 & 14.93 & 207.33 & 230.33 \\
50,000 & 9.59 & 214.23 & 286.47 \\
\hline
\end{tabular}




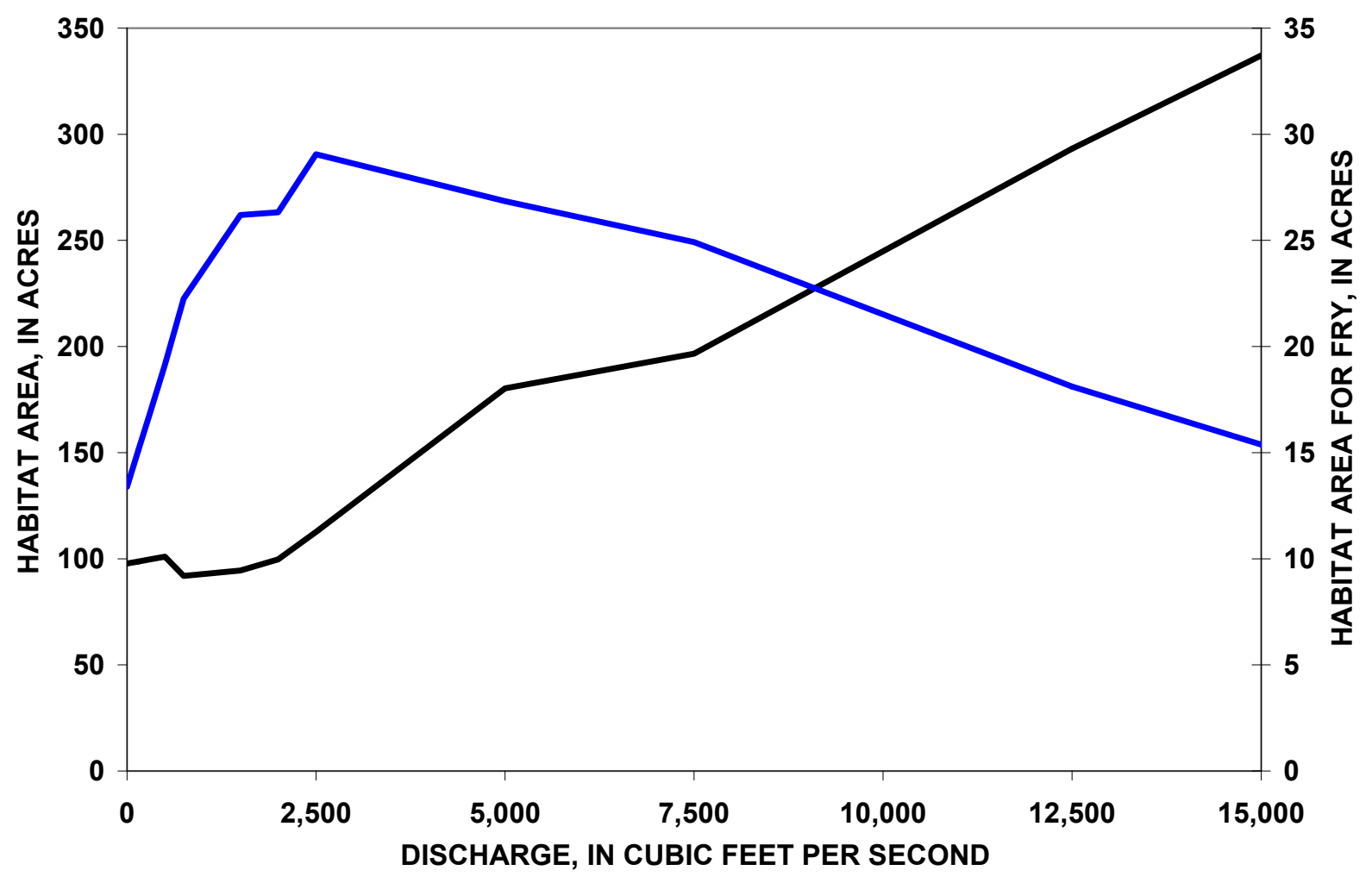

Figure 2-33. Total habitat area as a function of stream discharge for two life stages of fall chinook ( 0 . tshawytscha) in the Wapato reach.

Table 2-22. Total habitat lookup table for fall chinook (0. tshawytscha) in the Wapato reach. [ $\mathrm{ft}^{3} / \mathrm{s}$, cubic feet per second]

\begin{tabular}{rrr}
\hline \multicolumn{2}{c}{ Habitat area, in acres } \\
\hline $\begin{array}{r}\text { Discharge, } \\
\text { in } \mathbf{f t}^{3} \mathbf{s}\end{array}$ & \multicolumn{1}{c}{ Fry } & $\begin{array}{c}\text { Subyearling } \\
\text { summer }\end{array}$ \\
\hline 0 & 13.38 & 97.69 \\
150 & 15.11 & 98.68 \\
300 & 16.85 & 99.68 \\
500 & 19.15 & 101.01 \\
750 & 22.25 & 91.92 \\
1,125 & 24.22 & 93.20 \\
1,500 & 26.19 & 94.49 \\
2,000 & 26.32 & 99.69 \\
2,500 & 29.07 & 112.67 \\
5,000 & 26.84 & 180.35 \\
7,500 & 24.92 & 196.64 \\
10,000 & 21.52 & 244.94 \\
12,500 & 18.11 & 293.25 \\
15,000 & 15.39 & 337.12 \\
50,000 & 9.94 & 424.86 \\
\hline
\end{tabular}




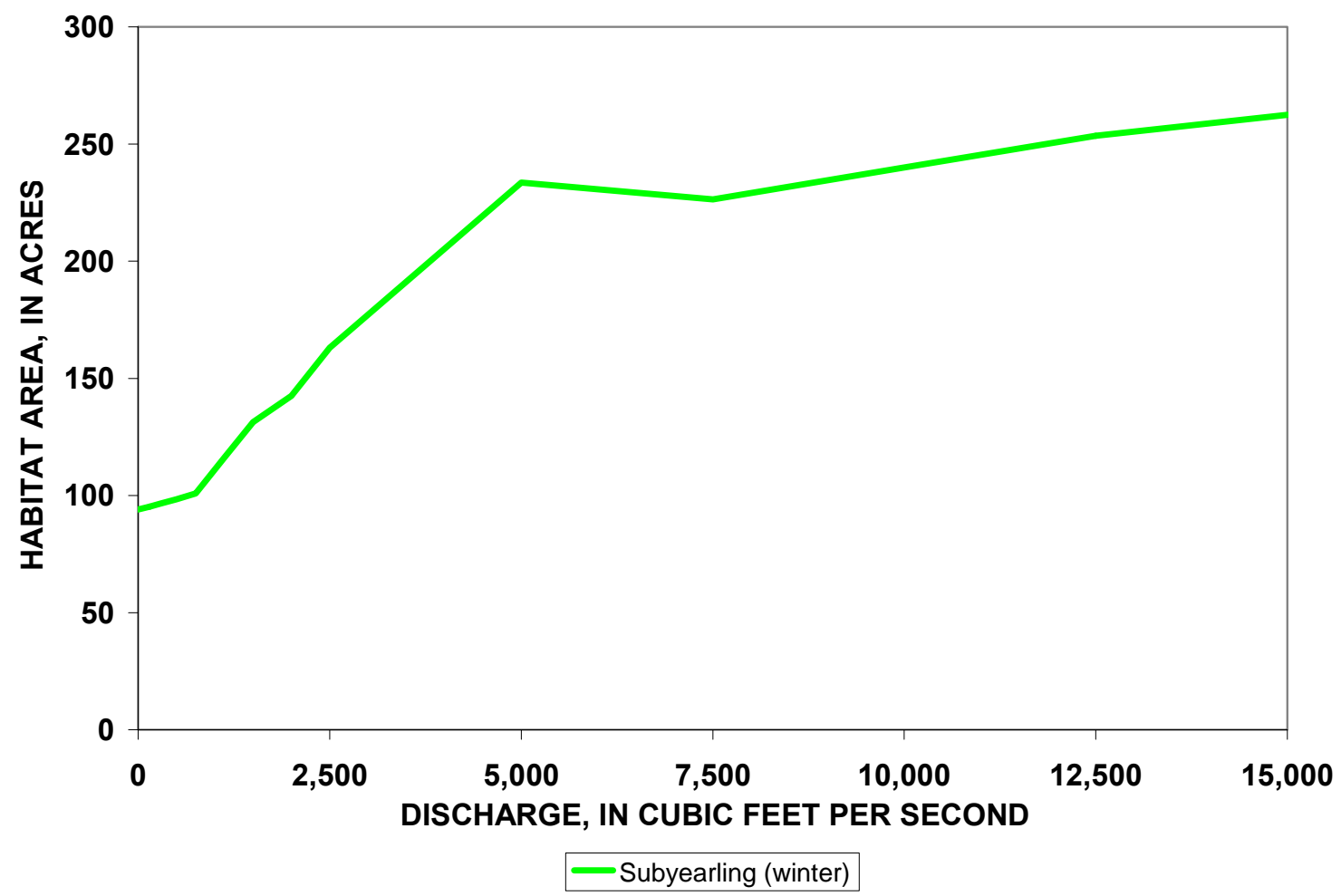

Figure 2-34. Total habitat area as a function of stream discharge for overwintering spring chinook $(0$. tshawytscha) subyearlings in the Wapato reach.

Table 2-23. Total habitat lookup table for overwintering spring chinook (0. tshawytscha) subyearlings in the Wapato reach. [ $\left[\mathrm{ft}^{3} / \mathrm{s}\right.$, cubic feet per second]

\begin{tabular}{rc}
\hline $\begin{array}{c}\text { Discharge, } \\
\text { in ft } \mathbf{s}\end{array}$ & $\begin{array}{c}\text { Habitat area, in acres } \\
\text { winter }\end{array}$ \\
\hline 0 & 93.96 \\
150 & 95.26 \\
300 & 96.55 \\
500 & 98.28 \\
750 & 100.93 \\
1,125 & 116.12 \\
1,500 & 131.32 \\
2,000 & 142.53 \\
2,500 & 163.00 \\
5,000 & 233.47 \\
7,500 & 226.38 \\
10,000 & 239.94 \\
12,500 & 253.49 \\
15,000 & 262.50 \\
50,000 & 280.50 \\
\hline
\end{tabular}




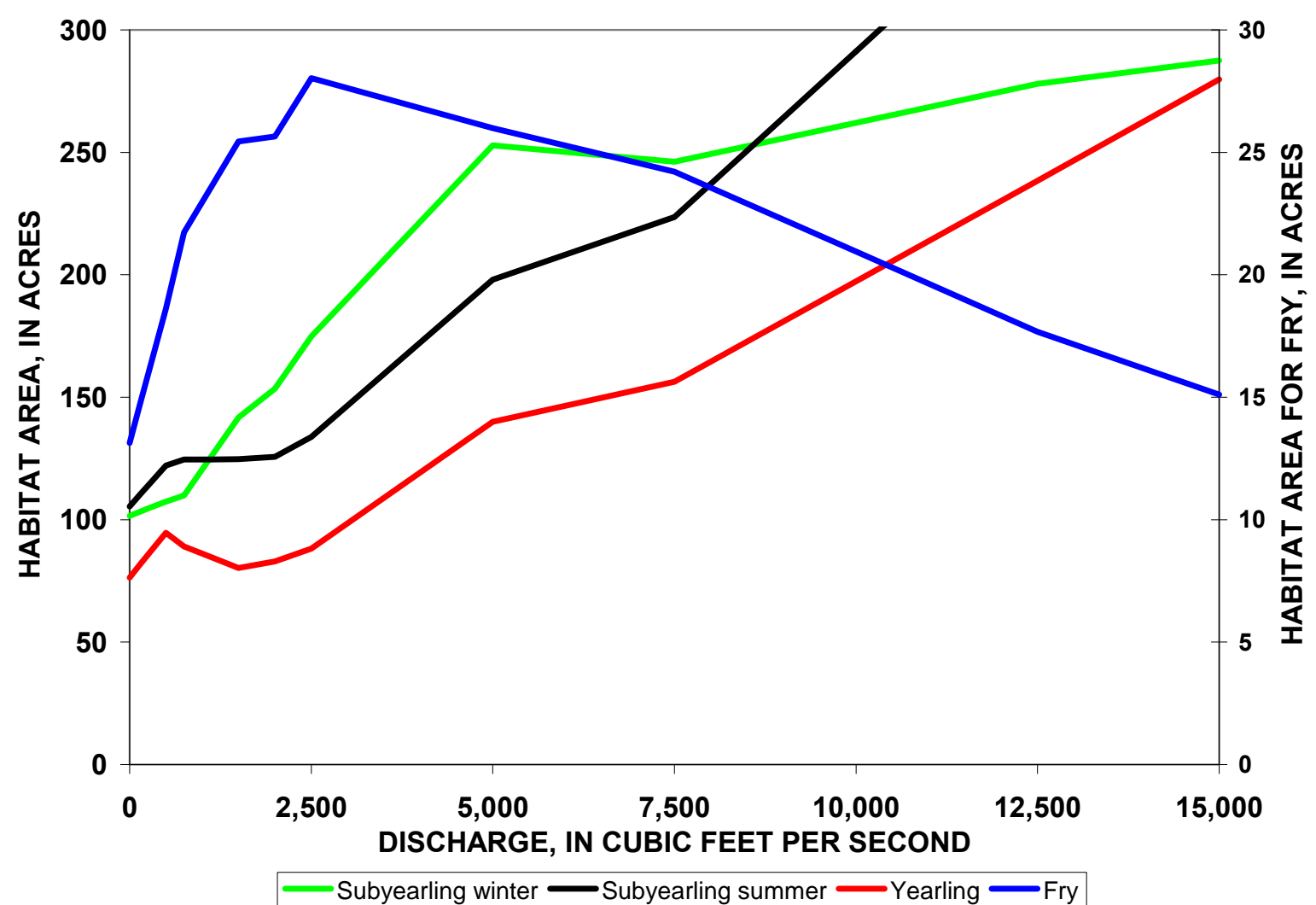

Figure 2-35. Total habitat area as a function of stream discharge for four life stages of resident rainbow trout ( 0 . mykiss) in the Wapato reach.

Table 2-24. Total habitat lookup table for resident rainbow trout (0. mykiss) in the Wapato reach. $\left[\mathrm{ft}^{3} / \mathrm{s}\right.$, cubic feet per second]

\begin{tabular}{|c|c|c|c|c|}
\hline & \multicolumn{4}{|c|}{ Habitat area, in acres } \\
\hline $\begin{array}{c}\text { Discharge, } \\
\text { in } \mathrm{ft}^{3} / \mathrm{s}\end{array}$ & Fry & $\begin{array}{c}\text { Subyearling } \\
\text { winter }\end{array}$ & $\begin{array}{l}\text { Subyearling } \\
\text { summer }\end{array}$ & Yearling \\
\hline 0 & 13.13 & 101.56 & 105.33 & 76.40 \\
\hline 150 & 14.77 & 103.31 & 110.36 & 81.87 \\
\hline 300 & 16.42 & 105.07 & 115.39 & 87.34 \\
\hline 500 & 18.61 & 107.40 & 122.11 & 94.64 \\
\hline 750 & 21.74 & 109.92 & 124.54 & 89.09 \\
\hline 1,125 & 23.59 & 125.79 & 124.62 & 84.67 \\
\hline 1,500 & 25.44 & 141.67 & 124.69 & 80.25 \\
\hline 2,000 & 25.65 & 153.53 & 125.67 & 82.97 \\
\hline 2,500 & 28.03 & 174.82 & 133.79 & 88.17 \\
\hline 5,000 & 25.99 & 252.88 & 198.01 & 140.03 \\
\hline 7,500 & 24.21 & 246.15 & 223.52 & 156.32 \\
\hline 10,000 & 20.94 & 262.06 & 291.25 & 197.35 \\
\hline 12,500 & 17.68 & 277.97 & 358.99 & 238.38 \\
\hline 15,000 & 15.11 & 287.45 & 425.85 & 279.74 \\
\hline 50,000 & 9.99 & 306.42 & 559.58 & 362.48 \\
\hline
\end{tabular}




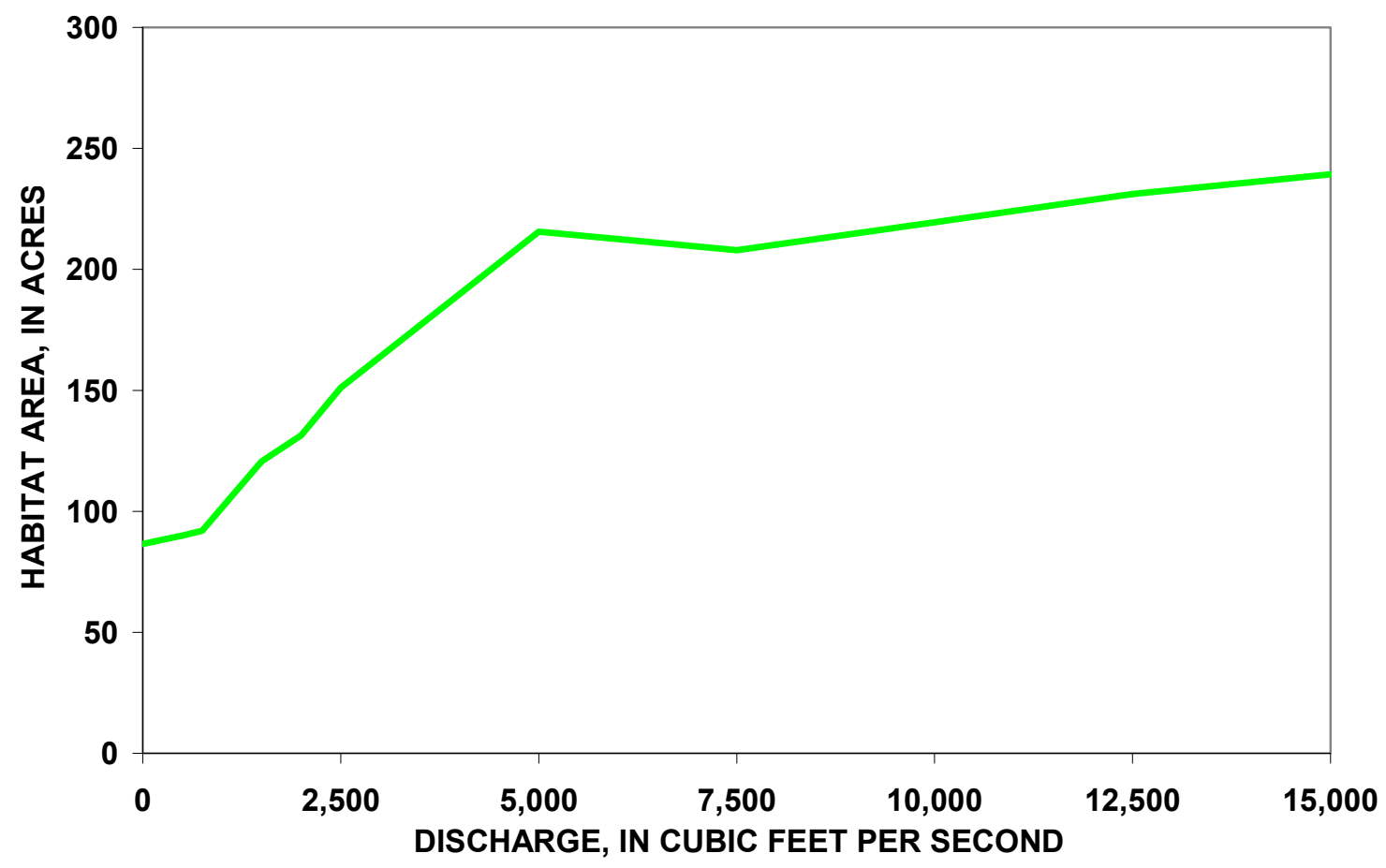

Subyearling (winter

Figure 2-36. Total habitat area as a function of stream discharge for overwintering steelhead $(0$. mykiss) subyearlings in the Wapato reach.

Table 2-25. Total habitat lookup table for overwintering steelhead (0. mykiss) subyearlings in the Wapato reach. [ft ${ }^{3} / \mathrm{s}$, cubic feet per second]

\begin{tabular}{rc}
\hline & Habitat area, in acres \\
\hline $\begin{array}{c}\text { Discharge, } \\
\text { in } \mathbf{f t}^{3} / \mathbf{s}\end{array}$ & $\begin{array}{c}\text { Subyearling } \\
\text { winter }\end{array}$ \\
\hline 0 & 86.47 \\
150 & 87.53 \\
300 & 88.60 \\
500 & 90.02 \\
750 & 91.98 \\
1,125 & 106.30 \\
1,500 & 120.62 \\
2,000 & 131.43 \\
2,500 & 151.01 \\
5,000 & 215.55 \\
7,500 & 207.88 \\
10,000 & 219.50 \\
12,500 & 231.12 \\
15,000 & 239.24 \\
50,000 & 255.48 \\
\hline
\end{tabular}


Figures 2-37 through 2-57 illustrate the spawning-incubation response surfaces for the target species, by study site. These three-dimensional surfaces should be read like a topographic map, with contours of equal area rather than equal elevation. Tables 2-26 through 2-46 contain the persistence tables for spawning-incubation analysis. Like the flow versus habitat lookup tables, and for similar reasons, the persistence tables were linearly extrapolated beyond the bounds of the simulated discharges. The YRDSS is formatted for a 15 by 15 matrix table, so the tables were filled by linear interpolation of adjacent simulated flows. In some cases, linear extrapolation of the tables yielded unrealistic results, such as negative or unrealistically high values. In these cases, a value was stipulated either as a near-zero value (for example, spawning or incubation habitat at near-zero discharge was assumed to be near-zero as well) or as the value for the adjacent flow combination in the table.

Extrapolated values in the lookup tables are indicated by a pink background, interpolations by a tan background, and stipulated values by a light blue background. 


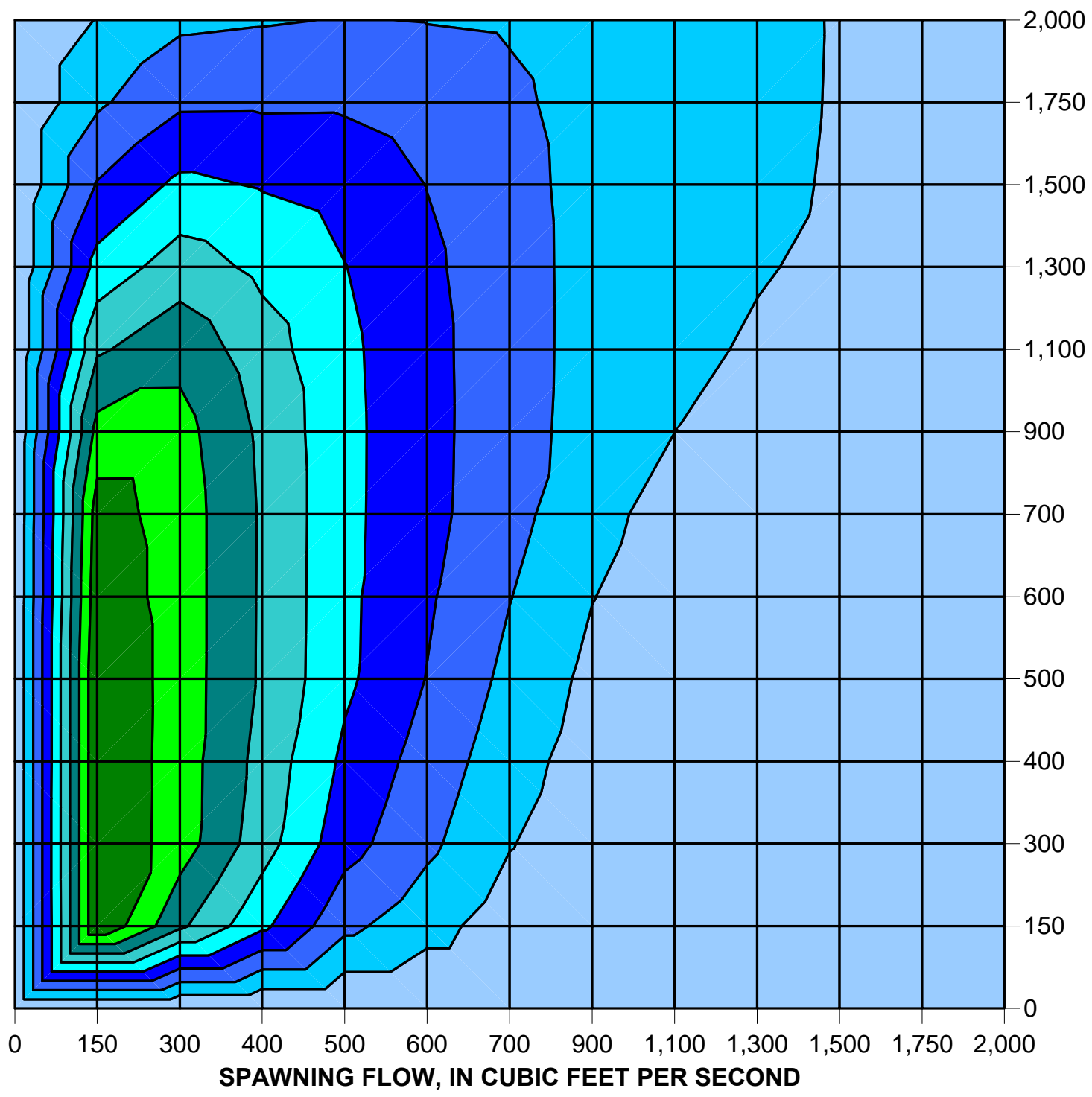

Persistent

habitat,

in acres

口40-45

ㅁ35-40

प30-35

ㄴ25-30

ㅁ20-25

- 15-20

ㅁ10-15

5-10

ㅁ0-5

Figure 2-37. Spawning-incubation response surface for bull trout ( $S$. confluentus) in the Easton reach. 
Table 2-26. Spawning-incubation persistence table for bull trout (S. confluentus) in the Easton reach.

\begin{tabular}{|c|c|c|c|c|c|c|c|c|c|c|c|c|c|c|c|c|}
\hline & & \multicolumn{15}{|c|}{ INCUBATION DISCHARGE, IN CUBIC FEET PER SECOND } \\
\hline \multirow{16}{*}{ 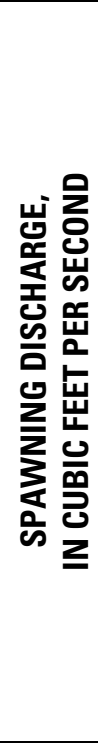 } & & $\mathbf{0}$ & 150 & 300 & 400 & 500 & 600 & 700 & 900 & 1,100 & 1,300 & 1,500 & 1,750 & 2,000 & 3,500 & 11,500 \\
\hline & $\mathbf{0}$ & 0.01 & 0.01 & 0.01 & 0.01 & 0.01 & 0.01 & 0.01 & 0.01 & 0.01 & 0.01 & 0.01 & 0.01 & 0.01 & 0.01 & 0.01 \\
\hline & 150 & 0.01 & 44.69 & 44.85 & 44.79 & 44.74 & 43.57 & 42.40 & 36.81 & 29.30 & 21.79 & 15.31 & 9.17 & 5.23 & 0.01 & 0.01 \\
\hline & 300 & 0.01 & 30.97 & 37.48 & 37.58 & 37.69 & 37.68 & 37.67 & 36.83 & 33.43 & 27.50 & 21.05 & 14.17 & 8.99 & 0.01 & 0.01 \\
\hline & 400 & 0.01 & 21.11 & 27.19 & 28.27 & 29.34 & 29.40 & 29.45 & 29.04 & 27.24 & 23.81 & 19.63 & 14.25 & 9.60 & 0.01 & 0.01 \\
\hline & 500 & 0.01 & 11.25 & 16.90 & 18.95 & 20.99 & 21.12 & 21.24 & 21.24 & 21.05 & 20.12 & 18.20 & 14.33 & 10.20 & 0.01 & 0.01 \\
\hline & 600 & 0.01 & 6.84 & 11.08 & 12.96 & 14.83 & 15.64 & 16.44 & 16.55 & 16.47 & 15.98 & 14.90 & 12.61 & 9.86 & 0.01 & 0.01 \\
\hline & 700 & 0.01 & 2.43 & 5.26 & 6.97 & 8.67 & 10.16 & 11.64 & 11.85 & 11.89 & 11.84 & 11.59 & 10.89 & 9.52 & 1.29 & 1.29 \\
\hline & 900 & 0.01 & 0.54 & 1.80 & 2.80 & 3.80 & 5.13 & 6.45 & 8.22 & 8.39 & 8.42 & 8.39 & 8.24 & 7.76 & 4.83 & 4.83 \\
\hline & 1,100 & 0.01 & 0.09 & 0.52 & 1.02 & 1.52 & 2.36 & 3.20 & 5.02 & 6.37 & 6.52 & 6.56 & 6.55 & 6.42 & 5.64 & 5.64 \\
\hline & 1,300 & 0.01 & 0.03 & 0.15 & 0.36 & 0.57 & 1.02 & 1.47 & 2.74 & 4.31 & 5.41 & 5.53 & 5.56 & 5.54 & 5.44 & 5.44 \\
\hline & 1,500 & 0.01 & 0.01 & 0.05 & 0.14 & 0.23 & 0.44 & 0.66 & 1.41 & 2.58 & 3.93 & 4.76 & 4.85 & 4.87 & 5.02 & 5.02 \\
\hline & 1,750 & 0.01 & 0.01 & 0.02 & 0.06 & 0.10 & 0.19 & 0.29 & 0.67 & 1.41 & 2.40 & 3.49 & 4.33 & 4.39 & 4.79 & 4.79 \\
\hline & 2,000 & 0.01 & 0.01 & 0.01 & 0.04 & 0.06 & 0.11 & 0.16 & 0.38 & 0.81 & 1.41 & 2.21 & 3.36 & 4.06 & 3.37 & 3.37 \\
\hline & 3,500 & 0.01 & 0.01 & 0.01 & 0.01 & 0.01 & 0.01 & 0.01 & 0.01 & 0.01 & 0.01 & 0.01 & 0.01 & 2.07 & 2.47 & 2.34 \\
\hline & 11,500 & 0.01 & 0.01 & 0.01 & 0.01 & 0.01 & 0.01 & 0.01 & 0.01 & 0.01 & 0.01 & 0.01 & 0.01 & 0.08 & 0.87 & 1.66 \\
\hline
\end{tabular}




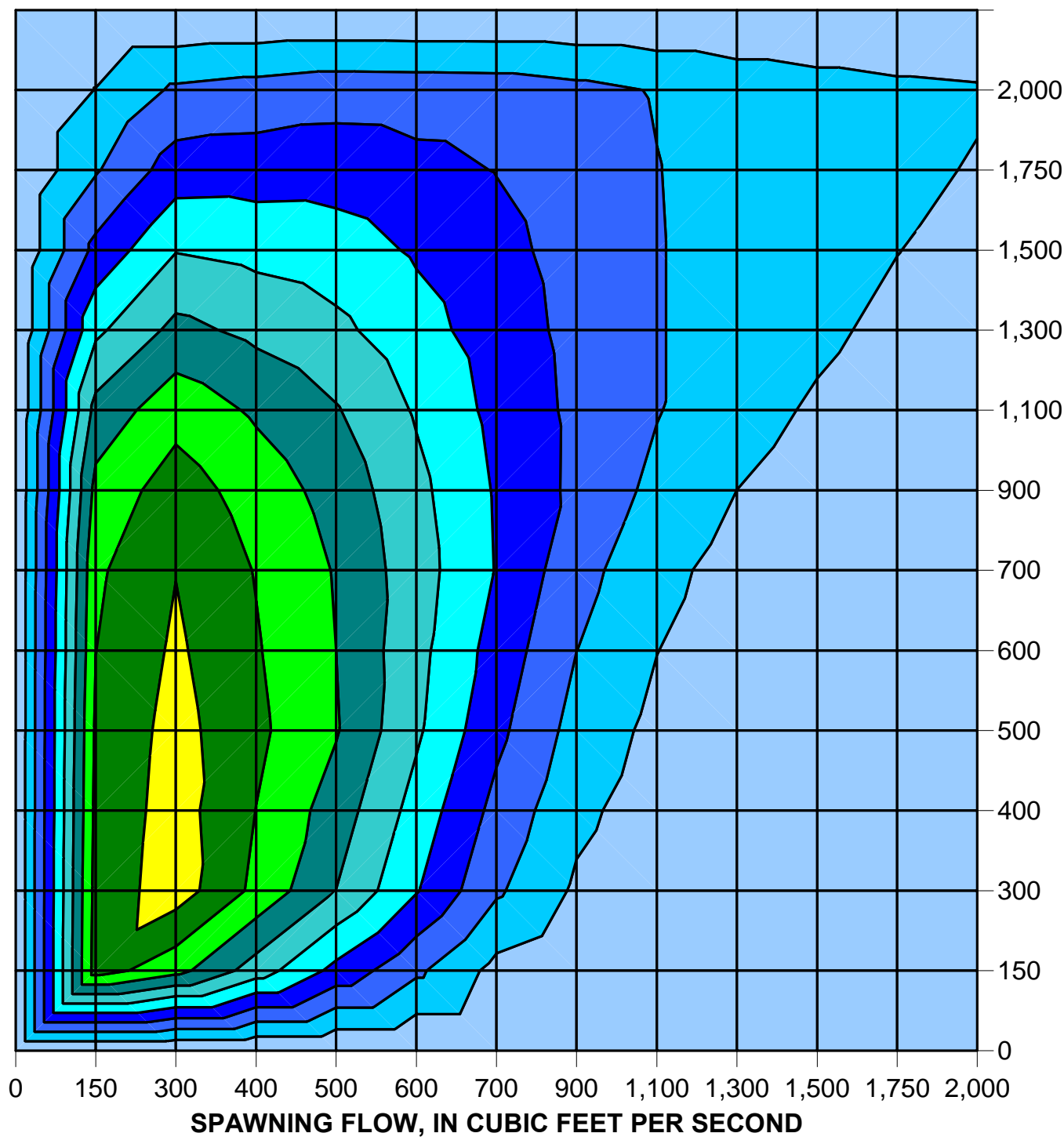

Persistent habitat,

in acres

口45-50

口40-45

ㅁ 35-40

ㅁ 30-35

ㄴ25-30

ㅁ20-25

-15-20

ㅁ10-15

ㄷ-10

ㅁ0-5

Figure 2-38. Spawning-incubation response surface for coho (0. kisutch) in the Easton reach. 
Table 2-27. Spawning-incubation persistence table for coho ( 0 . kisutch) in the Easton reach.

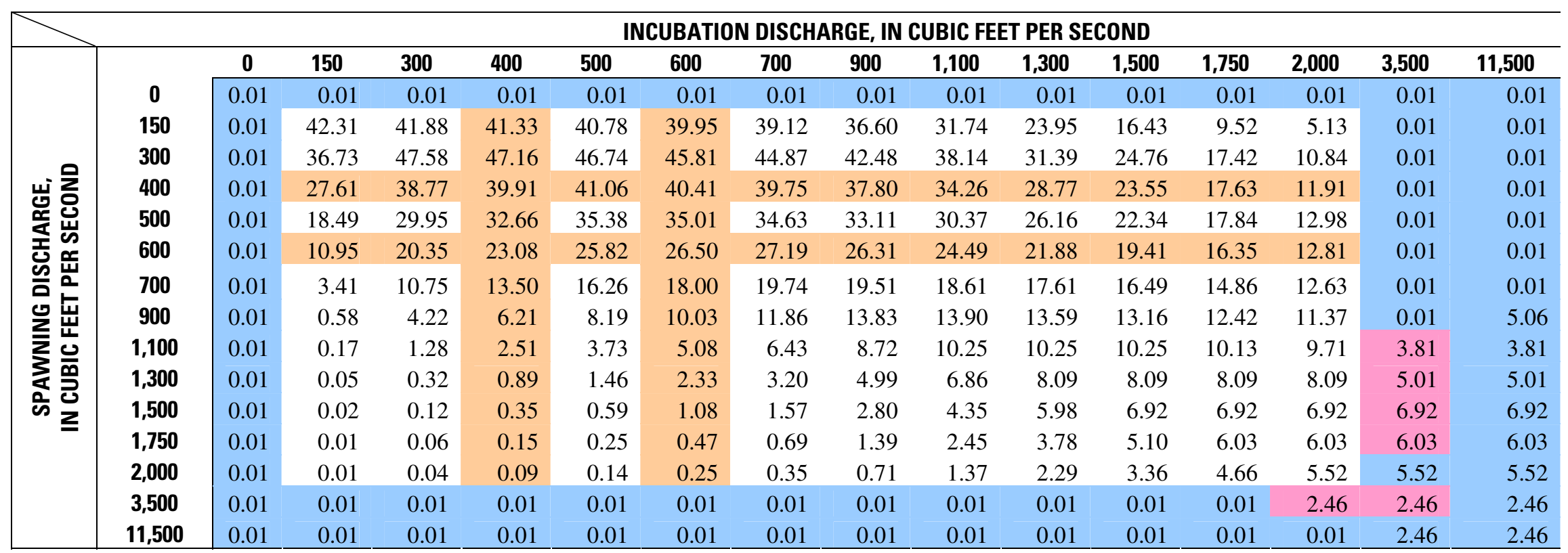




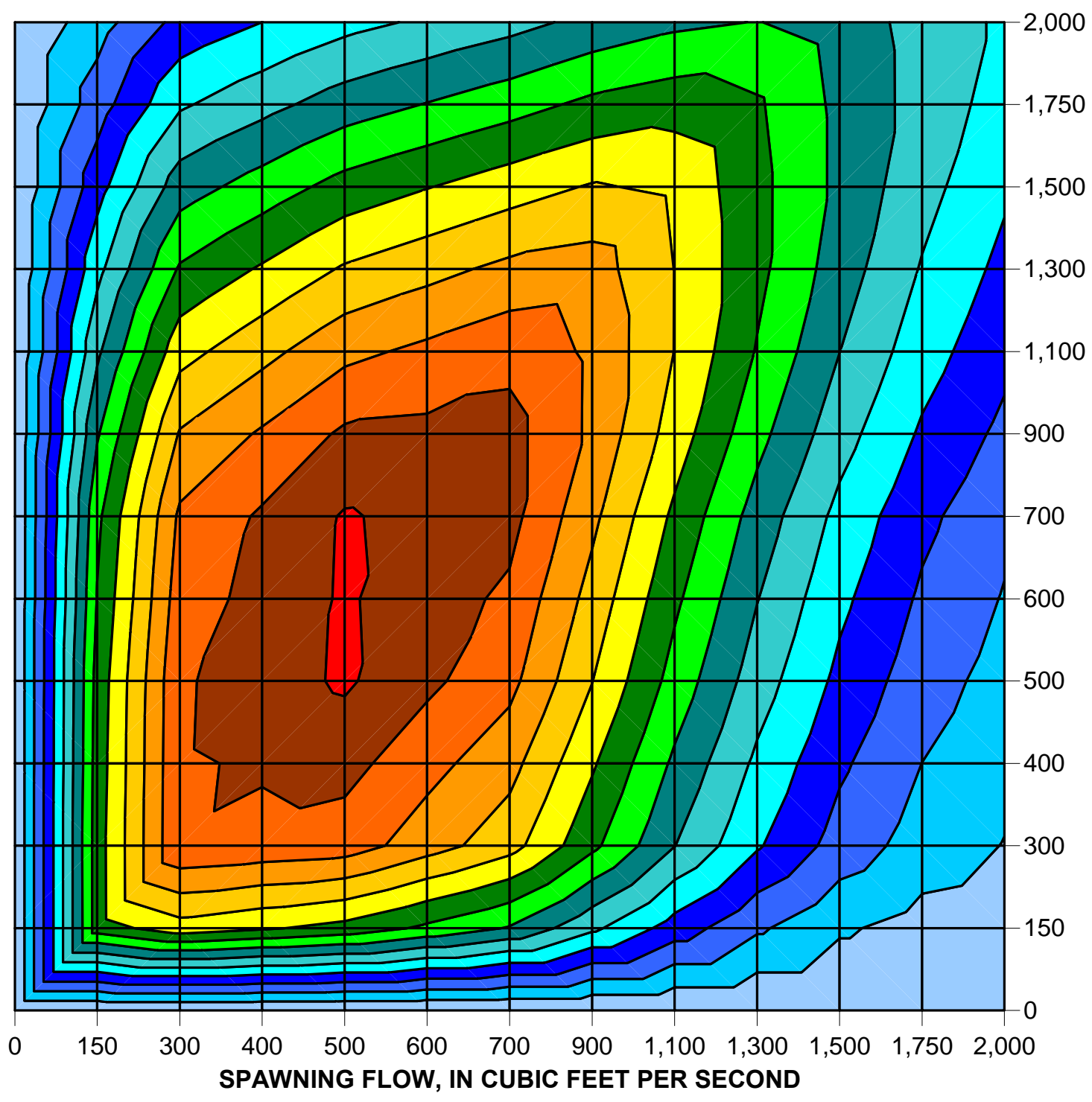

Persistent

habitat,

in acres

口70-75

$\square 65-70$

$\square$ 60-65

$\square$ 55-60

$\square$ 50-55

$\square 45-50$

$\square$ 40-45

$\square 35-40$

$\square 30-35$

$\square 25-30$

$\square 20-25$

15-20

$\square$ 10-15

$\square$ 5-10

$\square 0-5$

Figure 2-39. Spawning-incubation response surface for spring chinook (0. tshawytscha) in the Easton reach. 
Table 2-28. Spawning-incubation persistence table for spring chinook (0. tshawytscha) in the Easton reach.

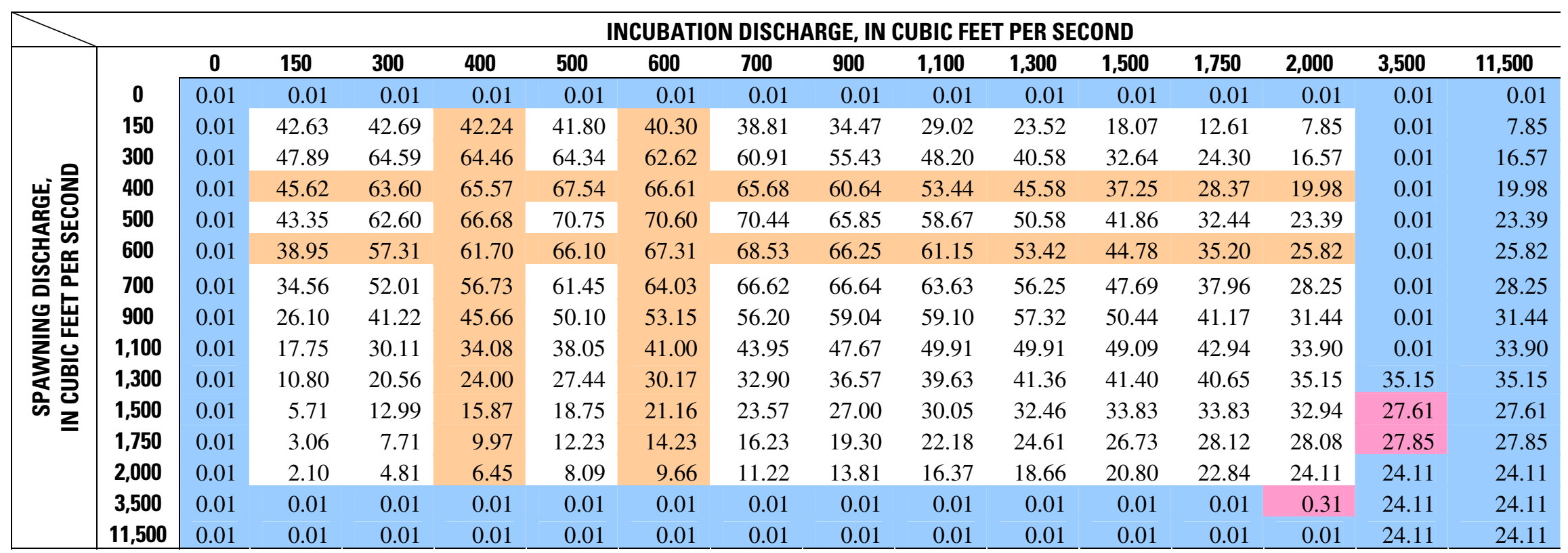




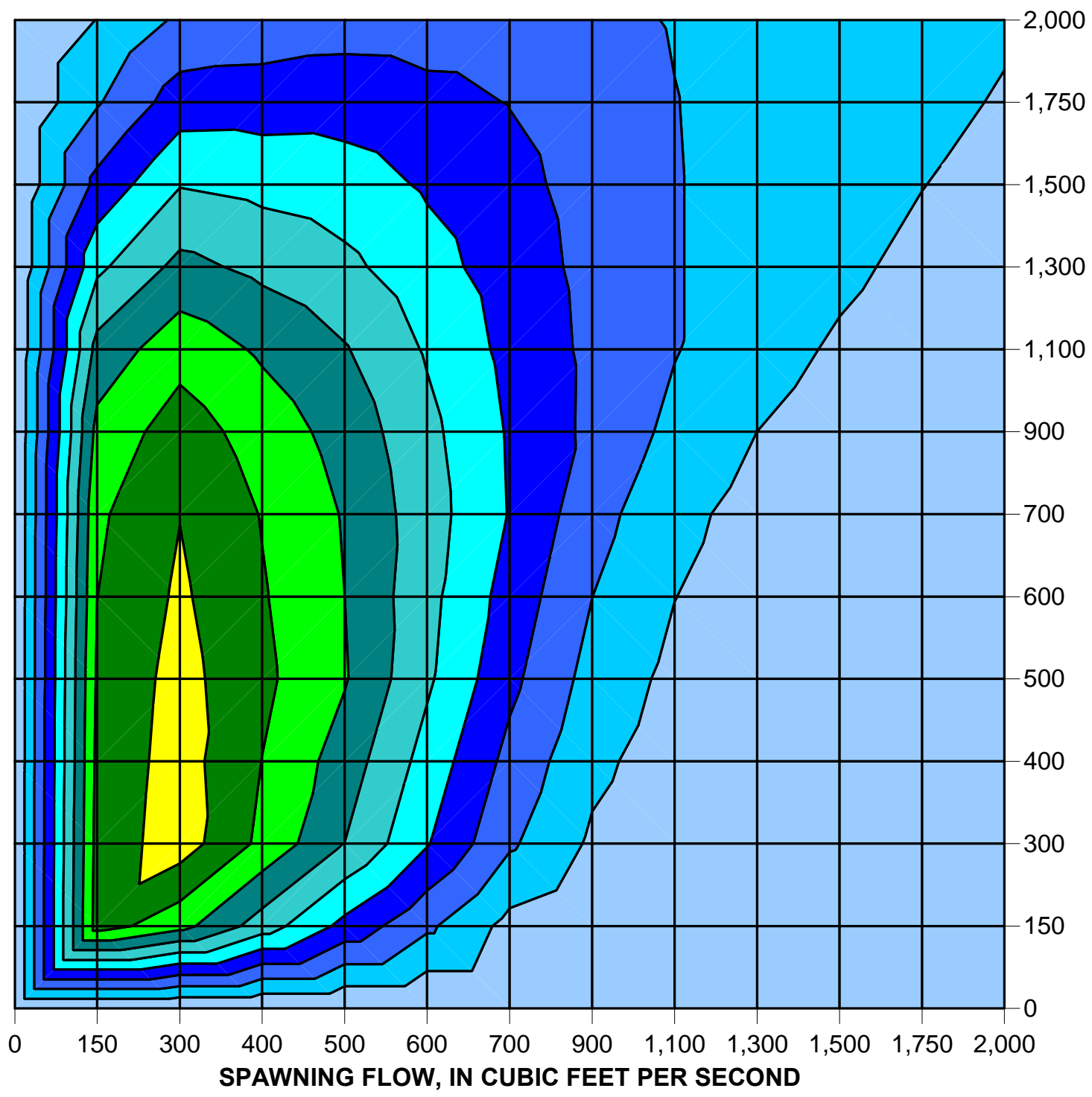

Persistent habitat, in acres 口45-50

ㄴ 40-45

ㅁ 35-40

口 30-35

ㄴ25-30

ㅁ20-25

- 15-20

ㅁ10-15

ㄷ-10

ㅁ $0-5$

Figure 2-40. Spawning-incubation response surface for resident rainbow trout (0. mykiss) in the Easton reach. 
Table 2-29. Spawning-incubation persistence table for resident rainbow trout (0. mykiss) in the Easton reach.

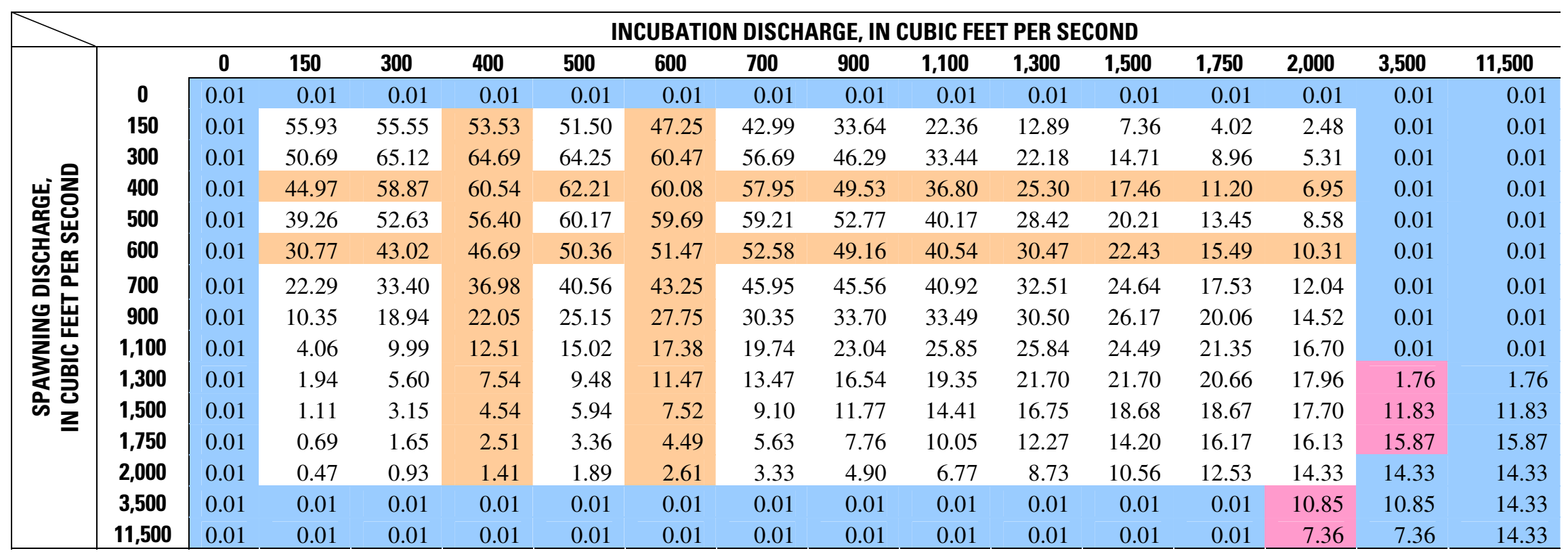




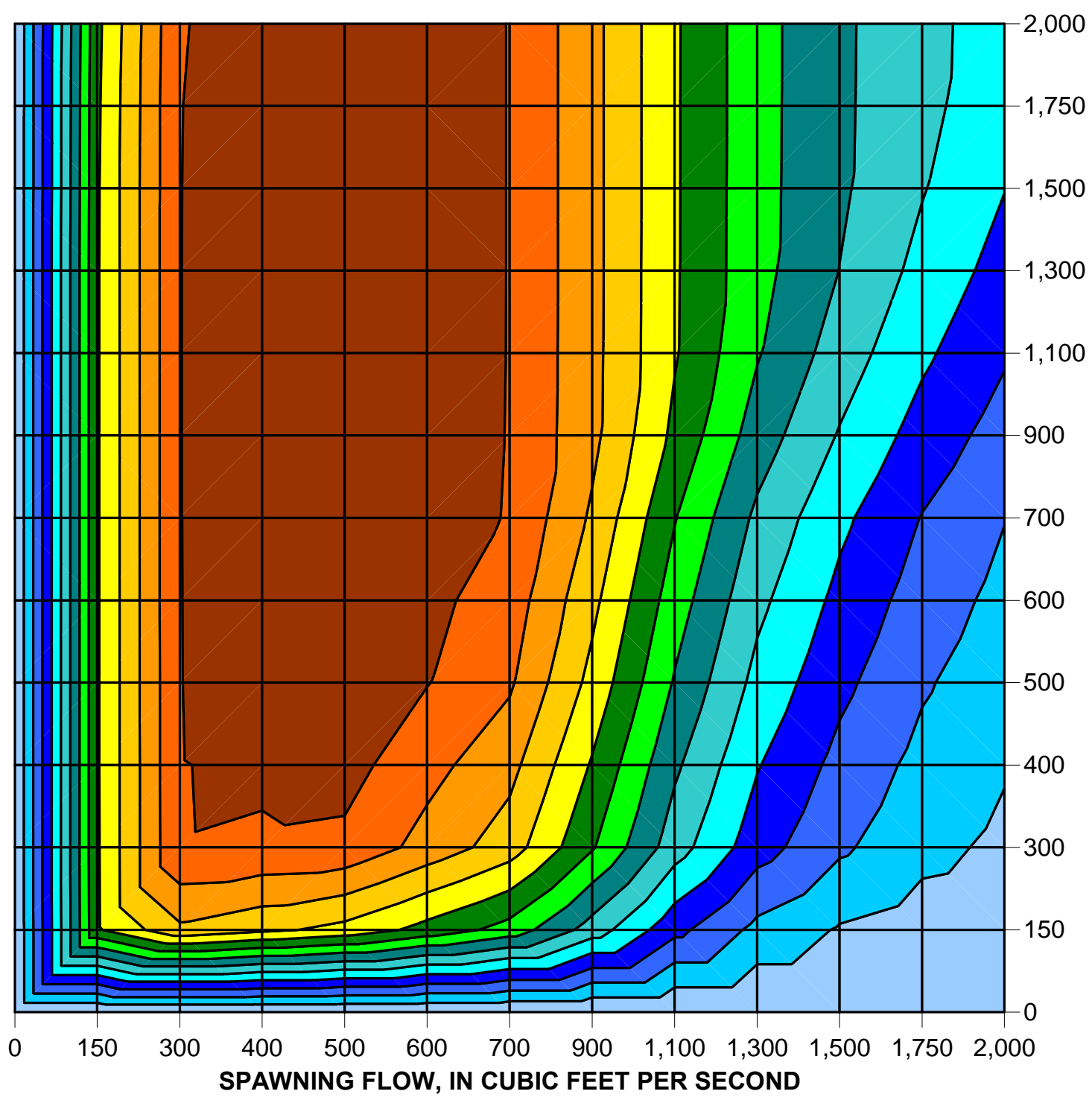

Persistent habitat,

in acres

口65-70

ㅁ60-65

ㅁ55-60

ㄴ50-55

$\square 45-50$

$\square 40-45$

ㄴ35-40

ㅁ30-35

ㅁ25-30

ㅁ20-25

- 15-20

ㅁ10-15

ㄷ-10

ㅁ0-5

Figure 2-41. Spawning-incubation response surface for steelhead (0. mykiss) in the Easton reach. 
Table 2-30. Spawning-incubation persistence table for steelhead (0. mykiss) in the Easton reach.

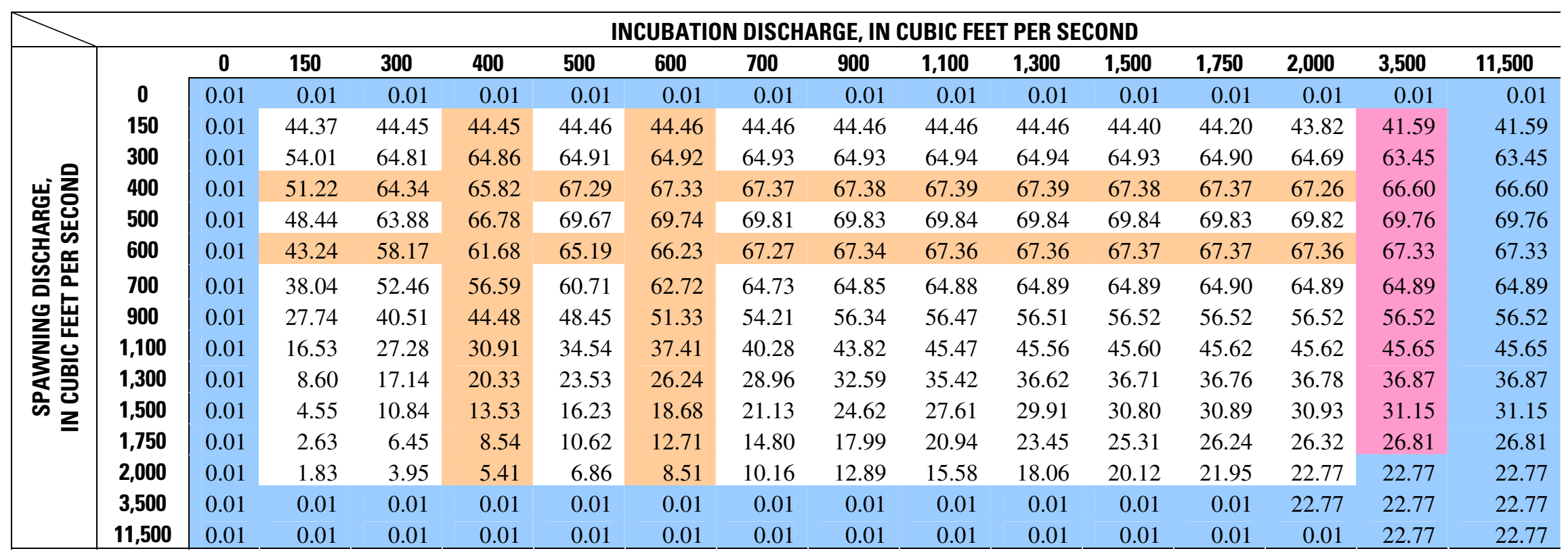




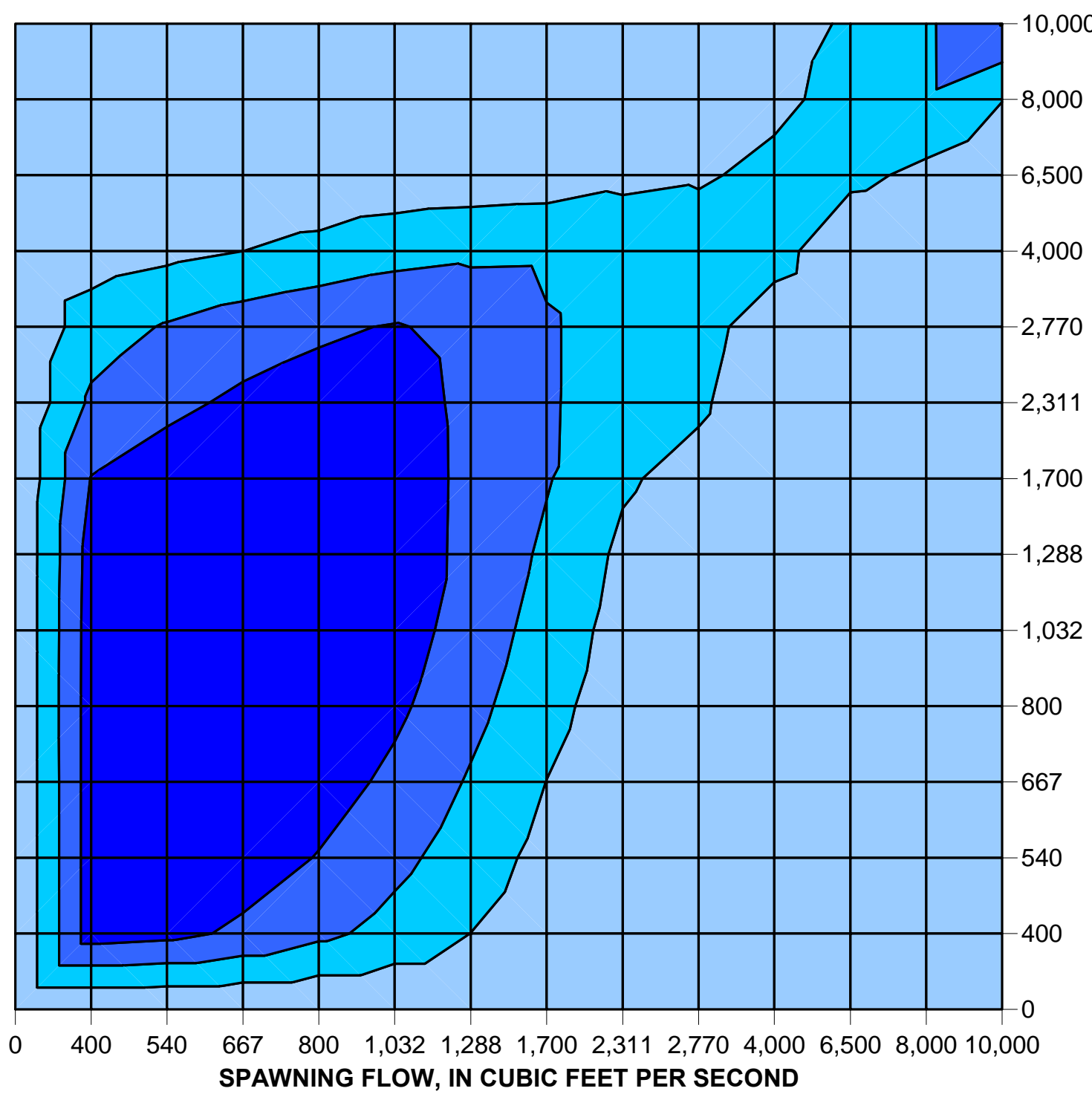

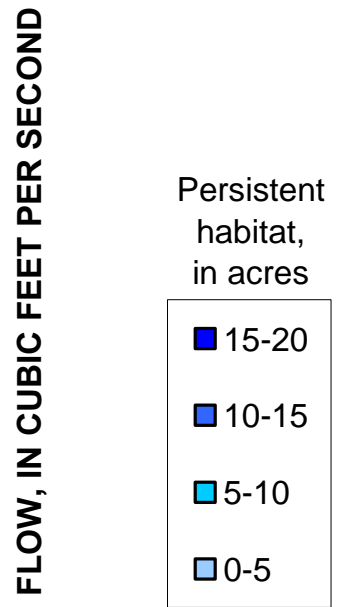

Figure 2-42. Spawning-incubation response surface for bull trout (S. confluentus) in the Kittitas reach. 
Table 2-31. Spawning-incubation persistence table for bull trout (S. confluentus) in the Kittitas reach.

\begin{tabular}{|c|c|c|c|c|c|c|c|c|c|c|c|c|c|c|c|c|}
\hline \multirow{17}{*}{ 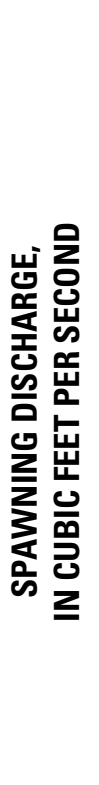 } & & \multicolumn{15}{|c|}{ INCUBATION DISCHARGE, IN CUBIC FEET PER SECOND } \\
\hline & & 0 & 400 & 540 & 667 & 800 & 1,032 & 1,288 & 1,700 & 2,311 & 2,770 & 4,000 & 6,500 & 8,000 & 10,000 & 30,000 \\
\hline & $\mathbf{0}$ & 0.01 & 0.01 & 0.01 & 0.01 & 0.01 & 0.01 & 0.01 & 0.01 & 0.01 & 0.01 & 0.01 & 0.01 & 0.01 & 0.01 & 0.01 \\
\hline & 400 & 0.01 & 17.27 & 17.28 & 17.29 & 17.31 & 17.25 & 16.95 & 15.16 & 10.85 & 7.64 & 2.32 & 0.55 & 0.25 & 0.03 & 0.01 \\
\hline & 540 & 0.01 & 16.38 & 18.24 & 18.27 & 18.29 & 18.30 & 18.25 & 17.56 & 13.82 & 10.41 & 3.69 & 0.70 & 0.32 & 0.04 & 0.01 \\
\hline & 667 & 0.01 & 14.05 & 17.56 & 18.53 & 18.57 & 18.59 & 18.59 & 18.43 & 15.93 & 12.56 & 4.99 & 0.87 & 0.39 & 0.05 & 0.01 \\
\hline & 800 & 0.01 & 11.14 & 14.75 & 17.29 & 18.58 & 18.58 & 18.63 & 18.60 & 17.16 & 14.18 & 6.35 & 1.25 & 0.51 & 0.06 & 0.01 \\
\hline & 1,032 & 0.01 & 8.28 & 11.36 & 13.87 & 16.01 & 17.13 & 17.18 & 17.20 & 16.84 & 15.31 & 8.07 & 1.85 & 0.80 & 0.10 & 0.01 \\
\hline & 1,288 & 0.01 & 4.97 & 7.45 & 9.50 & 11.46 & 13.08 & 14.00 & 14.08 & 14.05 & 13.73 & 8.95 & 2.14 & 0.97 & 0.16 & 0.01 \\
\hline & 1,700 & 0.01 & 1.99 & 3.47 & 4.95 & 6.48 & 7.77 & 9.06 & 10.37 & 10.43 & 10.43 & 9.08 & 2.56 & 1.21 & 0.26 & 0.01 \\
\hline & 2,311 & 0.01 & 0.42 & 0.87 & 1.63 & 2.56 & 3.24 & 4.06 & 5.61 & 8.11 & 8.18 & 8.07 & 3.92 & 1.88 & 0.57 & 0.01 \\
\hline & 2,770 & 0.01 & 0.22 & 0.38 & 0.70 & 1.27 & 1.65 & 2.14 & 3.30 & 5.79 & 6.90 & 6.96 & 4.54 & 2.49 & 0.87 & 0.01 \\
\hline & 4,000 & 0.01 & 0.01 & 0.01 & 0.01 & 0.04 & 0.10 & 0.21 & 0.47 & 1.23 & 2.14 & 7.01 & 5.95 & 4.14 & 2.21 & 0.01 \\
\hline & 6,500 & 0.01 & 0.01 & 0.01 & 0.01 & 0.01 & 0.01 & 0.01 & 0.01 & 0.05 & 0.12 & 0.77 & 6.24 & 6.31 & 5.87 & 4.76 \\
\hline & 8,000 & 0.01 & 0.01 & 0.01 & 0.01 & 0.01 & 0.01 & 0.01 & 0.01 & 0.01 & 0.01 & 0.17 & 3.81 & 9.21 & 9.24 & 9.30 \\
\hline & 10,000 & 0.01 & 0.01 & 0.01 & 0.01 & 0.01 & 0.01 & 0.01 & 0.01 & 0.01 & 0.01 & 0.06 & 1.51 & 5.11 & 15.15 & 15.15 \\
\hline & 30,000 & 0.01 & 0.01 & 0.01 & 0.01 & 0.01 & 0.01 & 0.01 & 0.01 & 0.01 & 0.01 & 0.01 & 0.01 & 0.01 & 15.15 & 16.55 \\
\hline
\end{tabular}




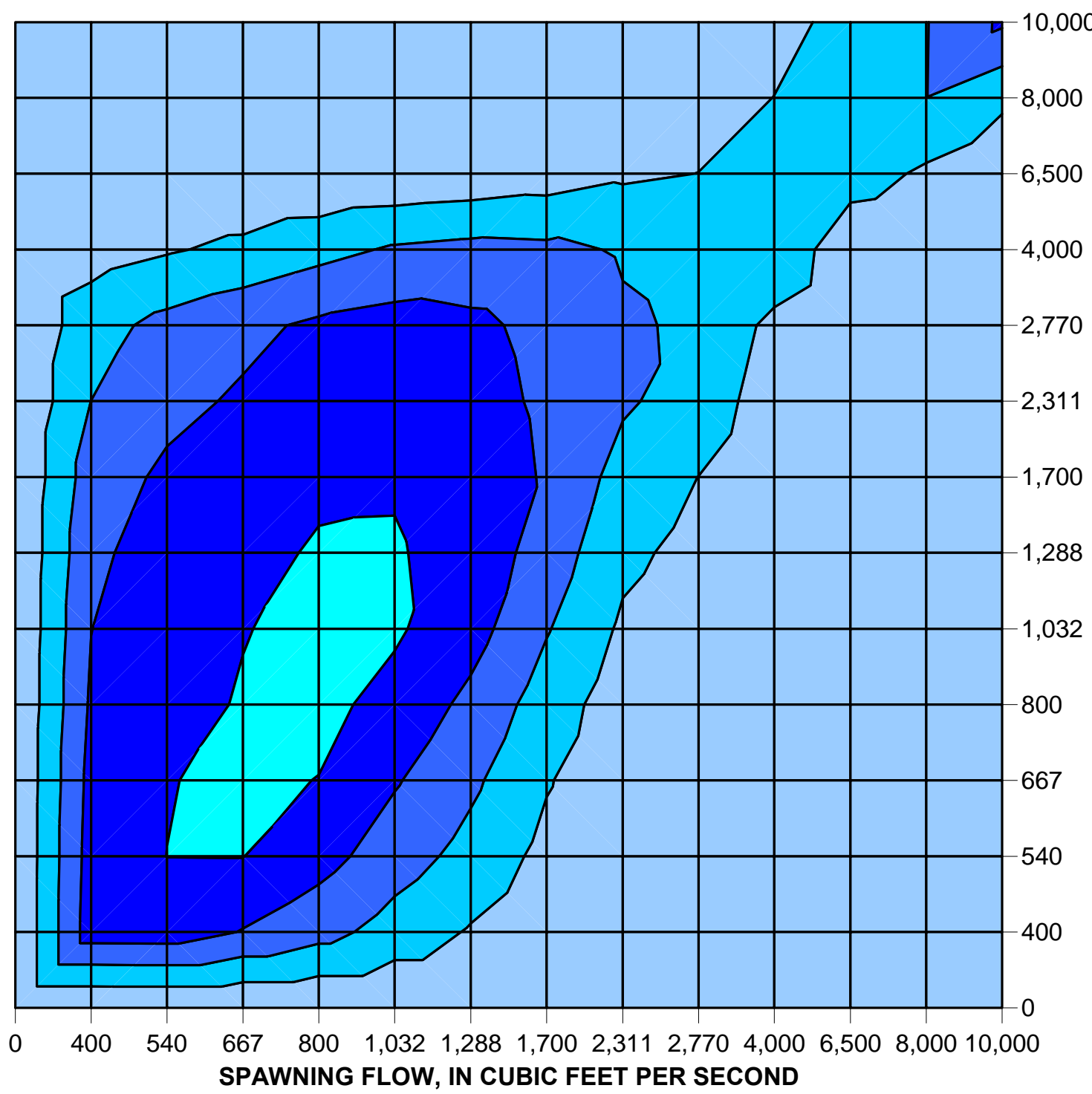

\begin{tabular}{|c|c|}
\hline 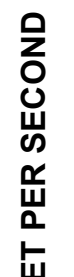 & $\begin{array}{l}\text { Persistent } \\
\text { habitat, } \\
\text { in acres }\end{array}$ \\
\hline 岀 & $\square 20-25$ \\
\hline$\frac{0}{\underline{m}}$ & -15-20 \\
\hline $\begin{array}{l}\text { ग } \\
\mathbf{z}\end{array}$ & 口10-15 \\
\hline 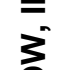 & $\square 5-10$ \\
\hline бర્త & $\square 0-5$ \\
\hline
\end{tabular}

Figure 2-43. Spawning-incubation response surface for coho (0. kisutch) in the Kittitas reach. 
Table 2-32. Spawning-incubation persistence table for coho ( 0 . kisutch) in the Kittitas reach.

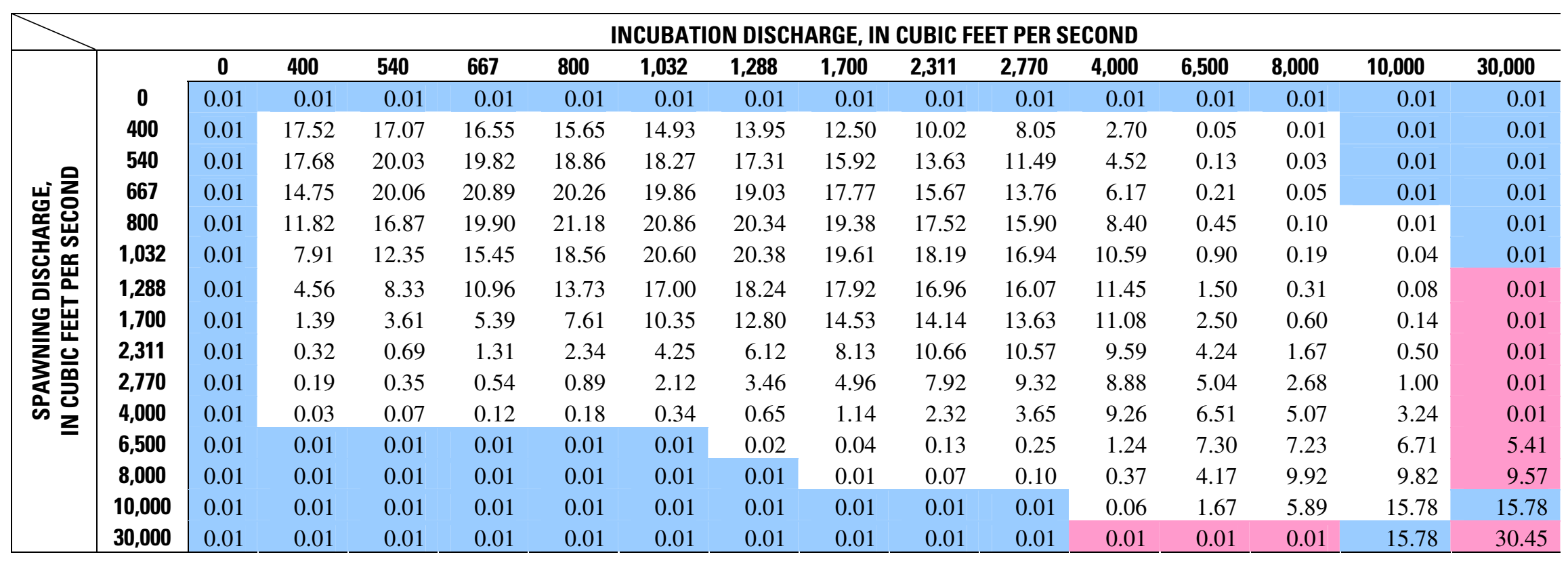




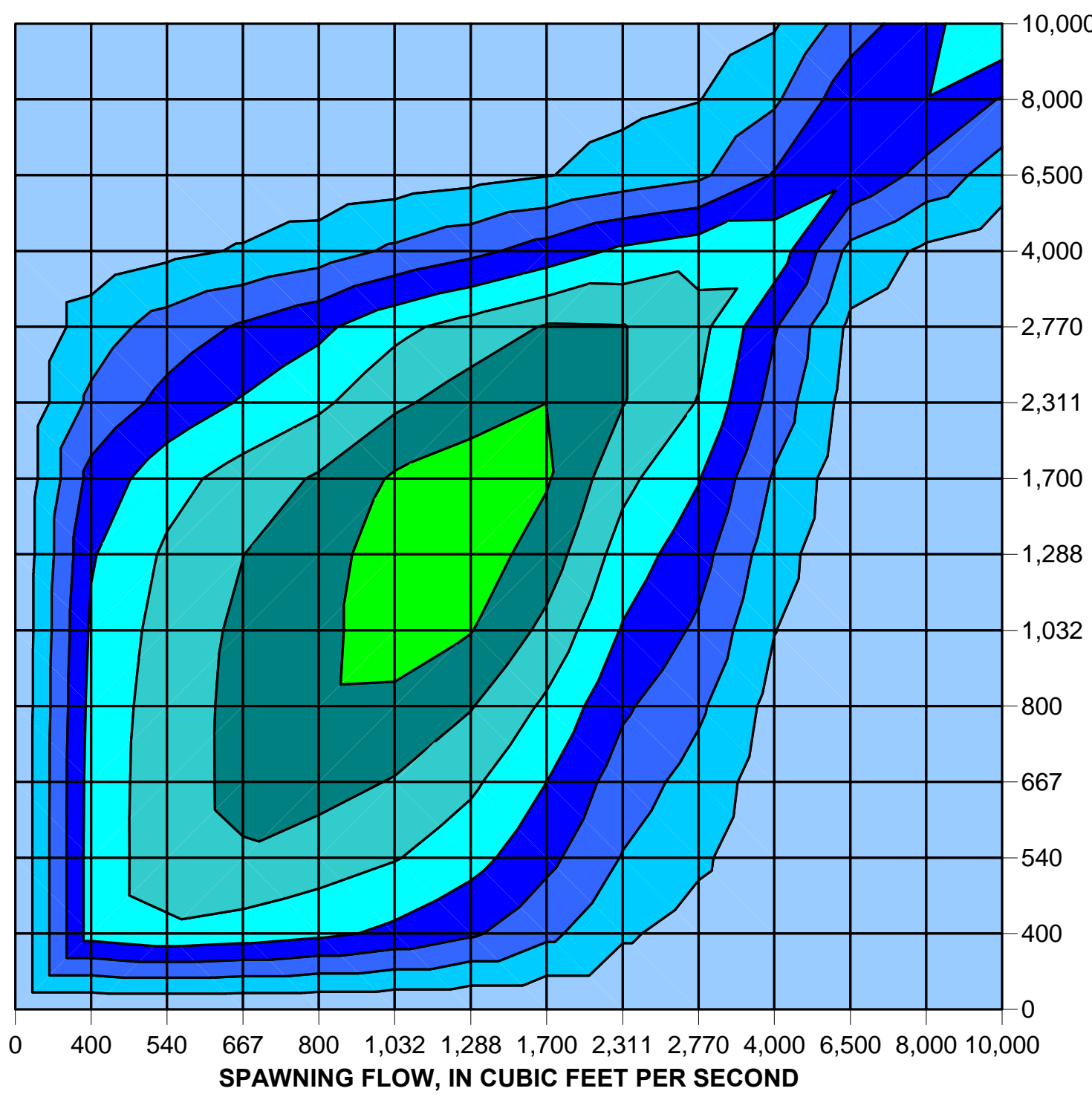

Persistent

habitat,

in acres

$\square 35-40$

$\square 30-35$

$\square 25-30$

$\square 20-25$

ㅁ15-20

$\square$ 10-15

$\square$ 5-10

$\square 0-5$

Figure 2-44. Spawning-incubation response surface for spring chinook (0. tshawytscha) in the Kittitas reach. 
Table 2-33. Spawning-incubation persistence table for spring chinook (O. tshawytscha) in the Kittitas reach.

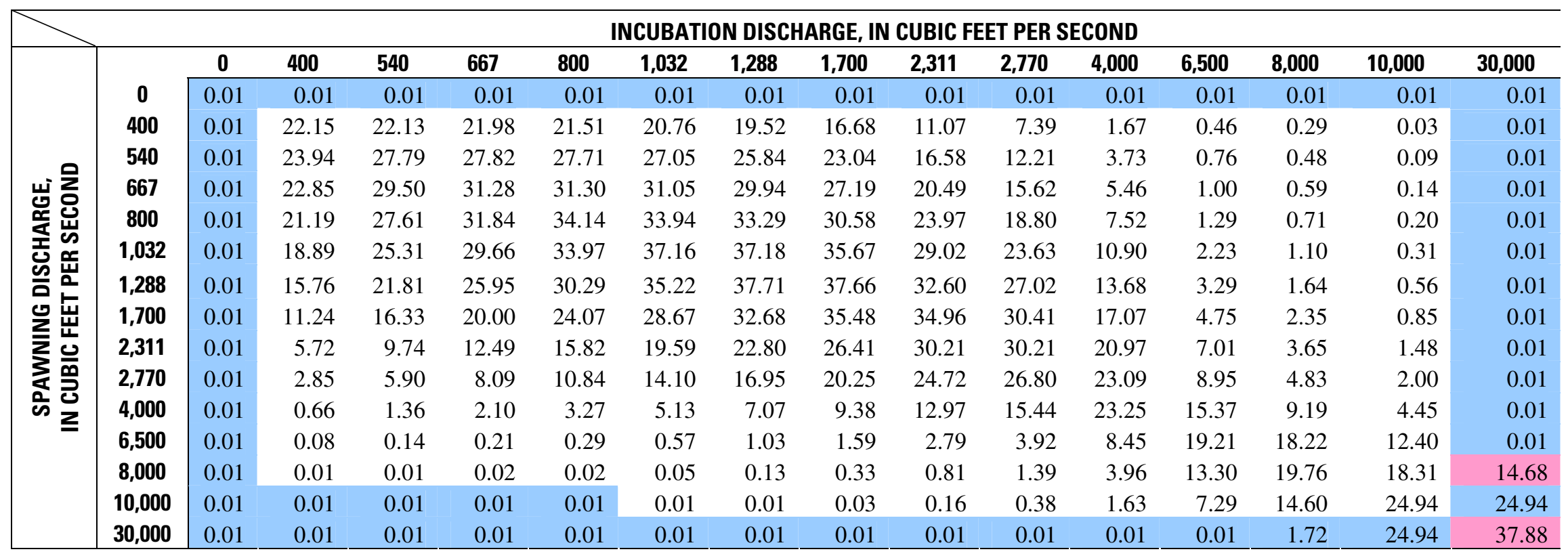




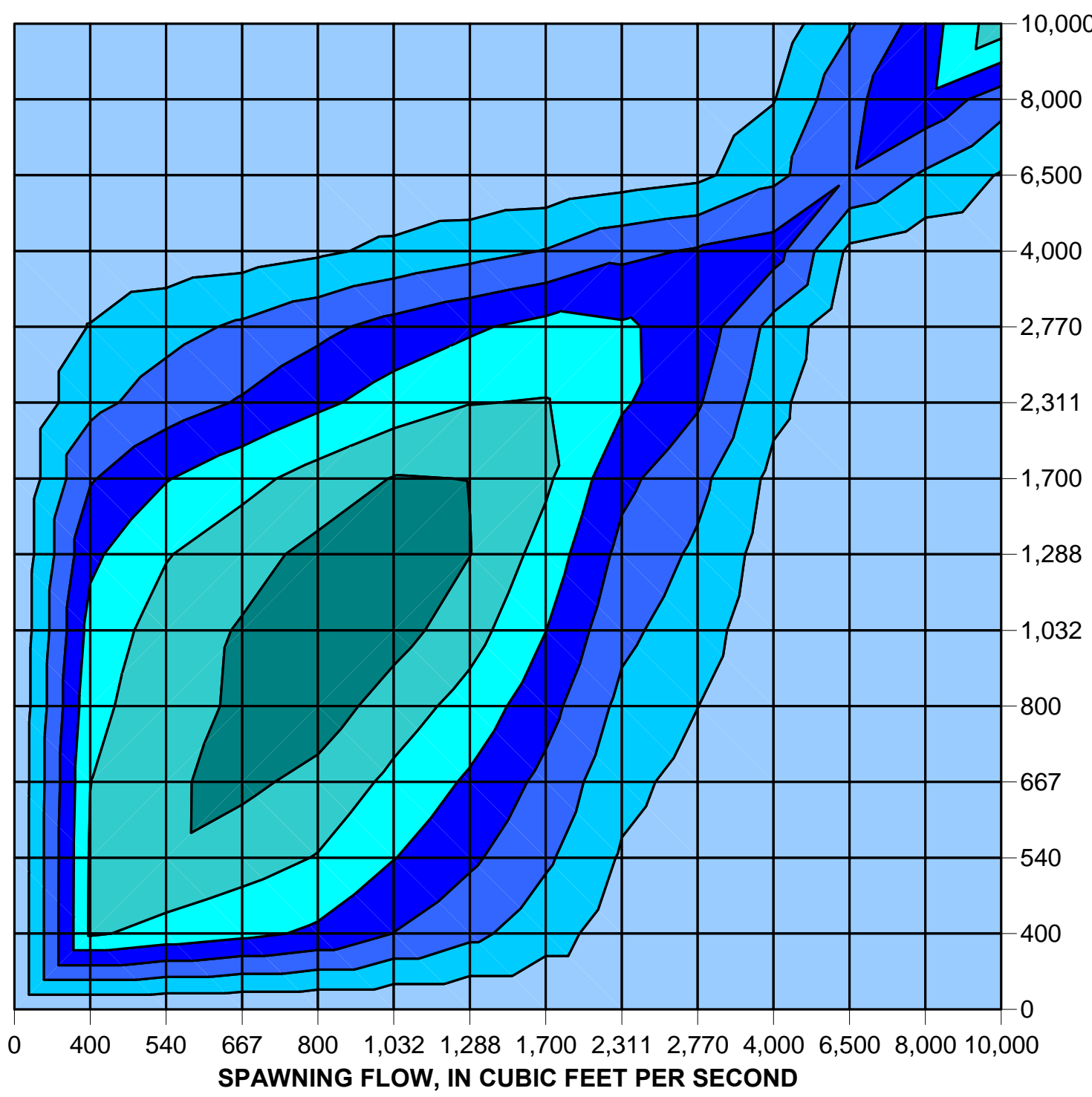

\begin{tabular}{|c|c|}
\hline 号 & $\begin{array}{c}\text { Persistent } \\
\text { habitat, } \\
\text { in acres }\end{array}$ \\
\hline & 口30-35 \\
\hline$\overline{7}$ & ㅁ25-30 \\
\hline U & $\square 20-25$ \\
\hline క & 口15-20 \\
\hline$z$ & 口10-15 \\
\hline$\frac{\vec{u}}{4}$ & \\
\hline & \\
\hline
\end{tabular}

Figure 2-45. Spawning-incubation response surface for resident rainbow trout (0. mykiss) in the Kittitas reach. 
Table 2-34. Spawning-incubation persistence table for resident rainbow trout ( 0 . mykiss) in the Kittitas reach.

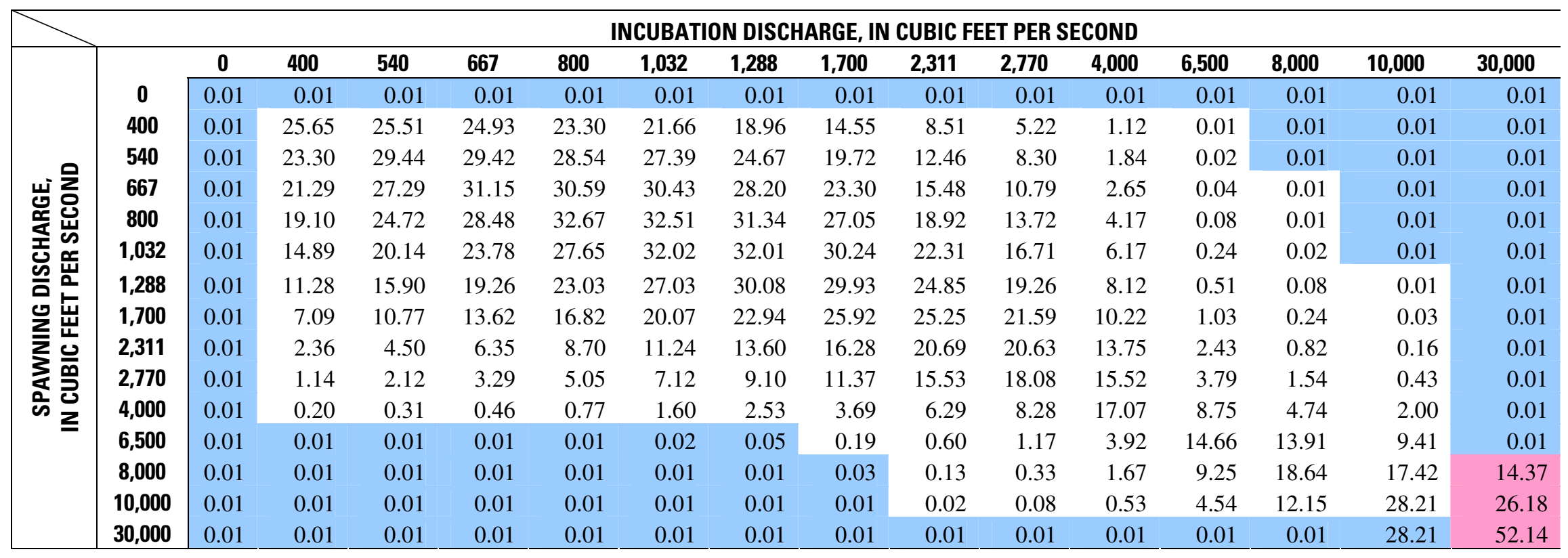




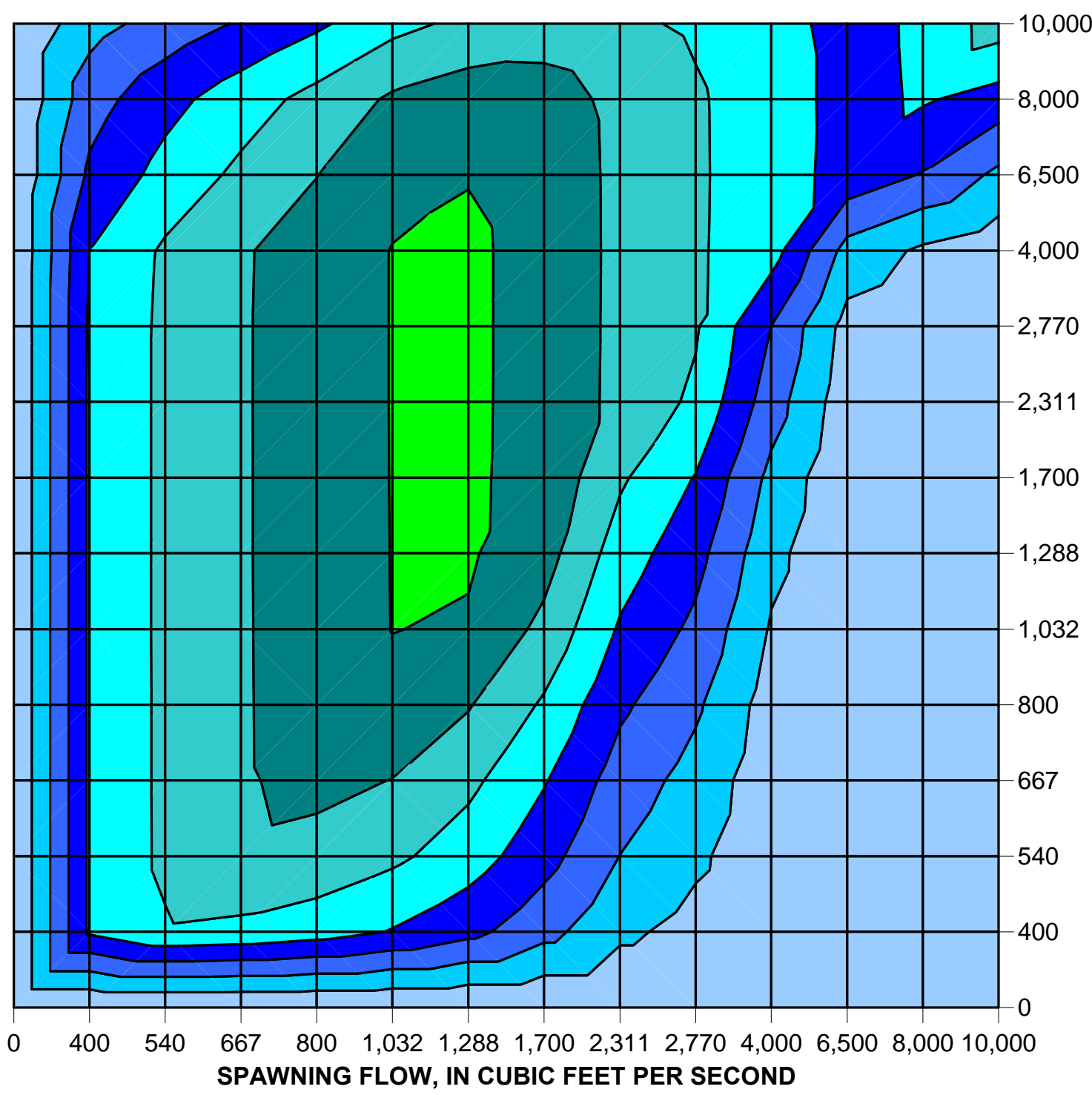

\begin{tabular}{|c|c|}
\hline 0 & $\begin{array}{c}\text { Persistent } \\
\text { habitat, } \\
\text { in acres }\end{array}$ \\
\hline $\begin{array}{l}\text { D্ } \\
\text { U్ }\end{array}$ & $\square 35-40$ \\
\hline 品 & $\square 30-35$ \\
\hline 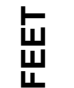 & $\square 25-30$ \\
\hline$\frac{u}{M}$ & $\square 20-25$ \\
\hline$\underline{z}$ & 口15-20 \\
\hline 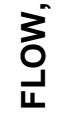 & 口10-15 \\
\hline$\underset{\mathrm{O}}{\mathrm{O}}$ & $\square 5-10$ \\
\hline 恖 & $\square 0-5$ \\
\hline
\end{tabular}

Figure 2-46. Spawning-incubation response surface for steelhead (0. mykiss) in the Kittitas reach. 
Table 2-35. Spawning-incubation persistence table for steelhead (0. mykiss) in the Kittitas reach.

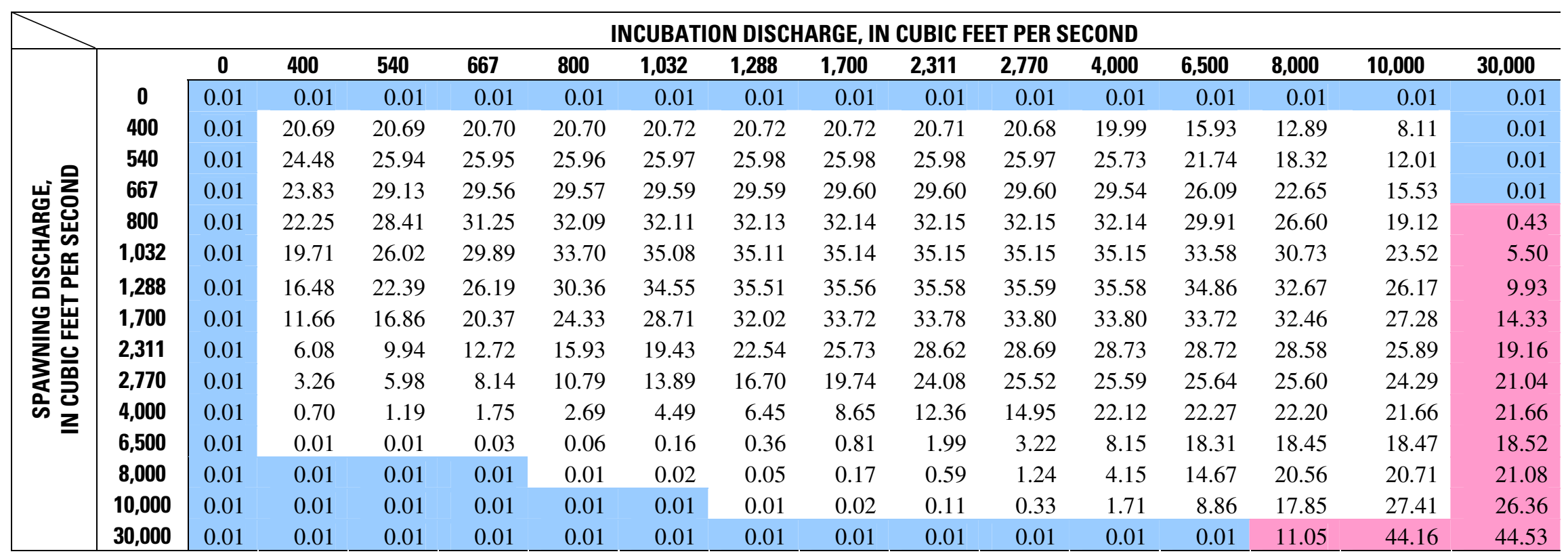




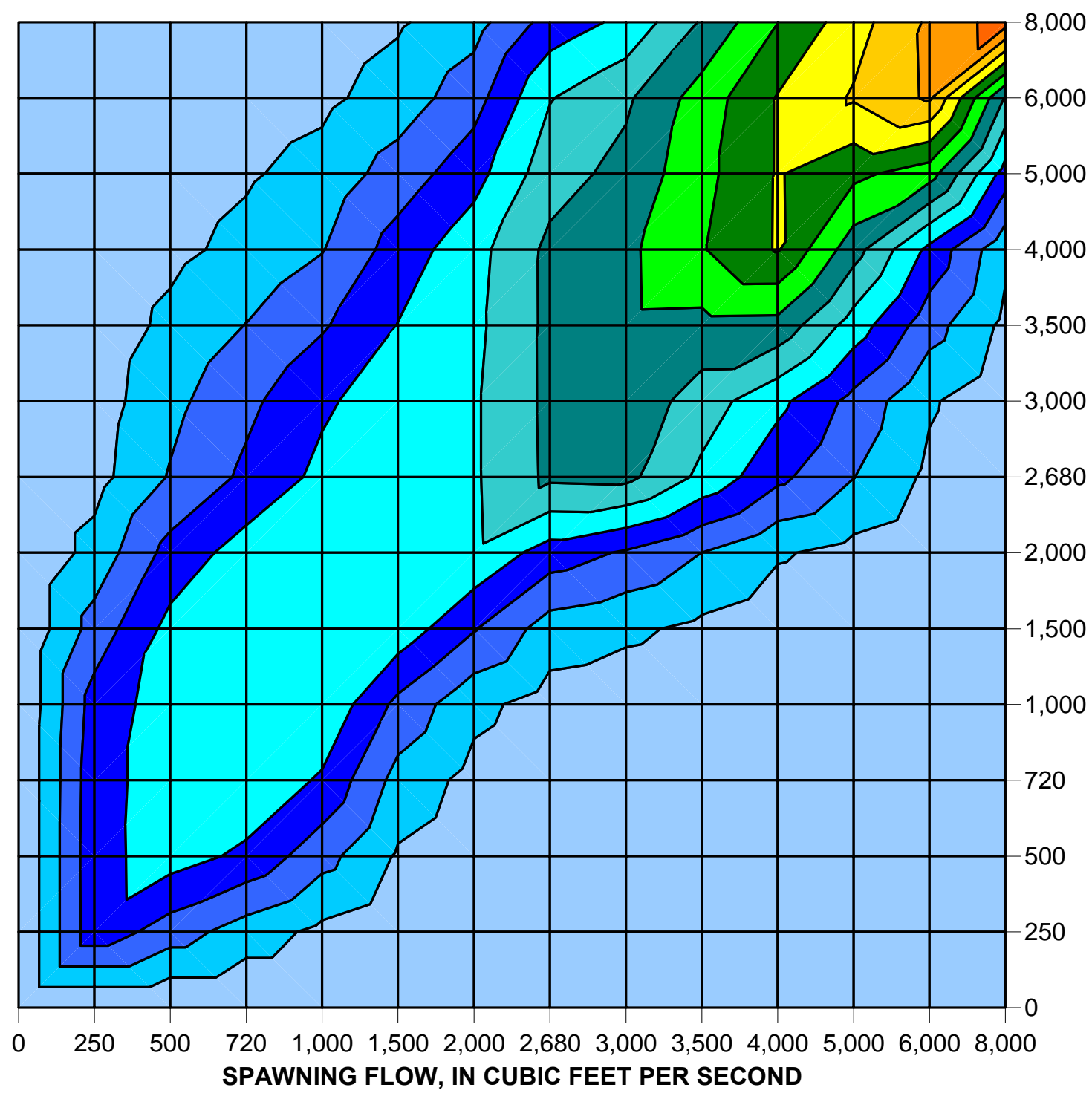

Persistent habitat,

in acres

ㅁ60-65

$\square 55-60$

ㅁ50-55

口45-50

$\square 40-45$

ㅁ35-40

口 30-35

$\square 25-30$

ㄴ20-25

- 15-20

ㅁ10-15

ㅁ 5-10

ㅁ $0-5$

Figure 2-47. Spawning-incubation response surface for bull trout (S. confluentus) in the Naches reach. 
Table 2-36. Spawning-incubation persistence table for bull trout (S. confluentus) in the Naches reach.

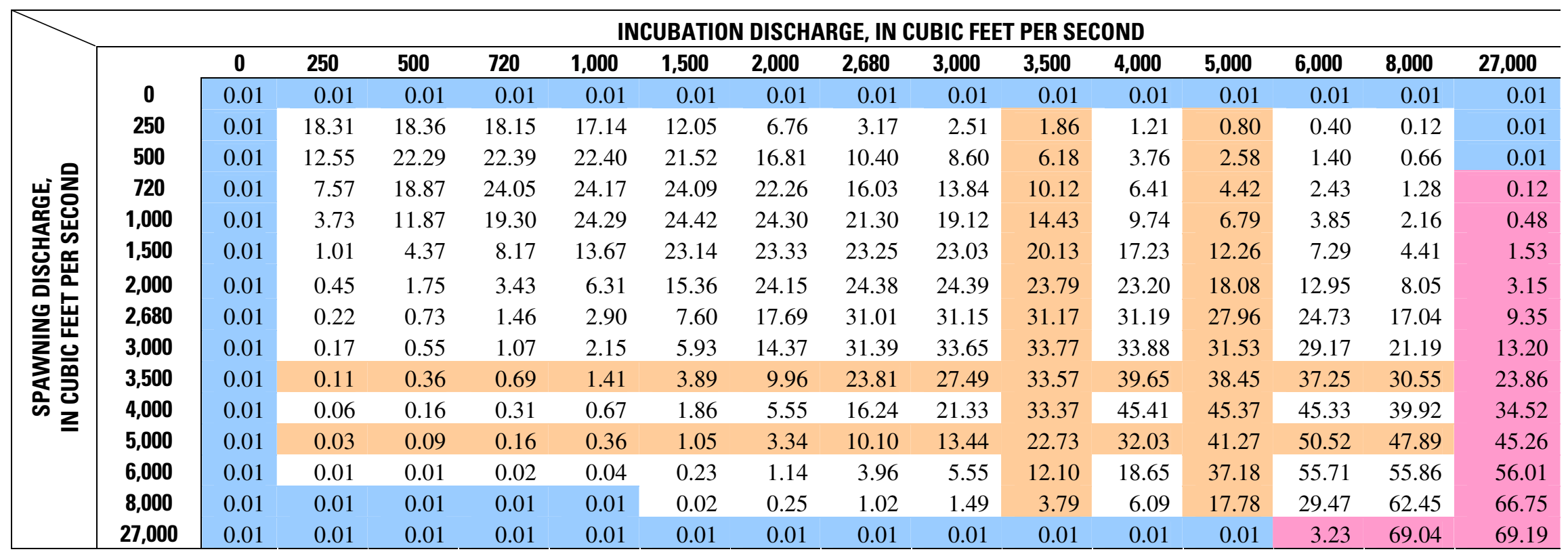




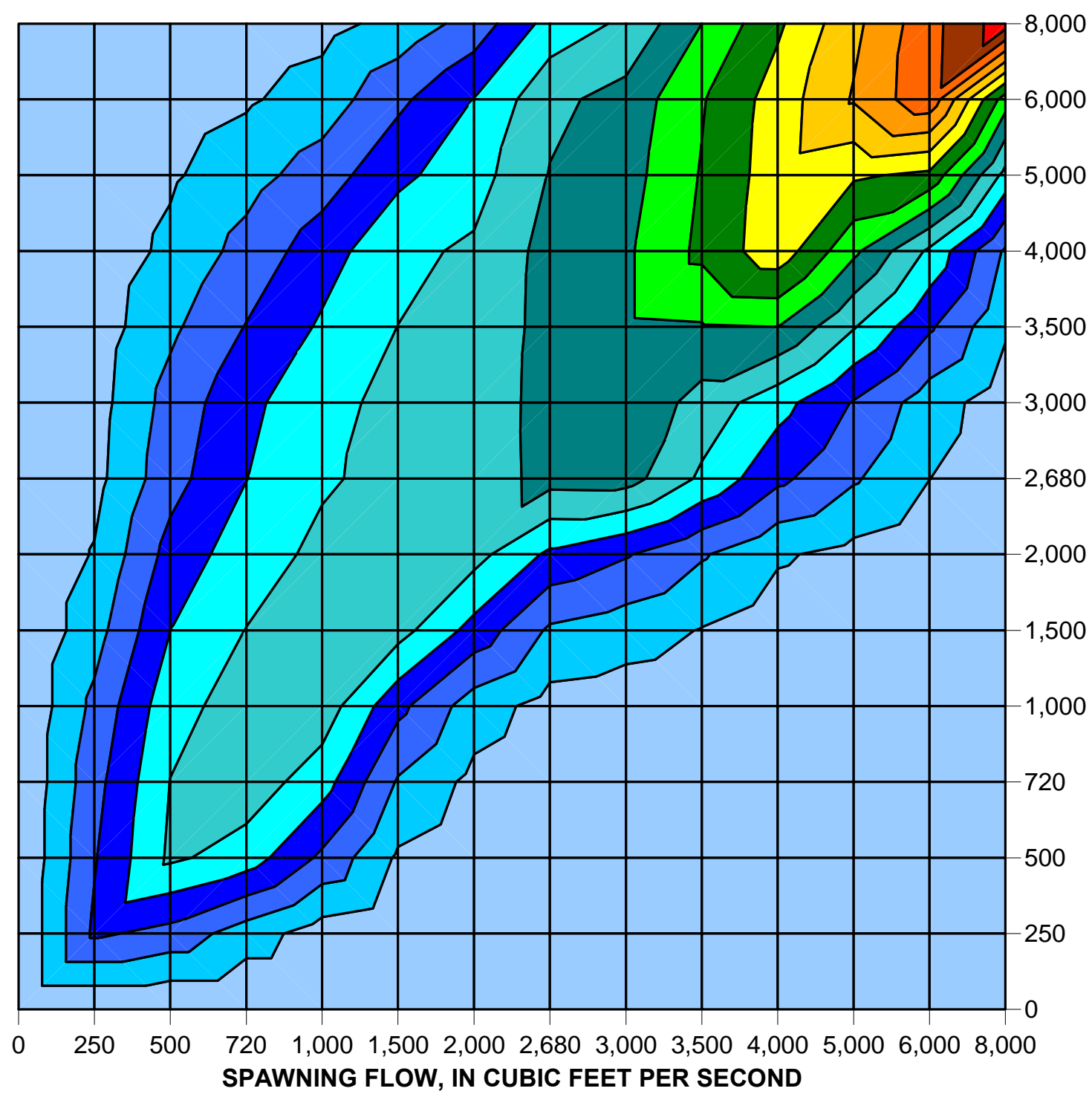

Persistent habitat, in acres

口70-75

$\square 65-70$

$\square 60-65$

$\square 55-60$

$\square$ 50-55

$\square 45-50$

$\square 40-45$

口35-40

$\square 30-35$

$\square 25-30$

$\square 20-25$

口15-20

$\square$ 10-15

口5-10

口0-5

Figure 2-48. Spawning-incubation response surface for coho (0. kisutch) in the Naches reach. 
Table 2-37. Spawning-incubation persistence table for coho ( 0 . kisutch) in the Naches reach.

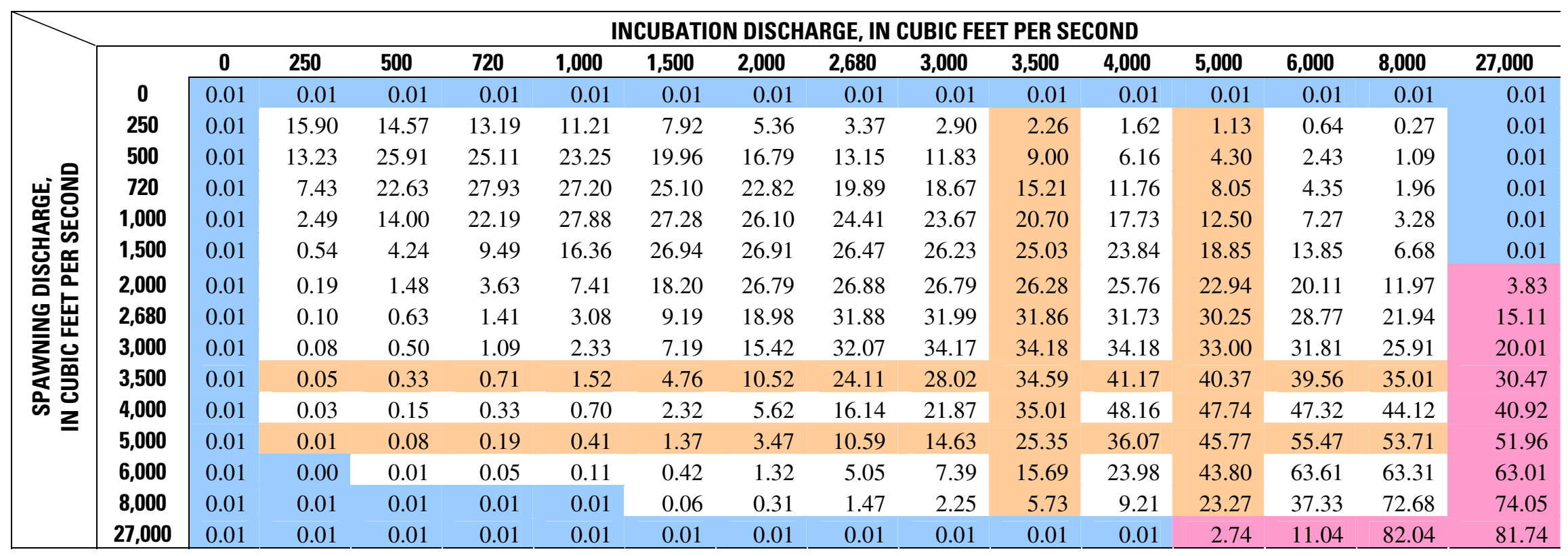




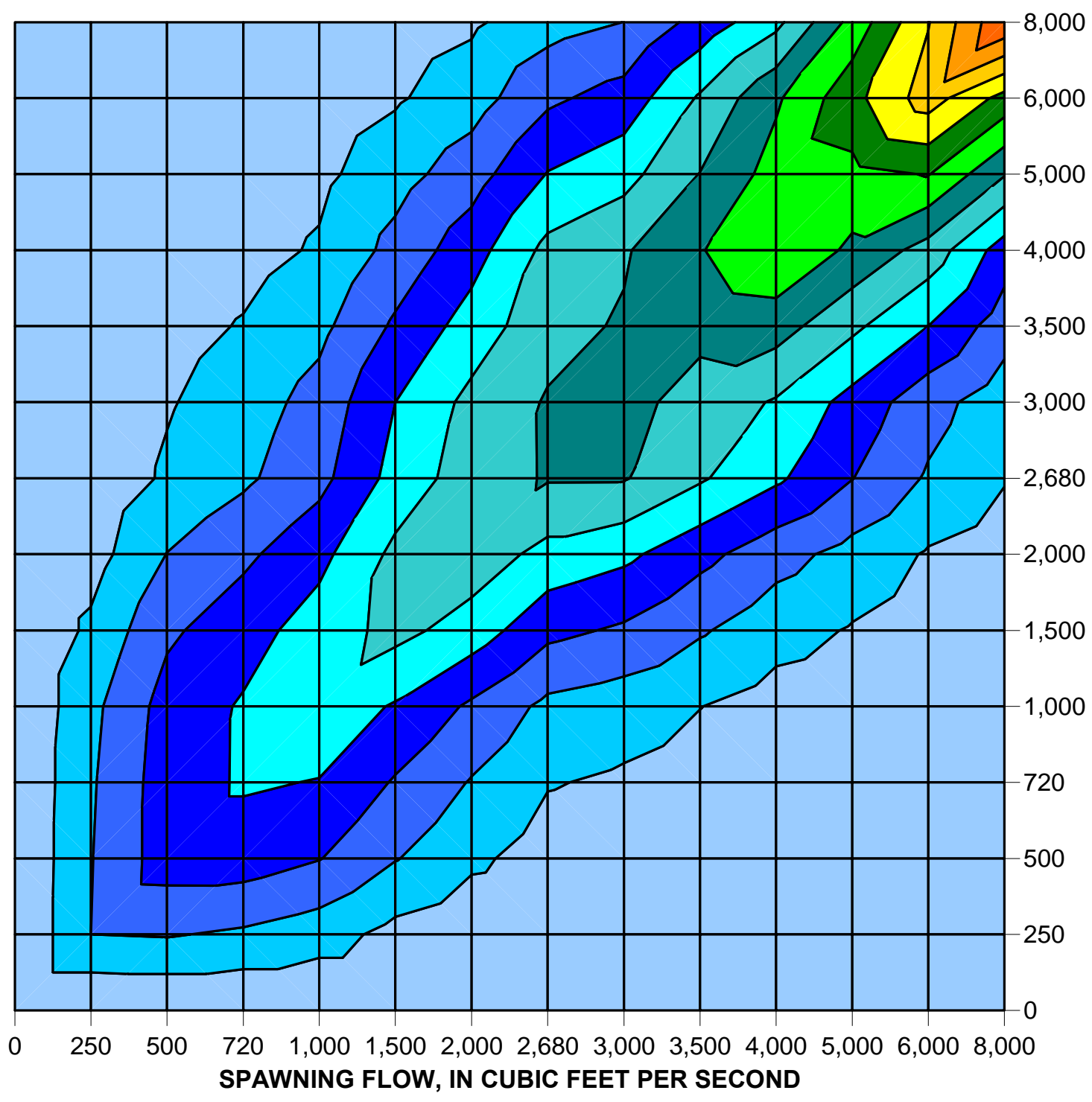

Persistent habitat,

in acres

120-130

110-120

100-110

$\square$ 90-100

80-90

$\square 70-80$

60-70

口50-60

$\square$ 40-50

๑30-40

$\square$ 20-30

$\square$ 10-20

$\square$ 0-10

Figure 2-49. Spawning-incubation response surface for spring chinook (0. tshawytscha) in the Naches reach. 
Table 2-38. Spawning-incubation persistence table for spring chinook (O. tshawytscha) in the Naches reach.

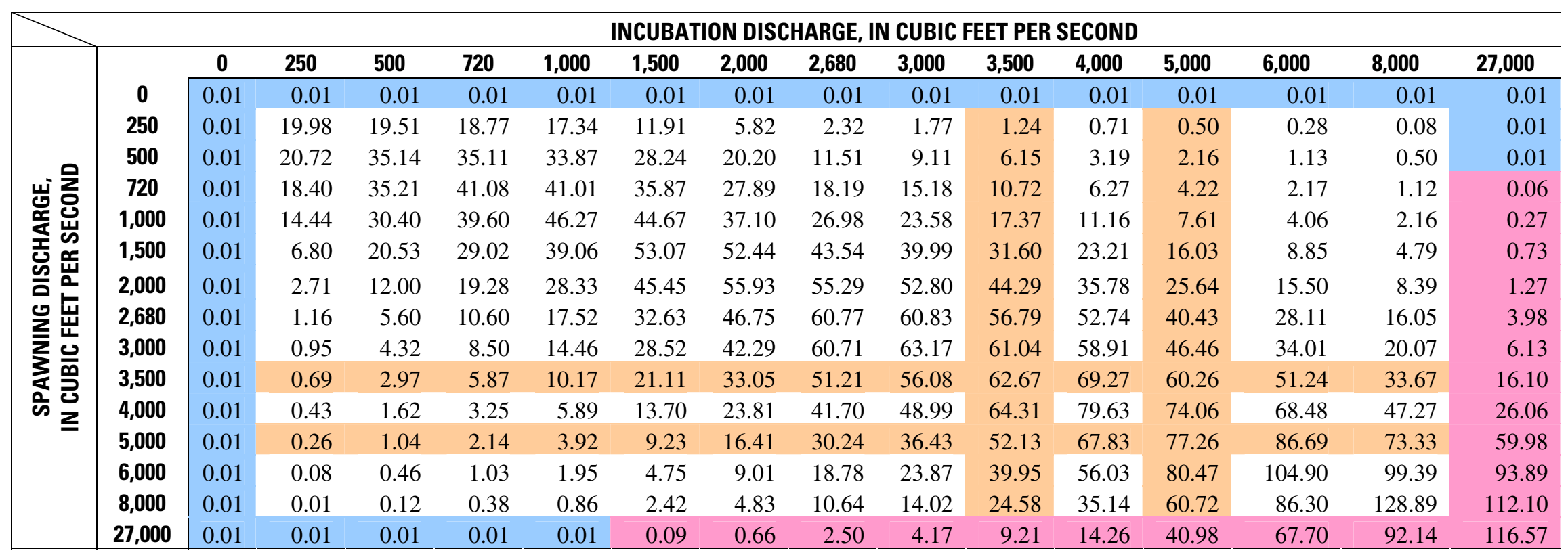




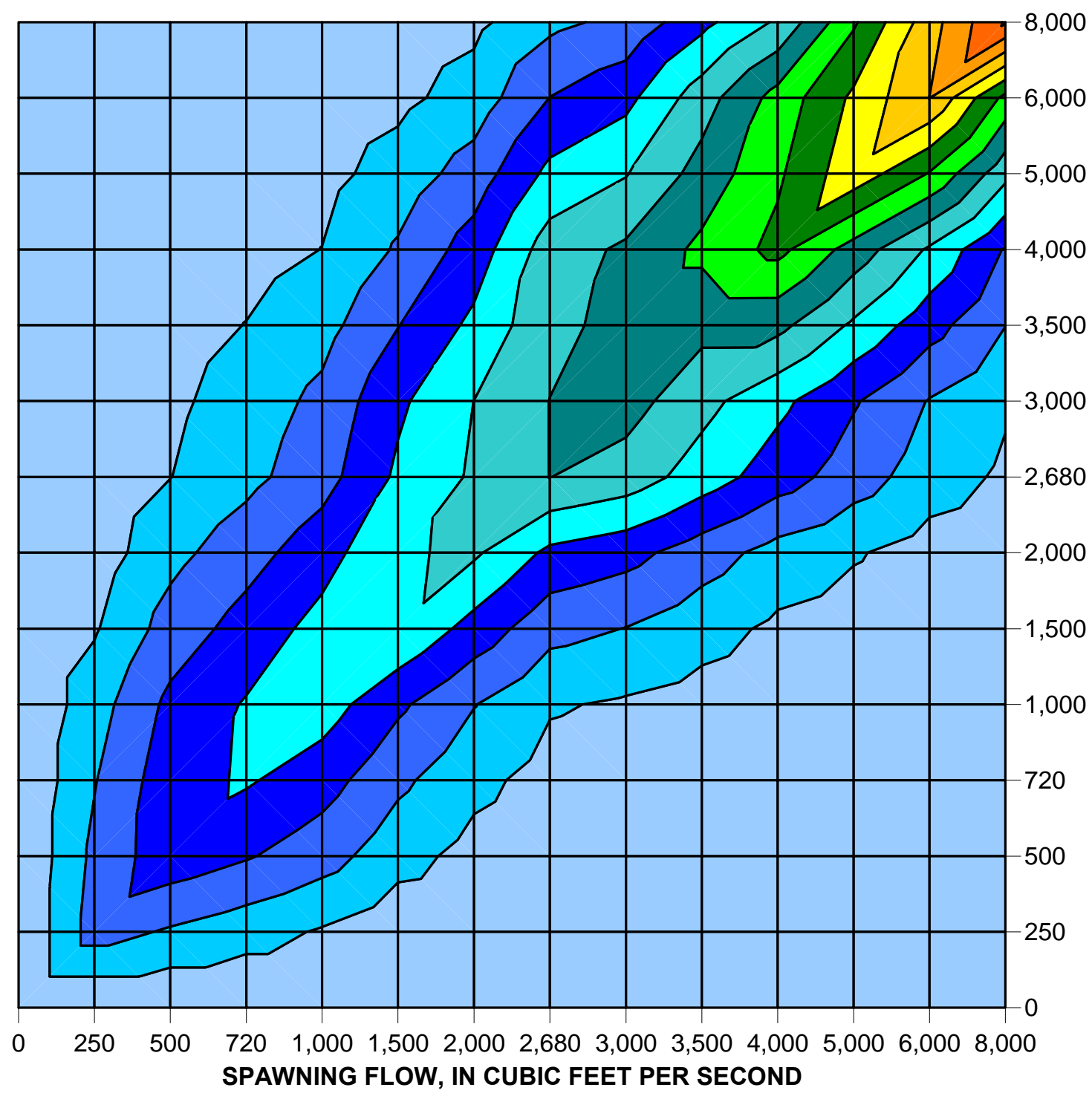

Persistent habitat,

in acres

$\square 130-140$

$\square$ 120-130

$\square 110-120$

$\square$ 100-110

口90-100

$\square 80-90$

$\square 70-80$

$\square 60-70$

$\square$ 50-60

$\square 40-50$

口30-40

$\square 20-30$

$\square 10-20$

$\square$ 0-10

Figure 2-50. Spawning-incubation response surface for resident rainbow trout (0. mykiss) in the Naches reach. 
Table 2-39. Spawning-incubation persistence table for resident rainbow trout (O. mykiss) in the Naches reach.

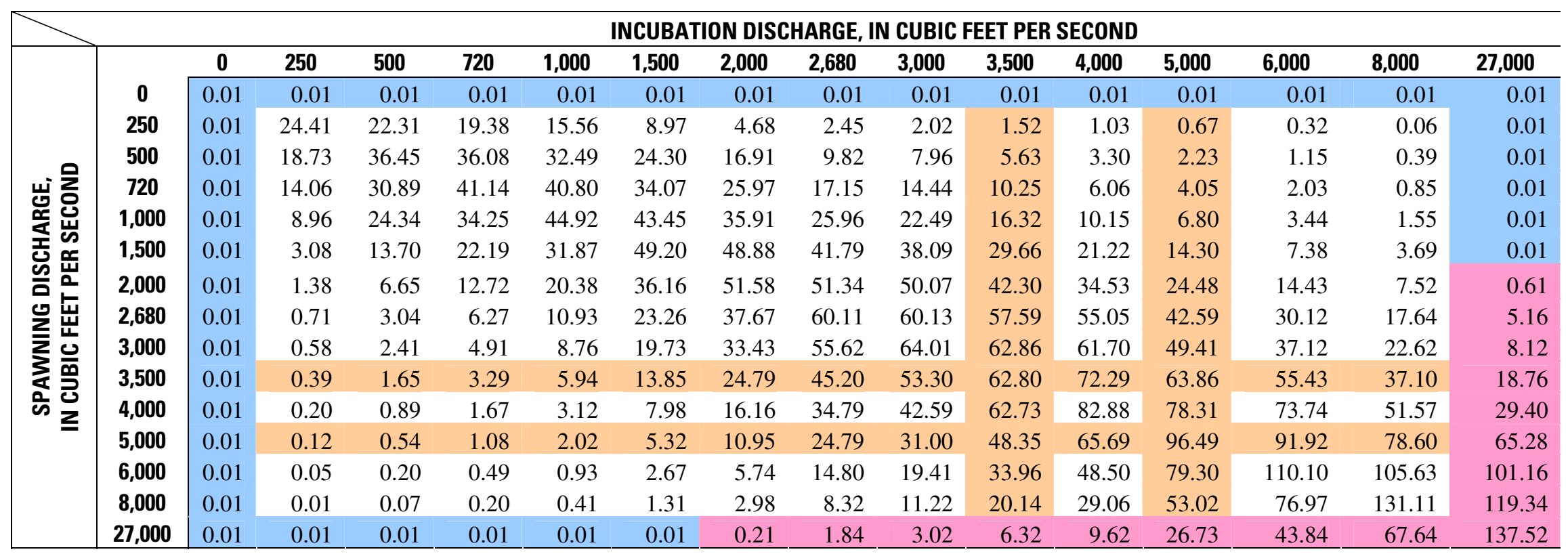




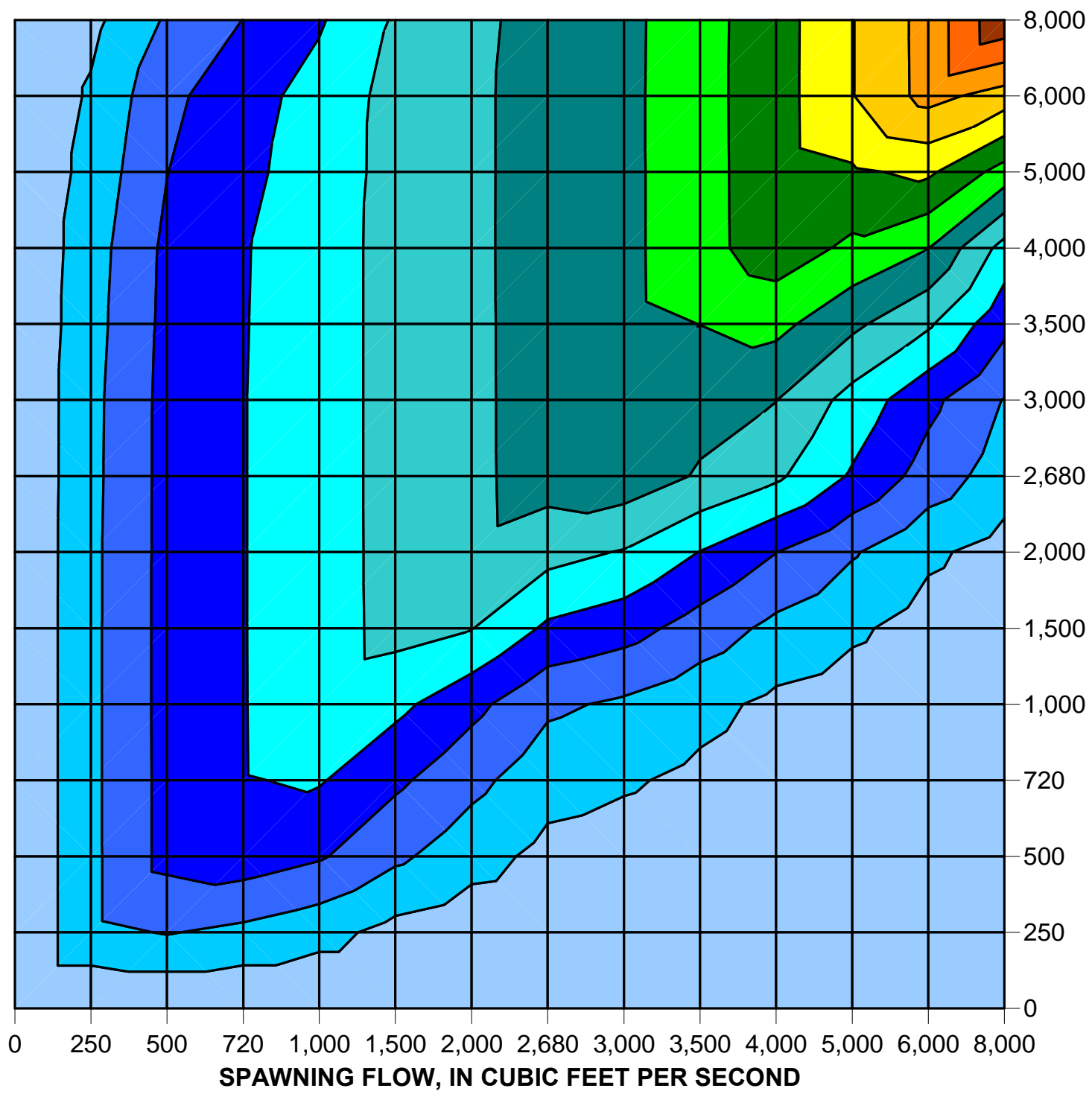

Persistent habitat,

in acres

$\square$ 130-140

$\square$ 120-130

$\square$ 110-120

$\square$ 100-110

$\square$ 90-100

$\square 80-90$

$\square 70-80$

$\square 60-70$

$\square$ 50-60

$\square$ 40-50

口 30-40

$\square$ 20-30

$\square 10-20$

$\square$ 0-10

Figure 2-51. Spawning-incubation response surface for steelhead (0. mykiss) in the Naches reach. 
Table 2-40. Spawning-incubation persistence table for steelhead (0. mykiss) in the Naches reach.

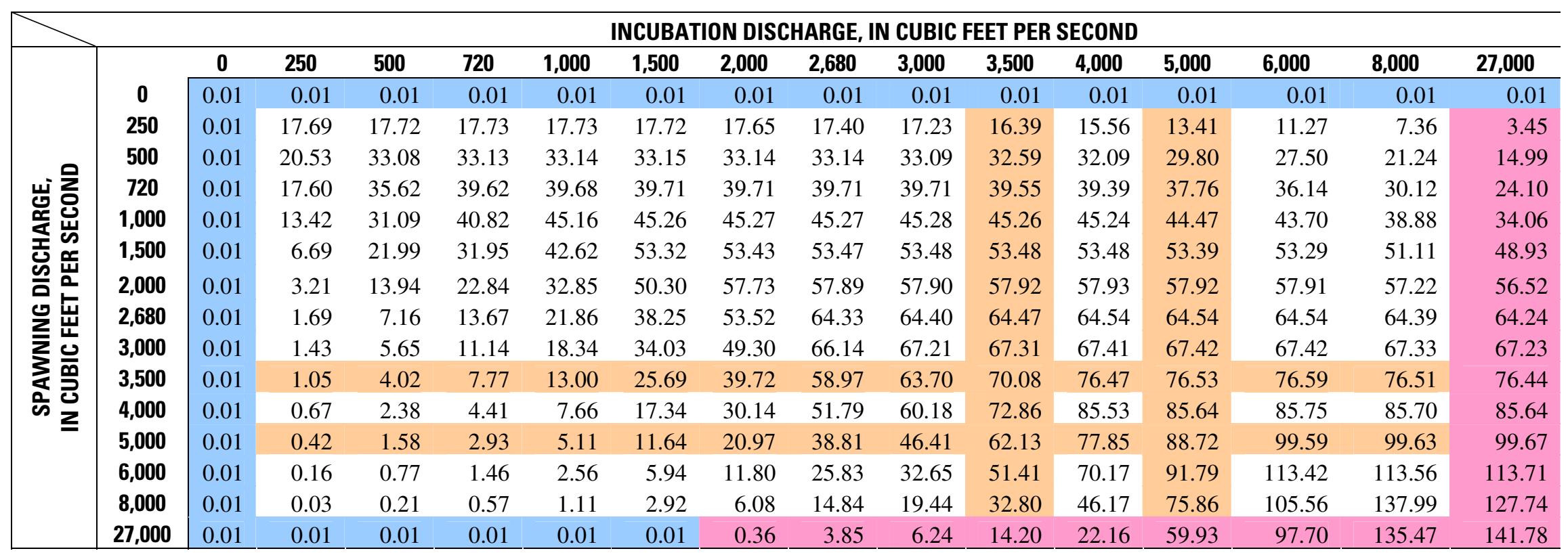




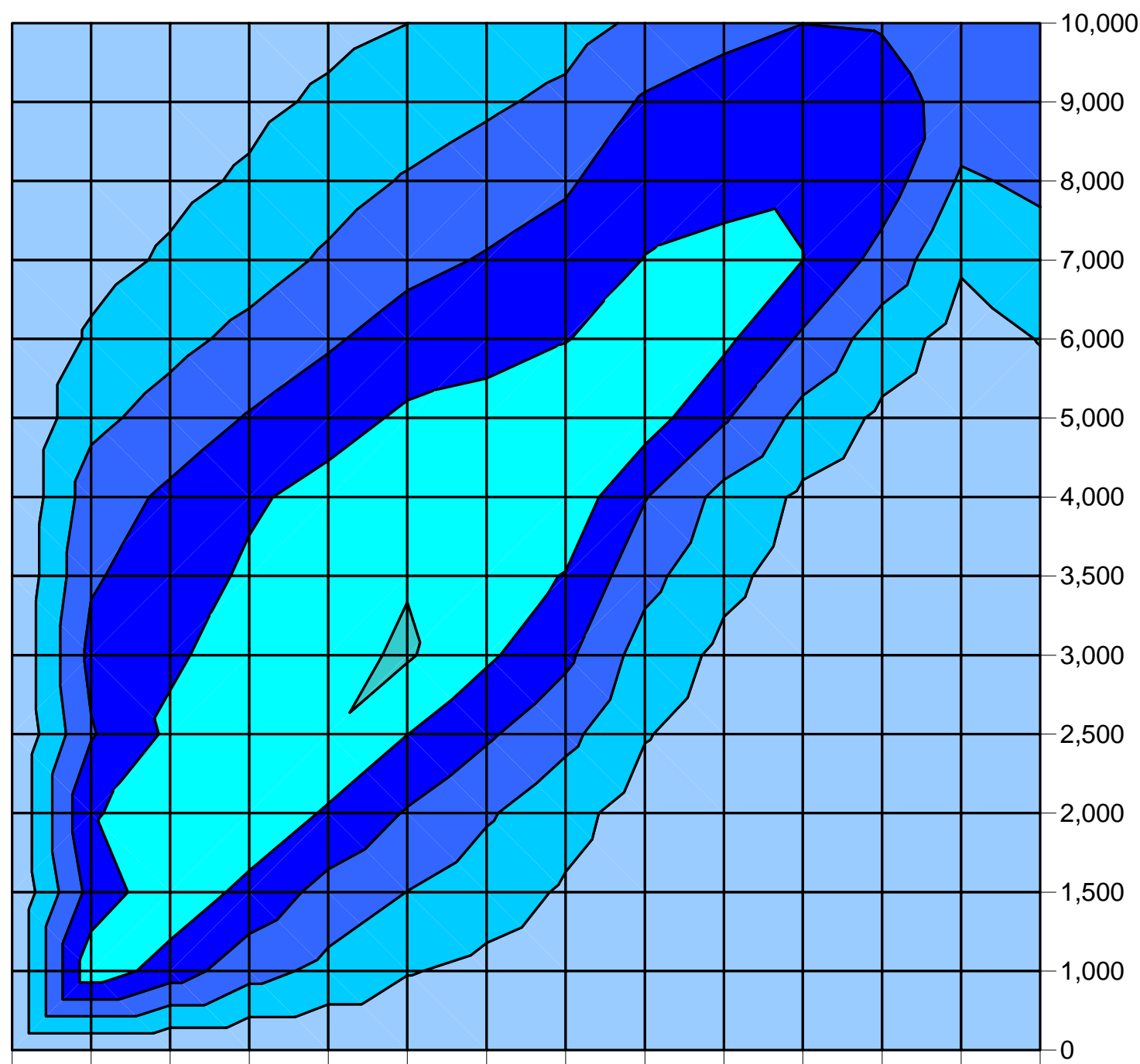

10,000

, 000

8,000

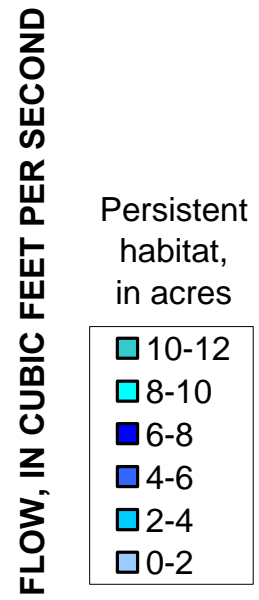

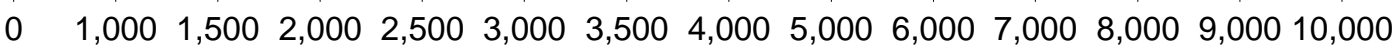
SPAWNING FLOW, IN CUBIC FEET PER SECOND

Figure 2-52. Spawning-incubation response surface for coho (0. kisutch) in the Union Gap reach. 
Table 2-41. Spawning-incubation persistence table for coho ( 0 . kisutch) in the Union Gap reach.

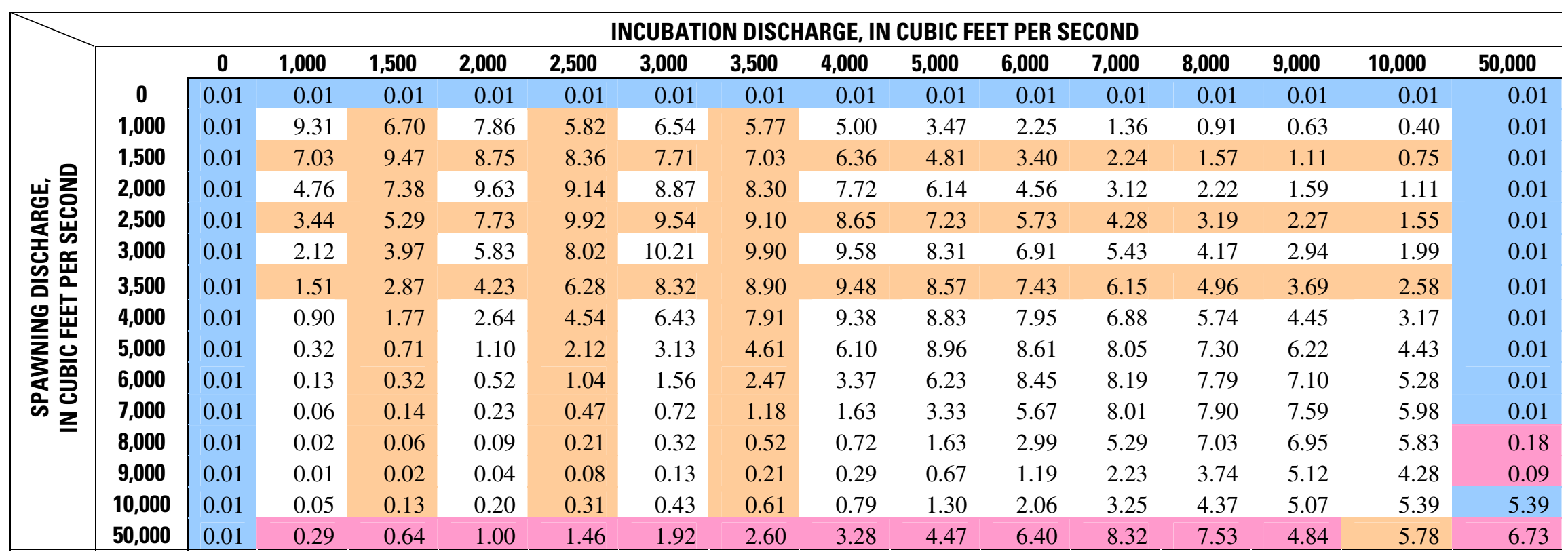




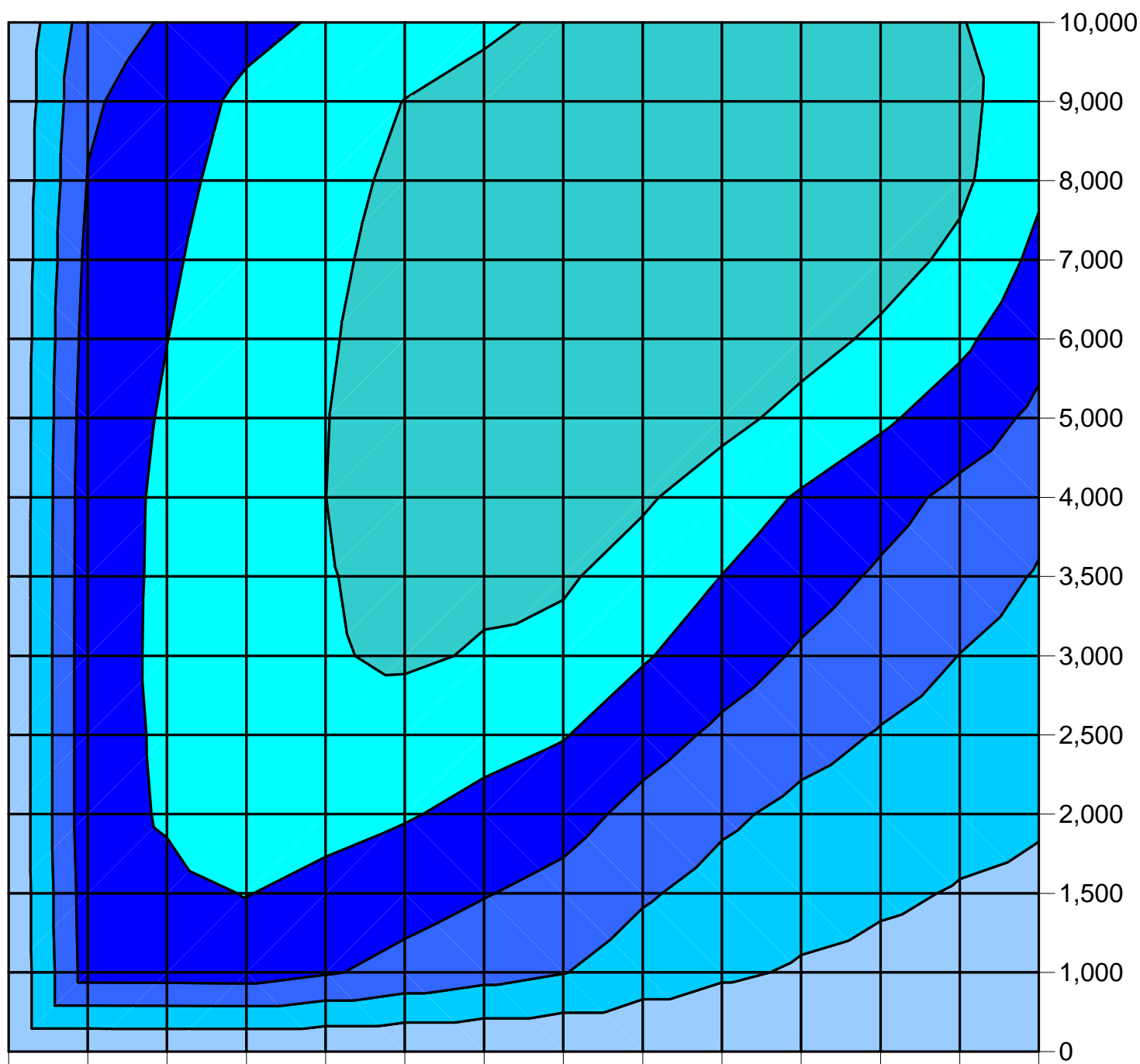

\section{0,000} 9,000 , 000 7,000

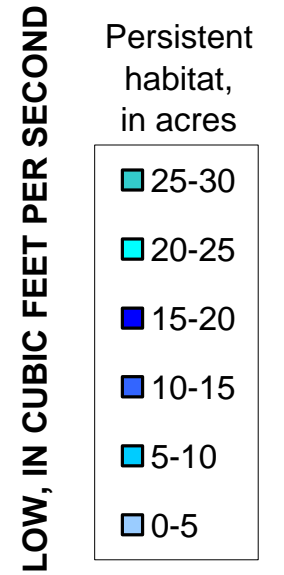

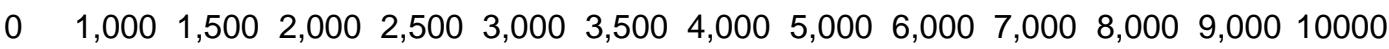
SPAWNING FLOW, IN CUBIC FEET PER SECOND

Figure 2-53. Spawning-incubation response surface for fall chinook (0. tshawytscha) in the Union Gap reach. 
Table 2-42. Spawning-incubation persistence table for fall chinook (O. tshawytscha) in the Union Gap reach.

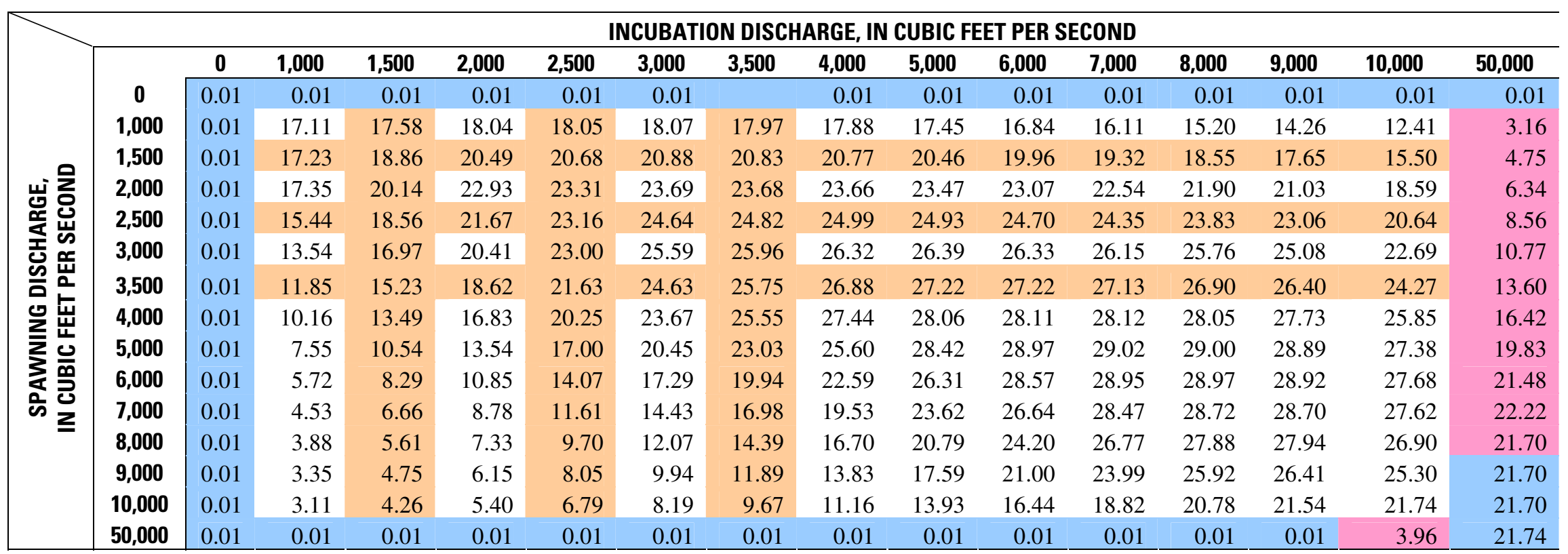




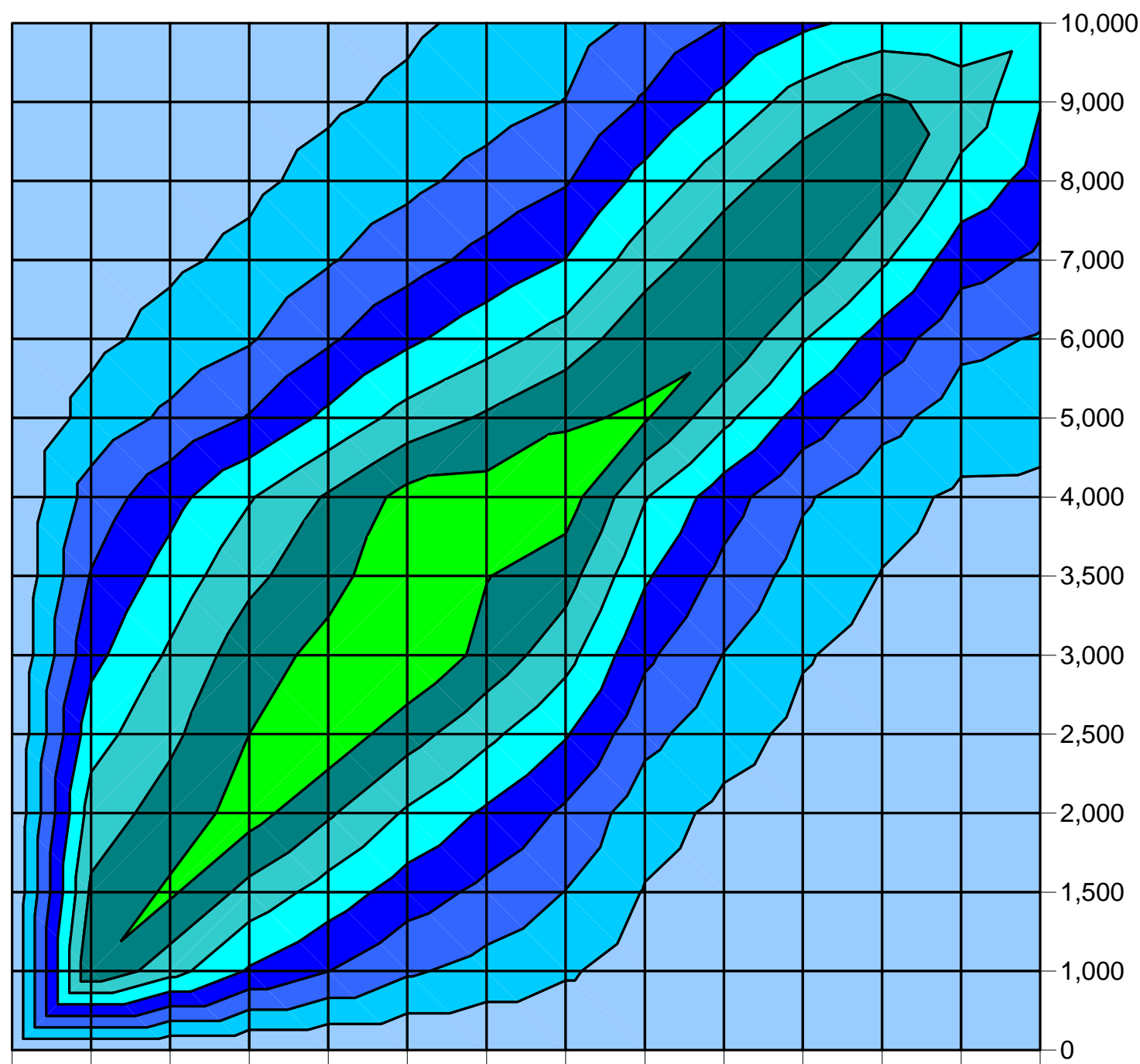

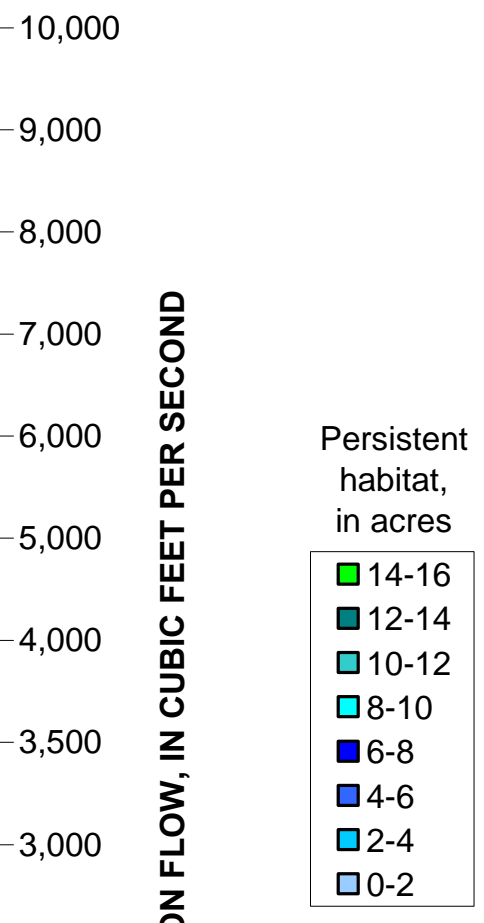

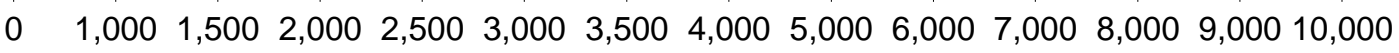
SPAWNING FLOW, IN CUBIC FEET PER SECOND

Figure 2-54. Spawning-incubation response surface for resident rainbow trout (0. mykiss) in the Union Gap reach. 
Table 2-43. Spawning-incubation persistence table for resident rainbow trout ( 0. mykiss) in the Union Gap reach.

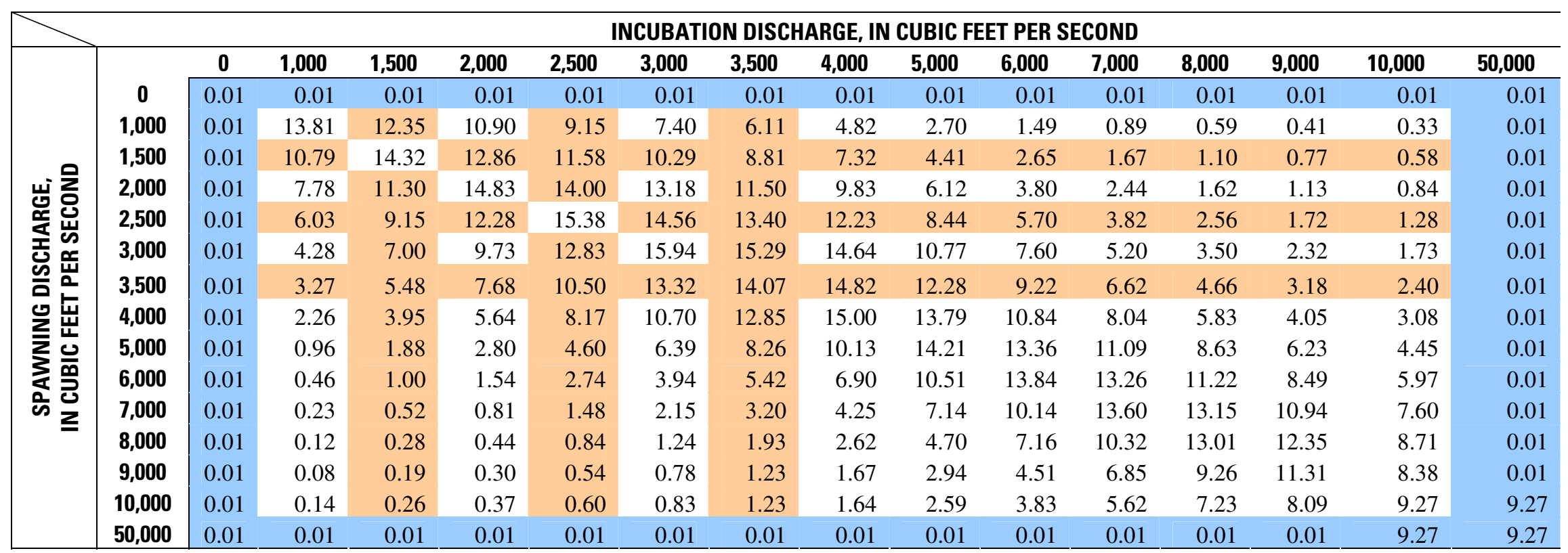



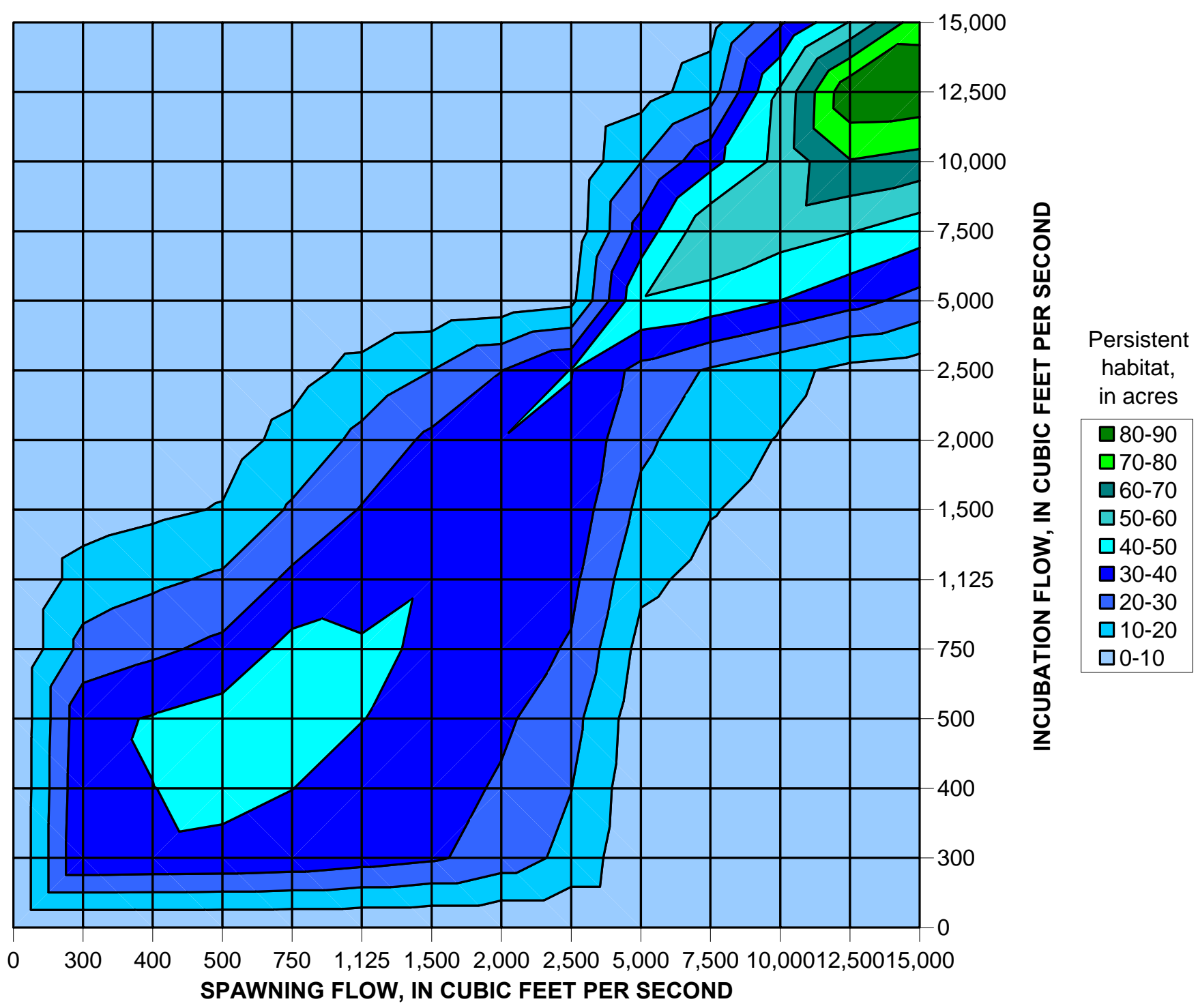

Figure 2-55. Spawning-incubation response surface for coho (0. kisutch) in the Wapato reach. 
Table 2-44. Spawning-incubation persistence table for coho (O. kisutch) in the Wapato reach.

\begin{tabular}{|c|c|c|c|c|c|c|c|c|c|c|c|c|c|c|c|c|}
\hline & & \multicolumn{15}{|c|}{ INCUBATION DISCHARGE, IN CUBIC FEET PER SECOND } \\
\hline \multirow{16}{*}{ 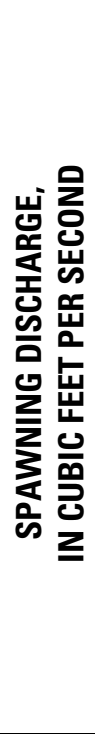 } & & $\mathbf{0}$ & 300 & 400 & 500 & 750 & 1,125 & 1,500 & 2,000 & 2,500 & 5,000 & 7,500 & 10,000 & 12,500 & 15,000 & 50,000 \\
\hline & $\mathbf{0}$ & 0.01 & 0.01 & 0.01 & 0.01 & 0.01 & 0.01 & 0.01 & 0.01 & 0.01 & 0.01 & 0.01 & 0.01 & 0.01 & 0.01 & 0.01 \\
\hline & 300 & 0.01 & 39.61 & 39.13 & 38.65 & 37.30 & 34.40 & 31.49 & 25.48 & 17.03 & 1.78 & 0.75 & 0.43 & 0.11 & 0.04 & 0.01 \\
\hline & 400 & 0.01 & 38.39 & 39.91 & 41.43 & 40.07 & 37.27 & 34.47 & 28.71 & 20.18 & 2.75 & 1.28 & 0.77 & 0.26 & 0.11 & 0.01 \\
\hline & 500 & 0.01 & 37.18 & 40.69 & 44.21 & 42.83 & 40.14 & 37.44 & 31.94 & 23.33 & 3.72 & 1.82 & 1.11 & 0.41 & 0.19 & 0.01 \\
\hline & 750 & 0.01 & 23.22 & 27.93 & 32.64 & 43.19 & 41.16 & 39.13 & 35.05 & 28.96 & 6.84 & 3.58 & 2.24 & 0.90 & 0.53 & 0.01 \\
\hline & 1,125 & 0.01 & 14.27 & 17.95 & 21.63 & 32.23 & 35.89 & 39.56 & 36.70 & 32.50 & 12.15 & 7.04 & 4.62 & 2.20 & 1.52 & 0.18 \\
\hline & 1,500 & 0.01 & 5.32 & 7.97 & 10.62 & 21.27 & 30.63 & 39.98 & 38.35 & 36.04 & 17.47 & 10.50 & 7.00 & 3.49 & 2.52 & 0.57 \\
\hline & 2,000 & 0.01 & 2.61 & 4.12 & 5.63 & 13.05 & 22.63 & 32.21 & 39.96 & 38.29 & 22.05 & 13.96 & 9.45 & 4.93 & 3.42 & 0.40 \\
\hline & 2,500 & 0.01 & 1.16 & 1.92 & 2.69 & 6.16 & 13.05 & 19.94 & 29.80 & 40.31 & 26.86 & 18.78 & 12.92 & 7.07 & 4.69 & 4.69 \\
\hline & 5,000 & 0.01 & 0.14 & 0.21 & 0.27 & 0.48 & 1.36 & 2.24 & 3.88 & 7.20 & 49.35 & 46.29 & 39.87 & 33.45 & 26.50 & 12.62 \\
\hline & 7,500 & 0.01 & 0.08 & 0.12 & 0.16 & 0.26 & 0.57 & 0.88 & 1.57 & 2.82 & 33.93 & 58.46 & 54.44 & 50.41 & 44.17 & 31.67 \\
\hline & 10,000 & 0.01 & 0.04 & 0.06 & 0.08 & 0.14 & 0.31 & 0.47 & 0.85 & 1.57 & 19.81 & 36.87 & 53.14 & 69.41 & 66.00 & 59.20 \\
\hline & 12,500 & 0.01 & 0.01 & 0.01 & 0.01 & 0.02 & 0.04 & 0.07 & 0.13 & 0.31 & 5.69 & 15.28 & 51.84 & 88.40 & 87.84 & 86.73 \\
\hline & 15,000 & 0.01 & 0.01 & 0.01 & 0.01 & 0.01 & 0.01 & 0.02 & 0.04 & 0.14 & 2.44 & 6.22 & 28.48 & 50.75 & 76.18 & 76.18 \\
\hline & 50,000 & 1.01 & 0.01 & 0.01 & 0.01 & 0.01 & 0.01 & 0.01 & 0.01 & 0.01 & 0.01 & 0.01 & 0.01 & 0.01 & 52.85 & 51.74 \\
\hline
\end{tabular}



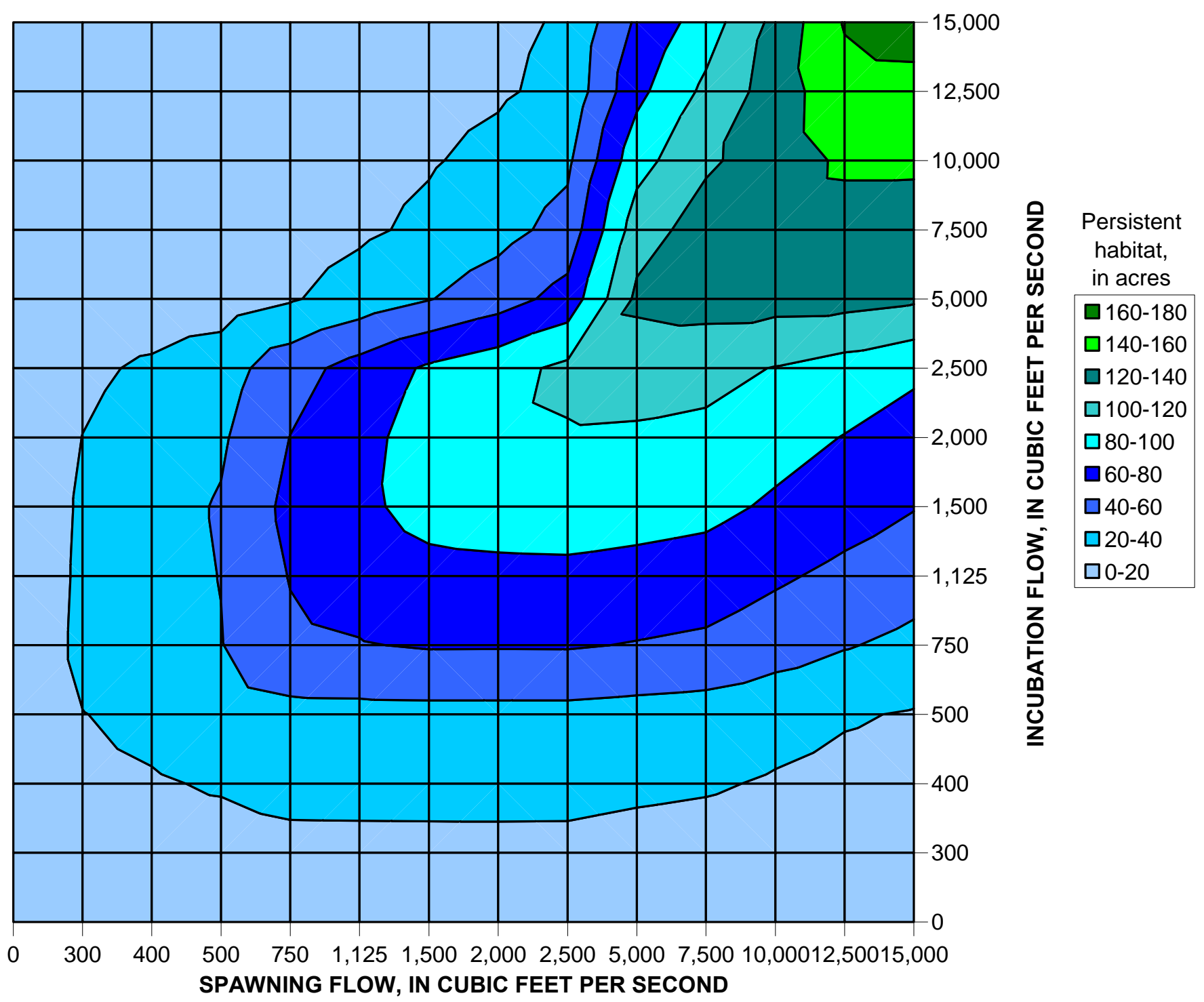

Figure 2-56. Spawning-incubation response surface for fall chinook (0. tshawytscha) in the Wapato reach. 
Table 2-45. Spawning-incubation persistence table for fall chinook (0. tshawytscha) in the Wapato reach.

\begin{tabular}{|c|c|c|c|c|c|c|c|c|c|c|c|c|c|c|c|c|}
\hline & & \multicolumn{15}{|c|}{ INCUBATION DISCHARGE, IN CUBIC FEET PER SECOND } \\
\hline \multirow{16}{*}{ 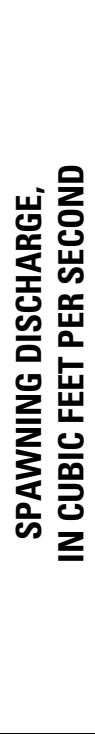 } & & $\mathbf{0}$ & 300 & 400 & 500 & 750 & 1,125 & 1,500 & 2,000 & 2,500 & 5,000 & 7,500 & 10,000 & 12,500 & 15,000 & 50,000 \\
\hline & $\mathbf{0}$ & 0.01 & 0.01 & 0.01 & 0.01 & 0.01 & 0.01 & 0.01 & 0.01 & 0.01 & 0.01 & 0.01 & 0.01 & 0.01 & 0.01 & 0.01 \\
\hline & 300 & 0.01 & 11.44 & 12.55 & 13.67 & 15.60 & 15.66 & 15.71 & 15.72 & 15.67 & 13.85 & 12.46 & 10.12 & 7.79 & 7.00 & 5.42 \\
\hline & 400 & 0.01 & 15.51 & 18.50 & 21.50 & 24.86 & 25.00 & 25.13 & 25.16 & 25.10 & 23.27 & 21.80 & 18.28 & 14.76 & 12.79 & 8.84 \\
\hline & 500 & 0.01 & 19.58 & 24.45 & 29.32 & 34.12 & 34.34 & 34.55 & 34.59 & 34.53 & 32.69 & 31.14 & 26.44 & 21.73 & 18.58 & 12.26 \\
\hline & 750 & 0.01 & 25.26 & 32.27 & 39.29 & 56.62 & 59.09 & 61.55 & 61.54 & 61.56 & 59.03 & 56.27 & 48.80 & 41.33 & 35.22 & 22.99 \\
\hline & 1,125 & 0.01 & 24.15 & 32.30 & 40.44 & 60.89 & 67.52 & 74.15 & 75.31 & 75.68 & 73.54 & 70.82 & 62.94 & 55.07 & 48.02 & 33.94 \\
\hline & 1,500 & 0.01 & 23.05 & 32.32 & 41.59 & 65.16 & 75.96 & 86.75 & 89.08 & 89.81 & 88.04 & 85.36 & 77.09 & 68.81 & 60.83 & 44.88 \\
\hline & 2,000 & 0.01 & 20.24 & 28.78 & 37.32 & 60.34 & 74.37 & 88.39 & 95.50 & 98.27 & 97.51 & 95.23 & 87.26 & 79.29 & 71.12 & 54.79 \\
\hline & 2,500 & 0.01 & 15.77 & 23.41 & 31.04 & 52.09 & 67.49 & 82.90 & 92.71 & 104.48 & 107.81 & 106.31 & 99.15 & 92.00 & 83.80 & 67.41 \\
\hline & 5,000 & 0.01 & 3.96 & 6.96 & 9.96 & 18.20 & 28.66 & 39.12 & 51.01 & 67.46 & 124.35 & 127.61 & 127.20 & 126.78 & 122.98 & 115.37 \\
\hline & 7,500 & 0.01 & 2.26 & 3.70 & 5.15 & 9.46 & 16.73 & 24.00 & 33.13 & 47.07 & 110.58 & 129.14 & 130.58 & 132.03 & 131.45 & 130.28 \\
\hline & 10,000 & 0.01 & 1.76 & 2.92 & 4.07 & 7.42 & 12.93 & 18.43 & 25.39 & 36.09 & 92.61 & 116.79 & 129.99 & 143.19 & 143.19 & 143.19 \\
\hline & 12,500 & 0.01 & 1.26 & 2.13 & 3.00 & 5.38 & 9.12 & 12.87 & 17.66 & 25.11 & 74.64 & 104.44 & 129.39 & 154.35 & 154.93 & 156.09 \\
\hline & 15,000 & 0.01 & 1.34 & 2.26 & 3.17 & 5.24 & 8.52 & 11.80 & 15.83 & 22.10 & 62.99 & 89.93 & 125.58 & 161.24 & 166.84 & 169.00 \\
\hline & 50,000 & 0.01 & 1.51 & 2.50976 & 3.51 & 4.97 & 7.32 & 9.67 & 12.18 & 16.08 & 39.70 & 60.92 & 117.96 & 161.24 & 166.84 & 169.00 \\
\hline
\end{tabular}




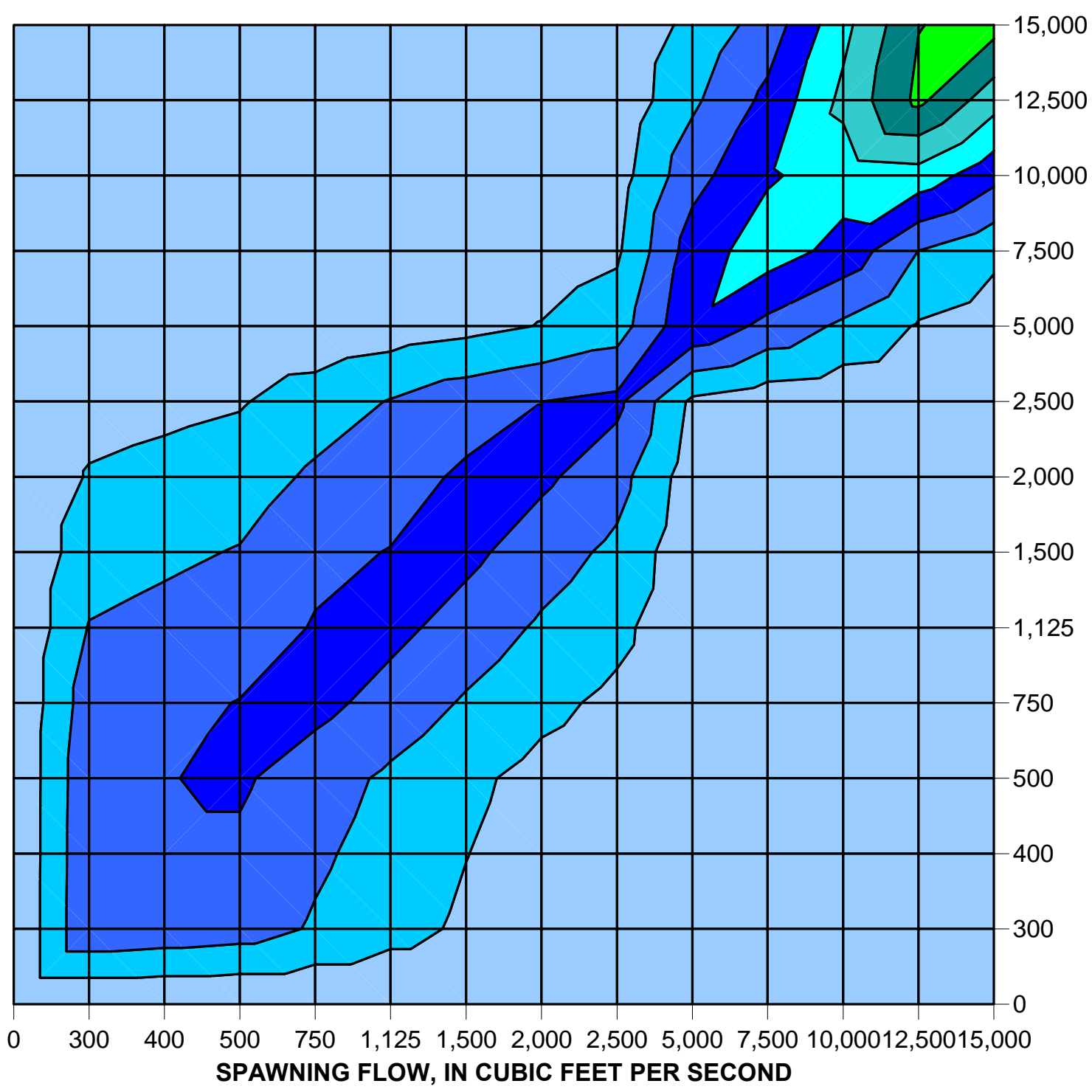

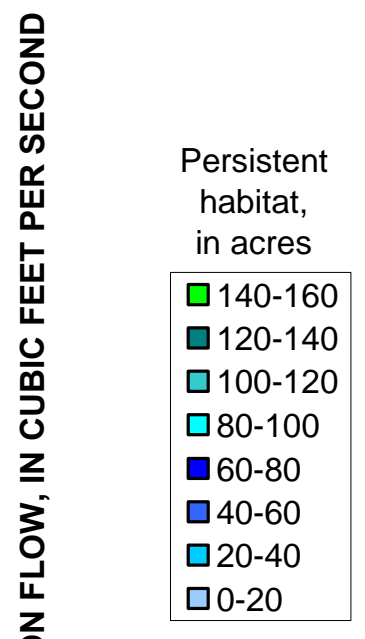

Figure 2-57. Spawning-incubation response surface for resident rainbow trout (0. mykiss) in the Wapato reach. 
Table 2-46. Spawning-incubation persistence table for resident rainbow trout (O. mykiss) in the Wapato reach.

\begin{tabular}{|c|c|c|c|c|c|c|c|c|c|c|c|c|c|c|c|c|}
\hline & & \multicolumn{15}{|c|}{ INCUBATION DISCHARGE, IN CUBIC FEET PER SECOND } \\
\hline \multirow{16}{*}{ 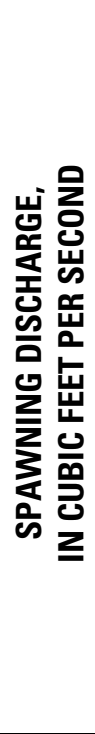 } & & $\mathbf{0}$ & 300 & 400 & 500 & 750 & 1,125 & 1,500 & 2,000 & 2,500 & 5,000 & 7,500 & 10,000 & 12,500 & 15,000 & 50,000 \\
\hline & $\mathbf{0}$ & 0.01 & 0.01 & 0.01 & 0.01 & 0.01 & 0.01 & 0.01 & 0.01 & 0.01 & 0.01 & 0.01 & 0.01 & 0.01 & 0.01 & 0.01 \\
\hline & 300 & 0.01 & 57.00 & 56.28 & 55.55 & 50.43 & 40.93 & 31.43 & 21.74 & 11.82 & 0.99 & 0.44 & 0.26 & 0.08 & 0.03 & 0.01 \\
\hline & 400 & 0.01 & 53.42 & 56.33 & 59.24 & 55.50 & 45.89 & 36.29 & 25.84 & 15.11 & 1.63 & 0.74 & 0.44 & 0.14 & 0.06 & 0.01 \\
\hline & 500 & 0.01 & 49.84 & 56.39 & 62.94 & 60.57 & 50.86 & 41.15 & 29.94 & 18.41 & 2.28 & 1.05 & 0.63 & 0.21 & 0.09 & 0.01 \\
\hline & 750 & 0.01 & 37.80 & 43.35 & 48.89 & 66.35 & 61.18 & 56.01 & 43.47 & 29.72 & 4.69 & 2.12 & 1.31 & 0.51 & 0.30 & 0.01 \\
\hline & 1,125 & 0.01 & 27.24 & 31.88 & 36.52 & 52.07 & 65.75 & 60.58 & 53.10 & 41.03 & 9.34 & 4.39 & 2.85 & 1.30 & 0.84 & 0.01 \\
\hline & 1,500 & 0.01 & 16.68 & 20.42 & 24.15 & 37.80 & 51.47 & 65.14 & 62.74 & 52.34 & 13.99 & 6.67 & 4.38 & 2.09 & 1.37 & 0.01 \\
\hline & 2,000 & 0.01 & 8.29 & 11.12 & 13.95 & 25.15 & 37.21 & 49.26 & 63.86 & 59.86 & 20.78 & 10.33 & 6.81 & 3.30 & 2.05 & 0.01 \\
\hline & 2,500 & 0.01 & 3.91 & 5.91 & 7.90 & 15.44 & 25.45 & 35.45 & 47.48 & 64.66 & 30.52 & 16.87 & 11.01 & 5.15 & 3.25 & 0.01 \\
\hline & 5,000 & 0.01 & 0.27 & 0.46 & 0.64 & 1.36 & 3.33 & 5.30 & 9.21 & 15.79 & 76.37 & 69.77 & 53.01 & 36.25 & 25.39 & 3.66 \\
\hline & 7,500 & 0.01 & 0.11 & 0.19 & 0.26 & 0.58 & 1.55 & 2.53 & 4.27 & 7.55 & 54.18 & 90.27 & 77.65 & 65.03 & 48.73 & 16.14 \\
\hline & 10,000 & 0.01 & 0.06 & 0.10 & 0.14 & 0.33 & 0.92 & 1.51 & 2.55 & 4.55 & 36.18 & 73.19 & 89.01 & 104.83 & 94.04 & 72.46 \\
\hline & 12,500 & 0.01 & 0.01 & 0.02 & 0.02 & 0.08 & 0.29 & 0.49 & 0.82 & 1.54 & 18.18 & 39.77 & 92.20 & 144.63 & 139.34 & 128.77 \\
\hline & 15,000 & 0.01 & 0.00 & 0.01 & 0.01 & 0.04 & 0.19 & 0.34 & 0.52 & 0.90 & 10.72 & 24.14 & 66.18 & 108.21 & 147.22 & 147.22 \\
\hline & 50,000 & 0.01 & 0.01 & 0.01 & 0.01 & 0.01 & 0.01 & 0.01 & 0.01 & 0.01 & 0.01 & 0.01 & 14.14 & 35.38 & 147.22 & 152.42 \\
\hline
\end{tabular}


Appendix 3. Sediment Transport Lookup Tables from the SIAM Model 
Table 3-1. Potential fine-sediment transport rates, in megatons per day, as functions of discharge and simulated alternative from the SIAM model, for the Easton and Kittitas reaches. [ft3/s, cubic feet per second].

\begin{tabular}{|c|c|c|c|c|c|c|c|c|c|}
\hline \multicolumn{5}{|c|}{ Easton } & \multicolumn{5}{|c|}{ Kittitas } \\
\hline Discharge $\left(\mathrm{ft}^{3} / \mathrm{s}\right)$ & No Action & Blackrock_2 & Wymer1 & WymerPlus & Discharge $\left(\mathrm{ft}^{3} / \mathbf{s}\right)$ & No Action & Blackrock_2 & Wymer1 & WymerPlus \\
\hline 0 & 0.000 & 0.000 & 0.000 & 0.000 & 0 & 0.000 & 0.000 & 0.000 & 0.000 \\
\hline 69 & 0.001 & 0.001 & 0.001 & 0.002 & 97 & 0.002 & 0.002 & 0.003 & 0.002 \\
\hline 164 & 0.005 & 0.005 & 0.005 & 0.005 & 893 & 0.053 & 0.048 & 0.053 & 0.053 \\
\hline 304 & 0.013 & 0.012 & 0.012 & 0.013 & 1,542 & 0.120 & 0.106 & 0.121 & 0.121 \\
\hline 432 & 0.024 & 0.022 & 0.021 & 0.022 & 1,939 & 0.173 & 0.156 & 0.173 & 0.173 \\
\hline 565 & 0.034 & 0.033 & 0.032 & 0.034 & 2,216 & 0.214 & 0.195 & 0.214 & 0.214 \\
\hline 720 & 0.046 & 0.048 & 0.048 & 0.050 & 2,469 & 0.237 & 0.226 & 0.240 & 0.235 \\
\hline 870 & 0.059 & 0.065 & 0.065 & 0.067 & 2,701 & 0.281 & 0.234 & 0.281 & 0.273 \\
\hline 1,018 & 0.072 & 0.082 & 0.083 & 0.086 & 2,905 & 0.317 & 0.251 & 0.317 & 0.318 \\
\hline 1,177 & 0.088 & 0.103 & 0.104 & 0.108 & 3,084 & 0.351 & 0.285 & 0.371 & 0.378 \\
\hline 1,330 & 0.107 & 0.123 & 0.127 & 0.130 & 3,252 & 0.403 & 0.308 & 0.405 & 0.419 \\
\hline 1,489 & 0.125 & 0.145 & 0.152 & 0.154 & 3,417 & 0.454 & 0.337 & 0.431 & 0.454 \\
\hline 1,643 & 0.145 & 0.169 & 0.177 & 0.177 & 3,559 & 0.457 & 0.395 & 0.451 & 0.467 \\
\hline 1,801 & 0.167 & 0.194 & 0.204 & 0.203 & 3,687 & 0.461 & 0.449 & 0.462 & 0.476 \\
\hline 1,986 & 0.193 & 0.227 & 0.239 & 0.235 & 3,811 & 0.468 & 0.463 & 0.473 & 0.486 \\
\hline 2,180 & 0.221 & 0.259 & 0.279 & 0.272 & 3,966 & 0.494 & 0.505 & 0.496 & 0.508 \\
\hline 2,622 & 0.255 & 0.342 & 0.365 & 0.360 & 4,268 & 0.546 & 0.589 & 0.547 & 0.562 \\
\hline 3,161 & 0.342 & 0.445 & 0.465 & 0.462 & 4,813 & 0.715 & 0.713 & 0.712 & 0.699 \\
\hline 3,613 & 0.444 & 0.534 & 0.571 & 0.556 & 5,645 & 0.844 & 0.906 & 0.852 & 0.848 \\
\hline 4,668 & 0.533 & 0.768 & 0.908 & 0.869 & 6,845 & 1.116 & 1.216 & 1.114 & 1.112 \\
\hline 7,192 & 0.762 & 1.289 & 1.547 & 1.535 & 8,523 & 1.465 & 1.501 & 1.458 & 1.453 \\
\hline 10,182 & 1.102 & 1.937 & 1.682 & 1.643 & 11,065 & 1.930 & 2.130 & 1.947 & 1.941 \\
\hline 11,523 & 1.283 & 2.171 & 1.740 & 1.691 & 12,488 & 2.132 & 2.344 & 2.148 & 2.146 \\
\hline 15,000 & 1.752 & 2.778 & 1.890 & 1.817 & 30,000 & 4.619 & 4.007 & 4.470 & 4.480 \\
\hline
\end{tabular}


Table 3-2. Potential fine-sediment transport rates, in megatons per day, as functions of discharge and simulated alternative from the SIAM model, for the Naches reach. [ft3/s, cubic feet per second].

\begin{tabular}{|c|c|c|c|c|}
\hline \multirow[b]{2}{*}{ Discharge $\left(\mathrm{ft}^{3} / \mathrm{s}\right)$} & \multicolumn{3}{|c|}{ Naches } & \multirow[b]{2}{*}{ WymerPlus } \\
\hline & No Action & Blackrock_2 & Wymer1 & \\
\hline 0 & 0.000 & 0.000 & 0.00 & 0.00 \\
\hline 1 & 0.000 & 0.000 & 0.000 & 0.000 \\
\hline 687 & 0.122 & 0.123 & 0.123 & 0.123 \\
\hline 1,166 & 0.273 & 0.274 & 0.274 & 0.273 \\
\hline 1,458 & 0.389 & 0.390 & 0.390 & 0.389 \\
\hline 1,694 & 0.495 & 0.496 & 0.495 & 0.494 \\
\hline 1,954 & 0.621 & 0.623 & 0.621 & 0.623 \\
\hline 2,258 & 0.785 & 0.784 & 0.785 & 0.786 \\
\hline 2,562 & 0.963 & 0.963 & 0.964 & 0.963 \\
\hline 2,856 & 1.150 & 1.150 & 1.153 & 1.150 \\
\hline 3,151 & 1.348 & 1.348 & 1.349 & 1.350 \\
\hline 3,433 & 1.554 & 1.554 & 1.553 & 1.553 \\
\hline 3,700 & 1.756 & 1.757 & 1.757 & 1.757 \\
\hline 3,971 & 1.952 & 1.957 & 1.953 & 1.974 \\
\hline 4,287 & 2.234 & 2.228 & 2.234 & 2.234 \\
\hline 4,679 & 2.572 & 2.574 & 2.573 & 2.575 \\
\hline 5,128 & 2.982 & 2.984 & 2.983 & 2.984 \\
\hline 5,622 & 3.462 & 3.452 & 3.461 & 3.453 \\
\hline 6,208 & 4.026 & 4.027 & 4.027 & 4.026 \\
\hline 6,955 & 4.800 & 4.799 & 4.799 & 4.800 \\
\hline 8,444 & 6.427 & 6.424 & 6.425 & 6.428 \\
\hline 11,214 & 9.647 & 9.643 & 9.690 & 9.638 \\
\hline 12,771 & 11.462 & 11.444 & 11.442 & 11.444 \\
\hline 27,000 & 28.046 & 27.896 & 27.447 & 27.945 \\
\hline
\end{tabular}


Table 3-3. Potential fine-sediment transport rates, in megatons per day, as functions of discharge and simulated alternative from the SIAM model, for the Union Gap and Wapato reaches. [ft3/s, cubic feet per second].

\begin{tabular}{|c|c|c|c|c|c|c|c|c|c|}
\hline \multicolumn{5}{|c|}{ Union Gap } & \multicolumn{5}{|c|}{ Wapato } \\
\hline $\begin{array}{c}\text { Discharge } \\
\left(\mathrm{ft}^{3} / \mathrm{s}\right)\end{array}$ & No Action & Blackrock_2 & Wymer1 & WymerPlus & $\begin{array}{c}\text { Discharge } \\
\left(\mathrm{ft}^{3} / \mathbf{s}\right)\end{array}$ & No Action & Blackrock_2 & Wymer1 & WymerPlus \\
\hline 0 & 0.000 & 0.000 & 0.00 & 0.00 & 0 & 0.000 & 0.000 & 0.00 & 0.00 \\
\hline 769 & 0.003 & 0.003 & 0.003 & 0.003 & 378 & 0.008 & 0.011 & 0.013 & 0.012 \\
\hline 1,699 & 0.010 & 0.011 & 0.010 & 0.010 & 1,282 & 0.048 & 0.048 & 0.048 & 0.048 \\
\hline 2,530 & 0.018 & 0.019 & 0.018 & 0.019 & 2,173 & 0.100 & 0.100 & 0.101 & 0.106 \\
\hline 2,968 & 0.025 & 0.025 & 0.025 & 0.025 & 2,865 & 0.149 & 0.148 & 0.148 & 0.155 \\
\hline 3,305 & 0.030 & 0.030 & 0.030 & 0.030 & 3,529 & 0.200 & 0.201 & 0.201 & 0.201 \\
\hline 3,524 & 0.034 & 0.034 & 0.035 & 0.035 & 4,201 & 0.250 & 0.250 & 0.252 & 0.253 \\
\hline 3,907 & 0.043 & 0.041 & 0.042 & 0.041 & 4,877 & 0.301 & 0.305 & 0.303 & 0.303 \\
\hline 4,543 & 0.055 & 0.055 & 0.055 & 0.055 & 5,561 & 0.358 & 0.360 & 0.357 & 0.356 \\
\hline 5,229 & 0.073 & 0.073 & 0.073 & 0.074 & 6,233 & 0.410 & 0.411 & 0.412 & 0.413 \\
\hline 5,942 & 0.094 & 0.097 & 0.093 & 0.097 & 6,854 & 0.463 & 0.463 & 0.468 & 0.472 \\
\hline 6,655 & 0.117 & 0.117 & 0.117 & 0.118 & 7,510 & 0.521 & 0.533 & 0.521 & 0.522 \\
\hline 7,373 & 0.145 & 0.145 & 0.147 & 0.145 & 8,296 & 0.586 & 0.586 & 0.591 & 0.587 \\
\hline 8,138 & 0.181 & 0.181 & 0.181 & 0.181 & 9,106 & 0.648 & 0.658 & 0.647 & 0.651 \\
\hline 8,930 & 0.221 & 0.221 & 0.224 & 0.222 & 9,954 & 0.725 & 0.732 & 0.718 & 0.729 \\
\hline 9,794 & 0.273 & 0.273 & 0.275 & 0.273 & 10,957 & 0.810 & 0.814 & 0.812 & 0.816 \\
\hline 10,816 & 0.342 & 0.343 & 0.345 & 0.343 & 12,195 & 0.928 & 0.924 & 0.927 & 0.923 \\
\hline 12,111 & 0.437 & 0.437 & 0.441 & 0.439 & 13,496 & 1.048 & 1.044 & 1.048 & 1.044 \\
\hline 13,590 & 0.560 & 0.561 & 0.563 & 0.562 & 15,556 & 1.238 & 1.237 & 1.231 & 1.236 \\
\hline 16,271 & 0.823 & 0.827 & 0.826 & 0.826 & 18,114 & 1.466 & 1.471 & 1.463 & 1.477 \\
\hline 20,012 & 1.263 & 1.281 & 1.265 & 1.273 & 19,777 & 1.634 & 1.619 & 1.634 & 1.634 \\
\hline 27,989 & 2.459 & 2.477 & 2.458 & 2.462 & 26,734 & 2.251 & 2.239 & 2.242 & 2.251 \\
\hline 33,020 & 3.399 & 3.398 & 3.394 & 3.392 & 31,908 & 2.707 & 2.707 & 2.707 & 2.706 \\
\hline 50,000 & 6.571 & 6.508 & 6.553 & 6.528 & 50,000 & 4.302 & 4.342 & 4.336 & 4.299 \\
\hline
\end{tabular}


Table 3-4. Geomorphic work, in foot-megatons per day, as functions of discharge and simulated alternative from the SIAM model, for the Easton and Kittitas reaches. [ft3/s, cubic feet per second].

\begin{tabular}{|c|c|c|c|c|c|c|c|c|c|}
\hline \multicolumn{5}{|c|}{ Easton } & \multicolumn{5}{|c|}{ Kittitas } \\
\hline $\begin{array}{c}\text { Discharge } \\
\left(\mathrm{ft}^{3} / \mathbf{s}\right)\end{array}$ & No Action & Blackrock_2 & Wymer1 & WymerPlus & $\begin{array}{c}\text { Discharge } \\
\left(\mathrm{ft}^{3} / \mathbf{s}\right)\end{array}$ & No Action & Blackrock_2 & Wymer1 & WymerPlus \\
\hline 0 & 0.00 & 0.00 & 0.00 & 0.00 & 0 & 0.00 & 0.00 & 0.00 & 0.00 \\
\hline 69 & 6.33 & 6.05 & 6.19 & 6.83 & 97 & 15.88 & 16.08 & 16.70 & 15.99 \\
\hline 166 & 16.05 & 16.19 & 16.26 & 16.33 & 893 & 175.49 & 176.03 & 175.81 & 175.86 \\
\hline 304 & 29.16 & 28.27 & 28.39 & 30.13 & 1,542 & 330.18 & 329.68 & 329.99 & 329.83 \\
\hline 432 & 46.55 & 44.17 & 43.81 & 44.36 & 1,939 & 441.53 & 442.52 & 442.39 & 442.08 \\
\hline 565 & 62.96 & 61.41 & 60.71 & 61.87 & 2,216 & 526.60 & 526.71 & 526.79 & 526.22 \\
\hline 720 & 79.98 & 82.38 & 82.20 & 84.18 & 2,469 & 584.70 & 581.37 & 585.15 & 576.63 \\
\hline 870 & 98.43 & 104.44 & 104.43 & 105.92 & 2,701 & 656.24 & 657.51 & 656.12 & 643.37 \\
\hline 1,018 & 115.72 & 126.32 & 126.38 & 128.72 & 2,905 & 723.81 & 726.61 & 723.14 & 724.92 \\
\hline 1,177 & 135.72 & 151.16 & 151.66 & 154.94 & 3,084 & 785.87 & 806.18 & 849.13 & 869.38 \\
\hline 1,330 & 159.34 & 173.76 & 176.53 & 178.36 & 3,252 & 900.27 & 907.65 & 907.88 & 951.17 \\
\hline 1,489 & 179.94 & 199.87 & 204.14 & 205.34 & 3,417 & $1,009.77$ & 994.25 & 950.84 & $1,009.62$ \\
\hline 1,643 & 203.30 & 225.96 & 231.75 & 231.76 & 3,559 & 998.44 & $1,007.49$ & 987.26 & $1,027.32$ \\
\hline 1,801 & 229.41 & 254.55 & 261.30 & 259.92 & 3,687 & $1,007.02$ & $1,011.48$ & $1,010.98$ & $1,039.41$ \\
\hline 1,986 & 259.82 & 290.95 & 295.49 & 295.50 & 3,811 & $1,026.27$ & $1,034.16$ & $1,033.96$ & $1,051.42$ \\
\hline 2,180 & 290.59 & 324.06 & 330.32 & 328.89 & 3,966 & $1,057.62$ & $1,065.54$ & $1,069.12$ & $1,088.55$ \\
\hline 2,622 & 327.31 & 399.33 & 412.70 & 409.72 & 4,268 & $1,139.70$ & $1,151.93$ & $1,142.69$ & $1,180.46$ \\
\hline 3,161 & 417.49 & 503.55 & 517.12 & 515.24 & 4,813 & $1,458.27$ & $1,351.74$ & $1,451.21$ & $1,426.31$ \\
\hline 3,613 & 524.67 & 594.86 & 605.05 & 601.28 & 5,645 & $1,665.54$ & $1,666.92$ & $1,680.21$ & $1,671.47$ \\
\hline 4,668 & 613.54 & 784.52 & 806.37 & 800.05 & 6,845 & $2,110.95$ & $2,098.33$ & $2,104.26$ & $2,101.48$ \\
\hline 7,192 & 821.97 & $1,191.24$ & $1,271.65$ & $1,266.98$ & 8,523 & $2,649.97$ & $2,599.69$ & $2,636.00$ & $2,629.35$ \\
\hline 10,182 & $1,103.15$ & $1,676.57$ & $1,447.06$ & $1,411.56$ & 11,065 & $3,334.23$ & $3,336.77$ & $3,363.12$ & $3,356.74$ \\
\hline 11,523 & $1,273.13$ & $1,775.81$ & $1,522.39$ & $1,476.40$ & 12,488 & $3,675.24$ & $3,705.12$ & $3,700.21$ & $3,698.67$ \\
\hline 15,000 & $1,713.86$ & $2,033.15$ & $1,717.71$ & $1,644.54$ & 30,000 & $7,872.95$ & $6,396.23$ & $7,709.91$ & $7,734.17$ \\
\hline
\end{tabular}


Table 3-5. Geomorphic work, in foot-megatons per day, as functions of discharge and simulated alternative from the SIAM model, for the Naches reach. [ft3/s, cubic feet per second].

\begin{tabular}{|c|c|c|c|c|}
\hline \multicolumn{5}{|c|}{ Naches } \\
\hline Discharge (ft3/s) & No Action & Blackrock_2 & Wymer1 & WymerPlus \\
\hline 0 & 0.00 & 0.00 & 0.00 & 0.00 \\
\hline 1 & 0.16 & 0.14 & 0.20 & 0.19 \\
\hline 687 & 157.09 & 157.71 & 157.94 & 157.73 \\
\hline 1,166 & 303.78 & 305.27 & 304.73 & 304.93 \\
\hline 1,458 & 405.44 & 405.77 & 405.76 & 405.52 \\
\hline 1,694 & 494.35 & 492.82 & 492.70 & 491.99 \\
\hline 1,954 & 592.48 & 593.84 & 592.28 & 593.84 \\
\hline 2,258 & 717.86 & 715.96 & 718.10 & 717.24 \\
\hline 2,562 & 846.31 & 845.80 & 846.84 & 845.30 \\
\hline 2,856 & 977.65 & 977.53 & 980.44 & 976.62 \\
\hline 3,151 & $1,112.44$ & $1,112.51$ & $1,113.11$ & $1,113.13$ \\
\hline 3,433 & $1,249.19$ & $1,249.42$ & $1,249.00$ & $1,247.87$ \\
\hline 3,700 & $1,382.43$ & $1,382.61$ & $1,382.67$ & $1,382.32$ \\
\hline 3,971 & $1,511.38$ & $1,514.40$ & $1,512.27$ & $1,523.39$ \\
\hline 4,287 & $1,686.98$ & $1,683.10$ & $1,687.03$ & $1,686.39$ \\
\hline 4,679 & $1,892.23$ & $1,892.25$ & $1,892.55$ & $1,892.73$ \\
\hline 5,128 & $2,133.41$ & $2,134.13$ & $2,133.58$ & $2,134.51$ \\
\hline 5,622 & $2,407.26$ & $2,401.34$ & $2,406.73$ & $2,402.76$ \\
\hline 6,208 & $2,725.28$ & $2,725.68$ & $2,725.85$ & $2,725.18$ \\
\hline 6,955 & $3,151.19$ & $3,150.32$ & $3,150.20$ & $3,150.69$ \\
\hline 8,444 & $4,006.32$ & $4,004.41$ & $4,005.02$ & $4,006.43$ \\
\hline 11,214 & $5,601.53$ & $5,600.12$ & $5,620.72$ & $5,596.94$ \\
\hline 12,771 & $6,474.41$ & $6,466.71$ & $6,466.04$ & $6,466.81$ \\
\hline 27,000 & $14,449.81$ & $14,384.51$ & $14,188.10$ & $14,414.59$ \\
\hline
\end{tabular}


Table 3-6. Geomorphic work, in foot-megatons per day, as functions of discharge and simulated alternative from the SIAM model, for the Union Gap and Wapato reaches. [ft3/s, cubic feet per second] .

\begin{tabular}{|c|c|c|c|c|c|c|c|c|c|}
\hline \multicolumn{5}{|c|}{ Union Gap } & \multicolumn{5}{|c|}{ Wapato } \\
\hline $\begin{array}{c}\text { Discharge } \\
\left(\mathrm{ft}^{3} / \mathrm{s}\right)\end{array}$ & No Action & Blackrock_2 & Wymer1 & WymerPlus & $\begin{array}{c}\text { Discharge } \\
\left(\mathrm{ft}^{3} / \mathbf{s}\right)\end{array}$ & No Action & Blackrock_2 & Wymer1 & WymerPlus \\
\hline 0 & 0.00 & 0.00 & 0.00 & 0.00 & 0 & 0.00 & 0.00 & 0.00 & 0.00 \\
\hline 769 & 5.82 & 6.35 & 6.16 & 6.20 & 378 & 286.83 & 313.81 & 325.89 & 318.37 \\
\hline 1,699 & 17.08 & 17.67 & 17.06 & 17.20 & 1,282 & $1,140.49$ & $1,142.11$ & $1,138.61$ & $1,139.66$ \\
\hline 2,530 & 26.89 & 27.52 & 26.91 & 27.70 & 2,173 & $2,103.99$ & $2,100.30$ & $2,088.53$ & $2,144.17$ \\
\hline 2,968 & 34.11 & 33.97 & 34.11 & 34.01 & 2,865 & $2,841.28$ & $2,822.70$ & $2,824.40$ & $2,942.45$ \\
\hline 3,305 & 39.54 & 39.03 & 39.63 & 39.69 & 3,529 & $3,649.26$ & $3,648.33$ & $3,641.20$ & $3,658.64$ \\
\hline 3,524 & 43.04 & 42.19 & 44.15 & 44.28 & 4,201 & $4,355.75$ & $4,368.47$ & $4,398.85$ & $4,413.01$ \\
\hline 3,907 & 51.00 & 47.87 & 49.97 & 48.27 & 4,877 & $5,141.44$ & $5,182.62$ & $5,163.46$ & $5,175.32$ \\
\hline 4,543 & 58.28 & 58.19 & 58.26 & 58.32 & 5,561 & $5,943.52$ & $5,984.43$ & $5,928.95$ & $5,942.89$ \\
\hline 5,229 & 69.99 & 69.87 & 69.96 & 71.08 & 6,233 & $6,727.31$ & $6,754.18$ & $6,759.57$ & $6,751.44$ \\
\hline 5,942 & 81.19 & 83.95 & 80.65 & 84.16 & 6,854 & $7,449.32$ & $7,451.52$ & $7,527.42$ & $7,572.46$ \\
\hline 6,655 & 92.08 & 92.13 & 92.13 & 92.84 & 7,510 & $8,232.43$ & $8,390.39$ & $8,232.82$ & $8,243.94$ \\
\hline 7,373 & 104.28 & 104.29 & 105.88 & 104.52 & 8,296 & $9,138.00$ & $9,133.84$ & $9,202.17$ & $9,141.54$ \\
\hline 8,138 & 118.96 & 119.01 & 119.52 & 119.09 & 9,106 & $9,964.78$ & $10,095.02$ & $9,949.95$ & $9,999.86$ \\
\hline 8,930 & 133.11 & 133.29 & 135.24 & 133.37 & 9,954 & $10,978.67$ & $11,085.27$ & $10,907.76$ & $11,046.04$ \\
\hline 9,794 & 150.40 & 150.67 & 152.35 & 150.62 & 10,957 & $12,073.70$ & $12,123.98$ & $12,098.20$ & $12,159.73$ \\
\hline 10,816 & 172.17 & 172.62 & 173.44 & 172.67 & 12,195 & $13,550.64$ & $13,469.42$ & $13,528.08$ & $13,497.27$ \\
\hline 12,111 & 198.30 & 198.15 & 199.68 & 198.36 & 13,496 & $14,935.21$ & $14,905.85$ & $14,937.38$ & $14,965.88$ \\
\hline 13,590 & 225.51 & 225.75 & 226.11 & 225.64 & 15,556 & $17,181.34$ & $17,140.86$ & $17,090.79$ & $17,132.88$ \\
\hline 16,271 & 274.16 & 274.47 & 275.07 & 274.82 & 18,114 & $19,748.63$ & $19,779.76$ & $19,742.03$ & $19,829.89$ \\
\hline 20,012 & 341.06 & 342.51 & 340.86 & 340.39 & 19,777 & $21,531.09$ & $21,391.51$ & $21,530.78$ & $21,532.67$ \\
\hline 27,989 & 482.39 & 491.50 & 479.46 & 480.04 & 26,734 & $28,009.58$ & $27,867.74$ & $27,891.10$ & $28,013.50$ \\
\hline 33,020 & 584.72 & 584.44 & 585.42 & 584.88 & 31,908 & $32,618.59$ & $32,616.59$ & $32,640.28$ & $32,628.60$ \\
\hline 50,000 & 930.14 & 898.16 & 943.08 & 938.74 & 50,000 & $48,734.33$ & $49,221.28$ & $49,246.13$ & $48,765.61$ \\
\hline
\end{tabular}


Table 3-7. Depth of redd scour, in feet, as functions of discharge and simulated alternative from the SIAM model, for the Easton and Kittitas reaches. [ft3/s, cubic feet per second].

\begin{tabular}{|c|c|c|c|c|c|c|c|c|c|}
\hline \multicolumn{5}{|c|}{ Easton } & \multicolumn{5}{|c|}{ Kittitas } \\
\hline $\begin{array}{c}\text { Discharge } \\
\left(\mathrm{ft}^{3} / \mathrm{s}\right)\end{array}$ & No Action & Blackrock_2 & Wymer1 & WymerPlus & $\begin{array}{c}\text { Discharge } \\
\left(\mathrm{ft}^{3} / \mathbf{s}\right)\end{array}$ & No Action & Blackrock_2 & Wymer1 & WymerPlus \\
\hline 0 & 0.00 & 0.00 & 0.00 & 0.00 & 0 & 0.00 & 0.000 & 0.00 & 0.00 \\
\hline 69 & 0.01 & 0.01 & 0.010 & 0.011 & 97 & 0.01 & 0.009 & 0.010 & 0.009 \\
\hline 166 & 0.01 & 0.01 & 0.008 & 0.008 & 893 & 0.01 & 0.006 & 0.006 & 0.006 \\
\hline 304 & 0.01 & 0.01 & 0.007 & 0.007 & 1,542 & 0.01 & 0.005 & 0.005 & 0.005 \\
\hline 432 & 0.01 & 0.01 & 0.007 & 0.007 & 1,939 & 0.00 & 0.005 & 0.005 & 0.005 \\
\hline 565 & 0.01 & 0.01 & 0.006 & 0.006 & 2,216 & 0.00 & 0.005 & 0.005 & 0.005 \\
\hline 720 & 0.01 & 0.01 & 0.006 & 0.006 & 2,469 & 0.00 & 0.005 & 0.005 & 0.005 \\
\hline 870 & 0.01 & 0.01 & 0.005 & 0.005 & 2,701 & 0.00 & 0.005 & 0.005 & 0.005 \\
\hline 1,018 & 0.01 & 0.00 & 0.005 & 0.005 & 2,905 & 0.00 & 0.004 & 0.004 & 0.004 \\
\hline 1,177 & 0.01 & 0.00 & 0.005 & 0.006 & 3,084 & 0.00 & 0.004 & 0.004 & 0.004 \\
\hline 1,330 & 0.01 & 0.01 & 0.007 & 0.008 & 3,252 & 0.00 & 0.004 & 0.004 & 0.004 \\
\hline 1,489 & 0.01 & 0.01 & 0.011 & 0.012 & 3,417 & 0.00 & 0.004 & 0.004 & 0.004 \\
\hline 1,643 & 0.01 & 0.01 & 0.016 & 0.016 & 3,559 & 0.00 & 0.004 & 0.004 & 0.004 \\
\hline 1,801 & 0.02 & 0.02 & 0.021 & 0.020 & 3,687 & 0.00 & 0.004 & 0.004 & 0.004 \\
\hline 1,986 & 0.02 & 0.02 & 0.027 & 0.026 & 3,811 & 0.00 & 0.004 & 0.004 & 0.004 \\
\hline 2,180 & 0.03 & 0.03 & 0.033 & 0.032 & 3,966 & 0.00 & 0.004 & 0.004 & 0.004 \\
\hline 2,622 & 0.03 & 0.04 & 0.054 & 0.052 & 4,268 & 0.00 & 0.004 & 0.004 & 0.004 \\
\hline 3,161 & 0.06 & 0.07 & 0.087 & 0.085 & 4,813 & 0.00 & 0.004 & 0.004 & 0.004 \\
\hline 3,613 & 0.09 & 0.11 & 0.120 & 0.116 & 5,645 & 0.00 & 0.004 & 0.004 & 0.004 \\
\hline 4,668 & 0.13 & 0.18 & 0.212 & 0.205 & 6,845 & 0.00 & 0.004 & 0.004 & 0.004 \\
\hline 7,192 & 0.23 & 0.37 & 0.462 & 0.460 & 8,523 & 0.01 & 0.005 & 0.006 & 0.005 \\
\hline 10,182 & 0.38 & 0.67 & 0.557 & 0.538 & 11,065 & 0.01 & 0.012 & 0.012 & 0.012 \\
\hline 11,523 & 0.46 & 0.71 & 0.597 & 0.573 & 12,488 & 0.01 & 0.015 & 0.015 & 0.014 \\
\hline 15,000 & 0.69 & 0.84 & 0.703 & 0.664 & 30,000 & 0 & 0.047 & 0.042 & 0.042 \\
\hline
\end{tabular}


Table 3-8. Depth of redd scour, in feet, as functions of discharge and simulated alternative from the SIAM model, for the Naches reach. [ft3/s, cubic feet per second].

\begin{tabular}{|c|c|c|c|c|}
\hline \multicolumn{5}{|c|}{ Naches } \\
\hline Discharge $\left(\mathrm{ft}^{3} / \mathrm{s}\right)$ & No Action & Blackrock_2 & Wymer1 & WymerPlus \\
\hline 0 & 0.00 & 0.000 & 0.00 & 0.00 \\
\hline 1 & 0.03 & 0.003 & 0.031 & 0.031 \\
\hline 687 & 0.01 & 0.005 & 0.006 & 0.006 \\
\hline 1,166 & 0.00 & 0.004 & 0.004 & 0.004 \\
\hline 1,458 & 0.00 & 0.004 & 0.004 & 0.004 \\
\hline 1,694 & 0.00 & 0.004 & 0.004 & 0.004 \\
\hline 1,954 & 0.00 & 0.004 & 0.004 & 0.004 \\
\hline 2,258 & 0.00 & 0.004 & 0.004 & 0.004 \\
\hline 2,562 & 0.00 & 0.003 & 0.003 & 0.004 \\
\hline 2,856 & 0.01 & 0.005 & 0.005 & 0.005 \\
\hline 3,151 & 0.01 & 0.009 & 0.009 & 0.009 \\
\hline 3,433 & 0.01 & 0.014 & 0.014 & 0.014 \\
\hline 3,700 & 0.02 & 0.021 & 0.021 & 0.021 \\
\hline 3,971 & 0.03 & 0.029 & 0.029 & 0.030 \\
\hline 4,287 & 0.04 & 0.042 & 0.042 & 0.043 \\
\hline 4,679 & 0.06 & 0.064 & 0.063 & 0.064 \\
\hline 5,128 & 0.10 & 0.096 & 0.096 & 0.096 \\
\hline 5,622 & 0.14 & 0.136 & 0.138 & 0.137 \\
\hline 6,208 & 0.19 & 0.194 & 0.194 & 0.194 \\
\hline 6,955 & 0.28 & 0.277 & 0.278 & 0.278 \\
\hline 8,444 & 0.46 & 0.461 & 0.462 & 0.462 \\
\hline 11,214 & 0.83 & 0.833 & 0.842 & 0.833 \\
\hline 12,771 & 1.05 & 1.046 & 1.047 & 1.047 \\
\hline 27,000 & 3.02 & 2.990 & 2.922 & 3.003 \\
\hline
\end{tabular}


Table 3-9. Depth of redd scour, in feet, as functions of discharge and simulated alternative from the SIAM model, for the Union Gap and Wapato reaches. [ft3/s, cubic feet per second].

\begin{tabular}{|c|c|c|c|c|c|c|c|c|c|}
\hline \multicolumn{5}{|c|}{ Union Gap } & \multicolumn{5}{|c|}{ Wapato } \\
\hline $\begin{array}{c}\text { Discharge } \\
\left(\mathrm{ft}^{3} / \mathbf{s}\right)\end{array}$ & No Action & Blackrock_2 & Wymer1 & WymerPlus & $\begin{array}{c}\text { Discharge } \\
\left(\mathrm{ft}^{3} / \mathbf{s}\right)\end{array}$ & No Action & Blackrock_2 & Wymer1 & WymerPlus \\
\hline 0 & 0.00 & 0.000 & 0.00 & 0.00 & 0 & 0.00 & 0.000 & 0.00 & 0.00 \\
\hline 769 & 0.04 & 0.027 & 0.030 & 0.042 & 378 & 0.01 & 0.010 & 0.012 & 0.003 \\
\hline 1,699 & 0.02 & 0.021 & 0.020 & 0.021 & 1,282 & 0.01 & 0.007 & 0.007 & 0.007 \\
\hline 2,530 & 0.01 & 0.014 & 0.014 & 0.015 & 2,173 & 0.01 & 0.006 & 0.006 & 0.006 \\
\hline 2,968 & 0.01 & 0.013 & 0.013 & 0.013 & 2,865 & 0.01 & 0.006 & 0.006 & 0.006 \\
\hline 3,305 & 0.01 & 0.012 & 0.012 & 0.012 & 3,529 & 0.01 & 0.005 & 0.005 & 0.005 \\
\hline 3,524 & 0.01 & 0.012 & 0.012 & 0.012 & 4,201 & 0.01 & 0.005 & 0.005 & 0.005 \\
\hline 3,907 & 0.01 & 0.012 & 0.012 & 0.012 & 4,877 & 0.00 & 0.005 & 0.005 & 0.005 \\
\hline 4,543 & 0.01 & 0.012 & 0.012 & 0.012 & 5,561 & 0.00 & 0.005 & 0.005 & 0.005 \\
\hline 5,229 & 0.01 & 0.012 & 0.013 & 0.013 & 6,233 & 0.00 & 0.005 & 0.005 & 0.005 \\
\hline 5,942 & 0.01 & 0.014 & 0.013 & 0.014 & 6,854 & 0.00 & 0.005 & 0.005 & 0.005 \\
\hline 6,655 & 0.01 & 0.014 & 0.014 & 0.014 & 7,510 & 0.00 & 0.004 & 0.004 & 0.004 \\
\hline 7,373 & 0.02 & 0.015 & 0.016 & 0.015 & 8,296 & 0.00 & 0.004 & 0.004 & 0.004 \\
\hline 8,138 & 0.02 & 0.017 & 0.017 & 0.017 & 9,106 & 0.00 & 0.004 & 0.004 & 0.004 \\
\hline 8,930 & 0.02 & 0.019 & 0.019 & 0.019 & 9,954 & 0.00 & 0.004 & 0.004 & 0.004 \\
\hline 9,794 & 0.02 & 0.021 & 0.021 & 0.021 & 10,957 & 0.00 & 0.004 & 0.004 & 0.004 \\
\hline 10,816 & 0.02 & 0.024 & 0.024 & 0.024 & 12,195 & 0.00 & 0.004 & 0.004 & 0.004 \\
\hline 12,111 & 0.03 & 0.027 & 0.028 & 0.027 & 13,496 & 0.00 & 0.004 & 0.004 & 0.004 \\
\hline 13,590 & 0.03 & 0.031 & 0.031 & 0.031 & 15,556 & 0.00 & 0.004 & 0.004 & 0.004 \\
\hline 16,271 & 0.04 & 0.036 & 0.036 & 0.036 & 18,114 & 0.00 & 0.004 & 0.004 & 0.004 \\
\hline 20,012 & 0.06 & 0.064 & 0.061 & 0.063 & 19,777 & 0.00 & 0.003 & 0.003 & 0.003 \\
\hline 27,989 & 0.18 & 0.185 & 0.181 & 0.181 & 26,734 & 0.00 & 0.003 & 0.003 & 0.003 \\
\hline 33,020 & 0.29 & 0.291 & 0.291 & 0.290 & 31,908 & 0.00 & 0.003 & 0.003 & 0.003 \\
\hline 50,000 & 0.66 & 0.649 & 0.664 & 0.659 & 50,000 & 0.00 & 0.003 & 0.003 & 0.003 \\
\hline
\end{tabular}


Appendix 4. YRDSS Run Results for the Blackrock_2 Scenario 


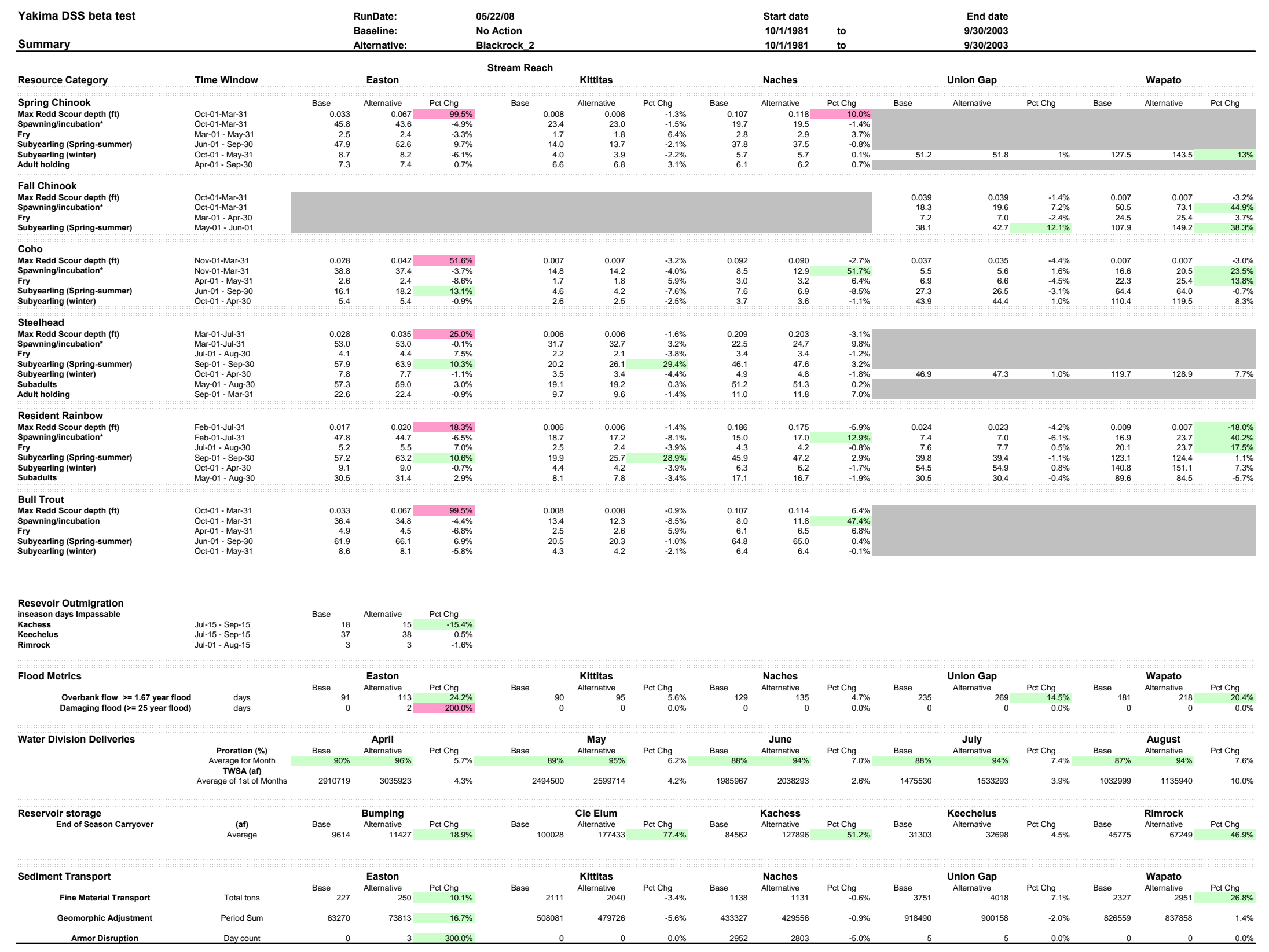

Figure 4-1. Habitat summary page for the Black Rock_2 scenario. 


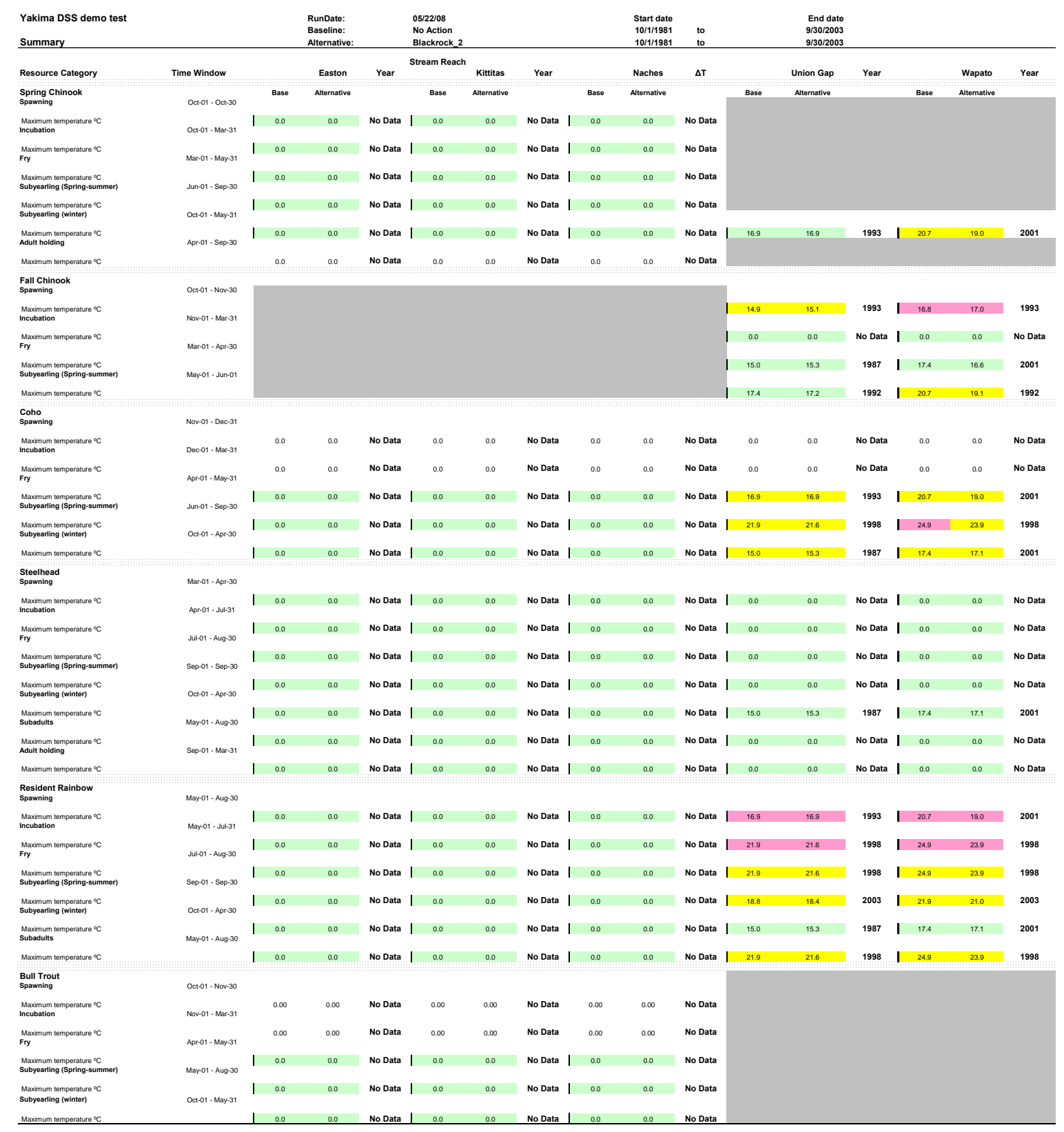

Figure 4-2. Temperature summary page for the Black Rock_2 scenario. 


\begin{tabular}{|c|c|c|c|c|c|c|c|c|c|c|c|c|c|c|c|c|c|c|c|}
\hline $\begin{array}{l}\text { Yakima DSS beta test } \\
\text { Version } \\
\text { Yearly Summary }\end{array}$ & & $\begin{array}{l}\text { RunDate: } \\
\text { Baseline: } \\
\text { Alternative: }\end{array}$ & & $\begin{array}{l}\text { 05/22/08 } \\
\text { No Action } \\
\text { Blackrock_2 }\end{array}$ & & & & $\begin{array}{l}\text { Start date } \\
10 / 1 / 1981 \\
10 / 1 / 1981\end{array}$ & $\begin{array}{l}\text { to } \\
\text { to }\end{array}$ & & $\begin{array}{l}\text { End date } \\
\text { 9/30/2003 } \\
\text { 9/30/2003 }\end{array}$ & & & & & & & & \\
\hline \multirow[t]{2}{*}{$\begin{array}{l}\text { Res Bull Trout outmigration } \\
\text { inseason days Impassable }\end{array}$} & Year & Base & $\begin{array}{c}\text { Bumping } \\
\text { Alternative }\end{array}$ & Pct Chg & Base & $\begin{array}{l}\text { Cle Elum } \\
\text { Alternative }\end{array}$ & Pct Chg & Base & $\begin{array}{l}\text { Kachess } \\
\text { Alternative }\end{array}$ & Pct Chg & Base & $\begin{array}{c}\text { Keechelus } \\
\text { Alternative }\end{array}$ & Pct Chg & Base & $\begin{array}{l}\text { Rimrock } \\
\text { Alternative } \\
\end{array}$ & Pct Chg & Base & $\begin{array}{c}\text { Wymer } \\
\text { Alternative }\end{array}$ & Pct Chg \\
\hline & $\begin{array}{l}1982 \\
1983 \\
1984 \\
1985 \\
1986 \\
1987 \\
1988 \\
1989 \\
1990 \\
1991 \\
1992 \\
1993 \\
1994 \\
1995 \\
1996 \\
1999 \\
1998 \\
1999 \\
2000 \\
2000 \\
2002 \\
2003 \\
\end{array}$ & & & & & & & $\begin{array}{l}0 \\
2 \\
0 \\
29 \\
17 \\
33 \\
49 \\
13 \\
14 \\
15 \\
29 \\
30 \\
47 \\
9 \\
4 \\
11 \\
31 \\
4 \\
23 \\
25 \\
3 \\
7 \\
\end{array}$ & $\begin{array}{c}0 \\
2 \\
0 \\
29 \\
17 \\
22 \\
42 \\
13 \\
14 \\
15 \\
11 \\
9 \\
43 \\
9 \\
4 \\
11 \\
31 \\
4 \\
23 \\
25 \\
3 \\
7 \\
\end{array}$ & $\begin{array}{c}0.0 \% \\
0.0 \% \\
0.0 \% \\
0.0 \% \\
0.0 \% \\
-3.3 \% \\
-14.3 \% \\
0.0 \% \\
0.0 \% \\
0.0 \% \\
-0.2 \% \\
-7.0 \% 9 \\
0.8 \% \\
0.0 \% \\
0.0 \% \\
0.0 \% \\
0.0 \% \\
0.0 \% \\
0.0 \% \\
0.0 \% \\
0.0 \% \\
0.0 \% \\
\end{array}$ & $\begin{array}{l}0 \\
29 \\
14 \\
49 \\
43 \\
54 \\
60 \\
42 \\
46 \\
35 \\
55 \\
61 \\
61 \\
58 \\
38 \\
14 \\
44 \\
9 \\
20 \\
32 \\
17 \\
40 \\
\end{array}$ & $\begin{array}{l}20 \\
32 \\
28 \\
49 \\
43 \\
54 \\
40 \\
27 \\
51 \\
43 \\
57 \\
42 \\
61 \\
57 \\
39 \\
14 \\
47 \\
9 \\
22 \\
32 \\
20 \\
38 \\
\end{array}$ & $\begin{array}{r}2000.0 \% \\
10.3 \% \\
100.0 \% \\
00.0 \% \\
0.0 \% \\
0.0 \% \\
-33.3 \% \\
-35.7 \% \\
10.9 \% \\
22.9 \% \\
3.6 \% \\
-31.1 \% \\
0.0 \% \\
-1.7 \% \\
2.6 \% \\
0.0 \% \\
6.8 \% \\
0.0 \% \\
10.0 \% \\
0.0 \% \\
17.6 \% \\
-5.0 \% \\
\end{array}$ & $\begin{array}{c}0 \\
0 \\
0 \\
0 \\
0 \\
0 \\
0 \\
0 \\
1 \\
0 \\
0 \\
0 \\
18 \\
0 \\
0 \\
0 \\
0 \\
0 \\
0 \\
44 \\
0 \\
0 \\
\end{array}$ & $\begin{array}{c}0 \\
0 \\
0 \\
0 \\
0 \\
0 \\
0 \\
0 \\
1 \\
0 \\
0 \\
0 \\
17 \\
0 \\
0 \\
0 \\
0 \\
0 \\
0 \\
44 \\
0 \\
0 \\
\end{array}$ & $\begin{array}{l}0.0 \% \\
0.0 \% \\
0.0 \% \\
0.0 \% \\
0.0 \% \\
0.0 \% \\
0.0 \% \\
0.0 \% \\
0.0 \% \\
0.0 \% \\
0.0 \% \\
0.0 \% \\
-5.6 \% \\
0.0 \% \\
0.0 \% \\
0.0 \% \\
0.0 \% \\
0.0 \% \\
0.0 \% \\
0.0 \% \\
0.0 \% \\
0.0 \% \\
\end{array}$ & & & $\begin{array}{l}0.0 \% \\
0.0 \% \\
0.0 \% \\
0.0 \% \\
0.0 \% \\
0.0 \% \\
0.0 \% \\
0.0 \% \\
0.0 \% \\
0.0 \% \\
0.0 \% \\
0.0 \% \\
0.0 \% \\
0.0 \% \\
0.0 \% \\
0.0 \% \\
0.0 \% \\
0.0 \% \\
0.0 \% \\
0.0 \% \\
0.0 \% \\
0.0 \% \\
\end{array}$ \\
\hline \multirow{19}{*}{ Average proration $\%$ by Month } & Year & $\begin{array}{l}\text { April } \\
\text { Base }\end{array}$ & Alternative & & $\begin{array}{l}\text { May } \\
\text { Base }\end{array}$ & Alternative & & $\begin{array}{c}\text { June } \\
\text { Base }\end{array}$ & Alternative & & $\begin{array}{l}\text { July } \\
\text { Base }\end{array}$ & Alternative & & $\begin{array}{c}\text { August } \\
\text { Base }\end{array}$ & & & $\begin{array}{l}\text { Septembe } \\
\text { Base }\end{array}$ & Alternative & \\
\hline & $\begin{array}{l}\text { Year } \\
1982 \\
\end{array}$ & & Alternative & PctChg & & Alternative & Pctchg & & Alternative & Pctchg & & Alternative & Pct Chg & & Alternative & Pct Chg & Base & Afternative & \\
\hline & 1983 & 1.000 & 1.000 & $0.0 \%$ & 1.000 & 1.000 & $0.0 \%$ & 1.000 & 1.000 & $0.0 \%$ & 1.000 & 1.000 & & 1.000 & 1.000 & $0.0 \%$ & 1.000 & & $0.0 \%$ \\
\hline & 1984 & 1.000 & $\begin{array}{l}1.000 \\
1.000\end{array}$ & & 1.000 & 1.000 & $0.0 \%$ & 1.000 & 1.000 & $0.0 \%$ & 1.000 & 1.000 & $0.0 \%$ & 1.000 & 1.000 & $0.0 \%$ & & 1.000 & $0.0 \%$ \\
\hline & 年1985 & $\begin{array}{l}1.000 \\
\end{array}$ & 1.000 & $0.0 \%$ & $\begin{array}{l}1.0000 \\
1.002\end{array}$ & 1.000 & .0.0\% & $\begin{array}{l}1.000 \\
1.007\end{array}$ & $\begin{array}{l}1.000 \\
\end{array}$ & $0.0 \%$ & $\begin{array}{l}1.0000 \\
\end{array}$ & 1.000 & $0.0 \%$ & $\begin{array}{l}1.0000 \\
1.002\end{array}$ & 1.000 & . & 1.000 & 1.000 & $0.0 \%$ \\
\hline & $\begin{array}{l}1968 \\
1987\end{array}$ & 0.848 & 0.963 & $\begin{array}{l}0.0 \% \\
13.6 \%\end{array}$ & 0.743 & $\begin{array}{l}0.862 \\
0.862\end{array}$ & $15.9 \%$ & 0.707 & 0.826 & 16.08\% & 0.698 & $\begin{array}{l}1.1000 \\
0.826\end{array}$ & 18.4\% & $\begin{array}{l}0.993 \\
0.692\end{array}$ & $\begin{array}{l}1.0006 \\
0.826\end{array}$ & 年 & 0.068 & $\begin{array}{l}1.000 \\
0.826\end{array}$ & $\begin{array}{l}10.80 \% \\
200 \%\end{array}$ \\
\hline & 1988 & $\begin{array}{l}0.842 \\
0.842\end{array}$ & 0.989 & $17.4 \%$ & 0.767 & 0.939 & $22.4 \%$ & 0.739 & 0.919 & $24.4 \%$ & $\begin{array}{l}0.728 \\
0.728\end{array}$ & 0.919 & $26.3 \%$ & 0.723 & 0.919 & $27.0 \%$ & 0.721 & 0.919 & $27.4 \%$ \\
\hline & 1989 & 0.999 & $\begin{array}{l}1.000 \\
1000\end{array}$ & $\begin{array}{l}0.1 \% \\
0.0 \%\end{array}$ & 0.987 & 1.000 & $1.3 \%$ & 0.978 & 1.000 & $2.2 \%$ & 0.967 & 1.000 & $3.4 \%$ & 0.963 & 1.000 & $3.9 \%$ & 0.960 & 1.000 & \\
\hline & $\begin{array}{l}{ }_{1999}^{1991} \\
191\end{array}$ & $\begin{array}{l}1.000 \\
1.000\end{array}$ & $\begin{array}{l}1.000 \\
1.000\end{array}$ & $\left.\begin{array}{l}0.0 \% \\
0.0 \%\end{array}\right]$ & $\begin{array}{l}1.000 \\
1.000\end{array}$ & $\begin{array}{l}1.000 \\
1.000\end{array}$ & $\begin{array}{l}0.0 \% \\
0.0 \%\end{array}$ & $\begin{array}{l}1.000 \\
1.000\end{array}$ & 1.000 & $0.0 \%$ & 1.000 & 1.000 & 0 & 1.000 & 1.000 & $0.0 \%$ & 1.000 & 1.000 & $0.0 \%$ \\
\hline & $\begin{array}{l}1991 \\
1992\end{array}$ & $\begin{array}{l}1.10000 \\
0.722\end{array}$ & $\begin{array}{l}1.1 .000 \\
0.845\end{array}$ & $\begin{array}{c}0.0 \% \\
17.1 \%\end{array}$ & $\begin{array}{l}1.1000 \\
0.712\end{array}$ & $\begin{array}{l}1.1 .000 \\
0.821\end{array}$ & $\begin{array}{c}0.0 \% \\
15.3 \%\end{array}$ & $\begin{array}{l}1.000 \\
0.704\end{array}$ & $\begin{array}{l}1.000 \\
0.809\end{array}$ & $\begin{array}{r}0.0 \% \\
15.0 \%\end{array}$ & $\begin{array}{l}1.000 \\
0.697\end{array}$ & $\begin{array}{l}1.000 \\
0.804\end{array}$ & $\begin{array}{r}0.0 \% \\
15.2 \%\end{array}$ & $\begin{array}{l}1.000 \\
0.697\end{array}$ & $\begin{array}{l}1.000 \\
0.803\end{array}$ & $\begin{array}{r}0.0 \% \\
15.3 \%\end{array}$ & $\begin{array}{l}1.000 \\
0.697\end{array}$ & $\begin{array}{l}1.000 \\
0.803\end{array}$ & $\begin{array}{l}0.00 \% \\
15 \%\end{array}$ \\
\hline & 1993 & 0.669 & 0.839 & $25.4 \%$ & 0.635 & 0.789 & $24.4 \%$ & 0.600 & 0.740 & $23.2 \%$ & 0.589 & 0.740 & $25.5 \%$ & 0.581 & 0.736 & $26.6 \%$ & 0.576 & 0.732 & $27.1 \%$ \\
\hline & 1994 & 0.361 & 0.700 & $93.9 \%$ & 0.301 & 0.700 & $132.7 \%$ & 0.292 & 0.700 & $140.0 \%$ & 0.292 & 0.700 & $140.0 \%$ & 0.289 & 0.700 & $142.6 \%$ & 0.279 & 0.700 & $150.8 \%$ \\
\hline & $\begin{array}{l}1995 \\
1996\end{array}$ & $\begin{array}{l}1.000 \\
1000\end{array}$ & $\begin{array}{l}1.000 \\
1000\end{array}$ & 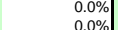 & $\begin{array}{l}1.000 \\
1000\end{array}$ & $\begin{array}{l}1.000 \\
1.000\end{array}$ & $\begin{array}{l}0.0 \% \\
0.0 \%\end{array}$ & $\begin{array}{l}1.000 \\
1000\end{array}$ & $\begin{array}{l}1.000 \\
1000\end{array}$ & $\begin{array}{l}0.0 \% \\
0.0 \%\end{array}$ & $\begin{array}{l}1.000 \\
1000\end{array}$ & $\begin{array}{l}1.000 \\
1000\end{array}$ & $\mid \begin{array}{l}0.0 \% \\
0.00 \%\end{array}$ & 1.000 & 1.000 & $0.0 \%$ & 1.000 & 1.000 & $0.0 \%$ \\
\hline & $\begin{array}{l}{ }_{1996} \\
1997\end{array}$ & $\begin{array}{l}1.000 \\
1.000\end{array}$ & $\begin{array}{l}1.000 \\
1.000\end{array}$ & 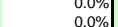 & $\begin{array}{l}1.000 \\
1.000\end{array}$ & $\begin{array}{l}1.000 \\
1.000\end{array}$ & $\begin{array}{l}0.0 \% \\
0.0 \%\end{array}$ & $\begin{array}{l}1.000 \\
1.000\end{array}$ & $\begin{array}{l}1.000 \\
1.000\end{array}$ & & $\begin{array}{l}1.000 \\
1.000\end{array}$ & $\begin{array}{l}1.000 \\
1.000\end{array}$ & & 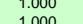 & $\begin{array}{l}1.1000 \\
\end{array}$ & . & 1.10000 & $\begin{array}{l}1.10000 \\
\end{array}$ & $0.0 \%$ \\
\hline & 1998] & 1.000 & 1.000 & 0.0\% & $\begin{array}{l}1.000 \\
1.000\end{array}$ & $\begin{array}{l}1.000 \\
1.000\end{array}$ & . & $\begin{array}{l}1.0000 \\
1.000\end{array}$ & $\begin{array}{l}1.000 \\
1.000\end{array}$ & $0.0 \%$ & $\begin{array}{l}1.0000 \\
1.000\end{array}$ & $\begin{array}{l}1.000 \\
1.000\end{array}$ & $0.0 \% \%$ & $\begin{array}{l}1.000 \\
1.000\end{array}$ & $\begin{array}{l}1.000 \\
1.000\end{array}$ & $0.00 \%$ & $\begin{array}{l}1.0000 \\
1.00\end{array}$ & $\begin{array}{l}1.000 \\
1.000\end{array}$ & $\begin{array}{l}0.0 \% \\
0.0 \%\end{array}$ \\
\hline & 1999 & 1.000 & 1.000 & $0.0 \%$ & 1.000 & 1.000 & $0.0 \%$ & 1.000 & 1.000 & $0.0 \%$ & 1.000 & 1.000 & $0.0 \%$ & 1.000 & 1.000 & $0.0 \%$ & 1.000 & 1.000 & $0.0 \%$ \\
\hline & 2000 & $\begin{array}{l}1.000 \\
\end{array}$ & 1.000 & & 1.000 & 1.000 & $\begin{array}{r}0.0 \% \\
55.0 \%\end{array}$ & 1.000 & 1.000 & & 1.000 & 000 & & 1.000 & & & & & $0.0 \%$ \\
\hline & $\begin{array}{l}20001 \\
2002\end{array}$ & & $\begin{array}{l}0.700 \\
1000\end{array}$ & $52.4 \%$ & 0.459 & $\begin{array}{l}0.700 \\
1000\end{array}$ & $52.4 \%$ & 0.459 & 0.700 & 52.4\% & 0.459 & 0.700 & $52.5 \%$ & 0.453 & 0.7 & $54.4 \%$ & 0.446 & 0.70 & $56.9 \%$ \\
\hline & $\begin{array}{l}2002 \\
2003\end{array}$ & 1.000 & $\begin{array}{l}1.000 \\
1.000\end{array}$ & 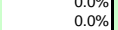 & $\begin{array}{l}1.1000 \\
1.000\end{array}$ & $\begin{array}{l}1.1 .000 \\
1.000\end{array}$ & 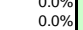 & $\begin{array}{l}1.1000 \\
0.938\end{array}$ & $\begin{array}{l}1.1000 \\
1.000\end{array}$ & 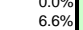 & $\begin{array}{l}1.0000 \\
0.922\end{array}$ & $\begin{array}{l}1.000 \\
1.000\end{array}$ & 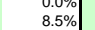 & 0.921 & $\begin{array}{l}1.1000 \\
1.000\end{array}$ & 每.0\%\% & 0.921 & $\begin{array}{l}1.000 \\
1.000\end{array}$ & $\begin{array}{l}0.0 \% \% \\
8.6 \%\end{array}$ \\
\hline \multirow{20}{*}{$\begin{array}{l}\text { TWSA On First of Month } \\
\end{array}$} & & & $\begin{array}{c}\text { April } \\
\text { Alternative }\end{array}$ & & & $\begin{array}{c}\text { May } \\
\text { Alternative }\end{array}$ & & & $\begin{array}{l}\text { June } \\
\text { Jternation }\end{array}$ & Pechro & & July & Pat $C$ ha & & August & & & September & \\
\hline & $\begin{array}{l}\text { Year } \\
1982 \\
\end{array}$ & $\frac{\text { Base }}{\text { B.455.023 }}$ & $\begin{array}{l}\text { Alternative } \\
3.535 .573\end{array}$ & $\frac{\text { Pct Chg }}{2.6 \%}$ & $\frac{\text { Base }}{3.1111 .013}$ & $\begin{array}{l}\text { Alternative } \\
3.144 .418\end{array}$ & Pct Chg & $\begin{array}{c}\text { Base } \\
25158.618\end{array}$ & $\begin{array}{l}\text { Alternative } \\
2476464\end{array}$ & Pct Chg & $\begin{array}{c}\text { Base } \\
1765875\end{array}$ & $\begin{array}{l}\text { Alternative } \\
\end{array}$ & Pct Chg & $\begin{array}{c}\text { Base } \\
12271330\end{array}$ & $\begin{array}{l}\text { Alternative } \\
1377^{2682}\end{array}$ & Pct Chg & $\begin{array}{l}\text { Base } \\
826639\end{array}$ & $\begin{array}{l}\text { Alternative } \\
100934345\end{array}$ & $\begin{array}{l}\text { Pct Chg } \\
221010\end{array}$ \\
\hline & 1983 & $3,390,500$ & 3,469,287 & $2.3 \%$ & $\begin{array}{l}\text {, } \\
2,920,7713\end{array}$ & $\begin{array}{l}3,144,418 \\
2,988,153\end{array}$ & 2.3\% & $\begin{array}{l}2,4,485,618 \\
2,309,257\end{array}$ & $\begin{array}{l}2,4,66,4600 \\
2,362,682\end{array}$ & 2.3\% & $\begin{array}{l}1,6759,815 \\
1,709,447\end{array}$ & $\begin{array}{l}1,880,854 \\
1,741,349\end{array}$ & $1.9 \%$ & $\begin{array}{l}1,211,330 \\
1,236,846\end{array}$ & $\begin{array}{l}1,388,682 \\
1,336,683\end{array}$ & 8.1\% & 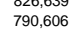 & $\begin{array}{l}1,009,345 \\
967,916\end{array}$ & $22.4 \%$ \\
\hline & 1984 & $3,286,618$ & 33 & $1.9 \%$ & $2,893,845$ & $2,936,650$ & $1.5 \%$ & $2,479,559$ & $2,417,495$ & $-2.5 \%$ & $1,779,942$ & 78 & $3.7 \%$ & $1,277,044$ & & $8.3 \%$ & 832.721 & 886 & $21.9 \%$ \\
\hline & & 06,493 & $2,984,567$ & $6.3 \%$ & $2,437,602$ & $2,577,402$ & $5.7 \%$ & 1,998,693 & & $3.0 \%$ & $1,505,885$ & 1,55 & $\%$ & $1,065,032$ & 1,17 & $10.7 \%$ ] & 629,785 & 811,559 & $28.9 \%$ \\
\hline & 1986 & & 33 & $7.1 \%$ & $2,245,607$ & $2,397,943$ & $6.8 \%$ & $1,804,030$ & 1,8 & $5.3 \%$ & 1,35 & 1,45 & $6.8 \%$ & 921,826 & 1,08 & $17.2 \%$ & 502,356 & & $44.3 \%$ \\
\hline & 1987] & $2,335,499$ & $2,489,705$ & $6.6 \%$ & $2,019,340$ & 2,161,515 & $7.0 \%$ & $1,530,345$ & $1,639,674$ & $7.1 \%$ & $1,141,415$ & $1,266,278$ & $10.9 \%$ & 748,243 & 910 & $21.7 \%$ & 369,238 & & \\
\hline & ${ }_{1988}^{1980}$ & $\begin{array}{l}2,360,115 \\
2714251\end{array}$ & $\begin{array}{l}2,577,874 \\
29030377\end{array}$ & $9.2 \%$ & $\begin{array}{l}1,977,808 \\
0.808\end{array}$ & $\begin{array}{r}2,188,003 \\
2\end{array}$ & $10.6 \%$ & $\begin{array}{l}1,567,951 \\
1828890\end{array}$ & $\begin{array}{l}1,731,972 \\
1\end{array}$ & 10.5\% & $\begin{array}{l}1,175,239 \\
139355\end{array}$ & $\begin{array}{l}1,354,760 \\
148,556\end{array}$ & $15.3 \% \%$ & $\begin{array}{l}777,408 \\
7508\end{array}$ & $\begin{array}{l}982,021 \\
9827\end{array}$ & $27.3 \%$ & $\begin{array}{l}386,663 \\
{ }_{3}^{2}\end{array}$ & $\begin{array}{l}638,140 \\
6307\end{array}$ & $65.1 \%$ \\
\hline & 1980 & , & $\begin{array}{l}2,9,90,3017 \\
32323\end{array}$ & 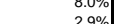 & $\begin{array}{l}2,263,196 \\
2,571901\end{array}$ & 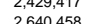 & 年, & $\begin{array}{l}1,828,280 \\
2,727\end{array}$ & $\begin{array}{l}1,921,480 \\
2,11505\end{array}$ & $5.4 \%$ & 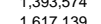 & (6) & . & $\begin{array}{l}952,242 \\
1126842\end{array}$ & $1,082,311$ & 13.6\% & 5251,510 & 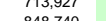 & $36.9 \%$ \\
\hline & $\begin{array}{l}19911 \\
1991\end{array}$ & 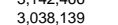 & $\begin{array}{l}3,2,24,239 \\
3,101,141\end{array}$ & $2.1 \%$ & $\begin{array}{l}2,62,231 \\
2\end{array}$ & $\begin{array}{l}2,644,458 \\
2,663,364\end{array}$ & $\begin{array}{l}2.6 \% \% \\
1.6 \%\end{array}$ & $\begin{array}{l}2,1,12,464 \\
2,167,928\end{array}$ & $\begin{array}{l}2,118,525 \\
2,154,416\end{array}$ & 年 & $\begin{array}{l}1,667,139 \\
1,664,369\end{array}$ & 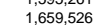 & - & $\begin{array}{l}1,1,160,844 \\
12652\end{array}$ & $\begin{array}{l}1,217,063 \\
127063\end{array}$ & 6 & $\begin{array}{l}7.30,061 \\
765732\end{array}$ & $\begin{array}{l}848,400 \\
91049\end{array}$ & $\begin{array}{l}16.3 \% \% \\
180 \%\end{array}$ \\
\hline & 1992 & 476 & $2,325,023$ & $7.7 \%$ | & $1,909,985$ & $2,046,595$ & $7.2 \%$ & $1,538,304$ & $1,599,827$ & $4.0 \%$ & $1,152,100$ & $1,225,080$ & $6.3 \%$ & 762,107 & 880,225 & $15.5 \%$ & 386,269 & & . \\
\hline & 1993 & 10,385 & $2,320,310$ & $9.9 \%$ & $1,843,988$ & $2,029,974$ & $10.1 \%$ & $1,430,982$ & $1,554,193$ & $8.6 \%$ & $1,066,030$ & $1,186,303$ & $11.3 \%$ & 695,869 & 844,607 & $21.4 \%$ & 343,100 & & $57.3 \%$ \\
\hline & $\begin{array}{l}{ }_{1}^{19994} \\
1995\end{array}$ & $\begin{array}{l}1,749,881 \\
2,930,020\end{array}$ & $\begin{array}{l}2,0,010,824 \\
2,950,873\end{array}$ & 年. & $\begin{array}{l}1,4552,215 \\
2,580,256\end{array}$ & $\begin{array}{l}1,705,257 \\
2,583,291\end{array}$ & $\begin{array}{r}17.4 \% \\
0.1 \%\end{array}$ & $\begin{array}{l}1,145,307 \\
2,022,644\end{array}$ & $\begin{array}{l}1,281,348 \\
2,014,053\end{array}$ & 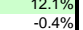 & $\begin{array}{c}862,326 \\
1,510,108\end{array}$ & $\begin{array}{c}924,4077 \\
1,522,800\end{array}$ & $\begin{array}{l}7.22 \% \\
0.8 \% \\
\end{array}$ & $\begin{array}{l}\begin{array}{c}571,1,196 \\
1.050,094\end{array} \\
\text { S }\end{array}$ & $\begin{array}{r}596,4,49 \\
1,142,233\end{array}$ & $\begin{array}{l}4.4 \\
8.8\end{array}$ & $\begin{array}{l}2900,37 \\
615,238\end{array}$ & $\begin{array}{l}314,4607 \\
774,789\end{array}$ & $\begin{array}{r}8.4 \% \% \\
25.5 \%\end{array}$ \\
\hline & 1996 & $3,232,316$ & $3,295,113$ & 1.9\% & $\begin{array}{l}2,300,050 \\
2,613,245\end{array}$ & $\begin{array}{l}2,038,291 \\
2,675,650\end{array}$ & $2.4 \%$ & $\begin{array}{l}2,0<2,044 \\
2,131,115\end{array}$ & $2,150,230$ & . & $\begin{array}{l}1,615,539 \\
1\end{array}$ & $\begin{array}{l}1,1322,800 \\
1,625,032\end{array}$ & . $0.6 \% \%$ & $\begin{array}{l}1,0,100,0,044 \\
1,71,852\end{array}$ & $\begin{array}{l}1,1,242,433 \\
1,246,473\end{array}$ & 6.4 & 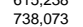 & $\begin{array}{l}817,179 \\
880,566\end{array}$ & \\
\hline & 1997] & $4,458,054$ & $\begin{array}{l}4,643,946 \\
\end{array}$ & $2.1 \%$ & $\begin{array}{l}2,75,040 \\
3\end{array}$ & $\begin{array}{l}2,829,628 \\
3,82,628\end{array}$ & $2.1 \%$ & $\begin{array}{l}2,121,1183 \\
2,821\end{array}$ & $2,699,331$ & $3.0 \%$ & $\begin{array}{l}1,912,826 \\
1,10\end{array}$ & $1,1977,675$ & $3.4 \%$ & 1.381 .597 & $1.465,311$ & $6.1 \%$ & $\begin{array}{l}932,328 \\
932,0\end{array}$ & 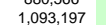 & $\begin{array}{l}17.3 \% \\
173 \%\end{array}$ \\
\hline & 1998 & $3,167,633$ & $3,227,047$ & $1.9 \%$ & $2,6993,913$ & $2,758,719$ & $2.4 \%$ & $2,009,134$ & $2,073,149$ & $3.2 \%$ & $1,500,375$ & $1,512,630$ & $0.8 \%$ & $1,065,654$ & $1,139,485$ & $6.9 \%$ & 630,353 & 771,596 & $22.4 \%$ \\
\hline & & 4,036,0944 & $\begin{array}{l}4,129,078 \\
\end{array}$ & $2.3 \%$ & $\begin{array}{l}3,583,732 \\
\end{array}$ & $3,6477,871$ & 1.8\% & $2,843,055$ & $2,908,033$ & $2.3 \%$ / & $2,111,556$ & $2,176,5344$ & $3.1 \%[$ & $1,478,312$ & $1,550,457$ & & $1,025,912$ & 1,16 & $13.4 \%$ \\
\hline & 2001 & $\begin{array}{l}3,286,264 \\
1,857,197\end{array}$ & $\begin{array}{l}3,3020,309 \\
2,056,063\end{array}$ & $\begin{array}{l}1.0 \% \\
10.7 \%\end{array}$ & $\begin{array}{l}2,678,612 \\
1,631,300\end{array}$ & $\begin{array}{l}2,1,33,166 \\
1,802,206\end{array}$ & $\begin{array}{r}2.0 \% \% \\
10.5 \%\end{array}$ & $\begin{array}{l}2,200,665 \\
1,310,142\end{array}$ & $\begin{array}{l}2,2808,6997 \\
1,362,392\end{array}$ & 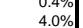 & $\begin{array}{c}1,6615,996 \\
982,608\end{array}$ & $\begin{array}{l}1,663,689 \\
1,001,321\end{array}$ & $\begin{array}{l}3.0 \% \% \\
1.9 \%\end{array}$ & $\begin{array}{l}1,1,66,1,148 \\
650,165\end{array}$ & $\begin{array}{c}1,266,159 \\
676,322\end{array}$ & $\begin{array}{l}8.6 \% \\
4.0 \%\end{array}$ & $\begin{array}{l}3744,253 \\
325,751\end{array}$ & $\begin{array}{l}90,2,234 \\
386,018\end{array}$ & $\begin{array}{l}22.9 \% \\
18.5 \%\end{array}$ \\
\hline & 2002 & $\begin{array}{l}3,269,823 \\
, 61509\end{array}$ & $3,339,478$ & $2.1 \%$ & $\begin{array}{l}2,799,652 \\
, 79,620\end{array}$ & $\begin{array}{l}2,839,025 \\
24170093\end{array}$ & $1.4 \%$ & $2,292,068$ & $2,287,638$ & $-0.2 \%$ & $1,644,665$ & $1,701,494$ & $25 \%$ & $1,178,350$ & $1,264,281$ & 78 & 744,260 & 897,603 & $20.6 \%$ \\
\hline & & & & & & & & & & & & & & & & & & & \\
\hline
\end{tabular}

Figure 4-3. Bull trout outmigration, proration, and TWSA tables from yearly summary page for the Black Rock_2 scenario. 
Reservoir storage

End of Season Carryover

Bumping

Cle Elum

Kachess

Keechelus

Rimrock

\begin{tabular}{|c|c|c|c|c|c|c|c|c|c|c|c|c|c|c|c|}
\hline Year & Base & Alternative & Pct Chg & Base & Alternative & Pct Chg & Base & Alternative & Pct Chg & Base & Alternative & Pct Chg & Base & Alternative & Pct Chg \\
\hline 1981 & 10,563 & $\begin{array}{ll}12,024 \\
\end{array}$ & $13.8 \%$ & 52,640 & 121,868 & $131.5 \%$ & 112,061 & 148,548 & $32.6 \%$ & 10,890 & 21,795 & $100.1 \% \mid$ & 66,230 & 86,333 & \\
\hline 1982 & 14,883 & 15,217 & $2.2 \%$ & 160,780 & 293,228 & $82.4 \%$ & 118,393 & 153,703 & $29.8 \%$ & 71,613 & 54,346 & $-24.1 \%$ & 61,539 & 97,192 & $57.9 \%$ \\
\hline 1983 & 11,601 & 15,094 & $30.1 \%$ & 152,349 & 266,418 & $74.9 \%$ & 109,269 & 144,071 & $31.8 \%$ & 45,961 & 23,551 & $-48.8 \%$ & 55,473 & 106,597 & \\
\hline 1984 & 13,285 & 14,617 & $10.0 \%$ & 162,323 & 292,375 & $80.1 \%$ & 112,808 & 150,057 & $33.0 \%$ & 69,658 & 49,623 & $-28.8 \%$ & 76,395 & 112,253 & \\
\hline 1985 & 10,858 & 12,671 & $16.7 \%$ & 77,663 & 177,812 & $129.0 \%$ & 92,510 & 127,112 & $37.4 \%$ & 11,467 & 41,924 & $265.6 \%$ & 31,333 & 40,075 & \\
\hline 1986 & 7,810 & 11,315 & $44.9 \%$ & 22,361 & 129,394 & $478.7 \%$ & 92,465 & 117,238 & $26.8 \%$ & 5,434 & 27,924 & $413.9 \%$ & 51,578 & 31,796 & \\
\hline 1987 & 3,115 & 7,363 & $136.3 \%$ & 4,613 & & $844.6 \%$ & 28,564 & & $357.8 \%$ & 1,815 & & $104.3 \%$ & & 49,710 & $840.8 \%$ \\
\hline 1988] & 5,564 & 10,061 & $80.8 \%$ & 35,587 & 99,466 & $179.5 \%$ & 29,531 & 138,874 & $370.3 \%$ & 14,269 & 28,249 & $98.0 \%$ & 32,254 & 60,173 & \\
\hline 1989 & 8,461 & & $30.4 \%$ & 38,835 & 118,308 & $204.6 \%$ & 97,628 & 117,577 & $20.4 \%$ & & & $1136.6 \%$ & & 17,071 & $64.8 \%$ \\
\hline${ }_{1990}^{1990}$ & $\begin{array}{l}14,742 \\
078\end{array}$ & $\begin{array}{l}15,149 \\
\end{array}$ & $2.8 \%$ & $\begin{array}{l}142,357 \\
131231\end{array}$ & $\begin{array}{l}216,166 \\
\end{array}$ & $51.8 \%$ & $\begin{array}{l}121,753 \\
105\end{array}$ & $\begin{array}{l}146,822 \\
13766\end{array}$ & $20.6 \%$ & $\begin{array}{l}54,526 \\
55778\end{array}$ & & $\begin{array}{r}2.3 \% \\
\end{array}$ & 38,584 & 47,623 & \\
\hline $\begin{array}{l}1991 \\
1992\end{array}$ & $\begin{array}{l}9,978 \\
3,249\end{array}$ & $\begin{array}{c}12,092 \\
7,216\end{array}$ & $\begin{array}{r}21.2 \% \\
122.1 \%\end{array}$ & $\begin{array}{l}134,231 \\
132303\end{array}$ & $\begin{array}{l}250,439 \\
667774\end{array}$ & $\begin{array}{r}86.6 \% \\
426.5 \%\end{array}$ & $\begin{array}{l}105,208 \\
22546\end{array}$ & $\begin{array}{l}137,660 \\
124,464\end{array}$ & $\begin{array}{r}30.8 \% \\
321.3 \%\end{array}$ & $\begin{array}{r}58,778 \\
9198\end{array}$ & & $-56.8 \%$ & $\begin{array}{r}34,780 \\
\end{array}$ & 56,147 & $61.4 \%$ \\
\hline $\begin{array}{l}1992 \\
1993\end{array}$ & $\begin{array}{l}3,249 \\
2,116\end{array}$ & $\begin{array}{l}7,216 \\
6702\end{array}$ & $\begin{array}{l}122.1 \% \\
2167 \%\end{array}$ & $\begin{array}{l}12,303 \\
4672\end{array}$ & $\begin{array}{l}64,774 \\
1\end{array}$ & $426.5 \%$ & $\begin{array}{r}29,546 \\
0.951\end{array}$ & $\begin{array}{l}124,464 \\
135\end{array}$ & $\begin{array}{r}321.3 \% \\
\end{array}$ & $\begin{array}{r}9,198 \\
2,87\end{array}$ & $\begin{array}{l}16,486 \\
271\end{array}$ & $\begin{array}{r}79.2 \% \\
3.0 \%\end{array}$ & $\begin{array}{l}27,405 \\
2778\end{array}$ & $\begin{array}{l}47,134 \\
70.64\end{array}$ & $\begin{array}{l}72.0 \% \\
78320\end{array}$ \\
\hline $\begin{array}{l}1993 \\
1994\end{array}$ & $\begin{array}{l}2,116 \\
2,136\end{array}$ & 2,132 & $\begin{array}{r}216.7 \% \\
-2.2 \%\end{array}$ & $\begin{array}{l}4,672 \\
6087\end{array}$ & $\begin{array}{c}12,214 \\
4,256\end{array}$ & $\begin{array}{l}161.4 \% \\
-30.1 \%\end{array}$ & $\begin{array}{l}9,951 \\
4514\end{array}$ & $\begin{array}{c}135,302 \\
9781\end{array}$ & $\begin{array}{r}1259.7 \% \\
1167 \%\end{array}$ & 2,1 & $\begin{array}{l}2,271 \\
3,925\end{array}$ & $\begin{array}{r}3.9 \% \\
710 \%\end{array}$ & $\begin{array}{c}24,798 \\
2992\end{array}$ & $\begin{array}{c}70,164 \\
2026\end{array}$ & $\begin{array}{l}183.2 \% \\
-32.3 \%\end{array}$ \\
\hline 1995 & 14,392 & 14,868 & $3.3 \%$ & $\begin{array}{l}0,017 \\
144,122\end{array}$ & 226,712 & $57.3 \%$ & 78,164 & 98,129 & $25.5 \%$ & 16,372 & 16,407 & $0.2 \%$ & $\begin{array}{l}2,, 992 \\
50,364\end{array}$ & $\begin{array}{l}8,020 \\
88,350\end{array}$ & 75.4 \\
\hline 1996 & 12,083 & 12,91 & $6.9 \%$ & 132,560 & 224,318 & $69.2 \%$ & 102,781 & 138 & $34.5 \%$ & 52,079 & 27,494 & $-47.2 \%$ & 45,193 & 75,922 & 68.0 \\
\hline 1997 & 15,349 & 15,9 & $3.7 \%$ & 250,810 & 35 & $42.8 \%$ & 136 & 169 & $24.1 \%$ & 85 & 73 & $-14.2 \%$ & 142,661 & 164,381 & $15.2 \%$ \\
\hline 1998 & 9,492 & 11,4 & $20.3 \%$ & 89,0 & & $83.0 \%$ & 96 & & $29.2 \%$ & 4,6 & & $369.1 \%$ & 31,714 & 44,227 & 39.5 \\
\hline 1999 & 15,395 & 12,5 & $-18.4 \%$ & 315,2 & 379 & 20.3 & 136 & & $12.9 \%$ & 79, & 2 & $7.7 \%$ & 78, & 138 & 76. \\
\hline 2000 & 13,226 & 15 & $13.7 \%$ & 131, & 227 & 73. & 117 & & $24.2 \%$ & 40 & 3 & $30.3 \%$ & 51 & 2 & 41. \\
\hline 2001 & 2,217 & 3,101 & $39.9 \%$ & 8,494 & & $-0.5 \%$ & & & $272.0 \%$ & & & $3.6 \%$ & & 22,562 & \\
\hline 2002 & 10,986 & 12,873 & $17.2 \%$ & 122,529 & 225,940 & $84.4 \%$ & 110,427 & 134,957 & $22.2 \%$ & 44,164 & 47,407 & $7.3 \%$ & 35,064 & 47,699 & 36.0 \\
\hline
\end{tabular}

Critical Reservoir Storage

Smolt Passage
Days below threshold

Cle Elum

\begin{tabular}{|r|ccr|}
\multicolumn{1}{c}{ Year } & Base & $\begin{array}{c}\text { Cle Elum } \\
\text { Alternative }\end{array}$ & \multicolumn{1}{c|}{ Pct Chg } \\
\hline 1982 & 29 & 43 & $48.3 \%$ \\
1933 & 0 & 0 & $0.0 \%$ \\
1984 & 0 & 0 & $0.0 \%$ \\
1985 & 12 & 0 & $-100.0 \%$ \\
1986 & 0 & 0 & $0.0 \%$ \\
1987 & 32 & 27 & $-15.6 \%$ \\
1988 & 51 & 66 & $29.4 \%$ \\
1989 & 19 & 19 & $0.0 \%$ \\
1990 & 2 & 0 & $-100.0 \%$ \\
1992 & 0 & 0 & $0.0 \%$ \\
1993 & 47 & 62 & $31.9 \%$ \\
1994 & 51 & 66 & $29.4 \%$ \\
1995 & 12 & 41 & $241.7 \%$ \\
1996 & 0 & 0 & $0.0 \%$ \\
1997 & 0 & 0 & $0.0 \%$ \\
1998 & 0 & 0 & $0.0 \%$ \\
1999 & 0 & 0 & $0.0 \%$ \\
2000 & 0 & 0 & $0.0 \%$ \\
2001 & 66 & 66 & $0.0 \%$ \\
2002 & 23 & 55 & $139.1 \%$ \\
2003 & 0 & 0 & $0.0 \%$ \\
\hline
\end{tabular}

Figure 4-4. Reservoir storage tables from yearly summary page for the Black Rock_2 scenario. 


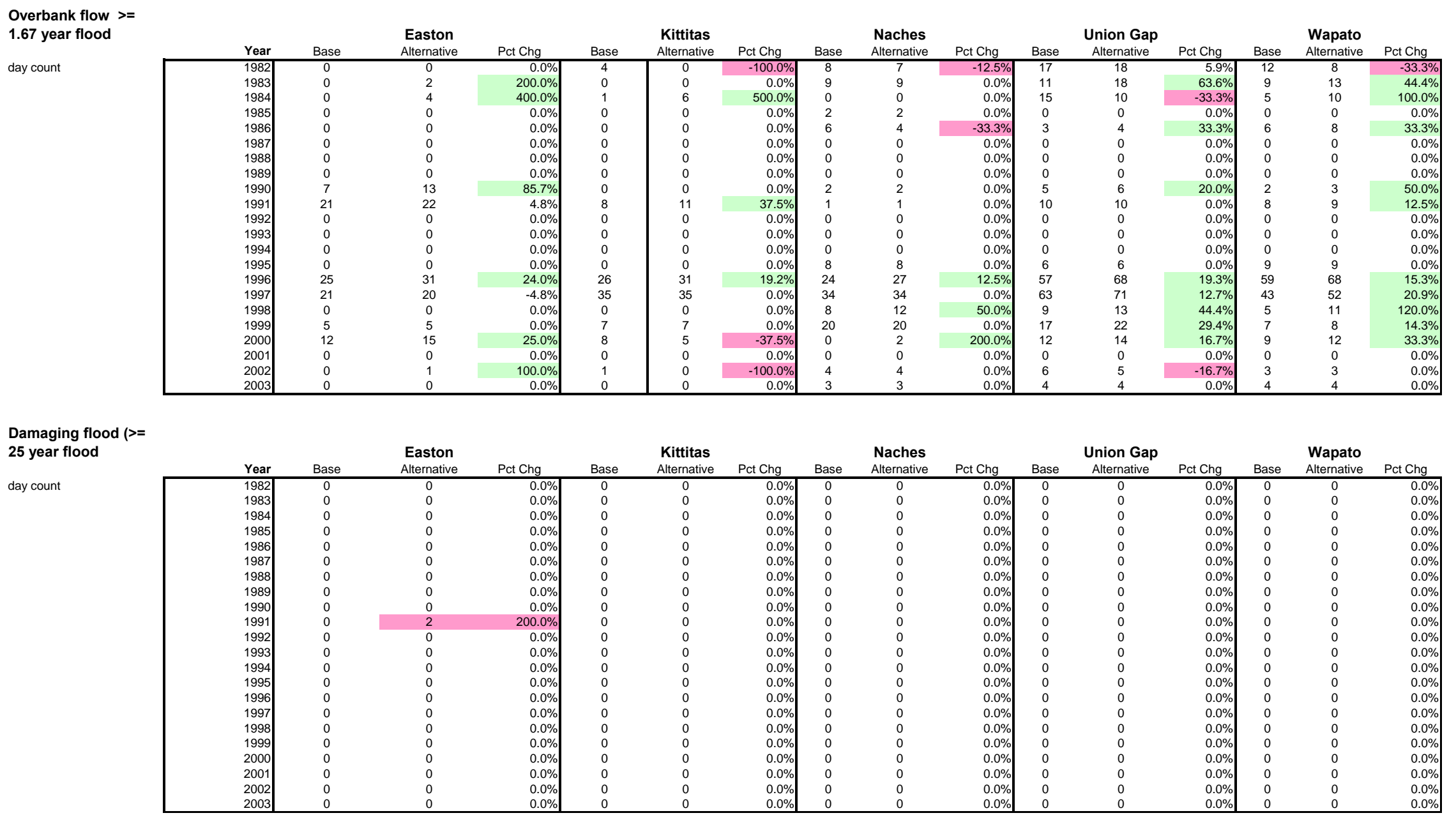

Figure 4-5. Overbank flow and damaging flood tables from yearly summary page for the Black Rock_2 scenario. 


\begin{tabular}{|c|c|c|c|c|c|c|c|c|c|c|c|c|c|c|c|c|}
\hline \multirow{2}{*}{$\begin{array}{l}\text { Sediment Transport } \\
\text { Fine-Material } \\
\text { Transport }\end{array}$} & \multirow[b]{2}{*}{ Year } & \multicolumn{3}{|c|}{ Easton } & \multicolumn{3}{|c|}{ Kittitas } & \multicolumn{3}{|c|}{ Naches } & \multicolumn{3}{|c|}{ Union Gap } & \multicolumn{3}{|c|}{ Wapato } \\
\hline & & Base & Alternative & Pct Chg & Base & Alternative & Pct Chg & Base & Alternative & Pct Chg & Base & Alternative & Pct Chg & Base & Alternative & Pct Chg \\
\hline & 1982 & 9 & 12 & $33.3 \%$ & 108 & 103 & $-4.7 \%$ & 64 & 63 & $-1.6 \%$ & 220 & 229 & $4.0 \%$ & 142 & 171 & $20.2 \%$ \\
\hline & 1983 & 8 & 9 & $22.9 \%$ & 110 & 108 & $-2.3 \%$ & 66 & 65 & $-2.3 \%$ & 209 & 225 & $7.3 \%$ & 140 & 170 & $21.3 \%$ \\
\hline & 1984 & 10 & 11 & $10.5 \%$ & 111 & 105 & $-5.2 \%$ & 56 & 57 & $0.5 \%$ & 205 & 221 & $7.6 \%$ & 134 & 165 & $23.3 \%$ \\
\hline & 1985 & 7 & 6 & $-17.3 \%$ & 74 & 72 & $-2.1 \%$ & 35 & 36 & $1.8 \%$ & 114 & 133 & $16.5 \%$ & 43 & 83 & $93.5 \%$ \\
\hline & 1986 & 7 & 7 & $-0.8 \%$ & 81 & 79 & $-2.5 \%$ & 42 & 41 & $-0.7 \%$ & 137 & 155 & $13.0 \%$ & 76 & 110 & $45.0 \%$ \\
\hline & 1987 & 10 & 6 & $-35.0 \%$ & 63 & 61 & $-2.9 \%$ & 36 & 33 & $-8.5 \%$ & 106 & 120 & $12.4 \%$ & 51 & 80 & $57.8 \%$ \\
\hline & 1988 & 6 & 5 & $-21.9 \%$ & 58 & 51 & $-11.4 \%$ & 27 & 29 & $6.5 \%$ & 93 & 105 & $12.7 \%$ & 37 & 64 & $72.1 \%$ \\
\hline & 1989 & 6 & 9 & $48.4 \%$ & 75 & 76 & $0.3 \%$ & 37 & 41 & $11.2 \%$ & 122 & 149 & $22.5 \%$ & 57 & 101 & $76.2 \%$ \\
\hline & 1990 & 11 & 15 & $37.3 \%$ & 100 & 100 & $0.1 \%$ & 47 & 45 & $-5.0 \%$ & 161 & 175 & $8.8 \%$ & 89 & 125 & $39.9 \%$ \\
\hline & 1991 & 21 & 29 & $36.5 \%$ & 133 & 131 & $-1.3 \%$ & 53 & 51 & $-4.0 \%$ & 222 & 236 & $6.2 \%$ & 149 & 185 & $23.5 \%$ \\
\hline & 1992 & 11 & 5 & $-50.4 \%$ & 76 & 70 & $-8.3 \%$ & 24 & 23 & $-5.1 \%$ & 101 & 111 & $10.0 \%$ & 48 & 70 & $47.0 \%$ \\
\hline & 1993 & 7 & 4 & $-37.7 \%$ & 57 & 54 & $-5.5 \%$ & 24 & 22 & $-7.4 \%$ & 77 & 87 & $13.9 \%$ & 28 & 48 & $68.9 \%$ \\
\hline & 1994 & 7 & 8 & $1.9 \%$ & 43 & 47 & $8.4 \%$ & 20 & 22 & $7.8 \%$ & 64 & 76 & $19.1 \%$ & 25 & 43 & $74.2 \%$ \\
\hline & 1995 & 6 & 6 & $0.4 \%$ & 87 & 78 & $-10.9 \%$ & 63 & 61 & $-3.7 \%$ & 189 & 192 & $1.4 \%$ & 124 & 151 & $21.6 \%$ \\
\hline & 1996 & 23 & 29 & $24.8 \%$ & 206 & 202 & $-1.8 \%$ & 111 & 112 & $0.8 \%$ & 385 & 380 & $-1.1 \%$ & 320 & 339 & $6.0 \%$ \\
\hline & 1997 & 21 & 25 & $21.6 \%$ & 177 & 170 & $-4.0 \%$ & 106 & 104 & $-1.4 \%$ & 339 & 346 & $1.9 \%$ & 271 & 286 & $5.5 \%$ \\
\hline & 1998 & 9 & 9 & $8.2 \%$ & 99 & 97 & $-2.3 \%$ & 61 & 63 & $3.3 \%$ & 197 & 213 & $8.4 \%$ & 121 & 155 & $28.0 \%$ \\
\hline & 1999 & 13 & 16 & $25.3 \%$ & 113 & 112 & $-0.7 \%$ & 91 & 89 & $-3.2 \%$ & 238 & 251 & $5.4 \%$ & 156 & 183 & $17.5 \%$ \\
\hline & 2000 & 14 & 17 & $22.3 \%$ & 119 & 112 & $-5.8 \%$ & 56 & 58 & $4.0 \%$ & 213 & 220 & $3.6 \%$ & 135 & 166 & $23.0 \%$ \\
\hline & 2001 & 11 & 8 & $-29.1 \%$ & 47 & 53 & $12.7 \%$ & 15 & 15 & $-3.4 \%$ & 61 & 76 & $23.7 \%$ & 19 & 38 & $99.4 \%$ \\
\hline & 2002 & 7 & 9 & $41.7 \%$ & 93 & 83 & $-11.4 \%$ & 55 & 55 & $-0.7 \%$ & 166 & 175 & $5.3 \%$ & 92 & 115 & $25.6 \%$ \\
\hline & 2003 & 5 & 5 & $-9.9 \%$ & 81 & 77 & $-5.1 \%$ & 46 & 46 & $0.7 \%$ & 133 & 145 & $9.4 \%$ & 69 & 103 & $49.5 \%$ \\
\hline \multirow{2}{*}{$\begin{array}{l}\text { Sediment Transport } \\
\text { Geomorphic } \\
\text { Adjustment }\end{array}$} & & \multicolumn{3}{|c|}{ Easton } & \multicolumn{3}{|c|}{ Kittitas } & \multicolumn{3}{|c|}{ Naches } & \multicolumn{3}{|c|}{ Union Gap } & \multicolumn{3}{|c|}{ Wapato } \\
\hline & Year & Base & Alternative & Pct Chg & Base & Alternative & Pct Chg & Base & Alternative & Pct Chg & Base & Alternative & Pct Chg & Base & Alternative & Pct Chg \\
\hline \multirow[t]{22}{*}{ Highest 15 -day period } & 1982 & 2,169 & 2,592 & \multirow{3}{*}{$\begin{array}{l}19.5 \% \\
70.9 \% \\
54.6 \%\end{array}$} & 28,267 & 21,670 & $-23.3 \%$ & 26,444 & 25,757 & \multirow{2}{*}{$\begin{array}{l}-2.6 \% \\
-2.1 \%\end{array}$} & 54,116 & 47,163 & $-12.8 \% \mid$ & 54,632 & 52,426 & \multirow{2}{*}{$\begin{array}{l}-4.0 \% \\
-9.3 \%\end{array}$} \\
\hline & 1983 & 1,862 & 3,183 & & 20,541 & 22,787 & $10.9 \%$ & 27,727 & 27,146 & & 48,440 & 44,994 & $-7.1 \%$ & 49,135 & 44,566 & \\
\hline & 1984 & 2,094 & 3,236 & & 29,298 & 22,200 & $-24.2 \%$ & 19,683 & 15,772 & $-19.9 \%$ & 46,531 & 40,384 & $-13.2 \%$ & 42,934 & 40,968 & $-4.6 \%$ \\
\hline & 1985 & 1,491 & 1,266 & $-15.1 \%$ & 16,861 & 15,108 & $-10.4 \%$ & 16,914 & 16,105 & $-4.8 \%$ & 26,503 & 28,756 & $8.5 \%$ & 18,404 & 25,221 & $37.0 \%$ \\
\hline & 1986 & 1,541 & 1,802 & $16.9 \%$ & 20,500 & 20,888 & $1.9 \%$ & 21,906 & 19,464 & $-11.1 \%$ & 44,021 & 45,793 & $4.0 \%$ & 45,110 & 46,813 & $3.8 \%$ \\
\hline & 1987 & 2,981 & 1,531 & $-48.6 \%$ & 15,064 & 11,387 & $-24.4 \%$ & 21,102 & 19,808 & $-6.1 \%$ & 27,821 & 32,821 & $18.0 \%$ & 20,645 & 25,987 & $25.9 \%$ \\
\hline & 1988 & 1,363 & 1,434 & $5.2 \%$ & 14,748 & 12,838 & $-12.9 \%$ & 10,830 & 11,055 & $2.1 \%$ & 24,447 & 27,741 & $13.5 \%$ & 17,295 & 22,934 & $32.6 \%$ \\
\hline & 1989 & 1,769 & 3,440 & $94.5 \%$ & 16,437 & 18,783 & $14.3 \%$ & 14,135 & 16,347 & $15.7 \%$ & 32,183 & 41,083 & $27.7 \%$ & 25,664 & 37,035 & $44.3 \%$ \\
\hline & 1990 & 3,908 & 5,332 & $36.4 \%$ & 23,391 & 25,648 & $9.6 \%$ & 20,177 & 18,560 & $-8.0 \%$ & 41,721 & 43,592 & $4.5 \%$ & 36,785 & 39,122 & $6.4 \%$ \\
\hline & 1991 & 6,306 & 10,224 & $62.1 \%$ & 33,455 & 39,073 & $16.8 \%$ & 11,899 & 12,015 & $1.0 \%$ & 53,978 & 54,519 & $1.0 \%$ & 53,978 & 54,519 & $1.0 \%$ \\
\hline & 1992 & 3,114 & 941 & $-69.8 \%$ & 15,855 & 15,164 & $-4.4 \%$ & 7,507 & 8,309 & $10.7 \%$ & 16,519 & 19,574 & $18.5 \%$ & 16,726 & 17,059 & $2.0 \%$ \\
\hline & 1993 & 2,619 & 997 & $-61.9 \%$ & 15,104 & 10,578 & $-30.0 \%$ & 13,243 & 13,571 & $2.5 \%$ & 19,135 & 21,983 & $14.9 \%$ & 9,585 & 15,008 & $56.6 \%$ \\
\hline & 1994 & 2,900 & 1,975 & $-31.9 \%$ & 10,293 & 10,185 & $-1.0 \%$ & 8,133 & 8,196 & $0.8 \%$ & 13,421 & 18,355 & $36.8 \%$ & 7,181 & 11,400 & $58.8 \%$ \\
\hline & 1995 & 1,613 & 1,722 & $6.8 \%$ & 19,374 & 19,904 & $2.7 \%$ & 21,146 & 21,866 & $3.4 \%$ & 46,684 & 44,183 & $-5.4 \%$ & 52,107 & 47,803 & $-8.3 \%$ \\
\hline & 1996 & 4,059 & 5,743 & $41.5 \%$ & 49,294 & 42,434 & $-13.9 \%$ & 36,404 & 36,702 & $0.8 \%$ & 84,914 & 72,424 & $-14.7 \%$ & 92,549 & 76,853 & $-17.0 \%$ \\
\hline & 1997 & 6,135 & 7,034 & $14.6 \%$ & 43,268 & 44,105 & $1.9 \%$ & 38,135 & 39,368 & $3.2 \%$ & 83,805 & 73,744 & $-12.0 \%$ & 76,280 & 70,708 & $-7.3 \%$ \\
\hline & 1998 & 2,568 & 2,844 & $10.7 \%$ & 25,532 & 23,153 & $-9.3 \%$ & 25,612 & 26,220 & $2.4 \%$ & 54,551 & 48,417 & $-11.2 \%[$ & 41,038 & 40,632 & $-1.0 \%$ \\
\hline & 1999 & 3,714 & 4,208 & $13.3 \%$ & 33,970 & 34,414 & $1.3 \%$ & 29,814 & 30,024 & $0.7 \%$ & 67,524 & 61,786 & $-8.5 \%$ & 56,020 & 51,747 & $-7.6 \%$ \\
\hline & 2000 & 4,342 & 6,762 & $55.7 \%$ & 25,439 & 26,939 & $5.9 \%$ & 17,858 & 17,982 & $0.7 \%$ & 51,898 & 43,975 & $-15.3 \%$ & 44,636 & 41,358 & $-7.3 \%$ \\
\hline & 2001 & 3,948 & 2,927 & $-25.9 \%$ & 11,486 & 12,302 & 7.1\% & 5,915 & 6,249 & $5.6 \%$ & 9,675 & 19,620 & $102.8 \%$ & 4,968 & 11,250 & $126.4 \%$ \\
\hline & 2002 & 1,474 & 3,232 & $119.3 \%$ & 23,429 & 15,361 & $-34.4 \%$ & 17,423 & 17,946 & $3.0 \%$ & 38,569 & $\begin{array}{l}37,226 \\
\end{array}$ & $-3.5 \%$ & 28,155 & 31,136 & $10.6 \%$ \\
\hline & 2003 & 1,301 & 1,389 & $6.8 \%$ & 16,474 & 14,803 & $-10.1 \%$ & 21,320 & 21,094 & $-1.1 \%$ & 32,035 & 32,025 & $0.0 \%$ & 32,733 & 33,315 & $1.8 \%$ \\
\hline
\end{tabular}

Figure 4-6. Fine-sediment transport and geomorphic adjustment tables from yearly summary page for the Black Rock_2 scenario. 


\begin{tabular}{|c|c|c|c|c|c|c|c|c|c|c|c|c|c|c|c|c|}
\hline \multirow{24}{*}{$\begin{array}{l}\text { Sediment Transport } \\
\text { Armor Disruption }\end{array}$} & & \multicolumn{3}{|c|}{ Easton } & \multicolumn{3}{|c|}{ Kittitas } & \multicolumn{3}{|c|}{ Naches } & \multicolumn{3}{|c|}{ Union Gap } & \multicolumn{3}{|c|}{ Wapato } \\
\hline & Year & Base & Alternative & $\frac{\text { Pct Chg }}{0.0 \%}$ & Base & Alternative & Pct Chg & Base & Alternative & Pct Chg & Base & Alternative & Pct Chg & Base & Alternative & Pct Chg \\
\hline & 1982 & 0 & 0 & $0.0 \%$ & 0 & 0 & $0.0 \%$ & 162 & 155 & $-4.3 \%$ & 0 & 0 & $0.0 \%$ & 0 & 0 & $0.0 \%$ \\
\hline & 1983 & 0 & 0 & $0.0 \%$ & 0 & 0 & $0.0 \%$ & 187 & 152 & $-18.7 \%$ & 0 & 0 & $0.0 \%$ & 0 & 0 & $0.0 \%$ \\
\hline & 1984 & 0 & 0 & $0.0 \%$ & 0 & 0 & $0.0 \%$ & 179 & 163 & $-8.9 \%$ & 0 & 0 & $0.0 \%$ & 0 & 0 & $0.0 \%$ \\
\hline & 1985 & 0 & 0 & $0.0 \%$ & 0 & 0 & $0.0 \%$ & 87 & 94 & $8.0 \%$ & 0 & 0 & $0.0 \%$ & 0 & 0 & $0.0 \%$ \\
\hline & 1986 & 0 & 0 & $0.0 \%$ & 0 & 0 & $0.0 \%$ & 111 & 117 & $5.4 \%$ & 0 & 0 & $0.0 \%$ & 0 & 0 & $0.0 \%$ \\
\hline & 1987 & 0 & 0 & $0.0 \%$ & 0 & 0 & $0.0 \%$ & 88 & 76 & $-13.6 \%$ & 0 & 0 & $0.0 \%$ & 0 & 0 & $0.0 \%$ \\
\hline & 1988 & 0 & 0 & $0.0 \%$ & 0 & 0 & $0.0 \%$ & 75 & 82 & $9.3 \%$ & 0 & 0 & $0.0 \%$ & 0 & 0 & $0.0 \%$ \\
\hline & 1989 & 0 & 0 & $0.0 \%$ & 0 & 0 & $0.0 \%$ & 85 & 107 & $25.9 \%$ & 0 & 0 & $0.0 \%$ & 0 & 0 & $0.0 \%$ \\
\hline & 1990 & 0 & 0 & $0.0 \%$ & 0 & 0 & $0.0 \%$ & 135 & 131 & $-3.0 \%$ & 0 & 0 & $0.0 \%$ & 0 & 0 & $0.0 \%$ \\
\hline & 1991 & 0 & 3 & $300.0 \%$ & 0 & 0 & $0.0 \%$ & 207 & 198 & $-4.3 \%$ & 0 & 0 & $0.0 \%$ & 0 & 0 & $0.0 \%$ \\
\hline & 1992 & 0 & 0 & $0.0 \%$ & 0 & 0 & $0.0 \%$ & 53 & 60 & $13.2 \%$ & 0 & 0 & $0.0 \%$ & 0 & 0 & $0.0 \%$ \\
\hline & 1993 & 0 & 0 & $0.0 \%$ & 0 & 0 & $0.0 \%$ & 51 & 46 & $-9.8 \%$ & 0 & 0 & $0.0 \%$ & 0 & 0 & $0.0 \%$ \\
\hline & 1994 & 0 & 0 & $0.0 \%$ & 0 & 0 & $0.0 \%$ & 50 & 47 & $-6.0 \%$ & 0 & 0 & $0.0 \%$ & 0 & 0 & $0.0 \%$ \\
\hline & 1995 & 0 & 0 & $0.0 \%$ & 0 & 0 & $0.0 \%$ & 191 & 168 & $-12.0 \%$ & 0 & 0 & $0.0 \%$ & 0 & 0 & $0.0 \%$ \\
\hline & 1996 & 0 & 0 & $0.0 \%$ & 0 & 0 & $0.0 \%$ & 262 & 234 & $-10.7 \%$ & 5 & 5 & $0.0 \%$ & 0 & 0 & $0.0 \%$ \\
\hline & 1997 & 0 & 0 & $0.0 \%$ & 0 & 0 & $0.0 \%$ & 205 & 188 & $-8.3 \%$ & 0 & 0 & $0.0 \%$ & 0 & 0 & $0.0 \%$ \\
\hline & 1998 & 0 & 0 & $0.0 \%$ & 0 & 0 & $0.0 \%$ & 150 & 152 & $1.3 \%$ & 0 & 0 & $0.0 \%$ & 0 & 0 & $0.0 \%$ \\
\hline & 1999 & 0 & 0 & $0.0 \%$ & 0 & 0 & $0.0 \%$ & 202 & 173 & $-14.4 \%$ & 0 & 0 & $0.0 \%$ & 0 & 0 & $0.0 \%$ \\
\hline & 2000 & 0 & 0 & $0.0 \%$ & 0 & 0 & $0.0 \%$ & 168 & 167 & $-0.6 \%$ & 0 & 0 & $0.0 \%$ & 0 & 0 & $0.0 \%$ \\
\hline & 2001 & 0 & 0 & $0.0 \%$ & 0 & 0 & $0.0 \%$ & 29 & 34 & $17.2 \%$ & 0 & 0 & $0.0 \%$ & 0 & 0 & $0.0 \%$ \\
\hline & 2002 & 0 & 0 & $0.0 \%$ & 0 & 0 & $0.0 \%$ & 128 & 123 & $-3.9 \%$ & 0 & 0 & $0.0 \%$ & 0 & 0 & $0.0 \%$ \\
\hline & 2003 & 0 & 0 & $0.0 \%$ & 0 & 0 & $0.0 \%$ & 147 & 136 & $-7.5 \%$ & 0 & 0 & $0.0 \%$ & 0 & 0 & $0.0 \%$ \\
\hline
\end{tabular}

Figure 4-7. Armor disruption table from yearly summary page for the Black Rock_2 scenario. 


\begin{tabular}{|c|c|c|c|c|c|c|c|c|c|c|c|c|c|c|c|c|c|c|c|c|}
\hline Spring Chinook & \multicolumn{3}{|c|}{ Redd Scour } & \multicolumn{3}{|c|}{ Spawning/incubation } & \multicolumn{3}{|c|}{ Fry } & \multicolumn{3}{|c|}{ Subyearling (Spring-summer) } & \multicolumn{3}{|c|}{ Subyearling (winter) } & \multicolumn{2}{|r|}{ Subadult } & \multicolumn{3}{|c|}{ Adult holding } \\
\hline & Base & Alternative & Pct Chg & Base & Alternative & Pct Chg & Base & Alternative & Pct Chg & Base & Alternative & Pct Chg & Base & Alternative & Pct Chg & Base & Alternative Pct Chg & Base & Alternative & Pct Chg \\
\hline 1982 & 0.008 & 0.013 & $66.2 \%$ & 47.55 & 48.73 & $2.47 \%$ & 2.23 & 2.17 & $-2.69 \%$ & 51.15 & 51.12 & $-0.08 \%$ & 6.89 & 6.41 & \begin{tabular}{|l|}
$-6.93 \%$ \\
\end{tabular} & & & 7.18 & 7.21 & $0.53 \%$ \\
\hline 1983 & 0.018 & 0.027 & $50.8 \%$ & 45.14 & 39.00 & $-13.60 \%$ & 2.24 & 2.41 & $7.65 \%$ & 60.44 & 59.56 & $-1.44 \%$ & 7.47 & 7.68 & $2.85 \%$ & & & 7.15 & 7.15 & $0.00 \%$ \\
\hline 1984 & 0.010 & 0.039 & $303.9 \%$ & 46.09 & 40.14 & $-12.90 \%$ & 2.38 & 2.34 & $-1.63 \%$ & 45.30 & 48.07 & $6.11 \%$ & 6.95 & 6.85 & $-1.40 \%$ & & & 7.15 & 7.34 & $2.71 \%$ \\
\hline 1985 & 0.008 & 0.008 & $0.0 \%$ & 52.88 & 52.88 & $0.00 \%$ & 2.86 & 2.42 & $-15.34 \%$ & 39.14 & 52.07 & $33.05 \%$ & 11.90 & 10.06 & $-15.48 \%$ & & & 7.95 & 7.44 & $-6.41 \%$ \\
\hline 1986 & 0.008 & 0.008 & $0.0 \%$ & 52.88 & 52.88 & $0.00 \%$ & 2.28 & 2.22 & $-2.58 \%$ & 43.43 & 56.52 & $30.15 \%$ & 9.03 & 7.52 & $-16.78 \%$ & & & 7.15 & 7.36 & $2.97 \%$ \\
\hline 1987 & 0.008 & 0.008 & $0.0 \%$ & 48.98 & 48.98 & $0.00 \%$ & 2.39 & 2.35 & $-1.64 \%$ & 37.96 & 52.00 & $36.98 \%$ & 9.74 & 8.84 & $-9.19 \%$ & & & 7.74 & 7.58 & $-2.08 \%$ \\
\hline 1988 & 0.008 & 0.008 & $0.0 \%$ & 52.88 & 52.88 & $0.00 \%$ & 2.35 & 2.35 & $-0.02 \%$ & 48.77 & 60.44 & $23.92 \%$ & 10.26 & 9.68 & $-5.68 \%$ & & & 7.15 & 7.15 & $0.00 \%$ \\
\hline 1980 & 0.008 & 0.008 & $0.0 \%$ & 52.23 & 52.88 & $1.24 \%$ & 2.93 & 2.48 & $-15.61 \%$ & 55.78 & 52.10 & $-6.61 \%$ & 7.99 & 7.48 & $-6.37 \%$ & & & 7.15 & 7.65 & $7.02 \%$ \\
\hline 1990 & 0.008 & 0.018 & $130.9 \%$ & 47.33 & 48.10 & $1.61 \%$ & 2.56 & 2.48 & $-3.08 \%$ & 49.86 & 52.91 & $6.12 \%$ & 7.44 & 7.27 & $-2.40 \%$ & & & 7.15 & 7.37 & $3.00 \%$ \\
\hline 1991 & 0.188 & 0.617 & $227.6 \%$ & 5.24 & 4.81 & $-8.25 \%$ & 2.53 & 2.41 & $-4.77 \%$ & 60.44 & 59.60 & $-1.38 \%$ & 6.84 & 6.92 & $1.11 \%$ & & & 7.15 & 7.15 & $0.00 \%$ \\
\hline 1992 & 0.008 & 0.008 & $0.0 \%$ & 52.88 & 52.88 & $0.00 \%$ & 2.59 & 2.46 & $-5.11 \%$ & 36.70 & 60.37 & $64.49 \%$ & 8.16 & 7.62 & $-6.52 \%$ & & & 7.52 & 7.16 & $-4.76 \%$ \\
\hline 1993 & 0.008 & 0.008 & $0.0 \%$ & 50.31 & 50.31 & $0.00 \%$ & 2.73 & 2.64 & $-3.23 \%$ & 37.21 & 54.45 & $46.34 \%$ & 11.56 & 10.77 & $-6.78 \%$ & & & 7.15 & 7.27 & $1.70 \%$ \\
\hline 1994 & 0.008 & 0.008 & $0.0 \%$ & 51.22 & 51.22 & $0.00 \%$ & 2.44 & 2.42 & $-0.81 \%$ & 42.53 & 37.85 & $-11.02 \%$ & 10.64 & 9.51 & $-10.60 \%$ & & & 7.15 & 8.22 & $15.02 \%$ \\
\hline 1995 & 0.008 & 0.008 & $0.0 \%$ & 52.88 & 52.88 & $0.00 \%$ & 2.46 & 2.45 & $-0.46 \%$ & 60.44 & 60.30 & $-0.22 \%$ & 7.72 & 7.72 & $0.00 \%$ & & & 7.15 & 7.15 & $0.00 \%$ \\
\hline 1996 & 0.102 & 0.122 & $19.6 \%$ & 15.47 & 5.25 & $-66.07 \%$ & 2.56 & 2.52 & $-1.64 \%$ & 59.85 & 58.59 & $-2.11 \%$ & 7.04 & 7.21 & $2.52 \%$ & & & 7.15 & 7.15 & $0.00 \%$ \\
\hline 1997 & 0.186 & 0.288 & $54.6 \%$ & 29.70 & 20.75 & $-30.15 \%$ & 2.33 & 2.42 & $4.05 \%$ & 46.59 & 47.34 & $1.62 \%$ & 7.35 & 7.57 & $3.07 \%$ & & & 7.36 & 7.38 & $0.24 \%$ \\
\hline 1998 & 0.008 & 0.019 & $135.6 \%$ & 52.88 & 44.31 & $-16.21 \%$ & 2.35 & 2.36 & $0.21 \%$ & 53.20 & 58.59 & $10.12 \%$ & 7.79 & 7.35 & $-5.72 \%$ & & & 7.42 & 7.15 & $-3.74 \%$ \\
\hline 1999 & 0.008 & 0.016 & $86.4 \%$ & 52.88 & 47.82 & $-9.57 \%$ & 2.27 & 2.21 & $-2.73 \%$ & 43.73 & 45.99 & $5.18 \%$ & 6.88 & 6.57 & $-4.46 \%$ & & & 8.01 & 7.73 & $-3.46 \%$ \\
\hline 2000 & 0.104 & 0.213 & $104.5 \%$ & 43.02 & 36.62 & $-14.87 \%$ & 2.65 & 2.57 & $-2.94 \%$ & 46.02 & 48.28 & $4.92 \%$ & 8.58 & 8.13 & $-5.33 \%$ & & & 8.15 & 7.43 & $-8.91 \%$ \\
\hline 2001 & 0.008 & 0.008 & $0.0 \%$ & 52.88 & 52.88 & $0.00 \%$ & 2.67 & 2.46 & $-7.98 \%$ & 33.76 & 40.01 & $18.50 \%$ & 12.00 & 10.34 & $-13.91 \%$ & & & 7.44 & 8.43 & $13.26 \%$ \\
\hline 2002 & 0.008 & 0.008 & $0.0 \%$ & & 54.07 & $-0.04 \%$ & 2.73 & 2.68 & $-1.65 \%$ & 46.57 & 40.22 & $-13.64 \%$ & & 8.76 & $-1.09 \%$ & & & 7.15 & 7.18 & $0.32 \%$ \\
\hline 2003 & 0.008 & 0.008 & $0.0 \%$ & 48.68 & 48.68 & $0.00 \%$ & 2.53 & 2.46 & $-2.99 \%$ & 55.23 & 60.28 & $9.15 \%$ & 10.25 & 9.35 & $-8.78 \%$ & & & 7.15 & 7.15 & $0.00 \%$ \\
\hline \multirow{24}{*}{$\begin{array}{l}\text { Y } \\
19 \\
19 \\
19 \\
19 \\
19\end{array}$} & \multicolumn{3}{|c|}{ Redd Scour } & \multicolumn{3}{|c|}{ Spawning/incubation } & \multicolumn{3}{|c|}{ Fry } & \multicolumn{3}{|c|}{ Subyearling (Spring-summer) } & \multicolumn{3}{|c|}{ Subyearling (winter) } & \multicolumn{2}{|r|}{ Subadult } & & Adult holdir & \\
\hline & Base & Alternative & Pct Chg & Base & Alternative & Pct Chg & Base & Alternative & Pct Chg & Base & Alternative & Pct Chg & Base & Alternative & Pct Chg & Base & Alternative Pct Chg & Base & Alternative & Pct Chg \\
\hline & 0.008 & 0.013 & $66.2 \%$ & 41.68 & 41.13 & $-1.33 \%$ & 2.22 & 2.14 & $-3.48 \%$ & 18.32 & 17.81 & $-2.78 \%$ & 4.57 & 4.39 & $-4.03 \%$ & & & & & \\
\hline & 0.018 & 0 & $508 \%$ & 40.40 & & $\%$ & 229 & 231 & $0.61 \%$ & 2528 & & $-6.4>2>$ & 4.60 & 479 & & & & & & \\
\hline & 0.010 & 0.039 & $303.9 \%$ & 40.59 & 37.23 & $-8.27 \%$ & 2.32 & 2.27 & $-2.44 \%$ & 15.60 & 16.55 & $6.08 \%$ & 4. & & & & & & & \\
\hline & 0.008 & 0.008 & $0.0 \%$ & 44.77 & 44.77 & $0.00 \%$ & 2.73 & 2.27 & $-16.86 \%$ & 10.48 & 16.56 & $58.04 \%$ & 7.50 & 7.2. & -3.40 & & & & & \\
\hline & 0.008 & 0.008 & $0.0 \%$ & 43.58 & 43.98 & $0.90 \%$ & 3.01 & 2.43 & $-19.20 \%$ & 11.77 & 18.05 & $53.34 \%$ & 5.51 & 5.2 & -5.06 & & & & & \\
\hline & 0.008 & 0.008 & $0.0 \%$ & 42.52 & 42.52 & $0.00 \%$ & 2.67 & 2.37 & $-11.13 \%$ & 11.71 & 15.13 & $29.20 \%$ & 5.90 & 5.91 & $0.00 \%$ & & & & & \\
\hline & 0.008 & 0.008 & $0.0 \%$ & 44.77 & 44.77 & $0.00 \%$ & 2.49 & 2.31 & $-7.33 \%$ & 14.49 & 24.16 & $66.78 \%$ & 6.27 & 6. & $0.00 \%$ & & & & & \\
\hline & 0.008 & 0.008 & $0.0 \%$ & 43.78 & 44.77 & $2.27 \%$ & 2.60 & 2.43 & $-6.57 \%$ & 17.80 & 15.19 & $-14.66 \%$ & 4.86 & 4. & $-0.04 \%$ & & & & & \\
\hline & 0.008 & 0.018 & $138.7 \%$ & 41.63 & 41.00 & $-1.52 \%$ & 2.69 & 2.44 & $-9.39 \%$ & 16. & 17.81 & $9.84 \%$ & 4.64 & 4. & $1.52 \%$ & & & & & \\
\hline & 0.069 & 0.083 & $21.0 \%$ & 3.43 & 3.15 & $-8.24 \%$ & 2.97 & 2.49 & $-16.27 \%$ & 25. & 21.72 & $-14.49 \%$ & 4.32 & 4. & $1.30 \%$ & & & & & \\
\hline & 0.008 & 0.008 & $0.0 \%$ & 43.46 & 44.65 & $2.72 \%$ & 3.04 & 2.47 & $-18.74 \%$ & 11.5 & 22.22 & $92.05 \%$ & 4.93 & 4.8 & $-0.99 \%$ & & & & & \\
\hline & 0.008 & 0.008 & $0.0 \%$ & 43.73 & 43.73 & $0.00 \%$ & 3.08 & 2.69 & $-12.75 \%$ & 10.92 & 16.84 & $54.22 \%$ & 7.20 & 7.0 & $-1.89 \%$ & & & & & \\
\hline & 0.008 & 0.008 & $0.0 \%$ & 43.95 & 43.95 & $0.00 \%$ & 2.59 & 2.37 & $-8.45 \%$ & 15.06 & 10.60 & $-29.60 \%$ & 6.52 & 6.56 & $0.55 \%$ & & & & & \\
\hline & 0.008 & 0.008 & $0.3 \%$ & 44.56 & 44.56 & $0.00 \%$ & 3.15 & 3.02 & $-3.93 \%$ & 25.42 & 23.89 & $-6.03 \%$ & 4.72 & 4.72 & $0.00 \%$ & & & & & \\
\hline & 0.102 & 0.122 & $19.6 \%$ & 10.47 & 3.43 & $-67.22 \%$ & 2.50 & 2.39 & $-4.51 \%$ & 23.25 & 21.64 & $-6.91 \%$ & 4.52 & 4.60 & $1.59 \%$ & & & & & \\
\hline & 0.186 & 0.288 & $54.6 \%$ & 24.50 & 16.85 & $-31.20 \%$ & 2.24 & 2.27 & $1.03 \%$ & 16.28 & 16.32 & $0.23 \%$ & 4.89 & 5.05 & $3.13 \%$ & & & & & \\
\hline & 0.008 & 0.019 & $138.2 \%$ & 43.75 & 40.23 & $-8.03 \%$ & 2.27 & 2.26 & $-0.46 \%$ & 14.85 & 22.60 & $52.19 \%$ & 4.95 & 4.64 & $-6.10 \%$ & & & & & \\
\hline & 0.008 & 0.016 & $86.4 \%$ & 42.96 & 40.94 & $-4.69 \%$ & 2.17 & 2.26 & $4.54 \%$ & 13.73 & 14.83 & $7.97 \%$ & 4.62 & 4.40 & $-4.76 \%$ & & & & & \\
\hline & 0.104 & 0.213 & $104.5 \%$ & 37.56 & 31.51 & $-16.11 \%$ & 2.69 & 2.47 & $-7.91 \%$ & 12.73 & 15.40 & $20.94 \%$ & 5.43 & 5.61 & $3.39 \%$ & & & & & \\
\hline & 0.008 & 0.008 & $0.0 \%$ & 44.77 & 44.77 & $0.00 \%$ & 2.68 & 2.41 & $-10.22 \%$ & 10.64 & 11.66 & $9.61 \%$ & 7.73 & 7.39 & $-4.40 \%$ & & & & & \\
\hline & 0.008 & 0.008 & $0.0 \%$ & 45.06 & 45.06 & $-0.01 \%$ & 2.84 & 2.56 & $-9.93 \%$ & 13.91 & 13.14 & $-5.54 \%$ & 5.49 & 5.47 & $-0.36 \%$ & & & & & \\
\hline & 0.008 & 0.008 & $0.0 \%$ & 42.44 & 42.44 & $0.00 \%$ & 2.96 & 2.55 & $-13.86 \%$ & 17.74 & 23.78 & $34.00 \%$ & 6.23 & 6.23 & $0.00 \%$ & & & & & \\
\hline
\end{tabular}

Figure 4-8. Annual habitat summaries for spring chinook and coho in the Easton reach for the Black Rock_2 scenario. 


\begin{tabular}{|c|c|c|c|c|c|c|c|c|c|c|c|c|c|c|c|c|c|c|c|c|c|}
\hline Steelhead & \multicolumn{3}{|c|}{ Redd Scour } & \multicolumn{3}{|c|}{ Spawning/incubation } & \multirow{2}{*}{\multicolumn{3}{|c|}{\begin{tabular}{lcl}
\multicolumn{3}{c}{ Fry } \\
Base & Alternative & Pct Chg
\end{tabular}}} & \multicolumn{3}{|c|}{ Subyearling (Spring-summer) } & \multicolumn{3}{|c|}{ Subyearling (winter) } & \multicolumn{3}{|c|}{$\begin{array}{l}\text { Subadult } \\
\end{array}$} & \multicolumn{3}{|c|}{ Adult holding } \\
\hline Year & Base & Alternative & Pct Chg & Base & Alternative & Pct Chg & & & & & Alternative & Pct Chg & Base & Alternative & Pct Chg & Base & Alternative & Pct Chg & Base & Alternative & \\
\hline 1982 & 0.010 & 0.011 & $6.2 \%$ & 51.66 & 53.91 & $4.35 \%$ & 4.34 & 4.22 & $-2.95 \%$ & $\begin{array}{l}64.03 \\
\end{array}$ & $\begin{array}{ll}64.03 \\
\end{array}$ & $0.00 \%$ & 6.53 & $\begin{array}{l}6.09 \\
\end{array}$ & $-6.71 \%$ & 53.67 & 553.36 & $-0.57 \%$ & 22.83 & 20.82 & $-8.82 \%$ \\
\hline 1983 & 0.008 & 0.008 & $4.7 \%$ & 52.27 & 51.22 & $-2.00 \%$ & 5.29 & 5.24 & $-0.88 \%$ & 64.03 & 64.03 & $0.00 \%$ & 6.46 & 6.75 & $4.47 \%$ & 62.49 & 62.49 & $0.00 \%$ & 21.78 & 21.49 & $-1.31 \%$ \\
\hline 1984 & 0.008 & 0.008 & $0.0 \%$ & 53.43 & 52.92 & $-0.95 \%$ & 4.42 & 4.19 & $-5.23 \%$ & 64.03 & 64.03 & $0.00 \%$ & 6.03 & 6.01 & $-0.37 \%$ & 55.73 & 57.58 & $3.33 \%$ & 21.81 & 21.46 & $-1.63 \%$ \\
\hline 1985 & 0.008 & 0.008 & $0.0 \%$ & 53.91 & 53.91 & $0.00 \%$ & 3.34 & 3.89 & $16.29 \%$ & 52.27 & 64.03 & $22.49 \%$ & 10.78 & 10.44 & $-3.16 \%$ & 58.31 & 58.73 & $0.72 \%$ & 23.86 & 24.05 & $0.83 \%$ \\
\hline 1986 & 0.008 & 0.011 & $37.6 \%$ & 53.91 & 53.91 & $0.00 \%$ & 3.37 & 4.16 & $23.56 \%$ & 58.91 & 64.03 & $8.69 \%$ & 7.87 & 7.47 & $-5.03 \%$ & 57.36 & 60.84 & $6.07 \%$ & 23.22 & 23.04 & $-0.78 \%$ \\
\hline 1987 & 0.008 & 0.008 & $0.0 \%$ & 51.52 & 51.52 & $0.00 \%$ & 3.87 & 3.46 & $-10.44 \%$ & 45.85 & 64.03 & $39.66 \%$ & 8.50 & 8.50 & $0.00 \%$ & 53.09 & 62.58 & $17.86 \%$ & 22.90 & 23.38 & $2.12 \%$ \\
\hline 1988 & 0.008 & 0.008 & $0.0 \%$ & 53.91 & 53.91 & $0.00 \%$ & 3.85 & 5.23 & $35.86 \%$ & 53.19 & 64.03 & $20.38 \%$ & 9.00 & 9.00 & $0.00 \%$ & 61.89 & 62.51 & $0.99 \%$ & 23.96 & 24.05 & $0.37 \%$ \\
\hline 1989 & 0.008 & 0.023 & $192.1 \%$ & 53.70 & 53.91 & $0.39 \%$ & 4.26 & 3.73 & $-12.51 \%$ & 63.87 & 64.03 & $0.25 \%$ & 7.00 & 6.96 & $-0.54 \%$ & 62.51 & 60.17 & $-3.73 \%$ & 25.25 & 24.17 & $-4.30 \%$ \\
\hline 1990 & 0.066 & 0.080 & $21.6 \%$ & 51.45 & 53.91 & $4.79 \%$ & 4.14 & 4.66 & $12.52 \%$ & 64.03 & 64.03 & $0.00 \%$ & 6.57 & 6.67 & $1.46 \%$ & 57.87 & 60.55 & $4.64 \%$ & 23.25 & 21.41 & $-7.93 \%$ \\
\hline 1991 & 0.105 & 0.134 & $27.9 \%$ & 50.35 & 51.43 & $2.15 \%$ & 5.29 & 5.24 & $-0.89 \%$ & 64.03 & 64.03 & $0.00 \%$ & 5.94 & 6.02 & $1.26 \%$ & 62.51 & 62.64 & $0.21 \%$ & 17.12 & 17.28 & $0.91 \%$ \\
\hline 1992 & 0.008 & 0.008 & $0.0 \%$ & 53.91 & 53.91 & $0.00 \%$ & 3.63 & 5.18 & $42.67 \%$ & 45.69 & 64.03 & $40.15 \%$ & 7.14 & 7.09 & $-0.68 \%$ & 51.33 & 62.71 & $22.18 \%$ & 22.87 & 23.94 & $4.67 \%$ \\
\hline 1993 & 0.008 & 0.008 & $0.0 \%$ & 51.59 & 51.59 & $0.00 \%$ & 3.43 & 3.78 & $10.49 \%$ & 40.50 & 63.49 & $56.79 \%$ & 10.42 & 10.24 & $-1.69 \%$ & 56.68 & 62.80 & $10.81 \%$ & 23.09 & 24.05 & $4.16 \%$ \\
\hline 1994 & 0.008 & 0.008 & $0.0 \%$ & 52.44 & 52.44 & $0.00 \%$ & 4.05 & 3.37 & $-16.74 \%$ & 43.02 & 62.79 & $45.96 \%$ & 9.42 & 9.47 & $0.53 \%$ & 55.35 & 54.74 & $-1.09 \%$ & 23.20 & 24.02 & $3.52 \%$ \\
\hline 1995 & 0.008 & 0.008 & $0.0 \%$ & 53.91 & 53.91 & $0.00 \%$ & 5.29 & 5.25 & $-0.78 \%$ & 64.03 & 64.03 & $0.00 \%$ & 6.80 & 6.80 & $0.00 \%$ & 62.51 & 62.51 & $0.00 \%$ & 23.49 & 23.49 & $0.00 \%$ \\
\hline 1996 & 0.035 & 0.043 & $22.4 \%$ & 52.16 & 50.33 & $-3.50 \%$ & 4.67 & 5.10 & $9.27 \%$ & 64.03 & 64.03 & $0.00 \%$ & 6.12 & 6.25 & $2.13 \%$ & 62.37 & 62.51 & $0.22 \%$ & 15.53 & 15.81 & $1.80 \%$ \\
\hline 1997 & 0.110 & 0.145 & $32.0 \%$ & 53.91 & 53.22 & $-1.28 \%$ & 4.17 & 4.14 & $-0.76 \%$ & 64.03 & 64.03 & $0.00 \%$ & 6.90 & 7.11 & $3.06 \%$ & 50.88 & 51.72 & $1.66 \%$ & 21.41 & 20.82 & $-2.75 \%$ \\
\hline 1998 & 0.017 & 0.019 & $7.7 \%$ & 53.91 & & $-4.96 \%$ & 3.68 & 5.23 & $42.33 \%$ & & & $2.98 \%$ & 7.05 & 6.57 & $-6.78 \%$ & 59.73 & 59.73 & $0.00 \%$ & 23.93 & 22.81 & $-4.70 \%$ \\
\hline 1999 & 0.088 & 0.104 & $18.0 \%$ & 53.91 & & & 3.84 & 4.09 & $6.48 \%$ & & & & 6.51 & 6.06 & $-6.96 \%$ & 50.89 & & & 22.56 & 21.39 & $-5.17 \%$ \\
\hline 2000 & 0.076 & 0.091 & $19.6 \%$ & 53.91 & 53.91 & $0.00 \%$ & 3.58 & 4.29 & $19.81 \%$ & 64.03 & 64.03 & $0.00 \%$ & 7.72 & 7.93 & $2.75 \%$ & 56.44 & 7.53 & $1.93 \%$ & 22.85 & 22.52 & $-1.45 \%$ \\
\hline 2001 & 0.008 & 0.008 & $0.0 \%$ & 53.91 & 53.91 & $0.00 \%$ & 3.65 & 34 & & 39.52 & 62.62 & & 11.09 & 10.62 & $-4.26 \%$ & .25 & 43 & & 2.86 & 4.01 & $5.01 \%$ \\
\hline 2002 & 0.008 & 0.025 & $215.3 \%$ & 55.04 & 55.02 & $-0.04 \%$ & 3.79 & 3.86 & $1.73 \%$ & 64.03 & 64.03 & $0.00 \%$ & 8.05 & 8.02 & $-0.39 \%$ & 56.50 & 51.31 & $-9.18 \%$ & 25.64 & 25.19 & $-1.79 \%$ \\
\hline 2003 & 0.008 & 0.008 & $0.0 \%$ & 51.22 & 51.22 & $0.00 \%$ & 4.20 & 5.25 & $25.08 \%$ & 64.62 & 64.03 & $-0.91 \%$ & 8.98 & 8.98 & $0.00 \%$ & 62.51 & 62.51 & $0.00 \%$ & 23.41 & 23.41 & $0.00 \%$ \\
\hline \multirow{2}{*}{ Resident Rainbow } & \multicolumn{3}{|c|}{ Redd Scour } & \multicolumn{3}{|c|}{ Spawning/incubation } & \multicolumn{3}{|c|}{ Fry } & \multicolumn{3}{|c|}{ Subyearling (Spring-summer) } & \multicolumn{3}{|c|}{ Subyearling (winter) } & & Subadult & & & Adult holdin & \\
\hline & Base & Alternative & Pct Chg & Base & Alternative & Pct Chg & Base & Alternative & Pct Chg & Base & Alternative & Pct Chg & Base & Alternative & Pct Chg & Base & Alternative & Pct Chg & Base & & Pct Chg \\
\hline 1982 & 0.010 & 0.011 & $6.2 \%$ & 50.57 & 44.96 & $-11.09 \%$ & 5.42 & 5.29 & $-2.40 \%$ & 63.34 & 63.34 & $0.00 \%$ & 7.68 & 7.39 & $-3.72 \%$ & 25.28 & 23.27 & $-7.95 \%$ & & & \\
\hline 1983 & 0.008 & & $0.0 \%$ & 44.25 & 33.57 & $-24.13 \%$ & 6.51 & 6.46 & $-0.76 \%$ & 63.34 & 63 & & 7.76 & 8.09 & 4. & 39.60 & 38.61 & $-2.51 \%$ & & & \\
\hline 1984 & 0.008 & 0.008 & 0.0 & 44.44 & 33 & $-24.48 \%$ & 5.49 & 5.25 & $-4.44 \%$ & 63.34 & & & 7.29 & 7.23 & & 28.36 & 29.02 & $2.31 \%$ & & & \\
\hline 1985 & 0.008 & 0.008 & $0.0 \%$ & 60.22 & 60. & $0.00 \%$ & 4.27 & 4.95 & $15.87 \%$ & 51 & 63.34 & 23. & 12.34 & 11.94 & & 24.23 & 29.12 & $20.22 \%$ & & & \\
\hline 1986 & 0.008 & 0.011 & $37.6 \%$ & 56.50 & 57.21 & $1.24 \%$ & 4.27 & 5.30 & $24.21 \%$ & 58.0 & 63.34 & $9.14 \%$ & 9.14 & 8.71 & $-4.73 \%$ & 29.77 & 32.36 & $8.67 \%$ & & & \\
\hline 1987 & 0.008 & 0.008 & $0.0 \%$ & 54.60 & 54.60 & $0.00 \%$ & 4.91 & 4.49 & $-8.65 \%$ & 45.02 & 63.33 & $40.69 \%$ & 9.83 & 9.83 & $0.00 \%$ & 27.66 & 31.75 & $14.77 \%$ & & & \\
\hline & 0.008 & 0.008 & 0.0 & 60.22 & 60.22 & $0.00 \%$ & 4.92 & 6.45 & $31.19 \%$ & 52.3 & 63. & $21.07 \%$ & 10.38 & 10.38 & $0.00 \%$ & 35. & 40.12 & $14.17 \%$ & & & \\
\hline 1989 & 0.008 & 0.008 & $1.8 \%$ & 58.38 & 60.22 & $3.16 \%$ & 5.40 & 4.80 & $-11.02 \%$ & 63.06 & 63.34 & $0.45 \%$ & 8.17 & 8.22 & $0.53 \%$ & 37.23 & 29.70 & $-20.23 \%$ & & & \\
\hline 1990 & 0.010 & 0.008 & $-16.6 \%$ & 50.47 & 44.84 & $-11.16 \%$ & 5.23 & 5.79 & $10.59 \%$ & 63. & 63.34 & $0.00 \%$ & 7.80 & 7.92 & $1.64 \%$ & 31.45 & 31.42 & $-0.10 \%$ & & & \\
\hline 1991 & 0.008 & 0.008 & $0.0 \%$ & 1.66 & 1.53 & $-8.22 \%$ & 6.51 & 6.46 & $-0.77 \%$ & 63. & 63.3 & $0.00 \%$ & 7.27 & 7.38 & $1.46 \%$ & 40.26 & 37.90 & $-5.86 \%$ & & & \\
\hline 1992 & 0.008 & 0.008 & $0.0 \%$ & 56.29 & 60.10 & $6.77 \%$ & 4.68 & 6.40 & $36.94 \%$ & 44. & 63. & $41.14 \%$ & 8.28 & 8.20 & $-0.96 \%$ & 23.91 & 38.14 & $59.55 \%$ & & & \\
\hline & 0.008 & 8 & $0.0 \%$ & 58.75 & 58.75 & $0.00 \%$ & 4.35 & 4.8 & $11.87 \%$ & 39 & 62 & $57.90 \%$ & 11.90 & 11.69 & $-1.73 \%$ & 29.07 & 35.41 & $21.81 \%$ & & & \\
\hline 1994 & 0.008 & 0. & 0.0 & 59.13 & 59. & 0.0 & 4.98 & 4.2 & $-14.94 \%$ & 42 & 62 & $46.78 \%$ & 10.80 & 10.85 & $0.52 \%$ & 31. & 22.79 & $-27.62 \%$ & & & \\
\hline & 0.008 & $0 . c$ & 0.0 & 58.25 & 58. & 0.0 & 6.5 & & -0.6 & 63 & 63 & & 7.94 & 7. & $0 . c$ & 40 & 40.07 & $-0.53 \%$ & & & \\
\hline & 0.008 & & 0.0 & 4.9 & 1. & -66 & 5. & & & & 63 & & 7. & 7. & & 38 & 37.39 & -3.6 & & & \\
\hline 1997 & 0.110 & & 32. & 14 & 8. & & 5.2 & 5. & & & & & 8. & 8. & & 21 & 22 & 2.1 & & & \\
\hline & 0.009 & & 4.1 & 56.79 & 44 & & 4.7 & & 35. & 61 & 63 & & 8. & 7 & & 31 & 34 & $12.01 \%$ & & & \\
\hline 1999 & 0.088 & 0.1 & 18. & 53.02 & 44 & & 4.8 & 5 & & 63 & 63 & & 7. & 7 & & 20 & $2]$ & 2.8 & & & \\
\hline & 0.018 & 5 & $-15.0 \%$ & 33.52 & 22 & & 4.6 & 5. & & 63 & 63 & & 9. & 9 & & 25 & 27.38 & $8.62 \%$ & & & \\
\hline 2001 & 0.008 & 0.008 & $0.0 \%$ & 60.22 & 60.22 & $0.00 \%$ & 4.51 & 4.27 & $-5.38 \%$ & 38. & 61.92 & $59.50 \%$ & 12.69 & 12.16 & $-4.20 \%$ & 24.32 & 24.06 & $-1.05 \%$ & & & \\
\hline 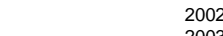 & 0.008 & 0.025 & $215.3 \%$ & 60.73 & 60.72 & $-0.02 \%$ & 4.82 & 4.89 & $1.32 \%$ & 63.34 & 63.34 & $0.00 \%$ & 9.24 & 9.20 & $-0.36 \%$ & 28.80 & 23.83 & $-17.26 \%$ & & & \\
\hline & & & & 54.47 & 54.47 & $0.00 \%$ & 5.32 & 6.48 & $21.74 \%$ & 63.82 & 63.34 & $-0.75 \%$ & 10.35 & 10.35 & $0.00 \%$ & 36.69 & 39.70 & $8.21 \%$ & & & \\
\hline
\end{tabular}

Figure 4-9. Annual habitat summaries for steelhead and resident rainbow trout in the Easton reach for the Black Rock_2 scenario. 
Bull Trout

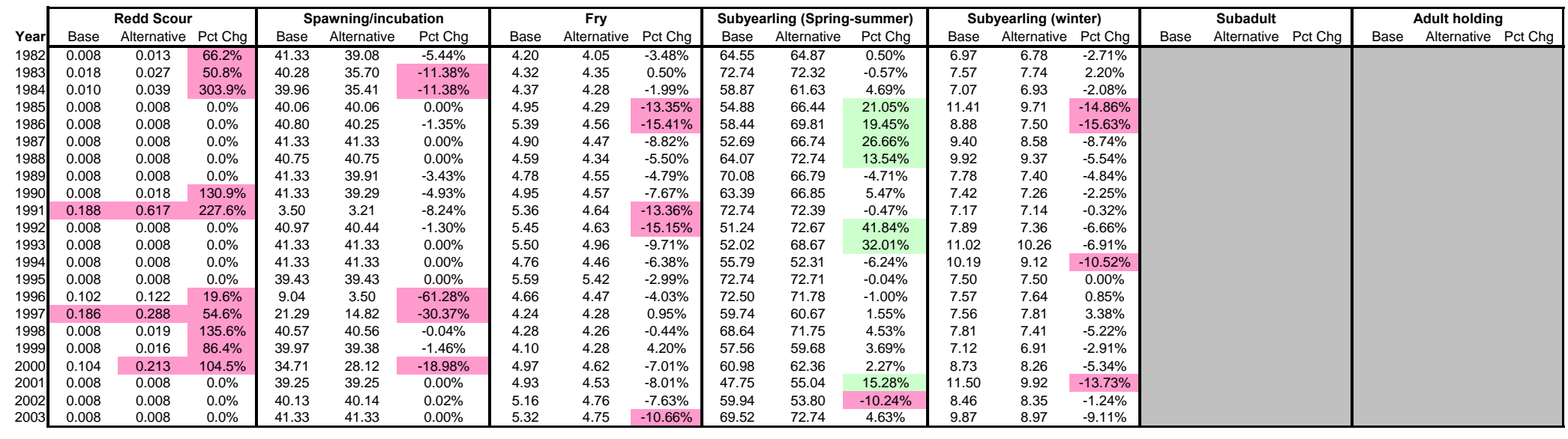

Figure 4-10. Annual habitat summaries for bull trout in the Easton reach for the Black Rock_2 scenario. 


\begin{tabular}{|c|c|c|c|c|c|c|c|c|c|c|c|c|c|c|c|c|c|c|c|c|}
\hline Spring Chinook & \multicolumn{3}{|c|}{ Redd Scour } & \multicolumn{3}{|c|}{ Spawning/incubation } & \multirow{2}{*}{\multicolumn{3}{|c|}{$\begin{array}{c}\text { Fry } \\
\end{array}$}} & \multicolumn{3}{|c|}{ Subyearling (Spring-summer) } & \multicolumn{3}{|c|}{ Subyearling (winter) } & \multicolumn{2}{|r|}{ Subadult } & \multicolumn{3}{|c|}{ Adult holding } \\
\hline Yea & Base & Alternative & Pct Chg & Base & Alternative & Pct Chg & Base & & Pct Chg & Base & Alternative & Pct Chg & Base & Alternative & Pct Chg & Base & Alternative Pct Chg & Base & Alternative & Pct Chg \\
\hline 198 & 0.007 & 0.006 & $-10.91 \%$ & 21.22 & 24.20 & $14.06 \%$ & 1.84 & 1.89 & $2.66 \%$ & 14.32 & 13.46 & $-5.97 \%$ & 4.30 & 3.69 & $-14.18 \%$ & & & 6.51 & 6.67 & $2.44 \%$ \\
\hline 198 & 0.006 & 0.006 & $-4.60 \%$ & 22.11 & 15.90 & $-28.06 \%$ & 1.90 & 1.91 & $0.81 \%$ & 13.94 & 13.77 & $-1.21 \%$ & 3.81 & 3.65 & $-4.15 \%$ & & & 6.48 & 6.59 & $1.78 \%$ \\
\hline 198 & 0.007 & 0.006 & $-11.88 \%$ & 14.57 & 16.86 & $15.73 \%$ & 1.75 & 1.84 & $5.12 \%$ & 14.47 & 13.49 & $-6.79 \%$ & 3.81 & 3.78 & $-0.99 \%$ & & & 6.53 & 6.59 & $0.93 \%$ \\
\hline 198 & 0.007 & 0.006 & $-11.12 \%$ & 30.09 & 29.66 & $-1.43 \%$ & 1.46 & 1.56 & $6.74 \%$ & 14.06 & 13.47 & $-4.25 \%$ & 3.85 & 3.51 & $-8.83 \%$ & & & 6.46 & 6.63 & $2.67 \%$ \\
\hline 198 & 0.007 & 0.006 & $-12.32 \%$ & 23.70 & 21.08 & $-11.03 \%$ & 1.69 & 1.86 & $10.00 \%$ & 14.20 & 13.41 & $-5.54 \%$ & 4.12 & 3.78 & $-8.17 \%$ & & & 6.59 & 6.85 & $3.95 \%$ \\
\hline 198 & 0.007 & 0.006 & $-16.39 \%$ & 30.50 & 29.64 & $-2.82 \%$ & 1.59 & 1.77 & $11.30 \%$ & 13.74 & 13.39 & $-2.53 \%$ & 4.21 & 3.71 & $-11.86 \%$ & & & 6.79 & 7.08 & $4.36 \%$ \\
\hline 198 & 0.008 & 0.006 & $-15.41 \%$ & 29.18 & 33.12 & $13.50 \%$ & 1.39 & 1.57 & $13.36 \%$ & 13.72 & 14.71 & $7.17 \%$ & 3.99 & 3.86 & $-3.43 \%$ & & & 6.86 & 7.43 & $8.35 \%$ \\
\hline 198 & 0.007 & 0.006 & $-13.86 \%$ & 34.53 & 29.85 & $-13.55 \%$ & 1.57 & 1.72 & $9.86 \%$ & 14.03 & 13.72 & $-2.16 \%$ & 3.49 & 3.46 & $-0.80 \%$ & & & 6.49 & 6.69 & $2.98 \%$ \\
\hline 199 & 0.006 & 0.006 & $-11.02 \%$ & 29.81 & 28.22 & $-5.31 \%$ & 1.78 & 1.87 & $4.72 \%$ & 14.45 & 13.60 & $-5.92 \%$ & 3.65 & 3.52 & $-3.60 \%$ & & & 6.43 & 6.53 & $1.51 \%$ \\
\hline 199 & 0.013 & 0.018 & $40.19 \%$ & 6.95 & 9.99 & $43.61 \%$ & 1.89 & 1.91 & $0.73 \%$ & 13.93 & 13.42 & $-3.68 \%$ & 4.67 & 5.19 & $11.13 \%$ & & & 6.46 & 6.63 & $2.65 \%$ \\
\hline 199 & 0.006 & 0.006 & $-6.74 \%$ & 29.77 & 34.23 & $14.98 \%$ & 1.54 & 1.77 & $15.10 \%$ & 14.08 & $\begin{array}{l}13.37 \\
137\end{array}$ & $-5.08 \%$ & 3.69 & 3.56 & $-3.61 \%$ & & & 6.51 & 6.84 & $5.14 \%$ \\
\hline 199 & 0.007 & 0.006 & $-11.53 \%$ & 30.74 & 33.31 & $8.36 \%$ & 1.44 & 1.61 & $12.34 \%$ & 13.75 & 13.63 & $-0.87 \%$ & 4.15 & 3.76 & $-9.35 \%$ & & & 6.84 & 7.25 & $5.99 \%$ \\
\hline 199 & 0.007 & 0.007 & $-3.52 \%$ & 28.86 & 28.62 & $-0.85 \%$ & $\begin{array}{l}1.34 \\
1.30\end{array}$ & 1.55 & $19.67 \%$ & 13.43 & 13.89 & $3.44 \%$ & 3.87 & 4.17 & $7.64 \%$ & & & 7.48 & 7.29 & $-2.53 \%$ \\
\hline 199 & 0.007 & 0.007 & $-1.19 \%$ & $\begin{array}{l}13.29 \\
13.00\end{array}$ & $\begin{array}{l}12.02 \\
12.90\end{array}$ & $-2.96 \%$ & 1.76 & 1.86 & $5.99 \%$ & $\begin{array}{l}13.45 \\
13.99\end{array}$ & 13.83 & $\begin{array}{l}-.09 \% \\
-1.09 \%\end{array}$ & $\begin{array}{l}5.01 \\
3.93\end{array}$ & $\begin{array}{l}4.11 \\
3.99\end{array}$ & $1.44 \%$ & & & $\begin{array}{l}1.40 \\
6.63\end{array}$ & $\begin{array}{l}7.22 \\
\text {. }\end{array}$ & $8.86 \%$ \\
\hline 199 & 0.019 & 0.020 & $7.60 \%$ & 3.03 & 2.74 & $-9.69 \%$ & $\begin{array}{l}1.94 \\
1.94\end{array}$ & $\begin{array}{l}1.00 \\
1.94\end{array}$ & $0.26 \%$ & 13.95 & $\begin{array}{l}13.60 \\
13.69\end{array}$ & $-1.86 \%$ & 5.94 & 6.37 & $7.27 \%$ & & & $\begin{array}{l}0.03 \\
6.48\end{array}$ & 6.59 & $1.73 \%$ \\
\hline 199 & 0.013 & 0.014 & $8.92 \%$ & 3.72 & 7.05 & $89.40 \%$ & 2.01 & 2.05 & $2.08 \%$ & 14.29 & 14.02 & $-1.90 \%$ & 3.84 & 3.70 & $-3.57 \%$ & & & 6.45 & 6.80 & $5.39 \%$ \\
\hline 199 & 0.006 & 0.006 & $-5.46 \%$ & 29.44 & 21.20 & $-27.98 \%$ & 1.77 & 1.80 & $1.90 \%$ & 13.95 & 13.75 & $-1.43 \%$ & 3.49 & 3.74 & $7.06 \%$ & & & 6.45 & 6.66 & $3.30 \%$ \\
\hline 199 & 0.006 & 0.006 & $-10.11 \%$ & 29.16 & 27.74 & $-4.84 \%$ & 1.75 & 1.90 & $8.48 \%$ & 13.87 & 14.08 & $1.47 \%$ & 3.67 & 3.70 & $0.74 \%$ & & & 6.57 & 6.62 & $0.84 \%$ \\
\hline 200 & 0.006 & 0.007 & $9.33 \%$ & 14.31 & 16.29 & $13.80 \%$ & 1.71 & 1.76 & $2.99 \%$ & 14.09 & 13.48 & $-4.35 \%$ & 3.70 & 3.74 & $1.14 \%$ & & & 6.44 & 6.58 & $2.10 \%$ \\
\hline 200 & 0.006 & 0.006 & $-10.50 \%$ & 29.83 & 34.73 & $16.45 \%$ & 1.36 & 1.49 & $9.68 \%$ & 13.24 & 14.27 & $7.75 \%$ & 3.90 & 3.71 & $-5.02 \%$ & & & 7.13 & 7.31 & $2.46 \%$ \\
\hline 200 & 0.008 & 0.008 & $3.47 \%$ & 30.42 & 21.44 & $-29.51 \%$ & 1.62 & 1.71 & $5.60 \%$ & 14.30 & 13.70 & $-4.15 \%$ & 3.53 & 3.49 & $-1.17 \%$ & & & 6.52 & 6.59 & $0.96 \%$ \\
\hline 200 & 0.006 & 0.006 & $-6.50 \%$ & 28.63 & 27.58 & $-3.65 \%$ & 1.80 & 1.83 & $1.68 \%$ & 14.28 & 13.59 & $-4.87 \%$ & $\begin{array}{l}3.89 \\
\end{array}$ & 3.50 & $-10.04 \%$ & & & 6.58 & 6.81 & $3.59 \%$ \\
\hline \multirow{24}{*}{$\begin{array}{l} \\
1 \\
1 \\
1 \\
1 \\
1 \\
1 \\
1 \\
1 \\
1 \\
1 \\
1 \\
1 \\
1 \\
1 \\
1 \\
1 \\
1 \\
2 \\
2 \\
2 \\
2\end{array}$} & \multicolumn{3}{|c|}{ Redd Scour } & \multicolumn{3}{|c|}{ Spawning/incubation } & \multicolumn{3}{|c|}{ Fry } & \multicolumn{3}{|c|}{ Subyearling (Spring-summer) } & \multicolumn{3}{|c|}{ Subyearling (winter) } & \multirow{2}{*}{\multicolumn{2}{|c|}{$\begin{array}{cc}\text { Subadult } \\
\text { Base } \\
\text { Alternative Pct Cha }\end{array}$}} & & Adult holdin & \\
\hline & Base & Alternative & Pct Chg & Base & Alternative & Pct Chg & Base & Alternative & Pct Chg & Base & Alternative & Pct Chg & Base & Alternative & Pct Chg & & Alternative Pct Chg & Base & Alternative & Pct Chg \\
\hline & 0.007 & 0.006 & $-10.91 \%$ & 14.93 & 12.95 & $-13.3 \%$ & 1.79 & 1.85 & $3.2 \%$ & 4.70 & 4.20 & $-10.7 \%$ & 2.57 & 2.27 & $-11.7 \%$ & t & 年 & 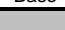 & & \\
\hline & 0.006 & 0.006 & $-2.36 \%$ & 16.10 & 12.68 & $-21.3 \%$ & 1.85 & 1.86 & $0.3 \%$ & 4.46 & 4.25 & $-4.8 \%$ & 2.32 & 2.26 & $-2.4 \%$ & & & & & \\
\hline & 0.007 & 0.006 & $-11.88 \%$ & 13.06 & 13.21 & $1.1 \%$ & 1.79 & 1.85 & $3.3 \%$ & 4.78 & 4.20 & $-12.2 \%$ & 2.42 & 2.39 & $-1.3 \%$ & & & & & \\
\hline & 0.007 & 0.006 & $-11.12 \%$ & 14.28 & 12.41 & $-13.1 \%$ & 1.78 & 1.85 & $3.5 \%$ & 4.63 & 4.19 & $-9.5 \%$ & 2.34 & 2.22 & $-5.2 \%$ & & & & & \\
\hline & 0.007 & 0.006 & $-12.42 \%$ & 15.74 & 15.53 & $-1.3 \%$ & 1.58 & 1.81 & $14.3 \%$ & 4.66 & 4.17 & $-10.6 \%$ & 2.55 & 2.31 & $-9.7 \%$ & & & & & \\
\hline & 0.006 & 0.006 & $-9.47 \%$ & 19.33 & 18.66 & $-3.5 \%$ & 1.60 & 1.78 & $11.8 \%$ & 4.42 & 4.06 & $-8.3 \%$ & 2.67 & 2.28 & $-14.5 \%$ & & & & & \\
\hline & 0.007 & 0.006 & $-6.31 \%$ & 18.83 & 19.10 & $1.4 \%$ & 1.59 & 1.80 & $13.3 \%$ & 4.36 & 4.30 & $-1.3 \%$ & 2.55 & 2.40 & $-5.9 \%$ & & & & & \\
\hline & 0.006 & 0.006 & $-2.36 \%$ & 19.96 & 18.83 & $-5.7 \%$ & 1.78 & 1.85 & $4.2 \%$ & 4.64 & 4.26 & $-8.2 \%$ & 2.21 & 2.2 & $0.1 \%$ & & & & & \\
\hline & 0.006 & 0.006 & $-5.54 \%$ & 18.79 & 17.35 & $-7.7 \%$ & 1.87 & 1.89 & $1.4 \%$ & 5.08 & 4.31 & $-15.2 \%$ & 2.35 & 2.2 & $-5.9 \%$ & & & & & \\
\hline & 0.005 & 0.005 & $-3.15 \%$ & 5.88 & 7.75 & $31.8 \%$ & 1.86 & 1.86 & $-0.3 \%$ & 4.64 & 4.14 & $-10.8 \%$ & 3.43 & 3.8 & $11.8 \%$ & & & & & \\
\hline & 0.006 & 0.006 & $-7.20 \%$ & 18.76 & 17.52 & $-6.6 \%$ & 1.47 & 1.72 & $17.3 \%$ & 4.79 & 4.13 & $-13.8 \%$ & 2.43 & 2.24 & $-7.5 \%$ & & & & & \\
\hline & 0.007 & 0.006 & $-11.53 \%$ & 19.98 & 18.98 & $-5.0 \%$ & 1.52 & 1.80 & $18.6 \%$ & 4.43 & 4.11 & $-7.2 \%$ & 2.64 & 2.30 & $-13.2 \%$ & & & & & \\
\hline & 0.007 & 0.007 & $-1.75 \%$ & 18.75 & 16.18 & $-13.7 \%$ & 1.40 & 1.81 & $29.8 \%$ & 4.06 & 4.17 & $2.7 \%$ & 2.56 & 2.51 & $-2.0 \%$ & & & & & \\
\hline & 0.006 & 0.006 & $-2.69 \%$ & 12.22 & 11.96 & $-2.1 \%$ & 1.68 & 1.82 & $8.0 \%$ & 4.45 & 4.16 & -6.40 & 2.50 & 2.52 & $0.8 \%$ & & & & & \\
\hline & 0.019 & 0.020 & $7.60 \%$ & 1.25 & 0.97 & $-22.6 \%$ & 1.86 & 1.87 & $0.1 \%$ & 4.64 & 4.30 & $-7.3 \%$ & 4.82 & 5.10 & $5.9 \%$ & & & & & \\
\hline & 0.013 & 0.014 & $8.92 \%$ & 3.01 & 5.99 & $99.0 \%$ & 1.98 & 2.01 & $1.4 \%$ & 4.91 & 4.45 & $-9.4 \%$ & 2.34 & 2.27 & $-3.0 \%$ & & & & & \\
\hline & 0.006 & 0.006 & $-6.48 \%$ & 11.95 & 13.15 & $10.0 \%$ & 1.85 & 1.84 & $-0.5 \%$ & 4.53 & 4.26 & $-5.8 \%$ & 2.25 & 2.57 & $14.3 \%$ & & & & & \\
\hline & 0.006 & 0.006 & $-2.35 \%$ & 18.30 & 16.84 & $-8.0 \%$ & 1.88 & 1.86 & $-0.7 \%$ & 4.53 & 4.41 & $-2.7 \%$ & 2.40 & 2.38 & $-0.9 \%$ & & & & & \\
\hline & 0.006 & 0.007 & $9.33 \%$ & 12.89 & 12.89 & $0.0 \%$ & 1.88 & 1.86 & $-0.9 \%$ & 4.71 & 4.23 & $-10.1 \%$ & 2.32 & 2.40 & $3.2 \%$ & & & & & \\
\hline & 0.006 & 0.006 & $-10.50 \%$ & 15.00 & 17.61 & $17.4 \%$ & 1.49 & 1.77 & $18.7 \%$ & 4.04 & 4.25 & $5.4 \%$ & 2.54 & 2.28 & $-10.3 \%$ & & & & & \\
\hline & 0.006 & 0.006 & $-2.45 \%$ & 19.29 & 15.77 & $-18.3 \%$ & 1.84 & 1.84 & $0.2 \%$ & 4.76 & 4.42 & $-7.1 \%$ & 2.26 & 2.27 & $0.7 \%$ & & & & & \\
\hline & 0.006 & 0.006 & $-6.50 \%$ & 17.78 & 16.67 & $-6.2 \%$ & 1.86 & 1.85 & $-0.6 \%$ & 4.70 & 4.26 & $-9.4 \%$ & 2.39 & 2.19 & $-8.4 \%$ & & & & & \\
\hline
\end{tabular}

Figure 4-11. Annual habitat summaries for spring chinook and coho salmon in the Kittitas reach for the Black Rock_2 scenario. 


\begin{tabular}{|c|c|c|c|c|c|c|c|c|c|c|c|c|c|c|c|c|c|c|c|c|c|}
\hline Steelhead & \multicolumn{3}{|c|}{ Redd Scour } & \multicolumn{3}{|c|}{ Spawning/incubation } & \multicolumn{3}{|c|}{ Fry } & \multicolumn{3}{|c|}{ Subyearling (Spring-summer) } & \multicolumn{3}{|c|}{ Subyearling (winter) } & \multicolumn{3}{|c|}{ Subadult } & \multicolumn{3}{|c|}{ Adult holding } \\
\hline $\mathrm{Ye}$ & Base & Alternative & Pct Chg & Base & Alternative & Pct Chg & Base & Alternative & Pct Chg & Base & Alternative & Pct Chg & Base & Alternative & e Pct Chg & Base & Alternative & Pct Chg & Base & Alternative & Pct Chg \\
\hline 198 & 0.005 & 0.005 & $-5.73 \%$ & 30.03 & 29.98 & $-0.2 \%$ & 2.21 & 2.11 & $-4.4 \%$ & 19.88 & 25.15 & $26.5 \%$ & 3.73 & 3.17 & $-15.1 \%$ & 19.16 & 19.01 & $-0.7 \%$ & 8.45 & 8.62 & $2.1 \%$ \\
\hline 198 & 0.005 & 0.005 & $8.24 \%$ & 33.83 & 34.41 & $1.7 \%$ & 2.17 & 2.09 & $-3.9 \%$ & 19.65 & 23.64 & $20.3 \%$ & 3.24 & 3.06 & $-5.6 \%$ & 19.10 & 19.06 & $-0.2 \%$ & 8.16 & 8.05 & $-1.4 \%$ \\
\hline 198 & 0.005 & 0.005 & $-6.10 \%$ & 32.49 & 33.98 & $4.6 \%$ & 2.21 & 2.11 & $-4.4 \%$ & 18.90 & 23.55 & $24.6 \%$ & 3.29 & 3.19 & $-2.9 \%$ & 19.20 & 19.04 & $-0.9 \%$ & 8.19 & 8.04 & $-1.8 \%$ \\
\hline 198 & 0.005 & 0.005 & $-7.58 \%$ & 30.21 & 29.72 & $-1.6 \%$ & 2.23 & 2.11 & $-5.1 \%$ & 17.61 & 24.13 & $37.0 \%$ & 3.31 & 3.05 & $-7.8 \%$ & 19.15 & 19.02 & $-0.7 \%$ & 11.82 & 11.73 & $-0.8 \%$ \\
\hline 198 & 0.005 & 0.005 & $-2.53 \%$ & 29.59 & 33.92 & $14.6 \%$ & 2.21 & 2.11 & $-4.7 \%$ & 19.05 & 25.54 & $34.1 \%$ & 3.65 & 3.24 & $-11.1 \%$ & 19.17 & 19.00 & $-0.9 \%$ & 9.35 & 9.70 & $3.8 \%$ \\
\hline 198 & 0.005 & 0.005 & $-7.42 \%$ & 30.53 & 33.96 & $11.2 \%$ & 2.14 & 2.10 & $-2.1 \%$ & 22.38 & 25.93 & $15.9 \%$ & 3.81 & 3.23 & $-15.1 \%$ & 19.06 & 19.09 & $0.2 \%$ & 10.99 & 10.82 & $-1.6 \%$ \\
\hline 198 & 0.005 & 0.005 & $-1.70 \%$ & 27.86 & 32.72 & $17.4 \%$ & 2.14 & 2.10 & $-1.6 \%$ & 20.80 & 26.04 & $25.2 \%$ & 3.64 & 3.35 & $-8.0 \%$ & 19.07 & 20.66 & $8.3 \%$ & 11.99 & 11.91 & $-0.7 \%$ \\
\hline 198 & 0.005 & 0.005 & $-7.38 \%$ & 33.60 & 33.52 & $-0.2 \%$ & 2.18 & 2.12 & $-2.8 \%$ & 20.24 & 27.68 & $36.8 \%$ & 3.06 & 3.03 & $-1.2 \%$ & 19.14 & 19.04 & $-0.5 \%$ & 10.60 & 10.33 & $-2.6 \%$ \\
\hline 199 & 0.005 & 0.005 & $-3.21 \%$ & 33.60 & 34.28 & $2.0 \%$ & 2.22 & 2.12 & $-4.7 \%$ & 20.44 & 27.18 & $33.0 \%$ & 3.18 & 3.05 & $-4.2 \%$ & 19.19 & 19.05 & $-0.7 \%$ & 9.50 & 9.20 & $-3.2 \%$ \\
\hline 199 & 0.005 & 0.005 & $5.62 \%$ & 34.14 & 29.28 & $-14.2 \%$ & 2.18 & 2.09 & $-4.4 \%$ & 21.45 & 28.31 & $32.0 \%$ & 4.08 & 4.43 & $8.4 \%$ & 19.10 & 19.01 & $-0.5 \%$ & 7.06 & 7.04 & $-0.2 \%$ \\
\hline 199 & 0.005 & 0.005 & $-4.34 \%$ & 33.34 & 34.27 & $2.8 \%$ & 2.17 & 2.09 & $-3.5 \%$ & 22.74 & 29.67 & $30.5 \%$ & 3.25 & 3.10 & $-4.7 \%$ & 19.09 & 19.00 & $-0.5 \%$ & 9.35 & 9.47 & $1.3 \%$ \\
\hline 199 & 0.005 & 0.005 & $-7.89 \%$ & 30.26 & 32.94 & $8.9 \%$ & 2.15 & 2.11 & $-1.7 \%$ & 20.40 & 26.32 & $29.0 \%$ & 3.79 & 3.25 & $-14.1 \%$ & 19.07 & 19.30 & $1.2 \%$ & 12.72 & 12.12 & $-4.7 \%$ \\
\hline 199 & 0.006 & 0.005 & $-13.40 \%$ & 28.13 & 29.13 & $3.6 \%$ & 2.09 & 1.91 & $-8.9 \%$ & 22.12 & 31.13 & $40.7 \%$ & 3.67 & 3.61 & $-1.8 \%$ & 19.62 & 19.61 & $0.0 \%$ & 13.23 & 13.37 & $1.1 \%$ \\
\hline 199 & 0.005 & 0.006 & $9.64 \%$ & 30.33 & 30.39 & $0.2 \%$ & 2.17 & 1.97 & $-8.9 \%$ & 20.41 & 24.98 & $22.4 \%$ & 3.41 & 3.39 & $-0.6 \%$ & 19.12 & 19.40 & $1.5 \%$ & 8.20 & 8.07 & $-1.5 \%$ \\
\hline 199 & 0.008 & 0.008 & $-2.54 \%$ & 34.19 & 33.44 & $-2.2 \%$ & 2.19 & 2.13 & $-2.8 \%$ & 20.13 & 24.51 & $21.8 \%$ & 5.59 & 5.86 & $4.8 \%$ & 19.08 & 19.04 & $-0.2 \%$ & 6.71 & 6.68 & $-0.5 \%$ \\
\hline 199 & 0.013 & 0.014 & $4.42 \%$ & 33.17 & 34.10 & $2.8 \%$ & 2.21 & 2.13 & $-3.8 \%$ & 19.92 & 24.81 & $24.6 \%$ & 3.25 & 3.09 & $-4.9 \%$ & 19.18 & 19.14 & $-0.2 \%$ & 8.30 & 8.41 & $1.3 \%$ \\
\hline 199 & 0.005 & 0.005 & $6.22 \%$ & 29.49 & 32.76 & $11.1 \%$ & 2.19 & 2.11 & $-3.7 \%$ & 19.71 & 27.29 & $38.5 \%$ & 3.07 & 3.24 & $5.7 \%$ & 19.12 & 19.04 & $-0.4 \%$ & 9.11 & 8.37 & $-8.1 \%$ \\
\hline 199 & 0.011 & 0.011 & $2.46 \%$ & 34.03 & 35.25 & $3.6 \%$ & 2.17 & 2.14 & $-1.4 \%$ & 20.40 & 25.66 & $25.8 \%$ & 3.18 & 3.20 & $0.6 \%$ & 19.11 & 19.16 & $0.2 \%$ & 9.02 & 8.46 & $-6.2 \%$ \\
\hline 200 & 0.005 & 0.005 & $0.63 \%$ & 33.48 & 34.30 & $2.5 \%$ & 2.18 & 2.10 & $-3.8 \%$ & 18.44 & 23.69 & $28.5 \%$ & 3.17 & 3.15 & $-0.5 \%$ & 19.16 & 19.02 & $-0.7 \%$ & 8.41 & 8.11 & $-3.5 \%$ \\
\hline 200 & 0.005 & 0.005 & $-5.11 \%$ & 30.01 & 34.22 & $14.0 \%$ & 2.10 & 2.14 & $1.7 \%$ & 21.13 & 30.07 & $42.3 \%$ & 3.60 & 3.21 & $-10.6 \%$ & 19.05 & 19.77 & $3.8 \%$ & 13.07 & 12.91 & $-1.2 \%$ \\
\hline 200 & 0.005 & 0.005 & $-3.38 \%$ & 30.93 & 28.25 & $-8.7 \%$ & 2.22 & 2.14 & $-3.6 \%$ & 18.82 & 23.65 & $25.7 \%$ & 3.08 & 3.06 & $-0.7 \%$ & 19.11 & 19.04 & $-0.4 \%$ & 10.20 & 9.96 & $-2.4 \%$ \\
\hline 200 & 0.005 & 0.005 & $-2.96 \%$ & 33.79 & 34.37 & $1.7 \%$ & 2.22 & 2.12 & $-4.2 \%$ & 19.18 & 25.20 & $31.4 \%$ & 3.34 & 3.05 & $-8.9 \%$ & 19.19 & 19.03 & $-0.8 \%$ & 9.18 & 9.32 & $1.5 \%$ \\
\hline \multirow{2}{*}{ Resident Rainbow } & \multicolumn{3}{|c|}{ Redd Scour } & \multicolumn{3}{|c|}{ Spawning/incubation } & \multicolumn{3}{|c|}{ Fry } & \multicolumn{3}{|c|}{ Subyearling (Spring-summer) } & \multicolumn{3}{|c|}{ Subyearling (winter) } & & Subadult & & & Adult holdin & \\
\hline & Base & Alternative & Pct Chg & Base & Alternative & Pct Chg & Base & Alternative & Pct Chg & Base & Alternative & Pct Chg & Base & Alternative & Pct Chg & Base & Alternative & Pct Chg & Base & Alternative & Pct Chg \\
\hline 198 & 0.005 & 0.005 & $0.65 \%$ & 14.64 & 16.70 & $14.1 \%$ & 2.54 & 2.41 & & 19.64 & 24.76 & $26.1 \%$ & 4.62 & 4.03 & $-12.9 \%$ & 8.21 & 7.77 & & & & \\
\hline $\begin{array}{l}19 c^{2}-208 \\
198\end{array}$ & 0.005 & 0.005 & $\begin{array}{l}.0 .05 \% \\
8.24 \%\end{array}$ & $\begin{array}{l}15.404 \\
15.40\end{array}$ & 10.04 & $\begin{array}{l}14.1 \% \\
-34.8 \%\end{array}$ & $\begin{array}{l}2.54 \\
2.49\end{array}$ & $\begin{array}{l}2.41 \\
2.39\end{array}$ & $\begin{array}{l}-5.0 \% \\
-4.0 \% \\
-10\end{array}$ & $\begin{array}{l}19.64 \\
19.41\end{array}$ & $\begin{array}{l}23.100 \\
23.30\end{array}$ & $\begin{array}{l}20.1 \% \\
20.0 \%\end{array}$ & $\begin{array}{l}4.02 \\
4.11\end{array}$ & $\begin{array}{l}4.03 \\
3.89\end{array}$ & $-5.3 \%$ & $\begin{array}{l}8.21 \\
7.88\end{array}$ & 7.84 & $\begin{array}{l}-0.3 \% \\
-0.5 \%\end{array}$ & & & \\
\hline 198 & 0.005 & 0.005 & $-6.10 \%$ & 9.68 & 10.87 & $12.3 \%$ & 2.54 & 2.42 & $-5.0 \%$ & 18.69 & 23.21 & $24.2 \%$ & 4.13 & 4. & & 8.41 & 7.77 & $-7.5 \%$ & & & \\
\hline $\begin{array}{l}1908 \\
198\end{array}$ & 0.005 & 0.005 & $-8.24 \%$ & $\begin{array}{l}5.00 \\
23.27\end{array}$ & 21.88 & $-6.0 \%$ & 2.57 & 2.42 & $-5.7 \%$ & $\begin{array}{l}10.09 \\
17.43\end{array}$ & 23.77 & $36.4 \%$ & 4.18 & 3.88 & $-7.0 \%$ & $\begin{array}{l}0.41 \\
8.15\end{array}$ & 7.74 & $-5.0 \%$ & & & \\
\hline $\begin{array}{l}198 \\
198\end{array}$ & $\begin{array}{l}0.005 \\
0.005\end{array}$ & 0.005 & $\begin{array}{l}-8.24 \% \\
-2.53 \%\end{array}$ & $\begin{array}{l}37.18 \\
17.28\end{array}$ & $\begin{array}{l}11.88 \\
14.52\end{array}$ & $\begin{array}{l}-0.0 \% \\
-15.5 \% \\
\end{array}$ & $\begin{array}{l}2.51 \\
2.55\end{array}$ & $\begin{array}{l}2.42 \\
2.41\end{array}$ & $\begin{array}{l}-5.1 \% \\
-5.4 \%\end{array}$ & $\begin{array}{l}17.43 \\
18.84\end{array}$ & 25.14 & $\begin{array}{l}3.40 \% \\
33.5 \%\end{array}$ & $\begin{array}{l}4.18 \\
4.53\end{array}$ & $\begin{array}{l}3.11 \\
4.11\end{array}$ & $\begin{array}{l}-1.0 \% \\
-9.2 \%\end{array}$ & $\begin{array}{l}8.15 \\
8.43\end{array}$ & $\begin{array}{l}7.14 \\
7.69\end{array}$ & $\begin{array}{l}-5.0 \% \\
-8.8 \%\end{array}$ & & & \\
\hline $\begin{array}{l}198 \\
198\end{array}$ & $\begin{array}{l}0.005 \\
0.005\end{array}$ & 0.005 & $\begin{array}{l}-2.53 \% \\
-8.35 \%\end{array}$ & 27.20 & $\begin{array}{l}24.52 \\
24.18\end{array}$ & $-11.1 \%$ & $\begin{array}{l}2.55 \\
2.45\end{array}$ & $\begin{array}{l}2.41 \\
2.40\end{array}$ & $\begin{array}{l}-5.4 \% \\
-2.3 \%\end{array}$ & $\begin{array}{l}18.84 \\
22.07\end{array}$ & $\begin{array}{l}25.14 \\
25.52\end{array}$ & $\begin{array}{l}35.6 \% \\
15.6 \%\end{array}$ & $\begin{array}{l}4.53 \\
4.70\end{array}$ & $\begin{array}{l}4.11 \\
4.11\end{array}$ & $-12.6 \%$ & $\begin{array}{l}8.43 \\
7.95\end{array}$ & $\begin{array}{l}7.69 \\
7.60\end{array}$ & $\begin{array}{l}-8.8 \% \\
-4.4 \%\end{array}$ & & & \\
\hline 98 & $\begin{array}{l}0.005 \\
0.005\end{array}$ & 0.005 & $\begin{array}{l}-8.35 \% \\
-1.70 \%\end{array}$ & $\begin{array}{l}27.99 \\
27.20\end{array}$ & $\begin{array}{l}24.18 \\
27.98\end{array}$ & $0.0 \%$ & $\begin{array}{l}2.45 \\
2.45\end{array}$ & $\begin{array}{l}2.40 \\
2.41\end{array}$ & $-1.5 \%$ & $\begin{array}{l}22.017 \\
20.55\end{array}$ & $\begin{array}{l}25.52 \\
25.63\end{array}$ & $\begin{array}{l}15.7 \% \% \\
24.7 \%\end{array}$ & $\begin{array}{l}4.10 \\
4.54\end{array}$ & $\begin{array}{l}4.11 \\
4.20\end{array}$ & $\begin{array}{l}-11.60 \% \\
-7.6 \%\end{array}$ & $\begin{array}{l}7.95 \\
7.98\end{array}$ & $\begin{array}{l}7.00 \\
7.95\end{array}$ & $\begin{array}{l}-4.4 \% \\
-0.4 \%\end{array}$ & & & \\
\hline 90 & $\begin{array}{l}0.005 \\
0.00\end{array}$ & 0.005 & $-7.38 \%$ & 30.77 & 24.84 & $-19.3 \%$ & $\begin{array}{l}2.45 \\
2.51\end{array}$ & $\begin{array}{l}2.41 \\
2.43\end{array}$ & $\begin{array}{l}-1.5 \% \\
-3.2 \%\end{array}$ & $\begin{array}{l}20.53 \\
19.99\end{array}$ & $\begin{array}{l}25.03 \\
27.22\end{array}$ & $36.2 \%$ & $\begin{array}{l}4.54 \\
3.89\end{array}$ & $\begin{array}{l}4.85 \\
3.85\end{array}$ & $-1.1 \%$ & 8.05 & 7.78 & $\begin{array}{l}-0.4 \% \\
-3.3 \%\end{array}$ & & & \\
\hline $\begin{array}{l}190 \\
195\end{array}$ & 0.005 & 0.005 & $-3.21 \%$ & 24.70 & $\begin{array}{l}24.64 \\
21.10\end{array}$ & $\begin{array}{l}-19.3 \% \\
-14.6 \%\end{array}$ & $\begin{array}{l}2.51 \\
2.56\end{array}$ & $\begin{array}{l}2.45 \\
2.43\end{array}$ & $\begin{array}{l}-5.270 \\
-5.3 \%\end{array}$ & $\begin{array}{l}19.99 \\
20.18\end{array}$ & $\begin{array}{l}27.72 \\
26.73\end{array}$ & 32. & $\begin{array}{l}3.09 \\
4.00\end{array}$ & 3. & -3. & $\begin{array}{l}8.05 \\
8.21\end{array}$ & 7.88 & $\begin{array}{l}-3.3 \% \% \\
-4.0 \%\end{array}$ & & & \\
\hline 190 & $\begin{array}{l}0.005 \\
0\end{array}$ & 0.005 & $\begin{array}{l}-3.21 \% \\
6.87 \%\end{array}$ & $\begin{array}{l}2.170 \\
3.23\end{array}$ & 5.19 & $\begin{array}{l}-14.0 \% \\
60.6 \%\end{array}$ & $\begin{array}{l}2.50 \\
2.51\end{array}$ & $\begin{array}{l}2.45 \\
2.39\end{array}$ & $\begin{array}{l}-5.37 \% \\
-4.7 \%\end{array}$ & $\begin{array}{l}20.10 \\
21.17\end{array}$ & $\begin{array}{l}20.175 \\
27.84\end{array}$ & 31. & $\begin{array}{l}4.00 \\
4.97\end{array}$ & 5. & 6. & 8. & 7. & $\begin{array}{l}-4.0 \% \% \\
-5.7 \%\end{array}$ & & & \\
\hline 190 & $\begin{array}{l}0.005 \\
0\end{array}$ & 0.005 & $-7.07 \%$ & $\begin{array}{r}3.28 \\
24.58\end{array}$ & $\begin{array}{l}57.19 \\
27.24\end{array}$ & $\begin{array}{l}0.0 \% \% \\
10.8 \%\end{array}$ & $\begin{array}{l}2.51 \\
2.49\end{array}$ & $\begin{array}{l}2.39 \\
2.39\end{array}$ & $-4.0 \%$ & $\begin{array}{l}21.11 \\
22.42\end{array}$ & 29 & 30 & $\begin{array}{l}4.97 \\
4.07\end{array}$ & $\begin{array}{l}5.11 \\
3.94\end{array}$ & $\begin{array}{l}-3.3 \% \\
-3.0\end{array}$ & 8. & 7.67 & $\begin{array}{l}-5.1 \% \% \\
-4.9 \%\end{array}$ & & & \\
\hline 190 & $\begin{array}{l}0.005 \\
0\end{array}$ & 0.005 & $-7.89 \%$ & $\begin{array}{l}27.92 \\
27.92\end{array}$ & $\begin{array}{r}27.24 \\
27.91\end{array}$ & $0.0 \%$ & $\begin{array}{l}2.49 \\
2.46\end{array}$ & 2.41 & $\begin{array}{l}-4.0 \% \\
-2.0 \%\end{array}$ & $\begin{array}{l}22.42 \\
20.16\end{array}$ & 25 & 28 & $\begin{array}{l}4.01 \\
4.68\end{array}$ & $\begin{array}{l}3.144 \\
4.13\end{array}$ & $-11.6 \%$ & $\begin{array}{l}0.01 \\
8.02\end{array}$ & 7.63 & $\begin{array}{l}-4.49 \% \\
-4.8 \%\end{array}$ & & & \\
\hline 199 & 0.006 & 0.005 & $-15.27 \%$ & 27.90 & 24.26 & $-13.0 \%$ & $\begin{array}{l}2.40 \\
2.39\end{array}$ & 2.23 & $-6.7 \%$ & 21.83 & 30.57 & $40.0 \%$ & $\begin{array}{l}4.00 \\
4.56\end{array}$ & $\begin{array}{l}4.49 \\
4.49\end{array}$ & $-1.5 \%$ & $\begin{array}{l}7.67 \\
7.67\end{array}$ & $\begin{array}{l}7.700 \\
7.72\end{array}$ & $0.6 \%$ & & & \\
\hline 199 & 0.005 & 0.006 & $11.77 \%$ & 8.89 & 8.57 & $-3.6 \%$ & 2.49 & 2.30 & $-7.8 \%$ & 20.15 & 24.60 & $22.1 \%$ & 4.25 & $\begin{array}{l}4.24 \\
4.24\end{array}$ & $-0.3 \%$ & $\begin{array}{l}8.02 \\
8.02\end{array}$ & 7.74 & $-3.5 \%$ & & & \\
\hline $19 \mathrm{c}$ & 0.005 & 0.005 & $-1.94 \%$ & $\begin{array}{l}0.09 \\
0.43\end{array}$ & 0.35 & $-19.2 \%$ & $\begin{array}{l}2.49 \\
2.52\end{array}$ & 2.44 & $-3.2 \%$ & 19.88 & 24.15 & $21.5 \%$ & 6.42 & 6.66 & $3.7 \%$ & 7.97 & 7.88 & $-1.1 \%$ & & & \\
\hline 19 & 0.013 & 0.014 & $3.99 \%$ & 1.34 & 3.30 & $145.5 \%$ & 2.54 & 2.43 & $-4.3 \%$ & $\begin{array}{l}19.67 \\
\end{array}$ & 24.44 & $24.2 \%$ & 4.11 & $\begin{array}{l}3.92 \\
3.92\end{array}$ & $-4.7 \%$ & 8.51 & 8.08 & $-5.0 \%$ & & & \\
\hline 15 & 0.005 & 0.005 & $6.51 \%$ & 21.48 & $\begin{array}{l}5.30 \\
13.97\end{array}$ & $-35.0 \%$ & 2.51 & 2.41 & $-4.0 \%$ & 19.47 & $\begin{array}{l}26.84 \\
26.44\end{array}$ & $37.9 \%$ & $\begin{array}{l}4.11 \\
3.88\end{array}$ & $\begin{array}{l}4.03 \\
4.03\end{array}$ & $3.8 \%$ & 8.03 & $\begin{array}{l}0.000 \\
7.83\end{array}$ & $-2.5 \%$ & & & \\
\hline 199 & 0.011 & 0.011 & $2.46 \%$ & 22.74 & 20.37 & $-10.4 \%$ & 2.49 & 2.45 & $-1.5 \%$ & 20.14 & 25.26 & $25.4 \%$ & $\begin{array}{l}3.00 \\
3.99\end{array}$ & 4.02 & $0.6 \%$ & 8.09 & 8.09 & $-0.1 \%$ & & & \\
\hline 200 & 0.005 & 0.005 & $8.24 \%$ & 9.43 & 10.38 & $10.0 \%$ & 2.51 & 2.40 & $-4.1 \%$ & 18.24 & 23.35 & $28.0 \%$ & 4.01 & $\begin{array}{l}3.97 \\
3.97\end{array}$ & $-0.8 \%$ & 8.15 & 7.76 & $-4.8 \%$ & & & \\
\hline 200 & 0.005 & 0.005 & $-9.87 \%$ & 23.59 & 27.27 & $15.6 \%$ & 2.40 & 2.46 & $2.2 \%$ & 20.87 & 29.54 & $41.6 \%$ & 4.48 & 4.07 & $-9.0 \%$ & 7.60 & 7.85 & $3.4 \%$ & & & \\
\hline 200 & 0.005 & 0.005 & $-3.38 \%$ & 27.34 & 17.07 & $-37.6 \%$ & 2.56 & 2.45 & $-4.1 \%$ & 18.61 & 23.31 & $25.2 \%$ & 3.90 & 3.87 & $-0.6 \%$ & 8.06 & 7.92 & $-1.8 \%$ & & & \\
\hline 200 & 0.005 & 0.005 & $-2.96 \%$ & 21.72 & 20.12 & $-7.3 \%$ & 2.55 & 2.43 & $-4.8 \%$ & 18.95 & 24.81 & $30.9 \%$ & 4.21 & 3.89 & $-7.5 \%$ & 8.16 & 7.77 & $-4.8 \%$ & & & \\
\hline
\end{tabular}

Figure 4-12. Annual habitat summaries for steelhead and resident rainbow trout in the Kittitas reach for the Black Rock_2 scenario. 


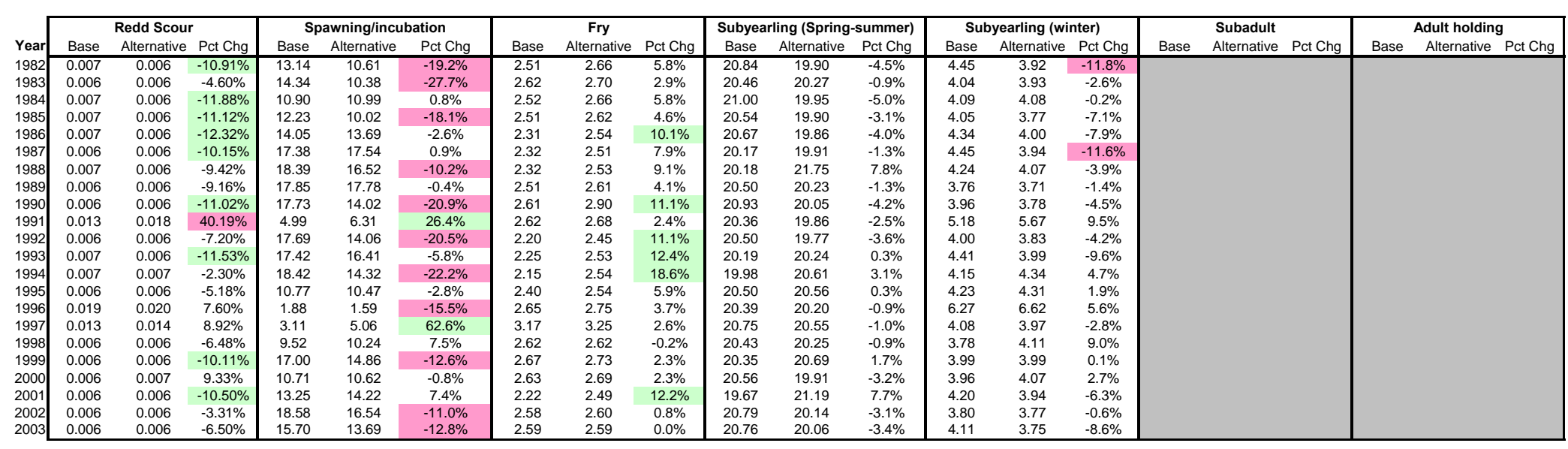

Figure 4-13. Annual habitat summary for bull trout in the Kittitas reach for the Black Rock_2 scenario. 


\begin{tabular}{|c|c|c|c|c|c|c|c|c|c|c|c|c|c|c|c|c|c|c|c|}
\hline \multicolumn{3}{|c|}{ Redd Scour } & \multicolumn{3}{|c|}{ Spawning/incubation } & \multicolumn{3}{|c|}{ Fry } & \multicolumn{3}{|c|}{ Subyearling (Spring-summer) } & \multicolumn{3}{|c|}{ Subyearling (winter) } & \multicolumn{2}{|r|}{ Subadult } & \multicolumn{3}{|c|}{ Adult holding } \\
\hline Base & Alternative & Pct Chg & Base & Alternative & Pct Chg & Base & Alternative & Pct Chg & Base & Alternative & & Base & Alternativ & Pct Chg & Base & Alternative Pct Chg & Base & & \\
\hline 0.102 & $\overline{0.102}$ & $0.15 \%$ & 9.62 & 8.72 & $-9.3 \%$ & 3.15 & 3.22 & $1.9 \%$ & 37.16 & 37.24 & $0.2 \%$ & 5.25 & 5.52 & $5.2 \%$ & & & 5.44 & 5.79 & $6.4 \%$ \\
\hline 0.057 & 0.057 & $-0.03 \%$ & 18.57 & 18.90 & $1.8 \%$ & 3.45 & 3.48 & $0.9 \%$ & 36.22 & 37.28 & $2.9 \%$ & 5.35 & 5.28 & $-1.3 \%$ & & & 5.29 & 5.45 & $3.1 \%$ \\
\hline 0.134 & 0.124 & $-6.91 \%$ & 19.38 & 25.36 & $30.9 \%$ & 2.75 & 2.96 & $7.5 \%$ & 38.00 & 38.81 & $2.1 \%$ & 5.50 & 5.36 & $-2.5 \%$ & & & 5.60 & 5.23 & $-6.6 \%$ \\
\hline 0.018 & 0.013 & $-30.70 \%$ & 15.19 & 30.72 & $102.2 \%$ & 2.33 & 2.45 & $4.9 \%$ & 38.23 & 36.95 & $-3.3 \%$ & 6.00 & 5.19 & $-13.5 \%$ & & & 6.08 & 5.88 & $-3.2 \%$ \\
\hline 0.030 & 0.029 & $-0.09 \%$ & 16.88 & 22.71 & $34.6 \%$ & 2.85 & 3.13 & $9.8 \%$ & 38.33 & 37.31 & $-2.7 \%$ & 5.65 & 5.56 & $-1.7 \%$ & & & 8.08 & 7.22 & $-10.7 \%$ \\
\hline 0.017 & 0.022 & $30.04 \%$ & 26.91 & 8.64 & $-67.9 \%$ & 2.61 & 2.64 & $0.9 \%$ & 36.42 & 38.02 & $4.4 \%$ & 5.45 & 5.41 & $-0.8 \%$ & & & 7.74 & 7.96 & $2.9 \%$ \\
\hline 0.023 & 0.013 & $-41.25 \%$ & 27.77 & 27.58 & $-0.7 \%$ & 2.29 & 2.33 & $1.6 \%$ & 35.98 & 36.14 & $0.5 \%$ & 5.25 & 5.14 & $-2.1 \%$ & & & 6.98 & 6.41 & $-8.2 \%$ \\
\hline 0.017 & 0.012 & $-30.55 \%$ & 31.12 & 29.17 & $-6.3 \%$ & 2.37 & 2.52 & $6.3 \%$ & 36.16 & 35.40 & $-2.1 \%$ & 4.74 & 4.75 & $0.1 \%$ & & & 6.05 & 5.66 & $-6.4 \%$ \\
\hline 0.041 & 0.041 & $-0.06 \%$ & 26.20 & 22.51 & $-14.1 \%$ & 2.58 & 2.71 & $5.2 \%$ & 39.03 & 37.22 & $-4.6 \%$ & 4.76 & 4.75 & $-0.1 \%$ & & & 5.02 & 4.96 & $-1.2 \%$ \\
\hline 0.222 & 0.221 & $-0.29 \%$ & 29.49 & 27.33 & $-7.3 \%$ & 2.91 & 3.15 & $8.3 \%$ & 37.09 & 35.92 & $-3.2 \%$ & 5.76 & 5.63 & $-2.1 \%$ & & & 5.05 & 5.28 & $4.6 \%$ \\
\hline 0.020 & 0.013 & $-33.25 \%$ & 19.09 & 24.94 & $30.7 \%$ & 2.34 & 2.49 & $6.3 \%$ & 39.33 & 41.88 & $6.5 \%$ & 5.20 & 5.26 & $1.3 \%$ & & & 9.13 & 9.23 & $1.1 \%$ \\
\hline 0.019 & 0.014 & $-27.29 \%$ & 27.93 & 15.63 & $-44.0 \%$ & 2.28 & 2.30 & $0.5 \%$ & 38.38 & 40.20 & $4.8 \%$ & 5.93 & 6.28 & $6.0 \%$ & & & 7.33 & 7.83 & $6.8 \%$ \\
\hline 0.021 & 0.014 & $-31.87 \%$ & 9.30 & $\begin{array}{l}16.96 \\
16.96\end{array}$ & $82.4 \%$ & 2.31 & 2.33 & $0.7 \%$ & 40.77 & 37.77 & $\begin{array}{l}-7.3 \% \\
-7.06\end{array}$ & $\begin{array}{l}5.91 \\
5.91\end{array}$ & 6.21 & $5.2 \%$ & & & 6.91 & $\begin{array}{l}8.13 \\
8.13\end{array}$ & $17.7 \%$ \\
\hline 0.144 & 0.142 & $-1.44 \%$ & 25.27 & 9.80 & $-61.2 \%$ & 3.34 & 3.36 & $0.5 \%$ & 36.50 & 37.09 & $1.6 \%$ & 5.73 & 5.83 & $1.8 \%$ & & & 5.05 & 5.28 & $4.5 \%$ \\
\hline 0.889 & 0.887 & $-0.23 \%$ & 4.19 & 2.17 & $-48.3 \%$ & 3.64 & 3.81 & $4.7 \%$ & 35.68 & 36.26 & $1.6 \%$ & 9.13 & 9.58 & $4.8 \%$ & & & 5.03 & 4.92 & $-2.0 \%$ \\
\hline 0.218 & 0.214 & $-1.56 \%$ & 18.54 & 13.96 & $-24.7 \%$ & 3.65 & 3.65 & $0.0 \%$ & 38.28 & 37.86 & $-1.1 \%$ & 5.73 & 5.93 & $3.5 \%$ & & & 5.26 & 5.61 & $6.5 \%$ \\
\hline 0.121 & 0.255 & $110.15 \%$ & 26.47 & 25.80 & $-2.6 \%$ & 2.90 & 2.93 & $1.2 \%$ & 36.44 & 35.65 & $-2.2 \%$ & 4.86 & 4.82 & $-0.8 \%$ & & & 5.54 & 5.83 & $5.3 \%$ \\
\hline 0.032 & 0.031 & $-1.33 \%$ & 18.03 & 26.75 & $48.4 \%$ & 2.95 & 3.10 & $5.0 \%$ & 37.97 & 37.67 & $-0.8 \%$ & 5.34 & 5.27 & $-1.2 \%$ & & & 5.14 & 5.34 & $3.9 \%$ \\
\hline 0.027 & 0.187 & $581.81 \%$ & 18.95 & 9.88 & $-47.8 \%$ & 2.65 & 2.83 & $7.1 \%$ & 37.64 & 36. & $-2.7 \%$ & 5.24 & 5.3 & $1.4 \%$ & & & 4.86 & 4.7 & $-3.1 \%$ \\
\hline 0.018 & 0.013 & $-27.07 \%$ & 17.25 & 14.05 & $-18.5 \%$ & 2.28 & 2.25 & $-1.4 \%$ & 42.28 & 41. & -0. & 6.80 & 6.7 & $-1.4 \%$ & & & 7.92 & 7. & $-0.1 \%$ \\
\hline 0.059 & 0.059 & $0.30 \%$ & 21.86 & 26.14 & $19.6 \%$ & 2.39 & 2.50 & 5.0 & 38.68 & 36 & -6 & 4.81 & 4.7 & $-0.8 \%$ & & & 4.89 & 4. & $-1.8 \%$ \\
\hline 0.133 & 0.132 & $-0.75 \%$ & 6.38 & 20.65 & $224.0 \%$ & 2.93 & 3.11 & $6.0 \%$ & 36.73 & 35.38 & $-3.7 \%$ & 6.29 & 6.22 & $-1.2 \%$ & & & 6.37 & 6.20 & $-2.7 \%$ \\
\hline
\end{tabular}

Coho

\begin{tabular}{|c|c|c|c|c|c|c|c|c|c|c|c|c|c|c|c|c|c|c|}
\hline \multirow[b]{2}{*}{ Year[ } & \multicolumn{3}{|c|}{ Redd Scour } & \multicolumn{3}{|c|}{ Spawning/incubation } & \multicolumn{3}{|c|}{ Fry } & \multicolumn{3}{|c|}{ Subyearling (Spring-summer) } & \multicolumn{3}{|c|}{ Subyearling (winter) } & \multicolumn{2}{|r|}{ Subadult } & $\begin{array}{l}\text { Adult holding } \\
\end{array}$ \\
\hline & Base & Alternative & Pct Chg & Base & Alternative & Pct Chg & Base & Alternative & Pct Chg & Base & Alternative & Pct Chg & Base & Alternative & Pct Chg & Base & Alternative Pct Chg & Base Alternative Pct Chg \\
\hline 1982 & $\overline{0.102}$ & 0.102 & $0.15 \%$ & 10.57 & 9.34 & $-11.7 \%$ & 3.01 & 3.10 & $3.0 \%$ & 7.81 & 6.82 & $-12.7 \%$ & 3.28 & 3.36 & $2.6 \%$ & & & \\
\hline 1983 & 0.057 & 0.057 & $-0.03 \%$ & 3.67 & 18.80 & $411.7 \%$ & 3.46 & 3.50 & $1.3 \%$ & 7.63 & 6.65 & $-12.8 \%$ & 3.42 & 3.45 & $0.7 \%$ & & & \\
\hline 1984 & 0.134 & 0.124 & $-6.91 \%$ & 3.91 & 11.24 & $187.8 \%$ & 2.92 & 3.20 & $9.8 \%$ & 7.96 & 7.03 & $-11.7 \%$ & 3.62 & 3.56 & $-1.8 \%$ & & & \\
\hline 1985 & 0.018 & 0.012 & $-30.28 \%$ & 2.71 & 22.14 & $717.7 \%$ & 2.64 & 3.04 & $15.2 \%$ & 7.45 & 6.82 & $-8.5 \%$ & 3.60 & 3.20 & $-11.1 \%$ & & & \\
\hline 1986 & 0.030 & 0.029 & $-0.09 \%$ & 3.19 & 9.79 & $206.9 \%$ & 2.64 & 2.97 & $12.8 \%$ & 6.63 & 6.69 & $0.8 \%$ & 3.49 & 3.42 & $-1.9 \%$ & & & \\
\hline 1987 & 0.014 & 0.010 & $-28.11 \%$ & 17.25 & 1.50 & $-91.3 \%$ & 2.68 & 2.71 & $1.3 \%$ & 6.78 & 6.82 & $0.7 \%$ & 3.41 & 3.39 & $-0.5 \%$ & & & \\
\hline 1988 & 0.017 & 0.012 & $-30.19 \%$ & 17.80 & 19.06 & $7.1 \%$ & 2.71 & 2.83 & $4.5 \%$ & 6.76 & 6.67 & $-1.3 \%$ & 3.35 & 3.33 & $-0.8 \%$ & & & \\
\hline 1989 & 0.013 & 0.010 & $-25.93 \%$ & 19.98 & 18.71 & $-6.4 \%$ & 3.11 & 3.39 & $9.0 \%$ & 6.86 & 6.82 & $-0.6 \%$ & 3.14 & 3.14 & $-0.1 \%$ & & & \\
\hline 1990 & 0.041 & 0.041 & $-0.06 \%$ & 18.32 & 14.39 & $-21.4 \%$ & 2.98 & 3.56 & $19.3 \%$ & 8.58 & 7.47 & $-13.0 \%$ & 3.20 & 3.21 & $0.2 \%$ & & & \\
\hline 1991 & 0.018 & 0.018 & $-0.08 \%$ & $\begin{array}{l}11.02 \\
11.02\end{array}$ & 22.39 & $103.3 \%$ & 2.87 & $\begin{array}{l}3.23 \\
3.23\end{array}$ & $12.7 \%$ & $\begin{array}{l}8.34 \\
8.30\end{array}$ & $\begin{array}{l}7.41 \\
7.08\end{array}$ & $-15.1 \%$ & 3.91 & $\begin{array}{l}3.74 \\
3.74\end{array}$ & $-4.4 \%$ & & & \\
\hline 1992 & 0.014 & 0.011 & $-25.84 \%$ & 3.82 & 11.01 & $188.0 \%$ & 2.27 & 2.51 & $10.5 \%$ & 6.80 & 7.03 & $3.4 \%$ & 3.40 & 3.40 & $-0.1 \%$ & & & \\
\hline 1993 & 0.019 & 0.014 & $-27.29 \%$ & 17.90 & 9.98 & $-44.2 \%$ & 2.37 & 2.41 & $1.5 \%$ & 7.35 & 7.33 & $-0.2 \%$ & 3.72 & 3.80 & $2.3 \%$ & & & \\
\hline 1994 & 0.019 & 0.014 & $-27.87 \%$ & 1.61 & 10.83 & $573.6 \%$ & 2.61 & 2.83 & $8.1 \%$ & 7.56 & 6.47 & $-14.3 \%$ & 3.69 & 3.75 & $1.5 \%$ & & & \\
\hline 1995 & 0.144 & 0.142 & $-1.44 \%$ & 11.19 & 10.81 & $-3.4 \%$ & 3.27 & 3.30 & $0.8 \%$ & 7.50 & 6.87 & $-8.4 \%$ & 3.69 & 3.6 & $-0.9 \%$ & & & \\
\hline 1996 & 0.889 & 0.887 & $-0.23 \%$ & 7.89 & 4.32 & $-45.2 \%$ & 3.46 & 3.70 & $7.0 \%$ & 7.38 & 6.71 & $-9.1 \%$ & 6.56 & 6.5 & $0.4 \%$ & & & \\
\hline 1997 & 0.218 & 0.214 & -1.5 & 3.67 & 16.83 & $359.3 \%$ & 3.61 & 3.6 & 0.0 & 8. & 6.6 & $-18.0 \%$ & 3.64 & 3.7 & $1.7 \%$ & & & \\
\hline 1998 & 0.011 & 0.011 & -0.59 & 11.85 & 11.48 & $-3.1 \%$ & 3.29 & 3.35 & $1.7 \%$ & 7.61 & 6.9 & -8.4 & 3.34 & 3.3 & -0.3 & & & \\
\hline 1999 & 0.032 & 0.031 & $-1.33 \%$ & 3.52 & 17.14 & $386.9 \%$ & 3.36 & 3.42 & $1.8 \%$ & 8.64 & 7.5 & $-12.9 \%$ & 3.50 & 3.4 & $-1.1 \%$ & & & \\
\hline 00 & 0.026 & 0.026 & $0.24 \%$ & 3.78 & 10.92 & $188.8 \%$ & 3.35 & $\begin{array}{l}3.69 \\
3.69\end{array}$ & $10.1 \%$ & 7.75 & 6.87 & $-11.3 \%$ & 3.47 & 3.4 & $-0.2 \%$ & & & \\
\hline 001 & 0.018 & 0.013 & $-27.07 \%$ & 3.30 & 5.68 & $72.2 \%$ & 2.33 & 2.29 & $-1.7 \%$ & 8.12 & 7.48 & $-7.9 \%$ & 4.29 & 4.0 & $-5.0 \%$ & & & \\
\hline 年 & 0.059 & 0.059 & $0.30 \%$ & $\begin{array}{l}0.33 \\
9.33\end{array}$ & 18.27 & $95.9 \%$ & 3.16 & 3.38 & $7.2 \%$ & $\begin{array}{l}8.48 \\
8.48\end{array}$ & 7.18 & $-15.4 \%$ & 3.21 & 3.2 & $-0.2 \%$ & & & \\
\hline 23 & 0.13 & 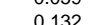 & 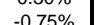 & 051 & 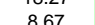 & 年 & 309 & 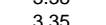 & $8.10 \%$ & 6.40 & 682 6 & 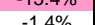 & $\begin{array}{ll}3.21 \\
382\end{array}$ & $\begin{array}{l}3.20 \\
3.67\end{array}$ & - & & & \\
\hline
\end{tabular}

Figure 4-14. Annual habitat summaries for spring chinook and coho salmon in the Naches reach for the Black Rock_2 scenario. 


\begin{tabular}{|c|c|c|c|c|c|c|c|c|c|c|c|c|c|c|c|c|c|c|c|c|c|}
\hline \multirow{2}{*}{ Steelhead } & \multicolumn{3}{|c|}{ Redd Scour } & \multicolumn{3}{|c|}{ Spawning/incubation } & \multicolumn{3}{|c|}{ Fry } & \multicolumn{3}{|c|}{ Subyearling (Spring-summer) } & \multicolumn{3}{|c|}{ Subyearling (winter) } & \multicolumn{3}{|c|}{ Subadult } & \multicolumn{3}{|c|}{ Adult holding } \\
\hline & Base & Alternative & Pct Chg & Base & Alternative & Pct Chg & Base & Alternative & Pct Chg & Base & Alternative & Pct Chg & Base & Alternativ & Pct Chg & Base & Alternative & Pct Chg & Base & Alternative & Pct Chg \\
\hline 198 & 0.295 & 0.294 & $-0.27 \%$ & 28.00 & 25.10 & $-10.3 \%$ & 3.43 & 3.36 & $-2.1 \%$ & 45.51 & 46.63 & $2.5 \%$ & 4.51 & 4.72 & $4.7 \%$ & 53.21 & 53.65 & $0.8 \%$ & 10.86 & 10.84 & $-0.1 \%$ \\
\hline 198 & 0.433 & 0.354 & $-18.13 \%$ & 19.23 & 30.57 & $58.9 \%$ & 3.44 & 3.32 & $-3.7 \%$ & 45.40 & 47.81 & $5.3 \%$ & 4.56 & 4.49 & $-1.6 \%$ & 50.48 & 51.60 & $2.2 \%$ & 8.24 & 9.40 & $14.1 \%$ \\
\hline 198 & 0.125 & 0.056 & $-54.74 \%$ & 20.38 & 25.43 & $24.8 \%$ & 3.47 & 3.36 & $-3.3 \%$ & 45.63 & 47.61 & $4.3 \%$ & 4.65 & 4.44 & $-4.7 \%$ & 49.12 & 50.54 & $2.9 \%$ & 8.43 & 9.37 & $11.2 \%$ \\
\hline 198 & 0.411 & 0.375 & $-8.61 \%$ & 14.48 & 28.80 & $98.9 \%$ & 3.35 & 3.34 & $-0.3 \%$ & 45.73 & 45.50 & $-0.5 \%$ & 5.30 & 4.45 & $-16.1 \%$ & 51.17 & 51.37 & $0.4 \%$ & 16.78 & 17.20 & $2.5 \%$ \\
\hline 198 & 0.308 & 0.310 & $0.49 \%$ & 16.85 & 22.45 & $33.2 \%$ & 3.31 & 3.33 & $0.3 \%$ & 47.86 & 46.05 & $-3.8 \%$ & 4.92 & 4.73 & $-4.0 \%$ & 51.74 & 50.73 & $-2.0 \%$ & 10.56 & 10.97 & $3.9 \%$ \\
\hline 198 & 0.130 & 0.129 & $-0.67 \%$ & 26.98 & 8.03 & $-70.2 \%$ & 3.34 & 3.35 & $0.3 \%$ & 45.79 & 48.73 & $6.4 \%$ & 4.69 & 4.65 & $-0.9 \%$ & 51.37 & 51.87 & $1.0 \%$ & 11.26 & 12.59 & $11.8 \%$ \\
\hline 198 & 0.035 & 0.035 & $-0.38 \%$ & 27.87 & 26.72 & $-4.1 \%$ & 3.33 & 3.34 & $0.5 \%$ & 46.20 & 49.13 & $6.3 \%$ & 4.51 & 4.39 & $-2.8 \%$ & 50.02 & 48.99 & $-2.1 \%$ & 13.40 & 14.87 & $11.0 \%$ \\
\hline 198 & 0.049 & 0.087 & $77.46 \%$ & 31.37 & 29.33 & $-6.5 \%$ & 3.36 & 3.32 & $-1.3 \%$ & 45.23 & 45.24 & $0.0 \%$ & 4.17 & 4.17 & $0.0 \%$ & 50.37 & 50.64 & $0.5 \%$ & 12.95 & 12.32 & $-4.9 \%$ \\
\hline 199 & 0.169 & 0.168 & $-0.64 \%$ & 26.90 & 22.40 & $-16.7 \%$ & 3.37 & 3.34 & $-0.7 \%$ & 47.95 & 45.63 & $-4.8 \%$ & 4.18 & 4.18 & $0.0 \%$ & 49.19 & 49.91 & $1.5 \%$ & 10.83 & 10.50 & $-3.0 \%$ \\
\hline 199 & 0.023 & 0.012 & $-47.71 \%$ & 31.66 & 38.49 & $21.6 \%$ & 3.45 & 3.34 & $-3.1 \%$ & 45.92 & 45.27 & $-1.4 \%$ & 4.81 & 4.63 & $-3.8 \%$ & 48.85 & 49.07 & $0.5 \%$ & 7.72 & 7.80 & $1.1 \%$ \\
\hline 199 & 0.016 & 0.007 & $-54.51 \%$ & 19.96 & 24.96 & $25.0 \%$ & 3.35 & 3.35 & $-0.1 \%$ & 47.46 & 52.94 & $11.6 \%$ & 4.55 & 4.46 & $-1.9 \%$ & 53.11 & 52.26 & $-1.6 \%$ & 9.08 & 10.92 & $20.3 \%$ \\
\hline 199 & 0.029 & 0.029 & $1.76 \%$ & 28.04 & 15.49 & $-44.7 \%$ & 3.38 & 3.36 & $-0.5 \%$ & 46.41 & 53.25 & $14.7 \%$ & 5.09 & 5.25 & $3.3 \%$ & 51.14 & 51.52 & $0.7 \%$ & 16.05 & 19.21 & $19.7 \%$ \\
\hline 199 & 0.016 & 0.010 & $-38.52 \%$ & 8.64 & 16.81 & $94.6 \%$ & 3.45 & 3.30 & $-4.4 \%$ & 45.99 & 50.99 & $10.9 \%$ & 5.10 & 5.17 & $1.3 \%$ & 50.49 & 50.00 & $-1.0 \%$ & 16.16 & 18.12 & $12.1 \%$ \\
\hline 199 & 0.247 & 0.246 & $-0.22 \%$ & 25.33 & 24.58 & $-3.0 \%$ & 3.35 & 3.35 & $-0.1 \%$ & 45.61 & 46.67 & $2.3 \%$ & 4.80 & 4.78 & $-0.4 \%$ & 52.00 & 52.12 & $0.2 \%$ & 8.12 & 8.85 & $9.0 \%$ \\
\hline 199 & 0.075 & 0.075 & $-1.00 \%$ & 39.02 & 32.45 & $-16.8 \%$ & 3.43 & 3.34 & $-2.6 \%$ & 45.27 & 47.10 & $4.0 \%$ & 8.03 & 8.17 & $1.8 \%$ & 48.75 & 49.55 & $1.6 \%$ & 8.95 & 9.64 & $7.6 \%$ \\
\hline 199 & 0.695 & 0.694 & $-0.20 \%$ & 19.19 & 29.84 & $55.5 \%$ & 3.41 & 3.37 & $-1.1 \%$ & 45.70 & 48.24 & $5.6 \%$ & 4.79 & 4.85 & $1.1 \%$ & 54.98 & 53.96 & $-1.8 \%$ & 8.20 & 8.63 & $5.3 \%$ \\
\hline 199 & 0.400 & 0.432 & $7.96 \%$ & 26.68 & 25.92 & $-2.8 \%$ & 3.38 & 3.34 & $-1.0 \%$ & 45.80 & 45.27 & $-1.2 \%$ & 4.22 & 4.21 & $-0.3 \%$ & 51.69 & 52.26 & $1.1 \%$ & 9.34 & 9.17 & $-1.8 \%$ \\
\hline 199 & 0.449 & 0.448 & $-0.27 \%$ & 18.48 & 26.82 & $45.1 \%$ & 4.04 & 4.11 & $1.6 \%$ & 46.05 & 46.13 & $0.2 \%$ & 4.45 & 4.41 & $-0.8 \%$ & 56.49 & 56.26 & $-0.4 \%$ & 8.49 & 8.92 & $5.0 \%$ \\
\hline 00 & 0.112 & 0.112 & $-0.43 \%$ & 19.77 & 27.33 & $38.3 \%$ & 3.43 & 3.34 & $-2.6 \%$ & 45.77 & 45.43 & $-0.8 \%$ & 4.40 & 4.43 & $0.7 \%$ & 49.33 & 50.63 & $2.7 \%$ & 8.42 & 8.73 & $3.7 \%$ \\
\hline 200 & 0.018 & 0.009 & $-51.35 \%$ & 17.37 & 13.44 & $-22.6 \%$ & 3.42 & 3.40 & $-0.7 \%$ & 47.77 & 52.32 & $9.5 \%$ & 6.46 & 5.96 & $-7.7 \%$ & 51.17 & 49.35 & $-3.5 \%$ & 18.01 & 20.01 & $11.1 \%$ \\
\hline 200 & 0.382 & 0.390 & $2.13 \%$ & 21.49 & 27.25 & $26.8 \%$ & 3.42 & 3.35 & $-2.0 \%$ & 45.76 & 45.14 & $-1.3 \%$ & 4.19 & 4.18 & $-0.1 \%$ & 51.83 & 52.61 & $1.5 \%$ & 10.21 & 10.68 & $4.6 \%$ \\
\hline 200 & 0.185 & 0.186 & $0.53 \%$ & 6.27 & 20.13 & $221.0 \%$ & 3.34 & 3.34 & $-0.1 \%$ & 45.37 & 45.24 & $-0.3 \%$ & 5.43 & 5.17 & $-4.8 \%$ & 50.12 & 49.60 & $-1.0 \%$ & 10.75 & 11.04 & $2.7 \%$ \\
\hline \multirow{2}{*}{ Resident Rainbow } & \multicolumn{3}{|c|}{ Redd Scour } & \multicolumn{3}{|c|}{ Spawning/incubation } & \multicolumn{3}{|c|}{ Fry } & \multicolumn{3}{|c|}{ Subyearling (Spring-summer) } & \multicolumn{3}{|c|}{ Subyearling (winter) } & & Subadult & & & \begin{tabular}{|l|l} 
Adult \\
\end{tabular} & \\
\hline & Base & Alternative & Pct Chg & Base & Alternative & Pct Chg & Base & Alternative & Pct Chg & Base & Alternative & Pct Chg & Base & Alternativ & Pct Chg & Base & Alternative & Pct Chg & Base & Alternative & Pct Chg \\
\hline 198 & 0.295 & 0.294 & $-0.27 \%$ & 8.11 & 7.30 & $-10.0 \%$ & 4.29 & 4.23 & $-1.4 \%$ & 45.34 & 46.35 & $2.2 \%$ & 5.80 & 6.04 & $4.1 \%$ & 19.97 & 18.45 & $-7.6 \%$ & & & \\
\hline 198 & 0.433 & 0.354 & $-18.13 \%$ & 12.17 & 17.06 & $40.2 \%$ & 4.30 & 4.19 & $-2.4 \%$ & 45.22 & 47. & $5.0 \%$ & 5.89 & 5.82 & $-1.1 \%$ & 17.20 & 16.89 & $-1.8 \%$ & & & \\
\hline 198 & 0.125 & 0.056 & $-54.74 \%$ & 12.81 & 20.03 & $56.4 \%$ & 4.32 & 4.23 & $-2.1 \%$ & 45.46 & 47. & $4.0 \%$ & 6.06 & 5.79 & $-4.5 \%$ & 15.79 & 16.73 & $6.0 \%$ & & & \\
\hline 198 & 0.411 & 0.375 & $-8.61 \%$ & 9.54 & 32.21 & $237.5 \%$ & 4.21 & 4.19 & $-0.4 \%$ & 45.56 & 45 & $-0.6 \%$ & 6.70 & 5.73 & $-14.4 \%$ & 16.68 & 16.44 & $-1.4 \%$ & & & \\
\hline 198 & 0.308 & 0.310 & $0.49 \%$ & 10.86 & 17.76 & $63.6 \%$ & 4.20 & 4.20 & $0.0 \%$ & 47.51 & 45. & $-3.6 \%$ & 6.29 & 6.06 & $-3.6 \%$ & 15.71 & 15.69 & $-0.1 \%$ & & & \\
\hline $198>$ & 0.130 & 0.129 & $-0.67 \%$ & 23.93 & 5.36 & $-77.6 \%$ & 4.21 & 4.20 & $-0.2 \%$ & 45.59 & 48.33 & $6.0>>2>>0$ & $6.0>>2>>0$ & 6.00 & $-1.1 \%$ & 15.85 & 16.24 & $2.5 \%$ & & & \\
\hline 198 & 0.011 & 0.008 & $-23.40 \%$ & 24.65 & 27.03 & $9.7>30>3$ & 4.21 & 4.21 & $0.0 \%$ & 45.96 & 48. & 6.6 & 5. & 5.6 & $-2.5 \%$ & 15.11 & 14.61 & $-3.3 \%$ & & & \\
\hline 198 & 0.049 & 0.049 & $0.41 \%$ & 27.46 & 25.82 & $-6.0 \%$ & 4.23 & 4.19 & $-1.0<-3>0$ & 45.04 & 45. & 0. & $5.2>3$ & 5.40 & $0.1 \%$ & 15.39 & 15. & $1.7 \%$ & & & \\
\hline 199 & 0.021 & 0.008 & $-62.33 \%$ & 22.66 & 20.24 & $-10.7 \%$ & 4.24 & 4.21 & $-0.7 \%$ & 47.77 & 45.46 & $-4.8 \%$ & 5.41 & $5.2>3>0$ & $0.0 \%$ & 15.48 & 16.50 & $6.6 \%$ & & & \\
\hline 199 & 0.023 & 0.008 & $-65.67 \%$ & 22.92 & 25.96 & $13.3 \%$ & 4.29 & 4.21 & $-1.9 \%$ & 45.76 & 45.08 & $-1.5 \%$ & 6. & 6. & $-3.9 \%$ & 15.69 & 15.96 & $1.7 \%$ & & & \\
\hline 199 & 0.016 & 0.007 & $-54.51 \%$ & 12.58 & 19.67 & $56.4 \%$ & 4.21 & 4.19 & $-0.4 \%$ & 47.14 & 52.20 & 10.7 & 5.9 & 5. & $-1.5 \%$ & 17.12 & 16 & $-2.7 \%$ & & & \\
\hline 199 & 0.029 & 0.029 & $1.76 \%$ & 24.78 & 14.13 & $-43.0 \%$ & 4.22 & 4.20 & -0.6 & 46.18 & 52. & 13. & 6. & & 2. & 17.33 & 16. & $-2.0 \%$ & & & \\
\hline 199 & 0.016 & 0.007 & $-58.62 \%$ & 5.77 & 15.34 & $165.9 \%$ & 4.26 & 4.20 & $-1.5 \%$ & 45.78 & 50. & $10.2 \%$ & 6.52 & 6. & $0.8 \%$ & 16.30 & 15. & $-7.7 \%$ & & & \\
\hline 199 & 0.247 & 0.246 & $-0.22 \%$ & 19.95 & 8.28 & $-58.5 \%$ & 4.22 & 4.21 & $-0.2 \%$ & 45.44 & 46.39 & $2.1 \%$ & 6.24 & 6.22 & $-0.3 \%$ & 17.75 & 17.82 & $0.4 \%$ & & & \\
\hline 199 & 0.058 & 0.035 & $-39.90 \%$ & 3.92 & 2.15 & $-45.2 \%$ & 4.28 & 4.19 & $-2.0 \%$ & 45.09 & 46.79 & $3.8 \%$ & 10.53 & 10.69 & $1.6 \%$ & 15.59 & 15.92 & $2.1 \%$ & & & \\
\hline 199 & 0.695 & 0.694 & $-0.20 \%$ & 12.15 & 12.91 & $6.2 \%$ & 4.26 & 4.25 & $-0.3 \%$ & 45.54 & 47.87 & $5.1 \%$ & 6.24 & 6.30 & $0.9 \%$ & 21.39 & 19.07 & $-10.9 \%$ & & & \\
\hline 199 & 0.400 & 0.432 & $7.96 \%$ & 20.98 & 20.40 & $-2.8 \%$ & 4.24 & 4.20 & $-0.9 \%$ & 45.65 & 45.08 & $-1.2 \%$ & 5.48 & 5.45 & $-0.6 \%$ & 17.62 & 16.99 & $-3.5 \%$ & & & \\
\hline 199 & 0.449 & 0.448 & $-0.27 \%$ & 11.76 & 23.80 & $102.4 \%$ & 5.01 & 5.09 & $1.8 \%$ & 45.88 & 45.88 & $0.0 \%$ & 5.80 & 5.76 & $-0.6 \%$ & 21.14 & 20.94 & $-1.0 \%$ & & & \\
\hline 200 & 0.092 & 0.085 & $-7.86 \%$ & 12.47 & 8.35 & $-33.1 \%$ & 4.30 & 4.20 & $-2.4 \%$ & 45.62 & 45.23 & $-0.9 \%$ & 5.71 & 5.73 & $0.4 \%$ & 16.11 & 16.77 & $4.1 \%$ & & & \\
\hline 200 & 0.018 & 0.009 & $-51.35 \%$ & 11.15 & 10.74 & $-3.6 \%$ & 4.23 & 4.21 & $-0.4 \%$ & 47.44 & 51.72 & $9.0 \%$ & 8.02 & 7.39 & $-7.8 \%$ & 17.36 & 15.47 & $-10.9 \%$ & & & \\
\hline 200 & 0.091 & 0.089 & $-1.90 \%$ & 17.03 & 22.62 & $32.8 \%$ & 4.27 & 4.21 & $-1.5 \%$ & 45.59 & 44.95 & $-1.4 \%$ & 5.44 & 5.43 & $-0.3 \%$ & 19.56 & 18.27 & $-6.6 \%$ & & & \\
\hline 200 & 0.185 & 0.186 & $0.53 \%$ & 2.89 & 15.99 & $454.0 \%$ & 4.23 & 4.21 & $-0.4 \%$ & 45.20 & 45.06 & $-0.3 \%$ & 6.88 & 6.55 & $-4.8 \%$ & 15.24 & 15.21 & $-0.2 \%$ & & & \\
\hline
\end{tabular}

Figure 4-15. Annual habitat summaries for steelhead and resident rainbow trout in the Naches reach for the Black Rock_2 scenario. 
Bull Trout

\begin{tabular}{|c|c|c|c|c|c|c|c|c|c|c|c|c|c|c|c|c|c|c|c|}
\hline \multirow[b]{2}{*}{ Year } & \multirow{2}{*}{\multicolumn{3}{|c|}{\begin{tabular}{l}
\multicolumn{2}{c}{ Redd Scour } \\
Base \\
Alternative Pct Chg
\end{tabular}}} & \multicolumn{3}{|c|}{ Spawning/incubation } & \multicolumn{3}{|c|}{ Fry } & \multirow{2}{*}{\multicolumn{3}{|c|}{$\begin{array}{l}\text { Subyearling (Spring-summer) } \\
\text { Base Alternative Pct Chg }\end{array}$}} & \multicolumn{3}{|c|}{ Subyearling (winter) } & \multirow{2}{*}{\multicolumn{2}{|c|}{$\begin{array}{lll} & \text { Subadult } \\
\text { Base } & \text { Alternative Pct Chg }\end{array}$}} & \multirow{2}{*}{\multicolumn{2}{|c|}{ 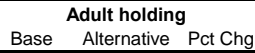 }} \\
\hline & Base & & Pct Chg & Base & Alternative & Pct Chg & Base & Alternative & Pct Chg & & & & Base & Alternat & e Pct Chg & & & & \\
\hline & 0.102 & 0.102 & $0.15 \%$ & 9.19 & 8.61 & $-6.3 \%$ & 6.10 & 6.25 & $2.5 \%$ & 64.41 & 65.07 & $1.0 \%$ & 5.71 & 5.95 & $4.3 \%$ & & & & \\
\hline 1983 & 0.057 & 0.057 & $-0.03 \%$ & 4.16 & 16.30 & $291.5 \%$ & 7.24 & 7.41 & $2.4 \%$ & 63.97 & 65.39 & $2.2 \%$ & 6.01 & 5.97 & $-0.6 \%$ & & & & \\
\hline 1984 & 0.134 & 0.124 & $-6.91 \%$ & 4.25 & 10.06 & $136.9 \%$ & 5.82 & 6.40 & $10.1 \%$ & 64.20 & 66.50 & $3.6 \%$ & 6.31 & 6.22 & $-1.4 \%$ & & & & \\
\hline 1985 & 0.018 & 0.012 & $-30.28 \%$ & 3.81 & 21.25 & $457.5 \%$ & 5.29 & 6.11 & $15.5 \%$ & 65.54 & 64.62 & $-1.4 \%$ & 6.32 & 5.62 & $-11.0 \%$ & & & & \\
\hline 1986 & 0.030 & 0.029 & $-0.09 \%$ & 3.99 & 9.11 & $128.5 \%$ & 5.24 & 5.92 & $12.9 \%$ & 66.23 & 65.11 & $-1.7 \%$ & 6.15 & 6.09 & $-1.0 \%$ & & & & \\
\hline 1987 & 0.014 & 0.022 & $61.74 \%$ & 15.25 & 2.24 & $-85.3 \%$ & 5.33 & 5.41 & $1.4 \%$ & 64.20 & 65.56 & $2.1 \%$ & 5.94 & 5.91 & $-0.5 \%$ & & & & \\
\hline 1988 & 0.023 & 0.013 & $-41.25 \%$ & 15.62 & 20.63 & $32.0 \%$ & 5.43 & 5.67 & $4.6 \%$ & 63.68 & 63.86 & $0.3 \%$ & 5.82 & 5.72 & $-1.7 \%$ & & & & \\
\hline 1989 & 0.016 & 0.011 & $-27.54 \%$ & 17.08 & 16.23 & $-5.0 \%$ & 6.28 & 6.99 & $11.3 \%$ & 63.67 & 62.85 & $-1.3 \%$ & 5.36 & 5.36 & $0.0 \%$ & & & & \\
\hline 1990 & 0.041 & 0.041 & $-0.06 \%$ & 20.69 & 13.33 & $-35.6 \%$ & 5.97 & 7.22 & $21.0 \%$ & 66.41 & 65.26 & $-1.7 \%$ & 5.41 & 5.41 & $0.0 \%$ & & & & \\
\hline 1991 & 0.222 & 0.221 & $-0.29 \%$ & 9.42 & 19.10 & $102.8 \%$ & 5.71 & 6.46 & $13.2 \%$ & 64.33 & 63.70 & $-1.0 \%$ & 6.75 & 6.60 & $-2.2 \%$ & & & & \\
\hline 1992 & 0.016 & 0.011 & $-28.23 \%$ & 4.22 & 9.91 & $135.0 \%$ & 4.58 & 5.01 & $9.5 \%$ & 66.42 & 69.15 & $4.1 \%$ & 5.85 & 5.88 & $0.5 \%$ & & & & \\
\hline 1993 & 0.019 & 0.014 & $-27.29 \%$ & 15.69 & 9.47 & $-39.7 \%$ & 4.74 & 4.81 & $1.5 \%$ & 65.37 & 67.45 & $3.2 \%$ & 6.51 & 6.74 & $3.5 \%$ & & & & \\
\hline 1994 & 0.021 & 0.014 & $-31.87 \%$ & 2.41 & 10.27 & $326.8 \%$ & 5.20 & 5.64 & $8.5 \%$ & 64.89 & 65.50 & $0.9 \%$ & 6.48 & 6.66 & $2.7 \%$ & & & & \\
\hline 1995 & 0.144 & 0.142 & $-1.44 \%$ & 10.03 & 9.30 & $-7.3 \%$ & 6.67 & 6.70 & $0.4 \%$ & 64.53 & 65.04 & $0.8 \%$ & 6.52 & 6.55 & $0.4 \%$ & & & & \\
\hline 1996 & 0.889 & 0.887 & $-0.23 \%$ & 4.30 & 2.52 & $-41.4 \%$ & 7.17 & 7.72 & $7.7 \%$ & 62.81 & 64.06 & $2.0 \%$ & 10.84 & 11.30 & $4.2 \%$ & & & & \\
\hline 1997 & 0.218 & 0.214 & $-1.56 \%$ & 4.16 & 12.69 & $205.0 \%$ & 9.05 & 9.05 & $0.0 \%$ & 65.87 & 65.87 & $0.0 \%$ & 6.50 & 6.71 & $3.2 \%$ & & & & \\
\hline 1998 & 0.121 & 0.163 & $34.09 \%$ & 10.46 & 10.22 & $-2.3 \%$ & 6.94 & 7.04 & $1.3 \%$ & 64.28 & 63.22 & $-1.7 \%$ & 5.63 & 5.57 & $-1.0 \%$ & & & & \\
\hline 1999 & 0.032 & 0.031 & $-1.33 \%$ & 4.11 & 15.18 & $269.4 \%$ & 7.07 & 7.20 & $1.9 \%$ & 66.29 & 65.71 & $-0.9 \%$ & 6.14 & 6.07 & $-1.1 \%$ & & & & \\
\hline 2000 & 0.027 & 0.187 & $581.81 \%$ & 4.20 & 9.35 & $122.5 \%$ & 6.91 & 7.70 & $11.4 \%$ & 63.91 & 64.39 & $0.8 \%$ & 6.03 & 6.08 & $0.9 \%$ & & & & \\
\hline 2001 & 0.018 & 0.013 & $-27.07 \%$ & 4.03 & 5.78 & $43.6 \%$ & 4.70 & 4.71 & $0.3 \%$ & 64.97 & 65.60 & $1.0 \%$ & 7.28 & 7.25 & $-0.3 \%$ & & & & \\
\hline 2002 & 0.059 & 0.059 & $0.30 \%$ & 8.81 & 20.68 & $\begin{array}{l}134.7 \% \\
\end{array}$ & 6.63 & 7.19 & $8.5 \%$ & 65.17 & 63.80 & $-2.1 \%$ & 5.48 & 5.43 & $-0.9 \%$ & & & & \\
\hline 2003 & 0.133 & 0.132 & $-0.75 \%$ & 0.95 & 8.38 & $785.2 \%$ & 6.18 & 6.72 & $8.8 \%$ & 64.37 & 62.81 & $-2.4 \%$ & 6.82 & 6.62 & $-3.0 \%$ & & & & \\
\hline
\end{tabular}

Figure 4-16. Annual habitat summary for bull trout in the Naches reach for the Black Rock_2 scenario. 
Fall Chinook

\begin{tabular}{|c|c|c|c|c|c|c|c|c|c|c|c|c|c|c|c|c|}
\hline \multirow[b]{2}{*}{ Year } & \multicolumn{3}{|c|}{ Redd Scour } & \multicolumn{3}{|c|}{ Spawning/incubation } & \multicolumn{3}{|c|}{ Fry } & \multicolumn{3}{|c|}{ Subyearling (Spring-summer) } & \multirow{2}{*}{$\begin{array}{l}\text { Subyearling (winter) } \\
\text { Base Alternative Pct Chg }\end{array}$} & \multirow{2}{*}{\multicolumn{2}{|c|}{\begin{tabular}{ll}
\multicolumn{3}{c}{ Subadult } \\
Base & Alternative Pct Chg
\end{tabular}}} & \multirow{2}{*}{\begin{tabular}{ll}
\multicolumn{3}{c}{ Adult holding } \\
Base & Alternative Pct Chg
\end{tabular}} \\
\hline & Base & Alternativ & Pct Chg & Base & Alternative & & Base & Alternative & Pct Chg & Base & Alternative & & & & & \\
\hline & 0.031 & 0.032 & $0.86 \%$ & 19.76 & 21.22 & $7.4 \%$ & 7.24 & 6.92 & $-4.5 \%$ & 43.20 & 45.57 & $5.5 \%$ & & & & \\
\hline 1983 & 0.028 & 0.030 & $7.55 \%$ & 19.32 & 19.51 & $0.9 \%$ & 6.41 & 6.27 & $-2.2 \%$ & 40.59 & 43.94 & $8.2 \%$ & & & & \\
\hline 1984 & 0.028 & 0.031 & $10.51 \%$ & 19.78 & 19.34 & $-2.2 \%$ & 7.11 & 6.96 & $-2.0 \%$ & 35.79 & 43.12 & $20.5 \%$ & & & & \\
\hline 1985 & 0.030 & 0.024 & $-21.85 \%$ & 19.67 & 21.08 & $7.2 \%$ & 7.73 & 7.36 & $-4.8 \%$ & 35.51 & 41.27 & $16.2 \%$ & & & & \\
\hline 1986 & 0.028 & 0.025 & $-11.54 \%$ & 16.51 & 19.54 & $18.3 \%$ & 6.82 & 6.75 & $-1.1 \%$ & 34.91 & 39.72 & $13.8 \%$ & & & & \\
\hline 1987 & 0.030 & 0.026 & $-13.62 \%$ & 18.21 & 18.31 & $0.6 \%$ & 7.69 & 7.55 & $-1.8 \%$ & 35.31 & 39.24 & $11.2 \%$ & & & & \\
\hline 1988 & 0.035 & 0.027 & $-22.41 \%$ & 18.29 & 18.38 & $0.5 \%$ & 7.72 & 7.51 & $-2.6 \%$ & 35.06 & 39.04 & $11.4 \%$ & & & & \\
\hline 1989 & 0.025 & 0.022 & $-9.81 \%$ & 20.85 & 20.54 & $-1.5 \%$ & 7.19 & 6.81 & $-5.4 \%$ & 35.52 & 40.91 & $15.2 \%$ & & & & \\
\hline 1990 & 0.029 & 0.025 & $-14.58 \%$ & 19.32 & 20.81 & $7.7 \%$ & 6.58 & 6.33 & $-3.8 \%$ & 35.74 & 43.37 & $21.4 \%$ & & & & \\
\hline 1991 & 0.052 & 0.079 & $51.43 \%$ & 22.97 & 21.05 & $-8.4 \%$ & 7.10 & 6.98 & $-1.7 \%$ & 35.38 & 42.52 & $20.2 \%$ & & & & \\
\hline 1992 & 0.027 & 0.024 & $-11.48 \%$ & 19.87 & 20.92 & $5.3 \%$ & 7.96 & 7.86 & $-1.3 \%$ & 34.91 & 39.22 & $12.4 \%$ & & & & \\
\hline 1993 & 0.034 & 0.030 & $-12.11 \%$ & 17.57 & 18.14 & $3.2 \%$ & 8.28 & 8.09 & $-2.3 \%$ & 34.84 & 39.18 & $12.5 \%$ & & & & \\
\hline 1994 & 0.035 & 0.033 & $-7.69 \%$ & 18.28 & 18.06 & $-1.3 \%$ & 8.19 & 8.00 & $-2.4 \%$ & 33.80 & 38.77 & $14.7 \%$ & & & & \\
\hline 1995 & 0.031 & 0.031 & $0.86 \%$ & 18.21 & 17.52 & $-3.8 \%$ & 7.12 & 7.02 & $-1.4 \%$ & 40.01 & 42.28 & $5.7 \%$ & & & & \\
\hline 1996 & 0.199 & 0.201 & $0.80 \%$ & 9.65 & 17.51 & $81.4 \%$ & 5.91 & 5.88 & $-0.6 \%$ & 36.65 & 42.95 & $17.2 \%$ & & & & \\
\hline 1997 & 0.057 & 0.055 & $-2.89 \%$ & 19.08 & 21.33 & $11.8 \%$ & 5.78 & 5.78 & $-0.1 \%$ & 62.39 & 63.85 & $2.3 \%$ & & & & \\
\hline 1998 & 0.019 & 0.025 & $33.41 \%$ & 20.52 & 21.19 & $3.3 \%$ & 6.65 & 6.60 & $-0.8 \%$ & 41.81 & 44.26 & $5.9 \%$ & & & & \\
\hline 1999 & 0.028 & 0.025 & $-11.13 \%$ & 19.56 & 21.17 & $8.2 \%$ & 6.99 & 6.70 & $-4.1 \%$ & 42.02 & 44.23 & $5.3 \%$ & & & & \\
\hline 2000 & 0.029 & 0.031 & $6.95 \%$ & 17.78 & 20.41 & $14.8 \%$ & 6.50 & 6.42 & $-1.2 \%$ & 36.26 & 43.09 & $18.9 \%$ & & & & \\
\hline 2001 & 0.035 & 0.030 & $-12.19 \%$ & 16.02 & 18.65 & $16.4 \%$ & 8.46 & 8.28 & $-2.1 \%$ & 34.22 & 39.14 & $14.4 \%$ & & & & \\
\hline $\begin{array}{l}2002 \\
2003\end{array}$ & $\begin{array}{l}0.026 \\
0.032\end{array}$ & $\begin{array}{l}0.023 \\
0.028\end{array}$ & $\begin{array}{l}-10.78 \% \\
-13.73 \%\end{array}$ & $\begin{array}{l}19.09 \\
12.80\end{array}$ & $\begin{array}{l}18.29 \\
19.07\end{array}$ & $\begin{array}{l}-4.2 \% \\
48.9 \%\end{array}$ & $\begin{array}{l}7.22 \\
7.47\end{array}$ & $\begin{array}{l}6.91 \\
7.35\end{array}$ & $\begin{array}{l}-4.4 \% \\
-1.6 \%\end{array}$ & $\begin{array}{l}38.33 \\
35.18\end{array}$ & $\begin{array}{l}\begin{array}{l}43.67 \\
39.77\end{array} \\
3\end{array}$ & $\begin{array}{l}13.9 \% \\
13.1 \% \%\end{array}$ & & & & \\
\hline
\end{tabular}

Coho

\begin{tabular}{|c|c|c|c|c|c|c|c|c|c|c|c|c|c|c|c|c|c|c|c|}
\hline \multirow[b]{2}{*}{ Year } & \multicolumn{3}{|c|}{ Redd Scour } & \multicolumn{3}{|c|}{ Spawning/incubation } & \multicolumn{3}{|c|}{ Fry } & \multirow{2}{*}{\multicolumn{3}{|c|}{ Subyearling (Spring-summer) }} & \multicolumn{3}{|c|}{ Subyearling (winter) } & \multicolumn{2}{|r|}{ Subadult } & \multirow{2}{*}{\multicolumn{2}{|c|}{ Adult holding }} \\
\hline & Base & Alternativ & Pct Chg & Base & Alternative & Pct Chg & Base & Alternative & Pct Chg & & & & & Alternativ & Pct Chg & Base & Alternative Pct Chg & & Alternative Pct Chg \\
\hline & 0.031 & 0.032 & $0.86 \%$ & 4.58 & 3.23 & $-29.6 \%$ & 6.40 & 6.19 & $-3.3 \%$ & 28.03 & 26.88 & $-4.1 \%$ & 44.28 & 44.68 & $0.9 \%$ & & & & \\
\hline 1983 & 0.028 & 0.030 & $7.55 \%$ & 4.60 & 3.22 & $-30.0 \%$ & 6.36 & 6.18 & $-2.9 \%$ & 28.05 & 26.89 & $-4.2 \%$ & 44.42 & 44.89 & $1.1 \%$ & & & & \\
\hline 1984 & 0.028 & 0.031 & $10.51 \%$ & 4.59 & 3.19 & $-30.6 \%$ & 7.31 & 6.85 & $-6.2 \%$ & 28.11 & 26.92 & $-4.2 \%$ & 45.10 & 45.55 & $1.0 \%$ & & & & \\
\hline 1985 & 0.030 & 0.024 & $-21.85 \%$ & 7.32 & 8.97 & $22.4 \%$ & 7.17 & 6.71 & $-6.5 \%$ & 27.66 & 26.90 & $-2.7 \%$ & 42.74 & 43.58 & $2.0 \%$ & & & & \\
\hline 1986 & 0.028 & 0.025 & $-11.54 \%$ & 4.53 & 4.63 & $2.3 \%$ & 7.61 & 7.10 & $-6.7 \%$ & 27.02 & 26.61 & $-1.5 \%$ & 43.12 & 43.67 & $1.3 \%$ & & & & \\
\hline 1987 & 0.030 & 0.026 & $-13.62 \%$ & 7.15 & 7.16 & $0.2 \%$ & 7.20 & 6.89 & $-4.3 \%$ & 26.50 & 25.82 & $-2.6 \%$ & 42.72 & 43.24 & $1.2 \%$ & & & & \\
\hline 1988 & 0.031 & 0.027 & $-13.15 \%$ & 7.16 & 7.17 & $0.1 \%$ & 7.38 & 7.03 & $-4.7 \%$ & 26.55 & 26.13 & $-1.6 \%$ & 41.94 & 42.53 & $1.4 \%$ & & & & \\
\hline 1989 & 0.025 & 0.022 & $-9.81 \%$ & 9.07 & 8.57 & $-5.5 \%$ & 6.83 & 6.39 & $-6.5 \%$ & 27.12 & 26.89 & $-0.8 \%$ & 44.05 & 44.43 & $0.9 \%$ & & & & \\
\hline 1990 & 0.026 & 0.022 & $-14.59 \%$ & 7.28 & 7.41 & $1.7 \%$ & 6.43 & 6.14 & $-4.5 \%$ & 27.73 & 26.90 & $-3.0 \%$ & 44.08 & 44.45 & $0.9 \%$ & & & & \\
\hline 1991 & 0.019 & 0.021 & $6.66 \%$ & 3.15 & 2.23 & $-29.2 \%$ & 6.92 & 6.71 & $-3.0 \%$ & 27.83 & 26.90 & $-3.3 \%$ & 46.61 & 47.01 & $0.9 \%$ & & & & \\
\hline 1992 & 0.025 & 0.022 & $-8.55 \%$ & 7.35 & 8.16 & $11.0 \%$ & 8.05 & 7.40 & $-8.1 \%$ & 26.54 & 25.49 & $-3.9 \%$ & 43.56 & 44.07 & $1.2 \%$ & & & & \\
\hline 1993 & 0.034 & 0.030 & $-12.11 \%$ & 7.07 & 8.15 & $15.2 \%$ & 7.77 & 7.25 & $-6.6 \%$ & & 25.35 & $-3.4 \%$ & 41.88 & 42.29 & $1.0 \%$ & & & & \\
\hline 1994 & 0.033 & 0.032 & $-3.46 \%$ & 8.25 & 8.03 & $-2.7 \%$ & 7.96 & 7.41 & $-6.8 \%$ & 25.63 & 24.70 & $-3.6 \%$ & 41.51 & 41.63 & $0.3 \%$ & & & & \\
\hline 1995 & 0.031 & 0.031 & $0.86 \%$ & 3.30 & 2.25 & $-31.9 \%$ & 6.98 & 6.71 & $-3.8 \%$ & 27.70 & 26.87 & $-3.0 \%$ & 44.12 & 44.06 & $-0.1 \%$ & & & & \\
\hline 1996 & 0.199 & 0.201 & $0.80 \%$ & 0.28 & 0.99 & $254.8 \%$ & 6.20 & 6.12 & $-1.1 \%$ & & & $-2.9 \%$ & 49.43 & 50.15 & $1.4 \%$ & & & & \\
\hline 1997 & 0.057 & 0.055 & $-2.89 \%$ & 2.23 & 2.22 & $-0.2 \%$ & 5.64 & 5.64 & $0.0 \%$ & 28.30 & 26.94 & $-4.8 \%$ & 44.55 & 45.04 & $1.1 \%$ & & & & \\
\hline 1998 & 0.019 & 0.018 & $-0.13 \%$ & 7.47 & 5.86 & $-21.5 \%$ & 6.08 & 6.07 & $-0.2 \%$ & 27.67 & 26.89 & $-2.8 \%$ & 45.31 & 45.81 & $1.1 \%$ & & & & \\
\hline 1999 & 0.022 & 0.020 & $-9.40 \%$ & 6.26 & 6.21 & $-0.8 \%$ & 6.07 & 6.00 & $-1.1 \%$ & 28.39 & 27.48 & $-3.2 \%$ & 44.41 & 44.79 & $0.8 \%$ & & & & \\
\hline 2000 & 0.029 & 0.031 & $6.95 \%$ & 4.95 & 5.86 & $18.4 \%$ & 6.16 & 6.18 & $0.3 \%$ & 27.79 & 26.94 & $-3.1 \%$ & 44.62 & 45.02 & $0.9 \%$ & & & & \\
\hline 2001 & 0.035 & 0.030 & $-12.19 \%$ & 4.39 & 7.20 & $64.0 \%$ & 8.15 & 7.43 & $-8.9 \%$ & 26.00 & 24.86 & $-4.4 \%$ & 41.25 & 41.70 & $1.1 \%$ & & & & \\
\hline 2002 & 0.022 & 0.020 & $\begin{array}{l}-9.74 \% \\
\end{array}$ & 7.26 & 6.80 & $-6.3 \%$ & 6.66 & 6.41 & $-3.7 \%$ & $\begin{array}{r}27.72 \\
\end{array}$ & 26.87 & $-3.0 \%$ & 43.99 & 43.99 & $0.0 \%$ & & & & \\
\hline 2003 & 0.032 & & $-13.73 \%$ & 3.51 & & $76.8 \%$ & 7.51 & & $-5.6 \%$ & 27.04 & 26.65 & $-1.4 \%$ & 42.64 & 43.15 & & & & & \\
\hline
\end{tabular}

Figure 4-17. Annual habitat summaries for fall chinook and coho salmon in the Union Gap reach for the Black Rock_2 scenario. 


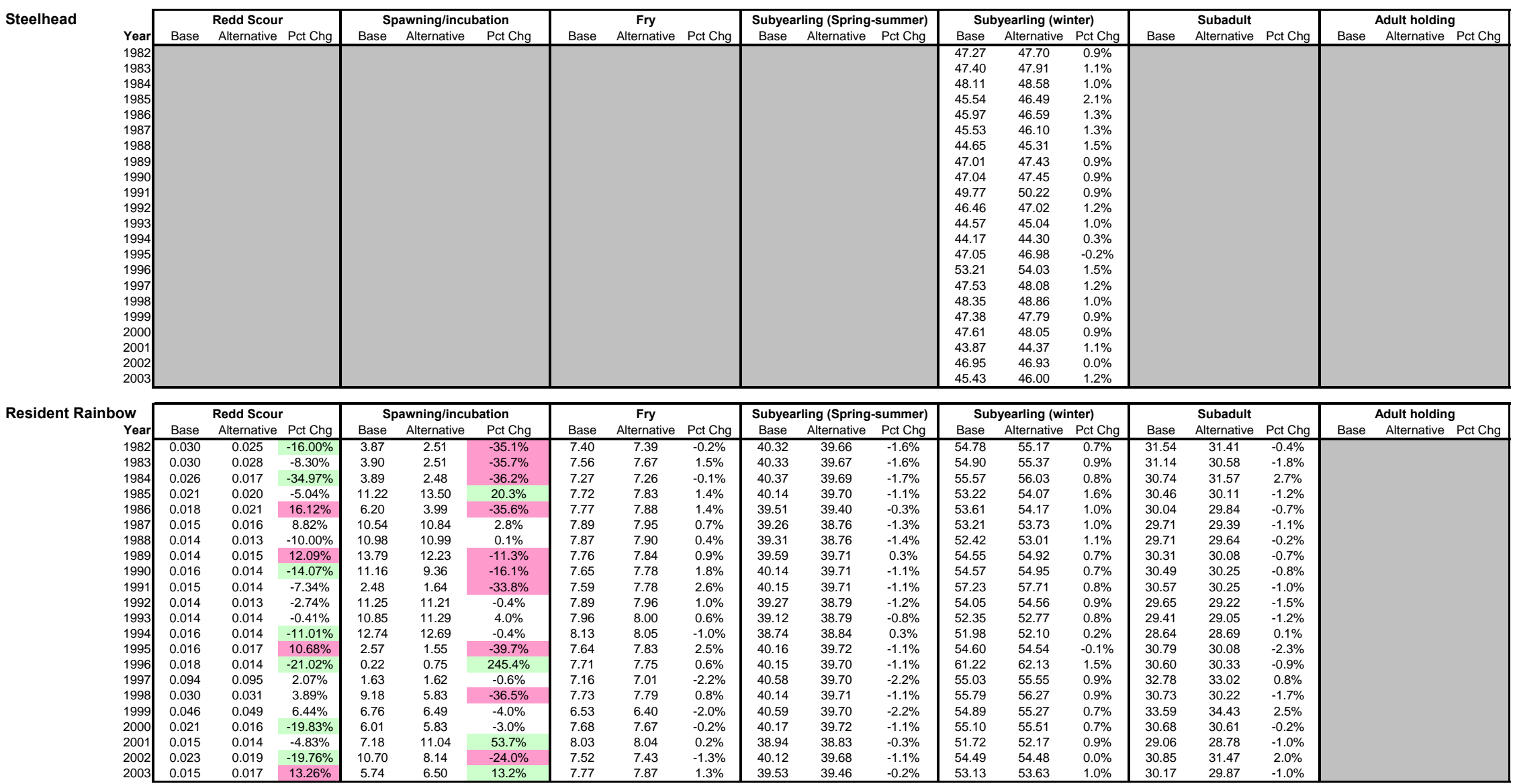

Figure 4-18. Annual habitat summaries for steelhead and resident rainbow trout in the Union Gap reach for the Black Rock_2 scenario. 


\begin{tabular}{|c|c|c|c|c|c|c|c|c|c|c|c|c|c|c|c|c|c|c|c|}
\hline \multicolumn{2}{|l|}{ Fall Chinook } & \multicolumn{3}{|c|}{ Redd Scour } & \multicolumn{3}{|c|}{ Spawning/incubation } & \multicolumn{3}{|c|}{ Fry } & \multicolumn{3}{|c|}{ Subyearling (Spring-summer) } & \multicolumn{3}{|c|}{ Subyearling (winter) } & \multicolumn{2}{|r|}{ Subadult } & Adult holding \\
\hline & Year[ & Base & Alternative & Pct Chg & Base & Alternative & Pct Chg & Base & Alternative & Pct Chg & Base & Alternative & Pct Chg & Base & Alternative & Pct Chg & Base & Alternative Pct Chg & Base Alternative Pct Chg \\
\hline & 1982 & 0.007 & 0.007 & $-2.27 \%$ & $\frac{53}{53}$ & 69 & $30 \%$ & $\frac{d a s e}{26}$ & 26 & $1 \%$ & $\frac{0 \text { ast }}{139}$ & 164 & $18 \%$ & & & & & & \\
\hline & 1983 & 0.007 & 0.006 & $-2.21 \%$ & 60 & 77 & $29 \%$ & 24 & 24 & $-3 \%$ & 118 & 161 & $37 \%$ & & & & & & \\
\hline & 1984 & 0.007 & 0.006 & $-3.74 \%$ & 62 & 76 & $22 \%$ & 26 & 27 & $0 \%$ & 92 & 159 & $73 \%$ & & & & & & \\
\hline & 1985 & 0.007 & 0.007 & $-4.75 \%$ & 61 & 80 & $31 \%$ & 25 & 26 & $6 \%$ & 94 & 144 & $54 \%$ & & & & & & \\
\hline & 1986 & 0.007 & 0.007 & $-1.84 \%$ & 47 & 77 & $63 \%$ & 22 & 25 & $11 \%$ & 96 & 131 & $35 \%$ & & & & & & \\
\hline & 1987 & 0.007 & 0.007 & $-3.51 \%$ & 44 & 69 & $56 \%$ & 26 & 27 & $5 \%$ & 99 & 125 & $26 \%$ & & & & & & \\
\hline & 1988 & 0.008 & 0.007 & $-9.82 \%$ & 38 & 68 & $77 \%$ & 26 & 27 & $1 \%$ & 93 & 125 & $34 \%$ & & & & & & \\
\hline & 1989 & 0.007 & 0.007 & $-10.50 \%$ & 62 & 79 & $27 \%$ & 26 & 25 & $-2 \%$ & 96 & 141 & $46 \%$ & & & & & & \\
\hline & 1990 & 0.007 & 0.007 & $-2.63 \%$ & 64 & 82 & $28 \%$ & 25 & 25 & $-2 \%$ & 94 & 159 & $69 \%$ & & & & & & \\
\hline & 1991 & 0.006 & 0.006 & $-0.64 \%$ & 56 & 74 & $32 \%$ & 26 & 26 & $2 \%$ & 95 & 152 & $60 \%$ & & & & & & \\
\hline & 1992 & 0.007 & 0.007 & $-2.00 \%$ & 47 & 79 & $67 \%$ & 22 & 27 & $22 \%$ & 99 & 126 & $28 \%$ & & & & & & \\
\hline & 1993 & 0.008 & 0.007 & $-1.71 \%$ & 44 & 64 & $46 \%$ & 24 & 27 & $14 \%$ & 94 & 125 & $32 \%$ & & & & & & \\
\hline & 1994 & 0.008 & 0.008 & $0.07 \%$ & 40 & 62 & $56 \%$ & 24 & 26 & $7 \%$ & 96 & 124 & $29 \%$ & & & & & & \\
\hline & 1995 & 0.007 & 0.007 & $-2.15 \%$ & 49 & 60 & $22 \%$ & 26 & 26 & $2 \%$ & 115 & 157 & $36 \%$ & & & & & & \\
\hline & 1996 & 0.006 & 0.006 & $-2.59 \%$ & 31 & 70 & $129 \%$ & 22 & 22 & $-1 \%$ & 96 & 159 & $66 \%$ & & & & & & \\
\hline & 1997 & 0.007 & 0.007 & $-2.19 \%$ & 39 & 73 & $87 \%$ & 18 & 18 & $-1 \%$ & 220 & 237 & $8 \%$ & & & & & & \\
\hline & 1998 & 0.006 & 0.006 & $-4.65 \%$ & 72 & 88 & $23 \%$ & 26 & 26 & $0 \%$ & 123 & 159 & $29 \%$ & & & & & & \\
\hline & 1999 & 0.007 & 0.007 & $-1.80 \%$ & 47 & 83 & $77 \%$ & 26 & 26 & $-1 \%$ & 127 & 161 & $27 \%$ & & & & & & \\
\hline & 2000 & 0.006 & 0.006 & $-2.38 \%$ & 59 & 81 & $37 \%$ & 25 & 25 & $1 \%$ & 93 & 159 & $71 \%$ & & & & & & \\
\hline & 2001 & 0.008 & 0.008 & $-1.16 \%$ & 50 & 74 & $48 \%$ & 21 & 26 & $23 \%$ & 98 & 125 & $27 \%$ & & & & & & \\
\hline & 2002 & 0.007 & 0.007 & $-2.04 \%$ & 44 & 51 & $16 \%$ & 26 & 26 & $-1 \%$ & 102 & 159 & $56 \%$ & & & & & & \\
\hline & 2003 [ & 0.007 & 0.007 & $-4.78 \%$ & 43 & 76 & $78 \%$ & 26 & 27 & $3 \%$ & 96 & 133 & $38 \%$ & & & & & & \\
\hline \multirow{24}{*}{ Coho } & & \multicolumn{3}{|c|}{ Redd Scour } & \multicolumn{3}{|c|}{ Spawning/incubation } & \multicolumn{3}{|c|}{ Fry } & \multicolumn{3}{|c|}{ Subyearling (Spring-summer) } & \multirow{2}{*}{\multicolumn{3}{|c|}{ Subyearling (winter) }} & \multicolumn{2}{|r|}{ Subadult } & Adult holding \\
\hline & Year & Base & Alternative & Pct Chg & Base & Alternative & Pct Chg & Base & Alternative & Pct Chg & Base & Alternative & Pct Chg & Base & & & Base & Alternative $\mathrm{Pct}$ Chg & Base Alternative $\mathrm{Pct} C \mathrm{Chg}$ \\
\hline & 1982 & 0.007 & 0.006 & $-2.33 \%$ & 7 & & $126 \%$ & 26 & 26 & $0 \%$ & 60 & 65 & $8 \%$ & 112 & 119 & $7 \%$ & & & \\
\hline & 1983 & 0.007 & 0.006 & $\begin{array}{l}-2.335 \% \\
-3.55 \%\end{array}$ & 7 & 11 & $63 \%$ & 26 & 25 & $-1 \%$ & 60 & 65 & $8 \%$ & 115 & 125 & $9 \%$ & & & \\
\hline & 1984 & 0.007 & 0.006 & $\begin{array}{l}-3.55 \% \\
-3.74 \%\end{array}$ & 7 & $\begin{array}{l}11 \\
11\end{array}$ & $\begin{array}{l}63 \% \% \\
62 \%\end{array}$ & 23 & 27 & $\begin{array}{l}-1 \% \% \\
15 \%\end{array}$ & 60 & $\begin{array}{l}65 \\
65\end{array}$ & $7 \%$ & $\begin{array}{l}115 \\
121\end{array}$ & $\begin{array}{l}125 \\
134\end{array}$ & $11 \%$ & & & \\
\hline & 1984 & 0.007 & 0.007 & $\begin{array}{l}-3.14 \% \\
-4.75 \%\end{array}$ & 38 & $\begin{array}{l}11 \\
36\end{array}$ & $-4 \%$ & 22 & 26 & $\begin{array}{l}15 \% \\
18 \%\end{array}$ & $\begin{array}{l}60 \\
63\end{array}$ & $\begin{array}{l}65 \\
65\end{array}$ & $2 \%$ & $\begin{array}{l}121 \\
102\end{array}$ & $\begin{array}{l}134 \\
113\end{array}$ & $11 \%$ & & & \\
\hline & 1986 & 0.007 & 0.007 & $\begin{array}{l}-4.15 \% \\
-1.84 \%\end{array}$ & $\begin{array}{c}38 \\
4\end{array}$ & 11 & $216 \%$ & 20 & 27 & $\begin{array}{l}18 \% \\
35 \%\end{array}$ & $\begin{array}{l}63 \\
67\end{array}$ & 64 & $-5 \%$ & 101 & 113 & $12 \%$ & & & \\
\hline & 1987 & 0.007 & 0.007 & $\begin{array}{l}-1.84 \% \\
-3.51 \%\end{array}$ & $\begin{array}{c}4 \\
16\end{array}$ & 29 & $\begin{array}{l}217 \% \\
77 \%\end{array}$ & 23 & 27 & $\begin{array}{l}35 \% \\
18 \%\end{array}$ & $\begin{array}{l}68 \\
68\end{array}$ & $\begin{array}{l}64 \\
62\end{array}$ & - & 103 & 110 & $7 \%$ & & & \\
\hline & 1988 & 0.007 & 0.007 & $\begin{array}{l}-3.51 \% \\
-4.29 \%\end{array}$ & $\begin{array}{l}16 \\
32\end{array}$ & 34 & $7 \%$ & 23 & 27 & $\begin{array}{l}18 \% \\
18 \%\end{array}$ & $\begin{array}{l}68 \\
68\end{array}$ & 63 & $\begin{array}{l}-8 \% \\
-8 \%\end{array}$ & 98 & 105 & $8 \%$ & & & \\
\hline & 19889 & 0.007 & 0.007 & $\begin{array}{l}-4.29 .50 \% \\
-10.5\end{array}$ & $\begin{array}{l}52 \\
29\end{array}$ & $\begin{array}{l}34 \\
28\end{array}$ & $-2 \%$ & 23 & 25 & $10 \%$ & $\begin{array}{l}60 \\
67\end{array}$ & $\begin{array}{l}65 \\
65\end{array}$ & $-3 \%$ & $\begin{array}{l}90 \\
110\end{array}$ & 116 & $6 \%$ & & & \\
\hline & 1999 1990 & 0.007 & 0.007 & $-2.95 \%$ & $\begin{array}{l}29 \\
25\end{array}$ & 25 & $1 \%$ & $\begin{array}{l}23 \\
21\end{array}$ & 24 & $14 \%$ & $\begin{array}{l}61 \\
63\end{array}$ & $\begin{array}{l}65 \\
65\end{array}$ & $3 \%$ & 111 & $\begin{array}{l}110 \\
119\end{array}$ & $7 \%$ & & & \\
\hline & 1991 & 0.006 & 0.006 & $-0.64 \%$ & 4 & 7 & $96 \%$ & $\begin{array}{l}21 \\
22\end{array}$ & 26 & $16 \%$ & $\begin{array}{l}03 \\
62\end{array}$ & $\begin{array}{l}65 \\
65\end{array}$ & $4 \%$ & 133 & $\begin{array}{l}147 \\
147\end{array}$ & $10 \%$ & & & \\
\hline & 1992 & 0.007 & 0.007 & $\begin{array}{l}-0.04 \% \\
-2.16 \%\end{array}$ & $\begin{array}{l}4 \\
15\end{array}$ & 26 & $76 \%$ & 19 & 27 & $42 \%$ & $\begin{array}{l}68 \\
68\end{array}$ & $\begin{array}{l}60 \\
61\end{array}$ & $-11 \%$ & 98 & $\begin{array}{l}147 \\
114\end{array}$ & $16 \%$ & & & \\
\hline & 1993 & 0.008 & 0.007 & $-1.71 \%$ & $\begin{array}{l}35 \\
36\end{array}$ & $\begin{array}{l}20 \\
37\end{array}$ & $3 \%$ & $\begin{array}{l}19 \\
21\end{array}$ & 27 & $29 \%$ & $\begin{array}{l}60 \\
68\end{array}$ & $\begin{array}{l}01 \\
61\end{array}$ & $-11 \%$ & 95 & $\begin{array}{l}114 \\
102\end{array}$ & $8 \%$ & & & \\
\hline & 1994 & 0.008 & 0.008 & $0.04 \%$ & $\begin{array}{l}30 \\
37\end{array}$ & $\begin{array}{l}11 \\
38\end{array}$ & $4 \%$ & 20 & 27 & $38 \%$ & 69 & $\begin{array}{l}61 \\
65\end{array}$ & $-6 \%$ & 93 & 96 & $4 \%$ & & & \\
\hline & 1995 & 0.007 & 0.006 & $-2.65 \%$ & 4 & $\begin{array}{l}30 \\
7\end{array}$ & $91 \%$ & 26 & 26 & $0 \%$ & 63 & 65 & $3 \%$ & 110 & 118 & $8 \%$ & & & \\
\hline & 1996 & 0.005 & 0.005 & $-0.65 \%$ & $\begin{array}{l}4 \\
0\end{array}$ & 3 & $611 \%$ & 23 & 24 & $5 \%$ & 63 & 65 & $3 \%$ & 156 & $\begin{array}{l}1163 \\
163\end{array}$ & $5 \%$ & & & \\
\hline & 1997 & 0.007 & 0.007 & $-2.19 \%$ & 2 & 7 & $249 \%$ & 17 & 16 & $-2 \%$ & 61 & 65 & $6 \%$ & 116 & 125 & $8 \%$ & & & \\
\hline & 1998 & 0.006 & 0.006 & $-4.65 \%$ & 15 & 17 & $14 \%$ & 24 & 24 & $0 \%$ & 63 & $\begin{array}{l}85 \\
65\end{array}$ & $2 \%$ & 124 & 135 & $8 \%$ & & & \\
\hline & 1999 & 0.007 & 0.006 & $-2.33 \%$ & 13 & 22 & $68 \%$ & 23 & 23 & $-1 \%$ & 61 & 65 & $6 \%$ & 115 & 124 & $9 \%$ & & & \\
\hline & 2000 & 0.006 & 0.006 & $-2.38 \%$ & 7 & 11 & $60 \%$ & 23 & 25 & $8 \%$ & 63 & 65 & $3 \%$ & 116 & 125 & $8 \%$ & & & \\
\hline & 2001 & 0.008 & 0.008 & $-1.16 \%$ & 40 & 37 & $-5 \%$ & 19 & 26 & $39 \%$ & 69 & 63 & $-8 \%$ & 89 & 101 & $13 \%$ & & & \\
\hline & 2002 & 0.007 & 0.007 & $-2.21 \%$ & 17 & 12 & $-28 \%$ & 25 & 25 & $2 \%$ & 63 & 65 & $3 \%$ & 110 & 113 & $3 \%$ & & & \\
\hline & 2003 & 0.007 & 0.007 & $-4.78 \%$ & 12 & 22 & $86 \%$ & 22 & 27 & $21 \%$ & 67 & 64 & $-5 \%$ & 101 & 110 & $9 \%$ & & & \\
\hline
\end{tabular}

Figure 4-19. Annual habitat summaries for fall chinook and coho salmon in the Wapato reach for the Black Rock_2 scenario. 


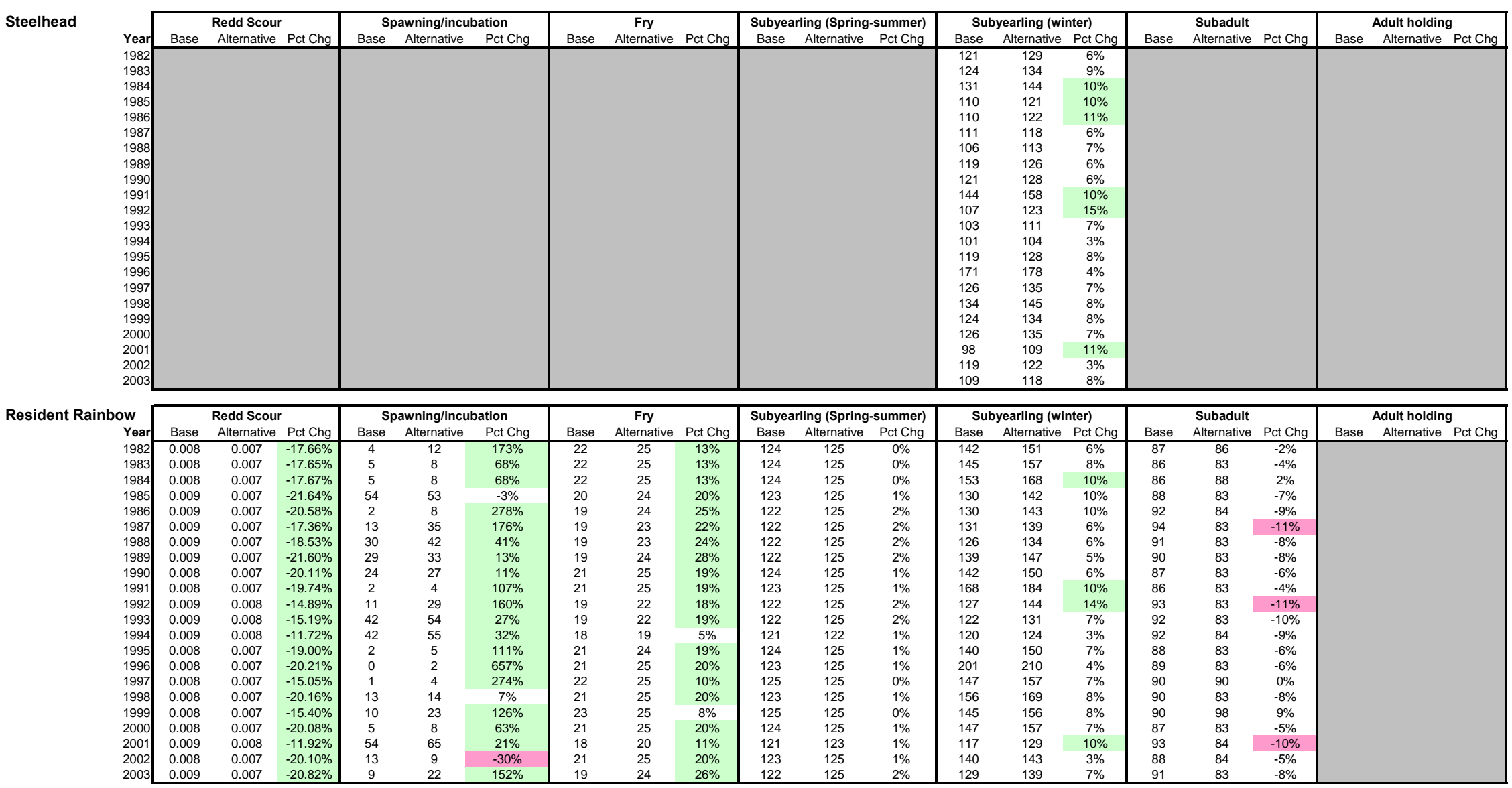

Figure 4-20. Annual habitat summaries for steelhead and resident rainbow trout in the Wapato reach for the Black Rock_2 scenario. 
Fall Chinook

\begin{tabular}{|c|c|c|c|c|c|c|c|c|c|c|c|c|c|c|c|c|}
\hline \multirow[b]{2}{*}{ Year } & \multirow{2}{*}{\multicolumn{3}{|c|}{ 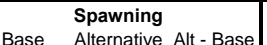 }} & \multirow{2}{*}{\multicolumn{3}{|c|}{$\begin{array}{ll}\text { Incubation } \\
\end{array}$}} & \multicolumn{3}{|c|}{ Fry } & \multicolumn{3}{|c|}{ Subyearling (Spring-summer) } & Subyearling (winter) & \multicolumn{2}{|r|}{$\begin{array}{l}\text { Subadult } \\
\end{array}$} & \multirow{2}{*}{ 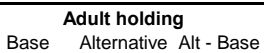 } \\
\hline & & & & & & & Base & & Alt - Base & & & & & Base & Alternative Alt - Base & \\
\hline 1982 & 0.0 & 0.0 & No Data & 0.0 & 0.0 & No Data & 0.0 & 0.0 & No Data & 0.0 & 0.0 & No Data & & & & \\
\hline 1983 & 0.0 & 0.0 & No Data & 0.0 & 0.0 & No Data & 0.0 & 0.0 & No Data & 0.0 & 0.0 & No Data & & & & \\
\hline 1984 & 12.4 & 13.4 & 1.0 & 0.0 & 0.0 & No Data & 11.6 & 11.7 & 0.1 & 14.6 & 14.9 & 0.3 & & & & \\
\hline 1985 & 12.8 & 13.8 & 1.0 & 0.0 & 0.0 & No Data & 13.5 & 13.3 & -0.2 & 15.8 & 16.1 & 0.4 & & & & \\
\hline 1986 & 11.6 & 12.8 & 1.2 & 0.0 & 0.0 & No Data & 12.7 & 13.0 & 0.3 & 16.1 & 16.8 & 0.7 & & & & \\
\hline 1987 & 13.0 & 13.3 & 0.4 & 0.0 & 0.0 & No Data & 15.0 & 15.3 & 0.3 & 15.7 & 15.8 & 0.2 & & & & \\
\hline 1988 & 13.7 & 14.5 & 0.8 & 0.0 & 0.0 & No Data & 12.9 & 13.0 & 0.1 & 14.6 & 14.8 & 0.2 & & & & \\
\hline 1989 & 14.7 & 14.7 & 0.0 & 0.0 & 0.0 & No Data & 12.9 & 12.9 & 0.0 & 16.1 & 16.1 & 0.1 & & & & \\
\hline 1990 & 13.1 & 13.5 & 0.4 & 0.0 & 0.0 & No Data & 12.9 & 13.1 & 0.2 & 14.2 & 14.0 & -0.1 & & & & \\
\hline 1991 & 12.9 & 13.7 & 0.8 & 0.0 & 0.0 & No Data & 12.8 & 12.9 & 0.1 & 14.8 & 14.7 & -0.1 & & & & \\
\hline 1992 & 14.0 & 14.8 & 0.7 & 0.0 & 0.0 & No Data & 14.3 & 14.3 & 0.0 & 17.4 & 17.2 & -0.1 & & & & \\
\hline 1993 & 14.9 & 15.1 & 0.2 & 0.0 & 0.0 & No Data & 13.5 & 13.6 & 0.1 & 16.6 & 16.9 & 0.3 & & & & \\
\hline 1994 & 14.0 & 14.3 & 0.3 & 0.0 & 0.0 & No Data & 14.4 & 14.6 & 0.2 & 16.0 & 16.1 & 0.1 & & & & \\
\hline 1995 & 13.6 & 14.2 & 0.6 & 0.0 & 0.0 & No Data & 12.3 & 12.5 & 0.2 & 14.4 & 14.5 & 0.2 & & & & \\
\hline 1996 & 12.7 & 13.8 & 1.1 & 0.0 & 0.0 & No Data & 12.0 & 12.0 & 0.0 & 15.0 & 15.2 & 0.2 & & & & \\
\hline 1997 & 12.3 & 13.3 & 1.0 & 0.0 & 0.0 & No Data & 11.1 & 11.2 & 0.1 & 14.1 & 14.4 & 0.3 & & & & \\
\hline 1998 & 12.8 & 13.9 & 1.1 & 0.0 & 0.0 & No Data & 12.9 & 12.8 & 0.0 & 15.0 & 15.2 & 0.2 & & & & \\
\hline 1999 & 12.8 & 13.7 & 1.0 & 0.0 & 0.0 & No Data & 11.1 & 11.3 & 0.2 & 14.2 & 14.3 & 0.1 & & & & \\
\hline 2000 & 14.1 & 14.6 & 0.4 & 0.0 & 0.0 & No Data & 11.8 & 11.9 & 0.1 & 15.0 & 15.0 & 0.0 & & & & \\
\hline 2001 & 13.1 & 14.0 & 0.9 & 0.0 & 0.0 & No Data & 13.9 & 13.8 & -0.1 & 16.5 & 16.7 & 0.2 & & & & \\
\hline 2002 & 13.6 & 14.0 & 0.4 & 0.0 & 0.0 & No Data & 12.1 & 12.3 & 0.2 & 14.2 & 14.4 & 0.2 & & & & \\
\hline 2003 & 12.9 & 13.7 & 0.8 & 0.0 & 0.0 & No Data & 12.8 & 13.0 & 0.2 & 15.6 & 15.7 & 0.1 & & & & \\
\hline
\end{tabular}

Coho

\begin{tabular}{|c|c|c|c|c|c|c|c|c|c|c|c|c|c|c|c|c|c|c|}
\hline \multirow[b]{2}{*}{ Year } & \multirow{2}{*}{\multicolumn{3}{|c|}{ 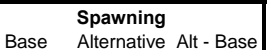 }} & \multirow{2}{*}{\multicolumn{3}{|c|}{\begin{tabular}{ll|}
\multicolumn{1}{|c|}{ Incubation } \\
Base & Alternative Alt - Base
\end{tabular}}} & \multirow{2}{*}{\multicolumn{3}{|c|}{ Fry }} & \multirow{2}{*}{\multicolumn{3}{|c|}{ Subyearling (Spring-summer) }} & \multicolumn{3}{|c|}{ Subyearling (winter) } & \multirow{2}{*}{\multicolumn{2}{|c|}{ 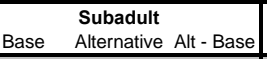 }} & \multirow{2}{*}{ 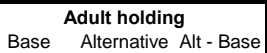 } \\
\hline & & & & & & & Base & Alternative & & & & & Base & Alternativ & Alt - Base & & & \\
\hline 1982 & 0.0 & 0.0 & No Data & 0.0 & 0.0 & No Data & 0.0 & 0.0 & No Data & 0.0 & 0.0 & No Data & 0.0 & 0.0 & No Data & & & \\
\hline 1983 & 0.0 & 0.0 & No Data & 0.0 & 0.0 & No Data & 0.0 & 0.0 & No Data & 0.0 & 0.0 & No Data & 0.0 & 0.0 & No Data & & & \\
\hline 1984 & 0.0 & 0.0 & No Data & 0.0 & 0.0 & No Data & 14.6 & 14.9 & 0.3 & 20.1 & 20.0 & -0.1 & 12.6 & 13.4 & 0.8 & & & \\
\hline 1985 & 0.0 & 0.0 & No Data & 0.0 & 0.0 & No Data & 15.8 & 16.1 & 0.4 & 20.4 & 20.2 & -0.2 & 13.5 & 13.8 & 0.3 & & & \\
\hline 1986 & 0.0 & 0.0 & No Data & 0.0 & 0.0 & No Data & 16.1 & 16.8 & 0.7 & 20.6 & 20.3 & -0.3 & 12.7 & 13.0 & 0.3 & & & \\
\hline 1987 & 0.0 & 0.0 & No Data & 0.0 & 0.0 & No Data & 15.7 & 15.8 & 0.2 & 19.3 & 19.3 & 0.0 & 15.0 & 15.3 & 0.3 & & & \\
\hline 1988 & 0.0 & 0.0 & No Data & 0.0 & 0.0 & No Data & 14.6 & 14.8 & 0.2 & 19.3 & 19.3 & 0.0 & 13.7 & 14.5 & 0.8 & & & \\
\hline 1989 & 0.0 & 0.0 & No Data & 0.0 & 0.0 & No Data & 14.8 & 14.3 & -0.5 & 19.2 & 19.1 & -0.1 & 14.7 & 14.7 & 0.0 & & & \\
\hline 1990 & 0.0 & 0.0 & No Data & 0.0 & 0.0 & No Data & 14.2 & 14.0 & -0.1 & 20.9 & 20.6 & -0.3 & 13.1 & 13.5 & 0.4 & & & \\
\hline 1991 & 0.0 & 0.0 & No Data & 0.0 & 0.0 & No Data & 14.5 & 14.4 & 0.0 & 20.0 & 19.7 & -0.3 & 13.9 & 14.5 & 0.6 & & & \\
\hline 1992 & 0.0 & 0.0 & No Data & 0.0 & 0.0 & No Data & 16.9 & 16.7 & -0.2 & 20.5 & 20.4 & -0.1 & 14.3 & 14.8 & 0.4 & & & \\
\hline 1993 & 0.0 & 0.0 & No Data & 0.0 & 0.0 & No Data & 16.6 & 16.9 & 0.3 & 18.6 & 18.5 & -0.1 & 14.9 & 15.1 & 0.2 & & & \\
\hline 1994 & 0.0 & 0.0 & No Data & 0.0 & 0.0 & No Data & 16.0 & 16.1 & 0.1 & 20.5 & 20.6 & 0.1 & 14.4 & 14.6 & 0.2 & & & \\
\hline 1995 & 0.0 & 0.0 & No Data & 0.0 & 0.0 & No Data & 14.4 & 14.5 & 0.2 & 19.9 & 19.7 & -0.1 & 13.6 & 14.2 & 0.6 & & & \\
\hline 1996 & 0.0 & 0.0 & No Data & 0.0 & 0.0 & No Data & 15.0 & 15.2 & 0.2 & 20.4 & 20.2 & -0.2 & 13.7 & 14.0 & 0.3 & & & \\
\hline 1997 & 0.0 & 0.0 & No Data & 0.0 & 0.0 & No Data & 14.1 & 14.4 & 0.3 & 20.7 & 20.4 & -0.3 & 13.6 & 14.3 & 0.7 & & & \\
\hline 1998 & 0.0 & 0.0 & No Data & 0.0 & 0.0 & No Data & 15.0 & 15.2 & 0.2 & 21.9 & 21.6 & -0.3 & 13.4 & 14.1 & 0.7 & & & \\
\hline 1999 & 0.0 & 0.0 & No Data & 0.0 & 0.0 & No Data & 14.2 & 14.3 & 0.1 & 20.2 & 19.6 & -0.6 & 12.8 & 13.7 & 1.0 & & & \\
\hline 2000 & 0.0 & 0.0 & No Data & 0.0 & 0.0 & No Data & 15.0 & 15.0 & 0.0 & 20.7 & 20.5 & -0.2 & 14.1 & 14.6 & 0.4 & & & \\
\hline 2001 & 0.0 & 0.0 & No Data & 0.0 & 0.0 & No Data & 16.5 & 16.7 & 0.2 & 19.9 & 19.6 & -0.3 & 13.9 & 14.1 & 0.2 & & & \\
\hline 2002 & 0.0 & 0.0 & No Data & 0.0 & 0.0 & No Data & 14.2 & 14.3 & 0.1 & 21.1 & 21.3 & 0.2 & 13.6 & 14.0 & 0.4 & & & \\
\hline 2003 & 0.0 & 0.0 & No Data & 0.0 & 0.0 & No Data & 15.6 & 15.7 & 0.1 & 21.1 & 20.8 & -0.3 & 14.1 & 14.6 & 0.5 & & & \\
\hline
\end{tabular}

Figure 4-21. Annual temperature summaries for fall chinook and coho salmon in the Union Gap reach for the Black Rock_2 scenario. 


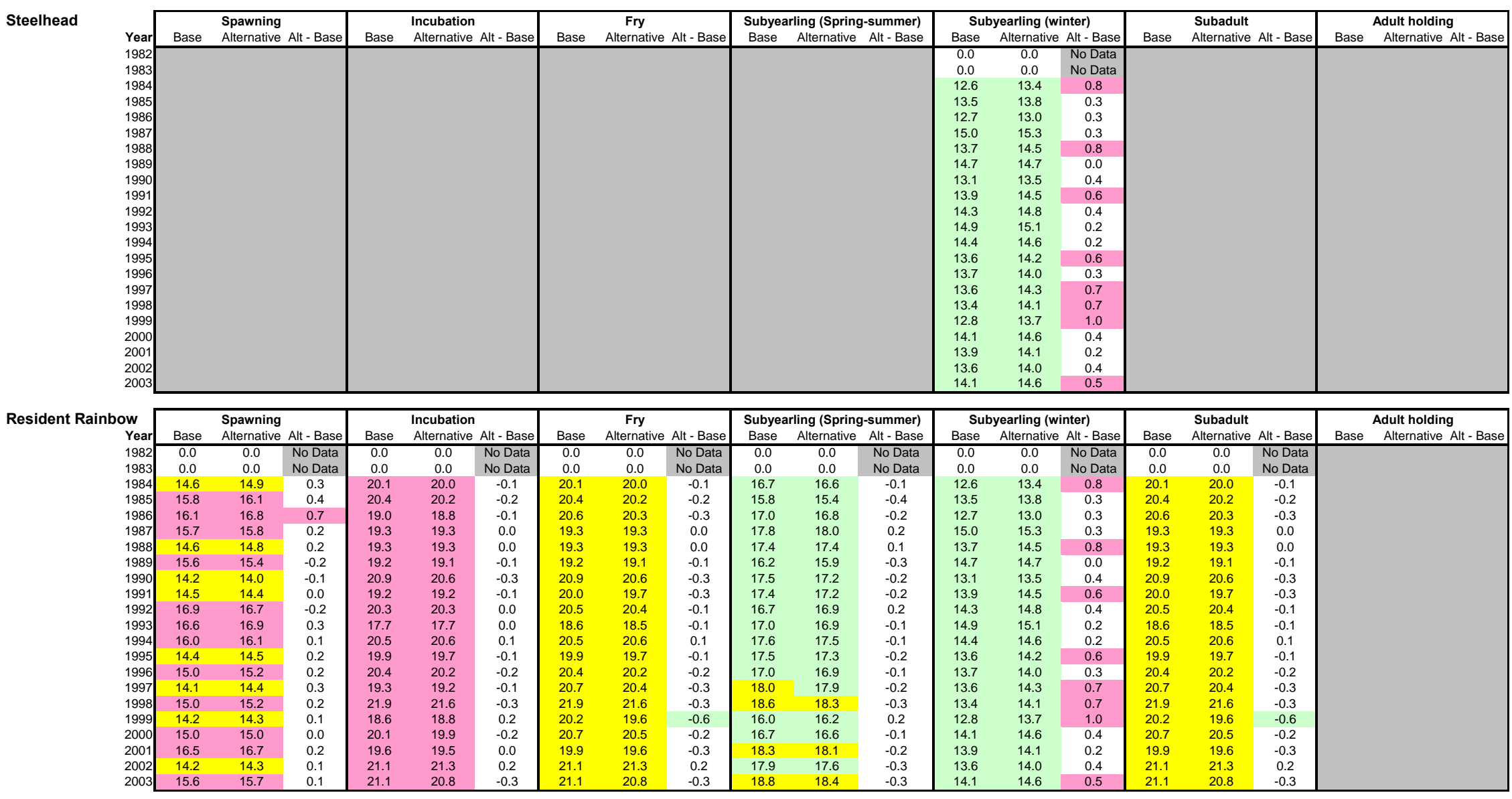

Figure 4-22. Annual temperature summaries for steelhead and resident rainbow trout in the Union Gap reach for the Black Rock_2 scenario. 


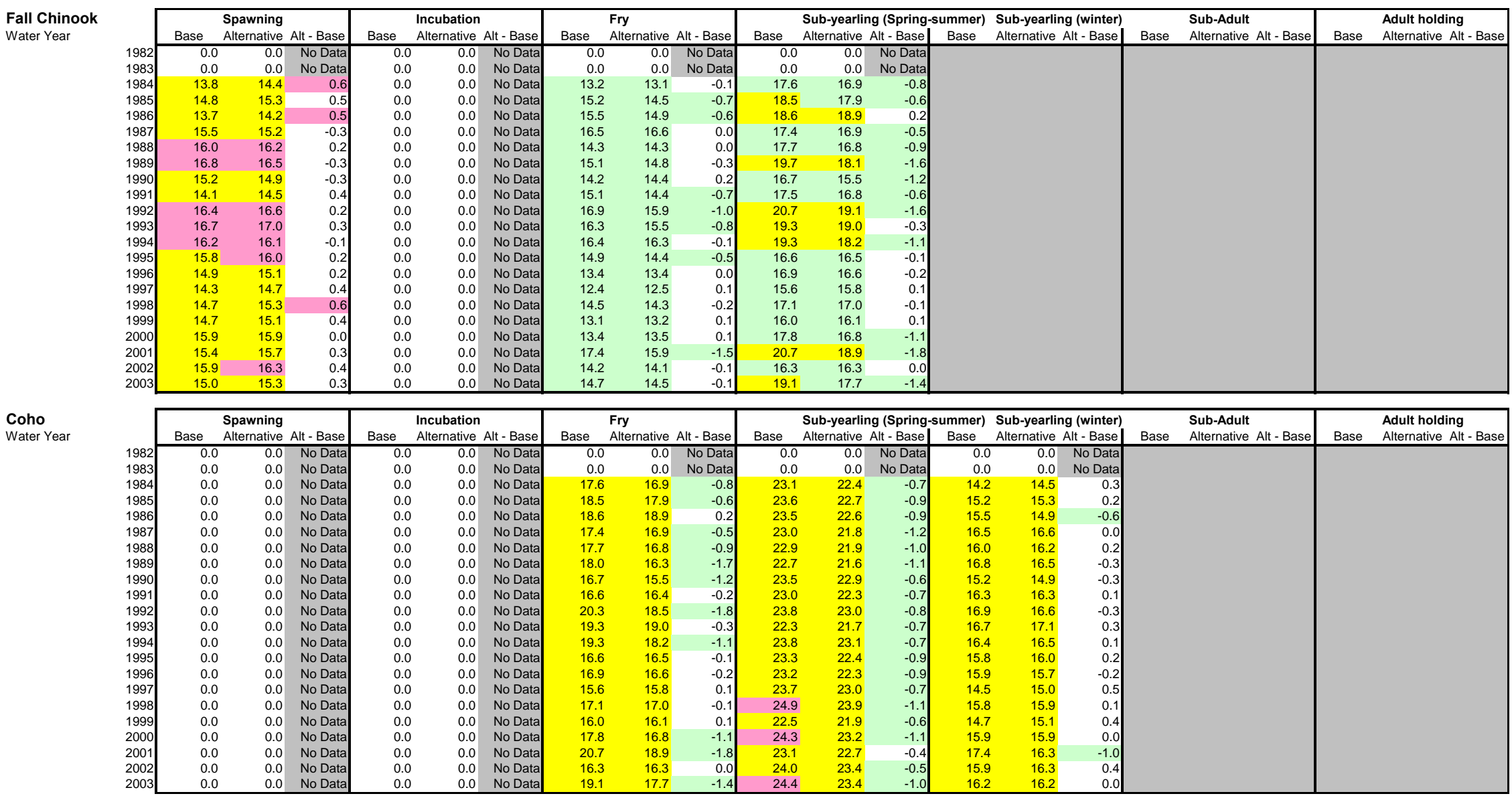

Figure 4-23. Annual temperature summaries for fall chinook and coho salmon in the Wapato reach for the Black Rock_2 scenario. 


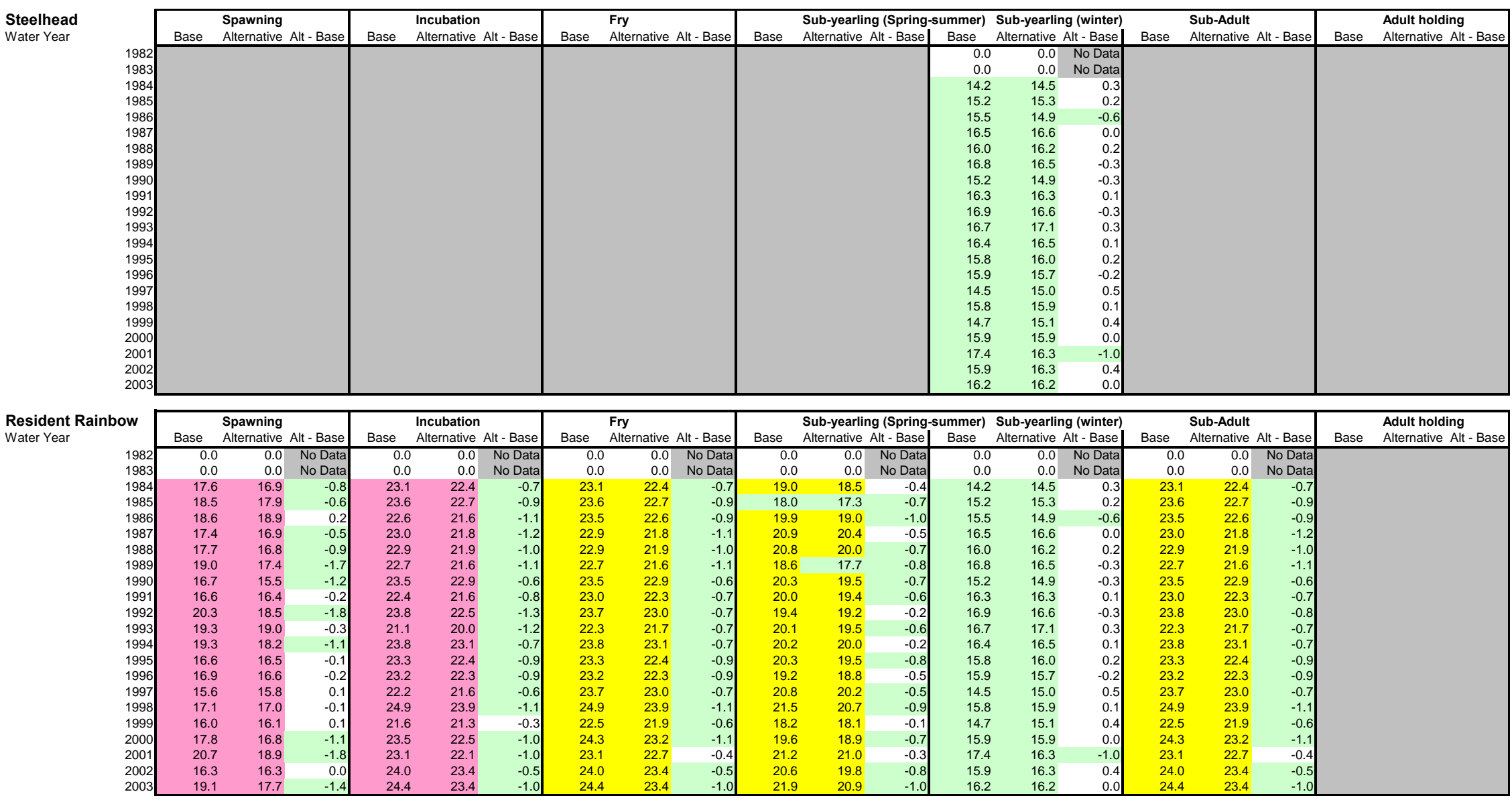

Figure 4-24. Annual temperature summaries for steelhead and resident rainbow trout in the Wapato reach for the Black Rock_2 scenario. 


\section{Appendix 5. YRDSS Run Results for the Wymer_1 Scenario}




\begin{tabular}{|c|c|c|c|c|c|c|c|c|c|c|c|c|c|c|c|c|}
\hline $\begin{array}{l}\text { Yakima DSS beta test } \\
\text { Summary }\end{array}$ & & & $\begin{array}{l}\text { RunDate: } \\
\text { Baseline: } \\
\text { Alternative: }\end{array}$ & & $\begin{array}{l}\text { O2/21/108 } \\
\text { No Action } \\
\text { Wymer_1 }\end{array}$ & & & & $\begin{array}{l}\text { Start date } \\
101 / 1 / 1981 \\
10 / 1 / 1981 \\
\end{array}$ & $\begin{array}{l}\text { to } \\
\text { to }\end{array}$ & & $\begin{array}{r}\text { End date } \\
9 / 30 / 2003 \\
9 / 30 / 2003 \\
\end{array}$ & & & & \\
\hline Resource Category & Time Window & & Easton & & Stream Reach & Kittitas & & & Naches & & & Union Gap & & & Wapato & \\
\hline $\begin{array}{l}\text { Spring Chinook } \\
\text { Max Redd Scour depth (ft) } \\
\text { SFawninglincubation" } \\
\text { Fubyearling (Spring-summer) } \\
\text { Subyearlig (winter) } \\
\text { Adult holding }\end{array}$ & $\begin{array}{l}\text { Oct-01-Mar-31 } \\
\text { Ott-01-Mar-31 } \\
\text { Mar-01 - May-31 } \\
\text { Jun-01 - Sep-30 } \\
\text { Oct-01 - May-31 } \\
\text { Apr-01 - Sep-30 }\end{array}$ & $\begin{array}{c}\text { Base } \\
0.033 \\
45.8 \\
2.5 \\
47.9 \\
8.7 \\
7.3\end{array}$ & $\begin{array}{c}\text { Alternative } \\
0.053 \\
45.2 \\
2.5 \\
49.3 \\
8.7 \\
7.2\end{array}$ & $\begin{array}{l}\text { Pct chg } \\
58.7 \% \\
-1.5 \% \\
0.5 \% \\
2.8 \% \\
0.4 \% \\
-1.7 \%\end{array}$ & $\begin{array}{c}\text { Base } \\
0.008 \\
23.4 \\
1.7 \\
14.0 \\
4.0 \\
6.6\end{array}$ & $\begin{array}{l}\text { Alternative } \\
0.008 \\
23.2 \\
1.8 \\
1.8 \\
3.9 \\
6.8\end{array}$ & $\begin{array}{l}\text { Pct Chg } \\
-1.5 \% \\
-0.7 \% \\
4.5 \% \\
-1.7 \% \\
-2.5 \% \\
2.7 \%\end{array}$ & $\begin{array}{l}\text { Base } \\
0.107 \\
19.7 \\
2.8 \\
37.8 \\
5.7 \\
6.1\end{array}$ & $\begin{array}{c}\text { Alternative } \\
0.107 \\
16.5 \\
2.8 \\
37.9 \\
5.7 \\
6.1\end{array}$ & $\begin{array}{l}\text { Pct chg } \\
-0.2 \% \\
-16.2 \% \\
0.2 \% \\
0.3 \% \\
1.4 \% \\
-0.6 \%\end{array}$ & $\begin{array}{l}\text { Base } \\
51.2\end{array}$ & Alternative & $\begin{array}{l}\text { Pct Chg } \\
0 \%\end{array}$ & $\begin{array}{l}\text { Base } \\
127.5\end{array}$ & Alternative & $\begin{array}{l}\text { Pet Chg } \\
-1 \% \\
\end{array}$ \\
\hline $\begin{array}{l}\text { Fall Chinook } \\
\text { Max Redd Scour depth (ft) } \\
\text { Spawninglincubation* } \\
\text { Fry } \\
\text { Subyearling (Spring-summer) }\end{array}$ & 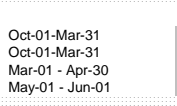 & & & & & & & & & & $\begin{array}{l}0.039 \\
13.3 \\
7.2 . \\
38.1\end{array}$ & $\begin{array}{l}0.039 \\
17.1 \\
7.2 \\
38.0\end{array}$ & $\begin{array}{l}-1.3 \% \\
-6.6 \% \\
0.2 \% \% \\
-0.2 \%\end{array}$ & $\begin{array}{l}0.007 \\
50.5 \\
24.5 \\
107.9\end{array}$ & $\begin{array}{l}0.007 \\
49.7 \\
24.5 \\
106.9\end{array}$ & $\begin{array}{l}-4.9 \% \\
-1.5 \% \\
0.0 \% \% \\
-1.0 \%\end{array}$ \\
\hline $\begin{array}{l}\text { Coho } \\
\text { Max Redd Scour depth (ft) } \\
\text { Spawninglincubation* } \\
\text { Fy } \\
\text { Subyearling (Spring-summer) } \\
\text { Subyearling (winter) }\end{array}$ & $\begin{array}{l}\text { Nov-01-Mar-31 } \\
\text { Nov-01-1-ar-31 } \\
\text { Apr-1- May-31 } \\
\text { Jun-01- Sep-30 } \\
\text { Oct-1- }- \text { Apr-30 }\end{array}$ & $\begin{array}{l}0.028 \\
38.8 \\
2.6 \\
16.1 \\
5.4\end{array}$ & $\begin{array}{l}0.041 \\
33.4 \\
2.6 \\
17.3 \\
5.5\end{array}$ & $\begin{array}{l}46.9 \% \\
-1.0 \% \\
0.0 \% \\
7.9 \% \\
0.6 \%\end{array}$ & $\begin{array}{l}0.007 \\
14.8 \\
1.7 \\
4.6 \\
2.6\end{array}$ & $\begin{array}{l}0.007 \\
14.3 \\
1.8 \\
4.3 \\
2.5\end{array}$ & $\begin{array}{l}-3.6 \% \\
-3.3 \% \\
3.5 \% \\
-5.4 \% \\
-2.2 \%\end{array}$ & $\begin{array}{c}0.092 \\
8.5 \\
3.0 \\
7.6 \\
3.7\end{array}$ & $\begin{array}{l}0.094 \\
7.0 \\
3.0 \\
7.8 \\
3.7\end{array}$ & $\begin{array}{c}1.8 \% \\
-17.7 \% \\
0.1 \% \\
2.3 \% \\
1.8 \% \\
\end{array}$ & $\begin{array}{c}0.037 \\
5.5 \\
6.9 \\
27.3 \\
43.9\end{array}$ & $\begin{array}{l}0.036 \\
5.1 \\
7.0 \\
27.4 \\
43.8\end{array}$ & $\begin{array}{l}-1.6 \% \\
-7.7 \% \% \\
0.3 \% \% \\
0.2 \% \% \\
-0.3 \%\end{array}$ & $\begin{array}{l}0.007 \\
16.6 \\
22.3 \\
64.4 \\
110.4\end{array}$ & $\begin{array}{l}0.007 \\
16.4 \\
22.3 \\
64.1 \\
109.4\end{array}$ & $\begin{array}{l}4.4 \% \\
-0.9 \% \% \\
0.11 \% \\
-0.6 \% \\
-0.9 \%\end{array}$ \\
\hline $\begin{array}{l}\text { Steelhead } \\
\text { Maxa Redd Scour depth (ft) } \\
\text { SFawninglincubation* } \\
\text { Fry } \\
\text { Subyearling (Spring-summer) } \\
\text { Subyearling (winter) } \\
\text { Subadults } \\
\text { Adult holding }\end{array}$ & $\begin{array}{l}\text { Mar-01-Jul-31 } \\
\text { Mar-01-Jul-31 } \\
\text { Jul-01- Aug-30 } \\
\text { Sep-01- Sep-30 } \\
\text { Oct-01 - App-30 } \\
\text { May-01- Aug-30 } \\
\text { Sep-01- Mar-31 }\end{array}$ & $\begin{array}{l}0.028 \\
53.0 \\
44.1 \\
57.9 \\
7.8 \\
57.3 \\
22.6\end{array}$ & $\begin{array}{l}0.039 \\
53.0 \\
4.4 \\
58.6 \\
7.8 \\
55.6 \\
22.6\end{array}$ & $\begin{array}{l}38.2 \% \\
0.0 \% \\
6.4 \% \\
1.2 \% \\
0.6 \% \\
0.6 \% \\
-0.1 \%\end{array}$ & $\begin{array}{c}0.006 \\
31.7 \\
2.2 \\
20.2 \\
3.5 \\
19.1 \\
9.7\end{array}$ & $\begin{array}{l}0.006 \\
32.5 \\
2.1 \\
20.5 \\
3.4 \\
19.3 \\
9.3\end{array}$ & $\begin{array}{l}1.3 \% \\
2.7 \% \\
-2.2 \% \\
1.8 \% \\
-3.6 \% \\
-0.9 \% \\
-4.6 \%\end{array}$ & $\begin{array}{l}0.209 \\
22.5 \\
3.4 \\
46.1 \\
4.9 \\
51.2 \\
11.0\end{array}$ & $\begin{array}{c}0.219 \\
19.7 \\
3.4 \\
46.1 \\
5.0 \\
51.2 \\
10.9\end{array}$ & $\begin{array}{c}4.7 \% \\
-1.3 \% \\
0.7 .7 \% \\
0.0 \% \\
1.3 \% \\
-0.1 \% \\
-1.2 \%\end{array}$ & 46.9 & 46.7 & $-0.3 \%$ & 119.7 & 118.7 & $-0.9 \%$ \\
\hline $\begin{array}{l}\text { Resident Rainbow } \\
\text { Maxaend Scour depth (ft) } \\
\text { Spawninglincubation } \\
\text { Fut } \\
\text { Subyearling (Spring-summer) } \\
\text { Subyearling (winter) } \\
\text { Subadults }\end{array}$ & $\begin{array}{l}\text { Feb-01--Jul-31 } \\
\text { FFb-01-Jul-31 } \\
\text { Jul-01 - Aug-30 } \\
\text { Sep-01- Sep-30 } \\
\text { Oct-01 - App-30 } \\
\text { May-01 - Aug-30 }\end{array}$ & $\begin{array}{l}0.017 \\
47.8 \\
5.2 \\
57.2 \\
9.1 \\
30.5\end{array}$ & $\begin{array}{l}0.022 \\
47.2 \\
5.4 \\
57.9 \\
9.2 \\
31.5\end{array}$ & $\begin{array}{l}33.2 \% \\
-1.3 \% \\
5.5 \% \\
1.2 \% \\
0.6 \% \\
3.3 \%\end{array}$ & $\begin{array}{c}0.006 \\
18.7 \\
2.5 \\
19.9 \\
4.4 \\
8.1\end{array}$ & $\begin{array}{l}0.006 \\
17.7 \\
2.4 \\
20.3 \\
4.2 \\
7.9\end{array}$ & $\begin{array}{l}0.4 \% \\
-5.1 \% \\
-2.4 \% \\
1.8 \% \\
-3.1 \% \\
-2.4 \%\end{array}$ & $\begin{array}{l}0.186 \\
15.0 \\
4.3 \\
45.9 \\
6.3 \\
17.1\end{array}$ & $\begin{array}{l}0.196 \\
12.4 \\
4.3 \\
45.9 \\
6.4 \\
17.3\end{array}$ & \begin{tabular}{|c|}
$5.0 \%$ \\
$-17.6 \%$ \\
$0.4 \%$ \\
$0.0 \%$ \\
$1.3 \%$ \\
$1.2 \%$
\end{tabular} & $\begin{array}{c}0.024 \\
7.4 \\
7.6 \\
39.8 \\
54.5 \\
30.5\end{array}$ & $\begin{array}{c}0.023 \\
6.9 \\
7.6 \\
39.9 \\
54.3 \\
30.5\end{array}$ & $\begin{array}{l}-3.4 \% \\
-6.8 \% \\
0.0 \% \\
0.1 \% \% \\
-0.3 \% \\
0.0 \%\end{array}$ & $\begin{array}{l}0.009 \\
16.9 \\
20.1 \\
123.1 \\
140.8 \\
89.6\end{array}$ & $\begin{array}{l}0.010 \\
17.1 \\
20.3 \\
123.2 \\
139.6 \\
89.3\end{array}$ & $\begin{array}{c}20.5 \% \\
1.2 \% \\
0.7 \% \\
0.1 \% \\
-0.8 \% \\
-0.3 \%\end{array}$ \\
\hline $\begin{array}{l}\text { Bull Trout } \\
\text { Max Redd Scour depth (ft) } \\
\text { Spawning/incubation } \\
\text { Fyubyearling (Spring-summer) } \\
\text { Subyearling (winter) }\end{array}$ & $\begin{array}{l}\text { Oct-1- Mar-31 } \\
\text { oct-1- Mar-31 } \\
\text { Apr-1- May-31 } \\
\text { Aun-01- Sep-30 } \\
\text { Oct-101- May-31 }\end{array}$ & $\begin{array}{c}0.033 \\
36.4 \\
4.9 \\
61.9 \\
8.6\end{array}$ & $\begin{array}{l}0.053 \\
36.0 \\
4.9 \\
62.9 \\
8.6\end{array}$ & $\begin{array}{l}58.7 \% \\
-1.1 \% \\
0.1 \% \\
1.8 \% \\
0.4 \%\end{array}$ & $\begin{array}{l}0.008 \\
13.4 \\
2.5 \\
20.5 \\
4.3\end{array}$ & $\begin{array}{l}0.007 \\
12.3 \\
2.6 \\
20.3 \\
4.2\end{array}$ & $\begin{array}{l}-3.0 \% \\
-8.5 \% \\
2.3 \% \\
-1.0 \% \\
-2.0 \%\end{array}$ & $\begin{array}{l}0.107 \\
8.0 \\
6.1 \\
64.8 \\
6.4\end{array}$ & $\begin{array}{l}0.107 \\
66.6 \\
64.1 \\
64.8 \\
6.5\end{array}$ & $\begin{array}{l}0.0 \% \\
-1.0 \% \\
0.1 .1 \% \\
0.0 \% \\
1.7 \%\end{array}$ & & & & & & \\
\hline $\begin{array}{l}\text { Resevoir Outmigration } \\
\text { inseason days Impassable } \\
\text { Kachess } \\
\text { Keechelus } \\
\text { Rimrock }\end{array}$ & $\begin{array}{l}\text { Jul-1.-5-Sep-15 } \\
\text { Jul-15. Sep-15 } \\
\text { Jul-101. Aug-15 }\end{array}$ & $\begin{array}{c}\text { Base } \\
18 \\
37 \\
3\end{array}$ & $\begin{array}{c}\text { Alternative } \\
18 \\
37 \\
1\end{array}$ & $\begin{array}{c}\text { Pct Chg } \\
-2.0 \% \\
-1.5 \% \\
-74.6 \% \\
\end{array}$ & & & & & & & & & & & & \\
\hline $\begin{array}{l}\text { Flood Metrics } \\
\begin{array}{l}\text { Overbank flow }>=1.67 \text { year flood } \\
\text { Damaging flood }(>=25 \text { year flood) }\end{array}\end{array}$ & $\begin{array}{l}\text { days } \\
\text { days }\end{array}$ & $\begin{array}{l}\text { Base } \\
91 \\
0\end{array}$ & $\begin{array}{l}\text { Easton } \\
\text { Alternative } \\
91 \\
0\end{array}$ & $\begin{array}{l}\text { Ptt Chg } \\
0.0 \% \\
0.0 \%\end{array}$ & $\begin{array}{c}\begin{array}{c}\text { Base } \\
90 \\
0\end{array} \\
0\end{array}$ & $\begin{array}{c}\text { Kittitas } \\
\text { Alternative } \\
85 \\
0\end{array}$ & $\begin{array}{l}\text { Pet hy } \\
\text { s.5.6\% } \\
0.0 \%\end{array}$ & $\begin{array}{c}\text { Base } \\
129 \\
0\end{array}$ & $\begin{array}{l}\text { Naches } \\
\text { Alternative } \\
133 \\
0\end{array}$ & $\begin{array}{l}\text { Pct Chg } \\
3.1 \% \% \\
0.0 \%\end{array}$ & $\begin{array}{c}\begin{array}{c}\text { Base } \\
235 \\
0\end{array} \\
0\end{array}$ & $\begin{array}{l}\text { Union Gap } \\
\text { Alternative } \\
211 \\
0\end{array}$ & $\begin{array}{l}\text { Pct hy } \\
-10.2 \% \\
0.0 \%\end{array}$ & $\begin{array}{c}\begin{array}{c}\text { Base } \\
181 \\
0\end{array} \\
0\end{array}$ & $\begin{array}{c}\text { Wapato } \\
\text { Alternative } \\
166 \\
0\end{array}$ & $\begin{array}{l}\text { Pct Cch } \\
-8.3 \% \\
0.0 \%\end{array}$ \\
\hline Water Division Deliveries & $\begin{array}{l}\text { Pvoration (\%) } \\
\text { Average or (r) (Month } \\
\text { TWSA } \\
\text { Average of 1st of Months }\end{array}$ & $\begin{array}{c}\begin{array}{c}\text { Base } \\
90 \% \\
2910719\end{array} \\
290\end{array}$ & $\begin{array}{c}\text { April } \\
\text { Alterative } \\
922 \% \\
2950885\end{array}$ & $\begin{array}{l}\text { Pct chg } \\
1.4 \% \\
1.4 \%\end{array}$ & $\begin{array}{c}\text { Base } \\
899 \% \\
2494500\end{array}$ & $\begin{array}{c}\text { May } \\
\text { Alterative } \\
910 \% \\
2544105\end{array}$ & $\begin{array}{l}\text { Pet hyg } \\
1.8 \% \\
2.0 \%\end{array}$ & $\begin{array}{c}\text { Base } \\
88 \% \\
1985967\end{array}$ & $\begin{array}{c}\text { June } \\
\text { Alternative } \\
900 \% \\
2034584\end{array}$ & $\begin{array}{l}\text { Pct Chy } \\
2.5 \% \\
2.4 \%\end{array}$ & $\begin{array}{c}\substack{\text { Base } \\
888 \%} \\
1475530\end{array}$ & $\begin{array}{c}\text { July } \\
\text { Alterative } \\
900 \% \\
1539639\end{array}$ & $\begin{array}{l}\text { Pct hig } \\
2.5 \% \\
4.3 \%\end{array}$ & $\begin{array}{c}\text { Base } \\
87 \% \\
1032999\end{array}$ & $\begin{array}{c}\begin{array}{c}\text { August } \\
\text { Alternative }\end{array} \\
900 \% \\
1093143\end{array}$ & $\begin{array}{l}\text { Pct che } \\
2.6 \% \\
5.8 \%\end{array}$ \\
\hline $\begin{array}{l}\text { Reservoir storage } \\
\text { End of Season Carryover }\end{array}$ & $\begin{array}{c}\text { (aff) } \\
\text { Average }\end{array}$ & $\begin{array}{l}\text { Base } \\
9614\end{array}$ & $\begin{array}{l}\text { Bumping } \\
\text { Alternative } \\
10214\end{array}$ & $\begin{array}{l}\text { Pct Chg } \\
6.2 \%\end{array}$ & $\begin{array}{c}\text { Base } \\
100028\end{array}$ & $\begin{array}{l}\text { Cle Elum } \\
\text { Alternative } \\
127394\end{array}$ & $\begin{array}{l}\text { Pet chg } \\
27.4 \%\end{array}$ & $\begin{array}{c}\text { Base } \\
84562\end{array}$ & $\begin{array}{l}\text { Kachess } \\
\text { Alternative } \\
88802\end{array}$ & $\begin{array}{l}\text { Pct Chg } \\
5.0 \%\end{array}$ & $\begin{array}{c}\text { Base } \\
31303\end{array}$ & $\begin{array}{c}\text { Keechelus } \\
\text { Alternative } \\
34085\end{array}$ & $\begin{array}{l}\text { Pct Chg } \\
8.9 \%\end{array}$ & $\begin{array}{c}\text { Base } \\
45775\end{array}$ & $\begin{array}{c}\text { Rimrock } \\
\text { Alternative } \\
48942\end{array}$ & $\begin{array}{l}\text { Pct Chg } \\
6.9 \%\end{array}$ \\
\hline $\begin{array}{l}\text { Sediment Transport } \\
\qquad \text { Fine Material Transport }\end{array}$ & Total tons & 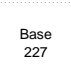 & $\begin{array}{l}\text { Easton } \\
\text { Alternative } \\
252\end{array}$ & $\begin{array}{l}\text { Pct hyg } \\
10.8 \%\end{array}$ & $\begin{array}{l}\text { Base } \\
2111\end{array}$ & $\begin{array}{l}\text { Kittitas } \\
\text { Alternative } \\
2067\end{array}$ & $\begin{array}{l}\text { Pct chg } \\
-2.1 \% \%\end{array}$ & $\begin{array}{l}\text { Base } \\
1138\end{array}$ & $\begin{array}{l}\text { Naches } \\
\text { Alternative } \\
1143\end{array}$ & $\begin{array}{l}\text { Pct Chg } \\
0.5 \% \%\end{array}$ & $\begin{array}{l}\text { Base } \\
3751\end{array}$ & $\begin{array}{c}\text { Union Gap } \\
\text { Alternative } \\
3668\end{array}$ & $\begin{array}{l}\text { Pct chg } \\
-2.2 \%\end{array}$ & $\begin{array}{l}\text { Base } \\
\text { 23277 }\end{array}$ & $\begin{array}{l}\text { Wapato } \\
\text { Alternative } \\
2230\end{array}$ & $\begin{array}{l}\text { Pct Chg } \\
-4.1 \%\end{array}$ \\
\hline Geomorphic Adjustment & Period Sum & 63270 & 72531 & $14.6 \%$ & 508081 & 489140 & $-3.7 \%$ & 433327 & 440061 & $1.6 \%$ & 918490 & 887623 & $-3.4 \%$ & 826559 & 799080 & $-3.3 \%$ \\
\hline Armor Disruption & Day count & 0 & 0 & $0.0 \%$ & 0 & 0 & $0.0 \%$ & 2952 & 2989 & $1.3 \%$ & 5 & 5 & $0.0 \%$ & 0 & 0 & $0.0 \%$ \\
\hline
\end{tabular}

Figure 5-1. Habitat summary page for the Wymer_1 scenario. 


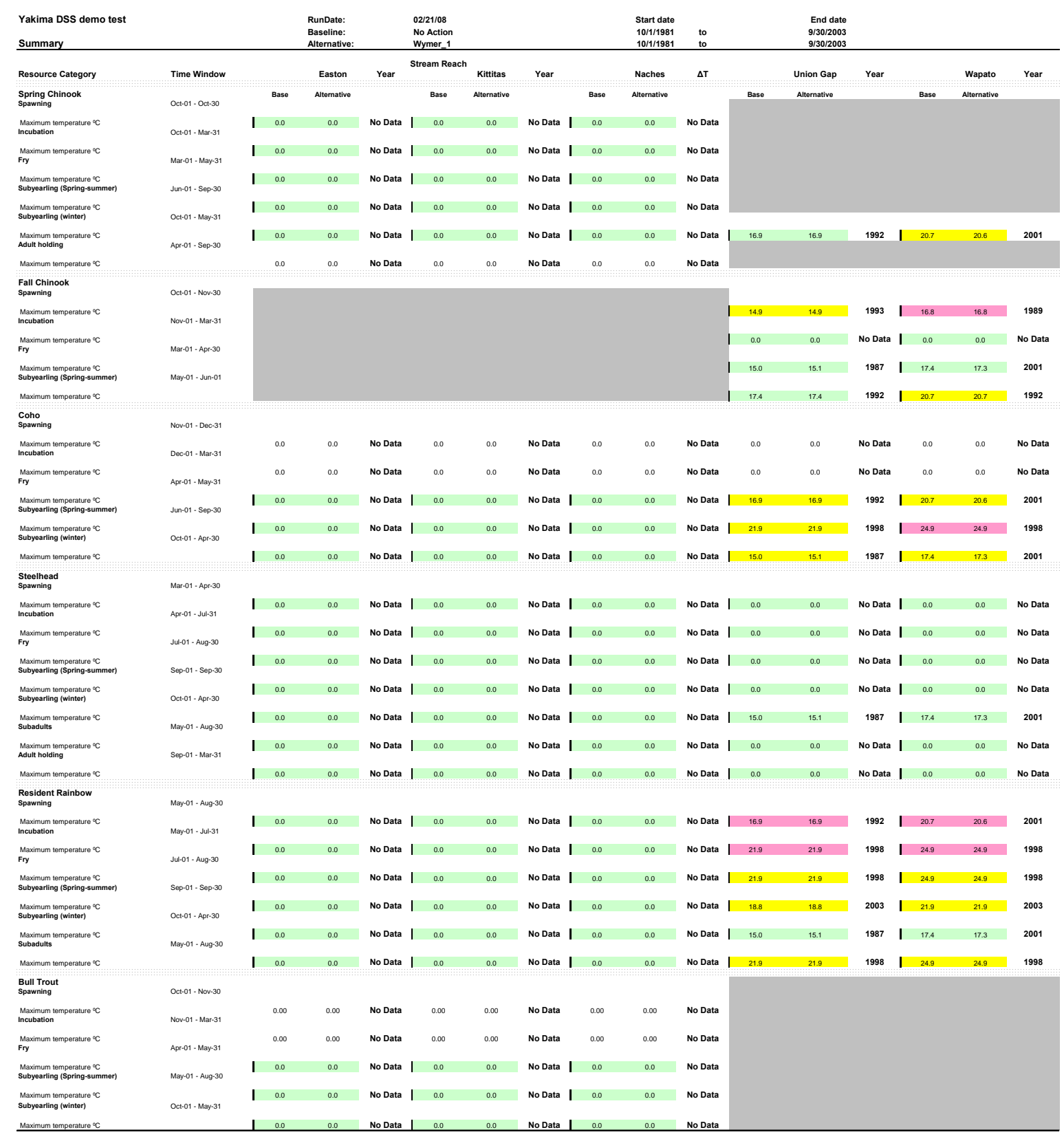

Figure 5-2. Temperature summary page for the Wymer_1 scenario. 


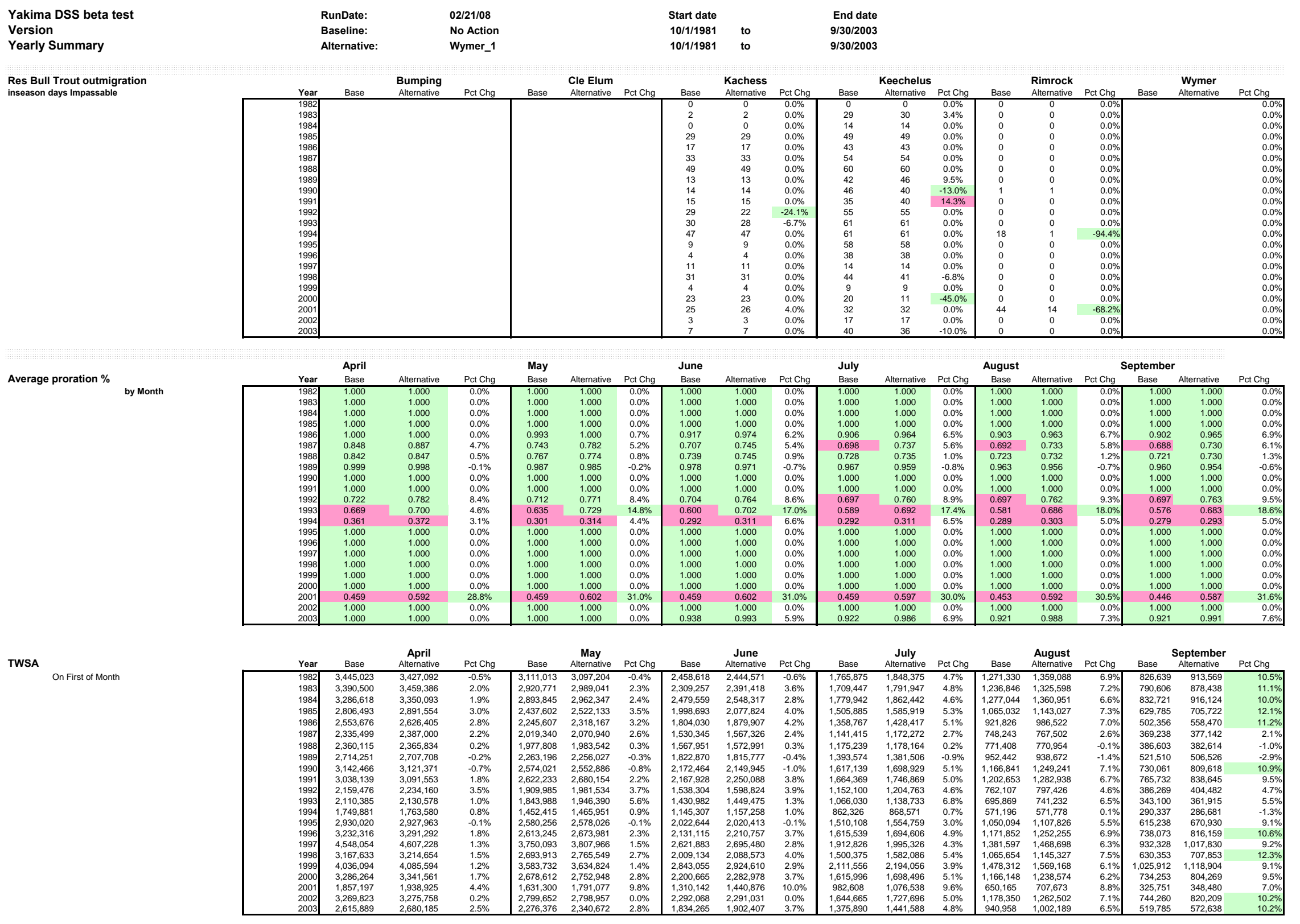

Figure 5-3. Bull trout outmigration, proration, and TWSA tables from yearly summary page for the Wymer_1 scenario. 
Reservoir storage End of Season Carryover

\begin{tabular}{|c|c|c|c|c|c|c|c|c|c|c|c|c|c|c|c|}
\hline \multirow[b]{2}{*}{ Year } & \multicolumn{3}{|c|}{ Bumping } & \multicolumn{3}{|c|}{ Cle Elum } & \multicolumn{3}{|c|}{ Kachess } & \multicolumn{3}{|c|}{ Keechelus } & \multicolumn{3}{|c|}{ Rimrock } \\
\hline & Base & Alternative & Pct Chg & Base & Alternative & Pct Chg & Base & Alternative & Pct Chg & Base & Alternative & Pct Chg & Base & Alternative & Pct Chg \\
\hline & 10,563 & 10,625 & $0.6 \%$ & 52,640 & 31,802 & $-39.6 \%$ & 112,061 & 107,940 & $-3.7 \%$ & 10,890 & 11,128 & $2.2 \%$ & 66,230 & 72,794 & \\
\hline 1982 & 14,883 & 15,053 & $1.1 \%$ & 160,780 & 227,238 & $41.3 \%$ & 118,393 & 129,336 & $9.2 \%$ & 71,613 & 65,826 & & & & \\
\hline 1983 & 11,601 & 14,185 & $22.3 \%$ & 152,349 & 213,373 & 40. & 109,269 & 121,522 & $11.2 \%$ & 45,9 & 33,708 & $-26.7 \%$ & 55,473 & 69,646 & \\
\hline 84 & 13,285 & 14,086 & $6.0 \%$ & 162,323 & 228,133 & $40.5 \%$ & 112,808 & 123,988 & 9.9 & 69,658 & 60,973 & $-12.5 \%$ & 76,395 & 80,601 & $5 \%$ \\
\hline 85 & 10,858 & 11,790 & $8.6 \%$ & 77,663 & 115,780 & $49.1 \%$ & 92,510 & 102,023 & $10.3 \%$ & 11,467 & 30,472 & $165.7 \%$ & 31,333 & 29,618 & \\
\hline 1986 & 7,810 & 9,182 & $17.6 \%$ & 22,361 & 37,625 & $68.3 \%$ & 92,465 & 106,462 & $15.1 \%$ & 5,434 & 5,980 & $10.1 \%$ & 51,578 & 61,749 & $19.7 \%$ \\
\hline 1987 & 3,115 & 3,115 & $0.0 \%$ & 4,613 & 4,327 & $-6.2 \%$ & 28,564 & 25,753 & $-9.8 \%$ & 1,815 & 1,855 & $2.2 \%$ & 5,284 & 9,297 & $75.9 \%$ \\
\hline 1988 & 5,564 & 5,386 & $-3.2 \%$ & & 28,523 & $-19.9 \%$ & 29,531 & & $-22.4 \%$ & 14,269 & & 0.8 & & & \\
\hline 1989 & 8,461 & & $-3.7 \%$ & & & $-69.5 \%$ & & & & & & $-0.2 \%$ & & & $8.7 \%$ \\
\hline $\begin{array}{l}1990 \\
1991\end{array}$ & $\begin{array}{l}14,742 \\
0978\end{array}$ & & $\begin{array}{l}2.2 \% \\
\end{array}$ & 142,357 & $\begin{array}{l}189,220 \\
186607\end{array}$ & & $\begin{array}{l}121,753 \\
105\end{array}$ & $\begin{array}{l}124,858 \\
114,760\end{array}$ & & $\begin{array}{l}54,526 \\
55778\end{array}$ & 68,034 & $24.8 \%$ & 38,584 & & 14.3\% \\
\hline 1991 & $\begin{array}{l}9,978 \\
3249\end{array}$ & $\begin{array}{l}11,448 \\
3,293\end{array}$ & $14.7 \%$ & 134,231 & $\begin{array}{l}186,607 \\
9119\end{array}$ & $\begin{array}{l}39.0 \% \\
-25.9 \%\end{array}$ & $\begin{array}{l}105,208 \\
20546\end{array}$ & $\begin{array}{l}114,760 \\
25\end{array}$ & $9.1 \%$ & 58,778 & 48,936 & $-16.7 \%$ & $\begin{array}{l}34,780 \\
27,05\end{array}$ & $\begin{array}{l}34,130 \\
30598\end{array}$ & $-1.9 \%$ \\
\hline $\begin{array}{l}1992 \\
1993\end{array}$ & $\begin{array}{l}3,249 \\
2116\end{array}$ & $\begin{array}{l}3,293 \\
2551\end{array}$ & $\begin{array}{l}1.3 \% \\
20.5 \%\end{array}$ & $\begin{array}{c}12,303 \\
4,672\end{array}$ & $\begin{array}{l}9,119 \\
4022\end{array}$ & $\begin{array}{l}-25.9 \% \\
-13.9 \%\end{array}$ & $\begin{array}{l}29,546 \\
9951\end{array}$ & $\begin{array}{l}35,484 \\
10,120\end{array}$ & $\begin{array}{l}20.1 \% \\
1.7 \%\end{array}$ & $\begin{array}{l}9,198 \\
2187\end{array}$ & $\begin{array}{l}9,183 \\
2,092\end{array}$ & $\begin{array}{l}-0.2 \% \\
-4.3 \%\end{array}$ & $\begin{array}{l}27,405 \\
24,78\end{array}$ & $\begin{array}{l}30,598 \\
29,437\end{array}$ & $\begin{array}{l}11.6 \% \\
18.8 \%\end{array}$ \\
\hline $\begin{array}{l}1993 \\
1994\end{array}$ & $\begin{array}{l}2,116 \\
2,136\end{array}$ & $\begin{array}{l}2,551 \\
2,136\end{array}$ & $\begin{array}{l}20.5 \% \\
0.0 \%\end{array}$ & $\begin{array}{l}4,662 \\
6,087\end{array}$ & $\begin{array}{l}\begin{array}{l}4,022 \\
4,524\end{array} \\
-\end{array}$ & $\begin{array}{l}-13.9 \% \\
-25.7 \%\end{array}$ & $\begin{array}{l}9,951 \\
4,514\end{array}$ & ${ }_{3,447}^{10,120}$ & $\begin{array}{l}1.1 \% \% \\
-23.7 \%\end{array}$ & $\begin{array}{l}2,187 \\
2,296\end{array}$ & & $\begin{array}{l}-4.3 \% \\
-3.1 \%\end{array}$ & $\begin{array}{l}2,7,188 \\
2,992\end{array}$ & $\begin{array}{l}2,431 \\
1,090\end{array}$ & $\begin{array}{l}18.8 \% \\
-63.6 \%\end{array}$ \\
\hline 1995 & 14,392 & & $1.5 \%$ & 144 & & $28.0 \%$ & & & -1. & & & & & & \\
\hline 1996 & 12,083 & & & 132 & 183,992 & $38.8 \%$ & 102,781 & 113,979 & $10.9 \%$ & & 45,069 & $-13.5 \%$ & 45,193 & & $25.4 \%$ \\
\hline 1997 & 15,349 & & $2.1 \%$ & 250,810 & 326,821 & $30.3 \%$ & 136,887 & 150,846 & $10.2 \%$ & 85,457 & 76,968 & $\begin{array}{l}-9.9 \% \\
\end{array}$ & 142,661 & 136,726 & \\
\hline 1998 & $\begin{array}{r}9,492 \\
\end{array}$ & $\begin{array}{l}10,640 \\
15687\end{array}$ & $12.1 \%$ & $\begin{array}{l}89,032 \\
315\end{array}$ & $\begin{array}{l}119,197 \\
358,122\end{array}$ & $\begin{array}{l}33.9 \% \\
13.6 \%\end{array}$ & $\begin{array}{r}96,430 \\
\end{array}$ & $\begin{array}{r}99,633 \\
\end{array}$ & $3.3 \%$ & $\begin{array}{l}4,619 \\
7\end{array}$ & $\begin{array}{l}37,206 \\
87592\end{array}$ & $705.5 \%$ & $\begin{array}{l}31,714 \\
7850\end{array}$ & 32,011 & \\
\hline 1999 & $\begin{array}{l}15,395 \\
13,226\end{array}$ & $\begin{array}{l}15,687 \\
14,440\end{array}$ & $\begin{array}{l}1.9 \% \\
99 \%\end{array}$ & $\begin{array}{l}315,201 \\
131,073\end{array}$ & $\begin{array}{l}358,122 \\
166228\end{array}$ & $\begin{array}{l}13.6 \% \\
26.8 \%\end{array}$ & $\begin{array}{l}136,128 \\
117,533\end{array}$ & $\begin{array}{l}136,128 \\
118,471\end{array}$ & $\begin{array}{l}0.0 \% \\
0.8 \%\end{array}$ & $\begin{array}{l}9,880 \\
40,133\end{array}$ & $\begin{array}{l}87,592 \\
62,260\end{array}$ & $\begin{array}{l}9.1 \% \\
55.1 \%\end{array}$ & $\begin{array}{l}78,580 \\
51,82 ?\end{array}$ & $\begin{array}{l}76,847 \\
52,489\end{array}$ & $-2.2 \%$ \\
\hline 2001 & $\begin{array}{r}10,220 \\
2,217\end{array}$ & 2,3 & $7.0 \%$ & $\begin{array}{l}1 \\
8,494\end{array}$ & $\begin{array}{c}100 \\
8,1\end{array}$ & $\begin{array}{l}20.0 \% \\
-4.3 \%\end{array}$ & 17,813 & 18,343 & $\begin{array}{l}3.0 \% \\
3.0 \%\end{array}$ & 5,0 & 5,1 & $\begin{array}{l}1.7 \% \\
1.7 \%\end{array}$ & $\begin{array}{l}1,1,02 \\
14,559\end{array}$ & $\begin{array}{l}12,4093 \\
19,228\end{array}$ & \\
\hline 2002 & 10,986 & 11,968 & $8.9 \%$ & 122,529 & 163,509 & $33.4 \%$ & 110,427 & 112,964 & $2.3 \%$ & 44,164 & 61,680 & $39.7 \%$ & 35,064 & 28,904 & $17.6 \%$ \\
\hline
\end{tabular}

Critical Reservoir Storage Smolt Passage

Days below threshold

\begin{tabular}{|c|c|c|c|}
\hline Year & Base & $\begin{array}{l}\text { Cle Elum } \\
\text { Alternative }\end{array}$ & Pct Chg \\
\hline 1982 & 29 & 53 & $82.8 \%$ \\
\hline 1983 & 0 & 0 & $0.0 \%$ \\
\hline 1984 & 0 & 0 & $0.0 \%$ \\
\hline $\begin{array}{l}1985 \\
1986\end{array}$ & 12 & 10 & $-16.7 \%$ \\
\hline $\begin{array}{l}1986 \\
1987\end{array}$ & $\begin{array}{c}0 \\
32\end{array}$ & $\begin{array}{c}0 \\
40\end{array}$ & $\begin{array}{l}0.0 \% \\
25.0 \%\end{array}$ \\
\hline $\begin{array}{l}1988 \\
1988\end{array}$ & $\begin{array}{l}32 \\
51\end{array}$ & $\begin{array}{l}40 \\
66\end{array}$ & $\begin{array}{l}29.4 \% \\
29.4 \%\end{array}$ \\
\hline 1989 & 19 & 36 & $89.5 \%$ \\
\hline $\begin{array}{l}19900 \\
1992\end{array}$ & $\begin{array}{l}2 \\
0\end{array}$ & $\begin{array}{c}21 \\
0\end{array}$ & $\begin{array}{c}950.0 \% \\
0.0 \%\end{array}$ \\
\hline 1993 & 47 & 66 & $40.4 \%$ \\
\hline 1994 & 51 & 66 & $29.4 \%$ \\
\hline 1995 & 12 & 41 & $241.7 \%$ \\
\hline 1996 & 0 & 0 & $0.0 \%$ \\
\hline 1997 & 0 & 0 & $0.0 \%$ \\
\hline $\begin{array}{l}19998 \\
1999\end{array}$ & $\begin{array}{l}0 \\
0\end{array}$ & $\begin{array}{c}0 \\
23 \\
23\end{array}$ & $\begin{array}{r}0.0 \% \\
0\end{array}$ \\
\hline 2000 & $\begin{array}{l}0 \\
0\end{array}$ & $\begin{array}{c}23 \\
0\end{array}$ & $\begin{array}{r}2300.0 \% \\
0.0 \%\end{array}$ \\
\hline 2001 & 66 & 66 & $0.0 \%$ \\
\hline 2002 & 23 & 49 & $113.0 \%$ \\
\hline 2003 & 0 & 0 & $0.0 \%$ \\
\hline
\end{tabular}

Figure 5-4. Reservoir storage tables from yearly summary page for the Wymer_1 scenario. 


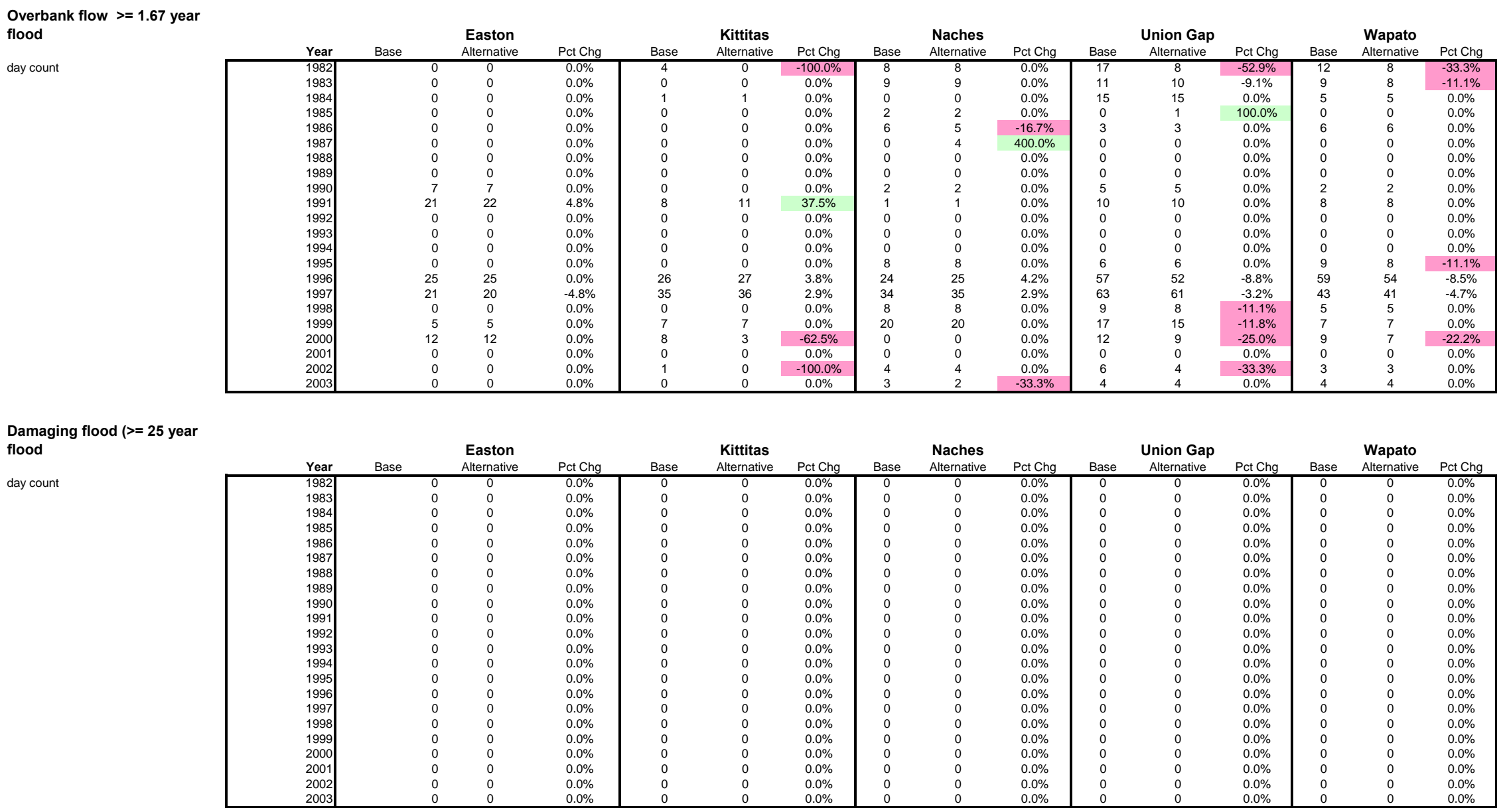

Figure 5-5. Overbank flow and damaging flood tables from yearly summary page for the Wymer_1 scenario. 


\begin{tabular}{|c|c|c|c|c|c|c|c|c|c|c|c|c|c|c|c|c|}
\hline \multirow[t]{23}{*}{$\begin{array}{l}\text { Sediment Transport } \\
\text { Fine-Material Transport }\end{array}$} & Year & \multicolumn{3}{|c|}{ Easton } & \multicolumn{3}{|c|}{ Kittitas } & \multicolumn{3}{|c|}{ Naches } & \multicolumn{3}{|c|}{ Union Gap } & \multicolumn{3}{|c|}{ Wapato } \\
\hline & 1982 & 9 & 9 & $-0.4 \%$ & 108 & 98 & $-9.5 \%$ & 64 & 64 & $0.3 \%$ & 220 & 203 & $-7.7 \%$ & 142 & 129 & $-9.0 \%$ \\
\hline & 1983 & 8 & 8 & $8.9 \%$ & 110 & 109 & $-1.6 \%$ & 66 & 66 & $-0.6 \%$ & 209 & 202 & $-3.3 \%$ & 140 & 135 & $-3.7 \%$ \\
\hline & 1984 & 10 & 11 & $4.5 \%$ & 111 & 107 & $-3.3 \%$ & 56 & 57 & $1.0 \%$ & 205 & 201 & $-1.8 \%$ & 134 & 132 & $-1.7 \%$ \\
\hline & 1985 & 7 & 6 & $-14.6 \%$ & 74 & 75 & $1.6 \%$ & 35 & 37 & $4.7 \%$ & 114 & 113 & $-1.1 \%$ & 43 & 42 & $-3.3 \%$ \\
\hline & 1986 & 7 & 7 & $0.0 \%$ & 81 & 84 & $3.8 \%$ & 42 & 41 & $-1.3 \%$ & 137 & 137 & $0.2 \%$ & 76 & 75 & $-0.5 \%$ \\
\hline & 1987 & 10 & 11 & $14.1 \%$ & 63 & 64 & $2.2 \%$ & 36 & 37 & $1.2 \%$ & 106 & 111 & $4.2 \%$ & 51 & 52 & $2.2 \%$ \\
\hline & 1988 & 6 & 6 & $1.3 \%$ & 58 & 55 & $-3.7 \%$ & 27 & 28 & $2.2 \%$ & 93 & 94 & $1.1 \%$ & 37 & 35 & $-4.6 \%$ \\
\hline & 1989 & 6 & 6 & $-4.2 \%$ & 75 & 73 & $-3.3 \%$ & 37 & 37 & $1.9 \%$ & 122 & 122 & $-0.1 \%$ & 57 & 57 & $-0.6 \%$ \\
\hline & 1990 & 11 & 11 & $6.6 \%$ & 100 & 89 & $-10.9 \%$ & 47 & 48 & $1.6 \%$ & 161 & 150 & $-7.2 \%$ & 89 & 80 & $-10.6 \%$ \\
\hline & 1991 & 21 & 29 & $38.9 \%$ & 133 & 134 & $1.0 \%$ & 53 & 53 & $-0.2 \%$ & 222 & 222 & $-0.3 \%$ & 149 & 147 & $-1.3 \%$ \\
\hline & 1992 & 11 & 11 & $-2.8 \%$ & 76 & 79 & $3.6 \%$ & 24 & 23 & $-3.2 \%$ & 101 & 103 & $2.1 \%$ & 48 & 46 & $-3.4 \%$ \\
\hline & 1993 & 7 & 6 & $-16.4 \%$ & 57 & 53 & $-6.9 \%$ & 24 & 23 & $-1.8 \%$ & 77 & 80 & $3.9 \%$ & 28 & 26 & $-6.6 \%$ \\
\hline & 1994 & 7 & 8 & $5.6 \%$ & 43 & 43 & $-0.9 \%$ & 20 & 20 & $-0.1 \%$ & 64 & 63 & $-1.6 \%$ & 25 & 23 & $-5.2 \%$ \\
\hline & 1995 & 6 & 5 & $-2.3 \%$ & 87 & 82 & $-5.3 \%$ & 63 & 63 & $-0.1 \%$ & 189 & 181 & $-4.2 \%$ & 124 & 112 & $-9.5 \%$ \\
\hline & 1996 & 23 & 28 & $21.5 \%$ & 206 & 205 & $-0.4 \%$ & 111 & 110 & $-0.7 \%$ & 385 & 370 & $-3.9 \%$ & 320 & 304 & $-4.9 \%$ \\
\hline & 1997 & 21 & 27 & $28.0 \%$ & 177 & 172 & $-2.7 \%$ & 106 & 107 & $1.4 \%$ & 339 & 336 & $-0.9 \%$ & 271 & 266 & $-1.9 \%$ \\
\hline & 1998 & 9 & 9 & $1.8 \%$ & 99 & 99 & $-0.6 \%$ & 61 & 62 & $1.5 \%$ & 197 & 190 & $-3.2 \%$ & 121 & 120 & $-1.1 \%$ \\
\hline & 1999 & 13 & 16 & $23.7 \%$ & 113 & 111 & $-1.3 \%$ & 91 & 92 & $0.7 \%$ & 238 & 236 & $-1.0 \%$ & 156 & 154 & $-1.2 \%$ \\
\hline & 2000 & 14 & 16 & $14.0 \%$ & 119 & 117 & $-1.4 \%$ & 56 & 57 & $1.8 \%$ & 213 & 205 & $-3.5 \%$ & 135 & 130 & $-3.5 \%$ \\
\hline & 2001 & 11 & 11 & $1.3 \%$ & 47 & 51 & $8.7 \%$ & 15 & 15 & $-2.0 \%$ & 61 & 66 & $7.4 \%$ & 19 & 18 & $-6.6 \%$ \\
\hline & 2002 & 7 & 6 & $-6.8 \%$ & 93 & 84 & $-10.5 \%$ & 55 & 56 & $1.5 \%$ & 166 & 157 & $-5.5 \%$ & 92 & 81 & $-11.5 \%$ \\
\hline & 2003 & 5 & 5 & $-1.6 \%$ & 81 & 83 & $1.9 \%$ & 46 & 45 & $-1.4 \%$ & 133 & 129 & $-3.3 \%$ & 69 & 64 & $-6.9 \%$ \\
\hline Sediment Transport & & & Easton & & & Kittitas & & & Naches & & & Union Gap & & & Wapato & \\
\hline Geomorphic Adjustment & Year & Base & Alternative & Pct Chg & Base & Alternative & Pct Chg & Base & Alternative & Pct Chg & Base & Alternative & Pct Chg & Base & Alternative & Pct Chg \\
\hline Highest 15 -day period & 1982 & 2,169 & 2,433 & $12.2 \%$ & 28,267 & 21,648 & $-23.4 \%$ & 26,444 & 26,193 & $-0.9 \%$ & 54,116 & 53,616 & $-0.9 \%$ & 54,632 & 55,407 & $1.4 \%$ \\
\hline & 1983 & 1,862 & 2,659 & $42.8 \%$ & 20,541 & 21,088 & $2.7 \%$ & 27,727 & 28,572 & $3.0 \%$ & 48,440 & 44,840 & $-7.4 \%$ & 49,135 & 47,980 & $-2.4 \%$ \\
\hline & 1984 & 2,094 & 2,517 & $20.2 \%$ & 29,298 & 28,200 & $-3.7 \%$ & 19,683 & 19,743 & $0.3 \%$ & 46,531 & 45,407 & $-2.4 \%$ & 42,934 & 39,314 & $-8.4 \%$ \\
\hline & 1985 & 1,491 & 1,325 & $-11.1 \%$ & 16,861 & 15,608 & $-7.4 \%$ & 16,914 & 18,063 & $6.8 \%$ & 26,503 & 25,152 & $-5.1 \%$ & 18,404 & 18,430 & $0.1 \%$ \\
\hline & 1986 & 1,541 & 1,383 & $-10.2 \%$ & 20,500 & 21,583 & $5.3 \%$ & 21,906 & 21,021 & $-4.0 \%$ & 44,021 & 44,616 & $1.4 \%$ & 45,110 & 45,935 & $1.8 \%$ \\
\hline & 1987 & 2,981 & 3,532 & $18.5 \%$ & 15,064 & 14,265 & $-5.3 \%$ & 21,102 & 22,914 & $8.6 \%$ & 27,821 & 29,718 & $6.8 \%$ & 20,645 & 20,680 & $0.2 \%$ \\
\hline & 1988 & 1,363 & 1,467 & $7.6 \%$ & 14,748 & 14,018 & $-5.0 \%$ & 10,830 & 10,883 & $0.5 \%$ & 24,447 & 24,673 & $0.9 \%$ & 17,295 & 17,055 & $-1.4 \%$ \\
\hline & 1989 & 1,769 & 1,926 & $8.9 \%$ & 16,437 & 15,839 & $-3.6 \%$ & 14,135 & 14,434 & $2.1 \%$ & 32,183 & 32,337 & $0.5 \%$ & 25,664 & 26,166 & $2.0 \%$ \\
\hline & 1990 & 3,908 & 4,654 & $19.1 \%$ & 23,391 & 24,524 & $4.8 \%$ & 20,177 & 20,270 & $0.5 \%$ & 41,721 & 42,309 & $1.4 \%$ & 36,785 & 37,268 & $1.3 \%$ \\
\hline & 1991 & 6,306 & 9,595 & $52.2 \%$ & 33,455 & 37,688 & $12.7 \%$ & 11,899 & 12,004 & $0.9 \%$ & 53,978 & 57,277 & $6.1 \%$ & 53,978 & 57,792 & $7.1 \%$ \\
\hline & 1992 & 3,114 & 3,227 & $3.6 \%$ & 15,855 & 16,094 & $1.5 \%$ & 7,507 & 7,455 & $-0.7 \%$ & 16,519 & 16,587 & $0.4 \%$ & 16,726 & 16,549 & $-1.1 \%$ \\
\hline & 1993 & 2,619 & 1,866 & $-28.8 \%$ & 15,104 & 13,226 & $-12.4 \%$ & 13,243 & 13,297 & $0.4 \%$ & 19,135 & 18,680 & $-2.4 \%$ & 9,585 & 9,488 & $-1.0 \%$ \\
\hline & 1994 & 2,900 & 2,972 & $2.5 \%$ & 10,293 & 8,921 & $-13.3 \%$ & 8,133 & 8,405 & $3.3 \%$ & 13,421 & 13,391 & $-0.2 \%$ & 7,181 & 7,128 & $-0.7 \%$ \\
\hline & 1995[ & \begin{tabular}{|l|}
1,613 \\
\end{tabular} & 1,713 & $6.2 \%$ & 19,374 & 20,444 & $5.5 \%$ & 21,146 & 21,027 & $-0.6 \%$ & 46,684 & 46,211 & $-1.0 \%$ & 52,107 & 46,657 & $-10.5 \%$ \\
\hline & 1996 & 4,059 & 4,846 & $19.4 \%$ & 49,294 & 49,751 & $0.9 \%$ & 36,404 & 36,664 & $0.7 \%$ & 84,914 & 79,417 & $-6.5 \%$ & 92,549 & 85,603 & $-7.5 \%$ \\
\hline & 1997 & 6,135 & 7,392 & $20.5 \%$ & 43,268 & 43,280 & $0.0 \%$ & 38,135 & 39,335 & $3.1 \%$ & 83,805 & 81,734 & $-2.5 \%$ & 76,280 & 72,197 & $-5.4 \%$ \\
\hline & 1998 & 2,568 & 2,960 & $15.3 \%$ & 25,532 & 23,905 & $-6.4 \%$ & 25,612 & 25,910 & $1.2 \%$ & 54,551 & 45,350 & $-16.9 \%$ & 41,038 & 37,839 & $-7.8 \%$ \\
\hline & 1999 & 3,714 & 4,344 & $17.0 \%$ & 33,970 & 33,867 & $-0.3 \%$ & 29,814 & 30,468 & $2.2 \%$ & 67,524 & 67,780 & $0.4 \%$ & 56,020 & 56,032 & $0.0 \%$ \\
\hline & 2000 & 4,342 & 5,024 & $15.7 \%$ & 25,439 & 22,860 & $-10.1 \%$ & 17,858 & 18,167 & $1.7 \%$ & 51,898 & 42,440 & $-18.2 \%$ & 44,636 & 37,093 & $-16.9 \%$ \\
\hline & 2001[ & 3,948 & 3,889 & $-1.5 \%$ & 11,486 & 10,924 & $-4.9 \%$ & 5,915 & 6,156 & $4.1 \%$ & 9,675 & 11,170 & $15.5 \%$ & 4,968 & 4,661 & $-6.2 \%$ \\
\hline & 2002 & 1,474 & 1,431 & $-2.9 \%$ & 23,429 & 16,261 & $-30.6 \%$ & 17,423 & 18,272 & $4.9 \%$ & 38,569 & 35,566 & $-7.8 \%$ & 28,155 & 28,603 & $1.6 \%$ \\
\hline & 2003 & 1,301 & 1,375 & $5.7 \%$ & 16,474 & 15,146 & $-8.1 \%$ & 21,320 & 20,810 & $-2.4 \%$ & 32,035 & 29,350 & $-8.4 \%$ & 32,733 & 31,201 & $-4.7 \%$ \\
\hline
\end{tabular}

Figure 5-6. Fine-sediment transport and geomorphic adjustment tables from yearly summary page for the Wymer_1 scenario. 


\begin{tabular}{|c|c|c|c|c|c|c|c|c|c|c|c|c|c|c|c|c|}
\hline \multirow[b]{2}{*}{ Year } & \multicolumn{4}{|c|}{ Easton } & \multicolumn{3}{|c|}{ Kittitas } & \multicolumn{3}{|c|}{ Naches } & \multicolumn{3}{|c|}{ Union Gap } & \multicolumn{3}{|c|}{ Wapato } \\
\hline & Base & & Alternative & Pct Chg & Base & Alternative & Pct Chg & Base & Alternative & Pct Chg & Base & Alternative & Pct Chg & Base & Alternative & Pct Chg \\
\hline 1982 & & $\overline{0}$ & 0 & $0.0 \%$ & 0 & 0 & $0.0 \%$ & 162 & 161 & $-0.6 \%$ & 0 & 0 & $0.0 \%$ & 0 & 0 & $0.0 \%$ \\
\hline 1983 & & 0 & 0 & $0.0 \%$ & 0 & 0 & $0.0 \%$ & 187 & 188 & $0.5 \%$ & 0 & 0 & $0.0 \%$ & 0 & 0 & $0.0 \%$ \\
\hline 1984 & & 0 & 0 & $0.0 \%$ & 0 & 0 & $0.0 \%$ & 179 & 185 & $3.4 \%$ & 0 & 0 & $0.0 \%$ & 0 & 0 & $0.0 \%$ \\
\hline 1985 & & 0 & 0 & $0.0 \%$ & 0 & 0 & $0.0 \%$ & 87 & 94 & $8.0 \%$ & 0 & 0 & $0.0 \%$ & 0 & 0 & $0.0 \%$ \\
\hline 1986 & & 0 & 0 & $0.0 \%$ & 0 & 0 & $0.0 \%$ & 111 & 115 & $3.6 \%$ & 0 & 0 & $0.0 \%$ & 0 & 0 & $0.0 \%$ \\
\hline 1987 & & 0 & 0 & $0.0 \%$ & 0 & 0 & $0.0 \%$ & 88 & 84 & $-4.5 \%$ & 0 & 0 & $0.0 \%$ & 0 & 0 & $0.0 \%$ \\
\hline 1988 & & 0 & 0 & $0.0 \%$ & 0 & 0 & $0.0 \%$ & 75 & 76 & $1.3 \%$ & 0 & 0 & $0.0 \%$ & 0 & 0 & $0.0 \%$ \\
\hline 1989 & & 0 & 0 & $0.0 \%$ & 0 & 0 & $0.0 \%$ & 85 & 87 & $2.4 \%$ & 0 & 0 & $0.0 \%$ & 0 & 0 & $0.0 \%$ \\
\hline 1990 & & 0 & 0 & $0.0 \%$ & 0 & 0 & $0.0 \%$ & 135 & 137 & $1.5 \%$ & 0 & 0 & $0.0 \%$ & 0 & 0 & $0.0 \%$ \\
\hline 1991 & & 0 & 0 & $0.0 \%$ & 0 & 0 & $0.0 \%$ & 207 & 214 & $3.4 \%$ & 0 & 0 & $0.0 \%$ & 0 & 0 & $0.0 \%$ \\
\hline 1992 & & 0 & 0 & $0.0 \%$ & 0 & 0 & $0.0 \%$ & 53 & 53 & $0.0 \%$ & 0 & 0 & $0.0 \%$ & 0 & 0 & $0.0 \%$ \\
\hline 1993 & & 0 & 0 & $0.0 \%$ & 0 & 0 & $0.0 \%$ & 51 & 48 & $-5.9 \%$ & 0 & 0 & $0.0 \%$ & 0 & 0 & $0.0 \%$ \\
\hline 1994 & & 0 & 0 & $0.0 \%$ & 0 & 0 & $0.0 \%$ & 50 & 53 & $6.0 \%$ & 0 & 0 & $0.0 \%$ & 0 & 0 & $0.0 \%$ \\
\hline 1995 & & 0 & 0 & $0.0 \%$ & 0 & 0 & $0.0 \%$ & 191 & 198 & $3.7 \%$ & 0 & 0 & $0.0 \%$ & 0 & 0 & $0.0 \%$ \\
\hline 1996 & & 0 & 0 & $0.0 \%$ & 0 & 0 & $0.0 \%$ & 262 & 253 & $-3.4 \%$ & 5 & 5 & $0.0 \%$ & 0 & 0 & $0.0 \%$ \\
\hline 1997 & & 0 & 0 & $0.0 \%$ & 0 & 0 & $0.0 \%$ & 205 & 211 & $2.9 \%$ & 0 & 0 & $0.0 \%$ & 0 & 0 & $0.0 \%$ \\
\hline 1998 & & 0 & 0 & $0.0 \%$ & 0 & 0 & $0.0 \%$ & 150 & 151 & $0.7 \%$ & 0 & 0 & $0.0 \%$ & 0 & 0 & $0.0 \%$ \\
\hline 1999 & & 0 & 0 & $0.0 \%$ & 0 & 0 & $0.0 \%$ & 202 & 203 & $0.5 \%$ & 0 & 0 & $0.0 \%$ & 0 & 0 & $0.0 \%$ \\
\hline 2000 & & 0 & 0 & $0.0 \%$ & 0 & 0 & $0.0 \%$ & 168 & 172 & $2.4 \%$ & 0 & 0 & $0.0 \%$ & 0 & 0 & $0.0 \%$ \\
\hline 2001 & & 0 & 0 & $0.0 \%$ & 0 & 0 & $0.0 \%$ & 29 & 31 & $6.9 \%$ & 0 & 0 & $0.0 \%$ & 0 & 0 & $0.0 \%$ \\
\hline 2002 & & 0 & 0 & $0.0 \%$ & 0 & 0 & $0.0 \%$ & 128 & 128 & $0.0 \%$ & 0 & 0 & $0.0 \%$ & 0 & 0 & $0.0 \%$ \\
\hline 2003 & & 0 & 0 & $0.0 \%$ & 0 & 0 & $0.0 \%$ & 147 & 147 & $0.0 \%$ & 0 & 0 & $0.0 \%$ & 0 & 0 & $0.0 \%$ \\
\hline
\end{tabular}

Figure 5-7. Armor disruption table from yearly summary page for the Wymer_1 scenario. 


\begin{tabular}{|c|c|c|c|c|c|c|c|c|c|c|c|c|c|c|c|c|c|c|c|c|}
\hline Spring Chinook & \multicolumn{3}{|c|}{ Redd Scour } & \multicolumn{3}{|c|}{ Spawning/incubation } & \multicolumn{3}{|c|}{ Fry } & \multicolumn{3}{|c|}{ Subyearling (Spring-summer) } & \multicolumn{3}{|c|}{ Subyearling (winter) } & \multicolumn{2}{|r|}{ Subadult } & \multicolumn{3}{|c|}{ Adult holding } \\
\hline & Base & Alternative & Pct Chg & Base & Alternative & Pct Chg & Base & Alternative & Pct Chg & Base & Alternative & Pct Chg & Base & Alternative & Pct Chg & Base & Alternative Pct Chg & Base & Alternative & Pct Chg \\
\hline 1982 & 0.008 & 0.013 & $66.2 \%$ & 47.55 & 48.73 & $2.47 \%$ & 2.23 & 2.17 & $-2.69 \%$ & 51.15 & 51.12 & $-0.08 \%$ & 6.89 & 6.41 & \begin{tabular}{l|l|}
$-6.93 \%$ \\
\end{tabular} & & & 7.18 & 7.21 & $0.53 \%$ \\
\hline 1983 & 0.018 & 0.027 & $50.8 \%$ & 45.14 & 39.00 & $-13.60 \%$ & 2.24 & 2.41 & $7.65 \%$ & 60.44 & 59.56 & $-1.44 \%$ & 7.47 & 7.68 & $2.85 \%$ & & & 7.15 & 7.15 & $0.00 \%$ \\
\hline 1984 & 0.010 & 0.039 & $303.9 \%$ & 46.09 & 40.14 & $-12.90 \%$ & 2.38 & 2.34 & $-1.63 \%$ & 45.30 & 48.07 & $6.11 \%$ & 6.95 & 6.85 & $-1.40 \%$ & & & 7.15 & 7.34 & $2.71 \%$ \\
\hline 1985 & 0.008 & 0.008 & $0.0 \%$ & 52.88 & 52.88 & $0.00 \%$ & 2.86 & 2.42 & $-15.34 \%$ & 39.14 & 52.07 & $33.05 \%$ & 11.90 & 10.06 & $-15.48 \%$ & & & 7.95 & 7.44 & $-6.41 \%$ \\
\hline 1986 & 0.008 & 0.008 & $0.0 \%$ & 52.88 & 52.88 & $0.00 \%$ & 2.28 & 2.22 & $-2.58 \%$ & 43.43 & 56.52 & $30.15 \%$ & 9.03 & 7.52 & $-16.78 \%$ & & & 7.15 & 7.36 & $2.97 \%$ \\
\hline 1987 & 0.008 & 0.008 & $0.0 \%$ & 48.98 & 48.98 & $0.00 \%$ & 2.39 & 2.35 & $-1.64 \%$ & 37.96 & 52.00 & $36.98 \%$ & 9.74 & 8.84 & $-9.19 \%$ & & & 7.74 & 7.58 & $-2.08 \%$ \\
\hline 1988 & 0.008 & 0.008 & $0.0 \%$ & 52.88 & 52.88 & $0.00 \%$ & 2.35 & 2.35 & $-0.02 \%$ & 48.77 & 60.44 & $23.92 \%$ & 10.26 & 9.68 & $-5.68 \%$ & & & 7.15 & 7.15 & $0.00 \%$ \\
\hline 1980 & 0.008 & 0.008 & $0.0 \%$ & 52.23 & 52.88 & $1.24 \%$ & 2.93 & 2.48 & $-15.61 \%$ & 55.78 & 52.10 & $-6.61 \%$ & 7.99 & 7.48 & $-6.37 \%$ & & & 7.15 & 7.65 & $7.02 \%$ \\
\hline 1990 & 0.008 & 0.018 & $130.9 \%$ & 47.33 & 48.10 & $1.61 \%$ & 2.56 & 2.48 & $-3.08 \%$ & 49.86 & 52.91 & $6.12 \%$ & 7.44 & 7.27 & $-2.40 \%$ & & & 7.15 & 7.37 & $3.00 \%$ \\
\hline 1991 & 0.188 & 0.617 & $227.6 \%$ & 5.24 & 4.81 & $-8.25 \%$ & 2.53 & 2.41 & $-4.77 \%$ & 60.44 & 59.60 & $-1.38 \%$ & 6.84 & 6.92 & $1.11 \%$ & & & 7.15 & 7.15 & $0.00 \%$ \\
\hline 1992 & 0.008 & 0.008 & $0.0 \%$ & 52.88 & 52.88 & $0.00 \%$ & 2.59 & 2.46 & $-5.11 \%$ & 36.70 & 60.37 & $64.49 \%$ & 8.16 & 7.62 & $-6.52 \%$ & & & 7.52 & 7.16 & $-4.76 \%$ \\
\hline 1993 & 0.008 & 0.008 & $0.0 \%$ & 50.31 & 50.31 & $0.00 \%$ & 2.73 & 2.64 & $-3.23 \%$ & 37.21 & 54.45 & $46.34 \%$ & 11.56 & 10.77 & $-6.78 \%$ & & & 7.15 & 7.27 & $1.70 \%$ \\
\hline 1994 & 0.008 & 0.008 & $0.0 \%$ & 51.22 & 51.22 & $0.00 \%$ & 2.44 & 2.42 & $-0.81 \%$ & 42.53 & 37.85 & $-11.02 \%$ & 10.64 & 9.51 & $-10.60 \%$ & & & 7.15 & 8.22 & $15.02 \%$ \\
\hline 1995 & 0.008 & 0.008 & $0.0 \%$ & 52.88 & 52.88 & $0.00 \%$ & 2.46 & 2.45 & $-0.46 \%$ & 60.44 & 60.30 & $-0.22 \%$ & 7.72 & 7.72 & $0.00 \%$ & & & 7.15 & 7.15 & $0.00 \%$ \\
\hline 1996 & 0.102 & 0.122 & $19.6 \%$ & 15.47 & 5.25 & $-66.07 \%$ & 2.56 & 2.52 & $-1.64 \%$ & 59.85 & 58.59 & $-2.11 \%$ & 7.04 & 7.21 & $2.52 \%$ & & & 7.15 & 7.15 & $0.00 \%$ \\
\hline 1997 & 0.186 & 0.288 & $54.6 \%$ & 29.70 & 20.75 & $-30.15 \%$ & 2.33 & 2.42 & $4.05 \%$ & 46.59 & 47.34 & $1.62 \%$ & 7.35 & 7.57 & $3.07 \%$ & & & 7.36 & 7.38 & $0.24 \%$ \\
\hline 1998 & 0.008 & 0.019 & $135.6 \%$ & 52.88 & 44.31 & $-16.21 \%$ & 2.35 & 2.36 & $0.21 \%$ & 53.20 & 58.59 & $10.12 \%$ & 7.79 & 7.35 & $-5.72 \%$ & & & 7.42 & 7.15 & $-3.74 \%$ \\
\hline 1999 & 0.008 & 0.016 & $86.4 \%$ & 52.88 & 47.82 & $-9.57 \%$ & 2.27 & 2.21 & $-2.73 \%$ & 43.73 & 45.99 & $5.18 \%$ & 6.88 & 6.57 & $-4.46 \%$ & & & 8.01 & 7.73 & $-3.46 \%$ \\
\hline 2000 & 0.104 & 0.213 & $104.5 \%$ & 43.02 & 36.62 & $-14.87 \%$ & 2.65 & 2.57 & $-2.94 \%$ & 46.02 & 48.28 & $4.92 \%$ & 8.58 & 8.13 & $-5.33 \%$ & & & 8.15 & 7.43 & $-8.91 \%$ \\
\hline 2001 & 0.008 & 0.008 & $0.0 \%$ & 52.88 & 52.88 & $0.00 \%$ & 2.67 & 2.46 & $-7.98 \%$ & 33.76 & 40.01 & $18.50 \%$ & 12.00 & 10.34 & $-13.91 \%$ & & & 7.44 & 8.43 & $13.26 \%$ \\
\hline 2002 & 0.008 & 0.008 & $0.0 \%$ & & 54.07 & $-0.04 \%$ & 2.73 & 2.68 & $-1.65 \%$ & 46.57 & 40.22 & $-13.64 \%$ & & & $-1.09 \%$ & & & 7.15 & & $0.32 \%$ \\
\hline 2003 & 0.008 & 0.008 & $0.0 \%$ & 48.68 & 48.68 & $0.00 \%$ & 2.53 & 2.46 & $\begin{array}{r}-2.99 \% \\
\end{array}$ & 55.23 & 60.28 & $9.15 \%$ & $\begin{array}{l}0.00 \\
10.25\end{array}$ & 9.35 & $-8.78 \%$ & & & 7.15 & 7.15 & $0.00 \%$ \\
\hline \multirow{24}{*}{$\begin{array}{l}\text { Y } \\
19 \\
19 \\
19 \\
19 \\
19\end{array}$} & \multicolumn{3}{|c|}{ Redd Scour } & \multicolumn{3}{|c|}{ Spawning/incubation } & \multicolumn{3}{|c|}{ Fry } & \multicolumn{3}{|c|}{ Subyearling (Spring-summer) } & \multicolumn{3}{|c|}{ Subyearling (winter) } & \multicolumn{2}{|r|}{ Subadult } & & Adult holdin & \\
\hline & Base & Alternative & Pct Chg & Base & Alternative & Pct Chg & Base & Alternative & Pct Chg & Base & Alternative & Pct Chg & Base & Alternative & Pct Chg & Base & Alternative Pct Chg & Base & Alternative & Pct Chg \\
\hline & 0.008 & 0.013 & $66.2 \%$ & 41.68 & 41.13 & $-1.33 \%$ & 2.22 & 2.14 & $-3.48 \%$ & 18.32 & 17.81 & $-2.78 \%$ & 4.57 & 4.39 & $-4.03 \%$ & & & & & \\
\hline & 0.018 & 0 & $508 \%$ & 40.40 & & $\%$ & 229 & 231 & $0.61 \%$ & 2528 & & $-6.4>2>$ & 4.60 & 479 & & & & & & \\
\hline & 0.010 & 0.039 & $303.9 \%$ & 40.59 & 37.23 & $-8.27 \%$ & 2.32 & 2.27 & $-2.44 \%$ & 15.60 & 16.55 & $6.08 \%$ & 4. & & & & & & & \\
\hline & 0.008 & 0.008 & $0.0 \%$ & 44.77 & 44.77 & $0.00 \%$ & 2.73 & 2.27 & $-16.86 \%$ & 10.48 & 16.56 & $58.04 \%$ & 7.50 & 7.2 & 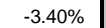 & & & & & \\
\hline & 0.008 & 0.008 & $0.0 \%$ & 43.58 & 43.98 & $0.90 \%$ & 3.01 & 2.43 & $-19.20 \%$ & 11.77 & 18.0 & $53.34 \%$ & 5.51 & 5.2 & -5.06 & & & & & \\
\hline & 0.008 & 0.008 & $0.0 \%$ & 42.52 & 42.52 & $0.00 \%$ & 2.67 & 2.37 & $-11.13 \%$ & 11.71 & 15.13 & $29.20 \%$ & 5.90 & 5.91 & $0.00 \%$ & & & & & \\
\hline & 0.008 & 0.008 & $0.0 \%$ & 44.77 & 44.77 & $0.00 \%$ & 2.49 & 2.31 & $-7.33 \%$ & 14.49 & 24.16 & $66.78 \%$ & 6.27 & 6. & $0.00 \%$ & & & & & \\
\hline & 0.008 & 0.008 & $0.0 \%$ & 43.78 & 44.77 & $2.27 \%$ & 2.60 & 2.43 & $-6.57 \%$ & 17.80 & 15.19 & $-14.66 \%$ & 4.86 & 4. & $-0.04 \%$ & & & & & \\
\hline & 0.008 & 0.018 & $138.7 \%$ & 41.63 & 41.00 & $-1.52 \%$ & 2.69 & 2.44 & $-9.39 \%$ & 16. & 17.81 & $9.84 \%$ & 4.64 & 4.7 & $1.52 \%$ & & & & & \\
\hline & 0.069 & 0.083 & $21.0 \%$ & 3.43 & 3.15 & $-8.24 \%$ & 2.97 & 2.49 & $-16.27 \%$ & 25. & 21.72 & $-14.49 \%$ & 4.32 & 4.3 & $1.30 \%$ & & & & & \\
\hline & 0.008 & 0.008 & $0.0 \%$ & 43.46 & 44.65 & $2.72 \%$ & 3.04 & 2.47 & $-18.74 \%$ & 11.57 & 22.22 & $92.05 \%$ & 4.93 & 4.8 & $-0.99 \%$ & & & & & \\
\hline & 0.008 & 0.008 & $0.0 \%$ & 43.73 & 43.73 & $0.00 \%$ & 3.08 & 2.69 & $-12.75 \%$ & 10.92 & 16.84 & $54.22 \%$ & 7.20 & 7.0 & $-1.89 \%$ & & & & & \\
\hline & 0.008 & 0.008 & $0.0 \%$ & 43.95 & 43.95 & $0.00 \%$ & 2.59 & 2.37 & $-8.45 \%$ & 15.06 & 10.60 & $-29.60 \%$ & 6.52 & 6.56 & $0.55 \%$ & & & & & \\
\hline & 0.008 & 0.008 & $0.3 \%$ & 44.56 & 44.56 & $0.00 \%$ & 3.15 & 3.02 & $-3.93 \%$ & 25.42 & 23.89 & $-6.03 \%$ & 4.72 & 4.72 & $0.00 \%$ & & & & & \\
\hline & 0.102 & 0.122 & $19.6 \%$ & 10.47 & 3.43 & $-67.22 \%$ & 2.50 & 2.39 & $-4.51 \%$ & 23.25 & 21.64 & $-6.91 \%$ & 4.52 & 4.60 & $1.59 \%$ & & & & & \\
\hline & 0.186 & 0.288 & $54.6 \%$ & 24.50 & 16.85 & $-31.20 \%$ & 2.24 & 2.27 & $1.03 \%$ & 16.28 & 16.32 & $0.23 \%$ & 4.89 & 5.05 & $3.13 \%$ & & & & & \\
\hline & 0.008 & 0.019 & $138.2 \%$ & 43.75 & 40.23 & $-8.03 \%$ & 2.27 & 2.26 & $-0.46 \%$ & 14.85 & 22.60 & $52.19 \%$ & 4.95 & 4.64 & $-6.10 \%$ & & & & & \\
\hline & 0.008 & 0.016 & $86.4 \%$ & 42.96 & 40.94 & $-4.69 \%$ & 2.17 & 2.26 & $4.54 \%$ & 13.73 & 14.83 & $7.97 \%$ & 4.62 & 4.40 & $-4.76 \%$ & & & & & \\
\hline & 0.104 & 0.213 & $104.5 \%$ & 37.56 & 31.51 & $-16.11 \%$ & 2.69 & 2.47 & $-7.91 \%$ & 12.73 & 15.40 & $20.94 \%$ & 5.43 & 5.61 & $3.39 \%$ & & & & & \\
\hline & 0.008 & 0.008 & $0.0 \%$ & 44.77 & 44.77 & $0.00 \%$ & 2.68 & 2.41 & $-10.22 \%$ & 10.64 & 11.66 & $9.61 \%$ & 7.73 & 7.39 & $-4.40 \%$ & & & & & \\
\hline & 0.008 & 0.008 & $0.0 \%$ & 45.06 & 45.06 & $-0.01 \%$ & 2.84 & 2.56 & $-9.93 \%$ & 13.91 & 13.14 & $-5.54 \%$ & 5.49 & 5.47 & $-0.36 \%$ & & & & & \\
\hline & 0.008 & 0.008 & $0.0 \%$ & 42.44 & 42.44 & $0.00 \%$ & 2.96 & 2.55 & $-13.86 \%$ & 17.74 & 23.78 & $34.00 \%$ & 6.23 & 6.23 & $0.00 \%$ & & & & & \\
\hline
\end{tabular}

Figure 5-8. Annual habitat summaries for spring chinook and coho in the Easton reach for the Wymer_1 scenario. 


\begin{tabular}{|c|c|c|c|c|c|c|c|c|c|c|c|c|c|c|c|c|c|c|c|c|c|}
\hline \multirow{2}{*}{ Steelhead } & \multicolumn{3}{|c|}{ Redd Scour } & \multicolumn{3}{|c|}{ Spawning/incubation } & \multicolumn{3}{|c|}{ Fry } & \multicolumn{3}{|c|}{ Subyearling (Spring-summer) } & \multicolumn{3}{|c|}{ Subyearling (winter) } & \multicolumn{3}{|c|}{ Subadult } & \multicolumn{3}{|c|}{ Adult holding } \\
\hline & Base & Alternative & Pct Chg & Base & Alternative & Pct Chg & Base & Alternative & Pct Chg & Base & Alternative & Pct Chg & Base & Alternative & Pct Chg & Base & Alternative & Pct Cha & Base & Alternative & Pct Chg \\
\hline 198 & 0.010 & 0.014 & $39.7 \%$ & 51.66 & 51.66 & $0.00 \%$ & 4.34 & 4.58 & $5.33 \%$ & 64.03 & 6403 & $0.00 \%$ & 6.53 & 6.75 & $3.38 \%$ & 53.67 & 54.58 & $1.69 \%$ & 22.83 & 2283 & $0.00 \%$ \\
\hline $198>>2>>2>$ & 0.008 & 0.011 & $40.0 \%$ & 52.27 & 53.69 & $272 \%$ & 5.29 & 529 & $0.00 \%$ & 64.03 & 64.03 & $0.00 \%$ & 6.46 & 6.47 & $0.24 \%$ & 6249 & 62.49 & $0.00 \%$ & 2178 & 2181 & $0.13 \%$ \\
\hline 198 & 0.008 & 0.008 & $0.3 \%$ & 53.43 & 53.91 & $0.90 \%$ & 4.42 & 4.40 & $-0.48 \%$ & 64.03 & 6403 & $0.00 \%$ & 603 & 613 & $160 \%$ & 5573 & 56,31 & $104 \%$ & 2181 & 22.25 & $199 \%$ \\
\hline 198 & 0.008 & 0.030 & $275.2 \%$ & 53.91 & 53.91 & $0.00 \%$ & 3.34 & 3.42 & $237 \%$ & 52.27 & 6403 & $22.49 \%$ & 10.78 & 1078 & $0.00 \%$ & 58.31 & 5970 & $239 \%$ & 2386 & 24.05 & $0.03 \%$ \\
\hline $198>>2>>2>$ & 0.008 & 0.008 & $0.3 \%$ & 53.91 & 53.91 & $0.00 \%$ & 3.37 & 3.33 & $-1.12 \%$ & 58.91 & 5111 & $-13.25 \%$ & 787 & 787 & $0.00 \%$ & 5736 & 60.95 & $626 \%$ & 23.22 & 23.01 & $\begin{array}{l}-0.07 \% \\
-0.90 \%\end{array}$ \\
\hline $198>>2>>C$ & 0.008 & 0.008 & $0.3 \%$ & 51.52 & 51.52 & $0.00 \%$ & 3.87 & 4.06 & $4.92 \%$ & 45.85 & 41.56 & $-937 \%$ & 850 & 8.50 & $-0.07 \%$ & 53.09 & 51.10 & $-375 \%$ & 2290 & 2257 & $-1.42 \%$ \\
\hline 198 & 0.008 & 0.008 & $0.3 \%$ & 53.91 & 53.91 & $0.00 \%$ & 3.85 & 3.93 & $2.25 \%$ & 53.19 & 53.33 & $0.25 \%$ & 9.00 & 9.00 & $0.00 \%$ & 61.89 & 60.78 & $-1.80 \%$ & 23.96 & 23.91 & $-0.25 \%$ \\
\hline 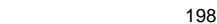 & 0.008 & 0.008 & $0.3 \%$ & 53.70 & 53.70 & $0.00 \%$ & 4.26 & 4.84 & $1364 \%$ & 63.87 & 63.36 & $-081 \%$ & 700 & 700 & $0.00 \%$ & 6251 & 6251 & $0.00 \%$ & 25.25 & 25.25 & $0.00 \%$ \\
\hline 199 & 0.066 & 0.093 & $41.9 \%$ & 51.45 & 51.45 & $0.00 \%$ & 4.14 & 4.90 & $18.23 \%$ & 64.03 & 64.03 & $0.00 \%$ & 6.57 & 6.57 & $0.00 \%$ & 57.87 & 58.97 & $1.90 \%$ & 23.25 & 22.97 & $-1.21 \%$ \\
\hline 199 & 0.105 & 0.149 & $41.9 \%$ & 50.35 & 50.47 & $0.24 \%$ & 5.29 & 5.29 & $0.00 \%$ & 64.03 & 64.03 & $0.00 \%$ & 5.94 & 5.95 & $0.05 \%$ & 62.51 & 62.51 & $0.00 \%$ & 17.12 & 17.29 & $0.96 \%$ \\
\hline 199 & 0.008 & 0.008 & $0.3 \%$ & 53.91 & 53.91 & $0.00 \%$ & 3.63 & 3.93 & $8.24 \%$ & 45.69 & 43.08 & $-5.71 \%$ & 7.14 & 7.33 & $258 \%$ & 51.33 & 50.70 & $-1.22 \%$ & 22.87 & 23.37 & $219 \%$ \\
\hline 199 & 0.008 & 0.008 & $0.3 \%$ & 51.59 & 51.59 & $0.00 \%$ & 3.43 & 3.4 & $-0.40 \%$ & 40.50 & 51.50 & $27.18 \%$ & 10.42 & 10.42 & $-0.01 \%$ & 56.68 & 56.97 & $0.52 \%$ & 23.09 & 23.92 & $3.57 \%$ \\
\hline 199 & 0.008 & 0.008 & $0.3 \%$ & 52.44 & 52.44 & $0.00 \%$ & 4.05 & 3.98 & $-1.83 \%$ & 43.02 & 46.95 & $9.15 \%$ & 9.42 & 9.39 & $-0.36 \%$ & 55.35 & 54.26 & $-1.97 \%$ & 23.20 & 23.39 & $0.82 \%$ \\
\hline 199 & 0.008 & 0.008 & $0.3 \%$ & 53.91 & 52.78 & $-2.10 \%$ & 5.29 & 5.29 & $0.00 \%$ & 64.03 & 64.03 & $0.00 \%$ & 6.80 & 6.8 & $0.00 \%$ & 62.51 & 62.51 & $0.00 \%$ & 23.49 & 23.46 & $-0.12 \%$ \\
\hline 199 & 0.035 & 0.055 & $55.5 \%$ & 52.16 & 51.88 & $-0.54 \%$ & 4.67 & 5.21 & $11.56 \%$ & 64.03 & 64.03 & 0.00 & 6.12 & 6.1 & $0.36 \%$ & 62.37 & 62.37 & $0.00 \%$ & 15.53 & 15.57 & $0.21 \%$ \\
\hline 199 & 0.110 & 0.167 & $51.8 \%$ & 53.91 & 53.74 & $-0.31 \%$ & 4.17 & 4.23 & $1.35 \%$ & 64.03 & 64.03 & $0.00 \%$ & 6.90 & 719 & $4.20 \%$ & 50.88 & 52.22 & $265 \%$ & 21.41 & 21.71 & $1.40 \%$ \\
\hline 199 & 0.017 & 0.024 & $36.8 \%$ & 53.91 & 53.91 & $0.00 \%$ & 3.68 & 5.29 & $43.78 \%$ & 62.18 & 64.03 & $2.98 \%$ & 7.05 & 7.80 & $10.59 \%$ & 59.73 & 59.73 & $0.00 \%$ & 23.93 & 23.00 & $-3.90 \%$ \\
\hline 199 & 0.088 & 0.114 & $30.0 \%$ & 53.91 & 53.57 & $-0.62 \%$ & 3.84 & 4.14 & $7.80 \%$ & 64.03 & 64.03 & $0.00 \%$ & 6.51 & 6.18 & $-5.02 \%$ & 50.89 & 51.98 & $2.15 \%$ & 22.56 & 21.71 & $-3.76 \%$ \\
\hline 200 & 0.076 & 0.103 & $34.3 \%$ & 53.91 & 53.91 & $0.00 \%$ & 3.58 & 4.07 & $13.67 \%$ & 64.03 & 64.03 & $0.00 \%$ & 7.72 & 7.50 & $-2.87 \%$ & 56.44 & 56.64 & $0.34 \%$ & 22.85 & 22.51 & $-1.48 \%$ \\
\hline 200 & 0.008 & 0.008 & $0.3 \%$ & 53.91 & 53.91 & $0.00 \%$ & 3.65 & 3.74 & $2.45 \%$ & 39.52 & 41.08 & $3.93 \%$ & 11.09 & 11.12 & $0.28 \%$ & 49.25 & 49.12 & $-0.28 \%$ & 22.86 & 23.17 & $1.36 \%$ \\
\hline 200 & 0.008 & 0.008 & $0.3 \%$ & 55.04 & 55.04 & $0.00 \%$ & 3.79 & 4.40 & $15.87 \%$ & 64.03 & 64.03 & $0.00 \%$ & 8.05 & 8.05 & $0.00 \%$ & 56.50 & 58.23 & $3.06 \%$ & 25.64 & 25.28 & $-1.40 \%$ \\
\hline 200 & 0.008 & 0.008 & $0.3 \%$ & 51.22 & 51.22 & $0.00 \%$ & 4.20 & 4.20 & $0.06 \%$ & 64.62 & 64.69 & $0.10 \%$ & 8.98 & 8.98 & $0.00 \%$ & 62.51 & 62.51 & $0.00 \%$ & 23.41 & 23.41 & $0.00 \%$ \\
\hline \multirow{2}{*}{ Resident Rainbow } & \multicolumn{3}{|c|}{ Redd Scour } & \multicolumn{3}{|c|}{ Spawning/incubation } & \multirow{2}{*}{\multicolumn{3}{|c|}{$\begin{array}{c}\text { Fry } \\
\text { Alternative }\end{array}$}} & \multirow{2}{*}{\multicolumn{3}{|c|}{ Subyearling (Spring-summer) }} & \multicolumn{3}{|c|}{ Subyearling (winter) } & & Subadult & & & Adult h & \\
\hline & Base & Alternative & Pct Chg & Base & Alternative & Pct Chg & & & & & & & Base & Alternative & Pct Chg & Base & Alternative & Pct Chg & Base & Alternative & Pct Chg \\
\hline 198 & 0.010 & 0.014 & $39.7 \%$ & 50.57 & 50.57 & $0.00 \%$ & 5.42 & 5.70 & $4.99 \%$ & 63.34 & 63.34 & $0.00 \%$ & 7.68 & 7.91 & $3.01 \%$ & 25.28 & 26.23 & $3.74 \%$ & & & \\
\hline 198 & 0.008 & 0.008 & $0.3 \%$ & 44.25 & 44.48 & $0.52 \%$ & 6.51 & 6.51 & $0.00 \%$ & 63.34 & 63.34 & 0.0 & 7.76 & 7.79 & $0.38 \%$ & 39.60 & 39.60 & & & & \\
\hline 198 & 0.008 & 0.008 & $0.3 \%$ & 44.44 & 44.62 & & 5.49 & 5.48 & $-0.18 \%$ & 63.34 & 63.34 & 0.00 & 7.29 & 7. & $1.28 \%$ & 28.36 & & $0.99 \%$ & & & \\
\hline 198 & 0.008 & 0.030 & $275.2 \%$ & 60.22 & & & 4.27 & 4.41 & $3.31 \%$ & 51.41 & 63.34 & $23.21 \%$ & 12.34 & 12.34 & $0.00 \%$ & 24.23 & 27.90 & $15.18 \%$ & & & \\
\hline 198 & 0.008 & 0.008 & $0.3 \%$ & 56.50 & 56.50 & $0.00 \%$ & 4.27 & 4.28 & $0.32 \%$ & 58.04 & 50.22 & $-13.46 \%$ & 9.14 & 9.14 & $0.00 \%$ & 29.77 & 27.70 & $-6.96 \%$ & & & \\
\hline & 0.008 & 0.008 & $0.3 \%$ & 54.60 & & & 4.91 & 5.01 & $1.89 \%$ & 45. & 40.79 & $-9.38 \%$ & 9. & 9. & $-0.07 \%$ & 27.66 & & $1.93 \%$ & & & \\
\hline & 0.008 & 0.008 & $0.3 \%$ & 60.22 & & & 4.92 & 4.99 & $1.60 \%$ & 52 & 52.47 & 0.2 & 10.38 & 10.38 & $0.00 \%$ & 35.14 & & $-0.24 \%$ & & & \\
\hline 19 & 0.008 & 0.008 & $0.3 \%$ & 58.38 & 58 & $0.00 \%$ & 5.40 & 6.04 & $11.91 \%$ & 63.06 & 62.53 & $-0.83 \%$ & 8.17 & 8.17 & $0.00 \%$ & 37.23 & 39.74 & $6.74 \%$ & & & \\
\hline & 0.010 & 0.013 & $39.2 \%$ & 50.47 & & & 5.23 & 6.07 & $15.99 \%$ & 63.34 & 63 & 0.0 & 7.8 & 7.8 & $-0.01 \%$ & 31.45 & 33.64 & $6.97 \%$ & & & \\
\hline & 0.008 & 0.008 & $0.3 \%$ & 1.66 & & & 6.51 & 6.51 & & 63.34 & 63.34 & 0.0 & 7. & 7. & $0.04 \%$ & 40.26 & & $0.00 \%$ & & & \\
\hline & 0.008 & 0.008 & $0.3 \%$ & 56.29 & & & 4.68 & 4. & & 44 & 42.32 & $-5.69 \%$ & 8.28 & 8. & 1.9 & & & $8.68 \%$ & & & \\
\hline & 0.008 & $0 . c^{-}$ & $0.3 \%$ & 58.75 & & & 4.35 & 4. & $-0.91 \%$ & 39 & 50.63 & $27.35 \%$ & 11.90 & 11.90 & $-0.01 \%$ & 29.07 & 29.79 & $2.45 \%$ & & & \\
\hline & 0.008 & & & 59.13 & & & 4.98 & 4. & & 42.30 & 46.23 & 9.2 & 10.80 & 10.76 & $-0.36 \%$ & 31.49 & 30.56 & $-2.97 \%$ & & & \\
\hline & 0.008 & & & 58.25 & 58.25 & & 6.51 & 6. & & & 63 & & 7.9 & 7.9 & 0.0 & 40.28 & & & & & \\
\hline & 0.008 & $0 . c^{-}$ & 0.3 & 4.95 & 4. & $0.00 \%$ & 5.86 & 6.4 & & & 63 & 0.0 & 7. & 7.7 & 0.5 & & & $1.51 \%$ & & & \\
\hline & 0.110 & 0.1 & & 14.13 & 8. & -42 & 5.20 & 5.2 & 1.7 & 63 & 63 & 0.0 & 8.2 & 8.5 & 3.5 & 21.98 & 23.28 & $5.89 \%$ & & & \\
\hline & 0.009 & 0.6 & & 56.79 & 53.69 & -5.4 & 4.78 & 6.5 & 36 & 61 & 63 & 3.1 & 8.3 & 9.23 & $10.94 \%$ & 31.16 & 36.89 & $18.40 \%$ & & & \\
\hline 19 & 0.088 & 0.1 & $30.0 \%$ & 53.02 & 44.46 & -16 & 4.85 & 5.2 & 7.5 & & 63 & 0.0 & 7.8 & 7. & -3.1 & 20.48 & & $4.25 \%$ & & & \\
\hline & 0.018 & 0.0 & 36. & 33.52 & 33. & & 4.62 & 5.17 & $11.73 \%$ & 63 & 63. & 0.0 & 9. & 8. & $-2.51 \%$ & 25.21 & 26.99 & $7.06 \%$ & & & \\
\hline $20 \quad-$ & 0.008 & 0.008 & $0.3 \%$ & 60.22 & 60 & 0.0 & 4.51 & 4.61 & 2.3 & 38.82 & 40.33 & $3.87 \%$ & 12.69 & 12.72 & $0.27 \%$ & 24.32 & 23.91 & $-1.69 \%$ & & & \\
\hline 200 & 0.008 & 0.008 & $0.3 \%$ & 60.73 & 60.7 & $0.00 \%$ & 4.82 & 5.52 & $14.40 \%$ & 63. & 63. & 0.0 & 9.24 & 9.2 & 0.0 & 28.80 & 31.24 & $8.48 \%$ & & & \\
\hline 200 & 0.008 & 0.008 & $0.3 \%$ & 54.47 & 54.47 & $0.00 \%$ & 5.32 & 5.32 & $0.08 \%$ & 63.82 & 63.87 & $0.08 \%$ & 10.35 & 10.35 & $0.00 \%$ & 36.69 & 36.56 & $-0.34 \%$ & & & \\
\hline
\end{tabular}

Figure 5-9. Annual habitat summaries for steelhead and resident rainbow trout in the Easton reach for the Wymer_1 scenario. 
Bull Trout

\begin{tabular}{|c|c|c|c|c|c|c|c|c|c|c|c|c|c|c|c|c|c|c|}
\hline \multirow[b]{2}{*}{ Year } & \multicolumn{3}{|c|}{ Redd Scour } & \multicolumn{3}{|c|}{ Spawning/incubation } & \multicolumn{3}{|c|}{ Fry } & \multicolumn{3}{|c|}{ Subyearling (Spring-summer) } & \multicolumn{3}{|c|}{ Subyearling (winter) } & \multicolumn{2}{|r|}{ Subadult } & \multirow{2}{*}{\begin{tabular}{cc}
\multicolumn{2}{c}{ Adult holding } \\
Base & Alternative Pct Chg
\end{tabular}} \\
\hline & Base & Alternative & Pct Chg & Base & Alternative & Pct Chg & Base & Alternative & Pct Chg & Base & Alternative & Pct Chg & Base & Alternative & Pct Chg & Base & Alternative Pct Chg & \\
\hline 1982 & 0.008 & 0.008 & $0.3 \%$ & 41.33 & 41.33 & $0.00 \%$ & 4.20 & 4.33 & $3.25 \%$ & 64.55 & 65.93 & \begin{tabular}{ll|}
$2.14 \%$ \\
\end{tabular} & 6.97 & 7.13 & $2.19 \%$ & & & \\
\hline 1983 & 0.018 & 0.021 & $19.2 \%$ & 40.28 & 39.89 & $-0.96 \%$ & 4.32 & 4.35 & $0.48 \%$ & 72.74 & 72.74 & $0.00 \%$ & 7.57 & 7.56 & $-0.21 \%$ & & & \\
\hline 1984 & 0.010 & 0.019 & $98.5 \%$ & 39.96 & 39.65 & $-0.79 \%$ & 4.37 & 4.38 & $0.20 \%$ & 58.87 & 59.31 & $0.76 \%$ & 7.07 & 7.12 & $0.66 \%$ & & & \\
\hline 1985 & 0.008 & 0.008 & $0.3 \%$ & 40.06 & 40.06 & $0.00 \%$ & 4.95 & 4.90 & $-0.84 \%$ & 54.88 & 62.03 & $13.02 \%$ & 11.41 & 11.37 & $-0.35 \%$ & & & \\
\hline 1986 & 0.008 & 0.008 & $0.3 \%$ & 40.80 & 40.80 & $0.00 \%$ & 5.39 & 5.11 & $-5.06 \%$ & 58.44 & 58.12 & $-0.56 \%$ & 8.88 & 8.64 & $-2.73 \%$ & & & \\
\hline 1987 & 0.008 & 0.008 & $0.3 \%$ & 41.33 & 41.33 & $0.00 \%$ & 4.90 & 4.88 & $-0.32 \%$ & 52.69 & 48.99 & $-7.02 \%$ & 9.40 & 9.38 & $-0.22 \%$ & & & \\
\hline 1988 & 0.008 & 0.008 & $0.3 \%$ & 40.75 & 40.75 & $0.00 \%$ & 4.59 & 4.59 & $0.00 \%$ & 64.07 & 63.58 & $-0.75 \%$ & 9.92 & 9.92 & $0.00 \%$ & & & \\
\hline 1989 & 0.008 & 0.008 & $0.3 \%$ & 41.33 & 41.33 & $0.00 \%$ & 4.78 & 4.78 & $0.00 \%$ & 70.08 & 71.79 & $2.43 \%$ & 7.78 & 7.78 & $0.00 \%$ & & & \\
\hline 1990 & 0.008 & 0.008 & $0.3 \%$ & 41.33 & 41.33 & $0.00 \%$ & 4.95 & 4.95 & $-0.01 \%$ & 63.39 & 65.59 & $3.48 \%$ & 7.42 & 7.42 & $0.00 \%$ & & & \\
\hline 1991 & 0.188 & 0.359 & $90.8 \%$ & 3.50 & 3.46 & $-0.93 \%$ & 5.36 & 5.36 & $0.00 \%$ & 72.74 & 72.74 & $0.00 \%$ & 7.17 & 7.17 & $0.06 \%$ & & & \\
\hline 1992 & 0.008 & 0.008 & $0.3 \%$ & 40.97 & 40.44 & $-1.30 \%$ & 5.45 & 5.32 & $-2.36 \%$ & 51.24 & 49.69 & $-3.01 \%$ & 7.89 & 7.89 & $-0.02 \%$ & & & \\
\hline 1993 & 0.008 & 0.008 & $0.3 \%$ & 41.33 & 41.33 & $0.00 \%$ & 5.50 & 5.50 & $-0.02 \%$ & 52.02 & 56.11 & $7.88 \%$ & 11.02 & 11.02 & $-0.01 \%$ & & & \\
\hline 1994 & 0.008 & 0.008 & $0.3 \%$ & 41.33 & 41.33 & $0.00 \%$ & 4.76 & 4.76 & $-0.03 \%$ & 55.79 & 55.59 & $-0.37 \%$ & 10.19 & 10.16 & $-0.31 \%$ & & & \\
\hline 1995 & 0.008 & 0.008 & $4.2 \%$ & 39.43 & 39.43 & $0.00 \%$ & 5.59 & 5.59 & $0.00 \%$ & 72.74 & 72.74 & $0.00 \%$ & 7.50 & 7.50 & $0.00 \%$ & & & \\
\hline 1996 & 0.102 & 0.127 & $24.7 \%$ & 9.04 & 9.04 & $0.00 \%$ & 4.66 & 4.66 & $0.00 \%$ & 72.50 & 72.67 & $0.23 \%$ & 7.57 & 7.61 & $0.46 \%$ & & & \\
\hline 1997 & 0.186 & 0.345 & $85.7 \%$ & 21.29 & 14.79 & $-30.51 \%$ & 4.24 & 4.26 & $0.53 \%$ & 59.74 & 61.56 & $3.05 \%$ & 7.56 & 7.72 & $2.15 \%$ & & & \\
\hline 1998 & 0.008 & 0.025 & $211.2 \%$ & 40.57 & 39.55 & $-2.53 \%$ & 4.28 & 4.27 & $-0.21 \%$ & 68.64 & 72.74 & $5.96 \%$ & 7.81 & 8.58 & $9.76 \%$ & & & \\
\hline 1999 & 0.008 & 0.012 & $38.3 \%$ & 39.97 & 39.92 & $-0.11 \%$ & 4.10 & 4.31 & $5.02 \%$ & 57.56 & 60.22 & $4.62 \%$ & 7.12 & 7.05 & $-1.07 \%$ & & & \\
\hline 2000 & 0.104 & 0.147 & $40.9 \%$ & 34.71 & 34.71 & $0.00 \%$ & 4.97 & 4.97 & $0.00 \%$ & 60.98 & 62.60 & $2.66 \%$ & 8.73 & 8.57 & $-1.78 \%$ & & & \\
\hline 2001 & 0.008 & 0.008 & $0.3 \%$ & 39.25 & 39.25 & $0.00 \%$ & 4.93 & 5.09 & $3.19 \%$ & 47.75 & 47.56 & $-0.39 \%$ & 11.50 & 11.64 & $1.27 \%$ & & & \\
\hline 2002 & 0.008 & 0.008 & $0.3 \%$ & 40.13 & 40.13 & $0.00 \%$ & 5.16 & 5.16 & $0.00 \%$ & 59.94 & 62.90 & $4.93 \%$ & 8.46 & 8.46 & $0.00 \%$ & & & \\
\hline 200 & 0.008 & 0.008 & $0.3 \%$ & 41.33 & 41.33 & $0.00 \%$ & 5.32 & 5.32 & $0.00 \%$ & 69.52 & 69.52 & $0.01 \%$ & 9.87 & 9.87 & $0.00 \%$ & & & \\
\hline
\end{tabular}

Figure 5-10. Annual habitat summaries for bull trout in the Easton reach for the Wymer_1 scenario. 


\begin{tabular}{|c|c|c|c|c|c|c|c|c|c|c|c|c|c|c|c|c|c|c|c|c|}
\hline Spring Chinook & \multicolumn{3}{|c|}{ Redd Scour } & \multicolumn{3}{|c|}{ Spawning/incubation } & \multicolumn{3}{|c|}{ Fry } & \multicolumn{3}{|c|}{ Subyearling (Spring-summer) } & \multicolumn{3}{|c|}{ Subyearling (winte } & \multicolumn{2}{|r|}{ Subadult } & \multicolumn{3}{|c|}{ Adult holding } \\
\hline Yea & Base & Alternative & Pct Chg & Base & Alternative & Pct Chg & Base & Alternative & Pct Chg & Base & & Pct Chg & Base & Alternative & Pct Chg & Base & Alternative Pct Chg & Base & Alternative & Pct Chg \\
\hline 198 & 0.007 & 0.006 & $-10.9 \%$ & 21.22 & 16.55 & $-22.01 \%$ & 1.84 & 1.86 & $0.68 \%$ & 14.32 & 13.67 & $-4.49 \%$ & 4.30 & 3.71 & $-13.63 \%$ & & & 6.51 & 6.60 & $1.44 \%$ \\
\hline 198 & 0.006 & 0.006 & $-4.6 \%$ & 22.11 & 18.23 & $-17.53 \%$ & 1.90 & 1.90 & $0.31 \%$ & 13.94 & 13.60 & $-2.42 \%$ & 3.81 & 3.61 & $-5.24 \%$ & & & 6.48 & 6.58 & $1.65 \%$ \\
\hline 198 & 0.007 & 0.006 & $-10.7 \%$ & 14.57 & 19.84 & $36.18 \%$ & 1.75 & 1.82 & $4.10 \%$ & 14.47 & 13.72 & $-5.17 \%$ & 3.81 & 3.66 & $-3.89 \%$ & & & 6.53 & 6.67 & $2.06 \%$ \\
\hline 198 & 0.007 & 0.006 & $-11.1 \%$ & 30.09 & 29.71 & $-1.27 \%$ & 1.46 & 1.54 & $5.58 \%$ & 14.06 & 13.78 & $-2.02 \%$ & 3.85 & 3.51 & $-8.68 \%$ & & & 6.46 & 6.58 & $1.86 \%$ \\
\hline 198 & 0.007 & 0.006 & $-10.2 \%$ & 23.70 & 21.39 & $-9.76 \%$ & 1.69 & 1.78 & $5.11 \%$ & 14.20 & 13.72 & $-3.38 \%$ & 4.12 & 3.72 & $-9.53 \%$ & & & 6.59 & 6.70 & $1.80 \%$ \\
\hline 198 & 0.007 & 0.006 & $-9.7 \%$ & 30.50 & 29.85 & $-2.13 \%$ & 1.59 & 1.70 & $7.31 \%$ & 13.74 & 13.37 & $-2.72 \%$ & 4.21 & 3.82 & $-9.26 \%$ & & & 6.79 & 6.98 & $2.82 \%$ \\
\hline 1988 & 0.008 & 0.008 & $7.4 \%$ & 29.18 & 26.50 & $-9.19 \%$ & 1.39 & 1.61 & $15.65 \%$ & 13.72 & 13.33 & $-2.83 \%$ & 3.99 & 4.29 & $7.28 \%$ & & & 6.86 & 6.99 & $1.96 \%$ \\
\hline 198 & 0.007 & 0.007 & $1.1 \%$ & 34.53 & 35.60 & $3.08 \%$ & 1.57 & 1.65 & $5.15 \%$ & 14.03 & 13.59 & $-3.12 \%$ & 3.49 & 3.45 & $-1.04 \%$ & & & 6.49 & 6.70 & $3.10 \%$ \\
\hline 199 & 0.006 & 0.007 & $1.2 \%$ & 29.81 & 34.06 & $14.28 \%$ & 1.78 & 1.82 & $2.10 \%$ & 14.45 & 13.85 & $-4.15 \%$ & 3.65 & 3.58 & $-1.90 \%$ & & & 6.43 & 6.62 & $2.91 \%$ \\
\hline 199 & 0.013 & 0.014 & $8.8 \%$ & 6.95 & 10.36 & $48.93 \%$ & 1.89 & 1.89 & $0.07 \%$ & 13.93 & 13.73 & $-1.41 \%$ & 4.67 & 4.98 & $6.65 \%$ & & & 6.46 & 6.59 & $2.10 \%$ \\
\hline 199 & 0.006 & 0.006 & $-7.2 \%$ & 29.77 & 34.33 & $15.33 \%$ & 1.54 & 1.68 & $9.17 \%$ & 14.08 & 13.63 & $-3.20 \%$ & 3.69 & 3.54 & $-3.95 \%$ & & & 6.51 & 6.61 & $1.64 \%$ \\
\hline 199 & 0.007 & 0.007 & $-1.1 \%$ & 30.74 & 30.39 & $-1.13 \%$ & 1.44 & 1.58 & $9.98 \%$ & 13.75 & 13.38 & $-2.71 \%$ & 4.15 & 3.99 & $-3.95 \%$ & & & 6.84 & 7.16 & $4.77 \%$ \\
\hline 199 & 0.007 & 0.008 & $5.7 \%$ & 28.86 & 26.12 & $-9.50 \%$ & 1.30 & 1.53 & $17.53 \%$ & 13.43 & 15.36 & $14.34 \%$ & 3.87 & 4.09 & $5.77 \%$ & & & 7.48 & 7.93 & $6.08 \%$ \\
\hline 199 & 0.007 & 0.008 & $7.5 \%$ & 13.29 & 8.41 & $-36.69 \%$ & 1.76 & 1.83 & $4.26 \%$ & 13.99 & 13.89 & $-0.71 \%$ & 3.93 & 3.99 & $1.55 \%$ & & & 6.63 & 7.00 & $5.54 \%$ \\
\hline 199 & 0.019 & 0.019 & $-0.4 \%$ & 3.03 & 2.91 & $-3.98 \%$ & 1.94 & 1.93 & $-0.60 \%$ & 13.95 & 13.65 & $-2.20 \%$ & 5.94 & 6.06 & $2.01 \%$ & & & 6.48 & 6.58 & $1.61 \%$ \\
\hline 199 & 0.013 & 0.014 & $8.6 \%$ & 3.72 & 6.96 & $87.03 \%$ & 2.01 & 2.03 & $1.15 \%$ & 14.29 & 13.50 & $-5.53 \%$ & 3.84 & 3.67 & $-4.38 \%$ & & & 6.45 & 6.68 & $3.51 \%$ \\
\hline 199 & 0.006 & 0.006 & $-4.3 \%$ & 29.44 & 30.90 & $4.96 \%$ & 1.77 & 1.80 & $2.06 \%$ & 13.95 & 13.70 & $-1.82 \%$ & 3.49 & 3.63 & $3.82 \%$ & & & 6.45 & 6.60 & $2.38 \%$ \\
\hline 199 & 0.006 & 0.006 & $-10.1 \%$ & 29.16 & 28.00 & $-3.97 \%$ & 1.75 & 1.84 & $5.22 \%$ & 13.87 & 13.76 & $-0.80 \%$ & 3.67 & 3.67 & $-0.11 \%$ & & & 6.57 & 6.66 & $1.47 \%$ \\
\hline 200 & 0.006 & 0.006 & $-9.4 \%$ & 14.31 & 12.42 & $-13.24 \%$ & 1.71 & 1.75 & $2.01 \%$ & 14.09 & 13.80 & $-2.07 \%$ & 3.70 & 3.68 & $-0.61 \%$ & & & 6.44 & 6.55 & $1.68 \%$ \\
\hline 200 & 0.006 & 0.006 & $-10.5 \%$ & 29.83 & 34.69 & $16.31 \%$ & 1.36 & 1.43 & $5.37 \%$ & 13.24 & 13.90 & $4.96 \%$ & 3.90 & 3.65 & $-6.44 \%$ & & & 7.13 & 7.56 & $5.96 \%$ \\
\hline 200 & 0.008 & 0.008 & $5.9 \%$ & 30.42 & 25.16 & $-17.29 \%$ & 1.62 & 1.72 & $6.08 \%$ & 14.30 & 13.96 & $-2.36 \%$ & 3.53 & 3.49 & $-1.01 \%$ & & & 6.52 & 6.53 & $0.13 \%$ \\
\hline 200 & 0.006 & 0.006 & $-6.5 \%$ & 28.63 & 27.64 & $-3.46 \%$ & 1.80 & 1.83 & $1.50 \%$ & 14.28 & 13.83 & $-3.13 \%$ & 3.89 & 3.52 & $-9.66 \%$ & & & 6.58 & 6.67 & $1.43 \%$ \\
\hline \multirow{24}{*}{$\begin{array}{l}Y \\
19 \\
19 \\
19 \\
19 \\
19 \\
19 \\
19 \\
19 \\
19 \\
19 \\
19 \\
19 \\
19 \\
19 \\
19 \\
19 \\
19 \\
19 \\
20 \\
20\end{array}$} & \multicolumn{3}{|c|}{ Redd Scour } & \multicolumn{3}{|c|}{ Spawning/incubation } & \multicolumn{3}{|c|}{ Fry } & \multicolumn{3}{|c|}{\begin{tabular}{|l|} 
Subyearling (Spring-summer) \\
\end{tabular}} & \multicolumn{3}{|c|}{ Subyearling (winter) } & \multicolumn{2}{|r|}{ Subadult } & & Adult holdin & \\
\hline & Base & Alternative & Pct Chg & Base & Alternative & Pct Chg & Base & Alternative & Pct Chg & Base & Alternative & Pct Chg & Base & Alternative & Pct Chg & Base & Alternative Pct Chg & Base & Alternative & Pct Chg \\
\hline & 0.007 & 0.006 & $-10.9 \%$ & 14.93 & 13.03 & $-12.71 \%$ & 1.79 & 1.80 & $0.45 \%$ & 4.70 & 4.33 & $-7.91 \%$ & 2.57 & 2.29 & $-10.81 \%$ & & & & & \\
\hline & 0006 & 0.006 & $-23 \%$ & 1610 & 13.96 & $-1328 \%$ & 185 & 185 & $-0.04 \%$ & 4.46 & 427 & $-4.41 \%$ & 232 & 222 & $-4.19 \%$ & & & & & \\
\hline & 0.007 & 0.006 & $-10.7 \%$ & 13.06 & 14.85 & $13.72 \%$ & 1.79 & 1.84 & $2.78 \%$ & 4.78 & 4.39 & $-8.30 \%$ & 2.42 & 2.36 & $-2.64 \%$ & & & & & \\
\hline & 0.007 & 0.006 & $-11.1 \%$ & 14.28 & 12.51 & $-12.35 \%$ & 1.78 & 1.83 & $2.63 \%$ & 4.63 & 4.4 & $-4.46 \%$ & 2.34 & 2.2 & $-4.94 \%$ & & & & & \\
\hline & 0.007 & 0.006 & $-10.4 \%$ & 15.74 & 15.70 & $-0.26 \%$ & 1.58 & 1.70 & $7.38 \%$ & 4. & 4.3. & $-5.06 \%$ & 2. & 2.32 & $-9.24 \%$ & & & & & \\
\hline & 0.006 & 0.006 & $-9.3 \%$ & 19.33 & 18.82 & $-2.66 \%$ & 1.60 & 1.71 & $6.99 \%$ & 4. & 4. & $-7.04 \%$ & 2. & 2.35 & $-11.81 \%$ & & & & & \\
\hline & 0.007 & 0.007 & $4.1 \%$ & 18.83 & 17.54 & $-6.87 \%$ & 1.59 & 1.79 & $12.54 \%$ & 4. & 4. & $-6.89 \%$ & 2. & 2.6 & $3.58 \%$ & & & & & \\
\hline & 0.006 & 0.006 & $-2.5 \%$ & 19.96 & 19.55 & $-2.04 \%$ & 1.78 & 1.80 & $1.18 \%$ & 4. & 4.2 & $-7.73 \%$ & 2. & 2. & & & & & & \\
\hline & 0.006 & 0.006 & $-5.4 \%$ & 18.79 & 17.58 & $-6.46 \%$ & 1.87 & 1.85 & $-0.85 \%$ & 5. & 4.43 & $-12.86 \%$ & 2. & 2. & -2 & & & & & \\
\hline & 0.005 & 0.005 & $-3.4 \%$ & 5.88 & 8.12 & $38.11 \%$ & 1.86 & 1.86 & $0.11 \%$ & 4 & 4.44 & $-4.16 \%$ & 3. & 3.7 & $8.41 \%$ & & & & & \\
\hline & 0.006 & 0.006 & $-7.2 \%$ & 18.76 & 17.59 & $-6.22 \%$ & 1.47 & 1.62 & $10.15 \%$ & 4 & 4.4 & $-7.74 \%$ & 2.43 & 2.2 & $-7.37 \%$ & & & & & \\
\hline & 0.007 & 0.007 & $-1.1 \%$ & 19.98 & 19.28 & $-3.51 \%$ & 1.52 & 1.75 & $15.18 \%$ & 4.43 & 4.1 & $-7.40 \%$ & 2.64 & 2.4 & $-8.06 \%$ & & & & & \\
\hline & 0.007 & $0 . c$ & $3.8 \%$ & 18.75 & 16.21 & $-13.54 \%$ & 1.40 & 1.67 & $19.70 \%$ & 4 & 4. & 9.7 & 2.56 & 2.5 & $0.82 \%$ & & & & & \\
\hline & 0.006 & 0.006 & $-2.7 \%$ & 12.22 & 8.49 & $-30.51 \%$ & 1.68 & 1.78 & $5.56 \%$ & 4.45 & 4.4 & -0.1 & 2.5 & 2.5 & $2.53 \%$ & & & & & \\
\hline & 0.019 & 0.0 & $-0.4 \%$ & 1.25 & 1.14 & $-9.27 \%$ & 1.86 & 1.86 & $-0.47 \%$ & 4.64 & 4.39 & -5.26 & 4.82 & 4.9 & $3.34 \%$ & & & & & \\
\hline & 0.013 & 0.014 & $8.6 \%$ & 3.01 & 5.88 & $95.50 \%$ & 1.98 & 1.99 & $0.44 \%$ & 4.91 & 4.24 & $-13.48 \%$ & 2.34 & 2.25 & $-3.81 \%$ & & & & & \\
\hline & 0.006 & 0.006 & $-4.3 \%$ & 11.95 & 14.37 & $20.25 \%$ & 1.85 & 1.85 & $0.08 \%$ & 4.53 & 4.34 & $-4.22 \%$ & 2.25 & 2.45 & $8.94 \%$ & & & & & \\
\hline & 0.006 & 0.006 & $-2.3 \%$ & 18.30 & 17.11 & $-6.47 \%$ & 1.88 & 1.85 & $-1.56 \%$ & 4.53 & 4.25 & $-6.11 \%$ & 2.40 & 2.37 & $-1.20 \%$ & & & & & \\
\hline & 0.006 & 0.006 & $-11.2 \%$ & 12.89 & 11.61 & $-9.87 \%$ & 1.88 & 1.87 & $-0.23 \%$ & 4.71 & 4.50 & $-4.46 \%$ & 2.32 & 2.33 & $0.13 \%$ & & & & & \\
\hline & 0.006 & 0.006 & $-10.5 \%$ & 15.00 & 17.66 & $17.71 \%$ & 1.49 & 1.62 & $8.53 \%$ & 4.04 & 4.20 & $4.04 \%$ & 2.54 & 2.29 & $-9.82 \%$ & & & & & \\
\hline & 0.006 & 0.006 & $-2.7 \%$ & 19.29 & 17.61 & $-8.71 \%$ & 1.84 & 1.85 & $0.53 \%$ & 4.76 & 4.47 & $-6.16 \%$ & 2.26 & 2.28 & $0.87 \%$ & & & & & \\
\hline & 0.006 & 0.006 & $-6.5 \%$ & 17.78 & 16.73 & $-5.90 \%$ & 1.86 & 1.84 & $-0.69 \%$ & 4.70 & 4.47 & $-4.88 \%$ & 2.39 & 2.20 & $-7.94 \%$ & & & & & \\
\hline
\end{tabular}

Figure 5-11. Annual habitat summaries for spring chinook and coho salmon in the Kittitas reach for the Wymer_1 scenario. 


\begin{tabular}{|c|c|c|c|c|c|c|c|c|c|c|c|c|c|c|c|c|c|c|c|c|c|}
\hline Steelhead & \multicolumn{3}{|c|}{ Redd Scour } & \multicolumn{3}{|c|}{ Spawning/incubation } & \multirow{2}{*}{\multicolumn{3}{|c|}{\begin{tabular}{cc}
\multicolumn{2}{c}{ Fry } \\
Base & Alternative Pct Cha
\end{tabular}}} & \multicolumn{3}{|c|}{ Subyearling (Spring-summer) } & \multicolumn{3}{|c|}{ Subyearling (winter) } & \multicolumn{3}{|c|}{ Subadult } & \multicolumn{3}{|c|}{ Adult holding } \\
\hline $\mathrm{Ye}$ & Base & Alternative & Pct Chg & Base & Alternative & Pct Chg & & & & Base & Alternative & Pct Chg & Base & Alternativ & e Pct Chg & Base & Alternative & Pct Chg & Base & Alternative & Pct Chg \\
\hline 198 & 0.005 & 0.005 & $0.1 \%$ & 30.03 & 34.31 & $14.25 \%$ & 2.21 & 2.15 & $-2.49 \%$ & 19.88 & 19.80 & $-0.40 \%$ & 3.73 & 3.21 & $-13.92 \%$ & 19.16 & 19.06 & $-0.50 \%$ & 8.45 & 8.16 & $-3.39 \%$ \\
\hline 198 & 0.005 & 0.005 & $3.5 \%$ & 33.83 & 34.38 & $1.63 \%$ & 2.17 & 2.13 & $-1.98 \%$ & 19.65 & 19.57 & $-0.42 \%$ & 3.24 & 3.04 & $-6.10 \%$ & 19.10 & 19.04 & $-0.28 \%$ & 8.16 & 7.93 & $-2.77 \%$ \\
\hline 198 & 0.005 & 0.005 & $-2.4 \%$ & 32.49 & 33.94 & $4.47 \%$ & 2.21 & 2.14 & $-3.06 \%$ & 18.90 & 18.52 & $-1.97 \%$ & 3.29 & 3.15 & $-4.06 \%$ & 19.20 & 19.10 & $-0.54 \%$ & 8.19 & 7.92 & $-3.31 \%$ \\
\hline 198 & 0.005 & 0.005 & $-0.7 \%$ & 30.21 & 29.77 & $-1.47 \%$ & 2.23 & 2.17 & $-2.73 \%$ & 17.61 & 18.41 & $4.52 \%$ & 3.31 & 3.06 & $-7.66 \%$ & 19.15 & 19.07 & $-0.41 \%$ & 11.82 & 11.25 & $-4.76 \%$ \\
\hline 198 & 0.005 & 0.006 & $0.3 \%$ & 29.59 & 33.89 & $14.54 \%$ & 2.21 & 2.14 & $-3.22 \%$ & 19.05 & 18.65 & $-2.10 \%$ & 3.65 & 3.22 & $-11.85 \%$ & 19.17 & 19.08 & $-0.49 \%$ & 9.35 & 9.00 & $-3.68 \%$ \\
\hline 198 & 0.005 & 0.005 & $-2.4 \%$ & 30.53 & 33.07 & $8.32 \%$ & 2.14 & 2.11 & $-1.72 \%$ & 22.38 & 21.61 & $-3.43 \%$ & 3.81 & 3.35 & $-11.95 \%$ & 19.06 & 19.03 & $-0.15 \%$ & 10.99 & 10.39 & $-5.47 \%$ \\
\hline 198 & 0.005 & 0.005 & $-6.4 \%$ & 27.86 & 27.75 & -0.41\% & 2.14 & 2.10 & $-1.81 \%$ & 20.80 & 21.45 & $3.13 \%$ & $\begin{array}{l}3.01 \\
3.64\end{array}$ & 3.78 & $3.75 \%$ & 19.07 & $\begin{array}{l}19.21 \\
\end{array}$ & $0.72 \%$ & 11.99 & 11.64 & $-2.93 \%$ \\
\hline 198 & 0.005 & 0.005 & $0.4 \%$ & 33.60 & 35.15 & $4.60 \%$ & 2.18 & 2.13 & $-2.29 \%$ & 20.24 & 20.02 & $-1.11 \%$ & $\begin{array}{l}3.04 \\
3.06\end{array}$ & $\begin{array}{l}3.02 \\
3.02\end{array}$ & $-1.30 \%$ & 19.14 & $\begin{array}{l}19.04 \\
19.4\end{array}$ & $-0.50 \%$ & 10.60 & 9.90 & $-6.62 \%$ \\
\hline 199 & 0.005 & 0.005 & $3.5 \%$ & 33.60 & 34.24 & $1.91 \%$ & 2.22 & 2.15 & $-3.11 \%$ & 20.44 & 21.44 & $4.88 \%$ & 3.18 & 3.10 & $-2.60 \%$ & 19.19 & 19.07 & $-0.59 \%$ & 9.50 & 8.98 & $-5.50 \%$ \\
\hline 199 & 0.005 & 0.005 & $7.7 \%$ & 34.14 & 29.33 & $-14.09 \%$ & 2.18 & 2.15 & $-1.31 \%$ & 21.45 & 21.33 & $-0.59 \%$ & 4.08 & 4.32 & $5.78 \%$ & 19.10 & 19.07 & $-0.17 \%$ & 7.06 & 7.02 & $-0.51 \%$ \\
\hline 199 & 0.005 & 0.005 & $-2.4 \%$ & 33.34 & 34.23 & $2.68 \%$ & 2.17 & 2.12 & $-2.51 \%$ & 22.74 & 21.97 & $-3.38 \%$ & 3.25 & 3.10 & $-4.71 \%$ & 19.09 & 19.03 & $-0.34 \%$ & 9.35 & 8.95 & $-4.32 \%$ \\
\hline 199 & 0.005 & 0.005 & $-6.1 \%$ & 30.26 & 31.15 & $2.96 \%$ & 2.15 & 2.09 & $-2.70 \%$ & 20.40 & 23.71 & $16.22 \%$ & 3.79 & 3.48 & $-8.09 \%$ & 19.07 & 19.11 & $0.20 \%$ & 12.72 & 12.03 & $-5.38 \%$ \\
\hline 199 & 0.006 & 0.005 & $-6.7 \%$ & 28.13 & 26.97 & $-4.12 \%$ & 2.09 & 2.07 & $-1.09 \%$ & 22.12 & 23.98 & $8.41 \%$ & 3.67 & 3.73 & $1.58 \%$ & 19.62 & 22.79 & $16.19 \%$ & 13.23 & 12.77 & $-3.43 \%$ \\
\hline 199 & 0.005 & 0.006 & $8.4 \%$ & 30.33 & 27.74 & $-8.53 \%$ & 2.17 & 2.06 & $-4.91 \%$ & 20.41 & 20.44 & $0.15 \%$ & 3.41 & 3.39 & $-0.56 \%$ & 19.12 & 19.17 & $0.28 \%$ & 8.20 & 7.85 & $-4.17 \%$ \\
\hline 199 & 0.008 & 0.009 & $10.2 \%$ & 34.19 & 33.88 & $-0.90 \%$ & 2.19 & 2.15 & $-2.06 \%$ & 20.13 & 20.08 & $-0.24 \%$ & 5.59 & 5.72 & $2.30 \%$ & 19.08 & 19.04 & $-0.25 \%$ & 6.71 & 6.68 & $-0.52 \%$ \\
\hline 199 & 0.013 & 0.014 & $3.1 \%$ & 33.17 & 34.30 & $3.40 \%$ & 2.21 & 2.11 & $-4.54 \%$ & 19.92 & 20.01 & $0.46 \%$ & 3.25 & 3.07 & $-5.55 \%$ & 19.18 & 19.06 & $-0.67 \%$ & 8.30 & 8.10 & $-2.42 \%$ \\
\hline 199 & 0.005 & 0.005 & $3.5 \%$ & 29.49 & 33.01 & $11.92 \%$ & 2.19 & 2.14 & $-1.93 \%$ & 19.71 & 21.39 & $8.54 \%$ & 3.07 & 3.16 & $3.18 \%$ & 19.12 & 19.06 & $-0.28 \%$ & 9.11 & 8.36 & $-8.32 \%$ \\
\hline 199 & 0.011 & 0.011 & $6.6 \%$ & 34.03 & 34.36 & $0.98 \%$ & 2.17 & 2.14 & $-1.32 \%$ & 20.40 & 20.57 & $0.83 \%$ & 3.18 & 3.19 & $0.40 \%$ & 19.11 & 19.15 & $0.18 \%$ & 9.02 & 8.38 & $-7.11 \%$ \\
\hline 200 & 0.005 & 0.005 & $-7.3 \%$ & 33.48 & 34.37 & $2.66 \%$ & 2.18 & 2.15 & $-1.60 \%$ & 18.44 & 19.26 & $4.46 \%$ & 3.17 & 3.16 & $-0.40 \%$ & 19.16 & 19.09 & $-0.39 \%$ & 8.41 & 8.00 & $-4.84 \%$ \\
\hline 200 & 0.005 & 0.005 & $-2.4 \%$ & 30.01 & 34.19 & $13.92 \%$ & 2.10 & 2.18 & $3.82 \%$ & 21.13 & 21.84 & $3.32 \%$ & 3.60 & 3.20 & $-10.89 \%$ & 19.05 & 20.41 & 7.11\% & 13.07 & 12.28 & $-6.04 \%$ \\
\hline 200 & 0.005 & 0.005 & $6.7 \%$ & 30.93 & 31.20 & $0.90 \%$ & 2.22 & 2.18 & $-1.67 \%$ & 18.82 & 18.69 & $-0.69 \%$ & 3.08 & 3.06 & $-0.55 \%$ & 19.11 & 19.09 & $-0.10 \%$ & 10.20 & 9.46 & $-7.31 \%$ \\
\hline 200 & 0.005 & 0.005 & $-0.2 \%$ & 33.79 & 34.34 & $1.62 \%$ & 2.22 & 2.15 & $-2.84 \%$ & 19.18 & 19.04 & $-0.75 \%$ & 3.34 & 3.06 & $-8.37 \%$ & 19.19 & 19.08 & $-0.55 \%$ & 9.18 & 8.82 & $-3.95 \%$ \\
\hline \multirow{2}{*}{ Resident Rainbow } & \multicolumn{3}{|c|}{ Redd Scour } & \multicolumn{3}{|c|}{ Spawning/incubation } & \multicolumn{3}{|c|}{ Fry } & \multicolumn{3}{|c|}{ Subyearling (Spring-summer) } & \multicolumn{3}{|c|}{ Subyearling (winter) } & & Subadult & & & Adult holdin & \\
\hline & Base & Alternative & Pct Chg & Base & Alternative & Pct Chg & Base & Alternative & Pct Chg & Base & Alternative & Pct Chg & Base & Alternativ & e Pct Chg & Base & Alternative & Pct Chg & Base & Alternative & Pct Chg \\
\hline 198 & 0.005 & 0.005 & $1.0 \%$ & 14.64 & 10.60 & $-27.56 \%$ & 2.54 & 2.47 & $-2.82 \%$ & 19.64 & 19.56 & $-0.42 \%$ & 4.62 & 4.07 & $-11.91 \%$ & 8.21 & 7.92 & $-3.55 \%$ & & & \\
\hline $\begin{array}{l}19 c^{2}-208 \\
198\end{array}$ & 0.005 & 0.005 & $\begin{array}{l}3.0 \% \\
3.5 \%\end{array}$ & $\begin{array}{l}14.04 \\
15.40\end{array}$ & 12.05 & $-21.73 \%$ & $\begin{array}{l}2.54 \\
2.49\end{array}$ & $\begin{array}{l}2.41 \\
2.44\end{array}$ & $\begin{array}{l}-2.020 \% \\
-2.20 \%\end{array}$ & 19 & 19 & -0. & $\begin{array}{l}4.02 \\
4.11\end{array}$ & 38 & $-5.56 \%$ & $\begin{array}{l}8.21 \\
7.88\end{array}$ & $\begin{array}{l}7.92 \\
7.81\end{array}$ & $-1.01 \%$ & & & \\
\hline $\begin{array}{l}19 \varepsilon^{2}-20 \\
198\end{array}$ & $\begin{array}{l}0.005 \\
0.005\end{array}$ & 0.005 & $\begin{array}{l}3.5 \% \\
-2.4 \%\end{array}$ & $\begin{array}{l}15.40 \\
9.68\end{array}$ & $\begin{array}{l}12.05 \\
13.44\end{array}$ & $\begin{array}{l}-21.13 \% \\
38.91 \%\end{array}$ & $\begin{array}{l}2.49 \\
2.54\end{array}$ & $\begin{array}{l}2.44 \\
2.45\end{array}$ & $\begin{array}{l}-2.20 \% \\
-3.50 \%\end{array}$ & $\begin{array}{l}19.41 \\
18.69\end{array}$ & 18. & $\begin{array}{l}-0.43 \% \\
-1.99 \%\end{array}$ & $\begin{array}{l}4.1 \\
4.1\end{array}$ & $\begin{array}{l}3.88 \\
3.98\end{array}$ & $\begin{array}{l}-5.5 \% \% \\
-3.68 \% \\
\end{array}$ & 8.41 & $\begin{array}{l}7.81 \\
8.00\end{array}$ & $\begin{array}{l}-1.01 \% \\
-4.85 \%\end{array}$ & & & \\
\hline $\begin{array}{l}1908 \\
198\end{array}$ & 0.005 & 0.005 & $0.0 \%$ & $\begin{array}{r}23.00 \\
23.27\end{array}$ & $\begin{array}{l}21.94 \\
21.97\end{array}$ & $-5.60 \%$ & 2.57 & $\begin{array}{l}2.45 \\
2.49\end{array}$ & $-3.13 \%$ & $\begin{array}{l}10.09 \\
17.43\end{array}$ & 18. & $4.44 \%$ & 4.18 & 3.89 & 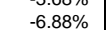 & $\begin{array}{l}0.41 \\
8.15\end{array}$ & $\begin{array}{l}0.80 \\
7.89\end{array}$ & $-3.20 \%$ & & & \\
\hline 98 & 0.005 & 0.006 & $0.3 \%$ & $\begin{array}{l}23.27 \\
17.18\end{array}$ & $\begin{array}{l}21.97 \\
14.78\end{array}$ & $\begin{array}{l}-5.60 \% \\
-13.96 \%\end{array}$ & $\begin{array}{l}2.51 \\
2.55\end{array}$ & $\begin{array}{l}2.49 \\
2.45\end{array}$ & $\begin{array}{l}-3.13 \% \\
-3.67 \% \\
-1\end{array}$ & $\begin{array}{l}17.43 \\
18.84\end{array}$ & $\begin{array}{l}18.40 \\
18.44\end{array}$ & $\begin{array}{l}4.44 \% \\
-2.10 \%\end{array}$ & $\begin{array}{l}4.18 \\
4.53\end{array}$ & $\begin{array}{l}3.89 \\
4.07\end{array}$ & $\begin{array}{l}-0.88 \% \\
-10.22 \%\end{array}$ & $\begin{array}{l}8.15 \\
8.43\end{array}$ & $\begin{array}{l}7.89 \\
8.00\end{array}$ & $\begin{array}{l}-3.20 \% \% \\
-5.07 \%\end{array}$ & & & \\
\hline प्र & 0.005 & 0.005 & $\begin{array}{l}.3 .3 \% \\
-2.4 \%\end{array}$ & $\begin{array}{l}17.18 \\
27.20\end{array}$ & $\begin{array}{l}14.18 \\
24.82\end{array}$ & $\begin{array}{l}-8.350 \% \\
-8.75 \%\end{array}$ & $\begin{array}{l}2.55 \\
2.45\end{array}$ & $\begin{array}{l}2.45 \\
2.41\end{array}$ & $\begin{array}{l}-3.07 \% \\
-1.96 \%\end{array}$ & $\begin{array}{l}18.84 \\
22.07\end{array}$ & $\begin{array}{l}18.44 \\
21.33\end{array}$ & $\begin{array}{l}-2.100 \% \\
-3.37 \%\end{array}$ & $\begin{array}{l}4.53 \\
4.70\end{array}$ & $\begin{array}{l}4.01 \\
4.22\end{array}$ & $\begin{array}{l}-10.22 \% \\
-10.08 \%\end{array}$ & $\begin{array}{l}8.43 \\
7.95\end{array}$ & $\begin{array}{l}8.60 \\
7.67\end{array}$ & $\begin{array}{l}-5.07 \% \\
-3.62 \%\end{array}$ & & & \\
\hline $\begin{array}{l}198 \\
198\end{array}$ & $\begin{array}{l}0.005 \\
0.005\end{array}$ & $\begin{array}{l}0.005 \\
0.005\end{array}$ & $\begin{array}{l}-2.4 \% \\
-6.4 \%\end{array}$ & $\begin{array}{l}27.90 \\
27.99\end{array}$ & $\begin{array}{r}24.82 \\
24.00\end{array}$ & $\begin{array}{l}-8.15 \% \\
-14.26 \%\end{array}$ & $\begin{array}{l}2.45 \\
2.45\end{array}$ & $\begin{array}{l}2.41 \\
2.40\end{array}$ & $\begin{array}{l}-1.90 \% \\
-2.06 \%\end{array}$ & 20.55 & 21. & $3.07 \%$ & $\begin{array}{l}4.10 \\
4.54\end{array}$ & $\begin{array}{l}\text { - } 4.22 \\
4.71\end{array}$ & $\begin{array}{c}-10.08 \% \\
3.77 \%\end{array}$ & $\begin{array}{l}7.95 \\
7.98\end{array}$ & $\begin{array}{l}7.61 \\
7.62\end{array}$ & $\begin{array}{l}-3.02 \% \\
-4.56 \%\end{array}$ & & & \\
\hline $\begin{array}{l}198 \\
198\end{array}$ & $\begin{array}{l}0.005 \\
0\end{array}$ & $\begin{array}{l}0.005 \\
0.00\end{array}$ & $\begin{array}{l}-0.4 \% \\
0.4 \%\end{array}$ & 30.77 & 30.13 & $\begin{array}{l}-2.08 \% \\
-2.08 \%\end{array}$ & $\begin{array}{l}2.45 \\
2.51\end{array}$ & $\begin{array}{l}2.40 \\
2.44\end{array}$ & $-2.68 \%$ & $\begin{array}{l}20.55 \\
19.99\end{array}$ & 19 . & $-1.11 \%$ & $\begin{array}{l}4.54 \\
3.89\end{array}$ & $\begin{array}{l}3.11 \\
3.84\end{array}$ & $-1.11 \%$ & 8.05 & 7.75 & $\begin{array}{l}-4.300 \% \\
-3.75 \%\end{array}$ & & & \\
\hline $\begin{array}{l}190 \\
195\end{array}$ & 0.005 & $\begin{array}{l}0.005 \\
0.00\end{array}$ & $\begin{array}{l}3.4 \% \% \\
3.5 \%\end{array}$ & 24.70 & $\begin{array}{l}20.13 \\
27.26\end{array}$ & $10.38 \%$ & $\begin{array}{l}2.51 \\
2.56\end{array}$ & $\begin{array}{l}2.44 \\
2.47\end{array}$ & $\begin{array}{l}-2.087 \% \\
-3.57 \%\end{array}$ & $\begin{array}{l}19.99 \\
20.18\end{array}$ & 21. & $\begin{array}{l}-1.1 \\
4.8\end{array}$ & $\begin{array}{l}3.09 \\
4.00\end{array}$ & 3. & $-1.95 \%$ & 8. & $\begin{array}{l}7.815 \\
7.83\end{array}$ & $\begin{array}{l}-3.15 \% \\
-4.59 \%\end{array}$ & & & \\
\hline 190 & $\begin{array}{l}0.005 \\
0\end{array}$ & $\begin{array}{l}0.005 \\
0\end{array}$ & $\begin{array}{l}-1.5 \% \\
-1.2 \%\end{array}$ & 3.23 & 5.48 & $69.64 \%$ & $\begin{array}{l}2.50 \\
2.51\end{array}$ & $\begin{array}{l}2.41 \\
2.47\end{array}$ & $-1.48 \%$ & $\begin{array}{l}20.10 \\
21.17\end{array}$ & 21 & $\begin{array}{l}4.00 \\
-0.5\end{array}$ & $\begin{array}{l}4.9 \\
4.9\end{array}$ & 5. & $5.01 \%$ & 8. & $\begin{array}{l}7.85 \\
7.92\end{array}$ & $\begin{array}{l}-4.55 \% \\
-3.04 \%\end{array}$ & & & \\
\hline 190 & $\begin{array}{l}0.005 \\
0\end{array}$ & $\begin{array}{l}0.005 \\
0.00\end{array}$ & $\begin{array}{l}-1.2 \% \% \\
-3.0 \%\end{array}$ & $\begin{array}{l}24.58 \\
24.58\end{array}$ & 27 & $\begin{array}{l}09.04 \% \% \\
10.92 \%\end{array}$ & $\begin{array}{l}2.51 \\
2.49\end{array}$ & $\begin{array}{l}2.41 \\
2.42\end{array}$ & $\begin{array}{l}-1.480 \% \\
-2.87 \%\end{array}$ & $\begin{array}{l}21.11 \\
22.42\end{array}$ & 21 & $\begin{array}{l}-0.5 \\
-3.3\end{array}$ & $\begin{array}{l}4.0 \\
4.0\end{array}$ & 3. & $\begin{array}{r}-3.39 \% \\
-3.39 \% \\
\end{array}$ & 8. & 7.85 & $-2.70 \%$ & & & \\
\hline 190 & $\begin{array}{l}0.005 \\
0\end{array}$ & $\begin{array}{l}0.005 \\
0.00\end{array}$ & $\begin{array}{l}-3.0 \% \% \\
-6.1 \%\end{array}$ & $\begin{array}{l}27.92 \\
27.92\end{array}$ & 27 & -1.8 & $\begin{array}{l}2.49 \\
2.46\end{array}$ & $\begin{array}{l}2.42 \\
2.39\end{array}$ & $-2.95 \%$ & $\begin{array}{l}22.42 \\
20.16\end{array}$ & 23 & 每 $15.921 \%$ & 4.6 & 4. & 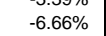 & $\begin{array}{l}0.01 \\
8.02\end{array}$ & $\begin{array}{l}7.60 \\
7.63\end{array}$ & $-4.88 \%$ & & & \\
\hline 199 & 0.006 & 0.005 & $-6.7 \%$ & 27.90 & 23.64 & $-15.26 \%$ & $\begin{array}{l}2.40 \\
2.39\end{array}$ & 2.39 & $-0.23 \%$ & 21.83 & 23 & $8.26 \%$ & 4.56 & 4.64 & $1.73 \%$ & $\begin{array}{l}0.62 \\
7.67\end{array}$ & $\begin{array}{l}8.53 \\
8.53\end{array}$ & $11.16 \%$ & & & \\
\hline 199 & 0.005 & 0.006 & $10.5 \%$ & 8.89 & 5.12 & $-42.36 \%$ & 2.49 & 2.38 & $-4.49 \%$ & 20.15 & 20.18 & $0.14 \%$ & 4.25 & $\begin{array}{l}4.23 \\
4.23\end{array}$ & $-0.52 \%$ & 8.02 & $\begin{array}{l}8.03 \\
8.01\end{array}$ & $-0.11 \%$ & & & \\
\hline 15 & 0.005 & 0.005 & $-1.7 \%$ & $\begin{array}{l}.09 \\
0.43\end{array}$ & 0.40 & $-7.88 \%$ & $\begin{array}{l}2.49 \\
2.52\end{array}$ & 2.46 & $\begin{array}{l}-2.37 \% \\
-2.37 \%\end{array}$ & 19.88 & 19.83 & $-0.26 \%$ & 6.42 & $\begin{array}{l}6.53 \\
6.53\end{array}$ & $1.66 \%$ & 7.97 & 7.76 & $-2.68 \%$ & & & \\
\hline 19 & 0.013 & 0.014 & $0.6 \%$ & $\begin{array}{l}1.34 \\
1.34\end{array}$ & 3.23 & $140.56 \%$ & 2.54 & 2.41 & $-5.15 \%$ & $\begin{array}{l}19.67 \\
\end{array}$ & $\begin{array}{l}19.76 \\
\text { a }\end{array}$ & $0.45 \%$ & 4.1 & 3.90 & $\begin{array}{l}-5.11 \% \% \\
\end{array}$ & 8.51 & 7.88 & $-7.36 \%$ & & & \\
\hline 19 & 0.005 & $\begin{array}{l}0.005 \\
0\end{array}$ & $3.8 \%$ & $\begin{array}{l}21.48 \\
21.48\end{array}$ & $\begin{array}{l}\text {.2. } \\
22.32\end{array}$ & $3.93 \%$ & 2.51 & 2.46 & $-2.08 \%$ & 19.47 & 21. & $8.40 \%$ & 3.88 & $\begin{array}{l}3.96 \\
3.96\end{array}$ & $2.06 \%$ & 8.03 & $\begin{array}{l}7.00 \\
7.91\end{array}$ & $-1.41 \%$ & & & \\
\hline 19 & 0.011 & 0.011 & $6.6 \%$ & 22.74 & 20.76 & $-8.69 \%$ & 2.49 & 2.45 & $-1.59 \%$ & 20.14 & 20.31 & $0.82 \%$ & $\begin{array}{l}3.00 \\
3.99\end{array}$ & 4.01 & $0.37 \%$ & 8.09 & 7.84 & $-3.19 \%$ & & & \\
\hline 20 & 0.005 & 0.005 & $-0.3 \%$ & 9.43 & 7.62 & $-19.20 \%$ & 2.51 & 2.46 & $-1.80 \%$ & 18.24 & 19.03 & $4.37 \%$ & 4.01 & 3.99 & $-0.45 \%$ & 8.15 & 7.95 & $-2.41 \%$ & & & \\
\hline 200 & 0.005 & 0.005 & $-2.7 \%$ & $\begin{array}{l}23.59 \\
23.59\end{array}$ & 27.29 & $15.70 \%$ & 2.40 & 2.50 & $3.93 \%$ & 20.87 & 21.55 & $3.26 \%$ & 4.48 & 4.05 & $-9.45 \%$ & 7.60 & 7.90 & $3.93 \%$ & & & \\
\hline 200 & 0.005 & 0.005 & $6.7 \%$ & 27.34 & 20.54 & $-24.85 \%$ & 2.56 & 2.51 & $-1.96 \%$ & 18.61 & 18.48 & $-0.71 \%$ & 3.90 & 3.88 & $-0.58 \%$ & 8.06 & 7.98 & $-1.02 \%$ & & & \\
\hline 200 & 0.005 & 0.005 & $-0.2 \%$ & 21.72 & 20.21 & $-6.95 \%$ & 2.55 & 2.47 & $-3.25 \%$ & 18.95 & 18.81 & $-0.75 \%$ & 4.21 & 3.91 & $-7.11 \%$ & 8.16 & 7.82 & $-4.11 \%$ & & & \\
\hline
\end{tabular}

Figure 5-12. Annual habitat summaries for steelhead and resident rainbow trout in the Kittitas reach for the Wymer_1 scenario. 
Bull Trout

\begin{tabular}{|c|c|c|c|c|c|c|c|c|c|c|c|c|c|c|c|c|c|}
\hline \multirow[b]{2}{*}{ Year } & \multicolumn{3}{|c|}{ Redd Scour } & \multicolumn{3}{|c|}{ Spawning/incubation } & \multirow{2}{*}{\multicolumn{3}{|c|}{\begin{tabular}{cc|}
\multicolumn{2}{c|}{ Fry } \\
Base & Alternative Pct Cha
\end{tabular}}} & \multicolumn{3}{|c|}{ Subyearling (Spring-summer) } & \multicolumn{3}{|c|}{ Subyearling (winter) } & \begin{tabular}{ll|}
\multicolumn{3}{c|}{ Subadult } \\
Base & Alternative Pct Cha
\end{tabular} & Adult holding \\
\hline & Base & Alternative & Pct Chg & Base & Alternative & Pct Chg & & Alternative & Pct Chg & Base & Alternative & Pct Chg & Base & Alternative & Pct Chg & Base Alternative Pct Chg & Base Alternative Pct Chg \\
\hline 1982 & 0.007 & 0.006 & $-10.9 \%$ & 13.14 & 10.79 & $-17.90 \%$ & $\frac{2.51}{2.51}$ & 2.53 & $0.75 \%$ & 20.84 & 20.12 & $-3.42 \%$ & 4.45 & 3.96 & $-11.07 \%$ & & \\
\hline 1983 & 0.006 & 0.006 & $-4.6 \%$ & 14.34 & 11.87 & $-17.28 \%$ & 2.62 & 2.64 & $0.64 \%$ & 20.46 & 20.07 & $-1.88 \%$ & 4.04 & 3.88 & $-3.93 \%$ & & \\
\hline 1984 & 0.007 & 0.006 & $-10.7 \%$ & 10.90 & 12.89 & $18.25 \%$ & 2.52 & 2.59 & $2.87 \%$ & 21.00 & 20.18 & $-3.91 \%$ & 4.09 & 3.97 & $-3.00 \%$ & & \\
\hline 1985 & 0.007 & 0.006 & $-11.1 \%$ & 12.23 & 10.14 & $-17.13 \%$ & 2.51 & 2.56 & $2.31 \%$ & 20.54 & 20.24 & $-1.45 \%$ & 4.05 & 3.78 & $-6.83 \%$ & & \\
\hline 1986 & 0.007 & 0.006 & $-10.2 \%$ & 14.05 & 13.88 & $-1.21 \%$ & 2.31 & 2.42 & $4.85 \%$ & 20.67 & 20.16 & $-2.50 \%$ & 4.34 & $\begin{array}{l}3.99 \\
3.99\end{array}$ & $-8.10 \%$ & & \\
\hline 1987 & 0.006 & 0.006 & $-9.9 \%$ & 17.38 & $\begin{array}{l}16.30 \\
16.34\end{array}$ & $-6.00 \%$ & 2.32 & 2.43 & $4.63 \%$ & 20.17 & 19.82 & $-1.76 \%$ & 4.45 & 4.05 & 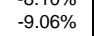 & & \\
\hline 1988 & 0.007 & 0.007 & $5.1 \%$ & 18.39 & 17.36 & $-5.60 \%$ & 2.32 & 2.51 & $8.34 \%$ & 20.18 & $\begin{array}{l}19.82 \\
19.82\end{array}$ & $-1.79 \%$ & 4.24 & 4.50 & $6.34 \%$ & & \\
\hline $\begin{array}{l}1989 \\
1989\end{array}$ & 0.006 & 0.006 & $\begin{array}{l}-8.9 \% \\
\end{array}$ & 17.85 & $\begin{array}{l}16.59 \\
16.59\end{array}$ & $-7.07 \%$ & 2.51 & 2.52 & $\begin{array}{l}0.46 \% \\
0.46 \%\end{array}$ & 20.50 & 20.02 & $-2.33 \%$ & $\begin{array}{l}4.74 \\
3.76\end{array}$ & $\begin{array}{l}4.70 \\
3.70\end{array}$ & $-1.71 \%$ & & \\
\hline 1990 & 0.006 & 0.007 & $1.2 \%$ & 17.73 & 14.16 & $-20.15 \%$ & 2.61 & 2.59 & $-0.70 \%$ & 20.93 & 20.31 & $-2.97 \%$ & 3.96 & $\begin{array}{l}3.88 \\
3.88\end{array}$ & $-1.92 \%$ & & \\
\hline 1991 & 0.013 & 0.014 & $8.8 \%$ & 4.99 & 6.58 & $31.72 \%$ & 2.62 & 2.61 & $-0.38 \%$ & 20.36 & 20.16 & $-1.02 \%$ & 5.18 & 5.51 & $6.45 \%$ & & \\
\hline 1992 & 0.006 & 0.006 & $-7.2 \%$ & $\begin{array}{l}17.69 \\
\text { a }\end{array}$ & 14.19 & $-19.75 \%$ & 2.20 & 2.34 & $6.12 \%$ & 20.50 & 20.05 & $-2.19 \%$ & 4.00 & 3.83 & $-4.25 \%$ & & \\
\hline 1993 & 0.007 & 0.007 & $-1.1 \%$ & 17.42 & 17.30 & $-0.65 \%$ & 2.25 & 2.47 & $9.89 \%$ & 20.19 & 19.85 & $-1.70 \%$ & 4.41 & 4.22 & $-4.25 \%$ & & \\
\hline 1994 & 0.007 & 0.008 & $4.9 \%$ & 18.42 & 14.53 & $-21.10 \%$ & 2.15 & 2.40 & $11.63 \%$ & 19.98 & 22.72 & $13.70 \%$ & 4.15 & 4.34 & $4.79 \%$ & & \\
\hline $\begin{array}{l}1995 \\
\end{array}$ & 0.006 & 0.006 & $-4.6 \%$ & 10.77 & 7.36 & $-31.67 \%$ & 2.40 & 2.50 & $4.11 \%$ & 20.50 & 20.45 & $-0.20 \%$ & 4.23 & 4.34 & $2.59 \%$ & & \\
\hline 1996 & 0.019 & 0.019 & $-0.4 \%$ & 1.88 & 1.76 & $-6.36 \%$ & 2.65 & 2.63 & $-1.09 \%$ & 20.39 & 20.07 & $-1.60 \%$ & 6.27 & 6.39 & $1.97 \%$ & & \\
\hline 1997 & 0.013 & 0.014 & $8.6 \%$ & 3.11 & 4.99 & $60.38 \%$ & 3.17 & 3.20 & $0.81 \%$ & 20.75 & 19.94 & $-3.91 \%$ & 4.08 & 3.94 & $-3.43 \%$ & & \\
\hline 1998 & 0.006 & 0.006 & $-4.3 \%$ & 9.52 & 10.63 & $11.66 \%$ & 2.62 & 2.61 & $-0.58 \%$ & 20.43 & 20.14 & $-1.43 \%$ & 3.78 & 3.98 & $5.46 \%$ & & \\
\hline 1999 & 0.006 & 0.006 & $-10.1 \%$ & 17.00 & 13.72 & $-19.30 \%$ & 2.67 & 2.60 & $-2.61 \%$ & 20.35 & 20.33 & $-0.12 \%$ & 3.99 & 3.96 & $-0.67 \%$ & & \\
\hline 2000 & 0.006 & 0.006 & $-11.2 \%$ & 10.71 & 9.24 & $-13.70 \%$ & 2.63 & 2.62 & $-0.32 \%$ & 20.56 & 20.24 & $-1.55 \%$ & 3.96 & 3.96 & $0.09 \%$ & & \\
\hline 2001 & 0.006 & 0.006 & $-10.5 \%$ & 13.25 & 14.32 & $8.09 \%$ & 2.22 & 2.34 & $5.19 \%$ & 19.67 & 20.65 & $5.00 \%$ & 4.20 & 3.92 & $-6.62 \%$ & & \\
\hline 2002 & 0.006 & 0.006 & $-3.4 \%$ & 18.58 & 17.63 & $-5.08 \%$ & 2.58 & 2.60 & $0.74 \%$ & 20.79 & 20. & $-1.59 \%$ & 3.80 & 3.78 & $-0.42 \%$ & & \\
\hline 2003 & 0.006 & 0.006 & $-6.5 \%$ & 15.70 & 13.79 & $-12.12 \%$ & 2.59 & 2.57 & $-0.76 \%$ & 20.76 & 20.26 & $-2.37 \%$ & 4.11 & 3.77 & $-8.08 \%$ & & \\
\hline
\end{tabular}

Figure 5-13. Annual habitat summary for bull trout in the Kittitas reach for the Wymer_1 scenario. 


\begin{tabular}{|c|c|c|c|c|c|c|c|c|c|c|c|c|c|c|c|c|c|c|c|c|}
\hline \multirow{2}{*}{$\underset{\text { Year }}{\text { Spring Chinook }}$} & \multicolumn{3}{|c|}{ Redd Scour } & \multicolumn{3}{|c|}{ Spawning/incubation } & \multicolumn{3}{|c|}{ Fry } & \multirow{2}{*}{\multicolumn{3}{|c|}{ Subyearling (Spring-summer) }} & \multicolumn{3}{|c|}{ Subyearling (winter) } & \multicolumn{2}{|r|}{ Subadult } & \multicolumn{3}{|c|}{ Adult holding } \\
\hline & Base & Alternative & Pct Chg & Base & Alternative & Pct Chg & Base & Alternative & Pct Chg & & & & Base & & Pct Chg & Base & Alternative Pct Chg & Base & Alternativ & Pct Chg \\
\hline 198 & 0.102 & 0.102 & $0.30 \%$ & 9.62 & 9.29 & $-3.5 \%$ & 3.15 & 3.15 & $0.0 \%$ & 37.16 & 37.40 & $0.6 \%$ & 5.25 & 5.23 & $-0.3 \%$ & & & 5.44 & 5.47 & $0.6 \%$ \\
\hline 198 & 0.057 & 0.057 & $0.32 \%$ & 18.57 & 18.53 & $-0.2 \%$ & 3.45 & 3.45 & $0.0 \%$ & 36.22 & 36.38 & $0.4 \%$ & 5.35 & 5.44 & $1.8 \%$ & & & 5.29 & 5.35 & $1.2 \%$ \\
\hline 198 & 0.134 & 0.134 & $0.39 \%$ & 19.38 & 9.64 & $-50.3 \%$ & 2.75 & 2.75 & $0.0 \%$ & 38.00 & 38.28 & $0.7 \%$ & 5.50 & 5.58 & $1.5 \%$ & & & 5.60 & 5.62 & $0.4 \%$ \\
\hline 198 & 0.018 & 0.022 & $20.91 \%$ & 15.19 & 4.83 & $-68.2 \%$ & 2.33 & 2.35 & $0.6 \%$ & 38.23 & 37.58 & $-1.7 \%$ & 6.00 & 6.08 & $1.3 \%$ & & & 6.08 & 5.62 & $-7.5 \%$ \\
\hline 198 & 0.030 & 0.030 & $0.29 \%$ & 16.88 & 17.53 & $3.9 \%$ & 2.85 & 2.86 & $0.4 \%$ & 38.33 & 38.61 & $0.7 \%$ & 5.65 & 5.73 & $1.3 \%$ & & & 8.08 & 7.74 & $-4.2 \%$ \\
\hline 198 & 0.017 & 0.020 & $16.02 \%$ & 26.91 & 28.54 & $6.1 \%$ & 2.61 & 2.61 & $0.1 \%$ & 36.42 & 36.82 & $1.1 \%$ & 5.45 & 5.48 & $0.4 \%$ & & & 7.74 & 7.93 & $2.6 \%$ \\
\hline 198 & 0.023 & 0.026 & $16.39 \%$ & 27.77 & 16.23 & $-41.6 \%$ & 2.29 & 2.29 & $0.0 \%$ & 35.98 & 36.21 & $0.6 \%$ & 5.25 & 5.26 & $0.1 \%$ & & & 6.98 & 6.90 & $-1.1 \%$ \\
\hline 198 & 0.017 & 0.020 & $17.26 \%$ & 31.12 & 31.12 & $0.0 \%$ & 2.37 & 2.37 & $0.1 \%$ & 36.16 & 36.18 & $0.1 \%$ & 4.74 & 4.75 & $0.0 \%$ & & & 6.05 & 6.02 & $-0.5 \%$ \\
\hline 199 & 0.041 & 0.041 & $0.29 \%$ & 26.20 & 16.78 & $-36.0 \%$ & 2.58 & 2.62 & $1.6 \%$ & 39.03 & 39.59 & $1.5 \%$ & 4.76 & 4.76 & $0.1 \%$ & & & 5.02 & 4.99 & $-0.5 \%$ \\
\hline 199 & 0.222 & 0.222 & $0.04 \%$ & 29.49 & 29.27 & $-0.7 \%$ & 2.91 & 2.91 & $0.0 \%$ & 37.09 & 38.09 & $2.7 \%$ & 5.76 & 5.84 & $1.4 \%$ & & & 5.05 & 4.97 & $-1.5 \%$ \\
\hline 199 & 0.020 & 0.024 & $17.67 \%$ & 19.09 & 8.74 & $-54.2 \%$ & 2.34 & 2.34 & $0.0 \%$ & 39.33 & 39.76 & $1.1 \%$ & 5.20 & 5.19 & $-0.1 \%$ & & & 9.13 & 9.10 & $-0.3 \%$ \\
\hline 199 & 0.019 & 0.024 & $25.77 \%$ & 27.93 & 13.80 & $-50.6 \%$ & 2.28 & 2.29 & $0.2 \%$ & 38.38 & 37.70 & $-1.8 \%$ & 5.93 & 6.21 & $4.7 \%$ & & & 7.33 & 7.57 & $3.3 \%$ \\
\hline 199 & 0.021 & 0.025 & $19.06 \%$ & 9.30 & 8.76 & $-5.8 \%$ & 2.31 & 2.31 & $0.0 \%$ & 40.77 & 40.45 & $-0.8 \%$ & 5.91 & 6.08 & $3.0 \%$ & & & 6.91 & 7.12 & $3.0 \%$ \\
\hline 199 & 0.144 & 0.145 & $0.15 \%$ & 25.27 & 23.90 & $-5.4 \%$ & 3.34 & 3.34 & $-0.1 \%$ & 36.50 & 36.70 & $0.6 \%$ & 5.73 & 5.89 & $2.8 \%$ & & & 5.05 & 5.04 & $-0.2 \%$ \\
\hline 199 & 0.889 & 0.895 & $0.59 \%$ & 4.19 & 4.18 & $-0.2 \%$ & 3.64 & 3.64 & $0.0 \%$ & 35.68 & 35.77 & $0.2 \%$ & 9.13 & 9.13 & $0.0 \%$ & & & 5.03 & 5.11 & $1.6 \%$ \\
\hline 199 & 0.218 & 0.214 & $-1.53 \%$ & 18.54 & 18.00 & $-2.9 \%$ & 3.65 & $\begin{array}{l}3.04 \\
3.65\end{array}$ & $0.0 \%$ & 38.28 & 37.89 & $-1.0 \%$ & 5.73 & 5.89 & $2.8 \%$ & & & 5.26 & 5.22 & $-0.8 \%$ \\
\hline 199 & 0.121 & 0.080 & $-33.83 \%$ & 26.47 & 27.13 & $2.5 \%$ & 2.90 & 2.90 & $0.0 \%$ & 36.44 & 36.67 & $0.6 \%$ & 4.86 & 4.87 & $0.2 \%$ & & & 5.54 & 5.25 & $-5.2 \%$ \\
\hline 199 & 0.032 & 0.032 & $0.29 \%$ & 18.03 & 18.32 & $1.6 \%$ & 2.95 & 2.95 & $0.1 \%$ & 37.97 & 38.28 & $0.8 \%$ & 5.34 & 5.36 & $0.4 \%$ & & & 5.14 & 5.10 & $-0.8 \%$ \\
\hline 200 & 0.027 & 0.029 & $4.46 \%$ & 18.95 & 29.83 & $57.4 \%$ & 2.65 & 2.65 & $0.0 \%$ & 37.64 & 37.74 & $0.3 \%$ & 5.24 & 5.23 & $-0.2 \%$ & & & 4.86 & 4.93 & $1.4 \%$ \\
\hline 200 & 0.018 & 0.023 & $25.90 \%$ & 17.25 & 5.88 & $-65.9 \%$ & 2.28 & 2.29 & $0.4 \%$ & 42.28 & 41.87 & $-1.0 \%$ & 6.80 & 7.07 & $4.0 \%$ & & & 7.92 & 7.79 & $-1.7 \%$ \\
\hline 200 & 0.059 & 0.059 & $0.32 \%$ & 21.86 & 21.86 & $0.0 \%$ & 2.39 & 2.41 & $0.9 \%$ & 38.68 & 38.60 & $-0.2 \%$ & 4.81 & 4.81 & $0.1 \%$ & & & 4.89 & 4.85 & $-0.9 \%$ \\
\hline 200 & 0.133 & 0.133 & $0.39 \%$ & 6.38 & 1.90 & $-70.2 \%$ & 2.93 & 2.93 & $0.0 \%$ & 36.73 & 37.04 & $0.8 \%$ & 6.29 & 6.60 & $4.8 \%$ & & & 6.37 & $\begin{array}{l}6.22 \\
6.02\end{array}$ & $-2.4 \%$ \\
\hline \multirow{24}{*}{$\begin{array}{l}Y \\
19 \\
15 \\
15 \\
15 \\
15 \\
19 \\
15\end{array}$} & \multicolumn{3}{|c|}{ Redd Scour } & \multicolumn{3}{|c|}{ Spawning/incubation } & \multicolumn{3}{|c|}{ Fry } & \multicolumn{3}{|c|}{\begin{tabular}{|l|} 
Subyearling (Spring-summer) \\
\end{tabular}} & \multirow{2}{*}{\multicolumn{3}{|c|}{ Subyearling (winter) }} & \multicolumn{2}{|r|}{ Subadult } & & Adult hold & \\
\hline & Base & Alternative & Pct Chg & Base & Alternative & Pct Chg & Base & Alternative & Pct Chg & Base & Alternative & Pct Chg & Base & & Pct Chg & Base & Alternative Pct Chg & Base & Alternativ & Pct Chg \\
\hline & 0.102 & 0.102 & $0.30 \%$ & 10.57 & 10.11 & $-4.3 \%$ & 3.01 & 3.01 & $0.0 \%$ & 7.81 & 7.81 & $0.0 \%$ & 3.28 & 3.27 & $-0.1 \%$ & & & & & \\
\hline & 0.057 & 0.057 & $0.32 \%$ & 367 & 366 & $-0.3 \%$ & 3.46 & 3.46 & $0.0 \%$ & 763 & 779 & $21 \%$ & 3.42 & 3.48 & 1 & & & & & \\
\hline & 0.134 & 0.134 & $0.39 \%$ & 3.91 & 1.05 & $-73.0 \%$ & 2.92 & 2.92 & $0.0 \%$ & 7. & 7.92 & $-0.4 \%$ & 3.62 & 3.7 & $2.1 \%$ & & & & & \\
\hline & 0.018 & 0.022 & $26.27 \%$ & 2.71 & 0.39 & $-85.7 \%$ & 2.64 & 2.64 & $0.0 \%$ & 7.45 & 7.56 & $1.6 \%$ & 3.60 & 3.6 & $1.5 \%$ & & & & & \\
\hline & 0.030 & 0.030 & $0.29 \%$ & 3.19 & 3.38 & $5.8 \%$ & 2.64 & 2.65 & $0.6 \%$ & 6. & 6.7. & $1.9 \%$ & 3.49 & 3. & 2. & & & & & \\
\hline & 0.014 & 0.016 & $17.65 \%$ & 17.25 & 18.31 & $6.1 \%$ & 2.68 & 2.68 & $0.0 \%$ & 6.78 & 6.7 & $-0.4 \%$ & 3.41 & 3.4 & $0.3 \%$ & & & & & \\
\hline & 0.017 & 0.021 & $18.47 \%$ & 17.80 & 6.55 & $-63.2 \%$ & 2.71 & 2.71 & $0.0 \%$ & 6.76 & 6.6 & $-1.6 \%$ & 3.35 & 3.3 & $0.0 \%$ & & & & & \\
\hline & 0.013 & 0.016 & $21.20 \%$ & 19.98 & 19.98 & $0.0 \%$ & 3.11 & 3.11 & $0.1 \%$ & 6.86 & 6.90 & $0.5 \%$ & 3.14 & 3.1 & $0.0 \%$ & & & & & \\
\hline & 0.041 & 0.041 & $0.29 \%$ & 18.32 & 13.12 & $-28.3 \%$ & 2.98 & 2.98 & $0.0 \%$ & 8.58 & 9.70 & $13.0 \%$ & 3.20 & 3.1 & $-0.2 \%$ & & & & & \\
\hline & 0.018 & 0.018 & $0.37 \%$ & 11.02 & 10.31 & $-6.4 \%$ & 2.87 & 2.87 & $0.0 \%$ & 8.34 & 9.06 & $8.7 \%$ & 3.91 & 3.9 & $2.0 \%$ & & & & & \\
\hline & 0.014 & 0.018 & $23.06 \%$ & 3.82 & 0.89 & $-76.7 \%$ & 2.27 & 2.27 & $0.0 \%$ & 6.80 & 6.88 & 1.2 & 3.40 & 3.41 & $0.2 \%$ & & & & & \\
\hline & 0.019 & 0.024 & $25.77 \%$ & 17.90 & 5.57 & $-68.9 \%$ & 2.37 & 2.37 & $0.1 \%$ & 7.35 & 6.77 & $-7.9 \%$ & 3.72 & 3.8 & $4.1 \%$ & & & & & \\
\hline & 0.019 & 0.023 & $24.67 \%$ & 1.61 & 1.52 & $-5.8 \%$ & 2.61 & 2.61 & $0.0 \%$ & 7.56 & 7.48 & $-1.0 \%$ & 3.69 & 3.85 & $4.1 \%$ & & & & & \\
\hline & 0.144 & 0.145 & $0.15 \%$ & 11.19 & 10.44 & $-6.7 \%$ & 3.27 & 3.28 & $0.2 \%$ & 7.50 & 7.75 & $3.3 \%$ & 3.69 & 3.77 & $2.1 \%$ & & & & & \\
\hline & 0.889 & 0.895 & $0.59 \%$ & 7.89 & 7.85 & $-0.5 \%$ & 3.46 & 3.46 & $0.0 \%$ & 7.38 & 7.64 & $3.5 \%$ & 6.56 & 6.57 & $0.1 \%$ & & & & & \\
\hline & 0.218 & 0.214 & $-1.53 \%$ & 3.67 & 3.51 & $-4.2 \%$ & 3.61 & 3.61 & $0.0 \%$ & 8.12 & 8.02 & $-1.3 \%$ & 3.64 & 3.76 & $3.3 \%$ & & & & & \\
\hline & 0.011 & 0.011 & $4.49 \%$ & 11.85 & 12.21 & $3.0 \%$ & 3.29 & 3.29 & $0.0 \%$ & 7.61 & 8.19 & $7.6 \%$ & 3.34 & 3.34 & $0.0 \%$ & & & & & \\
\hline & 0.032 & 0.032 & $0.29 \%$ & 3.52 & 3.60 & $2.4 \%$ & 3.36 & 3.36 & $0.0 \%$ & 8.64 & 8.78 & $1.6 \%$ & 3.50 & 3.52 & $0.5 \%$ & & & & & \\
\hline & 0.026 & 0.027 & $0.57 \%$ & 3.78 & 12.14 & $221.0 \%$ & 3.35 & 3.35 & $0.0 \%$ & 7.75 & 8.31 & $7.3 \%$ & 3.47 & 3.47 & $-0.1 \%$ & & & & & \\
\hline & 0.018 & 0.023 & $25.90 \%$ & 3.30 & 0.47 & $-85.8 \%$ & 2.33 & 2.33 & $0.0 \%$ & 8.12 & 7.85 & $-3.3 \%$ & 4.29 & 4.63 & $7.9 \%$ & & & & & \\
\hline & 0.059 & 0.059 & $0.32 \%$ & 9.33 & 9.33 & $0.0 \%$ & 3.16 & 3.20 & $1.4 \%$ & 8.48 & 9.06 & $6.8 \%$ & 3.21 & 3.21 & $0.0 \%$ & & & & & \\
\hline & 0.133 & 0.133 & $0.39 \%$ & 0.51 & 0.14 & $-73.3 \%$ & 3.09 & 3.09 & $0.0 \%$ & 6.92 & 7.25 & $4.8 \%$ & 3.82 & 4.04 & $5.6 \%$ & & & & & \\
\hline
\end{tabular}

Figure 5-14. Annual habitat summaries for spring chinook and coho salmon in the Naches reach for the Wymer_1 scenario. 


\begin{tabular}{|c|c|c|c|c|c|c|c|c|c|c|c|c|c|c|c|c|c|c|c|c|c|}
\hline \multirow{2}{*}{ Steelhead } & \multicolumn{3}{|c|}{ Redd Scour } & \multicolumn{3}{|c|}{ Spawning/incubation } & \multicolumn{3}{|c|}{ Fry } & \multicolumn{3}{|c|}{ Subyearling (Spring-summer) } & \multicolumn{3}{|c|}{ Subyearling (winter) } & \multicolumn{3}{|c|}{ Subadult } & \multicolumn{3}{|c|}{ Adult holding } \\
\hline & Base & Alternative & Pct Chg & Base & Alternative & Pct Chg & Base & Alternative & Pct Chg & Base & Alternativ & Pct Chg & Base & Alternative & Pct Chg & Base & Alternative & Pct Cha & Base & Alternative & Pct Chg \\
\hline 198 & 0.295 & 0.295 & $0.05 \%$ & 28.00 & 27.09 & $-3.2 \%$ & 3.43 & 3.43 & $0.0 \%$ & 4551 & 45.54 & $0.1 \%$ & 4.51 & 4.49 & $-0.4 \%$ & 53.21 & 53.37 & $0.3 \%$ & 10.86 & 11114 & $\frac{26 \%}{26 \%}$ \\
\hline $198>>2>>2>$ & 0.433 & 0.433 & $0.01 \%$ & 19.23 & 1917 & $-0.3 \%$ & 3.44 & 3.44 & $0.0 \%$ & 45.40 & 45.45 & $0.1 \%$ & 456 & 461 & $11 \%$ & 50.48 & 50.52 & $0.1 \%$ & 8.24 & 8.07 & $-20 \%$ \\
\hline 198 & 0.125 & 0.125 & $0.37 \%$ & 20.38 & 10.64 & $-47.8 \%$ & 3.47 & 3.44 & $-1.1 \%$ & 45.63 & 4575 & $0.3 \%$ & 465 & 469 & $09 \%$ & 4912 & 49,25 & $0.3 \%$ & 8.43 & 837 & $-07 \%$ \\
\hline 198 & 0.411 & 0.411 & $0.02 \%$ & 14.48 & 4.75 & $-67.2 \%$ & 3.35 & 3.41 & $19 \%$ & 45.73 & 45.73 & $0.0 \%$ & 5.30 & 530 & $0.0 \%$ & 51.17 & 5002 & $-22 \%$ & 1678 & 1589 & $-53 \%$ \\
\hline 198 & 0.308 & 0.310 & $0.80 \%$ & 16.85 & 17.77 & $5.4 \%$ & 3.31 & 3.33 & $0.6 \%$ & 47.86 & 47.48 & $-0.8 \%$ & 4.92 & 4.95 & $0.5 \%$ & 51.74 & 51.73 & $0.0 \%$ & 10.56 & 10.48 & $-0.8 \%$ \\
\hline 198 & 0.130 & 0.320 & $146.65 \%$ & 26.98 & 28.68 & $6.3 \%$ & 3.34 & 3.32 & $-0.5 \%$ & 45.79 & 45.86 & $0.1 \%$ & 4.69 & 4.71 & $0.5 \%$ & 51.37 & 51.88 & $1.0 \%$ & 11.26 & 11.33 & $0.7 \%$ \\
\hline $198>>2>>>C$ & 0.035 & 0.035 & $0.29 \%$ & 2787 & 15.52 & $-44.3 \%$ & 3.33 & 331 & $-0.6 \%$ & 4620 & 46.10 & $-0.2 \%$ & 451 & 4.52 & $0.1 \%$ & 50.02 & 50.29 & $0.6 \%$ & 13.40 & 13.18 & $-16 \%$ \\
\hline 198 & 0.049 & 0.049 & $0.31 \%$ & 31.37 & 31.37 & $0.0 \%$ & 3.36 & 3.35 & $-0.2 \%$ & 45.23 & 45.22 & $0.0 \%$ & 4.17 & 4.17 & $0.0 \%$ & 50.37 & 50.39 & $0.0 \%$ & 12.95 & 12.93 & $-0.2 \%$ \\
\hline 199 & 0.169 & 0.170 & $0.28 \%$ & 26.90 & 26.77 & $-0.5 \%$ & 3.37 & 3.51 & $4.3 \%$ & 47.95 & 47.63 & $-0.7 \%$ & 4.18 & 4.18 & $0.0 \%$ & 49.19 & 49.14 & $-0.1 \%$ & 10.83 & 10.56 & $-25 \%$ \\
\hline 199 & 0.023 & 0.023 & $0.46 \%$ & 31.66 & 31.80 & $0.4 \%$ & 3.45 & 3.50 & $1.4 \%$ & 45.92 & 46.56 & $1.4 \%$ & 4.81 & 4.88 & $1.5 \%$ & 48.85 & 48.79 & $-0.1 \%$ & 7.72 & 7.68 & $-0.5 \%$ \\
\hline 199 & 0.016 & 0.018 & $13.35 \%$ & 19.96 & 9.40 & $-52.9 \%$ & 3.35 & 3.35 & $0.1 \%$ & 47.46 & 46.79 & $-1.4 \%$ & 4.55 & 4.55 & $-0.1 \%$ & 53.11 & 53.47 & $0.7 \%$ & 9.08 & 9.01 & $-0.7 \%$ \\
\hline 199 & 0.029 & 0.029 & $0.47 \%$ & 28.04 & 13.20 & $-52.9 \%$ & 3.38 & 3.34 & $-1.0 \%$ & 46.41 & 47.10 & $1.5 \%$ & 5.09 & 5.23 & $2.8 \%$ & 51.14 & 51.02 & $-0.2 \%$ & 16.05 & 15.90 & $-0.9 \%$ \\
\hline 199 & 0.016 & 0.019 & $12.43 \%$ & 8.64 & 8.14 & $-5.8 \%$ & 3.45 & 3.40 & $-1.4 \%$ & 45.99 & 45.73 & $-0.6 \%$ & 5.10 & 5.24 & $2.7 \%$ & 50.49 & 50.79 & $0.6 \%$ & 16.16 & 15.88 & $-1.7 \%$ \\
\hline 199 & 0.247 & 0.247 & $0.08 \%$ & 25.33 & 23.78 & $-6.1 \%$ & 3.35 & 3.38 & $0.9 \%$ & 45.61 & 45.65 & $0.1 \%$ & 4.80 & 4.88 & $1.5 \%$ & 52.00 & 51.89 & $-0.2 \%$ & 8.12 & 8.03 & $-1.2 \%$ \\
\hline 199 & 0.075 & 0.075 & $0.29 \%$ & 39.02 & 39.30 & $0.7 \%$ & 3.43 & 3.48 & $1.7 \%$ & 45.27 & 45.34 & $0.2 \%$ & 8.03 & 8.02 & $0.0 \%$ & 48.75 & 49.16 & $0.8 \%$ & 8.95 & 8.91 & $-0.5 \%$ \\
\hline 199 & 0.695 & 0.700 & $0.68 \%$ & 19.19 & 18.43 & $-3.9 \%$ & 3.41 & 3.41 & $0.2 \%$ & 45.70 & 45.76 & $0.1 \%$ & 4.79 & 4.89 & $2.0 \%$ & 54.98 & 54.68 & $-0.5 \%$ & 8.20 & 7.98 & $-2.6 \%$ \\
\hline 199 & 0.400 & 0.400 & $0.02 \%$ & 26.68 & 27.42 & $2.8 \%$ & 3.38 & 3.43 & $1.6 \%$ & 45.80 & 45.85 & $0.1 \%$ & 4.22 & 4.22 & $0.0 \%$ & 51.69 & 50.47 & $-2.4 \%$ & 9.34 & 9.12 & $-2.4 \%$ \\
\hline 199 & 0.449 & 0.449 & $0.01 \%$ & 18.48 & 18.89 & $2.2 \%$ & 4.04 & 4.04 & $0.0 \%$ & 46.05 & 46.31 & $0.6 \%$ & 4.45 & 4.47 & $0.5 \%$ & 56.49 & 56.51 & $0.0 \%$ & 8.49 & 8.46 & $-0.4 \%$ \\
\hline 200 & 0.112 & 0.112 & $0.33 \%$ & 19.77 & 31.45 & $59.1 \%$ & 3.43 & 3.48 & $1.5 \%$ & 45.77 & 45.74 & $-0.1 \%$ & 4.40 & 4.39 & $-0.3 \%$ & 49.33 & 49.37 & $0.1 \%$ & 8.42 & 8.26 & $-1.9 \%$ \\
\hline 200 & 0.018 & 0.020 & $9.48 \%$ & 17.37 & 5.79 & $-66.7 \%$ & 3.42 & 3.50 & $2.1 \%$ & 47.77 & 47.23 & $-1.1 \%$ & 6.46 & 6.94 & $7.4 \%$ & 51.17 & 51.12 & $-0.1 \%$ & 18.01 & 18.05 & $0.2 \%$ \\
\hline 200 & 0.382 & 0.391 & $2.36 \%$ & 21.49 & 21.49 & $0.0 \%$ & 3.42 & 3.56 & $4.0 \%$ & 45.76 & 45.90 & $0.3 \%$ & 4.19 & 4.19 & $0.0 \%$ & 51.83 & 51.42 & $-0.8 \%$ & 10.21 & 10.06 & $-1.5 \%$ \\
\hline 200 & 0.185 & 0.187 & $1.08 \%$ & 6.27 & 2.26 & $-64.0 \%$ & 3.34 & 3.35 & $0.3 \%$ & 45.37 & 45.57 & $0.4 \%$ & 5.43 & 5.73 & $5.6 \%$ & 50.12 & 50.06 & $-0.1 \%$ & 10.75 & 10.71 & $-0.4 \%$ \\
\hline \multirow{2}{*}{ Resident Rainbow } & \multirow{2}{*}{\multicolumn{3}{|c|}{ Redd Scour }} & \multicolumn{3}{|c|}{ Spawning/incubation } & \multirow{2}{*}{\multicolumn{3}{|c|}{\begin{tabular}{cc}
\multicolumn{2}{c}{ Fry } \\
Base & Alternative \\
Pct Chg
\end{tabular}}} & \multirow{2}{*}{\multicolumn{3}{|c|}{ Subyearling (Spring-summer) }} & \multicolumn{3}{|c|}{ Subyearling (winter) } & & Subadult & & & Adult holdin & \\
\hline & Base & & Pct Chg & Base & Alternative & Pct Chg & & & & & & & Base & Alternative & Pct Chg & Base & Alternative & Pct Chg & Base & Alternative & Pct Chg \\
\hline 198 & 0.295 & 0.295 & $0.05 \%$ & 8.11 & 7.81 & $-3.7 \%$ & 4.29 & 4.29 & $0.0 \%$ & 45.34 & 45.37 & $0.1 \%$ & 5.80 & 5.77 & $-0.4 \%$ & 19.97 & 20.10 & $0.6 \%$ & & & \\
\hline 198 & 0.433 & 0.433 & $0.01 \%$ & 12.17 & 12.14 & $-0.3 \%$ & 4.30 & 4.30 & $0.0 \%$ & 45.22 & 45.28 & $0.1 \%$ & 5.89 & 5.95 & $1.0 \%$ & 17.20 & 17.78 & $3.4 \%$ & & & \\
\hline 198 & 0.125 & 0.125 & $0.37 \%$ & 12.81 & 5.02 & $-60.8 \%$ & 4.32 & 4.29 & $-0.7 \%$ & 45.46 & 45.57 & $0.3 \%$ & 6.06 & 6.12 & $1.0 \%$ & 15.79 & 16.00 & $1.3 \%$ & & & \\
\hline 198 & 0.411 & 0.411 & $0.02 \%$ & 9.54 & 2.19 & $-77.1 \%$ & 4.21 & 4.26 & $1.3 \%$ & 45.56 & 45.57 & $0.0 \%$ & 6.70 & 6.72 & $0.4 \%$ & 16.68 & 17.51 & $5.0 \%$ & & & \\
\hline 198 & 0.308 & 0.310 & $0.80 \%$ & 10.86 & 11.36 & $4.7 \%$ & 4.20 & 4.20 & $0.0 \%$ & 47.51 & 47.16 & $-0.7 \%$ & 6.29 & 6.35 & $1.1 \%$ & 15.71 & 15.95 & $1.5 \%$ & & & \\
\hline 198 & 0.130 & 0.320 & $146.65 \%$ & 23.93 & 25.30 & $5.7 \%$ & 4.21 & 4.19 & $-0.3 \%$ & 45.59 & 45.66 & $0.2 \%$ & 6.06 & 6.0 & $0.4 \%$ & 15.85 & 16.05 & $1.2 \%$ & & & \\
\hline 198 & 0.011 & 0.008 & $-25.09 \%$ & 24.65 & 12.40 & $-49.7 \%$ & 4.21 & 4.20 & $-0.2 \%$ & 45.96 & 45.88 & $-0.2 \%$ & 5.81 & 5.82 & $0.1 \%$ & 15.11 & & $-0.1 \%$ & & & \\
\hline 198 & 0.049 & 0.049 & $0.31 \%$ & 27.46 & 27.46 & $0.0 \%$ & 4.23 & 4.20 & $-0.6 \%$ & 45.04 & 45.03 & $0.0 \%$ & 5.40 & 5.40 & $0.0 \%$ & 15.39 & 15.40 & $0.0 \%$ & & & \\
\hline & 0.021 & 0.021 & & 22.66 & 13.63 & $-39.9 \%$ & 4.24 & 4.33 & $2.1 \%$ & 47 & 47 & -0.6 & 5.41 & 5.41 & $0.0 \%$ & 15.48 & 15.71 & $1.5 \%$ & & & \\
\hline & 0.023 & 0.023 & $0.46 \%$ & 22.92 & 22.58 & $-1.5 \%$ & 4.29 & 4.32 & 0. & 45.76 & 46 & 1.4 & 6.33 & 6.4 & 1.5 & 15.69 & 16.01 & $2.0 \%$ & & & \\
\hline & 0.016 & 0.018 & $13.35 \%$ & 12.58 & 4.41 & -64. & 4.21 & 4.22 & 0. & 47.14 & 46.50 & -1.3 & 5.92 & 5.9 & $-0.1 \%$ & 17.12 & 17.48 & $2.1 \%$ & & & \\
\hline 199 & 0.029 & 0.029 & $0.47 \%$ & 24.78 & 10.55 & $-57.4 \%$ & 4.22 & 4.21 & $-0.2 \%$ & 46.18 & 46.81 & 1.4 & 6.55 & 6.72 & $2.6 \%$ & 17.33 & 16.36 & $-5.6 \%$ & & & \\
\hline 18 & 0.016 & $0 . c_{-1}$ & 12.4 & 5.77 & 5. & -5.8 & 4.26 & $4.2 \quad$ & & 45 & & -0. & 6.52 & $6.7 \mathrm{C}$ & $2.7 \%$ & 16.30 & 16.42 & $0.7 \%$ & & & \\
\hline & 0.247 & 0.2 & 0.0 & 19.95 & 18.77 & -5 . & 4.22 & 4.2 & $0.4 \%$ & 45.44 & 45.47 & 0.1 & 6.24 & 6.3 & 1. & 17.75 & 18.18 & $2.4 \%$ & & & \\
\hline & 0.058 & 0.059 & 0.3 & 3.92 & 3. & -0.7 & 4.28 & 4.33 & $1.1 \%$ & 45 & 45. & 0.2 & 10.53 & 10.53 & 0.6 & 15.59 & 16.08 & $3.1 \%$ & & & \\
\hline & 0.695 & & $0.68 \%$ & 12.15 & 11. & -3.2 & 4.26 & 4.2 & 0.2 & 45. & 45. & 0.1 & 6.24 & 6.3 & 2.1. & 21.39 & 20.91 & $-2.2 \%$ & & & \\
\hline 19 & 0.400 & 0.4 & $0.02 \%$ & 20.98 & 21 & $2.7 \%$ & 4.24 & 4.2 & 1.8 & 45 & 45 & 0.1 & 5.48 & 5. & $0 . c$ & 17.62 & 18.66 & $5.9 \%$ & & & \\
\hline & 0.449 & 0.4 & $0.01 \%$ & 11.76 & 11. & $1.9 \%$ & 5.01 & $5 . C^{-}$ & 0. & & 46 & 0.6 & 5.80 & $5 . \varepsilon$ & 0. & 21.14 & 21.18 & $0.2 \%$ & & & \\
\hline & 0.092 & 0.093 & $0.27 \%$ & 12.47 & 23.46 & 88.1 & 4.30 & 4.33 & $0.7 \%$ & 45. & 45 & -0.1 & 5.71 & 5.6 & $-0.3 \%$ & 16.11 & 16.64 & $3.3 \%$ & & & \\
\hline 200 & 0.018 & $0 . c^{-}$ & $9.48 \%$ & 11.15 & 2.66 & -76 & 4.23 & 4.30 & $1.8 \%$ & 47. & 46.93 & -1.1. & 8.02 & 8.56 & $6.8 \%$ & 17.36 & 16.95 & $-2.4 \%$ & & & \\
\hline 200 & 0.091 & 0.091 & $0.27 \%$ & 17.03 & 17.03 & $0.0 \%$ & 4.27 & 4.37 & $2.3 \%$ & 45. & 45.7 & 0.3 & 5.44 & 5.44 & $0.0 \%$ & 19.56 & 20.04 & $2.4 \%$ & & & \\
\hline 200 & 0.185 & 0.187 & $1.08 \%$ & 2.89 & 0.97 & $-66.3 \%$ & 4.23 & 4.22 & $-0.2 \%$ & 45.20 & 45.41 & $0.5 \%$ & 6.88 & 7.27 & $5.6 \%$ & 15.24 & 15.33 & $0.6 \%$ & & & \\
\hline
\end{tabular}

Figure 5-15. Annual habitat summaries for steelhead and resident rainbow trout in the Naches reach for the Wymer_1 scenario. 


\begin{tabular}{|c|c|c|c|c|c|c|c|c|c|c|c|c|c|c|c|c|c|c|}
\hline \multirow[b]{2}{*}{ Year } & \multirow{2}{*}{\multicolumn{3}{|c|}{ Redd Scour }} & \multicolumn{3}{|c|}{ Spawning/incubation } & \multirow{2}{*}{\multicolumn{3}{|c|}{ Fry }} & \multirow{2}{*}{\multicolumn{3}{|c|}{$\begin{array}{l}\text { Subyearling (Spring-summer) } \\
\text { Base Alternative Pct Chg }\end{array}$}} & \multicolumn{3}{|c|}{ Subyearling (winter) } & \multirow{2}{*}{\multicolumn{2}{|c|}{$\begin{array}{c}\text { Subadult } \\
\text { Suternative }\end{array}$}} & Adult holding \\
\hline & & & Pct Chg & Base & Alternative & Pct Chg & Base & & Pct Chg & & & & Base & Alternative & Pct Chg & & & Base Alternative Pct Chg \\
\hline 1982 & 0.102 & $\overline{0.102}$ & $0.30 \%$ & 9.19 & 8.98 & $-2.3 \%$ & 6.10 & 6.10 & $0.0 \%$ & 64.41 & 64.37 & $-0.1 \%$ & 5.71 & 5.70 & $-0.2 \%$ & & & \\
\hline 1983 & 0.057 & 0.057 & $0.32 \%$ & 4.16 & $\begin{array}{l}0.160 \\
4.16\end{array}$ & $-0.1 \%$ & 7.24 & 7.24 & $0.0 \%$ & 63.97 & 63.81 & $-0.2 \%$ & 6.01 & 6.13 & $2.0 \%$ & & & \\
\hline 1984 & 0.134 & 0.134 & $0.39 \%$ & 4.25 & 1.41 & $-66.8 \%$ & 5.82 & 5.82 & $0.0 \%$ & 64.20 & 64.41 & $0.3 \%$ & 6.31 & 6.43 & $2.0 \%$ & & & \\
\hline 1985 & 0.018 & 0.022 & $26.27 \%$ & 3.81 & 0.72 & $-81.1 \%$ & 5.29 & 5.29 & $0.0 \%$ & 65.54 & 63.82 & $-2.6 \%$ & 6.32 & 6.45 & $2.1 \%$ & & & \\
\hline 1986 & 0.030 & 0.030 & $0.29 \%$ & 3.99 & 4.06 & $1.7 \%$ & 5.24 & 5.27 & $0.6 \%$ & 66.23 & 66.30 & $0.1 \%$ & 6.15 & 6.31 & $2.5 \%$ & & & \\
\hline 1987 & 0.014 & 0.019 & $39.10 \%$ & 15.25 & 15.96 & $4.7 \%$ & 5.33 & 5.34 & $0.0 \%$ & 64.20 & 64.69 & $0.8 \%$ & 5.94 & 5.97 & $0.5 \%$ & & & \\
\hline 1988 & 0.023 & 0.026 & $16.39 \%$ & 15.62 & 6.67 & $-57.3 \%$ & 5.43 & 5.43 & $0.0 \%$ & 63.68 & 63.97 & $0.4 \%$ & 5.82 & 5.83 & $0.2 \%$ & & & \\
\hline 1989 & 0.016 & 0.019 & $21.61 \%$ & 17.08 & 17.08 & $0.0 \%$ & 6.28 & 6.28 & $0.1 \%$ & 63.67 & 63.58 & $-0.1 \%$ & 5.36 & 5.36 & $0.0 \%$ & & & \\
\hline 1990 & 0.041 & 0.041 & $0.29 \%$ & 20.69 & 14.85 & $-28.3 \%$ & 5.97 & 5.97 & $0.0 \%$ & 66.41 & 65.55 & $-1.3 \%$ & 5.41 & 5.42 & $0.1 \%$ & & & \\
\hline 1991 & 0.222 & 0.222 & $0.04 \%$ & 9.42 & 8.84 & $-6.2 \%$ & 5.71 & 5.71 & $0.0 \%$ & 64.33 & 65.17 & $1.3 \%$ & 6.75 & 6.86 & $1.6 \%$ & & & \\
\hline 1992 & 0.016 & 0.019 & $23.95 \%$ & 4.22 & 1.28 & $-69.6 \%$ & 4.58 & 4.57 & $0.0 \%$ & 66.42 & 66.74 & $0.5 \%$ & 5.85 & 5.86 & $0.1 \%$ & & & \\
\hline 1993 & 0.019 & 0.024 & $25.77 \%$ & 15.69 & 5.68 & $-63.8 \%$ & 4.74 & 4.75 & $0.1 \%$ & 65.37 & 65.29 & $-0.1 \%$ & 6.51 & 6.79 & $4.3 \%$ & & & \\
\hline 1994 & 0.021 & 0.025 & $19.06 \%$ & 2.41 & 2.27 & $-5.8 \%$ & 5.20 & 5.20 & $0.0 \%$ & 64.89 & 65.55 & $1.0 \%$ & 6.48 & 6.75 & $4.1 \%$ & & & \\
\hline 1995 & 0.144 & 0.145 & $0.15 \%$ & 10.03 & 9.54 & $-4.9 \%$ & 6.67 & 6.68 & $0.2 \%$ & 64.53 & 64.56 & $0.0 \%$ & 6.52 & 6.69 & $2.5 \%$ & & & \\
\hline 1996 & 0.889 & 0.895 & $0.59 \%$ & 4.30 & 4.27 & $-0.6 \%$ & 7.17 & 7.17 & $0.0 \%$ & 62.81 & 63.15 & $0.5 \%$ & 10.84 & 10.85 & $0.1 \%$ & & & \\
\hline 1997 & 0.218 & 0.214 & $-1.53 \%$ & 4.16 & 4.11 & $-1.3 \%$ & 9.05 & 9.05 & $0.0 \%$ & 65.87 & 65.64 & $-0.4 \%$ & 6.50 & 6.73 & $3.5 \%$ & & & \\
\hline 1998 & 0.121 & 0.080 & $-33.83 \%$ & 10.46 & 10.70 & $2.3 \%$ & 6.94 & 6.94 & $0.0 \%$ & 64.28 & 63.72 & $-0.9 \%$ & 5.63 & 5.64 & $0.2 \%$ & & & \\
\hline 1999 & 0.032 & 0.032 & $0.29 \%$ & 4.11 & 4.14 & $0.7 \%$ & 7.07 & 7.07 & $0.0 \%$ & 66.29 & 66.68 & $0.6 \%$ & 6.14 & 6.19 & $0.7 \%$ & & & \\
\hline 2000 & 0.027 & 0.029 & $4.46 \%$ & 4.20 & 10.35 & $146.1 \%$ & 6.91 & 6.91 & $0.0 \%$ & 63.91 & 63.91 & $0.0 \%$ & 6.03 & 6.03 & $0.0 \%$ & & & \\
\hline 2001 & 0.018 & 0.023 & $25.90 \%$ & 4.03 & 0.87 & $-78.3 \%$ & 4.70 & 4.70 & $0.0 \%$ & 64.97 & 64.96 & $0.0 \%$ & 7.28 & 7.66 & $5.2 \%$ & & & \\
\hline 2002 & 0.059 & 0.059 & $0.32 \%$ & 8.81 & 8.81 & $0.0 \%$ & 6.63 & 6.75 & $1.9 \%$ & 65.17 & 65.32 & $0.2 \%$ & 5.48 & 5.49 & $0.1 \%$ & & & \\
\hline & 0.133 & 0.133 & $0.39 \%$ & 0.95 & 0.32 & $-66.4 \%$ & 6.18 & 6.18 & $0.0 \%$ & 64.37 & 64.56 & $0.3 \%$ & 6.82 & 7.18 & $5.3 \%$ & & & \\
\hline
\end{tabular}

Figure 5-16. Annual habitat summary for bull trout in the Naches reach for the Wymer_1 scenario. 
Fall Chinook

\begin{tabular}{|c|c|c|c|c|c|c|c|c|c|c|c|c|c|c|c|}
\hline \multirow[b]{2}{*}{ Year } & \multirow{2}{*}{\multicolumn{3}{|c|}{\begin{tabular}{ll}
\multicolumn{1}{c}{ Redd Scour } \\
Base & Alternative Pct Chg
\end{tabular}}} & \multicolumn{3}{|c|}{ Spawning/incubation } & \multirow{2}{*}{\multicolumn{3}{|c|}{ Fry }} & \multicolumn{3}{|c|}{ Subyearling (Spring-summer) } & Subyearling (winter) & $\begin{array}{l}\text { Subadult } \\
\end{array}$ & Adult holding \\
\hline & & & & Base & Alternative & Pct Chg & Base & & & Base & Alternative & Pct Chg & Base Alternative Pct Chg & Base Alternative Pct Chg & Base Alternative Pct Chg \\
\hline 1982 & 0.031 & 0.031 & $-1.09 \%$ & 19.76 & 19.63 & $-0.6 \%$ & 7.24 & 7.33 & $1.1 \%$ & 43.20 & 43.13 & $-0.2 \%$ & & & \\
\hline 1983 & 0.028 & 0.028 & $0.78 \%$ & 19.32 & 19.27 & $-0.3 \%$ & 6.41 & 6.40 & $-0.2 \%$ & 40.59 & 40.15 & $-1.1 \%$ & & & \\
\hline 1984 & 0.028 & 0.029 & $1.49 \%$ & 19.78 & 17.97 & $-9.1 \%$ & 7.11 & 7.06 & $-0.7 \%$ & 35.79 & 35.91 & $0.3 \%$ & & & \\
\hline 1985 & 0.030 & 0.030 & $0.71 \%$ & 19.67 & 19.39 & $-1.4 \%$ & 7.73 & 7.74 & $0.1 \%$ & 35.51 & 35.48 & $-0.1 \%$ & & & \\
\hline 1986 & 0.028 & 0.028 & $-0.36 \%$ & 16.51 & 9.87 & $-40.2 \%$ & 6.82 & 6.83 & $0.1 \%$ & 34.91 & 34.98 & $0.2 \%$ & & & \\
\hline 1987 & 0.030 & 0.030 & $-1.91 \%$ & 18.21 & 18.04 & $-0.9 \%$ & 7.69 & 7.70 & $0.1 \%$ & 35.31 & 35.35 & $0.1 \%$ & & & \\
\hline 1988 & 0.035 & 0.034 & $-2.90 \%$ & 18.29 & 18.19 & $-0.5 \%$ & 7.72 & 7.73 & $0.2 \%$ & 35.06 & 35.02 & $-0.1 \%$ & & & \\
\hline 1989 & 0.025 & 0.025 & $2.23 \%$ & 20.85 & 20.72 & $-0.6 \%$ & 7.19 & 7.20 & $0.1 \%$ & 35.52 & 35.50 & $0.0 \%$ & & & \\
\hline 1990 & 0.029 & 0.029 & $-0.18 \%$ & 19.32 & 19.13 & $-1.0 \%$ & 6.58 & 6.59 & $0.1 \%$ & 35.74 & 35.73 & $0.0 \%$ & & & \\
\hline 1991 & 0.052 & 0.054 & $4.23 \%$ & 22.97 & 20.64 & $-10.1 \%$ & 7.10 & 7.14 & $0.6 \%$ & 35.38 & 35.64 & $0.7 \%$ & & & \\
\hline 1992 & 0.027 & 0.028 & $1.35 \%$ & 19.87 & 18.03 & $-9.2 \%$ & 7.96 & 7.98 & $0.2 \%$ & 34.91 & 35.02 & $0.3 \%$ & & & \\
\hline 1993 & 0.034 & 0.034 & $-1.05 \%$ & 17.57 & 12.02 & $-31.6 \%$ & 8.28 & 8.28 & $0.1 \%$ & 34.84 & 34.86 & $0.1 \%$ & & & \\
\hline 1994 & 0.035 & 0.034 & $-2.67 \%$ & 18.28 & 16.54 & $-9.5 \%$ & 8.19 & 8.20 & $0.1 \%$ & 33.80 & 33.82 & $0.1 \%$ & & & \\
\hline 1995 & 0.031 & 0.030 & $-1.10 \%$ & 18.21 & 12.78 & $-29.8 \%$ & 7.12 & 7.21 & $1.2 \%$ & 40.01 & 39.91 & $-0.2 \%$ & & & \\
\hline 1996 & 0.199 & 0.188 & $-5.49 \%$ & 9.65 & 9.51 & $-1.4 \%$ & 5.91 & 6.00 & $1.5 \%$ & 36.65 & 36.67 & $0.0 \%$ & & & \\
\hline 1997 & 0.057 & 0.056 & $-1.37 \%$ & 19.08 & 18.98 & $-0.5 \%$ & 5.78 & 5.78 & $0.0 \%$ & 62.39 & 61.89 & $-0.8 \%$ & & & \\
\hline 1998 & 0.019 & 0.020 & $8.76 \%$ & 20.52 & 20.38 & $-0.7 \%$ & 6.65 & 6.69 & $0.6 \%$ & 41.81 & 42.00 & $0.5 \%$ & & & \\
\hline 1999 & 0.028 & 0.028 & $0.19 \%$ & 19.56 & 19.33 & $-1.2 \%$ & 6.99 & 6.92 & $-0.9 \%$ & 42.02 & 40.09 & $-4.6 \%$ & & & \\
\hline 2000 & 0.029 & 0.028 & $-2.88 \%$ & 17.78 & 17.74 & $-0.2 \%$ & 6.50 & 6.51 & $0.1 \%$ & 36.26 & 36.23 & $-0.1 \%$ & & & \\
\hline 2001 & 0.035 & 0.034 & $-1.21 \%$ & 16.02 & 14.50 & $-9.5 \%$ & 8.46 & 8.45 & $-0.1 \%$ & 34.22 & 34.61 & $1.2 \%$ & & & \\
\hline 2002 & 0.026 & 0.026 & $1.67 \%$ & 19.09 & 18.93 & $-0.8 \%$ & 7.22 & 7.21 & $-0.2 \%$ & 38.33 & 38.25 & $-0.2 \%$ & & & \\
\hline 2003 & 0.032 & 0.031 & $-2.88 \%$ & 12.80 & 15.01 & $17.2 \%$ & 7.47 & 7.55 & $1.0 \%$ & 35.18 & 35.17 & $0.0 \%$ & & & \\
\hline
\end{tabular}

Coho

\begin{tabular}{|c|c|c|c|c|c|c|c|c|c|c|c|c|c|c|c|c|c|c|}
\hline \multirow[b]{2}{*}{ Year } & \multicolumn{3}{|c|}{ Redd Scour } & \multicolumn{3}{|c|}{ Spawning/incubation } & \multicolumn{3}{|c|}{ Fry } & \multicolumn{3}{|c|}{ Subyearling (Spring-summer) } & \multicolumn{3}{|c|}{ Subyearling (winter) } & \multicolumn{2}{|r|}{ Subadult } & \multirow{2}{*}{\begin{tabular}{cc}
\multicolumn{2}{c}{ Adult holding } \\
Base & Alternative Pct Chg
\end{tabular}} \\
\hline & Base & Alternative & Pct Chg & Base & Alternative & Pct Chg & Base & Alternative & Pct Chg & Base & Alternative & Pct Chg & Base & Alternative & Pct Chg & Base & Alternative Pct Chg & \\
\hline 1982 & 0.031 & 0.031 & $-1.09 \%$ & 4.58 & 4.61 & $0.5 \%$ & 6.40 & 6.41 & $0.1 \%$ & 28.03 & 27.99 & $-0.1 \%$ & 44.28 & 44.17 & $-0.3 \%$ & & & \\
\hline 1983 & 0.028 & 0.028 & $0.78 \%$ & 4.60 & 4.61 & $0.3 \%$ & 6.36 & 6.39 & $0.4 \%$ & 28.05 & 28.01 & $-0.2 \%$ & 44.42 & 44.33 & $-0.2 \%$ & & & \\
\hline 1984 & 0.028 & 0.029 & $1.49 \%$ & 4.59 & 5.03 & $9.6 \%$ & 7.31 & 7.31 & $0.1 \%$ & 28.11 & 28.09 & $-0.1 \%$ & 45.10 & 45.07 & $-0.1 \%$ & & & \\
\hline 1985 & 0.030 & 0.030 & $0.71 \%$ & 7.32 & 7.29 & $-0.5 \%$ & 7.17 & 7.17 & $-0.1 \%$ & 27.66 & 27.74 & $0.3 \%$ & 42.74 & 42.51 & $-0.5 \%$ & & & \\
\hline 1986 & 0.028 & 0.028 & $-0.36 \%$ & 4.53 & 2.20 & $-51.4 \%$ & 7.61 & 7.59 & $-0.3 \%$ & 27.02 & 27.13 & $0.4 \%$ & 43.12 & 42.96 & $-0.4 \%$ & & & \\
\hline 1987 & 0.030 & 0.030 & $-1.91 \%$ & 7.15 & 7.13 & $-0.3 \%$ & 7.20 & 7.16 & $-0.6 \%$ & 26.50 & 26.60 & $0.4 \%$ & 42.72 & 42.58 & $-0.3 \%$ & & & \\
\hline 1988 & 0.031 & 0.031 & $-2.43 \%$ & 7.16 & 7.15 & $-0.2 \%$ & 7.38 & 7.39 & $0.2 \%$ & 26.55 & 26.56 & $0.1 \%$ & 41.94 & 41.74 & $-0.5 \%$ & & & \\
\hline 1989 & 0.025 & 0.025 & $1.55 \%$ & 9.07 & 9.05 & $-0.2 \%$ & 6.83 & 6.84 & $0.2 \%$ & 27.12 & 27.11 & $0.0 \%$ & 44.05 & 43.92 & $-0.3 \%$ & & & \\
\hline 990 & 0.026 & 0.026 & $-0.38 \%$ & 7.28 & 7.26 & $-0.3 \%$ & 6.43 & 6.44 & $0.1 \%$ & 27.73 & 27.74 & $0.0 \%$ & 44.08 & 43.96 & $-0.3 \%$ & & & \\
\hline 991 & 0.019 & 0.020 & $4.41 \%$ & 3.15 & 3.16 & $0.4 \%$ & 6.92 & 7.11 & $2.8 \%$ & 27.83 & 28.07 & $0.9 \%$ & 46.61 & 46.52 & $-0.2 \%$ & & & \\
\hline 1992 & 0.025 & 0.025 & 3.07 & 7.35 & 5.06 & $-31.1 \%$ & 8.05 & 8.03 & $-0.2 \%$ & 26.54 & 26.71 & $0.6 \%$ & 43.56 & 43.47 & $-0.2 \%$ & & & \\
\hline 993 & 0.034 & 0.034 & $-1.05 \%$ & 7.07 & 3.30 & $-53.4 \%$ & 7.77 & 7.79 & $0.3 \%$ & 26.26 & 26.46 & 0.8 & 41.88 & 41.60 & $-0.7 \%$ & & & \\
\hline .994 & 0.033 & 0.033 & $-0.81 \%$ & 8.25 & 6.75 & $-18.2 \%$ & 7.96 & 7.96 & $0.1 \%$ & 25.63 & 25.67 & $0.1 \%$ & 41.51 & 41.26 & $-0.6 \%$ & & & \\
\hline 995 & 0.031 & 0.030 & $-1.10 \%$ & 3.30 & 3.33 & $0.9 \%$ & 6.98 & 6.99 & $0.2 \%$ & 27.70 & 27.61 & $-0.3 \%$ & 44.12 & 43.96 & $-0.3 \%$ & & & \\
\hline 996 & 0.199 & 0.188 & $-5.49 \%$ & 0.28 & 0.27 & $-4.0 \%$ & 6.20 & 6.26 & $1.0 \%$ & 27.73 & 27.77 & $0.1 \%$ & 49.43 & 49.19 & $-0.5 \%$ & & & \\
\hline 1997 & 0.057 & 0.056 & $-1.37 \%$ & 2.23 & 2.23 & $0.0 \%$ & 5.64 & 5.64 & $0.0 \%$ & 28.30 & 28.29 & 0. & 44.55 & 44.51 & $-0.1 \%$ & & & \\
\hline 1998 & 0.019 & 0.019 & $0.41 \%$ & 7.47 & 7.44 & $-0.4 \%$ & 6.08 & 6.15 & $1.1 \%$ & 27.67 & 27.70 & $0.1 \%$ & 45.31 & 45.25 & $-0.1 \%$ & & & \\
\hline 1999 & 0.022 & 0.022 & $2.21 \%$ & 6.26 & 6.26 & $0.0 \%$ & 6.07 & 6.19 & $2.0 \%$ & 28.39 & 28.33 & $-0.2 \%$ & 44.41 & 44.34 & $-0.2 \%$ & & & \\
\hline 2000 & 0.029 & 0.028 & $-2.88 \%$ & 4.95 & 4.93 & $-0.4 \%$ & 6.16 & 6.21 & $0.8 \%$ & 27.79 & 27.80 & $0.0 \%$ & 44.62 & 44.63 & $0.0 \%$ & & & \\
\hline 2001 & 0.035 & 0.034 & $-1.21 \%$ & 4.39 & 3.98 & $-9.5 \%$ & 8.15 & 8.10 & $-0.6 \%$ & 26.00 & 26.30 & $1.1 \%$ & 41.25 & 40.97 & $-0.7 \%$ & & & \\
\hline 2002 & 0.022 & 0.023 & $1.86 \%$ & 7.26 & 7.24 & $-0.3 \%$ & 6.66 & 6.64 & $-0.2 \%$ & 27.72 & 27.98 & $1.0 \%$ & 43.99 & 43.90 & $-0.2 \%$ & & & \\
\hline 2003 & 0.032 & 0.031 & $-2.88 \%$ & 3.51 & 4.12 & $17.2 \%$ & 7.51 & 7.55 & $0.5 \%$ & 27.04 & 27.15 & $0.4 \%$ & 42.64 & 42.50 & $-0.3 \%$ & & & \\
\hline
\end{tabular}

Figure 5-17. Annual habitat summaries for fall chinook and coho salmon in the Union Gap reach for the Wymer_1 scenario. 


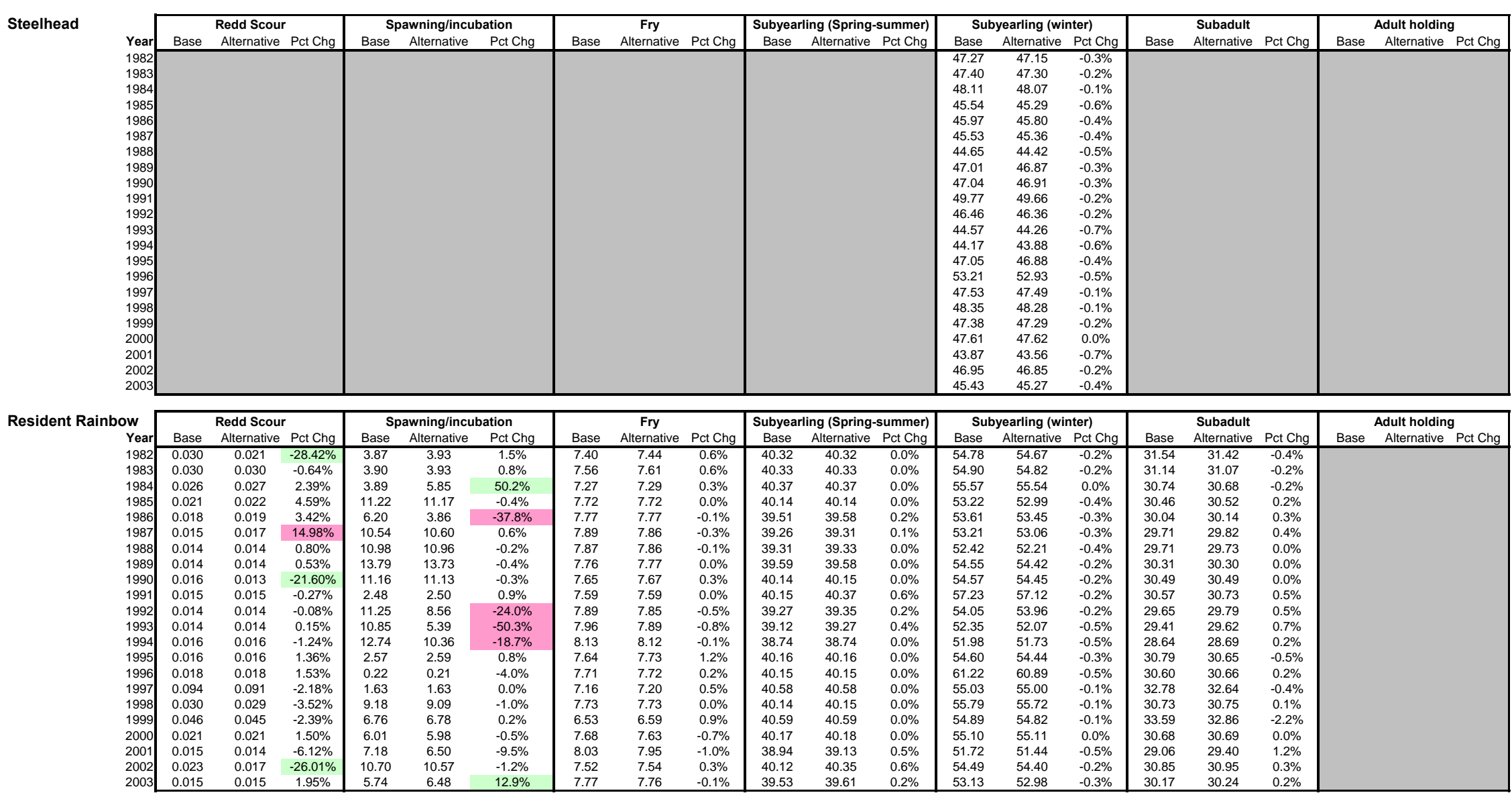

Figure 5-18. Annual habitat summaries for steelhead and resident rainbow trout in the Union Gap reach for the Wymer_1 scenario. 
Fall Chinook

\begin{tabular}{|c|c|c|c|c|c|c|c|c|c|c|c|c|c|c|c|}
\hline \multirow{3}{*}{ Year } & \multirow{2}{*}{\multicolumn{3}{|c|}{$\begin{array}{ll} & \text { Redd Scour } \\
\text { Base } & \text { Alternative Pct Chg }\end{array}$}} & \multicolumn{3}{|c|}{ Spawning/incubation } & \multirow{2}{*}{\multicolumn{3}{|c|}{ Fry }} & \multicolumn{3}{|c|}{ Subyearling (Spring-summer) } & Subyearling (winter) & Subadult & Adult holding \\
\hline & & & & Base & Alternative & Pct Chg & Base & Alternative & & Base & & & Base Alternative Pct Chg & Base Alternative Pct Chg & Base Alternative Pct Chg \\
\hline & 0.007 & 0.007 & $0.74 \%$ & 53 & 39 & $-26 \%$ & 26 & 26 & $0 \%$ & 139 & 138 & $-1 \%$ & & & \\
\hline 1983 & 0.007 & 0.007 & $0.89 \%$ & 60 & 59 & $-1 \%$ & 24 & 24 & $0 \%$ & 118 & 115 & $-3 \%$ & & & \\
\hline 1984 & 0.007 & 0.007 & $0.75 \%$ & 62 & 61 & $-1 \%$ & 26 & 26 & $-1 \%$ & 92 & 92 & $0 \%$ & & & \\
\hline 1985 & 0.007 & 0.008 & $8.46 \%$ & 61 & 60 & $-2 \%$ & 25 & 25 & $0 \%$ & 94 & 94 & $0 \%$ & & & \\
\hline 1986 & 0.007 & 0.007 & $1.00 \%$ & 47 & 47 & $0 \%$ & 22 & 22 & $0 \%$ & 96 & 97 & $0 \%$ & & & \\
\hline 1987 & 0.007 & 0.007 & $2.78 \%$ & 44 & 44 & $-2 \%$ & 26 & 26 & $0 \%$ & 99 & 99 & $0 \%$ & & & \\
\hline 1988 & 0.008 & 0.009 & $13.19 \%$ & 38 & 42 & $10 \%$ & 26 & 26 & $0 \%$ & 93 & 93 & $0 \%$ & & & \\
\hline 1989 & 0.007 & 0.008 & $7.29 \%$ & 62 & 51 & $-17 \%$ & 26 & 26 & $0 \%$ & 96 & 96 & $0 \%$ & & & \\
\hline 1990 & 0.007 & 0.007 & $1.17 \%$ & 64 & 62 & $-3 \%$ & 25 & 25 & $0 \%$ & 94 & 94 & $0 \%$ & & & \\
\hline 1991 & 0.006 & 0.006 & $4.03 \%$ & 56 & 44 & $-22 \%$ & 26 & 26 & $0 \%$ & 95 & & $-3 \%$ & & & \\
\hline 1992 & 0.007 & 0.007 & $1.26 \%$ & 47 & 64 & $35 \%$ & 22 & 22 & $-1 \%$ & 99 & 99 & $0 \%$ & & & \\
\hline 1993 & 0.008 & 0.008 & $13.23 \%$ & 44 & 43 & $-2 \%$ & 24 & 24 & $0 \%$ & 94 & 96 & $2 \%$ & & & \\
\hline 1994 & 0.008 & 0.009 & $16.99 \%$ & 40 & 38 & $-4 \%$ & 24 & 24 & $0 \%$ & 96 & 96 & $1 \%$ & & & \\
\hline 1995 & 0.007 & 0.007 & $1.33 \%$ & 49 & 48 & $-2 \%$ & 26 & 26 & $0 \%$ & 115 & 114 & $-1 \%$ & & & \\
\hline 1996 & 0.006 & 0.006 & $0.88 \%$ & 31 & 30 & $-2 \%$ & 22 & 22 & $3 \%$ & 96 & 94 & $-2 \%$ & & & \\
\hline 1997 & 0.007 & 0.007 & $0.72 \%$ & 39 & 39 & $-1 \%$ & 18 & 18 & $0 \%$ & 220 & 215 & $-2 \%$ & & & \\
\hline 1998 & 0.006 & 0.006 & $0.76 \%$ & 72 & 72 & $1 \%$ & 26 & 26 & $0 \%$ & 123 & 125 & $1 \%$ & & & \\
\hline 1999 & 0.007 & 0.007 & $1.07 \%$ & 47 & 48 & $2 \%$ & 26 & 27 & $1 \%$ & 127 & 112 & $-12 \%$ & & & \\
\hline 2000 & 0.006 & 0.006 & $0.82 \%$ & 59 & 59 & $1 \%$ & 25 & 25 & $2 \%$ & 93 & 93 & $0 \%$ & & & \\
\hline 2001 & 0.008 & 0.009 & $14.74 \%$ & 50 & 46 & $-8 \%$ & 21 & 21 & $-1 \%$ & 98 & 100 & $1 \%$ & & & \\
\hline 002 & 0.007 & 0.007 & $1.90 \%$ & 44 & 44 & $0 \%$ & 26 & 26 & $-1 \%$ & 102 & 102 & $0 \%$ & & & \\
\hline 200 & 0.007 & 0.008 & $5.49 \%$ & 43 & 54 & $26 \%$ & 26 & 26 & $0 \%$ & 96 & 96 & $0 \%$ & & & \\
\hline
\end{tabular}

Coho

\begin{tabular}{|c|c|c|c|c|c|c|c|c|c|c|c|c|c|c|c|c|c|c|}
\hline \multirow[b]{2}{*}{ Year } & \multicolumn{3}{|c|}{ Redd Scour } & \multicolumn{3}{|c|}{ Spawning/incubation } & \multicolumn{3}{|c|}{ Fry } & \multicolumn{3}{|c|}{ Subyearling (Spring-summer) } & \multicolumn{3}{|c|}{ Subyearling (winter) } & & Adult holding \\
\hline & Base & Alternative & Pct Chg & Base & Alternative & Pct Chg & Base & Alternative & Pct Chg & Base & Alternative & Pct Chg & Base & Alternative & Pct Chg & Base & Alternative Pct Chg & Base Alternative Pct Chg \\
\hline 1982 & 0.007 & 0.007 & $0.77 \%$ & 7 & 7 & $0 \%$ & 26 & 26 & $0 \%$ & 60 & 60 & $0 \%$ & 112 & 111 & $-1 \%$ & & & \\
\hline 1983 & 0.007 & 0.007 & $0.80 \%$ & 7 & 7 & $0 \%$ & 26 & 26 & $0 \%$ & 60 & 60 & $0 \%$ & 115 & 114 & $-1 \%$ & & & \\
\hline 1984 & 0.007 & 0.007 & $0.75 \%$ & 7 & 7 & $0 \%$ & 23 & 23 & $-1 \%$ & 60 & 60 & $0 \%$ & 121 & 121 & $-1 \%$ & & & \\
\hline 1985 & 0.007 & 0.008 & $8.46 \%$ & 38 & 38 & $0 \%$ & 22 & 22 & $0 \%$ & 63 & 63 & $0 \%$ & 102 & 100 & $-2 \%$ & & & \\
\hline 1986 & 0.007 & 0.007 & $1.00 \%$ & 4 & 8 & $123 \%$ & 20 & 20 & $0 \%$ & 67 & 67 & $0 \%$ & 101 & 100 & $-1 \%$ & & & \\
\hline 1987 & 0.007 & 0.007 & $2.78 \%$ & 16 & 17 & $1 \%$ & 23 & 23 & $0 \%$ & 68 & 68 & $0 \%$ & 103 & 101 & $-1 \%$ & & & \\
\hline 1988 & 0.007 & 0.007 & $4.56 \%$ & 32 & 36 & $13 \%$ & 23 & 23 & $-1 \%$ & 68 & 68 & $0 \%$ & 98 & 96 & $-2 \%$ & & & \\
\hline 1989 & 0.007 & 0.008 & $7.29 \%$ & 29 & 12 & $-58 \%$ & 23 & 23 & $0 \%$ & 67 & 67 & $0 \%$ & 110 & 109 & & & & \\
\hline 1990 & 0.007 & 0.007 & $0.74 \%$ & 25 & 25 & $1 \%$ & 21 & 21 & $0 \%$ & 63 & 62 & $-1 \%$ & 111 & 111 & $-1 \%$ & & & \\
\hline 1991 & 0.006 & 0.006 & $4.03 \%$ & 4 & 2 & $-41 \%$ & 22 & 23 & $1 \%$ & 62 & 60 & $-3 \%$ & 133 & 131 & $-1 \%$ & & & \\
\hline 1992 & 0.007 & 0.007 & $0.73 \%$ & 15 & 26 & $74 \%$ & 19 & 19 & $0 \%$ & 68 & 68 & $0 \%$ & 98 & 98 & $-1 \%$ & & & \\
\hline 1993 & 0.008 & 0.008 & $13.23 \%$ & 36 & 36 & $0 \%$ & 21 & 21 & $-2 \%$ & 68 & 68 & $0 \%$ & 95 & 93 & $-2 \%$ & & & \\
\hline 1994 & 0.008 & 0.009 & $16.99 \%$ & 37 & 37 & $0 \%$ & 20 & 20 & $-1 \%$ & 69 & 69 & $0 \%$ & 93 & 91 & $-2 \%$ & & & \\
\hline 1995 & 0.007 & 0.007 & $0.77 \%$ & 4 & 4 & $0 \%$ & 26 & 26 & $0 \%$ & 63 & 63 & $0 \%$ & 110 & 109 & $-1 \%$ & & & \\
\hline 1996 & 0.005 & 0.005 & $0.97 \%$ & 0 & 0 & $-1 \%$ & 23 & 23 & $1 \%$ & 63 & 62 & $-1 \%$ & 156 & 155 & $-1 \%$ & & & \\
\hline 997 & 0.007 & 0.007 & $0.72 \%$ & 2 & 2 & $-1 \%$ & 17 & 17 & $1 \%$ & 61 & 61 & $0 \%$ & 116 & 116 & $0 \%$ & & & \\
\hline 1998 & 0.006 & 0.006 & $\%$ & 15 & 14 & $-8 \%$ & 24 & 24 & $2 \%$ & 63 & 63 & $0 \%$ & 124 & 123 & $-1 \%$ & & & \\
\hline 999 & 0.007 & 0.007 & $\%$ & 13 & 12 & $-9 \%$ & 23 & 24 & $1 \%$ & 61 & 61 & $0 \%$ & 115 & 115 & $0 \%$ & & & \\
\hline 000 & 0.006 & 0. & $0.82 \%$ & 7 & 7 & $0 \%$ & 23 & 23 & $2 \%$ & 63 & 63 & $0 \%$ & 116 & 117 & $1 \%$ & & & \\
\hline 2001 & 0.008 & 0.009 & $14.74 \%$ & 40 & 40 & $0 \%$ & 19 & 19 & $1 \%$ & 69 & 68 & $0 \%$ & 89 & 88 & $-2 \%$ & & & \\
\hline 1 & 0.007 & 0.007 & $2.56 \%$ & 17 & 17 & $0 \%$ & 25 & 25 & $-1 \%$ & 63 & 60 & $-5 \%$ & 110 & 109 & $-1 \%$ & & & \\
\hline 003 & 0.007 & 0.008 & $5.49 \%$ & 12 & 9 & $-27 \%$ & 22 & 22 & $0 \%$ & 67 & 67 & $0 \%$ & 101 & 100 & $-1 \%$ & & & \\
\hline
\end{tabular}

Figure 5-19. Annual habitat summaries for fall chinook and coho salmon in the Wapato reach for the Wymer_1 scenario. 


\begin{tabular}{|c|c|c|c|c|c|c|c|c|c|c|c|c|c|c|c|c|c|c|c|c|}
\hline \multirow[b]{3}{*}{$\begin{array}{l}Y \\
15 \\
15 \\
15 \\
15 \\
15 \\
15 \\
15 \\
15 \\
15 \\
15 \\
15 \\
15 \\
15 \\
15 \\
20 \\
20 \\
20\end{array}$} & \multicolumn{3}{|c|}{ Redd Scour } & \multicolumn{3}{|c|}{ Spawning/incubation } & \multicolumn{3}{|c|}{ Fry } & \multirow{2}{*}{\multicolumn{3}{|c|}{$\begin{array}{l}\text { Subyearling (Spring-summer) } \\
\text { Base Alternative Pct Chg }\end{array}$}} & \multicolumn{3}{|c|}{ Subyearling (winter) } & \multirow{2}{*}{\multicolumn{3}{|c|}{$\begin{array}{ll}\text { Subadult } \\
\end{array}$}} & \multirow{2}{*}{\multicolumn{2}{|c|}{$\begin{array}{c}\text { Adult holding } \\
\text { A }\end{array}$}} \\
\hline & Base & Alternative & Pct Chg & Base & Alternative & Pct Chg & Base & Alternative & Pct Chg & & Alternativ & & Base & Alternative & Pct Chg & & & & & \\
\hline & & & & & & & & & & & & & $\begin{array}{l}121 \\
124 \\
131 \\
110 \\
110 \\
111 \\
106 \\
119 \\
121 \\
144 \\
107 \\
103 \\
101 \\
119 \\
171 \\
126 \\
134 \\
124 \\
126 \\
98 \\
119 \\
109 \\
\end{array}$ & $\begin{array}{l}120 \\
123 \\
130 \\
108 \\
109 \\
110 \\
105 \\
118 \\
120 \\
142 \\
107 \\
101 \\
100 \\
118 \\
170 \\
126 \\
132 \\
124 \\
126 \\
97 \\
118 \\
108 \\
\end{array}$ & $\begin{array}{l}-1 \% \\
-1 \% \\
-1 \% \\
-2 \% \\
-1 \% \\
-1 \% \\
-2 \% \\
-1 \% \\
-1 \% \\
-1 \% \\
-1 \% \\
-2 \% \\
-2 \% \\
-1 \% \\
-1 \% \\
0 \% \\
-1 \% \\
0 \% \\
1 \% \\
-1 \% \\
-1 \% \\
-1 \% \\
\end{array}$ & & & & & \\
\hline \multirow[t]{2}{*}{ Resident Rainbow } & \multicolumn{3}{|c|}{ Redd Scour } & \multicolumn{3}{|c|}{ Spawning/incubation } & \multicolumn{3}{|c|}{ Fry } & \multirow{2}{*}{\multicolumn{3}{|c|}{ Subyearling (Spring-summer) }} & \multicolumn{3}{|c|}{ Subyearling (winter) } & \multirow{2}{*}{\multicolumn{3}{|c|}{ Subadult }} & \multicolumn{2}{|c|}{$\begin{array}{l}\text { Adult holding } \\
\end{array}$} \\
\hline & Base & Alternative & Pct Chg & Base & Alternative & Pct Chg & Base & Alternative & Pct Chg & & & Pct Chg & Base & Alternative & Pct Chg & & & & Base & Alternative Pct Chg \\
\hline 1982 & 0.008 & 0.010 & $17.36 \%$ & 4 & 4 & $0 \%$ & 22 & 22 & $0 \%$ & 124 & 124 & $0 \%$ & 142 & 141 & $-1 \%$ & 87 & 87 & $0 \%$ & & \\
\hline 1983 & 0.008 & 0.010 & $17.34 \%$ & 5 & 5 & $0 \%$ & 22 & 22 & $0 \%$ & 124 & 124 & $0 \%$ & 145 & 144 & $-1 \%$ & 86 & 86 & $0 \%$ & & \\
\hline 1984 & 0.008 & 0.010 & $17.37 \%$ & 5 & 5 & $0 \%$ & 22 & 22 & $0 \%$ & 124 & 124 & $0 \%$ & 153 & 152 & $-1 \%$ & 86 & 86 & $-1 \%$ & & \\
\hline 1985 & 0.009 & 0.010 & $16.95 \%$ & 54 & 55 & $0 \%$ & 20 & 21 & $0 \%$ & 123 & 123 & $0 \%$ & 130 & 128 & $-1 \%$ & 88 & 87 & $-1 \%$ & & \\
\hline 1986 & 0.009 & 0.011 & $23.50 \%$ & 2 & 6 & $164 \%$ & 19 & 19 & $0 \%$ & 122 & 122 & $0 \%$ & 130 & 129 & $-1 \%$ & 92 & 92 & $0 \%$ & & \\
\hline 1987 & 0.009 & 0.011 & $24.83 \%$ & 13 & 13 & $1 \%$ & 19 & 19 & $0 \%$ & 122 & 122 & $0 \%$ & 131 & 130 & $-1 \%$ & 94 & 94 & $0 \%$ & & \\
\hline 1988 & 0.009 & 0.011 & $24.97 \%$ & 30 & 43 & $43 \%$ & 19 & 19 & $0 \%$ & 122 & 122 & $0 \%$ & 126 & 124 & $-1 \%$ & 91 & 91 & $0 \%$ & & \\
\hline 1989 & 0.009 & 0.011 & $23.99 \%$ & 29 & 9 & $-69 \%$ & 19 & 19 & $0 \%$ & 122 & 122 & $0 \%$ & 139 & 139 & $-1 \%$ & 90 & 90 & $0 \%$ & & \\
\hline 1990 & 0.008 & 0.010 & $20.90 \%$ & 24 & 25 & $1 \%$ & 21 & 21 & $0 \%$ & 124 & 124 & $0 \%$ & 142 & 141 & $-1 \%$ & 87 & 86 & $-1 \%$ & & \\
\hline 1991 & 0.008 & 0.010 & $13.96 \%$ & 2 & 1 & $-42 \%$ & 21 & 22 & $6 \%$ & 123 & 124 & $1 \%$ & 168 & 166 & $-1 \%$ & 86 & 85 & $-1 \%$ & & \\
\hline 1992 & 0.009 & 0.011 & $24.20 \%$ & 11 & 26 & $128 \%$ & 19 & 19 & $\%$ & 122 & 122 & $0 \%$ & 127 & 126 & $-1 \%$ & 93 & 93 & $0 \%$ & & \\
\hline 1993 & 0.009 & 0.011 & $24.41 \%$ & 42 & 42 & $0 \%$ & 19 & 19 & $\%$ & 122 & 122 & $0 \%$ & 122 & 120 & $-2 \%$ & 92 & 92 & $0 \%$ & & \\
\hline 1994 & 0.009 & 0.011 & 26. & 42 & 42 & $0 \%$ & 18 & 18 & $\%$ & 121 & 121 & $0 \%$ & 120 & 118 & $-2 \%$ & 92 & 92 & $0 \%$ & & \\
\hline 1995 & 0.008 & 0.010 & 20. & 2 & 2 & $0 \%$ & 21 & 21 & $\%$ & 1 & 124 & $0 \%$ & 140 & 138 & $-1 \%$ & 88 & 89 & $2 \%$ & & \\
\hline 1996 & 0.008 & 0.010 & 20. & 0 & 0 & $-1 \%$ & 21 & 21 & $\%$ & 1 & 123 & $0 \%$ & 201 & 200 & $-1 \%$ & 89 & 87 & $-2 \%$ & & \\
\hline 1997 & 0.008 & 0.009 & 14. & 1 & 1 & -1 & 22 & 22 & $0 \%$ & 125 & 125 & $0 \%$ & 147 & 147 & $0 \%$ & 90 & 89 & $0 \%$ & & \\
\hline 1998 & 0.008 & 0.010 & 20 & 13 & 11 & $-12 \%$ & 21 & 21 & $0 \%$ & 123 & 124 & 0 & 156 & 154 & $-1 \%$ & 90 & 90 & $0 \%$ & & \\
\hline 1999 & 0.008 & 0.009 & & 10 & 9 & $-10 \%$ & 23 & 22 & $\%$ & 25 & 125 & 00 & 145 & 145 & $0 \%$ & 90 & 88 & $-2 \%$ & & \\
\hline 2000 & 0.008 & 0.010 & $20.50 \%$ & 5 & 5 & $0 \%$ & 21 & 21 & $\%$ & 4 & 124 & 0 & 147 & 148 & $1 \%$ & 87 & 87 & $0 \%$ & & \\
\hline 2001 & 0.009 & 0.011 & & 54 & 54 & $-1 \%$ & 18 & 19 & $1 \%$ & 121 & 122 & 0 & 117 & 115 & $-1 \%$ & 93 & 94 & $1 \%$ & & \\
\hline $\begin{array}{l}2002 \\
2003\end{array}$ & $\begin{array}{l}0.008 \\
0.009\end{array}$ & $\begin{array}{l}0.010 \\
0.011\end{array}$ & $\begin{array}{l}13.88 \% \\
23.44 \%\end{array}$ & $\begin{array}{c}13 \\
9\end{array}$ & $\begin{array}{c}13 \\
6\end{array}$ & $\begin{array}{c}0 \% \\
-30 \%\end{array}$ & $\begin{array}{l}21 \\
19\end{array}$ & $\begin{array}{l}22 \\
19\end{array}$ & $\begin{array}{l}6 \% \\
1 \%\end{array}$ & $\begin{array}{l}123 \\
122\end{array}$ & $\begin{array}{l}124 \\
122\end{array}$ & $\begin{array}{l}1 \% \\
0 \%\end{array}$ & $\begin{array}{l}140 \\
129\end{array}$ & $\begin{array}{l}139 \\
128\end{array}$ & $\begin{array}{l}-1 \% \\
-1 \%\end{array}$ & $\begin{array}{l}88 \\
91\end{array}$ & $\begin{array}{l}87 \\
91\end{array}$ & $\begin{array}{l}-2 \% \\
0 \%\end{array}$ & & \\
\hline
\end{tabular}

Figure 5-20. Annual habitat summaries for steelhead and resident rainbow trout in the Wapato reach for the Wymer_1 scenario. 
Fall Chinook

\begin{tabular}{|c|c|c|c|c|c|c|c|c|c|c|c|c|c|c|c|c|}
\hline \multirow[b]{2}{*}{ Year } & \multirow{2}{*}{\multicolumn{3}{|c|}{ 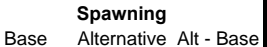 }} & \multicolumn{3}{|c|}{ Incubation } & \multicolumn{3}{|c|}{ Fry } & \multirow{2}{*}{\multicolumn{3}{|c|}{ Subyearling (Spring-summer) }} & \multirow{2}{*}{$\begin{array}{l}\text { Subyearling (winter) } \\
\text { Base Alternative Alt - Base }\end{array}$} & \multirow{2}{*}{\multicolumn{2}{|c|}{ 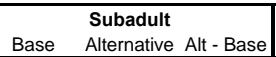 }} & \multirow[t]{2}{*}{\begin{tabular}{lc}
\multicolumn{2}{c}{ Adult holding } \\
Base & Alternative Alt - Base
\end{tabular}} \\
\hline & & & & Base & & Alt - Base & Base & & Alt - Base & & & & & & & \\
\hline 1982 & 0.0 & 0.0 & No Data & 0.0 & 0.0 & No Data & 0.0 & 0.0 & No Data & 0.0 & 0.0 & No Data & & & & \\
\hline 1983 & 0.0 & 0.0 & No Data & 0.0 & 0.0 & No Data & 0.0 & 0.0 & No Data & 0.0 & 0.0 & No Data & & & & \\
\hline 1984 & 12.4 & 12.4 & 0.0 & 0.0 & 0.0 & No Data & 11.6 & 11.7 & 0.1 & 14.6 & 14.6 & 0.0 & & & & \\
\hline 1985 & 12.8 & 12.8 & 0.0 & 0.0 & 0.0 & No Data & 13.5 & 13.6 & 0.1 & 15.8 & 15.8 & 0.1 & & & & \\
\hline 1986 & 11.6 & 11.6 & 0.0 & 0.0 & 0.0 & No Data & 12.7 & 12.8 & 0.0 & 16.1 & 16.1 & 0.0 & & & & \\
\hline 1987 & 13.0 & 13.0 & 0.0 & 0.0 & 0.0 & No Data & 15.0 & 15.1 & 0.1 & 15.7 & 15.7 & 0.0 & & & & \\
\hline 1988 & 13.7 & 13.7 & 0.0 & 0.0 & 0.0 & No Data & 12.9 & 12.9 & 0.1 & 14.6 & 14.6 & 0.0 & & & & \\
\hline 1989 & 14.7 & 14.7 & 0.0 & 0.0 & 0.0 & No Data & 12.9 & 13.0 & 0.0 & 16.1 & 16.1 & 0.1 & & & & \\
\hline 1990 & 13.1 & 13.1 & 0.0 & 0.0 & 0.0 & No Data & 12.9 & 13.0 & 0.1 & 14.2 & 14.2 & 0.0 & & & & \\
\hline 1991 & 12.9 & 12.9 & 0.0 & 0.0 & 0.0 & No Data & 12.8 & 12.8 & 0.0 & 14.8 & 14.8 & 0.0 & & & & \\
\hline 1992 & 14.0 & 14.0 & 0.0 & 0.0 & 0.0 & No Data & 14.3 & 14.3 & 0.0 & 17.4 & 17.4 & 0.0 & & & & \\
\hline 1993 & 14.9 & 14.9 & 0.0 & 0.0 & 0.0 & No Data & 13.5 & 13.5 & 0.0 & 16.6 & 16.6 & 0.0 & & & & \\
\hline 1994 & 14.0 & 14.0 & 0.0 & 0.0 & 0.0 & No Data & 14.4 & 14.4 & 0.0 & 16.0 & 16.0 & 0.0 & & & & \\
\hline 1995 & 13.6 & 13.5 & -0.1 & 0.0 & 0.0 & No Data & 12.3 & 12.4 & 0.1 & 14.4 & 14.4 & 0.0 & & & & \\
\hline 1996 & 12.7 & 12.7 & 0.0 & 0.0 & 0.0 & No Data & 12.0 & 12.0 & 0.0 & 15.0 & 15.0 & 0.0 & & & & \\
\hline 1997 & 12.3 & 12.3 & 0.0 & 0.0 & 0.0 & No Data & 11.1 & 11.1 & 0.0 & 14.1 & 14.1 & 0.0 & & & & \\
\hline 1998 & 12.8 & 12.9 & 0.1 & 0.0 & 0.0 & No Data & 12.9 & 12.9 & 0.1 & 15.0 & 15.0 & 0.0 & & & & \\
\hline 1999 & 12.8 & 12.8 & 0.0 & 0.0 & 0.0 & No Data & 11.1 & 11.2 & 0.1 & 14.2 & 14.2 & 0.0 & & & & \\
\hline 2000 & 14.1 & 14.1 & 0.0 & 0.0 & 0.0 & No Data & 11.8 & 11.9 & 0.1 & 15.0 & 15.1 & 0.1 & & & & \\
\hline 001 & 13.1 & 13.1 & 0.0 & 0.0 & 0.0 & No Data & 13.9 & 13.9 & 0.1 & 16.5 & 16.5 & -0.1 & & & & \\
\hline 2002 & 13.6 & 13.6 & 0.0 & 0.0 & 0.0 & No Data & 12.1 & 12.2 & 0.1 & 14.2 & 14.2 & 0.0 & & & & \\
\hline 2003 & 12.9 & 12.8 & -0.1 & 0.0 & 0.0 & No Data & 12.8 & 12.8 & 0.0 & 15.6 & 15.6 & 0.1 & & & & \\
\hline
\end{tabular}

Coho

\begin{tabular}{|c|c|c|c|c|c|c|c|c|c|c|c|c|c|c|c|c|c|c|}
\hline \multirow[b]{2}{*}{ YearL } & \multicolumn{3}{|c|}{ Spawning } & \multirow{2}{*}{\multicolumn{3}{|c|}{\begin{tabular}{ll}
\multicolumn{1}{c}{ Incubation } \\
Basernative Alt - Base & Alternat
\end{tabular}}} & \multirow{2}{*}{\multicolumn{3}{|c|}{ Fry }} & \multicolumn{3}{|c|}{ Subyearling (Spring-summer) } & \multicolumn{3}{|c|}{ Subyearling (winter) } & & Adult holding \\
\hline & Base & Alternative & Alt - Base & & & & Base & & & Base & Alternat & Alt - Base & Base & Alternati & Alt - Base & Base & Alternative Alt - Base & Base Alternative Alt - Base \\
\hline 1982 & 0.0 & 0.0 & No Data & 0.0 & 0.0 & No Data & 0.0 & 0.0 & No Data & 0.0 & 0.0 & No Data & 0.0 & 0.0 & No Data & & & \\
\hline 1983 & 0.0 & 0.0 & No Data & 0.0 & 0.0 & No Data & 0.0 & 0.0 & No Data & 0.0 & 0.0 & No Data & 0.0 & 0.0 & No Data & & & \\
\hline 1984 & 0.0 & 0.0 & No Data & 0.0 & 0.0 & No Data & 14.6 & 146 & 0.0 & 201 & 201 & 00 & 126 & 127 & 01 & & & \\
\hline 1985 & 0.0 & 0.0 & No Data & 0.0 & 0.0 & No Data & 15.8 & 15.8 & 0.1 & 20.4 & 20.4 & 0.0 & 13.5 & 13.6 & 0.1 & & & \\
\hline 1986 & 0.0 & 0.0 & No Data & 0.0 & 0.0 & No Data & 16.1 & 161 & 0.0 & 20.6 & 20.5 & 00 & 127 & 128 & 00 & & & \\
\hline 1987 & 0.0 & 0.0 & No Data & 0.0 & 0.0 & No Data & 15.7 & 157 & 0.0 & 19.3 & 19.3 & 0.0 & 150 & 15.1 & 0.1 & & & \\
\hline 1988 & 0.0 & 0.0 & No Data & 0.0 & 0.0 & No Data & 146 & 146 & 0.0 & 193 & 19.3 & 00 & 137 & 137 & 00 & & & \\
\hline 1989 & 0.0 & 00 & No Data & 0.0 & 00 & No Data & 14.8 & 148 & 0.0 & 192 & 192 & 00 & 147 & 147 & 00 & & & \\
\hline 1990 & 0.0 & 0.0 & No Data & 0.0 & 0.0 & No Data & 142 & 142 & 0.0 & 20.9 & 208 & -01 & 131 & 131 & 0.0 & & & \\
\hline 1991 & 0.0 & 0.0 & No Data & 0.0 & 00 & No Data & 145 & 141 & -0.3 & 200 & 200 & 00 & 139 & 139 & 01 & & & \\
\hline 1992 & 0.0 & 0.0 & No Data & 0.0 & 0.0 & No Data & 169 & 169 & 0.0 & 20.5 & 20.5 & 01 & 14.3 & 143 & 0.0 & & & \\
\hline 1993 & 0.0 & 0.0 & No Data & 0.0 & 0.0 & No Data & 16.6 & 16.6 & 00 & 186 & 186 & 00 & 14.9 & 149 & 00 & & & \\
\hline 1994 & 0.0 & 0.0 & No Data & 00 & 00 & No Data & 160 & 160 & 00 & 20.5 & 20.5 & 00 & 144 & 14.4 & 00 & & & \\
\hline 1995 & 0.0 & 0.0 & No Data & 0.0 & 0.0 & No Data & 14.4 & 14.4 & 00 & 19.9 & 199 & 00 & 13.6 & 135 & -01 & & & \\
\hline 1996 & 0.0 & 0.0 & No Data & 0.0 & 0.0 & No Data & 15.0 & 15.0 & 00 & 204 & 204 & 00 & 137 & 137 & 00 & & & \\
\hline 1997 & 0.0 & 0.0 & No Data & 0.0 & 0.0 & No Data & 14.1 & 14.1 & 0 & 20.7 & 20.6 & 0 & 136 & 136 & 0 & & & \\
\hline 1998 & 0.0 & 0.0 & No Data & 0.0 & 0.0 & No Data & 15.0 & 15.0 & 0.0 & 21.9 & 21.9 & 0.0 & 13.4 & 13.4 & 0.0 & & & \\
\hline 1999 & 0.0 & 0.0 & No Data & 0.0 & 0.0 & No Data & 14.2 & 14.2 & 0.0 & 20.2 & 20.0 & -0.2 & 128 & 128 & 0.0 & & & \\
\hline 2000 & 0.0 & 0.0 & No Data & 0.0 & 0.0 & No Data & 15.0 & 15.1 & 0.1 & 20.7 & 20.7 & 0.0 & 14.1 & 14.1 & 0.0 & & & \\
\hline 2001 & 0.0 & 0.0 & No Data & 0.0 & 0.0 & No Data & 16.5 & 16.5 & -01 & 19.9 & 20.0 & 0.1 & 13.9 & 13.9 & 01 & & & \\
\hline 2 & 0.0 & 0.0 & No Data & 0.0 & 00 & No Data & 142 & 142 & 00 & 211 & 212 & 01 & 136 & 136 & 00 & & & \\
\hline 2003 & 0.0 & 0.0 & No Data & 0.0 & 0.0 & No Data & 15.6 & 15.6 & 0.1 & 21.1 & 21.1 & 0.0 & 14.1 & 14.0 & -0.1 & & & \\
\hline
\end{tabular}

Figure 5-21. Annual temperature summaries for fall chinook and coho salmon in the Union Gap reach for the Wymer_1 scenario. 


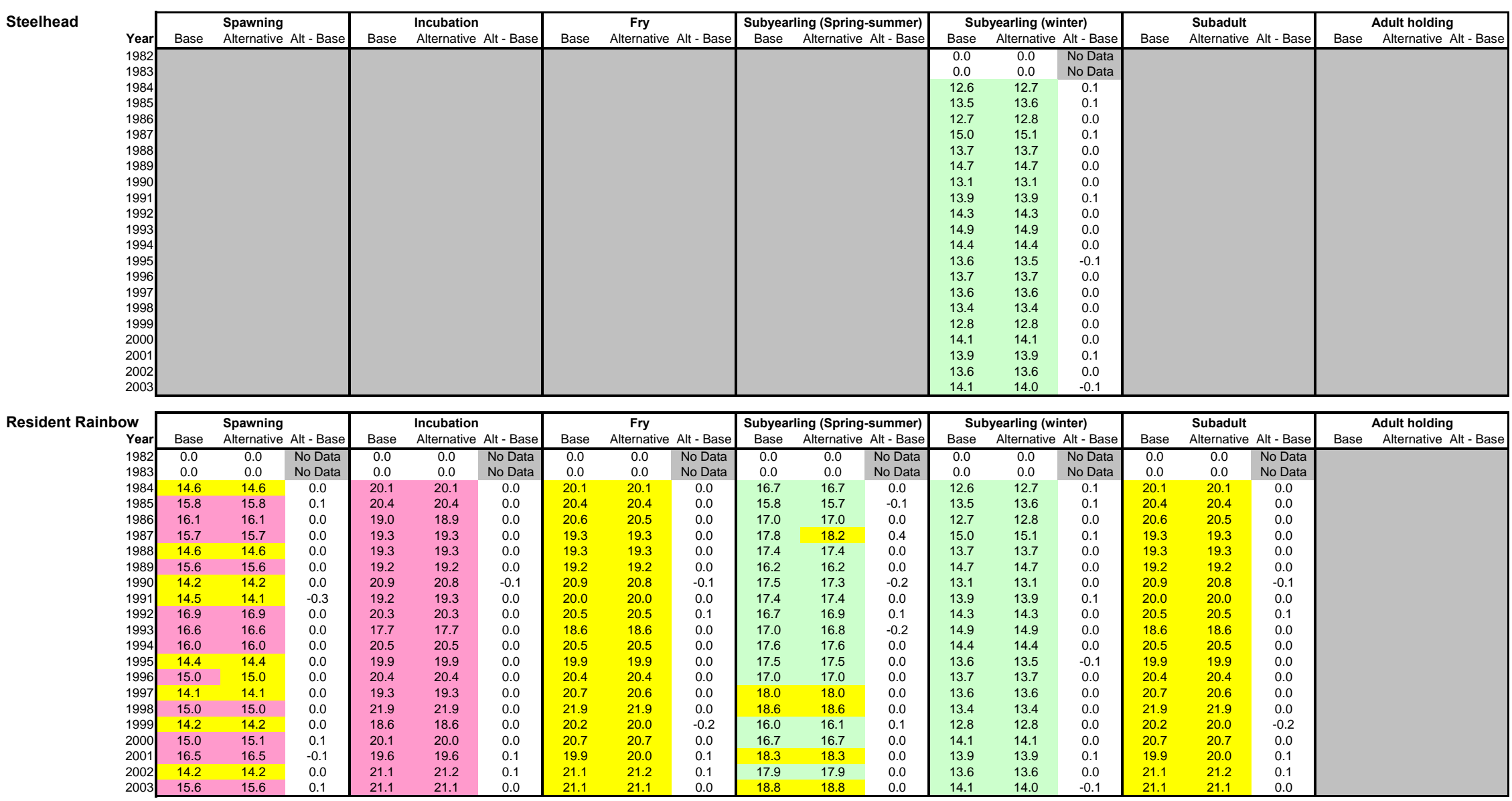

Figure 5-22. Annual temperature summaries for steelhead and resident rainbow trout in the Union Gap reach for the Wymer_1 scenario. 
Fall Chinook

\begin{tabular}{|c|c|c|c|c|c|c|c|c|c|c|c|c|c|c|c|c|}
\hline \multirow[b]{2}{*}{ Year } & \multirow{2}{*}{\multicolumn{3}{|c|}{$\begin{array}{|ll|} & \text { Spawning } \\
\text { Base } & \text { Alternative Alt - Base }\end{array}$}} & \multirow{2}{*}{\multicolumn{3}{|c|}{$\begin{array}{ll} & \text { Incubation } \\
\text { Base } & \text { Alternative Alt - Base }\end{array}$}} & \multicolumn{3}{|c|}{ Fry } & \multicolumn{3}{|c|}{ Subyearling (Spring-summer) } & Subyearling (winter) & \multirow{2}{*}{\multicolumn{2}{|c|}{ Subadult }} & \multirow{2}{*}{ 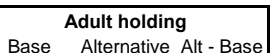 } \\
\hline & & & & & & & Base & Alternative & Alt - Base & Base & Alternative & & Base Alternative Alt - Base & Base & & \\
\hline & 0.0 & 0.0 & No Data & 0.0 & 0.0 & No Data & 0.0 & 0.0 & No Data & 0.0 & 0.0 & No Data & & & & \\
\hline 1983 & 0.0 & 0.0 & No Data & 0.0 & 0.0 & No Data & 0.0 & 0.0 & No Data & 0.0 & 0.0 & No Data & & & & \\
\hline 1984 & 13.8 & 13.8 & 0.0 & 0.0 & 0.0 & No Data & 13.2 & 13.2 & 0.0 & 17.6 & 17.6 & 0.0 & & & & \\
\hline 1985 & 14.8 & 14.9 & 0.0 & 0.0 & 0.0 & No Data & 15.2 & 15.2 & 0.1 & 18.5 & 18.6 & 0.0 & & & & \\
\hline 1986 & 13.7 & 13.7 & 0.0 & 0.0 & 0.0 & No Data & 15.5 & 15.6 & 0.1 & 18.6 & 18.6 & -0.1 & & & & \\
\hline 1987 & 15.5 & 15.5 & 0.0 & 0.0 & 0.0 & No Data & 16.5 & 16.6 & 0.1 & 17.4 & 17.4 & 0.0 & & & & \\
\hline 1988 & 16.0 & 16.0 & 0.0 & 0.0 & 0.0 & No Data & 14.3 & 14.3 & 0.0 & 17.7 & 17.8 & 0.0 & & & & \\
\hline 1989 & 16.8 & 16.8 & 0.0 & 0.0 & 0.0 & No Data & 15.1 & 15.2 & 0.0 & 19.7 & 19.7 & 0.1 & & & & \\
\hline 1990 & 15.2 & 15.2 & 0.0 & 0.0 & 0.0 & No Data & 14.2 & 14.3 & 0.0 & 16.7 & 16.7 & 0.0 & & & & \\
\hline 1991 & 14.1 & 14.1 & 0.0 & 0.0 & 0.0 & No Data & 15.1 & 15.2 & 0.1 & 17.5 & 17.6 & 0.1 & & & & \\
\hline 1992 & $\begin{array}{l}14.1 \\
16.4\end{array}$ & 16.3 & 0.0 & 0.0 & 0.0 & No Data & $\begin{array}{l}16.9 \\
16.9\end{array}$ & $\begin{array}{l}16.9 \\
16.9\end{array}$ & 0.0 & 20.7 & 20.7 & 0.0 & & & & \\
\hline 1993 & 16.7 & 16.7 & 0.0 & 0.0 & 0.0 & No Data & 16.3 & 16.3 & 0.0 & 19.3 & 19.5 & 0.2 & & & & \\
\hline 1994 & 16.2 & 16.2 & 0.0 & 0.0 & 0.0 & No Data & 16.4 & 16.5 & 0.1 & 19.3 & 19.3 & 0.0 & & & & \\
\hline $\begin{array}{l}1994 \\
1995\end{array}$ & $\begin{array}{l}15.2 \\
15.8\end{array}$ & $\begin{array}{l}15.2 \\
15.8\end{array}$ & $\begin{array}{l}-0.1 \\
-0.1\end{array}$ & 0.0 & 0.0 & No Data & $\begin{array}{l}1.4 \\
14.9\end{array}$ & $\begin{array}{l}10.5 \\
15.0\end{array}$ & $\begin{array}{l}0.1 \\
0.1\end{array}$ & $\begin{array}{l}19.3 \\
16.6\end{array}$ & $\begin{array}{l}16.5 \\
16.7\end{array}$ & 0.1 & & & & \\
\hline 1996 & $\begin{array}{l}14.8 \\
14.9\end{array}$ & $\begin{array}{l}14.8 \\
14.9\end{array}$ & $\begin{array}{l}-0.1 \\
0.0\end{array}$ & 0.0 & 0.0 & No Data & $\begin{array}{l}14.9 \\
13.4\end{array}$ & $\begin{array}{l}15.0 \\
13.4\end{array}$ & 0.1 & $\begin{array}{l}16.0 \\
16.9\end{array}$ & $\begin{array}{l}16.1 \\
16.9\end{array}$ & $\begin{array}{l}0.1 \\
0.0\end{array}$ & & & & \\
\hline 1997 & $\begin{array}{l}14.9 \\
14.3\end{array}$ & $\begin{array}{l}14.9 \\
14.3\end{array}$ & 0.0 & 0.0 & 0.0 & No Data & $\begin{array}{l}13.4 \\
12.4\end{array}$ & $\begin{array}{l}13.4 \\
12.4\end{array}$ & 0.1 & $\begin{array}{l}15.9 \\
15.6\end{array}$ & $\begin{array}{l}15.9 \\
15.6\end{array}$ & 0.0 & & & & \\
\hline 1998 & $\begin{array}{l}14.3 \\
14.7\end{array}$ & $\begin{array}{l}14.3 \\
14.7\end{array}$ & 0.0 & 0.0 & 0.0 & No Data & $\begin{array}{l}14.4 \\
14.5\end{array}$ & $\begin{array}{l}12.4 \\
14.6\end{array}$ & 0.1 & $\begin{array}{l}15.0 \\
17.1\end{array}$ & $\begin{array}{l}17.6 \\
17.1\end{array}$ & 0.0 & & & & \\
\hline 1999 & $\begin{array}{l}14.1 \\
14.7\end{array}$ & $\begin{array}{l}14.7 \\
14.7\end{array}$ & 0.0 & 0.0 & 0.0 & No Data & $\begin{array}{l}14.5 \\
13.1\end{array}$ & $\begin{array}{l}14.6 \\
13.1\end{array}$ & 0.1 & $\begin{array}{l}16.1 \\
16.0\end{array}$ & $\begin{array}{l}1.1 \\
16.0\end{array}$ & 0.0 & & & & \\
\hline 2000 & $\begin{array}{l}14.1 \\
15.9\end{array}$ & $\begin{array}{l}1.7 \\
15.9\end{array}$ & 0.0 & 0.0 & 0.0 & No Data & $\begin{array}{l}13.1 \\
13.4\end{array}$ & $\begin{array}{l}13.1 \\
13.5\end{array}$ & $\begin{array}{l}0.1 \\
0.1\end{array}$ & $\begin{array}{l}16.0 \\
17.8\end{array}$ & $\begin{array}{l}17.0 \\
17.9\end{array}$ & 0.1 & & & & \\
\hline 2001 & $\begin{array}{l}15.9 \\
15.4\end{array}$ & $\begin{array}{l}15.9 \\
15.4\end{array}$ & 0.0 & 0.0 & 0.0 & No Data & $\begin{array}{l}13.4 \\
17.4\end{array}$ & $\begin{array}{l}13.5 \\
17.3\end{array}$ & $\begin{array}{l}0.1 \\
0.0\end{array}$ & $\begin{array}{l}20.8 \\
20.7\end{array}$ & $\begin{array}{l}1.9 \\
20.6\end{array}$ & $\begin{array}{l}-0.1 \\
-0.1\end{array}$ & & & & \\
\hline 2002 & 15.9 & 15.9 & 0.0 & 0.0 & 0.0 & No Data & 14.2 & 14.3 & 0.1 & 16.3 & 16.3 & 0.0 & & & & \\
\hline 2003 & $\begin{array}{l}15.9 \\
15.0\end{array}$ & $\begin{array}{l}15.9 \\
14.8\end{array}$ & $\begin{array}{l}0.0 \\
-0.2\end{array}$ & $\begin{array}{l}0.0 \\
0.0\end{array}$ & 0.0 & No Data & $\begin{array}{l}14.2 \\
14.7\end{array}$ & $\begin{array}{l}14.3 \\
14.7\end{array}$ & $\begin{array}{l}0.1 \\
0.0\end{array}$ & $\begin{array}{l}10.3 \\
19.1\end{array}$ & $\begin{array}{l}19.3 \\
19.2\end{array}$ & 0.1 & & & & \\
\hline
\end{tabular}

Coho

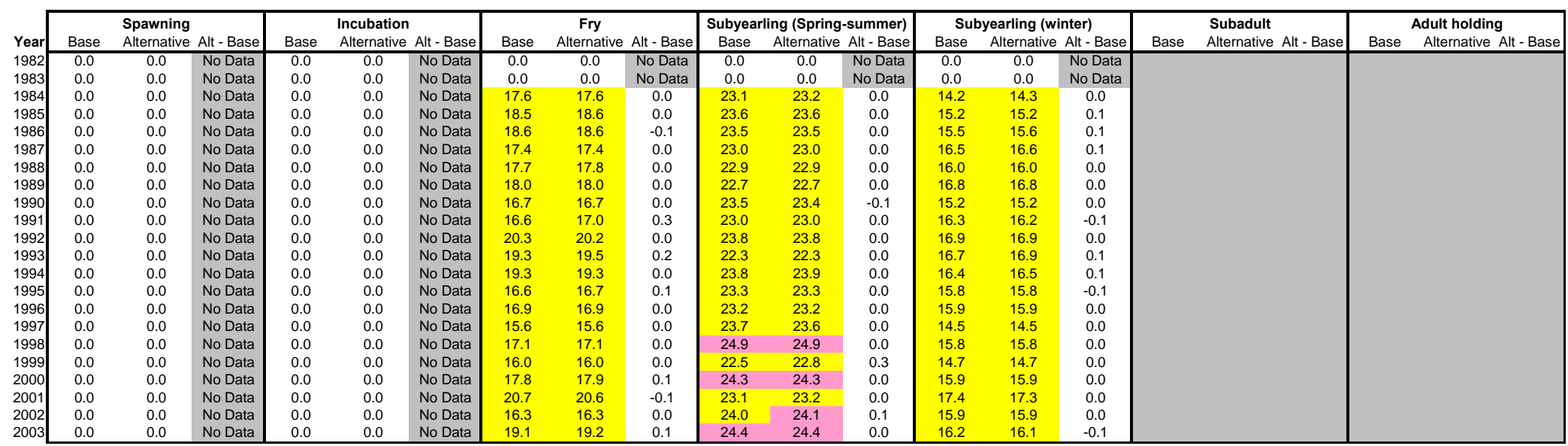

Figure 5-23. Annual temperature summaries for fall chinook and coho salmon in the Wapato reach for the Wymer_1 scenario. 


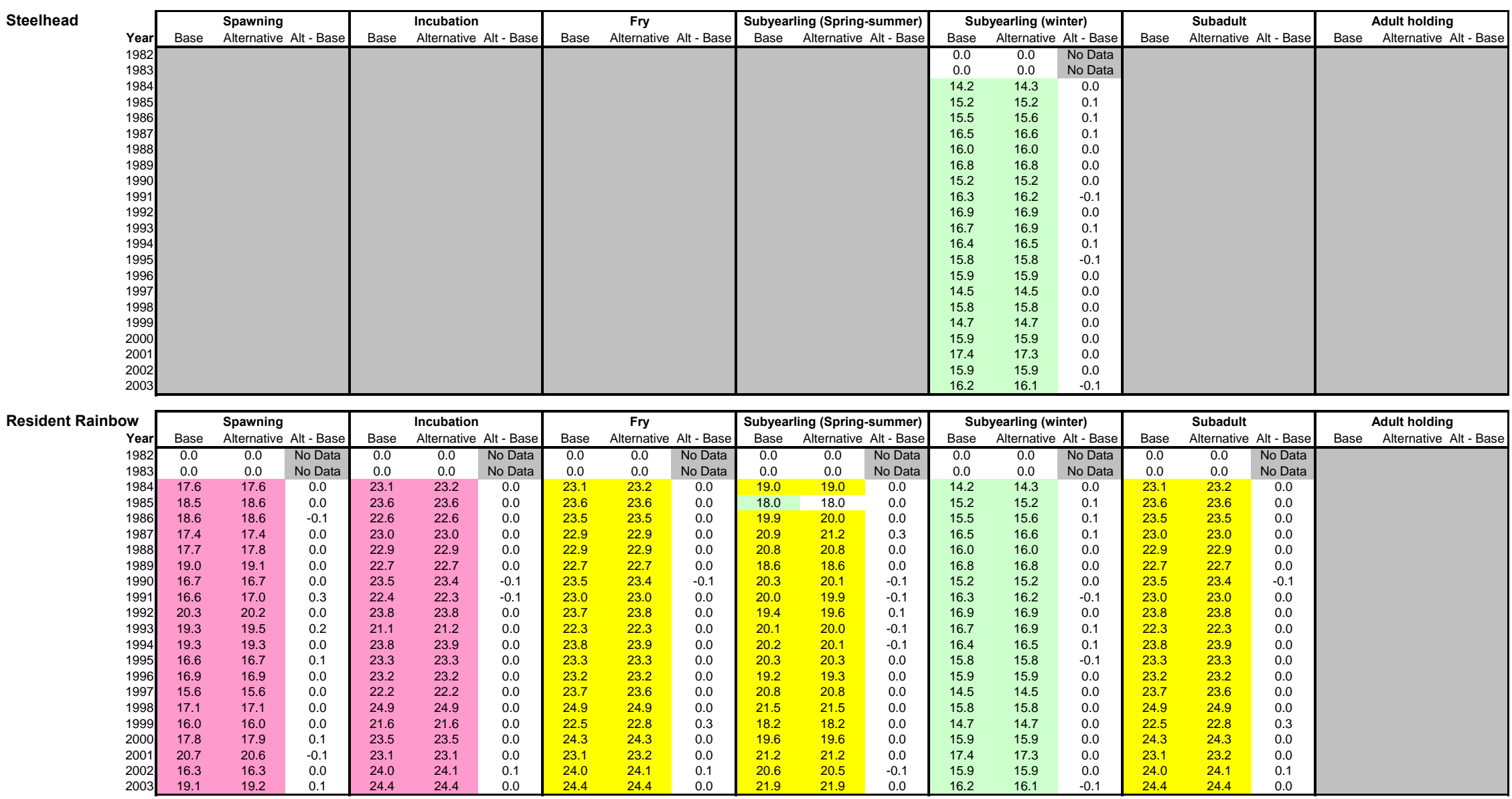

Figure 5-24. Annual temperature summaries for steelhead and resident rainbow trout in the Wapato reach for the Wymer_1 scenario. 
Appendix 6. YRDSS Run Results for the WymerPlus Scenario 


\begin{tabular}{|c|c|c|c|c|c|c|c|c|c|c|c|c|c|c|c|c|}
\hline $\begin{array}{l}\text { Yakima DSS beta test } \\
\text { Summary }\end{array}$ & & & $\begin{array}{l}\text { RunDate: } \\
\text { Baseline: } \\
\text { Alternative: }\end{array}$ & & $\begin{array}{l}02 / 21 / 08 \\
\text { No Action } \\
\text { WymerPlus }\end{array}$ & & & & $\begin{array}{l}\text { Start date } \\
10 / 1 / 1981 \\
10 / 1 / 1981 \\
\end{array}$ & $\begin{array}{l}\text { to } \\
\text { to }\end{array}$ & & $\begin{array}{l}\text { End date } \\
9 / 30 / 2003 \\
9 / 30 / 2003 \\
\end{array}$ & & & & \\
\hline Resource Category & Time Window & & Easton & & & Kittitas & & & $\begin{array}{l}\text { Stream React } \\
\text { Naches }\end{array}$ & & & Union Gap & & & Wapato & \\
\hline $\begin{array}{l}\text { Spring Chinook } \\
\text { Max Redd Scour repth (ft) } \\
\text { Spawninglincubation } \\
\text { Fry } \\
\text { Subyearling (Spring-summer) } \\
\text { Subyearling (winter) } \\
\text { Adult holding }\end{array}$ & $\begin{array}{l}\text { Oct-01-Mar-31 } \\
\text { Oct-01-Mar-31 } \\
\text { Mar-01 - May-31 } \\
\text { Jun-01 - Sep-30 } \\
\text { Oct-01 - May-31 } \\
\text { Apr-01 - Sep-30 }\end{array}$ & $\begin{array}{l}\text { Base } \\
0.033 \\
45.8 \\
2.5 \\
47.9 \\
8.7 \\
7.3\end{array}$ & $\begin{array}{c}\text { Alternative } \\
0.053 \\
45.3 \\
2.5 \\
50.9 \\
8.7 \\
7.2\end{array}$ & $\begin{array}{l}\text { Pct Chg } \\
59.7 \% \\
-1.2 \% \\
0.4 \% \\
6.2 \% \\
0.5 \% \\
-2.1 \%\end{array}$ & $\begin{array}{l}\text { Base } \\
0.008 \\
23.4 \\
1.7 \\
14.0 \\
4.0 \\
6.6\end{array}$ & $\begin{array}{c}\text { Alternative } \\
0.008 \\
24.0 \\
1.7 \\
13.7 \\
3.9 \\
6.9\end{array}$ & $\begin{array}{l}\text { Pct Chg } \\
-3.4 \% \% \\
2.8 \% \\
3.9 \% \\
-2.4 \% \\
-2.9 \% \\
3.9 \%\end{array}$ & $\begin{array}{l}\text { Base } \\
0.107 \\
19.7 \\
2.8 \\
37.8 \\
5.7 \\
6.1\end{array}$ & $\begin{array}{l}\text { Alternative } \\
0.122 \\
17.8 \\
2.8 \\
37.8 \\
5.7 \\
6.2\end{array}$ & $\begin{array}{l}\text { Pct Chg } \\
1.5 \% \\
-10.1 \% \\
0.7 \% \\
0.1 \% \\
1.2 \% \\
1.0 \%\end{array}$ & $\begin{array}{l}\text { Base } \\
51.2 \\
\end{array}$ & Alternative & $\begin{array}{l}\text { Pct Chg } \\
0 \%\end{array}$ & 127.5 & Alternative & $\begin{array}{l}\text { Pct Chg } \\
8 \%\end{array}$ \\
\hline $\begin{array}{l}\text { Fall Chinook } \\
\text { Max Redd Scour depth (ft) } \\
\text { Spawninglincubation } \\
\text { Fry } \\
\text { Subyearling (Spring-summer) }\end{array}$ & 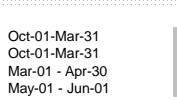 & & & & & & & & & & $\begin{array}{l}0.039 \\
18.3 \\
7.2 \\
38.1\end{array}$ & $\begin{array}{l}0.041 \\
17.8 \\
7.1 \\
39.1\end{array}$ & $\begin{array}{l}4.0 \% \\
-2.0 \% \\
-0.9 \% \\
2.0 \%\end{array}$ & $\begin{array}{l}0.007 \\
55.5 \\
2.5 \\
107.9\end{array}$ & $\begin{array}{l}0.007 \\
76.9 \\
25.3 \\
117.5\end{array}$ & $\begin{array}{l}-1.4 \% \\
55.2 \% \\
3.2 \% \\
8.9 \%\end{array}$ \\
\hline $\begin{array}{l}\text { Coho } \\
\text { Max Red Scour depth (ft) } \\
\text { Spawninglincubation } \\
\text { Fry } \\
\text { Subyearling (Spring-summer) } \\
\text { Subyearling (winter) }\end{array}$ & $\begin{array}{l}\text { Nov-01-Mar-31 } \\
\text { Nov-01-arar-31 } \\
\text { Apr-01- May-31 } \\
\text { Jun-1- - Spp-30 } \\
\text { Oct-01- App-30 }\end{array}$ & $\begin{array}{l}0.028 \\
38.8 \\
2.6 \\
16.1 \\
5.4\end{array}$ & $\begin{array}{l}0.039 \\
33.5 \\
2.6 \\
18.0 \\
5.5\end{array}$ & $\begin{array}{l}40.6 \% \\
-0.8 \% \\
-0.2 \% \\
12.2 \% \\
0.9 \%\end{array}$ & $\begin{array}{l}0.007 \\
14.8 \\
1.7 \\
4.6 \\
2.6\end{array}$ & $\begin{array}{l}0.007 \\
14.4 \\
1.8 \\
4.3 \\
2.5\end{array}$ & $\begin{array}{l}-3.4 \% \\
-2.9 \% \% \\
3.7 .2 \% \\
-2.1 \%\end{array}$ & $\begin{array}{c}0.092 \\
8.5 \\
3.0 \\
7.6 \\
3.7\end{array}$ & $\begin{array}{l}0.093 \\
7.4 \\
3.0 \\
7.4 \\
3.7\end{array}$ & $\begin{array}{c}0.9 \% \\
-13.2 \% \\
0.8 \% \\
-2.1 \% \\
2.0 \%\end{array}$ & $\begin{array}{l}0.037 \\
5.5 \\
6.9 \\
27.3 \\
43.9\end{array}$ & $\begin{array}{l}0.038 \\
5.0 \\
6.8 \\
28.0 \\
43.9\end{array}$ & $\begin{array}{l}3.5 \% \\
-.97 \% \\
-1.8 \% \\
2.3 \% \\
0.0 \%\end{array}$ & $\begin{array}{l}0.007 \\
16.6 \\
22.3 \\
64.4 \\
110.4\end{array}$ & $\begin{array}{l}0.007 \\
20.8 \\
24.7 \\
66.4 \\
117.2\end{array}$ & $\begin{array}{l}-1.8 \% \\
25.3 \% \\
10.7 \% \\
3.1 .1 \% \\
6.2 \%\end{array}$ \\
\hline $\begin{array}{l}\text { Steelhead } \\
\text { Max Redd Scour depth (ft) } \\
\text { Spawninglincubation } \\
\text { Fry } \\
\text { Subyearling (Spring-summer) } \\
\text { Subyearling (winter) } \\
\text { Subaduluts } \\
\text { Adult holding }\end{array}$ & $\begin{array}{l}\text { Mar-01-Jul-31 } \\
\text { Mar-01-Jul-31 } \\
\text { Jul-01- Aug-30 } \\
\text { Sep-01- Sep-30 } \\
\text { Oct-01- }- \text { Apr-30 } \\
\text { May-01 - Aug-30 } \\
\text { Sep-01 - Mar-31 }\end{array}$ & $\begin{array}{l}0.028 \\
53.0 \\
4.1 \\
57.9 \\
77.8 \\
27.3 \\
22.6\end{array}$ & $\begin{array}{l}0.038 \\
53.0 \\
4.4 \\
60.7 \\
7.8 \\
58.3 \\
22.6\end{array}$ & $\begin{array}{l}33.9 \% \\
0.1 \% \\
6.8 \% \\
4.9 \% \\
0.9 \% \\
1.8 \% \\
0.1 \%\end{array}$ & $\begin{array}{l}0.006 \\
31.7 \\
2.2 \\
20.2 \\
3.5 \\
19.1 \\
9.7\end{array}$ & $\begin{array}{l}0.006 \\
32.7 \\
2.1 \\
20.8 \\
3.4 \\
19.3 \\
9.2\end{array}$ & $\begin{array}{l}1.2 \% \\
3.2 \% \\
-.3 .1 \% \\
3.0 \% \\
-3.6 \% \\
0.8 \% \\
-4.8 \%\end{array}$ & $\begin{array}{l}0.209 \\
22.5 \\
3.4 \\
46.1 \\
4.9 \\
51.2 \\
11.0\end{array}$ & $\begin{array}{l}0.210 \\
20.2 \\
3.4 \\
46.2 \\
41.0 \\
51.0 \\
10.9\end{array}$ & $\begin{array}{c}0.4 \% \\
-10.1 \% \\
0.8 \% \\
0.2 \% \\
0.8 \% \\
-0.4 \% \\
-1.1 \%\end{array}$ & 46.9 & 46.8 & $0.0 \%$ & 119.7 & 126.3 & $5.5 \%$ \\
\hline $\begin{array}{l}\text { Resident Rainbow } \\
\text { Max Redd Scour repth (ft) } \\
\text { Spawning/incubation } \\
\text { Fry } \\
\text { Subyearling (Spring-summer) } \\
\text { Subyearing (winter) } \\
\text { Subadults }\end{array}$ & $\begin{array}{l}\text { Feb-01-Jul-31 } \\
\text { Feb-01-Jul-31 } \\
\text { Jul-01-Aug-30 } \\
\text { Sep-01- Sep-30 } \\
\text { Oct-01- Apr-30 } \\
\text { May-01 - Aug-30 }\end{array}$ & $\begin{array}{l}0.017 \\
47.8 \\
55.2 \\
97.2 \\
93.1 \\
30.5\end{array}$ & $\begin{array}{l}0.022 \\
47.4 \\
5.5 \\
60.0 \\
9.2 \\
32.1\end{array}$ & $\begin{array}{l}29.9 \% \\
-0.8 \% \\
6.2 \% \\
4.9 \% \\
0.9 \% \\
5.3 \%\end{array}$ & $\begin{array}{l}0.006 \\
18.7 \\
2.5 \\
19.9 \\
4.4 \\
8.1\end{array}$ & $\begin{array}{l}0.006 \\
18.3 \\
2.4 \\
20.5 \\
4.2 \\
7.8\end{array}$ & $\begin{array}{l}1.3 .3 \% \\
-2.2 .2 \% \\
-3.3 .3 \% \\
-3.2 .2 \% \\
-2.29 \%\end{array}$ & $\begin{array}{l}0.186 \\
15.0 \\
4.3 \\
45.9 \\
6.3 \\
17.1\end{array}$ & $\begin{array}{l}0.187 \\
13.4 \\
4.3 \\
46.0 \\
6.4 \\
17.4\end{array}$ & $\begin{array}{l}0.2 \% \\
-10.7 \% \\
0.5 \% \\
0.1 \% \\
1.0 \% \\
1.9 \%\end{array}$ & $\begin{array}{c}0.024 \\
7.4 \\
7.6 \\
39.8 \\
54.5 \\
30.5\end{array}$ & $\begin{array}{c}0.025 \\
6.9 \\
7.5 \\
40.2 \\
54.5 \\
31.2\end{array}$ & $\begin{array}{l}4.8 .6 \% \\
-6.60 \% \\
-1.5 \% \% \\
0.0 \% \% \\
0.0 \%\end{array}$ & $\begin{array}{c}0.009 \\
16.9 \\
20.1 \\
123.1 \\
140.8 \\
89.6\end{array}$ & $\begin{array}{l}0.007 \\
24.4 \\
25.4 \\
124.7 \\
148.2 \\
81.7\end{array}$ & $\begin{array}{l}-22.3 \% \\
44.4 \% \\
26.2 \% \\
1.3 \% \\
5.3 .3 \% \\
-8.8 \%\end{array}$ \\
\hline $\begin{array}{l}\text { Bull Trout } \\
\text { Max Redd Scour depth (ft) } \\
\text { Spawninglincubation } \\
\text { Fun } \\
\text { Subyearling (Spring-summer) } \\
\text { Subyearling (winter) }\end{array}$ & $\begin{array}{l}\text { Oct-01- Mar-31 } \\
\text { Oct-1- Mar-31 } \\
\text { Apr-1- May-31 } \\
\text { Jun-1-1- Sep-30 } \\
\text { Oct-101- May-31 }\end{array}$ & $\begin{array}{l}0.033 \\
36.4 \\
4.9 \\
61.9 \\
8.6\end{array}$ & $\begin{array}{l}0.053 \\
35.9 \\
4.8 \\
64.5 \\
8.6\end{array}$ & $\begin{array}{l}59.7 \% \\
-1.2 \% \\
-0.2 \% \\
4.3 \% \\
0.6 \%\end{array}$ & $\begin{array}{l}0.008 \\
13.4 \\
2.5 \\
20.5 \\
4.3\end{array}$ & $\begin{array}{l}0.007 \\
12.4 \\
2.6 \\
20.2 \\
4.2\end{array}$ & $\begin{array}{l}-3.5 \% \\
-7.7 \% \\
2.1 \% \% \\
-1.4 \% \\
-2.4 \%\end{array}$ & $\begin{array}{l}0.107 \\
8.0 \\
6.1 \\
64.8 \\
6.4\end{array}$ & $\begin{array}{l}0.117 \\
6.9 \\
6.2 \\
64.6 \\
6.5\end{array}$ & $\begin{array}{l}9.7 \% \\
-13.9 \% \\
0.8 \% \\
-0.3 \% \\
1.8 \%\end{array}$ & & & & & & \\
\hline $\begin{array}{l}\text { Resevoir Outmigration } \\
\text { inseason ayys Impassable } \\
\text { Kachess } \\
\text { Keechelus } \\
\text { Rimrock }\end{array}$ & $\begin{array}{l}\text { Jul-15- Sep-15 } \\
\text { Jul-15- Sep-15 } \\
\text { Jul-101 Aug-15 }\end{array}$ & $\begin{array}{c}\text { Base } \\
18 \\
37 \\
3\end{array}$ & $\begin{array}{c}\text { Alternative } \\
15 \\
37 \\
0\end{array}$ & $\begin{array}{l}\text { Pct chg } \\
-17.7 \% \\
-2.1 \% \\
-96.8 \%\end{array}$ & & & & & & & & & & & & \\
\hline $\begin{array}{l}\text { Flood Metrics } \\
\begin{array}{l}\text { Overbank flow }>1.67 \text { year flood } \\
\text { Damaging flood }\end{array}>=25 \text { year flood) }\end{array}$ & $\begin{array}{l}\text { days } \\
\text { days }\end{array}$ & $\begin{array}{c}\text { Base } \\
91 \\
0\end{array}$ & $\begin{array}{c}\text { Easton } \\
\text { Alternative } \\
94 \\
0\end{array}$ & $\begin{array}{l}\text { Pct Chg } \\
3.3 \% \\
0.0 \%\end{array}$ & $\begin{array}{c}\text { Base } \\
90 \\
0\end{array}$ & $\begin{array}{l}\text { Kittitas } \\
\text { Alternative } \\
98 \\
0\end{array}$ & $\begin{array}{l}\text { Pct Chg } \\
8.9 \% \% \\
0.0 \%\end{array}$ & $\begin{array}{c}\text { Base } \\
129 \\
0\end{array}$ & $\begin{array}{l}\text { Naches } \\
\text { Alternative } \\
139\end{array}$ & $\begin{array}{l}\text { Pct Chg } \\
7.8 \% \\
0.0 \%\end{array}$ & $\begin{array}{c}\text { Base } \\
235 \\
235\end{array}$ & $\begin{array}{l}\text { Union Gap } \\
\text { Alteremative } \\
256 \\
0\end{array}$ & $\begin{array}{l}\text { Pct Chg } \\
8.8 \% \% \\
0.0 \%\end{array}$ & $\begin{array}{c}\text { Base } \\
181 \\
01\end{array}$ & $\begin{array}{c}\text { Wapato } \\
\text { Alterative } \\
213 \\
0\end{array}$ & $\begin{array}{l}\text { Pct Chg } \\
17.7 \% \% \\
0.0 \%\end{array}$ \\
\hline Water Division Deliveries & $\begin{array}{c}\text { Proration (\%) } \\
\text { Average for Month } \\
\text { TWSA (af) } \\
\text { Average of 1st of Months }\end{array}$ & $\begin{array}{c}\begin{array}{c}\text { Base } \\
90 \% \\
2910719\end{array} \\
\end{array}$ & $\begin{array}{c}\begin{array}{c}\text { April } \\
\text { Alternative } \\
93 \% \%\end{array} \\
2992155\end{array}$ & $\begin{array}{l}\text { Pct Chg } \\
3.1 \% \\
2.8 \%\end{array}$ & $\begin{array}{c}\text { Base } \\
89 \% \\
2494500\end{array}$ & $\begin{array}{c}\text { May } \\
\text { Alternative } \\
93 \% \\
2584591\end{array}$ & $\begin{array}{l}\text { Pct chg } \\
3.9 \% \\
3.6 \%\end{array}$ & $\begin{array}{c}\begin{array}{c}\text { Base } \\
88 \% \\
885967\end{array} \\
198597\end{array}$ & $\begin{array}{l}\text { June } \\
\text { Alternative } \\
920 \% \\
2076581\end{array}$ & $\begin{array}{l}\text { Pet chg } \\
5.0 \% \\
4.6 \%\end{array}$ & $\begin{array}{c}\text { Base } \\
88 \% \\
1475530\end{array}$ & $\begin{array}{l}\text { July } \\
\text { Alternative } \\
\text { 92\% } \\
1569118\end{array}$ & $\begin{array}{l}\text { Pct Chg } \\
5.5 \% \\
6.3 \%\end{array}$ & $\begin{array}{c}\text { Base } \\
87 \% \\
1032999\end{array}$ & $\begin{array}{c}\text { August } \\
\text { Alternative } \\
93 \% \\
1133100\end{array}$ & $\begin{array}{l}\text { Pct Chg } \\
5.9 \% \% \\
9.7 \%\end{array}$ \\
\hline $\begin{array}{l}\text { Reservoir storage } \\
\text { End of Season Carryover }\end{array}$ & $\begin{array}{l}\text { (af) } \\
\text { Average }\end{array}$ & $\begin{array}{l}\text { Base } \\
9614\end{array}$ & $\begin{array}{c}\text { Bumping } \\
\text { Alternative } \\
10923\end{array}$ & $\begin{array}{l}\text { Pct Chg } \\
13.6 \%\end{array}$ & $\begin{array}{c}\text { Base } \\
100028\end{array}$ & $\begin{array}{c}\text { Cle Elum } \\
\text { Alternative } \\
159601\end{array}$ & $\begin{array}{l}\text { Pct Chg } \\
59.6 \%\end{array}$ & $\begin{array}{l}\text { Base } \\
84562\end{array}$ & $\begin{array}{c}\text { Kachess } \\
\text { Alternative } \\
101590\end{array}$ & $\begin{array}{l}\text { Pct Chg } \\
20.1 \%\end{array}$ & $\begin{array}{l}\text { Base } \\
31303\end{array}$ & $\begin{array}{c}\text { Keechelus } \\
\text { Alternative } \\
33318\end{array}$ & $\begin{array}{l}\text { Pct Chg } \\
6.4 \%\end{array}$ & $\begin{array}{l}\text { Base } \\
45775\end{array}$ & $\begin{array}{c}\text { Rimrock } \\
\text { Alternative } \\
67126\end{array}$ & $\begin{array}{l}\text { Pct chg } \\
46.6 \%\end{array}$ \\
\hline $\begin{array}{l}\text { Sediment Transport } \\
\text { Fine Material Transport }\end{array}$ & Total tons & $\begin{array}{l}\text { Base } \\
227\end{array}$ & $\begin{array}{l}\text { Easton } \\
\text { Alternative } \\
243\end{array}$ & $\begin{array}{l}\mathrm{Pctchg} \\
6.9 \%\end{array}$ & $\begin{array}{l}\text { Base } \\
2111\end{array}$ & $\begin{array}{c}\text { Kittitas } \\
\text { Alternative } \\
2066\end{array}$ & $\begin{array}{l}\text { Pct Chg } \\
-2.1 \%\end{array}$ & $\begin{array}{l}\text { Base } \\
1138\end{array}$ & $\begin{array}{l}\text { Naches } \\
\text { Alternative } \\
1149\end{array}$ & $\begin{array}{l}\text { Pct Chg } \\
1.0 \%\end{array}$ & $\begin{array}{l}\text { Base } \\
3751\end{array}$ & $\begin{array}{c}\text { Union Gap } \\
\text { Alternative } \\
4039\end{array}$ & $\begin{array}{l}\text { Pct Chg } \\
7.7 \%\end{array}$ & $\begin{array}{l}\text { Base } \\
{ }_{2327}\end{array}$ & $\begin{array}{c}\text { Wapato } \\
\text { Alternative } \\
2937\end{array}$ & $\begin{array}{l}\text { Pct Chg } \\
26.2 \%\end{array}$ \\
\hline Geomorphic Adjustment & Period Sum & 63270 & 68491 & $8.3 \%$ & 508081 & 504260 & $-0.8 \%$ & 433327 & 443208 & $2.3 \%$ & 918490 & 937562 & $2.1 \%$ & 826559 & 872190 & $5.5 \%$ \\
\hline
\end{tabular}

Figure 6-1. Habitat summary page for the WymerPlus scenario. 


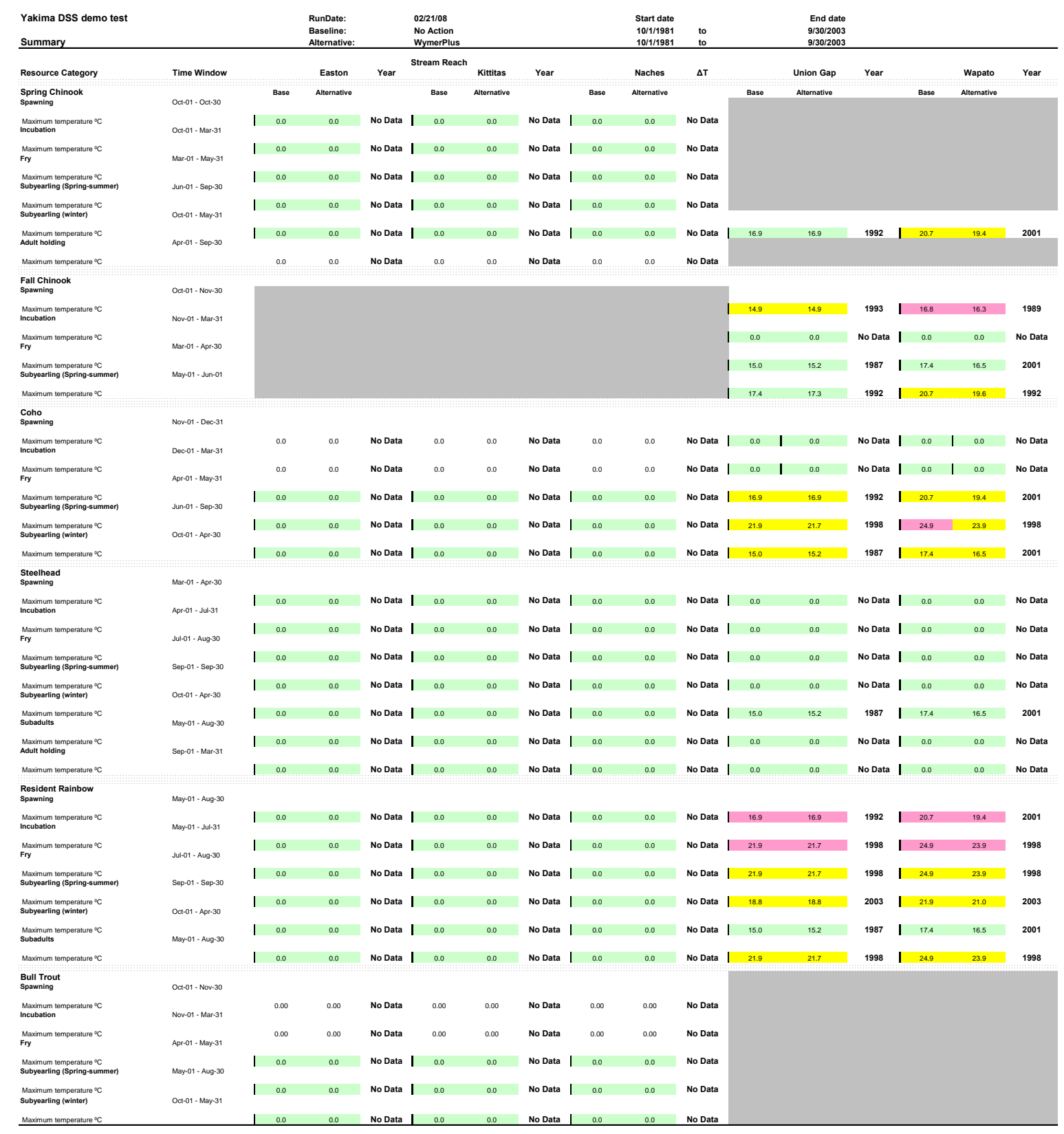

Figure 6-2. Temperature summary page for the WymerPlus scenario. 


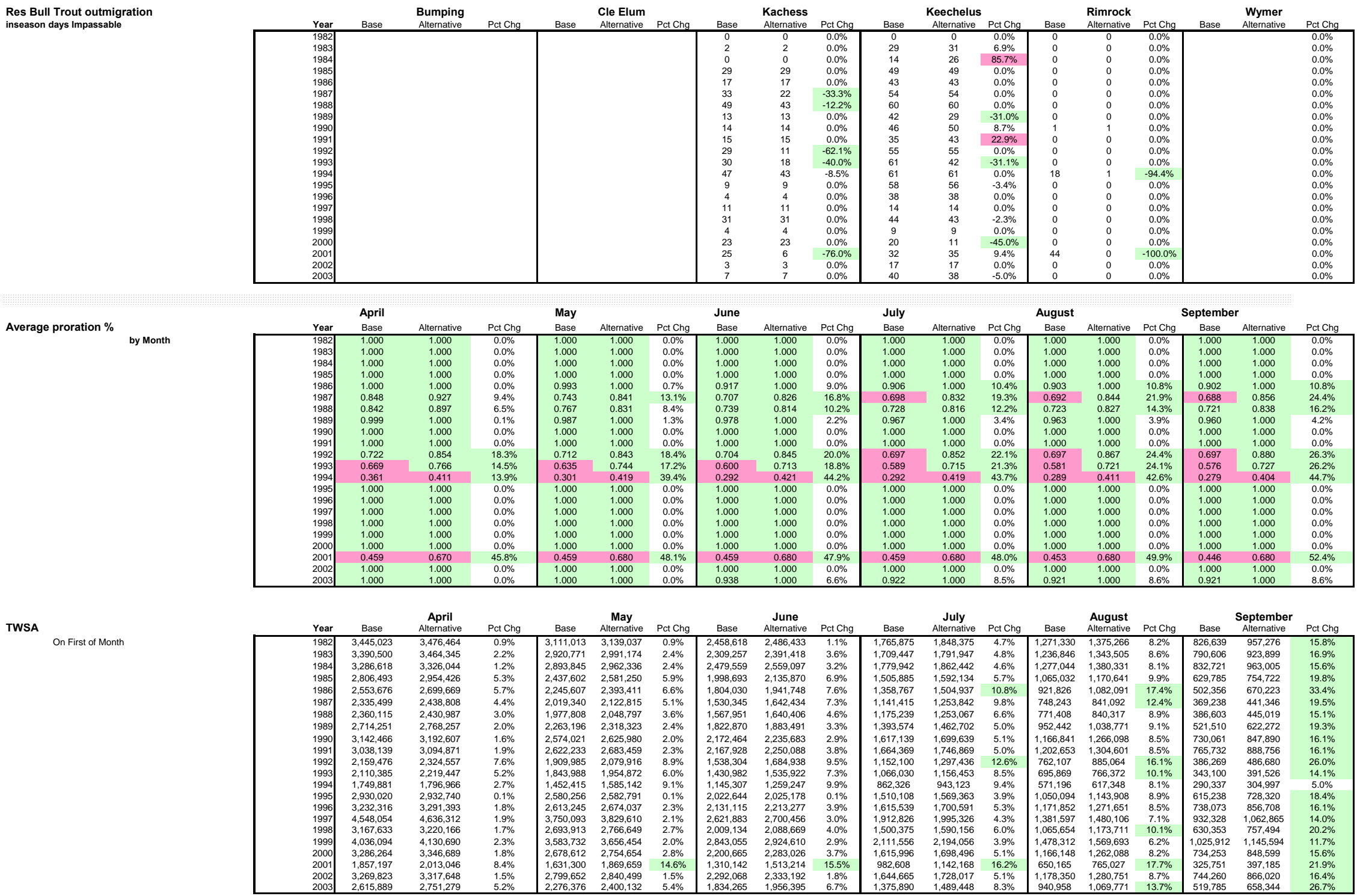

Figure 6-3. Bull trout outmigration, proration, and TWSA tables from yearly summary page for the WymerPlus scenario. 


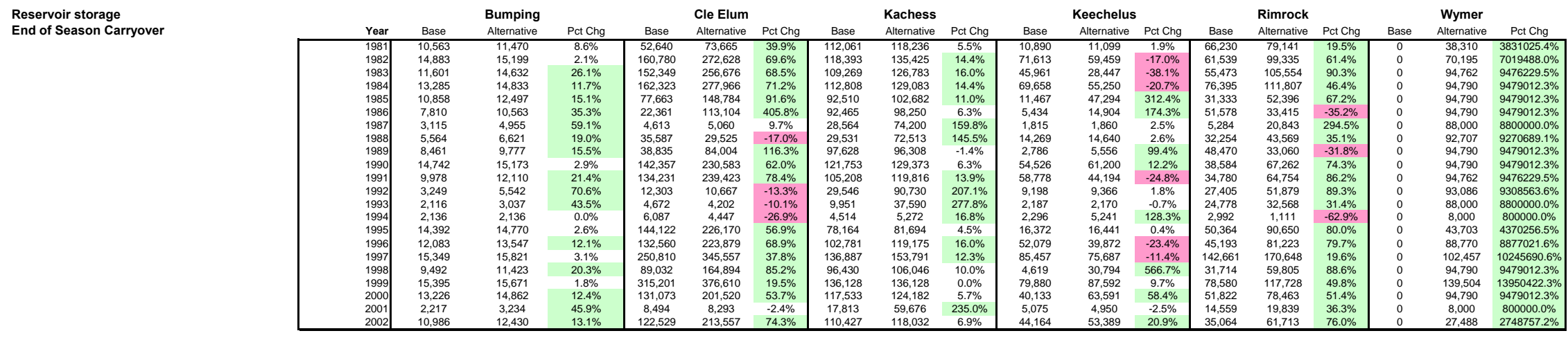

Critical Reservoir Storage Smolt Passage
Days below threshold

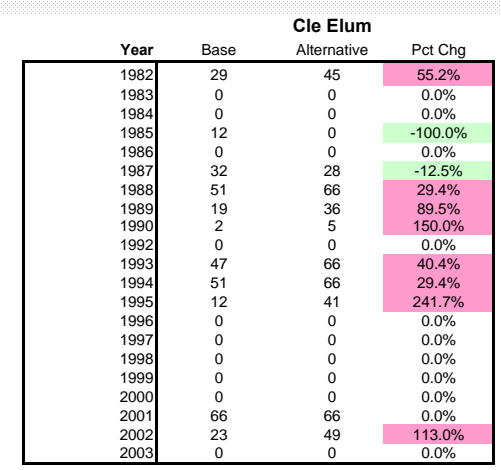

Figure 6-4. Reservoir storage tables from yearly summary page for the WymerPlus scenario. 


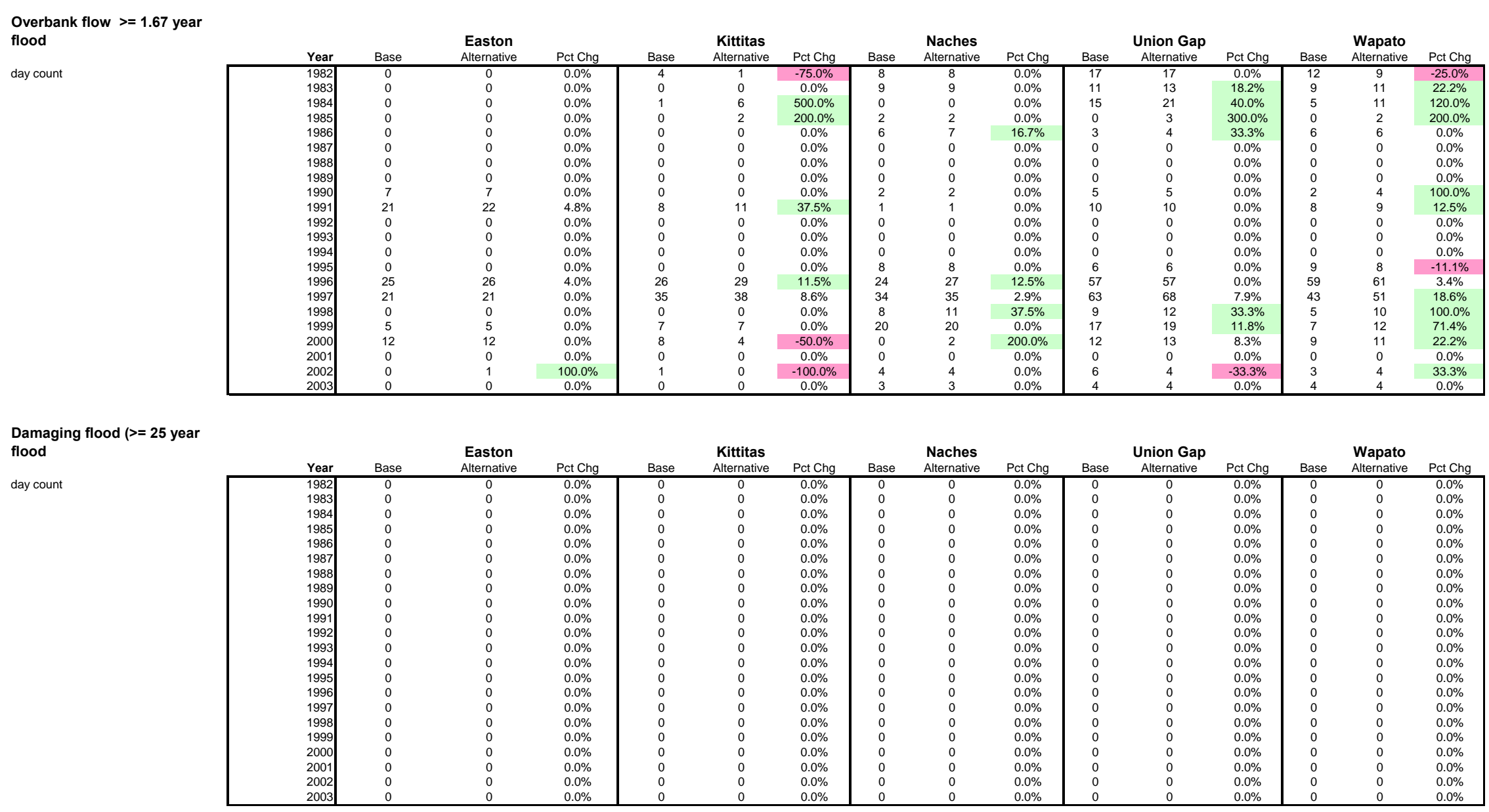

Figure 6-5. Overbank flow and damaging flood tables from yearly summary page for the WymerPlus scenario. 


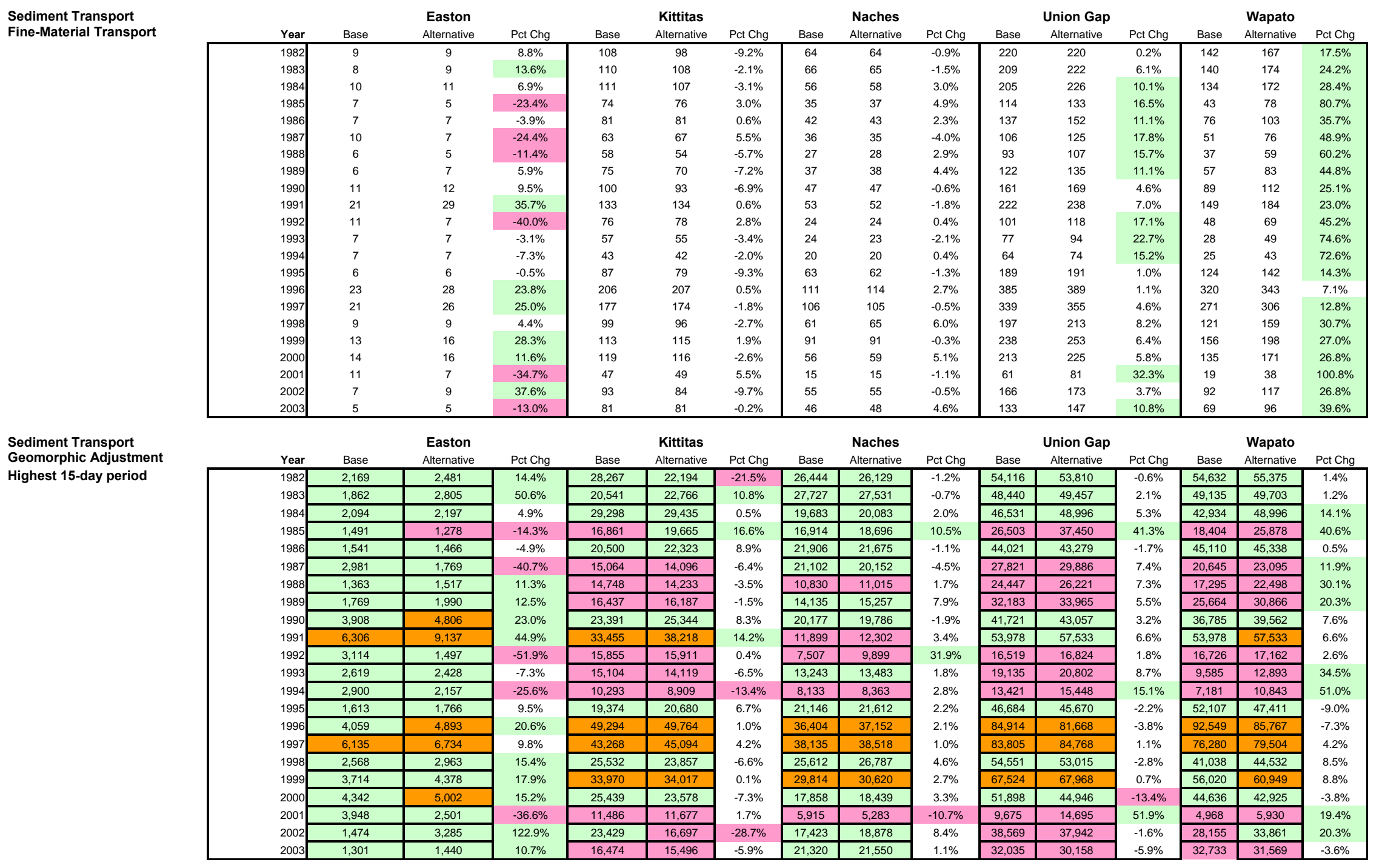

Figure 6-6. Fine-sediment transport and geomorphic adjustment tables from yearly summary page for the WymerPlus scenario. 


\begin{tabular}{|c|c|c|c|c|c|c|c|c|c|c|c|c|c|c|c|}
\hline \multirow[b]{2}{*}{ Year } & \multicolumn{3}{|c|}{ Easton } & \multicolumn{3}{|c|}{ Kittitas } & \multicolumn{3}{|c|}{ Naches } & \multicolumn{3}{|c|}{ Union Gap } & \multicolumn{3}{|c|}{ Wapato } \\
\hline & Base & Alternative & Pct Chg & Base & Alternative & Pct Chg & Base & Alternative & Pct Chg & Base & Alternative & Pct Chg & Base & Alternative & Pct Chg \\
\hline 1982 & 0 & 0 & $0.0 \%$ & 0 & 0 & $0.0 \%$ & 162 & 141 & $-13.0 \%$ & 0 & 0 & $0.0 \%$ & 0 & 0 & $0.0 \%$ \\
\hline 1983 & 0 & 0 & $0.0 \%$ & 0 & 0 & $0.0 \%$ & 187 & 158 & $-15.5 \%$ & 0 & 0 & $0.0 \%$ & 0 & 0 & $0.0 \%$ \\
\hline 1984 & 0 & 0 & $0.0 \%$ & 0 & 0 & $0.0 \%$ & 179 & 164 & $-8.4 \%$ & 0 & 0 & $0.0 \%$ & 0 & 0 & $0.0 \%$ \\
\hline 1985 & 0 & 0 & $0.0 \%$ & 0 & 0 & $0.0 \%$ & 87 & 82 & $-5.7 \%$ & 0 & 0 & $0.0 \%$ & 0 & 0 & $0.0 \%$ \\
\hline 1986 & 0 & 0 & $0.0 \%$ & 0 & 0 & $0.0 \%$ & 111 & 111 & $0.0 \%$ & 0 & 0 & $0.0 \%$ & 0 & 0 & $0.0 \%$ \\
\hline 1987 & 0 & 0 & $0.0 \%$ & 0 & 0 & $0.0 \%$ & 88 & 86 & $-2.3 \%$ & 0 & 0 & $0.0 \%$ & 0 & 0 & $0.0 \%$ \\
\hline 1988 & 0 & 0 & $0.0 \%$ & 0 & 0 & $0.0 \%$ & 75 & 71 & $-5.3 \%$ & 0 & 0 & $0.0 \%$ & 0 & 0 & $0.0 \%$ \\
\hline 1989 & 0 & 0 & $0.0 \%$ & 0 & 0 & $0.0 \%$ & 85 & 98 & $15.3 \%$ & 0 & 0 & $0.0 \%$ & 0 & 0 & $0.0 \%$ \\
\hline 1990 & 0 & 0 & $0.0 \%$ & 0 & 0 & $0.0 \%$ & 135 & 132 & $-2.2 \%$ & 0 & 0 & $0.0 \%$ & 0 & 0 & $0.0 \%$ \\
\hline 1991 & 0 & 0 & $0.0 \%$ & 0 & 0 & $0.0 \%$ & 207 & 212 & $2.4 \%$ & 0 & 0 & $0.0 \%$ & 0 & 0 & $0.0 \%$ \\
\hline 1992 & 0 & 0 & $0.0 \%$ & 0 & 0 & $0.0 \%$ & 53 & 58 & $9.4 \%$ & 0 & 0 & $0.0 \%$ & 0 & 0 & $0.0 \%$ \\
\hline 1993 & 0 & 0 & $0.0 \%$ & 0 & 0 & $0.0 \%$ & 51 & 46 & $-9.8 \%$ & 0 & 0 & $0.0 \%$ & 0 & 0 & $0.0 \%$ \\
\hline 1994 & 0 & 0 & $0.0 \%$ & 0 & 0 & $0.0 \%$ & 50 & 47 & $-6.0 \%$ & 0 & 0 & $0.0 \%$ & 0 & 0 & $0.0 \%$ \\
\hline 1995 & 0 & 0 & $0.0 \%$ & 0 & 0 & $0.0 \%$ & 191 & 184 & $-3.7 \%$ & 0 & 0 & $0.0 \%$ & 0 & 0 & $0.0 \%$ \\
\hline 1996 & 0 & 0 & $0.0 \%$ & 0 & 0 & $0.0 \%$ & 262 & 241 & $-8.0 \%$ & 5 & 5 & $0.0 \%$ & 0 & 0 & $0.0 \%$ \\
\hline 1997 & 0 & 0 & $0.0 \%$ & 0 & 0 & $0.0 \%$ & 205 & 194 & $-5.4 \%$ & 0 & 0 & $0.0 \%$ & 0 & 0 & $0.0 \%$ \\
\hline 1998 & 0 & 0 & $0.0 \%$ & 0 & 0 & $0.0 \%$ & 150 & 152 & $1.3 \%$ & 0 & 0 & $0.0 \%$ & 0 & 0 & $0.0 \%$ \\
\hline 1999 & 0 & 0 & $0.0 \%$ & 0 & 0 & $0.0 \%$ & 202 & 204 & $1.0 \%$ & 0 & 0 & $0.0 \%$ & 0 & 0 & $0.0 \%$ \\
\hline 2000 & 0 & 0 & $0.0 \%$ & 0 & 0 & $0.0 \%$ & 168 & 161 & $-4.2 \%$ & 0 & 0 & $0.0 \%$ & 0 & 0 & $0.0 \%$ \\
\hline 2001 & 0 & 0 & $0.0 \%$ & 0 & 0 & $0.0 \%$ & 29 & 24 & $-17.2 \%$ & 0 & 0 & $0.0 \%$ & 0 & 0 & $0.0 \%$ \\
\hline 2002 & 0 & 0 & $0.0 \%$ & 0 & 0 & $0.0 \%$ & 128 & 123 & $-3.9 \%$ & 0 & 0 & $0.0 \%$ & 0 & 0 & $0.0 \%$ \\
\hline 2003 & 0 & 0 & $0.0 \%$ & 0 & 0 & $0.0 \%$ & 147 & 145 & $-1.4 \%$ & 0 & 0 & $0.0 \%$ & 0 & 0 & $0.0 \%$ \\
\hline
\end{tabular}

Figure 6-7. Armor disruption table from yearly summary page for the WymerPlus scenario. 


\begin{tabular}{|c|c|c|c|c|c|c|c|c|c|c|c|c|c|c|c|c|c|c|c|c|}
\hline \multirow{2}{*}{ Spring Chinook } & \multicolumn{3}{|c|}{ Redd Scour } & \multicolumn{3}{|c|}{ Spawning/incubation } & \multicolumn{3}{|c|}{ Fry } & \multicolumn{3}{|c|}{ Subyearling (Spring-summer) } & \multicolumn{3}{|c|}{ Subyearling (winter) } & \multicolumn{2}{|r|}{ Subadult } & \multicolumn{3}{|c|}{ Adult holding } \\
\hline & Base & Alternative & Pct Chg & Base & Alternative & Pct Chg & Base & Alternative & Pct Chg & Base & Alternative & Pct Chg & Base & Alternative & Pct Chg & Base & Alternative Pct Chg & Base & Alternativ & \\
\hline 198 & 0.008 & 0.008 & $-0.3 \%$ & 47.55 & 47.80 & $0.52 \%$ & 2.23 & 2.19 & $-1.58 \%$ & 51.15 & 52.39 & $2.41 \%$ & 6.89 & 6.69 & $-2.81 \%$ & & & 7.18 & 7.15 & $-0.39 \%$ \\
\hline 198 & $0.018>>2$ & 0.020 & $142 \%$ & 4514 & 4630 & $256 \%$ & 224 & 240 & $7.22 \%$ & 60.44 & 60.44 & $0.00 \%$ & 7.47 & 8.01 & $726 \%$ & & & 715 & 7.15 & $0.00 \%$ \\
\hline 198 & 0.010 & 0.014 & $41.8 \%$ & 46.09 & 47.16 & $233 \%$ & 2.38 & 237 & $-0.50 \%$ & 4530 & 45.46 & $0.035 \%$ & 6.95 & 662 & $-0.40 \%$ & & & 715 & 715 & $0.00 \%$ \\
\hline 198 & 0.008 & 0.008 & $-0.3 \%$ & $5288>>28$ & 52.88 & $0.00 \%$ & 286 & 2.70 & $-531 \%$ & 3914 & $4933>193$ & $27.58 \%$ & 1190 & 1160 & $-2.49 \%$ & & & 795 & 715 & $\begin{array}{l}0.00 \% \\
-10.04 \%\end{array}$ \\
\hline 198 & 0.008 & 0.008 & $-0.3 \%$ & 52.88 & 52.88 & $0.00 \%$ & 2.28 & 2.28 & $0.20 \%$ & 43.43 & 52.62 & $21.18 \%$ & 9.03 & 8.84 & $-2.18 \%$ & & & 7.15 & 7.16 & $0.12 \%$ \\
\hline 198 & 0.008 & 0.008 & $-0.3 \%$ & 48.98 & 48.98 & $0.00 \%$ & 2.39 & 2.39 & $0.00 \%$ & 37.96 & 42.82 & $12.79 \%$ & 9.74 & 9.74 & $0.00 \%$ & & & 7.74 & 7.15 & $-7.71 \%$ \\
\hline 198 & 0.008 & 0.008 & $-0.3 \%$ & 52.88 & 52.88 & $0.00 \%$ & 2.35 & 2.35 & $0.00 \%$ & 48.77 & 55.23 & $13.24 \%$ & 10.26 & 10.26 & $0.00 \%$ & & & 7.15 & 7.15 & $0.00 \%$ \\
\hline 198 & 0.008 & 0.008 & $-0.3 \%$ & 52.23 & 52.23 & $0.00 \%$ & 2.93 & 2.93 & $0.00 \%$ & 55.78 & 52.65 & $-5.62 \%$ & 7.99 & 7.99 & $0.00 \%$ & & & 7.15 & 7.15 & $0.00 \%$ \\
\hline 199 & 0.008 & 0.008 & $-0.3 \%$ & 47.33 & 47.33 & $0.00 \%$ & 2.56 & 2.55 & $-0.25 \%$ & 49.86 & 51.46 & $3.21 \%$ & 7.44 & 7.45 & $0.06 \%$ & & & 7.15 & 7.15 & $-0.05 \%$ \\
\hline 199 & 0.188 & 0.379 & $101.1 \%$ & 5.24 & 5.20 & $-0.84 \%$ & 2.53 & 2.53 & $-0.14 \%$ & 60.44 & 60.44 & $0.00 \%$ & 6.84 & 6.87 & $0.33 \%$ & & & 7.15 & 7.15 & $0.00 \%$ \\
\hline 199 & 0.008 & 0.008 & $-0.3 \%$ & 52.88 & 52.88 & $0.00 \%$ & 2.59 & 2.54 & $-1.87 \%$ & 36.70 & 45.55 & $24.11 \%$ & 8.16 & 8.23 & $0.85 \%$ & & & 7.52 & 7.15 & $-4.96 \%$ \\
\hline 199 & 0.008 & 0.008 & $-0.3 \%$ & 50.31 & 50.31 & $0.00 \%$ & 2.73 & 2.73 & $0.04 \%$ & 37.21 & 40.85 & $9.81 \%$ & 11.56 & 11.56 & $0.02 \%$ & & & 7.15 & 7.34 & $2.75 \%$ \\
\hline 199 & 0.008 & 0.008 & $-0.3 \%$ & 51.22 & 52.31 & $2.13 \%$ & 2.44 & 2.44 & $0.06 \%$ & 42.53 & 40.72 & $-4.26 \%$ & 10.64 & 10.59 & $-0.52 \%$ & & & 7.15 & 7.15 & $0.00 \%$ \\
\hline 199 & 0.008 & 0.009 & $15.0 \%$ & 52.88 & 52.88 & $0.00 \%$ & 2.46 & 2.46 & $0.00 \%$ & 60.44 & 60.44 & $0.00 \%$ & 7.72 & 7.72 & $0.00 \%$ & & & 7.15 & 7.15 & $0.00 \%$ \\
\hline 199 & 0.102 & 0.134 & $31.2 \%$ & 15.47 & 15.47 & $0.00 \%$ & 2.56 & 2.56 & $0.00 \%$ & 59.85 & 60.31 & $0.77 \%$ & 7.04 & 7.12 & $1.17 \%$ & & & 7.15 & 7.15 & $0.00 \%$ \\
\hline 199 & 0.186 & 0.334 & $79.8 \%$ & 29.70 & 20.31 & $-31.64 \%$ & 2.33 & 2.47 & $6.20 \%$ & 46.59 & 48.00 & $3.03 \%$ & 7.35 & 7.75 & $5.41 \%$ & & & 7.36 & 7.30 & $-0.75 \%$ \\
\hline 199 & 0.008 & 0.023 & $192.7 \%$ & 52.88 & 52.88 & $0.00 \%$ & 2.35 & 2.37 & $0.66 \%$ & 53.20 & 60.44 & $13.59 \%$ & 7.79 & 8.34 & $7.03 \%$ & & & 7.42 & 7.15 & $-3.74 \%$ \\
\hline 199 & 0.008 & 0.019 & $131.1 \%$ & 52.88 & 47.06 & $-11.01 \%$ & 2.27 & 2.36 & $3.90 \%$ & 43.73 & 46.58 & $6.53 \%$ & 6.88 & 6.96 & $1.14 \%$ & & & 8.01 & 7.66 & $-4.31 \%$ \\
\hline 200 & 0.104 & 0.139 & $33.1 \%$ & 43.02 & 43.02 & $0.00 \%$ & 2.65 & 2.65 & $0.00 \%$ & 46.02 & 51.29 & $11.45 \%$ & 8.58 & 8.38 & $-2.41 \%$ & & & 8.15 & 7.15 & $-12.35 \%$ \\
\hline 200 & 0.008 & 0.008 & $-0.3 \%$ & 52.88 & 52.88 & $0.00 \%$ & 2.67 & 2.76 & $3.21 \%$ & 33.76 & 39.05 & $15.68 \%$ & 12.00 & 12.17 & $1.38 \%$ & & & 7.44 & 7.34 & $-1.34 \%$ \\
\hline 200 & 0.008 & 0.008 & $-0.3 \%$ & 54.09 & 54.09 & $0.00 \%$ & 2.73 & 2.73 & $-0.07 \%$ & 46.57 & 42.04 & $-9.73 \%$ & 8.86 & 8.85 & $-0.03 \%$ & & & 7.15 & 7.15 & $-0.07 \%$ \\
\hline 200 & 0.008 & $\begin{array}{l}0.008 \\
0.00\end{array}$ & $-0.3 \%$ & 48.68 & 48.68 & $0.00 \%$ & 2.53 & 2.53 & $0.00 \%$ & 55.23 & $\begin{array}{l}60.44 \\
60.04\end{array}$ & $9.42 \%$ & $\begin{array}{l}0.00 \\
10.25\end{array}$ & $\begin{array}{l}.0 .03 \\
10.25\end{array}$ & $0.00 \%$ & & & 7.15 & 7.15 & $0.00 \%$ \\
\hline \multirow{24}{*}{$\begin{array}{l}Y \\
1 \\
1 \\
1 \\
1 \\
1 \\
1\end{array}$} & \multirow{2}{*}{\multicolumn{3}{|c|}{ Redd Scour }} & \multicolumn{3}{|c|}{ Spawning/incubation } & \multicolumn{3}{|c|}{ Fry } & \multirow{2}{*}{\multicolumn{3}{|c|}{ Subyearling (Spring-summer) }} & \multicolumn{3}{|c|}{ Subyearling (winter) } & \multirow{2}{*}{\multicolumn{2}{|c|}{\begin{tabular}{ll}
\multicolumn{3}{c}{ Subadult } \\
Base & Alternative Pct Chg
\end{tabular}}} & & Adult holdi & \\
\hline & & & & Base & Alternative & Pct Chg & Base & Alternative & Pct Chg & & & & Base & Alternative & Pct Chg & & & Base & Alternativ & Pct Chg \\
\hline & 0.008 & 0.008 & $-0.3 \%$ & 41.68 & 41.74 & $0.14 \%$ & 2.22 & 2.17 & $-2.04 \%$ & 18.32 & 19.12 & $4.38 \%$ & 4.57 & 4.45 & $-2.77 \%$ & & & & & \\
\hline & 0.018 & 0.020 & $14.2 \%$ & 40.40 & 40.64 & $0.58 \%$ & 2.29 & 2.31 & $0.59 \%$ & 25.28 & 25.28 & $0.00 \%$ & 4.60 & 4.96 & $7.92 \%$ & & & & & \\
\hline & 0.010 & 0.014 & $41.8 \%$ & 40.59 & 40.81 & $0.54 \%$ & 2.32 & 2.32 & $-0.21 \%$ & 15.60 & 15.49 & $-0.73 \%$ & 4.33 & 4.31 & $-0.42 \%$ & & & & & \\
\hline & 0.008 & 0.008 & $-0.3 \%$ & 44.77 & 44.77 & $0.00 \%$ & 2.73 & 2.53 & $-7.36 \%$ & 10.48 & 15.68 & $49.65 \%$ & 7.50 & 7.50 & $0.00 \%$ & & & & & \\
\hline & 0.008 & 0.008 & $-0.3 \%$ & 43.58 & 43.58 & $0.00 \%$ & 3.01 & 2.90 & $-3.68 \%$ & 11.77 & 14.94 & $26.96 \%$ & 5.51 & 5.51 & $0.00 \%$ & & & & & \\
\hline & 0.008 & 0.008 & $-0.3 \%$ & 42.52 & 42.52 & $0.00 \%$ & 2.67 & 2.67 & $0.00 \%$ & 11.71 & 13.12 & $12.01 \%$ & 5.90 & 5.91 & $0.03 \%$ & & & & & \\
\hline & 0.008 & 0.008 & $-0.3 \%$ & 44.77 & 44.77 & $0.00 \%$ & 2.49 & 2.49 & $0.00 \%$ & 14.49 & 18.41 & $27.05 \%$ & 6.27 & 6.27 & $0.00 \%$ & & & & & \\
\hline & 0.008 & 0.008 & $-0.3 \%$ & 43.78 & 43.78 & $0.00 \%$ & 2.60 & 2.60 & $0.00 \%$ & 17.80 & 14.94 & $-16.07 \%$ & 4.86 & 4.86 & $0.00 \%$ & & & & & \\
\hline & 0.008 & 0.008 & $-0.5 \%$ & 41.63 & 41.63 & $0.00 \%$ & 2.69 & 2.71 & $0.65 \%$ & 16.22 & 18.98 & $17.01 \%$ & 4.64 & 4.63 & $-0.03 \%$ & & & & & \\
\hline & 0.069 & 0.069 & $1.1 \%$ & 3.43 & 3.40 & $-0.84 \%$ & 2.97 & 2.97 & $0.00 \%$ & 25.40 & 25.40 & $0.00 \%$ & 4.32 & 4.31 & $-0.26 \%$ & & & & & \\
\hline & 0.008 & 0.008 & $-0.3 \%$ & 43.46 & 44.65 & $2.72 \%$ & 3.04 & 3.00 & $-1.52 \%$ & 11.57 & $\begin{array}{l}13.85 \\
13.85\end{array}$ & $19.71 \%$ & 4.93 & 5.17 & $4.88 \%$ & & & & & \\
\hline & 0.008 & 0.008 & $-0.3 \%$ & 43.73 & 43.73 & $0.00 \%$ & 3.08 & 3.08 & $0.05 \%$ & 10.92 & 11.27 & $3.23 \%$ & 7.20 & 7.20 & $0.02 \%$ & & & & & \\
\hline & 0.008 & 0.008 & $-0.3 \%$ & 43.95 & 44.21 & $0.60 \%$ & 2.59 & 2.59 & $0.09 \%$ & 15.06 & 12.99 & $-13.76 \%$ & 6.52 & 6.48 & $-0.69 \%$ & & & & & \\
\hline & 0.008 & 0.009 & $19.5 \%$ & 44.56 & 44.56 & $0.00 \%$ & 3.15 & 3.15 & $0.00 \%$ & 25.42 & 25.42 & $0.00 \%$ & 4.72 & 4.72 & $0.00 \%$ & & & & & \\
\hline & 0.102 & 0.134 & $31.2 \%$ & 10.47 & 10.47 & $0.00 \%$ & 2.50 & 2.50 & $0.00 \%$ & 23.25 & 24.98 & $7.47 \%$ & 4.52 & 4.56 & $0.78 \%$ & & & & & \\
\hline & 0.186 & 0.334 & $79.8 \%$ & 24.50 & 16.78 & $-31.49 \%$ & 2.24 & 2.26 & $0.84 \%$ & 16.28 & 16.7 & $3.10 \%$ & 4.89 & 5.15 & $5.31 \%$ & & & & & \\
\hline & 0.008 & 0.023 & $196.0 \%$ & 43.75 & 44.62 & $1.99 \%$ & 2.27 & 2.26 & $-0.21 \%$ & 14.85 & 25.42 & $71.20 \%$ & 4.95 & 5.30 & $7.17 \%$ & & & & & \\
\hline & 0.008 & 0.01 & $131.1 \%$ & 42.96 & 40.79 & $-5.04 \%$ & 2.17 & 2.2 & $4.72 \%$ & 13.73 & 15. & 10. & 4.6 & 4. & $1.41 \%$ & & & & & \\
\hline & 0.104 & 0.139 & $33.1 \%$ & 37.56 & 37.56 & $0.00 \%$ & 2.69 & 2.65 & $0.00 \%$ & 12.73 & 17. & $38.09 \%$ & 5. & 5. & $-2.42 \%$ & & & & & \\
\hline & 0.008 & 0.008 & $-0.3 \%$ & 44.77 & 44.77 & $0.00 \%$ & 2.68 & 2.81 & $4.69 \%$ & 10.64 & 10 & 3.1 & 7. & 7.. & & & & & & \\
\hline & 0.008 & 0.008 & $-0.3 \%$ & 45.06 & 45.06 & $0.00 \%$ & 2.84 & 2.84 & $0.00 \%$ & 13.91 & 14 & & 5. & 5. & & & & & & \\
\hline & 0.008 & 0.008 & $-0.3 \%$ & 42.44 & 42.44 & $0.00 \%$ & 296 & 2.96 & $0.00 \%$ & 17.74 & 25.42 & $43.29 \%$ & 6.23 & 6.23 & $0.00 \%$ & & & & & \\
\hline
\end{tabular}

Figure 6-8. Annual habitat summaries for spring chinook and coho in the Easton reach for the WymerPlus scenario. 
Steelhead

\begin{tabular}{|c|c|c|c|c|c|c|c|c|c|c|c|c|c|c|c|c|c|c|c|c|c|}
\hline \multirow[b]{2}{*}{ Year- } & \multirow{2}{*}{\multicolumn{3}{|c|}{\begin{tabular}{ll}
\multicolumn{2}{c}{ Redd Scour } \\
Base & Alternative Pct Chg
\end{tabular}}} & \multicolumn{3}{|c|}{ Spawning/incubation } & \multicolumn{3}{|c|}{ Fry } & \multicolumn{3}{|c|}{ Subyearling (Spring-summer) } & \multicolumn{3}{|c|}{ Subyearling (winter) } & \multicolumn{3}{|c|}{$\begin{array}{l}\text { Subadult } \\
\end{array}$} & \multicolumn{3}{|c|}{ Adult holding } \\
\hline & & & & Base & Alternative & Pct Chg & Base & Alternative & Pct Chg & Base & Alternative & Pct Chg & Base & Alternative & Pct Chg & Base & Alternative & Pct Chg & Base & Alternative & Pct Chg \\
\hline 198 & 0.010 & 0.015 & $41.0 \%$ & 51.66 & 51.91 & $0.48 \%$ & 4.34 & 4.54 & $4.57 \%$ & 64.03 & 64.03 & $0.00 \%$ & 6.53 & 6.31 & $-3.34 \%$ & 53.67 & 54.59 & $1.72 \%$ & 22.83 & 22.72 & $-0.48 \%$ \\
\hline 983 & 0.008 & 0.012 & $47.1 \%$ & 52.27 & & $2.72 \%$ & 5.29 & 5.29 & $0.00 \%$ & 64.03 & 64.03 & $0.00 \%$ & 6.46 & 700 & $8.47 \%$ & 62.49 & 62.49 & $0.00 \%$ & 21.78 & 21.57 & $-0.94 \%$ \\
\hline 84 & 0.008 & 0.008 & $1.2 \%$ & 43 & 53.91 & $0.90 \%$ & 4.42 & 4.35 & $-1.61 \%$ & 64.03 & .03 & $0.00 \%$ & 6.03 & 6.00 & $-0.50 \%$ & 55.73 & 56.31 & $\begin{array}{l}1.04 \% \\
-1.04 \%\end{array}$ & 21.81 & 21.85 & $0.19 \%$ \\
\hline ot & 0.008 & 0.008 & $-0.3 \%$ & & 5301 & $0.00 \%$ & 3.34 & 3.61 & $7.84 \%$ & 52.27 & .03 & $22.49 \%$ & 10.78 & 10.78 & $0.00 \%$ & 58.31 & 9.97 & $2.84 \%$ & 23.86 & 24.05 & $0.83 \%$ \\
\hline 986 & 0.008 & 0.015 & $82.8 \%$ & & & & 3 & 1 & & & 50 & $9.49 \%$ & 7.87 & 707 & $0.00 \%$ & 57.36 & 40 & & 23.22 & 23.22 & $0.00 \%$ \\
\hline 87 & 0.008 & & $-0.3^{4}-13 x-3$ & & & & 37 & & $-1.47 \%$ & & 40 & $7.74 \%$ & 50 & & & 53.09 & 08 & & 22.90 & & $0.89 \%$ \\
\hline 1988 & 0.008 & & $-0.3 \%$ & 53.91 & & & 3.85 & 66 & $21.21 \%$ & & .09 & $12.96 \%$ & 9.00 & & $0.00 \%$ & 61.89 & 2.51 & & 23.96 & 24.05 & $0.37 \%$ \\
\hline 989 & 0.008 & & $-0.3 \%$ & & & & 4.26 & & $-16.00 \%$ & & & & & & & 62.51 & & & 25.25 & & $-1.52 \%$ \\
\hline & 0.066 & & 38.9 & & & & 4.14 & & $14.60 \%$ & & & & & & & & & & 23.25 & & $-1.45 \%$ \\
\hline 1991 & 0.105 & & 33.7 & & & & 5.29 & & 0.0 & & & & & & & & & & 17.12 & & $-0.27 \%$ \\
\hline 1992 & 0.008 & & $-0.3^{\circ}$ & 53.91 & & & 3.63 & & & & & $14.23 \%$ & 7.7 & & & 51 & 23 & $15.40 \%$ & 22.87 & & $4.83 \%$ \\
\hline 1 & 0.008 & & -0.3 & 51. & & & 3.43 & & 5.7 & & & & 10.42 & & & 56 & & & 23.09 & & $2.04 \%$ \\
\hline 19 & 0.008 & & $-0.3^{\circ}$ & & & & 4.05 & & $-15.20 \%$ & & & 23. & 9.42 & 10 & & 55 & & & 23.20 & & $2.84 \%$ \\
\hline 1995 & 0.008 & & -0.3 & & & & 5.29 & & 0.00 & & & & & & & 62 & & & 23.49 & & $0.00 \%$ \\
\hline 1996 & 0.035 & & 49.9 & & & & 4.67 & & 11.5 & & & & 6.12 & & & 62. & 62. & $0.00 \%$ & 15.53 & 15.56 & $0.17 \%$ \\
\hline 1997 & 0.110 & & 39. & & & & 4.17 & 23 & 1.3 & & & & 6.5 & & & 50.88 & 52. & 2.5 & 21.41 & 21.85 & $2.07 \%$ \\
\hline 195 & 0.017 & & & & & & & & 43.7 & & & & 7. & & 7. & 59.73 & 59. & $0.00 \%$ & 23.93 & 23.00 & $-3.88 \%$ \\
\hline 195 & 0.088 & & & & & & 3.84 & & & & & & 6. & & & 50.89 & 51. & 2.1 & 22.56 & & $-4.04 \%$ \\
\hline 20 & 0.076 & & 31. & & & & 3.58 & 4. & 28 & & & 0. & 7.7 & & & 56 & $56-2$ & 0.5 & 22.85 & & $-1.47 \%$ \\
\hline $20 c$ & 0.008 & & -0.3 & 53 & 53 & $0 . c$ & 3. & 3.57 & & 39 & 51. & 30. & 11. & 11. & 0 & 49 & 54.67 & 10 & 22.86 & 2 & $4.55 \%$ \\
\hline 20 & 0.008 & 0.029 & $262.4 \%$ & 55.04 & 55.04 & $0.00 \%$ & 3.79 & 4.38 & $15.36 \%$ & 64. & 64. & $0.00 \%$ & 8.0 & 8.05 & & 56.50 & 51.77 & $-8.37 \%$ & 25.64 & 25.28 & $-1.40 \%$ \\
\hline & 0.008 & 0.008 & $-0.3 \%$ & 51.22 & 51.22 & $0.00 \%$ & 4.20 & 5.29 & $25.93 \%$ & 64.62 & 64.03 & $-0.91 \%$ & 8.98 & 8.98 & $0.00 \%$ & 62.51 & 62.51 & $0.00 \%$ & 23.41 & 23.41 & $0.00 \%$ \\
\hline
\end{tabular}

Resident Rainbow

\begin{tabular}{|c|c|c|c|c|}
\hline Redd Scour & Spawning/incubation \\
\hline
\end{tabular}

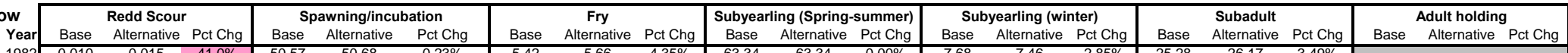

\begin{tabular}{l|lll|lll|l}
1982 & 0.010 & 0.015 & $41.0 \%$ & 50.57 & 50.68 & $0.23 \%$ & 5.42 \\
1983 & 0.008 & 0.008 & $-0.3 \%$ & 44.25 & 44.48 & $0.52 \%$ & 6.51
\end{tabular}

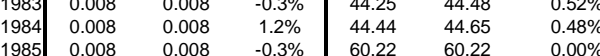

\begin{tabular}{l|lll|lll}
1985 & 0.008 & 0.008 & $-0.3 \%$ & 60.22 & 60.22 & $0.00 \%$ \\
1986 & 0.008 & 0.015 & $82.8 \%$ & 56.50 & 56.50 & $0.00 \%$
\end{tabular}

$1987 \quad 0.008 \quad 0.008 \quad-0.3 \%$

\begin{tabular}{l|lll|}
1988 & 0.008 & 0.008 & $-0.3 \%$ \\
1989 & 0.008 & 0.008 & $-0.3 \%$ \\
199 & 0.000 & 0.008 & $-0.3 \%$
\end{tabular}

\begin{tabular}{l|lll|}
1990 & 0.010 & 0.014 & $42.2 \%$ \\
1991 & 0.008 & 0.008 & $-0.3 \%$ \\
\hline & 0.008 & 0.088 & $-0.3 \%$
\end{tabular}

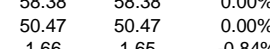

\begin{tabular}{l|lll|}
1992 & 0.008 & 0.008 & $-0.3 \%$ \\
1993 & 0.008 & 0.008 & $-0.3 \%$ \\
\hline
\end{tabular}

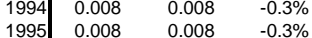

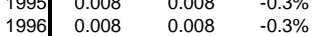

$1997 \quad 0.110 \quad 0.154$

\begin{tabular}{l|lll|}
1998 & 0.009 & 0.012 & $43.7 \%$ \\
1999 & 0.088 & 0.111 & $263 \%$ \\
\hline & 0.018 & 0.023 & $28.3 \%$
\end{tabular}

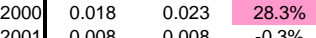

\begin{tabular}{l|l|l|l|}
2002 & 0.008 & 0.029 & $-0.3 \%$ \\
\hline & $0.02 .4 \%$ \\
\hline
\end{tabular}

\begin{tabular}{llr}
4.27 & 4.67 & $8.49 \%$ \\
\hline & $9.48 \%$ \\
\hline
\end{tabular}

$\begin{array}{ll}5.42 & -1.19 \% \\ 4.63 & 8.49 \% \\ 4.67 & 9.49 \%\end{array}$

\begin{tabular}{rr}
4.67 & $9.48 \%$ \\
4.75 & $-3.29 \%$ \\
\hline
\end{tabular}

\begin{tabular}{ll}
4.75 & $-3.29 \%$ \\
5.84 & $18.75 \%$ \\
\hline 4.65 & $-13.86 \%$ \\
\hline 5.90 & $12.67 \%$
\end{tabular}

\begin{tabular}{|l|l|}
\hline 4.65 & $-13.86 \%$ \\
5.90 & $12.67 \%$ \\
\hline 6.51 & $0.00 \%$
\end{tabular}

\begin{tabular}{ll}
6.51 & $0.00 \%$ \\
4.80 & $2.74 \%$ \\
\hline
\end{tabular}

\begin{tabular}{rr|}
4.65 & $6.85 \%$ \\
\hline .28 & $-13.98 \%$ \\
\hline & $0.00 \%$ \\
\hline
\end{tabular}

\begin{tabular}{rr}
4.28 & $-13.98 \%$ \\
6.51 & $0.00 \%$ \\
\hline & $0.718 \%$ \\
\hline & 1.73
\end{tabular}

\begin{tabular}{ll}
6.43 & $9.71 \%$ \\
5.29 & $1.78 \%$ \\
6.51 & $36.36 \%$ \\
\hline 5.21 & $7.58 \%$
\end{tabular}

\begin{tabular}{ll}
6.51 & $36.36 \%$ \\
5.21 & $7.58 \%$ \\
\hline & $2.22 \%$ \\
\hline
\end{tabular}

\begin{tabular}{l|l|}
5.74 & $24.22 \%$ \\
\hline .51 & $-0.03 \%$ \\
\hline
\end{tabular}

$5.46 \quad 13.17 \%$

\begin{tabular}{lll|lll|lll}
\hline 63.34 & 63.34 & $0.00 \%$ & 7.68 & 7.46 & $-2.85 \%$ & 25.28 & 26.17 & $3.49 \%$ \\
63.34 & 63.34 & $0.00 \%$ & 7.76 & 8.42 & $8.60 \%$ & 39.60 & 39.60 & $0.00 \%$ \\
6334 & 3.34 & $0.00 \%$ & 7.29 & 7.26 & $0.41 \%$ & 28.36 & 28.45 & $031 \%$
\end{tabular}

\begin{tabular}{ccc|ccc|ccc}
5 & 3.31 & $0.00 \%$ & 7.29 & 7.26 & $-0.41 \%$ & 28.36 & 28.45 & $0.31 \%$ \\
\hline & 63.34 & $23.21 \%$ & 12.34 & 12.34 & $0.00 \%$ & 24.23 & 30.76 & $2699 \%$ \\
\hline
\end{tabular}

\begin{tabular}{|lll|lll|lll}
58.04 & 63.77 & $9.88 \%$ & 9.14 & 9.14 & $0.00 \%$ & 29.77 & 31.11 & $4.48 \%$ \\
\hline 4502 & 48.52 & $7.79 \%$ & 9.83 & 9.83 & $003 \%$ & 27.70 & 31.93 & $15.43 \%$ \\
\hline & 52.21 & $13.17 \%$ & 10.38 & 10.38 & $0.00 \%$ & 3.14 & 38.69 & $10.10 \%$
\end{tabular}

\begin{tabular}{ccc|ccc|ccc}
52.32 & 59.21 & $13.17 \%$ & 10.38 & 10.38 & $0.03 \%$ & 27.66 & 31.93 & $15.43 \%$ \\
& 55.14 & 38.69 & $10.10 \%$ \\
\hline
\end{tabular}

\begin{tabular}{ccc}
63.34 & 62.12 & $-1.49 \%$ \\
63.34 & $0.00 \%$ \\
\hline & 63.34 & 0 \\
\hline 4.88 & 51.31 & $14.32 \%$
\end{tabular}

\begin{tabular}{ccc|ccc|ccc|}
\hline 43.34 & 63.34 & $0.00 \%$ & 7.27 & 7.26 & $-0.06 \%$ & 31.45 & 32.89 & $4.57 \%$ \\
\hline 4.88 & 51.31 & $14.32 \%$ & 8.28 & 8.68 & $4.76 \%$ & 40.26 & 40.26 & $0.00 \%$ \\
\hline
\end{tabular}

\begin{tabular}{ccc|cccc|ccc}
44.88 & 51.31 & $14.32 \%$ & 8.28 & 8.68 & $4.78 \%$ & 20.26 & 40.26 & $0.00 \%$ \\
39.76 & 4.96 & $13.09 \%$ & 11.90 & 11.90 & $0.02 \%$ & 29.07 & 29.19 & $30.70 \%$ \\
\hline $4.40 \%$ \\
\hline
\end{tabular}

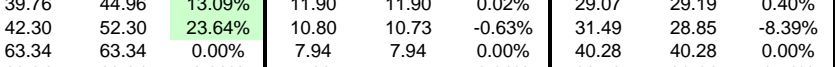

\begin{tabular}{lll|lll|lll}
63.34 & 63.34 & $0.00 \%$ & 7.90 & 7.94 & $0.00 \%$ & 40.28 & 40.28 & $0.00 \%$ \\
7.68 & 7.75 & $0.91 \%$ & 38.56 & 39.14 & $1.51 \%$ \\
63.34 & 63.34 & $0.00 \%$ & 8.25 & 8.72 & $5.69 \%$ & 21.98 & 23.01 & $4.60 \%$
\end{tabular}

\begin{tabular}{lll|lll|lll}
63.34 & 63.34 & $0.00 \%$ & 8.25 & 8.72 & $5.69 \%$ & 21.98 & 23.01 & $4.66 \%$ \\
61.38 & 63.34 & $3.19 \%$ & 8.32 & 8.96 & $7.66 \%$ & 31.16 & 36.89 & $18.40 \%$ \\
63.34 & 63.34 & $0.00 \%$ & 7.82 & 7.96 & $1.81 \%$ & 20.48 & 21.35 & $4.25 \%$ \\
\hline
\end{tabular}

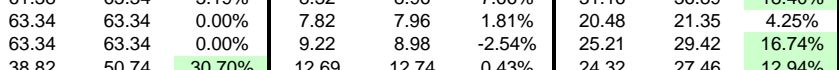

Figure 6-9. Annual habitat summaries for steelhead and resident rainbow trout in the Easton reach for the WymerPlus scenario. 
Bull Trout

\begin{tabular}{|c|c|c|c|c|c|c|c|c|c|c|c|c|c|c|c|c|c|c|}
\hline \multirow[b]{2}{*}{ Year } & \multicolumn{3}{|c|}{ Redd Scour } & \multicolumn{3}{|c|}{ Spawning/incubation } & \multicolumn{3}{|c|}{ Fry } & \multicolumn{3}{|c|}{ Subvearling (Spring-summer) } & \multicolumn{3}{|c|}{ Subvearling (winter) } & \multicolumn{2}{|r|}{ Subadult } & \multirow{2}{*}{$\begin{array}{l}\text { Adult holding } \\
\text { Alternative }\end{array}$} \\
\hline & Base & Alternative & Pct Chg & Base & Alternative & Pct Chg & Base & Alternative & Pct Chg & Base & Alternative & Pct Chg & Base & Alternative & Pct Chg & Base & Alternative Pct Chg & \\
\hline 1982 & 0.008 & 0.008 & $-0.3 \%$ & 41.33 & 41.33 & $0.00 \%$ & 4.20 & 4.11 & $-1.99 \%$ & 64.55 & 65.89 & $2.07 \%$ & 6.97 & 6.84 & $-1.93 \%$ & & & \\
\hline 1983 & 0.018 & 0.020 & $14.2 \%$ & 40.28 & 39.89 & $-0.96 \%$ & 4.32 & 4.35 & $0.48 \%$ & 72.74 & 72.74 & $0.00 \%$ & 7.57 & 8.11 & $7.15 \%$ & & & \\
\hline 1984 & 0.010 & 0.014 & $41.8 \%$ & 39.96 & 39.60 & $-0.90 \%$ & 4.37 & 4.36 & $-0.16 \%$ & 58.87 & 59.15 & $0.48 \%$ & 7.07 & 7.05 & $-0.29 \%$ & & & \\
\hline 1985 & 0.008 & 0.008 & $-0.3 \%$ & 40.06 & 40.06 & $0.00 \%$ & 4.95 & 4.66 & $-5.78 \%$ & 54.88 & 64.36 & $17.27 \%$ & 11.41 & 11.15 & $-2.29 \%$ & & & \\
\hline 1986 & 0.008 & 0.008 & $-0.3 \%$ & 40.80 & 40.80 & $0.00 \%$ & 5.39 & 5.25 & $-2.54 \%$ & 58.44 & 67.18 & $14.95 \%$ & 8.88 & 8.73 & $-1.76 \%$ & & & \\
\hline 1987 & 0.008 & 0.008 & $-0.3 \%$ & 41.33 & 41.33 & $0.00 \%$ & 4.90 & 4.90 & $0.00 \%$ & 52.69 & 57.27 & $8.68 \%$ & 9.40 & 9.40 & $0.05 \%$ & & & \\
\hline 1988 & 0.008 & 0.008 & $-0.3 \%$ & 40.75 & 40.75 & $0.00 \%$ & 4.59 & 4.59 & $0.00 \%$ & 64.07 & 69.53 & $8.53 \%$ & 9.92 & 9.92 & $0.00 \%$ & & & \\
\hline 1989 & 0.008 & 0.008 & $-0.3 \%$ & 41.33 & 41.33 & $0.00 \%$ & 4.78 & 4.78 & $0.00 \%$ & 70.08 & 67.99 & $-2.99 \%$ & 7.78 & 7.78 & $0.00 \%$ & & & \\
\hline 1990 & 0.008 & 0.008 & $-0.3 \%$ & 41.33 & 41.33 & $0.00 \%$ & 4.95 & 4.97 & $0.39 \%$ & & & $2.23 \%$ & 7.42 & 7.41 & $-0.15 \%$ & & & \\
\hline 1991 & 0.188 & 0.379 & $101.1 \%$ & 3.50 & 3.47 & $-0.84 \%$ & 5.36 & 5.36 & $0.00 \%$ & 72.74 & 72.74 & $0.00 \%$ & 7.17 & 7.24 & $1.11 \%$ & & & \\
\hline 1992 & 0.008 & 0.008 & $-0.3 \%$ & 40.97 & 40.44 & $-1.30 \%$ & 5.45 & 5.38 & $-1.42 \%$ & 51.24 & 60.52 & $18.12 \%$ & 7.89 & 7.89 & $0.00 \%$ & & & \\
\hline 1993 & 0.008 & 0.008 & $-0.3 \%$ & 41.33 & 41.33 & $0.00 \%$ & 5.50 & 5.50 & $0.04 \%$ & & & $7.69 \%$ & 11.02 & 11.02 & $0.02 \%$ & & & \\
\hline 1994 & 0.008 & 0.008 & $-0.3 \%$ & 41.33 & 41.33 & $0.00 \%$ & 4.76 & 4.76 & $0.07 \%$ & 55.79 & 54.78 & $-1.82 \%$ & 10.19 & 10.14 & $-0.55 \%$ & & & \\
\hline 1995 & 0.008 & 0.009 & $15.0 \%$ & 39.43 & 39.43 & $0.00 \%$ & 5.59 & 5.59 & $0.00 \%$ & 72.74 & 72.74 & $0.00 \%$ & 7.50 & 7.50 & $0.00 \%$ & & & \\
\hline 1996 & 0.102 & 0.134 & $31.2 \%$ & 9.04 & 9.04 & $0.00 \%$ & 4.66 & 4.66 & $0.00 \%$ & 72.50 & 72.67 & $0.23 \%$ & 7.57 & 7. & $0.90 \%$ & & & \\
\hline 1997 & 0.186 & 0.334 & $79.8 \%$ & 21.29 & 14.90 & $-29.99 \%$ & 4.24 & 4.28 & $0.78 \%$ & 59.74 & 61.25 & $2.53 \%$ & 7.56 & 7.82 & $3.42 \%$ & & & \\
\hline 1998 & 0.008 & 0.023 & $192.7 \%$ & 40.57 & 39.35 & $-3.02 \%$ & 4.28 & 4.27 & $-0.21 \%$ & 68.64 & 72.74 & $5.96 \%$ & 7.81 & 8.35 & $6.86 \%$ & & & \\
\hline 1999 & 0.008 & 0.019 & $131.1 \%$ & 39.97 & 39.64 & $-0.83 \%$ & 4.10 & 4.29 & $4.42 \%$ & 57.56 & 60.22 & $4.62 \%$ & 7.12 & 7.33 & $2.91 \%$ & & & \\
\hline 2000 & 0.104 & 0.139 & $33.1 \%$ & 34.71 & 34.71 & $0.00 \%$ & 4.97 & 4.97 & $0.00 \%$ & 60.98 & 64.66 & $6.04 \%$ & 8.73 & 8.57 & $-1.80 \%$ & & & \\
\hline 2001 & 0.008 & 0.008 & $-0.3 \%$ & 39.25 & 39.25 & $0.00 \%$ & 4.93 & 5.11 & $3.59 \%$ & 47.75 & 54.07 & $13.25 \%$ & 11.50 & 11.66 & $1.41 \%$ & & & \\
\hline 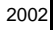 & 0.008 & 0.008 & $-0.3 \%$ & 40.13 & 40.13 & $0.00 \%$ & 5.16 & 5.16 & $0.00 \%$ & 59.94 & 55.07 & $-8.12 \%$ & 8.46 & 8.46 & $0.00 \%$ & & & \\
\hline & 0.008 & 0.008 & $-0.3 \%$ & 41.33 & 41.33 & $0.00 \%$ & 5.32 & 5.32 & $0.00 \%$ & 69.52 & 72.74 & $4.63 \%$ & 9.87 & 9.87 & $0.00 \%$ & & & \\
\hline
\end{tabular}

Figure 6-10. Annual habitat summaries for bull trout in the Easton reach for the WymerPlus scenario. 


\begin{tabular}{|c|c|c|c|c|c|c|c|c|c|c|c|c|c|c|c|c|c|c|c|c|}
\hline Spring Chinook & \multicolumn{3}{|c|}{ Redd Scour } & \multicolumn{3}{|c|}{ Spawning/incubation } & \multirow{2}{*}{\multicolumn{3}{|c|}{ Fry }} & \multicolumn{3}{|c|}{ Subyearling (Spring-summer) } & \multicolumn{3}{|c|}{ Subyearling (winter) } & \multicolumn{2}{|r|}{ Subadult } & \multicolumn{3}{|c|}{ Adult holding } \\
\hline & Base & Alternative & Pct Chg & Base & Alternative & Pct Chg & Base & & & Base & Alternative & Pct Chg & Base & Alternative & Pct Chg & Base & Alternative Pct Chg & Base & Alternative & Pct Chg \\
\hline $198:$ & 0.007 & 0.006 & $-10.93 \%$ & 21.22 & 25.18 & $18.68 \%$ & 1.84 & 1.89 & $2.40 \%$ & 14.32 & 13.44 & $-6.15 \%$ & 4.30 & 3.72 & $-13.46 \%$ & & & 6.51 & 6.72 & $3.32 \%$ \\
\hline 198 & 0.006 & 0.006 & $-4.58 \%$ & 22.11 & 16.82 & $-23.93 \%$ & 1.90 & 1.91 & $0.44 \%$ & 13.94 & 13.43 & $-3.62 \%$ & 3.81 & 3.61 & $-5.29 \%$ & & & 6.48 & 6.68 & $3.10 \%$ \\
\hline 198 & 0.007 & 0.007 & $0.66 \%$ & 14.57 & 16.80 & $15.29 \%$ & 1.75 & 1.78 & $1.42 \%$ & 14.47 & 13.65 & $-5.64 \%$ & 3.81 & 3.68 & $-360 \%$ & & & 6.53 & 6.91 & $576 \%$ \\
\hline 198 & 0.007 & 0.006 & $-11.14 \%$ & 30.09 & 29.71 & $-1.27 \%$ & 1.46 & 1.52 & $4.09 \%$ & 14.06 & 13.62 & $-3.17 \%$ & 3.85 & 3.51 & $-8.77 \%$ & & & 6.46 & 6.65 & $3.03 \%$ \\
\hline 198 & 0.007 & 0.006 & $-11.09 \%$ & 23.70 & 21.39 & $-9.76 \%$ & 1.69 & 1.70 & $0.20 \%$ & 14.20 & 13.58 & $-4.37 \%$ & 4.12 & 3.67 & $-10.74 \%$ & & & 6.59 & 6.78 & $3.01 \%$ \\
\hline 198 & 0.007 & 0.006 & $-16.39 \%$ & 30.50 & 29.68 & $-2.68 \%$ & 1.59 & 1.72 & $8.25 \%$ & 13.74 & 13.40 & $-2.46 \%$ & 4.21 & 3.72 & $-11.53 \%$ & & & 6.79 & 6.93 & $2.08 \%$ \\
\hline 1988 & 0.008 & 0.007 & $-2.05 \%$ & 29.18 & 26.80 & $-8.15 \%$ & 1.39 & 1.60 & $15.59 \%$ & 13.72 & 13.54 & $-1.33 \%$ & 3.99 & 4.27 & $6.79 \%$ & & & 6.86 & 7.07 & $3.11 \%$ \\
\hline 198 & 0.007 & 0.006 & $-5.44 \%$ & 34.53 & 35.43 & $2.60 \%$ & 1.57 & 1.64 & $4.94 \%$ & 14.03 & 13.53 & $-3.51 \%$ & 3.49 & 3.45 & $-1.16 \%$ & & & 6.49 & 6.78 & $4.38 \%$ \\
\hline 199 & 0.006 & 0.006 & $-11.03 \%$ & 29.81 & 33.94 & $13.87 \%$ & 1.78 & 1.83 & $2.56 \%$ & 14.45 & 13.56 & $-6.19 \%$ & 3.65 & 3.52 & $-3.73 \%$ & & & 6.43 & 6.65 & $3.51 \%$ \\
\hline 199 & 0.013 & 0.014 & $8.14 \%$ & 6.95 & 10.32 & $48.37 \%$ & 1.89 & 1.87 & $-1.00 \%$ & 13.93 & 13.37 & $-4.02 \%$ & 4.67 & 4.96 & $6.23 \%$ & & & 6.46 & 6.70 & $3.74 \%$ \\
\hline 199 & 0.006 & 0.006 & $-7.19 \%$ & 29.77 & 34.33 & $15.32 \%$ & 1.54 & 1.65 & $6.94 \%$ & 14.08 & 13.68 & $-2.88 \%$ & 3.69 & 3.53 & $-4.18 \%$ & & & 6.51 & 6.64 & $2.08 \%$ \\
\hline 199 & 0.007 & 0.007 & $-4.62 \%$ & 30.74 & 29.09 & $-5.37 \%$ & 1.44 & 1.56 & $8.31 \%$ & 13.75 & 13.44 & $-2.32 \%$ & 4.15 & 3.87 & $-6.77 \%$ & & & 6.84 & 7.11 & $4.01 \%$ \\
\hline 199 & 0.007 & 0.007 & $-0.63 \%$ & 28.86 & 26.03 & $-9.80 \%$ & 1.30 & 1.53 & $17.62 \%$ & 13.43 & 15.13 & $12.64 \%$ & 3.87 & 4.08 & $5.54 \%$ & & & 7.48 & 7.90 & $5.60 \%$ \\
\hline 199 & 0.007 & 0.007 & $-0.01 \%$ & 13.29 & 12.62 & $-5.02 \%$ & 1.76 & 1.83 & $4.26 \%$ & 13.99 & 13.92 & $-0.50 \%$ & 3.93 & 3.97 & $0.95 \%$ & & & 6.63 & 7.17 & $8.18 \%$ \\
\hline 199 & 0.019 & 0.019 & $-0.23 \%$ & 3.03 & 2.80 & $-7.66 \%$ & 1.94 & 1.93 & $-0.72 \%$ & 13.95 & 13.42 & $-3.79 \%$ & 5.94 & 6.10 & $2.77 \%$ & & & 6.48 & 6.68 & $3.08 \%$ \\
\hline 199 & 0.013 & 0.014 & $7.54 \%$ & 3.72 & 6.93 & $86.43 \%$ & 2.01 & 2.05 & $2.15 \%$ & 14.29 & 13.95 & $-2.37 \%$ & 3.84 & 3.67 & $-4.38 \%$ & & & 6.45 & 6.81 & $5.61 \%$ \\
\hline 199 & 0.006 & 0.006 & $-4.48 \%$ & 29.44 & 30.72 & $4.35 \%$ & 1.77 & 1.80 & $1.81 \%$ & 13.95 & 13.51 & $-3.16 \%$ & 3.49 & 3.64 & $4.27 \%$ & & & 6.45 & 6.70 & $3.90 \%$ \\
\hline 199 & 0.006 & 0.006 & $-10.13 \%$ & 29.16 & 27.82 & $-4.59 \%$ & 1.75 & 1.81 & $3.18 \%$ & 13.87 & 14.00 & $0.94 \%$ & 3.67 & 3.64 & $-0.79 \%$ & & & 6.57 & 6.72 & $2.27 \%$ \\
\hline 200 & 0.006 & 0.006 & $-2.32 \%$ & 14.31 & 19.04 & $33.03 \%$ & 1.71 & 1.72 & $0.57 \%$ & 14.09 & 13.54 & $-3.93 \%$ & 3.70 & 3.72 & $0.60 \%$ & & & 6.44 & 6.65 & $3.11 \%$ \\
\hline 200 & 0.006 & 0.006 & $-10.51 \%$ & 29.83 & 34.69 & $16.31 \%$ & 1.36 & 1.43 & $5.07 \%$ & 13.24 & 13.86 & $4.67 \%$ & 3.90 & 3.65 & $-6.57 \%$ & & & 7.13 & 7.65 & $7.19 \%$ \\
\hline 200 & 0.008 & 0.008 & $-1.99 \%$ & 30.42 & 30.37 & $-0.18 \%$ & 1.62 & 1.72 & $6.08 \%$ & 14.30 & 13.52 & $-5.40 \%$ & 3.53 & 3.49 & $-1.05 \%$ & & & 6.52 & 6.64 & $1.77 \%$ \\
\hline 200 & 0.006 & 0.006 & $-6.49 \%$ & 28.63 & 27.64 & $-3.46 \%$ & 1.80 & 1.83 & $1.73 \%$ & 14.28 & 13.61 & $-4.74 \%$ & 3.89 & 3.52 & $-9.66 \%$ & & & 6.58 & 6.76 & $2.78 \%$ \\
\hline \multirow[t]{24}{*}{ Coho } & \multicolumn{3}{|c|}{ Redd Scour } & \multicolumn{3}{|c|}{ Spawning/incubation } & \multicolumn{3}{|c|}{ Fry } & \multicolumn{3}{|c|}{ 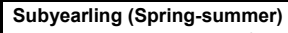 } & \multicolumn{3}{|c|}{ Subyearling (winter) } & \multirow{2}{*}{\multicolumn{2}{|c|}{$\begin{array}{cc} & \begin{array}{c}\text { Subadult } \\
\text { Base }\end{array} \\
\text { Alternative }\end{array}$}} & & Adult holdir & \\
\hline & Base & Alternative & Pct Chg & Base & Alternative & Pct Chg & Base & Alternative & Pct Chg & Base & Alternative & Pct Chg & Base & Alternative & Pct Chg & & & Base & Alternative & Pct Chg \\
\hline & 0.007 & 0.006 & $-10.93 \%$ & 14.93 & 13.04 & $-12.7 \%$ & 1.79 & 1.85 & $3.1 \%$ & 4.70 & 4.17 & $-11.3 \%$ & 2.57 & 2.28 & $-11.1 \%$ & & & & & \\
\hline & 0.006 & 0.006 & $-2.30 \%$ & 16.10 & 13.18 & $-18.1 \%$ & 1.85 & 1.85 & $0.0 \%$ & 4.46 & 4.12 & $-7.6 \%$ & 2.32 & 2.21 & $-4.4 \%$ & & & & & \\
\hline & 0.007 & 0.007 & $0.66 \%$ & 13.06 & 13.17 & $0.9 \%$ & 1.79 & 1.78 & $-0.6 \%$ & 4.78 & 4.19 & $-12.4 \%$ & 2.42 & 2.38 & $-1.8 \%$ & & & & & \\
\hline & 0.007 & 0.006 & $-11.14 \%$ & 14.28 & 12.51 & $-12.4 \%$ & 1.78 & 1.80 & $0.9 \%$ & 4.63 & 4.33 & $-6.4 \%$ & 2.34 & 2.23 & $-4.9 \%$ & & & & & \\
\hline & 0.007 & 0.006 & $-11.16 \%$ & 15.74 & 15.70 & $-0.3 \%$ & 1.58 & 1.61 & $1.7 \%$ & 4.66 & 4.31 & $-7.5 \%$ & 2.55 & 2.32 & $-9.3 \%$ & & & & & \\
\hline & 0.006 & 0.006 & $-9.48 \%$ & 19.33 & 18.69 & $-3.3 \%$ & 1.60 & 1.73 & $8.3 \%$ & 4.42 & 4.19 & $-5.3 \%$ & 2.67 & 2.29 & $-13.9 \%$ & & & & & \\
\hline & 0.007 & 0.007 & $-0.90 \%$ & 18.83 & 17.64 & $-6.3 \%$ & 1.59 & 1.79 & $12.6 \%$ & 4.36 & 4.13 & $-5.2 \%$ & 2.55 & 2.63 & $3.1 \%$ & & & & & \\
\hline & 0.006 & 0.006 & $-2.38 \%$ & 19.96 & 19.41 & $-2.8 \%$ & 1.78 & 1.81 & $1.8 \%$ & 4.64 & 4.27 & $-8.1 \%$ & 2.21 & 2.19 & $-0.5 \%$ & & & & & \\
\hline & 0.006 & 0.006 & $-5.52 \%$ & 18.79 & 18.12 & $-3.6 \%$ & 1.87 & 1.88 & $0.6 \%$ & 5.08 & 4.35 & $-14.4 \%$ & 2. & 2.2 & $-5.7 \%$ & & & & & \\
\hline & 0.005 & 0.005 & $-2.82 \%$ & 5.8 & 8.08 & $37.4 \%$ & 1.86 & 1.83 & $-1.4 \%$ & 4. & 4. & $-10.1 \%$ & 3. & 3. & $13.0 \%$ & & & & & \\
\hline & 0.006 & 0.006 & $-7.19 \%$ & 18.76 & 17.59 & $-6.2 \%$ & 1.47 & 1.5 & $7.2 \%$ & 4. & 4. & $-6.7 \%$ & 2 & 2 & $-7.3 \%$ & & & & & \\
\hline & 0.007 & 0.007 & $-4.62 \%$ & 19.98 & 15.85 & $-20.7 \%$ & 1.52 & 1.7 & $12.8 \%$ & 4. & 4. & -7. & 2 & 2. & -9 & & & & & \\
\hline & 0.007 & 0.007 & $-0.69 \%$ & 18.7 & 16.1 & $-13.7 \%$ & 1.40 & 1. & $19.7 \%$ & 4 & 4. & & 2 & 2 & & & & & & \\
\hline & 0.006 & 0.0 & $-2.78 \%$ & 12.22 & 11. & $-3.6 \%$ & 1.68 & 1. & 5. & 4. & 4 & -3 & 2. & 2 & & & & & & \\
\hline & 0.019 & & -0.2 & 1.2 & 1. & -17 & 1.86 & 1. & & 4 & 4. & -9 & 4. & 5 & & & & & & \\
\hline & 0.013 & 0. & & 3. & 5. & 94 & 1.98 & 2.01 & & & 4. & $-12.8 \%$ & & & & & & & & \\
\hline & 0.006 & & -4 & 11.95 & 13.87 & & 1.85 & 1. & & & 4. & -7. & & 2 & & & & & & \\
\hline & 0.006 & 0.006 & -2 & 18.30 & 16.92 & & 1.88 & 1.86 & $-0.9 \%$ & & 4. & & 2 & 2 & & & & & & \\
\hline & 0.006 & 0.006 & -2.3 & 12.89 & 14.41 & $11.8 \%$ & 1.88 & 1.85 & $-1.2 \%$ & & 4.2 & -9 & 2. & 2. & & & & & & \\
\hline & 0.006 & 0.006 & $-10.51 \%$ & 15.00 & 17.66 & $17.7 \%$ & 1.49 & 1.60 & $7.7 \%$ & 4.04 & 4.1 & 3. & 2.54 & 2. & $-9.8 \%$ & & & & & \\
\hline & 0.006 & 0.006 & $-2.74 \%$ & 19.29 & 19.22 & $-0.4 \%$ & 1.84 & 1.85 & $0.5 \%$ & 4.76 & 4.3 & -9.7 & 2.26 & 2.2 & $0.8 \%$ & & & & & \\
\hline & 0.006 & 0.006 & $-6.49 \%$ & 17.78 & 16.73 & $-5.9 \%$ & 1.86 & 1.85 & $-0.2 \%$ & 4.70 & 4.30 & $-8.5 \%$ & 2.39 & 2.20 & $-8.0 \%$ & & & & & \\
\hline
\end{tabular}

Figure 6-11. Annual habitat summaries for spring chinook and coho salmon in the Kittitas reach for the WymerPlus scenario. 
Steelhead

\begin{tabular}{|c|c|c|c|c|c|c|c|c|c|c|c|c|c|c|c|c|c|c|c|c|c|}
\hline \multirow[b]{2}{*}{ Year } & \multirow{2}{*}{\multicolumn{3}{|c|}{\begin{tabular}{ll}
\multicolumn{2}{c}{ Redd Scour } \\
Base & Alternative Pct Chg
\end{tabular}}} & \multicolumn{3}{|c|}{ Spawning/incubation } & \multirow{2}{*}{\multicolumn{3}{|c|}{ Fry }} & \multirow{2}{*}{\multicolumn{3}{|c|}{$\begin{array}{l}\text { Subyearling (Spring-summer) } \\
\text { Base Alternative Pct Chg }\end{array}$}} & \multicolumn{3}{|c|}{ Subyearling (winter) } & \multicolumn{3}{|c|}{ Subadult } & \multicolumn{3}{|c|}{ Adult holding } \\
\hline & & & & Base & Alternative & Pct Chg & Base & & & & & & Base & Alternativ & e Pct Chg & Base & Alternative & Pct Chg & Base & Alternative & Pct Chg \\
\hline 1982 & 0.005 & 0.005 & $-2.61 \%$ & 30.03 & 30.03 & $0.0 \%$ & 2.21 & 2.11 & $-4.5 \%$ & 19.88 & 19.89 & $0.1 \%$ & 3.73 & 3.20 & $-14.3 \%$ & $\begin{array}{ll}19.16 \\
\end{array}$ & \begin{tabular}{l|l}
19.01 \\
\end{tabular} & $-0.7 \%$ & 8.45 & 8.16 & \\
\hline 1983 & 0.005 & 0.005 & $3.79 \%$ & 33.83 & 34.38 & $1.6 \%$ & 2.17 & 2.11 & $-3.1 \%$ & 19.65 & 19.10 & $-2.8 \%$ & 3.24 & 3.04 & $-6.2 \%$ & 19.10 & 19.02 & $-0.4 \%$ & 8.16 & 7.81 & $-4.3 \%$ \\
\hline 1984 & 0.005 & 0.005 & $0.86 \%$ & 2.49 & 33.94 & $4.5 \%$ & 2.21 & 2.11 & $-4.8 \%$ & 18.90 & 19.17 & $1.5 \%$ & 3.29 & 3.18 & $-3.3 \%$ & 19.20 & 19.11 & $-0.5 \%$ & 8.19 & 7.90 & $-3.5 \%$ \\
\hline 1985 & 0.005 & 0.005 & $0.22 \%$ & 30.21 & 29.77 & $-1.5 \%$ & 2.23 & 2.14 & $-4.0 \%$ & 17.61 & 19.29 & $9.5 \%$ & 3.31 & 3.06 & $-7.7 \%$ & 19.15 & 19.04 & $-0.6 \%$ & 11.82 & 11.30 & $-4.4 \%$ \\
\hline 1986 & 0.005 & 0.006 & $0.30 \%$ & 29.59 & 33.89 & $14.5 \%$ & 2.21 & 2.13 & $-3.8 \%$ & 19.05 & 19.38 & $1.7 \%$ & 3.65 & 3.21 & $-12.0 \%$ & 19.17 & 19.06 & $-0.6 \%$ & 9.35 & 9.11 & $-2.5 \%$ \\
\hline 1987 & 0.005 & 0.005 & $-3.25 \%$ & 30.53 & 33.87 & $10.9 \%$ & 2.14 & 2.11 & $-1.5 \%$ & 22.38 & 21.54 & $-3.7 \%$ & 3.81 & 3.26 & $-14.4 \%$ & 19.06 & 19.01 & $-0.3 \%$ & 10.99 & 10.37 & $-5.6 \%$ \\
\hline 1988 & 0.005 & 0.005 & $-6.57 \%$ & 27.86 & 28.56 & $2.5 \%$ & 2.14 & 2.10 & $-1.5 \%$ & 20.80 & 21.66 & $4.1 \%$ & 3.64 & 3.75 & $3.1 \%$ & 19.07 & 19.49 & $2.2 \%$ & 11.99 & 11.52 & $-4.0 \%$ \\
\hline 1989 & 0.005 & 0.005 & $0.40 \%$ & 33.60 & 35.17 & $4.7 \%$ & 2.18 & 2.13 & $-2.4 \%$ & 20.24 & 19.63 & $-3.0 \%$ & 3.06 & 3.02 & $-1.4 \%$ & 19.14 & 19.15 & & 10.60 & 9.96 & $-6.1 \%$ \\
\hline 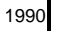 & 0.005 & & & 33.60 & & & 2.22 & 2.12 & $-4.9 \%$ & 20.44 & & $6.5 \%$ & 3.18 & 3.05 & $-4.1 \%$ & 19.19 & 19.03 & & 9.50 & 000 & $-5.3 \%$ \\
\hline 1991 & 0.005 & & & & & & 2.18 & & & & & & 4.08 & 4.48 & $9.6 \%$ & 19.10 & & $-0.5 \%$ & 7.06 & & $-1.0 \%$ \\
\hline 20 & 0.005 & & & & & & 2.17 & & & & & & 3.25 & & -4. & 19.09 & & & 9.35 & & $-5.0 \%$ \\
\hline & 0.005 & & -4.7 & & & & 2.15 & & $-1.7 \%$ & & & & 3. & 3.39 & $-10.4 \%$ & 19.07 & & 0 & 12.72 & & $-8.3 \%$ \\
\hline 94 & 0.006 & & $-7.03 \%$ & & & & 2.09 & & & & & 13 & & & $1.4 \%$ & 19.62 & & $14.4 \%$ & 13.23 & 12.73 & $-3.8 \%$ \\
\hline 95 & 0.005 & & 11.5 & & & & 2.17 & & & & & 1. & & & & & & $1.8 \%$ & 8.20 & & $-4.2 \%$ \\
\hline 96 & 0.008 & & 7.1 & & & & 2.19 & & & & & & & & & & & & 71 & & $-0.7 \%$ \\
\hline 997 & 0.013 & & & & & & 2.21 & & & & & & & & & & & & 30 & & $-6.4 \%$ \\
\hline 998 & 0.005 & & & & & 10 & 2.19 & & & & & & & & & & & & 11 & & $-8.3 \%$ \\
\hline 1999 & 0.011 & & & & & & 2.17 & & & & & & & & & & & & & & $-5.4 \%$ \\
\hline 2000 & 0.005 & & & & & & 2.18 & & & & & & & & -0. & & & & & & $-5.5 \%$ \\
\hline 20 & 0.005 & 0.0 & & 30 & & 13. & 2.10 & & & & & & 3. & 3 & -11 & & & & 13.07 & 40 & $-5.1 \%$ \\
\hline 20 & 0.005 & & -1.2 & 30. & & & 2.22 & 2. & & & & 0. & 3 & & -0 & 19 & & & 10.20 & & \\
\hline & 0.005 & 0.005 & $-2.33 \%$ & 33.79 & 34.34 & $1.6 \%$ & 2.22 & 2.13 & $-3.7 \%$ & 19.18 & 20.27 & $5.7 \%$ & 3.34 & 3.06 & $-8.4 \%$ & 19.19 & 19.06 & $-0.7 \%$ & 9.18 & 8.93 & $-2.7 \%$ \\
\hline
\end{tabular}

Resident Rainbow

\begin{tabular}{|c|c|c|c|c|c|c|c|c|c|c|c|c|c|c|c|c|c|c|}
\hline \multicolumn{3}{|c|}{ Redd Scour } & \multicolumn{3}{|c|}{ Spawning/incubation } & \multicolumn{3}{|c|}{ Fry } & \multirow{2}{*}{\multicolumn{3}{|c|}{ Subyearling (Spring-summer) }} & \multicolumn{3}{|c|}{ Subyearling (winter) } & \multicolumn{3}{|c|}{$\begin{array}{l}\text { Subadult } \\
\end{array}$} & \multirow{2}{*}{$\begin{array}{l}\text { Adult holding } \\
\end{array}$} \\
\hline Base & Alternative & Pct Chg & Base & Alternative & Pct Chg & Base & Alternative & Pct Chg & Base & & & Base & Alternative & Pct Chg & Base & Alternative & Pct Chg & \\
\hline 0.005 & 0.005 & $3.98 \%$ & 14.64 & 17.59 & $20.2 \%$ & 2.54 & 2.41 & $-5.1 \%$ & 19.64 & 19.66 & $0.1 \%$ & 4.62 & 4.06 & $-12.2 \%$ & 8.21 & 7.72 & $-6.0 \%$ & \\
\hline 0.005 & 0.005 & $3.79 \%$ & 15.40 & 10.83 & $-29.7 \%$ & 2.49 & 2.41 & $-3.4 \%$ & 19.41 & 18.89 & $-2.7 \%$ & 4.11 & 3.87 & $-5.6 \%$ & 7.88 & 7.67 & $-2.7 \%$ & \\
\hline 0.005 & 0.005 & $0.86 \%$ & 9.68 & 10.82 & $11.8 \%$ & 2.54 & 2.41 & $-5.4 \%$ & 18.69 & 18.96 & $1.4 \%$ & 4.13 & 4.01 & $-3.0 \%$ & 8.41 & 7.85 & $-6.6 \%$ & \\
\hline 0.005 & 0.005 & $-0.13 \%$ & 23.27 & 21.97 & $-5.6 \%$ & 2.57 & 2.45 & $-4.5 \%$ & 17.43 & 19.07 & $9.4 \%$ & 4.18 & 3.89 & $-6.9 \%$ & 8.15 & 7.84 & $-3.8 \%$ & \\
\hline 0.005 & 0.006 & $0.30 \%$ & 17.18 & 14.78 & $-14.0 \%$ & 2.55 & 2.44 & $-4.4 \%$ & 18.84 & 19.15 & $1.7 \%$ & 4.53 & 4.06 & $-10.4 \%$ & 8.43 & 7.93 & $-6.0 \%$ & \\
\hline 0.005 & 0.005 & $-3.25 \%$ & 27.20 & 24.32 & $-10.6 \%$ & 2.45 & 2.41 & $-1.7 \%$ & 22.07 & 21.26 & $-3.7 \%$ & 4.70 & 4.13 & $-12.1 \%$ & 7.95 & 7.72 & $-2.9 \%$ & \\
\hline 0.005 & 0.005 & $-6.57 \%$ & 27.99 & 23.70 & $-15.3 \%$ & 2.45 & 2.40 & $-1.7 \%$ & 20.55 & 21.38 & $4.1 \%$ & 4.54 & 4.68 & $3.1 \%$ & 7.98 & 7.69 & $-3.6 \%$ & \\
\hline 0.005 & 0.005 & $0.40 \%$ & 30.77 & 29.83 & $-3.0 \%$ & 2.51 & 2.44 & $-2.7 \%$ & 19.99 & 19.40 & $-3.0 \%$ & 3.89 & 3.84 & $-1.2 \%$ & 8.05 & 7.83 & $-2.7 \%$ & \\
\hline 0.005 & 0.005 & $2.48 \%$ & 24.70 & 27.20 & $10.2 \%$ & 2.56 & 2.42 & $-5.5 \%$ & 20.18 & 21.47 & $6.4 \%$ & 4.00 & 3.88 & $-3.1 \%$ & 8.21 & 7.82 & $-4.7 \%$ & \\
\hline 0.005 & 0.005 & $1.67 \%$ & 3.23 & 5.45 & $68.7 \%$ & 2.51 & 2.40 & $-4.2 \%$ & 21.17 & 21.71 & $2.6 \%$ & 4.97 & 5.37 & $8.1 \%$ & 8.17 & 7.73 & $-5.4 \%$ & \\
\hline 0.005 & 0.005 & $-2.23 \%$ & 24.58 & 27.27 & $10.9 \%$ & 2.49 & 2.44 & $-2.0 \%$ & 22.42 & 20.54 & $-8.4 \%$ & 4.07 & 3.92 & $-3.6 \%$ & 8.07 & 7.89 & $-2.2 \%$ & \\
\hline 0.005 & 0.005 & $-4.79 \%$ & 27.92 & 24.05 & $-13.9 \%$ & 2.46 & 2.41 & $-2.0 \%$ & 20.16 & 22.09 & $9.6 \%$ & 4.68 & 4.27 & $-8.7 \%$ & 8.02 & 7.67 & $-4.3 \%$ & \\
\hline 0.006 & 0.005 & $-7.03 \%$ & 27.90 & 23.58 & $-15.5 \%$ & 2.39 & 2.32 & $-2.8 \%$ & 21.83 & 24.72 & $13.2 \%$ & 4.56 & 4.63 & $1.5 \%$ & 7.67 & 8.41 & $9.6 \%$ & \\
\hline 0.005 & 0.006 & $13.73 \%$ & 8.89 & 8.34 & $-6.1 \%$ & 2.49 & 2.36 & $-5.1 \%$ & 20.15 & 20.40 & $1.2 \%$ & 4.25 & 4.22 & $-0.9 \%$ & 8.02 & 7.87 & $-1.8 \%$ & \\
\hline 0.005 & 0.005 & $-0.19 \%$ & 0.43 & 0.37 & $-15.2 \%$ & 2.52 & 2.42 & $-3.8 \%$ & 19.88 & 20.07 & $1.0 \%$ & 6.42 & 6.65 & $3.6 \%$ & 7.97 & 7.69 & $-3.6 \%$ & \\
\hline 0.013 & 0.014 & $6.61 \%$ & 1.34 & 3.22 & $139.3 \%$ & 2.54 & 2.48 & $-2.5 \%$ & 19.67 & 17.81 & $-9.5 \%$ & 4.11 & 3.90 & $-5.1 \%$ & 8.51 & 8.13 & $-4.4 \%$ & \\
\hline 0.005 & 0.005 & $9.20 \%$ & 21.48 & 22.06 & $2.7 \%$ & 2.51 & 2.42 & $-3.6 \%$ & 19.47 & 21.47 & $10.3 \%$ & 3.88 & 3.97 & $2.3 \%$ & 8.03 & 7.79 & $-2.9 \%$ & \\
\hline 0.011 & 0.011 & $5.01 \%$ & 22.74 & 20.48 & $-9.9 \%$ & 2.49 & 2.44 & $-2.0 \%$ & 20.14 & 20.82 & $3.4 \%$ & 3.99 & 3.99 & $0.0 \%$ & 8.09 & 8.05 & $-0.5 \%$ & \\
\hline 0.005 & 0.005 & $1.91 \%$ & 9.43 & 12.75 & $35.2 \%$ & 2.51 & 2.43 & $-3.0 \%$ & 18.24 & 19.39 & $6.3 \%$ & 4.01 & 4.00 & $-0.2 \%$ & 8.15 & 7.84 & $-3.7 \%$ & \\
\hline 0.005 & 0.005 & $-2.80 \%$ & 23.59 & 27.29 & $15.7 \%$ & 2.40 & 2.44 & $1.7 \%$ & 20.87 & 24.29 & $16.4 \%$ & 4.48 & 4.04 & $-9.6 \%$ & 7.60 & 7.87 & $3.6 \%$ & \\
\hline 0.005 & 0.005 & $-1.24 \%$ & 27.34 & 26.39 & $-3.5 \%$ & 2.56 & 2.43 & $-4.9 \%$ & 18.61 & 18.69 & $0.4 \%$ & 3.90 & 3.87 & $-0.6 \%$ & 8.06 & 7.82 & $-3.0 \%$ & \\
\hline 0.005 & 0.005 & $-2.33 \%$ & 21.72 & 20.21 & $-7.0 \%$ & 2.55 & 2.44 & $-4.3 \%$ & 18.95 & 20.02 & $5.6 \%$ & 4.21 & 3.91 & $-7.2 \%$ & 8.16 & 7.78 & $-4.7 \%$ & \\
\hline
\end{tabular}

Figure 6-12. Annual habitat summaries for steelhead and resident rainbow trout in the Kittitas reach for the WymerPlus scenario. 
Bull Trout

\begin{tabular}{|c|c|c|c|c|c|c|c|c|c|c|c|c|c|c|c|c|c|}
\hline \multirow[b]{2}{*}{ Year } & \multirow{2}{*}{\multicolumn{3}{|c|}{\begin{tabular}{ll}
\multicolumn{2}{c}{ Redd Scour } \\
Base & Alternative Pct Cha
\end{tabular}}} & \multicolumn{3}{|c|}{ Spawning/incubation } & \multirow{2}{*}{\multicolumn{3}{|c|}{\begin{tabular}{cc}
\multicolumn{2}{c}{ Fry } \\
Base & Alternative Pct Cha
\end{tabular}}} & \multicolumn{3}{|c|}{ Subyearling (Spring-summer) } & \multicolumn{3}{|c|}{ Subyearling (winter) } & $\begin{array}{ll} & \text { Subadult } \\
\text { Base } & \text { Alternative Pct Cha }\end{array}$ & Adult holding \\
\hline & & Alternative & Pct Chg & Base & Alternative & Pct Chg & & & Pct Chg & Base & Alternative & Pct Chg & Base & Alternative & Pct Chg & Base Alternative Pct Chg & Base Alternative Pct Chg \\
\hline 1982 & 0.007 & 0.006 & $-10.93 \%$ & 13.14 & 10.71 & $-18.5 \%$ & $\frac{2.51}{2.51}$ & 2.58 & $2.8 \%$ & 20.84 & 19.88 & $-4.6 \%$ & 4.45 & 3.95 & $-11.2 \%$ & & \\
\hline 1983 & 0.006 & 0.006 & $-4.58 \%$ & 14.34 & 10.96 & $-23.6 \%$ & 2.62 & 2.64 & $0.6 \%$ & 20.46 & 19.91 & $-2.6 \%$ & 4.04 & 3.87 & $-4.1 \%$ & & \\
\hline 1984 & 0.007 & 0.007 & $0.66 \%$ & 10.90 & 10.95 & $0.4 \%$ & 2.52 & 2.51 & $-0.5 \%$ & 21.00 & 20.18 & $-3.9 \%$ & 4.09 & 3.98 & $-2.6 \%$ & & \\
\hline 1985 & 0.007 & 0.006 & $-11.14 \%$ & 12.23 & 10.14 & $-17.1 \%$ & 2.51 & 2.53 & $1.0 \%$ & 20.54 & 20.05 & $-2.4 \%$ & 4.05 & 3.78 & $-6.8 \%$ & & \\
\hline 1986 & 0.007 & 0.006 & $-11.09 \%$ & 14.05 & 13.88 & $-1.2 \%$ & 2.31 & 2.33 & $0.7 \%$ & 20.67 & 20.01 & $-3.2 \%$ & 4.34 & $\begin{array}{l}3.97 \\
3.97\end{array}$ & $-8.5 \%$ & & \\
\hline 1987 & 0.006 & 0.006 & $-10.15 \%$ & 17.38 & 17.59 & $1.2 \%$ & 2.32 & 2.45 & $5.5 \%$ & 20.17 & 19.83 & $-1.7 \%$ & 4.45 & $\begin{array}{l}3.96 \\
3.96\end{array}$ & $-11.0 \%$ & & \\
\hline 1988 & 0.007 & 0.007 & $-1.26 \%$ & 18.39 & 17.54 & $-4.7 \%$ & 2.32 & 2.51 & $8.3 \%$ & 20.18 & 20.12 & $-0.3 \%$ & 4.24 & 4.48 & $5.8 \%$ & & \\
\hline $\begin{array}{l}1989 \\
1989\end{array}$ & 0.006 & 0.006 & $-9.06 \%$ & $\begin{array}{l}17.85 \\
17.85\end{array}$ & $\begin{array}{l}16.37 \\
167\end{array}$ & $-8.3 \%$ & 2.51 & 2.53 & $\begin{array}{l}1.0 \% \\
1.0 \%\end{array}$ & 20.50 & 19.96 & $-2.6 \%$ & $\begin{array}{l}4.74 \\
3.76\end{array}$ & $\begin{array}{l}4.46 \\
3.69\end{array}$ & $\begin{array}{l}.1 .0 \% \\
-1.9 \%\end{array}$ & & \\
\hline 1990 & 0.006 & 0.006 & $-11.03 \%$ & 17.73 & 15.43 & $-13.0 \%$ & 2.61 & 2.61 & $0.2 \%$ & 20.93 & $\begin{array}{l}19.97 \\
\end{array}$ & $-4.6 \%$ & 3.96 & $\begin{array}{l}3.78 \\
3.78\end{array}$ & $-4.4 \%$ & & \\
\hline 1991 & 0.013 & 0.014 & $8.14 \%$ & 4.99 & 6.55 & $31.2 \%$ & 2.62 & 2.59 & $-1.2 \%$ & 20.36 & 19.78 & $-2.9 \%$ & 5.18 & 5.50 & $6.2 \%$ & & \\
\hline 1992 & 0.006 & 0.006 & $-7.19 \%$ & 17.69 & $\begin{array}{l}14.19 \\
\text { S }\end{array}$ & $-19.8 \%$ & 2.20 & 2.30 & $4.3 \%$ & 20.50 & 20.08 & $-2.1 \%$ & 4.00 & 3.82 & $-4.4 \%$ & & \\
\hline 1993 & 0.007 & 0.007 & $-4.62 \%$ & 17.42 & 14.12 & $-18.9 \%$ & 2.25 & 2.43 & $8.2 \%$ & 20.19 & 19.93 & $-1.3 \%$ & 4.41 & 4.13 & $-6.4 \%$ & & \\
\hline 1994 & 0.007 & 0.007 & $-0.52 \%$ & 18.42 & $\begin{array}{l}14.52 \\
\end{array}$ & $-21.2 \%$ & 2.15 & 2.39 & $11.6 \%$ & 19.98 & 22.40 & $12.1 \%$ & 4.15 & 4.34 & $4.6 \%$ & & \\
\hline $\begin{array}{l}1995 \\
\end{array}$ & 0.006 & 0.006 & $-4.76 \%$ & 10.77 & 10.26 & $-4.7 \%$ & 2.40 & 2.50 & $4.1 \%$ & 20.50 & 20.61 & $0.6 \%$ & 4.23 & 4.28 & $1.1 \%$ & & \\
\hline 1996 & 0.019 & 0.019 & $-0.23 \%$ & 1.88 & 1.65 & $-12.2 \%$ & 2.65 & 2.62 & $-1.1 \%$ & 20.39 & 19.86 & $-2.6 \%$ & 6.27 & 6.41 & $2.3 \%$ & & \\
\hline 1997 & 0.013 & 0.014 & $7.54 \%$ & 3.11 & 4.98 & $59.8 \%$ & 3.17 & 3.24 & $2.1 \%$ & 20.75 & 20.56 & $-0.9 \%$ & 4.08 & 3.94 & $-3.4 \%$ & & \\
\hline 1998 & 0.006 & 0.006 & $-4.48 \%$ & 9.52 & 10.08 & $5.9 \%$ & 2.62 & 2.61 & $-0.2 \%$ & 20.43 & 19.94 & $-2.4 \%$ & 3.78 & 4.01 & $6.1 \%$ & & \\
\hline 1999 & 0.006 & 0.006 & $-10.13 \%$ & 17.00 & 14.25 & $-16.2 \%$ & 2.67 & 2.68 & $0.1 \%$ & 20.35 & 20.60 & $1.2 \%$ & 3.99 & 3.95 & $-1.0 \%$ & & \\
\hline 2000 & 0.006 & 0.006 & $-2.32 \%$ & 10.71 & 12.38 & $15.7 \%$ & 2.63 & 2.60 & $-1.0 \%$ & 20.56 & 19.98 & $-2.8 \%$ & 3.96 & 4.01 & $1.3 \%$ & & \\
\hline 2001 & 0.006 & 0.006 & $-10.51 \%$ & 13.25 & 14.32 & $8.1 \%$ & 2.22 & 2.32 & $4.6 \%$ & 19.67 & 20.57 & 4.6 & 4.20 & 3.92 & $-6.7 \%$ & & \\
\hline 2002 & 0.006 & 0.006 & $-3.56 \%$ & 18.58 & 17.67 & $-4.9 \%$ & 2.58 & 2.60 & $0.7 \%$ & 20.79 & 19.95 & $-4.1 \%$ & 3.80 & 3.78 & $-0.5 \%$ & & \\
\hline 2003 & 0.006 & 0.006 & $-6.49 \%$ & 15.70 & 13.79 & $-12.1 \%$ & 2.59 & 2.58 & $-0.3 \%$ & 20.76 & 20.05 & $-3.4 \%$ & 4.11 & 3.77 & $-8.1 \%$ & & \\
\hline
\end{tabular}

Figure 6-13. Annual habitat summary for bull trout in the Kittitas reach for the WymerPlus scenario. 


\begin{tabular}{|c|c|c|c|c|c|c|c|c|c|c|c|c|c|c|c|c|c|c|c|c|}
\hline Spring Chinook & \multicolumn{3}{|c|}{ Redd Scour } & \multicolumn{3}{|c|}{ Spawning/incubation } & \multicolumn{3}{|c|}{ Fry } & \multicolumn{3}{|c|}{ Subyearling (Spring-summer) } & \multicolumn{3}{|c|}{ Subyearling (winter) } & \multicolumn{2}{|r|}{ Subadult } & \multicolumn{3}{|c|}{ Adult holding } \\
\hline Yea & Base & Alternative & Pct Chg & Base & Alternative & Pct Chg & Base & Alternative & Pct Chg & Base & Alternative & Pct Chg & Base & Alternati & Pct Chg & Base & Alternative Pct Chg & Base & Alternative & Pct Chg \\
\hline 198 & 0.102 & 0.102 & $0.28 \%$ & 9.62 & 9.77 & $1.5 \%$ & 3.15 & 3.15 & $0.0 \%$ & 37.16 & 37.95 & $2.1 \%$ & 5.25 & 5.27 & $0.4 \%$ & & & 5.44 & 5.66 & $3.9 \%$ \\
\hline 198 & 0.057 & 0.057 & $0.20 \%$ & 18.57 & 17.50 & $-5.8 \%$ & 3.45 & 3.45 & $0.0 \%$ & 36.22 & 37.21 & $2.7 \%$ & 5.35 & 5.45 & $1.9 \%$ & & & 5.29 & 5.44 & $2.9 \%$ \\
\hline 198 & 0.134 & 0.125 & $-6.46 \%$ & 19.38 & 18.58 & $-4.1 \%$ & 2.75 & 2.77 & $0.8 \%$ & 38.00 & 39.22 & $3.2 \%$ & 5.50 & 5.45 & $-0.7 \%$ & & & 5.60 & 5.71 & $2.0 \%$ \\
\hline 198 & 0.018 & 0.022 & $17.16 \%$ & 15.19 & 22.09 & $45.4 \%$ & 2.33 & 2.36 & $1.0 \%$ & 38.23 & 37.84 & $-1.0 \%$ & 6.00 & 5.21 & $-13.2 \%$ & & & 6.08 & 5.71 & $-6.0 \%$ \\
\hline 198 & 0.030 & 0.031 & $3.79 \%$ & 16.88 & 16.12 & $-4.5 \%$ & 2.85 & 2.99 & $4.9 \%$ & 38.33 & 37.73 & $-1.6 \%$ & 5.65 & 5.73 & $1.4 \%$ & & & 8.08 & 6.88 & $-14.9 \%$ \\
\hline 198 & 0.017 & 0.024 & $39.11 \%$ & 26.91 & 5.40 & $-80.0 \%$ & 2.61 & 2.55 & $-2.4 \%$ & 36.42 & 37.24 & $2.3 \%$ & 5.45 & 5.59 & $2.5 \%$ & & & 7.74 & 7.97 & $3.1 \%$ \\
\hline 1988 & 0.023 & 0.024 & $5.83 \%$ & 27.77 & 26.23 & $-5.5 \%$ & 2.29 & 2.29 & $0.0 \%$ & 35.98 & 35.68 & $-0.8 \%$ & 5.25 & 5.25 & $0.0 \%$ & & & 6.98 & 7.01 & $0.4 \%$ \\
\hline 198 & 0.017 & 0.020 & $16.97 \%$ & 31.12 & 28.78 & $-7.5 \%$ & 2.37 & 2.46 & $3.6 \%$ & 36.16 & 36.27 & $0.3 \%$ & 4.74 & 4.75 & $0.1 \%$ & & & 6.05 & 5.61 & $-7.3 \%$ \\
\hline 199 & 0.041 & 0.042 & $1.44 \%$ & 26.20 & 15.42 & $-41.1 \%$ & 2.58 & 2.43 & $-5.8 \%$ & 39.03 & 38.18 & $-2.2 \%$ & 4.76 & 4.79 & $0.6 \%$ & & & 5.02 & 5.20 & $3.5 \%$ \\
\hline 199 & 0.222 & 0.221 & $-0.15 \%$ & 29.49 & 39.46 & $33.8 \%$ & 2.91 & 2.91 & $0.0 \%$ & 37.09 & 37.16 & $0.2 \%$ & 5.76 & 5.98 & $3.9 \%$ & & & 5.05 & 5.36 & $6.2 \%$ \\
\hline 199 & 0.020 & 0.023 & $17.50 \%$ & 19.09 & 17.98 & $-5.8 \%$ & 2.34 & 2.44 & $4.5 \%$ & 39.33 & 41.00 & $4.3 \%$ & 5.20 & 5.33 & $2.6 \%$ & & & 9.13 & 8.22 & $-10.0 \%$ \\
\hline 199 & 0.019 & 0.024 & $25.59 \%$ & 27.93 & 11.29 & $-59.6 \%$ & 2.28 & 2.29 & $0.2 \%$ & 38.38 & 36.96 & $-3.7 \%$ & 5.93 & 6.23 & $5.0 \%$ & & & 7.33 & 8.03 & $9.6 \%$ \\
\hline 199 & 0.021 & 0.025 & $18.93 \%$ & 9.30 & 8.28 & $-11.0 \%$ & 2.31 & 2.31 & $0.0 \%$ & 40.77 & 39.72 & $-2.6 \%$ & 5.91 & 6.05 & $2.4 \%$ & & & 6.91 & 7.67 & $11.0 \%$ \\
\hline 199 & 0.144 & 0.143 & $-0.84 \%$ & 25.27 & 22.87 & $-9.5 \%$ & 3.34 & 3.34 & $-0.1 \%$ & 36.50 & 36.75 & $0.7 \%$ & 5.73 & 5.81 & $1.5 \%$ & & & 5.05 & 5.00 & $-1.1 \%$ \\
\hline 199 & 0.889 & 0.888 & $-0.19 \%$ & 4.19 & 2.17 & $-48.2 \%$ & 3.64 & 3.64 & $0.0 \%$ & 35.68 & 36.08 & $1.1 \%$ & 9.13 & 9.34 & $2.3 \%$ & & & 5.03 & 5.18 & $3.1 \%$ \\
\hline 199 & 0.218 & 0.215 & $-1.30 \%$ & 18.54 & 17.71 & $-4.5 \%$ & 3.65 & 3.65 & $0.0 \%$ & 38.28 & 40.16 & $4.9 \%$ & 5.73 & 6.12 & $6.8 \%$ & & & 5.26 & 5.57 & $5.8 \%$ \\
\hline 1998 & 0.121 & 0.255 & $110.35 \%$ & 26.47 & 29.86 & $12.8 \%$ & 2.90 & 2.90 & $0.0 \%$ & 36.44 & 36.16 & $-0.8 \%$ & 4.86 & 4.94 & $1.6 \%$ & & & 5.54 & 5.42 & $-2.2 \%$ \\
\hline 199 & 0.032 & 0.033 & $2.50 \%$ & 18.03 & 18.23 & $1.1 \%$ & 2.95 & 3.09 & $4.7 \%$ & 37.97 & 37.55 & $-1.1 \%$ & 5.34 & 5.66 & $6.1 \%$ & & & 5.14 & 5.48 & $6.5 \%$ \\
\hline 200 & 0.027 & 0.192 & $599.55 \%$ & 18.95 & 23.08 & $21.8 \%$ & 2.65 & 2.65 & $0.0 \%$ & 37.64 & 37.90 & $0.7 \%$ & 5.24 & 5.10 & $-2.5 \%$ & & & 4.86 & 5.02 & $3.3 \%$ \\
\hline 200 & 0.018 & 0.023 & $25.71 \%$ & 17.25 & 4.83 & $-72.0 \%$ & 2.28 & 2.28 & $0.1 \%$ & 42.28 & 39.93 & $-5.6 \%$ & 6.80 & 6.92 & $1.7 \%$ & & & 7.92 & 8.86 & $11.8 \%$ \\
\hline 200 & 0.059 & 0.060 & $0.59 \%$ & 21.86 & 29.62 & $35.5 \%$ & 2.39 & 2.41 & $1.1 \%$ & 38.68 & 38.51 & $-0.4 \%$ & 4.81 & 4.82 & $0.1 \%$ & & & 4.89 & 5.10 & $4.2 \%$ \\
\hline 200 & 0.133 & 0.133 & $-0.23 \%$ & 6.38 & 5.42 & $-15.0 \%$ & 2.93 & 3.01 & $2.6 \%$ & 36.73 & 36.57 & $-0.5 \%$ & 6.29 & 6.38 & $1.4 \%$ & & & 6.37 & 5.98 & $-6.1 \%$ \\
\hline \multirow{24}{*}{$\begin{array}{l}Y \\
Y 9 \\
19 \\
19 \\
19 \\
19 \\
19 \\
19 \\
19 \\
19 \\
19\end{array}$} & \multicolumn{3}{|c|}{ Redd Scour } & \multicolumn{3}{|c|}{ Spawning/incubation } & \multicolumn{3}{|c|}{ Fry } & \multicolumn{3}{|c|}{\begin{tabular}{|l|} 
Subyearling (Spring-summer) \\
\end{tabular}} & \multicolumn{3}{|c|}{ Subyearling (winter) } & \multirow{2}{*}{\multicolumn{2}{|c|}{$\begin{array}{ll} & \text { Subadult } \\
& \text { Slternative }\end{array}$}} & & Adult holdi & \\
\hline & Base & Alternative & Pct Chg & Base & Alternative & Pct Chg & Base & Alternative & Pct Chg & Base & Alternative & Pct Chg & Base & Alternat & Pct Chg & & Alternative Pct Chg & Base & Alternative & Pct Chg \\
\hline & 0.102 & 0.102 & $0.28 \%$ & 10.57 & 10.77 & $1.9 \%$ & 3.01 & 3.01 & $0.0 \%$ & 7.81 & 7.22 & $-7.5 \%$ & 3.28 & 3.31 & $1.1 \%$ & & & & & \\
\hline & 0.057 & 0.057 & $020 \%$ & 367 & 3.37 & $-8.3 \%$ & 346 & 3.6 & $0.0 \%$ & 763 & 713 & $-66 \%$ & 342 & 355 & $38 \%$ & & & & & \\
\hline & 0.134 & 0.125 & $-6.46 \%$ & 3.91 & 3.68 & $-5.9 \%$ & 2.92 & 2.92 & $0.0 \%$ & 7.96 & 7.51 & $-5.6 \%$ & 3.62 & 3.71 & $2.4 \%$ & & & & & \\
\hline & 0.018 & 0.021 & $18.50 \%$ & 2.71 & 9.45 & $248.9 \%$ & 2.64 & 2.68 & $1.4 \%$ & 7.45 & 7.38 & $-0.8 \%$ & 3.60 & 3.23 & $-10.3 \%$ & & & & & \\
\hline & 0.030 & 0.031 & $3.79 \%$ & 3.19 & 2.97 & $-6.9 \%$ & 2.64 & 2.79 & $5.9 \%$ & 6.63 & 6.8 & $2.6 \%$ & 3.49 & 3.58 & $2.7 \%$ & & & & & \\
\hline & 0.014 & 0.016 & $17.23 \%$ & 17.25 & 0.43 & $-97.5 \%$ & 2.68 & 2. & $-3.6 \%$ & 6. & 6. & $1.9 \%$ & 3. & 3.44 & & & & & & \\
\hline & 0.017 & 0.020 & $18.21 \%$ & 17.80 & 16.80 & $-5.6 \%$ & 2.71 & 2.71 & $0.0 \%$ & 6.7 & 6.66 & $-1.4 \%$ & $\begin{array}{l}0.41 \\
3.35\end{array}$ & 3. & 0. & & & & & \\
\hline & 0.013 & 0.016 & $20.72 \%$ & 19.98 & 18.46 & $-7.6 \%$ & 3.11 & 3.2 & $4.7 \%$ & 6.8 & 7. & 3.6 & 3. & 3. & & & & & & \\
\hline & 0.041 & 0.042 & $1.44 \%$ & 18.32 & 2.77 & $-84.9 \%$ & 2.98 & 2.98 & $0.0 \%$ & 8. & 8.8 & 3.5 & 3. & 3. & & & & & & \\
\hline & 0.018 & 0.018 & $-0.71 \%$ & 11.02 & 20.70 & $87.9 \%$ & 2.87 & 2.87 & $0.0 \%$ & 8.34 & 8. & -2 . & 3.91 & 4.14 & & & & & & \\
\hline & 0.014 & 0.017 & $22.65 \%$ & 3.82 & 3.51 & $-8.3 \%$ & 2.27 & 2.41 & $6.1 \%$ & 6.80 & 7. & 7.8 & 3.40 & & & & & & & \\
\hline & 0.019 & 0.024 & $25.59 \%$ & 17.90 & 4.56 & $-74.5 \%$ & 2.37 & 2.37 & $-0.1 \%$ & 7.35 & 6. & -7. & 3. & 3.88 & 4. & & & & & \\
\hline & 0.019 & 0.023 & $24.49 \%$ & 1.61 & 1.43 & $-11.0 \%$ & 2.61 & 2.61 & $-0.2 \%$ & 7.56 & $6 . \varepsilon$ & -9 . & 3. & 3.82 & $3.3 \%$ & & & & & \\
\hline & 0.144 & 0.143 & -0.8 & 11.19 & 9.87 & $-11.8 \%$ & 3.27 & 3.28 & $0.2 \%$ & 7.50 & 7.4 & -0 . & 3.69 & 3.74 & 1.3 & & & & & \\
\hline & 0.889 & 0.8 & -0.1 & 7.89 & 4.33 & $-45.0 \%$ & 3.46 & 3.46 & $0.0 \%$ & 7.38 & 7.3 & $0.0 \%$ & 6.56 & 6.73 & 2. & & & & & \\
\hline & 0.218 & 0.215 & $-1.30 \%$ & 3.67 & 3.43 & $-6.5 \%$ & 3.61 & 3.61 & $0.0 \%$ & 8.12 & 7.89 & $-2.8 \%$ & 3.64 & 3.87 & 6. & & & & & \\
\hline & 0.011 & 0.011 & $3.68 \%$ & 11.85 & 12.24 & $3.3 \%$ & 3.29 & 3.29 & $0.0 \%$ & 7.61 & 7.72 & $1.5 \%$ & 3.34 & 3.38 & $1.2 \%$ & & & & & \\
\hline & 0.032 & 0.033 & $2.50 \%$ & 3.52 & 3.58 & $1.6 \%$ & 3.36 & 3.36 & $0.1 \%$ & 8.64 & 7.68 & $-11.1 \%$ & 3.50 & 3.74 & $6.9 \%$ & & & & & \\
\hline & 0.026 & 0.027 & $2.83 \%$ & 3.78 & 9.99 & $164.1 \%$ & 3.35 & 3.35 & $0.0 \%$ & 7.75 & 8.04 & $3.8 \%$ & 3.47 & 3.41 & $-1.9 \%$ & & & & & \\
\hline & 0.018 & 0.023 & $25.71 \%$ & 3.30 & 0.39 & $-88.3 \%$ & 2.33 & 2.32 & $-0.4 \%$ & 8.12 & 6.85 & $-15.6 \%$ & 4.29 & 4.55 & $6.0 \%$ & & & & & \\
\hline & 0.059 & 0.060 & $0.59 \%$ & 9.33 & 19.00 & $103.8 \%$ & 3.16 & 3.21 & $1.6 \%$ & 8.48 & 8.32 & $-1.9 \%$ & 3.21 & 3.21 & $0.1 \%$ & & & & & \\
\hline & 0.133 & 0.133 & $-0.23 \%$ & 0.51 & 0.43 & $-14.7 \%$ & 3.09 & 3.19 & $3.0 \%$ & 6.92 & 7.46 & $7.8 \%$ & 3.82 & 3.96 & $3.7 \%$ & & & & & \\
\hline
\end{tabular}

Figure 6-14. Annual habitat summaries for spring chinook and coho salmon in the Naches reach for the WymerPlus scenario. 
Steelhead

\begin{tabular}{|c|c|c|c|c|c|c|c|c|c|c|c|c|c|c|c|c|c|c|c|c|c|}
\hline \multirow[b]{2}{*}{ Year } & \multirow{2}{*}{\multicolumn{3}{|c|}{ Redd Scour }} & \multicolumn{3}{|c|}{ Spawning/incubation } & \multicolumn{3}{|c|}{ Fry } & \multirow{2}{*}{\multicolumn{3}{|c|}{$\begin{array}{l}\text { Subyearling (Spring-summer) } \\
\text { Base Alternative Pct Chg }\end{array}$}} & \multirow{2}{*}{\multicolumn{3}{|c|}{$\begin{array}{l}\text { Subyearling (winter) } \\
\text { Base Alternative Pct Chg }\end{array}$}} & \multicolumn{3}{|c|}{ Subadult } & \multicolumn{3}{|c|}{ Adult holding } \\
\hline & Base & & Pct Chg & Base & Alternative & Pct Chg & Base & Alternative & Pct Chg & & & & & & & Base & Alternative & Pct Chg & Base & Alternativ & Pct Chg \\
\hline 1982 & 0.295 & 0.295 & $-0.03 \%$ & 28.00 & 28.40 & $1.4 \%$ & 3.43 & 3.43 & $0.0 \%$ & 45.51 & 46.29 & $1.7 \%$ & 4.51 & 4.52 & $0.3 \%$ & 53.21 & 53.47 & $0.5 \%$ & 10.86 & 10.97 & $1.0 \%$ \\
\hline 1983 & 0.433 & 0.433 & $0.05 \%$ & 19.23 & 17.72 & $-7.8 \%$ & 3.44 & 3.42 & $-0.5 \%$ & 45.40 & 47.21 & $4.0 \%$ & 4.56 & 4.64 & $1.8 \%$ & 50.48 & 50.63 & $0.3 \%$ & 8.24 & 8.87 & $7.7 \%$ \\
\hline 1984 & 0.125 & 0.124 & $-0.15 \%$ & 20.38 & 19.24 & $-5.6 \%$ & 3.47 & 3.42 & $-1.7 \%$ & 45.63 & 46.88 & $2.8 \%$ & 4.65 & 4.59 & $-1.3 \%$ & 49.12 & 49.40 & $0.6 \%$ & 8.43 & 8.90 & $5.6 \%$ \\
\hline 85 & 0.411 & 0.411 & $0.04 \%$ & 14.48 & 21.75 & $50.2 \%$ & 3.35 & 3.52 & $5.0 \%$ & 45.73 & 45.69 & $-0.1 \%$ & 5.30 & 4.45 & $-16.0 \%$ & 51.17 & 49.78 & $-2.7 \%$ & 16.78 & 15.83 & $-5.7 \%$ \\
\hline 86 & 0.308 & 0.310 & $0.74 \%$ & 16.85 & 15.78 & $-6.4 \%$ & 3.31 & 3.36 & $1.3 \%$ & 47.86 & 45.86 & $-4.2 \%$ & 4.92 & 4.93 & $0.2 \%$ & 51.74 & 50.62 & $-2.2 \%$ & 10.56 & 10.06 & $-4.7 \%$ \\
\hline 87 & 0.130 & & $-0.18 \%$ & 26.98 & 5.31 & $-80.3 \%$ & 3.34 & 34 & $0.0 \%$ & 45.79 & 45.91 & $0.3 \%$ & 4.69 & 4.83 & $3.0 \%$ & 51.37 & 52.20 & $1.6 \%$ & 11.26 & 10.59 & $-5.9 \%$ \\
\hline & 0.035 & & $1.76 \%$ & 27.87 & 26.27 & $-5.8 \%$ & 3.33 & 32 & $-0.2 \%$ & 46.20 & 46.42 & $0.5 \%$ & 4.51 & 4.51 & $0.0 \%$ & 50.02 & 49.57 & $-0.9 \%$ & 13.40 & 13.38 & $-0.1 \%$ \\
\hline 89 & 0.049 & 0.049 & $0.40 \%$ & 31.37 & 28.93 & $-7.8 \%$ & 3.36 & 38 & $0.7 \%$ & 45.23 & 45.40 & $0.4 \%$ & 4.17 & 4.17 & $0.1 \%$ & 50.37 & 49.96 & $-0.8 \%$ & 12.95 & 12.80 & $-1.2 \%$ \\
\hline & 0.169 & & $-0.25 \%$ & & & $-45.0 \%$ & 3.37 & 51 & & 47.95 & & $-4.3 \%$ & 4.18 & 18 & & 49.19 & & & 10.83 & 10.14 & $-6.4 \%$ \\
\hline & 0.023 & & $0.71 \%$ & & & $30.4 \%$ & 15 & & & & & & 4.81 & & & 48.85 & & & 7.72 & & $-1.1 \%$ \\
\hline & 0.016 & & $11.42 \%$ & & & $-7.8 \%$ & 35 & & 1.3 & & & & 4.55 & & & 53.11 & & & 9.08 & & $2.5 \%$ \\
\hline & 0.029 & & 3.80 & 28 & & -61 & 38 & & -0 . & & & & 5.09 & & & 51.14 & & & 16.05 & & $-2.9 \%$ \\
\hline 94 & 0.016 & & 10.4 & & & & 15 & & -3. & & & & 5.10 & & & 50.49 & & & 16.16 & & $-0.5 \%$ \\
\hline & 0.247 & & & & & & & & & & & & & & & & & & 8.12 & & $1.9 \%$ \\
\hline & 0.075 & & & & & & & & & & & & 8.03 & & & 48.75 & & & & & $4.6 \%$ \\
\hline & 0.695 & & & & & -6 & & & & & & & 4. & & & & & -0 . & & & $3.3 \%$ \\
\hline & 0.400 & & & & 31 & 17. & & & & & & & 4. & & & & & & 34 & & $-5.4 \%$ \\
\hline & 0.449 & & & & & 1. & & & & & & & & & & & & & & & $-3.5 \%$ \\
\hline & 0.112 & & & 19 & 22 & 15. & 3.43 & & 1.2 & & & & 4.4 & & -2. & 49 & & & 8.42 & 8 & $4.4 \%$ \\
\hline 2001 & 0.018 & & & 17. & 4. & & 3.42 & 3.3 & & & 4 & & 6.4 & & 5. & 51 & 51 & & 18.01 & & $-3.6 \%$ \\
\hline & 0.382 & 0.39 & $2.41 \%$ & 21.49 & 29.8 & $38.7 \%$ & & & 2.3 & & & $-0.8 \%$ & 4.19 & 4.19 & 0.00 & 51.83 & 51. & $-0.1 \%$ & 10.21 & 10 & $-0.1 \%$ \\
\hline & 0.185 & 0.186 & $0.81 \%$ & 6.27 & 5.33 & $-15.0 \%$ & 3.34 & 3.37 & $0.8 \%$ & 45.37 & 45.56 & $0.4 \%$ & 5.43 & 5.51 & $1.5 \%$ & 50.12 & 49.99 & $-0.3 \%$ & 10.75 & 10.43 & $-2.9 \%$ \\
\hline
\end{tabular}

Resident Rainbow

\begin{tabular}{|c|c|c|c|c|c|c|c|c|c|c|c|c|c|c|c|c|c|c|}
\hline \multicolumn{3}{|c|}{ Redd Scour } & \multicolumn{3}{|c|}{ Spawning/incubation } & \multicolumn{3}{|c|}{ Fry } & \multirow{2}{*}{\multicolumn{3}{|c|}{$\begin{array}{l}\text { Subyearling (Spring-summer) } \\
\text { Base Alternative Pct Cha }\end{array}$}} & \multicolumn{3}{|c|}{ Subyearling (winter) } & \multicolumn{3}{|c|}{$\begin{array}{l}\text { Subadult } \\
\end{array}$} & \multirow{2}{*}{\begin{tabular}{ll}
\multicolumn{3}{c}{ Adult holding } \\
Base $\quad$ Alternative Pct Chg
\end{tabular}} \\
\hline Base & Alternative & Pct Chg & Base & Alternative & Pct Chg & Base & Alternative & Pct Chg & & & & Base & Alternative & Pct Chg & Base & Alternative & Pct Chg & \\
\hline 0.295 & 0.295 & $-0.03 \%$ & 8.11 & 8.25 & $1.6 \%$ & 4.29 & 4.29 & $0.2 \%$ & 45.34 & 46.03 & $1.5 \%$ & 5.80 & 5.82 & $0.3 \%$ & 19.97 & 20.23 & $1.3 \%$ & \\
\hline 0.433 & 0.433 & $0.05 \%$ & 12.17 & 11.34 & $-6.9 \%$ & 4.30 & 4.29 & $-0.3 \%$ & 45.22 & 46.90 & $3.7 \%$ & 5.89 & 6.02 & $2.3 \%$ & 17.20 & 17.74 & $3.1 \%$ & \\
\hline 0.125 & 0.124 & $-0.15 \%$ & 12.81 & 12.18 & $-4.9 \%$ & 4.32 & 4.28 & $-1.0 \%$ & 45.46 & 46.59 & $2.5 \%$ & 6.06 & 6.00 & $-1.0 \%$ & 15.79 & 16.03 & $1.5 \%$ & \\
\hline 0.411 & 0.411 & $0.04 \%$ & 9.54 & 17.22 & $80.5 \%$ & 4.21 & 4.36 & $3.6 \%$ & 45.56 & 45.48 & $-0.2 \%$ & 6.70 & 5.79 & $-13.6 \%$ & 16.68 & 17.95 & $7.6 \%$ & \\
\hline 0.308 & 0.310 & $0.74 \%$ & 10.86 & 10.26 & $-5.5 \%$ & 4.20 & 4.23 & $0.8 \%$ & 47.51 & 45.64 & $-3.9 \%$ & 6.29 & 6.34 & $0.9 \%$ & 15.71 & 16.35 & $4.1 \%$ & \\
\hline 0.130 & 0.130 & $-0.18 \%$ & 23.93 & 2.44 & $-89.8 \%$ & 4.21 & 4.19 & $-0.4 \%$ & 45.59 & 45.70 & $0.3 \%$ & 6.06 & 6.20 & $2.3 \%$ & 15.85 & 16.32 & $3.0 \%$ & \\
\hline 0.011 & 0.008 & $-25.20 \%$ & 24.65 & 23.36 & $-5.2 \%$ & 4.21 & 4.21 & $-0.2 \%$ & 45.96 & 46.15 & $0.4 \%$ & 5.81 & 5.81 & $-0.1 \%$ & 15.11 & 14.76 & $-2.4 \%$ & \\
\hline 0.049 & 0.049 & $0.40 \%$ & 27.46 & 25.50 & $-7.1 \%$ & 4.23 & 4.24 & $0.4 \%$ & 45.04 & 45.22 & $0.4 \%$ & 5.40 & 5.40 & $0.0 \%$ & 15.39 & 15.75 & $2.3 \%$ & \\
\hline 0.021 & 0.021 & $1.18 \%$ & 22.66 & 9.72 & $-57.1 \%$ & 4.24 & 4.32 & $1.8 \%$ & 47.77 & 45.76 & $-4.2 \%$ & 5.41 & 5.41 & $0.1 \%$ & 15.48 & 15.85 & $2.4 \%$ & \\
\hline 0.023 & 0.023 & $0.71 \%$ & 22.92 & 33.64 & $46.8 \%$ & 4.29 & 4.29 & $0.1 \%$ & 45.76 & 45.33 & $-0.9 \%$ & 6.33 & 6.62 & $4.6 \%$ & 15.69 & 16.02 & $2.1 \%$ & \\
\hline 0.016 & 0.018 & $11.42 \%$ & 12.58 & 11.72 & $-6.9 \%$ & 4.21 & 4.24 & $0.7 \%$ & 47.14 & 47.36 & $0.5 \%$ & 5.92 & 5.92 & $0.1 \%$ & 17.12 & 18.23 & $6.5 \%$ & \\
\hline 0.029 & 0.030 & $3.80 \%$ & 24.78 & 8.63 & $-65.2 \%$ & 4.22 & 4.21 & $-0.2 \%$ & 46.18 & 45.79 & $-0.8 \%$ & 6.55 & 6.73 & $2.8 \%$ & 17.33 & 16.41 & $-5.3 \%$ & \\
\hline 0.016 & 0.018 & $10.43 \%$ & 5.77 & 5.13 & $-11.0 \%$ & 4.26 & 4.21 & $-1.3 \%$ & & 46.47 & $1.5 \%$ & 6.52 & 6.66 & $2.1 \%$ & 16.30 & 15.78 & $-3.2 \%$ & \\
\hline 0.247 & 0.247 & $0.01 \%$ & 19.95 & 17.89 & $-10.3 \%$ & 4.22 & 4.33 & $2.6 \%$ & 45.44 & 45.06 & $-0.8 \%$ & 6.24 & 6.29 & $0.8 \%$ & 17.75 & 18.49 & $4.2 \%$ & \\
\hline 0.058 & 0.059 & $0.44 \%$ & 3.92 & 2.09 & $-46.6 \%$ & 4.28 & 4.33 & $1.3 \%$ & 45.09 & 45.78 & $1.5 \%$ & 10.53 & 10.80 & $2.6 \%$ & 15.59 & 16.24 & $4.2 \%$ & \\
\hline 0.695 & 0.694 & $-0.12 \%$ & 12.15 & 11.50 & $-5.3 \%$ & 4.26 & 4.26 & $0.0 \%$ & 45.54 & 48.52 & $6.5 \%$ & 6.24 & 6.53 & $4.6 \%$ & 21.39 & 21.33 & $-0.3 \%$ & \\
\hline 0.400 & 0.400 & $0.03 \%$ & 20.98 & 23.50 & $12.0 \%$ & 4.24 & 4.34 & $2.4 \%$ & 45.65 & 45.19 & $-1.0 \%$ & 5.48 & 5.52 & $0.7 \%$ & 17.62 & & $9.9 \%$ & \\
\hline 0.449 & 0.449 & $0.05 \%$ & 11.76 & 11.91 & $1.3 \%$ & 5.01 & 5.00 & $-0.1 \%$ & 45.88 & 45.11 & $-1.7 \%$ & 5.80 & 6.16 & $6.2 \%$ & 21.14 & 21.16 & $0.1 \%$ & \\
\hline 0.092 & 0.093 & $0.73 \%$ & 12.47 & 18.07 & $44.9 \%$ & 4.30 & 4.33 & $0.6 \%$ & 45.62 & 45.27 & $-0.8 \%$ & 5.71 & 5.59 & $-2.1 \%$ & 16.11 & 16.88 & $4.8 \%$ & \\
\hline 0.018 & 0.019 & $7.96 \%$ & 11.15 & 2.19 & $-80.4 \%$ & 4.23 & 4.22 & $-0.1 \%$ & 47.44 & 47.04 & $-0.9 \%$ & 8.02 & 8.36 & $4.2 \%$ & 17.36 & 16.05 & $-7.5 \%$ & \\
\hline 0.091 & 0.092 & $0.64 \%$ & 17.03 & 26.20 & $53.9 \%$ & 4.27 & 4.32 & $1.2 \%$ & 45.59 & 45.21 & $-0.8 \%$ & 5.44 & 5.45 & $0.1 \%$ & 19.56 & 20.25 & $3.5 \%$ & \\
\hline 0.185 & 0.186 & 0.81\% & 2.89 & 2.45 & $-15.0 \%$ & 4.23 & 4.23 & $0.1 \%$ & 45.20 & 45.39 & $0.4 \%$ & 6.88 & 6.99 & $1.6 \%$ & 15.24 & 15.51 & $1.8 \%$ & \\
\hline
\end{tabular}

Figure 6-15. Annual habitat summaries for steelhead and resident rainbow trout in the Naches reach for the WymerPlus scenario. 


\begin{tabular}{|c|c|c|c|c|c|c|c|c|c|c|c|c|c|c|c|c|c|c|c|}
\hline \multirow[b]{2}{*}{ YearL } & \multicolumn{3}{|c|}{ Redd Scour } & \multicolumn{3}{|c|}{ Spawning/incubation } & \multicolumn{3}{|c|}{ Fry } & \multicolumn{3}{|c|}{ Subyearling (Spring-summer) } & \multicolumn{3}{|c|}{ Subyearling (winter) } & \multicolumn{2}{|r|}{ Subadult } & \multicolumn{2}{|r|}{ Adult holding } \\
\hline & Base & Alternative & Pct Chg & Base & Alternative & Pct Chg & Base & Alternative & Pct Chg & Base & Alternative & Pct Chg & & Alternative & & Base & Alternative Pct Chg & Base & Alternative Pct Chg \\
\hline 1982 & 0.102 & 0.102 & $0.28 \%$ & 9.19 & 9.28 & $1.0 \%$ & 6.10 & 6.10 & $0.0 \%$ & 64.41 & 64.68 & $0.4 \%$ & 5.71 & 5.76 & $0.8 \%$ & & & & \\
\hline 1983 & 0.057 & 0.057 & $0.20 \%$ & 4.16 & 4.05 & $-2.7 \%$ & 7.24 & 7.24 & $0.0 \%$ & 63.97 & 64.62 & $1.0 \%$ & 6.01 & 6.18 & & & & & \\
\hline 1984 & 0.134 & 0.125 & $-6.46 \%$ & 4.25 & 4.17 & $-2.0 \%$ & 5.82 & 5.82 & $0.0 \%$ & 64.20 & 65.13 & $1.5 \%$ & 6.31 & 6.37 & $0.9 \%$ & & & & \\
\hline 1985 & 0.018 & 0.021 & $18.50 \%$ & 3.81 & 8.89 & $133.2 \%$ & 5.29 & 5.36 & $1.4 \%$ & 65.54 & 63.54 & $-3.0 \%$ & 6.32 & 5.69 & $-9.9 \%$ & & & & \\
\hline 1986 & 0.030 & 0.031 & $3.79 \%$ & 3.99 & 3.91 & $-2.0 \%$ & 5.24 & 5.56 & $6.0 \%$ & 66.23 & 64.57 & $-2.5 \%$ & 6.15 & 6.34 & $3.0 \%$ & & & & \\
\hline 1987 & 0.014 & 0.022 & $57.27 \%$ & 15.25 & 0.80 & $-94.7 \%$ & 5.33 & 5.14 & $-3.7 \%$ & 64.20 & 65.06 & $1.3 \%$ & 5.94 & 6.0 & $2.0 \%$ & & & & \\
\hline 1988 & 0.023 & 0.024 & $5.83 \%$ & 15.62 & 14.95 & $-4.3 \%$ & 5.43 & 5.43 & $0.0 \%$ & 63.68 & 63.23 & $-0.7 \%$ & 5.82 & 5.82 & $0.1 \%$ & & & & \\
\hline 1989 & 0.016 & 0.019 & $21.27 \%$ & 17.08 & 16.06 & $-6.0 \%$ & 6.28 & 6.58 & $4.9 \%$ & 63.67 & 63.64 & $0.0 \%$ & 5.36 & 5.37 & $0.1 \%$ & & & & \\
\hline 1990 & 0.041 & 0.042 & $1.44 \%$ & 20.69 & 3.84 & $-81.5 \%$ & 5.97 & 5.97 & $0.0 \%$ & 66.41 & 64.54 & $-2.8 \%$ & & 5.45 & $0.6 \%$ & & & & \\
\hline 1991 & 0.222 & 0.221 & $-0.15 \%$ & 9.42 & 17.85 & $89.5 \%$ & 5.71 & 5.71 & $0.0 \%$ & 64.33 & 63.69 & $-1.0 \%$ & 6.75 & 7.0 & $4.6 \%$ & & & & \\
\hline 1992 & 0.016 & 0.019 & $19.62 \%$ & 4.22 & 4.10 & $-2.7 \%$ & 4.58 & 4.83 & $5.5 \%$ & 66.42 & 66.70 & $0.4 \%$ & 5.85 & 5.9 & $1.7 \%$ & & & & \\
\hline 1993 & 0.019 & 0.024 & $25.59 \%$ & 15.69 & 4.65 & $-70.4 \%$ & 4.74 & 4.74 & $-0.1 \%$ & 65.37 & 64.71 & $-1.0 \%$ & 6.51 & 6.8 & $4.4 \%$ & & & & \\
\hline 1994 & 0.021 & 0.025 & $18.93 \%$ & 2.41 & 2.14 & $-11.0 \%$ & 5.20 & 5.19 & $-0.2 \%$ & 64.89 & 66.50 & $2.5 \%$ & 6.48 & 6.7 & $3.5 \%$ & & & & \\
\hline 1995 & 0.144 & 0.143 & $-0.84 \%$ & 10.03 & 9.17 & $-8.6 \%$ & 6.67 & 6.68 & $0.2 \%$ & 64.53 & 63.34 & $-1.8 \%$ & 6.52 & 6.6 & $1.2 \%$ & & & & \\
\hline 1996 & 0.889 & 0.888 & $-0.19 \%$ & 4.30 & 2.47 & $-42.4 \%$ & 7.17 & 7.17 & 0.0 & 62.81 & 63.31 & $0.8 \%$ & 10.84 & 11.09 & $2.3 \%$ & & & & \\
\hline 1997 & 0.218 & 0.215 & $-1.30 \%$ & 4.16 & 4.08 & $-2.1 \%$ & 9.05 & 9.05 & $0.0 \%$ & 65.87 & 67.49 & $2.5 \%$ & 6.50 & 6.97 & $7.2 \%$ & & & & \\
\hline 1998 & 0.121 & 0.163 & $34.50 \%$ & 10.46 & 10.43 & $-0.3 \%$ & 6.94 & 6.94 & $0.0 \%$ & 64.28 & 62.84 & $-2.2 \%$ & 5.63 & 5.7 & $2.2 \%$ & & & & \\
\hline 1999 & 0.032 & 0.033 & $2.50 \%$ & 4.11 & 4.13 & $0.5 \%$ & 7.07 & 7.08 & $0.1 \%$ & 66.29 & 65.34 & $-1.4 \%$ & 6.14 & 6.5 & $7.2 \%$ & & & & \\
\hline 2000 & 0.027 & 0.192 & $599.55 \%$ & 4.20 & 9.25 & $119.9 \%$ & 6.91 & 6.91 & $0.0 \%$ & 63.91 & 63.67 & $-0.4 \%$ & 6.03 & 5.88 & $-2.5 \%$ & & & & \\
\hline 2001 & 0.018 & 0.023 & $25.71 \%$ & 4.03 & 0.72 & $-82.2 \%$ & 4.70 & 4.69 & $-0.2 \%$ & 64.97 & 66.06 & $1.7 \%$ & 7.28 & 7.53 & $3.4 \%$ & & & & \\
\hline 2002 & 0.059 & 0.060 & $0.59 \%$ & 8.81 & 16.43 & $86.5 \%$ & 6.63 & 6.77 & $2.1 \%$ & 65.17 & 64.77 & -0. & 5.48 & 5.49 & $0.2 \%$ & & & & \\
\hline 2003 & 0.133 & 0.133 & $-0.23 \%$ & 0.95 & 0.81 & $-14.9 \%$ & 6.18 & 6.37 & $3.2 \%$ & 64.37 & 64.04 & $-0.5 \%$ & 6.82 & 6.99 & $2.5 \%$ & & & & \\
\hline
\end{tabular}

Figure 6-16. Annual habitat summary for bull trout in the Naches reach for the WymerPlus scenario. 
Fall Chinook

\begin{tabular}{|c|c|c|c|c|c|c|c|c|c|c|c|c|c|c|c|c|}
\hline \multirow{3}{*}{ Year } & \multirow{2}{*}{\multicolumn{3}{|c|}{\begin{tabular}{ll}
\multicolumn{2}{c}{ Redd Scour } \\
Base & Alternative Pct Cho
\end{tabular}}} & \multicolumn{3}{|c|}{ Spawning/incubation } & \multicolumn{3}{|c|}{ Fry } & \multirow{2}{*}{\multicolumn{3}{|c|}{$\begin{array}{l}\text { Subyearling (Spring-summer) } \\
\text { Base Alternative Pct Chg }\end{array}$}} & \multirow{2}{*}{$\begin{array}{l}\text { Subyearling (winter) } \\
\text { Base } \quad \text { Alternative Pct Chg }\end{array}$} & \multirow{2}{*}{\multicolumn{2}{|c|}{$\begin{array}{ll} & \text { Subadult } \\
\text { Base } & \text { Alternative Pct Cho }\end{array}$}} & \multirow{2}{*}{\begin{tabular}{lc}
\multicolumn{2}{c}{ Adult holding } \\
Base & Alternative Pct Chg
\end{tabular}} \\
\hline & & & & Base & Alternativ & & Base & Alternative & Pct Chg & & & & & & & \\
\hline & 0.031 & 0.031 & $-1.44 \%$ & 19.76 & 19.65 & $-0.6 \%$ & 7.24 & 7.27 & $0.3 \%$ & 43.20 & 44.65 & $3.3 \%$ & & & & \\
\hline 1983 & 0.028 & 0.028 & $-0.85 \%$ & 19.32 & 17.75 & $-8.1 \%$ & 6.41 & 6.30 & $-1.7 \%$ & 40.59 & 41.67 & $2.6 \%$ & & & & \\
\hline 1984 & 0.028 & 0.033 & $17.35 \%$ & 19.78 & 17.81 & $-10.0 \%$ & 7.11 & 7.11 & $0.0 \%$ & 35.79 & 36.49 & $1.9 \%$ & & & & \\
\hline 1985 & 0.030 & 0.030 & $-1.28 \%$ & 19.67 & 19.74 & $0.4 \%$ & 7.73 & 7.60 & $-1.7 \%$ & 35.51 & 36.27 & $2.1 \%$ & & & & \\
\hline 1986 & 0.028 & 0.032 & $11.13 \%$ & 16.51 & 17.55 & $6.3 \%$ & 6.82 & 6.80 & $-0.4 \%$ & 34.91 & 35.55 & $1.9 \%$ & & & & \\
\hline 1987 & 0.030 & 0.033 & $8.92 \%$ & 18.21 & 15.77 & $-13.4 \%$ & 7.69 & 7.64 & $-0.6 \%$ & 35.31 & 36.26 & $2.7 \%$ & & & & \\
\hline 1988 & 0.035 & 0.038 & $6.85 \%$ & 18.29 & 18.08 & $-1.1 \%$ & 7.72 & 7.61 & $-1.4 \%$ & 35.06 & 35.93 & $2.5 \%$ & & & & \\
\hline 1989 & 0.025 & 0.027 & $11.62 \%$ & 20.85 & 20.72 & $-0.6 \%$ & 7.19 & 7.10 & $-1.2 \%$ & 35.52 & 36.60 & $3.0 \%$ & & & & \\
\hline 1990 & 0.029 & 0.031 & $7.18 \%$ & 19.32 & 19.72 & $2.1 \%$ & 6.58 & 6.53 & $-0.8 \%$ & 35.74 & 36.30 & $1.6 \%$ & & & & \\
\hline 1991 & 0.052 & 0.052 & $0.93 \%$ & 22.97 & 21.07 & $-8.3 \%$ & 7.10 & 7.07 & $-0.3 \%$ & 35.38 & 35.93 & $1.6 \%$ & & & & \\
\hline 1992 & 0.027 & 0.030 & $10.69 \%$ & 19.87 & 18.06 & $-9.1 \%$ & 7.96 & 7.96 & $0.0 \%$ & 34.91 & 36.22 & $3.8 \%$ & & & & \\
\hline 1993 & 0.034 & 0.038 & $12.06 \%$ & 17.57 & 11.64 & $-33.8 \%$ & 8.28 & 8.21 & $-0.8 \%$ & 34.84 & 35.78 & $2.7 \%$ & & & & \\
\hline 1994 & 0.035 & 0.039 & $10.18 \%$ & 18.28 & 14.71 & $-19.5 \%$ & 8.19 & 8.09 & $-1.2 \%$ & 33.80 & 34.57 & $2.3 \%$ & & & & \\
\hline 1995 & 0.031 & 0.030 & $-1.61 \%$ & 18.21 & 18.16 & $-0.3 \%$ & 7.12 & 7.16 & $0.5 \%$ & 40.01 & 41.52 & $3.8 \%$ & & & & \\
\hline 1996 & 0.199 & 0.188 & $-5.37 \%$ & 9.65 & 17.34 & $79.7 \%$ & 5.91 & 5.95 & $0.7 \%$ & 36.65 & 37.55 & $2.5 \%$ & & & & \\
\hline 1997 & 0.057 & 0.056 & $-1.36 \%$ & 19.08 & 17.91 & $-6.1 \%$ & 5.78 & 5.78 & $0.0 \%$ & 62.39 & 63.36 & $1.6 \%$ & & & & \\
\hline 1998 & 0.019 & 0.024 & $28.65 \%$ & 20.52 & 19.68 & $-4.1 \%$ & 6.65 & 6.60 & $-0.9 \%$ & 41.81 & 43.77 & $4.7 \%$ & & & & \\
\hline 1999 & 0.028 & 0.031 & $11.61 \%$ & 19.56 & 18.11 & $-7.5 \%$ & 6.99 & 6.64 & $-5.0 \%$ & & 42.85 & $2.0 \%$ & & & & \\
\hline 2000 & 0.029 & 0.029 & $-0.31 \%$ & 17.78 & 18.04 & $1.4 \%$ & 6.50 & 6.41 & $-1.3 \%$ & 36.26 & 37.04 & $2.2 \%$ & & & & \\
\hline 2001 & 0.035 & 0.039 & $12.20 \%$ & 16.02 & 14.97 & $-6.6 \%$ & 8.46 & 8.42 & $-0.4 \%$ & 34.22 & 35.39 & $3.4 \%$ & & & & \\
\hline 2002 & 0.026 & 0.029 & $11.27 \%$ & 19.09 & 18.93 & $-0.8 \%$ & 7.22 & 7.09 & $-1.8 \%$ & 38.33 & 39.69 & $3.6 \%$ & & & & \\
\hline 2003 & 0.032 & 0.035 & $9.35 \%$ & 12.80 & 16.02 & $25.1 \%$ & 7.47 & 7.35 & $-1.7 \%$ & 35.18 & 35.94 & $2.2 \%$ & & & & \\
\hline
\end{tabular}

Coho

\begin{tabular}{|c|c|c|c|c|c|c|c|c|c|c|c|c|c|c|c|c|c|}
\hline \multirow{3}{*}{ Year } & \multirow{2}{*}{\multicolumn{3}{|c|}{\begin{tabular}{ll|} 
& Redd Scour \\
Base & Alternative Pct Cha
\end{tabular}}} & \multirow{2}{*}{\multicolumn{3}{|c|}{ Spawning/incubation }} & \multirow{2}{*}{\multicolumn{3}{|c|}{ Fry }} & \multicolumn{3}{|c|}{ Subyearling (Spring-summer) } & \multicolumn{3}{|c|}{ Subyearling (winter) } & \multirow{2}{*}{ Subadult } & Adult holding \\
\hline & & & & Base & & Pct Chg & Base & & & Base & Alternative & Pct Chg & Base & & & & Base Alternative Pct Chg \\
\hline & 0.031 & 0.031 & $-1.44 \%$ & 4.58 & 4.59 & $0.1 \%$ & 6.40 & 6.27 & $-2.1 \%$ & 28.03 & 28.20 & $0.6 \%$ & 44.28 & 44.20 & $-0.2 \%$ & & \\
\hline 1983] & 0.028 & 0.028 & $-0.85 \%$ & 4.60 & 4.93 & $7.3 \%$ & 6.36 & 6.25 & $-1.8 \%$ & 28.05 & 28.24 & $0.7 \%$ & 44.42 & 44.51 & $0.2 \%$ & & \\
\hline 1984 & 0.028 & 0.033 & $17.35 \%$ & 4.59 & 4.42 & $-3.7 \%$ & 7.31 & 7.37 & $0.9 \%$ & 28.11 & 28.30 & $0.7 \%$ & 45.10 & 45.28 & $0.4 \%$ & & \\
\hline 1985 & 0.030 & 0.030 & $-1.28 \%$ & 7.32 & 7.33 & $0.1 \%$ & 7.17 & 6.91 & $-3.6 \%$ & 27.66 & 28.22 & $2.0 \%$ & 42.74 & 42.86 & $0.3 \%$ & & \\
\hline 1986 & 0.028 & 0.032 & $11.13 \%$ & 4.53 & 4.85 & $7.0 \%$ & 7.61 & 7.32 & $-3.8 \%$ & 27.02 & 28.17 & $4.3 \%$ & 43.12 & 43.00 & $-0.3 \%$ & & \\
\hline 1987 & 0.030 & 0.033 & $8.92 \%$ & 7.15 & 4.33 & $-39.5 \%$ & 7.20 & 7.11 & $-1.2 \%$ & 26.50 & 27.57 & $4.0 \%$ & 42.72 & 42.59 & $-0.3 \%$ & & \\
\hline 1988 & 0.031 & 0.034 & $8.85 \%$ & 7.16 & 7.14 & $-0.3 \%$ & 7.38 & 7.22 & $-2.1 \%$ & 26.55 & 27.50 & $3.6 \%$ & 41.94 & 41.82 & $-0.3 \%$ & & \\
\hline 1989 & 0.025 & 0.027 & $11.62 \%$ & 9.07 & 8.58 & $-5.4 \%$ & 6.83 & 6.70 & $-1.8 \%$ & 27.12 & 28.18 & $3.9 \%$ & 44.05 & 43.96 & $-0.2 \%$ & & \\
\hline 1990 & 0.026 & 0.027 & $5.81 \%$ & 7.28 & 7.33 & $0.7 \%$ & 6.43 & 6.35 & $-1.2 \%$ & 27.73 & 28.24 & $1.8 \%$ & 44.08 & 44.00 & $-0.2 \%$ & & \\
\hline 1991 & 0.019 & 0.020 & $1.94 \%$ & 3.15 & 3.16 & $0.5 \%$ & 6.92 & 6.85 & $-1.0 \%$ & 27.83 & 28.28 & $1.6 \%$ & 46.61 & 46.96 & $0.8 \%$ & & \\
\hline 1992 & 0.025 & 0.028 & $13.52 \%$ & 7.35 & 5.07 & $-31.0 \%$ & 8.05 & 7.81 & $-3.0 \%$ & 26.54 & 27.66 & $4.2 \%$ & 43.56 & 43.57 & $0.0 \%$ & & \\
\hline 1993 & 0.034 & 0.038 & $12.06 \%$ & 7.07 & 3.19 & $-54.9 \%$ & 7.77 & 7.63 & $-1.8 \%$ & 26.26 & 27.24 & $3.8 \%$ & 41.88 & 41.64 & $-0.6 \%$ & & \\
\hline 1994 & 0.033 & 0.037 & $12.16 \%$ & 8.25 & 6.01 & $-27.2 \%$ & 7.96 & 7.84 & $-1.5 \%$ & 25.63 & 26.25 & $2.4 \%$ & 41.51 & 41.29 & $-0.5 \%$ & & \\
\hline 1995 & 0.031 & 0.030 & $-1.61 \%$ & 3.30 & 3.32 & $0.5 \%$ & 6.98 & 6.82 & $-2.3 \%$ & 27.70 & 28.13 & $1.5 \%$ & 44.12 & 44.02 & $-0.2 \%$ & & \\
\hline 1996 & 0.199 & 0.188 & $-5.37 \%$ & 0.28 & 0.97 & $248.4 \%$ & 6.20 & 6.15 & $-0.7 \%$ & 27.73 & 28.26 & $1.9 \%$ & 49.43 & 49.65 & $0.4 \%$ & & \\
\hline 1997 & 0.057 & 0.056 & $-1.36 \%$ & 2.23 & 3.17 & $42.3 \%$ & 5.64 & 5.64 & $0.0 \%$ & 28.30 & 28.25 & $-0.2 \%$ & 44.55 & 44.63 & $0.2 \%$ & & \\
\hline 1998 & 0.019 & 0.019 & $0.44 \%$ & 7.47 & 5.62 & -24 & 6.08 & 6.05 & -0.6 & & 28.19 & $1.9 \%$ & 45.31 & 45.66 & $0.8 \%$ & & \\
\hline 999 & 0.022 & 0.024 & $10.64 \%$ & 6.26 & 5.09 & $-18.6 \%$ & 6.07 & 92 & $-2.4 \%$ & 28.39 & & $0.3 \%$ & 44.41 & 44.43 & $0.0 \%$ & & \\
\hline 00 & 0.029 & 0.029 & $-0.31 \%$ & 4.95 & 5.06 & $2.3 \%$ & 6.16 & 6.08 & $-1.3 \%$ & 27.79 & 28.29 & $1.8 \%$ & 44.62 & 44.68 & $0.1 \%$ & & \\
\hline 2001 & 0.035 & 0.039 & $12.20 \%$ & 4.39 & 4.11 & & 8.15 & 99 & -2.6 & & 27.21 & $4.6 \%$ & 41.25 & 40.97 & & & \\
\hline 2002 & 0.022 & 0.024 & $10.45 \%$ & 7.26 & 7.24 & $-0.3 \%$ & 6.66 & 6.49 & $-2.5 \%$ & 27.72 & 28.19 & 1.79 & 43.99 & 43.94 & $-0.1 \%$ & & \\
\hline 2003 & 0.032 & 0.035 & $9.35 \%$ & 3.51 & 4.39 & $25.0 \%$ & 7.51 & 7.23 & $-3.7 \%$ & 27.04 & 28.19 & $4.2 \%$ & 42.64 & 42.51 & $-0.3 \%$ & & \\
\hline
\end{tabular}

Figure 6-17. Annual habitat summaries for fall chinook and coho salmon in the Union Gap reach for the WymerPlus scenario. 


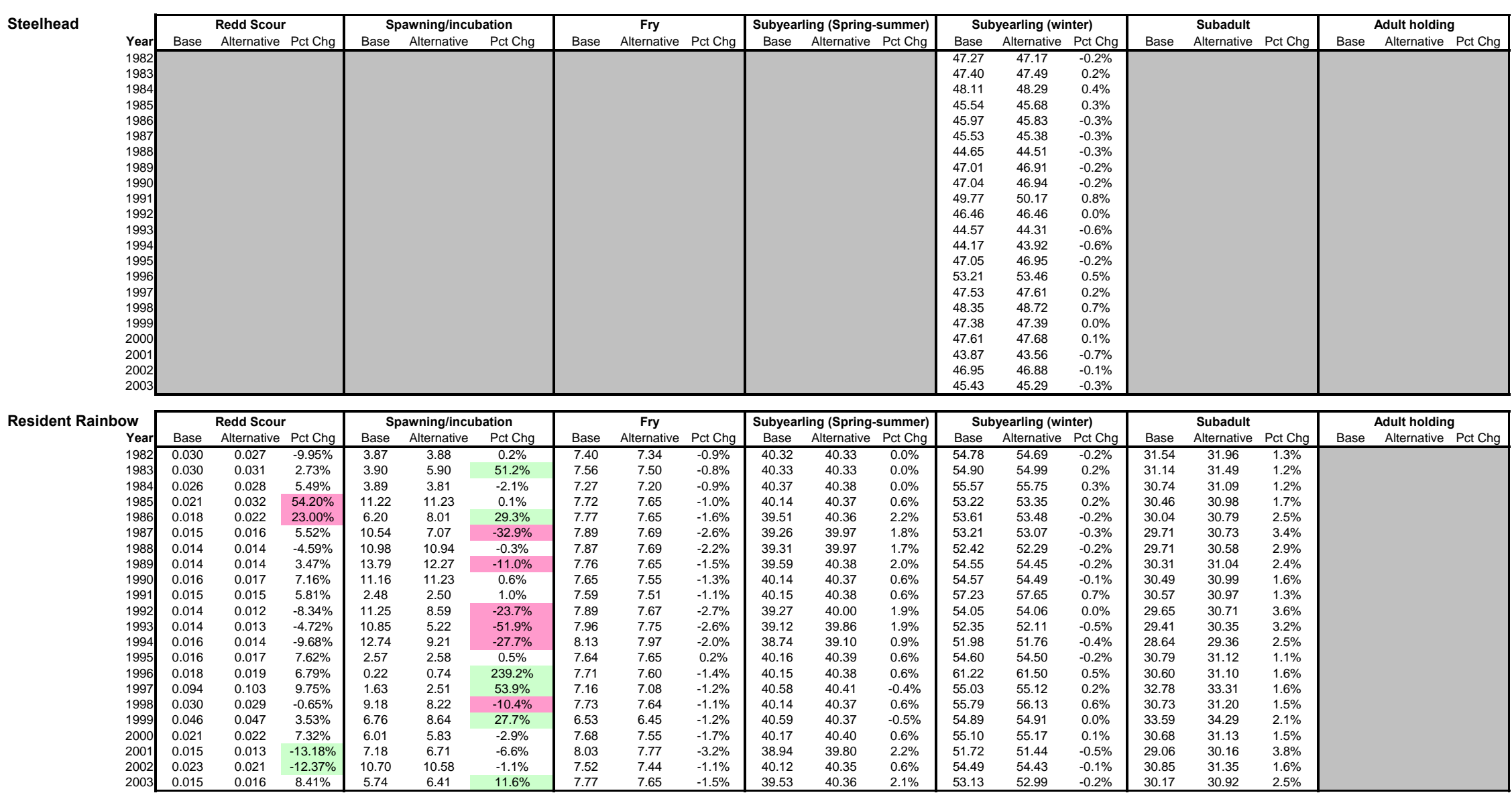

Figure 6-18. Annual habitat summaries for steelhead and resident rainbow trout in the Union Gap reach for the WymerPlus scenario. 
Fall Chinook

\begin{tabular}{|c|c|c|c|c|c|c|c|c|c|c|c|c|c|c|c|c|}
\hline \multirow[b]{2}{*}{ Year } & \multicolumn{3}{|c|}{ Redd Scour } & \multicolumn{3}{|c|}{ Spawning/incubation } & \multicolumn{3}{|c|}{ Fry } & \multirow{2}{*}{\multicolumn{3}{|c|}{$\begin{array}{l}\text { Subyearling (Spring-summer) } \\
\text { Base Alternative Pct Chg }\end{array}$}} & \multirow{2}{*}{$\begin{array}{l}\text { Subyearling (winter) } \\
\text { Base } \quad \text { Alternative Pct Chg }\end{array}$} & \multicolumn{2}{|r|}{ Subadult } & \multirow{2}{*}{$\begin{array}{c}\text { Adult holding } \\
\text { Alt }\end{array}$} \\
\hline & Base & Alternative & Pct Chg & Base & Alternative & Pct Chg & Base & Alternative & Pct Chg & & & & & Base & Alternative Pct Chg & \\
\hline 1982 & 0.007 & 0.007 & $0.48 \%$ & 53 & 78 & $47.5 \%$ & 26 & 27 & $2.8 \%$ & 139 & 169 & $21.7 \%$ & & & & \\
\hline 1983 & 0.007 & 0.007 & $0.51 \%$ & 60 & 82 & $36.6 \%$ & 24 & 24 & $-2.6 \%$ & 118 & 146 & $23.7 \%$ & & & & \\
\hline 1984 & 0.007 & 0.007 & $-1.09 \%$ & 62 & 81 & $29.9 \%$ & 26 & 26 & $-0.4 \%$ & 92 & 97 & $5.4 \%$ & & & & \\
\hline 1985 & 0.007 & 0.007 & $-8.17 \%$ & 61 & 83 & $36.6 \%$ & 25 & 26 & $5.8 \%$ & 94 & 97 & $4.1 \%$ & & & & \\
\hline 1986 & 0.007 & 0.007 & $1.08 \%$ & 47 & 74 & $56.9 \%$ & 22 & 25 & $9.8 \%$ & 96 & 95 & $-1.9 \%$ & & & & \\
\hline 1987 & 0.007 & 0.007 & $-0.37 \%$ & 44 & 71 & $59.8 \%$ & 26 & 27 & $4.9 \%$ & 99 & 95 & $-4.5 \%$ & & & & \\
\hline 1988 & 0.008 & 0.007 & $-3.43 \%$ & 38 & 70 & $82.1 \%$ & 26 & 27 & $2.9 \%$ & 93 & 96 & $3.3 \%$ & & & & \\
\hline 1989 & 0.007 & 0.007 & $-8.70 \%$ & 62 & 81 & $30.9 \%$ & 26 & 26 & $0.5 \%$ & 96 & 95 & $-0.9 \%$ & & & & \\
\hline 1990 & 0.007 & 0.007 & $0.27 \%$ & 64 & 81 & $27.0 \%$ & 25 & 25 & $-2.1 \%$ & 94 & 95 & $0.8 \%$ & & & & \\
\hline 1991 & 0.006 & 0.006 & $0.41 \%$ & 56 & 86 & $53.7 \%$ & 26 & 26 & $1.5 \%$ & 95 & 95 & $0.3 \%$ & & & & \\
\hline 1992 & 0.007 & 0.007 & $0.87 \%$ & 47 & 82 & $72.8 \%$ & 22 & 26 & $17.4 \%$ & 99 & 95 & $-4.1 \%$ & & & & \\
\hline 1993 & 0.008 & 0.007 & $-1.17 \%$ & 44 & 67 & $53.8 \%$ & 24 & 26 & $11.0 \%$ & 94 & 96 & $2.1 \%$ & & & & \\
\hline 1994 & 0.008 & 0.007 & $-6.76 \%$ & 40 & 65 & $62.9 \%$ & 24 & 26 & $8.5 \%$ & 96 & 94 & $-1.8 \%$ & & & & \\
\hline 1995 & 0.007 & 0.007 & $1.15 \%$ & 49 & 65 & $33.0 \%$ & 26 & 26 & $3.1 \%$ & 115 & 147 & $27.4 \%$ & & & & \\
\hline 1996 & 0.006 & 0.006 & $0.49 \%$ & 31 & 70 & $127.6 \%$ & 22 & 22 & $0.5 \%$ & 96 & 109 & $13.3 \%$ & & & & \\
\hline 1997 & 0.007 & 0.007 & $0.66 \%$ & 39 & 81 & $106.5 \%$ & 18 & 17 & $-3.7 \%$ & 220 & 241 & $10.0 \%$ & & & & \\
\hline 1998 & 0.006 & 0.006 & $-0.17 \%$ & 72 & 91 & $27.8 \%$ & 26 & 25 & $-1.8 \%$ & 123 & 157 & $27.1 \%$ & & & & \\
\hline 1999 & 0.007 & 0.007 & $1.14 \%$ & 47 & 82 & $76.8 \%$ & 26 & 26 & $-3.3 \%$ & 127 & 152 & $19.8 \%$ & & & & \\
\hline 2000 & 0.006 & 0.006 & $0.21 \%$ & 59 & 82 & $40.0 \%$ & 25 & 24 & $-2.0 \%$ & 93 & 103 & $10.5 \%$ & & & & \\
\hline 2001 & 0.008 & 0.007 & $-5.04 \%$ & 50 & 73 & $44.0 \%$ & 21 & 25 & $19.5 \%$ & 98 & 95 & $-3.7 \%$ & & & & \\
\hline 2002 & 0.007 & 0.007 & $0.82 \%$ & 44 & 75 & $71.8 \%$ & 26 & 26 & $-0.9 \%$ & 102 & 123 & $20.9 \%$ & & & & \\
\hline 200 & 0.007 & 0.007 & $-1.02 \%$ & 43 & 71 & $66.7 \%$ & 26 & 27 & $2.0 \%$ & 96 & 95 & $-1.0 \%$ & & & & \\
\hline
\end{tabular}

Coho

\begin{tabular}{|c|c|c|c|c|c|c|c|c|c|c|c|c|c|c|c|c|c|}
\hline \multirow{3}{*}{ Year } & \multicolumn{3}{|c|}{ Redd Scour } & \multicolumn{3}{|c|}{ Spawning/incubation } & \multirow{2}{*}{\multicolumn{3}{|c|}{ Fry }} & \multicolumn{3}{|c|}{ Subyearling (Spring-summer) } & \multicolumn{3}{|c|}{ Subyearling (winter) } & \multirow{2}{*}{ Subadult } & Adult holding \\
\hline & Base & Alternative & Pct Chg & Base & Alternative & Pct Chg & Base & & & Base & Alternative & Pct Chg & Base & & & & Base Alternative Pct Chg \\
\hline & 0.007 & 0.007 & $0.38 \%$ & 7 & 16 & $135.5 \%$ & 26 & 25 & $-1.0 \%$ & 60 & 6 & $10.3 \%$ & 112 & 117 & $4.1 \%$ & & \\
\hline 1983 & 0.007 & 0.006 & $-1.00 \%$ & 7 & 11 & $58.2 \%$ & 26 & 25 & $-2.8 \%$ & 60 & 66 & $10.3 \%$ & 115 & 122 & $6.6 \%$ & & \\
\hline 1984 & 0.007 & 0.007 & $-1.09 \%$ & 7 & 11 & $56.2 \%$ & 23 & 26 & $12.2 \%$ & 60 & 66 & $10.3 \%$ & 121 & 131 & $7.8 \%$ & & \\
\hline 1985 & 0.007 & 0.007 & $-8.17 \%$ & 38 & 38 & $1.8 \%$ & 22 & 26 & $16.0 \%$ & 63 & 66 & $5.1 \%$ & 102 & 111 & $9.3 \%$ & & \\
\hline 1986 & 0.007 & 0.007 & $1.08 \%$ & 4 & 18 & $392.1 \%$ & 20 & 26 & $27.5 \%$ & 67 & 66 & $-1.1 \%$ & 101 & 111 & $8.9 \%$ & & \\
\hline 1987 & 0.007 & 0.007 & $-0.37 \%$ & 16 & 23 & $39.7 \%$ & 23 & 26 & $14.4 \%$ & 68 & 66 & $-2.4 \%$ & 103 & 108 & $5.3 \%$ & & \\
\hline 1988 & 0.007 & 0.007 & $-0.90 \%$ & 32 & 31 & $-0.8 \%$ & 23 & 26 & $14.4 \%$ & 68 & 66 & $-2.2 \%$ & 98 & 101 & $3.1 \%$ & & \\
\hline 1989 & 0.007 & 0.007 & $-8.87 \%$ & 29 & 26 & $-8.7 \%$ & 23 & 25 & $11.9 \%$ & 67 & 66 & $-0.4 \%$ & 110 & 114 & $4.3 \%$ & & \\
\hline 1990 & 0.007 & 0.007 & $-0.20 \%$ & 25 & 23 & $-6.0 \%$ & 21 & 24 & $11.9 \%$ & 63 & 66 & $5.6 \%$ & 111 & 116 & $3.6 \%$ & & \\
\hline 1991 & 0.006 & 0.006 & $-1.77 \%$ & 4 & 10 & $187.5 \%$ & 22 & 25 & $12.8 \%$ & 62 & 66 & $6.4 \%$ & 133 & 147 & $10.5 \%$ & & \\
\hline 1992 & 0.007 & 0.007 & $0.08 \%$ & 15 & 22 & $51.6 \%$ & 19 & 26 & $33.5 \%$ & 68 & 66 & $-2.1 \%$ & 98 & 110 & $12.1 \%$ & & \\
\hline 1993 & 0.008 & 0.007 & $-1.17 \%$ & 36 & 32 & $-12.8 \%$ & 21 & 26 & $22.7 \%$ & 68 & 66 & $-2.7 \%$ & 95 & 99 & $4.8 \%$ & & \\
\hline 1994 & 0.008 & 0.007 & $-8.43 \%$ & 37 & 38 & $1.8 \%$ & 20 & 26 & $29.1 \%$ & 69 & 66 & $-5.2 \%$ & 93 & 96 & $4.0 \%$ & & \\
\hline 1995 & 0.007 & 0.007 & $0.26 \%$ & 4 & 12 & $218.5 \%$ & 26 & 26 & $0.9 \%$ & 63 & 66 & $5.2 \%$ & 110 & 116 & $5.7 \%$ & & \\
\hline 1996 & 0.005 & 0.005 & $0.74 \%$ & 0 & 3 & $613.5 \%$ & 23 & 23 & $2.7 \%$ & 63 & 66 & $5.3 \%$ & 156 & 162 & $4.3 \%$ & & \\
\hline 1997 & 0.007 & 0.007 & $0.66 \%$ & 2 & 10 & $412.3 \%$ & 17 & 16 & $-4.6 \%$ & 61 & 66 & $9.0 \%$ & 116 & 123 & $5.7 \%$ & & \\
\hline 1998 & 0.006 & 0.006 & $-0.17 \%$ & 15 & 21 & $41.1 \%$ & 24 & 23 & $-2.3 \%$ & 63 & 66 & $4.9 \%$ & 124 & 135 & $8.2 \%$ & & \\
\hline 1999 & 0.007 & 0.007 & $0.31 \%$ & 13 & 20 & $49.2 \%$ & 23 & 22 & $-3.9 \%$ & 61 & 68 & $10.5 \%$ & 115 & 122 & $6.5 \%$ & & \\
\hline 2000 & 0.006 & 0.006 & $0.21 \%$ & 7 & 11 & $58.6 \%$ & 23 & 24 & $4.1 \%$ & 63 & 66 & $5.1 \%$ & 116 & 124 & $6.2 \%$ & & \\
\hline 2001 & 0.008 & 0.007 & $-5.04 \%$ & 40 & 31 & $-21.6 \%$ & 19 & 25 & $32.6 \%$ & 69 & 66 & $-3.2 \%$ & 89 & 94 & $5.5 \%$ & & \\
\hline I & 0.007 & 0.007 & $-1.80 \%$ & 17 & 29 & $68.6 \%$ & 25 & 25 & $0.9 \%$ & 63 & 66 & $5.1 \%$ & 11 & 114 & $4.0 \%$ & & \\
\hline 003 & 0.007 & 0.007 & $-1.02 \%$ & 12 & 20 & $68.7 \%$ & 22 & 26 & $16.7 \%$ & 67 & 66 & $-0.9 \%$ & 101 & 106 & $5.2 \%$ & & \\
\hline
\end{tabular}

Figure 6-19. Annual habitat summaries for fall chinook and coho salmon in the Wapato reach for the WymerPlus scenario. 


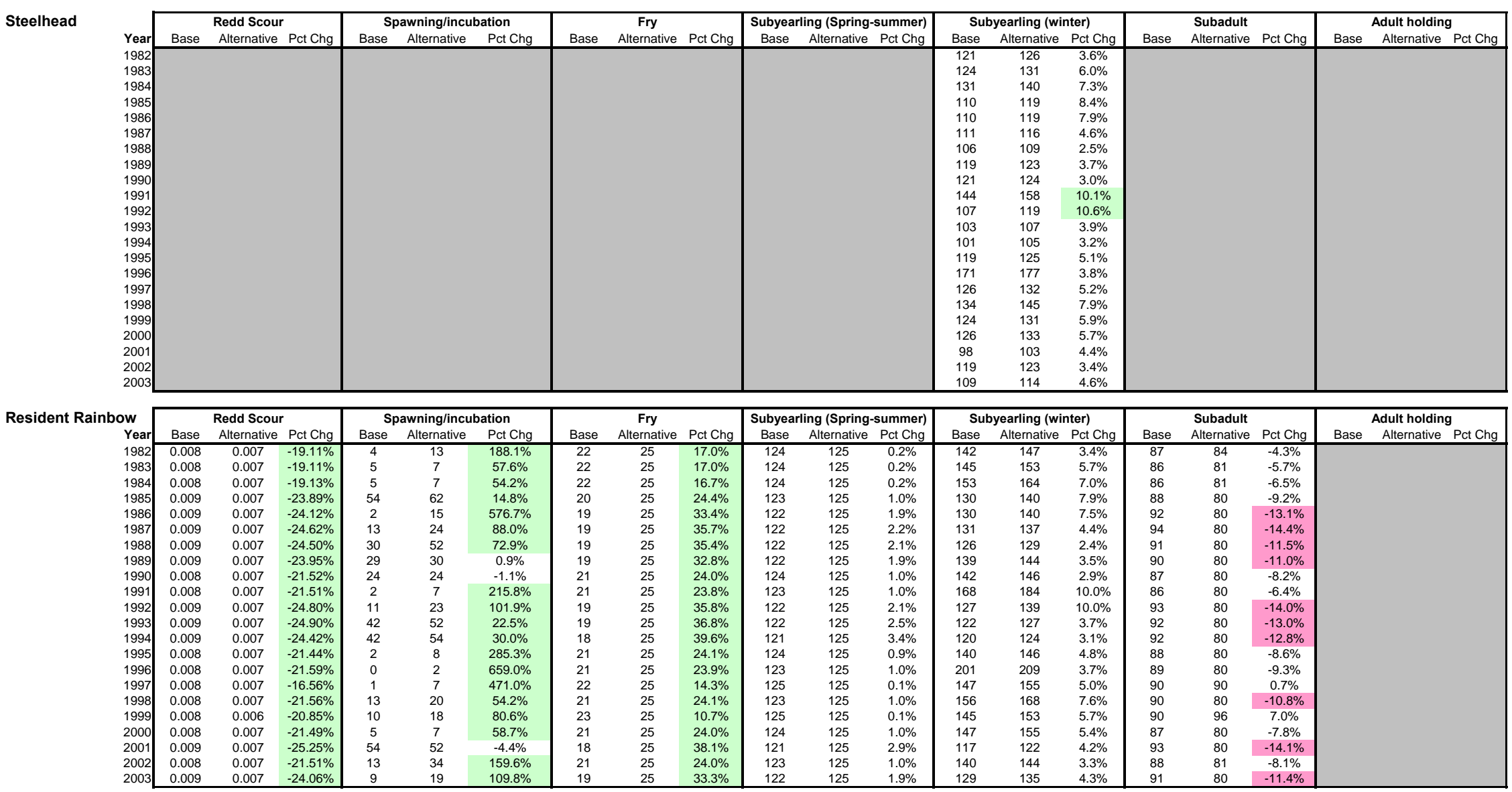

Figure 6-20. Annual habitat summaries for steelhead and resident rainbow trout in the Wapato reach for the WymerPlus scenario. 
Fall Chinook

\begin{tabular}{|c|c|c|c|c|c|c|c|c|c|c|c|c|c|c|c|c|}
\hline \multirow[b]{2}{*}{ Year } & \multirow{2}{*}{\multicolumn{3}{|c|}{ Spawning }} & \multicolumn{3}{|c|}{ Incubation } & \multicolumn{3}{|c|}{ Fry } & \multicolumn{3}{|c|}{ Subyearling (Spring-summer) } & Subyearling (winter) & \multicolumn{2}{|r|}{ Subadult } & \multirow{2}{*}{ 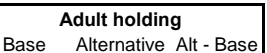 } \\
\hline & Base & & Alt - Base & Base & Alternativ & Alt - Base & Base & Alternative & Alt - Base & Base & Alternative & & Base Alternative Alt - Base & Base & Alternative Alt - Base & \\
\hline 1982 & 0.0 & 0.0 & No Data & 0.0 & 0.0 & No Data & 0.0 & 0.0 & No Data & 0.0 & 0.0 & No Data & & & & \\
\hline 1983 & 0.0 & 0.0 & No Data & 0.0 & 0.0 & No Data & 0.0 & 0.0 & No Data & 0.0 & 0.0 & No Data & & & & \\
\hline 1984 & 12.4 & 12.9 & 0.5 & 0.0 & 0.0 & No Data & 11.6 & 11.6 & 0.1 & 14.6 & 14.8 & 0.2 & & & & \\
\hline 1985 & 12.8 & 13.3 & 0.5 & 0.0 & 0.0 & No Data & 13.5 & 13.5 & 0.0 & 15.8 & 16.0 & 0.3 & & & & \\
\hline 1986 & 11.6 & 12.1 & 0.5 & 0.0 & 0.0 & No Data & 12.7 & 12.9 & 0.1 & 16.1 & 15.9 & -0.2 & & & & \\
\hline 1987 & 13.0 & 12.6 & -0.4 & 0.0 & 0.0 & No Data & 15.0 & 15.2 & 0.2 & 15.7 & 16.0 & 0.3 & & & & \\
\hline 1988 & 13.7 & 13.8 & 0.1 & 0.0 & 0.0 & No Data & 12.9 & 13.0 & 0.1 & 14.6 & 14.8 & 0.2 & & & & \\
\hline 1989 & 14.7 & 14.8 & 0.0 & 0.0 & 0.0 & No Data & 12.9 & 13.0 & 0.0 & 16.1 & 15.8 & -0.3 & & & & \\
\hline 1990 & 13.1 & 12.8 & -0.3 & 0.0 & 0.0 & No Data & 12.9 & 13.2 & 0.3 & 14.2 & 14.2 & 0.1 & & & & \\
\hline 1991 & 12.9 & 13.2 & 0.3 & 0.0 & 0.0 & No Data & 12.8 & 12.9 & 0.1 & 14.8 & 14.8 & 0.1 & & & & \\
\hline $\begin{array}{l}1991 \\
1992\end{array}$ & $\begin{array}{l}1.9 \\
14.0\end{array}$ & $\begin{array}{l}13.2 \\
14.0\end{array}$ & $\begin{array}{l}0.3 \\
-0.1\end{array}$ & 0.0 & 0.0 & $\begin{array}{l}\text { No vald } \\
\text { No Data }\end{array}$ & $\begin{array}{l}14.8 \\
14.3\end{array}$ & $\begin{array}{l}12.9 \\
14.4\end{array}$ & 0.1 & $\begin{array}{l}14.8 \\
17.4\end{array}$ & $\begin{array}{l}14.8 \\
17.3\end{array}$ & $\begin{array}{l}.1 \\
-0.1\end{array}$ & & & & \\
\hline $\begin{array}{l}19943 \\
1993\end{array}$ & $\begin{array}{l}14.0 \\
14.9\end{array}$ & $\begin{array}{l}14.9 \\
14.9\end{array}$ & $\begin{array}{l}-.1 \\
0.0\end{array}$ & 0.0 & 0.0 & No Data & $\begin{array}{l}13.5 \\
13.5\end{array}$ & $\begin{array}{l}14.4 \\
13.7\end{array}$ & 0.2 & $\begin{array}{l}17.4 \\
16.6\end{array}$ & $\begin{array}{l}17.3 \\
16.9\end{array}$ & 0.3 & & & & \\
\hline 1994 & $\begin{array}{l}14.9 \\
14.0\end{array}$ & $\begin{array}{l}14.9 \\
14.1\end{array}$ & 0.1 & 0.0 & 0.0 & No Data & $\begin{array}{l}14.5 \\
14.4\end{array}$ & $\begin{array}{l}13.1 \\
14.5\end{array}$ & 0.1 & $\begin{array}{l}10.6 \\
16.0\end{array}$ & $\begin{array}{l}10.9 \\
16.1\end{array}$ & $\begin{array}{l}0.3 \\
0.1\end{array}$ & & & & \\
\hline $\begin{array}{l}1994 \\
1995\end{array}$ & $\begin{array}{l}14.0 \\
13.6\end{array}$ & $\begin{array}{l}14.1 \\
13.8\end{array}$ & $\begin{array}{l}0.1 \\
0.2\end{array}$ & 0.0 & 0.0 & $\begin{array}{l}\text { IN Data } \\
\text { No Data }\end{array}$ & $\begin{array}{l}12.4 \\
12.3\end{array}$ & $\begin{array}{l}14.5 \\
12.6\end{array}$ & $\begin{array}{l}0.1 \\
0.3\end{array}$ & $\begin{array}{l}16.0 \\
14.4\end{array}$ & $\begin{array}{l}14.1 \\
14.5\end{array}$ & $\begin{array}{l}0.1 \\
0.1\end{array}$ & & & & \\
\hline $\begin{array}{l}1995 \\
1996\end{array}$ & $\begin{array}{l}13.6 \\
12.7\end{array}$ & $\begin{array}{l}13.8 \\
13.1\end{array}$ & $\begin{array}{l}0.2 \\
0.4\end{array}$ & $\begin{array}{l}0.0 \\
0.0\end{array}$ & 0.0 & $\begin{array}{l}\text { No Data } \\
\text { No Data }\end{array}$ & $\begin{array}{l}12.3 \\
12.0\end{array}$ & $\begin{array}{l}12.6 \\
12.0\end{array}$ & $\begin{array}{l}0.3 \\
0.0\end{array}$ & $\begin{array}{l}14.4 \\
15.0\end{array}$ & $\begin{array}{l}14.5 \\
15.1\end{array}$ & $\begin{array}{l}0.1 \\
0.1\end{array}$ & & & & \\
\hline $\begin{array}{l}1997 \\
1997\end{array}$ & $\begin{array}{l}12.1 \\
12.3\end{array}$ & $\begin{array}{l}13.1 \\
12.7\end{array}$ & $\begin{array}{l}0.4 \\
0.4\end{array}$ & $\begin{array}{l}0.0 \\
0.0\end{array}$ & 0.0 & $\begin{array}{l}\text { No vata } \\
\text { No Data }\end{array}$ & $\begin{array}{l}11.0 \\
11.1\end{array}$ & $\begin{array}{l}12.0 \\
11.1\end{array}$ & 0.1 & $\begin{array}{l}15.0 \\
14.1\end{array}$ & $\begin{array}{l}14.1 \\
14.2\end{array}$ & $\begin{array}{l}0.1 \\
0.1\end{array}$ & & & & \\
\hline $\begin{array}{l}1998 \\
1998\end{array}$ & $\begin{array}{l}12.3 \\
12.8\end{array}$ & $\begin{array}{l}12.7 \\
13.6\end{array}$ & $\begin{array}{l}0.4 \\
0.8\end{array}$ & $\begin{array}{l}0.0 \\
0.0\end{array}$ & 0.0 & $\begin{array}{l}\text { No vata } \\
\text { No Data }\end{array}$ & 12.9 & $\begin{array}{l}11.1 \\
12.9\end{array}$ & $\begin{array}{l}0.1 \\
0.1\end{array}$ & $\begin{array}{l}14.1 \\
15.0\end{array}$ & $\begin{array}{l}14.2 \\
15.1\end{array}$ & $\begin{array}{l}0.1 \\
0.1\end{array}$ & & & & \\
\hline $\begin{array}{l}1999 \\
1999\end{array}$ & $\begin{array}{l}12.8 \\
12.8\end{array}$ & $\begin{array}{l}13.6 \\
13.1\end{array}$ & $\begin{array}{l}0.8 \\
0.3\end{array}$ & 0.0 & 0.0 & $\begin{array}{l}\text { No Data } \\
\text { No Data }\end{array}$ & $\begin{array}{l}11.9 \\
11.1\end{array}$ & $\begin{array}{l}12.9 \\
11.4\end{array}$ & $\begin{array}{l}0.1 \\
0.3\end{array}$ & $\begin{array}{l}15.0 \\
14.2\end{array}$ & $\begin{array}{l}14.1 \\
14.2\end{array}$ & $\begin{array}{l}0.1 \\
0.1\end{array}$ & & & & \\
\hline 2000 & $\begin{array}{l}12.8 \\
14.1\end{array}$ & $\begin{array}{l}13.1 \\
14.3\end{array}$ & $\begin{array}{l}0.3 \\
0.2\end{array}$ & $\begin{array}{l}0.0 \\
0.0\end{array}$ & $\begin{array}{l}0.0 \\
0.0\end{array}$ & $\begin{array}{l}\text { No Data } \\
\text { No Data }\end{array}$ & $\begin{array}{l}11.1 \\
11.8\end{array}$ & $\begin{array}{l}11.4 \\
11.9\end{array}$ & $\begin{array}{l}0.3 \\
0.1\end{array}$ & $\begin{array}{l}14.2 \\
15.0\end{array}$ & $\begin{array}{l}14.2 \\
15.1\end{array}$ & $\begin{array}{l}0.1 \\
0.1\end{array}$ & & & & \\
\hline 2001 & 13.1 & 13.4 & 0.3 & 0.0 & 0.0 & No Data & 13.9 & 13.9 & 0.1 & 16.5 & 16.7 & 0.2 & & & & \\
\hline 2002 & 13.6 & 13.6 & 0.1 & 0.0 & 0.0 & No Data & 12.1 & 12.3 & 0.2 & 14.2 & 14.3 & 0.1 & & & & \\
\hline 2003 & $\begin{array}{l}13.6 \\
12.9\end{array}$ & $\begin{array}{l}13.6 \\
13.2\end{array}$ & $\begin{array}{l}0.1 \\
0.3\end{array}$ & $\begin{array}{l}0.0 \\
0.0\end{array}$ & 0.0 & $\begin{array}{l}\text { No vata } \\
\text { No Data }\end{array}$ & $\begin{array}{l}12.1 \\
12.8\end{array}$ & $\begin{array}{l}12.3 \\
12.9\end{array}$ & $\begin{array}{l}0.2 \\
0.1\end{array}$ & $\begin{array}{l}14.2 \\
15.6\end{array}$ & $\begin{array}{l}1.3 \\
15.7\end{array}$ & $\begin{array}{l}0.1 \\
0.2\end{array}$ & & & & \\
\hline
\end{tabular}

Coho

\begin{tabular}{|c|c|c|c|c|c|c|c|c|c|c|c|c|c|c|c|c|c|c|}
\hline \multirow[b]{2}{*}{ Year } & \multirow{2}{*}{\multicolumn{3}{|c|}{ Spawning }} & \multirow{2}{*}{\multicolumn{3}{|c|}{ 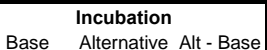 }} & \multirow{2}{*}{\multicolumn{3}{|c|}{ Fry }} & \multirow{2}{*}{\multicolumn{3}{|c|}{ Subyearling (Spring-summer) }} & \multicolumn{3}{|c|}{ Subyearling (winter) } & \multicolumn{2}{|r|}{ Subadult } & \multirow{2}{*}{ 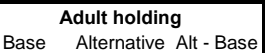 } \\
\hline & Base & Alternativ & & & & & Base & & & & & & Base & Alternati & Alt - Base & Base & Alternative Alt-Base & \\
\hline 1982 & 0.0 & 0.0 & No Data & 0.0 & 0.0 & No Data & 0.0 & 0.0 & No Data & 0.0 & 0.0 & No Data & 0.0 & 0.0 & No Data & & & \\
\hline 1983 & 0.0 & 0.0 & No Data & 0.0 & 0.0 & No Data & 0.0 & 0.0 & No Data & 0.0 & 0.0 & No Data & 0.0 & 0.0 & No Data & & & \\
\hline 1984 & 0.0 & 0.0 & No Data & 0.0 & 0.0 & No Data & 14.6 & 14.8 & 0.2 & 20.1 & 20.0 & -0.1 & 12.6 & 13.0 & 0.3 & & & \\
\hline 1985 & 0.0 & 0.0 & No Data & 0.0 & 0.0 & No Data & 15.8 & 16.0 & 0.3 & 20.4 & 20.3 & 0.0 & 13.5 & 13.5 & 0.0 & & & \\
\hline 1986 & 0.0 & 0.0 & No Data & 0.0 & 0.0 & No Data & 16.1 & 15.7 & -0.4 & 20.6 & 20.4 & -0.1 & 12.7 & 12.9 & 0.1 & & & \\
\hline 1987 & 0.0 & 0.0 & No Data & 0.0 & 0.0 & No Data & 15.7 & 16.0 & 0.3 & 19.3 & 19.3 & 0.0 & 15.0 & 15.2 & 0.2 & & & \\
\hline 1988 & 0.0 & 0.0 & No Data & 0.0 & 0.0 & No Data & 14.6 & 14.8 & 0.2 & 19.3 & 19.4 & 0.0 & 13.7 & 13.8 & 0.1 & & & \\
\hline 1989 & 0.0 & 0.0 & No Data & 0.0 & 0.0 & No Data & 14.8 & 14.6 & -0.2 & 19.2 & 19.1 & -0.1 & 14.7 & 14.8 & 0.0 & & & \\
\hline 1990 & 0.0 & 0.0 & No Data & 0.0 & 0.0 & No Data & 14.2 & 14.2 & 0.1 & 20.9 & 20.7 & -0.2 & 13.1 & 13.2 & 0.1 & & & \\
\hline 1991 & 0.0 & 0.0 & No Data & 0.0 & 0.0 & No Data & 14.5 & 14.5 & 0.0 & 20.0 & 19.9 & -0.1 & 13.9 & 14.2 & 0.3 & & & \\
\hline 1992 & 0.0 & 0.0 & No Data & 0.0 & 0.0 & No Data & 16.9 & 16.8 & -0.1 & 20.5 & 20.6 & 0.1 & 14.3 & 14.4 & 0.1 & & & \\
\hline 1993 & 0.0 & 0.0 & No Data & 0.0 & 0.0 & No Data & 16.6 & 16.9 & 0.3 & 18.6 & 18.6 & 0.0 & 14.9 & 14.9 & 0.0 & & & \\
\hline 1994 & 0.0 & 0.0 & No Data & 0.0 & 0.0 & No Data & 16.0 & 16.1 & 0.1 & 20.5 & 20.7 & 0.2 & 14.4 & 14.5 & 0.1 & & & \\
\hline & 0.0 & 0.0 & No Data & 0.0 & 0.0 & No Data & 14.4 & 14.5 & 0.1 & 19.9 & 19.8 & -0.1 & 13.6 & 13.8 & 0.2 & & & \\
\hline 1996 & 0.0 & 0.0 & No Data & 0.0 & 0.0 & No Data & $\begin{array}{l}15.4 \\
15.0\end{array}$ & $\begin{array}{l}15.1 \\
15.1\end{array}$ & $\begin{array}{l}0.1 \\
0.1\end{array}$ & 20.4 & 20.3 & -0.1 & $\begin{array}{l}13.0 \\
13.7\end{array}$ & $\begin{array}{l}13.0 \\
13.9\end{array}$ & 0.2 & & & \\
\hline 1997 & 0.0 & 0.0 & No Data & 0.0 & 0.0 & No Data & 14.1 & $\begin{array}{l}14.2 \\
14.2\end{array}$ & $\begin{array}{l}0.1 \\
0.1\end{array}$ & 20.7 & 20.5 & $\begin{array}{l}-0.1 \\
-0.1\end{array}$ & $\begin{array}{l}13.6 \\
13.6\end{array}$ & $\begin{array}{l}14.2 \\
14.2\end{array}$ & 0.7 & & & \\
\hline 1998 & 0.0 & 0.0 & No Data & 0.0 & 0.0 & No Data & $\begin{array}{l}15.1 \\
15.0\end{array}$ & $\begin{array}{l}15.1 \\
15.1\end{array}$ & $\begin{array}{l}0.1 \\
0.1\end{array}$ & 21.9 & 21.7 & $\begin{array}{l}-0.1 \\
-0.2\end{array}$ & $\begin{array}{l}13.0 \\
13.4\end{array}$ & 13.7 & 0.3 & & & \\
\hline 1999 & 0.0 & 0 & No Data & 0.0 & 0.0 & No Data & $\begin{array}{l}14.0 \\
14.2\end{array}$ & $\begin{array}{l}14.2 \\
14.2\end{array}$ & $\begin{array}{l}0.1 \\
0.1\end{array}$ & 20.2 & 19.8 & $\begin{array}{l}-0.4 \\
-0.4\end{array}$ & $\begin{array}{l}12.4 \\
12.8\end{array}$ & $\begin{array}{l}13.1 \\
13.1\end{array}$ & 0.3 & & & \\
\hline 2000 & 0.0 & 0 & No Data & 0.0 & 0.0 & No Data & $\begin{array}{l}15.2 \\
15.0\end{array}$ & $\begin{array}{l}15.2 \\
15.1\end{array}$ & $\begin{array}{l}0.1 \\
0.1\end{array}$ & 20.7 & $\begin{array}{l}19.8 \\
20.5\end{array}$ & $\begin{array}{l}-0.4 \\
-0.2\end{array}$ & $\begin{array}{l}14.8 \\
14.1\end{array}$ & $\begin{array}{l}13.1 \\
14.3\end{array}$ & $\begin{array}{l}0.3 \\
0.2\end{array}$ & & & \\
\hline 2001 & 0.0 & 0.0 & No Data & 0.0 & 0.0 & No Data & $\begin{array}{l}16.0 \\
16.5\end{array}$ & $\begin{array}{l}16.7 \\
16.7\end{array}$ & $\begin{array}{l}0.1 \\
0.2\end{array}$ & $\begin{array}{l}20.9 \\
19.9\end{array}$ & 20.1 & 0.2 & $\begin{array}{l}13.1 \\
13.9\end{array}$ & $\begin{array}{l}14.9 \\
13.9\end{array}$ & $\begin{array}{l}0.2 \\
0.1\end{array}$ & & & \\
\hline 2002 & 0.0 & 0.0 & No Data & 0.0 & 0.0 & No Data & 14.2 & 14.3 & 0.1 & 21.1 & 21.1 & 0.1 & 13.6 & 13.6 & 0.1 & & & \\
\hline 2003 & 0.0 & 0.0 & No Data & 0.0 & 0.0 & No Data & $\begin{array}{l}15.2 \\
15.6\end{array}$ & $\begin{array}{l}14.3 \\
15.7\end{array}$ & $\begin{array}{l}0.1 \\
0.2\end{array}$ & $\begin{array}{l}21.1 \\
21.1\end{array}$ & $\begin{array}{l}21.0 \\
21.0\end{array}$ & $\begin{array}{l}0.1 \\
-0.1\end{array}$ & $\begin{array}{l}14.6 \\
14.1\end{array}$ & $\begin{array}{l}13.6 \\
14.1\end{array}$ & $\begin{array}{l}0.1 \\
0.0\end{array}$ & & & \\
\hline
\end{tabular}

Figure 6-21. Annual temperature summaries for fall chinook and coho salmon in the Union Gap reach for the WymerPlus scenario. 


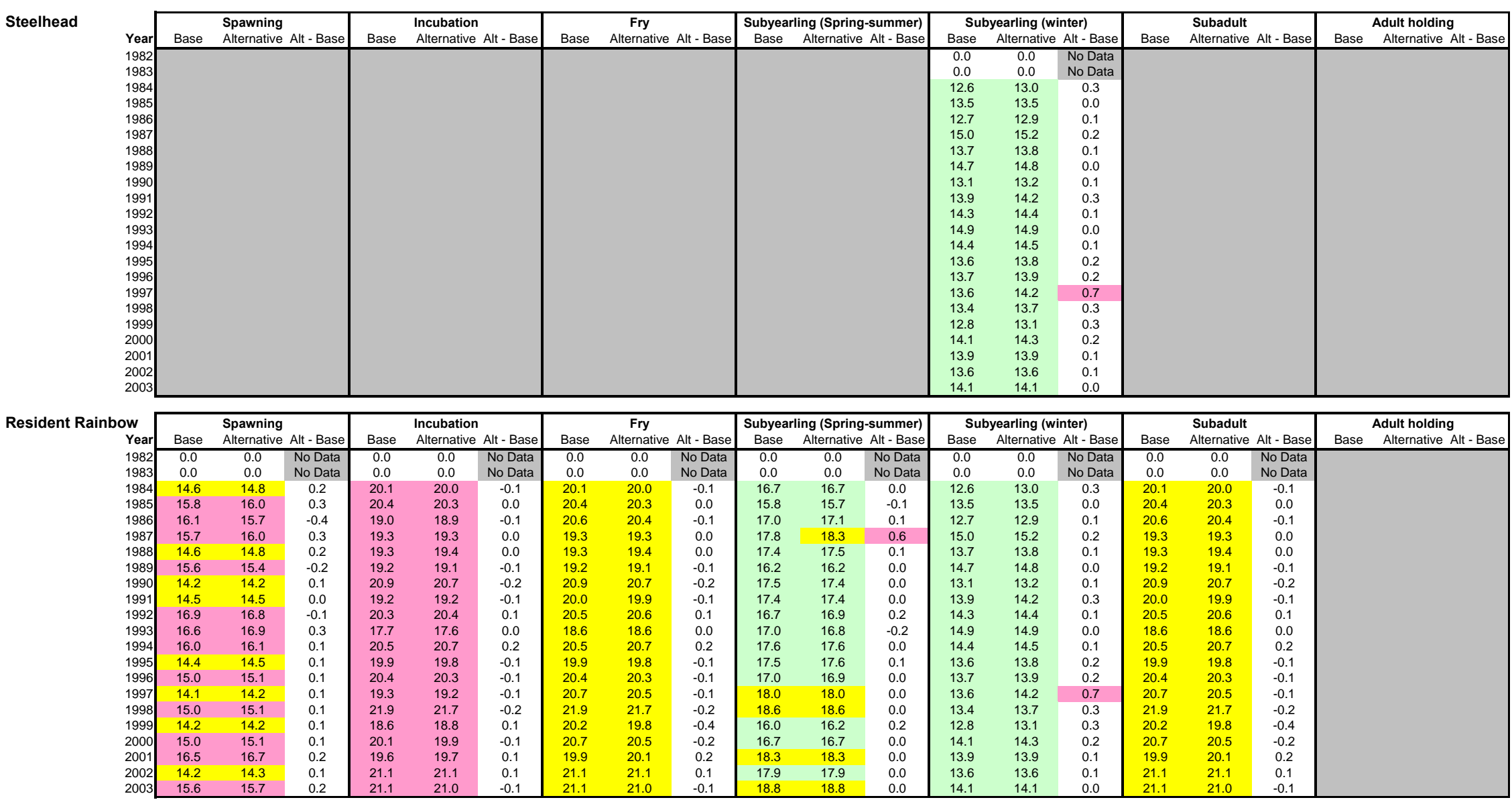

Figure 6-22. Annual temperature summaries for steelhead and resident rainbow trout in the Union Gap reach for the WymerPlus scenario. 
Fall Chinook

\begin{tabular}{|c|c|c|c|c|c|c|c|c|c|c|c|c|c|c|c|c|}
\hline \multirow[b]{2}{*}{ Year! } & \multirow{2}{*}{\multicolumn{3}{|c|}{ Spawning }} & \multirow{2}{*}{\multicolumn{3}{|c|}{ Incubation }} & \multirow{2}{*}{\multicolumn{3}{|c|}{ Fry }} & \multicolumn{3}{|c|}{ Subyearling (Spring-summer) } & Subyearling (winter) & \multicolumn{2}{|r|}{ Subadult } & \multirow{2}{*}{ 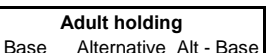 } \\
\hline & Base & Alternative & & Base & & Alt - Base & & & Alt - Base & Base & Alternative & Alt - Base & Base Alternative Alt - Base & Base & Alternative Alt - Base & \\
\hline 1982 & 0.0 & 0.0 & No Data & 0.0 & 0.0 & No Data & 0.0 & $\overline{0.0}$ & No Data & 0.0 & 0.0 & No Data & & & & \\
\hline 1983 & 0.0 & 0.0 & No Data & 0.0 & 0.0 & No Data & 0.0 & 0.0 & No Data & 0.0 & 0.0 & No Data & & & & \\
\hline 1984 & 13.8 & 14.0 & 0.2 & 0.0 & 0.0 & No Data & 13.2 & 13.1 & 0.0 & 17.6 & 17.2 & -0.4 & & & & \\
\hline 1985 & 14.8 & 14.9 & 0.0 & 0.0 & 0.0 & No Data & 15.2 & 14.9 & -0.3 & 18.5 & 18.1 & -0.5 & & & & \\
\hline 1986 & 13.7 & 13.6 & -0.1 & 0.0 & 0.0 & No Data & 15.5 & 15.0 & -0.5 & 18.6 & 17.8 & -0.9 & & & & \\
\hline 1987 & 15.5 & 14.5 & -1.0 & 0.0 & 0.0 & No Data & 16.5 & 16.5 & 0.0 & 17.4 & 17.2 & -0.3 & & & & \\
\hline 1988 & 16.0 & 15.6 & -0.5 & 0.0 & 0.0 & No Data & 14.3 & 14.2 & 0.0 & 17.7 & 17.0 & -0.7 & & & & \\
\hline 1989 & 16.8 & 16.3 & -0.5 & 0.0 & 0.0 & No Data & 15.1 & 15.0 & -0.2 & 19.7 & 18.4 & -1.3 & & & & \\
\hline 990 & 15.2 & 14.3 & -0.9 & 0.0 & 0.0 & No Data & 14.2 & 14.4 & 0.2 & 16.7 & 16.1 & -0.5 & & & & \\
\hline 1991 & 14.1 & 14.1 & 0.0 & 0.0 & 0.0 & No Data & 15.1 & 14.6 & -0.4 & 17.5 & 17.2 & -0.3 & & & & \\
\hline 1992 & 16.4 & 15.6 & -0.7 & 0.0 & 0.0 & No Data & 16.9 & 16.2 & -0.7 & 20.7 & 19.6 & -1.1 & & & & \\
\hline 1993| & 16.7 & 16.0 & -0.7 & 0.0 & 0.0 & No Data & 16.3 & 15.7 & -0.6 & 19.3 & 19.1 & -0.2 & & & & \\
\hline 1994 & 16.2 & 15.7 & -0.5 & 0.0 & 0.0 & No Data & 16.4 & 16.2 & -0.2 & 19.3 & 18.5 & -0.8 & & & & \\
\hline 1995| & 15.8 & 15.4 & -0.5 & 0.0 & 0.0 & No Data & 14.9 & 14.7 & -0.2 & 16.6 & 16.6 & 0.0 & & & & \\
\hline 1996 & 14.9 & 14.7 & -0.2 & 0.0 & 0.0 & No Data & 13.4 & 13.4 & 0.0 & 16.9 & 16.7 & -0.1 & & & & \\
\hline 1997| & 14.3 & 14.1 & -0.2 & 0.0 & 0.0 & No Data & 12.4 & 12.4 & 0.1 & 15.6 & 15.7 & 0.0 & & & & \\
\hline 1998| & 14.7 & 15.1 & 0.3 & 0.0 & 0.0 & No Data & 14.5 & 14.5 & 0.0 & 17.1 & 17.0 & -0.1 & & & & \\
\hline 1999| & 14.7 & 14.5 & -0.1 & 0.0 & 0.0 & No Data & 13.1 & 13.2 & 0.1 & 16.0 & 16.0 & 0.0 & & & & \\
\hline 2000 & 15.9 & 15.6 & -0.3 & 0.0 & 0.0 & No Data & 13.4 & 13.5 & 0.0 & 17.8 & 17.4 & -0.5 & & & & \\
\hline 2001 & 15.4 & 15.1 & -0.3 & 0.0 & 0.0 & No Data & 17.4 & 16.4 & -0.9 & 20.7 & 19.4 & -1.3 & & & & \\
\hline 20 & 15.9 & 15.4 & -0.6 & 0.0 & 0.0 & No Data & 14.2 & 14.1 & -0.1 & 16.3 & 16.2 & 0.0 & & & & \\
\hline & 15.0 & 14.8 & -0.2 & 0.0 & 0.0 & No Data & 14.7 & 14.5 & -0.1 & 19.1 & 18.3 & -0.8 & & & & \\
\hline
\end{tabular}

Coho

\begin{tabular}{|c|c|c|c|c|c|c|c|c|c|c|c|c|c|c|c|c|c|c|}
\hline \multirow[b]{2}{*}{ Year[ } & \multirow{2}{*}{\multicolumn{3}{|c|}{ 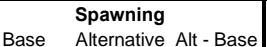 }} & \multirow{2}{*}{\multicolumn{3}{|c|}{ 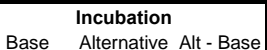 }} & \multirow{2}{*}{\multicolumn{3}{|c|}{$\begin{array}{c}\text { Fry } \\
\text { Pan }\end{array}$}} & \multirow{2}{*}{\multicolumn{3}{|c|}{$\begin{array}{c}\text { Subyearling (Spring-summer) } \\
\text { Base Alternative Alt - Base }\end{array}$}} & \multicolumn{3}{|c|}{ Subyearling (winter) } & & \multirow{2}{*}{ 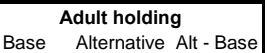 } \\
\hline & & & & & & & Base & & & Base & & & Base & Alternati & Alt - Base & Base & Alternative Alt-Base & \\
\hline 1982 & 0.0 & $\overline{0.0}$ & No Data & 0.0 & 0.0 & No Data & $\overline{0.0}$ & 0.0 & No Data & 0.0 & 0.0 & No Data & 0.0 & 0.0 & No Data & & & \\
\hline 1983 & 0.0 & 0.0 & No Data & 0.0 & 0.0 & No Data & 0.0 & 0.0 & No Data & 0.0 & 0.0 & No Data & 0.0 & 0.0 & No Data & & & \\
\hline 1984 & 0.0 & 0.0 & No Data & 0.0 & 0.0 & No Data & 17.6 & 17.2 & -0.4 & 23.1 & 22.4 & -0.8 & 14.2 & 14.3 & 0.0 & & & \\
\hline 1985 & 0.0 & 0.0 & No Data & 0.0 & 0.0 & No Data & 18.5 & 18.1 & -0.5 & 23.6 & 22.7 & -0.9 & 15.2 & 14.9 & -0.3 & & & \\
\hline 1986 & 0.0 & 0.0 & No Data & 0.0 & 0.0 & No Data & 18.6 & 17.8 & -0.9 & 23.5 & 22.5 & -1.0 & 15.5 & 15.0 & -0.5 & & & \\
\hline 1987 & 0.0 & 0.0 & No Data & 0.0 & 0.0 & No Data & 17.4 & 17.2 & -0.3 & 23.0 & 21.7 & -1.3 & 16.5 & 16.5 & 0.0 & & & \\
\hline 1988 & 0.0 & 0.0 & No Data & 0.0 & 0.0 & No Data & 17.7 & 17.0 & -0.7 & 22.9 & 21.8 & -1.1 & 16.0 & 15.6 & -0.5 & & & \\
\hline 1989 & 0.0 & 0.0 & No Data & 0.0 & 0.0 & No Data & 18.0 & 17.0 & -1.0 & 22.7 & 21.5 & -1.1 & 16.8 & 16.3 & -0.5 & & & \\
\hline 1990 & 0.0 & 0.0 & No Data & 0.0 & 0.0 & No Data & 16.7 & 16.1 & -0.5 & 23.5 & 22.9 & -0.7 & 15.2 & 14.4 & -0.7 & & & \\
\hline 1991 & 0.0 & 0.0 & & 0.0 & 0.0 & No Data & 16.6 & 16.6 & -0.1 & 23.0 & 22.3 & -0.7 & 16.3 & 16.0 & -0.3 & & & \\
\hline 1992 & 0.0 & 0.0 & No Data & 0.0 & 0.0 & No Data & 20.3 & 19.1 & -1.2 & 23.8 & 22.7 & -1.1 & 16.9 & 16.2 & -0.7 & & & \\
\hline 1993 & 0.0 & 0.0 & No Data & 0.0 & 0.0 & No Data & 19.3 & 19.1 & -0.2 & 22.3 & 21.1 & -1.2 & 16.7 & 16.3 & -0.5 & & & \\
\hline 1994 & 0.0 & 0.0 & No Data & 0.0 & 0.0 & No Data & 19.3 & 18.5 & -0.8 & 23.8 & 22.8 & -1.1 & 16.4 & 16.2 & -0.2 & & & \\
\hline 1995 & 0.0 & 0.0 & No Data & 0.0 & 0.0 & No Data & 16.6 & 16.6 & 0.0 & 23.3 & 22.3 & -1.0 & 15.8 & 15.4 & -0.5 & & & \\
\hline 1996 & 0.0 & 0.0 & No Data & 0.0 & 0.0 & No Data & 16.9 & 16.7 & -0.1 & 23.2 & 22.3 & -0.8 & 15.9 & 15.6 & -0.3 & & & \\
\hline 1997 & 0.0 & 0.0 & No Data & 0.0 & 0.0 & No Data & 15.6 & 15.7 & 0.0 & 23.7 & 230 & -0.7 & 14.5 & 14.9 & 0.4 & & & \\
\hline 1998 & 0.0 & 0.0 & No Data & 0.0 & 0.0 & № Data & 17.1 & 17.0 & -0.1 & 24.9 & 23.9 & -1.1 & 15.8 & 15.5 & -0.3 & & & \\
\hline 1999 & 0.0 & 0.0 & No Data & 0.0 & 0.0 & No Data & 16.0 & 16.0 & 0.0 & 22.5 & 22.1 & -0.4 & 14.7 & 14.5 & -0.1 & & & \\
\hline 2000 & 0.0 & 0.0 & No Data & 0.0 & 0.0 & No Data & 17.8 & 17.4 & -0.5 & 24.3 & 23.2 & -11 & 15.9 & 15.6 & -0.3 & & & \\
\hline 2001 & 0.0 & 0.0 & No Data & 0.0 & 0.0 & No Data & 20.7 & 19.4 & -1.3 & 23.1 & 22.1 & -1.0 & 17.4 & 16.4 & -0.9 & & & \\
\hline 2002 & 0 & 0.0 & No Data & 0.0 & 0.0 & No Data & 16.3 & 16.2 & 0.0 & 240 & 23.4 & -0.6 & 159 & 15.4 & $-0, \quad s \quad-$ & & & \\
\hline 2003 & 0.0 & 0.0 & No Data & 0.0 & 0.0 & No Data & 19.1 & 18.3 & -0.8 & 24.4 & 23.3 & -1.1 & 16.2 & 15.7 & -0.5 & & & \\
\hline
\end{tabular}

Figure 6-23. Annual temperature summaries for fall chinook and coho salmon in the Wapato reach for the WymerPlus scenario. 


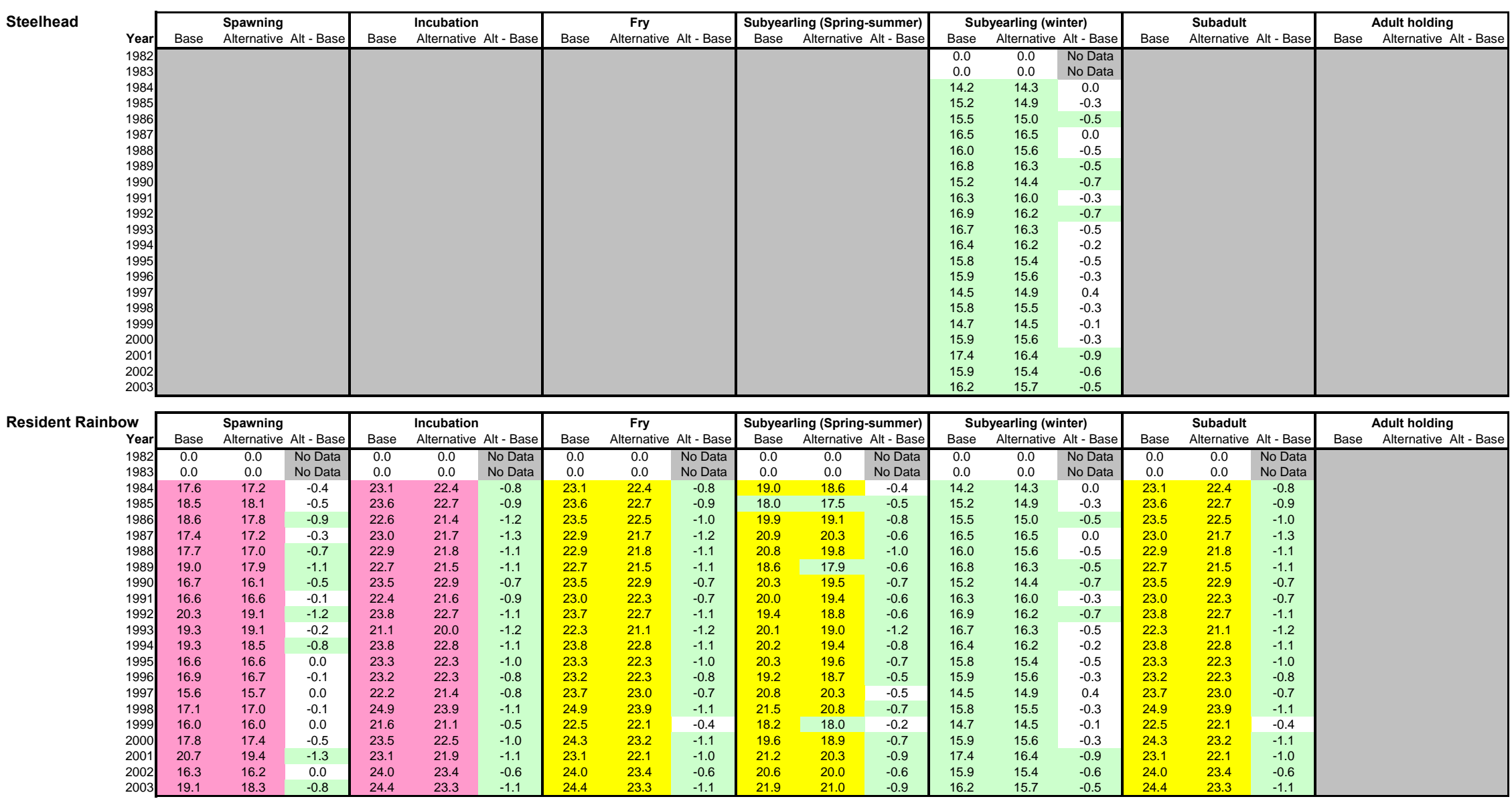

Figure 6-24. Annual temperature summaries for steelhead and resident rainbow trout in the Wapato reach for the WymerPlus scenario. 
Publishing support provided by:

Denver Publishing Service Center

For more information concerning this publication, contact:

Center Director, USGS Fort Collins Science Center

2150 Centre Ave., Bldg. C

Fort Collins, CO 80526-8118

(970)226-9398

Or visit the Fort Collins Science Center Web site at: http://www.fort.usgs.gov/ 